\title{
SAKRALMÖBEL AUS ÖSTERREICH
}

Von Tischlern und ihren Arbeiten im Zeitalter des Absolutismus

II: KUNSTLANDSCHAFTEN IM NORDEN, SÜDEN UND WESTEN

MICHAEL BOHR

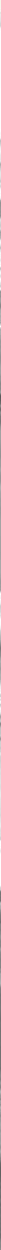


Publikation im Sinne der CC-Lizenz BY 4.0 
Publikation im Sinne der CC-Lizenz BY 4.0 
Michael Bohr

\section{Sakralmöbel aus Österreich}

Von Tischlern und ihren Arbeiten im Zeitalter des Absolutismus

II: Kunstlandschaften im Norden, Süden und Westen

BÖHLAU VERLAG WIEN KÖLN WEIMAR 
Der Wissenschaftsfonds.

\section{Veröffentlicht mit der Unterstützung des Austrian Science Fund (FWF): PUB 729-G}

Open Access: Wo nicht anders festgehalten, ist diese Publikation lizenziert unter der Creative-CommonsLizenz Namensnennung 4.0; siehe http://creativecommons.org/licenses/by/4.o/

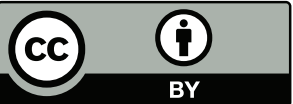

Die Publikation wurde einem anonymen, internationalen Peer-Review-Verfahren unterzogen

Bibliografische Information der Deutschen Nationalbibliothek:

Die Deutsche Nationalbibliothek verzeichnet diese Publikation in der Deutschen Nationalbibliografie; detaillierte bibliografische Daten sind im Internet über http://dnb.d-nb.de abrufbar.

Umschlagabbildung: Benediktinerabtei St. Georgenberg, Stiftskirche Vomp-Fiecht. Blick durch das Langhaus zum Chor: (C) Michael Bohr

(C) 202 I by Böhlau Verlag GmbH \& Co. KG, Wien Köln Weimar

Zeltgasse I, A-ıo8o Wien, www.boehlau-verlag.com

Korrektorat: Klara Vanek, Köln

Satz: Michael Rauscher, Wien

Einbandgestaltung: Michael Haderer, Wien

Druck und Bindung: Prime Rate, Budapest

Gedruckt auf chlor- und säurefreiem Papier

Printed in the EU

Vandenhoeck \& Ruprecht Verlage | www.vandenhoeck-ruprecht-verlage.com

ISBN 978-3-205-2 I 246-I 


\section{Inhalt}

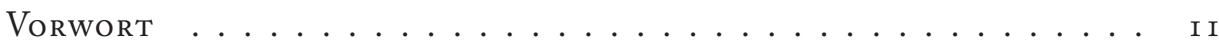

Teil i Vorbemerkungen

EINFÜHRUNG $\ldots \ldots \ldots \ldots \ldots \ldots \ldots$ I5

Methodische Vorgehensweise, Ziele und Fragestellungen . . . . . . . . . I5

Weshalb Sakralmöbel? . . . . . . . . . . . . . . . . . . I6

Original und Rekonstruktion . . . . . . . . . . . . . . . I 8

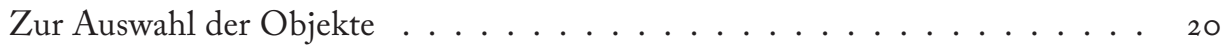

Zum Stand der Forschung . . . . . . . . . . . . . . 2 I

\section{Teil 2 Grundlegendes}

I. Die Auftragsvergabe . . . . . . . . . . . . . . 27

Der Vertrag zwischen Placidus Mally, Abt des Zisterzienserstiftes Rein, und dem Tischlergesellen Thomas Schiffer . . . . . . . . . . . . . . . 27

Allgemeines zu Handwerker- und Künstlerverträgen . . . . . . . . . . . . 33

II. Handwerker und Kunsthandwerker . . . . . . . . . . . . . . . . . . 35

Arbeitsgemeinschaften der Handwerker . . . . . . . . . . . . . . . . . 35

Zusammenarbeit von Tischlern mit anderen Gewerken . . . . . . . . . . . 38

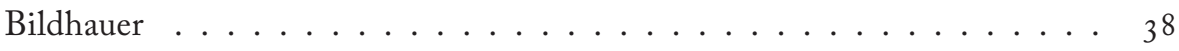

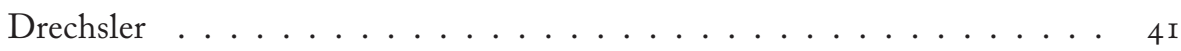

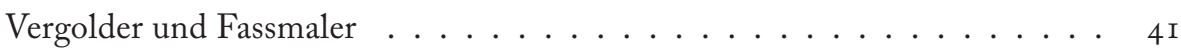

Schmiede ............................ 42

III. Künstlerische Inventionen, Modelle und Entwürfe . . . . . . 43

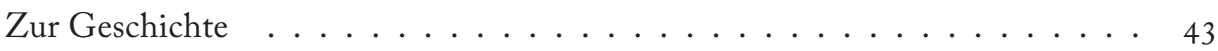

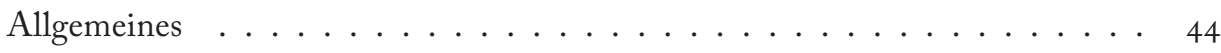

Modelle für Sakralmöbel . . . . . . . . . . . . . . . . . . . . 45

Die Frage nach der Urheberschaft von Entwürfen für Sakralmöbel . . . . . . . . . 47

Entwürfe und Modelle von Architekten und Baumeistern . . . . . . . . . . 47 
Entwürfe und Modelle von "Tischler-Architekten« . . . . . . . . . . . 50

Entwürfe und Modelle von Tischlern und Zimmerleuten . . . . . . . . . . . 5 I

Entwürfe von Bildhauern und Bildschnitzern . . . . . . . . . . 53

Entwürfe eines Theateringenieurs und eines Theaterdekorateurs . . . . . . 53

Entwürfe von Ornamentkünstlern und die Rezeption von Ornamentstichen . 54

Entwürfe von Stuckateuren und die Rezeption von Stuckarbeiten . . . . . 55

IV. Barocke Möbel und sakraler Raum . . . . . . . . . . . . . . . 57

Prunkappartements, Zeremoniell und Liturgie . . . . . . . . . . . . . 57

Sakristeimöbel . . . . . . . . . . . . . . . 58

Chorgestühle .................... 60

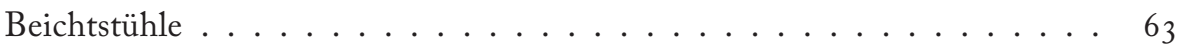

Kirchenbänke ........................ 64

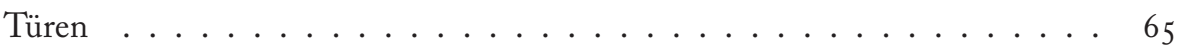

Resümee ............................ 66

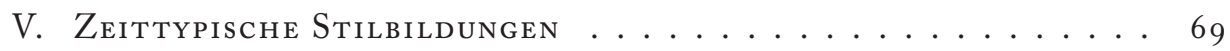

Süddeutschland, Italien und Frankreich . . . . . . . . . . . . . . . . . 69

Pilaster, Säulen, Lisenen und pilasterartige Stützen . . . . . . . . . . . . . 72

Zur Vermittlung und Weitergabe neuer Formen . . . . . . . . . . 73

VI. Österreichische Kunstlandschaften und regionale

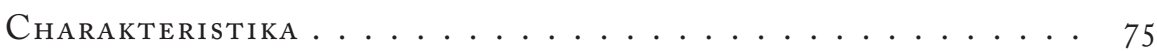

Wien und Niederösterreich . . . . . . . . . . . . . . 76

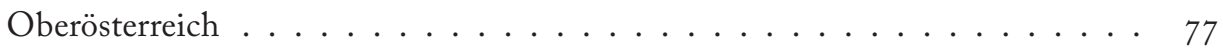

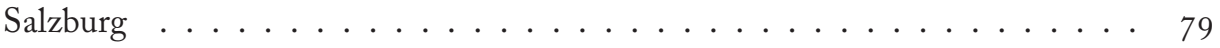

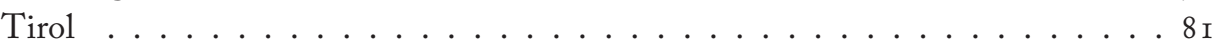

Kärnten und Steiermark . . . . . . . . . . . . . . . . . . . . . . . . 83

Vorarlberg und Burgenland . . . . . . . . . . . . . . 86

Teil 3 Katalog - Beiträge zu den Sakralanlagen - Tafeln

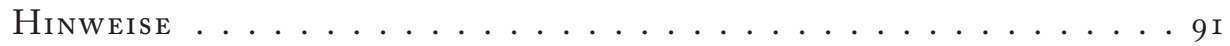

Hinweise zu Provenienzen, Datierungen und Materialien . . . . . . . . . . 9I

Hinweise zu den angegebenen Maßen . . . . . . . . . . . . . . . . . . .

Hinweise zu den zitierten Schriftquellen . . . . . . . . . . . . 92 


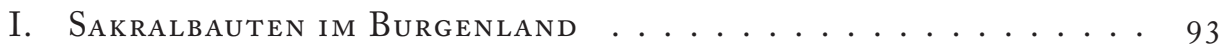

Eisenstadt, Rektoratskirche St. Michael . . . . . . . . . . . . . . . . . . . . 93

Frauenkirchen, Franziskanerkloster ～. . . . . . . . . . . . . . . . 98

Lockenhaus, Pfarr- und Wallfahrtskirche hl. Nikolaus . . . . . . . . . . . I03

Maria Loretto, Pfarr- und Wallfahrtskirche Zur Unbefleckten Empfängnis . . . I ro

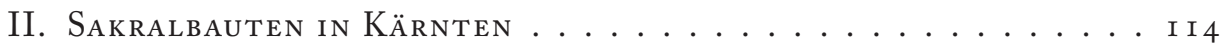

Friesach, Stadtpfarrkirche hl. Bartholomäus … . . . . . . . I I4

Gösseling, Filialkirche hl. Michael … . . . . . . . . . I 20

Griffen, Ehemaliges Prämonstratenserstift . . . . . . . . . . I 22

Griffen, Alte Pfarrkirche Unsere Liebe Frau _ . . . . . . . . . . . I 22

Griffen, Pfarr- und ehemalige Stiftskirche Mariae Himmelfahrt . . . . . . . . I 25

Gurk, Konkathedrale und Pfarrkirche Mariae Himmelfahrt . . . . . . . . . . I 29

Klagenfurt, Dom- und Stadtpfarrkirche St. Peter und Paul . . . . . . . . I46

Loschental, Filialkirche hl. Josef . . . . . . . . . . . . I5 I

Benediktinerstift St. Paul im Lavanttal . . . . . . . . . . . . . I54

Villach, Stadthauptpfarrkirche hl. Jakob d.Ä. . . . . . . . . . . I7I

Völkermarkt, Stadtpfarrkirche hl. Maria Magdalena . . . . . . . . . . . I 177

III.Sakralbauten in Salzburg/Stadt und Land . . . . . . . i 83

Maria Plain, Wallfahrtskirche Maria Plain (Maria Himmelfahrt) . . . . . . . I83

Mattsee, Kollegiatstift . . . . . . . . . . . . . . . . . . I I89

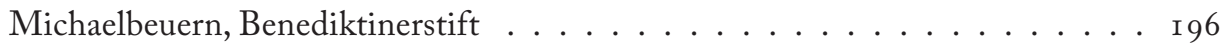

Salzburg, Benediktiner-Erzabtei St. Peter . . . . . . . . . . . . . . . 206

Salzburg, Dreifaltigkeitskirche . . . . . . . . . . . . . 2 I9

Salzburg, Metropolitankirche hll. Rupert und Virgil . . . . . . . . . . . 229

Salzburg, St. Markus . . . . . . . . . . . . . . . . . . . . . . . . . 244

Salzburg-Mülln, Stadtpfarrkirche zu Unserer Lieben Frau Mariae

Himmelfahrt . . . . . . . . . . . . . . . . . . 248

IV. Sakralbauten in der Steiermark $\ldots \ldots \ldots \ldots \ldots \ldots \ldots$

Frauenberg, Pfarr- und Wallfahrtskirche Mariä Opferung . . . . . . . . . . . . 255

Graz, Barmherzige Brüder, Kloster und Spital … . . . . . . . . 263

Graz, Dom- und Pfarrkirche St. Ägidius . . . . . . . . . . . . 272

Graz, Franziskanerkloster … . . . . . . . . . . . . 289

Graz, Pfarr- und Wallfahrtskirche Mariatrost . . . . . . . . . . . . . . 292

Graz, Pfarrkirche St. Andrä . . . . . . . . . . . . . . . . . 305

Graz, Welsche Kirche /Kirche hl. Franz de Paula . . . . . . . . . . . 309 
Gröbming, Pfarrkirche Mariä Himmelfahrt . . . . . . . . . . . . . 3 2

Mariahof, Pfarrkirche hl. Maria . . . . . . . . . . . . . 323

Neuberg an der Mürz, Pfarrkirche Maria Himmelfahrt . . . . . . . . . . . . 333

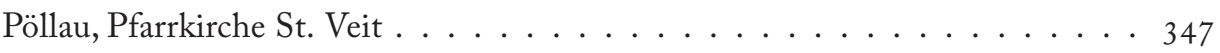

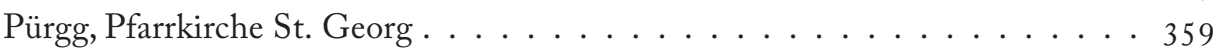

Rein, Zisterzienserstift . . . . . . . . . . . . . . . 365

Rottenmann, Stadtpfarrkirche St. Nikolaus . . . . . . . . . . . . . 38 I

St. Lambrecht, Benediktinerabtei . . . . . . . . . . . . . . . . . 386

Vorau, Augustiner-Chorherrenstift . . . . . . . . . . . . . 404

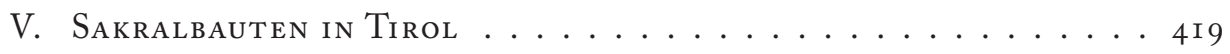

Bad Mehrn, Filialkirche hl. Bartholomäus . . . . . . . . . . . . . . . 4 I9

Brixlegg, Pfarrkirche Unsere Liebe Frau . . . . . . . . . . . . . . . . . . . . . . . . . . . 424

Innsbruck, Hofkirche zum hl. Kreuz . . . . . . . . . . . . . . . . . . . 430

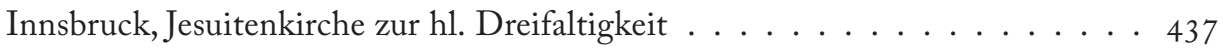

Innsbruck, Servitenkloster . . . . . . . . . . . . . . . . . . . . 449

Kramsach, Maria Thal, Pfarrkirche hl. Dominikus . . . . . . . . . . . . . 459

Kundl, Filial- und Wallfahrtskirche St. Leonhard auf der Wiese . . . . . . . . 469

St. Georgenberg, Benediktinerabtei . . . . . . . . . . . . . . . . . . 478

Stams, Zisterzienserabtei ． . . . . . . . . . . . . . . . 487

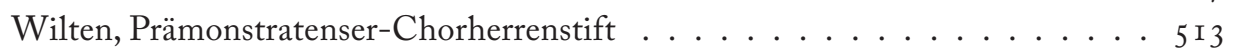

VI. Sakralbauten in Vorarlberg . . . . . . . . . . . . . 525

Bregenz, Stadtpfarrkirche St. Gallus . . . . . . . . . . . . . . 525

Dornbirn, Stadtpfarrkirche St. Martin . . . . . . . . . . . . . . . . . 532

Feldkirch-Altenstadt, Dominikanerinnenkloster . . . . . . . . . . . 534

Thüringen, Kirche St. Anna . . . . . . . . . . . . . . . . . . 54I

Viktorsberg, Pfarkirche hl. Viktor . . . . . . . . . . . 545

Teil 4 Zusammenfassung und Ausblick - Glossar - Verzeichnisse LiterATUR

Zusammenfassung und Ausblick

Ziele der Untersuchung . . . . . . . . . . . . . . 55 I

Zum strukturellen Aufbau der beiden Bücher . . . . . . . . . . . 55 I

Auftraggeber und Finanziers der Ausstattungen . . . . . . . . . . . . . . $55^{2}$

Wer waren die Tischler.$\ldots \ldots \ldots \ldots \ldots 53$ 
Wer waren die Entwerfer der Möbelgarnituren? . . . . . . . . . . . 555

Zusammenarbeit von Tischlern mit anderen Gewerken . . . . . . 556

Sakralmöbel und Ambiente . . . . . . . . . . . . . 558

Vermittlung und Weitergabe neuer Formen - Österreichische

Kunstlandschaften . . . . . . . . . . . . . . . . 560

Fazit und Ausblick . . . . . . . . . . . . . . . 562

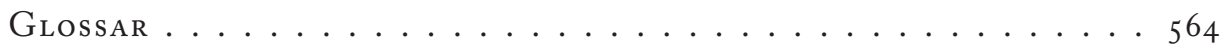

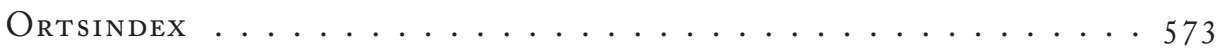

Künstlerverzeichnis $\ldots \ldots \ldots \ldots \ldots \ldots \ldots \ldots \ldots \ldots$

Aвкürzungsverzeichnis $\ldots \ldots \ldots \ldots \ldots \ldots \ldots \ldots \ldots \ldots \ldots \ldots \ldots$

Abbildungsnachweis $\ldots \ldots \ldots \ldots \ldots \ldots \ldots \ldots$

Literaturverzeichnis . . . . . . . . . . . . . 587 
Publikation im Sinne der CC-Lizenz BY 4.0 


\section{Vorwort}

Österreichische Sakralarchitekturen und ihre wandfesten barocken Ausstattungen stehen seit dem Jahrtausendwechsel wieder verstärkt im Fokus wissenschaftlicher Untersuchungen. Tagungen belegen das ebenso wie Fachbeiträge, die in letzter Zeit mit zunehmender Frequenz veröffentlicht werden. Schlechter bestellt ist es um unsere Kenntnisse bezüglich des Mobiliars in Klöstern und Weltkirchen. Was wir über seine Geschichte wissen, findet oft auf wenigen Seiten eines Kirchenführers Platz. Anders als Fresken, Gemäldezyklen oder Skulpturen werden die Einrichtungen in der relevanten Literatur meist nur am Rande berücksichtigt - wenn überhaupt. Wirklich erstaunen kann das jedoch nicht, denn wegen bestehender Forschungslücken ist es noch immer nahezu unmöglich, barocke Tischlerausstattungen in österreichischen Abteien und weltlichen Kirchen im Kontext ihrer Entwicklungsgeschichte zu studieren. In der Fachliteratur ist wenig über ihre Provenienz und Datierung zu erfahren, kaum etwas über die Begleitumstände ihrer Fertigung und noch weniger über die jeweiligen Entstehungsprozesse. Das Ziel der vorliegenden Untersuchung liegt deshalb vor allem darin, einen allgemeinen Überblick über die stilistische Entwicklung von Möbelformen und Ornamentik im Barockzeitalter zu liefern. Durch die Einbeziehung entsprechender Schriftquellen trägt die Studie zugleich zum besseren Verständnis von Auftragsvergabe, künstlerischem Prozedere und Produktionsabläufen im Umfeld der Kirche bei.

Großen Dank schulde ich den Äbten, Prioren und Weltpriestern, die mir in generöser Weise Zutritt zu Kirchen, Sakristeien, Schatzkammern, Bibliotheken und Klausuren gewährten. Ohne ihr verständnisvolles Engagement für das Forschungsvorhaben wäre die Realisierung der Studie nicht möglich gewesen. Danken möchte ich darüber hinaus den Kustoden und Archivaren der Sakralanlagen, ohne deren Hinweise ich vielfach zu unkorrekten Ergebnissen gekommen wäre. Sie kennen die Geschichte und das Inventar ihrer Klöster und Kirchen natürlich am besten und sind informiert über Reparaturen, Restaurierungen und Umbauten in den weitläufigen Gebäudekomplexen. Überdies ließen mir Kunsthistoriker der verschiedensten Forschungseinrichtungen sowie etliche Restauratoren ihr jeweiliges Fachwissen uneigennützig zugutekommen. Es ist nicht annähernd möglich, an dieser Stelle all jene, die mich in meiner Arbeit unterstützten, zu nennen, doch möchte ich folgende Konventangehörige, Weltgeistliche und Kollegen nicht unerwähnt lassen: Nikolaus Albrecht, Thorsten Albrecht, Pe- 
ter Allmaier, Franz Auer, Silvo M. Bachorík, Bernhard H. Backovsky, Bruno Becker, Karl C. Berger, Josef Bierbauer, Korbinian Birnbacher, Johann Dersula, Cristinel Dobos, Josef Ellensohn, Stephan Ellmeyer, Anna Engl, German Erd, Heinrich Ferenczy, Rainald Franz, Thomas Friedmann, Peter Fritzer, Roland Frühauf, Andreas Gamerith, Raphael Gebauer, Raphael Gimpl, Hermann Glettler, Henriette Graf, Reinhard Gratz, Michael Grünwald ( $\dagger$ ), Sebastian Hackenschmidt, Josef Häuptler, Lieselotte HanzlWachter, Philipp Helm, Elena Holzhausen, Willibald Hopfgartner, Johann Huber, Wolfgang Huber, Roger Ibounigg, August Janisch, Heimo Kaindl, Gerhard Christoph Kalidz, Peter Keller, Roland Kerschbaum, Anneliese Khom, Daniel Klee, Paulus Kohler, Peter Kopp, Maximilian Krenn, Petra Krutisch, Othmar Lässer, Gottfried Lafer, Gottfried Laireiter, Franz Lauterbacher, Gregor Martin Lechner ( $\dagger$ ), Christian Marte, Karin Mayer, Bernhard Mayrhofer, Birgit Meusburger, Norbert Müller, Thomas Naub, Johannes Neuhardt, Lukas Nierhaus, Eva B. Ottillinger, Zoltán Papp, Helga Penz, Johannes Perkmann, Benedikt Plank, Friedrich Polleroß, Johannes Pratl, Irene Rabl, Bernhard Rameder, Anton Ratelis, Gerhard Rechberger, Bernhard Röck, Péter Rostás, Dariusz Rot, Andrea Rusch, Andreas Scheuchenpflug, Maximilian Schiefermüller, Rosmarie Schiestl, Rupert Schindlauer, Michael Schlatzer, Peter Schleicher, Christa Schneider, Horst Schneider, Heinrich Schnuderl, Raimund Schreier, Balthasar Sieberer, Rudolf Silberberger, Gerfried Sitar, Siegfried Stattmann, Otto Strohmaier, Josef Sturm, Manfred Sutter, Gertrude Thaller, Werner Telesko, Elias Unegg, Hans-Walter Vavrovsky, Franz Wagner $(\dagger)$, Sybe Wartena, Alfons Wedenig, Agata Teresa Wierdak, Fritz Winsauer, Christian Witt-Dörring, Christiane Wolfgang, Markus Zechner, Anselm Zeller, Augustinus Zeman. Dank schulde ich darüber hinaus dem Team des Böhlau Verlags, mit dessen Hilfe das vorliegende Buch auf die gewohnte professionelle Art fertiggestellt wurde. Und schließlich gilt mein besonderer Dank dem Österreichischen Wissenschaftsfonds (FWF) und seinen Gutachtern. Ohne das in meine Arbeit gesetzte Vertrauen, ohne die Projektbetreuung und ohne die großzügige finanzielle Unterstützung wären die langjährige Forschungsarbeit sowie die Drucklegung des vorliegenden Buches nicht durchführbar gewesen. 
Teil I

VORBEMERKUNGEN 
Publikation im Sinne der CC-Lizenz BY 4.0 


\section{Einführung}

Das vorliegende Buch knüpft direkt an den 2017 erschienenen ersten Band zur Entwicklungsgeschichte barocker Kirchenmöbel an. Die den beiden Büchern zugrunde liegenden Untersuchungsergebnisse basieren auf Forschungsarbeiten ( $\mathrm{P}_{\text {I }}$ 29 98-G I $3, \mathrm{P}$ 2326I-G2I, P 2809 I-G24, P $32583-G)$, die der Österreichische Wissenschaftsfonds (FWF) mit namhaften Beträgen förderte und noch immer fördert.

\section{Methodische Vorgehensweise, Ziele und Fragestellungen}

Der erste Band ist Sakralbauten in Niederösterreich, Wien und Oberösterreich gewidmet, er führt mit grundlegenden Erläuterungen zum Entstehungsprozess sakraler Tischlerarbeiten in das Thema ein. Möbel, die der um 830 entstandene Klosterplan von St. Gallen im Grundriss abbildet und die in frühneuzeitlichen Quellen Erwähnung finden, werden erhaltenen Interieurs gegenübergestellt. Diesem Teil des Buchs folgt ein umfassender Katalog, der nicht chronologisch strukturiert ist, weil sich die Einrichtung der einzelnen Kirchen und Stifte oft über mehrere Jahrzehnte hinzog. Ein sich ausschließlich an der Entwicklungsgeschichte des Möbels orientierender Katalogaufbau hätte daher zu unerträglich vielen Wiederholungen und Querverweisen innerhalb des Textes geführt. Ähnliche Nachteile hätte eine typologische Vorgehensweise mit sich gebracht. Deshalb ist dieser Abschnitt geographisch nach Bundesländern in übergeordnete Abschnitte eingeteilt, innerhalb derer die Sakralbauten in alphabetischer Abfolge erscheinen. Das Buch beschreibt Weltkirchen und Klöster sowie ihre Ausstattungsbestandteile in monographischen Beiträgen, wobei einleitend jeweils auf die Geschichte der Bauwerke eingegangen wird. So entsteht ein Grundgerüst von Metadaten, in dem sich die untersuchten Möbel, in erster Linie Kirchenbänke, Beichtstühle, Chorgestühle und Sakristeimöbel, verorten lassen. Selbstredend geschieht das mit Blick auf jene Faktoren, die für das Gesamterscheinungsbild der vorgestellten Möbelgarnituren im jeweiligen historischen Kontext und regionalen Umfeld determinierend waren.

Der nun fertiggestellte zweite Band richtet seinen Fokus auf barocke Tischlerarbeiten in den übrigen österreichischen Bundesländern. Wie schon das erste beschreibt auch dieses Buch stilistische Besonderheiten, die für die jeweiligen Möbelgarnituren charakteristisch sind. Die beiden Studien bieten somit einen guten Überblick über die 
Entwicklung des frühneuzeitlichen Möbelbaus in allen Regionen der Republik. Der strukturelle Aufbau des zweiten Bandes entspricht dem bereits gewählten formalen Gerüst, wobei die Zeitspanne erneut das gesamte I7. Jahrhundert und das I8. bis ins letzte Viertel hinein umfasst. Wie so oft erwies sich bei dieser Recherche das unbedingte Festhalten an bestimmten Epochen oder vorgegebenen Zeiträumen, hier dem Absolutismus, als wenig zielführend, vielmehr war es sinnvoll, chronologisch etwas weiter auszugreifen. Darüber hinaus richtet der zweite Band das Augenmerk auf weitere Forschungsschwerpunkte: Zunächst wird exemplarisch ein Arbeitsvertrag zwischen Placidus Mally (reg. I7 Io-I 745), dem Abt des Stiftes Rein, und dem Gesellen Thomas Schiffer analysiert, der als Tischler und Bildhauer für das Kloster arbeitete. Dann werden Fragen nach den Urhebern von Modellen, Entwürfen und Rissen beantwortet, die den Erzeugnissen der Tischler zugrunde lagen. Ein weiteres Kapitel rückt die Zusammenarbeit von Tischlern mit anderen Gewerken ins Zentrum und schließlich wird ergründet, bis zu welchem Grad barocke Sakralmöbel in den sie umgebenden Raum integriert waren - all das sind Themenfelder, denen sich die hiesige Forschung noch nicht mit der gebührenden Tiefe gewidmet hat. Ähnlich wie in einem Aufsatzband bilden die jeweiligen Kapitel in sich geschlossene Beiträge.

Anders als im ersten Buch angekündigt, beschäftigt sich das nun vorliegende jedoch nicht mit den Lebensumständen der Tischler, nicht mit Migrationsbewegungen und nicht mit Zunftordnungen, die dem täglichen Leben der Meister und Gesellen ein festes Korsett verliehen. Bei der genauen Lektüre der relevanten Literatur und der Auswertung neu erschlossener Schriftquellen kam dermaßen viel Material zusammen, dass das entsprechende Kapitel den Rahmen des vorliegenden Buchs gesprengt hätte. Da der FWF auch die Recherchen zu einer dritten Publikation großzügig unterstützt, wird die Beantwortung wirtschafts- und sozialhistorischer Fragestellungen zur Lebensführung der Tischler dem nächsten Band der Reihe vorangestellt.

\section{Weshalb SAKRALMÖBEL?}

Es waren zwei Leitideen, die zur vorliegenden Forschungsarbeit führten: einerseits die Beschäftigung mit Sakralmöbeln, die von der österreichischen Forschung bislang eher stiefmütterlich behandelt wurden, andererseits der Wunsch nach Erfüllung eines wichtigen Desiderats der Kunstwissenschaft. Während nämlich Experten im europäischen Ausland profane Barockmöbel längst in überregionalen Studien erfasst haben, mangelt es hierzulande an einem Gesamtkatalog zum Mobiliar der Vormoderne. Zwar existieren zu diesem Themenkomplex einzelne Beiträge von Wissenschaftlern wie Liselotte Hanzl-Wachter, Franziska Hladky, Lucia Laschalt, Franz Wagner, Franz Windisch- 
Graetz oder Christian Witt-Dörring ${ }^{1}$, doch fehlte eine landesweite Untersuchung mit dem Ziel, die regionalen Spezifika von Barockmöbeln aufzuzeigen. Der Grund dafür dürfte in einer besonderen Facette der österreichischen Geschichte zu suchen sein: Anders als im Ausland, wo sich in Adelspalais noch immer etliche Möbelensembles befinden, die nachweislich an Ort und Stelle für den heutigen Standort gefertigt wurden, nahm der österreichische Hochadel, dessen Residenzen geographisch über halb Europa verteilt waren, bei seinen häufigen Wechseln des Aufenthaltsortes Einrichtungsgegenstände mit auf die Reise. ${ }^{2}$ Weitere Möbelstücke wurden bei militärischen Auseinandersetzungen zu entfernt liegenden Besitztümern verbracht. Unausweichliche Folge davon war hierzulande die Durchmischung des Mobiliars in vielen Schlössern und Palais.

Im Gegensatz zu den mit ausführlichen Beschreibungen aufwartenden Inventaren italienischer Sammlungen beschränken sich Inventare der Einrichtungen österreichischer Bauwerke häufig auf vage Hinweise zu den Möbeln, deren Maße auch nur in seltenen Fällen angegeben werden. Im Grunde handelt es sich bei diesen Aufzeichnungen um Listen mit Ausstattungsstücken, weshalb wir lediglich eine ungefähre Vorstellung davon besitzen, wie die Interieurs höfischer Appartements in Österreich beschaffen waren. Nur wenige Objekte lassen sich anhand der Schriftquellen sicher identifizieren, seriöse Antworten auf Fragen nach der Herkunft vieler Möbelgarnituren im Adelsbesitz oder ehemaligem Adelsbesitz können daher kaum geliefert werden, authentische Interieurs sind in den Palais der österreichischen Aristokratie aus heutiger Sicht eher selten. Einer Studie, die unter anderem auf stilistische Besonderheiten von Möbelstücken bestimmter Regionen fokussiert ist, können solche Beispiele selbstverständlich nicht als Ausgangspunkt dienen. Aus diesem Grunde wurde in der Fachliteratur schon mehrfach darauf hingewiesen, dass die Erforschung des österreichischen Barockmobiliars vom Bestand im sakralen Ambiente ausgehen müsse, da er sich in aller Regel noch an seinem ursprünglichen Standort befinde. Ferner erschließen sich aus der Bauchronologie der jeweiligen Sakralanlagen häufig die Herstellungsdaten, manchmal gehen aus Schriftquellen auch die Namen der verantwortlichen Handwerker hervor. Die an ihre Umgebung gebundenen Kirchenmöbel bilden folglich ein ideales Fundament, um der Frage nach den Regionalstilen im Möbelbau nachzugehen.

Das setzt jedoch voraus, dass sich die bei solch einer Studie gewonnen Erkenntnisse auf profane Interieurs übertragen lassen. In seinem Standardwerk zur Geschichte des Möbels zog Adolf Feulner genau das in Zweifel. ${ }^{3}$ Er interpretierte Kirchenmöbel als

I Vgl. hierzu die Literaturliste im Anhang.

2 Allerdings ist bisweilen auch in Deutschland mit einer ähnlichen Vorgehensweise zu rechnen. Rohr, Ceremonial-Wissenschaft (I 729), Teil r, Kap. 7, 47, p. 85; Friedhoff, Wohnen (r 998), 546.

3 Feulner, Kunstgeschichte (I 927), 7 ; ders., Kunstgeschichte (I 980), I 2. 
dreidimensionales Beiwerk des Baukörpers und verortete sie in der Nähe des skulpturalen Kirchenschmucks. Fakt ist, dass viele sakrale Einrichtungsgegenstände andere Maße als profane Exemplare aufweisen, da die Großform von Möbeln funktionsbedingt ist. ${ }^{4}$ Kirchenmöbel sind meist ausladender als ihre profanen Verwandten, zudem werden Beichtstühle und Chorgestühle in der Ausstattung profaner Räumlichkeiten nicht einmal benötigt. Gleichwohl stimmen nach heutigem Kenntnisstand Werkmaterialien und die verschiedenen Arten des Dekors an sakralen und profanen Möbeln aus dem gleichen geographischen Umfeld und zeitlichen Kontext weitgehend überein - mit der Einschränkung allerdings, dass sakrales Mobiliar im I7. Jahrhundert mit Schnitzarbeiten, nur selten aber mit Marketerien verziert wurde. ${ }^{5}$ Kunsthistoriker wie Frida Schottmüller, Giulio Ferrari oder Silvano Colombo beschäftigen sich denn auch mit Kirchenausstattungen in ihren Untersuchungen zum italienischen Möbelbau, sakrale Stücke nehmen sogar einen wichtigen Stellenwert in den jeweiligen Fachstudien ein. ${ }^{6}$ Es spricht somit vieles dafür, die These von Adolf Feulner einer eingehenden Prüfung zu unterziehen.

\section{Original und Rekonstruktion}

An dieser Stelle muss auf einen weiteren wichtigen Umstand hingewiesen werden: In Kirchenräumen sind Möbel erheblichen Klimaschwankungen ausgesetzt, außerdem befinden sie sich in ständiger Verwendung durch Kirchenbesucher, deren Achtsamkeit den Einrichtungsstücken gegenüber unterschiedlich stark ausgeprägt ist. Daher waren schon in den vergangenen Jahrhunderten immer wieder Schäden an den Möbeln zu beheben, wie ein Schreiben des Göttweiger Stiftstischlers Franz Anton Staudinger ( I 705-I 78 I) von I 746 eindrucksvoll dokumentiert. ${ }^{7}$ Ein weiteres Beispiel hierfür sind die Bänke der Stiftskirche zu Wilten (Abb. 372, 373), die im frühen I 9. Jahrhundert erstmals umfassend restauriert wurden. Eine zweite Überarbeitung des Gestühls geht auf die Mitte des 20. Jahrhunderts zurück, eine dritte auf die Jahre nach 2005. Andere Möbel, etwa die Sitzbänke der Innsbrucker Jesuitenkirche oder der Salzburger Domkirche (Abb. I 26-I 29, 303-305), mussten nach schweren Beschädigungen im Zweiten

4 Deshalb unterscheiden sich antike Sitz- und Liegemöbel, Tische und Kassetten hinsichtlich ihrer Großform kaum von ihren neuzeitlichen Gegenstücken. Richter, Furniture (1966).

5 Wagner, Kunsthandwerk (1994), 389-390.

6 Schottmüller, Wohnungskultur ( 192 I); Ferrari, Legno [ca. I 928]; Colombo, L'arte (I 98 I).

7 Bohr, Sakralmöbel (20I7), 5 I-55. Vgl. hierzu auch die Verteidungsschrift des Propstes Johann Michael Führer (reg. I715-I739) aus St. Pölten, mit der er die hohen Ausgaben für ein neues Chorgestühl begründete. Bohr, ebd., 440. 
Weltkrieg zur Rettung des noch erhaltenen Bestandes und zur Wiederherstellung des früheren Raumeindrucks teilweise erneuert oder überhaupt rekonstruiert werden. ${ }^{8}$

Kunstobjekte, die nicht mit dem Gütesiegel »original« oder "weitgehend original« ausgezeichnet werden können, zählen in aller Regel in Museen nicht zu den Ausstellungsexponaten und im seriösen Kunsthandel nicht zu den Gegenständen, die man veräußern würde. Problematisch ist selbstverständlich auch die Aufnahme solcher Möbel in eine Forschungsarbeit über barocke Kirchenausstattungen. Um aber Stücke wie jene in Wilten, Innsbruck oder Salzburg wegen ihrer Bedeutung für die Geschichte des Möbels nicht zu übergehen, sollen im anschließenden Katalog auch einige stark restaurierte Exemplare vorgestellt werden. Dabei sei jedoch betont, dass die Fotodokumentation fast ausschließlich Möbel bzw. Teile von Möbeln enthält, die noch der Barockzeit entstammen, und nur ausnahmsweise Möbelstücke, die bei der Wiederherstellung des dezimierten Bestandes stark zerstörter Interieurs als originalgetreue Rekonstruktionen angefertigt wurden. Allerdings fällt die auf einer rein makroskopischen Begutachtung beruhende Entscheidung, welche Stücke original und welche rekonstruiert sind, mitunter äußerst schwer. Hilfreich ist da die Suche nach typischen, bei der Herstellung der Garnituren entstandenen Bearbeitungsspuren sowie nach klimatischen Schäden und Gebrauchsspuren, die barocke Kirchenmöbel gewöhnlich aufweisen (Abb. 22, 20I , 23 I, 328). Ferner bekunden Inventarstücke, die sicher in der Frühneuzeit gefertigt wurden, in Verbindung mit Vorkriegsaufnahmen und Restaurierungsunterlagen die Vorgehensweise der Restauratoren in den zerstörten Sakralanlagen. Selbstverständlich gibt der Katalogteil aber Auskunft über die jeweilige Geschichte der präsentierten Beispiele und weist wie im Falle der Beichtstühle der Salzburger Domkirche (Abb. I2 2), bei deren Nachbau man interpretativ vorging, auf die im Kontext teils bedeutenden, teils weniger bedeutenden formalen Unterschiede hin.

Schließlich bezeugen häufige Nachfragen von verantwortlicher Seite die Notwendigkeit, mit solchen und ähnlichen Beispielen die gravierenden Differenzen zwischen unterschiedlichen Restaurierungskonzepten aufzuzeigen. Sie betreffen nicht nur ästhetische Überlegungen, sondern auch die gegensätzlichen Botschaften, die verschiedene Arten von Überarbeitungen transportieren. Tatsächlich tobt in vielen Gemeinden ein sich an diversen Fragen entzündender Kulturkampf zwischen Traditionalisten auf der einen und Befürworten von Erneuerungskonzepten auf der anderen Seite. Die radikalsten dieser zweiten Gruppe scheuen bei der Realisierung ihrer Pläne nicht davor zurück, massiv in den originalen Bestand einzugreifen und ein über die Jahrhunderte gewachsenes Gesamtbild zu verändern, manchmal gar zu zerstören. Die Dignität historischer Einrichtungen bleibt ihnen fremd. Diskussionen über eine sinnvolle Vor-

8 Vgl. zur Problematik etwa Reinhardt, Rekonstruktion (201 I), außerdem Bohrloch, Rekonstruktion (20 I I). 
gehensweise bei der Restaurierung und Modernisierung von Kirchenräumen werden im Sinne des Denkmalschutzes also bisweilen überaus unglücklich geführt, und noch immer ist eine fortschreitende Dezimierung historischer Möbelensembles zu konstatieren. ${ }^{9}$ Gleichwohl erfahren Sakralmöbel seit einiger Zeit einen gewissen Bedeutungswandel, weil sich die Erkenntnis durchsetzt, dass die kirchlichen Ausstattungsstücke nicht nur wegen ihrer Funktion geschätzt, sondern auch als Teil des kulturellen Erbes bewahrt werden müssen. In ihrer Vielfältigkeit legen sie Zeugnis von den jeweiligen Zeitströmungen in einem umgrenzten regionalen Raum ab. Indem die Studie Argumente für solche Debatten liefert und auf entsprechende Fragen zumindest indirekt eingeht, wird das ursprüngliche Vorhaben, nämlich die Beschreibung stilistischer Entwicklungen im österreichischen Möbelbau, um einen wichtigen Aspekt bereichert.

\section{Zur Auswahl der Objekte}

Mit der Vollendung des zweiten Bandes liegt nun ein Katalog über Möbelensembles aus über 90 österreichischen Klöstern und Weltkirchen vor. Wegen der schieren Menge an Sakralanlagen mit barocken Tischlerarbeiten auf dem heutigen österreichischen Staatsgebiet wäre jeder Versuch einer Vollständigkeit von vornherein zum Scheitern verurteilt gewesen. Deshalb musste eine Auswahl an Objekten getroffen werden, die hochkarätige Stücke ebenso umfasst wie einfache ländliche Arbeiten, bei denen die unscharfe Grenze zwischen Kunstgeschichte und Volkskunde bewusst überschritten wird. Um das ganze Spektrum barocker Sakralmöbel zu erschließen, schien es aber sinnvoll, auch Tischlerarbeiten mit eher sekundärer Bedeutung für die kunsthistorische Forschung in die Untersuchung aufzunehmen. Dass dabei so manches qualitätvolle Interieur nicht bearbeitet werden konnte, versteht sich von selbst. Da jede Auswahl nicht anders als subjektiv sein kann, birgt diese Vorgehensweise das Risiko einer gewissen Willkür in sich, doch stellte sich in Verbindung mit dem Forschungsvorhaben dieser methodische Ansatz als der einzig zielführende heraus. Eine wissenschaftliche Recherche, die wie die vorliegende mit dem Anspruch antritt, geographisch in die Breite zu gehen, kann selbstredend keine komplette Erfassung aller Exemplare einer bestimmten Kunstgattung ins Auge fassen.

9 Nach einer Untersuchung von Franz Wagner ist in Oberösterreich die Zahl der im Originalzustand erhaltenen historischen Kirchenbänke seit dem Ende des Zweiten Weltkrieges um etwa 75 Prozent zurückgegangen. Wagner, Kirchenbänke (2000), 564. Es steht zu befürchten, dass die unwiederbringlichen Verluste in den anderen Regionen des Landes ähnlich hohe Fallzahlen erreichen. 
Die Suche nach geeigneten Objekten entsprach der schon für den ersten Band erprobten: Sie ging von Fachbeiträgen, Kunstinventaren und Fotoarchiven in Denkmalämtern und in der Österreichischen Nationalbibliothek aus, hilfreich waren überdies Gespräche mit Fachkollegen, Diözesankonservatoren und Geistlichen.

\section{Zum Stand der Forschung}

Bereits die Einleitung zum ersten Band der Untersuchung listet die Fachliteratur auf, die der Forschungsarbeit zugrunde liegt. Hingewiesen wird dort auf allgemeine $\mathrm{Ar}-$ beiten zur Klosterbaukunst von Derek Beales, Wolfgang Braunfels und Peter Hersche, auf Studien zu Wiener Handwerkern von Herbert Haupt und Franz Wagner sowie auf Publikationen zu Kirchen- und Sakristeimöbeln von Franziska Hladky, Lucia Laschalt, Franz Wagner, Sybe Wartena und einigen anderen Autoren. Dem ist nicht viel hinzuzufügen: Sehr gut bearbeitet im Hinblick auf architekturgeschichtliche Fragestellungen, auf Gemäldezyklen und Altarwerke sind prominente Bauten wie die Domkirche und das Stift St. Peter in Salzburg, die Zisterzienserabtei Stams, die Jesuitenkirche in Innsbruck, der Grazer Dom, das Kloster St. Paul in Lavanttal oder das Stift St. Lambrecht. Dagegen liegen zu Sakralanlagen, die kulturhistorisch vielleicht nicht an erster Stelle stehen, bisweilen nicht einmal Kirchenführer vor - geschweige denn Beschreibungen des Mobiliars, das generell zu kurz kommt. So manches Mal übergeht die relevante Literatur die Tischlerarbeiten. Rühmliche Ausnahmen hiervon bilden die ausführlichen und gut bebilderten Studien zu den Beichtstühlen und Kirchenbänken in der Abteikirche von St. Georgenberg zu Fiecht (Abb. 340, 34I, 343-346) sowie die publizierten Restaurierungsberichte aus dem Stift Wilten von 2008, die dort in Verbindung mit der letzten Restaurierungskampagne entstanden. ${ }^{10}$ Auf eine Erörterung der formalen Besonderheiten der überarbeiteten Möbel und auf ihre Einordnung in einen kunstgeographischen und kunsthistorischen Kontext wird im Buch zu Wilten jedoch verzichtet. Zusätzlich wurde für die vorliegende Arbeit die unveröffentlichte Dissertation von Georg Gerlach zum Chorgestühl in der Steiermark und in Kärnten zurate gezogen. Obwohl die 193 I an der Universität Graz eingereichte Untersuchung nicht mehr heutigen Ansprüchen genügt, war sie für meine Arbeit insofern von Bedeutung, als Gerlach das Mobiliar sorgfältig auflistete, die einzelnen Stücke kurz beschrieb und mit Datierungsvorschlägen versah, die sich nach heutigem Wissensstand freilich als nicht immer ganz korrekt erweisen.

Io Vgl. zu den vorhergehenden und nachfolgenden Angaben die Literaturliste sowie die relevanten Beiträge im Katalogteil. 
Zu Modellen von Architekturen, Altären und Skulpturen gibt es etliche, zum Teil sehr ausführliche Darstellungen. Erinnert sei zunächst an den 1937 verfassten grundlegenden Beitrag zu Architekturmodellen von Ludwig Heinrich Heydenreich im Reallexikon zur deutschen Kunstgeschichte (RDK). Weiter wäre auf den I 995 von Bernd Evers herausgegebenen Katalog zu verweisen, der auf entsprechenden Ausstellungen in Venedig und Berlin aufbaut. In der Publikation beschäftigen sich namhafte Wissenschaftler eingehend mit italienischen Architekturmodellen aus der Frühen Neuzeit. Die Entstehungsprozesse barocker Skulpturen wurden 1985 von den Teilnehmern zweier Symposien erforscht, eines fand in München statt, das andere in Poznań (Posen). Peter Volk und Konstanty Kalinowski publizierten die dort gehaltenen Vorträge 1986 bzw. 1992. 1998 kuratierte Michael Krapf eine Ausstellung in Wien über Modelle und Zeichnungen von österreichischen Barockaltären und -skulpturen, 1999 folgte eine umfassende Studie von Johannes Myssok zur Vorbereitung und Fertigung von Plastiken und Reliefs in der italienischen Renaissance. Diese Kataloge, Tagungsbände und Beiträge, in denen unter anderem Fragen nach der Werkgenese aufgeworfen werden, waren für meine Arbeit von Bedeutung, obgleich sich zu Entwürfen und Modellen von Sakralmöbeln in den Beiträgen so gut wie keine direkten Hinweise finden. Immerhin machten aber Georg Himmelheber (1979), Alina Dobrzecki, Peter Volk (1985 bzw. I986) sowie Michael Krapf (1998) in Publikationen auf einige Modelle von Kanzeln und einem Beichtstuhl aufmerksam. Zweidimensionale Entwürfe zu Innenausstattungen haben sich dagegen aus dem 17 . und dem I8. Jahrhundert in großer Menge erhalten, Thomas Wilke stellt in einem 2016 erschienen Kompendium eine Vielzahl entsprechender Drucke vor. Wie der Titel seines Buches verrät, bearbeitete Wilke jedoch Vorlagen zur Dekoration französischer Appartements, sakrale Räume sind dort nicht zu finden. ${ }^{11}$

Ein weiteres Kapitel der vorliegenden Studie erhellt die nötigen Arbeitsprozesse bei Großaufträgen an Tischler und sucht eine Antwort auf die Frage nach der Anzahl von Mitarbeitern in vormodernen Tischlerwerkstätten. Mit der Abgrenzung der Tischler von anderen Gewerken setzte sich Fritz Hellwag in seiner 1924 publizierten Untersuchung zur Geschichte des deutschen Tischlerhandwerks auseinander. In Verbindung mit der Thematik müssen zudem Sigrid Sangl und Uta-Christiane Bergemann mit ihren I 990 bzw. 1999 erschienenen Büchern zu Bamberger und Ingolstädter Tischlern erwähnt werden. Sonst gehen Forschungsarbeiten auf diesen Gegenstand meist nur am Rande ein. Die Schwierigkeit der Beschäftigung mit dem Thema liegt in dem Umstand begründet, dass Schriftquellen nur relativ selten Auskunft darüber erteilen, welche Möbel bzw. welche Teilstücke an Möbeln von Zimmerleuten, welche von Tischlern

I I Vgl. dazu auch Graf, Besprechung (2016). 
und welche von Bildschnitzern gefertigt wurden. Eine von den Zünften geforderte scharfe Trennlinie zwischen den Berufen zu ziehen, scheint nachgerade unmöglich. Doppelzünftigkeit und das Arbeiten in zwei Professionen wurde zwar im Laufe der Jahrhunderte immer wieder behördlich untersagt, doch beweist schon die Notwendigkeit der Wiederholung des Verbots, dass eine ganze Reihe von (Kunst-)Handwerkern die zünftigen und behördlichen Anordnungen missachtete und mehreren Tätigkeiten nachging. Tatsächlich sind etliche Tischler namentlich bekannt, die als Bildhauer arbeiteten, und von verschiedenen Bildhauern wissen wir, dass sie als Nebenberuf den des Tischlers ausübten. Ähnliches gilt für Polsterer und Sattler. ${ }^{12}$

Sucht man nach wissenschaftlichen Beiträgen zu vormodernen Verträgen zwischen österreichischen Auftraggebern und Handwerkern, findet man zwar abgedruckte Vertragsdokumente, jedoch kaum weiterführende Analysen. Anderes gilt im Hinblick auf Verträge aus der italienischen Renaissance, die mit verschiedenen methodischen Ansätzen von Wissenschaftlern unterschiedlicher Disziplinen beleuchtet wurden. Vielfach handelt es sich um Schriftstücke, die im I 5. und frühen I6. Jahrhunderts in Florenz aufgesetzt wurden, was einerseits mit der überragenden kulturellen Bedeutung zu erklären ist, die der Stadt am Arno damals zukam, andererseits aber auch mit dem Umstand, dass sich dort eine große Anzahl von Urkunden erhalten hat, die zur Erörterung dieses Themengebietes von Relevanz sind. Zum Einstieg in die Materie könnte zur 2002 von Mareile Büscher veröffentlichten rechtshistorischen Forschungsarbeit gegriffen werden, die eine ganze Reihe renaissancezeitlicher Schriftquellen miteinander vergleicht. Eine weitere in diesem Kontext verfasste Studie ist das 2005 von Michelle O'Malley publizierte Buch über Künstlerverträge und die Praxis der Auftragsvergabe in der italienischen Renaissance. 20Io wurde der Forschungsgegenstand von der Zeitschrift Ricerche di Storia dell'Arte in einem Themenheft aufgegriffen und dabei in einen größeren zeitlichen Rahmen gestellt. Unter anderem widmen sich dort Patrizia Cavazzini, Cristiano Giometti und Cinzia Maria Sicca in ihren Beiträgen entsprechenden Gepflogenheiten im Seicento der Stadt Rom. Erwartungsgemäß unterscheiden sich die Verträge nur unwesentlich von Florentiner Kontrakten. Und die wiederum erinnern an spätgotische und frühneuzeitliche Verträge aus dem deutschsprachigen Kunstraum, die Hans Huth bereits 1923 vorstellte.

Ein weiterer Abschnitt des ersten Teils der vorliegenden Arbeit geht der Frage nach, inwieweit sich Kirchenmöbel durch Form und Dekor in das Ambiente einfügen, für das sie geschaffen wurden. Architekten planten profane Prunkräume im I7. und I 8. Jahrhundert häufig zusammen mit hölzernen Vertäfelungen oder textilen Wandbehängen, mit Parkettböden und verzierten Zimmerdecken, mit Kaminen und mit dem

I2 Sangl, Hofschreinerhandwerk (1990), 53 . 
notwendigen Mobiliar. Die Wechselwirkungen zwischen der Anordnung und Bedeutung der Räume im Schlossbau, dem Zeremoniell und der Innendekoration stehen schon lange im Mittelpunkt kunsthistorischer, soziologischer und historischer Untersuchungen. Hingewiesen sei hier lediglich auf das r 969 herausgegebene Buch Die böfische Gesellschaft von Norbert Elias, auf die r 980 und I 98 I veröffentlichten Studien von Hubert Ch. Ehalt zum Hofzeremoniell in der Frühen Neuzeit, weiter auf zwei I 997 bzw. 2002 erschienene Beiträge von Henriette Graf sowie auf die 2016 veröffentlichte Publikation von Petra Kalousek. Die beiden Autorinnen beschreiben unter anderem die Anlage und Ausstattung repräsentativer Appartements in der Wiener Hofburg. Wie sehr sich die Habsburger und weitere europäische Herrscherhäuser bei der Planung zur Situierung von Räumen und zu den entsprechenden Interieurs an französischen Vorgaben orientierten, war zuletzt Thema eines vom Deutschen Forum für Kunstgeschichte (DFK) in Paris organisierten Kongresses, dessen Akten 2017 erschienen. ${ }^{13}$ Aber lässt sich das, was für den profanen Bereich gilt, auf sakrale Ausstattungen übertragen? Zwar gab schon Susanne Mayer-Himmelheber einen Passus aus Carlo Borromeos (I 538-I584) Instructiones von I 577 wieder, mit dem Architekten aufgefordert werden, zusammen mit den Kirchenräumen auch Chorgestühle zu entwerfen ${ }^{14}$, doch mangelt es in Bezug auf österreichische Sakralmöbel noch weitgehend an Recherchen darüber, ob die Erfahrungen, die Architekten bei der Planung profaner Ausstattungen sammelten, in die Entwürfe zu Interieurs in Sakralräumen einflossen. Für den Kunstraum Süddeutschlands kann in diesem Kontext auf die Studien von Carolyn Renz-Krebber (1998) und Sybe Wartena (2008) verwiesen werden, die die Einbindung von Sakristeischränken und Chorgestühlen in den architektonischen Rahmen untersuchten und ergründeten, inwiefern Sakralmöbel Aufgaben der Repräsentation dienlich waren.

Das letzte Kapitel der Einführung beschäftigt sich mit einer Beschreibung der regionalen Besonderheiten barocker Sakralmöbel in Österreich. Das war in der Vergangenheit nicht möglich, da bislang noch keine Zusammenstellung österreichischer Möbel aus der Frühen Neuzeit erarbeitet wurde. Ein Vergleich, der solch einer Studie zugrunde liegen muss, um die regionalen Charakteristika zu erkennen, konnte folglich auch nicht gezogen werden. In ihrer Gesamtheit geben die beiden Bücher und der in Vorbereitung begriffene dritte Band mithin einen umfassenden Überblick über die Lebenswirklichkeiten österreichischer Tischler sowie über ihre Erzeugnisse im Zeitalter des Absolutismus.

I3 Gaehtgens/Castor/Bussmann u.a., Versailles (2017).

I4 Borromeo, Instructiones fabricae (I 577), liber I, cap. XII; Mayer-Himmelheber, Kunstpolitik (I 984), III. 
Teil 2

\section{Grundlegendes}


Publikation im Sinne der CC-Lizenz BY 4.0 
I.

\section{Die Auftragsvergabe}

\section{Der Vertrag Zwischen Placidus Mally, Abt des Zisterzienserstiftes Rein, und dem Tischlergesellen Thomas Schiffer}

Frühneuzeitliche Verträge zwischen Auftraggebern und Malern bzw. Handwerkern aus Österreich harren noch immer einer eingehenden Beurteilung durch Kunsthistoriker sowie durch Wirtschafts-, Sozial- und Rechtshistoriker. ${ }^{1}$ Wie in der Einleitung beschrieben, richtet sich der Fokus entsprechender Untersuchungen vor allem auf Künstlerverträge aus der italienischen Renaissance, vorzugsweise auf jene aus Florenz. ${ }^{2}$ Als Beispiel aus dem hier interessierenden Kontext sei ein Vertrag wiedergegeben, der zwischen Abt Placidus Mally (reg. I7ro-r 745) aus Rein und dem Tischlergesellen Thomas Schiffer geschlossen wurde. Vertragsgegenstand war der Bau eines neuen Chorgestühls für die steiermärkische Zisterzienserabtei (Abb. 236-239): ${ }^{3}$

\section{Contract über die Chorstüble im Presbyterium/Thüschler 1743 28/4.}

Anheündt zu endt geßezten dato ist zwischen ibro gnaden dem hochwürdig, in Gott hoch edl gebohrnen, auch hochgelehrten herrn herrn Placidum abbten des fürstlichen stüffts Rhein, [...] sr. röm. kay. may. rath etc. an ainem dann Thomas Schüffer bestelten tischlergesöllen albier andern thaills folgender contract hirmit aufgericht, und beschlossen worden.

Erstlichen verspricht, und verobligirt sich ernenter Thomas Schüffer in der stüfft rheinerischen kürchen, die in prosbyteris zu machen seyende chor stüell mit sonderbahren fleiß, zier, und formlichkheith /: iedoch mit beyschaffung aller darzue nöthigen requisiten:। bis auf die obern außzüg

I Zu solchen Urkunden aus Österreich s. beispielsweise die Verträge des Stiftes St. Lambrecht mit Valentin Kaut von I627, des Stifts Melk mit Michael Joseph Hegenwald von I 702 oder des Stiftes Göttweig mit Paul Troger (I698-г 762) von I 738. ÖKT, Krems (I 907), 45 I; ÖKT, Melk (I 909), г 85-I 86; ÖKT, St. Lambrecht (I95 I), I83. Zu einem I736 in Köln aufgesetzten Vertrag zur Errichtung eines Altars in der zerstörten Zisterzienserkirche St. Maria ad Ortum vgl. Hellwag, Geschichte (1 924), 330.

2 Büscher, Künstlerverträge (2002); O’Malley, Business (2005).

3 In diesem Kapitel werden unter anderem die Klöster Dürnstein, Göttweig, Klosterneuburg, Lambach, Melk und das Wiener Schottenkloster, außerdem St. Veit in Krems und die Deutschordenskirche in Linz erwähnt. Um den Anmerkungsapparat nicht unnötig auszuweiten, sei darauf hingewiesen, dass diese Sakralanlagen im ersten Band der Untersuchung vorgestellt werden. Vgl. hierzu die relevanten Abschnitte in Bohr, Sakralmöbel (2017). 
vollständig zu verfertigen, und anhero zu stellen, also zwar, das in solcher seiner tischler arbeith keine außstellung gemacht werden könne.

Dabingegen andertens verspröchen hochgedacht ibro gnaden herr herr prelath etc. vor obbesagte schen, formlich, und wohlgemachte tischler arbeith, und zwar für ain chorstellen $30 x$, item für ain muschl $30 x r$, tann für ain schildtl auf denen füllungen $12 x r$ und für ein haubt tokhen, sambt dem thürl 4 fl erhalten Thomas Schüffer nebst seiner gewöhnlichen kost in gnaden zu bezablen.

Getreulich, und obne gevärde, auch mit und bey verpindtung des allgemeinen landtschadenpundts in Steyer. Zu wahrer urkbundt dessen seint diser contract zway gleichlauthende aufgerichtet, und iedem [...] contrabirenden thaill einer unter des andern handtschrüft, und fertigung becröftiget worden. Stüft Rhein den 28. April I743 Thomas Schüffrar. ${ }^{4}$

Es ist davon auszugehen, dass sich Placidus Mally und Thomas Schiffer auf den Vertragstext verständigten, nachdem der Abt dem Tischler seine Erwartungen hinsichtlich des Aussehens und der Qualität des Gestühls erläutert hatte. Eventuell hatte der Abt auch eine Skizze zur Hand, um seine Vorstellungen zu veranschaulichen. ${ }^{5}$ Außerdem dürfte er im Gespräch über die Grazer Domkirche und ihre Ausstattung (Abb. I 52, I 57, I 58 ) informiert haben, finden sich etliche formale Lösungen an den dortigen Möbeln doch am Chorgestühl in Rein als Zitate wieder.

Wie üblich werden in der Vertragseinleitung Auftraggeber und Handwerker namentlich genannt, an prominenter Stelle steht außerdem das Datum, unter dem das Schreiben verfasst wurde. Die Formulierung Thomas Schüffer bestelten tischlergesöllen alhier zeugt davon, dass Schiffer eine eigene Werkstatt auf dem Herrschaftsgebiet des Klosters besaß und unter dem Schutz der Abtei stand. Wie ein Hofhandwerker war er damit nicht an die Gesetzgebung der Zünfte gebunden, sondern konnte als Geselle einen eigenen Handwerksbetrieb führen und die Herstellung des Chorgestühls ins Werk setzen. ${ }^{6}$

4 StAR, Lade M/XXXV: Tischler und Tapezierer. Die Quelle wurde bereits auszugsweise veröffentlicht. Gigler, Umbauten (1924), 65 (Quellenanhang). Zur Art der Transkription dieser und anderer Quellen vgl. die Einführung zum Katalogteil.

5 In Italien waren Vertragsskizzen bei der Bestellung eines Gemäldes seit der Mitte des I 5 . Jahrhunderts allgemein gebräuchlich. O'Malley, Business (2005), I97. Ob es eine vergleichbare Vorgehensweise in Österreich gab, ist nicht bekannt.

6 Wolfgang Dobras bezweifelt die These, dass Hofhandwerker grundsätzlich jenseits der Zünfte gestanden hätten. Dobras, Hofhandwerker (2017), 28. Vieles deutet jedoch darauf hin, dass Hofhandwerker von dem engen Korsett, das die Zunftgesetze bürgerlichen Handwerkern anlegten, befreit waren. Im nachfolgenden Kapitel, besonders aber im dritten Band der Untersuchung, der einen umfassenden Beitrag zu Zünften und Zunftordnungen zum Inhalt hat, wird dieser Frage im Hinblick auf österreichische Tischler nachgegangen. $\mathrm{Zu}$ den verschiedenen Rechtsformen, die mit dem Titel des Hofhandwerkers verbunden waren, vgl. Haupt, Hofhandwerk (2007), bes. I $3-26$. 
Der nächste Abschnitt der Urkunde betrifft die genaue Beschreibung der Arbeitsleistung, die Schiffer zu erbringen hatte. Der Auftrag umfasste nicht nur die Tischlerarbeiten, sondern auch den Schnitzzierrat an Dorsale, Brüstung und Außenwangen. Wahrscheinlich führte Schiffer selbst das Schnitzmesser, denn er war einer jener »Handwerker-Künstler«, die in zwei Gewerken bewandert waren. Denkbar wäre jedoch ebenfalls, dass er mit einem Bildschnitzer als »Subunternehmer« zusammenarbeitete oder einen Bildschnitzer in seiner Werkstatt beschäftigte. Der Passus im Vertragstext bis auf die obern außzüg muss so verstanden werden, dass Schiffer den Aufsatz nicht zu fertigen hatte. Die Bekrönung des Möbels könnte also auch schon Inhalt eines Vorgesprächs zwischen dem Handwerker und dem Abt gewesen sein; sie sollte von einem nicht genannten Bildhauer geschaffen werden. In diesem Fall zählte die Wahl des Schnitzers nicht zu den Aufgaben Schiffers, sondern zu jenen Mallys. Beides war aber prinzipiell möglich, wie aus zeitgenössischen Quellen hervorgeht. So wird im Vertrag des Göttweiger Abtes Odilo Piazol (reg. I749-1768) mit dem Tischler Franz Anton Staudinger (I705-I78I) über die Anfertigung eines neuen Chorgestühls für die Göttweiger Stiftskirche dezidiert betont, dass es Staudinger oblag, Tischlergesellen und Bildhauer als Mitarbeiter einzustellen. ${ }^{7}$ Er war der alleinige Ansprechpartner des Abtes und haftete persönlich für eventuelle Mängel am ausgeführten Produkt.

Die von Placidus Mally im Vertrag verwendeten Formeln mit sonderbahren fleiß, zier, und formlichkheith oder vor obbesagte schen, formlich, und wohlgemachte tischler arbeith offenbaren den hohen Anspruch des Abtes an die Arbeit seines Handwerkers. Andere Auftraggeber verwiesen auf Modelle, Risse oder bereits fertiggestellte Möbel, um ihre Forderung nach guter handwerklicher und ästhetischer Qualität zu unterstreichen. ${ }^{8}$

Schiffers Kontrakt ist weiterhin zu entnehmen, dass der Tischler das nötige Werkmaterial für den Bau des Gestühls bereitzustellen hatte, womit es in seinen Aufgabenbereich fiel, für geeignetes Holz zu sorgen. Für eventuelle Trocknungsschäden wäre er also haftbar gemacht worden. Um keine Zweifel an der Frage aufkommen zu lassen, wer gegebenenfalls für solche Schäden die Verantwortung zu übernehmen hätte, findet sich in Verträgen häufig der Zusatz, die Tischlerarbeit müsse mit ausreichend abgelagertem Holz ausgeführt werden, eine Forderung, die die Handwerker ohne vertragliche Vereinbarungen keineswegs immer erfüllten. ${ }^{9}$ Manchmal bestanden Auftraggeber deshalb auf einer zeitlich begrenzten Gewährleistung, wie ein Vertrag dokumentiert,

7 Der Kontrakt datiert vom Io. Dezember I764. StAGö, K-G/L. 8, Staudiger Umschlag »Chorgestühl«. Vgl. dazu einen Vertrag mit ähnlichen Formulierungen aus den I66oer-Jahren bei Koller, Entwurf ( 1998 ), 42 .

8 Vgl. etwa Penz, Kalendernotizen (2013), 25 I sowie das folgende Kapitel über Modelle und Entwürfe.

9 Der Zusatz findet sich beispielsweise im Vertrag über den Bau der Möbel für die Melker Sommersakristei. ÖKT, Melk ( 1909$)$, i 85 . 
den die Abtei Rein 1767 mit dem Tischler Johannes Kerner aushandelte. Der aus Graz stammende Handwerker verpflichtete sich, handwerkliche Mängel, die innerhalb eines Jahres an seinen Arbeiten auftreten würden, unentgeltlich zu beseitigen. ${ }^{10}$ Vor welche Schwierigkeiten sich Tischler zumindest in den Städten bei der Beschaffung geeigneten Holzes gestellt sahen, wurde bereits im ersten Band der Untersuchung thematisiert. In Zünften organisierte Holzhändler hatten das Monopol auf die Lagerung und den Verkauf des auf dem Wasser- und Landweg herbeigeschafften Holzes. Alte Stadtansichten zeigen es zu großen Stapeln aufgeschichtet an den Flussufern, während die Handwerker selbst aufgrund rechtlicher Bestimmungen bei ihrer Werkstatt normalerweise nur kleine Holzvorräte deponieren durften. ${ }^{11}$ Die Innungen der Tischler überwachten den Handel und teilten den Handwerkern bestimmte Tranchen zu. Kein Tischler sollte größere Holzmengen als seine Kollegen erhalten, keiner benachteiligt werden. Hilfreich war im Hinblick auf die Besorgung des Werkmaterials der Umstand, dass viele Abteien ausgedehnte Forstreviere und eigene Sägemühlen besaßen, zudem verfügten sie über weitreichende Netzwerke, die bei der Suche und dem Erwerb der gewünschten Materialien behilflich waren. Das Kloster Lambach etwa stellte das für den Bau von Sakristeimöbeln benötigte Fichtenholz zur Verfügung, während das Stift Dürnstein für die Herstellung neuer Möbel nicht nur das Blindholz, sondern auch die erforderlichen Furniere lieferte. Für die Fertigung des Klosterneuburger Chorgestühls wurde Holz von verschiedener Seite angekauft: vom Wiener Tischlermeister Leopold Morder, einem der wenigen Handwerker, denen die Einlagerung größerer Holzmengen gestattet war, von einem Händler namens Matthias Röschak sowie von nicht näher bezeichneten Bezugsquellen in Korneuburg, Steyr und Grein. Und die Grazer Jesuitenkommunität erwarb zum Bau der Möbel für ihre Stiftskirche Nussholz in Weiz sowie Olivenholz in Triest und Laibach. Wir werden im entsprechenden Abschnitt der Arbeit darauf zurückkommen.

Der Auflistung von Schiffers Pflichten folgen im Vertragstext die Obliegenheiten des Konvents. Zunächst wird die Höhe des Lohns fixiert. Abt Placidus versprach dem Tischler für jede Chorstalle und jede an der Rückwand angebrachte Muschel $30 \mathrm{kr}$, für die Spiegel auf den Füllungen I 2 kr, für Außenwangen und Türen jeweils 4 f. ${ }^{12}$ Mally und Schiffer haben also schon vor Arbeitsbeginn den Preis für das Werk ausgehandelt, sonst wurden solche Verhandlungen oft erst nach Beendigung der Arbeiten geführt.

Io StAR, Lade M/XXXV (Tischler), I 2. April I767.

I I Bohr, Sakralmöbel (20 I 7), 43-44.

I 2 60 Kreuzer entsprachen einem Gulden. Der Göttweiger Hoftischler Heinrich Johann Holdermann (I697-I 739) erhielt in den I730er-Jahren einen Tageslohn von $30 \mathrm{kr}$, je nach der Anzahl der arbeitsfreien Festtage wöchentlich etwa zweieinhalb bis drei $f$, darüber hinaus verrechnete er noch bestimmte Leistungen. Bohr, Handwerkersaläre (201 I), 35 2-357. 
Der Preis richtete sich dann nach der von Sachverständigen beurteilten Qualität des Produkts, wobei die Handwerker auf die Objektivität der Gutachter und die Großzügigkeit der Auftraggeber vertrauten. ${ }^{13}$ Zusätzlich zum Lohn in barer Münze erhielt Schiffer die tägliche Verpflegung, die aus relativ einfachen Gerichten bestand, also aus jenen Speisen, mit denen "gewöhnliche« Angestellte in Rein Vorlieb zu nehmen hatten. Es war folglich nicht die bessere Offizierskost, die höher gestellten Konventangehörigen, oft auch Handwerksmeistern, zustand. Einen aus heutiger Sicht wichtigen Punkt spart der Vertrag mit Schiffer freilich aus. Er betrifft eine genaue Vereinbarung über die Zahlungsmodalitäten, wobei solche Abmachungen in Vertragstexten tatsächlich eher selten gewesen zu sein scheinen. Ein Gegenbeispiel bietet ein entsprechender Absatz im Kontrakt, den der Stadtrat von Krems mit Bildhauer Joseph Matthias Götz (г696-г760) г 735 über den Bau des Gestühls für die dortige Pfarrkirche abschloss. Die Stadtoberhäupter verpflichteten sich zur Auszahlung von $900 \mathrm{fl}$, und zwar also gleich bey schlüßung gegenwärtigen contracts $200 \mathrm{f}$, dan bey aufsezung derselben [Stallen] $400 \mathrm{Al}$ und den überrest längstens bis ende angeregten 173 ten jabrs [... ${ }^{14}$

In Rein diente als Bestätigung der beiderseitigen Anerkennung des Vertragstextes durch Abt Mally und Thomas Schiffer der formelhafte Hinweis auf den »Landschadenbund « ${ }^{15}$, andere Verträge verweisen an dieser Stelle auf einen »Leihkauf «, eine Art von Anzahlung, die auch als Bekräftigung eines Vertrages verstanden wurde. Der Text endet mit dem Datum der Vertragsunterzeichnung und der Übereinkunft, dass jede der beiden Vertragsparteien eine unterschriebene Ausfertigung erhalten würde.

Über weitere Parameter, die in Urkunden oft $\mathrm{zu}$ finden sind, schweigt sich das Schreiben des Abtes aus: So fehlt der Hinweis auf die Anzahl der benötigten Stallen, ungewöhnlich ist überdies die Tatsache, dass dem Tischler keine zeitliche Frist gesetzt wurde, innerhalb der er das Gestühl zu liefern hatte. Wie eingangs vermutet, ging dem Vertrag wahrscheinlich eine mündlich geschlossene Abmachung voraus. Sie wird diese Punkte geregelt und per Handschlag Rechtskraft erlangt haben. Zudem verzichtete Abt Placidus auf die explizite Androhung einer Vertragsstrafe, die bei einer Zuwiderhandlung bzw. Nichteinhaltung der Abmachungen durch Schiffer fällig geworden wäre. Andere Kontrakte informieren darüber, dass in solch einem Fall der "Leihkauf « zu erstatten wäre, manchmal wird auch die Höhe einer möglichen Strafe präzise beziffert. ${ }^{16}$

I3 Ders., Sakralmöbel (20I7), 44-45. In Italien war das in der Frühen Neuzeit nicht anders. Cavazzini, Patto fermo (2010), 6; Sicca, Sculture (2010), 56.

I4 Stadtarchiv Krems, Ingedenkbuch der K.K.L.F. Staedte Krems und Stein, Bd. 8 ( I 730-1760), 76-77.

I5 Vgl. hierzu den bezüglichen Beitrag im Deutschen Rechtswörterbuch unter http://www.deutschesrechtswoerterbuch.de/ueber.htm [Zugriff Juni 2020].

I6 Penz, Kalendernotizen (2013), 25 I. Im Vertrag des Göttweiger Abtes Odilo Piazol (reg. I749-1768) mit dem Tischler Franz Anton Staudinger (1705-I78I) vom ro. Dezember I764 über die Anfertigung des 
Dennoch fühlten sich frühneuzeitliche Handwerker zur Einhaltung festgesetzter Fristen bei weitem nicht immer verpflichtet. So nennt der Vertrag über die Herstellung des Gestühls für St. Veit in Krems als gefordertes Lieferdatum den I 5. Juni I736, den Gedenktag des Kirchenheiligen, gleichwohl war der Tischler noch im Juli jenes Jahres mit dem Bau des Möbels beschäftigt. Um ein weiteres Beispiel anzufügen: Bei der Barockisierung des Wiener Schottenstiftes lieferte der Kunstschlosser Peter von Schärenstein die ihm übertragenen Arbeiten verschiedentlich mit erheblichem Zeitverzug. Problematisch wurde sein Verhalten, als er die Schlösser für die Kirchenportale nicht termingerecht fertigstellte. Als Folge davon konnte die Kirche nicht zum anvisierten Termin konsekriert werden, außerdem musste über Wochen hinweg ein Wachdienst den unverschlossenen Bau sichern. Und auch von den Wiener Schlossern war keine Hilfe zu erwarten, denn sie fühlten sich durch die frühere Auftragsvergabe an einen ortsfremden Meister offendiert. ${ }^{17}$

Nach unserem Kenntnisstand ist es fraglich, ob Vertragsstrafen bei der Übertretung zeitlicher Grenzen überhaupt verhängt wurden. Im deutschen Sprachraum war das zumindest im r 6. Jahrhundert vermutlich nicht der Fall, Ähnliches lässt sich von Rom berichten, wo Handwerker und Künstler im Seicento zugesagte Termine offenbar nur ausnahmsweise einhielten. ${ }^{18}$ Allerdings hatte der Kunde dann das Recht, den Auftrag anderweitig zu vergeben, wobei eine eventuelle Anzahlung zu restituieren war. Wie wir gesehen haben, gab es jedoch keinerlei Garantie dafür, schnellen Ersatz für den säumigen Handwerker zu finden.

Schließlich wird die Oberflächenbehandlung, die der Abt von Rein für sein Gestühl wünschte, im Schreiben mit keinem Wort erwähnt. Andere Kontrakte gehen auch auf diese Frage ein, etwa der des Melker Abtes Berthold Dietmayr (reg. I 70o-I 739) mit dem Wiener Tischler Franz Andreas Bogner (um r663-I 7 r4) über die Herstellung der Möbel für die Sommersakristei des Benediktinerstiftes. Das Schriftstück hält fest, dass Bogner die Möbel mit gutem Firnis anzustreichen hätte. ${ }^{19}$ Dagegen bekundet der sich auf das Laiengestühl in der Deutschordenskirche zu Linz beziehende Vertrag des Salzburger Erzbischofs Franz Anton Fürst von Harrach (1665-1727) mit Wolfgang Rachinger von I72I, dass die Möbel nicht gefirnisst, sondern lediglich mit Wachs poliert werden sollten. ${ }^{20}$

neuen Chorgestühls für die Stiftskirche wird eine Vertragsstrafe in Höhe von 50 fl festgelegt. StAGö, K-G/L. 8, Staudiger Umschlag »Chorgestühl«.

I7 Hübl, Baugeschichte (I 914), 67.

I8 Huth, Künstler (1923), 28; Cavazzini, Patto fermo (2010), 6.

I9 ÖKT, Melk (1909), I 85 .

20 DOZA, BÖ, Karton 136, fol. 28or-28 rv. Weitere Verträge finden sich in den Abschnitten zu den Abteien Rein und St. Lambrecht. 


\section{Allgemeines Zu Handwerker- und Künstlerverträgen}

Der Vertrag zwischen Abt Placidus Mally und seinem Tischlergesellen Thomas Schiffer ist relativ kurz. Trotzdem zeigt er beispielhaft, wie solche Abmachungen formal aufgebaut waren und welchen Inhalt sie besaßen. Da es in diesen Verträgen von Natur aus um Auftragsarbeiten mit vergleichbaren Anliegen ging, überrascht es nicht, dass sich die Form der österreichischen Handwerker- und Künstlerverträge kaum von spätgotischen deutschen sowie renaissancezeitlichen oder barocken Verträgen aus Italien unterschied $^{21}$ - abgesehen von der Tatsache, dass die Vertragsparteien im Süden ihre Urkunden meist notariell beglaubigen ließen, während es sich bei den hier untersuchten Schriftstücken um Verträge handelt, die ohne juristischen Beistand aufgesetzt und unterzeichnet wurden. Darüber hinaus vertrauten Auftraggeber und Künstler in Italien die unterschriebenen Originale oft Notaren zur Archivierung an, die Vertragspartner erhielten lediglich Abschriften. ${ }^{22}$ Bei uns wurden die Originalverträge dagegen in den Archiven von Kirchen und Klöstern bzw. von den Handwerkern selbst aufbewahrt.

Inhaltlich bezieht sich eine Vielzahl der veröffentlichten italienischen Verträge auf das Malen von Bildern oder das Schnitzen von Skulpturen, während die für die vorliegende Studie herangezogenen österreichischen Urkunden im Zusammenhang mit der Herstellung von Kirchenmöbeln ausgefertigt wurden. Vorbedingung für die Verträge war der direkte Dialog zwischen Handwerkern und Auftraggebern, die Urkunden basierten auf der Grundlage mündlicher Absprachen und gegenseitigen Vertrauens.

Kunsthistoriker und Juristen diskutieren in Bezug auf italienische Urkunden seit langem die Frage, wie solche Verträge rechtlich zu bewerten seien. Ging es den Auftraggebern in erster Linie um den Erwerb eines bestimmten Produkts für einen determinierten Zweck oder standen die Arbeitsleistung eines berühmten Künstlers und der Besitz eines seiner Werke im Vordergrund ${ }^{23}$ Im Zusammenhang mit der Produktion von Kirchenmobiliar müssen wir beide Interpretationsmöglichkeiten in Betracht ziehen: Wenn der Dürnsteiner Propst Hieronymus Übelbacher (reg. I710-I740) einen anonymen Tischler aus der näheren Umgebung des ehemaligen Chorherrenstiftes mit dem Bau einfacher Sakristeimöbel beauftragte, wird er von der Notwendigkeit geleitet worden sein, den Raum mit Behältnismöbeln einzurichten. Wählte er jedoch gezielt Hippolyt Nallenburg ( $1687^{-1}$ 733) aus St. Pölten für die Fertigung eines prachtvollen neuen Chorgestühls für seine Stiftskirche, so ist von der zweiten Variante auszuge-

2 I Zu spätmittelalterlichen Verträgen vgl. Huth, Künstler (r 923), bes. 23-30.

22 Glasser, Artist's contracts (I 965), 2 I-59; Büscher, Künstlerverträge (2002), 48-7I ; O’Malley, Business (2005), 3 ; Giometti, Formule (2010), 37 .

23 Wackernagel, Lebensraum (1938), 256; Glasser, ebd., 6-7; Büscher, ebd., 74-77. 
hen: Der Propst begnügte sich nicht mit der Aufstellung beliebiger Stallen, sondern wünschte ein spezielles Produkt von einem ganz bestimmten Tischler. Das Gleiche gilt für die Vereinbarung zwischen Abt Dietmayr und dem Wiener Hoftischler Bogner über den Bau der Möbel für die Melker Sommersakristei, für den Vertrag zwischen dem Salzburger Fürsterzbischof mit Wolfgang Rachinger aus Linz über die Herstellung der Kirchenbänke für die Deutschordenskirche und in vielen anderen Fällen. Diese Vorgehensweise muss als deutliches Indiz für die hohe Wertschätzung geistlicher Auftraggeber und weltlicher Mäzene namhaften Handwerkern gegenüber gedeutet werden. 
II.

\section{Handwerker und Kunsthandwerker}

\section{Arbeitsgemeinschaften der Handwerker}

Experten gehen davon aus, dass Arbeitsaufträge bei Baumaßnahmen im sakralen Bereich häufig an Handwerker- und Künstlergemeinschaften ergingen, die von einem Baumeister geleitet wurden. ${ }^{24}$ Einer dieser Baumeister war Jakob Prandtauer (I 660-I 726). Er stammte ursprünglich aus Tirol, fand vor der Jahrhundertwende aber in Niederösterreich eine neue Heimat. Bei Um- und Neubauten, die er in St. Pölten, Dürnstein, Melk und andernorts leitete, vergab er wiederholt Aufträge an bestimmte Bildhauer und Bauhandwerker, zu denen auch Kunsttischler zählten. ${ }^{25}$ Allerdings besaßen viele Ordenskommunitäten eigene Tischlereien, die verständlicherweise als erste zur Verrichtung notwendiger Arbeiten herangezogen wurden. Andernfalls wandten sich die Konvente an Betriebe in der näheren Umgebung, was sich schon aus Gründen der Arbeitsökonomie und zur Vermeidung hoher Transportkosten anbot. Fremde Tischler erhielten lediglich dann den Vorzug, wenn die Stiftsbetriebe ausgelastet und die Handwerker aus der Nachbarschaft nicht imstande waren, die anspruchsvollen Wünsche ihrer Kunden zu erfüllen. Es versteht sich von selbst, dass man bei der Ausstattung von Weltkirchen ebenfalls jene Handwerksbetriebe favorisiert haben wird, deren Meister man persönlich kannte. ${ }^{26}$ Daher lässt sich als Beleg für die in der Fachliteratur aufgestellte These in Verbindung mit der vorliegenden Studie nur der Tischler Hippolyt Nallenburg (1687-I733) anführen, der maßgeblichen Anteil an der Ausstattung der ehemaligen Augustiner-Chorherrenstifte in St. Pölten und Dürnstein hatte. Da er aber auch für das frühere Augustiner-Chorherrenstift St. Dorothea in Wien Möbel fertigte, stellt sich die Frage, ob seine Bestallung wirklich auf Betreiben Prandtauers hin erfolgte.

24 Das und die folgenden Angaben aus Schemper-Sparholz, Barockbildhauer (1992), 331-332. In diesem Abschnitt der Arbeit werden unter anderem das Schottenkloster und St. Dorothea in Wien, die Domkirche in St. Pölten sowie das ehemalige Stift Dürnstein, weiter die Abteien Göttweig, Klosterneuburg, Lilienfeld, Melk, St. Florian, Wilhering und Zwettl erwähnt. Diese Sakralanlagen werden bereits im ersten Band der Untersuchung vorgestellt. Bohr, Sakralmöbel (2017).

${ }_{2} \mathrm{Zu}$ Arbeitsgemeinschaften von Bildhauern, Tischlern und Malern in Kärnten s. Neubauer-Kienzl/ Deuer/Mahlknecht, Barock (2000), i 9-25.

26 Neubauer-Kienzl/Deuer/Mahlknecht, ebd., 20, 24, haben diese Vorgehensweise für Kärnten nachgewiesen. 
Eine entsprechende Empfehlung könnte ebenso Matthias Steinl (I643/44-I 727 ) unterbreitet haben, der in mehreren Professionen bewandert und in den drei Stiften zumindest mit beratender Funktion tätig war. Schließlich scheint denkbar, dass der Name Nallenburgs auf direktem Wege innerhalb des Ordens weitergereicht wurde.

Viele Zünfte im deutschsprachigen Raum untersagten den Handwerksmeistern die gleichzeitge Beschäftigung von mehr als zwei Gesellen und zwei Lehrlingen. Ausnahmen von dieser Anordnung wurden akzeptiert, wenn Handwerker Aufträge für den hohen Klerus und den Adel ausführten oder im Besitze des begehrten Titels eines Hof- bzw. hofbefreiten Handwerkers waren. ${ }^{27}$ So stand der Hoftischler Gregor

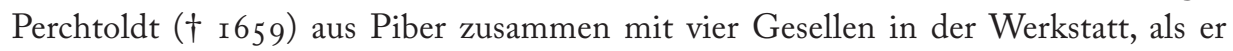
die Sakristeieinrichtung des Stiftes St. Lambrecht (Abb. 263-269) fertigte. In der Stiftstischlerei zu Stams waren im frühen I8. Jahrhundert zwölf Angestellte beschäftigt, in der Göttweiger nicht weniger als $15 .{ }^{28}$ Und 1764 errichtete der aus Wien gebürtige Hofschreiner Franz Anton Herrmann (I7 I I-I770) mit etwa I5 Gesellen in Frankfurt eine Ehrenpforte zur Krönung Josephs II. (I74I-I790), zugleich baute er an einem Chorgestühl für den Mainzer Dom. ${ }^{29}$ Während in der Frühen Neuzeit zünftige Tischlereien, in denen der Meister mit drei oder vier Mitarbeitern an der Hobelbank stand, zu den größeren Werkstätten zählten ${ }^{30}$, erzwangen im sakralen Ambiente die Menge und die schiere Größe des benötigten Kirchenmobiliars eine Zusammenarbeit mehrerer Handwerker. ${ }^{31}$ Mit der Herstellung der Bänke für die Wiener Schottenkirche wurden deshalb I7 I7 Jacob Kuontz und Jakob Müller (г664-I746) verpflichtet, denen man eine Frist von sechs Monaten zur Ausführung des Auftrags gewährte.

${ }_{27}$ Zum Hof- und hofbefreiten Handwerk s. bes. Haupt, Hofhandwerk (2007), bes. I3-164; Rescher, Jurisdiktion (2017). Zum Vergleich mit der Situation in anderen Städten des Römischen Reiches s. die relevanten Beiträge in Tacke/Fachbach/Müller, Hofkünstler (2017).

$28 \mathrm{Zu}$ Stams vgl. den entsprechenden Abschnitt im Katalog, zu Göttweig s. Ritter, Regesten [o. J.], RR I72 I, Nr. I40, I4I, I 43; RR I722, I78; Ritter, Forschungsergebnisse (I 961), 71 ; Ritter, Bauherr (I 972), I 24.

29 Dobras, Hofhandwerker (2017), 33. Zu Herrmann vgl. Wolf, Identifikation (r 988), 77-83; Zinnkann, Meisterstücke (1988), bes. 49-5 2 .

30 In den I640er-Jahren wurden in Innsbruck zehn Tischlereien mit insgesamt sieben Gesellen und sechs Lehrlingen gezählt, in Salzburg elf Tischlermeister mit sieben Gesellen, vier Lehrlingen und einem Meistersohn. Einmannbetriebe gehörten in vorindustriellen Städten zur Normalität, Werkstätten mit zwei oder drei Gehilfen waren die Ausnahme. Mathis, Bevölkerungsstruktur (I977), 20, 77, I75, 2 I 4, 26r. Das entspricht etwa der Größe Augsburger und Ingolstädter Werkstätten in jener Periode. Bergemann, Meisterrisse (I999), 48-5 I ; Loescher, Kistlerhandwerk (2000), 56 6-58.

3I Ähnliches galt ebenfalls für Maurerbetriebe. I 722 soll der in der Zunft der Maurer inkorporierte Architekt Johann Georg Stengg (I689-I 753) 45 Gesellen beschäftigt haben. Rust, Stengg (2009), 226. Und beim Bau von St. Veit in Pöllau wurden zusammen mit zwei Polieren im Durchschnitt 20 Gesellen, zwei Lehrjungen und bis zu 70 Tagelöhner beschäftigt. Vgl. zu Pöllau das Kapitel im vorliegenden Buch. 
Entsprechend ging der Konvent des Klosters Melk beim Bau des Gestühls für seine Stiftskirche vor. Verantwortlich waren die Tischler Augustin Keller (г680-I748) und Ferdinand Kreuzer (1692-1767), die die Möbel I736/37 mit je zwei Gesellen fertigten. ${ }^{32}$ Für den Schnitzzierrat war der Bildhauer Johann Georg Äxenmacher ( $\dagger$ I 763 ) zuständig, in dessen Atelier sicher ebenfalls mehrere Gesellen ihren Lebensunterhalt verdienten. Wir wissen nicht, ob Keller, Kreuzer und Äxenmacher jeweils eine eigene Werkstatt unterhielten oder eine Ateliergemeinschaft leiteten. ${ }^{33}$ Solch eine Gemeinschaft hätte zwar dem Geist der Zunftordnungen widersprochen, die für jede Werkstatt nur einen Meister vorsahen, dürfte aber dennoch vorgekommen sein, weil sich durch die Bildung von Sozietäten Kosten senken und Risiken beim Ausbleiben von Aufträgen oder bei einem Zahlungsverzug der Auftraggeber reduzieren ließen. Letzteres war in der vorbürgerlichen Epoche gang und gäbe. ${ }^{34}$ Neben langlebigen Gemeinschaften bildeten sich wahrscheinlich auch temporäre Werkstattgemeinschaften, die zur Ausführung eines besonders arbeits- und zeitintensiven Auftrags zustande kamen. ${ }^{35}$ Leider ist es in der Regel nicht möglich, eine überzeugende Händescheidung zwischen den in den Verträgen genannten Meistern und ihren Mitarbeitern vorzunehmen. ${ }^{36}$ Innerhalb der Betriebe war die Zusammenarbeit unter den Handwerkern so eng, dass die Identifizierung einzelner Persönlichkeiten anhand stilistischer Merkmale kaum zu bewerkstelligen ist. Als Gegenbeispiel mag auf das Chorgestühl von Dürnstein verwiesen werden. ${ }^{37}$ Die Herstellung der Tischlerarbeiten lag in der Obhut des bereits erwähnten Hippolyt Nallenburg, die Erzeugung der Reliefs in der des Bildhauers Johann Schmidt (I684-I76r). Die divergierende Qualität der Darstellungen ist nicht zu übersehen, weshalb davon auszugehen ist, dass einige Reliefs aus der Hand eines Mitarbeiters Schmidts stammen. Wer dieser Mitarbeiter gewesen sein könnte, entzieht sich allerdings unserer Kenntnis. Aus Abrechnungen mit Schmidt geht außerdem hervor, dass ein Geselle den Ornamentzierrat schnitt, doch kann auch dessen Name aus den relevanten Schriftquellen nicht erschlossen werden. ${ }^{38}$ Sicher dürfte in-

$32 \mathrm{Zu}$ Keller und Kreuzer vgl. https://data.matricula-online.eu/de/oesterreich/st-poelten/melk; Trauungsund Sterbebuch 02,3-03, Tod_or 54 bzw. Tod_0364 [Zugriff Juni 2020].

33 Ähnliche Arbeitsformen lassen sich bereits im I 5 . Jahrhundert in Italien nachweisen. Borsook, Business (1983), I 44 .

34 Sangl, Hofschreinerhandwerk (I 990), 80-82; Bohr, Sakralmöbel (201 7), 46.

35 Das wurde für Frankreich untersucht. Scott, Interior (I 995), I6-1 9.

36 Das gilt für Tischlerwerkstätten und Bildhauerateliers gleichermaßen. Schemper-Sparholz, Barockbildhauer (1992), 333 .

37 Bohr, Sakralmöbel (2017), 273-277. Ein weiteres Gegenbeispiel liegt mutmaßlich in Möbeln in der Pfarr- und ehemaligen Domkirche zu Gurk vor (Abb. 34-37).

38 Penz, Kalendernotizen (2013), 252-253, 265, 267. 
des sein, dass Ateliers und Werkstätten, die bedeutende Aufträge zur Ausstattung von Sakralräumen übernahmen, arbeitsteilig organisiert waren.

In Verbindung mit Dürnstein muss noch auf ein weiteres Detail aufmerksam gemacht werden: Am 7. März I725 schloss Propst Hieronymus Übelbacher (reg. I 7 IO-I 740) einen Vertrag mit Hippolyt Nallenburg über den Bau der Beichtstühle für die Stiftskirche. Der Tischler hatte drei Möbel bis zum 24. Juni I 725 fertigzustellen, zwei weitere bis zum 28. August jenes Jahres. Der Kontrakt mit dem Bildschnitzer Johann Schmidt über die Anfertigung der Aufsatzfiguren folgte über zwei Jahre danach, am 25. November I 727, vergoldet wurden die Schnitzarbeiten gar erst I 729. ${ }^{39}$ Demnach standen die Möbel jahrelang fast im Rohzustand unter der Westempore, eine Vorgehensweise, die keineswegs unüblich war. Aus finanziellen Gründen verschob man nicht selten die Fertigstellung eines Kunstobjekts oder einer handwerklichen Arbeit. ${ }^{40}$ Ähnliches lässt sich von den Sakristeimöbeln in der Domkirche zu Graz (Abb. I65) berichten. Die Möbel wurden um I720/23 aufgestellt, die skulptierten Bekrönungen jedoch erst I746/47 geliefert. Dabei deuten die bezüglichen Archivalien nicht darauf hin, dass die heute vorhandenen Schnitzarbeiten ältere Aufsätze ersetzt hätten. Vielmehr endeten die Möbel vermutlich ursprünglich auf traditionelle Weise mit einem geraden Gebälkabschluss.

\section{Zusammenarbeit von Tischlern mit anderen Gewerken}

In der Frühen Neuzeit legten die Zünfte präzise fest, welche Arbeiten von Tischlern, welche von Bildhauern und welche von anderen Gewerken erzeugt werden durften. Dennoch blieben Graubereiche, über die immer wieder aufs Neue vor Gericht gestritten wurde. ${ }^{41}$ Zudem waren die Zunftordnungen in vielen Regionen ähnlich, aber nicht einheitlich, mitunter wichen sie sogar in wichtigen Details voneinander ab. Was in manchen Gegenden des Alten Reichs verpönt war, wurde andernorts geduldet oder sogar ausdrücklich gestattet.

\section{Bildhauer}

Im I7. und I 8. Jahrhundert nahmen Bildschnitzer zwischen Handwerk und freier Kunst gesellschaftlich einen Rang ein, der nur schwer zu verorten ist. Falls sie sich

39 Penz, ebd., 327, 366, 375-377; allgemein zu den Beichtstühlen vgl. Bohr, Sakralmöbel (201 7), 279-282. 40 Wolfgang, Stams (2008), 26.

4I Hellwag, Geschichte (1924), bes. 44-88; Sangl, Hofschreinerhandwerk (1990), 50-54; Bergemann, Meisterrisse (1999), 52-55. 
nicht unter die Fittiche eines Klosters begaben oder eine Hoffreiheit erwarben, mussten sie mancherorts einer Zunft beitreten. Da die Zahl der Bildschnitzer relativ gering war, bildeten sie keine eigenen Berufsverbände, sondern schlossen sich bereits bestehenden Organisationen an. In Betracht kamen vor allem die Zünfte der Steinmetze, Maler, Drechsler oder Schreiner. ${ }^{42}$ Wie andere Handwerker konnten inkorporierte Bildschnitzer zwei Gesellen beschäftigen und gleichzeitig einen oder zwei Lehrlinge ausbilden. Zwar durften die Verbandsmitglieder den Zunftbestimmungen zufolge nur selten mehrere Berufe ausüben, doch zeugen häufige Rechtsstreitigkeiten davon, dass sich entsprechende Verbote im Falle der holzverarbeitenden Gewerke kaum durchsetzen ließen. Viele Tischler besaßen eine Doppelausbildung und waren zugleich als Bildschnitzer tätig, wie beispielsweise für Franz Anton Herrmann nachgewiesen werden konnte. Er stattete im Auftrag des Mainzer Kurfürsten in den I 740er-, 5oerund 6oer-Jahren Kirchen mit Altären und Sakralmöbeln aus. ${ }^{43}$ In Verbindung mit der vorliegenden Studie begegnen uns Christoph Paumgartner, der Konverse Mauritus Tauffer und Thomas Schiffer, die in Diensten der Stifte St. Lambrecht und Rein standen und in beiden Berufen arbeiteten. Welche Schwierigkeiten die Zeitgenossen damit hatten, die Gewerke gegeneinander abzugrenzen, zeigt der Umstand, dass Emporenbrüstungen, die Schiffer für Rein hergestellt hatte, in den I740er-Jahren in einem Schreiben des Konvents als Tischlerarbeit, in einem anderen als Bildthauerarbeit bezeichnet werden. ${ }^{44}$ Ein weiterer der in beiden Professionen geschulten Meister war Ludwig Kögel (I7ro/II-I74I). Geboren in Kirchberg an der Pielach (Niederösterreich) und ausgebildet als Bildhauer und Tischler, legte er I 739 als Laienbruder in Lilienfeld die Profess ab, nachdem er sich an verschiedenen Adelshöfen als Kunsttischler einen Namen gemacht hatte. ${ }^{45}$ Ferner sei auf Balthasar Reißmayer hingewiesen, der an der Ausführung des Chorgestühls für die Stiftskirche Klosterneuburg beteiligt war. Archivalien zufolge erhielt er als Tischler und Bildhauer einen höheren Lohn als seine Kollegen. ${ }^{46}$ Schließlich muss an Joseph Baumeister (erw. I697-I72 I) aus Wien erinnert werden, den Schriftquellen seit I 697 zunächst als Tischler, nach I 707 aber als Bildhauer führen. ${ }^{47}$

42 Hierzu etwa Kienzl, Bildhauer ( 1996 ), bes. 50-52; Schweikert, Brenck (2002), 53-55; Stainer, Bildhauerzeichnung (2018), bes. 46-54.

43 Wolf, Identifikation (1988), 78 ; Zinnkann, Meisterstücke (I 988), 5 0-5 r.

44 Gigler, Umbauten (1924), 31, 66 (jeweils Quellenanhang).

45 Oettinger/Matschik/Fitz, Lilienfeld (I 952), 2 I , 23; Mussbacher, Lilienfeld (1976), I4; Müller, Profeßbuch (1996), 280, Nr. I 552.

46 Bohr, Sakralmöbel (2017), 362.

47 Wagner, Regesten (20I4), ad vocem. 
In verschiedenen Städten durfte sich ein Bildschnitzer erst dann als Tischler betätigen, wenn er die Meisterprüfung der Tischlerzunft abgelegt und damit seine handwerklichen Fähigkeiten unter Beweis gestellt hatte. So konnte ein Meister wie Georg Brenck d.Ä. (I564/65-r635) im mittelfränkischen Bad Windsheim als zünftiger Handwerker eine Schreinerei betreiben, ja sogar ein wichtiges Amt in der Schreinerzunft innehaben, und dennoch als Bildschnitzer sein tägliches Brot verdienen. Eine Ausbildung in beiden Berufen erhielten auch seine Lehrlinge, was allerdings für Unmut bei den Zunftmeistern gesorgt zu haben scheint. ${ }^{48}$

Obwohl also viele Tischler in der Schnitzkunst bewandert waren, dürften sie sich in der Regel doch spezialisiert und nur zur Bewerkstelligung einfacher Arbeiten selbst zum Schnitzmesser gegriffen haben. Aufwendigere Stücke gaben sie zur Weiterbearbeitung an versierte Bildschnitzer $\mathrm{ab}^{49}$, Archivalien bekunden diesen Vorgang: So baute r 743 der in Furth ansässige Tischler Franz Anton Staudinger (I705-I78I) für die Abtei Göttweig einen Prunkspiegel, den er durch den Bildhauer Johann Schmidt mit Schnitzarbeiten dekorieren ließ. Und I 765 schuf der Tischler im Auftrag des niederösterreichischen Klosters einen Tisch für das Reliquiar des hl. Altmann, den ein Bildschnitzer vollendete; wahrscheinlich handelte es sich um Anton Caccon (I742I8I I). ${ }^{50}$ Während sich am Tisch die Arbeiten Staudingers und die des Bildschnitzers deutlich voneinander scheiden lassen, zählen andere Ausstattungsobjekte wie der Göttweiger Spiegel, die Beichtstühle im Stift Wilhering oder das Chorgestühl in Baumgartenberg zu jenen Bildhauermöbeln, bei denen der Schnitzzierrat nicht mehr reiner Dekor ist, sondern die vom Tischler geschaffene Struktur der Möbel fast vollständig überzieht. Die Grenzen zwischen den beiden Kunstgattungen verschwimmen dort völlig. Ein weiteres Beispiel für solche Inventarstücke liefern die Beichtstühle in Vomp-Fiecht (Abb. 343-346), die Franz Xaver Nissl (I73 I-I804) zugeschrieben werden. Nissl schuf die Bildhauerarbeiten und wahrscheinlich auch die Entwürfe zu den Möbeln, die jedoch wahrscheinlich nicht in seinem Atelier, sondern in der Werkstatt externer Meister entstanden. ${ }^{51}$ Die Arbeitsorganisation Nissls entsprach somit der des Admonter Stiftsbildhauers Josef Stammel (г695-1765), der Risse für Altäre und andere Ausstattungsstücke zeichnete, während er die jeweiligen Tischlerarbeiten von selbständigen Handwerkern ausführen ließ. ${ }^{52}$ In der relevanten Fachliteratur wird

48 Schweikert, Brenck (2002), 53-57.

49 S. hierzu auch Bergemann, Meisterrisse (1999), 54.

50 Zum Stift Göttweig s. Lechner, Göttweig (2000), 805; Bohr, Handwerkersaläre (20 I I), 349-35 2. Allgemein zu Caccon vgl. Harhammer, Barocke Holzskulptur (i 988), bes. 255-267.

5 I Hölzl, Nissl (I 976), г 9-20, 36.

52 Schweigert, Barockbildhauer (2004), 40. 
vermutet, dass letztlich die Auftraggeber entschieden hätten, wem welche Arbeiten übertragen wurden. ${ }^{53}$ Wahrscheinlich trifft diese These zu.

\section{Drechsler}

Obgleich viele Adlige zum Zeitvertreib drechselten, zählte das Drechslerhandwerk dennoch zu den in Zünften organisierten unfreien Berufen. In etlichen Städten untersagten die Regelwerke der Innungen den Tischlern das Drehen, in anderen Städten, in Ingolstadt etwa, scheint man es geduldet zu haben. ${ }^{54}$ Tischler dürften generell aber in der Lage gewesen sein, zumindest einfache Drechselarbeiten auszuführen, werden in den für die Recherche analysierten Schriftquellen doch nur in zwei Fällen Drechsler explizit genannt: Marzellin Georg Orthner (ı633-1692), der I677/78 die Schatzkammerschränke des Stiftes Klosterneuburg schuf, sowie Jakob Schildknecht, der um I 70o am Bau des Chorgestühls und der Kirchenbänke von St. Florian beteiligt war. Bezeichnend ist der Umstand, dass die Archivalien Orthner auch als Kunsttischler anführen und Schildknecht nicht nur drechselte, sondern auch für die Herstellung geschnitzter Säulenkapitelle zuständig war. ${ }^{55}$ Damit erinnert er an Johann Caspar Schenck (um r620-1674) aus Konstanz, der sich mit der Ausübung beider Berufe seinen Lebensunterhalt verdiente. ${ }^{56}$

\section{Vergolder und Fassmaler}

Im Katalogteil ausgewertete Schriftenquellen bekunden, dass Fr. Georg Zoller I733 für die Stiftstischlerei in Stams einen verarbeitungsbereiten Firnis erhielt, während er I 735 Ingredienzen zur Herstellung solch eines Alkohol- und Harzgemischs erwarb. Möglicherweise konnten fertige Lacke gekauft, jedenfalls aber in der eigenen Werkstatt angemischt werden. Tischler nahmen dann in aller Regel die Oberflächenbehandlung der Möbel selbst vor.

Bereits im ersten Band der Untersuchung wird eine detaillierte Aufstellung Franz Anton Staudingers wiedergegeben, in der der Tischler die verschiedenen Arbeitsschritte auflistete, die er bei der »Restaurierung« des damaligen Göttweiger Chorgestühls durchgeführt hatte. Nach vorbereitenden groben Arbeiten schliff Staudinger das Möbel mit Ö1 und firnisste es in einem letzten Arbeitsgang. Eine ähnliche

53 Sangl, Hofschreinerhandwerk (I 990), 5 I-53; Bergemann, Meisterrisse (I 999), 55.

54 Bergemann, ebd., 53.

55 Sigrid Sangl erwähnt den Drechslermeister Jakob Sandtner aus Straubing, der zwischen I 568 und I 574

verschiedene Stadtmodelle fertigte. Sangl, Modelle (2006), 464.

56 Haag, Schenck (1996), 93. 
Vorgehensweise geben Unterlagen von Heinrich Johann Holdermann (I697-1739), Staudingers Vorgänger in Göttweig, zu erkennen, der wiederholt berichtete, dass er die von ihm gefertigten Möbel mit einem Firnis überzog. Zur Erzeugung eines stärkeren Glanzes ballierdte er die Möbel zusätzlich. ${ }^{57}$ Und bei der Vertragsschließung mit Franz Andreas Bogner (um r663-r 7 r 4) zum Bau der Schränke für die Sommersakristei in Melk bestand Abt Berthold Dietmayr (reg. I 700-I739) I70 I ausdrücklich darauf, dass Bogner den Schutzanstrich der Möbel mit einem guten und widerstandsfähigen Firnis eigenhändig auftrug oder ihn zumindest in seiner Werkstatt und von seinen Mitarbeitern auftragen ließ. ${ }^{58}$

Wurden Vergoldungen, Fassmalereien und das Marmorieren von Möbeln normalerweise von ausgewiesenen Meistern ihres Fachs vorgenommen, so besitzen wir doch Kenntnis von zwei Schreinern, zu deren Tätigkeitsbereichen auch das Marmorieren von Möbeln gehörte: Es handelte sich dabei um den bürgerlichen Tischlermeister Franz Berger aus Weitra und den aus Šluknov (Schluckenau) in Böhmen gebürtigen Zwettler Konversen Ladislaus Maleg († I 749). Auch das war ein Verstoß gegen die geltenden Zunftordnungen und wurde wohl nur deshalb geduldet, da beide für den hohen Klerus arbeiteten und damit in den Genuss besonderer Privilegien kamen.

\section{Schmiede}

Schließlich müssen noch Schmiede erwähnt werden, die die Schlösser und Beschläge der Möbel ausführten und den Zunftregeln zufolge an den Möbeln anbrachten. Wie im Fall des Baus des Klosterneuburger Chorgestühls werden diese Handwerker nur gelegentlich in den Quellen genannt, doch wurde im Zusammenhang mit der Studie kein einziger Fall bekannt, in dem ein Tischler solche Arbeiten ausgeführt hätte. ${ }^{59}$

$57 \mathrm{Zu}$ den vorhergehenden Angaben Bohr, Sakralmöbel (2017), 52-53.

58 Bohr, ebd., 409-4I5.

$59 \mathrm{Zu}$ Tischlern, die auch als Architekten oder Baumeister tätig waren, vgl. das folgende Kapitel. 
III.

\section{Künstlerische Inventionen, Modelle und Entwürfe}

\section{Zur Geschichte}

Wie der um 830 gezeichnete Idealplan von St. Gallen dokumentiert, besaß man in der Karolingerzeit die nötigen Kenntnisse, um eine weitläufige und hochkomplexe Architekturanlage mit einer detailgenauen Zeichnung zu visualisieren. In einigen Räumen weist sie sogar Einrichtungsgegenstände aus. ${ }^{60} \mathrm{Ob}$ jedoch Entwurfs- und Ausführungsmodelle schon bekannt waren, wird in der Forschung kontrovers diskutiert, da sich Modelle, die erwiesenermaßen zur Vorbereitung von Bauvorhaben dienten, erst ab der Mitte des I 4. Jahrhunderts nachweisen lassen. Einigen Experten gelten sie deshalb als Erfindung der italienischen Frührenaissance. ${ }^{61}$ In jener Zeit wurden dort Modelle zu einem wichtigen Teil des Planungsprozesses vor der Realisierung anspruchsvoller Projekte, weshalb etliche italienische Exemplare aus der vorbürgerlichen Epoche erhalten sind. ${ }^{62}$ Ein gedanklicher Sprung führt uns nach Wien, wo der Tischler Friderich Fritz im I6. Jahrhundert Baumodelle für die Hofburg anfertigte. ${ }^{63}$ Ein weiterer Schritt, nun ins frühe I 8. Jahrhundert, ermöglicht es, an den Wettbewerb zur Errichtung der Karlskirche in der Residenzstadt des Habsburgerreiches zu erinnern. ${ }^{64}$ Das Vorhaben stand unter der Schirmherrschaft Kaiser Karls VI. (I685-I740), der verschiedene Architekten aufforderte, sich mit dreidimensionalen Entwürfen um

6o Sched1, St. Gallen (2014). Im folgenden Kapitel werden unter anderem die Piaristenkirche in Horn, die Karlskirche, St. Dorothea, St. Peter und St. Stephan in Wien, die Domkirche in St. Pölten, die Deutschordenskirche in Linz, St. Veit und die Piaristenkirche in Krems sowie die (ehemaligen) Stifte von Baumgartenberg, Dürnstein, Göttweig, Heiligenkreuz, Klosterneuburg, Kremsmünster, Lambach, Melk, St. Florian, Wilhering und Zwettl erwähnt. Es sei darauf hingewiesen, dass diese Sakralanlagen bereits im ersten Band der Untersuchung vorgestellt werden. Vgl. hierzu die relevanten Abschnitte in Bohr, Sakralmöbel (2017).

6r Zu den vorhergehenden Angaben Heydenreich, Architekturmodell (I 937), Sp. 922-924; Heisel, Bauzeichnungen (I 993); Lepik, Architekturmodell (I 995), bes. Io-I I ; Krapf, Modelle (I 998), I 5 ; Kreytenberg, Orcagna (2000), I 45 -I 46.

$62 \mathrm{Zu}$ den bekanntesten zählen sicher die für St. Peter in Rom von Antonio da Sangallo d.J. (I 484-I 546) und Michelangelo (I 475-I564). Vgl. hierzu bes. die Beiträge von Sandro Benedetti, Horst Bredekamp, Henry A. Millon, Craig Hugh Smith und Christof Thoenes in Evers, Architekturmodelle (I995).

63 Krapf, Modelle (I 998), I6.

64 Lorenz, Fischer von Erlach (I 992), I 50-157. 
die künstlerische Konzeption und die Bauleitung der Karlskirche zu bewerben. Johann Bernhard Fischer von Erlach (I656-I 723) überzeugte mit seinem Modell, er gewann den Auftrag und begann I7 5 mit der Verwirklichung seiner Pläne.

\section{Allgemeines}

Die Fachliteratur unterscheidet verschiedene Arten von Modellen - Stadtmodelle, Modelle nach bestehenden Bauwerken, Phantasiemodelle, Stiftermodelle, Lehrmodelle usw. -, an dieser Stelle interessieren in erster Linie Ausführungs- oder Werkmodelle zur Fertigung von Tischlerarbeiten. ${ }^{65}$ Während italienische Sammlungen eine Vielzahl von Kirchenmodellen aufbewahren, kennen wir aus Österreich zwar recht viele Modelle von Altären, aber nur wenige von Sakralarchitekturen. ${ }^{66}$ Es unterliegt jedoch keinem Zweifel, dass in der Vormoderne auch hierzulande dreidimensionale Darstellungen bei der Errichtung bedeutender Kirchen und Klöster Verwendung fanden. Dabei ist es unerheblich, welchem sachlichen, räumlichen und historischen Kontext Modelle entstammten, in aller Regel bildeten sie ein gesamtes Bauwerk oder Teilbereiche davon in kleinem Maßstab ab. Etliche Exemplare lassen sich öffnen und gestatten Einblicke ins Gebäudeinnere. Manchmal zeigen sie nicht nur die Raumschale, sondern auch die Ausstattung bis hin zu geplanten Stuckarbeiten und Deckengemälden. ${ }^{67}$ Meist wurde auf die Wiedergabe von wichtigen Details jedoch verzichtet, da ihr Aussehen erst während der Bauphase bestimmt wurde und sie sich in Zeichnungen oder maßstabsgerechten Teilstücken eines Werkes präziser darstellen ließen. ${ }^{68}$

Die für die Studie zu Sakralmöbeln zurate gezogenen Schriftquellen belegen seit I70r die Verwendung von Werkmodellen im Möbelbau, doch nahm man bei der Pla-

65 Heydenreich, Architekturmodell ( ( 937), Sp. 922, mit weiteren Modelltypen. Vgl. hierzu auch Ronzoni, Altarmodelle (1998), bes. 28, und Sangl, Modelle (2006) mit einem Beitrag zu Exemplaren im Bayerischen Nationalmuseum. Zu Modellen im Bereich der Barockplastik vgl. einführend etwa die verschiedenen Beiträge in Volk, Entwurf ( 1986 ) und Kalinowski, Werkstattpraxis (1992).

66 Heydenreich, Architekturmodelle (1937); Welt des Barock (1986), Bd. 2, 93; Volk, Bemerkungen (I992); Reuther/Berckenhagen, Architekturmodelle (I994), 86-88, IoI-IO3, I3 I-I 32, I4I-I 42, I 49I 50, I 59-160; Krapf, Triumph (1998); Jahn, Hildebrandt (201 I), 595-607.

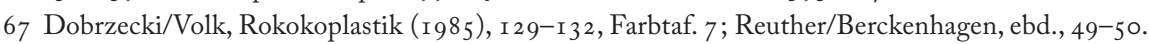

68 Ein Vertrag von 1694 zwischen dem Konvent von Heiligenkreuz sowie den Wiener Bildhauern Giovanni Giuliani ( $1663-1744)$ und Benedict Sundermayer über die Anfertigung dreier Altäre legt fest, dass die Bildhauer Kapitelle, Festons und anderen Zierrat im Maßstab i : I als Vorlagen schnitzen sollten, da Altarmodelle zu klein seien, um Details ausarbeiten zu können. ÖKT, Heiligenkreuz (I 926), 63-64; Volk, Bemerkungen (1992), 269 . 
nung wertvoller Ausstattungen wahrscheinlich schon früher Modelle zu Hilfe. ${ }^{69}$ Eine erneute Durchsicht entsprechender Archivalien würde das sicher bestätigen. Allerdings gibt die Fachliteratur zu bedenken, dass der Begriff »Modell« in frühen Quellen auch im Sinne von »Absprache« oder "mündlicher Übereinkunft« gemeint sein könnte. ${ }^{70}$ Hinzugefügt sei, dass man beim Lesen von Schriftquellen mitunter den Eindruck gewinnt, der Begriff stünde außerdem für »Entwurf« oder »Skizze«. Wie dem auch sei, unter den Wiener Tischlern des I6., I 7. und I8. Jahrhunderts kennen wir mit dem oben erwähnten Friderich Fritz, mit Andreas Ruspiliati, Johann Gottlieb Hasselmann, Heinrich Paumgartner (I624-I683), Matthias Rueff (I658-I 7 I 8) oder Johann Dietrich († I 774) namentlich mehrere Handwerker, die nachweislich Modelle schufen. Vielleicht waren sie sogar wie Hasselmann auf ihre Fertigung spezialisiert, führte er in den I 76oer-Jahren doch den Titel eines kaiserlichen Modelltischlers. ${ }^{71}$

\section{Modelle für Sakralmöbel}

Archivalien zufolge überließ man Tischlern neben den notwendigen Zeichnungen auch Modelle als Orientierungshilfe bei der Bewerkstelligung bedeutender Aufträge. Eines unter vielen Beispielen ist ein Vertrag von r 70r zwischen Abt Berthold Dietmayr (reg. I700-I739) und dem Wiener Tischlermeister Franz Andreas Bogner (um I663-I7 I4) über die Herstellung der Möbelgarnitur für die Melker Sommersakristei. Bogner sollte die Sakristeischränke nach dem hierüber verfertigten u. übergebenen Modell [...] ganz punctual u. gleichföhrmig verfassen, während er die Sakristeitüren nach einem einfachen Riss zu bauen hatte. ${ }^{72} \mathrm{Um}$ Fehlinterpretationen beim Lesen der komplizierten Risse auszuschließen, erhielt der Tischler also ein dreidimensionales Modell, das das Erscheinungsbild der Kastenmöbel wiedergab, für den Bau der Türen reichte eine Risszeichnung selbstverständlich aus. Wie in Melk wurden auch andernorts vor der Fertigung hochkarätiger Sakralmöbel kleine Modelle der benötigten Inventarstücke erzeugt, doch haben sich bis auf ein Exemplar aus der Mitte des I8. Jahrhunderts,

69 Zur Vorgehensweise im profanen Ambiente, aber ebenfalls im I 8. Jahrhundert vgl. Sangl, Hofschreinerhandwerk (I990), 52 . Und I 733 gab Johann Balthasar Neumann (I687-I 753) in Paris kleine Modelle von Sitz- und Liegemöbeln für den Würzburger Hof in Auftrag. Friedhoff, Wohnen (r 998), 696.

70 Wagner, Heiligenkreuz (2007), I 48, I 52 .

7I Wagner, Regesten (2014), ad voces; zu Hasselmann auch Haupt, Hofhandwerk (2007), 485; zu Fritz und Ruspiliati Krapf, Modelle ( I998), I6, I 9 ; zu Rueff vgl. Ronzoni, Altarmodelle (1998), 32. Übrigens erwähnte Friedrich Carl von Moser zusammen mit Schatzkammern und Bibliotheken spezielle »Modellzimmer in Schlossanlagen. Modelle waren als Lehr- und Anschauungsmaterial bei Architekturliebhabern gefragt. Moser, Hof-Recht (I 755), Bd. 2, Buch 7, Kap. 5, 398.

72 ÖKT, Melk (I 909), I 85. Von dort stammt auch das Zitat. 
das die Kanzel der Kapuzinerkirche von Urfahr bei Linz zeigt, keine österreichischen Werkmodelle für frühneuzeitliche sakrale Ausstattungsstücke erhalten. ${ }^{73}$ Wesentlich seltener kam es wie in Dürnstein oder Kremsmünster vor, dass Prälaten von den Tischlern zunächst Prototypen in Originalgröße verlangten. ${ }^{74}$ So konnten sie nicht nur die ästhetische Wirkung geplanter Möbelgarnituren besser einschätzen, sondern sich auch von den handwerklichen Fähigkeiten der jeweiligen Tischler überzeugen.

Es liegt in der Natur der Sache, dass manchmal bereits fertiggestellte Möbelensembles als Vorlagen für neues Mobiliar dienten. ${ }^{75}$ Auf die zeitaufwendige und mit Kosten verbundene Ausarbeitung von Entwürfen konnte damit verzichtet werden. So sind die Bankwangen von Mariahof und der Abtei St. Lambrecht (Abb. 202, 26I) von I640/50 nahezu identisch. Wahrscheinlich lieferte sie das Atelier von Christoph Paumgartner aus Neumarkt. Dabei würde es nicht überraschen, wenn er die Kirchenbänke zunächst für das Kloster gebaut hätte, dann erst für die kleine Dorfgemeinde. Entsprechend ging der Dürnsteiner Propst Hieronymus Übelbacher (reg. I 7 I O-I 740) vor, als er Anfang des Jahres I 724 dem mit der Herstellung von Kirchenbänken für seine Stiftskirche beauftragten Tischler eine Docke zum Kopieren überließ. ${ }^{76}$ Vielleicht stammte sie noch aus Beständen der Bauhütte von St. Stephan in Wien, denn die Laiengestühle in der Metropolitan- und in der Stiftskirche sind beinahe identisch. Und im Vertrag, mit dem der Propst 1725 den Tischler Hippolyt Nallenburg (I687-I 733) zur Fertigung der Beichtstühle verpflichtete, wird ausdrücklich festgehalten, dass die Möbel in ihrem Aussehen jenen in St. Dorothea zu Wien und in der Domkirche zu St. Pölten zu gleichen hätten. ${ }^{77}$ Weiter existieren Übereinstimmungen zwischen Möbelgarnituren im Grazer Dom, in Mariatrost und in der Abteikirche Rein (Abb. I 55, I 57, I7 1, 236239), zwischen Sitzbänken in einigen Salzburger Sakralbauten sowie in den Kirchen von Frauenberg, Gröbming und Pürgg (Farbtaf. 17; Abb. 125, I32, 194, 232). Diese Reihe ließe sich fortsetzen. ${ }^{78}$

73 Schultes/Schultes, Kanzel (r 995); Schultes, Kanzelmodell (I998). Zu einigen süddeutschen Modellen für Sakralmöbel aus dem fortgeschrittenen i 8. Jahrhundert s. Himmelheber, Kleine Möbel ( ( 979), 68-69, 7 I-73; Dobrzecki/Volk, Rokokoplastik (I 985), I I 5-I I 6; Brossette, Inszenierung (2002), Bd. 2, Abb. гог.

74 Im Stift Dürnstein war das beim Bau der Sakristeischränke der Fall, in der Abtei Kremsmünster ging es um die Möbel für die Bibliothek.

75 Für profane Möbel ist das schon lange bekannt. Erinnert sei nur an verschiedene Möbel aus der Roentgen-Manufaktur, den »Großen Kabinettschrank« beispielsweise, der in den I77oer-Jahren in drei Varianten gebaut wurde. Stiegel, Projekte (2009), bes. 57-63.

76 Penz, Kalendernotizen (2013), 271.

77 Penz, ebd., 327.

78 Beispielsweise mit den Tischen für die Bibliothek in Kremsmünster und das Refektorium in Lambach. Die Möbel entstanden zwischen 1707 und I 709 . 
Die Frage nach der Urheberschaft von Entwürfen für Sakralmöbel

Bei der Begutachtung des Kirchenmobiliars stellt sich stets die Frage nach dem Autor des Entwurfs. War es der für die Barockisierung einer Kirche zuständige Architekt? War es ein Ornamentkünstler oder Bildhauer? Vielleicht auch der Tischler selbst? Die nachfolgenden Abschnitte belegen, dass es auf diese Frage keine generelle Antwort gibt, sie kann nur für jeden Einzelfall gesondert beantwortet werden.

\section{Entwürfe und Modelle von Architekten und Baumeistern}

In der Fachliteratur wird häufig die These vertreten, dass Schreiner in der Regel jene Arbeiten selbst entworfen hätten, die sie ohne die Hilfe fremder Gewerke herzustellen imstande waren. ${ }^{79}$ Für Tischlerarbeiten im sakralen Umfeld trifft diese Annahme jedoch nur bedingt zu. Carlo Borromeo (I 538-I 584) forderte bereits 1577 von Architekten, zusammen mit Sakralbauten auch die jeweils benötigten Chorgestühle zu entwerfen. ${ }^{80}$ Aus der Phase der vorbereitenden Arbeiten zur Renovatio von Melk, Stams und vielen anderen Stiften haben sich tatsächlich Umbaupläne erhalten, die die mögliche Aufstellung von Chorgestühlen und Laienbänken in den Kirchen wiedergeben. ${ }^{81}$ Etliche Zeichnungen und Drucke bestätigen, dass Architekten zusammen mit den Planungen der Baukörper auch detaillierte Vorschläge zur erforderlichen Innenausstattung ausarbeiteten. Das entsprach der Vorgehensweise im profanen Bereich, wo unzählige Interieurentwürfe vollständige Zimmer oder Raumsegmente mit Deckenplafonds, geschnitzten Boiserien, textilen Wandbehängen und kompletten Möbelstücken zeigen. ${ }^{82}$

Wie im Kapitel zum Kloster Stams geschildert wird, zählte zu jenen Künstlern der Baumeister Johann Martin Gumpp d. Ä. (I643-I729). Er barockisierte zusammen mit seinem Sohn nach I 7 I 5 zunächst die Heilig-Blut-Kapelle der Zisterzienserabtei, seit den I 72oer-Jahren auch die Stiftskirche selbst. Gründe der Stilkritik weisen darauf hin, dass Gumpp darüber hinaus für die Gestaltung der Kirchenportale und des Laiengestühls in der Kapelle verantwortlich war (Abb. 347-350). Mit der Überarbeitung der

79 Bergemann, Meisterrisse (I 999), 55, I 29.

80 Borromeo, Instructiones fabricae (I 577), liber I, cap. XII; Mayer-Himmelheber, Kunstpolitik (I984), I I I.

8 I ÖKT, Melk (I 909), Taf. V; Neunhundert Jahre Benediktiner (I 989), 232, 234, 237, 240; Huber/Weigl, Prandtauer (2010), 26-27, 3 I, 32; Wolfgang, Stams (2008), Abb. 36, 50, 57 . Die Pläne von Melk datieren auf I701/02, die von Stams auf die Jahre um r680 sowie auf i 729. Zu etwas früheren Plänen mit eingezeichneten Chorgestühlen vgl. Hautecœur, Histoire (I 948), Abb. 552, 553, 559.

82 Kurth, Raumkunst (I 923). Speziell zu Architekten des I7. und I 8. Jahrhunderts aus Florenz und Frankreich s. Barocchi/Bertelà, Arredi (r 990) bzw. Wilke, Innendekoration (2016). 
Innenausstattung begann der Konvent während des Abbatiats von Augustin I. Haas (reg. I660-I672), nachfolgende Äbte führten das Projekt in Stams fort. Die Tischlerarbeiten entstanden höchstwahrscheinlich in dieser Phase der Umbaumaßnahmen. Bereits im ersten Band der Studie wurde die um I 720 von Johann Lukas von Hildebrandt ( $1668-\mathrm{r} 745$ ) errichtete ehemalige Deutschordenskirche in Linz vorgestellt und der an den Architekten ergangene Auftrag erörtert, Pläne für den Bau der Kirche und ihre Ausstattung zu liefern. Bauherr war der Salzburger Erzbischof Franz Anton Fürst von Harrach (r665-1727), dem Hildebrandt Skizzen und Modelle zusandte, die Harrach prüfte und erforderlichenfalls mit Änderungswünschen versah. Kirche und Einrichtung entstanden dabei aus einem Guss. Etwa zur gleichen Zeit wurde Hildebrandt und seinem Baumeister Franz Jänggl (I654-I734) die Barockisierung des Stiftes Göttweig anvertraut. Dem Anschein nach legten sie im Zuge dessen auch das Aussehen der Möbel in der dortigen Chorkapelle und in der Bibliothek fest, denn die zwischen 1727 und I 730 zusammengefügten Interieurs unterscheiden sich fundamental von barocken Tischlerarbeiten, die wir sonst aus Österreich kennen. Die beruhigte Großform und der reduzierte Schmuck mit Schnitzereien und Intarsien bewirken eine nahezu klassizistische Strenge, was dazu führte, dass das Gestühl der Chorkapelle in der Vergangenheit mitunter ein volles Jahrhundert zu spät datiert wurde.

Johann Bernhard Fischer von Erlach leitete in Salzburg seit I694 die Errichtung der Dreifaltigkeitskirche und seit der Jahrhundertwende den Bau der ehemaligen Ursulinenkirche. Die schweren Schnitzarbeiten, die als Zierornamente die Kommunionbänke beider Kirchen vervollständigen (Farbtaf. I 5 ; Abb. I I I, I30), sind nahezu identisch und wurden, so vermutet die Forschung, nach Skizzen von der Hand Fischers realisiert. ${ }^{83}$ Ähnliche Schnitzarbeiten bereichern die Bänke der Dreifaltigkeitskirche (Abb. Io6-I 10), die man nicht wie üblich rechtwinklig zur Kirchenlängsachse, sondern entlang der Außenwände des ovalen Baukörpers aufgereiht hat. Zudem erweist sich dort die Verzierung der Türen und der Kanzel mit stilisierten Velum- und $\mathrm{Mu}$ schelornamenten (Abb. Iо7, I I2) als so außergewöhnlich, dass man die Invention zu den Tischlerarbeiten nicht einem Handwerker, sondern nur Fischer selbst zutrauen möchte. Zwar bleibt wegen der formalen Differenzen zwischen den mit italienischem Akanthus und französischen Muschelmotiven verzierten Arbeiten ein gewisses Unbehagen bei der Zuschreibung an den Architekten, doch bestehen an der Tatsache, dass sich Fischer nicht nur mit Bauplänen, sondern auch mit Entwürfen für kunsthandwerkliche Erzeugnisse beschäftigte, keine Zweifel. Eines der bekanntesten von ihm inventierten Stücke ist ein verlorenes Bettgestell aus massivem Silber, dessen Fertigung

83 Im folgenden Katalogteil wird das in den Kapiteln zu den beiden Kirchen ausführlich beschrieben. 
I693/94 Graf Maximilian Thun (I638-I70I) veranlasste. ${ }^{84}$ Erhalten haben sich dagegen ein nach den Angaben des Architekten gefertigter Sarkophag in der Salzburger Dreifaltigkeitskirche und eine Zeichnung des Künstlers mit Prunkwaffen. Ein eigenhändiger Hinweis auf dem Blatt unterrichtet darüber, dass Fischer auch Skizzen für die Uniformen von Trabanten liefern könne. ${ }^{85}$

Ein im Kontext weiterer interessanter Bau ist die Wiener Karlskirche. Sie wurde nach einem Konzept Fischers errichtet, die Grundsteinlegung fiel in das Jahr I716. I723 übernahm Joseph Emanuel (I693-I742), der jüngere Fischer, die Bauführung, I 729 war der Rohbau vollendet. Stilistische Gründe deuten allerdings darauf hin, dass die Möbelensembles der Kirche nicht auf die beiden Fischer, sondern auf Claude Le Fort du Plessy (nachgew. 1707-1757) zurückgehen, einem der damals in Wien führenden Innenarchitekten. ${ }^{86}$ Die Großform der Möbel in der Karlskirche ist ebenso außergewöhnlich wie die Ausführung der Schnitzarbeiten, die sich durch ihr verspieltes Äußeres sowie die feine, detailgenaue und präzise Ausarbeitung von den Erzeugnissen vieler Wiener Bildschnitzer jener Zeit unterscheiden. Die Bekrönung der Beichtstühle mit einer hohen Kuppel, die Blumengirlanden bereichern, ist ein Motiv, das sich ein halbes Jahrhundert zuvor schon auf Stichen von Jean Lepautre (I6I 8-I682) nachweisen lässt. ${ }^{87}$ Hinzu kommt an den Kirchenbänken in der Karlskirche die Verwendung des Rosenholzes, das bei der Herstellung österreichischer Möbel so gut wie keine Rolle spielte, im französischen Möbelbau aber häufig genutzt wurde. Und bei der jüngsten Restaurierung von Sakristeimöbeln der Karlskirche wurde außerdem Olivenholz als Werkmaterial der in die Schränke eingelegten Adern bestimmt. ${ }^{88} \mathrm{Im}$ Norden und Nordosten Österreichs griffen die Tischler nur selten zu dieser Holzart. Wichtige Besonderheiten sprechen folglich für Le Fort du Plessy als Entwerfer der Möbel. ${ }^{89}$

84 Sedlmayr, Fischer von Erlach ( 1997 ), 93.

85 Thomas, Vorzeichnungen (I969), 74; Kreul, Fischer von Erlach (2006), 240. Bekannt sind überdies

Fischers Entwürfe für Vasen. Sedlmayr, Fischer von Erlach (1956), Abb. I5, I6, I9-22. Vgl. hierzu außerdem Kreul, ebd., I 99. Zu Türen, die offenbar auf Vorlagen Fischers zurückgehen, s. den Beitrag zur Dreifaltigkeitskirche in Salzburg in vorliegendem Katalog.

86 Kalousek, Hofburginterieurs (2016), bes. $366-368$.

87 Vgl. den Druck KI I-658-106 von Lepautre in der Ornamentstichsammlung des MAK in Wien unter https://sammlung.mak.at [Zugriff August 2020].

88 Freundliche Mitteilung von Peter Kopp, dem Restaurator der Sakristeiausstattung.

89 Der Reihe von Architekten, die auch Möbelentwürfe lieferten, könnte noch Pater Joseph Schaukegl (I72 I-I 798) aus Seitenstetten hinzugefügt werden. Weichesmüller, Schaukegl (I 978 ). 


\section{Entwürfe und Modelle von »Tischler-Architekten«}

Die Reihe von Architekten, die als Designer von Wanddekorationen und Möbelgarnituren in Erscheinung traten und zugleich den Beruf des Tischlers ausübten, ist ausgesprochen lang, auch sie beginnt spätestens in der Renaissance. Giorgio Vasari ( 5 I I-I 574) berichtet in seinen Vite ausführlich von den frühen Meistern. Einer der bekanntesten war sicher Giuliano da Maiano (I 432-I490), der als Architekt, Bildhauer und Tischler unter anderem in Florenz, Rom und Neapel arbeitete, ein weiterer der eingangs erwähnte Antonio da Sangallo. ${ }^{90}$ Um ein Beispiel aus dem hier besonders interessierenden Umfeld zu wählen, sei auf den in Ferrara geborenen Joseph (Giuseppe) Bricci (um I655-I 735) verwiesen, der als hofbefreiter Tischler, kaiserlicher Komödientischler und kaiserlicher Architekt im barocken Wien seinen Lebensunterhalt verdiente. ${ }^{91}$

Da Werkzeichnungen für Tischlerarbeiten in der Regel in den Tischlereien verblieben und bei ihrer Verwendung häufig unansehnlich wurden, sind direkte Vorlagen für Sakralmöbel nur in Ausnahmefällen erhalten. ${ }^{92}$ Dennoch lässt sich für einige österreichische Sakralbauten aus der Frühen Neuzeit mittels Schriftquellen und Stilvergleichen das Geheimnis um jene Personen lüften, die für entsprechende Entwürfe verantwortlich waren. So erwähnen Archivalien einen Meister namens Martin Schött, der in der Mitte des 17. Jahrhunderts als Architectus und Faber lignarius für das Stift Neuberg in der Steiermark tätig war. ${ }^{93}$ Er war in beiden Berufen bewandert. Ein weiterer jener Handwerker war Remigius Horner (I670-1750), der als Tischler immer wieder vom ehemaligen Augustiner-Chorherrenkloster in Pöllau mit Aufträgen bedacht wurde und als Baumeister die Errichtung der dortigen Abteikirche sowie anderer Sakralbauten in der Oststeiermark überwachte. ${ }^{94}$ Die grobe Planung der Jesuitenkirche in Innsbruck geht auf zwei Architekten zurück, dagegen stammen die Detailpläne aus der Feder des Hofbaumeisters und Hoftischlers Christoph Gumpp d.J. (I6oo-I672), der um I630 überdies die Beichtstühle der Kirche (Abb. 302) entworfen und hergestellt haben soll.

90 Vasari, Vite ( 1550 ), ad voces. Elam, Sangallo (2017), 76-77. Zur beruflichen Nähe zwischen Tischlern und Architekten s. Bergemann, Meisterrisse (1999), 77.

91 Haupt, Hofhandwerk (2007), 273, 274; Wagner, Regesten (2014), ad vocem.

$92 \mathrm{Zu}$ einer um 1750 entstandenen Risszeichnung für Kirchenbänke vgl. etwa Bohr, Sakralmöbel (2017), 257. Erhalten haben sich vor allem Blätter, die als Teil der Meisterprüfung bei einer Zunft eingereicht wurden. Arens, Meisterrisse (I 955); Zinnkann, Meisterstücke (I 988); Bergemann, Meisterrisse (1999).

93 Kohlbach, Stifte (1953), 242.

94 Hutz, Pöllau (2005), 230-23r. Zu Remigius Horner vgl. Allmer, Pöllau (I993), ror, 20 I-203; Horner verstarb am I 8. November 1750. https://data.matricula-online.eu/de/oesterreich/graz-seckau/poellau [Zugriff Juni 2020], Sterbebuch I, I74I-I 770, Sign. 7365, p. 52. 
Federführend bei Bau und Ausstattung der Abteikirche Zwettl waren der Architekt, Tischler und Bildschnitzer Matthias Steinl (I643/44-I727) aus Wien sowie der Baumeister Joseph Munggenast (I680-I74I) aus St. Pölten. Nach teilweise überarbeiteten Skizzen Steinls wurden in den frühen I $720 e r-J a h r e n$ die Modelle der Zwettler Kirchenfassade und des dortigen Hochaltars realisiert. ${ }^{95}$ Vermutlich gehen außerdem einige Beichtstühle in der Abteikirche auf seine Entwürfe zurück. Nachweislich zeichnete Steinl die Vorlagen für den Kanzelkorb und die ornamentale Stuckkomposition von St. Peter in Wien. Dabei sprechen Zierornamente, die an der Kanzel sowie in der Stuckdekoration vorkommen und sich am Laiengestühl wiederholen, dafür, dass er zudem als Autor der Entwürfe für die Kirchenbänke zu gelten hat. Indizien deuten überdies darauf hin, dass Steinl den Zierrat für die Beichtstühle in Dürnstein inventierte, denn im Gebälkfries der Möbel finden sich auffallende, in Steinls Formensprache häufig vorkommende gekreuzte S-Bögen. Außerdem vervollständigen dort die für den Künstler nicht minder charakteristischen Cherubim, deren Köpfe die Zwickel zwischen V-förmig ausgebreiteten Flügeln füllen, die Pilasterkapitelle. Darüber hinaus projektierte Steinl nach heutigem Wissensstand die Chorgestühle für die Domkirche in St. Pölten und die Stiftskirche in Klosterneuburg, auch im Falle dieser Möbel lassen die ungewöhnlichen Konturen und Zierformen an ihn als den verantwortlichen Meister denken. Schließlich wäre es gut möglich, dass Steinl der Entwurf des Dürnsteiner Chorgestühls zuzuschreiben ist. Im ersten Band der Studie wurde diese These bereits erörtert.

\section{Entwürfe und Modelle von Tischlern und Zimmerleuten}

Nur eine Quelle, die in Verbindung mit den Studien zur vorliegenden Recherche konsultiert wurde, bezeugt, dass Zimmerleute auch komplette Architekturmodelle fertigten. ${ }^{96}$ Es handelt sich um Philipp Schorn, der 1685 ein Exemplar zur Erweiterung der Wallfahrtskirche Maria Plain bei Salzburg baute und dafür als Lohn 3 I fl erhielt. ${ }^{97} \mathrm{Ob}$ Schorn auch die notwendigen Pläne dazu gezeichnet hatte, ist nicht bekannt. Anderes lässt sich von den Tischlern berichten: Als wichtigen Teil der Meisterprüfung verlangten die Zünfte Grundrisse, Querschnitte und Aufrisse der Meisterstücke, über deren Gestaltung die Handwerker nach gewissen Vorgaben selbst zu entscheiden hatten. ${ }^{98}$ Das Entwerfen und Zeichnen von Mobiliar gehörte deshalb wesentlich zur Lehrlings-

95 ÖKT, Zwettl (r 940), Abb. 66, 68; Schemper-Sparholz, Hochaltarprojekt (1998).

96 Modelle von Dachstühlen wurden häufiger in ihren Werkstätten zusammengesetzt.

97 ÖKT, Salzburg-Land, 2 ( I 916), 35 o.

98 Arens, Meisterrisse (1955); Zinnkann, Meisterstücke (I 988); Bergemann, Meisterrisse (1999). 
und Gesellenausbildung. Dementsprechend unterrichten Archivalien oft von Vorzeichnungen und Modellen, die Tischler ausgeführt hatten. Einer dieser Handwerker war Hippolyt Nallenburg ( (1687-I733), der Baumodelle fertigte, aber auch Modelle für einzelne Inventarstücke, I724 etwa für eine neue Kanzel oder I 725 für ein Portal. ${ }^{99}$ Weiter wurden im ersten Band der Untersuchung Kommuniongitter aus der Piaristenkirche zu Horn beschrieben. Ihr Dekor unterscheidet sich von den Arten der Verzierung, die wir sonst an Tischlerarbeiten unserer Kunstlandschaften vorfinden, lässt sich aber gut mit Möbeln aus dem Elsass vergleichen. Für den Piaristenkonvent war damals der Tischler Matthias Fieß tätig, der aus Westfrankreich zugewandert war. Offensichtlich plante er auch die Arbeiten, die er ausführte. Zudem dürfte ein Handwerker, der in Archivalien als Tischler aus Stein bezeichnet wird, Möbel für die Sakristei in Dürnstein entworfen haben ${ }^{100}$ und wirkte Frater Ludwig Kögel (I 7Io/I I-I 74I), ein Bildhauer und Tischler, als Planer beim Umbau der Lilienfelder Stiftskirche mit. Weiter baute Kögel ein Modell der geplanten Abteikirche, nachdem der damalige Abt Chrysostomus Wieser (reg. I716-I747) entsprechende Entwürfe aus Wien erhalten hatte. ${ }^{101}$ Darüber hinaus schufen die Tischler Simon Thaddäus Baldauf (I677-1 753) und Chrysostomus Lindemayr für die Domkirchen zu Salzburg und Graz Möbel nach eigenen Entwürfen (Abb. I I 7-I 20, I 52-I 56). I765/66 fertigte Franz Anton Staudinger (I705-I78I) das Chorgestühl für die Göttweiger Stiftskirche, musste aber zuvor einen detaillierten Riss zeichnen und dem Abt zur Approbation vorlegen. Der Riss basierte auf einem groben Entwurf, den die Ordensgemeinschaft bei einem unbekannten Künstler in Auftrag gegeben hatte.

Um abschließend noch ein besonders anschauliches Beispiel für das Eingreifen eines Tischlers in den Planungsprozess zur Erzeugung von Sakralmöbeln zu präsentieren, sei auf die Ausstattung der ehemaligen Deutschordenskirche in Linz aufmerksam gemacht, die bereits genannt wurde. Ein Brief des Architekten Hildebrandt vom 26. August I 72 I an den Bauherrn, Fürsterzbischof Harrach, berichtet von der Anfertigung eines Modells der Bankwangen für das Laiengestühl durch die Haustischler der Kommende. Außerdem, so das Schreiben weiter, sei Wolfgang Rachinger, ein externer Tischlermeister, mit der Herstellung eines Konkurrenzmodells nach eigenem Entwurf beschäftigt. ${ }^{102}$ Es entsprach den Erwartungen Harrachs, der sich daher für die Auftragsvergabe zum Bau der Kirchenbänke an Rachinger entschied. Die Docken der Bänke verblüffen im Hinblick auf die ungewöhnliche Umrissform, die auf einer In-

\footnotetext{
99 Penz, Kalendernotizen (2013), 286, 327.

Ioo Penz, ebd., 235.

Io I Oettinger/Matschik/Fitz, Lilienfeld (I 95 2), 21, 23 ; Mussbacher, Lilienfeld (I 976), I 4; Müller, Profeßbuch (I996), 280, Nr. I 552.

I02 Die Höhe von Rachingers Modell betrug etwa $66 \mathrm{~cm}$, das der ausgeführten Bankwangen I 6 cm.
} 
vention Hildebrandts beruhen dürfte. Dagegen werden Details wie die Verwendung von Furnieren statt der ursprünglich vorgesehenen Schnitzarbeiten oder die Form des intarsierten Bandlwerks auf dem Stilempfinden des Tischlers beruhen. ${ }^{103}$

\section{Entwürfe von Bildhauern und Bildschnitzern}

Der aus Süddeutschland zugewanderte Joseph Matthias Götz war einer jener Bildhauer, die nebenbei Kirchenausstattungen konzipierten. Ausweislich des Vertrags, den er mit dem Kremser Stadtrat wegen der Anfertigung eines neuen Gestühls für die Pfarrkirche St. Veit schloss, zeichnete Götz einen Riss des gewünschten Inventarstücks. Außerdem schuf er die in die Möbelrückwand eingesetzten Relieftafeln, während die rahmende Struktur der Gestühlsreihen in der Werkstatt des Kremser Tischlermeisters Joseph Gratwohl gefertigt wurde. Und noch zwei weitere Bildhauer sind uns im Zuge der vorliegenden Studie als Entwerfer von Tischlerarbeiten begegnet. Zum einen Franz Xaver Nissl ( 173 I-I 804), auf dessen künstlerischen Inventionen das Erscheinungsbild der in den I77oer-Jahren geschaffenen Bänke und Beichtstühle für die Stiftskirche von St. Georgenberg beruht (Abb. 340, 34 I, 345, 346). Zum anderen Georg Raphael Donner (I693-I74I), der in den frühen I73oer-Jahren für die Domkirche in Bratislava (Pressburg) das Chorgestühl entworfen haben soll. Die Büsten über dem Hauptgebälk bezeugen die Übernahme von Gestaltungsprinzipien, die für das Heiligenkreuzer Gestühl von I 707/og charakteristisch sind. An seiner Entstehung war der damals I 4- oder I 5-jährige Donner aktiv beteiligt. ${ }^{104}$

\section{Entwürfe eines Theateringenieurs und eines Theaterdekorateurs}

Weiter muss an dieser Stelle auf den Maler und Theateringenieur Antonio Maria Niccolò Beduzzi (I675-I735) sowie auf den Theaterdekorateur Giuseppe Galli Bibiena ( I696-I 757) hingewiesen werden. Allem Anschein nach waren beide Künstler als Entwurfszeichner am Bau des Melker Chorgestühls beteiligt, das auf I736/37 zu datieren ist. Im Hinblick auf die Gestaltung des Möbels bestand Abt Berthold Dietmayr auf einer außergewöhnlichen Großform, eine Forderung, der Beduzzi und Galli Bibiena überzeugend nachkamen, indem sie das Möbel mithilfe von Stuckarbeiten formal und

I03 Das entspräche der Arbeitsweise französischer Architekten des frühen r 8. Jahrhunderts, die die Wandgliederung entwarfen, vielleicht auch die Lage der Ornamente auf den Binnenfeldern andeuteten, doch fiel die Gestaltung der einzelnen Ziermotive in den Verantwortungsbereich der Bildschnitzer. Wilke, Innendekoration (2016), Bd. I, I32.

I04 Jávor, Donner (I 996), bes. I 40-I 42. 
konstruktiv mit der Chorwand der Kirche verknüpften. ${ }^{105}$ Vergleichbares kommt bei der barocken Ausstattung österreichischer Sakralbauten kein zweites Mal vor, verweist aber auf profane Rokokointerieurs, bei denen beispielsweise die geschwungenen Rückenlehnen von Sitzmöbeln den Verlauf der hinter ihnen angebrachten Boiserien nachzeichnen. ${ }^{106}$ Ferner sorgen Reliefs am Chorgestühl für dessen Einbindung in das ikonographische Programm der Stiftskirche. ${ }^{107}$ Schriftquellen und Risse bezeugen, dass sich Beduzzi außerdem mit dem Design anderer sakraler Ausstattungsstücke beschäftigte. So lieferte er bei den Planungen zum Bau der Melker Klosterkirche in den I7 Ioer- und 2oer-Jahren Entwürfe für Altäre und zeichnete um I 725 zusammen mit Joseph Munggenast einen Riss für den Bau des prachtvollen Tabernakels, der den Altar der Dürnsteiner Stiftskirche überragt. ${ }^{108}$

\section{Entwürfe von Ornamentkünstlern und die Rezeption von Ornamentstichen}

Ornamentkünstler schufen in erster Linie Vorlagen für Ziermotive, seltener Entwürfe vollständiger Möbel oder anderer Kunstgegenstände. Gleichwohl wäre für den hier interessierenden Zeitraum zunächst auf Jean Lepautre aufmerksam zu machen, dessen Stiche mit tempiettoförmigen Beichtstühlen bereits um I 7oo bei der Ausstattung von St. Josef zu Wien rezipiert wurden. ${ }^{109}$ Dann sind Johann Wilhelm Heel ( 1637 -1 709) und Johann Conrad Reuttimann (nachw. I676-r691) zu nennen, die in den r66oerund 7oer-Jahren italienischen Akanthus als Zierrat im überregionalen süddeutschen Kunstraum einführten. Ihre Zeichnungen präsentieren das Laubwerk als flächendeckendes Ornament in Spiralform, häufig mit eingestreuten Blüten, Putten und grotesken Mischwesen. ${ }^{110}$ Einen völlig anderen Eindruck vermitteln Musterblätter von Johann Indau ( 165 I-I 690) und Johannes Unselt (nachgew. I 68 I-I696). Der Hoftischler

I05 Beduzzi und Galli Bibliena führten damit eine künstlerische Invention weiter, die bereits die Gestühle von St. Pölten und Dürnstein auszeichnete.

ro6 Feulner, Kunstgeschichte (1980), Abb. 320; Langer, Zeremoniell (2002), I9. Ein vergleichbares Zusammenwirken von wandfester und mobiler Ausstattung gibt ein Stich von Jacques François Blondel (I705-I 774) wieder. Vg1. Blondel, Distribution (I 737/38), Bd. 2, Taf. 85.

I07 Vgl. hierzu den nächsten Abschnitt der Arbeit.

I08 Neunhundert Jahre Benediktiner (1989), bes. 245-252, 254-257; Kain/Penz, Inszenierung (2010), Abb. I 7 7, I 20; Penz, Kalendernotizen (2013), 342.

Io9 Ornamentstichsammlung MAK, Wien. https://sammlung.mak.at [Zugriff August 2020], beispielsweise KI I-658-106, KI I-658-108 oder KI I-658-ıo9 aus der Folge »Confessionaux nouvellement inventés et gravés par I. le Pautre«. Vgl. hierzu auch https://digi.ub.uni-heidelberg.de/diglit/lepautre I $75 \mathrm{Ibd}_{2} / \mathrm{O}_{2}$ Io bis I $75 \mathrm{Ibd}_{2} / \mathrm{O}_{2} \mathrm{I} 6$ [Zugriff August 2020].

I Io Rothe, Akanthusornament (1938), Taf. 8-1 5 ; Berliner/Egger, Vorlageblätter (I98 I), Bd. I, 87, Bd. 3, Abb. 1044-1050. 
Indau, der vermutlich in Nürnberg gebürtig war und sich nach einem Italienaufenthalt in den I68oer-Jahren in Wien niederließ, entwarf eine ganze Reihe akanthusverzierter Tische, Stühle, Hocker und Spiegelrahmen. Gleiches gilt für Johannes Unselt. ${ }^{111}$ Es ist ungewiss, ob die Entwürfe jemals ausgeführt wurden, da sich bisher noch keine Möbel mit den auf den Stichen dargestellten Exemplaren identifizieren lassen. ${ }^{112}$ Allerdings bestimmten sie zusammen mit anderen Ornamentstechern maßgeblich die Erscheinungsform der um die Wende vom i 7. zum i 8. Jahrhundert gebauten Möbelensembles in der Wiener Dominikaner- und der Kremser Piaristenkirche sowie in St. Florian oder Baumgartenberg. ${ }^{113}$ Bedeutung für die Verbreitung einer anderen Art von Ornamentik erlangte in jenen Jahren im Osten Österreichs der Wiener Juwelier Friedrich Jacob Morisson (nachw. I693 und r697). Er übernahm in seinen Ornamentstichen bereits französische Laub- und Bandlwerkstrukturen von Jean Bérain d.Ä. ( $637-$ I 7 I I) und Daniel Marot (I66I-I752), als andernorts auf Akanthusblattwerk fußende Kompositionen noch als modern galten. ${ }^{114}$ Wahrscheinlich lagen Morissons Vorlagen den um I701/02 gefertigten Tischlerarbeiten in der Bibliothek von Heiligenkreuz und der Sommersakristei von Melk zugrunde, den frühesten bislang nachgewiesenen österreichischen Möbeln im französischen Stil. Die Arbeiten in den beiden Stiften antizipierten mithin um einige Jahre die Ausrichtung österreichischer Kunsthandwerker nach Frankreich.

\section{Entwürfe von Stuckateuren und die Rezeption von Stuckarbeiten}

Zwar lässt sich diese These durch Archivalien nicht erhärten, doch scheinen die Schnitzornamente vieler Möbel unter dem direkten Einfluss von Stuckkünstlern und ihren Erzeugnissen entstanden zu sein. Ein gutes Beispiel hierfür bietet die Dekoration der Brüstung des Chorgestühls im Stift Heiligenkreuz von r707/o9. Während man das Dorsale des Gestühls mit frühen Bandlwerkformationen schmückte, charakterisieren lineare Laubspiralen die Brustwände. Damit werden Arbeiten im Stil der zarten Ranke zitiert, den der Stuckateur Santino Bussi (1663-1737) um I 700 in Wien eingeführt hatte. ${ }^{115}$ Als typisch für diesen Stil gelten weichgeschwungene, anmutige Triebe, zarte Pflanzenstängel, feingliedriger Akanthus sowie Blattlaub, das die Enden

I I I Rothe, ebd., Taf. 30-40; Berliner/Egger, ebd., Bd. I, 88-89, Bd. 3, Abb. 1060-1062, 1068-1072.

I 2 Auf einen Entwurf Indaus geht allerdings der Hochaltar der Kirche in Mariahilf zu Wien zurück. Schemper-Sparholz, Barockaltäre (I 998), 56 .

I 3 Vgl. zum Akanthus auch Teil 2, Kap. V der Arbeit.

I 4 Ornamentstichsammlung MAK, Wien, KI $2201-\mathrm{I}$.

I 5 Blazicek, Stuckateure (1964), bes. I2 I und Abb. I65; Preimesberger, ebd., 327-328; Werner, Bussi (1992), bes. I 3-I 4. Hierzu auch Irmscher, Akanthus (2000), 493, 5 IO. 
der Zweige umspielt. Der schwere und üppige Akanthus italienischer Prägung wird unter dem Einfluss französischer Ornamentformen modifiziert, er wirkt nun leicht, gekurvt und stark ausgedünnt. Antonio Aliprandi (* ${ }^{*} 654$ ) griff I 708 auf die Inventionen Bussis bei der Ausschmückung der Heiligenkreuzer Sakristei und anderer Räume des Klosters mit Stuckarbeiten zurück. ${ }^{116}$ Vegetabile Schnitzarbeiten, die stilistisch kaum Unterschiede zum Formenvokabular Aliprandis erkennen lassen, dominieren des Weiteren das Aussehen der Gestühlsbrüstung. Offensichtlich wurden die Formen der Stuckornamente beim Entwurf der Schnitzarbeiten übernommen, falls nicht Aliprandi selbst Muster für den Schnitzzierrat der Brüstungselemente gezeichnet hatte.

Ein weiteres Beispiel für diese Vorgehensweise liefert ein Doppelbeichtstuhl in der Stiftskirche Wilhering von I750/6o. Schon im ersten Band der Untersuchung wurde auf das Faktum hingewiesen, dass zwischen den Schnitzereien am Möbel und einem Teil der Stuckarbeiten des Kirchengewölbes erstaunlich große Übereinstimmungen bestehen. Das führt zur Annahme, dass zumindest von einer mittelbaren Einflussnahme der Stuckkünstler auf den Bildschnitzer auszugehen ist. Zu denken wäre dabei vor allem an das Fortwirken von Gestaltungsmustern, die Johann Georg Übelher (1703-1763) und Johann Michael Feichtmayr (I 709/10-1772), zwei bedeutende Meister der Wessobrunner Schule, um I744 mit ihren Arbeiten im Querschiff und im Chor der Klosterkirche einführten. Am Dekorationssystem, am Duktus und am Charakter der Schnitzarbeiten zeigt sich, wie sehr die Kunst der Stuckateure auf die der Bildhauer einwirkte. Möglich wäre aber ebenso, dass der Auszier des Beichtstuhls detailreiche Skizzen Feichtmayrs zugrunde lagen, ersann er doch Altarentwürfe mit vergleichbaren Verzierungselementen. ${ }^{117}$ Zuletzt sei noch auf die Stuckarbeiten in der Pfarrkirche Unsere Liebe Frau zu Brixlegg aus den späten I 76oer-Jahren aufmerksam gemacht. Die auffallend leichten und luftigen Rocaillemotive der Stuckkünstler finden ihren Widerhall im Zierrat der dortigen Bankgarnitur (Abb. 295).

Wichtig ist bei diesen Überlegungen der Hinweis, dass eine Beeinflussung im Gegensinn selbstverständlich ebenfalls möglich wäre, dass also Tischler auch die Arbeiten anderer Gewerke geprägt haben könnten. Allerdings ist davon auszugehen, dass Künstler und Handwerker, die wie Maler, Stuckkünstler oder Bildschnitzer aufgrund ihres Renommees überregional tätig waren, weniger bekannten Kräften die Arbeitsvorlagen lieferten, nicht umgekehrt. ${ }^{118}$

I 6 Neumann, Handwerk (1879), I63; Preimesberger, ebd., 327.

I 7 Maier, Stuckmarmor (201 2), Abb. 59, 60, 64, 80, 85 usw.

I 8 So entstanden die Stuckverzierungen in der Innsbrucker Hofkirche bis 1692 nach Entwürfen und unter Leitung des Hofgoldschmiedes Johann (?) »Senex« Fries. Felmayer, Hofkirche (1986), 239, 273. 
IV.

\section{Barocke Möbel und sakraler Raum}

\section{Prunkappartements, Zeremoniell und Liturgie}

Die mannigfaltigen Wechselwirkungen zwischen der Anordnung repräsentativer Appartements in Schlossanlagen, der Distribution von Räumen, den Raumausstattungen und dem Hofzeremoniell bilden schon lange den Gegenstand erhellender Studien. ${ }^{119}$ Das Mobiliar, so Germain Boffrand (I667-1754) im Livre d'architecture von I745, hatte nicht nur in seiner Funktion dem Zimmer, in dem es stehen sollte, angemessen zu sein, sondern auch in seiner Qualität. ${ }^{120}$ Die magnificence oder auch die simplicité der Möbel entsprachen dem jeweiligen Ambiente und dem Rang eines Raums innerhalb des Hofzeremoniells. Je höher die Stellung war, die eine Raumabfolge im Hierarchiegefüge eines Schlosses einnahm, umso prächtiger war die Ausstattung. Die Bedeutung eines Hofes und seiner Bewohner ließ sich am Grad des Aufwandes ablesen, der im Hinblick auf Fragen der Repräsentation betrieben wurde. In der Frühen Neuzeit zählte die Planung von Interieurs daher zur Aufgabe von Architekten, Einrichtungen wurden nach Konzepten entwickelt, die alle Raumkünste einschlossen. ${ }^{121}$ Jedem Objekt kam ein fester Platz zu, nichts konnte hinzugefügt, nichts entfernt, nichts verändert werden, ohne das Gesamtbild zu zerstören.

Vertreter des hohen Klerus entstammten oft einflussreichen Adelsfamilien, weshalb sich die Vermutung aufdrängt, dass von analogen Überlegungen bei der Innendekoration der wohlhabenden Klöster und der bedeutenden Palais der Geistlichkeit auszugehen ist. Die prunkvollen Interieurs von Kaiserzimmern, Prälaturen und Paradeappartements in Klöstern und (erz-)bischöflichen Palais untermauern diesen Verdacht. Aber lassen sich entsprechende Tendenzen auch im Hinblick auf die Ausstattung von Sakral-

I 9 Hingewiesen sei hier nur auf Lorenz, Raumfolge (r993); Graf, Zeremoniell (r 997); Kalousek, Hofburginterieurs (20I6) sowie die relevanten Beiträge in Grenzen und Möglichkeiten (20I I) und Gaehtgens/Castor/Bussmann, Versailles (2017). Im folgenden Kapitel werden unter anderem die Kirchen von Augustinern, Jesuiten und Franziskanern, weiter die Schottenkirche, die Peterskirche und die Karlskirche in Wien, die Piaristenkirche und St. Veit in Krems, die Domkirche in St. Pölten sowie die Abteien Altenburg, Dürnstein, Göttweig, Heiligenkreuz, Klosterneuburg, Lilienfeld, Melk, Rein, Schläg1 und St. Lambrecht erwähnt. Hinweise zu den Anlagen finden sich im ersten Band der Untersuchung. Bohr, Sakralmöbel (20I7).

I 20 Boffrand, Livre d'architecture (I 745), 44. Vgl. hierzu auch Pozsgai, Germain Boffrand (20 I2), I 9 I.

I 2 I Wilke, Innendekoration (2016). 
räumen beobachten, die ebenfalls strengen Hierarchien unterlagen? Das Presbyterium mit dem Hauptaltar stand selbstredend an der Spitze der hierarchischen Ordnung, die den Laien zugänglichen Abschnitte am Ende der Skala. In seinen Studien wies Ulrich Schütte nach, dass der Kirchenraum als irdischer Thronsaal Gottes verstanden wurde, Ursula Brossette kam bei ihren Recherchen zu ähnlichen Ergebnissen. ${ }^{122}$ Vergleichbar mit dem Hofrecht in Schlossanlagen galt in Sakralräumen ein dem jeweiligen Anlass angepasstes Zeremoniell. Es legte die Liturgie fest und normierte das Verhalten der Geistlichen und Kirchenbesucher. Eucharistiefeiern waren ritualisierter Dienst, auch darin entsprachen sie dem Zeremoniell im profanen Bereich. ${ }^{123}$ Folgt daraus, dass Architekten und raumausstattende Künstler gewisse Grundregeln, die sie im Schlossbau beachteten, auf die Gestaltung von Kirchenräumen übertrugen? Existierte ein $\mathrm{Zu}$ sammenhang zwischen der Qualität der Möbel und ihrem Aufstellungsort innerhalb des Sakralraums? Und war das Mobiliar im barocken Raum integriert oder war sein Standplatz beliebig und konnte jederzeit geändert werden? Der folgende Abschnitt der Studie versucht, einige Antworten auf diese Fragen zu geben.

\section{Sakristeimöbel}

Die Paramentenschränke von I 654 in der Prälatensakristei der Abtei Schlägl gelten als die frühesten freistehenden Exemplare in Österreich, deren Maße unmittelbar von der Größe des Raums bestimmt wurden, zu dessen Ausstattung sie gehören. ${ }^{124}$ Ältere Möbelstücke, etwa jene in Lilienfeld von I646, sind Aufsatzschränke, mit denen nahezu jedes Zimmer eingerichtet werden könnte, dagegen übernehmen die Möbel in Schlägl die Länge und Höhe der Wandfläche, vor der sie stehen. Die Möbel wurden speziell für diesen Raum geschaffen, mit ihrer Großform passen sie exakt in dieses Umfeld. Die mit Säulen, Pilastern und Ädikulen als zweigeschossige Fassaden konzipierten Schränke ersetzen im Grunde genommen die hinter ihnen liegende Wand. Unmittelbarer Vorläufer für diese Art von Sakristeimöbeln war vermutlich die Einrichtung von St. Zeno in Bad Reichenhall aus den I64oer-Jahren ${ }^{125}$, doch dürften sich solche Möbelgarnituren aus fest eingebauten Wandschränken wie jenen in der Domsakristei zu Graz heraus entwickelt haben (Abb. I62). Auf die Möbel in Schlägl folgte I657/58 die architekturgebundene Sakristeiausstattung von St. Lambrecht (Abb. 263-269), deren

\footnotetext{
I 22 Schütte, Zeremoniell (I 995); Brossette, Inszenierung (2002), Bd. I, 582.

I $3 \mathrm{Zu}$ den Analogien zwischen Zeremoniell und Liturgie vgl. Schütte, ebd.

I 24 Ausgeklammert seien hier fest montierte Wandschränke wie jene im Dom zu Graz (Abb. I62), die Nischen im Mauerwerk ausfüllen und schon lange bekannt waren.

I 25 Zur Einrichtung von St. Zeno s. Renz-Krebber, Sakristeischränke (I 998), 45 .
} 
Massengliederung nur in diesem Raum einen Sinn erhält, ausschließlich dort wird ihre Form verständlich.

Ein ungewöhnliches Aussehen weisen ferner die Ankleidekredenzen des Klosters Altenburg von I735/40 auf. Die von einer ovalen Kuppel bekrönte Sakristei erhebt sich über rechteckigem Grundriss, der Eingang befindet sich auf der Südseite. Hohe und schlanke Nischen strukturieren das Mauerwerk, das im Westen und Osten für Fenster durchbrochen ist. Aufsatzschränke, deren Breite und Höhe von den Nischengewänden und Fensteröffnungen begrenzt werden, schließen die seitlichen Wandvertiefungen, lediglich das Exemplar auf der Nordseite ist etwas größer. Die Schränke zeichnen sich durch zwei Besonderheiten aus: Die Tischler nutzten beim Bau der Ankleidekredenzen nicht die gesamte Raumtiefe und -breite, sondern passten die Möbel in relativ kleine Nischen ein, was ihr Aufnahmevermögen stark begrenzte. Darüber hinaus besitzen die Sakristeischränke eine konkave Vorderfront und spiegeln so in raffinierter Weise die Rundung der Kuppel wider. Auch diese Garnitur ist folglich mit dem Baukörper verzahnt.

Auf andere Art fügen sich die Sakristeiausstattungen der Domkirche zu Salzburg und der Barmherzigenkirche zu Graz in die Raumschale ein (Abb. I I7-I 20, I48I 5 I). Die Schränke und Wandverkleidungen wurden I 733/36 resp. um I 770 gefertigt. Reichen die Tischlerarbeiten in Salzburg bis unter den Gewölbeansatz, wo sie mit einem weitgehend gerade verlaufenden Gesims abschließen, so ragen in der Sakristei der Barmherzigenkirche die Hochschränke über den Gewölbeansatz hinaus bis knapp unter die Decke. Das Getäfel zwischen den Kästen verklammert die Möbel mit dem Raum.

Ähnliches ist in der Sakristei des Stiftes Vorau zu beobachten, die I7I6 mit Ankleidekredenzen und einer Wandvertäfelung ausstaffiert wurde (Abb. 271-274). Die an den Wandpfeilern angebrachten Verkleidungen und die in die Fensternischen eingesetzten Schränke nehmen etwa das untere Drittel der Raumhöhe ein, darüber folgen großflächige Malereien. Das Deckenfresko vergegenwärtigt das Jüngste Gericht, an der Westwand bilden der Höllenrachen und die Verdammten den Bildinhalt, die Fresken der übrigen Wände geben Passionsszenen wieder. ${ }^{126}$ Die Gemälde erzeugen mit ihren bewegten Darstellungen einen scharfen Kontrast zur blockhaften Geschlossenheit des zeitgleich entstandenen Mobiliars, die von den gebauchten Oberschränken kaum gemindert wird. Gleichwohl ist die Tatsache nicht zu übersehen, dass der Entwurf der Möbelgarnitur auf eine organische Einbeziehung der Tischlerarbeiten in die gesamte Raumdekoration abzielte.

I 26 Gierse, Bildprogramme (2010), 508-524; Mayrhofer, Stift Vorau (2017), I 48-I 56. 
In den meisten anderen Sakristeien, die für das Forschungsprojekt untersucht wurden, hat man die Möbel deutlich von der Gestaltung des Baukörpers geschieden. Die Sakristeieinrichtung in der ehemaligen Domkirche zu Gurk bietet hierfür ein gutes Beispiel (Abb. 38-4I). Die Tischler passten dort das Möbelensemble und die Vertäfelung um 1702 ein. Wie die Abbildungen zeigen, rhythmisieren zwar hohe Schnitzaufsätze die Sakristeischränke, doch stehen sie in keinerlei Beziehung zum architektonischen Gerüst des Gewölbes. Interieur und Raum wurden als voneinander getrennte Entitäten aufgefasst.

\section{Chorgestüble}

Das Chorgestühl der mittelalterlichen Piaristenkirche zu Krems stammt von etwa I620 oder I630. Es wurde zwischen den schlanken Chorpfeilern aufgerichtet, wobei es wegen der Sakristeitür auf der Kirchennordseite unumgänglich war, auf einen Teil der Brüstung und der Stallen zu verzichten. Außerdem musste die Rückwand dem Umriss der Tür angepasst werden. Schon das Gesamterscheinungsbild dokumentiert den nachträglichen Einbau des Möbels. Eine Verschmelzung von Mobiliar und Architektur war offensichtlich nicht angestrebt. Anders das Chorgestühl der AugustinerChorherren in St. Florian: Die Grundsteinlegung zur Neuerrichtung der Stiftskirche fiel in das Jahr r685, die Einwölbung des Chors erfolgte r689, das Möbelensemble entstand in den I69oer-Jahren. Zusammen mit den beiden Emporen und der Chororgel füllt es die kurzen Querhausflügel der Kirche aus. Beim Betreten des Sakralbaus beeindrucken den Besucher zunächst die weit in den Raum ragenden Emporen mit ihren schweren Brüstungen, das Chorgestühl selbst verbirgt sich zwischen den mächtigen Stützen, die die Vierung tragen. Wenngleich es archivalisch nicht zu belegen ist, ist die Wahrscheinlichkeit doch groß, dass das Gestühl zusammen mit der Kirche geplant und nach einem gemeinsamen Konzept ausgeführt wurde.

I72I/22 baute Hippolyt Nallenburg (I687-I733) das Chorgestühl der früheren Augustiner-Chorherrenkirche zu St. Pölten und fügte es zwischen flache Pilaster ein. Wie das bei Stallen des Augustinerordens häufig vorkommt, weichen die Sitzreihen in der Gestühlsmitte zwei Türen, die in diesem Fall zur Sakristei, gegenüber zu einer Kapelle führen. Das Abschlussgebälk des Möbels umfängt je ein ovales Supraportfenster mit einer kräftigen C-Spange, zudem stellt ein mit reichen Schnitzarbeiten verzierter Aufsatz einen optischen Bezug zu einem weiteren Fenster bzw. zu einem Blindfenster her. Auch dieses Chorgestühl tritt nicht als eigenständiges Möbel in Erscheinung, sondern als Inventarstück, dessen Gestaltung auf die Architektur Bezug nimmt. Die Türen bilden zusammen mit den Fensteröffnungen vertikale Spiegel- und Raumachsen, das Gestühl ist perfekt in die Architektur integriert. 
Die Stiftskirche zu Dürnstein, eine weitere ehemalige Augustinerkirche, wurde seit I 7 I 5 überformt. Joseph Munggenast (I680-I74I) war der hauptverantwortliche Baumeister, zeitweise zog Propst Hieronymus Übelbacher (reg. I710-1740) weitere Architekten beratend hinzu. 1723 ließ der Propst ein neues Chorgestühl fertigen, Tischler war wieder Hippolyt Nallenburg. Wir dürfen unterstellen, dass es in Konkurrenz zum nur wenig älteren St. Pöltener Inventarstück entstand. Offenkundig bemühte sich Übelbacher in Dürnstein um eine ähnliche Gesamterscheinung, obschon mit etwas sparsameren Mitteln: Auf beiden Chorseiten sind über dem Gestühl Balustraden und Oratorienfenster angeordnet. Erneut ist der Wandaufbau mehrzonig, nun verbinden Lisenen und Stuckornamente das Möbel mit den Wandfeldern.

Im Hinblick auf die Frage nach der Eingliederung von Möbelgarnituren in den Kirchenraum übertrifft das Melker Chorgestühl von I 736/37 diese Beispiele bei weitem. Über dem Möbel befinden sich Oratorien, die von kräftigen Stuckvoluten getragen werden. Die V-förmig nach unten geführten Stuckarbeiten greifen über das Gebälk des Gestühls, das dadurch unverrückbar an der Wand verankert wird. Darüber hinaus werden hier ikonographische Beziehungen zwischen dem Möbel, dem Hochaltar und dem Deckenfresko wirksam. Vergoldete Reliefplatten mit Bildern aus der Vita Benedikts zieren das Dorsale des Gestühls, Reliefs mit Szenen aus dem Leben der Kirchenpatrone Petrus und Paulus das Sockelgeschoss des Altars. Die in der irdischen Sphäre verorteten Darstellungen am Möbel enden mit dem Tod Benedikts, finden jedoch ihre Fortsetzung in der überirdischen Sphäre des Deckengemäldes, das in einem illusionären Raum den von Engeln in den Himmel geleiteten Heiligen zeigt. Das ikonographische Programm der Kirche dient der Verehrung Gottes, der Verherrlichung der Ecclesia sowie dem Ruhm des hl. Benedikt, des Benediktinerordens und des Klosters Melk. ${ }^{127}$ Eventuell als Reflex auf Baumaßnahmen und Einrichtungen in großen süddeutschen Klöstern hatte Abt Berthold Dietmayr (reg. I700-I 739) von den Ausstattungskünstlern Antonio Maria Niccolò Beduzzi (I675- I735) und Giuseppe Galli Bibiena (I696-I757) einen außergewöhnlichen Entwurf für das Chorgestühl verlangt. Sie nahmen die künstlerische Herausforderung an und stellten das Gestühl physisch in einen Verbund mit der barocken Raumschale, sodass Chorgestühl und Mauerwerk zu einer Einheit verschmolzen. Zudem verknüpften sie Gestühl und Hauptaltar durch die Anbringung von Reliefs auf der materiellen Ebene. Und schließlich kombinierten sie es durch die Fortsetzung der auf den Reliefs des Gestühls erzählten Heiligengeschichte auf einer gedanklichen Ebene mit dem Deckenfresko. Damit fügt sich das

I 27 Zum komplexen Programm, das die Fresken, Skulpturen und Reliefs der Stiftskirche zusammenfasst, vgl. Telesko, Benedictus triumphans (2006); ders., Ecclesia militans (2010); ders., Kosmos Barock (2013), bes. 35-1 30 . 
Gestühl mit einer solchen Konsequenz in den Raum ein, wie kein zweites in Österreich. Wandgestaltung, Malerei, Altäre und Chorgestühl bilden in der Stiftskirche eine untrennbare Einheit, offensichtlich zielten der Abt und seine Künstler auf eine bis ins Detail reichende Kohärenz des Raums und seines Interieurs, auf eine Vereinigung aller relevanten Künste. Die Stiftskirche zu Melk und ihre Ausstattung ist das prachtvolle Ergebnis einer außergewöhnlich stringenten Vorgehensweise von Auftraggeber, Architekten und Planern. Die materielle und inhaltliche Bezugnahme der einzelnen Ausstattungselemente aufeinander ist derart komplex, dass kein Teilstück beseitigt, auf keines verzichtet werden könnte, ohne das Ensemble in seiner Gesamtheit massiv zu beeinträchtigen. Im sakralen Bereich blieb der Sakralbau in dieser Hinsicht hierzulande ein singuläres Kunstwerk.

Als Standort von Gestühlen wie jenen in Gurk (r680/8 I ; Farbtaf. o5; Abb. 3 I-33), Heiligenkreuz ( I 707/o9) oder Lilienfeld (um I 740/45) dienen die beiden westlichen Chorjoche bzw. die östlichen Langhausjoche. Während in Gurk Skulpturen Christi und der Himmelskönigin das Möbel vor einem Mauerpfeiler bekrönen, ragen auf dem Abschlussgebälk des Gestühls in Lilienfeld jeweils in der Arkadenmitte dreieckige Schnitzauszüge in die Höhe. Auf diese Weise wird in Gurk und Lilienfeld zumindest ein lockerer Bezug zur Tektonik des Raums geschaffen, während er in Heiligenkreuz fehlt. Dort schließt das Gestühl mit einer gleichförmigen Reihe von Büsten, eine Zentrierung oder Verklammerung des Möbels mit der Raumstruktur ist nicht zu erkennen.

Nach den Forschungsergebnissen von Sybe Wartena lässt sich an vielen süddeutschen Gestühlen des I 8. Jahrhunderts eine Akzentuierung der Mitte beobachten ${ }^{128}$, eine Art der Gestaltung, die an barocken Möbeln häufig wiederkehrt. Die Exemplare in der Stiftskirche Altenburg (um 1735) und in der Pfarrkirche St. Veit zu Krems ( $1735 / 36)$ kommen dem in besonderem Maße nach, denn zum einen ist das Abschlussgebälk der Möbel bzw. der jeweilige Schnitzaufsatz entsprechend ausgeformt, zum anderen erfuhren die Rückwände eine originelle Formgebung, da sich die mittleren Füllungen durch ihr Aussehen von den seitlichen unterscheiden. Beim Bau sehr vieler österreichischer Gestühle verzichteten die Tischler jedoch auf eine Hervorhebung der Mittelachse, ein Beispiel hierfür ist das erwähnte Exemplar in Heiligenkreuz, ein weiteres das Franz Anton Staudinger (I705-I78I) I765/66 für die Stiftskirche zu Göttweig verfertigte. Staudingers Möbel, ein Vertreter für eines der vielen barocken Reihengestühle, ist sogar asymmetrisch angelegt, weil es mit besonderen Plätzen für Abt und Prior endet. Das Gestühl wurde ohne formale Anbindung an die Wandfläche im Chorraum der Abteikirche errichtet und könnte in fast jeder beliebigen Kirche platziert werden.

I 28 Wartena, Süddeutsche Chorgestühle (2008), I 28. 


\section{Beichtstühle}

In der Stiftskirche Dürnstein stimmen verschiedene Gestaltungsmerkmale des Chorgestühls und der Türen im Altarraum sowie in den Seitenkapellen überein, in einem der nächsten Abschnitte wird darauf einzugehen sein. Ein anderes Erscheinungsbild wurde dagegen für die um I725/29 erzeugten Beichtstühle in Dürnstein gewählt. Propst Hieronymus Übelbacher muss diesen formal-ästhetischen Bruch beabsichtigt haben, um auch mithilfe der Tischlerarbeiten Unterschiede in der Bedeutung des Kirchenraums für den Ritus zu betonen. ${ }^{129}$ Dennoch war sein Anspruch an die Qualität der unter der Westempore aufgestellten Beichtstühle außerordentlich hoch, was dem Umstand Rechnung trug, dass in den Jahren um I 700 die Läuterung der Gläubigen durch die Kraft der Beichte und die Spendung des Bußsakramentes eines der zentralen ikonographischen Motive im Eingangsbereich katholischer Sakralbauten in Österreich war. ${ }^{130}$ Büßerfiguren auf den Dürnsteiner Beichtstühlen sowie seitlich der Möbel angebrachte Reliefs mit szenischen Darstellungen erläutern diese Thematik, unterstrichen wird das eindrucksvolle Bild der Reinigung von Geist und Körper durch große Weihwasserbecken, die Übelbacher dort aufstellen ließ. ${ }^{131}$ Und wieder liegt die Verknüpfung der Möbel mit dem Baukörper auf mehreren Ebenen vor. Denn zusammen mit den inhaltlichen Botschaften, die in diesem Raumabschnitt vermittelt werden, schließen die Beichtstühle Nischen in der Kirchenaußenwand, wobei die Plastiken auf den Möbeln bis knapp unter den Abschlussbogen der Einbuchtungen reichen. Offensichtlich plante man die Möbel unter bestmöglicher Ausnutzung der räumlichen Gegebenheiten, sie sind bedeutender Teil einer bewussten Gestaltung des Baukörpers.

Die Beichtstühle in Bad Mehrn, Innsbruck, Kramsach und Vomp (Abb. 290, 302, 3 I 8, 343-346) sind zwar ebenfalls in Mauernischen eingesetzt, aber auf geistiger Ebene sehr viel lockerer in den Umraum integriert. Dennoch unterscheiden sie sich grundlegend vom überwiegenden Teil der für die Studie untersuchten Confessionalen, denen ein scheinbar zufällig gewählter Platz im Kirchenraum zugewiesen wurde. ${ }^{132}$ Während die um I725 gefertigten Beichtstühle in Zwettl durch Bildnisse von Büßern immerhin noch gedanklich auf den Sakralraum verweisen, existieren in vielen anderen Kirchen Exemplare, die man ohne jegliche Beziehung zur Umgebung scheinbar willkürlich an irgendeinem Platz positionierte. Beispiele hierfür werden in der Wiener Schottenkirche (I720er-/4oer-Jahre), in Neuberg (um I735/40; Abb. 2 I 2) oder in Vorau (um

I 29 Vgl. hierzu auch Bohr, Sakralmöbel (2017), 27 I-273.

I30 Euler-Rolle, Form (1983), 6r.

I3 I Kain/Penz, Inszenierung (2010), I33-136.

I32 Zum Aufstellungsort der Beichtstühle im Kirchenraum vgl. Bohr, Sakralmöbel (20 I 7), 9I. 
I 730/40, I 760/70; Abb. 282, 283) aufbewahrt. Dort stehen die Beichtstühle vor einer beliebigen Wand, ein kohärentes gestalterisches System ist nicht zu erkennen.

\section{Kirchenbänke}

Johann Bernhard Fischer von Erlach (1656-1723) errichtete die Salzburger Dreifaltigkeitskirche um I 70o. Konzipiert hatte er sie als ovalen Zentralbau mit vier gewölbten Kreuzarmen und tiefen Nischen in den mit mächtigen Pfeilern verstärkten Wandsegmenten, auf denen die Kuppel aufliegt. Die Bänke wurden um I 702 vermutlich in der Werkstatt des Hoftischlers Balthasar Köbl (1645-1 7 I I) gefertigt (Abb. Io6-ı го). Das Gestühl steht nicht wie üblich frei im Kirchenraum, sondern vor den bogenförmigen Außenwänden, wobei es der Tischler in die ebenfalls abgerundeten Nischen einpasste. Unterbrochen wird es lediglich von den Altarschranken und dem schmiedeeisernen Gitter, das das Emporenjoch mit dem Eingang zur Kirche vom Hauptraum abgrenzt. Damit verlieh man den Möbeln eine ringähnliche Form, die den Grundriss der barocken Architektur nachzeichnet. Durch die Gruppierung der Bänke um das räumliche Zentrum der Architektur führt Fischer den Zentralbaugedanken konsequent weiter. Die Bänke in der Dreifaltigkeitskirche unterscheiden sich deutlich vom Laiengestühl in anderen ovalen Bauten. Erinnert sei lediglich an die Möbel in der Peters- und der Karlskirche, beide in Wien. Dort stehen sie wie in Anlagen mit basilikalem Grundriss quer zur Kirchenlängsachse, wobei sie frontal auf den Altar hin ausgerichtet sind. Nur durch ihre unterschiedliche Länge spiegeln die Bänke in den beiden Wiener Kirchen die besonderen Grundrisse wider.

Schon im ersten Band der Untersuchung wurde auf das Laiengestühl in der Wiener Jesuitenkirche aufmerksam gemacht. Getragen von einem zweigeschossigen Sockel, überragt es durch seine Höhe die Bänke in den meisten österreichischen Kirchen um I 5 oder $20 \mathrm{~cm}$. Deshalb und wegen seiner massiven Wangen formt das Gestühl auf beiden Seiten des Mittelgangs eine brusthohe und optisch weitgehend geschlossene Wand, die den Blick der Kirchenbesucher beim Betreten des Baus direkt auf den Hauptaltar lenkt. Sie werden auf diese Weise angeleitet, ihre uneingeschränkte Aufmerksamkeit dem ideellen Zentrum des Kirchenraums zu widmen. ${ }^{133}$

An einigen Bankgarnituren schaffen ikonographische Verweise einen Bezug zum Sakralraum. Die im I 7. Jahrhundert gebauten Möbel in der Stiftskirche St. Lambrecht sowie in Mariahof und Pürgg (Abb. 202, 230, 26I) tragen die Monogramme Christi und Mariens. Ein jüngeres Gestühl befindet sich in der Wiener Augustinerkirche und ist mit Reliefs versehen, die kultische Geräte des Alten und Neuen Bundes so-

I33 Koller, Universitätskirche (2003), 58. 
wie szenische Darstellungen mit Begebenheiten aus der Heiligen Schrift präsentieren. Geschnitzte Bilder vervollständigen überdies die Bänke in der Wiener Franziskanerkirche, auf großen Tondi sind dort Ordensheilige zu erkennen. Ferner wären die Laiengestühle in der Wiener Peterskirche und der Melker Stiftskirche zu erwähnen, die Cherubim und Palmzweige sowie Reliefs mit der Tiara und den gekreuzten Schlüsseln Petri bereichern. Die Möbel in den genannten Sakralbauten sind auf die späten I720er- und 3oer-Jahren zu datieren. Und schließlich zählt zu dieser Art von Möbeln die Bankgarnitur der Benediktinerkirche in Vomp-Fiecht (Abb. 340, 34I) von 177 I/73. Die Schnitzarbeiten an den Wangen geben marianische Symbole, Szenen aus dem Leben der Heiligen Familie, ferner Heilige sowie Papstinsignien und Sakralgerätschaften wieder. In profanen Räumen ergäben Inventarstücke mit solchen inhaltlichen Aussagen selbstverständlich keinen Sinn.

\section{Türen}

Bei der Erwähnung des Dürnsteiner Chorgestühls wurde bereits der mehrzonige vertikale Aufbau beschrieben, der Gestühl und Mauerwerk charakterisiert. Die gleiche Aufteilung zeichnet zwei von Pfeilern flankierte schlanke Wandachsen im Altarbereich der Stiftskirche aus. In vier Register gegliedert, bestehen die senkrechten Bänder aus je einer Tür, einem Relief, einer Balustrade und einem Fenster. Die Höhe der verschiedenen Ebenen entspricht jener des Gestühls und der Einteilung des Mauerwerks darüber, zudem hatte Probst Übelbacher seinen Tischler Hippolyt Nallenburg angewiesen, für das Gestühl und die Portale die gleichen Werkmaterialien zu verwenden. ${ }^{134}$ Daher stimmt der an den Arbeiten vorherrschende Farbklang überein, den das relativ helle, nur leicht gemaserte Nussholz, das dunklere Pappelmaserholz und die vergoldeten Schnitzarbeiten bestimmen. Außerdem achtete Nallenburg auf eine identische Ausformung besonderer Details. So gleichen sich die Umrissformen der gebauchten Füllungen, die von geschnitzten Blüten und schmalen Rundprofilen gesäumt werden. Das Aussehen der Türen im Altarbereich wiederholte Nallenburg bei der Fertigung der Portale für die Seitenkapellen. Dem Propst war es augenscheinlich ein Anliegen, die Tischlerarbeiten zu vereinheitlichen und durch entsprechende gestalterische Mittel in die Architektur einzubinden. Auch in Dürnstein offenbart sich das Bestreben, die raumaustattenden Künste einer übergeordneten Leitidee unterzuordnen.

I 34 Kain/Penz, Inszenierung (20 Iо), I45, I 57-I 58 und Abb. I i 6; Penz, Kalendernotizen (20 1 3), 26 I-262. 


\section{REsÜMEE}

Der von Dekorationskünstlern betriebene Aufwand richtete sich im sakralen Bereich einerseits an die Kirchenbesucher, andererseits an die Konvente, die Angehörigen von Schwesterklöstern sowie an Geistliche aus nahegelegenen Abteien und Weltkirchen. Im Schlossbau dienten Repräsentation und Zeremoniell in erster Linie der fürstlichen Selbstinszenierung sowie der Sichtbarmachung von Rangunterschieden und gesellschaftlichen Hierarchien. Auf der Ebene der Peergruppen sollte der Prunk ebenso seine Wirkung entfalten wie den Untertanen gegenüber. Johann Christian Lünig ( 1662-1 740) betonte in einem seiner häufig zitierten Beiträge, dass Luxus und Pracht sowohl die Rechtmäßigkeit der auf göttlichem Willen beruhenden Gesellschaftsordnung als auch die Legitimität des Gewaltmonopols absolutistischer Herrscher unter Beweis stellten. ${ }^{135}$ Viele der theoretischen Grundlagen, Vorstellungen und Überzeugungen, die in der Profanarchitektur Bedeutung erlangten, lassen sich auf die Entwicklung des kirchlichen Ritus und die Ausstattungen sakraler Räume übertragen. ${ }^{136}$ Welch hohen Stellenwert man Fragen der Repräsentation beimaß, belegen die prachtvollen Kircheneinrichtungen, die nicht zuletzt darauf abzielten, römisch-katholische Sakralbauten im Sinne der Gegenreformation von Gebetshäusern anderer Glaubensrichtungen abzuheben und die Kirche als ecclesia triumphans zu präsentieren. Zugleich hatten bildliche Darstellungen, seien sie nun von einem Maler, einem Bildhauer oder einem Stuckateur, sorgsam gewählte Glaubensinhalte zu vermitteln. Oft wurden dieselben Künstler mit der Ausführung der Deckengemälde in Kirchenräumen und Sakristeien beauftragt, was den Schluss nahelegt, dass der Zwang zur visuellen Selbstinszenierung nach innen hin dem nach außen gerichteten kaum nachstand. ${ }^{137}$ Ein weiteres Indiz dafür sind die Sakristeimöbel in St. Florian, Lilienfeld oder in der Salzburger Domkirche (Abb. I I 7-1 20), die in ihrer Qualität kaum zu übertreffen sind. Das Gleiche gilt für die Chorgestühle auf den Emporen von Rein, St. Lambrecht und Vorau (Abb. 243-248, 254-259, 275-278) oder für Gestühle hinter dem Altar. ${ }^{138}$ Diese Kunsterzeugnisse waren dem Auge des Kirchenbesuchers selbstredend verborgen. Ein ähnlicher Befund gilt in Bezug auf die Gestühle in Heiligenkreuz, Krems, St. Pölten, Dürnstein und Melk, die zwar für jeden sichtbar im Langhaus bzw. im Chor der Sakralbauten ihren Platz haben, doch die Reliefs, die diese Gestühle auszeichnen, werfen unweigerlich Fragen nach der Lesbarkeit auf. Denn aus der Pers-

I 35 Lünig, Theatrum ceremoniale ( 17 I $9 / 20)$, Bd. I, 5 .

I36 Schütte, Zeremoniell ( 1995 ).

I37 Gierse, Bildprogramme (2010), I07-I Iо.

I $38 \mathrm{Zu}$ einem hinter dem Hauptaltar aufgestellten Gestühl vgl. Bohr, Sakralmöbel (20 I 7), I56- 5 8. 
pektive der Kirchenbesucher stehen die Möbel in einem denkbar ungünstigen Winkel zum Längsschiff. Laien, denen der Zugang zum Chorraum verwehrt ist, erkennen nur wenige Fragmente der »Reliefschauwände ${ }^{139}$ Der Inhalt der geschnittenen Bilder bleibt ihnen verborgen. Die Selbstdarstellung der Konvente richtete sich folglich an die eigene Mönchsgemeinschaft sowie an fremde Geistliche, die im Chorraum an Chorgesang und Eucharistiefeier teilnahmen. ${ }^{140}$ Eindrucksvoller können hierarchische Unterschiede kaum zum Ausdruck gebracht werden.

Anthony Blunt vertritt die These, in Mittel- und Osteuropa hätte es im I 8. Jahrhundert bei der Errichtung neuer und der Renovatio bestehender Kirchen zur Aufgabe der Architekten gehört, künstlerische Gesamtkonzepte zu entwickeln. ${ }^{141}$ Tatsächlich konnten für bedeutende schwäbische Klöster, die zwischen den I $720 e r-$ und den I76oer-Jahren barockisiert wurden, Bestrebungen nachgewiesen werden, den Innenraum durch eine Synthese aller Kunstgattungen zu einem großen Kunstwerk $\mathrm{zu}$ vereinen. ${ }^{142}$ Und auch bei den hier untersuchten Sakralbauten waren besonders in Verbindung mit St. Pölten, Melk und Dürnstein ähnliche Tendenzen zu beobachten. Andererseits ergaben Studien zu österreichischen Klöstern, zu denen ebenfalls Melk und Dürnstein zählen, dass das Aussehen der Interieurs oft erst während der Entstehung der Bauwerke geplant und festgelegt wurde. Das vermag schon deshalb nicht zu überraschen, da sich Bau und Innendekoration von Kirchen häufig über Jahrzehnte hinzogen, was einen natürlichen Wechsel von Auftraggebern und Handwerkern sowie Projektänderungen aufgrund neuer Modeerscheinungen zur Folge hatte. Die Annahme einer vor dem Baubeginn abgeschlossenen Planung entspricht wohl nur in außergewöhnlichen Fällen der historischen Realität. Gleichwohl achtete man beim Umbau von Kirchen häufig sehr genau auf ein einheitliches Erscheinungsbild. Unter anderem führte das dazu, dass man in Melk bereits fertiggestellte Ausstattungsstücke partiell überarbeitete, um sie neueren Objekten anzugleichen. ${ }^{143}$ Möbel, die zuvor klar vom Baukörper getrennt und »mobil« waren, konnten im zweiten Viertel des I8. Jahrhunderts zu einem festen Bestandteil der Architektur werden, sie konnten in ein Raumkunstwerk integriert und mit der Architektur fest verbunden werden. ${ }^{144}$

I39 So bezeichnet Ulrike Weiß diese besondere Art von Gestühlsrückwänden. Vgl. herzu auch Weiß, Bilder (1998), bes. 3 I-5 I.

I 40 Dass es wie in St. Florian Laien gestattet war, sich im Chorraum der Kirche aufzuhalten, wird eher die Ausnahme gewesen sein.

I4 I Blunt, Kunst (I 979), I 72 .

I 42 Weiß, Bilder (I 998), 50-5 I. Sybe Wartena vermutet, dass in seltenen Fällen schon im I 7. Jahrhundert mit Gesamtplanungen zu rechnen sei. Wartena, Süddeutsche Chorgestühle (2008), I 26-I 3 I .

I 43 Euler-Rolle, Form ( I 983), I 57-I 59; Lorenz, Raumfolge ( 1 993), bes. 29 I ; Erichsen, Gesamtkunstwerk (2OI I), bes. I34.

I 44 Um I780 standen in Pariser Salons »chaises courantes« im Rauminnern, »fauteuils« und »canapés 
Solche Möbelgarnituren müssen als plastisch modellierter Teil des Baukörpers und nicht als bewegliches Inventar interpretiert werden, womit sie die schon in der Einleitung wiedergegebene These von Adolf Feulner stützen, der in Kirchenmöbeln kaum mehr als eine Art skulpturaler Raumdekoration erblickte. ${ }^{145}$ Allerdings präsentiert die Studie auch etliche Beispiele, bei denen die Einbindung des Mobiliars in das jeweilige architektonische und künstlerische Ambiente als sekundär empfunden wurde. Über die Ursachen dafür können wir nur spekulieren, doch mag ein Grund in den Sehgewohnheiten liegen, schließlich erhielten in vielen Bauten barocke Ausstattungsstücke einen Platz neben Jahrhunderte alten Fresken und Skulpturen, stilistische Brüche waren dort evident. Zudem wählte man bei der Renovatio der Zisterzienserabtei Stams bewusst die Verknüpfung von Altem mit Neuem, um die Tradition des Ordens und die bedeutungsvolle Geschichte des Klosters zu dokumentieren. Sakrale Einrichtungen ordneten sich also bei weitem nicht immer einem vorgegebenen Umfeld unter. In dieser Hinsicht konnten sie sich fundamental von profanen Interieurs unterscheiden, die bei anspruchsvollen Schlossbauten im fortgeschrittenen I 7. und I 8. Jahrhundert in einem Zuge geschaffen wurden. Die Vermutung Anthony Blunts von einer Gesamtplanung, die Architektur und raumausstattende Künste beim Kirchenbau umfasste, muss also zumindest im Hinblick auf Österreich abgeschwächt werden. Das gilt auch für die These von Herbert Schindler, der barocke Chorgestühle fest mit der Architektur verquickt sieht und eingebunden in ein dichtes »Netz optischer Beziehungen «. ${ }^{146}$ In ihrer Absolutheit ist Schindlers These nicht zu halten. ${ }^{147}$

meublants« dagegen vor den Wänden. Die Etikette gestattete die Verwendung der Stühle, nicht aber die der Sessel und Kanapees. Letztere dienten nicht als Sitzmöbel, sondern waren anscheinend Dekor und notwendiger Teil der Raumgestaltung. Watson, Furniture (1960), 35.

I 45 Feulner, Kunstgeschichte (1927), 7; ders., Kunstgeschichte (1980), I 2. Eventuell erklärt sich so auch die Gestaltung der Sakristeischränke von St. Paul und Mariahof (Farbtaf. o9; Abb. 61, I98).

I46 Schindler, Chorgestühle (I 983), 64 .

I47 Vgl. hierzu auch Wartena, Süddeutsche Chorgestühle (2008), I 26-I 3 I. 
V.

\section{Zeittypische Stilbildungen}

\section{SÜDdeutschland, Italien und FrankReich}

In Österreich finden sich die frühesten Stuckarbeiten mit italienischem Akanthusdekor an Bauten aus dem späten r6. Jahrhundert in Salzburg und in der Steiermark. ${ }^{148}$ Nur wenig später gewann der italienische Einfluss, nun mit den charakteristischen frühbarocken Formen, landesweit an Boden. Nach I6I4 errichtete Santino Solari ( 576 - I646) den Salzburger Dom, nach I6 I6 Cipriano Biasino (I 580-I636) St. Veit in Krems. ${ }^{149}$ Die beiden Architekturen waren damit die ersten Barockkirchen in Österreich, die Baumeister kamen aus Italien. Gleichwohl trifft auf österreichische Tischlerarbeiten das vorherrschende Narrativ, dem zufolge Italien im I 7. Jahrhundert von überragender Bedeutung für die Ausgestaltung von Kunstobjekten gewesen wäre, erst gegen Ende jenes Säkulums vollumfänglich zu. ${ }^{150}$ Bildschnitzer verzierten sie nun mit italienischem Akanthus, Möbelgarnituren, die in den Jahren um die Jahrhundertwende in St. Florian, Baumgartenberg, Villach, Salzburg und andernorts entstanden (Abb. 68, 75, 76, I 25-132), können hierfür als treffende Beispiele angeführt werden. Schwere Blattranken überwuchern die Möbel und verbergen das struktive Gerüst, als Hochrelief ausgeführtes Blattwerk löst sich vom Untergrund und steht frei in den Raum ${ }^{151}$, aus schmückendem Beiwerk wird formgebendes Muster. Feststellbar ist eine Umkehrung von Form und Ornament. Die ausschlaggebenden Impulse zu dieser Entwicklung gaben nach heutigem Kenntnisstand Akanthusaltäre im oberösterreichischen Garsten aus den späten I68oer-Jahren und die nur wenig später entstandenen Entwürfe von Johann Indau (165 I-1690) und Johannes Unselt (nachgew.

I 48 Preimesberger, Stukkatur (I 964), 325; Saliger, Stuck (I 987); Irmscher, Akanthus (2000), 487-490, 504. S. prinzipiell auch Rothe, Akanthusornament (1938).

I 49 In diesem Kapitel werden unter anderem die Schottenkirche in Wien, St. Veit und die Piaristenkirche in Krems, die ehemaligen Abteien Baumgartenberg, Dürnstein und die heutige Domkirche in St. Pölten sowie die Stifte Göttweig, Heiligenkreuz, Melk und St. Florian erwähnt. Vgl. zu diesen Sakralanlagen die entsprechenden Beiträge in Bohr, Sakralmöbel (20I7). Zur Metropolitankirche in Salzburg s. den entsprechenden Abschnitt im nachfolgenden Katalogteil des Buchs.

I 50 Überregional ist erst ab etwa I680 im gesamten mitteleuropäischen Kunstraum eine verstärkte Rezeption südlicher Kunst zu beobachten. Lorenz, Architektur (I 999), 224.

I 5 I Vgl. hierzu Irmscher, Akanthus (2000), 478-479. 
I68I-I696). ${ }^{152}$ Bis etwa I710 war italienischer Akanthus eines der am häufigsten verwendeten Kompositionsmotive im österreichischen Möbelbau.

Trotz des frühen Einflusses welscher Baumeister und Stuckateure auf die Baukunst orientierten sich Tischler hierzulande bis weit ins letzte Viertel des I7. Jahrhunderts hinein an der Beschlagwerkornamentik sowie am knorpeligen und teigigen Formenschatz des nordischen Spätmanierismus und Frühbarocks. ${ }^{153}$ Länger als andere Kunstgattungen dominierten den Möbelbau künstlerische Vorgaben und Handwerkstraditionen, die auf einer Synthese aus eigenständigen Entwicklungen, italienischen Inventionen sowie Schöpfungen aus süddeutschen Kunstlandschaften beruhten, wobei Letztere oft das italienische Kunstschaffen rezipierten. Chorgestühle, die wie jene in St. Stephan zu Wien oder in der Innsbrucker Jesuitenkirche (Fabtaf. 30; Abb. 306, 308, 309) um die Mitte des I7. Jahrhunderts erzeugt wurden, zeigen mit den rundbogigen, von Stützen flankierten Arkaden und dem geraden Abschluss noch immer renaissancezeitliche, die Massivität und Schwere der Möbel betonende Strukturen. Gleichwohl bildete das Knorpelwerk bei der Gestaltung dieser Inventarstücke die Grundlage für Zierformen, die in zwei unterschiedlichen Ausprägungen auftraten: auf der einen Seite kräftige und voluminöse Motive wie an den Bänken der Innsbrucker Jesuitenkirche (Abb. 304, 305), auf der anderen jener atomistische Zierrat, wie er am Chorgestühl der Jesuitenkirche, aber auch an Möbeln der Innsbrucker Servitenkirche und in Bad Mehrn zu beobachten ist (Abb. 287, 288, 3 I 5). Für die Stilrichtungen finden sich Vorlagen von Lukas Kilian (I 579-I637), Friedrich Brentel (I $580-$ I65 I) und Friedrich Unteutsch (um r60o-г670), die Entwürfe stammen von I6 го bis I633 und von I $650 .{ }^{154}$ Flächendekor aus Akanthus wird man an österreichischen Möbeln bis ins späte I7. Jahrhundert hinein jedenfalls vergeblich suchen.

Zusammen mit der Entwicklung des Knorpelwerks lässt sich im Verlauf des I 7. Jahrhunderts eine deutliche Steigerung des Tiefenreliefs der Möbelfassaden beobachten. Interessante Erkenntnisse hierzu bietet ein Vergleich der Gestühle in der Innsbrucker Jesuitenkirche mit Möbeln in St. Stephan zu Wien und in der Stiftskirche Wilten (Farbtaf. 30; Abb. 306-3 10, 378, 379). Die Möbelgarnituren entstanden im zweiten Drittel des I 7. Jahrhunderts. Hochgesockelte Pilaster bilden die Grundlage des architektonischen Gefüges, das die Rückwände der Gestühle in Innsbruck auszeichnet. ${ }^{155}$

I $52 \mathrm{Zu}$ den Altären s. Euler-Rolle, Akanthusaltäre (1987), bes. 69. Zu Indau und Unselt vgl. Berliner/ Egger, Vorlageblätter (198 I), Bd. I, 88-89, Bd. 3, Abb. 1060-1062, 1068-1072.

I53 Allerdings beruhte der nordische Frühbarock wohl auch auf italienischen Inventionen. Einer der Wegbereiter barocker Ornamentik war Federico Zuccari (I 542-I609), dessen Stiche um oder kurz nach I 600 entstanden. Berliner/Egger, ebd., Bd. I, 72-73, Bd. 2, Abb. 73 I -734.

I 54 Berliner/Egger, ebd., Bd. I, 78-79, 8 I-82, Bd. 2, Abb. 864-869, 914-9I6, 948-950.

I5 5 Mit einer vergleichbaren Gestaltung warten das Chorgestühl in der Innsbrucker Hofkirche von 
Die seichten Stützen heben sich kaum von der Grundfläche ab und nehmen ähnlich flache Arkaden in ihre Mitte. Wie wenig andere erinnern diese Möbelgarnituren an renaissancezeitliche Architekturen. Im Gegensatz dazu werden die Rückwände der Gestühle in Wien und Wilten durch das Zusammenspiel von Nischenarkaden, die eine mehrfache Tiefenschichtung auszeichnet, mit kräftigen, sich deutlich von der Bezugsebene lösenden Pilastern oder Säulen unmissverständlich dreidimensional, die Dekorformen entfalten auf diese Weise eine kraftvolle Reliefwirkung. Das Licht fällt ungleichmäßig auf die skulptural wirkenden Flächen, was für ein kontrastreiches Wechselspiel zwischen Lichtreflexen und Schattenzonen sorgt. Dadurch gewinnen die Möbel optisch noch an räumlicher Tiefe - ein wichtiges Gestaltungsmittel im früh- und hochbarocken Möbelbau. In Verbindung damit treffen der Formensprache des Schweifwerks entlehnte leichte und luftige Ornamente auf frühbarocken knorpeligen Zierrat und werden bald danach von schweren amorphen Gebilden verdrängt. Es verblüfft, wie sehr sich das Erscheinungsbild der Möbel in jenem Zeitraum änderte. Pilaster werden durch Säulen ersetzt, die zudem nicht selten tordiert gedreht sind (Abb. 54, 25 5, 264), ursprünglich relativ flache Oberflächen gewinnen im zweiten Jahrhundertdrittel an Plastizität, die Vorderseiten der Möbel werden durchmodelliert (Abb. 66).Zugleich erhalten Chorgestühle, Schränke und Beichtstühle (Abb. I 24, I 33 , I 34, I4 I, I 42, I7 I) hohe Aufsatzüberbauten oder Schnitzauszüge, die die Betonung der horizontalen Strukturen zugunsten vertikaler Akzente aufbrechen.

Seit dem ausgehenden I7. Jahrhundert wird jedoch zunächst in Wien und in der näheren Umgebung der Residenzstadt, bald darauf auch in Graz französisches Bandlwerk rezipiert. Zunächst wirkte die stilistische Parallelströmung nur in Ausnahmefällen, im Laufe der Zeit aber immer häufiger. Schon ein Druck aus den I69oer-Jahren von Friedrich Jacob Morisson (nachw. I693 und r697) gibt deutliche Hinweise auf den französischen Einfluss, der im frühen i8. Jahrhundert im Möbelbau rasch zunimmt. ${ }^{156}$ I 701/02 werden die Sommersakristei in Melk und die Bibliothek zu Heiligenkreuz mit französischen Bandlwerkmotiven bereichert, I 706 bis I 709 die Bänke in der Domkirche zu Graz (Abb. I52, I53) mit einer Mischung von Akanthus und Bandlwerk. Um I 730/40 stellte der Göttweiger Abt Gottfried Bessel (reg. I 7 I 4-I 749) zur Ausstattung seines Klosters Handwerker ein, die in Paris ausgebildet worden waren, während der Konvent von St. Florian in jener Zeit noch venezianische Sitzmöbel ankaufte. Die Tischler sahen sich folglich mit ihren Erzeugnissen seit der Wende vom I 7.

${ }_{1562 / 63}$ oder auch das um I590/r6oo gebaute Gestühl in der Pfarrkirche Hl. Karl Borromäus in Hohenems auf. ÖKT, Innsbruck, Hofbauten (I 986), 29 I, Abb. 368; ÖKT, Feldkirch (I 958), 390, 39 I.

I 56 Zum Druck von Morisson vgl. Ornamentstichsammlung des Wiener Museums für angewandte Kunst (MAK), KI $220 \mathrm{I}^{-\mathrm{I}}$. 
zum i 8. Jahrhundert einem wachsenden Spannungsfeld zwischen dem italienischen und französischen Kunstschaffen ausgesetzt, was sich im Erscheinungsbild des Mobiliars jener Epoche deutlich widerspiegelt. Auf die überladenen Akanthusmöbel, die oft keinerlei klare Strukturen zu erkennen geben, reagieren die Handwerker seit dem Beginn des I 8. Jahrhunderts mit einer Beruhigung der Formen, auf die schweren vegetabilen Ornamentmotive wird zunehmend verzichtet, die Tiefe der Möbelfassaden und Schnitzarbeiten nimmt ab. An Chorgestühlen wie jenen in Heiligenkreuz, St. Pölten, Dürnstein und Melk lässt sich das sehr gut ablesen. In Verbindung damit wäre noch auf eine kurze Phase in den Jahren um I730/35 aufmerksam zu machen, in der namentlich im Osten Österreichs eine im Grunde antibarocke Stilströmung ein relativ schlichtes Äußeres von Möbeln zur Folge hatte. Stallen in der Göttweiger Chorkapelle und die dortigen Bibliotheksmöbel bestätigen das ebenso wie Sakristeimöbel in der Schottenkirche zu Wien oder in der Zisterzienserkirche in Wiener Neustadt.

\section{Pilaster, Säulen, Lisenen und pilasterartige Stützen}

Das Interesse österreichischer Tischler galt im I7. und frühen I8. Jahrhundert namentlich den Möbelfassaden, das Aussehen der Schmalseiten hielt man für zweitrangig. Konsequenterweise besitzen viele früh- und hochbarocke Möbelstücke zwar aufwendig gestaltete Fronten, aber einfache Stirnseiten. ${ }^{157}$ Der Einzelbeichtstuhl in der Kremser Piaristenkirche sowie der Schrank in der Sakristei der Salzburger Dreifaltigkeitskirche (Abb. I r6) sind dafür gute Beispiele.

Möbelvorderseiten besaßen im I7. Jahrhundert das Aussehen von Architekturfassaden, Säulen, Pilaster und Lisenen verliehen den Inventarstücken die geforderte tektonische Struktur. ${ }^{158}$ Gegen Ende des I 7. Jahrhunderts wurde die tragende Rolle der Stützensysteme aufgegeben, ein Motiv, das man in der ersten Hälfte des r6. Jahrhunderts im süddeutschen und österreichischen Möbelbau eingeführt hatte, verlor nach knapp zwei Jahrhunderten seine frühere Bedeutung. Bedeckte nicht Akanthus die Möbel, dienten Stützen zwar noch immer zur Gliederung der Flächen, doch formte man sie nun zu "pilasterartigen« Bändern um. Die Sakristeimöbel von I702/o4 in St. Augustin zu Wien, das Laiengestühl von I 706/og in der Grazer Domkirche (Farbtaf. I 9;

I57 Im Norden war das anders. Schütz, Interieur (2009), Abb. I29, mit einem Gemälde von Pieter de Hooch (I629-I684). Das I 663 entstandene Bild zeigt zwei Damen vor einem Wäscheschrank, dessen Seiten ebenso kostbar wie die Vorderseite gearbeitet waren. Vgl. dazu auch von de Hoochs Gemälde „Familie beim Musizieren« von 1663 im Cleveland Museum of Art [https://www.clevelandart.org/ art/1 95 I. 355 ; Zugriff Juni 2020].

I 58 Entsprechende Kastenmöbel werden als »Fassadenschränke« bezeichnet. 
Abb. I 52 ), die Bänke in Vorau von I724 (Abb. 279, 280) oder die Gestühle in Rein und Bregenz aus den I 740er-Jahren (Farbtaf. 32; Abb. 244, 246, 380) dokumentieren diese Entwicklung recht anschaulich. Pilasterbasen und Sockelleisten, Pilasterkapitelle und Gebälke liegen jetzt auf einer Ebene und durchdringen sich gegenseitig. Mit Ornamenten reliefierte Bänder ersetzen die Stützen und lassen aus einem statischen und steifen Gebilde ein bewegtes, oft auch naturalistisch überformtes Band entstehen. Pilaster und Säulen sind nicht mehr unverzichtbarer Bestandteil eines tektonischen Systems, das die Möbelfassaden zu tragen scheint, sondern werden zu einem reinen Ziermotiv.

\section{Zur Vermittlung und Weitergabe neuer Formen}

Der Transfer künstlerischer Inventionen vollzog sich auf verschiedenen Wegen: $\mathrm{Zu}$ nächst informierten sich naturgemäß die Architekten über die Inventionen ihrer Kollegen und beobachteten sehr genau das Baugeschehen unter deren Leitung. Künstler wie Johann Lukas von Hildebrandt (I 668-I 745) und Johann Bernhard Fischer von Erlach (г656-г723) gingen zum Studium ins Ausland, Vorlagenstiche von Architekten und Ornamentkünstlern waren europaweit käuflich zu erwerben. Darüber hinaus standen die österreichischen Äbte und Prälaten untereinander in engem Kontakt, auf ihren Reisen hatten sie ausgiebig Gelegenheit, sich durch Vergleiche eine gewisse Kompetenz in Fragen der Kunst anzueignen. Ihr Interesse daran belegt der Umstand, dass viele Äbte aktiv in die Planungen von Um- oder Neubauten ihrer Klöster eingriffen. Hieronymus Übelbacher (reg. I710-I740), Propst des ehemaligen Chorherrenstifts Dürnstein, suchte sogar verschiedene Abteien und Weltkirchen mit dem erklärten Ziel auf, sich Anregungen für die Renovatio seiner Klosteranlage zu holen. Dabei erkundigte er sich nach Künstlern und Handwerkern, deren Erzeugnisse ihn überzeugten. ${ }^{159}$ Weiter standen bei umfassenden Bauvorhaben neben den festangestellten Handwerkern eine ganze Reihe von Tagelöhnern bei den Klöstern in Lohn und Brot, da zusätzliche Mitarbeiter benötigt wurden. Nach Fertigstellung der Baumaßnahmen begaben sich die Arbeitskräfte zur nächsten Großbaustelle auf den Weg. Zudem forderten die Zunftregeln von den Gesellen räumliche Mobilität. Infolgedessen kamen Handwerker aus allen deutschsprachigen Gebieten nach Österreich, darüber hinaus aber auch aus Frankreich und Norditalien, aus Mittel- und Südosteuropa, sogar aus Polen und Schweden. ${ }^{160}$ Einige Gesellen erhielten geistliche Weihen und traten als Konversen in

I59 Penz, Kalendernotizen (2013).

I60 Diese Thematik wird im dritten Band der Studie erörtert. 
ein Kloster ein, andere befanden sich in der glücklichen Lage, eine Werkstatt übernehmen zu können, die meisten begaben sich aber nach Beendigung des Dienstverhältnisses erneut auf Wanderschaft. All das führte zu einem fortwährenden Ideenaustausch sowie zu einem regionalen und überregionalen Kulturtransfer. 
VI.

\section{Österreichische Kunstlandschaften und regionale Charakteristika}

Im Zentrum des folgenden Kapitels stehen stilistische Besonderheiten, die das Mobiliar in den verschiedenen Regionen Österreichs auszeichnen. Manches mag schon aus dem ersten Band der vorliegenden Forschungsarbeit bekannt sein, außerdem war diese Fragestellung Inhalt zweier Aufsätze, die in einem Katalog des Stiftes Schlägl sowie in den Barockberichte [n] publiziert wurden. Die Beiträge sind hier um wesentliche Details bereichert. ${ }^{161}$

Bei der Beschäftigung mit dem Thema darf die Tatsache nicht unberücksichtigt bleiben, dass formalästhetische Lösungen nicht an politische Grenzen gebunden waren. Stilmerkmale verschiedener Regionen überlagerten sich oder traten nebeneinander an einem einzigen Kunstobjekt auf, tatsächlich lässt sich an einer Vielzahl von Kirchenmöbeln der synkretistische Gebrauch verschiedener Ornamentformen nachweisen. An dieser Stelle sei nur an die Chorgestühle in Griffen von I715/25 und Stams von ca. I735 (Farbtaf. 04, 3 I) erinnert, deren Dekor aus einer Kombination von italienischem Akanthus und französischem Bandlwerk besteht, in Stams wird sie durch Blumenvasen und Gitterwerk ergänzt. Auf Ornamentvorlagen Jean Bérains d. Ä. (I637-I7 I I) kehren diese Motive wieder. ${ }^{162}$ Sie werden ihm auch zugesprochen, kamen in Italien aber sehr viel früher vor. Blumenvasen waren im I7. Jahrhundert für die Gestaltung Florentiner Steininkrustationen von zentraler Bedeutung, während Federico Zuccari (ca. I540-1609) Gitterwerk bereits im fortgeschrittenen I6. Jahrhundert auf einer Architekturskizze zeigte. ${ }^{163} \mathrm{Wie}$ auch immer: Ausschlaggebend für die Wahl der Formensprache waren letztlich die individuellen Vorlieben der jeweiligen Auftraggeber, manchmal standen auch deren politische Überzeugungen im Vorder-

I6I Bohr, Sakralmöbel (2017), bes. 58-80; ders., Kunstlandschaften (2019); ders., Kunsttransfer (2019). In diesem Kapitel werden unter anderem die Klöster Göttweig, Heiligenkreuz, Herzogenburg, Kremsmünster, Lambach, Melk, St. Florian, Schlägl, Schlierbach und Zwettl, die ehemaligen Klöster Baumgartenberg und Dürnstein, weiter St. Josef, die Dominikanerkirche, die Karlskirche und St. Stephan in Wien, die Priesterseminar- und die Jesuitenkirche in Linz sowie die Piaristenkirche in Krems genannt. Diese Sakralanlagen werden im ersten Band der Untersuchung vorgestellt. Bohr, Sakralmöbel (2017).

I62 Berliner/Egger, Vorlageblätter (I98I), Bd. I, 93-94, Bd. 3, Abb. II 35, I I37, I I40, I I4I, I I 45 mit Drucken, die um I69o bzw. um I 700 entstanden.

I63 Giusti, Splendori ( I 988), I I o-I I I, I 38-I 39, I 48-I 49; Walker/Hammond, Life (I 999), I68, Kat. 38a; Princi, Architectural Drawings (20 I 2), I 83. 
grund. ${ }^{164}$ Die Rolle, die Mäzene bei der Entwicklung und Etablierung neuer Kunstrichtungen spielten, kann jedenfalls kaum hoch genug eingeschätzt werden. Klammert man einmal die Kunstlandschaft um Innsbruck aus, so lässt sich konstatieren, dass im Möbelbau des I7. Jahrhunderts die Stilentwicklung österreichweit parallel vonstattenging, in den großen Kunstzentren etwas früher als auf dem flachen Land und in Gemeinden ohne eine finanzkräftige Kundschaft. Erst um die Wende vom i 7. zum I 8. Jahrhundert sollte sich das ändern.

\section{Wien UNd NiederösterREICH}

Im fortgeschrittenen I 7. Jahrhundert entwickelten in Frankreich Künstler wie Jean Bérain d. Ä. und Daniel Marot ( 66 I-I 752) eine Formensprache, die man im deutschen Sprachraum später als Laub- und Bandlwerk bezeichnen wird. Seine Grundstruktur besteht aus miteinander verflochtenen Bändern, die sich in Schleifen über eine Fläche legen und mit feinem Laubwerk verziert sind. In den I69oer-Jahren adaptierte der Wiener Juwelier Friedrich Jacob Morisson (nachw. I693 und r697) in seinen Entwürfen die neuen Ornamentmotive, mit den Interieurs der Sommersakristei in Melk und der Bibliothek in Heiligenkreuz entstanden bereits um I 7or/o2 entsprechende Tischlerarbeiten. ${ }^{165}$ In der habsburgischen Residenzstadt und im Großraum der Metropole präferierte man in jener Zeit französische Stilvorstellungen. Dabei waren vermutlich nicht die Handwerker, sondern die Auftraggeber die Hauptakteure der neuen Bewegung. Sie wandten sich um die Jahrhundertwende der Kunst Frankreichs zu, gleichwohl zeigt sich an vielen Möbeln aus jener Epoche noch italienischer Akanthus, das I708/o9 entstandene Laiengestühl der Piaristenkirche in Krems bietet hierfür ein gutes Beispiel. Meist war der Akanthusstil damals aber nicht mehr in Reinform vertreten, sondern quergeriffelte Bänder durchzogen und säumten nun das Laubwerk - ein erster Schritt hin auf dem Weg zur Übernahme des Bandlwerks. Ein Vergleich des Mobiliars in der Piaristenkirche mit dem wenige Jahre zuvor entstandenen in der Wiener Dominikanerkirche dokumentiert diese Entwicklung recht gut.

In den I 7 2oer- und 3oer-Jahren bauten Tischler in Wien und Niederösterreich eine Reihe von Möbelstücken, an denen Zierformen, die im I 7. Jahrhundert das Bild der Möbelgarnituren prägten, nur noch rudimentär vorhanden waren, falls sie nicht völlig fehlten. Das Gestühl in der Göttweiger Chorkapelle von I 727 verdeutlicht diese Phase

I64 Franz, Ornamentvorlagen (201 I), 33-45, 39; Polleroß, Einflüsse (2014).

I65 Zu Morisson vgl. Ornamentstichsammlung des Wiener Museums für angewandte Kunst (MAK), Druck: KI $220 I-I$. 
ebenso anschaulich wie die um I730/35 gefertigten Schränke in der Unteren Sakristei von St. Stephan in Wien. Eine Gegenüberstellung dieser Inventarstücke mit dem Laiengestühl in St. Paul von I725/35 oder dem um I 735 gefertigten Chorgestühl in Stams (Abb. 57, 58, 352-356) bringt die verschiedenen Ausdrucksmöglichkeiten jener Zeit deutlich zum Vorschein. Eine Spielart des Barockklassizismus in der Residenzstadt steht barockem Überschwang in den anderen Regionen Österreichs gegenüber. Wie die um I 745/55 erzeugten Sakristeimöbel von St. Josef belegen, griffen aber nach der kurzen protoklassizistischen Phase auch die Wiener Handwerker wieder verstärkt zu typisch barockem Formenvokabular.

An zahlreichen Möbeln, die im I8. Jahrhundert in den zwischen Wien und Salzburg gelegenen Regionen gebaut wurden, ist neben gestreiftem Nussholz und Nussmaserholz als Werkmaterial Pappelmaser in Füllungen und Binnenfeldern nachzuweisen. Das unterscheidet österreichische Möbel von vielen deutschen Erzeugnissen, für die eher Furniere aus Birkenmaserholz gewählt wurden. Es weist eine ähnliche Farbe und Strukturierung wie Pappel auf, ist aber härter und schwerer zu bearbeiten. Und auch im Süden Österreich kommt Pappelholz nur selten vor, vermutlich wurde dort unter dem Einfluss Italiens fast ausschließlich mit Nussfurnier oder massivem Nussholz gearbeitet.

\section{OBERÖSTERREICH}

Schon Franz Windisch-Graetz beobachtete an vielen spätbarocken Schränken im Großraum Linz eine dreiteilige Vertikalgliederung der Flächen. ${ }^{166}$ Eine querrechteckige Füllung liegt dort in der Regel zwischen zwei hochrechteckigen, das in den I740er-Jahren entstandene Mobiliar in der Prälatensakristei zu St. Florian bezeugt dies ebenso anschaulich wie Schränke in der Schatzkammer der Benediktinerabtei Kremsmünster oder in einem der Gästezimmer des Chorherrenstiftes Schlägl. ${ }^{167}$ Mit ihrer Gestaltung übernehmen die Fassaden dieser Möbel die Konstruktion von Portalen aus den I $720 e r-J a h r e n$, etwa jene in der Linzer Priesterseminarkirche oder in der ehemaligen Abtei Dürnstein. Ihnen gingen die Türen in der Melker Sommersakristei von I 70r/o2 voraus, die noch den frühen Typus mit gleichhohen Binnenfeldern vertreten. Auch die Entwürfe dieser Arbeiten, und damit letztlich die der Schrankfassaden, basierten auf französischen Modellen. Während traditionelle österreichische Portale mit einem Türblatt und zwei großen Füllungen versehen sind, die die Horizontale

i66 ÖKT, Kremsmünster, 2 (1977), 493.

r67 Zu einem Schrank in Schlägl vgl. Bohr, Kunsttransfer (2019), Abb. го, I r. 
unterstreichen, weisen die moderneren Exemplare zwei hohe und schmale Flügel mit drei Binnenfeldern auf, die die vertikale Ausrichtung betonen. Diese Türen konnten breiter als die herkömmlichen sein und wirkten dennoch leichter und eleganter, nebenbei trugen sie zur Ausdifferenzierung des Hofzeremoniells bei. ${ }^{168}$

Gitterwerk aus diagonal angeordneten Stäben und diamantförmigen Rauten bestimmt das Aussehen von Portalen der Stiftskirche in Schlägl sowie der Stadtpfarrkirche und der Jesuitenkirche in Linz. Die Türen datieren auf die I65oer- bzw. I 67oerJahre. ${ }^{169}$ Die ästhetische Wirkung der Diamantquader verleiht ihnen einen gewissen Fortifikationscharakter, ihre Rautenform ruft mittelalterliche, mit Eisenblechen und Metallbändern armierte Kircheneingänge in Erinnerung. Aus heutiger Sicht stand das Hauptportal in Schlägl von I 654 am Anfang dieser Reihe, frühere österreichische Beispiele kennen wir nicht. Allerdings gibt es in Italien nicht nur etliche barocke Palasttüren, die mit Diamantbossen verziert sind, sondern norditalienische Tischler experimentierten schon im I6. Jahrhundert mit ähnlichen Lösungen, zudem veröffentlichte der Architekturtheoretiker Sebastiano Serlio (I 475-ca. I 554) in seinen Büchern Vorschläge zu ihrer Gestaltung. ${ }^{170}$ Die Portale in Linz und Schlägl könnten folglich aus einer gedanklichen Fusion der Inventionen Serlios mit ausgeführten italienischen Arbeiten hervorgegangen sein. Vielleicht handelte es sich bei den Entwurfszeichnern der oberösterreichischen Exemplare um die italienischen Architekten Passibili Castellazzi († I656) und Pietro Francesco Carlone (um r 606-r68 I), die damals in Linz und in der Umgebung der Stadt tätig waren.

Möbelensembles in der Abtei Schlägl offenbaren eine Besonderheit, der persönliche Präferenzen des Abtes Johannes Wöss (reg. I72I-I 743) zugrunde lagen. Die Ausstattungsstücke überraschen mit einer ungewöhnlichen Auswahl der verarbeiteten Furnierhölzer, die aus dunklem Kernholz und auffallend hellem Splintholz bestehen. ${ }^{171}$ Mit besonders großem Nachdruck scheint man beim Bau der Aufsatzkredenz in der Priestersakristei auf ein apartes Aussehen geachtet zu haben. Die Tischler vervollständigten die Platte mit Sternfurnier, während sie die Fassade mit diagonal aufgebrachten und mehrfach gespiegelten Furnierstreifen belebten, die Dreiecke und Rauten formen und markante Kontraste zwischen hellen und dunklen Partien entstehen lassen. An

I68 Für hochgestellte Persönlichkeiten wurden beide Türflügel geöffnet, sonst nur einer. Moser, Hof-Recht (I755), Bd. 2, Buch 7, Kap. 3, p. 299.

r69 Zu den Türen der Stadtpfarrkirche vgl. ÖKT, Linzer Kirchen (r 964), 362-363, Abb. 395.

I70 Ferrari, Legno [ca. I 928], I9I, Taf. I 23. Serlio, Architettura (I 584), 4. Buch, I 38 v sowie Libro estraordinario [...], 3r. Das vierte Buch Serlios erschien 1537 , das Libro estraordinario, eigentlich das sechste Buch, I55.

I7 I Bohr, Kunstlandschaften (2019), 35, 36; ders., Kunsttransfer (2019), I66-I 79. Solch starke Kontraste kennen wir sonst von bemalten oberösterreichischen Bauernschränken. 
Werkmaterialien überwiegen gestreiftes Nussholz und Maserholz aus Nuss, außerdem Ahorn und Pappel. Entsprechend dekoriert präsentieren sich überdies die Chorstallen in Schlägl sowie einige profane Möbel in der Prälatur des Klosters, der oben erwähnte Schrank im Gästezimmer zum Beispiel. Er verfügt zudem über einen geschweiften Sockel, eine weitere Eigenart, die an Schränken aus Oberösterreich häufig vorkommt. Anders als dieses Möbel, das mit einem modernen Schnitzauszug schließt, bekrönt ein originaler Auszug den Schrank in der Schatzkammer zu Kremsmünster, auf den ebenfalls schon hingewiesen wurde. Er besteht aus einem mittleren hochrechteckigen und intarsierten Tableau, das seitliche Bandlwerkschnitzereien begleiten. Sie sind durchbrochen gearbeitet und vergoldet. Auch solche Aufsätze können an Möbeln der Region öfter als andernorts nachgewiesen werden.

Wie Franz Wagner feststellte, verwendeten oberösterreichische Tischler beim Bau ihrer Möbel häufig eine schwarze Paste, um kostbares Ebenholz zu imitieren. ${ }^{172}$ Das Surrogat besteht nach den Recherchen Wagners aus Holzkohle, Leim und Zellulosefasern, deren Zusammensetzung bisher noch nicht genau bestimmt werden konnte. ${ }^{173}$ Eines der Möbel, an denen der Edelholzersatz das Gesamterscheinungsbild entscheidend prägt, ist die um I 709 gefertigte Lesekanzel des früheren Refektoriums im Kloster Lambach. Ein weiteres Beispiel ist ein qualitätvoller Schrank, den der Tischler Stephan Jegg (I674-I 749) in Zusammenarbeit mit dem Bildhauer Leonhard Sattler ( $676-$ I 744) für das Stift St. Florian fertigte. ${ }^{174}$ Zwar wurden mit dem schwarzen Kitt auch Möbelgarnituren aus den I 72oer- und 3oer-Jahren im Kloster Dürnstein und in der Wiener Karlskirche vervollständigt, doch sind das im Osten Österreichs absolute Ausnahmen. Und auch in den anderen Regionen des Landes ließ sich die geheimnisvolle Masse nicht belegen.

\section{SALZBURG}

Nach wechselvoller Geschichte gehörten Stadt und Land Salzburg erst seit I 8 I 6 zu Österreich, im hier interessierenden Zeitraum war jene Gegend zwar Teil des Heiligen Römischen Reichs, nicht aber der habsburgischen Erblande. Um Möbel aus allen Regionen der Republik in die Forschungsarbeit aufzunehmen, wurden entgegen der historischen Entwicklung auch Inventarstücke aus dem ehemaligen Fürsterzbistum für den Katalog untersucht.

I72 Wagner, Kunsthandwerk (1999), 577.

I73 Ebd. Prinzipiell zu Surrogaten vgl. Michaelsen/Barthold/Weißmann, Helffenbein (2003).

I74 Lorenz, GbKÖ (I 999), г 90. 
Etliche Salzburger Möbel sind mit aufwendigen Furnieren versehen, das Interieur in der Sakristei der Salzburger Domkirche (Farbtaf. I3; Abb. I I 7-ı 20) liefert hierfür ein anschauliches Beispiel. ${ }^{175}$ Zugleich bestehen viele barocke Sakral- und Profanmöbel in der Stadt selbst und in ihrem Umland aus massivem, oft mit Schnitzarbeiten verziertem Zirbenholz. Dabei unterscheiden sich Salzburger Paramenten- und Kleiderschränke durch ihre Konstruktion von Exemplaren anderer österreichischer Kunstzentren: Der vertikale Aufbau mit Sockel, Hauptgeschoss und abschließendem Gebälk entspricht zwar der üblichen Massengliederung, doch stattete man die Kästen jener Kunstlandschaft nicht nur im Sockel, sondern auch im Möbelhaupt mit Schubladen aus (Abb. 80, I I 3, I I 6). Die Bekrönungen besitzen deshalb einen komplizierteren Aufbau, als wir das von anderen Schränken her kennen. Sie mussten um Lauf- und Streichleisten ergänzt werden und solide genug konstruiert sein, um der mechanischen Beanspruchung durch das Bewegen der Laden standzuhalten.

Ein besonderes Aussehen charakterisiert außerdem die Wangen von Kirchenbänken in der Stadt an der Salzach: Unzählige Beispiele belegen, dass die Wangen sonst in Österreich als Einheit aufgefasst wurden. Die durchlaufende Umrissform fasst sie zusammen, man ornamentierte sie vom Haupt bis zum Fuß, der Dekor legt sich über ihre gesamte Fläche (Abb. 05, 46, 53 usw.). In Salzburg liegt ein anderer Befund vor, da dort die Docken optisch geteilt sind (Abb. 76, I 29, I36). Über einem unteren querrechteckigen Block, der ohne Verzierung auskommen kann, erhebt sich ein schmaler, vom unteren Segment klar geschiedener oberer Teil, den Schnitzarbeiten aufwerten. ${ }^{176}$ Vermutlich entstand die Großform dieser Möbel unter dem Einfluss italienischer Kniebänke mit ihrer zweiteiligen Gliederung. ${ }^{177}$ Möbelensembles in Baumgartenberg, Schlierbach und Klagenfurt (Abb. 44) zeigen indes, dass diese Art der Gestaltung bisweilen auch von Tischlern aufgegriffen wurde, die in anderen österreichischen Kunstregionen beheimatet waren. Exemplare mit analog geformten Wangen kommen weiterhin in der Südschweiz vor, selten, wie in St. Kajetan zu München, auch in Süddeutschland. ${ }^{178}$

I75 ÖKT, Salzburg (I9 2 2), bes. 25-26, Fig. 34; Wagner, Baldauf (1978).

I76 Die Bänke in der Salzburger Dreifaltigkeitskirche (Abb. I08), deren Sockel ebenso breit ist wie der Anlauf des oberen Wangensegments, sind Ausnahmen.

I77 Dal Prà, Madruzzo (1993), 78 I, mit einem Beichtstuhl aus S. Maria Inviolata in Riva del Garda. Das mit entsprechenden Kniebänken ausstaffierte Möbel datiert auf das frühe i7. Jahrhundert. Oder Manni, Mobili ( (1993), Abb. 794, 8 1 3, 8 8 4, 8 I 6 mit seicentesken Möbeln aus der Emilia Romagna. Zu genealogischen und kirchenpolitischen Verbindungen Salzburgs nach Südtirol-Trentino vgl. Dopsch/ Hoffmann, Geschichte (I 996).

I78 Ganz/Seeger, Chorgestühl (I 946), Taf. 62, 63; Schütz, Barockarchitektur (2000), Abb. 97. 
Und noch eine Besonderheit muss im Hinblick auf Salzburger Möbel erwähnt werden. Sie betrifft nicht deren Ausgestaltung, sondern einen bestimmten Möbeltypus. In Salzburg wurden in der Barockzeit italienische cassapanche nachgebaut, bei denen es sich um Truhen handelt, die mit einer Rückenlehne, manchmal auch mit Armlehnen versehen sind. Auf der Apenninenhalbinsel gehörten solche Möbel im sakralen Ambiente zur Einrichtung von Sakristeien, im profanen Bereich zur Standardausstattung von Eingangshallen, Wartezimmern oder Loggien. Die Beurteilung fällt schwer, ob Truhenbänke in Salzburger Sakristeien als Teil der Möbelensembles zu finden waren, doch erlangten sie bei der Möblierung der fürsterzbischöflichen Residenz große Bedeutung. Wie in Italien stehen sie in der Residenz zumindest heute in Aufenthaltsräumen. Zwar ist davon auszugehen, dass solche Möbel ebenfalls im Süden Österreichs existierten bzw. noch immer existieren, doch konnten sie dort bislang nicht nachgewiesen werden. Im Osten waren sie lediglich im Wiener Salvatorianerkloster in Gebrauch. ${ }^{179}$

TirOL

Wie im gesamten österreichischen Alpenraum favorisierten die Tischler in Tirol Nadelholz, seltener wurden Nussbaum und Eiche verwendet. Im I7. Jahrhundert waren es vor allem Auftraggeber aus Innsbruck, die sich Mobiliar aus teurem Hartholz leisten konnten, dagegen kam im I8. Jahrhundert auch außerhalb der Stadt Nussholz in Gebrauch. Weichholzmöbel wurden häufig mit Schnitzdekor bereichert und mit einem dunkelbraunen Farbton gebeizt.

Erneut stehen die Kirchenbänke im Fokus des Interesses, nun sind es die Brüstungen und Rückenlehnen, die eine besondere Art der Konstruktion aufweisen: In Tirol behielt man die gewöhnliche Rahmenstruktur bei, verzichtete jedoch teilweise auf die Füllungen, weshalb sich die Lehnen mit großen Ovalen oder Rechtecken öffnen (Abb. 297, 303, 372). Manchmal sind die Rahmen geschweift und mit Schnitzarbeiten verziert, an den Gestühlen in der Stiftskirche zu Stams oder in der Jesuitenkirche zu Innsbruck ist das gut zu erkennen (Abb. 304, 349). Auf den Lehnen dieser Möbel beruht denn auch das charakteristische Erscheinungsbild der Möbelgarnituren, wahrscheinlich stehen sie ebenfalls in der Tradition des italienischen Möbelbaus. Den Rückenlehnen in Tirol eignet formal eine Zwitterstellung zwischen den komplett geöffneten italienischen Exemplaren und vollständig geschlossenen in den übrigen Regionen unseres Kulturraums. Deneben konnten Möbel mit gleichartigen Rücken-

I79 Bohr, Sakralmöbel (2017), I I3-I I 4 . 
lehnen noch in Vorarlberg vorkommen, gelegentlich übernahmen auch die Tischler angrenzender Regionen diese Gestaltung. ${ }^{180}$ Die Wangen vieler Tiroler Kirchenbänke wurden mit schweren Dekormotiven ergänzt, die um I640 gebauten Docken in der Innsbrucker Jesuitenkirche (Abb. 305) verdeutlichen das ebenso wie die kurz vor der Wende vom I7.zum I 8. Jahrhundert realisierten in Stams (Abb. 350).

Auffallend sind ferner die formalen Analogien der Beichtstühle in der Innsbrucker Jesuitenkirche, der Kirche in Maria Thal (Abb. 302, 3 I 8) sowie der Innsbrucker Spitalskirche. ${ }^{181}$ Die in Wandnischen eingesetzten zwei- bzw. dreiachsigen Möbel entstanden im zweiten Viertel des I 7. Jahrhunderts sowie im frühen I 8. Jahrhundert, ihre Fronten rekurrieren auf Portalarchitekturen. Pilaster flankieren rundbogige Arkaden, schwere Gebälke laufen in hohen Sprenggiebeln mit skulptierten Kartuschen aus, die die Monogramme Jesu und Mariens oder die Brustbilder büßender Heiliger tragen.

Dann darf das Gestühl des Zisterzienserklosters Stams nicht unerwähnt bleiben (Farbtaf. 3I ; Abb. 35 I-358), das Sybe Wartena zu Recht in seine Studie zu süddeutschen Chorgestühlen aufnahm. ${ }^{182}$ Beim Bau des Inventarstücks orientierte sich der Konverse Georg Zoller (I 700-I 764) am etwa zehn Jahre älteren Möbel der bayrischen Zisterze Pielenhofen. ${ }^{183} \mathrm{Im}$ Unterschied zu anderen Gestühlen in österreichischen Zisterzienserkirchen besitzt das Exemplar in Stams am Westende breite querstehende Flügel, vor denen auf der Seite der Laien Scheinaltäre stehen. Anders als in Bayern ist eine ähnliche Nutzung des Raumes hierzulande kein zweites Mal anzutreffen. Süddeutsch muten überdies die detailreichen Marketerien der Rückwandfelder an, französisch die Schnitzmotive der Außenwangen. ${ }^{184}$

Vor den Außenwänden von Kirchen und damit parallel zur Längsachse der Baukörper platzierte Bänke verbinden durch ihre Position Tiroler Möbelgarnituren mit solchen aus der westlichen Steiermark und Kärnten. In Pürgg kommt das ebenso vor wie in St. Paul und Völkermarkt (Abb. 56, 73, 74, 229), ein Kupferstich Lorenz Strauchs (I554-1630?) von I614 dokumentiert, dass sich solche Möbel einstmals auch in der Innsbrucker Hofkirche im Langhaus vor der Nord- und Südwand befanden. ${ }^{185} \mathrm{Im}$ Zuge des Umbaus der Kirche in den r68oer-Jahren wurde das alte Laiengestühl gegen

\footnotetext{
I 80 So etwa im Kloster Einsiedeln in der Schweiz, in Passau, in Friedrichshafen oder im Kloster Birnau. Waschgler, Kunstgeschichte Vorarlbergs (I930), Taf. III, Abb. 27 und 28; Möseneder, Passauer Dom (2014), 22.

I8 I ÖKT, Innsbruck, I (1995), Abb. 33 I.

I 82 Wartena, Süddeutsche Chorgestühle (2008), 743-754.

I 83 Wartena, ebd., 593-609 und Abb. I 9.I 4.

I 84 Sybe Wartena erkennt übrigens auch stilistische Gleichklänge zwischen den Innsbrucker Gestühlen und jenen aus dem süddeutschen Kunstraum. Wartena, ebd., I 98-200.

I8 5 Egg, Hofkirche (1974), Abb. I 8; ÖKT, Innsbruck, Hofbauten (I 986), Abb. 304.
} 
ein neues ausgetauscht, möglicherweise nahm man damals die Neugestaltung des Kirchenraums zum Anlass, auch die seitlichen Bänke zu entfernen. ${ }^{186}$

Und schließlich warten Möbelgarnituren in Bad Mehrn und in der Innsbrucker Servitenkirche (Abb. 287-289, 3 I5) mit einer charakteristischen Eigenart auf. Der dortige Schnitzzierrat besteht aus feinen amorphen, zugleich auffallend kleinteiligen, hölzernen und harten Strukturen. Als Vorlagen für diese Formen kommen Ornamententwürfe von Friedrich Brentel (I 580-165 I) aus der Zeit um I6 I 8 in Betracht. ${ }^{187}$ In Innsbruck finden sie sich im Stuckdekor der Kirche Maria Hilf von 1653 sowie an Palais, die Johann Martin Gumpp d. Ä. (1643-I729) um r680 errichtete, selbst im frühen I 8. Jahrhundert kommen sie noch vor. ${ }^{188}$ Und auch andernorts können ähnliche Motive die Stuckarbeiten prägen, so beispielsweise im Salzburger Dom, aufgebracht wurden sie dort in den r62oer- und I650er-Jahren. ${ }^{189}$ Im Möbelbau lässt sich diese Formensprache besonders häufig in Nordtirol nachweisen. Jene eigenartige Stilvariante hat mit den sonst vorherrschenden weichen, kräftigen und großflächig angelegten barocken Ornamenten kaum etwas gemein. ${ }^{190}$

\section{Kärnten und Steiermark}

In der nördlichen Steiermark, im Stift Vorau etwa oder in Neuberg an der Mürz, lehnt sich das Mobiliar durch sein Erscheinungsbild formal an Inventarstücke aus Niederösterreich und Wien an. Deutlich unterscheiden sich davon die Möbel aus dem Süden, hinsichtlich deren Gestaltung die Regionen zwischen Graz und Klagenfurt zu einer Kunstlandschaft zusammengefasst werden können. In diesem Großraum lassen die Brüstungen mit den markant ausgearbeiteten seitlichen Stollen die Laienbänke als in sich geschlossenen Bestand in Erscheinung treten (Abb. 57, I 52, I 73). Geben sich Pilaster, Säulen und Baluster an den Bänken in den übrigen Bundesländern oftmals als reines Zierwerk zu erkennen, so erwecken die Vorderwände vieler Möbel in den südlichen Landesteilen den Eindruck, ohne die seitlichen Stollen keinerlei Solidität

I 86 Zur Restaurierung ÖKT, ebd., bes. 244-245.

I 87 Berliner/Egger, Vorlageblätter (198 I), Bd. I, 8 I, Bd. 2, Abb. 9 14-9 6 .

I 88 Krapf, Gumpp (I 979), bes. 288, 289, 328, 329 sowie Taf. 2, Abb. 249, 250 ; ÖKT, Innsbruck, Hofbauten ( 1986 ), Abb. 345, 346; ÖKT, Innsbruck, I (I 995), Abb. 3 I 9, 320; ÖKT, Innsbruck, 2 ( I 995 ), Abb. 7 I 5 , $7 \mathrm{I} 7,7 \mathrm{I} 8$.

I 89 ÖKT, Salzburg (I 9 I 2), Taf. IV, Abb. 23, 26; Dehio, Salzburg (I 986), 529 ; Neuhardt, Dom (I 998), I 8, 20.

I 90 Eine Ausnahme liegt beispielsweise an den etwa auf die Jahrhundertmitte datierten Tischlererzeugnissen in der Kirche im steiermärkischen Frauenberg vor (Abb. I 40, I 4 I). 
zu besitzen. Die Wände, gleichgültig ob gebaucht oder gerade, scheinen erst durch die Stollen ihre nötige Beständigkeit zu erhalten, die Stützen bestimmen wesentlich das Gesamterscheinungsbild der Bänke. Die unterschiedliche Behandlung der Oberfläche betont noch die vorgebliche Funktion der Baluster, denn während Letztere schwere Schnitzarbeiten aufweisen, sind die folienartigen Flächen dazwischen mit Furnieren ausgelegt. Insgesamt wirken Kirchenbänke aus Kärnten und der Steiermark entschieden wuchtiger und schwerer als die aus anderen Kunstlandschaften. ${ }^{191}$ Diese Beobachtung wirft die Frage nach der Provenienz der Stilmerkmale auf, leider kann sie nicht mit Sicherheit beantwortet werden. Überzeugende Vorbilder für diesen Regionalstil sind nicht bekannt, doch lassen die Bänke durch ihr optisches Gewicht an italienische Renaissancemöbel denken, deren Vorderseiten oft von ähnlich massigen Akanthusvoluten flankiert werden. ${ }^{192}$ Vermutlich ist also auch in diesem Zusammenhang mit einer Übernahme italienischer Lösungen durch österreichische Handwerker zu rechnen. Dabei beeindruckt die Wahl der verwendeten Ornamentmotive, die vielfach ein exzessives Nebeneinander von italienischem und französischem Formenvokabular zu erkennen geben (Abb. 28, I 73, I 74, I82-1 86).

Weiter muss auf die Bänke in den steirischen Kirchen zu Gröbming, Pürgg und Frauenberg (Farbtaf. I 7; Abb. I 94, 232) aufmerksam gemacht werden. Die Entfernung zwischen den beiden erstgenannten Orten beträgt knapp $25 \mathrm{~km}$, die zwischen Gröbming und Frauenberg ca. $50 \mathrm{~km}$. Die Wangen in Gröbming und Pürgg sind nahezu identisch, die in Frauenberg etwas kunstvoller und aufwendiger. Die Docken weichen durch die Massengliederung deutlich von den Exemplaren in den übrigen österreichischen Regionen ab. Während in Frauenberg zwei aufeinander gestellte Hochrechtecke eine Achse mit geraden senkrechten Seiten bilden, formen die ebenfalls zweigeteilten Bankwangen in Gröbming und Pürgg Stelen mit geschweiften Vorderkanten. Die Tischler scheinen ein und dieselbe künstlerische Idee beim Bau ihrer Möbel mehrfach variiert zu haben. Über eine Antwort auf die Frage nach der Herkunft dieser Invention lässt sich bisher nur spekulieren.

Eine weitere formale Eigenart präsentieren Sakristeimöbel in jener Kunstlandschaft. In den anderen Landesteilen wurden Hochschränke vor Fensterpfeilern als voneinander unabhängige Einzelelemente konzipiert, als ein Beispiel unter vielen weist das Sakristeiinterieur im Servitenkloster zu Innsbruck (Abb. 3 I 3) entsprechende Merkmale auf. In den südwestlichen Regionen des Landes legen sich Gebälk und Schnitzauszug

I9I Eine Ausnahme liegt in der Abtstalle von St. Peter in Salzburg vor (Farbtaf. i I).

I92 Schmitz, Möbelwerk (I 929), 94; Colombo, L’arte (I98I), Abb. I75, I90, 266; Manni, Mobili (I 993), Abb. 53, 72. Die Abbildungen zeigen Truhen und einen Aufsatzschrank aus der Toskana, dem venezianisch-lombardischen Raum und aus der Emilia Romagna. 
dagegen manchmal in einem weiten Bogen über die Möbel und Fenster. Er verbindet Oberschränke und Fensteröffnungen und fasst sie zu einer optischen Einheit zusammen (Abb. 6r, I98).

Auf das Ornamentmotiv, das aus einem nach vorn gewölbten Hochoval im Zentrum einer Füllung besteht, wurde schon im ersten Band der Untersuchung aufmerksam gemacht. ${ }^{193}$ Es ist bereits am Dreisitz in der Stadtpfarrkirche hl. Bartholomäus in Friesach von I63 I fassbar (Abb. I 8), während es sich im Norden und Osten Österreichs an Möbeln etwa seit den I65oer-Jahren nachweisen lässt. Die bisherige Annahme, dass das Motiv dort auf einen Stich von Friedrich Unteutsch (um r600-i670) aus der Zeit um r 640 zurückgehe, muss also korrigiert werden. Es könnte ebenfalls von früheren Möbeln aus dem Süden Österreichs übernommen worden sein.

Darüber hinaus muss die Aufmerksamkeit auf einige ausgefallene Taufsteindeckel gerichtet werden, deren Form das Äußere von Tempietti widerspiegelt. ${ }^{194}$ Die Reihe beginnt mit dem r608 datierten Taufsteindeckel in St. Oswald zu Seefeld in Tirol ${ }^{195}$, ihm folgen ein um I620 wahrscheinlich von Konrad Scherer aus Velden verfertigtes Exemplar in der Stiftskirche von St. Paul in Kärnten (Farbtaf. o8) sowie ein drittes, um die Jahrhundertmitte oder bald danach entstandenes, in der kleinen steirischen Dorfkirche zu Pürgg (Farbtaf. 26).

Die Taufsteinaufsätze errichtete man über sechs- oder achteckigem Grundriss, mit Sockel, Hauptgeschoss, Gebälk und abschließender Kuppel weisen sie Parallelen zur Gestaltung eines bestimmten Typs von Tabernakeln auf. Als einer der ältesten im Alpenraum erhaltenen aus dieser Serie von Kleinarchitekturen gilt der Tabernakel in der Pfarrkirche S. Martino in Sessa bei Lugano aus der zweiten Hälfte des r6. Jahrhunderts. ${ }^{196}$ Weitere Beispiele geben I59I von Jacob Müller publizierte Entwürfe mit Sakramentshäusern und einem Tabernakel wieder. ${ }^{197}$ Zugleich übernahmen die Taufsteindeckel aber auch die Zentralbauform antiker und frühmittelalterlicher Grabbauten, Memorialarchitekturen und Taufkapellen. Hinweise auf die Grabeskirche in Jerusalem, auf San Giovanni in Laterano oder auf das Baptisterium in Florenz mögen an dieser Stelle genügen. Bei der Fertigung frühneuzeitlicher Möbel in Tempiettoform

I93 Bohr, Sakralmöbel (2017), 65-66.

I94 Die Idee, Taufbecken mit architektonisch anmutenden Deckeln zu versehen, war bekanntlich keineswegs neu. Vgl. hierzu etwa den Taufstein in St. Stephan zu Wien von I48I. Gruber, Stephansdom (20II), I36-I39.

I 95 Triendl, Seefeld Tirol (2006), 20-2 I.

I 96 Hamm, Altartabernakel (2010), 66. Eines der aufwendigsten Tabernakel aus jener Epoche im nordalpinen Raum ist das im Dom zu Salzburg von I630/35. ÖKT, Salzburg (I9I2), 3 I-33; Schommers, Goldschmiedearbeiten (2003), i i 8, Abb. I. Vgl. zu dieser Art von Tabernakeln auch Guinomet, Sakramentstabernakel (2017).

I 97 Müller, KirchenGeschmuck (I59I), 20, 2 I, I I 3. 
griffen die Tischler auf die Spezifika dieser bemerkenswerten Bauwerke und Tabernakel zurück. ${ }^{198}$ Letztere erweisen sich mit den Taufsteindeckeln typologisch als so verwandt, dass sie sogar gegeneinander ausgetauscht werden konnten. ${ }^{199}$

\section{Vorarlberg und Burgenland}

Das Burgenland wurde I 920/2 I Österreich zugesprochen, zuvor bestand es aus verschiedenen, auf dem Boden des Königreichs Ungarn angesiedelten Komitaten mit überwiegend deutschsprachiger Bevölkerung. Wie Möbelgarnituren aus Salzburg wurde auch burgenländisches Mobiliar in die Untersuchung aufgenommen, um die gesamte Bandbreite der Tischlerarbeiten in den heutigen österreichischen Kulturlandschaften zu erfassen. Die Region zählte zu den ärmeren Landschaften, was sich nicht zuletzt an den Sakralmöbeln zeigt, die man oft aus Weichholz fertigte und bemalte. Große Sakristei- und Schatzkammerschränke wurden nicht benötigt, da sich im Besitz der burgenländischen Kirchen nur verhältnismäßig wenige kostbare Paramente und Altargarnituren befanden, die sicher hätten verwahrt werden müssen. Zwar stifteten ungarische Magnaten wie die Nádasdy oder die Esterházy etliche Kirchen und Kapellen, doch sparte man an der Ausstattung.

Ähnliches traf auf Vorarlberg zu, das ein hoher Gebirgszug von den übrigen österreichischen Bundesländern trennt. Wie im Burgenland fehlten auch dort weitgehend die großen Stifte und Mäzene, die bedeutende Kunstwerke in Auftrag gegeben hätten. In Vorarlberg tritt für die vorliegende Untersuchung erschwerend hinzu, dass die aufblühende Textilindustrie in der Region um die Wende zum 20. Jahrhundert zu einem gewissen Wohlstand führte und damit die finanziellen Mittel vorhanden waren, Kirchen mit neuen Interieurs zu versehen. Wie in den anderen österreichischen Landesteilen wurden zudem in der zweiten Hälfte des vergangenen Jahrhunderts viele der verbliebenen Barockmöbel aus den Sakralbauten entfernt und durch moderne Möbelgarnituren ersetzt. Als Folge davon ist der originale Bestand an antikem Mobiliar in Vorarlberg besonders stark dezimiert. Es haben sich kaum Möbelensembles aus der vorbürgerlichen Epoche erhalten, und dort, wo das Mobiliar noch dem I 8. Jahrhundert entstammt, handelt es sich in erster Linie um Einzelstücke, vor allem um Chorgestühle. Die auf uns gekommenen Einrichtungen veranschaulichen, wie sehr die Kunst jener Region in der Tradition süddeutscher und eidgenössischer

I98 Die Inventarstücke können damit vermutlich als Symbol der Ecclesia verstanden werden. Hamm, Altartabernakel (2010), 63.

I99 Hamm, ebd., 64. 
Geschmacksvorstellungen zu verorten ist. Das Chorgestühl in Bregenz (Farbtaf. 32; Abb. 380-384) macht das besonders deutlich. Hier wird sehr viel mehr Wert auf eine Verzierung mit Marketerien als andernorts in Österreich gelegt, außerdem vergegenwärtigen die Furnierbilder figürliche Darstellungen, die sonst lediglich das Gestühl in der Stiftskirche zu Zwettl und dort auch nur vier Dorsalefelder vervollkommnen. Darüber hinaus war der für die Fertigung des Bregenzer Gestühls verantwortliche Tischler offenkundig bemüht, die starre hölzerne Struktur des Möbels zu überwinden. Wirken österreichische Chorgestühle in der Regel traditionsgebundenen, kantig und etwas steif, so schickte sich Fr. Clemens Seehuber an, die Fassade seiner Arbeit in Schwingung zu versetzen. Die Idee dazu dürfte auf Vorbilder aus dem süddeutschen Kunstraum zurückgehen. 
Publikation im Sinne der CC-Lizenz BY 4.0 
Teil 3

Katalog - Beiträge zu den Sakralanlagen - Tafeln 
Publikation im Sinne der CC-Lizenz BY 4.0 


\section{Hinweise}

\section{Hinweise zu Provenienzen, Datierungen und Materialien}

Wie bereits in den einleitenden Kapiteln erwähnt, besaßen viele Klöster eigene Tischlereien, doch fertigten die Stiftsbetriebe das benötigte Mobiliar keineswegs immer selbst. Waren ihre Kapazitäten durch die Herstellung von Fußböden, Wandvertäfelungen, Türen und Fenstern oder durch Reparaturarbeiten erschöpft, vergaben die Konvente Arbeitsaufträge an externe Handwerker. Wegen des Mangels entsprechender Archivalien lässt sich das jedoch nur selten nachweisen. Wissenschaftlich exakt wäre es infolgedessen, in Zweifelsfällen bei den Angaben zur Provenienz eines Werkstücks jeweils die Stiftstischlerei sowie den Namen des nahegelegenen Ortes zu nennen. Um jedoch den Katalog nicht unnötig auszuweiten, wurde darauf verzichtet und lediglich die nächste Stadt oder Ortschaft erwähnt, was die Möglichkeit einer Herstellung der betreffenden Einrichtungsgegenstände in der Klosterschreinerei miteinschließen soll. Zudem wird bei der Bearbeitung von Möbeln, die Teil eines Ensembles sind, die wiederholte Auflistung sämtlicher Daten unterlassen. In diesen Fällen habe ich die Angaben zusammengefasst und nur ein einziges Mal auf Provenienz, Datierung und verwendete Materialien aufmerksam gemacht.

\section{Hinweise Zu den Angegebenen Massen}

Viele der untersuchten Möbel ruhen auf Podesten, die formal und konstruktiv als eigenständige Möbelteile konzipiert und gebaut wurden. Je nach dem Grad ihrer Beanspruchung waren sie nicht selten schadhaft und mussten erneuert werden. Da die heutigen Maße nicht unbedingt mit den ursprünglichen übereinstimmen, ist die Höhe der Podeste gesondert angegeben, während auf eine Nennung von Tiefe und Länge der Sockel meist gänzlich verzichtet wird. Ferner sei bemerkt, dass die angeführten Maße stets Annäherungswerte darstellen. Die Steinböden, auf denen die Möbel stehen, sind nur selten eben, was natürlich zu unterschiedlichen Maßangaben führt. Hinzu kommen Schnitzaufsätze und Schleierbretter, die an Möbelgarnituren von Tischlern und Bildschnitzern in Handarbeit und insofern immer mit gewissen Abweichungen an den 
einzelnen Stücken ausgeführt wurden. Auch das hat zwangsläufig Differenzen bei den gemessenen Werten zur Folge.

\section{Hinweise zu den zitierten Schriftquellen}

Bei der Übernahme von Schriftquellen aus modernen Veröffentlichungen hielt ich mich an die dort gewählte Schreibweise, die sich hinsichtlich der Orthographie häufig nach den heute gültigen Regeln richtet. Dagegen wurde in handschriftlichen Unterlagen des I 7. und I 8. Jahrhunderts auf die Einhaltung bestimmter Regeln nur selten geachtet. Deshalb orientierte ich mich bei der Transkription von Schriftquellen, die ich selbst erschloss, an der Zitierweise von Historikern und Archivaren, die bis auf Satzanfänge und Eigennamen den gesamten Text in Minuskel setzen und normalerweise die Interpunktion der originalen Schriftstücke übernehmen. Nur in Fällen, in denen es für das Verständnis der wiedergegebenen Schriftquellen unumgänglich schien, trennte ich lange und komplizierte Satzgebilde durch einen Punkt, ein Semikolon oder einen Beistrich. Verdopplungsstriche über einem »n« und »m« wurden zu einem »nn« bzw. "mm« aufgelöst. 
I.

\section{Sakralbauten im Burgenland}

\section{Eisenstadt, Rektoratskirche St. Michael}

\section{Ehemaliges Franziskanerkloster}

Schon im frühen I 5. Jahrhundert existierte in Eisenstadt ein Minoritenkloster, damals mit einer Kirche, die unter dem Patronat des hl. Johannes Evangelist stand. ${ }^{1}$ Nach ihrer Zerstörung im Jahr $5_{52} 9$ verwaiste die Anlage, bis Graf Nikolaus Esterházy (I582/83-I645) I625 dort die Neugründung eines Franziskanerklosters veranlasste. In den folgenden Jahren wurde die Kirche unter Verwendung mittelalterlicher Spolien erbaut, ihre Weihe ist für I630 überliefert. Vergleichbar mit der Situation in der Wiener Franziskanerkirche, grenzt der aus dem frühen i 7. Jahrhundert stammende Hochaltar den zweijochigen Zelebrantenchor vom einjochigen Mönchschor ab. Der Raum dahinter findet heute als Beichtkammer Verwendung, außerdem errichtete man dort im fortgeschrittenen I8. Jahrhundert einen weiteren Altar. ${ }^{2}$ Die Kirche wurde mehrfach restauriert, an eine umfassende Renovierung erinnert eine in die Chornordwand eingelassene Gedenktafel von I898. I 975 übernahm die Diözese die Klostergebäude, 20 I 9 auch die Kirche.

\section{Empore}

Beichtstuhl

Eisenstadt, 2. H. I7. Jh.

H I $76 \mathrm{~cm} \times$ B I Io $\mathrm{cm} \times$ T 9 I $\mathrm{cm}$

Nadelholz, schwarz gebeizt. Eisen

Ein Beichtstuhl, der einfacher kaum sein könnte, nimmt die rechte Raumecke auf der Empore ein (Abb. or). Das Möbel setzt sich aus einer Kniebank für die Beichtenden, einer hohen Trennwand mit Sprechgitter und einem Kasten als Sitzgelegenheit für den Geistlichen zusammen. Nur der geschweifte Abschluss der Trennwand und der Metallbeschlag am Kasten lassen eine ungefähre Datierung des Möbels zu.

I Zu Kirche und Kloster vgl. ÖKT, Eisenstadt (I 932), 38-48; ÖKM, Burgenland (r 968), 62; Dehio, Burgenland (1980), 7 I-73; Czeike, Burgenland (I988), 75-76; Zelfel, Franziskanerkiche (2005), 2-23.

2 Zum Raum und seiner Ausstattung vgl. ÖKT, ebd., 43-44; Dehio, ebd., 72 ; Zelfel, ebd., I 5-1 7. 


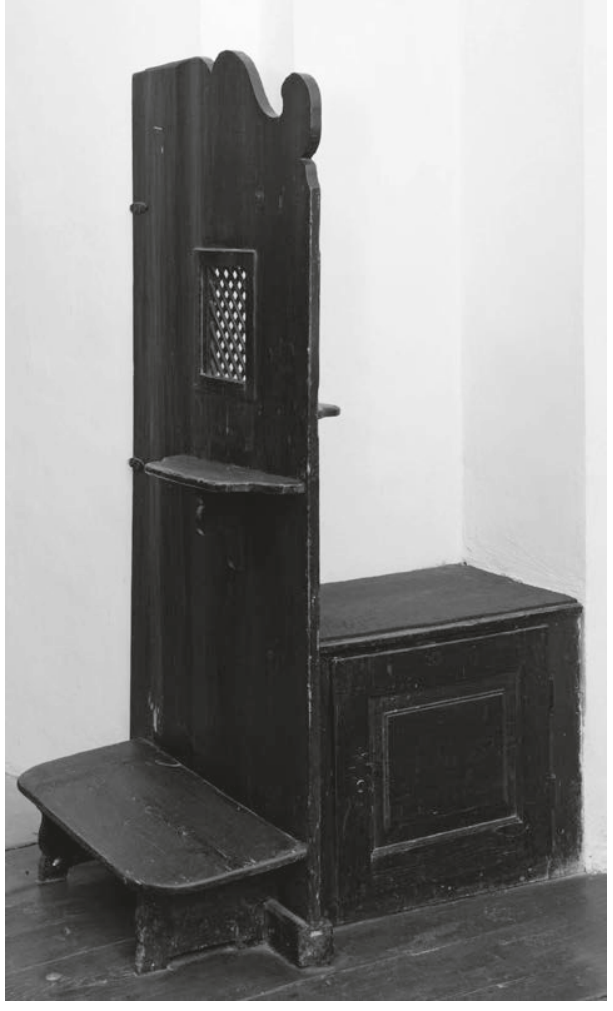

or Empore, Beichtstuhl. Eisenstadt, 2. H. I7. Jh.

\section{Chorgestübl}

Eisenstadt, um I 630/50

HS i $8,5 \mathrm{~cm}$

$\mathrm{H} 240 \mathrm{~cm}(+\mathrm{I} 8,5 \mathrm{~cm}) \times \mathrm{L}$

$52 \mathrm{I} \mathrm{cm} / \mathrm{I} 50 \mathrm{~cm} / 5$ IO cm

Nussbaum, Rückwände hinter Sitzen aus Eiche,

Boden aus Nadelholz

Seitlich des Beichtstuhls befindet sich ein Lförmiges Chorgestühl, dessen Reihen hinter der Orgel parallel zur Kirchenfassade (Teile I und 2) und auf der Emporensüdseite rechtwinklig dazu (Teil 3 ) verlaufen (Abb. 02, 03) ${ }^{3}$ Das Gestühl verfügt über I 4 Stallen, wobei die Eckstalle aus Platzgründen vermutlich unbesetzt blieb. Ionische Keilpilaster mit geschuppten Schäften unterteilen die Brüstungen und flankieren verkröpfte Füllungen mit eingesetzten Feldern. An der Brustwand von Teil I sind es drei hochovale zwischen vier rechteckigen Füllungen, Teil 2 wartet mit einem rechteckigen Kompartiment auf, Teil 3 mit zwei ovalen und ebenso vielen rechteckigen Segmenten im Rhythmus a-b-a-b.

Flammleisten rahmen die zentralen Felder.

Anders als Teil 2, der (heute?) ohne Rückwand auskommt, besitzen die Teilstücke I und 3 ein Dorsale. Wie das auch bei anderen Gestühlen der Zeit der Fall ist, zeigt sich die Rückwand mit Sockel, Hauptzone und verkröpftem Gebälk architektonisch gestaltet. Vor dem Sockel angeordnete Stehvoluten tragen korinthische Säulen. Die ädikulaartigen Füllungen in den Zwischenräumen dekorierte man mit Muschelarkaden und flachen Schnitzarbeiten. Sie unterscheiden sich deutlich von den Außenwangen, die schwere Knorpelschnitzereien schmücken.

Das Gestühl ist nicht im Originalzustand erhalten, vermutlich wurde es auch nicht für seinen jetzigen Standplatz geschaffen. Zunächst fällt auf, dass Teil r länger als das dahinter aufragende Mauerwerk ist, weshalb dieses Möbelsegment in zwei große

3 Zum Gestühl vgl. ÖKT, ebd., 43; ÖKM, Burgenland ( 1968), 62; Dehio, ebd., 72-73; Czeike, Burgenland (r 988), 76 ; Zelfel, ebd., I 7 . 


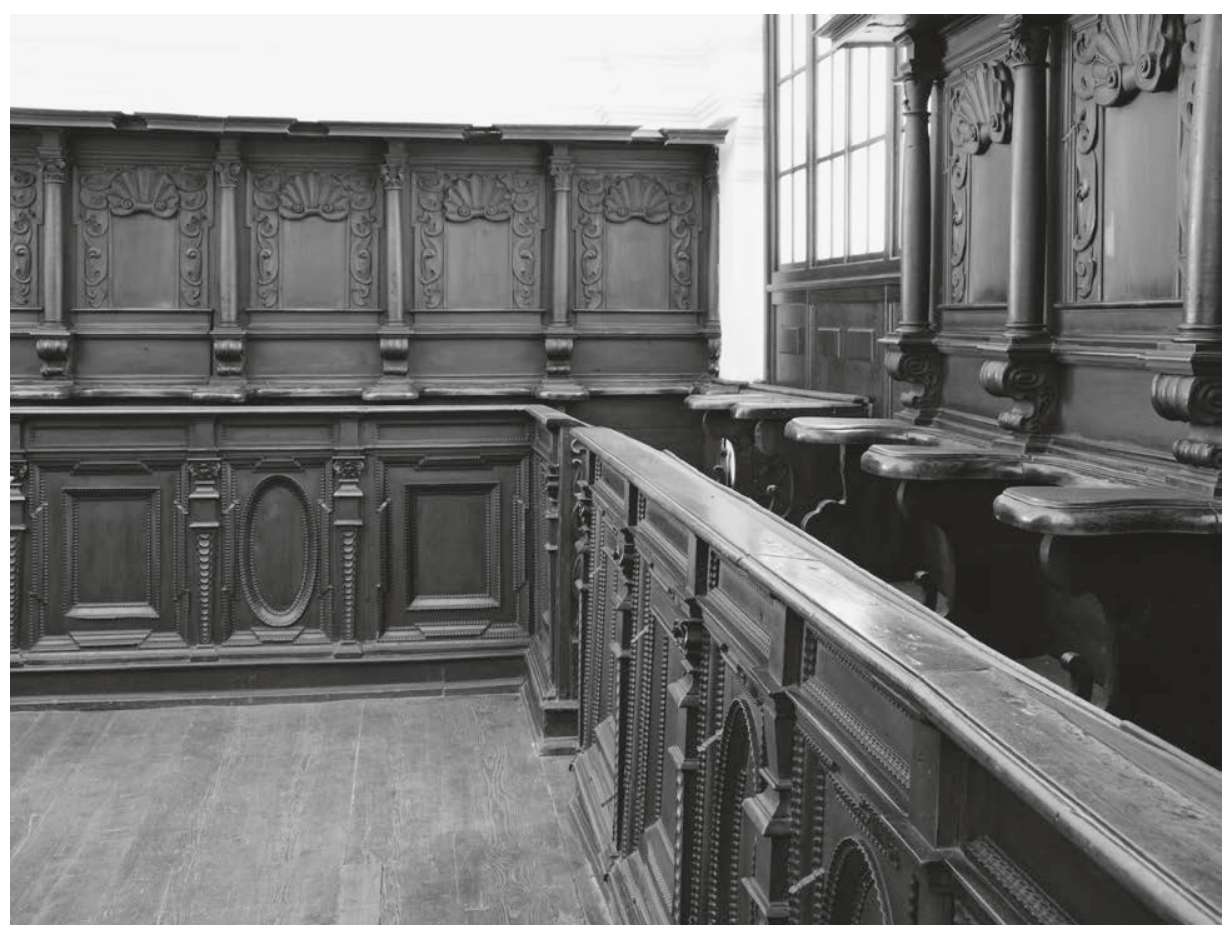

02, ${ }_{3}$ Empore, Teilansicht des Chorgestühls. Eisenstadt, um I 630/50

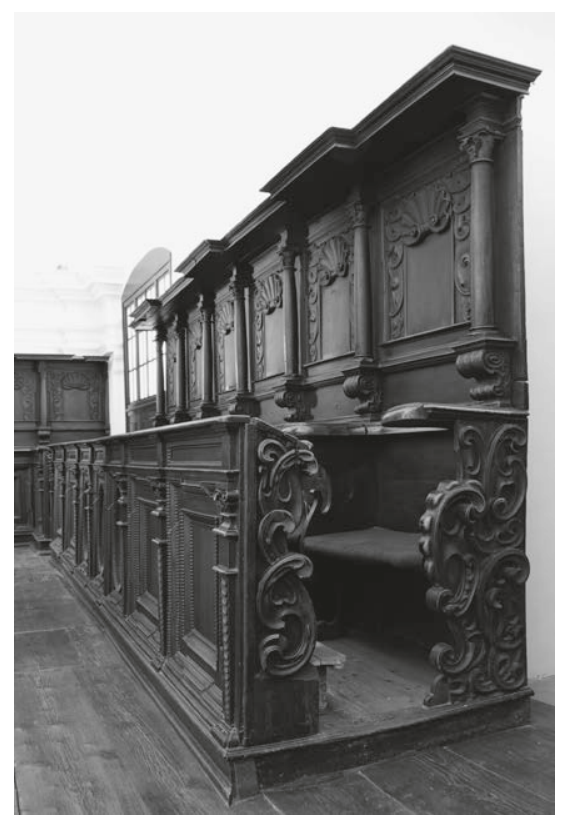


Fensternischen hineinragt. Weiter entspricht die Anordnung der Brüstungsfüllungen von Teil 3 sicher nicht dem originalen Zustand. Dann weisen die Teile I und 3 etwa in der Mitte einen vertikal verlaufenden Sägeschnitt in Rückwand und Brüstung auf zweigeteilt ließen sich die einzelnen Segmente natürlich leichter transportieren und umstellen. Und schließlich wurde die Rückwand der Südseite gekürzt, wie Schnittstellen am Gesims belegen.

Möglicherweise fertigten die Tischler das Gestühl ursprünglich für den Standort hinter dem Altar, da die Mönche des Minoritenordens dem Gottesdienst bevorzugt im abgeschiedenen Psallierchor beiwohnten. Die Aufstellung der Stallen in der Wiener Franziskanerkirche liefert hierfür ein Beispiel. ${ }^{4}$ Mit einer Raumtiefe von 6,20 m wäre in Eisenstadt das Platzangebot hinter dem Altar zwar knapp, aber doch ausreichend gewesen, um das Gestühl aufzurichten. Auf jeden Fall hätte es dann später dem erwähnten spätbarocken Altar weichen müssen. Allerdings befindet sich auf der Empore der Franziskanerkirche zu Frauenkirchen ein barockes Gestühl, das von Anfang an für diesen Standplatz geschaffen wurde (Farbtaf. or; Abb. o6). Demzufolge war in Kirchen der Franziskaner auch diese Art der Aufstellung möglich. In der Literatur wird das Gestühl in Eisenstadt um r630 datiert. Für das Dorsale mit den flachen Ziermotiven sowie für die Brüstung und zwei Wangen könnte das zutreffen, dagegen weisen die für die anderen Docken gewählten kraftvollen Schnitzornamente auf eine Entstehung um die Jahrhundertmitte. Sie dürften nachträglich hinzugefügt worden sein. Die Kniebänke und Laufböden sind relativ neu.

\section{Kirchenraum}

\section{Laiengestühl}

Eisenstadt, um I630/50

HS I0, $5 \mathrm{~cm}$

$\mathrm{H}$ i $22 \mathrm{~cm}(+\mathrm{IO}, 5 \mathrm{~cm}) \times \mathrm{L}_{2} 82 \mathrm{~cm}$

Nadelholz, dunkelbraun lasiert

Das seitlich des Kirchenmittelgangs platzierte Möbelensemble umfasst 25 Bankreihen und vier Vorderbrüstungen (Abb. O4, 05)..$^{5}$ Eine in Rahmen und schlichte Rechteckfüllungen gegliederte Hauptzone sowie ein mit wenigen Triglyphenfeldern ornamentiertes Gebälk formen die Brustwände. Sie erinnern an das Aussehen der Möbel in der steiermärkischen Abtei St. Lambrecht aus den frühen r640er-Jahren (Abb. 260). Die aufwendiger gearbeiteten Bankwangen bestehen aus einem hohen stelenförmigen

4 Bohr, Sakralmöbel (2017), 83-84, I 56-I 58.

5 ÖKT, Eisenstadt (1932), 43 . 


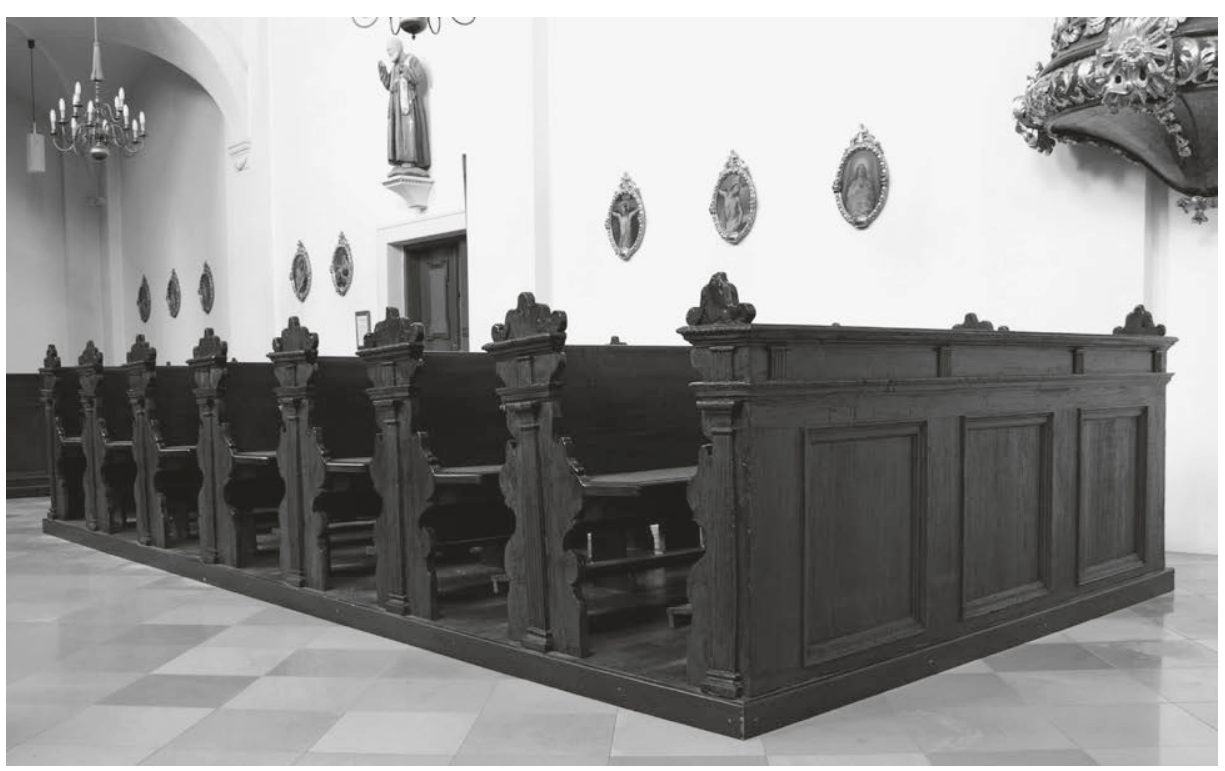

04 Laiengestühl. Eisenstadt, um I630/5O

O5 Laiengestühl, Bankwangen. Eisenstadt, um I $630 / 50$

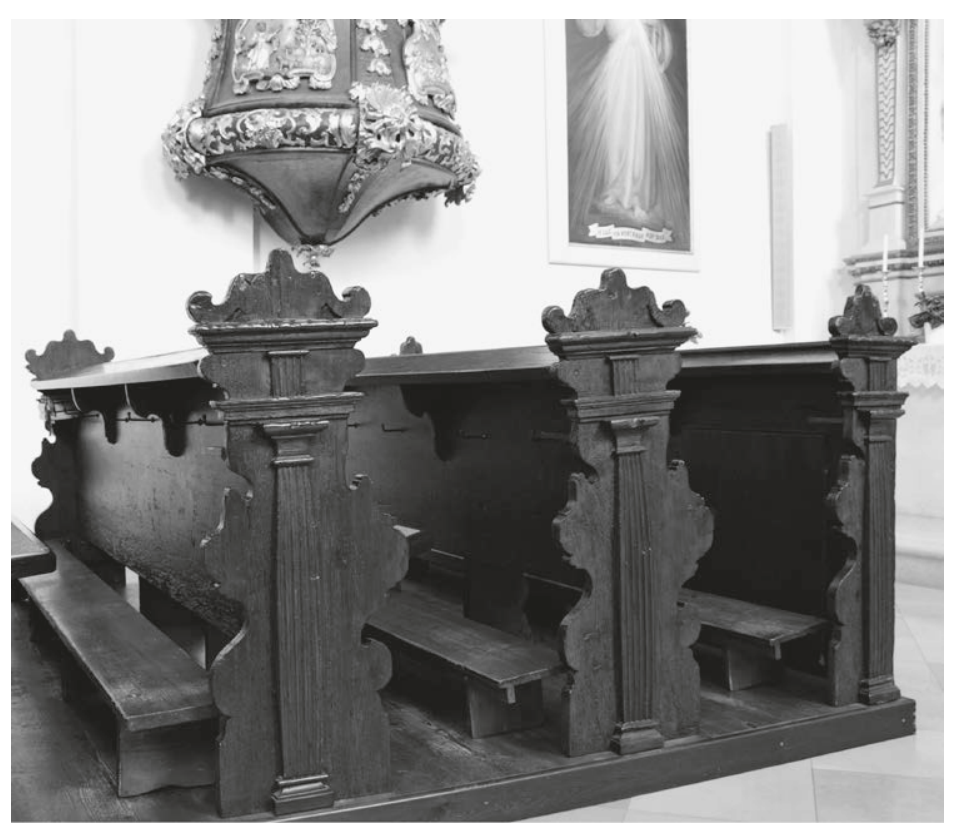


Brett mit stark konturierten asymmetrischen Seitenkanten. Ein kannelierter dorischer Pilaster mit akzentuierter Entasis trägt jeweils ein Gebälkstück und einen geschweiften Aufsatz als Bekrönung. Es ist nicht zu übersehen, dass die Bänke stilistisch auf einer früheren Entwicklungsstufe als die Wangen des Chorgestühls stehen. Gleichwohl ist auch eine Erzeugung der Möbel etwa zwischen I630 und I650 wahrscheinlich. Die Gestaltung der Oberfläche dürfte dem ursprünglichen Erscheinungsbild nahekommen $^{6}$, während die Laufböden und Kniebänke moderne Ergänzungen sind. Die originalen Sitzbänke wurden mit neuen Randleisten eingefasst.

\section{Frauenkirchen, Franziskanerkloster}

\section{Pfarr-und Wallfabrtskirche Mariae Geburt}

Schriftquellen berichten seit dem frühen I 4. Jahrhundert von Frauenkirchen als Wallfahrtsort. ${ }^{7}$ Eine Marienkirche, die sich bei der Pilgerstätte befand, wurde im r6. Jahrhundert verwüstet und lag lange Zeit in Trümmern. Ihre Wiedererrichtung erfolgte in den I66oer-Jahren, doch erwies sich das Gebäude für die wachsende Gemeinde und die zunehmende Zahl an Pilgern schon bald als zu klein. Hinzu kamen im Jahr I683 Verwüstungen durch osmanische Heere. Deshalb trug man die erst kurz zuvor renovierte Kirche ab und legte I694 den Grundstein zu einer größeren und prunkvolleren Architektur. Stifter war Fürst Paul Esterházy (I635-I7I3), als Baumeister trat Francesco Martinelli (I65I-I708) in Erscheinung. Acht Jahre später erfolgte die Weihe des Sakralbaus, der ein kreuzgratgewölbtes vierjochiges Langhaus mit Seitenkapellen besitzt, ebenso viele Joche umfasst der eingezogene Chor. Um I70o entstandene Stuckdekorationen von Pietro Antonio Conti (nachgew. I697-r7I I) und Wandmalereien von Luca Antonio Colombo (I66I-I737) schmücken das Mauerwerk im Kircheninnern. Die Malereien vergegenwärtigen Szenen aus der Heilsgeschichte sowie Darstellungen von Vertretern des Franziskanerordens. Im August r 990 wurde die Wallfahrtskirche zur Basilica minor erhoben.

6 Der Tischler Christoph Paumgartner erwähnte in einem Schreiben von I643, dass er die Bänke in der Stiftskirche St. Lambrecht nussfarben gebeizt, mit Leim getränkt und anschließend mit einem Firnis überzogen hätte. Vgl. hierzu den Beitrag zu St. Lambrecht.

7 Frauenkirchen, Burgenland (I96r); Hootz, Kunstdenkmäler (r965-I968), Bd. 3 (I967), 63-64, 38I ; ÖKM, Burgenland ( 1 968), I07-108; Raber, Frauenkirchen (1 975); Dehio, Burgenland ( 980 ), I00-103; Czeike, Burgenland (I 988), I 74-I78; Schlatzer, Frauenkirchen (2000); Brunner-Hammerl, Frauenkirchen (2007), bes. 34-43; Kriechbaum, Klöster (2008), 232-235; ÖKT, Neusiedl (201 2), I 90-2 23. 


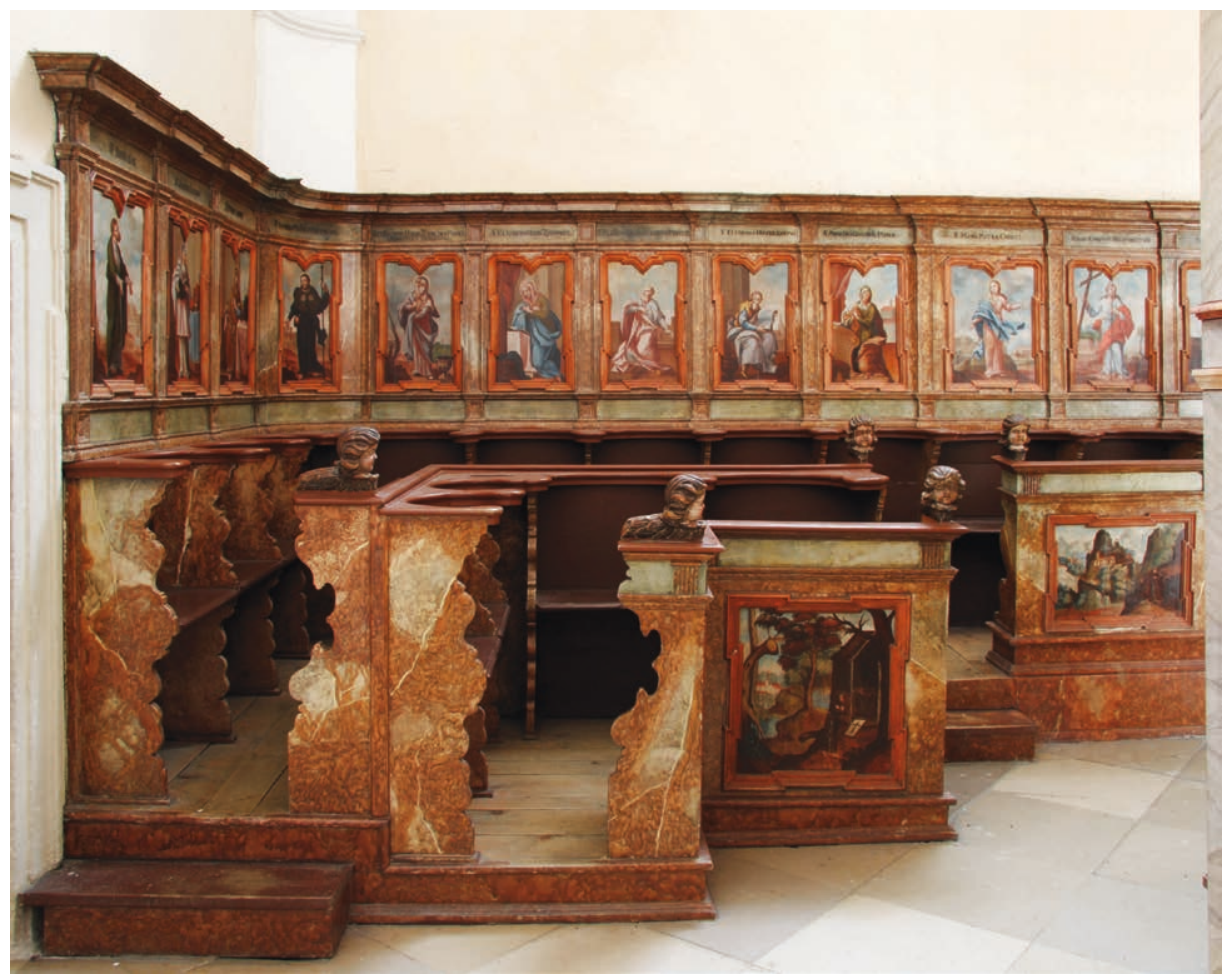

Farbtafel or Empore, Teilansicht des Chorgestühls. Frauenkirchen, um I 700/ Io

\section{Empore}

\section{Chorgestühl}

Frauenkirchen, um I 700/Io

$\mathrm{HS}_{\mathrm{I}} / 3 \mathrm{I} \mathrm{cm}$

$\mathrm{H} 233 \mathrm{~cm}(+3 \mathrm{I} \mathrm{cm}) \times$ Gesamtlänge ca. I 4,50 m

Nadelholz, bemalt und marmoriert, Nussholz, polychrom gefasst

Zusätzlich zur Balustrade schrankt ein hohes Gitter, das mit Akanthus verziert ist, die Empore ab (Farbtaf. o ; Abb. o6, o7). Über U-förmigem, zum Altar hin offenem Grundriss bietet das zweireihige Gestühl 27 Geistlichen Platz. ${ }^{8}$ Wie üblich sind die hinteren Sitze gegenüber den vorderen erhöht und befinden sich vor den drei Stallen der Klostervorsteher in der Mitte des Ensembles keine Sitzmöglichkeiten. Die Gestühlsbrüstung besteht aus glatten Rahmensegmenten und verkröpften Füllungen,

8 Zum Gestühl vgl. Frauenkirchen, ebd., 2 I ; Dehio, ebd., I o2; Czeike, ebd., I78; ÖKT, ebd., 2 Io-2 I 2. 


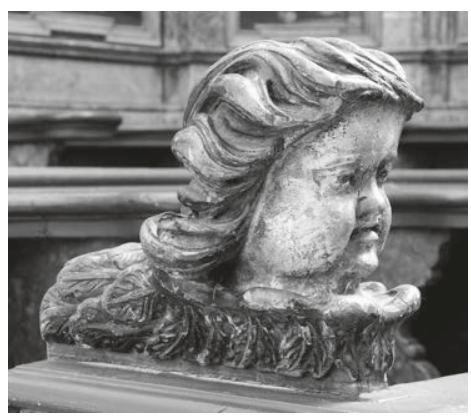

o6 Empore, Chorgestühl (Detail), Engel als Schnitzaufsatz. Frauenkirchen, um I700/ro

o7 Empore, Brüstung gegen das Kirchenschiff (Detail). Frauenkirchen, um I $700 /$ ro

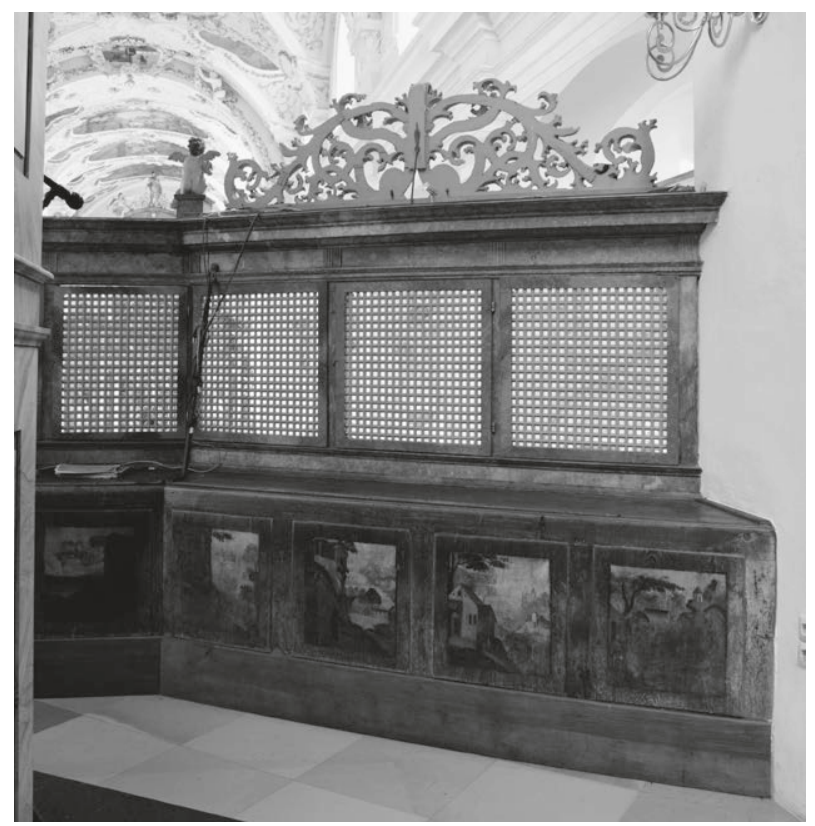

als Abschluss dient ein mit Triglyphen verziertes horizontales Band. Glatte, mit stark geschweiften Kanten versehene Bohlen bilden die Wangen. Das Dorsale setzt sich aus Sockelband, Hauptgeschoss und verkröpftem Gebälk zusammen, pilasterartige Bänder und schlanke hochrechteckige Binnenfelder strukturieren die Rückwand.

Die bemalten Füllungen und marmorierten Rahmen bestechen durch die qualitätvolle Ausarbeitung. Die Brustwände zeigen Ordensangehörige in kargen Landschaften mit Einsiedeleien und Klosteranlagen, ein Hinweis auf die Lebenswelt der Kommunität im franziskanischen Mutterkloster La Verna in der Toskana, während Darstellungen an den Rückwandfüllungen Mitglieder der Heiligen Familie versinnbildlichen. Rahmen und Wangen sind mit grünlichen und bräunlichen Farbtönen marmoriert, die Accoudoirs braun gestrichen. Vollrund geschnitzte Engelsköpfe aus polychromiertem Nussbaumholz zieren die Zugangswangen. Mit ihrem langgezogenen Leib, der mit Federn besetzt ist, erinnern sie an liegende Sphinxen. Eine vergleichbare Auszier kann an keinem zweiten Gestühl in Österreich nachgewiesen werden.

In der ÖKT wird eine Anfertigung des Gestühls um I 702 angenommen, als Referenzstück dient ein inzwischen leider umgebauter Sakristeischrank in der Klosterkirche. Anders als das erwähnte Brüstungsgitter kommt das Gestühl ohne Akanthusschmuck aus, wobei die Stallen eine konservative Formensprache aufweisen. 


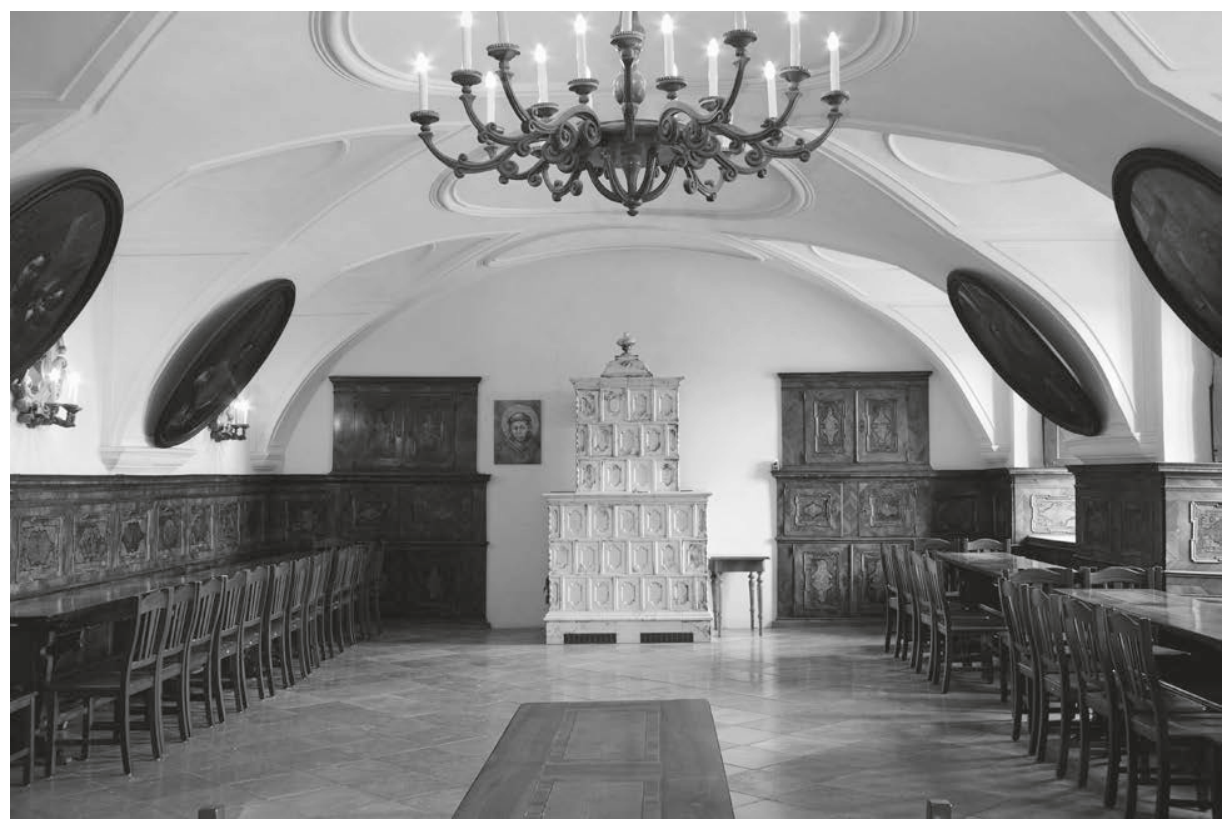

o8 Kloster, Refektorium. Frauenkirchen, um I 7 I 5/25

\section{Refektorium}

\section{Wandvertäfelung}

Raummaße ca. I7, Io $\mathrm{m} \times 7,55 \mathrm{~m}$

Gesimshöhe I $63 \mathrm{~cm}$, Schrankhöhe $267 \mathrm{~cm}$

\section{Tische}

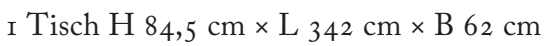

6 Tische $\mathrm{H} 84,5 \mathrm{~cm} \times \mathrm{L} 250,5 \mathrm{~cm} \times \mathrm{B} 62 \mathrm{~cm}$

Frauenkirchen, um I 7 I $5 / 25$

Nuss, massiv und furniert, Nussmaser, Pappelmaser, Ahorn, Zwetschke, furniert auf Nadelholz

Durch Proportion und Ausgestaltung greift der tonnengewölbte fünfjochige Speisesaal (Abb. 08, o9) das Beispiel des nur wenig früher entstandenen Refektoriums im Wiener Franziskanerkloster auf. ${ }^{9}$ Durch Fenster in einer Längswand fällt Licht in den Raum, schlichter Stuckdekor formt ovale und runde Spiegel an der weißgekalkten

9 Zum Refektorium in Eisenstadt Dehio, ebd., ı03; Schlatzer, Frauenkirchen (2000), 25 ; ÖKT, ebd., 22. Zum Speisesaal der Wiener Franziskaner vgl. Bohr, Sakralmöbel (2017), I63-r 65 . 


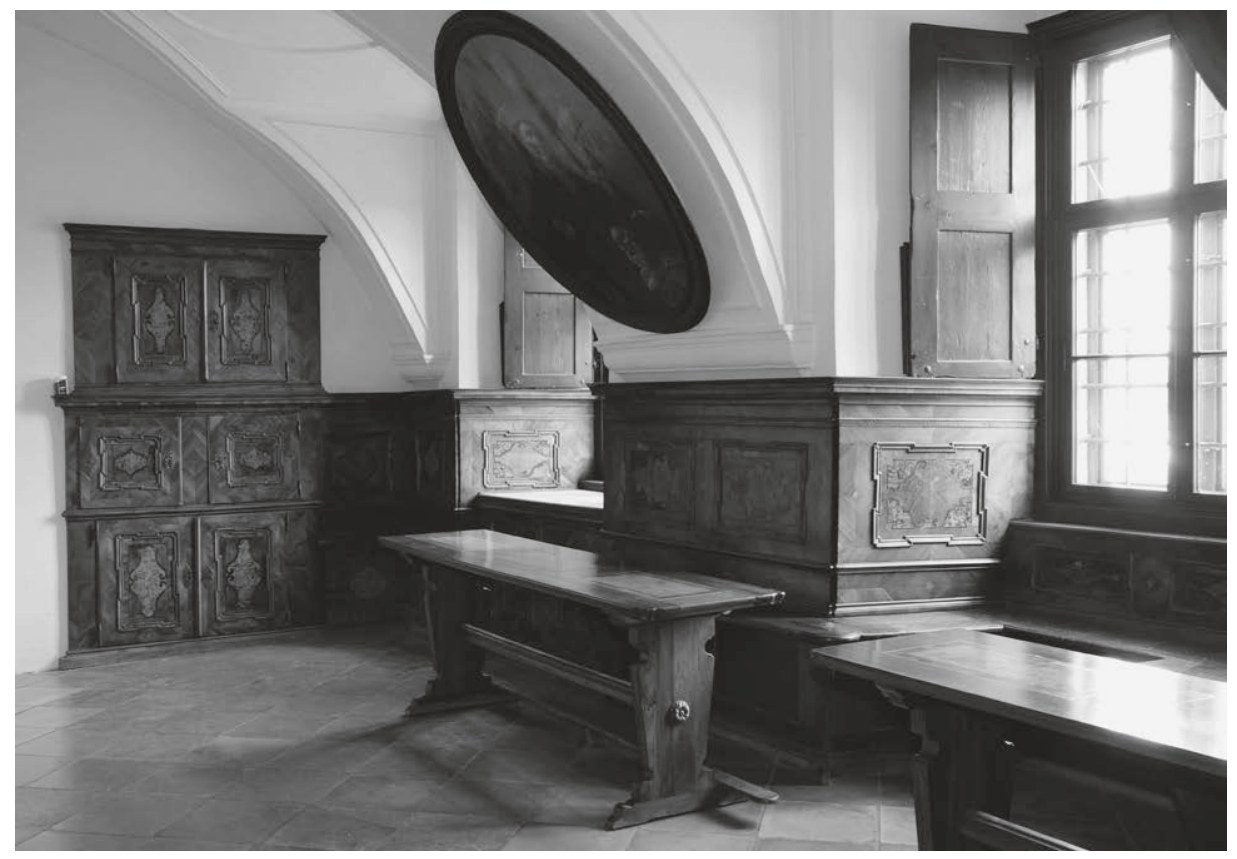

o9 Kloster, Refektorium, Wandschrank, Vertäfelung und Tische. Frauenkirchen, um I 7 I 5/25

Decke. Holzvertäfelungen schmücken die Wände dreier Raumseiten, während man seitlich eines Kachelofens in das Mauerwerk der vierten Wand Wandschränke mit Durchreichen einfügte. Weitere Kästen füllen den unteren Teil einiger Fensternischen, in einer Nische befindet sich eine Lesekanzel. Wie in Wien standen die Sitzbänke früher auf einem niedrigen Podest, das hier jedoch entfernt wurde, als man den Fußboden erneuerte. ${ }^{10}$

Das Getäfel ist in eine eher schlichte Sockelzone mit den Bänken und eine Hauptzone unterteilt, die wie das beschriebene Chorgestühldorsale drei waagrechte Register umfasst. Große querrechteckige und kompliziert verkröpfte Füllungen strukturieren die Hauptzone. Als Fischgratmuster zusammengefügtes Nussbaumfurnier liegt auf den Rahmen, Maserholz aus Nuss und Pappel auf den Füllungen. Geschwungene und miteinander verkettete Adern trennen die Furniere voneinander.

Vergleichbar mit dem Befund in Wien befinden sich über dem Gebälk Gemälde, die hier allerdings Ordensheilige präsentieren. Eine weitere Analogie zur Einrichtung des Refektoriums in der Hauptstadt ergibt sich aus der Gestaltung der Tische. Sie be-

ıo Freundliche Auskunft von Fr. Elias Unegg. 
sitzen einen breiten kufenartigen Fuß, darüber folgt ein sich verjüngender Baluster, auf dem die Platte aufliegt. An den furnierten Platten fassen breite Rahmen mit Ahorn ausgelegte Füllungen ein. Seitliche Gratleisten halten die Platten gerade, massive Querstreben in mittlerer Höhe stabilisieren die Möbel, Fußleisten auf der Wandseite gestatten den Mönchen ein angenehmes Sitzen. Im Gegensatz zu den auf drei Seiten geschlossenen Refektoriumstischen der alten Orden ${ }^{11}$, sind die Tische der Franziskaner zur Raummitte hin vollständig oder größtenteils geöffnet. Die Frage nach dem Bedeutungsgehalt der umlaufenden Bänke und solcher Tische wurde bereits im ersten Band der Untersuchung erörtert. Diese Art der wandfesten und mobilen Einrichtung ist allerdings nicht nur für Franziskaner charakteristisch, sie kommt ebenfalls in Speisesälen der Jesuiten vor, wie die ehemalige Refektoriumseinrichtung der Jesuitenkommunität in Trencin belegt. Auch das um 1735 gefertigte und heute im Budapester Kunstgewerbemuseum aufbewahrte Interieur besteht aus einer Wandvertäfelung, einer langen Sitzbank und Wangentischen. ${ }^{12}$

Eines der Gemälde über der Vertäfelung in Frauenkirchen trägt die Jahreszahl I 733, doch dürften die Bilder nach den Tischlerarbeiten entstanden sein. Dehio und ÖKT datieren die Ausstattung in Frauenkirchen ins erste Viertel des I 8. Jahrhunderts, das trifft zu. Die verkröpften und mit feinen Profilen gerahmten Füllungen sprechen für eine frühe Herstellungszeit. ${ }^{13}$ Ein zusätzlicher Hinweis ergibt sich aus der unterschiedlichen technischen Ausführung der Arbeiten im Refektorium und auf der Empore - hier aufwendig furnierte, dort prächtig bemalte Flächen. Eine gleichzeitige Entstehung von Chorgestühl und Speisesaalinterieur ist deshalb unwahrscheinlich.

\section{Lockenhaus, Pfarr- und Wallfahrtskirche hl. Nikolaus}

Die Anfänge der Pfarre liegen im Dunkeln, doch ist davon auszugehen, dass sich in der ehemaligen Burg Lockenhaus, die Schriftquellen seit I 242 erwähnen, bereits eine Kapelle befand. ${ }^{14}$ Im frühen I 4. Jahrhundert stifteten die einer ungarischen Adelsfamilie entstammenden Grafen von Güssing, die Eigentümer von Lockenhaus, in der Herrschaft ein Franziskanerkloster, das I 529 von Osmanen zerstört worden sein

I I Zu Refektorien in Göttweig, Heiligenkreuz und St. Florian vgl. Bohr, Sakralmöbel (2017), 302-306, 33 I-335, 597-601 und Abb. I32-I34, I 54, I 57, 360.

I 2 Batári/Vadászi, Furniture-Making (2000), 77-78.

I3 Michael Schlatzer, Frauenkirchen (2000), 25, nimmt dagegen eine Herstellung um I 740 an.

I4 ÖKM, Burgenland (I 968), I 45-I 46; Loibersbeck, Lockenhaus, I (I 972); ders., Lockenhaus, 2 (I972); ders., Lockenhaus, 3 (I972); Dehio, Burgenland (r980), I72-I74; Czeike, Burgenland (r988), 238; Horvath/Weiger, Lockenhaus (2005); ÖKT, Oberpullendorf (2005), 327-350. 
soll. ${ }^{15}$ Einige Jahre später ging der Besitz der Burg und der zugehörigen Herrschaft an die Nádasdy über, ein weiteres Adelsgeschlecht mit ungarischen Wurzeln. Vermutlich wurde damals zumindest der Sakralbau wiederinstandgesetzt. Seit I655 errichtete Graf Franz II. Nádasdy eine neue Pfarrkirche und ein Kloster, das er durch AugustinerEremiten besiedeln ließ. Baumeister des noch heute bestehenden Gebäudekomplexes war Pietro Orsolini. Die Weihe der Kirche fiel in das Jahr I669. Keine zehn Jahre später erwarb Fürst Paul Esterházy die Anlage. Augustiner-Mönche bewohnten sie bis I 820 , danach überließ man die Kirche weltlichen Geistlichen, während Beamte der Esterházy in das verwaiste Kloster einzogen. Um I 870 gestaltete es die Adelsfamilie zu einer Sommerresidenz um.

Die Kirche ist ein frühes Beispiel für einen Zentralraum, dessen Grundriss von der Form eines griechischen Kreuzes ausgeht. Schräg stehendes Mauerwerk verbindet die Kreuzesarme, sodass der Raum die Gestalt eines ungleichseitigen Oktogons annimmt, an das sich der einjochige Altarraum und das ebenfalls einjochige Emporenjoch anschließen. Kapellen werten die vier Diagonalen auf, zwei große Altäre die Querarme.

\section{Kirchenraum}

\section{Laiengestühl}

Lockenhaus, um I660/70

$\mathrm{H}$ I IO $\mathrm{cm} \times \mathrm{L} 294 \mathrm{~cm}$

Eiche, massiv, Nadelholz

Das Gestühl ruht seitlich des Mittelgangs auf vier Podesten, von denen die hinteren jeweils zehn, die vorderen sieben Bankreihen tragen, hinzu kommen die Brüstungen (Abb. го, I I). ${ }^{16}$ Die an den Außenseiten des Laufbodens befestigten Seitenwangen und Brustwände stehen direkt auf dem Fußboden. Von hohen Sockeln aufsteigende, geschuppte und sich verjüngende Lisenen rastern die Brustwände, hochrechteckige Felder mit Ohren und Füßen füllen die Zwischenräume. Die Stützen tragen kein Gebälk, sondern ein schlichtes Abschlussgesims. Aufwendiger gestaltete man die stark konturierten und nur teilweise symmetrisch angelegten Wangen. Lisenen heben ihre Mittelachsen hervor, aufgelegte Profile unterteilen sie. Die Docken sind mit knorpeligen Bögen und Schuppenfriesen dekoriert, je ein Diamantquader ziert die Postamente. ${ }^{17}$

I 5 Loibersbeck, Lockenhaus, I (1972), 38 , nennt das Jahr I 532.

I6 ÖKT, Oberpullendorf (2005), 342 .

17 Weitere Bänke werden auf dem Betchor aufbewahrt. 


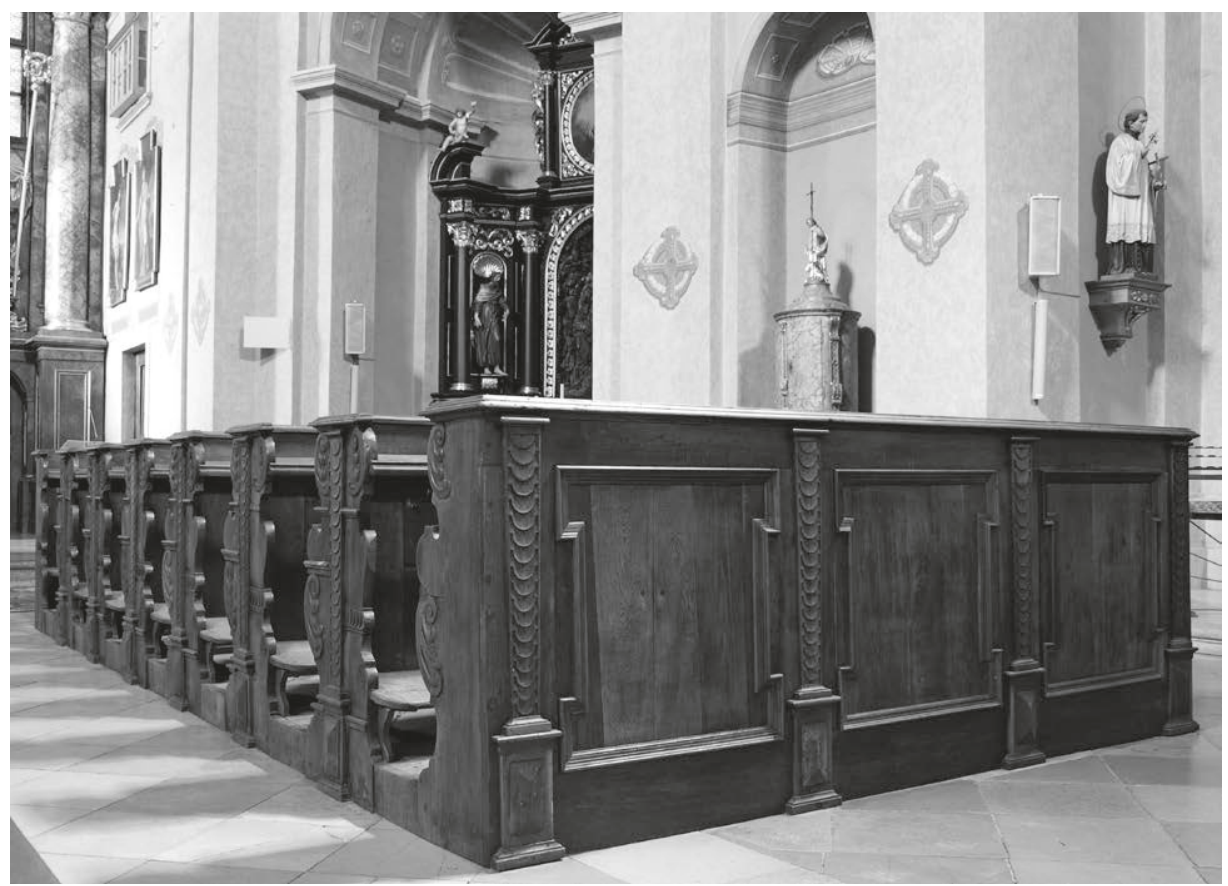

Io Laiengestühl. Lockenhaus, um I660/70

I I Laiengestühl, Bankwange. Lockenhaus, um I660/70

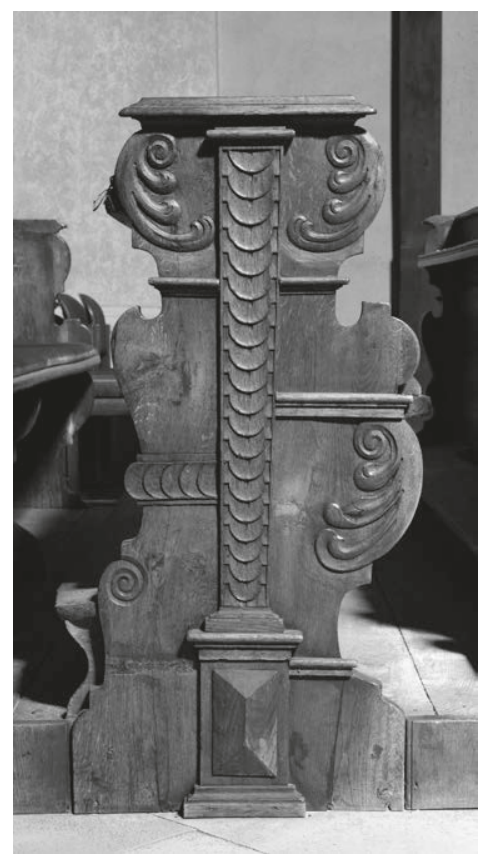




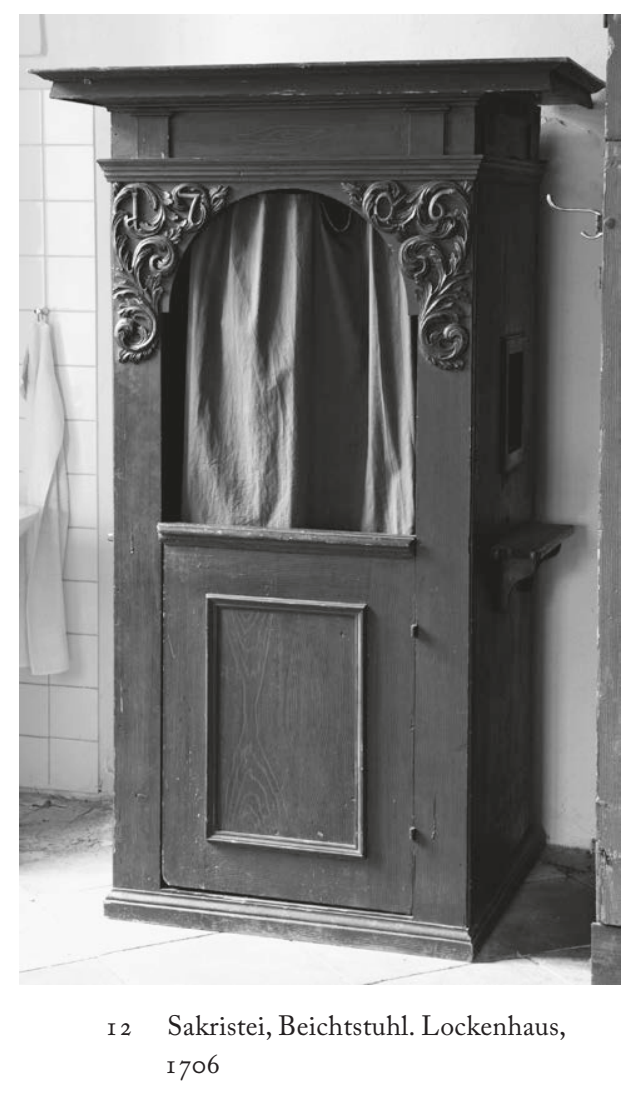

\section{Sakristei}

Die Sakristei bildet hinter dem Chor der Kirche einen in Nord-Süd-Richtung liegenden Querriegel. Im Westen verbinden zwei Türen den Raum mit dem Presbyterium, in die Ostwand wurden große Fenster eingesetzt. Zwei vor den Fensterpfeilern stehende Schränke reichen in ihrer Höhe bis knapp über bzw. unter den Ansatz des Tonnengewölbes, das den Longitudinalraum überspannt. Vor einer Stirnseite des Raumes befindet sich ein Beichtstuhl. ${ }^{18}$

\section{Beichtstuhl}

Lockenhaus, $\mathrm{I} 706$

$\mathrm{H}$ I $97,5 \mathrm{~cm} \times$ B I I $9 \mathrm{~cm} \times \mathrm{T} 93 \mathrm{~cm}$

Nadelholz, braun bemalt. Eisen, geschwärzt

Das Möbel besitzt lediglich eine Zelle, was im frühen 17 . Jahrhundert vermutlich häufig, im I8. Jahrhundert aber nur noch selten vorkam (Abb. I 2). ${ }^{19}$ Hinsichtlich seiner Gestaltung erinnert es an einen schmalen Schrank. Eine

Rundbogenarkade und zwei seitliche Stollen bilden die mit einer hüfthohen Tür verschlossene Vorderfront. ${ }^{20}$ In den Zwickelfeldern säumen Akanthusspiralen die Jahreszahl I7o6, ein weit nach außen reichendes Gebälk bildet den Hut. Unter den obligatorischen Sprechgittern in den Seitenwänden wurden Buchablagen befestigt. Früher standen beim Gebrauch des Beichtstuhls Kniebänke lose vor den Seiten des Möbels. Es ist nussbaumfarben bemalt, die Metallbeschläge sind geschwärzt.

I8 Dehio, Burgenland (I 980), I 73; ÖKT, Oberpullendorf (2005), 342.

I 9 Dehio, ebd.; ÖKT, ebd. Vgl. zur Entwicklung der Beichtstühle das entsprechende Kapitel im ersten Band der Untersuchung.

20 In der ÖKT, ebd., wird die Vermutung geäußert, die obere Hälfte der Tür sei verloren und durch einen Vorhang ersetzt worden. Das ist zu korrigieren. 


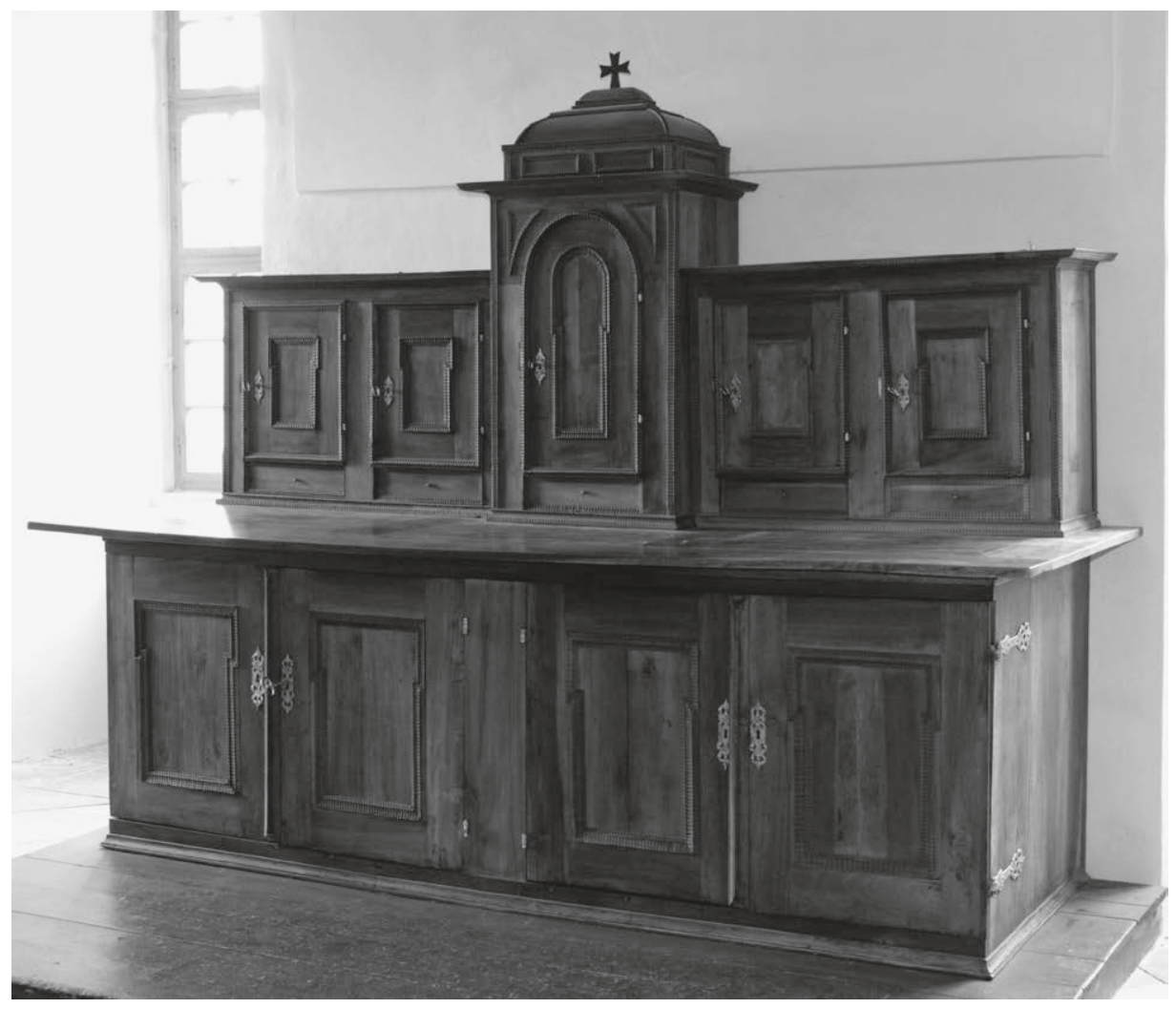

I3 Sakristei, Ankleidekredenz. Lockenhaus, um I 680/ I 700

\section{Ankleidekredenzen}

Lockenhaus, um I680/ I 700

$\mathrm{HS}$ I $4,5 \mathrm{~cm}$

Möbel vor dem nördlichen Fensterpfeiler: $\mathrm{H}_{2} 40 \mathrm{~cm}(+\mathrm{I} 4,5 \mathrm{~cm}) \times \mathrm{B} 3 \mathrm{I} 3 \mathrm{~cm} \times \mathrm{T} \mathrm{I} \mathrm{I} 2,5 \mathrm{~cm}$ Möbel vor dem südlichen Fensterpfeiler: H I 73,5 cm (+ I 4,5 cm) $\times$ B $322 \mathrm{~cm} \times \mathrm{T} \mathrm{I} \mathrm{I} 3,5 \mathrm{~cm}^{2}$ Nuss, massiv, Nadelholz. Eisen, ziseliert, verzinkt

Über profilierten Sockelleisten sind jeweils zwei Türpaare in den Korpus der Unterschränke eingesetzt (Abb. I3, I4). ${ }^{21}$ Die äußeren Türblätter reichen bis zu den Vorderkanten der Schmalseiten, die inneren werden von breiten Vertikalrahmen getrennt. Die Oberschränke beinhalten Kelchkästen und Schubladen, wobei ein hohes tabernakelförmiges Segment die Mitteltravée des vor dem linken Fensterpfeiler situierten

2i Zu den Schränken Dehio, Burgenland (I 980), I74; ÖKT, ebd., 343. 


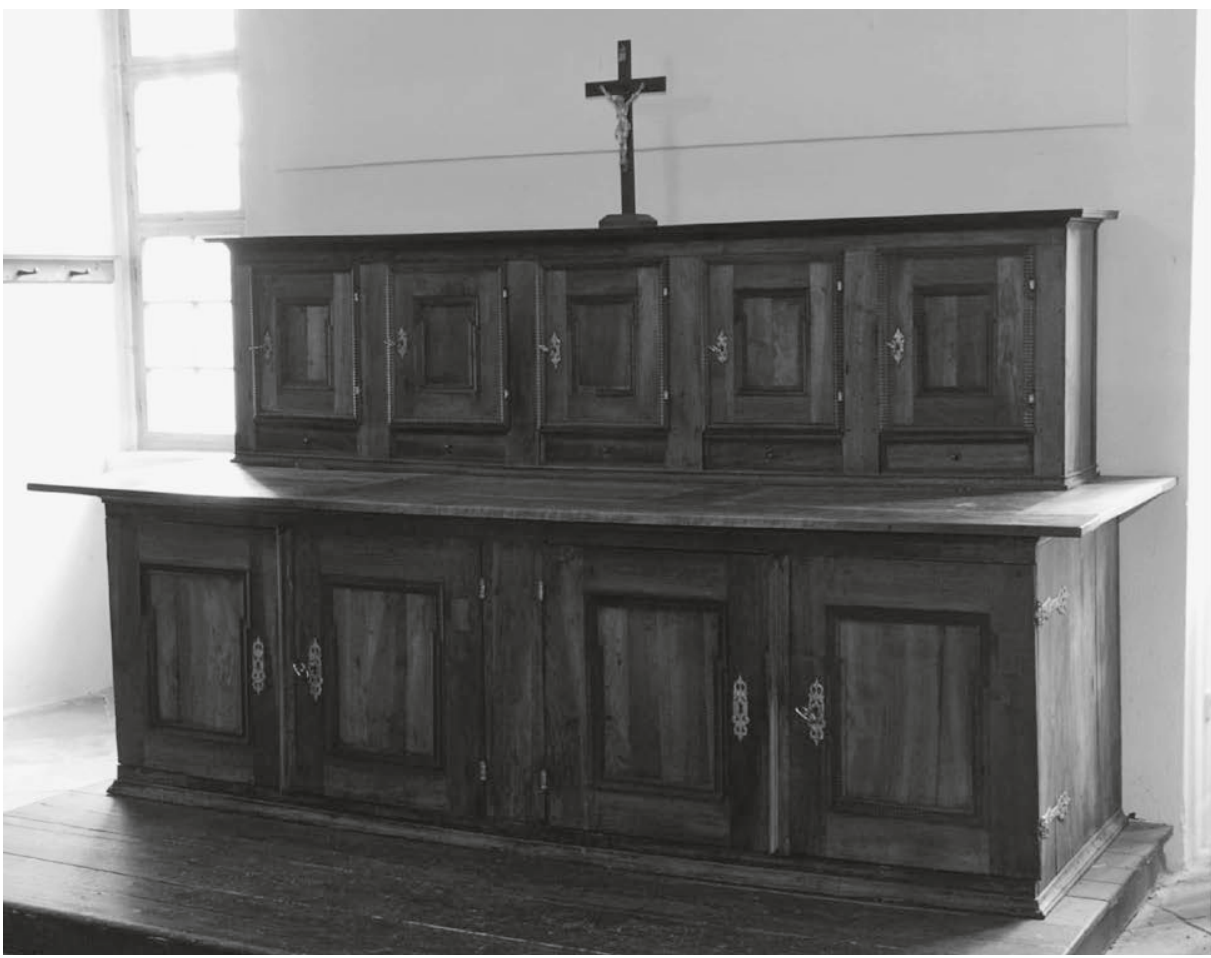

I4 Sakristei, Ankleidekredenz. Lockenhaus, um I680/ I700

Möbels einnimmt. Es schließt mit einer flachen Kuppel und einem kleinen Kreuz. Flammleisten fassen die geohrten Türfüllungen ein und säumen Kanten und Gesimse. Die Möbel überzeugen durch die schöne Patina des massiv verarbeiteten Nussholzes, die ziselierten und verzinnten Schlüsselschilder und Beschläge bilden weitere Zierelemente. Im Unterschrank des Möbels mit dem Tabernakelaufsatz verbergen sich hinter den Türen schwere Schubladen für Textilien, im anderen Möbel offene Fächer. ${ }^{22}$

\section{Betchor}

\section{Chorgestübl}

Lockenhaus, um I640/60

$\mathrm{H} 209 \mathrm{~cm} \times \mathrm{L} 324 \mathrm{~cm} / 33 \mathrm{I}, 5 \mathrm{~cm}$ (nördl./ südl. Möbel)

Eiche, massiv, Boden und Kniebank aus Nadelholz

22 Die ÖKT, ebd., erwähnt lediglich das mit dem tabernakelartigen Mittelsegment ausgestattete Möbel. Außerdem ist hier am Aufsatz von zweiblättrigen Türen die Rede, das ist nicht richtig. 


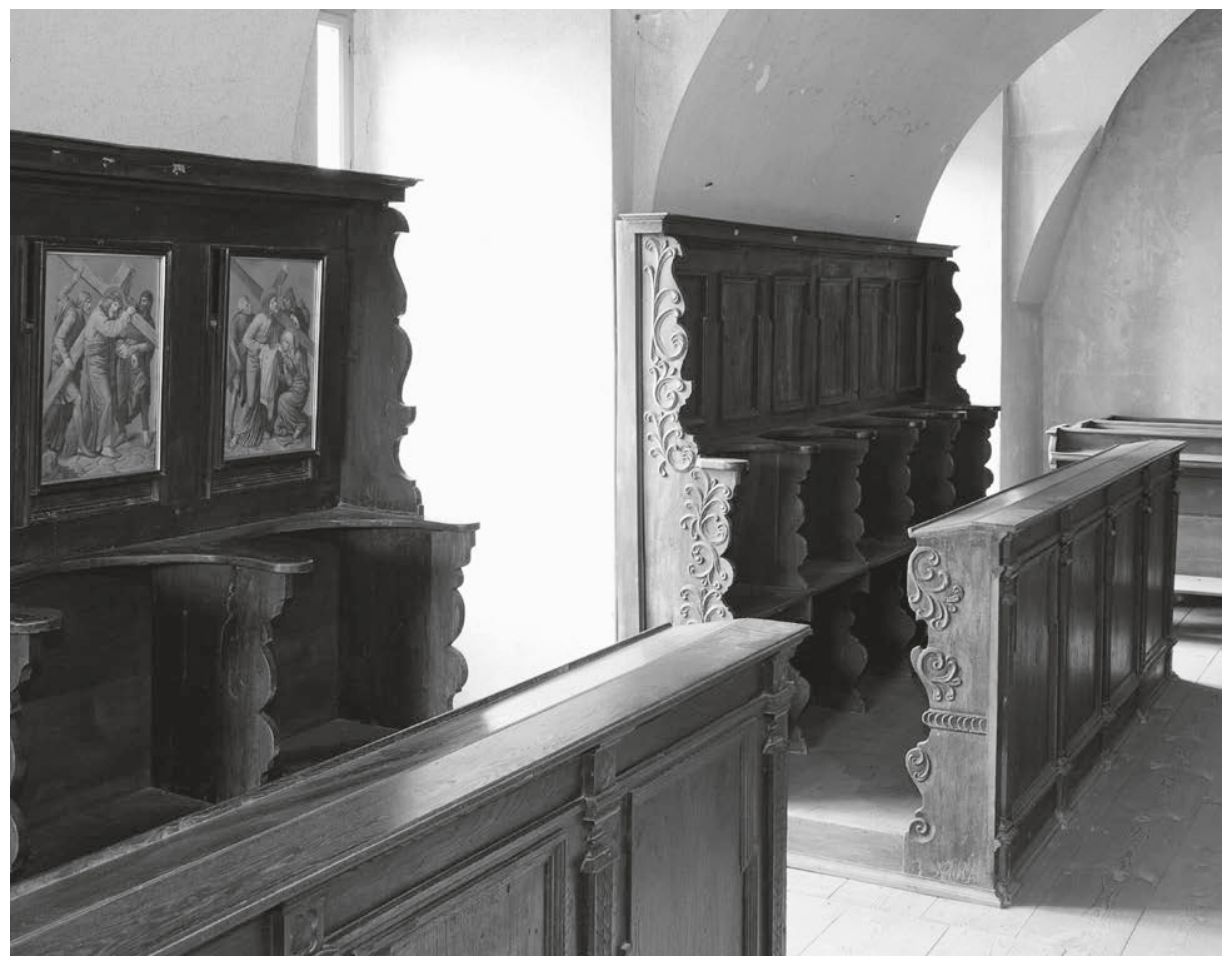

I 5 Betchor, Gestühl. Lockenhaus, um I640/6o

Der Betchor, auf den sich die Konventualen zum Stundengebet zurückzogen, liegt über der Sakristei. Mauerdurchbrüche stellen eine optische Verbindung zum Altarraum her, gegenüber befinden sich zwischen den Fenstern zwei Gestühlsreihen mit insgesamt zehn Stallen (Abb. 15). ${ }^{23}$ Auch hier stehen Brüstung und Außenwangen nicht auf einem Sockel, sondern direkt auf dem Boden. Anders als an den Kirchenbänken unterteilen Gesimse die Brüstungen nun jedoch in horizontale Streifen. Piedestale, deren Höhe derjenigen der Sockelzone entspricht, tragen vor der Hauptzone der Brustwände geschuppte dorische Keilpilaster. Darüber folgt ein verkröpftes, mit Konsolen und Vierpässen dekoriertes Gebälk.

Analog zu den Docken der Kirchenbänke schmückt in halber Höhe ein horizontal aufgebrachter Scheibenfries die schmalen Brüstungswangen, während aus dem massiven Holz herausgearbeitete feine Akanthusformationen entlang der geschweiften rückseitigen Kante verlaufen. Ähnlich gestaltete man die Seiten des Dorsales, die sich

23 Dehio, Burgenland (r 980), I 74; ÖKT, ebd., 342-343. Die ÖKT berichtet von einem Chorstuhl. 
als Hochwangen bis unter das Abschlussgesims nach oben ziehen. Der bewegten Kontur folgen hier Ornamente, die die Tischler jedoch auf die Oberfläche aufgeleimt haben. Auf eine Strukturierung der Rückwand mit Stützen wurde verzichtet, nun sorgen die Füllungen für eine Gliederung. Anders als die Binnenfelder der Brüstungen, die im oberen Bereich nach innen einspringen, sind jene der Rückwand in einer Gegenbewegung nach außen verkröpft. Die Zierornamente des Chorgestühls - geschuppte Pilaster mit manieristischen Kapitellen sowie frühbarocke, noch an Schweifwerkmotive erinnernde Bögen - belegen, dass das Gestühl vor den Kirchenbänken entstand. Es steht auf einer Entwicklungsstufe mit der Sakristeiausstattung und der Sakristeitür in der Stiftskirche zu Mattsee von I649 (Farbtaf. ıo; Abb. 83). Die Bilder mit Stationen des Kreuzwegs an der Rückwand eines Möbels datieren auf das I9. Jahrhundert, der Laufboden ist modern.

\section{Maria Loretto, Pfarr- und Wallfahrtskirche Zur Unbefleckten EMPFÄNGNIS}

Ab r65 I ließ Graf Franz von Nádasdy bei einer Lorettokapelle ein Servitenkloster errichten. ${ }^{24}$ Nachdem das Gebäude keine drei Jahrzehnte später bei einem Brand schwer beschädigt worden war, gab Fürst Esterházy ihre Renovierung in Auftrag, die Neuweihe der Kirche erfolgte I707. I787 untersagten die kaiserlichen Behörden zugleich mit der Aufhebung des Klosters die Wallfahrt nach Maria Loretto, die jedoch im I 9. Jahrhundert wiederauflebte. Die Pilger wurden damals von Weltpriestern, in weiterer Folge erneut von Serviten betreut, bis I964 die Kongregation der Oblaten der Jungfrau Maria, ebenfalls ein marianischer Orden, das Kloster übernahm. Die mit Seitenkapellen, Emporen und einer Stichkappentonne versehene Kirche besitzt eine Länge von vier Jochen. Stuckarbeiten und Fresken aus verschiedenen Bauphasen überziehen die Wände bis zur Höhe der Mittelschifffenster, das Gewölbe wurde nach dem Brand ohne Schmuck neu ausgeführt.

${ }_{24}$ ÖKT, Eisenstadt (1932), 229-244; Strauß, Loretto (1 959); ÖKM, Burgenland (I 968), I 47-I 50; Dehio, Burgenland (г980), г77-г80; Czeike, Burgenland (г988), ri6-гі 9; László, Loretto (1994); Steiner, Loretto (1994), o. S. 
Kirchenraum

Laiengestühl

Maria Loretto, um I 695/r 705

$\mathrm{HS}{ }_{4} \mathrm{~cm}$

$\mathrm{H}$ IO2 $\mathrm{cm}\left(+\mathrm{I}_{4} \mathrm{~cm}\right) \times \mathrm{L}_{2} \mathrm{I}_{5} \mathrm{~cm} / 3 \mathrm{I} 4 \mathrm{~cm}$

Nadelholz, gestrichen

Seitlich des Kirchenmittelgangs ordnete man zwei Postamentblöcke mit insgesamt $3 \mathrm{I}$ Bänken an (Farbtaf. o2; Abb. I6). ${ }^{25}$ Vorderbrüstung und erste Bank der Evangelienseite besitzen wegen der Kanzel eine Länge von lediglich $215 \mathrm{~cm}$.

Breite Rahmen und große Füllungen bestimmen das Aussehen der nicht weiter dekorierten Brustwände. Eine aufwendigere Ausgestaltung charakterisiert die Wangen des Gestühls, zumindest jene seitlich der Mittelachse des Kirchenschiffs. Die untere Hälfte der stelenartigen Docken besitzt gerade Kanten, während die obere wellenförmig ausgeschnitten ist und sich verjüngt. Den Abschluss bilden zwei gegenläufige, mit Blattwerk geschmückte C-Spangen. Die Wangen tragen je eine hochrechteckige, mit Flammleisten eingefasste und mit großflächigem Akanthus bereicherte Scheinfüllung. Darüber folgt ein Queroval mit gewölbter Fläche. Die dunkel-

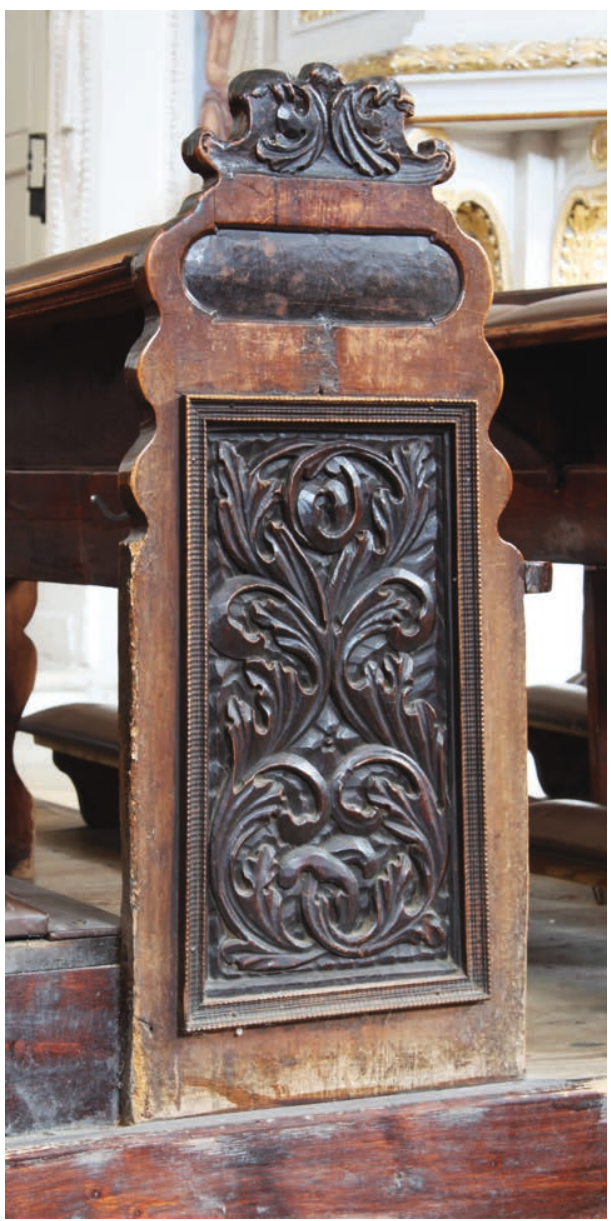

Farbtafel o2 Laiengestühl, Bankwange.

Maria Loretto, um I695/I 705 braunen, fast schwarzen Binnenflächen kontrastieren mit den rahmenden Friesen, die mit einem helleren Braun gefasst sind. Die Docken auf der Außenseite konturierte man zwar wie die inneren, verzierte sie aber nicht weiter, sieht man einmal von aufgelegten gewellten Profilen ab, die dort hochrechteckige Felder säumen.

Im Dehio wird das Gestühl auf die erste Hälfte des I 8. Jahrhunderts datiert, das kann genauer gefasst werden. Selbst wenn man wegen der geographischen Lage Lo-

25 ÖKT, ebd., 239; Dehio, ebd., I 79. 


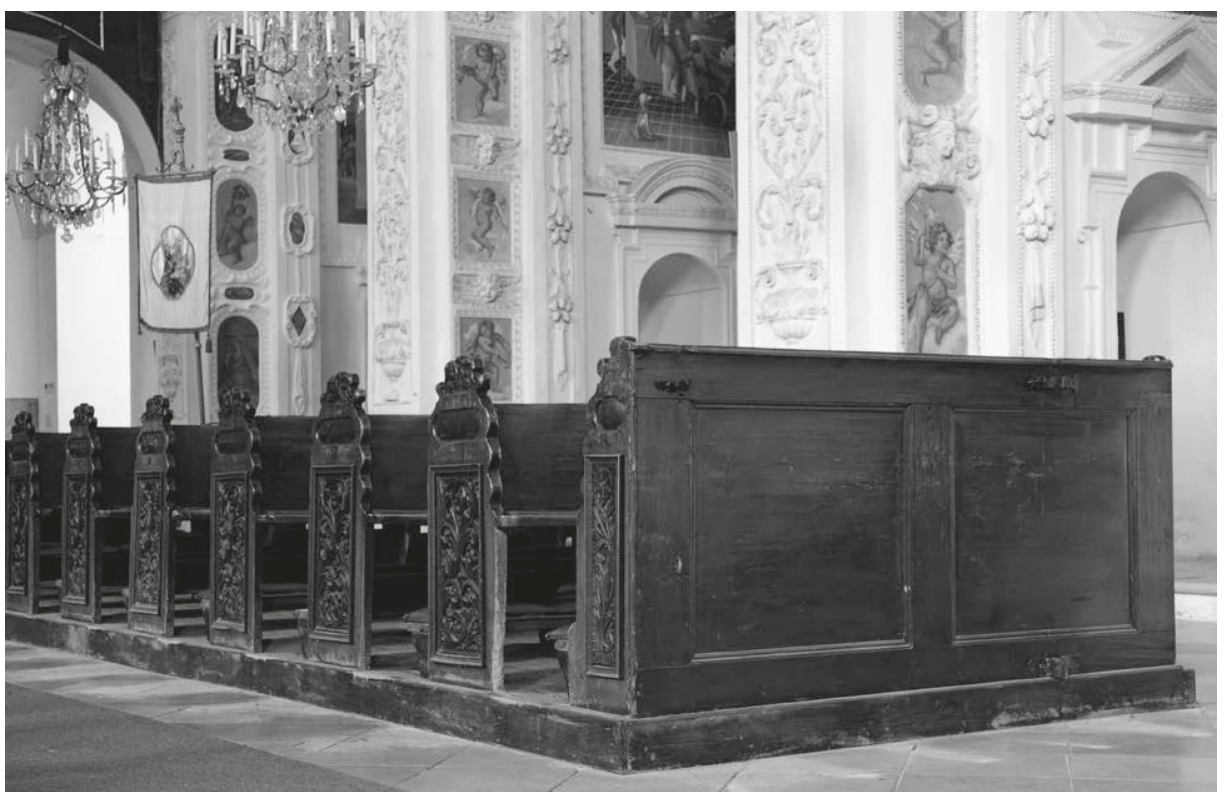

I6 Laiengestühl. Maria Loretto, um I695/I 705

rettos auf dem flachen Land eine Stilverschleppung in Betracht ziehen mag, ist aus stilistischen Gründen doch davon auszugehen, dass das Gestühl gegen Ende des I7., spätestens Anfang des I 8. Jahrhunderts in der von Fürst Esterházy geleiteten Bauphase hergestellt wurde. I707, bei der Neuweihe der Kirche, wird es den Besuchern bereits zur Verfügung gestanden haben.

\section{Bibliothek}

\section{Portal}

Maria Loretto, um I 750/6o

$\mathrm{H}_{3} 65 \mathrm{~cm} \times \mathrm{B} 2$ Iо $\mathrm{cm}$ (Außenmaße)

Nadelholz (?) dunkelbraun lasiert. Messing, teilweise bronziert

Den reichprofilierten Rahmen des Portals überragt ein Flachbogen, dessen Mittelachse ein großes Akanthusblatt akzentuiert (Abb. I 7). ${ }^{26}$ Der Rahmen trägt einen hohen Schnitzaufsatz mit Rocaillen und vereinzelten Rosenblüten. Die zwei schlanken Türflügel sind mit je drei Füllungen ausgestattet. Es entsprach dem zeitgenössischen Geschmacksempfinden, die mittleren Binnenfelder kleiner als die anderen zu wäh-

26 ÖKT, ebd., 244; Dehio, ebd., I 80. 
len und den Türrahmen den Schwung des äußeren Portalrahmens folgen zu lassen. Die Tischler gestalteten die zentralen Felder ana$\log$ dazu. Erhabene, von feinen Spangen und Muschelwerk eingefasste Spiegel bezeichnen die bossierten Binnenflächen der Füllungen. Die Tür ist deckend mit einer dunkelbraunen Farbe gestrichen, Bänder und Beschläge bestehen aus poliertem, teilweise auch bronziertem Messing.

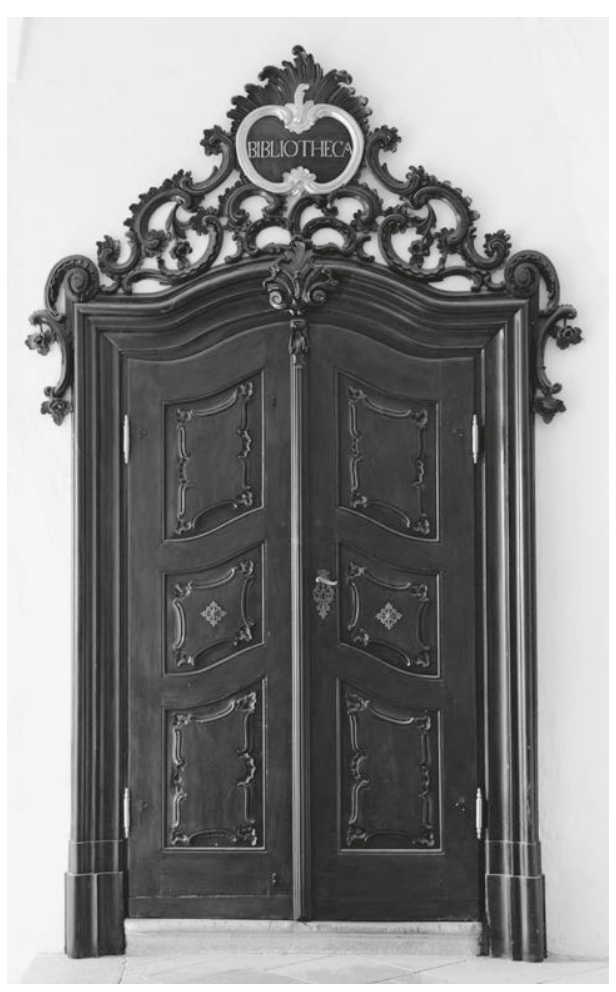

I 7 Bibliothek, Portal. Maria Loretto, um I $750 / 60$ 
II.

\section{Sakralbauten in Kärnten}

\section{Friesach, Stadtpfarrkirche hl. Bartholomäus}

Die Errichtung der romanischen Pfeilerbasilika mit mächtigem Westwerk fiel in die Jahre zwischen I I44 und I r67, bald danach folgte die Gründung eines Kollegiatkapitels. Das dreischiffige Langhaus verfügt über fünf Joche, wegen der eingestellten Türme ist das Mittelschiff um das Eingangsjoch erweitert. Der einschiffige und zweijochige Langchor geht auf das frühe I 4. Jahrhundert zurück, das Netzrippengewölbe des Langhauses auf das I 5. Im Barockzeitalter wurden die Seitenschiffe erhöht und erhielten ein Obergeschoss. Die Sakristei lehnt sich an die Nordseite des Chors an, ihre östliche Hälfte ist mittelalterlich, die westliche frühneuzeitlich. Nach etlichen Bränden und ebenso vielen Restaurierungen bestimmen Umbaumaßnahmen, die in den Jahren zwischen I 896 und I9 I 2 durchgeführt wurden, maßgeblich das heutige Erscheinungsbild des Sakralbaus. Eine weitere Restaurierungsphase datiert auf die Jahre zwischen I 989 und I $992 .{ }^{27}$

\section{Dreisitze im Presbyterium}

Friesach, I63 I und um I770

HS I $2,5 \mathrm{~cm}$

$\mathrm{H} 260 \mathrm{~cm}(+\mathrm{I} 2,5 \mathrm{~cm}) \times \mathrm{B} 250 \mathrm{~cm}$

Nuss, massiv und furniert, Buchsbaum, Nadelholz

Seitlich der Altarstufen stehen den Geistlichen, die die Messe zelebrieren, zwei Levitenstühle zur Verfügung (Abb. I 8, I 9). ${ }^{28}$ Die Brüstungen und Wangen wurden zusammen mit den Kirchenbänken im späten I 8. Jahrhundert verfertigt, sie werden anschließend in Verbindung mit dem Laiengestühl beschrieben. ${ }^{29}$

27 ÖK-T, Kärnten (I 889), 48-49; Hootz, Kunstdenkmäler (r 965-1968), Bd. 2 (r 966), I8, 334; ÖKM, Kärnten (1 977), 58-59; Dehio, Kärnten (2001), I62-I65; Reichmann-Endres, St. Bartholomäus (2001); Jernej, Kollegiatstift (1997); ders., Kollegiatstift (200I).

28 Gerlach, Chorgestühl (I93 I), 34; ÖKM, ebd., 58 ; Dehio, ebd., I65; Reichmann-Endres, ebd., I6.

29 Weder Gerlach noch Reichmann-Endres weisen in ihrer Arbeit auf die jüngeren Docken und Brustwände hin. 


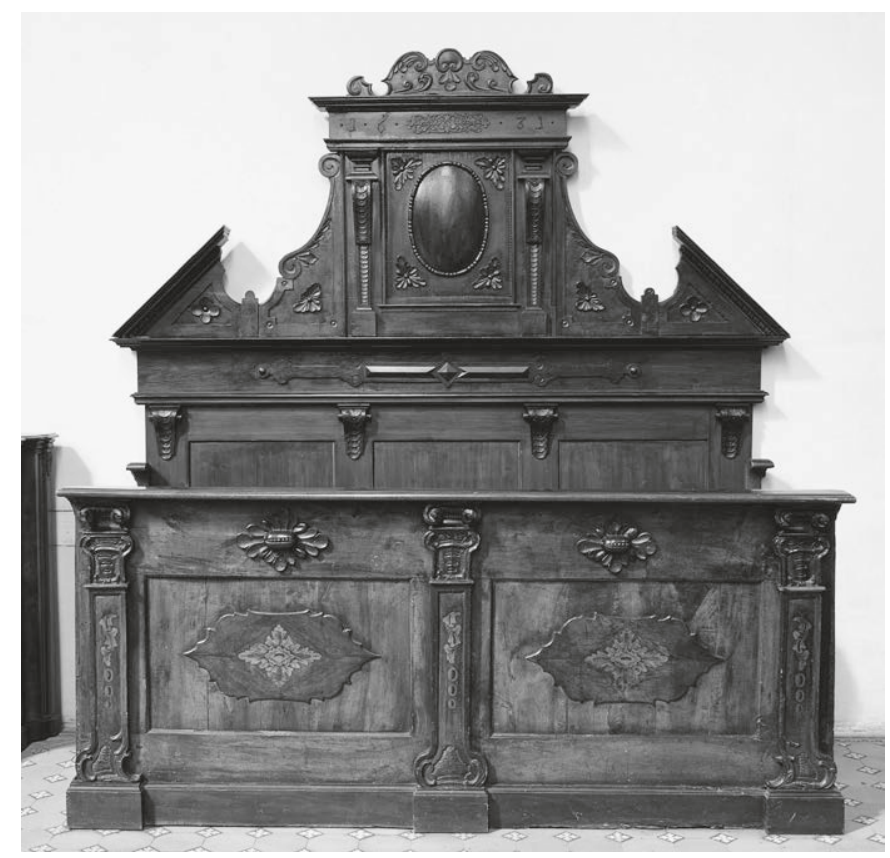

I8 Altarraum, Levitensitz. Friesach, I63 I und um I770

I9 Altarraum, Wange des Levitensitzes. Friesach, um I770

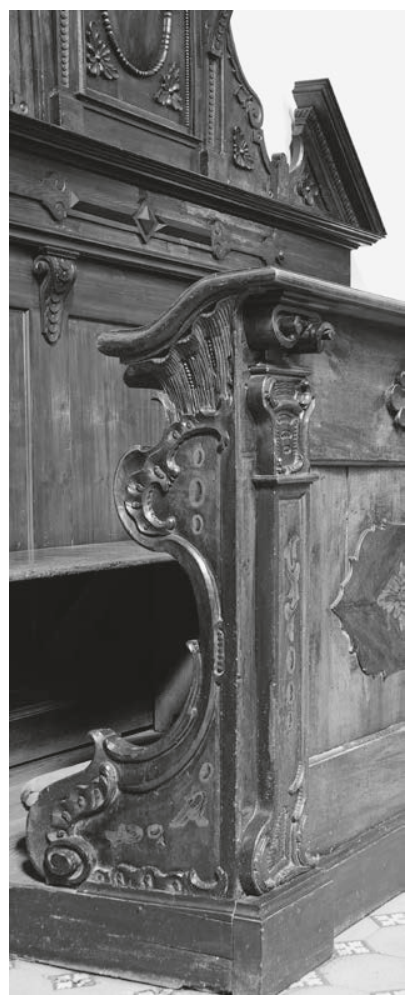

Konsolen, die einen gesprengten Dreiecksgiebel und einen Aufsatz tragen, bilden den einzigen Schmuck der ansonsten recht schlichten Rückenlehne. Den hochaufragenden Auszug zieren Volutenpilaster, Beschlag- und Schweifwerkformen sowie frühbarocke Dekormotive, datiert ist er auf I63 I. Ein nach vorn gewölbtes Hochoval nimmt die Mitte der Füllung ein, ein Motiv, auf das schon im ersten Band der Untersuchung eingegangen wurde. ${ }^{30}$ Die Rückwand besteht größtenteils aus Nadelholz, der Aufsatz aus Nuss, das Podest ist modern.

\section{Chorgestübl im ersten Chorraumjoch}

Friesach, um I630/50

$\mathrm{HS}_{30,5} \mathrm{~cm}\left(\mathrm{I}_{5}, 5 \mathrm{~cm}+\mathrm{I}_{5} \mathrm{~cm}\right)$

$\mathrm{H}_{2} \mathrm{I} 6,5 \mathrm{~cm}(+30,5 \mathrm{~cm}) \times \mathrm{L}_{46} 6 \mathrm{~cm}$

Nuss, massiv, aufgedoppelt, Eiche (Rüster?), Nadelholz, dunkelbraun gebeizt

30 Bohr, Sakralmöbel (20 1 7), 65-66. Vgl. auch Teil 2, Kap. VI des vorliegenden Kataloges. 


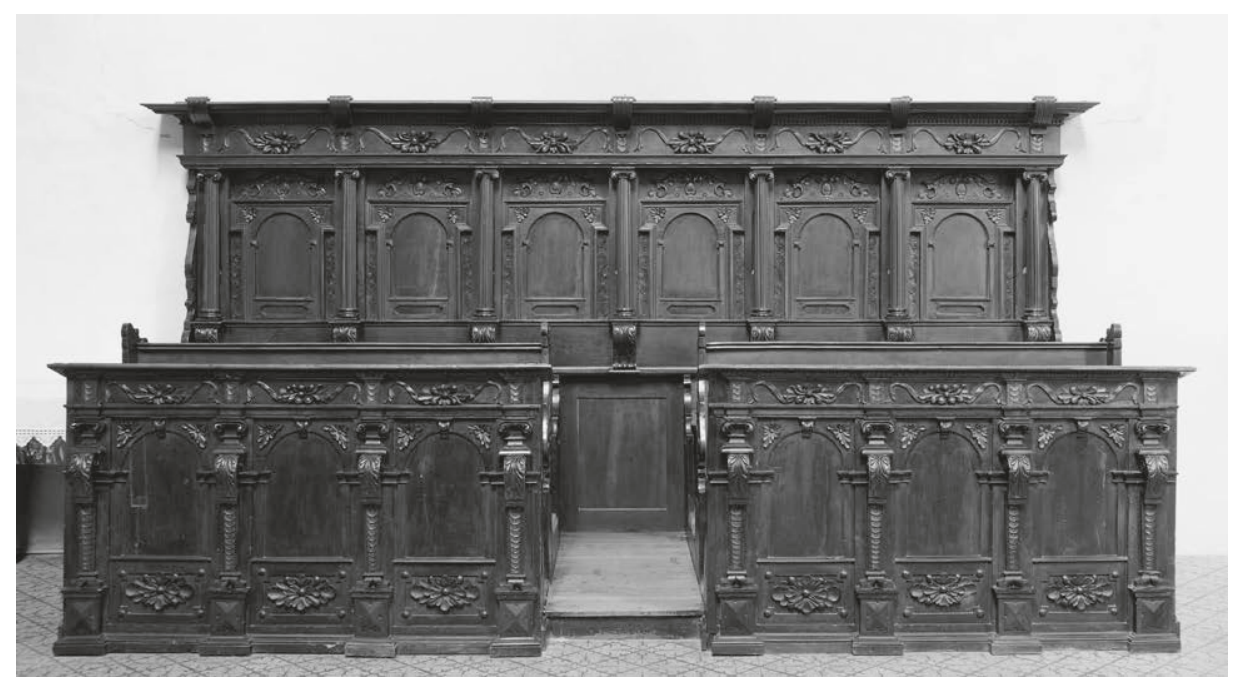

20 Chorgestühl. Friesach, um I630/50

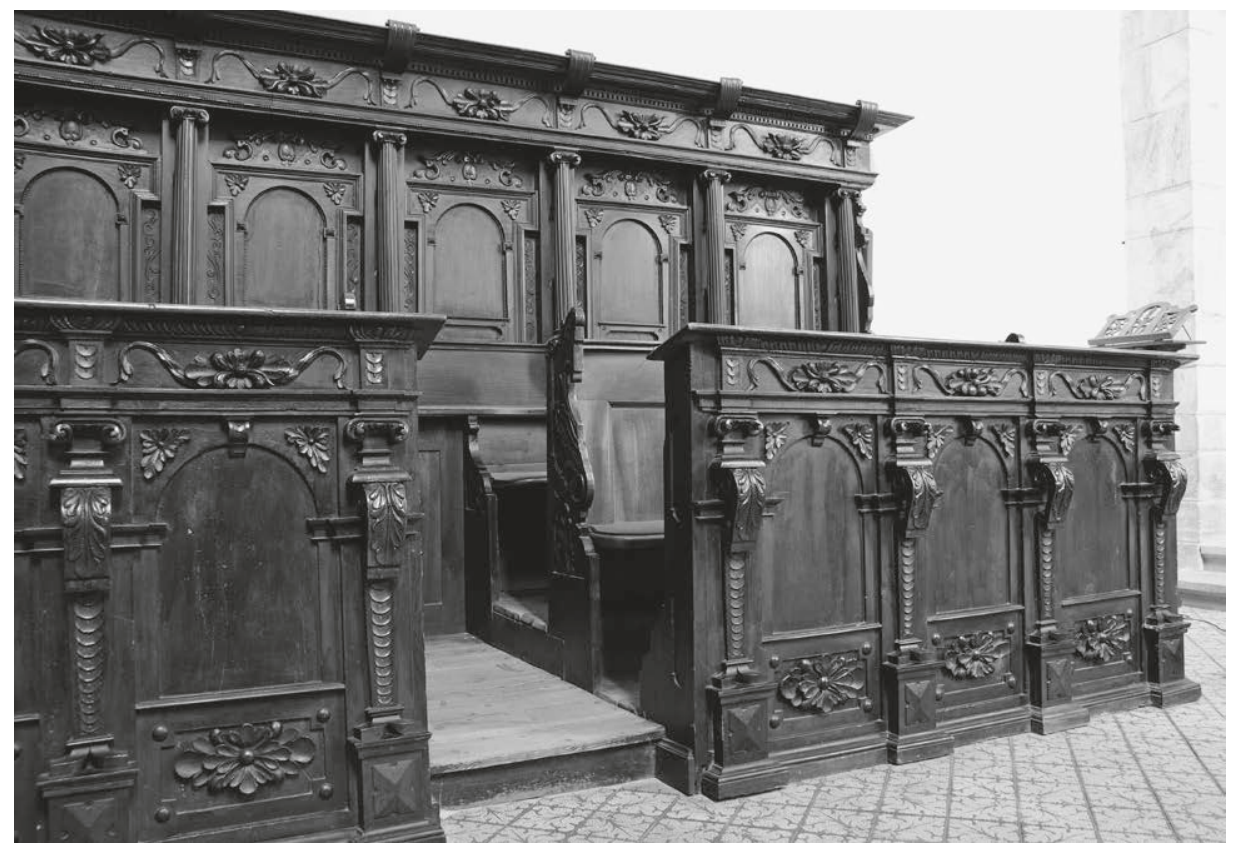

2 I Chorgestühl (Detail). Friesach, um I630/50 
Manieristische und frühbarocke Ornamentmotive bestimmen die Gesamterscheinung des zweireihigen Gestühls (Abb. 20, 2 I). ${ }^{31}$ Die Brüstungen weisen seitlich des Mitteleintritts arkadenförmige Füllungen auf, die ionische Pilaster vor breiten Rücklagen flankieren. Die Stützen stehen auf massiven Postamenten, Schuppenfriese zieren die Schäfte, schwere Voluten tragen die Kapitelle. Die Arkaden ruhen auf hohen Sockeln, die mit großen Ziernägeln am Untergrund befestigt zu sein scheinen. Blütenmedaillons füllen die Piedestale sowie die Zwickel seitlich der Arkadenbögen. Über dieser Zone folgt ein vollständiges, mit Konsolen und Blütenfestons dekoriertes Gebälk.

Das Dorsale spiegelt das architektonische Ordnungssystem der Brüstung wider, wenn auch mit ruhigeren Formen. Statt manieristischer Pilaster kommen kannelierte ionische Säulen zum Einsatz. Die mit Schnitzereien dekorierten Füllungen besitzen abermals die Form von Rundarkaden, die hier allerdings in geohrte Rahmen eingestellt und mit einem Giebel versehen sind. Die Ziermotive sind flacher und weniger dicht über die Fläche verteilt. Den Abschluss bildet ein schweres Gebälk. Das Formenrepertoire der Ornamente reicht von Würfel- und Zahnschnittfries bis hin zu Perlreihen, Konsolen, Agraffen, Bändern und Blütenmedaillons.

Die Tischler fertigten Dorsale, Brüstung und Rückenlehne der vorderen Sitzbank aus massivem und aufgedoppeltem Nussholz, die hintere Rückwand aus Nadelholz. Die Außenseiten des Möbels sind dunkelbraun, teilweise fast schwarz eingefärbt. Wie das an Gestühlen in Weltkirchen öfter zu beobachten ist, dienen hier keine Einzelstallen, sondern Bänke als Sitzgelegenheiten, doch unterteilen Konsolen die Lehne der Rückbank in einzelne Abschnitte.

In seiner Arbeit zu Chorgestühlen in der Steiermark und Kärnten berichtet Georg Gerlach I93 I von acht Sitzen pro Seite, das trifft zu. Gerlach datierte das Gestühl auf die Zeit um I635, während es der neueren Literatur zufolge um I680 oder gar erst gegen Ende des I7. Jahrhunderts entstanden sein soll. Die Spätdatierung ist zu korrigieren, zeigt die Ornamentik doch ausschließlich manieristische und frühbarocke Ziermotive. Entwicklungsgeschichtlich steht das Chorgestühl auf einer Stufe mit den Schatzkammerschränken in Lilienfeld von I646, wobei in Friesach noch auf Zierelemente zurückgegriffen wurde, die sich bereits am Regauer-Schrank in Kremsmünster von I6 8 und am Gestühl der Piaristenkirche in Krems von I620 oder I630 wiederfinden. ${ }^{32}$ Selbst wenn man eine gewisse Stilverschleppung unterstellen mag, lässt sich die These von einer Herstellung der Möbel im letzten Viertel des I7. Jahrhunderts nicht halten. Neu ist das Laufpodest.

3I Gerlach, Chorgestühl (r93r), 34; ÖKM, Kärnten (1977), 58; Reichmann-Endres, St. Bartholomäus (200I), I6.

32 Bohr, Sakralmöbel (201 7), 368-370, 387-389, 524-526. 


\section{Kirchenbänke}

Friesach, um I 770

$\mathrm{HS} 20 \mathrm{~cm}$

$\mathrm{H}$ I $20 \mathrm{~cm}(+20 \mathrm{~cm}) \times \mathrm{L} 256 \mathrm{~cm} / \mathrm{I} 8 \mathrm{I} \mathrm{cm}$

Nussbaum, Nussbaummaserholz, massiv und furniert, Buchsbaum, intarsiert, graviert, geschwärzt, Nadelholz

Die 36 Bänke und acht Brüstungen stehen seitlich des Mitteldurchgangs auf modernen Postamenten, hinzu kommen sechs kurze Einzelbänke (Farbtaf. 03; Abb. 22). ${ }^{33}$

Breite Rahmensegmente und große Rechteckfüllungen mit aufgedoppelten Binnenfeldern formen die Rück- und Vorderwände der Möbel. Während Furnierblätter aus Splint- und Kernholz senkrecht auf die Füllungsfelder aufgeleimt wurden, bestehen die flachen Bossen aus gespiegeltem und gestürztem Maserholz. Pilaster mit Fantasiebasen und -kapitellen bilden das tektonische Gerüst der Brustwände. Zusammen mit dem Abschlussgesims tragen sie einen geschweiften, mit Rocaillemotiven und einer großen mittleren Muschel verzierten Schnitzaufsatz.

Die schlanken Bankwangen beschreiben im Grunde ein nach vorn weisendes großes C, dessen Kontur sich in Bögen auflöst. Ihm folgt ein hoher eingeschnürter Hals mit geschwungenem Abschlussprofil. Rocailleornamente zieren den Hals und säumen die abgeschrägten Kanten der Docken, die Binnenfelder liegen leicht vertieft.

Die Tischler legten in die Nussholzmöbel vegetabile und muschelförmige Gebilde aus Buchsholz ein, die Binnenzeichnung ist graviert, brandschattiert und geschwärzt. Das Möbelensemble beeindruckt durch den Kontrast zwischen den großen und glatten, relativ starr wirkenden Flächen der Brustwände und den bewegten Außenwangen mit ihren kleinteiligen Schnitzereien. Die Bänke entstanden etwa zeitgleich mit dem Laiengestühl in der Stiftskirche zu Göttweig, das ebenfalls Rokokomotive zieren ${ }^{34}$, doch sind in Friesach die Ornamente relativ »trocken« wiedergegeben, was bereits den Einfluss des beginnenden Klassizismus erahnen lässt. Eine Restaurierung der Möbel wurde in den frühen I 99oer-Jahren bewerkstelligt, nach Auskunft des Restaurators waren vor allem ausgebrochene und von Insekten zerfressene Partien zu ersetzen.

33 ÖKM, Kärnten (I 977), 59; Dehio, Kärnten (2001), I65; Reichmann-Endres, St. Bartholomäus (2001), I6.

34 Bohr, Sakralmöbel, I (2017), 3 I3-3 I 5. 


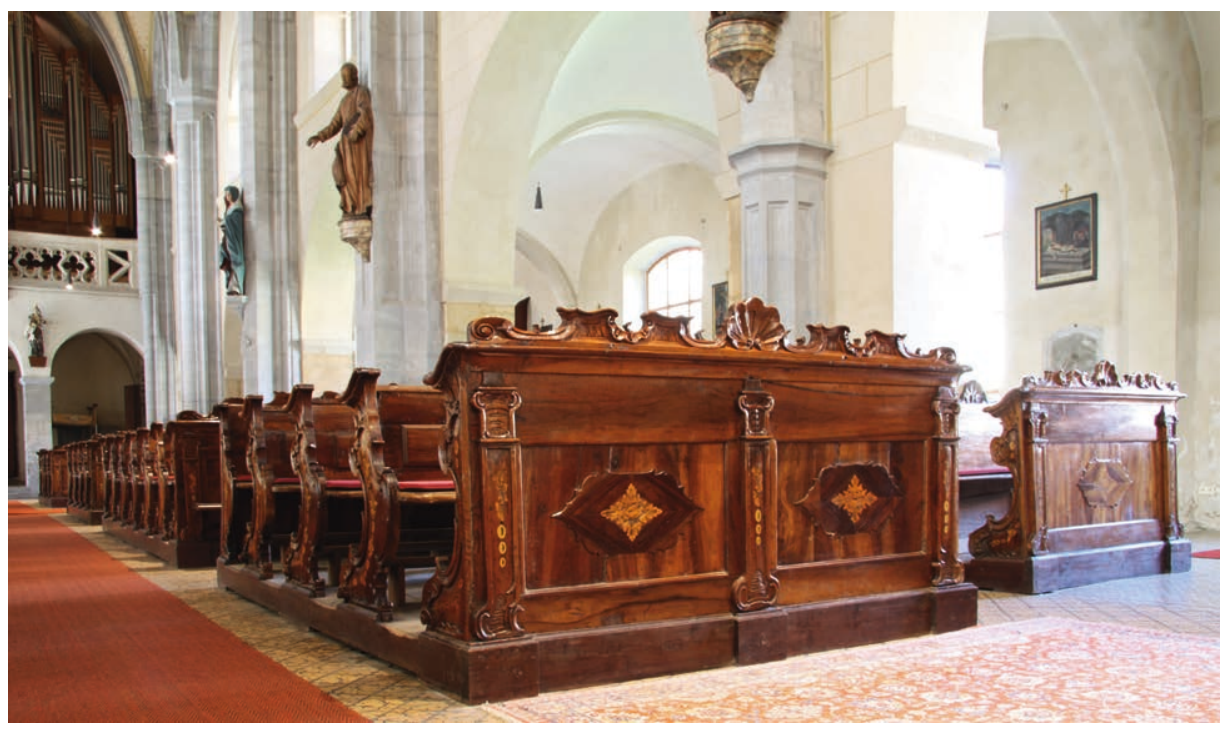

Farbtafel o3 Kirchenbänke. Friesach, um I 770

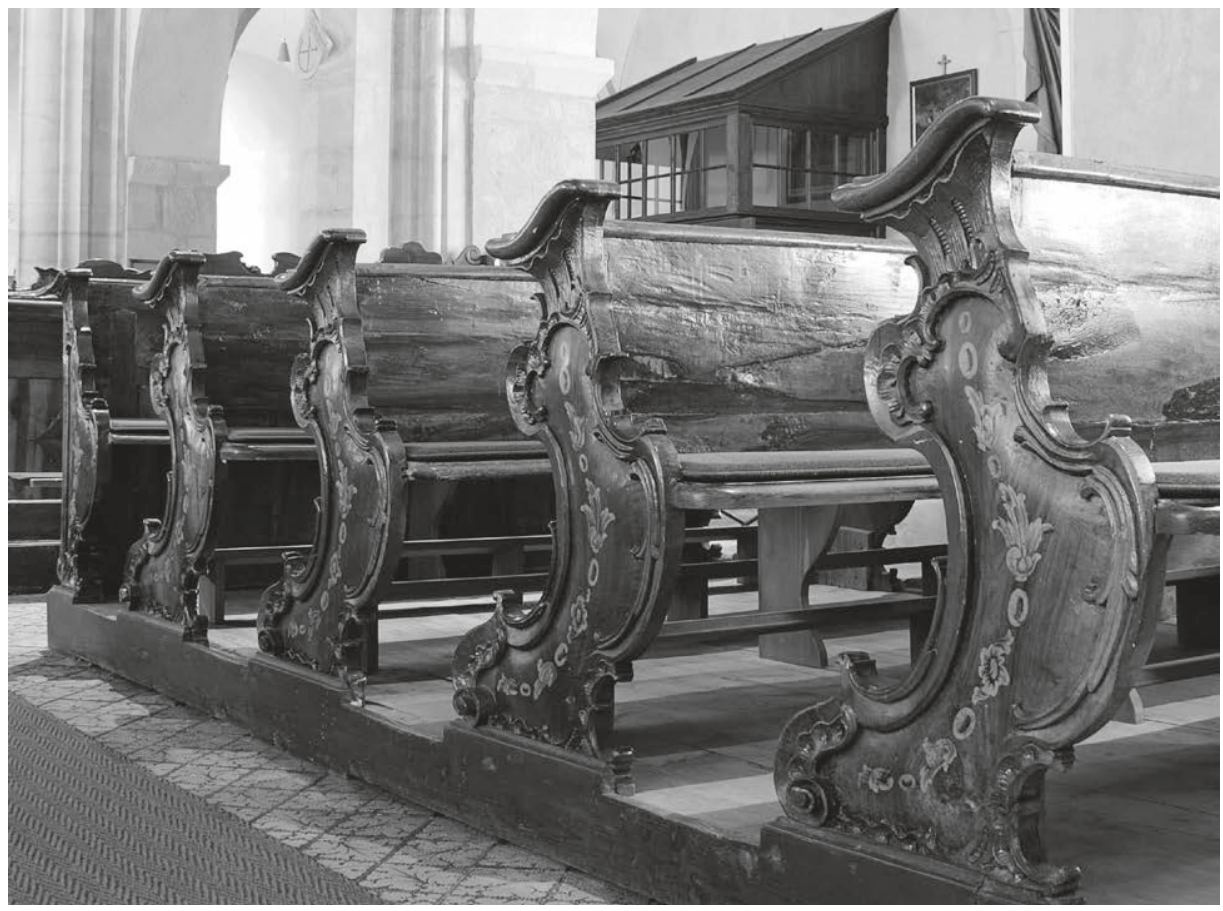

22 Kirchenbänke. Friesach, um I 770 
Gösseling, Filialkirche hl. Michael

Schriftquellen zufolge wurde der Sakralbau I 534 vollendet. Er besitzt ein dreijochiges, mit einem Sterngratgewölbe ausgestattetes Langhaus. Der mit einem Netzrippengewölbe überfangene einjochige Chor ist gegenüber dem Schiff um einige Stufen erhöht. Der Hochaltar entstand um I725, die Kanzel um I770. ${ }^{35}$

\section{Laiengestühl}

Gösseling, 2./3. D. I 7. Jh.

$\mathrm{HS} 2 \mathrm{I} \mathrm{cm}$

$\mathrm{H} 86 \mathrm{~cm}(+2 \mathrm{I} \mathrm{cm}) \times \mathrm{L} 267 \mathrm{~cm} / 3 \mathrm{I} 5 \mathrm{~cm}$

Nadelholz, ockerfarben gestrichen. Eisen

In der Filialkirche liegt der seltene Glücksfall vor, dass sich die originale Aufstellung eines Gestühls aus der vorbürgerlichen Epoche weitgehend erhalten hat (Abb. 23 , 24). ${ }^{36}$ Die noch immer mit geringem Abstand voneinander aufgereihten Kirchenbänke stehen seitlich des Mitteldurchgangs auf zwei hohen, stark abgetretenen Podesten, rechts sind es zehn Bänke, links acht. Einem Hinweis der Mesnerin zufolge mussten dort die beiden letzten Möbel vor einigen Jahren einem Ausspracheraum weichen. Brüstung und erste Bank auf der Evangelienseite wurden später hinzugefügt. Durch ihr Aussehen unterscheiden sie sich zwar von den anderen Inventarstücken, dennoch entstammen sie dem I 7. Jahrhundert. Die Möbel auf der linken Seite des Kirchenschiffs sind fast einen halben Meter länger als die Exemplare gegenüber, ungleichmäßig ist überdies die Tiefe der Sitze, sie schwankt etwa zwischen 25 und $30 \mathrm{~cm}$.

Die ockerfarben gestrichenen Bänke datieren auf das fortgeschrittene oder späte I7. Jahrhundert. Die Brüstungen sind mit blanken Bohlen geschlossen, die Außenwangen aus schlichten Stelen gefertigt. Sie besitzen symmetrisch angelegte, bis zur mittleren Höhe gerade, darüber geschweifte Kanten, wie wir das vergleichbar von den Möbelgarnituren in Mariahof oder in Maria Loretto her kennen (Abb. I6, 204). Diese Möbel entstanden um die Mitte des I7. Jahrhunderts resp. um I7oo. In Gösseling befestigten die Handwerker einige Sitzbänke mit Gratverbindungen an den Wangen, andere mit Zapfen. Die abgerundeten Oberkanten der Docken sägten sie passgerecht aus und fügten dort die Endstücke der schmalen, auf die Rückenlehnen aufgelegten Abschlussleisten ein. Während diese Verbindungen die Kenntnis von handwerklichen

35 Kunstdenkmäler Kärntens, St. Veit (I 93 I), 63; ÖKM, Kärnten (1977), 72-73; Dehio, Kärnten (200I), 220-22I.

36 Dehio, ebd., 22 I. 


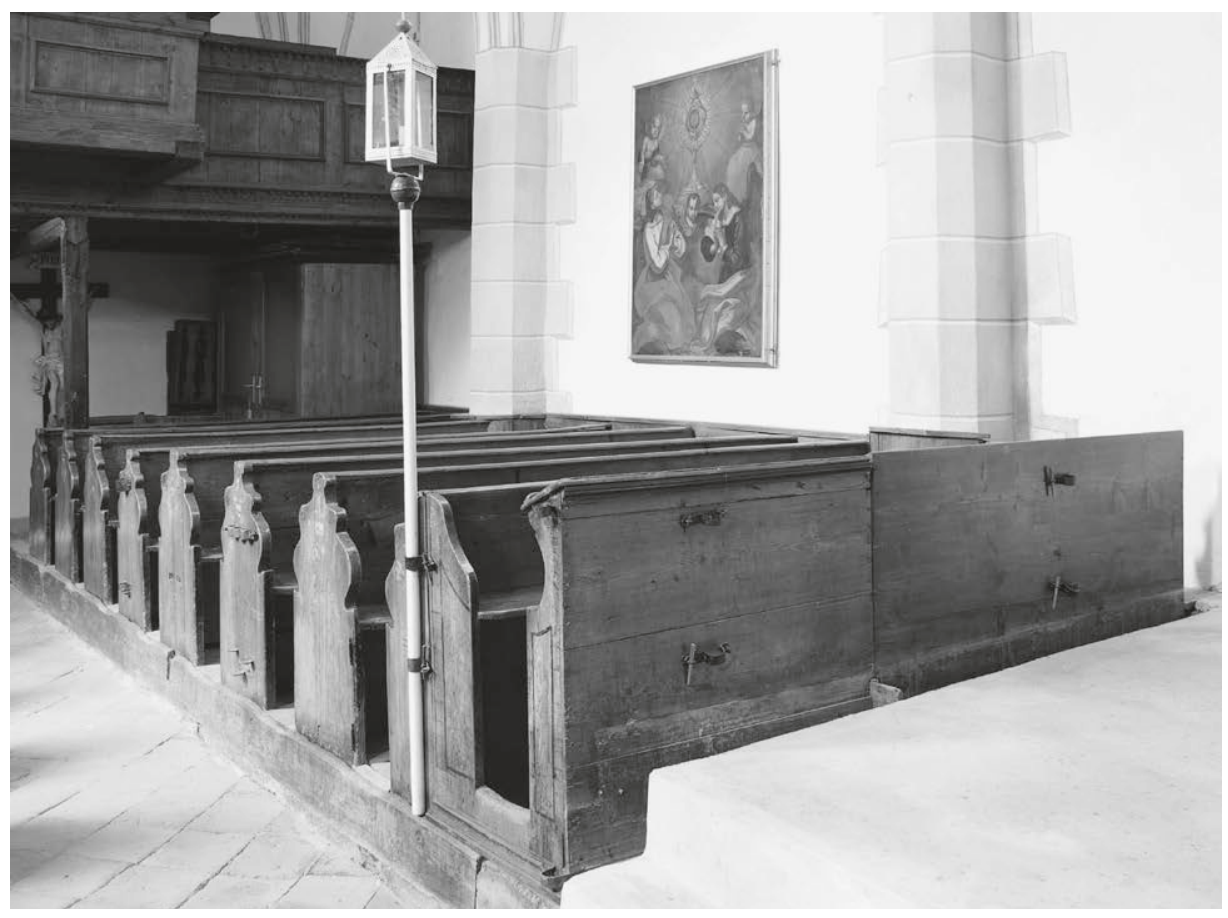

23 Kirchenbänke. Gösseling, 2./3. D. I7. Jh.

24 Kirchenbänke. Gösseling, 2./3. D. I 7. Jh. mit I645 datiertem Weihwasserbecken

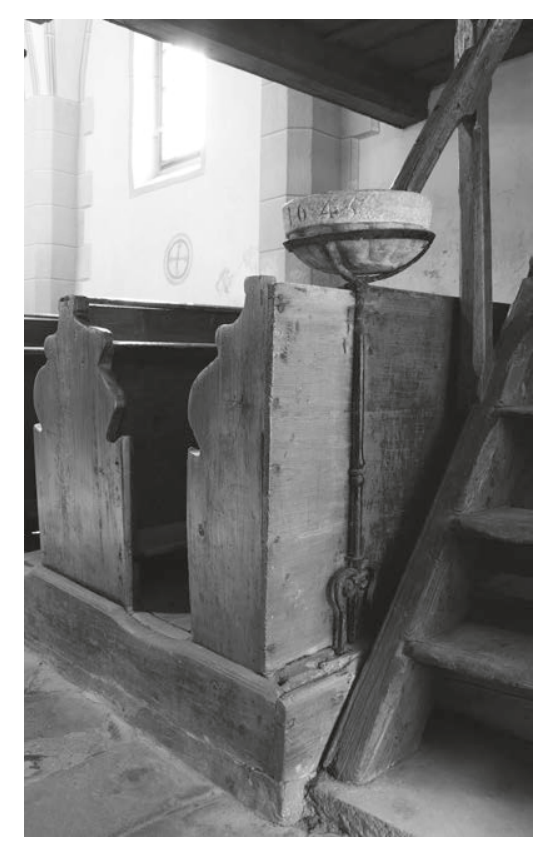


Techniken belegen, halten grob geschmiedete Eisennägel andere Möbel zusammen. Damit stellt sich die Frage nach den für die Herstellung verantwortlichen Handwerkern. Sollten es wirklich zünftige Tischlermeister gewesen sein, die die Möbel gefertigt haben? Zweifel daran sind berechtigt. Hinter der letzten Bank der Südseite führt eine steile Treppe auf die Empore. Vor dem Aufgang wurde ein kleines, I 645 datiertes Weihwasserbecken an der Gestühlsrückwand befestigt. Wäre die Verbindung zwischen dem Becken und der Bank in formaler und technischer Hinsicht enger und weniger beliebig, könnte die Jahreszahl als Hinweis auf das Herstellungsdatum des Gestühls verstanden werden. In Fall der Bänke in Gösseling vermag solch ein Rückschluss jedoch nicht zu überzeugen.

\section{Griffen, Ehemaliges Prämonstratenserstift}

Schriftquellen berichten seit 822 von der Ansiedlung. ${ }^{37}$ Ursprünglich gehörte Griffen zum Bistum Salzburg, gelangte im I 2. Jahrhundert aber in den Besitz der Bamberger Fürstbischöfe. I 236 gründete Bischof Ekbert von Andechs-Meranien (reg. I 203-I 237) bei der Ortschaft ein Stift, in das er Mönche aus der Abtei Veßra in Thüringen berief. Keine vier Jahrzehnte später waren der Bau des Klosters und der neuen Stiftskirche abgeschlossen. Brände vernichteten I648 und I750 Teile der I 786 aufgehobenen Abtei. Die frühere Stiftskirche wurde zur neuen Pfarrkirche bestimmt, die ebenfalls auf dem Klosterareal liegende ehemalige Pfarrkirche wird seither als »Alte Pfarrkirche« bezeichnet.

\section{Griffen, Alte Pfarririrche Unsere Liebe Frau}

Die Architektur geht auf das frühe I3. Jahrhundert zurück. Um den Baukörper zu vergrößern, fügte man im I 4. Jahrhundert an den stark eingezogenen Altarraum einen neuen Chor an, dessen Breite nicht ganz der des Langhauses entspricht. Folge davon ist ein eigenartiger $\mathrm{H}$-förmiger Grundriss, bei dem das frühere Presbyterium wie ein Verbindungsgang zwischen dem Langhaus und neuen Presbyterium wirkt (Abb. 25). Außerdem erweitert ein schmales Seitenschiff die wegen der qualitätvollen hochmittelalterlichen Wandmalereien bekannte Kirche auf der Evangelienseite. ${ }^{38}$

37 Kunstdenkmäler Kärntens, Völkermarkt (1933), 33-38; Hootz, Kunstdenkmäler (I 965-1968), Bd. 2

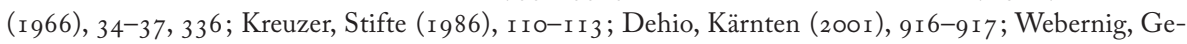
schichtliches (2005), 5-7, I5, 35-36, 41-42.

38 Kunstdenkmäler Kärntens, ebd., 36 ; Hootz, ebd.; Dehio, ebd., 920-92 I. 


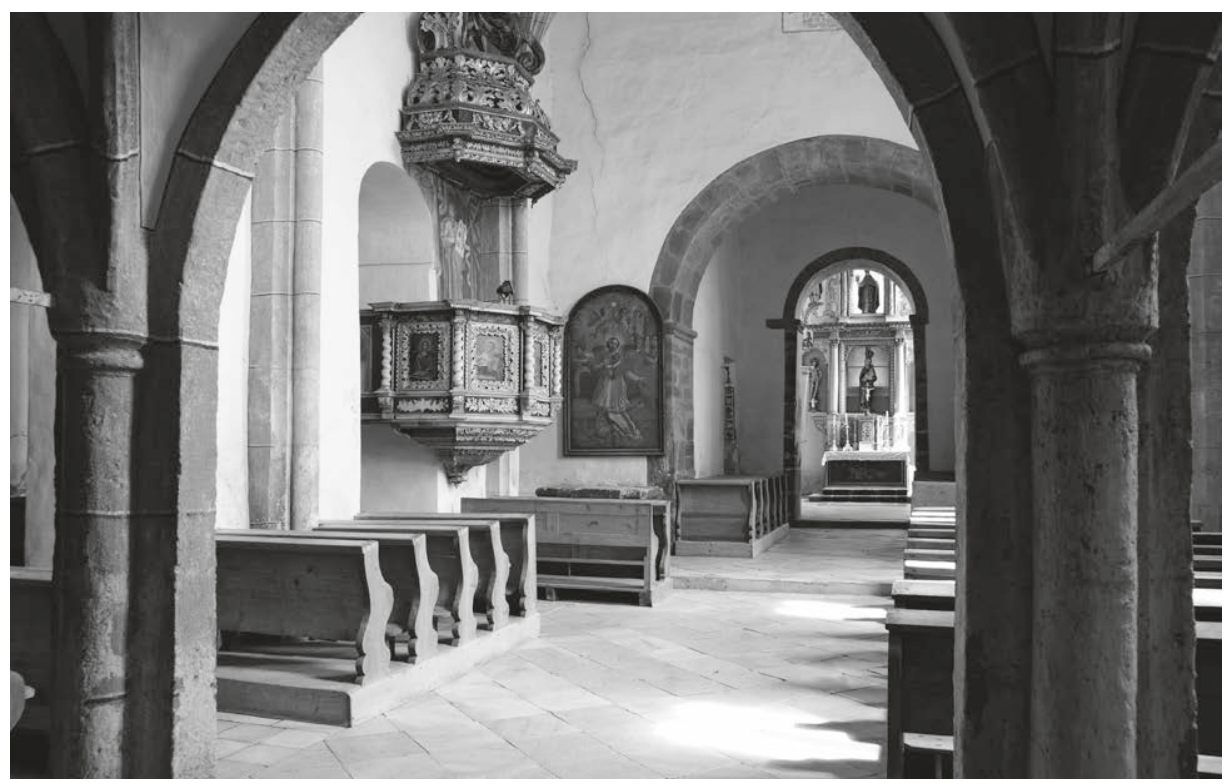

25 Alte Pfarrkirche, Innenansicht mit verschiedenen Garnituren von Kirchenbänken

\section{Kirchenbänke}

Griffen, I 8. Jh.

$\mathrm{HS}$ I $3 \mathrm{~cm} / 2 \mathrm{I} \mathrm{cm}$

$\mathrm{H} 82 \mathrm{~cm} / 85 \mathrm{~cm}(+\mathrm{I} 3 \mathrm{~cm} / 2 \mathrm{I} \mathrm{cm}) \times \mathrm{L}$ IO $5 \mathrm{~cm} / \mathrm{I}$ IO cm/ I $68 \mathrm{~cm} / 243 \mathrm{~cm}$

Nadelholz. Eisen

Ein Großteil der Bänke befindet sich im Langhaus (Abb. 25, 26) und im Vorjoch zum Altarraum, weitere Exemplare stehen im Seitenschiff. Die Rückenlehnen laufen senkrecht auf die schmalen Sitzbänke zu, die auf die Docken aufgelegten Buchablagen reichen weit über die Vorderseite der Lehnen hinaus. Wie das häufig festzustellen ist, existiert auch hier keine konstruktive Verbindung zwischen Wangen und Kniebänken, Letztere stehen lose zwischen den Docken.

Sitzbänke und Lehnen wurden in die Wangen eingegratet, während die mit massiven Nägeln befestigten Brustwände in einem Falz liegen. Sie bestehen auch nicht aus Rahmen und Füllungen, sondern aus blanken Bohlen. Die leicht gewellte Holzoberfläche, die bei der Bearbeitung der Bretter mit dem groben Schrupphobel entstand, ist im Streiflicht noch gut zu erkennen. ${ }^{39}$ Einige Gebetbuchablagen verbindet eine hand-

39 Gewöhnlich wird das Holz dann in weiteren Arbeitsgängen geebnet. 


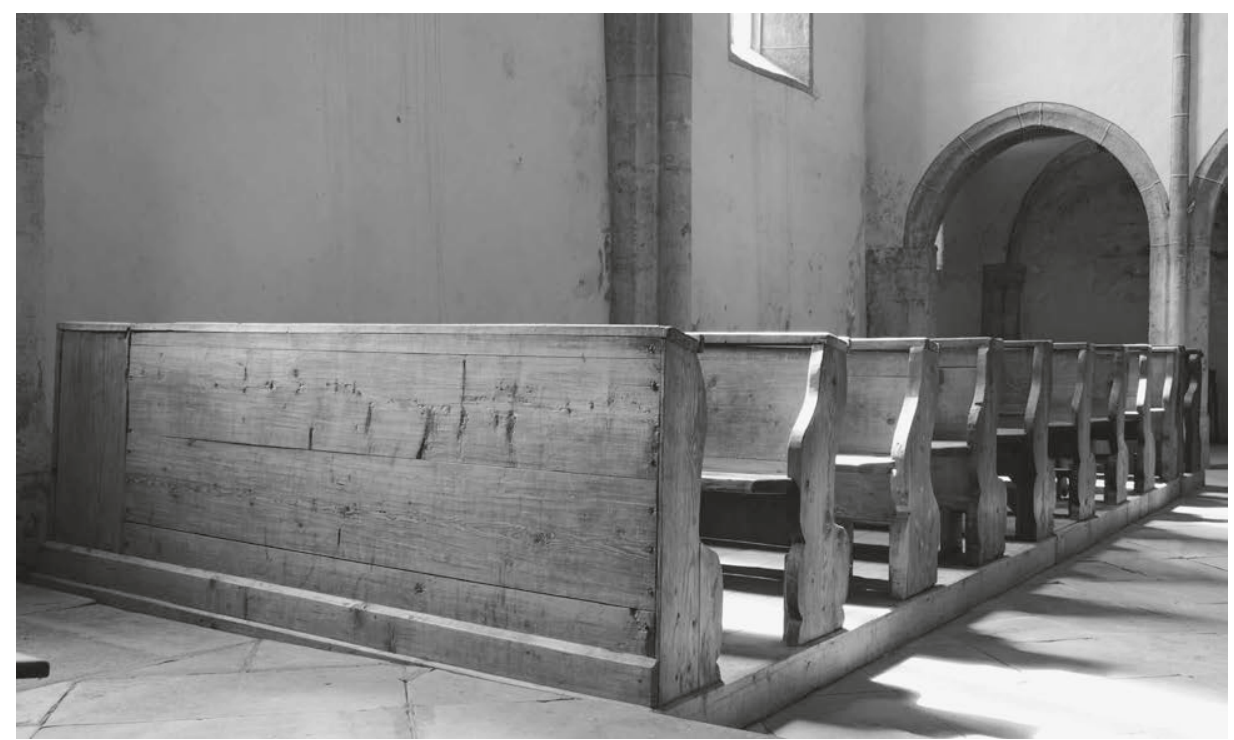

26 Alte Pfarrkirche, Kirchenbänke. Griffen, I 8. Jh.

werklich korrekte Zinkung mit den Wangen, andere wurden einfach mit schweren Nägeln befestigt. Die zur Wand gerichteten Seiten einiger Außenwangen weisen noch Schnittspuren der Gattersäge auf, ihre Flächen wurden nicht geglättet. Offensichtlich wurden die Wangen für diesen oder einen ähnlichen Standort gefertigt.

Wegen ihrer Schlichtheit erinnern die Bänke an frühere Exemplare, doch belegen die im Prinzip C-förmig konzipierten und asymmetrisch geformten Wangen ein Herstellungsdatum des Laiengestühls vermutlich nicht vor der Wende vom i 7. zum I 8. Jahrhundert. ${ }^{40}$ Ihre Form erinnert an die Möbel in der ehemaligen Stiftskirche zu Griffen (Abb. 29). Möglicherweise ist die Garnitur also ebenfalls im frühen r 8. Jahrhundert entstanden. Sicher dürfte indes sein, dass die Möbel zu einer Zeit produziert wurden, als der Bau noch als Pfarrkirche diente, vor I 786 mithin.

Die Bänke bestehen aus Nadelholz, die nur bedingt handwerksgerechte Bearbeitung, die einfachen Formen und die Verwendung von Zimmermannsnägeln geben Anlass zur Vermutung, dass die Möbel nicht in der Werkstatt eines ausgebildeten Tischlers entstanden. Die Exemplare auf der Evangelienseite besitzen eine andere Länge als jene der Epistelseite, doch schwankt auch die Länge der Bänke innerhalb der beiden Garnituren. Weitaus kürzer sind selbstverständlich die Möbel im Durchgang zum

40 Allerdings existieren hierzu wie in St. Lambrecht (Abb. 26I) und Mariahof (Abb. 202) auch Gegenbeispiele. 
Farbtafel o4 Pfarrkirche, Chorgestühl, Epistelseite, Griffen, um $1715 / 20$

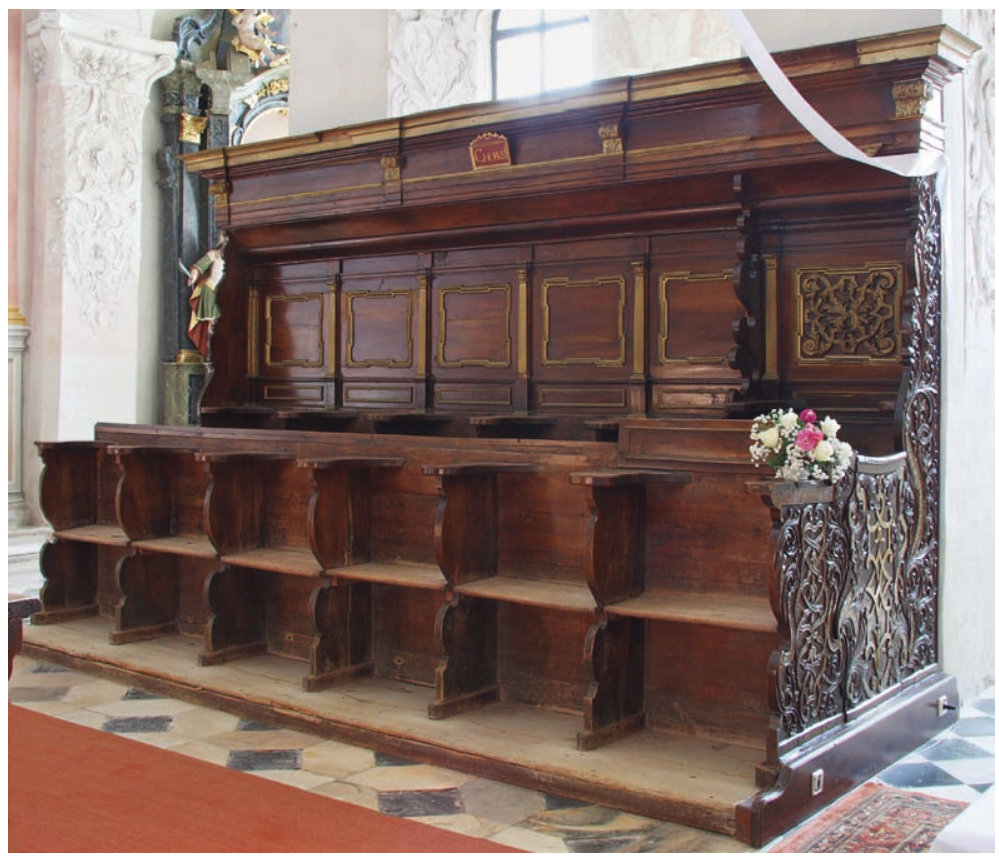

Chorraum. Bei aller Schlichtheit und bei allen handwerklichen Mängeln bieten die Bänke ein reizvolles Beispiel für eine Art der »Volkskunst«, wie sie in jener Zeit und in jener Gegend Kärntens gepflegt wurde. Die Möbel stehen auf modernen Podesten.

\section{Griffen, Pfarr- und ehemalige Stiftskirche Mariae Himmelfahrt}

Die ehemalige Stiftskirche wurde als dreischiffige Pfeilerbasilika errichtet, ihr Mittelschiff erreicht die doppelte Höhe der Seitenschiffe. ${ }^{41}$ Das Langhaus erhebt sich über einem fünfjochigen Grundriss, ein kräftiges Gurtgesims und ein Triumphbogen scheiden es vom Chorbereich. Eine Empore schließt es im Westen ab. Ursprünglich war die Kirche wahrscheinlich flach gedeckt, die barocken Gewölbe dürften unter Propst Petrus Bavarus (reg. I617-I632) eingezogen worden sein. Die Verzierung mit Stuckarbeiten erfolgte in den drei westlichen Jochen um I700, andere Teile des Sakralbaus wurden um i 7 10 bis I 720 dekoriert. Die Kanzel stammt Schriftquellen zufolge von

4I Zur Architektur und Geschichte des Bauwerks vgl. ÖK-T, Kärnten (I 889), 82-85; Kunstdenkmäler Kärntens, Völkermarkt (1933), 33-36; Hootz, Kunstdenkmäler ( ( 965-1 968), Bd. 2 (1 966), 34-37, 336; Dehio, Kärnten (200I), 916-920. 
I729, der Hochaltar, der die volle Höhe und Breite des Chors einnimmt, ist auf das Jahr I 776 datiert. Einschneidende Veränderungen erfuhr die Architektur also namentlich in der ersten Hälfte des I7. und im frühen I 8. Jahrhundert, doch ist die Struktur des romanischen Bauwerks noch immer deutlich erkennbar.

\section{Chorgestühl}

Griffen, um I 7 I $5 / 20$

HS I I cm $/ 22,5 \mathrm{~cm}$

$\mathrm{H} 280 \mathrm{~cm}(+22,5 \mathrm{~cm}) \times \mathrm{L} 472 \mathrm{~cm}$

Nuss massiv, dunkelbraun lasiert, Schnitzereien teilweise mit Goldfarbe bemalt

Das zweireihige Gestühl kommt ohne Brüstung aus, vermutlich war es auch nie mit einer Brustwand versehen (Farbtaf. o4; Abb. 27, 28). ${ }^{42}$ Das Podest dürfte noch das barocke sein, neben anderen typischen Gebrauchsspuren sind die Kanten, auch die vorderen, abgetreten und ausgebrochen. Türen verschließen die Eingänge zu den hinteren Stallen. Auf der Epistelseite scheidet eine Hochwange die Sessio des Priors von den anderen Plätzen, außerdem ist die Wange hüfthoch als Traverse bis zur Brüstung nach vorn geführt. Dagegen trennt auf der Evangelienseite eine tiefe Docke die drei westlichen Sitze ab. Andere österreichische Gestühle kennen solch eine Art der Konstruktion nicht. Und noch eine weitere Besonderheit fällt an dem Ensemble auf: Den Accoudoirs wurde nicht die übliche Form von Schulterstützen verliehen. Sie liegen nicht als halbrunde oder U-förmige Ringe, sondern als breite Lehnen auf den Wangen und enden vor der Rückwand. Eine ähnliche Gestaltung kennzeichnet die Gestühle der ehemaligen Chorherrenstiftskirche Pöllau und der Dominikanerinnenkirche zu Feldkirch (Farbtaf. 25; Abb. 389). Die Sitze des Gestühls sind aufklappbar, auf Miserikordien wurde verzichtet.

Die Außen- und Zwischenwangen besitzen geschweifte Kanten, die Außenwangen der hinteren Stallenreihe reichen als Hochwangen bis unter das Gesims. Schlanke Pilaster übernehmen die architektonische Gliederung der Rückwand. Unkonventionell ist im Hinblick auf die klassische Architekturlehre der Umstand, dass die Stützen ein verkröpftes Band und darüber einen Baldachin in Form eines nach vorn gekragten $\mathrm{Ab}$ schlussgebälkes tragen. An den Friesen hat man Kartuschen mit den Bezeichnungen Chorus.i bzw. Chorus.ii angebracht. Die Tischler verkröpften die Rückwandfüllungen, beließen die zentralen Felder aber ohne weitere Auszier und schmückten nur die Prälatenstalle mit geschnitztem Laub- und Bandlwerk. Weitere Ornamentmotive dominieren das Aussehen der Außenwangen, auch hier sind vegetabile Schnitzereien zusammen

42 Kunstdenkmäler Kärntens, ebd., 36; Dehio, ebd., 9 I 9. 


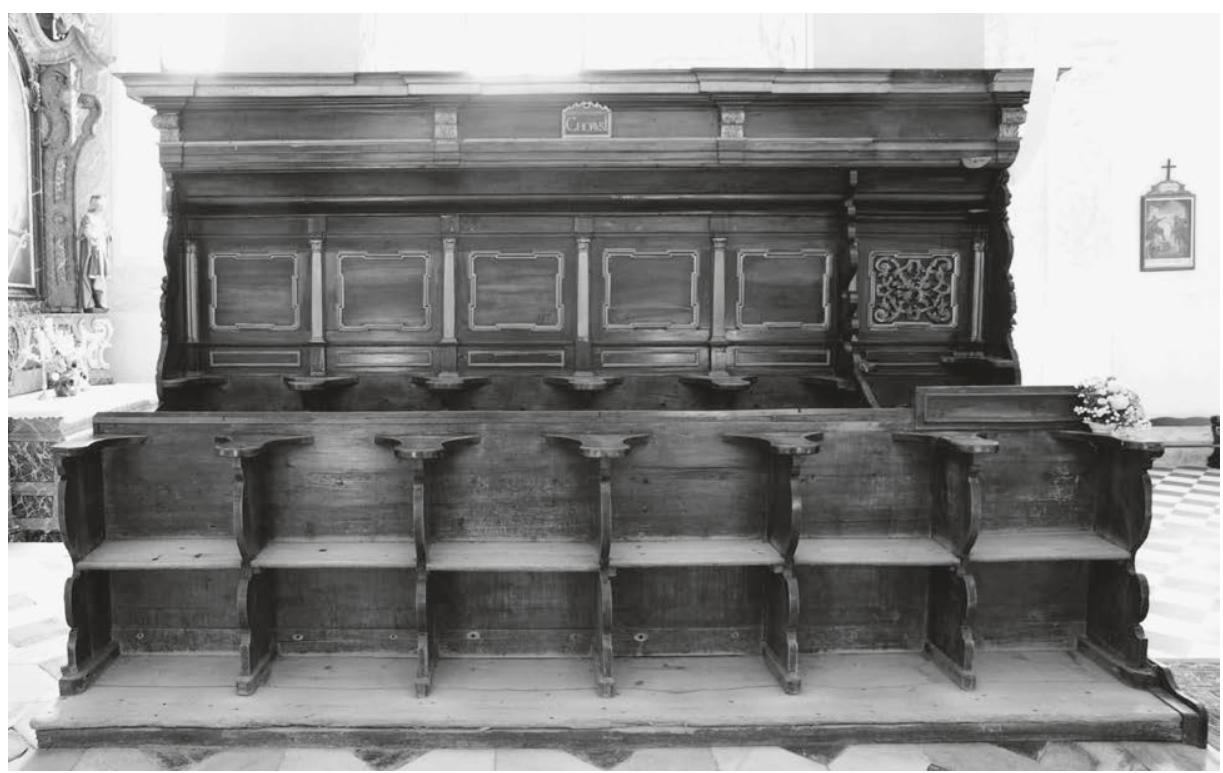

27 Pfarrkirche, Chorgestühl, Epistelseite, Griffen, um I 7 $5 / 20$

28 Pfarrkirche, Chorgestühl, Evangelienseite, Seitenansicht, Griffen, um I 7 I 5/20

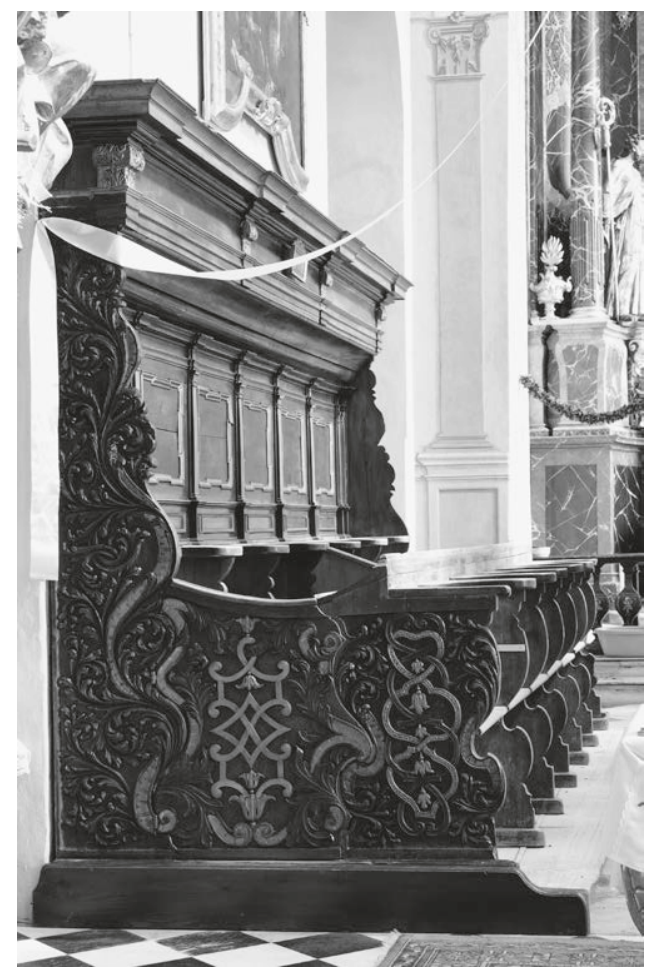


mit Bandlwerk zu finden. Mit den eingeflochtenen querschraffierten Bändern greifen sie eine Stilrichtung auf, die beispielsweise von Bibliotheksmöbeln in Kremsmünster oder von Refektoriumstischen in Lambach aus dem ersten Jahrzehnt des I8. Jahrhunderts vertreten wird. ${ }^{43}$ Insgesamt erinnert der Dekor der Hochwangen aber eher an gewisse spätgotische Malereien mit Spruchbändern und Laubmotiven als an barocke Kunst. Einer gänzlich anderen Formensprache bediente sich der Bildschnitzer bei der Fertigung des Bandlwerks an den Türen. Die Diskrepanz überrascht, denn für die Modellierung der entwickelten Bandlwerkstrukturen wurden Druckvorlagen aus Frankreich oder Süddeutschland im französischen Stil verwendet. Diese Zierformen belegen die Kenntnis von Entwürfen von Jean Bérain d.Ä. (I637-I 7 I I) oder Daniel Marot (I66I-I 752), die im süddeutschen Raum von Künstlern wie Paul Decker d.Ä. (I677-17I3) rezipiert wurden. Deckers Stiche aus der Zeit um r 7 ro muten ganz ähnlich an. ${ }^{44} \mathrm{Wie}$ in der relevanten Literatur angenommen wird, könnte das Gestühl demnach um I 720 entstanden sein, als das Kircheninnere mit Stuckverzierungen im Akanthusstil bereichert wurde. Das lässt auch ein Vergleich mit der in den späten I 72oer-Jahren entstandenen Kanzel der Kirche vermuten, deren Dekor sich bereits aus moderneren Ornamentmotiven speist.

Das Gestühl steht im ersten Chorjoch. Seine Nordseite lehnt sich an eine geschlossene Scheidewand, die Südseite an zwei massive Pfeiler. Die dazwischen liegende Arkade gibt die Gestühlsrückwand zu erkennen und bestätigt, was sich bereits in der Vorderansicht andeutet: Schlichte Planken in Längsrichtung des Möbels bilden die Konstruktion der Rückenlehne hinter den Stallen. Dagegen wurde das Dorsale handwerklich korrekt mit einer Konstruktion aus Rahmen und Füllungen gefertigt. Für seine Herstellung verwendeten die Handwerker massives Nussholz, für den Bau der anderen Möbelteile weniger teures Nadelholz. Die Weichholzteile wurden nussfarben gebeizt, Profile und Pilaster, teilweise auch die Schnitzarbeiten, mit Bronzierungen und Vergoldungen optisch abgesetzt. Ein glänzender Firnis schützt die Möbeloberfläche vor Staub und anderen Verunreinigungen.

\section{Kirchenbänke}

Griffen, I 7 I $/ 20$

$\mathrm{HS} 7 \mathrm{~cm}$

$\mathrm{H} 9 \mathrm{I} \mathrm{cm}(+7 \mathrm{~cm}) \times \mathrm{L}_{352} \mathrm{~cm}$

Nussholz, massiv, Nadelholz, dunkelbraun lackiert

43 Bohr, Sakralmöbel (2017), 528-53 I, 543-545.

$44 \mathrm{Zu}$ französischen Stichen von Bérain und Marot vgl. Berliner/Egger, Vorlageblätter (r 98 I), Bd. I, 93-95, Bd. 3, Abb. II 45, I I 54 mit Stichen aus der Zeit um I700. Zu Decker vgl. ebd., Bd. I, 99-100, Bd. 3, Abb. I2I3, I2I4, I22I. 
In der ehemaligen Stiftskirche befinden sich auf vier Podesten 36 Kirchenbänke, Brustwände sind nicht vorhanden (Abb. 29). ${ }^{45}$ Die seitlich des Mitteldurchgangs der Kirche aufgestellten Möbel reichen in die Seitenschiffe hinein. Nach der Mitte des 20. Jahrhunderts wurde die Möbelgarnitur originalgetreu rekonstruiert ${ }^{46}$, nur zwei Wangen tragen noch die alten Schnitzarbeiten.

Die Docken vertreten einen interessanten Zwitterstil: Großblättriger Akanthus, dessen glatte Oberfläche sich effektvoll vom aufgerauten Grund abhebt, überwuchert die Fläche. Allerdings ist das Blattwerk nicht mit Bändern durchsetzt, weshalb an eine Entstehung um die Wende vom I 7. zum I 8. Jahrhundert zu denken wäre. Zugleich besitzen die Wangen eine asymmetrische Umrissform mit Konturen, die aus Sund $\mathrm{C}$-Schwüngen bestehen, was für eine Herstellung im I 8. Jahrhundert spricht. Vermutlich entstanden auch sie um I 7 ro oder I 720 , in jenen Jahren also, in die eine zweite Ausstattungsphase der Kirche fiel.

\section{Gurk, Konkathedrale und Pfarrkirche Mariae Himmelfahrt}

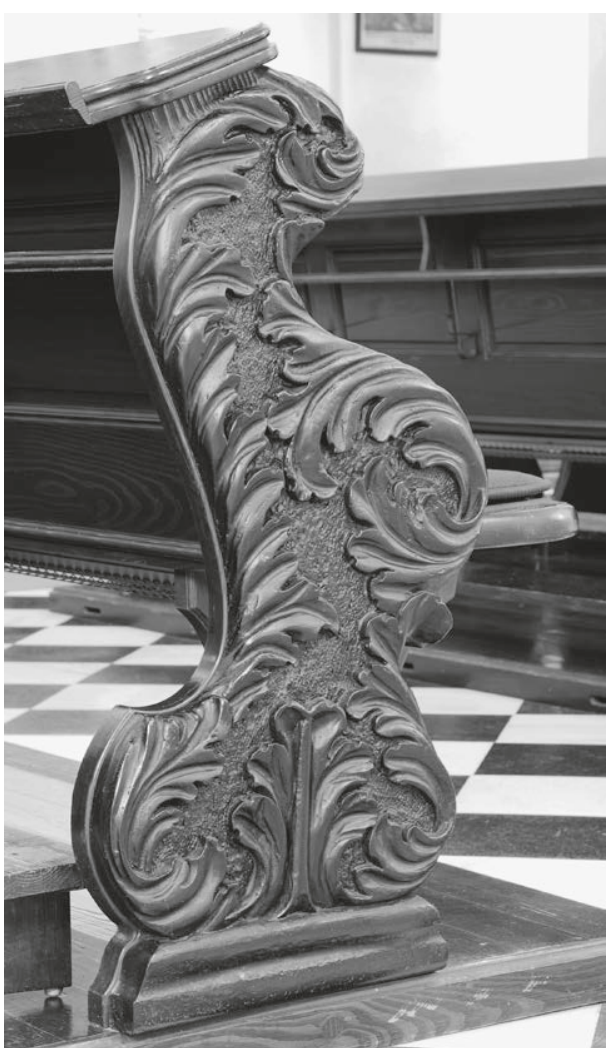

29 Pfarrkirche, Bankwange. Griffen, um I 7 IO $/ 20$

\section{Ehemaliges Augustiner-Chorherrenstift, jetzt Salvatorianerkloster}

I072 gründete der Salzburger Erzbischof Gebhard das Bistum Gurk und stattete den Bischofssitz mit Gütern eines aufgegebenen Benediktinerinnenklosters aus. ${ }^{47}$ Etwa

45 Kunstdenkmäler Kärntens, Völkermarkt (I 933), 36; Dehio, Kärnten (200I), 9 I 9.

46 Mündlicher Hinweis der Mesnerin.

47 ÖK-T, Kärnten (г 889), 89-97; Hann, Gurker Dom (г 897); Schnerich, Dom (1925); Löw, Domführer (г927); Ginhart/Grimschitz, Gurk (г 930); Kunstdenkmäler Kärntens, St. Veit (г 930), 66-86; Löw, Domführer (I 927); ders., Domführer (I 930); Hootz, Kunstdenkmäler (I 965-I 968), Bd. 2 ( I 966), 39-5 I, 337-340; Röhrig, Alte Stifte (r 967), 3 I-33; Hartwagner, Gurk (г 969); ÖKM, Kärnten ( I 977), 80-95; Stenzel, Stift (1 977), I I 8-1 23; Kreuzer, Stifte (1 986), 58, 97-99; Deuer, Gurk ( 1 995); Dehio, Kärnten (200I), bes. 254-267; Faust, Gurk (200I); Krassnig, Gurk (200I); Frankl/Tropper, Gurk (2005); Posch, Dom (2006). 
fünf Dezennien später wurde in Gurk ein Domstift errichtet, das der Augustinerregel folgte. I787 legten die Domherren die Regel ab und transferierten den Bischofssitz, der bereits lange zuvor in das nahegelegene Straßburg verlegt worden war, zusammen mit dem Domkapitel nach Klagenfurt. Der einstige Dom wurde damit zur Konkathedrale und Pfarrkirche. Nach mehrfachem Besitzerwechsel erwarben Salvatorianer I932 den Sakralbau.

Der Baubeginn der ehemaligen Domkirche, einem der bedeutendsten romanischen Bauten im deutschen Sprachraum, fiel in die Regierungszeit Bischof Romans I. (reg. I I3I-II67). I I74 wurde die Krypta geweiht, um i 200 der Hochaltar. Um I446 zog man ein Netzrippengewölbe im Querhaus ein und baute eine Sakristei an, um I 500 erhielt das Chorquadrat ein Sternrippengewölbe. I 525 zerstörte ein Brand die hölzernen Langhausdecken, woraufhin auch das Mittelschiff ein steinernes Gewölbe erhielt. Der Sakralbau besitzt eine mächtige Westturmanlage mit einer zweijochigen Bischofskapelle über einer ursprünglich offenen Vorhalle. Die Kirche ist für diese Kapelle ebenso berühmt wie für die mittelalterlichen Fresken und die Krypta, deren Gewölbe auf einem Wald dichtgestellter Säulen ruht. Das Langhaus der dreischiffigen Pfeilerbasilika misst fünfeinhalb Joche, das Bodenniveau des Chorraums ist gegenüber dem des Langhauses um knapp I,80 m erhöht. Das heutige Hochaltarretabel entstand größtenteils in den I620er- und 3oer-Jahren im Atelier von Michael Hönel (ca. I 590-I653). Durch seine Breite und Höhe grenzt es die Apsis vom Chor ab, sein Skulpturenprogramm umfasst eine Vielzahl von lebensgroßen Figuren und Engelsköpfen. Den nicht minder bedeutenden Kreuzaltar am Ende des Langhauses schuf Georg Raphael Donner (I693-I74I).

\section{Zu den Tischlern}

In den Gurker Pfarrmatriken des I7. und i 8. Jahrhunderts finden Tischler erstaunlicherweise kaum Erwähnung. ${ }^{48}$ Wenig überraschend kommen unter den in den Matriken genannten Berufen vor allem Bauern vor, gefolgt von Maurern, Schmieden, Webern und Schneidern, Tischler scheinen in Gurk und in den umliegenden Gemeinden relativ selten beheimatet gewesen zu sein. I627 wird ein Kind des Tischlers Matthes zu Grabe getragen ${ }^{49}$, zwei Jahre später beerdigt die Gemeinde einen Tischler namens Christian. ${ }^{50}$ I 652 erhielt die Tischlerin Magdalena die letzte Ölung. ${ }^{51}$ Im September

48 https://data.matricula-online.eu/de/oesterreich/gurk/gurk [Zugriff Juni 2020]. Auf dieser Webseite sind auch die nachfolgend genannten Schriftquellen zu finden.

49 Sterbbuch I (G24_ooI-3), p. 283v, I 8.09.I627.

50 Ebd., p. 285 r: 14.06 .1629$.

5I Sterbbuch II (G24_oo2-5), p. 40Iv, 26.II.I652. Es ist dies einer der wenigen Fälle, in dem eine Frau nachgewiesen werden kann, die dieses Handwerk ausübte. 
I654 heiratete Georg Mayrhofer, I653 und I655 sind Kinder von ihm in Archivalien erwähnt. ${ }^{52}$ I 660 wird von einer verstorbenen Angehörigen des Georgii arcularii berichtet, und auch im I8. Jahrhundert sind in den Gurker Schriftquellen noch arcularii zu finden. ${ }^{53} \mathrm{Im}$ Allgemeinen meint der Begriff arcularius einen Schmuckkästchen- oder Galanteriewarenhersteller, der auf dem flachen Land eher nicht zu erwarten wäre. Nicht ganz klar ist überdies, welchen Beruf der faber lignarius Georg Rieger I 666 ausübte.$^{54}$ Einschlägigen Wörterbüchern zufolge könnte Rieger ein Tischler, ein Holzhändler oder ein Zimmermann gewesen sein. Im zweiten Drittel des I8. Jahrhunderts lassen sich in den Archivalien weitere Personen mit dieser Berufsbezeichnung nachweisen. ${ }^{55}$ Wegen der geringen Zahl an Tischlern in Gurk scheint die Annahme jedenfalls naheliegend, dass die Stiftstischlerei über genügend qualifizierte Mitarbeiter verfügte, um anfallende Arbeiten in einem angemessenen zeitlichen Rahmen und ohne fremde Hilfe ausführen zu können.

\section{$Z u$ den aufgedoppelten Intarsienplatten an Beichtstüblen und Kirchenbänken}

In Gurk liegt der außergewöhnliche Umstand vor, dass intarsierte Holztafeln, die an Kirchenbänken und Beichtstühlen angebracht wurden, die Garnituren als einheitliches Ensemble in Erscheinung treten lassen. Zwar sind Möbel mit bossierten Füllungen grundsätzlich nicht ungewöhnlich, doch existiert in keiner anderen österreichischen Kirche ein vergleichbar umfassender Bestand an zusammengehörenden Inventarstücken.

Ein Typus dieser aufgedoppelten Platten ist schlicht rechteckig und mit geraden Außenkanten versehen, ein zweiter besitzt Kanten mit kleinteiligen Bögen, ein dritter vervollständigt die Bankwangen und nähert sich daher der Form eines $C$ an (Farbtaf. o6; Abb. 34-37). Die Intarsien bestehen aus hellem und geschwärztem (Ahorn-?) Holz. Steigen an den Bankwangen dichte kurvilineare und langstielige Blattranken vom Wangenfuß auf, so überziehen in weite Schwünge gelegte, dunkle Bänder mit eingeflochtenem hellem Laubwerk die großen Rechteckfelder. Blütenrosetten zieren die Zentren. Diese Intarsien gemahnen an den "Stil der zarten Ranke»

52 Trauungsbuch II (G24_002-3), p. 338v, 29.09.1654; Geburtsbuch II (G24_002-I), p. I00, I3.03.I653 und p. II 3 , I3.09.1655.

53 Sterbbuch II (G24_002-5), p. 409v, 05.09.I660; Trauungsbuch IIIa (G24_003-2), p. I64, I 8.05.I 738; p. I66, 06.04.1739; p. I93, 06.II.I748; p. 222, 03.11.1761.

54 Sterbbuch II (G24_002-5), p. 4I 3v, 25.09.I666.

55 Trauungsbuch IIIa (G24_003-2), pp. I 58-1 59 und I62 f. Die Einträge stammen vom I 4.02. (?) I 735, vom 06.02.I736 und vom 22.07.I737. Sterbbuch IIIa (G24_003-4), p. 356, Ir.or.I743, und p. 42I, $08.03 \cdot 1759$. 
aus der Zeit um 1700. ${ }^{56}$ Zugleich erinnern sie aber auch an Mauresken aus dem zweiten Drittel des r6. Jahrhunderts. ${ }^{57}$ Der Literatur zufolge soll Propst Franz II. Otto Kochler (reg. I715-I742) die Stiftstischler beim Bau der Möbelgarnituren unterstützt haben. Fakt ist, dass die Intarsien unterschiedliche Qualität aufweisen. Perfekt eingelegte und elegant geschwungene Dekormotive stehen etwas unsauber ausgeführten gegenüber, für deren Herstellung ein ungeübter Mitarbeiter verantwortlich gewesen sein dürfte. Vielleicht war es tatsächlich Kochler. Mehrere Platten an den Rückwänden der Beichtstühle wurden nicht fertiggestellt, die Intarsien brechen dort unvermittelt ab.

Da sich Intarsientafeln sogar im Innern der Möbel finden, wurden Bedenken hinsichtlich ihrer Datierung vorgebracht, doch sind bislang keine Archivalien erschlossen geworden, die von einer späteren Anfertigung der Schollen berichten würden. Überzeugender scheint die These, dass man sie zeitgleich mit der hölzernen Struktur von Beichtstühlen und Bänken produzierte, um die Möbelgarnituren optisch als Teil einer homogenen Ausstattung zu präsentieren. In einem der einleitenden Kapitel werden entsprechende Bestrebungen erörtert.

\section{Kirchenraum}

\section{Dreisitz}

Fassmaler Johann Seitlinger, Gurk, I625

HS I I $\mathrm{cm}$

$\mathrm{H}$ ca. $340 \mathrm{~cm}(+\mathrm{I} \mathrm{I} \mathrm{cm}) \times \mathrm{L} 237 \mathrm{~cm}$

Nadelholz, gebeizt und gefasst

Der mit einem eigenen Sockel versehene Dreisitz steht vor der Südwand des Chorraums auf einem langen, knapp $20 \mathrm{~cm}$ hohen Podest, das auch einige Kirchenbänke trägt (Abb. 30). ${ }^{58}$ Keilpilaster und ein mit Konsolen verziertes Gebälk strukturieren die Brüstung und die Brüstungsdocken, Hochwangen rahmen die Sitzbank. Im un-

56 Ähnliche Motive finden sich an der Brüstung des Chorgestühls in der Heiligenkreuzer Stiftskirche sowie an den Kirchenbänken im Grazer Dom (Abb. I 52, I 53 ). Zum Chorgestühl in Heiligenkreuz vgl. Bohr, Sakralmöbel (2017), 320-328.

57 Beispiele hierfür liegen in Blättern von Jean de Gourmont (* um I483), Jacques Androuet Ducerceau ( 5 Io/I 2 -nach I 584 ) und Hans Rudolf Manuel Deutsch (I 525 -I 57 I) vor. Berliner/Egger, Vorlageblätter (I 98 I), Bd. I, 57-59, 63-64 und Bd. 2, Abb. 420-422, 456-457, 559-560. Die Vorlagen entstanden um 1540 und um 1546 .

58 Hann, Gurker Dom (I 897), 26; ders., Gurker Dom (I910), 43; Schnerich, Dom (I925), 83; Ginhart/ Grimschitz, Gurk (1 930), I32; Kunstdenkmäler Kärntens, St. Veit (I 930), 84; Löw, Domführer (I 930), 52 ; ÖKM, Kärnten (1 977), 93; Dehio, Kärnten (2001), 262 ; Posch, Dom (2006), 27. 
teren Bereich sind ihre Vorderkanten gerade nach oben geführt, darüber geschweift beschnitten. Das Abschlussgebälk des Möbels formt einen Baldachin, ein hoher Giebel mit Auszug bekrönt es.

Das Möbel besteht aus dunkelbraun gebeiztem Nadelholz. Mit Triglyphen, Konsolenfries und einem Eierstab zieren Renaissanceornamente das Gebälk, der Formensprache des Roll- bzw. Beschlagwerks angehörende, sich in den Raum drehende Voluten ergänzen die Dorsalepilaster. Die Rückwandfüllungen tragen Darstellungen Mariens sowie der Heiligen Katharina und Barbara, Putten mit einem Doppelwappen vervollständigen den Auszug. Das heraldisch rechte Wappen zeigt rote und goldene Rauten, es ist das des Gurker Domkapitels. Der zweite Schild präsentiert in geteiltem Feld einen doppelschwänzigen Löwen, das Wappen des Dompropstes Georg III. von Vizdom (reg. I6 17-I648). Zudem ist der Auszug I 625 datiert und mit GPEAG, dem Monogramm Vizdoms, bezeichnet. ${ }^{59}$ Autor der Darstellungen war Johann Seitlin-

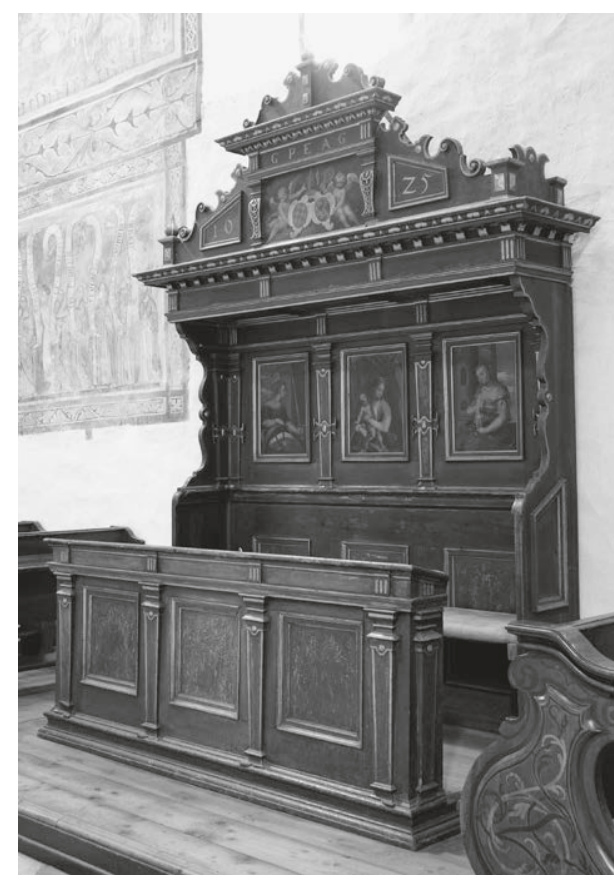

30 Levitensitz. Fassmaler Johann Seitlinger, Gurk, 1625 ger (1596-1666), den die Gurker Pfarrmatrikel als Bürger, Ratsbürger und Maler auflisten. ${ }^{60}$

\section{Orgel und Chorgestübl}

Orgel: Orgelbauer Hans Schlackwein und Bildhauer Michael Hönel, I625

Chorgestühl: Stiftstischler Emilian Sießenbacher und Fassmaler Bartholomäus Seitlinger, I $680 / 8 \mathrm{I}$

HS $44 \mathrm{~cm}(20 \mathrm{~cm}+24 \mathrm{~cm})$

Gesimshöhe $246 \mathrm{~cm}(+44 \mathrm{~cm}) \times \mathrm{L} 710 \mathrm{~cm}$

Nadelholz, vergoldet, polychrom gefasst

59 Georgius Praepositus Et Archidiaconus Gurcensis. Peter, Wappen (2015).

6o Löw, Domführer (I 927), I 50; ders., Domführer (I 930), 52. Etwa Sterbbuch II, p. 392V, 25.02.I643 oder ebd., p. 4I 4r: IO.I 2.I666. Der erste Eintrag bezieht sich auf den Tod der Ehefrau Seitlingers, der zweite auf sein eigenes Ableben. G24_002-5, 3-7-903_000I3 und 3-7-903_00056 in: https://data.matriculaonline.eu/de/oesterreich/gurk/gurk [Zugriff Juni 2020]. 


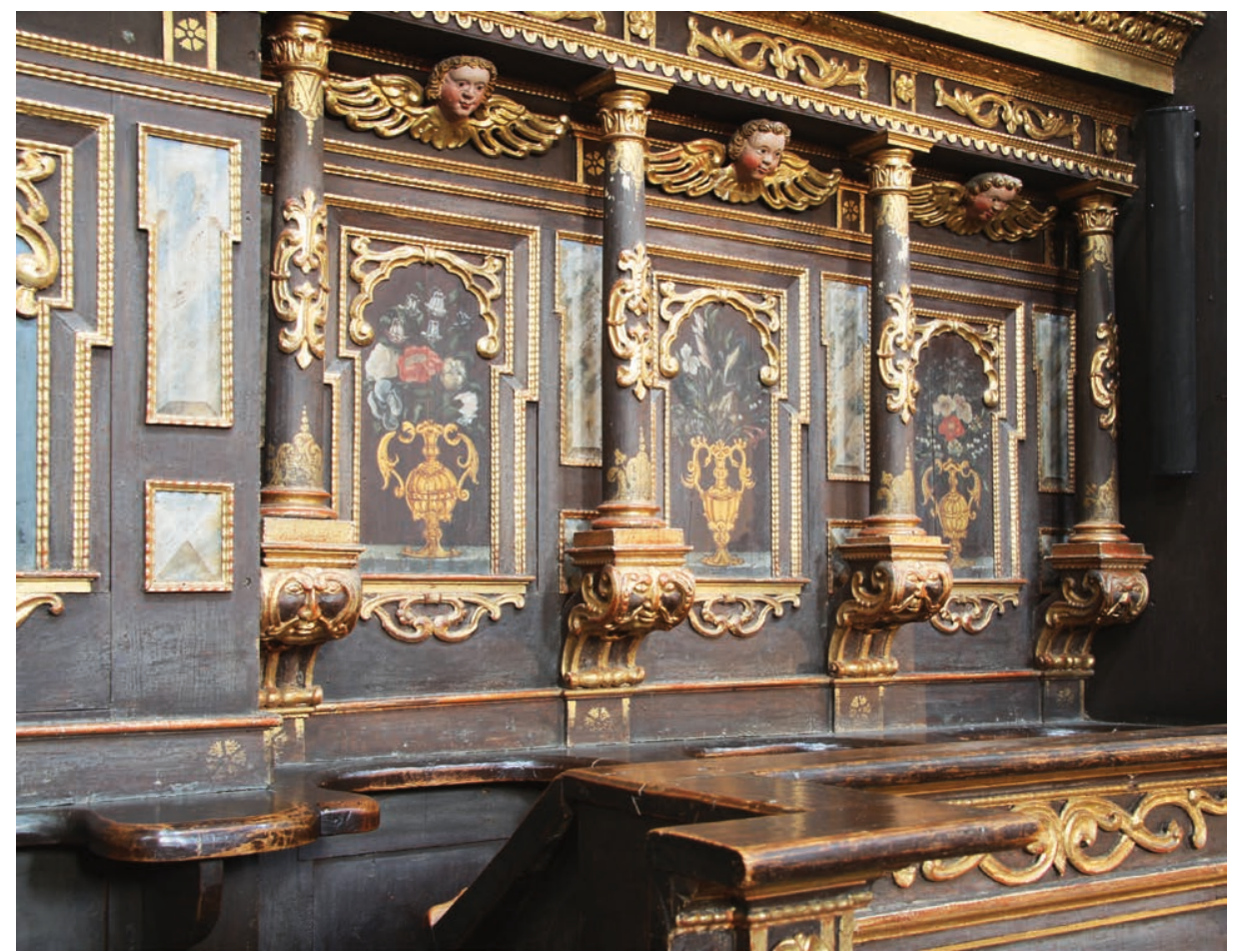

Farbtafel o5 Chorgestühl (Detail). Stiftstischler Emilian Sießenbacher, Fassmaler Bartholomäus Seitlinger, I $680 / 8$ I

Als Aufstellungsort von Orgel und Chorgestühl wählte man die beiden westlichen Chorjoche (Farbtaf. 05; Abb. 3I-33). ${ }^{61}$ Das südseitige Orgelgehäuse ist auf das Jahr I625 datiert und stammt aus der Werkstatt des Orgelbauers Hans Schlackwein aus Vaihingen an der Enz. ${ }^{62}$ Der aus Pirna oder Meißen zugewanderte Bildhauer Michael Hönel schuf den Engel, der das Instrument bekrönt. ${ }^{63}$ Dagegen ist das nördliche Gegenstück zur Orgel, das ursprünglich als Attrappe konzipiert worden war, mit der

6r Hann, Gurker Dom (I 897), 27; ders., Gurker Dom (r 910), 44; Schnerich, Dom (1 925), 8 r ; Löw, Domführer (I 927), 30, 85-86, I 23 ; ders., Domführer (1930), 48-49, I 37; Ginhart/Grimschitz, Gurk (I 930), I 32 ; Kunstdenkmäler Kärntens, St. Veit (r 930), 84; Gerlach, Chorgestühl (r 93 I), 38 ; ÖKM, Kärnten (1977), 93; Deuer, Gurk (I 995), 40-4I ; Dehio, Kärnten (2001), 262 ; Posch, Dom (2006), 26.

62 Schlackwein hatte sich damals bereits einen Namen gemacht, hatte er doch schon I622 die Orgel von St. Paul im Lavanttal gestimmt und I 624 die Orgel in der Stadtpfarrkirche zu Klagenfurt gebaut. Boisits, Schlackwein (200I); Heinz, Orgeln (2012).

63 Zu Hönel vgl. Löw, Domführer (r 930), I 29; allgemein auch Ginhart, Hönel (r 959). 


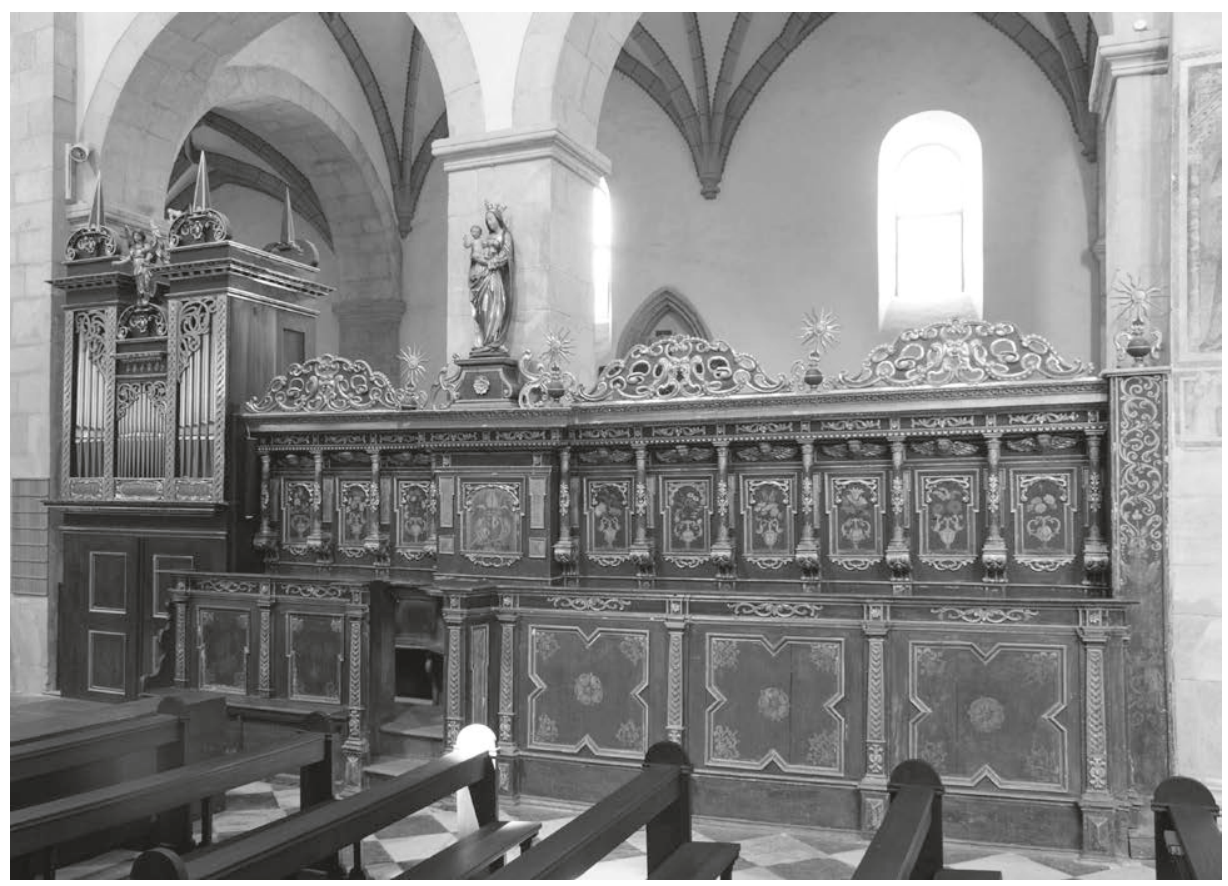

3 I Chorgestühl, Evangelienseite. Stiftstischler Emilian Sießenbacher, Fassmaler Bartholomäus Seitlinger, I680/8I

Jahreszahl I680 versehen, gefertigt wurde es von Emilian Sießenbacher, einem Tischler aus Straßburg (Kärnten). ${ }^{64}$ Die Engel auf den Gehäusen präsentieren Wappenschilder der Pröpste Georg von Vizdom und Wolfgang Andreas Gösel von Thurn (reg. I674-I688), außerdem finden sich dort die Namen der beiden Pröpste zwischen den Monogrammen Christi und Mariens.

Brustwand und Stallen schließen sich im Osten an. Die Brüstung ist geteilt, drei annähernd quadratischen Füllungen auf der Ostseite stehen westlich des Eintritts zwei hochrechteckige Felder gegenüber. Und werden die östlichen Kompartimente von Profilen gerahmt, die mit kurzen Spitzen nach innen weisen, zeichnen sich die westlichen durch ihre geohrte Form aus. Die vor Mauerpfeilern leicht nach vorn versetzten Stallen des Propstes und seines Stellvertreters sind etwas breiter als die übrigen Sitze. Wie die Brüstung besteht auch das Dorsale aus zwei Bereichen unterschiedlicher Länge. Die mit geflammten Profilstäben eingefassten Rückwandfüllungen ruhen

64 Ginhart/Grimschitz, Gurk (1930), I32. Erst in den I980er-Jahren verband man die Orgelpfeifen der Attrappe mit dem Positiv auf der Südseite. 


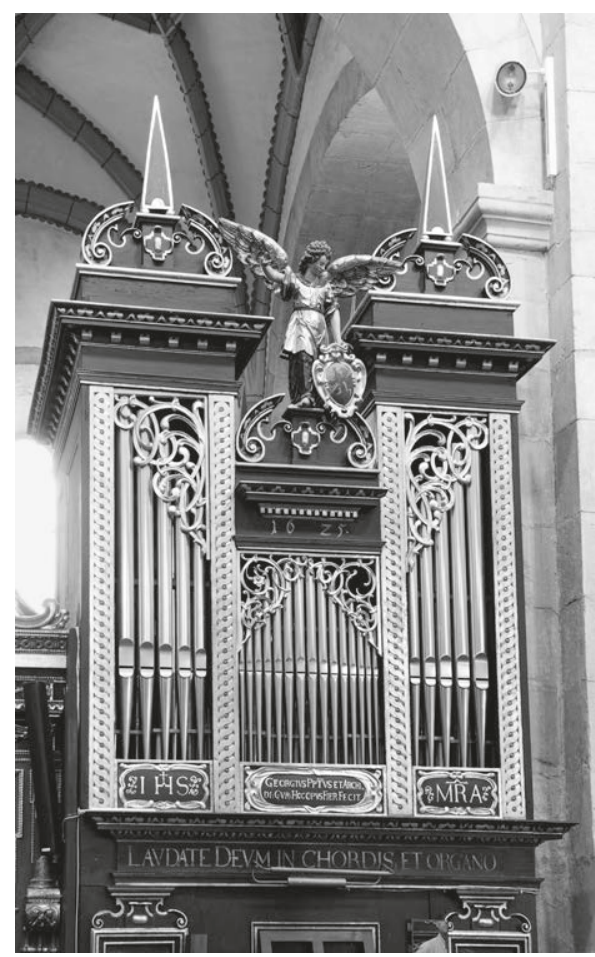

32 Orgel, Südseite. Orgelbauer Hans Schlackwein, Bildhauer Michael Hönel, I 625

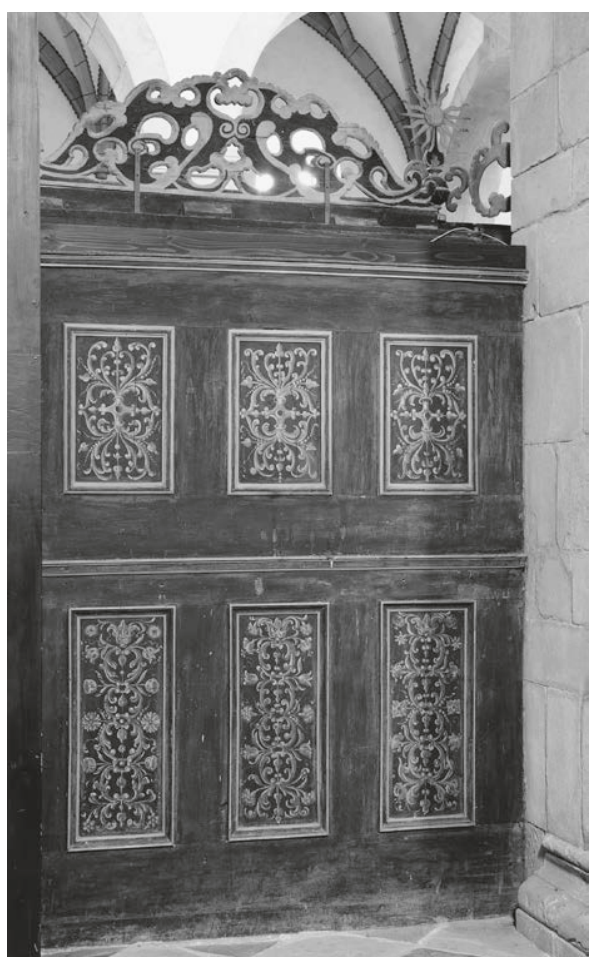

33 Chorgestühl, Rückwand zwischen Orgelkasten und Mauerpfeiler. Stiftstischler Emilian Sießenbacher, Fassmaler Bartholomäus Seitlinger, I680/8 I

auf Sockelleisten, die ihrerseits auf frühbarockem Zierrat aufliegen. Vorhangbögen lassen die Binnenfelder zu Arkaden werden, vollrunde Säulen auf Volutenkonsolen mit grimmig dreinschauenden Masken nehmen die Füllungen in ihre Mitte. Engel bereichern die Abschnitte zwischen den Kapitellen, miteinander verflochtene Bögen und mit Blüten besetzte Konsolen den Gebälkfries. Eine Statue des Salvator mundi aus dem späten I 5. Jahrhundert veredelt die südliche Stallenreihe, eine Skulptur der Mutter Gottes aus dem frühen I6. Jahrhundert die nördliche. Vasen mit dem Sonnensymbol und Knorpelschnitzereien lassen das Gestühl optisch etwas leichter erscheinen, indem sie die Betonung der Horizontalen aufheben, die die gleichförmige Abfolge der Dorsalefüllungen und das schwere Gebälk bewirken.

An den Stallen fallen zunächst die unterschiedlich gestalteten Brüstungsfüllungen auf, Vergleichbares kennen wir in Österreich nicht. Eigenartig mutet ferner das Faktum an, dass die Schnitzbekrönung um i680 hinsichtlich der Zierformen auf der 
Höhe der Zeit stand, während die übrigen Schnitzarbeiten frühbarocke Ornamentmotive wiedergeben und sich damit deutlich von der hochbarocken Formensprache des Auszugs unterscheiden. Das wirft die Frage auf, ob die in der Literatur vorgeschlagene Datierung der Sitzreihen auf I680/8 I zutrifft, denn in Verbindung mit den uneinheitlichen Brustwandkompartimenten lässt das Gesamterscheinungsbild des Gestühls an eine Herstellung in der ersten Jahrhunderthälfte und eine moderate Umarbeitung im späten I7. Jahrhundert denken. ${ }^{65}$ Als treffendes Beispiel für solch eine Vorgehensweise mag auf das Chorgestühl im Zisterzienserstift zu Wiener Neustadt verwiesen werden ${ }^{66}$, ohne die Bestätigung durch entsprechendes Archivmaterial bleibt diese Überlegung allerdings eine reine Vermutung.

Die strukturellen Elemente des Möbels sind dunkelbraun gestrichen, die schmalen Felder seitlich der Rückwandfüllungen blau-rot marmoriert. Mit den Vasen und Blumensträußen vor schwarzem Grund erinnern die Dorsalefüllungen an seicentesche Florentiner Steininkrustationen. ${ }^{67}$ An den hervorgehobenen Stallen ist das viergeteilte Wappen mit Greifen und Kugeln, Mitra und Krummstab sowie mit dem Monogramm WAPEAG von Wolfgang Andreas Gösel von Thurn zu erkennen ${ }^{68}$, gegenüber das gerautete Stiftswappen mit Fürstenhut, Hermelinaufschlag und Kreuz sowie die Datierung I68r. Der herrschenden Lehrmeinung zufolge wurde das Chorgestühl von dem Straßburger Tischler Emilian Sießenbacher erzeugt und von Bartholomäus Seitlinger (I632-I683), einem Sohn des oben genannten Johann Seitlinger, gefasst. ${ }^{69}$ Seitlinger stellte für die Malerarbeit 900 Gulden in Rechnung. ${ }^{70}$ Nicht ganz zu Unrecht charakterisiert Siegfried Hartwagner das Gestühl als »ländliche Arbeit mit [...] bäuerlicher Bemalung. $\aleph^{71}$ Beichtstühle stützen die Stallenreihen von der Rückseite her, ein freier Teil der Gestühlsrückseite ist schwarz gefasst und mit Ornamentmalereien verziert (Abb. 33).

65 Klassizistisch muten die Flechtbandfriese am Orgelgehäuse an, doch handelt es sich bei ihnen um ein renaissancezeitliches Motiv, das mitunter auch noch im frühen I7. Jahrhundert an Tischlerarbeiten anzutreffen ist.

66 Dort erhielt das Gestühl aus dem frühen I7. Jahrhundert um r69r einen neuen Schnitzaufsatz. Bohr, Sakralmöbel (2017), 467-469.

67 Giusti, Splendori (I 988), I IO-I I I I I38-I39, I48-I49. Gezeigt sind dort Pietre dure-Arbeiten aus dem frühen I7. Jahrhundert.

68 Peter, Wappen (2015). Wolfgangus Andreas Praepositus Et Archidiaconus Gurcensis.

69 Ginhart/Grimschitz, Gurk (1930), I 32 .

70 Zitat nach Löw, Domführer (1927), 86.

71 ÖKM, Kärnten (1977), 93. 


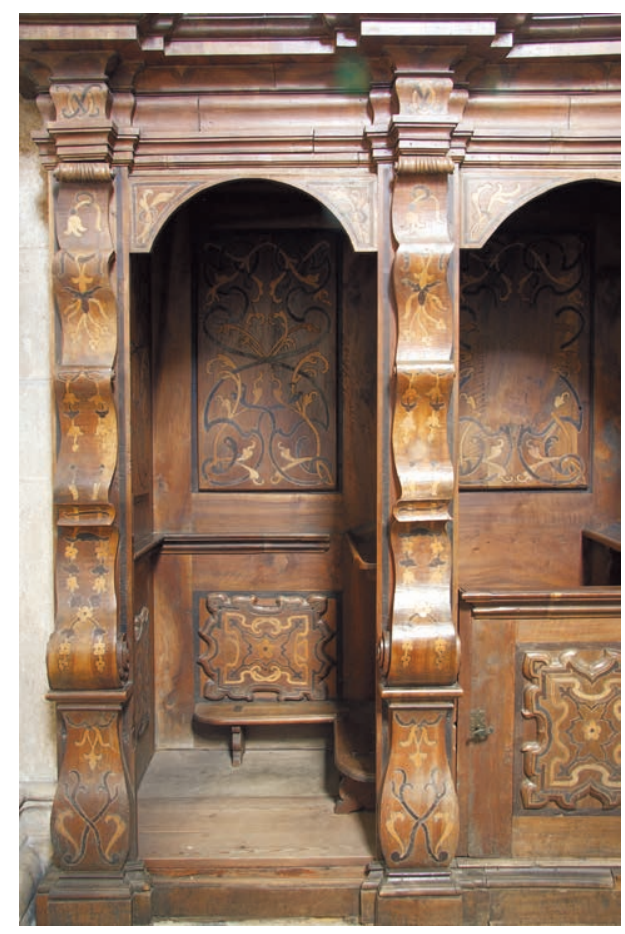

Farbtafel o6 Doppelbeichtstuhl, Teilansicht. Stiftstischler Niclas Michlodt und Propst Franz Otto Kochler (?), um I 735/45

\section{Doppelbeichtstüble}

Stiftstischler Niclas Michlodt, eventuell auch Propst Franz Otto Kochler, um I735/45

HS I $6,5 \mathrm{~cm}$

Gesimshöhe $246 \mathrm{~cm}(+\mathrm{I} 6,5 \mathrm{~cm}) \times \mathrm{L}_{429} \mathrm{~cm}$

Nuss, Ahorn, Buche, Holz geschwärzt

Die Doppelbeichtstühle befinden sich jeweils im ersten östlichen Seitenschiffsjoch vor den Rückwänden des Chorgestühls (Farbtaf. o6; Abb. 34). ${ }^{72}$ Die beiden mittleren, mit halbhohen Türen verschlossenen Gehäuse stehen den Geistlichen zur Verfügung, die seitlichen den Pönitenten. Rundarkaden gestatten den Zugang zu den Möbeln, Sockel, stilisierte Pilaster und Gebälke sorgen für den obligatorischen tektonischen Aufbau. Die Beichtstühle besitzen keinen Aufsatz, sondern einen geraden Abschluss, der ihnen ein etwas altertümliches Aussehen verleiht.

Die Qualität der Möbel ist ausgesprochen hoch. Das zeigt sich nicht nur im bewegten Gebälkfries, sondern ebenso in den volutenbesetzten Stützen, die abschnittsweise nach vorn und zu den Seiten hin ausschwingen. Hinzu kommen an den Füllungen der Möbelaußen- und -innenseiten die erwähnten Intarsienplatten. An den Schäften der Stützen sind Blütenzöpfe zu erkennen, an den Gebälkkonsolen sich kreuzende und mit einem Kreis verknüpfte S-förmige Strukturen, sonst mit lockerem Blattwerk verzierte Bänder. Josef Löw las die Intarsien an den Konsolen als $\mathrm{O}$ und $\mathrm{X}$, wobei das $\mathrm{X}$ als doppeltes $\mathrm{K}$ zu verstehen sei und die Buchstaben somit als Spiegelmonogramm von Propst Otto Kochler gedeutet werden müssten. ${ }^{73}$ Die Hauptarbeit an den Beichtstühlen gehe zwar auf den Stiftstischler Niclas Michlodt zurück, doch habe Kochler als »Tischlerdilettant« selbst Hand angelegt. ${ }^{74}$

72 Schnerich, Dom (I 925), 82; Löw, Domführer (1927), 83; ders., Domführer (I 930), 33, I39-140; Hartwagner, Gurk (I 969), 39; ÖKM, ebd., 83, 91 , 93; Dehio, Kärnten (2001), 262.

73 Löw, Domführer (1927), 83.

74 Löw, ebd.; ders., Domführer ( I930), I39-I 40. Mitunter schreibt die Literatur dem Stiftstischler Gregor Hillebrand die Beichtstühle zu. Er soll an den Möbeln noch unter Propst Maria Joseph Freiherr von 
34 Doppelbeichtstuhl. Stiftstischler Niclas Michlodt und Propst Franz Otto Kochler (?), um I 735/45

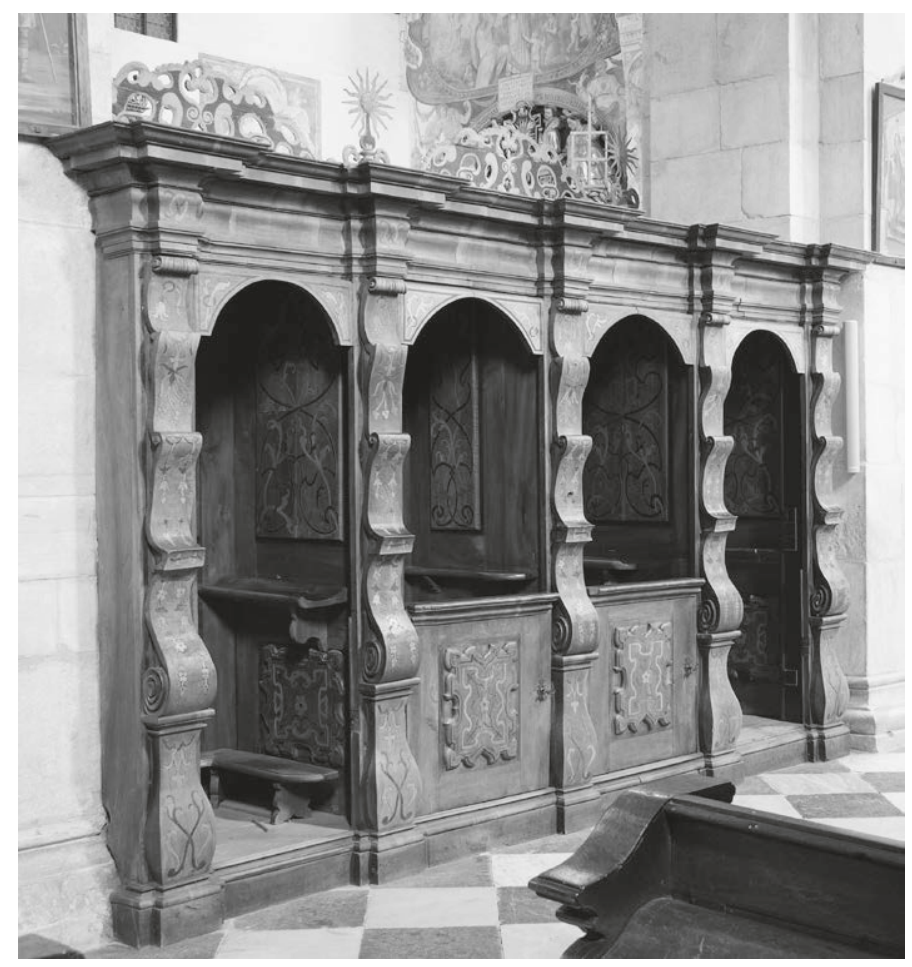

Da Kochler die Regierungsgeschäfte in Gurk von I7 I 5 bis 1742 führte, könnte Löws nur schwer zu verifizierende These tatsächlich zutreffen. Ein etwas später als die Doppelbeichtstühle gefertigtes Exemplar steht im südlichen Seitenschiff der Kirche. ${ }^{75}$ Es ist dreiteilig, besitzt aber im Prinzip ein analoges Aussehen.

\section{Kirchenbänke}

Stiftstischler Niclas Michlodt, eventuell auch Propst Franz Otto Kochler, um I 735/45 sowie

Gurk, um I796/97

HS I $9,5 \mathrm{~cm}$

$\mathrm{H} 95,5 \mathrm{~cm}(+\mathrm{I} 9,5 \mathrm{~cm}) \times \mathrm{L} \mathrm{I}, 95 \mathrm{~m} / 5,80 \mathrm{~m}$

Nuss massiv, furniert und intarsiert, Nadelholz, weitere Holzarten, teilweise geschwärzt

Rechbach (reg. I744-I787) gearbeitet haben. Allerdings sprechen das Gesamterscheinungsbild der Möbel ebenso wie die gewählten Ornamentmotive gegen eine Anfertigung um die Jahrhundertmitte oder später.

75 Löw, Domführer (r 927), 83; ders., Domführer (r 930), 58. 

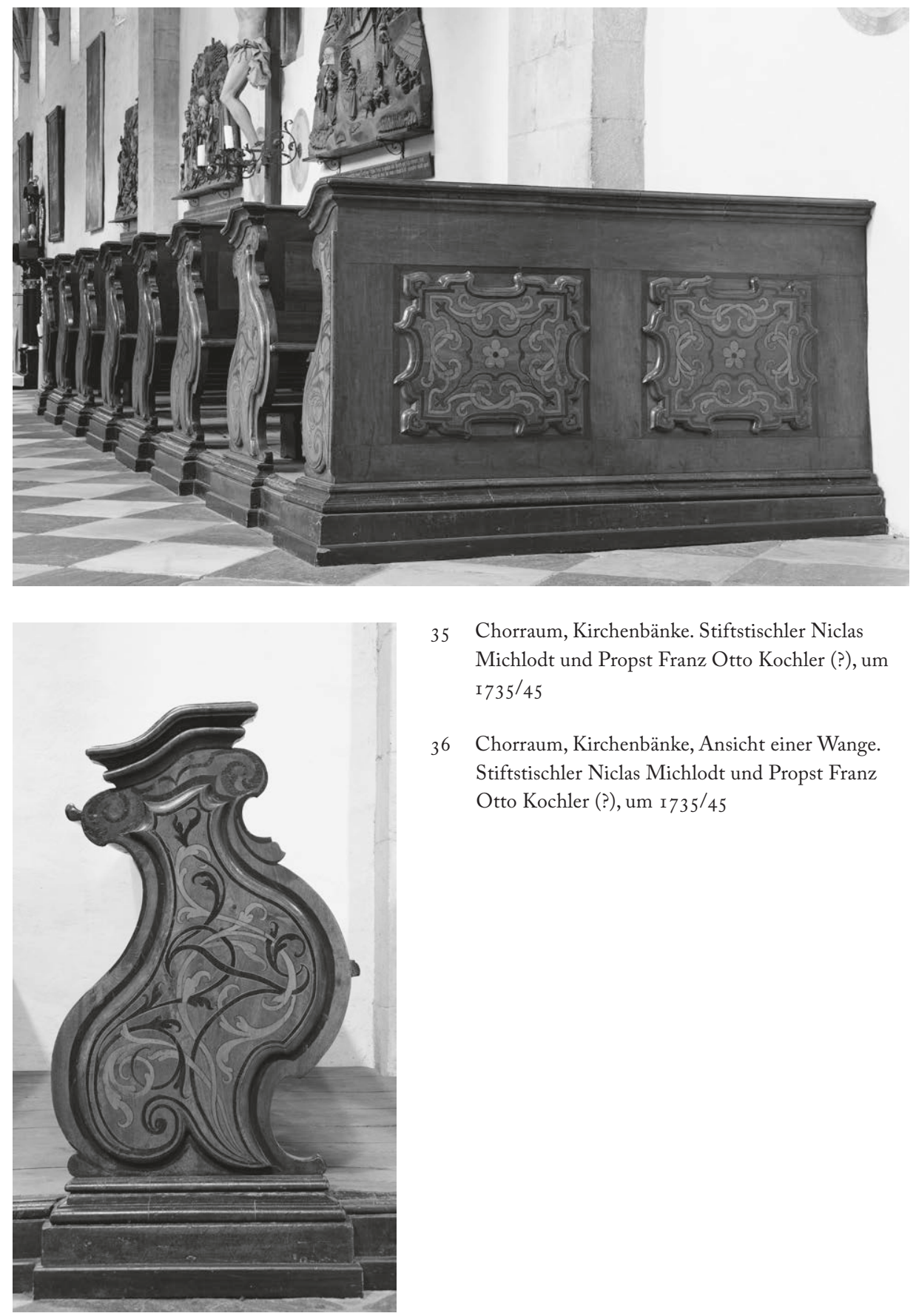

35 Chorraum, Kirchenbänke. Stiftstischler Niclas Michlodt und Propst Franz Otto Kochler (?), um I $735 / 45$

36 Chorraum, Kirchenbänke, Ansicht einer Wange. Stiftstischler Niclas Michlodt und Propst Franz Otto Kochler (?), um I 735/45 


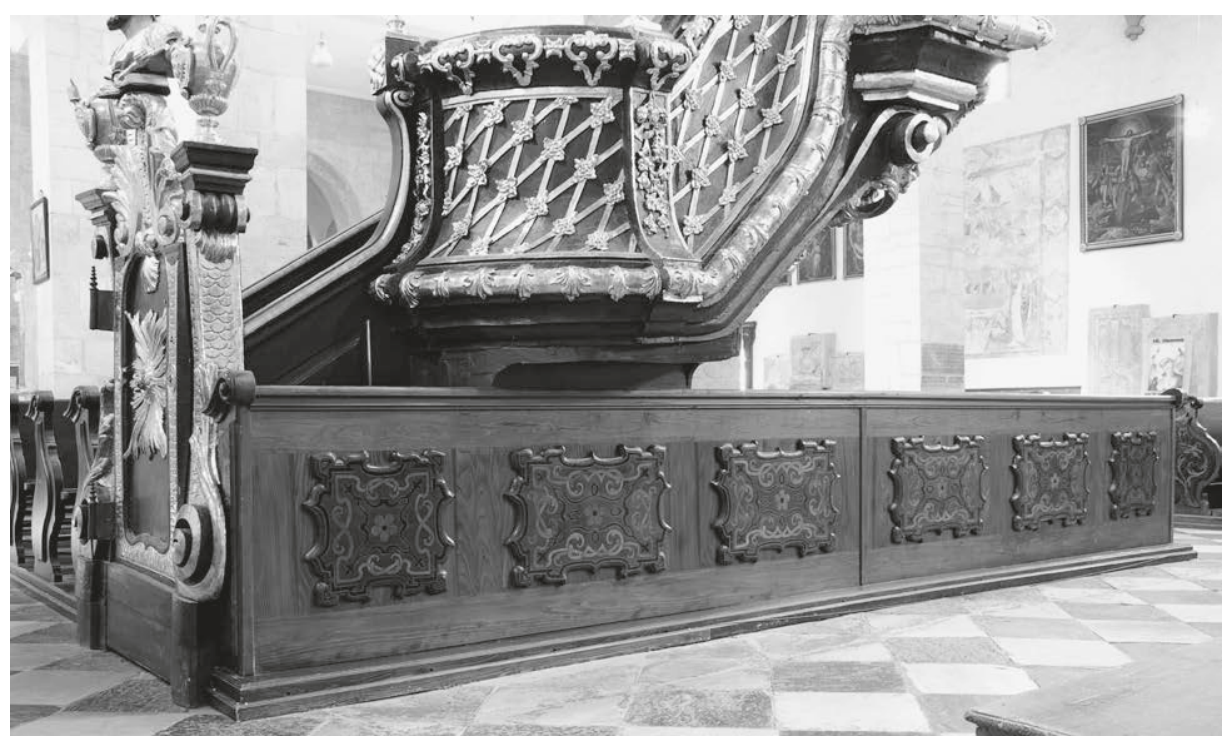

Langhaus, Laiengestühl, um I 735/45 und um I796/97

In den Seitenschiffen des Chorraums stehen links sieben Bänke, rechts elf, Brüstungen bilden den vorderen Abschluss (Abb. 35, 36). ${ }^{76}$ Glatte Rahmen fassen die mit Sockel und Abschlussgesims ausgestatteten Brustwände ein, mit kleinteiligen Schweifungen versehene Füllungsfelder stehen als Bossen über der Grundfläche erhaben nach vorn. Durch aufgedoppelte Binnenfelder zeichnen sich auch die Docken aus, das Lesepult ist gut zehn Zentimeter unterhalb des Abschlussprofils eingepasst. Als Werkmaterial überwiegt massives Nussholz, nur stellenweise kommt Nussfurnier vor.

Längere Exemplare dieser Bankgarnituren befinden sich in der Eingangshalle und im Langhaus entlang der Außenwände. Wahrscheinlich wurden diese Bänke im zweiten Viertel des I 8. Jahrhunderts unter der Leitung von Niclas Michlodt gebaut. ${ }^{77} \mathrm{Da}^{-}$ rüber hinaus stehen den Kirchenbesuchern im Mittelschiff weitere 36 Möbel dieses Typs zur Verfügung (Abb. 37). Sie sind auf die Zeit um I796/97 zu datieren, der verantwortliche Tischler ist nicht bekannt. ${ }^{78}$ Bei der Herstellung der Möbel übernahm er die Großform der alten Exemplare und brachte an den Brustwänden und Wangen der vorderen Bankreihen Intarsientafeln aus der ersten Jahrhunderthälfte an. Das

$76 \mathrm{Zu}$ diesen Bänken und weiteren Exemplaren vgl. Schnerich, Dom (r 925), 63; Löw, Domführer ( 1927 ), 64, I I 8-I I9; ders., Domführer (I930), 52, I39-I40; Hartwagner, Gurk (I969), 39; ÖKM, Kärnten (1 977), 83, 91, 93; Dehio, Kärnten (2001), 257, 262.

77 Schnerich, ebd., nennt dagegen den Tischlermeister André Ott und gibt als Datierung um I720 an. 78 Schnerich, ebd.; Löw, Domführer (1927), 64, I I 8-i I 9. 


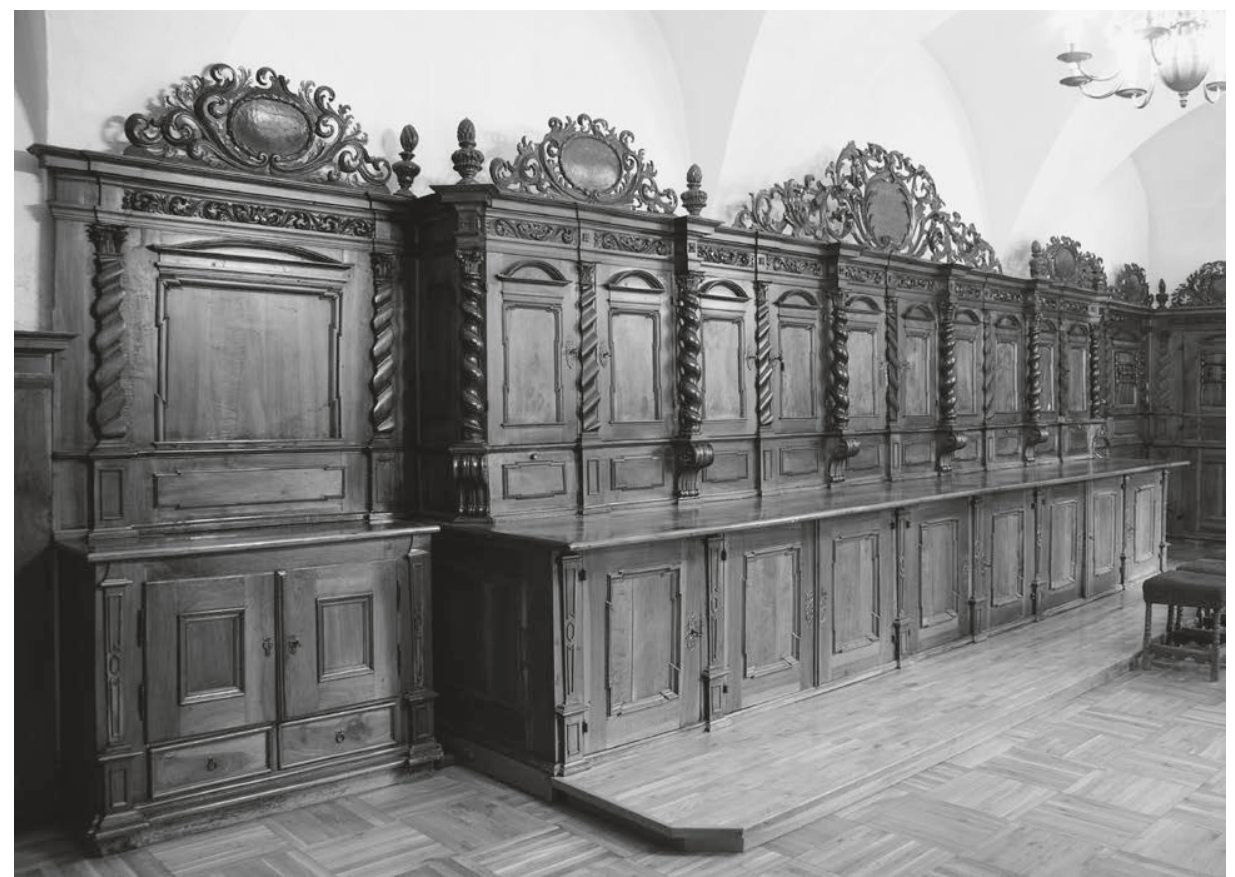

38 Sakristei, Nordseite, Aufsatzschränke. Gurk, um 1702

Rahmengerüst der Möbel stellte er jedoch nicht aus Nussholz her, sondern aus Nadelholz und beizte es nussfarben.

\section{Sakristei}

Die Sakristei, ein kreuzgratgewölbter Raum, der durch Fenster in der südlichen Längswand beleuchtet wird, liegt nördlich der Kirche in Ost-West-Richtung. ${ }^{79}$ Seitlich des Eingangs befindet sich vor der Westwand ein Lavabo (Abb. 4I), vor der Nordwand stehen ein Halbschrank und ein Aufsatzmöbel (Abb. 38). Den größten Teil der Ostseite des Raumes nimmt ein großer Kelchschrank mit tabernakelähnlichem Mittelfach ein, vor den Fensterpfeilern der Südwand hat man zwei weitere Möbelstücke platziert (Abb. 39, 40). Eine Tür in der Nordostecke des Raumes führt in den Konvent, ansonsten wurden freien Mauerabschnitten Wandvertäfelungen vorgeblendet. Die Gesimshöhe von Möbeln und Getäfel beträgt etwa 226,5 cm.

79 Löw, ebd., I3I-I32. 


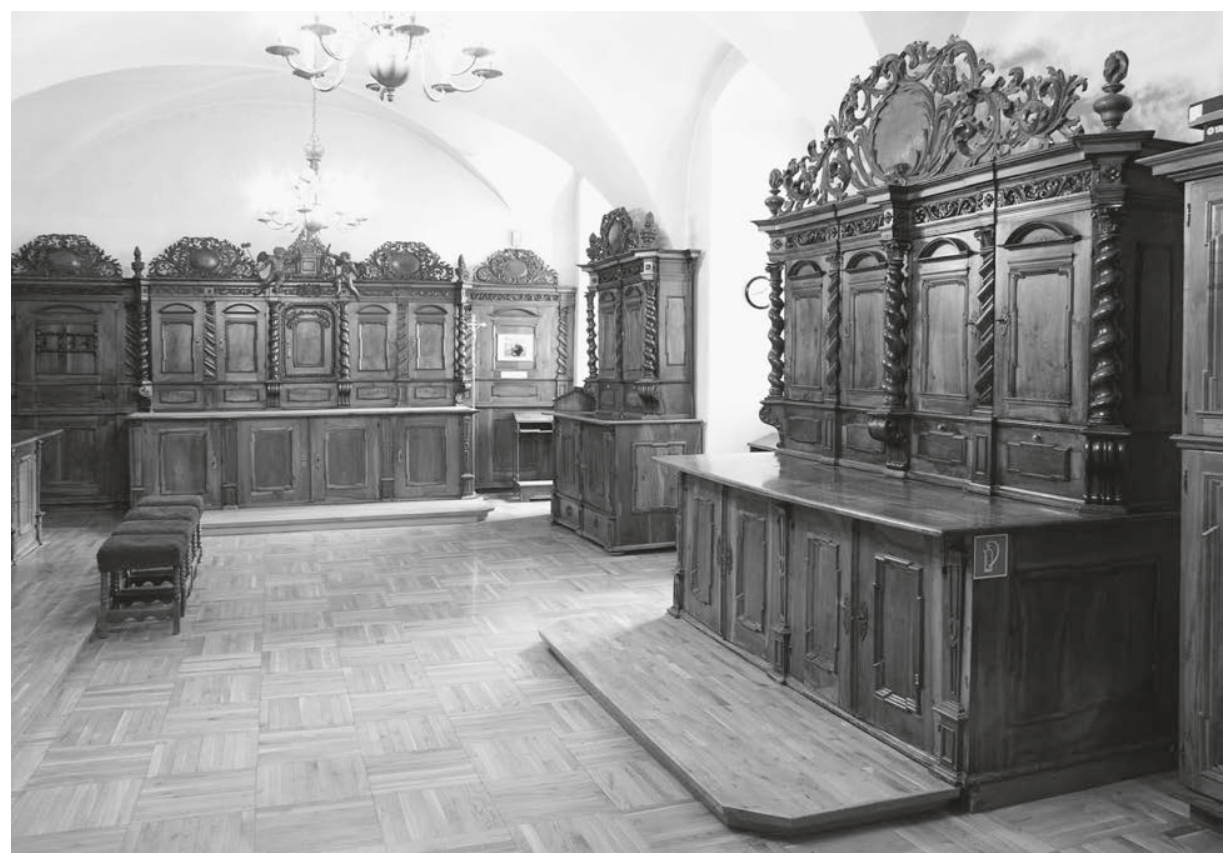

39 Sakristei, Ost- und Südseite, Aufsatzschränke. Gurk, um I 702

40 Sakristei, Möbel vor der Ostwand (Detail). Gurk, um I 702

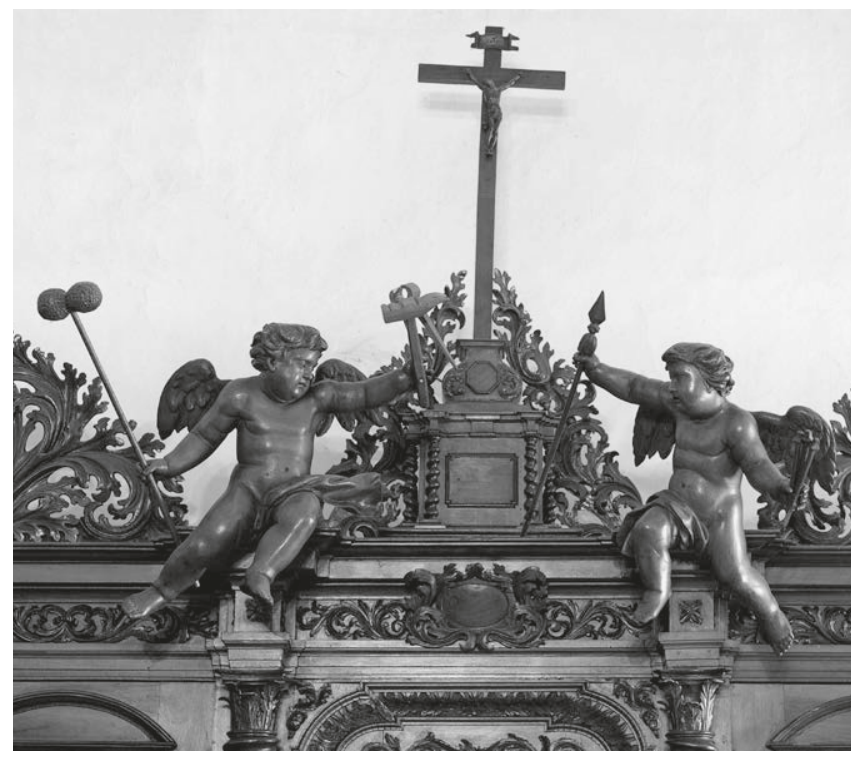




\section{Schränke}

Nordwand:

Halbschrank mit Getäfel als Aufsatz

HS $9,0 \mathrm{~cm}$

$\mathrm{H}_{273} \mathrm{~cm}(+9, \mathrm{Ocm}) \times \mathrm{L} \mathrm{I}_{37} \mathrm{~cm} \times \mathrm{T}_{44} \mathrm{~cm}$

Aufsatzschrank

HS I I, 5

$\mathrm{H}_{300,5} \mathrm{~cm}(+\mathrm{II}, 5 \mathrm{~cm}) \times \mathrm{L} 640 \mathrm{~cm} \times \mathrm{T}$ I I $5 \mathrm{~cm}$

Ostwand:

Aufsatzschrank mit Kelchfächern

HS I I, $5 \mathrm{~cm}$

H gesamt ca. $340 \mathrm{~cm}(+$ I I, $5 \mathrm{~cm}) \times \mathrm{L}_{346,5} \mathrm{~cm} \times \mathrm{T}$ Io9 $\mathrm{cm}$

Südwand:

Zweitüriger Schrank

Höhe der Ballenfüße 4,5 cm

$\mathrm{H} 282 \mathrm{~cm}(+4,5 \mathrm{~cm}) \times \mathrm{L} \mathrm{I} 78,5 \mathrm{~cm} \times \mathrm{T} 87 \mathrm{~cm}$

Viertüriger Schrank

HS $10 \mathrm{~cm}$

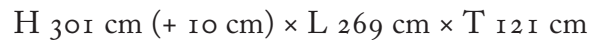

Gurk, um I 702

Nuss, massiv und furniert, Weichholz. Eisen verzinnt, geschwärzt, bronziert

\section{Lavabo}

Gurk, I 749 (?)

$\mathrm{H}_{2} 70 \mathrm{~cm} \times \mathrm{B}$ I $54 \mathrm{~cm} \times \mathrm{T} 6 \mathrm{I}, 5 \mathrm{~cm}$

Nuss, massiv und furniert, Weichholz. Zinn

Bei unterschiedlichen Maßen entsprechen sich die Sakristeischränke hinsichtlich ihrer Großformen. ${ }^{80} \mathrm{Wie}$ wir das von vielen anderen Exemplaren her kennen, besitzen die Unterschränke eine größere Tiefe als die Oberschränke. Von Pilastern flankierte Türen verschließen die Substruktionen, schlichte Basen und Kapitelle definieren die Ordnung der Stützen, Keilstäbe zieren die Schäfte. Die Türen wurden handwerksgerecht aus Rahmen und Füllungen konstruiert, die Binnenfelder mit verkröpften Seiten versehen, eine Art der Gestaltung, die in jener Zeit immer wieder zu finden ist.

Ein architektonisches Ordnungssystem bestimmt überdies das Aussehen der Oberschränke, deren Fassaden sich aus Sockelgeschoss, Hauptteil, Gebälk und ho-

80 Schnerich, Dom (1925), I07; Löw, ebd., I32; Dehio, Kärnten (2001), 265 ; Posch, Dom (2006), 42. Schnerich hielt die Schränke für Erzeugnisse des I 7. Jahrhunderts. 
hem Schnitzaufsatz zusammensetzen. Abwechselnd scheiden tordiert gedrehte Säulen und schräg gehobelte Pilaster die einzelnen Joche voneinander. Im Sockelbereich stehen die Füllungen erhaben nach vorn, während die zentralen Felder des Hauptgeschosses in der Tiefe zurückliegen. Flache Segmentgiebel vervollständigen sie zu Ädikulä. Vasen mit $\mathrm{Pi}$ nienzapfen, auf den hl. Augustinus deutende Flammenvasen sowie große dreieckige Tableaus aus Akanthusranken und Kartuschen bekrönen die Möbel. Einige Zwischenräume des Sockelgeschosses können geöffnet werden, andere sind geschlossen.

Ein davon abweichendes Aussehen weist lediglich die Mitteltravée des Schranks vor der Ostwand mit dem Kelchfach des Propstes auf. Die Tür ist nicht als welsches Fenster gestaltet, sondern als großes Hochrechteck mit abgerundeten oberen Ecken. Darüber brachte man eine kleine akanthusgeschmückte Kartusche an, auf dem Gebälk sitzen seitlich eines hohen Standkreuzes Engel mit den Leidenswerkzeugen Christi. Die Innenseiten der Fächer sind

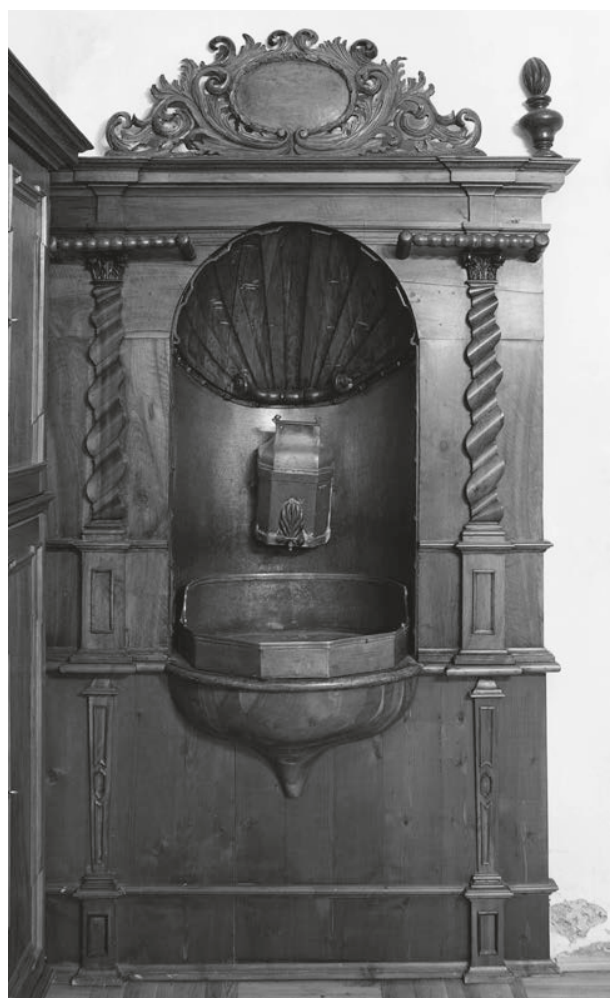

4I Sakristei, Westwand, Lavabo. Gurk, I 749 (?) blau gefasst, der »Tabernakel« an der Stirnseite ist zusätzlich mit Sternen verziert.

Der Halbschrank (Abb. 38) unterscheidet sich in einigen Details von den anderen Möbeln. Im Sockel laufen Schubladen, ein Querrahmen begrenzt die mit schlichten Rechteckfüllungen versehenen Türen, während die der anderen Möbel die gesamte Höhe des Unterschrankes einnehmen. Einst befand sich vor dem Halbschrank ein Laufpodest, das heute fehlt. Der Sockel des Lavabos (Abb. 4I), der aus aneinander geleimten Weichholzbrettern besteht, sowie die Konsole, die das Wasserbecken stützt, sind modern, dagegen dürften die übrigen Teile des Möbels zum ursprünglichen Bestand gehören. Naturgemäß zeichnet sich das Inventarstück durch eine besondere Gestaltung aus, doch knüpfte man bei seiner Herstellung am Design der übrigen Garnitur an. I702, so Josef Löw, erhielt ein Tischler 200 Gulden für den Bau der Sakristeiausstattung, außerdem seien Entwurfsskizzen, die momentan (2019) unauffindbar sind ${ }^{81}$,

8I Freundliche Auskunft von Robert Kluger, Archiv der Diözese Gurk. 
für den Bau der Möbel im Gurker Archiv vorhanden. Und das Lavabo ist nach Löw mit der Jahreszahl I 749 versehen. ${ }^{82}$ Auch diese Angabe kann nicht verifiziert werden.

Klagenfurt, Dom- und Stadtpfarrkirche St. Peter und Paul

Protestantische Landstände ließen die Kirche seit etwa I 58 I als Longitudinalbau errichten und mit Emporen versehen, die an drei Seiten des Schiffs umlaufen - eine Architekturform, die den besonderen Anforderungen des evangelischen Ritus Rechnung trägt. ${ }^{83}$ Auf Anweisung der Religions-Reformations-Kommission hin schloss man die Kirche um die Wende vom r6. zum i 7. Jahrhundert, wandelte sie in einen katholischen Sakralraum um und überließ sie r 604 der Obhut der Gesellschaft Jesu. ${ }^{84}$ Spätere Umbauten veränderten den Raumeindruck grundlegend. So wurden nach der Mitte des I7. Jahrhunderts barocke Wandgliederungselemente eingefügt, außerdem erweiterte man I66 I den Kirchenraum durch eine angrenzende Kapelle. I 665 begann man mit der Umgestaltung des Chors. Nach einem Brand mussten I723 Teile der Einrichtung erneuert werden. Unter Joseph II. verließen die Jesuiten die Stadt. Der Verlegung des Bischofssitzes von Gurk nach Klagenfurt folgte I 787 die Erhebung des Bauwerks zur Domkirche des (Fürst-)Bistums Gurk.

Die vierjochige und beiderseits mit vier Seitenkapellen ausgestattete Kirche wurde als tonnengewölbter Raum mit Stichkappen und Bogenfenstern geplant. Das leicht eingezogene Presbyterium ist über dreijochigem, mit einem Halbkreisschluss versehenem Grundriss errichtet. Auf etwa r66o lässt sich die Stuckausstattung zweier Seitenkapellen datieren, die übrigen Stuckarbeiten wurden nach I7I5 angebracht, Seitenaltäre und Kanzel um 1725/27 gefertigt. Umfassende Restaurierungsarbeiten in der Kirche gehen auf die Jahre um I 880 sowie um r 990/9i zurück.

\section{Sakristei}

Die beiden in Nord-Süd-Richtung liegenden Sakristeiräume befinden sich vor der Südseite des Chorraums. Der erste Raum ist ein Durchgangszimmer, der im Folgenden beschriebene monumentale Aufsatzschrank befindet sich im zweiten, sehr viel

82 Löw, Domführer (1927), I 32 .

83 Zur Architektur und Geschichte vgl. ÖK-T, Kärnten (r889), 44I-444; Kunstdenkmäler Kärntens, Stadt Klagenfurt (I93 I), 31-38; Rainer, Dom (I939); Hootz, Kunstdenkmäler (I965-1968), Bd. 2 (I966), 67, 342-343; ÖKM, Klagenfurt Stadt (r 980), 83-90; Dehio, Kärnten (2001), 350-353; Allmaier, Dom (2OII).

84 Die Kommission wurde 1600 ins Leben gerufen, um in Kärnten die Gegenreformation durchzusetzen. 


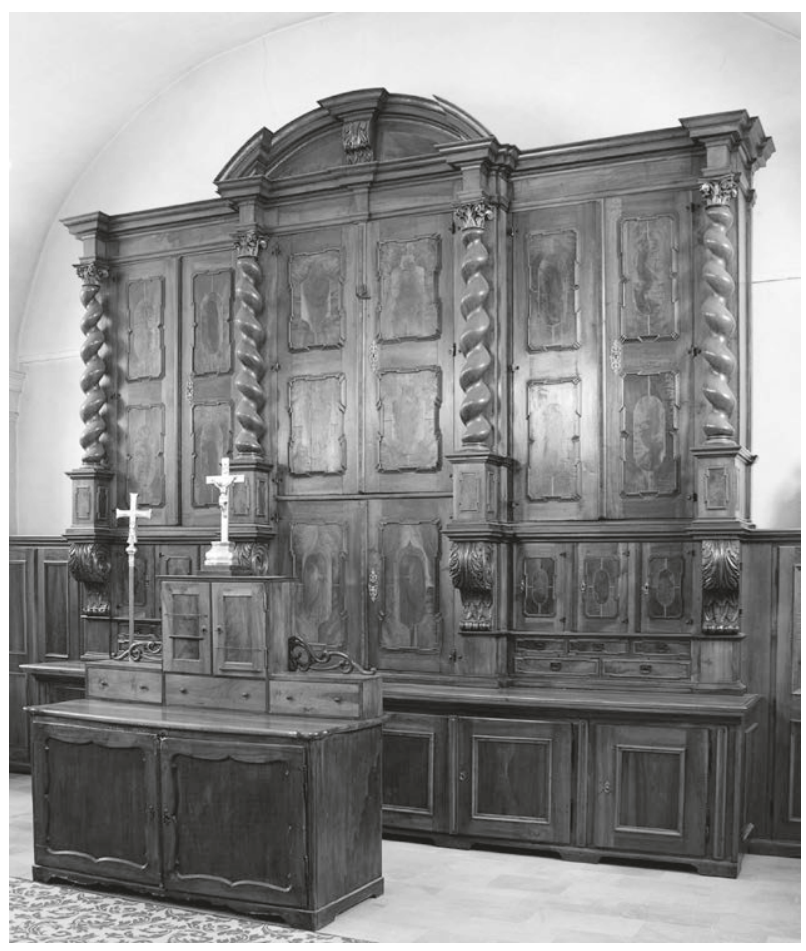

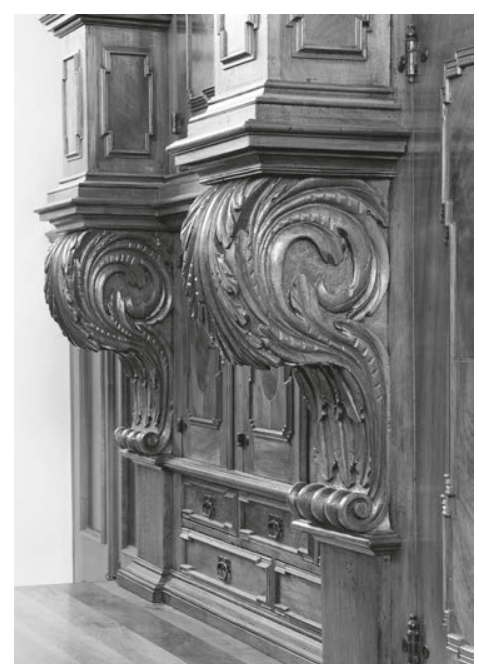

42 Sakristei, Ankleidekredenz. Klagenfurt, um I 7 Io/20. Der Unterschrank ist modern.

43 Sakristei, Ankleidekredenz (Detail). Klagenfurt, um I 7 IO $/ 20$

größeren Zimmer. Außerdem werden in beiden Räumen barocke Kniebänke aufbewahrt, auch sie sollen untersucht werden.

\section{Aufsatzschrank}

Klagenfurt, um I 7 Io/20

Maße des Unterschranks: $\mathrm{H} 96 \mathrm{~cm} \times \mathrm{B}_{505} \mathrm{~cm} \times \mathrm{T}$ i $16,5 \mathrm{~cm}$

Maße des Aufsatzes: $\mathrm{H}_{390} \mathrm{~cm} \times \mathrm{B}_{485} \mathrm{~cm} \times \mathrm{T} 76 \mathrm{~cm}$

Nussbaum, massiv, furniert, Nussmaser, Ahorn, Nadelholz. Eisen, geschwärzt, verzinnt

Beim Bau des modernen Unterschrankes dürfte man sich am alten Möbel orientiert haben. Durch Form, Maße und Proportionen entspricht er dem Aussehen vieler Exemplare dieses Typs, im vorliegenden Buch gibt es hierfür etliche Beispiele.

Der Oberschrank wurde zwar stark restauriert, geht aber auf das Barockzeitalter zurück (Abb. 42, 43) ${ }^{85}$ Wie das häufig an Möbeln jener Zeit zu beobachten ist, entwi-

85 Kunstdenkmäler Kärntens, Stadt Klagenfurt (r 93 I), 38 ; ÖKM, Klagenfurt Stadt ( 980 ), 89. 


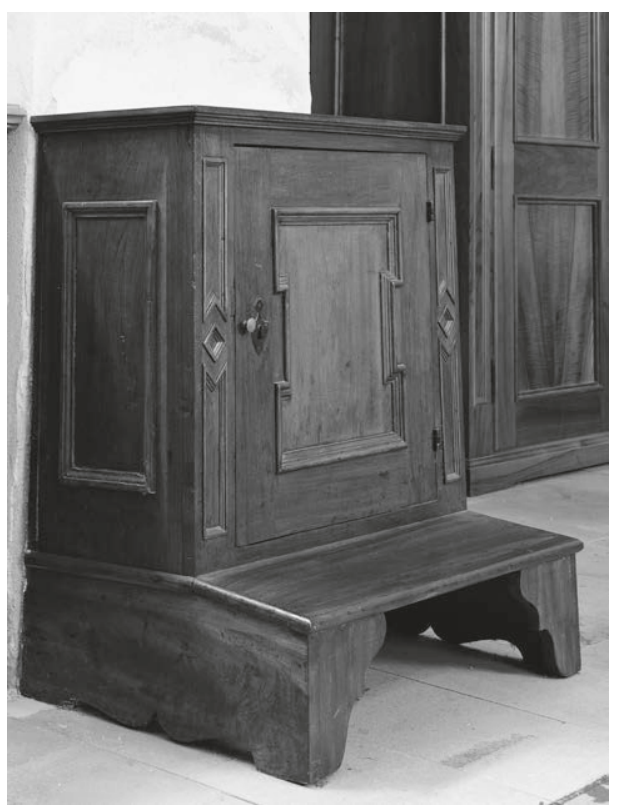

44 Sakristei, Kniebank. Klagenfurt, um I 690/I 720

ckelt sich das dreiachsige Inventarstück in der Vertikale über mehrere Register. Postamente mit schweren Stehvoluten definieren die Höhe des Sockels, darüber bilden massive korinthische Säulen auf zusätzlichen Piedestalen das architektonische Gerüst der Hauptzone. Ein verkröpftes Gebälk schließt das Möbel ab, ein flacher Segmentbogen überfängt die Mitte.

Die Seitentravéen besitzen einen Aufbau, der das leicht nach vorn tretende mittlere Schranksegment variiert. In der Sockelzone der äußeren Joche liegen Kelchfächer über flachen Schubladen, während ein hohes tabernakelähnliches Fach die Mittelachse dominiert. Schlanke zweitürige Kästen verschließen das Hauptgeschoss. Die Tischler furnierten die Türrahmen mit gestreiftem Nussholz, die leicht erhabenen und mit komplizierten Verkröpfungen versehenen Füllungen, in die sie zusätzliche Felder einlegten, mit Maserholz aus Nuss. Kaum in Erscheinung tretende Fadeneinlagen säumen die Binnenfelder. Damit zeigen die Intarsien stilistische und motivische Anklänge an die I 70 r geschaffene Bibliotheksausstattung des Stiftes Heiligenkreuz. ${ }^{86}$ Das Möbel überrascht durch die ungewöhnliche Schwere des Aufsatzes, der die Substruktion fast zu überlasten scheint. Zugleich erinnert es an die Sakristeischränke in St. Paul (Farbtaf. o9; Abb. 6r), die sich durch eine vergleichbare optische Wucht auszeichnen. Die plastische Modellierung der Fassade mit massiven gewendelten Säulen, die Schwere des Möbels und die nahezu ausschließliche Verwendung dunklen Nussholzes verraten einen machtvollen italienischen Einfluss bei der Gestaltung des Inventarstücks. ${ }^{87}$

\section{Drei Kniebänke}

Klagenfurt, um I690/ I 720

$\mathrm{H} 92 \mathrm{~cm} \times \mathrm{B} 62,5 \mathrm{~cm} \times \mathrm{T} 62 \mathrm{~cm}$

Nussholz, massiv, Nadelholz. Eisen, geschwärzt, Messing

86 Bohr, Sakralmöbel (2017), 3 16-320.

87 Vgl. dazu beispielsweise Colombo, L’arte (198I), Abb. I ro, mit Sakristeimöbeln in der Madonna della Steccata, Parma. Das Möbelensemble entstand um i666/70. 


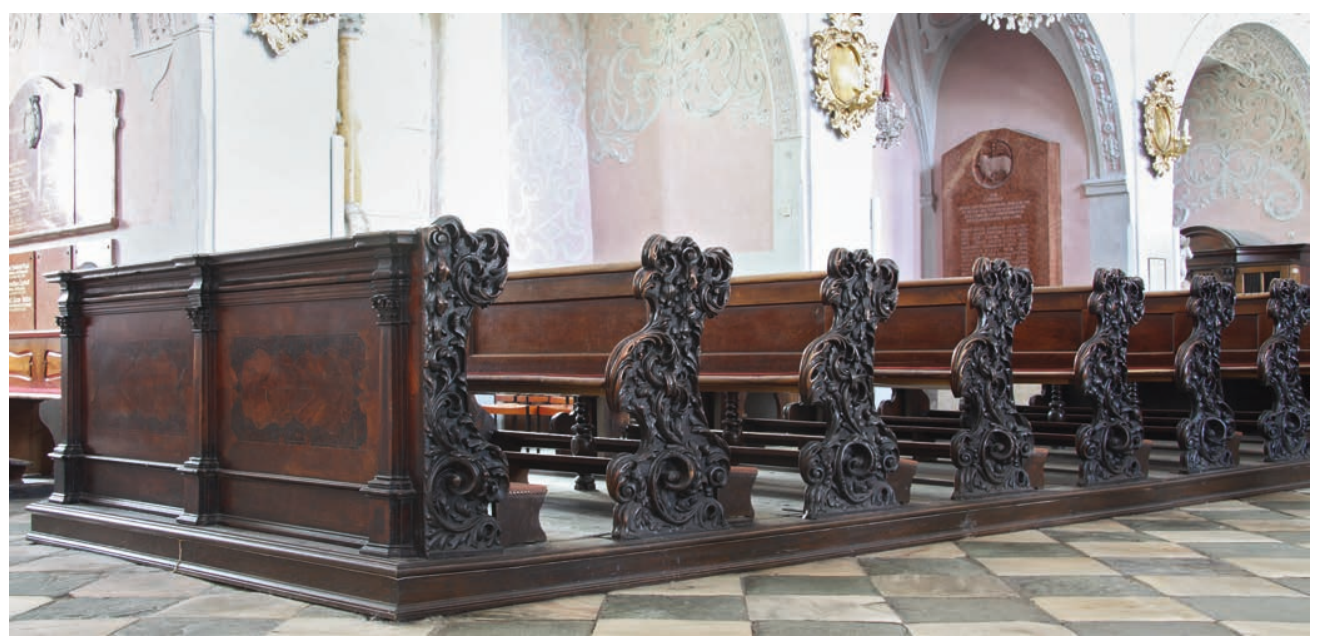

Farbtafel o7 Kirchenbänke. Klagenfurt, um I 7 10/15

Die Kniebänke ähneln hinsichtlich ihrer Form dem italienischen inginocchiatoio, nur der Sockel ist etwas anders gestaltet (Abb. 44). Bildet er bei den italienischen Exemplaren oft ein geschlossenes Teilstück mit aufklappbarer Platte, so erweist er sich hier als offene Substruktion. Ein schräg angeordnetes Brett dient als Kniebank, während in der hinteren Hälfte ein niedriger Kasten aufragt, den eine Tür verschließt. Die Füllungen der Stirnseiten formen ein einfaches, das zentrale Feld der Tür ein verkröpftes Rechteck, Winkelstäbe zieren die Frontstollen. Die Möbel bestechen durch die schlichten Formen und den warmen Braunton des alten Nussholzes, zu dem sich die geschwärzten Eisenbeschläge sehr gut fügen.

\section{Kirchenraum \\ Kirchenbänke}

Klagenfurt, um I7 I $0 /$ I 5

HS I 6,5

$\mathrm{H}$ I05, $5 \mathrm{~cm}(+\mathrm{I} 6,5 \mathrm{~cm}) \times \mathrm{L}_{28} 8 \mathrm{~cm}$

Nussbaum, Nussmaser, Pappelmaser (?), Ahorn, Nadelholz, teilweise dunkelbraun gebeizt

In der Domkirche stehen auf den beiden vorderen Podesten acht, auf den hinteren fünf Sitzreihen (Farbtaf. 07; Abb. 45, 46). ${ }^{88}$ Hinzu kommen die Brüstungen, die man als

88 Kunstdenkmäler Kärntens, Stadt Klagenfurt (I 93 I), 37; Rainer, Dom (1939), I4; ÖKM, Klagenfurt Stadt (1980), 89; Dehio, Kärnten (2001), 352; Allmaier, Dom (20 I ), I 7 . 


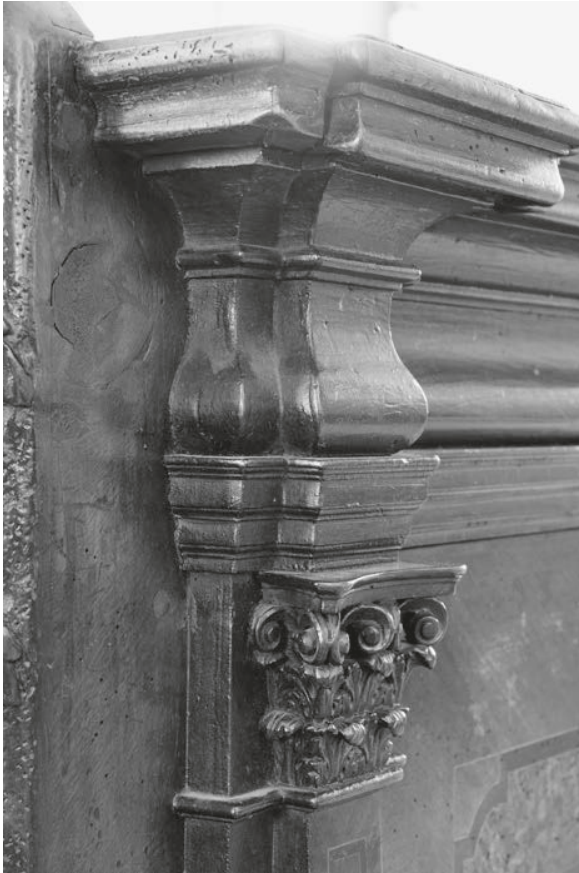

45 um I 7IO/I 5

46 Bankwange. Klagenfurt, um I 7 Io/ I 5

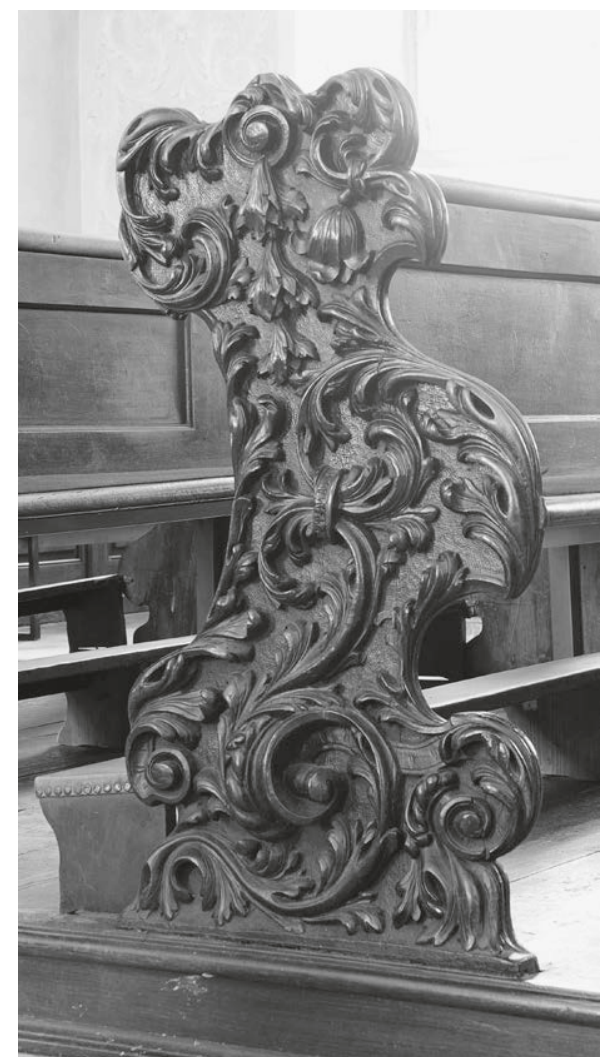

zweischichtige Wände interpretierte. Architekturelemente und Füllungen bilden die vordere Ebene, während die seitlichen Stollen zur hinteren zählen, was sich darin zeigt, dass Profile und Gesimse nicht über die gesamte Brüstungsbreite, sondern nur bis zu den äußeren Pilastern reichen. Ähnliches kann bei keinen anderen österreichischen Kirchenbänken beobachtet werden. In der Sockelzone formen schlichte Querrechtecke die Füllungen, dagegen bestehen die zentralen Felder der Hauptzone aus Nussund Pappelmaserholz (?) mit eingelegten und miteinander verketteten Adern.

Während die Tischler die Brüstungen furnierten, veredelten sie die Wangen mit außergewöhnlich kräftigen Schnitzarbeiten. Die Umrissform der Docken beschreibt einen langgezogenen C-Bogen mit tiefen Einzügen und großen Auswüchsen. Von schweren Akanthusvoluten gehen durch einen Ring gesteckte Blattstauden aus, die sich über die Fläche legen. Vom oberen Ende hängt eine Blütengirlande herab, in Höhe der Kniebank löst sich eine Volute vom Grund und dreht sich nach vorn in den Raum. Das großzügig angelegte und als Hochrelief ausgearbeitete Laubwerk könnte 
auf italienische Vorbilder zurückgehen, doch übernahmen Künstler und Kunsthandwerker auch im überregionalen süddeutschen Kunstraum solche Zierformen. Hinzuweisen wäre etwa auf den aus Süddeutschland stammenden Wiener Hoftischler Johann Indau (I65 I-I690) oder auf Markus (Marco) Nonnenmacher (I653-I720), der in Konstanz geboren wurde und in Prag verstarb. ${ }^{89}$

I93 I berichtet Otto Demus in den Kunstdenkmälern Kärntens von Kirchenbänken aus der "großen Ausstattungsperiode um I 725 «, um die Möbel im nächsten Abschnitt »auf eine frühere Zeit (bald nach I 70o)« zu datieren. Auch Otto Rainer machte I 939 die Leser seines Kunstführers auf die »nach I 700« geschnitzten Betstuhlwangen aufmerksam, während die jüngere Literatur von einer Herstellung der Möbel um I 725 ausgeht. Aus stilistischen Gründen ist das späte Datum jedoch kaum zu halten. Für eine Datierung um oder bald nach der Jahrhundertwende spricht nicht nur die Akanthusschnitzerei, sondern auch die Tatsache, dass die architektonische Instrumentierung der Brustwände die Pilaster noch als der klassischen Architekturlehre entsprechende Stützen und nicht als pilasterartige Bänder, Lisenen oder geschwungene Gebilde zeigt. Meist stellte man das Laiengestühl aus arbeitstechnischen Gründen nicht vor der Vollendung der Stuckarbeiten in der Kirche auf, doch vertritt der Stuck an einem Großteil der Gewölbe eine jüngere Stilstufe, weshalb hier von einer umgekehrten Vorgehensweise auszugehen ist. Weder die Stuckarbeiten noch die Seitenaltäre oder die Kanzel warten mit vergleichbar schwerem Laubwerk auf. Der Datierungsvorschlag Otto Demus' und Otto Rainers wirkt daher überzeugender als die Spätdatierung, modern sind die Laufpodeste und Kniebänke.

Loschental, Filialkirche hl. Josef

Die oberhalb von Loschental auf einer Bergspitze gelegene Kirche wurde nach I 7 i6 erbaut und I 784/85 nach einem Brand restauriert. Das dreijochige Langhaus trägt ein Tonnen-, der einjochige Chor ein Kreuzgratgewölbe. Eine kleine Sakristei lehnt sich im Süden an Chorraum und Langhaus. ${ }^{90}$

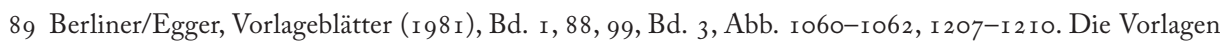
entstanden um r686 und i 7 Io.

90 Zur Architektur und Geschichte des Bauwerks vgl. Dehio, Kärnten (200I), 48 I-482. 


\section{Kirchenbänke}

Loschental oder St. Paul, um I 7 I 5/25

HS $16,5 \mathrm{~cm}$

$\mathrm{H} 98,5 \mathrm{~cm}(+\mathrm{r} 6,5 \mathrm{~cm}) \times \mathrm{L}_{279,5} \mathrm{~cm}$

Nuss, Nussmaser, Pappelmaser (?), Ahorn, Zwetschke, geschwärztes Holz

Den Kirchenbesuchern stehen I6 Bankreihen zur Verfügung (Abb. 47, 48). ${ }^{91}$ Geschweifte Baluster vor den Eckstollen der Möbel flankieren die Brüstungen, an denen breite Rahmen drei nahezu quadratische Füllungen umgeben. An den Stollen fassen geschwärzte Bänder schlichte geometrische Muster ein, während die Tischler für die Marketerien der Füllungen eine etwas kompliziertere Gestaltung wählten. Ein diagonalgestreifter Fries umgibt dort ein Quadrat mit eingelegtem Vierpass. Dunkel lasiertes Nussholz ziert das zentrale Feld, helles Maserholz den rahmenden Grund.

Anders als die mit Furnieren überzogenen Brustwände dekorierte man die Wangen mit Schnitzereien. Schmale Profile säumen den eingetieften Grund, den zu feinen Ranken umgedeutete Akanthusstilisierungen sowie einzelne Blüten und Blätter bedecken. Kleine Voluten und Spangen besitzen knorpelige Enden, wie sie ähnlich bereits im I7. Jahrhundert vorkommen, im frühen I8. Jahrhundert waren sie eigentlich nicht mehr modern. Auffallend sind ferner die zu Spiralen eingerollten und an Farnlaub erinnernden Blatt- und Stielendigungen. Solche Motive finden sich gelegentlich im Formenschatz italienischer Möbel, vermutlich gehen sie ursprünglich auf antike Ornamentmotive zurück. ${ }^{92}$ Die Stirnseiten der Gebetbuchablagen liegen auf den Docken auf, darunter zieht sich ein Bogenfries entlang. Auch dieses Motiv, das namentlich von Möbeln des I6. und I7. Jahrhunderts her bekannt ist, würde man in der Zeit, in der das Gestühl entstand, in dieser Form nicht mehr erwarten. Im Gegensatz zu den geglätteten Profilen und Ranken rauen Punzen den Grund auf und sorgen so für schimmernde Lichteffekte.

Als typisch für die Kunstregion im Süden Österreichs erweisen sich die markanten Eckstollen der Möbel, die vergleichbar etwa auch an Bänken in der Stiftskirche von St. Paul im Lavanttal (Abb. 56, 57) vorkommen. Dass Übereinstimmungen zwischen den Exemplaren in Loschental und jenen in St. Paul bestehen, kann allerdings nicht weiter verwundern, beträgt die Entfernung zwischen den beiden Sakralbauten doch nur wenige Kilometer. Stilistisch stehen die Brüstungen der Bänke in Loschental auf

9I Dehio, ebd., 482.

92 Colombo, L'arte (198I), Abb. I84 und 205 mit venezianischen und toskanischen Truhen aus dem I 5. Jahrhundert. Irmscher, Akanthus (2000), Abb. 7 mit einem Beispiel aus Attika, um 35 o v. Chr. 


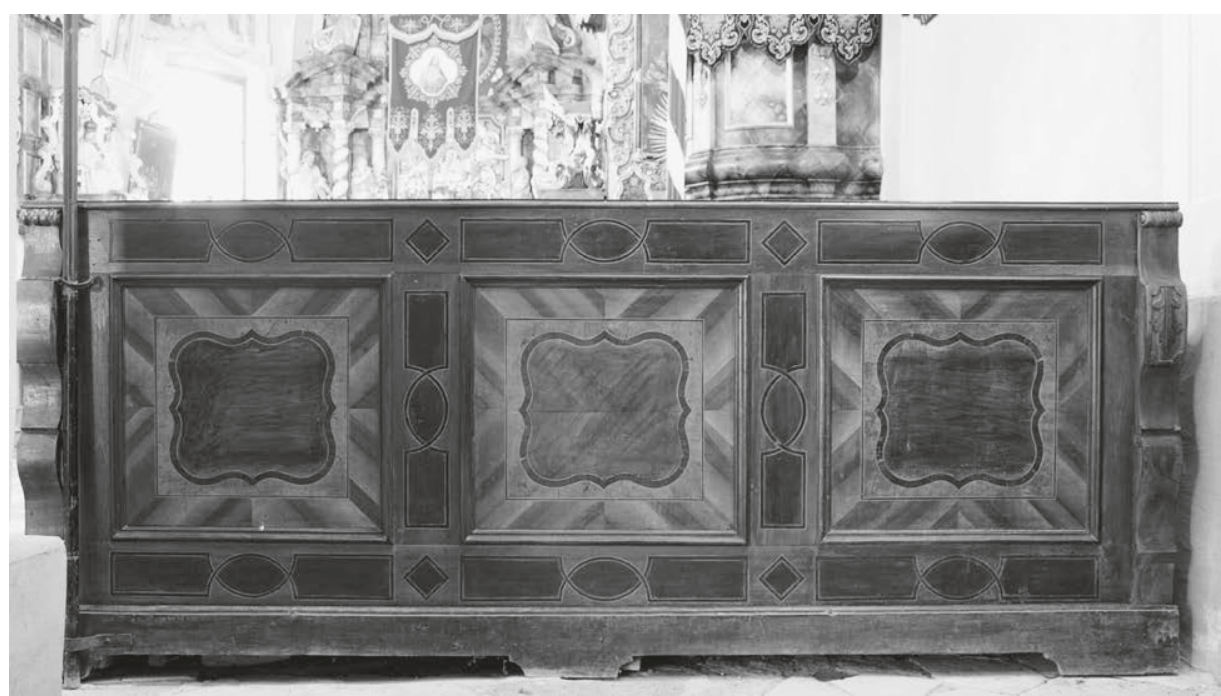

47 Kirchenbänke, Brustwand. Loschental/ St. Paul, um I 7 I 5/25

48 Bankwange. Loschental/St. Paul, um I 7 I $5 / 25$

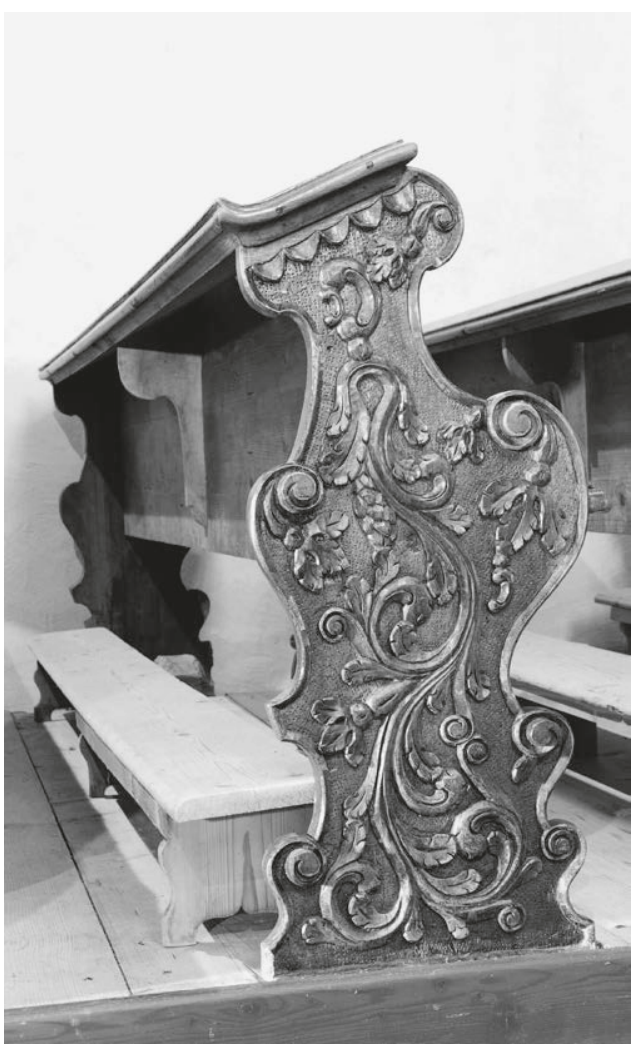


einer Stilstufe mit den auf r 7 I 9/22 datierten Sakristeimöbeln von Georg Schapper in St. Stephan zu Wien. ${ }^{93}$

Die Kniebänke und das Laufpodest sind moderne Ergänzungen. Die Möbel in der Filialkirche dienten einer Möbelgarnitur aus dem frühen 20. Jahrhundert in der Stiftskirche zu St. Paul als Vorlage.

\section{Benediktinerstift St. Paul im Lavanttal}

\section{Stifts- und Pfarrkirche bl. Paul}

Engelbert I. († ro96), Graf von Spanheim und Markgraf von Istrien, gründete die Abtei im Jahr ı09г, Mönche aus dem schwäbischen Hirsau besiedelten sie. ${ }^{94}$ Die benötigten Bauten entstanden in einem Burgareal auf dem heutigen Klosterberg, als Gotteshaus diente zunächst eine Eigenkirche des Grafen. Bereits I 064 hatte Graf Siegfried, Sohn Engelberts, mit der Errichtung einer zweiten Kirche begonnen, die I I 02 fertiggestellt und dem hl. Paulus geweiht wurde. Dieses Gotteshaus gilt als Vorgängerbau der heutigen Stiftskirche, die vermutlich auf die zweite Hälfte des I2. Jahrhunderts und auf das frühe I3. Jahrhundert zurückgeht. I367, nach einer Brandkatastrophe, wurden die zerstörten Holzdecken im Osten des Sakralbaus durch Kreuzrippengewölbe ersetzt, I 468 wölbte der Konvent auch die drei Schiffe ein. Auf eine Epoche des Niedergangs folgte seit dem frühen I7. Jahrhundert eine neue Blüte des Klosters. Abt Hieronymus Marchstaller (reg. I6I6-I638) begann schon bald nach seiner Amtsübernahme mit der Renovierung und Barockisierung von Kirche und Konvent. Das heutige Erscheinungsbild der Abtei lässt sich wesentlich auf Umbaumaßnahmen zurückführen, die Marchstaller in die Wege geleitet hatte. ${ }^{95}$ Im Zuge der josephinischen Reformen hoben kaiserliche Behörden I 782 das Kloster auf, doch zogen knapp drei Jahrzehnte später Mönche aus der Benediktinerabtei St. Blasien im Schwarzwald in die dem Orden rückerstattete Anlage ein.

93 Bohr, Sakralmöbel (2017), 230-232.

94 Zur Geschichte des Klosters s. ÖK-T, Kärnten (I 889), 258-272; Kunstdenkmäler Kärntens, Wolfsberg (1933), 70-80; Ginhart, Stift (1953); Moro, Festgabe (1959); Hootz, Kunstdenkmäler (r965-1968),

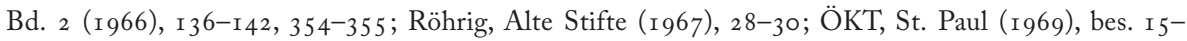
31; Milesi, Manierismus (1973), I5, I6; Stenzel, Stift (1977), I35-139; Schatzhaus Kärntens (199r), Bd. 2, mit etlichen relevanten Beiträgen; Sitar, St. Paul (2000); Dehio, Kärnten (200I), 793-80 I ; Faust, St. Paul (2002), 74-I05; Sitar, St. Paul (2005).

$95 \mathrm{Zu}$ den Baumaßnahmen unter Marchstaller vgl. außerdem Leitner, Bautätigkeit (I99I); Faust, ebd., I I 7 , II 8 . 
Die Stiftskirche dominiert das Zentrum eines nicht geschlossenen rechteckigen Klosterareals. ${ }^{96}$ An der West-, Nord- und Ostseite von Konventgebäuden umgeben, blieb ihre Südflanke ohne Bebauung, die Errichtung des dort geplanten Traktes kam nicht zustande. Es war die Intention Marchstallers, den unregelmäßigen mittelalterlichen Baukomplex zu vereinheitlichen und nach dem Schema des Escorial zu überformen. Der architektonische Bestand der Stiftskirche wurde nur geringfügig modifiziert, weshalb sie sich noch immer als romanische Pfeilerbasilika mit Westtürmen, vorspringendem Querhaus und hochmittelalterlichen Gewölben zu erkennen gibt. Das Mittelschiff ist fünfochig, wobei das letzte Joch die beiden Türme verbindet. Die Westempore wurde 1663 um eine Travée erweitert, sodass sie einen T-förmigen Grundriss erhielt. Im Mittelschiff ist sie seitdem zweijochig, während die seitlichen Achsen wegen der in den Grundriss einschneidenden Türme eine geringere Tiefe aufweisen.

\section{Zu den Tischlerarbeiten in St. Paul}

In der Barockepoche arbeitete der Konvent mit ausgezeichneten Tischlern zusammen, deren Namen leider nicht überliefert sind. ${ }^{97}$ Einige frühneuzeitliche Möbel in St. Paul wurden stark überarbeitet, andere aus verschiedenen Teilen zu einem Pasticcio zusammengesetzt, wiederum andere als barocke Stilmöbel gefertigt. So gehört eine Bank, die momentan vor der Außenmauer im nördlichen Seitenschiff steht, höchstwahrscheinlich nicht dem I 8. Jahrhundert an. Sie scheint relativ neu und nicht nur renoviert zu sein, wie es in der ÖKT heißt. ${ }^{98}$ Vermutlich baute man auch einige Beichtstühle um. Die ÖKT beurteilt sie als »technisch und künstlerisch meisterhafte spätbarocke Werke aus dem zweiten Viertel des I 8. Jhs.", eine Einschätzung, der sich die Verfasser des Dehio anschließen. ${ }^{99}$ Als sicher muss gelten, dass der Doppelbeichtstuhl vor der Nordwand der Kirche nicht in seiner heutigen Form entstand: Die Grundrisse der Möbelhälften sind nicht identisch, die Stellung der Volutenpilaster ist unterschiedlich, die Verkröpfungen des Abschlussgebälks sind nicht korrekt über den Pilastern angeordnet, selbst die Höhe der Sockel, die die Korpuswände der Beichtstühle tragen, weist an den beiden Teilstücken eine Differenz von einigen Zentimetern auf. Ursprünglich handelte es sich offensichtlich um zwei getrennte Möbel. Nicht ganz so gravierende Unstimmigkeiten geben auch einige andere Möbelstücke in St. Paul zu erkennen.

\footnotetext{
96 ÖKT, St. Paul (r 969), bes. 44-99; Dehio, Kärnten (2001), 794-804.

97 ÖKT, ebd., I 5 o.

98 ÖKT, ebd., I 47 .

99 ÖKT, ebd., I48-I 49; Dehio, Kärnten (200I), 799.
} 

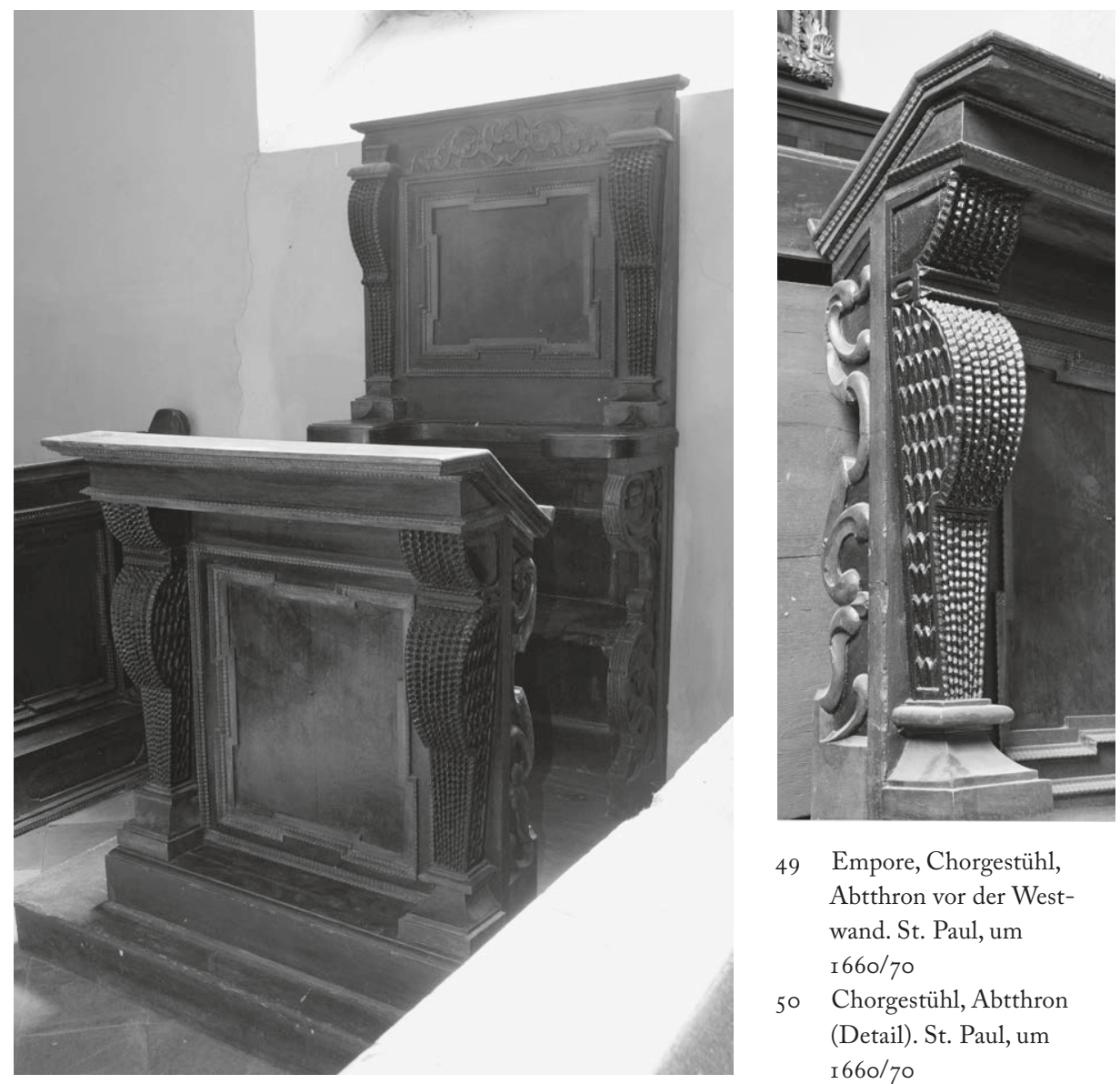

49 Empore, Chorgestühl, Abtthron vor der Westwand. St. Paul, um I $660 / 70$

50 Chorgestühl, Abtthron (Detail). St. Paul, um I $660 / 70$

\section{Westempore}

\section{Chorgestühl}

HS I $6 \mathrm{~cm}$

$\mathrm{H} \mathrm{I} 85 \mathrm{~cm}(+\mathrm{I} 6 \mathrm{~cm}) \times \mathrm{L} 47 \mathrm{I}, 5 \mathrm{~cm} / 438 \mathrm{~cm} / 4 \mathrm{I} 8 \mathrm{~cm}$

\section{Abtstalle}

HS $32 \mathrm{~cm}$

H $196 \mathrm{~cm}(+32 \mathrm{~cm}) \times$ B $105,5 \mathrm{~cm}$

St. Paul, um I660/70

Nussholz, massiv, Nadelholz, gefasst, Holz geschwärzt. Eisen, Leder 


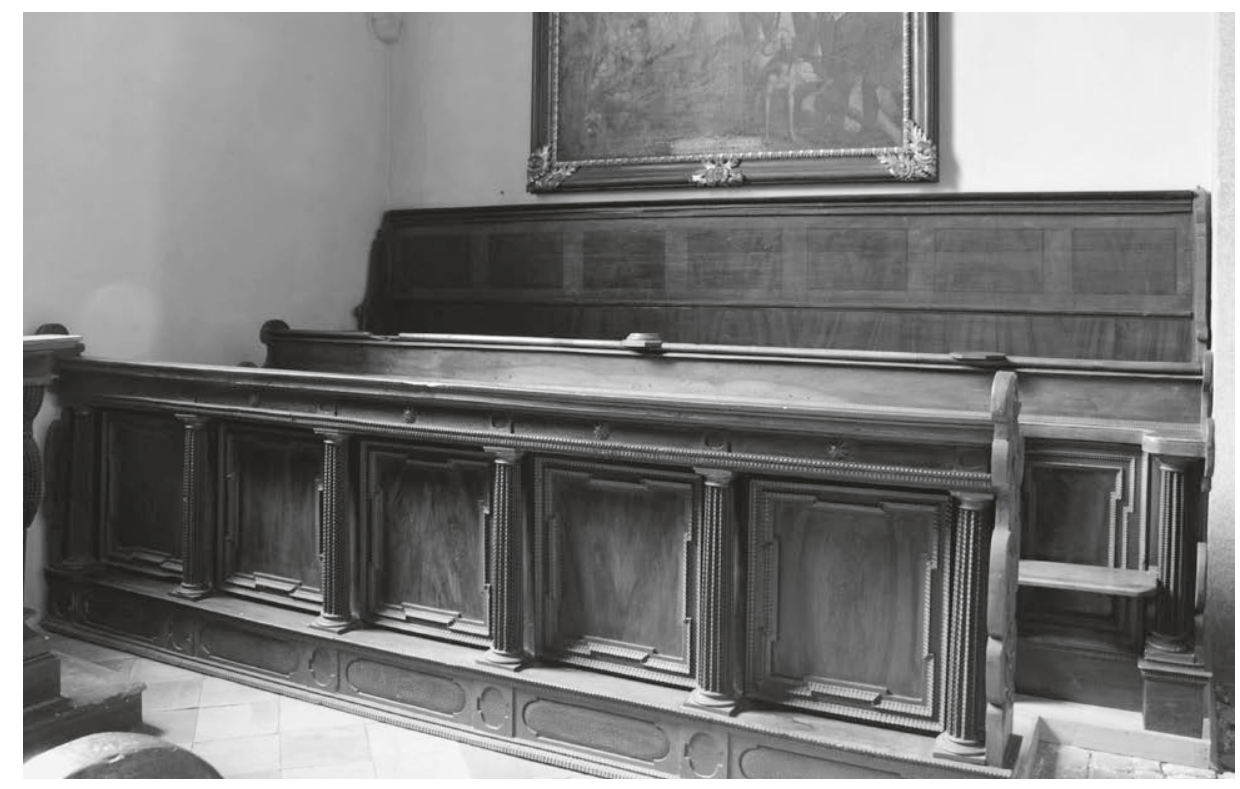

5 I Empore, Chorgestühl, Nordseite. St. Paul, um I66o/70, das Dorsale I 8./r 9. Jh.

Der Konvent ließ die Hauptteile des zweireihigen Gestühls auf der Orgelempore vor den Wänden der beiden Türme parallel zur Kirchenlängsachse positionieren, dagegen befindet sich die Abtstalle vor der Westwand des Sakralbaus (Abb. 49-53). ${ }^{100}$ Der hinteren, mit sieben Plätzen ausgestatteten Sitzreihe steht die vordere mit sechs Plätzen gegenüber. Noch etwas kürzer ist die Brüstung.

Vor der Pultfassade stützen aufgesockelte Säulen ein Gebälk, dessen Gesims die Vorderkante des Lesepultes bezeichnet. In den vertieft liegenden Interkolumnien fassen kantenparallele und verkröpfte Flammleisten die Rechteckfüllungen ein. Die vordere Stallenreihe kommt mit ihrem Aufbau der Brustwand formal recht nahe (Abb. 52 ). Ungewöhnlich ist der Umstand, dass keine Zwischenwangen, sondern Säulen die Plätze voneinander trennen. Die Sitze ruhen deshalb nicht wie sonst auf Halterungen, die man an den Wangen anbrachte, sondern auf L-förmigen Trägern, die an der Stallenrückwand befestigt sind. ${ }^{101}$

ıоo Zum Gestühl ÖKT, ebd., I 47-I48; Milesi, Manierismus (I973), Abb. I I 5 ; Sitar, St. Paul (2000), 88; Dehio, ebd.; Sitar, St. Paul (2005), 26.

го I Das Gestühl im Stift St. Florian weist ähnliche Gestaltungsmerkmale auf. Bohr, Sakralmöbel (20 I 7), $583-587$, Abb. 347,348 . 


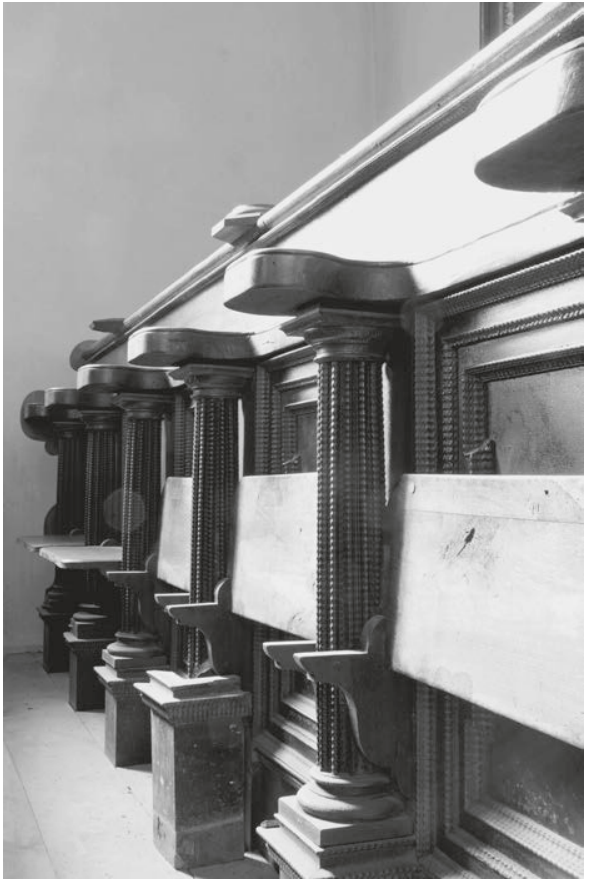

52 Empore, Chorgestühl, Stallenreihe auf der Nordseite. St. Paul, um I660/70

53 Empore, Chorgestühl (Seitenwange). St. Paul, um I660/70

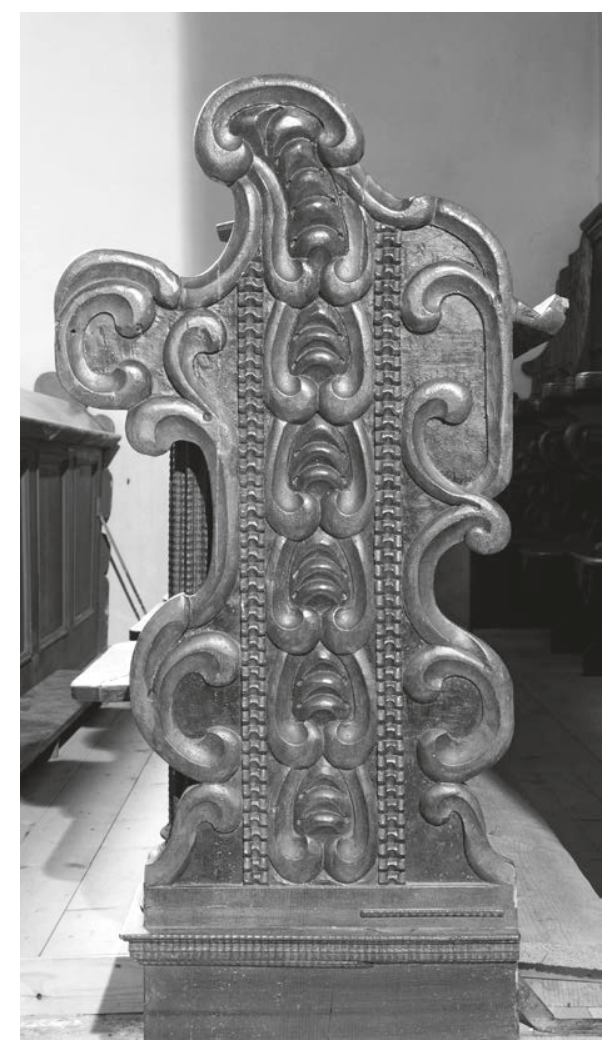

Die Außenkanten der vorderen Bankdocken (Abb. 53) verlaufen in akzentuierten Schwüngen, Profilstäbe flankieren in der Balustermitte ein vertikales Band mit stehenden und liegenden Schnörkeln, die schuppenförmige Strukturen mit knorpeligen Verdickungen bilden. Schnitzarbeiten vervollständigen die Wangen von Brüstung und vorderer Sitzreihe nicht nur auf der Ost-, sondern auch auf der Westseite, ein Indiz dafür, dass die Konventualen die vordere Sitzreihe ursprünglich auch von der Wandseite her betreten konnten.

Eine davon abweichende Art der Gestaltung präsentiert die zwischen einem Pfeiler und der Westwand eingepasste hintere Reihe: Sie ist mit Zwischenwangen versehen, wie wir sie von anderen Gestühlen her kennen. Die Außendocken sind bis zur Höhe der Schulterringe als massive Baluster nach oben geführt, darüber schwingen sie zum Dorsale zurück. In Sitzhöhe zieren kräftige Schnitzarbeiten die Dockeninnenseiten, über den Accoudoirs setzte man den Dekor fort, jedoch ohne die Arbeit zu beenden. Die Ornamentmotive sind hier lediglich angedeutet. Im Gegensatz zu den Docken 
von Vorderreihe und Brüstung wurden die Außenseiten der hinteren Stallen nur grob mit dem Schrupphobel bearbeitet. Sie müssen demzufolge schon immer vor den Blicken der Mönche verborgen gewesen sein. Ein hohes, durch ein Gesims unterteiltes Querbrett dient als Rückenlehne, die in dieser Form vermutlich nicht im I 7. Jahrhundert entstand. Es handelt sich bei ihr wohl um eine jüngere Zutat.

Die Abtstalle unterscheidet sich vom Aussehen der Sitzreihen (Abb. 49, 50). Die Massengliederung von Brüstung und Rückwand beruht nicht auf Säulen, sondern auf Volutenpilastern oder Balustern, die an der Rückwand auf manieristisch »geteilten Füßen« stehen. Über der Dorsalefüllung brachten die Tischler feine Schnitzornamente an. An Nagelköpfe oder Schmucksteine erinnernde Gebilde zieren die Vorderseiten der Stützen, Schuppenmuster schmücken deren Seiten, knorpelige Schwünge die Wangen.

Armlehnen und Sitze der Möbel bestehen aus Nuss-, die anderen Möbelteile aus dunkelbraun, teilweise fast schwarz gebeiztem Nadelholz. Fassungen imitieren "gewöhnliches« Nussholz sowie Nussmaserholz.

Wie oben berichtet, ließ der Konvent 1663 die Empore um ein Joch vergrößern. ${ }^{102}$ Außerdem baute man einer Schriftquelle zufolge um I670 auf der Empore ein Gestühl auf, das sich zuvor im Chorraum der Kirche befunden haben soll. ${ }^{103}$ Die Fachliteratur vermutet einen direkten Zusammenhang zwischen dieser Mitteilung und dem heutigen Gestühl. Darüber hinaus berichtet eine Schriftquelle, der Konvent habe I6 I7 den Tischlermeister Konrad Scherer aus Velden für die Anfertigung eines Prälatenstuhles entlohnt. ${ }^{104}$ Man bezog diese Notiz auf den Abtstuhl und folgerte, dass Scherer das gesamte Gestühl gebaut hätte. ${ }^{105}$ Aber vermögen Zuschreibung und Datierung wirklich zu überzeugen?

Die Wangen mit den massiven knorpeligen Ornamentmotiven werden kaum vor I630 oder 1640 entstanden sein, außerdem deuten das Schuppenmuster an den Balustern der Abtstalle und die reichhaltige Verwendung der Flammleisten auf eine Herstellung des Gestühls im fortgeschrittenen I7. Jahrhundert. Die in der Fachliteratur vorgeschlagene Datierung um i6 7 muss deshalb korrigiert werden. Zudem wirft die Zuschreibung des Gestühls an Konrad Scherer Fragen auf, denn bei einem Vergleich der künstlerischen und handwerklichen Qualität des von Scherer gebauten Taufbeckens (Farbtaf. 08; Abb. 54, 55) mit der des Gestühls offenbart sich der ländlich-schlichte Charakter der Chorstallen. Eine Herstellung der Möbel in ein und

\footnotetext{
I 2 ÖKT, St. Paul ( I 969), 98.

Iо3 ÖKT, ebd., I 47-I 48 .

ro4 Schroll, Marchstaller (г 89I), I 38 ; ÖKT, ebd.; Leitner, Bautätigkeit (r 991), 554; Dehio, Kärnten (200I), 799 .

I05 Nicht so die Autoren des Dehio, die zwar die Abtstalle, nicht aber das Chorgestühl erwähnen.
} 


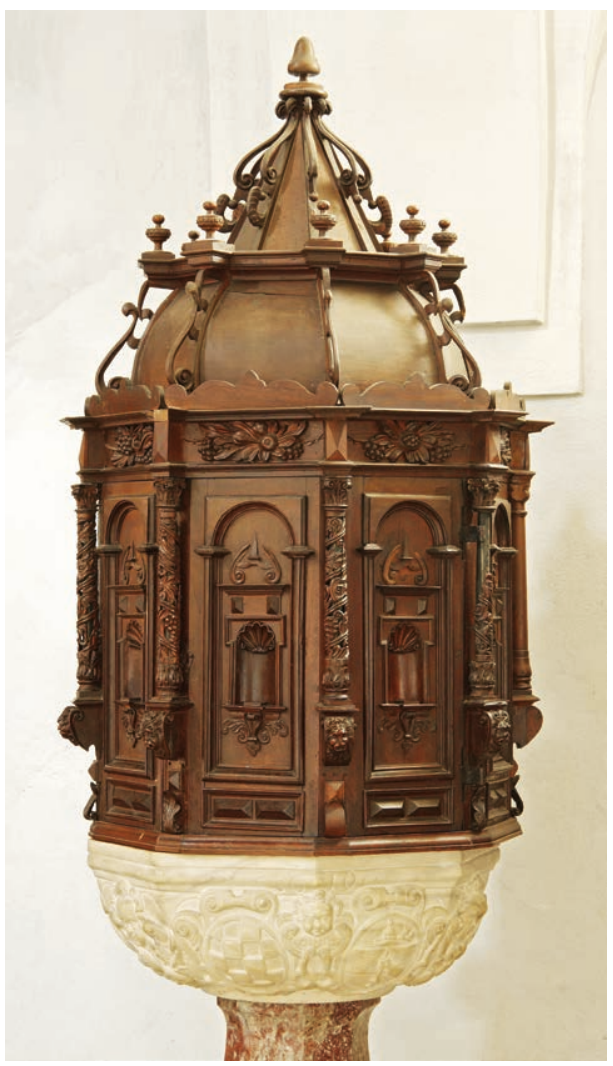

Farbtafel o8 Taufbecken. Steinmetz Martin Pacobello, der Aufsatz verm. von Konrad Scherer aus Velden, um I620

derselben Werkstatt ist nur schwer vorstellbar. Vielmehr dürfte die Sessio des Abtes aus dem frühen 17 . Jahrhundert verloren sein, während das erhaltene Gestühl einschließlich des Abtthrons um I 660 oder 1670 von einem weniger versierten Handwerker gefertigt worden sein wird.

\section{Kirchenraum \\ Taufbecken}

Steinmetz Martin Pacobello, der Aufsatz verm. von Konrad Scherer aus Velden, um I620 $\mathrm{H}$ des Taufbeckens I $20 \mathrm{~cm}, \mathrm{H}$ des Aufsatzes ca. I $56 \mathrm{~cm}$

Durchmesser des Aufsatzes ca. 83,5 cm Nussbaum, Nadelholz, dunkelbraun lasiert, teilweise gefasst

Der Taufstein wird heute im südlichen Seitenschiff aufbewahrt, ursprünglich befand er sich in einer Nische vor dem Nordturm (Farbtaf. 08; Abb. 54, 55). ${ }^{106}$ Martin Pacobello († I630) schuf das achteckige Becken aus weißem, den balusterartigen Fuß aus rötlichem bis grauviolettem Marmor. Reliefs zieren die Seitenwände: Engelsköpfe und Früchtegirlanden sind zu erkennen, weiter die Monogramme Christi und Mariens, außerdem das Stiftswappen mit dem Schachbrettmuster und das Wappen des Abtes Hieronymus Marchstaller mit dem Degen, auf dessen Spitze ein Hut steckt. Der Beckenrand trägt die Jahreszahl I6 $9 .{ }^{107}$

Über oktogonalem Grundriss erhebt sich auch das Aufsatzgehäuse. Vor den horizontalen Kanten tragen mit Diamantquadern, Blattwerk und Löwenköpfen besetzte Konsolen korinthische Säulen, um deren Schäfte sich freiplastisch ausgearbeitetes

Io6 Kunstdenkmäler Kärntens, Wolfsberg (1933), 77; Ginhart/Münzer, Stift St. Paul (1983), 23; ÖKT, St. Paul (I 969), I 46-I 47; Leitner, Bautätigkeit (I 99 I), 55 8; Schatzhaus Kärntens (I 99 I), Bd. I, 5 I 2 ; Sitar, St. Paul (2000), 88; Dehio, Kärnten (200I), 799.

I07 Zum Stiftswappen Faust, St. Paul (2002), I 4I. 

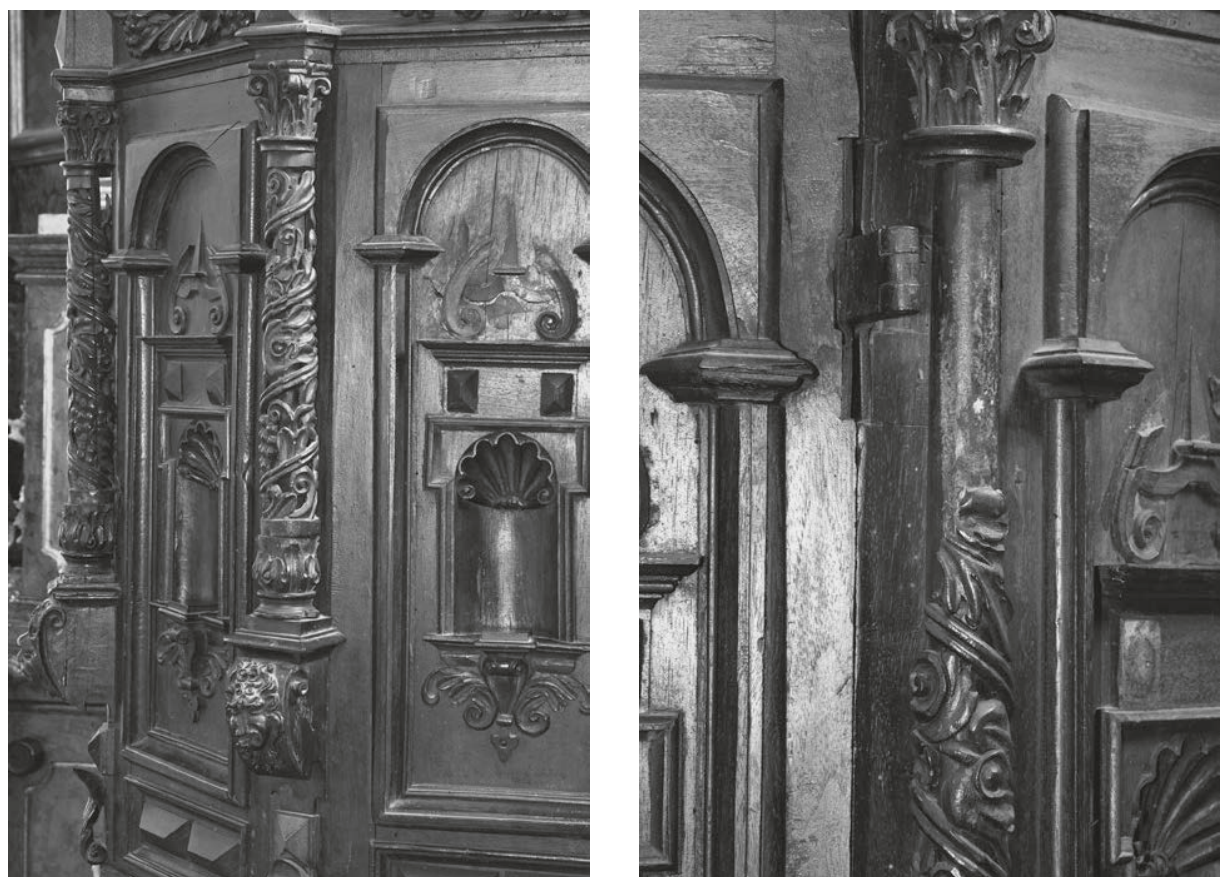

54, 55 Taufbecken (Detail). Verm. Konrad Scherer, um I620

Weinlaub windet. Die Wände präsentieren sich als schlanke Arkaden, die je eine Ädikula mit eingestellter Muschelnische rahmen, darüber fußt ein Sprenggiebel mit Obelisk. Die Architektur kulminiert über einem verkröpften und mit großen Blüten besetzten Gebälk in einer mehrzonigen Kuppel, deren aufstrebende Tendenz ein weit nach außen reichendes Gesims in mittlerer Höhe unterbricht. Die Kuppel läuft in einer hohen kegelförmigen Spitze und einem eichelförmigen Aufsatz aus. Grazile Schweifwerkornamente, Vasen und sich einrollende Spangen zieren das Gehäusedach. Das Inventarstück kann mit zwei Türen geöffnet werden. Es besteht aus dunkellasiertem Nussbaum, während man die Säulenschäfte unter der à jour ausgeführten Schnitzarbeit grünlichschwarz fasste. Ein blaugrau getöntes Weiß überzieht die Innenseiten des Möbels.

Vermutlich war die Werkstatt Konrad Scherers für den Bau des Aufsatzes zuständig, im frühen I 7. Jahrhundert arbeitete er immer wieder für die Abtei. ${ }^{108}$ Schriftquellen nennen ihn I6I7 und r629 namentlich, ansonsten sprechen sie vom Meister aus Vel-

Io8 Schroll, Marchstaller (I89I), I38-I 4 I, I 46, I 56, I 58-I6o; Leitner, Bautätigkeit (I 99 I), 555, 559 , 564. 
den. Ist die Form des achteckigen steinernen Taufbeckens nicht ungewöhnlich, so ist der tempiettoförmige Aufsatz umso bemerkenswerter. Grundsätzlich entspricht sein Erscheinungsbild der Gestalt vieler antiker und mittelalterlicher Grabbauten, Tempel und Baptisterien. ${ }^{109}$ Analoge Taufbeckenaufsätze aus der Mitte des I7. Jahrhunderts haben sich in der Pfarrkirche zu Pürgg (Farbtaf. 26; Abb. 233) und in Sant'Agata in der Gemeinde Commezzadura im Trentino erhalten. ${ }^{110}$ Der Taufbeckendeckel in St. Paul muss im Zusammenhang mit solchen Ausstattungsstücken gesehen werden, anders ist seine Gestalt nicht zu erklären. Er belegt den hohen Anspruch, den Abt Marchstaller an die Ausstattung seiner Stiftskirche stellte. Dem Urteil von Richard Milesi, der das Taufbecken als zweitrangig klassifizierte, kann keinesfalls beigepflichtet werden, und zwar weder im Hinblick auf die handwerkliche Verarbeitung und künstlerische Qualität noch hinsichtlich der programmatischen Aussagekraft des Inventarstücks. ${ }^{111}$

\section{Bänke}

St. Paul, um I7 IO/I 5

HS $44 \mathrm{~cm}$

$\mathrm{H}$ I $98 \mathrm{~cm}(+\mathrm{I} 4 \mathrm{~cm}) \times \mathrm{L} 320 \mathrm{~cm}$

Nussbaum, massiv und furniert, Pappelmaser, Zwetschke, Nadelholz

Vor der Außenwand des südlichen Seitenschiffs befindet sich eine Bank, die früher geistlichen oder weltlichen Würdenträgern vorbehalten gewesen sein mag (Abb. 56). ${ }^{112}$ Ähnliche Möbel stehen im nördlichen Seitenschiff, weitere in der Auferstehungskapelle; sie bildeten einst die Hälften einer langen Bank. ${ }^{113}$ Bis vor wenigen Jahrzehnten waren zwei dieser Möbel parallel zum Laiengestühl vor den Vierungspfeilern platziert. ${ }^{114}$ Die Kunsttopographie datiert die Inventarstücke ins I 8. Jahrhundert, eine Datierung, die für eine Bank nicht zutrifft; sie ist jünger. Bei den anderen Exemplaren erneuerte man Kniebänke und Laufböden, teilweise auch die hinteren Wangen.

Die Brüstung des Möbels im südlichen Seitenschiff, auf das sich die Maßangaben beziehen, besteht aus breiten Rahmen und großen Füllungen, massive Baluster mit

ro9 Vgl. hierzu Teil 2, Kap- VI der Arbeit.

I I o Dal Prà, Madruzzo (I 993), 583.

I I I Milesi, Manierismus (1973), 73. Vgl. zum Inventarstück außerdem den entsprechenden Abschnitt im VI. Kapitel der vorliegenden Arbeit.

I I 2 ÖKT, St. Paul (1 969), I 47.

I 3 Die beiden Hälften waren einst miteinander verschraubt oder verkeilt. Die Vorbohrungen für entsprechende Halterungen sind gut zu erkennen.

I 44 Ginhart, Stift (1953), I I ; Stenzel, Stift (r 977), I 37. 
56 Südliches Seitenschiff, Betbank. St. Paul, um I 7 Io/I 5

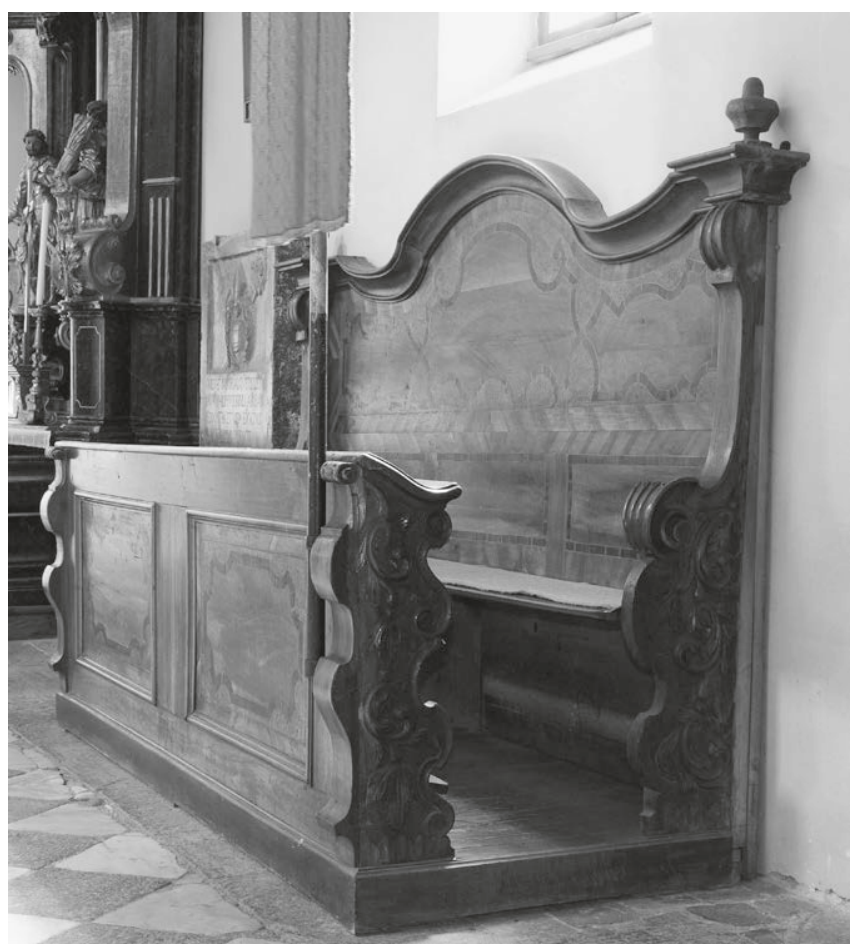

Volutenkapitellen nehmen die Binnenfelder in ihre Mitte. Vegetabil verzierte Bögen überziehen das mit einem breiten Steg gesäumte Zentrum der geschweiften Wangen, am Fuß kommt der Blattfries vor, der ähnlich auch die Bänke in Loschental (Abb. 48) bereichert. Der Fond ist aufgeraut, das Lesepult auf den Docken befestigt. Die Bankwangen enden mit einem Handknauf, der sich zu einer schweren Volute einrollt. Zwar unterbrechen keine Zwischenwangen Sitzbank und Rückwand, doch unterteilt das Furnierbild die Lehne in horizontale Streifen mit mehreren Kompartimenten. Nussbaummaser bedeckt die Binnenfelder, Pappelmaser die Zwickel. Ein konvex-konkavkonvex geschwungenes Gesims mit seitlichen Vasen bekrönt das Möbel.

Für die Datierung der Möbel ist entscheidend, dass sich die gewählten Schnitzmotive auf vegetabile Ornamente beschränken, von denen einige sogar noch frühbarocke Formen wiedergeben. Die Bank vertritt eine frühere Stilstufe als das Laiengestühl im Mittelschiff der Stiftskirche, was eine Fertigung des Möbels in den Jahren um I 7 Io/ 5 wahrscheinlich werden lässt. 


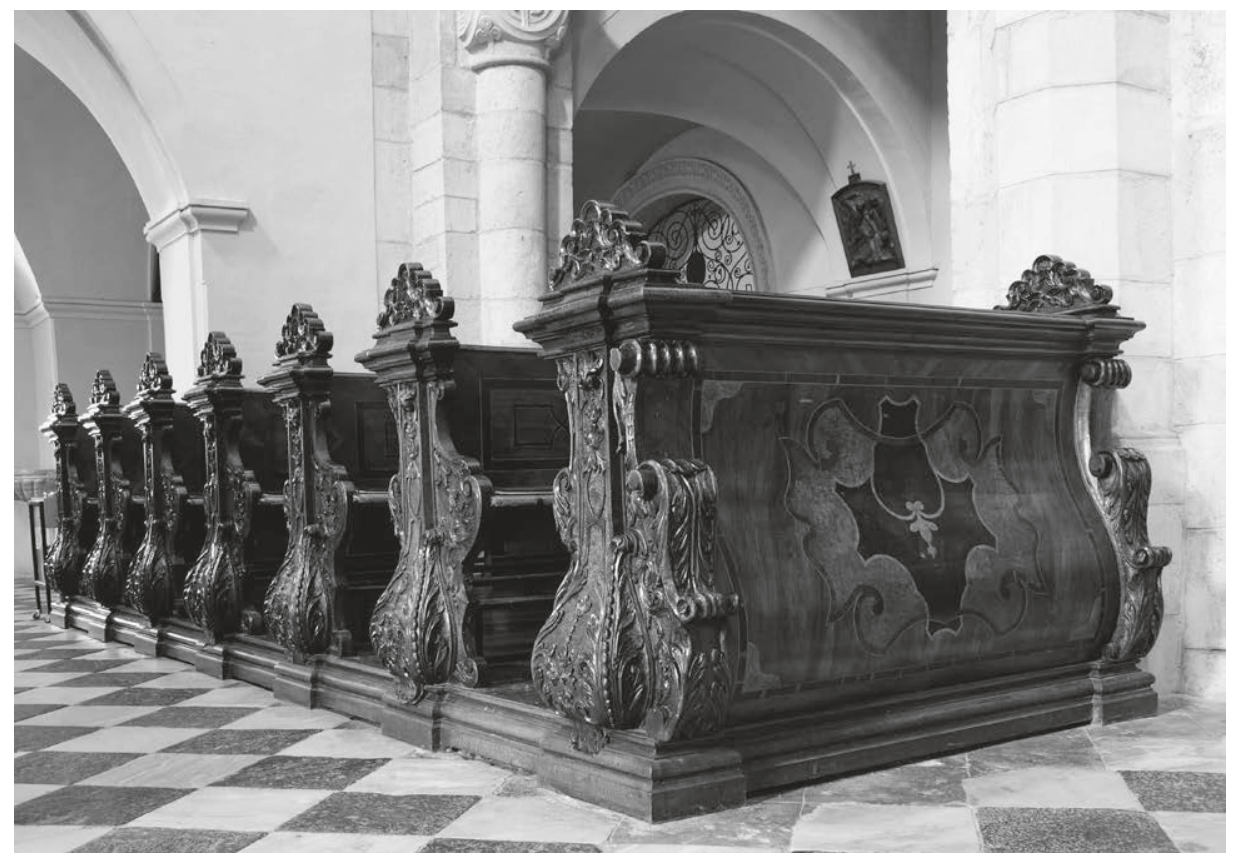

57 Laiengestühl. St. Paul, um I 725/35

\section{Laiengestühl}

St. Paul, um I $725 / 35$

HS $16,5 \mathrm{~cm}$

H I 2 I, $5 \mathrm{~cm}(+\mathrm{I} 6,5 \mathrm{~cm}) \times \mathrm{L}_{3} 62 \mathrm{~cm}$

Nuss, Nussmaser, Pappelmaser, zum Teil dunkelbraun gebeizt, Buche (?), graviert und geschwärzt, Zwetschke, Esche, furniert auf Nadelholz, dunkelbraune Lasur

Das Laiengestühl besteht im Mittelschiff der Kirche aus vier Einheiten. ${ }^{115}$ Die sich auf den beiden Podesten im Westen befindenden Möbel stammen aus der Barockzeit, während die anderen um 1935/36 im neobarocken Stil gefertigt wurden. ${ }^{116}$ Uns interessieren folglich die beiden westlichen Blöcke; sie umfassen zwölf Bankreihen, hinzu kommen die jeweiligen Vorderbrüstungen (Abb. 57-59).

I 5 Kunstdenkmäler Kärntens, Wolfsberg (1933), 77; ÖKT, St. Paul (I969), I47; Schatzhaus Kärntens (I 991), Bd. I, 5 I 5 ; Sitar, St. Paul (2000), 93; Dehio, Kärnten (2001), 799.

I 6 ÖKT, ebd.; Schatzhaus Kärntens, ebd.; Dehio, ebd. Die modernen Bänke wurden dem Gestühl in St. Josef im Loschental (Abb. 47, 48) nachempfunden. 


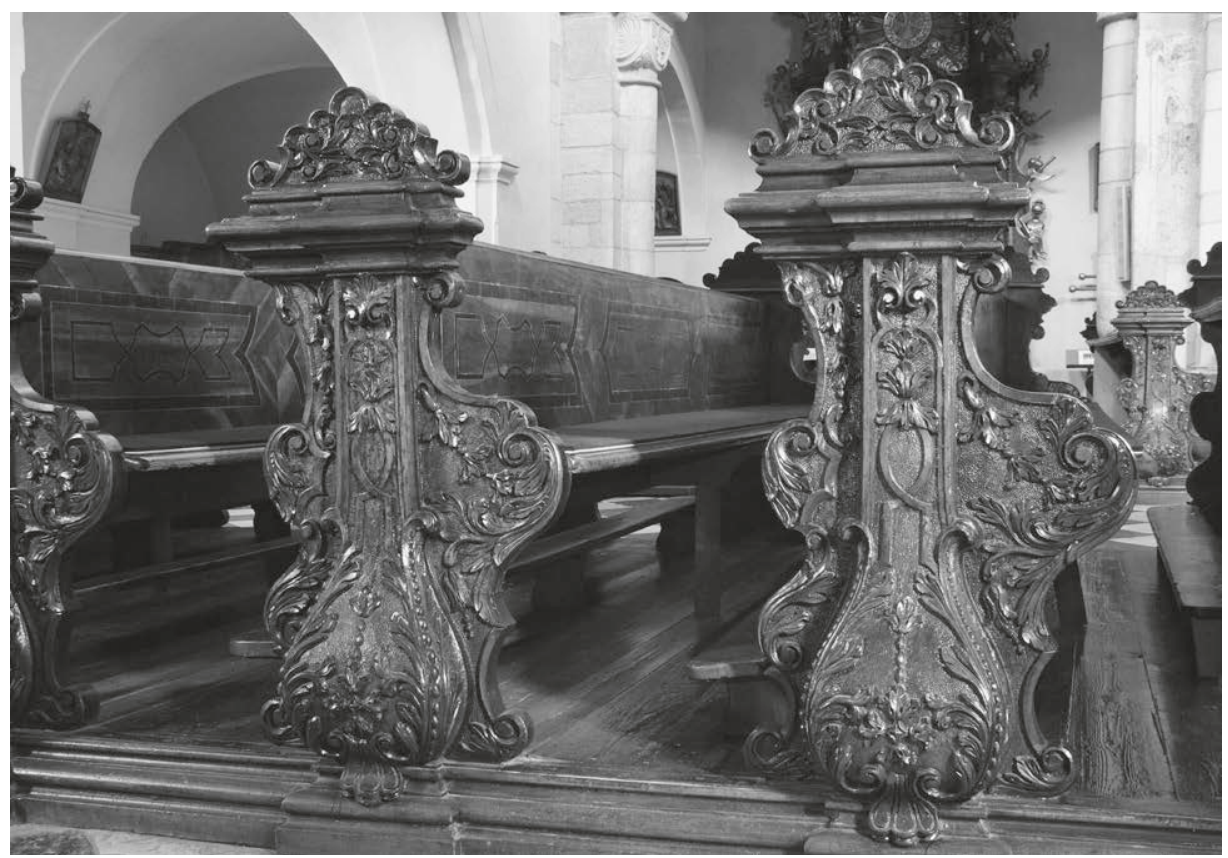

58 Bankwangen. St. Paul, um I 725/35

Akzentuierte Baluster flankieren die plastisch anschwellende Vorderbrüstung. Während schwere Voluten und kraftvolle Schnitzarbeiten die seitlichen Stützen zieren, überziehen Marketerien die Pultfläche. Ein querfurnierter schmaler Rahmen umgibt dort ein großes Rechteck, in dessen Zentrum Adern Binnenfelder säumen. Das äußere Feld ist mit Nussbaum furniert, die innen liegenden Kompartimente mit Pappelmaser und dunkelbraun, fast schwarz gebeiztem Holz. Eine an einem Band hängende lilienartige Blüte reicht in das Zentrum hinab. Die Ecken des äußeren Feldes sind mit hellem Buchenholz (?) abgesetzt, das eingravierte und geschwärzte Muschelornamente beleben. Marketerien überziehen überdies die Rückenlehnen der Bänke und die Buchablagen, was die hohe Qualität der Möbel unterstreicht.

Die Stützen, die von vorn als autonome Volutenpilaster erscheinen, bilden von der Seite betrachtet Teile der Brüstungswangen. Baluster mit verdicktem Anlauf bezeichnen die Mittelachse der asymmetrischen Docken, der Schaft ist jeweils über dem Anlauf bis unter das verkröpfte Gesims gerade nach oben geführt. Die Wangenvorderkanten sind stark gebaucht, die Hinterkanten deutlich weniger bewegt. Den oberen Abschluss bildet über einem reichprofilierten Gesims ein dreieckiger Schild mit geschnitzten Ornamenten und Blattwerk. Vegetabile Motive bereichern überdies die 


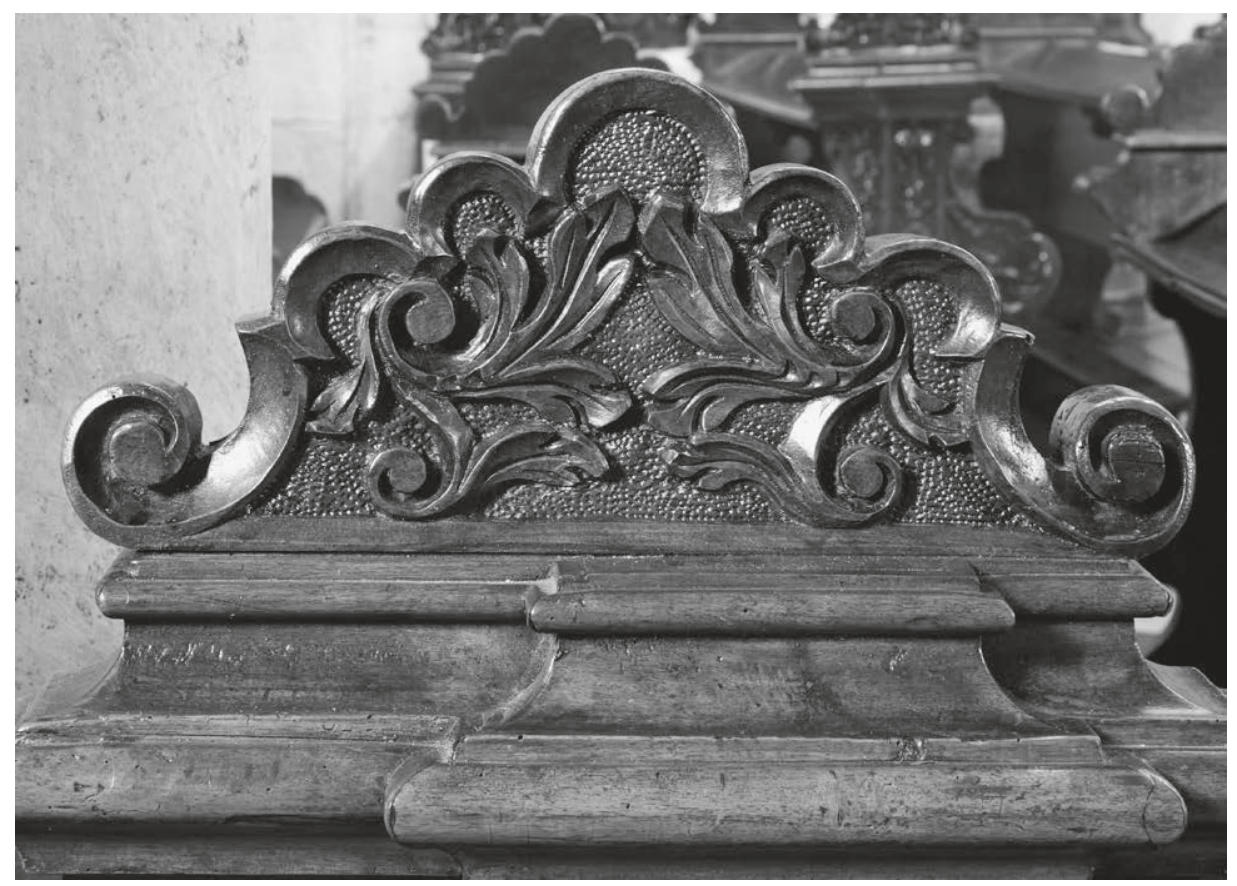

59 Laiengestühl (Detail). St. Paul, um I 725/35

Binnenflächen der Baluster, doch treten hier markante Bandlwerkmotive, Blütengehänge und erbsenartige Verdickungen hinzu. Vom ausgehobenen Grund, dem dichtgesetzte Punzen eine schaumartige Struktur verleihen, hebt sich der Dekor mit seinen glatten und glänzenden Flächen wirkungsvoll ab.

Mit der weitgehenden Verdrängung des italienischen Akanthus durch das französische Bandlwerk befinden sich die Bänke auf einer Stilstufe etwa mit dem Chorgestühl in der Stiftskirche zu Stams aus den I 73oer-Jahren (Farbtaf. 3 I ; Abb. 35 I-358). Nicht bekannt ist der Name des Tischlers, der die Bänke in St. Paul fertigte. Möglicherweise besaß die Abtei eine eigene Tischlerei, die in der Lage war, solche Arbeiten herzustellen, andernfalls muss von einer Werkstatt in der Nähe des Stiftes ausgegangen werden. Die Kniebänke sind Neuanfertigungen, den Bankrückseiten wurden moderne Eichenholzplatten aufgedoppelt. 


\section{Portale}

St. Paul, um I 740

Lichte Maße H $338 \mathrm{~cm} \times$ B I $77 \mathrm{~cm}$

Eiche, Nussbaum, Nussmaser, geschwärztes

Nussholz, Buche, graviert, geschwärzt, Zwetschke, furniert. Eisen, verzinkt

Die kassettierten Außenseiten der aus massivem Eichenholz gefertigten Eingangsportale im Westen und Süden der Stiftskirche kontrastieren mit den Innenseiten, die mit Furnierbildern geschmückt sind (Abb. 6o). ${ }^{117} \mathrm{Die}$ Marketerien der zweiflügeligen Türen zeigen Rahmen und Füllungen, wobei jeweils ein hochrechteckiges, mit einem Segmentbogen endendes Kompartiment zwischen zwei querrechteckigen $\mathrm{zu}$ liegen kommt. Wie wir an verschiedenen Beispielen gesehen haben, war die Aufteilung im frühen I 8. Jahrhundert eine andere: Damals besaßen die Felder die gleiche Größe oder es lag ein niedriges querrechteckiges Feld zwischen zwei hochrechteckigen. ${ }^{118}$ Die Rahmen sind mit gestreiftem Nussbaumholz diagonal furniert, die mit Adern und Friesen eingefassten Binnenfelder mit Nussbaummaser. Die Adern verlaufen teils

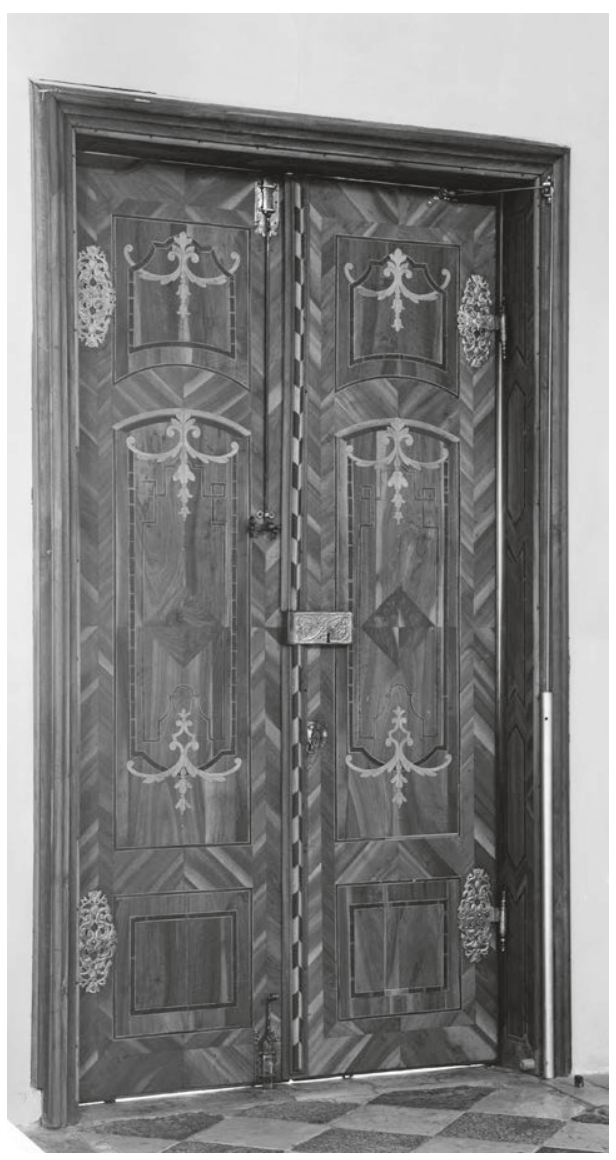

6o Stiftskirche, Portal. St. Paul, um I 740 kantenparallel, teils sind sie geschwungen und gebrochen, mit Blattwerk verzierte Bögen und Blütengehänge zieren die Felder. Ein außergewöhnliches Aussehen wurde überdies der Schlagleiste zuteil, denn sie besteht aus einem abgerundeten Profil, das sich aus dunklen und hellen Parallelogrammen zusammensetzt.

I 7 ÖKT, ebd., I 49-150.

I I 8 Bohr, Sakralmöbel (2017), beispielsweise die Abb. I 46, I 55, I 56, 2 I 8. 


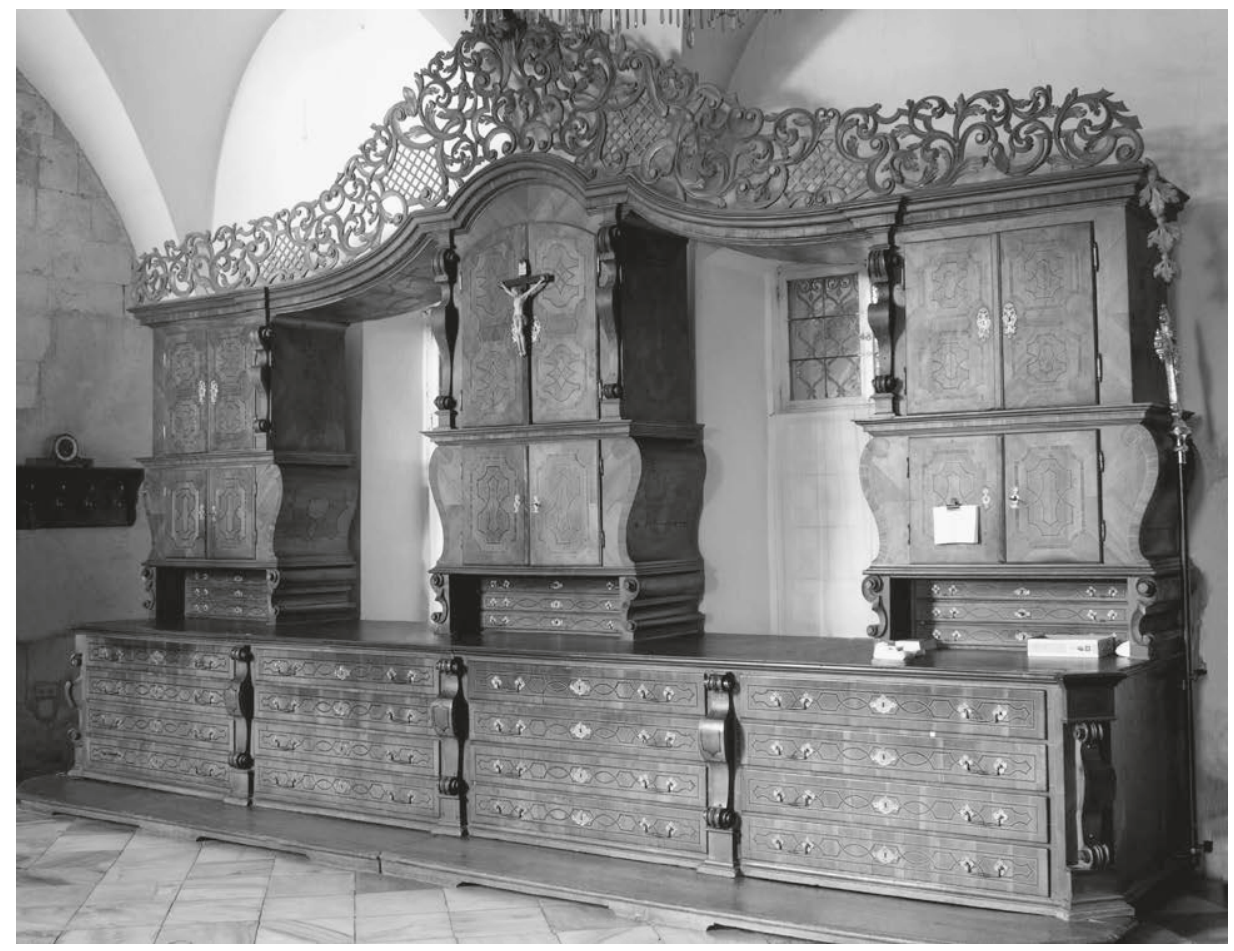

6I Sakristei, Ankleidekredenz. St. Paul, um I730/40

\section{Sakristei}

I6 I9 ließ der Konvent anstelle zweier älterer Sakristeien eine neue Sakristei errichten. ${ }^{119}$ Der längsrechteckige dreijochige Raum befindet sich nördlich des Querschiffs der Kirche zwischen der westlich liegenden Kapelle der Schmerzhaften Muttergottes und der Rabensteinerkapelle im Osten. Erhalten sind in der Sakristei mehrere kleine Schränke, die hinsichtlich ihrer künstlerischen und handwerklichen Qualität über das gewöhnliche Maß nicht hinausreichen, sowie zwei prachtvolle Sakristeikredenzen. Sie sollen genauer beschrieben werden. ${ }^{120}$

I 9 ÖKT, St. Paul ( 1969), 97; Sitar, St. Paul (2000), 84-86; Dehio, Kärnten (2001), 797.

I 20 Kunstdenkmäler Kärntens, Wolfsberg (I 933), 77; ÖKT, ebd., I50; Sitar, ebd., 85-86; ders., St. Paul (2005), 23. 


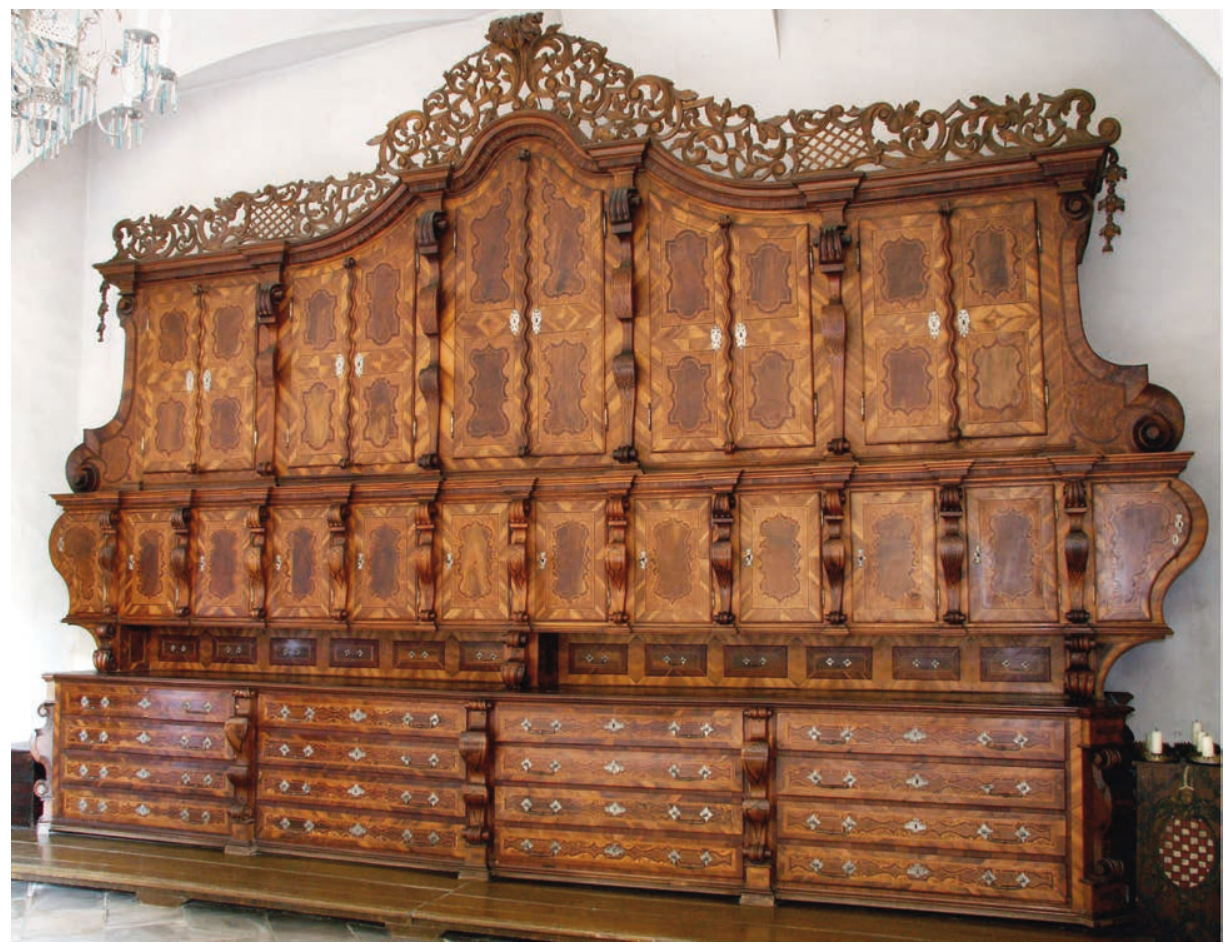

Farbtafel o9 Sakristei, Ankleidekredenz. St. Paul, um I 730/40

\section{Sakristeischränke}

St. Paul, um $1730 / 40$

HS I $2 \mathrm{~cm}$

Gesimshöhe ca. $365 \mathrm{~cm}(+\mathrm{I} 2 \mathrm{~cm}) \times \mathrm{L} 675 \mathrm{~cm} \times \mathrm{T} \mathrm{I} 44 \mathrm{~cm}$

Gesimshöhe ca. $440 \mathrm{~cm}(+\mathrm{I} 2 \mathrm{~cm}) \times \mathrm{L} 672 \mathrm{~cm} / 750 \mathrm{~cm} \times \mathrm{T} \mathrm{I} 25 \mathrm{~cm}$

Nussholz, teilweise geschwärzt, Nussmaser, Zwetschke, Ahorn, Pappelmaser, Nadelholz, Linde (?), massiv. Eisen, gegossen und verzinnt, Zinnblech, getrieben und ziseliert

Die Ankleidekredenz vor der Westwand rahmt kleine Fenster, die zur Muttergotteskapelle weisen (Abb. 6r). Das Möbel besteht aus einem Unterbau, den vor der Front drei Stützen mit bauchartig verdickten Schäften strukturieren. Die Tischler ordneten zwei weitere Stützen diagonal vor den äußeren Senkrechten an, nur sie tragen ein Gebälkstück. Der Korpus des Unterschranks enthält mehrere Reihen großer Schubladen.

Über der Substruktion erheben sich in der Tiefenausdehnung stark reduzierte Aufbauten, deren mittlerer die beiden seitlichen in der Höhe überragt. Die Ober- 


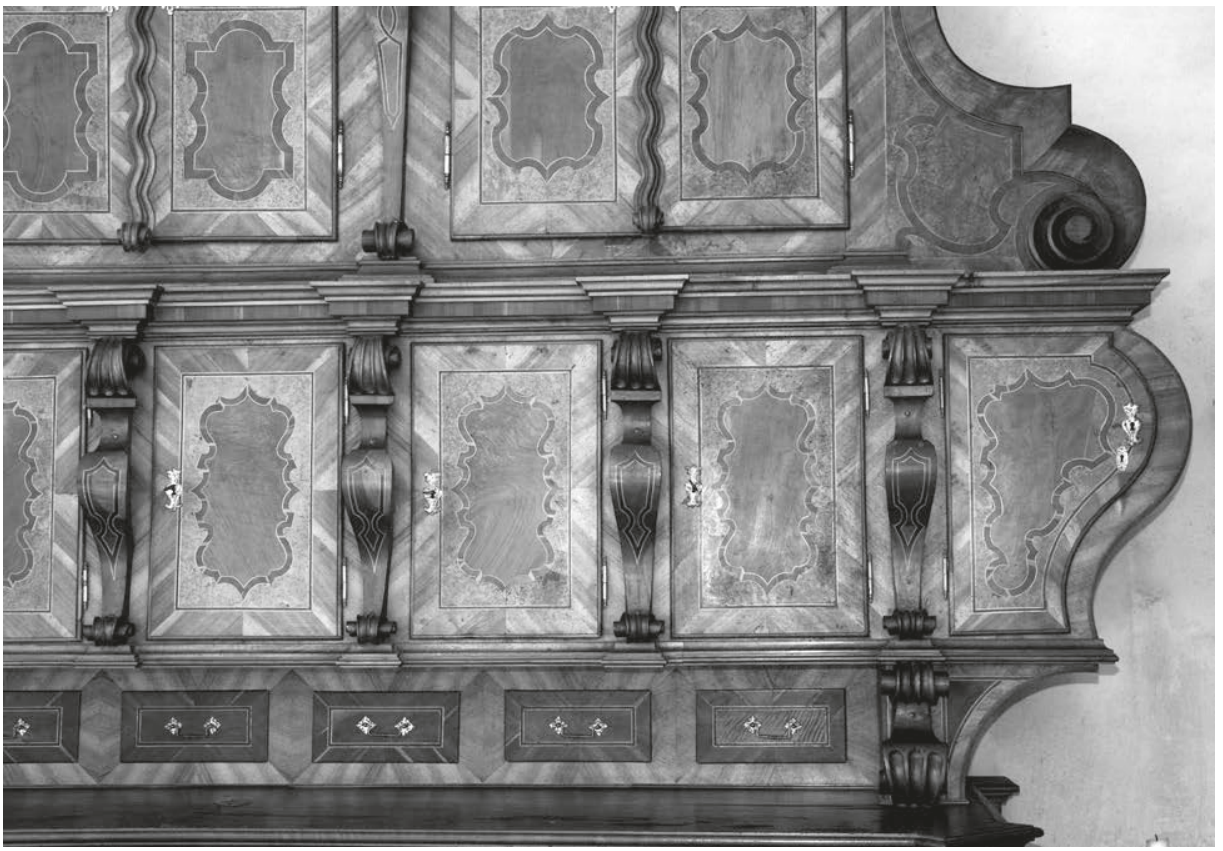

62 Sakristei, Ankleidekredenz (Detail). St. Paul, um I 730/40

schränke besitzen ein flaches Sockelgeschoss mit geschwungenen Seiten, das Laden für Kelchwäsche beherbergt. Darüber liegt ein ebenfalls gebauchtes Zwischengeschoss mit Kelchkästen. Ein Gesims isoliert es vom Obergeschoss, die größere Bedeutung des Zentrums heben weitere Stützen hervor. Das Kranzgesims zieht sich von den Seiten ausgehend über den Fensternischen entlang bis zur Mitte, die ein Segmentgiebel überfängt. Ein aus Gittern, Bandlwerk, Bögen und Blattranken bestehender Schnitzaufsatz bekrönt das Möbel. Seitlich hängt eine Blumengirlande herab. ${ }^{121}$

An diesem Möbel kommen geschnitzte Zierornamente lediglich am Aufsatz vor, nun dominieren furnierte Flächen das Möbel. Wie üblich geben sie Rahmen und Füllungen an, wobei geschwungene und miteinander verkettete Adern aus verschiedenen Holzarten Binnenfelder eingrenzen. Eine formal ungewöhnliche Lösung liegt in dem Umstand vor, dass die Schränke und das Abschlussgesims die Fensteröffnungen in die Formgebung einbeziehen. Wie etliche Beispiele im Katalog belegen, wurde sonst eine andere Lösung gewählt. Die Sakristeimöbel in der Innsbrucker Servitenkirche liefern hierfür ein treffendes Beispiel (Abb. 3 I3).

I 2 I Sie fehlt am linken Schrankende. 
Der Unterschrank der Sakristeikredenz vor der Nordwand entspricht weitgehend der Substruktion des Möbels vor der Westwand, mit einer anderen Gestaltung zeigt sich jedoch der ebenfalls dreigeschossige Aufsatz (Farbtaf. o9; Abb. 62). Sein Sockel besteht aus einer weit nach hinten versetzten Schubladenreihe, die kräftige Volutenkonsolen in ihre Mitte nehmen. Das dann folgende Geschoss mit Kelchkästen schwillt seitlich so weit an, dass es den Unterschrank um knapp $80 \mathrm{~cm}$ überragt. Eine vergleichbare oder auch nur ähnliche Modellierung des Schrankgehäuses kann an österreichischen Möbeln kein zweites Mal nachgewiesen werden. Pilasterartige Bänder flankieren die Kelchkästen. Über einem verkröpften Gesims erhebt sich ein hoher, mit weiteren Stützen strukturierter Aufsatz, den große Voluten auf die Breite des Unterschrankes zurückführen. Die an den Türen angebrachten Schlagleisten wurden nicht als gerades Profil, sondern als feingeschlängelte bewegte Linie ausgearbeitet. Das Gebälk ist verkröpft, Architrav und Fries sind auf die Breite der Stützen reduziert. Das Kranzgesims schwingt über den mittleren Achsen wieder nach oben, ein fein gearbeiteter Schnitzaufsatz bekrönt auch diese Kredenz.

Offensichtlich wurden die beiden Möbel gleichzeitig oder innerhalb eines kurzen Zeitraums in derselben Werkstatt geschaffen, wobei der Name des Meisters erneut im Dunkeln bleibt. Bei handwerklich perfekter Ausführung und künstlerisch überzeugenden Lösungen sind sie sowohl hinsichtlich ihrer Größe als auch im Hinblick auf ihre Form in der österreichischen Kunstlandschaft absolut einzigartig.

\section{Villach, Stadthauptpfarrkirche hl. Jakob D. $\ddot{A}$.}

Ein Vorgängerbau der Kirche, die zur Diözese Bamberg und zum Patriarchat Aquileia gehörte, fand I I 36 erstmals Erwähnung. ${ }^{122}$ Wer die Kirche bauen ließ, ob die Bewohner Villachs oder der Bamberger Bischof, ist nicht überliefert. Auf die Zerstörung der frühen Kirche durch ein Erdbeben folgte von I360 bis I 370 die Wiedererrichtung des Chores, knapp roo Jahre später auch die des Langhauses. Einer Schriftquelle von I 486 zufolge war es damals bereits eingewölbt, doch dürfte man das Gewölbe nach dem Stadtbrand von I 524 durch ein neues mit Schling- und Netzrippen ersetzt haben. Seit dem I 7. Jahrhundert verbindet eine querstehende dreijochige Vorhalle den Turm mit der Westfassade der Kirche, ursprünglich erhob er sich wie ein Campanile frei-

I 22 ÖK-T, Kärnten (I 889), 374-382; Kunstdenkmäler Kärntens, Villach (I929), Io-I 7; Neckheim, Stadthauptpfarrkirche (1957); Hootz, Kunstdenkmäler (1965-1 968), Bd. 2 (1966), I62-163, 359; Dehio, Kärnten (200I), I006-ıого; Schlager/Tropper, Stadthauptpfarrkirche (2014). Die neuere Forschung berichtet von zwei Vorgängerbauten. Schlager/Tropper, ebd., 8. 
stehend neben dem Sakralbau. Zu weiteren Erdbebenschäden kam es I690, I784 ließ ein Brand die Erneuerung des Chorgewölbes notwendig werden. Auf das Jahr I 908 geht die Ernennung von St. Jakob zur Stadthauptpfarrkirche zurück. Sie besitzt ein dreischiffiges und sechsjochiges Langhaus sowie einen dreijochigen, über vier Stufen erhöhten Chor mit 5/8-Schluss.

\section{Magistratsgestübl Südseite}

Villach, um I620/40 und 3. D. I8. Jh.

$\mathrm{HS} 26 \mathrm{~cm}$

$\mathrm{H} 209 \mathrm{~cm}(+26 \mathrm{~cm}) \times \mathrm{L} 7,50 \mathrm{~m}$

\section{Magistratsgestühl Nordseite}

Villach, um I620/40, um I650/60 und 3. D. I8. Jh.

HS $27 \mathrm{~cm}$

$\mathrm{H} 209,5 \mathrm{~cm} / 275 \mathrm{~cm}(+27 \mathrm{~cm}) \times \mathrm{L} \mathrm{9,45} \mathrm{m}$

Nussbaum, Nadelholz, dunkelbraun gebeizt, polychrome Fassung

Die Möbel wurden aus dem I 785 profanierten und zwischen I 894 und I 899 abgetragenen Villacher Minoritenkloster hierher transferiert (Abb. 63-66). ${ }^{123}$ Die Stallenreihe auf der Südseite des im Langchor der Kirche aufgestellten Gestühls (Abb. 63, 64) umfasst elf, die auf der Nordseite I 3 Sitze. Die Inventarstücke wurden mehrfach umgebaut. Die erste Modifikation geht auf die Mitte des I 7. Jahrhunderts zurück und betrifft Stallen, die nachträglich vor der Nordseite hinzugefügt wurden (Abb. 65, 66). Aus dem späteren bzw. ausgehenden I 8. Jahrhundert stammen die mit einem Flechtband versehenen klassizistischen Brüstungen, noch jüngeren Datums sind eventuell die Zwischenwangen, in jedem Falle aber die Außenwangen der Sitzreihen. Zwischen der fünften und der sechsten Achse weist das südseitige Dorsale eine Hochwange auf (Abb. 64). Diese Konzeption erinnert zwar an das Gestühl in Griffen (Farbtaf. o4; Abb. 27), gibt hier aber insofern zu denken, als die Rückenlehne an dieser Stelle konstruktiv geteilt ist. Falls man das Gestühl nicht schon bei seiner Herstellung in zwei getrennten Teilen anfertigte, um es besser transportieren zu können, wurde es zu einem unbekannten Zeitpunkt (bei seiner Translokation?) umgestaltet.

I 23 Kunstdenkmäler Kärntens, ebd., r6; Gerlach, Chorgestühl (r 93 I), 36; Neckheim, ebd., 34; Dehio, ebd., ro го; Schlager/Tropper, ebd., 22, 23. Zum ehemaligen Minoritenkloster vgl. Dehio, ebd., roo6; Schlager/Tropper, ebd., 22. 


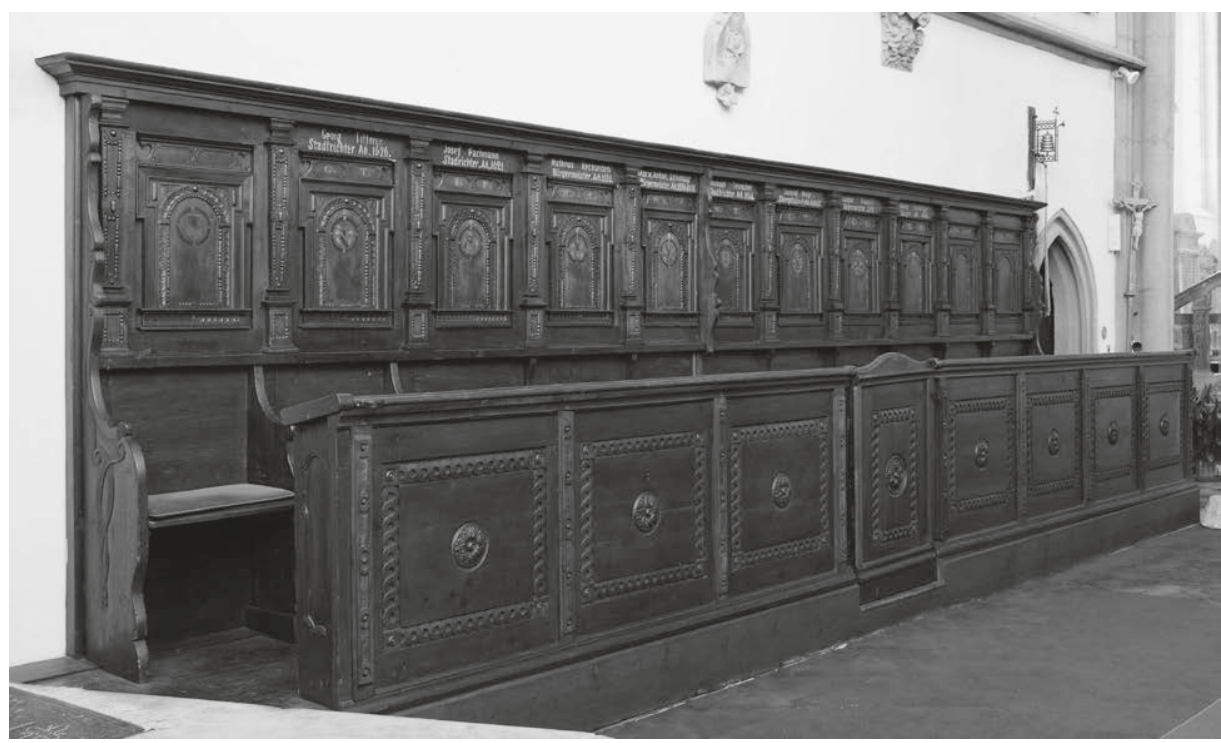

63 Chorraum, Südseite, Magistratsgestühl. Villach, um I620/40 und 3. D. I8. Jh.

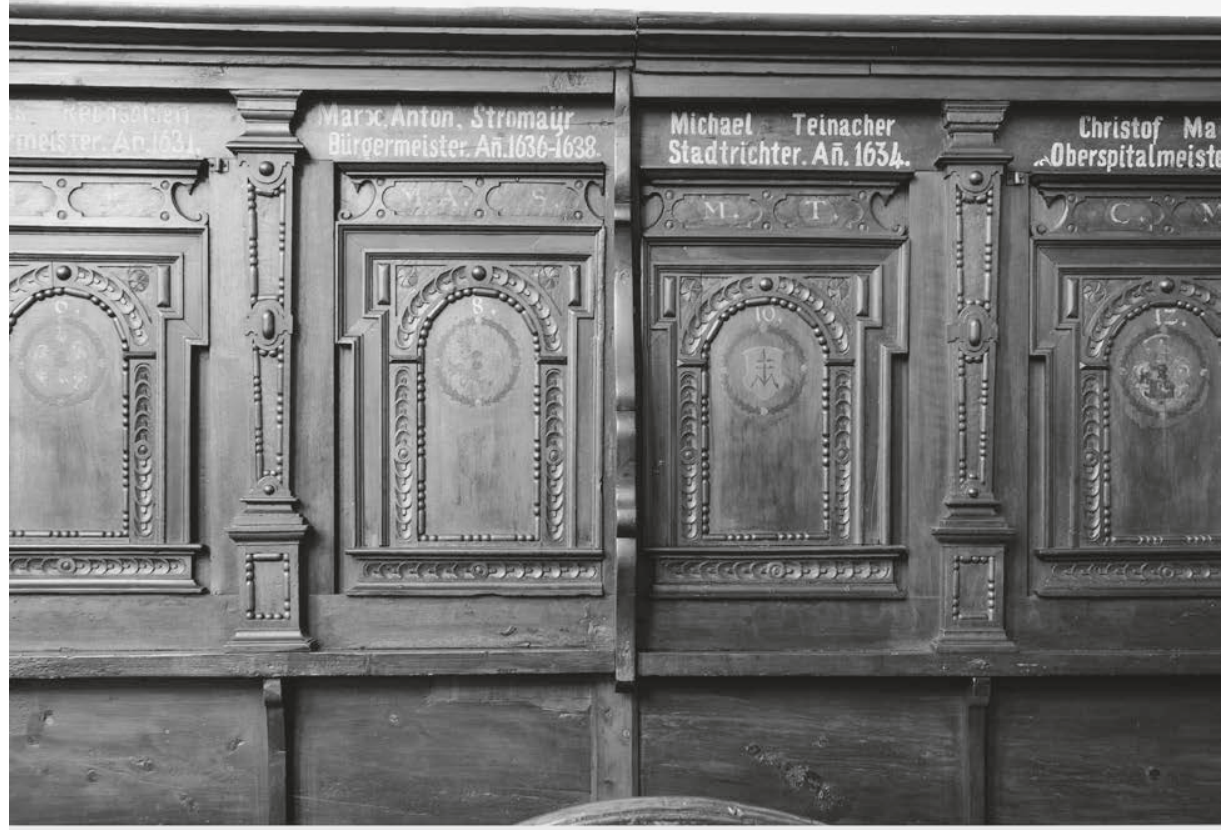

64 Chorraum, Südseite, Teilansicht des Gestühls. Villach, um i620/40 und 3. D. I8. Jh. 


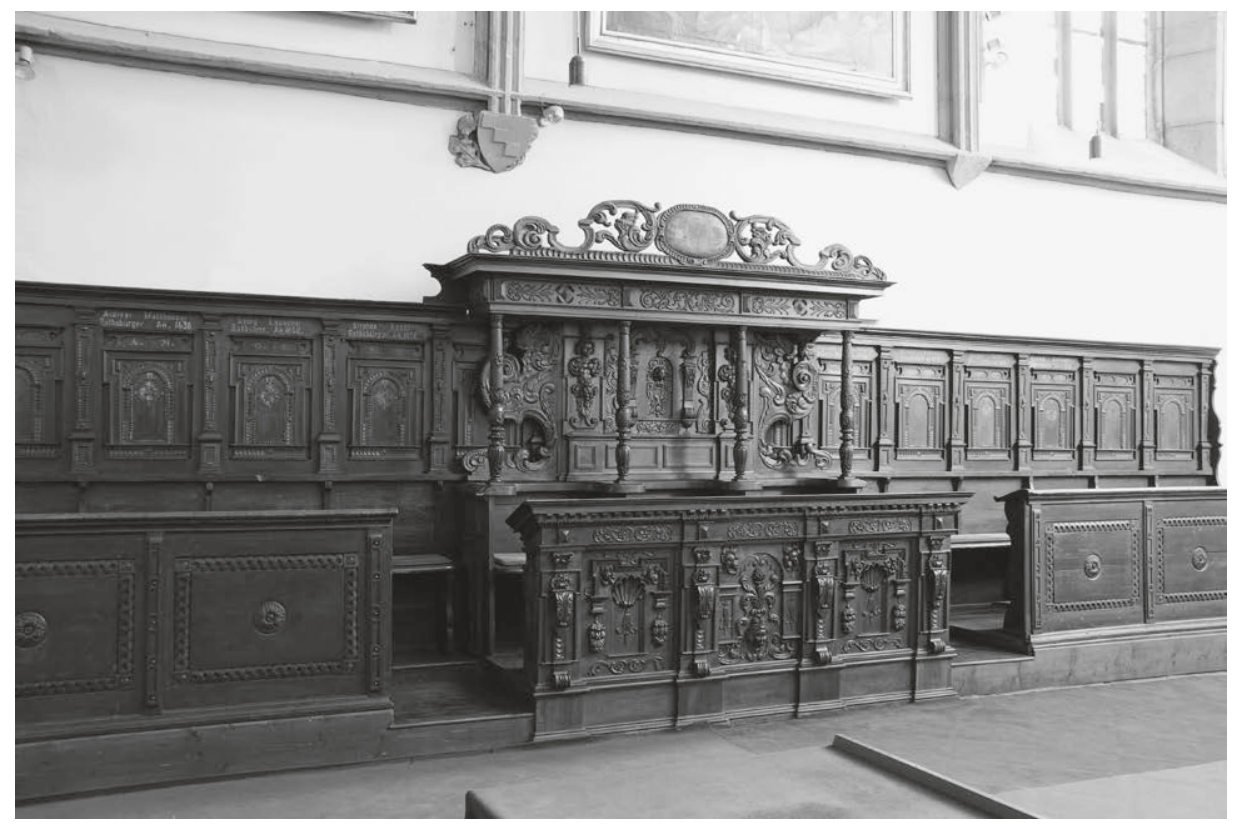

65 Chorraum, Nordseite, Teilansicht des Gestühls. Villach, um I620/40, um I650 und 3. D. I8. Jh.

Einige Zwischenwangen sind auf flache Leisten reduziert, auf Accoudoirs wurde verzichtet. Keilpilaster gliedern das Dorsale. Die Abstände zwischen den Wangen wurden geändert, sodass nicht mehr alle Docken und Pilaster in Supraposition übereinander zu stehen kommen (Abb. 63). Ädikulä mit rundbogigen Arkaden füllen die Räume zwischen den Stützen, ein profiliertes Gesims schließt das Dorsale ab. Schuppenmuster zieren die Arkaden, ansonsten sind die Rückwände mit Perlreihen, »Nagelköpfen« und Blütenmedaillons geschmückt, also mit Ornamentmotiven, die dem Formenschatz des Beschlagwerks angehören.

Auch die Nordseite des Gestühls (Abb. 65, 66) weist eine Verschiebung der Achsen auf, zudem wurde um 1650 für Honoratioren ein prachtvoller Dreisitz eingefügt, dessen Erscheinungsbild sich markant vom Aussehen der seitlichen Möbelteile unterscheidet. Volutenpilaster gliedern seine Brüstung, sie tragen stilisierte ionische Kapitelle und ein Gebälk. Welsche Fenster mit Muschelnischen zieren die seitlichen Füllungsfelder, eine Serliana hebt die Mittelachse der Brüstung hervor. Kegelförmige, von den Accoudoirs aufsteigende Baluster unterfangen den tiefen Baldachin, der dem Dreisitz einen besonderen Hoheitsraum verleiht. Die Rückwand besteht aus einem breiten, von weitausladenden Voluten flankierten Paneel, das über einem hohen Sockel verkröpfte Hochrechtecke und ein Mittelfeld mit einer Arkade zeigt. Während Flachreliefs den 


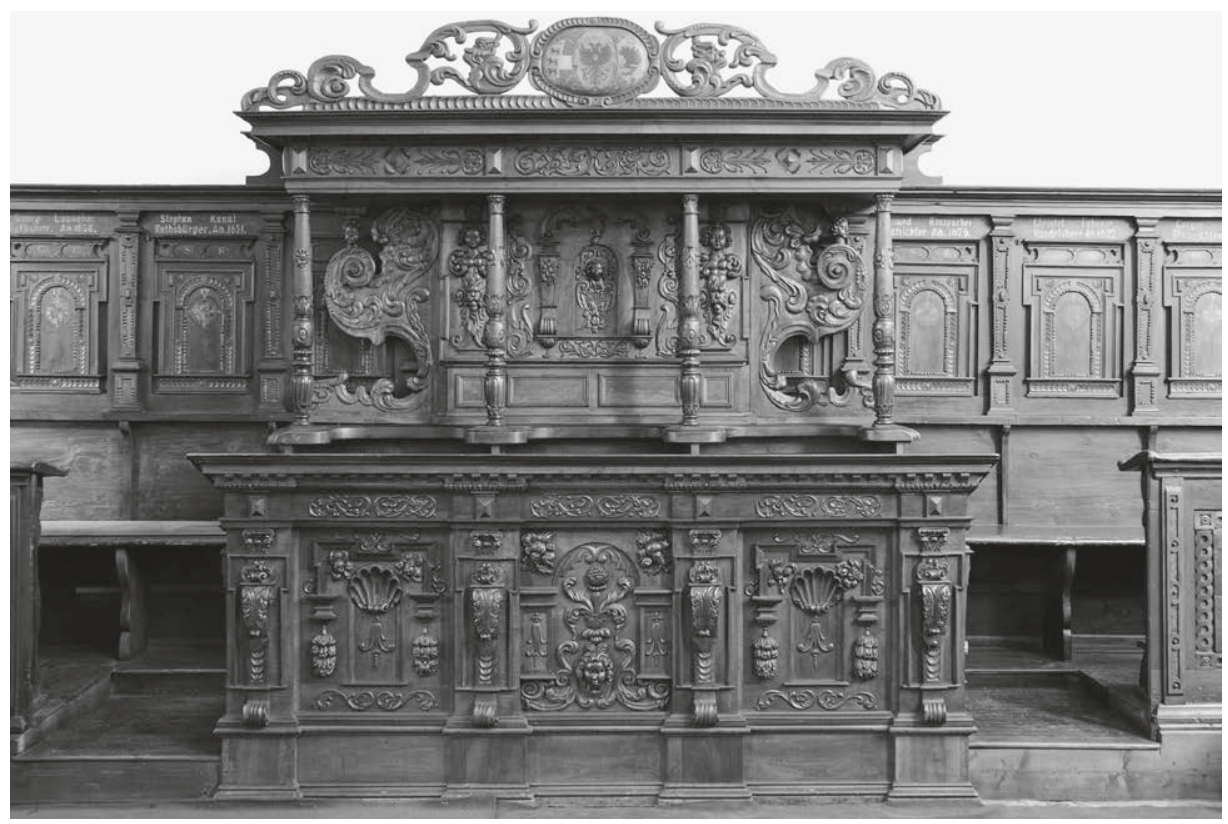

66 Chorraum, Nordseite, Gestühl, Mittelstück. Villach, um I650

Gebälkfries und die Baluster überziehen, zeichnen kraftvolle Schnitzarbeiten mit manieristischen und frühbarocken Motiven das Dorsale des Möbels aus. Frauenköpfe, Groteskmasken und weibliche Hermen kommen ebenso vor, wie die für die Zeit typischen keulenförmigen Bögen, amorphe Formationen und vegetabilische Ziermotive. Ein Schnitzauszug mit einer mittleren Wappenkartusche schließt das Inventarstück ab.

Das Gestühl besteht aus Nussbaum- und Nadelholz, es ist dunkelbraun gestrichen, Wappen und Namen von Villacher Ratsbürgern aus den Jahren I599 bis I664 sind aufgemalt. Der Baldachin trägt die Wappen Österreichs, Kärntens und der Stadt Villach, auf der Brüstung angebrachte Namensschilder von Bezirkshauptleuten geben darüber Auskunft, wem einstmals die Plätze unter dem Baldachin zukamen. Dreisitz und seitliche Stallen sind ein besonders beredtes Beispiel dafür, dass im Laufe der ersten Hälfte des I 7. Jahrhunderts die räumliche Tiefe der Möbelvorderseiten zunahm. Treten die früheren Dekorationselemente nur wenig in Erscheinung und bleiben an den Grund gebunden, sodass die Oberfläche relativ flach wirkt, zeichnet sich der Mittelteil der Nordseite durch eine effektvolle Schichtung der Oberfläche und durch Schnitzarbeiten aus, die sich als Hochreliefs von der Fläche lösen. Dabei generieren sie ein kontrastreiches Wechselspiel zwischen belichteten und beschatteten Segmenten. Durch die Wucht der schweren Formen erinnert dieses Möbelsegment an den Abtstuhl von 

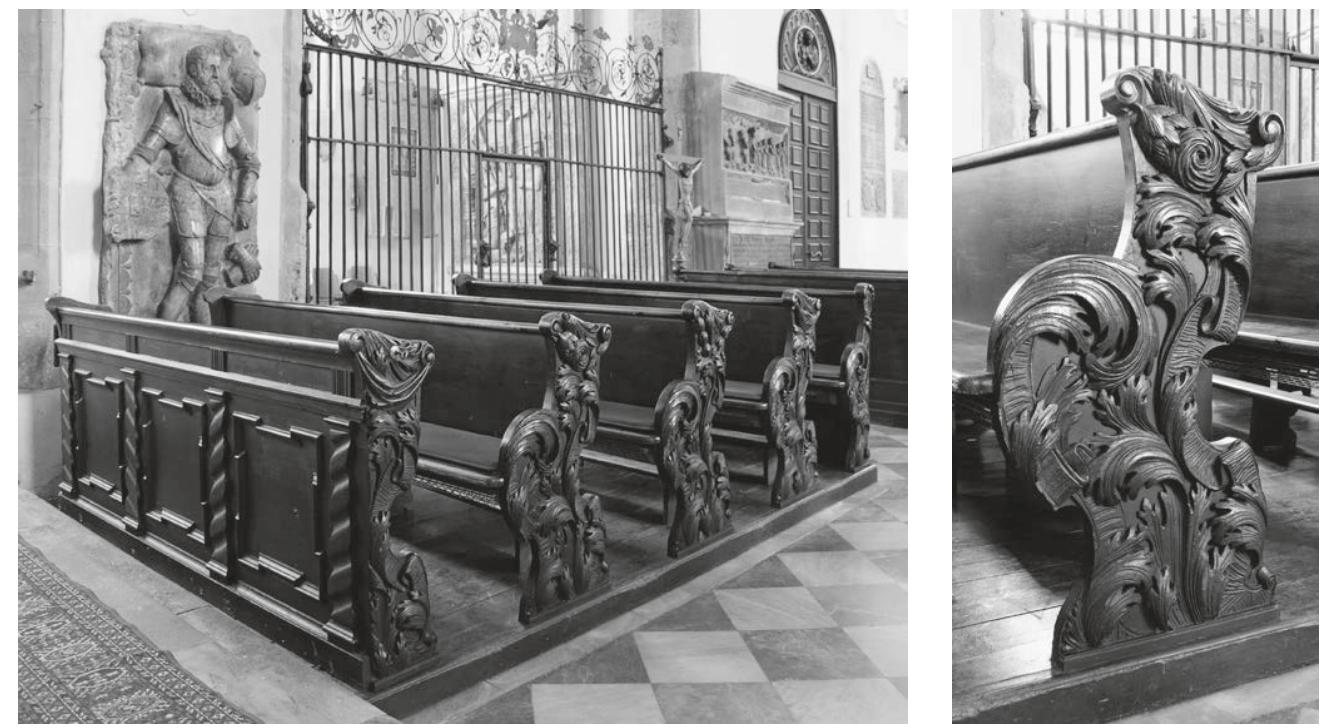

67 Gestühl. Villach, die Bankwangen entstanden um $\mathrm{I}_{705} / \mathrm{I}_{5}$, alles andere ist modern

68 Bankwange. Villach, um I705/15

1640/43 im steiermärkischen St. Lambrecht (Abb. 255). Der Laufboden wurde in jüngerer Zeit erneuert.

\section{Laiengestühl}

Villach, um $1705 / 15$

HS Io $\mathrm{cm}$

$\mathrm{H} 97 \mathrm{~cm}(+\mathrm{IO} \mathrm{cm}) \times \mathrm{L} 229 \mathrm{~cm}$

Nuss, Nadelholz, dunkel, fast schwarz gebeizt

Im Gegensatz zu einem Großteil des Laiengestühls in der Kirche, das wegen seiner späten Fertigung hier im Kontext keine Relevanz besitzt, stehen im südlichen Seitenschiff vier Bänke und die dazugehörende Brüstung, Schnitzarbeiten aus dem frühen 18. Jahrhundert vervollständigen die zum Kircheninneren weisenden Docken (Abb. 67, 68). ${ }^{124}$ Die dynamisch geschwungenen Wangen besitzen einen weit nach vorn gezogenen Bauch und einen nach hinten geführten relativ hohen Sockel. Sie enden mit einem schräg angeordneten Akanthusblatt zwischen Voluten, Laub- oder Stoffgirlanden und

I 24 Gerlach, ebd., 40; Schlager/Tropper, ebd., 40. Gerlach, ebd., datiert die Bänke um I725 und damit sicher etwas zu spät. 
Fruchtgehängen. Großblättriger Akanthus bedeckt die Flächen, zu Schlaufen gelegte breite quergeriffelte Bänder folgen ihrer Kontur. Damit weisen die Schnitzarbeiten Übereinstimmungen beispielsweise mit den Bibliotheksmöbeln in Kremsmünster aus dem frühen I8. Jahrhundert auf, doch sind die Schnitzarbeiten in Villach sehr viel kräftiger ausgeführt, man spürt die Kenntnis italienischer Arbeiten. ${ }^{125}$

\section{Völkermarkt, Stadtpfarrkirche hl. Maria Magdalena}

I 240 dokumentierte eine Urkunde den Ankauf eines Grundstücks aus dem Besitz des Klosters St. Paul zur Errichtung einer Kirche, I 463 wird der Sakralbau als Pfarre bezeichnet. ${ }^{126}$ Immer wieder setzten Brände dem Bauwerk zu, das I69o außerdem bei einem Erdbeben beschädigt wurde. Bei der Kirche handelt es sich um eine im Kern spätromanische, in der zweiten Hälfte des I 5. Jahrhunderts aber tiefgreifend überformte dreischiffige Basilika. Eine quadratische Eingangstravée, der älteste Bauteil der vierjochigen Kirche, verbindet die beiden den Seitenschiffen vorgelagerten Türme. Das Bauwerk schließt mit einem Staffelchor, wobei man die seitlichen Teilbereiche etwas breiter als die Seitenschiffe plante. Die quadratische Sakristei lehnt sich an Hauptund Nordchor. Das Eingangsjoch ist kreuzrippengewölbt, sonst stützt das Mauerwerk Netzrippen- bzw. Sternrippengewölbe, die wegen drohenden Einsturzes I 88 I erneuert werden musste. Die originalen Gewölbestücke wurden dabei wiederverwendet.

\section{Chorraum, Chorgestühl}

Völkermarkt, um i640/60 und I 9./20. Jh. (Schnitzaufsatz)

$\mathrm{HS} 22,5 \mathrm{~cm}$

Gesimshöhe $255 \mathrm{~cm}(+22,5 \mathrm{~cm}) \times \mathrm{L} 440 \mathrm{~cm}$

Schnitzaufsatz ca. I $20 \mathrm{~cm}$

Nuss massiv, Nuss aufgedoppelt, Nadelholz, Holz vergoldet. Eisenbänder und -beschläge

Als Standort für das Gestühl wurde das erste Chorjoch gewählt (Abb. 69-72). ${ }^{127}$ Die sechs Füllungsfelder umfassende Brüstung war ursprünglich um die beiden westlichen

I $25 \mathrm{Zu}$ den Möbeln in Kremsmünster vgl. Bohr, Sakralmöbel (2017), 528-53 I.

I 26 ÖK-T, Kärnten (г 889), 389-395; Kunstdenkmäler Kärntens, Völkermarkt (I933), 24-28; Hootz, Kunstdenkmäler (1965-1 968), Bd. 2 (1966), r66-167, 360; Mahlknecht, Völkermarkt (1993); ders., Stadtpfarrkirche (1998); Tropper, Geschichte (1998); Dehio, Kärnten (2001), 1029-I033.

I 27 Kunstdenkmäler Kärntens, ebd., 27; Mahlknecht, Völkermarkt (1993), ıo; ders., Stadtpfarrkirche (I998), I 28 ; Dehio, ebd., I032. 

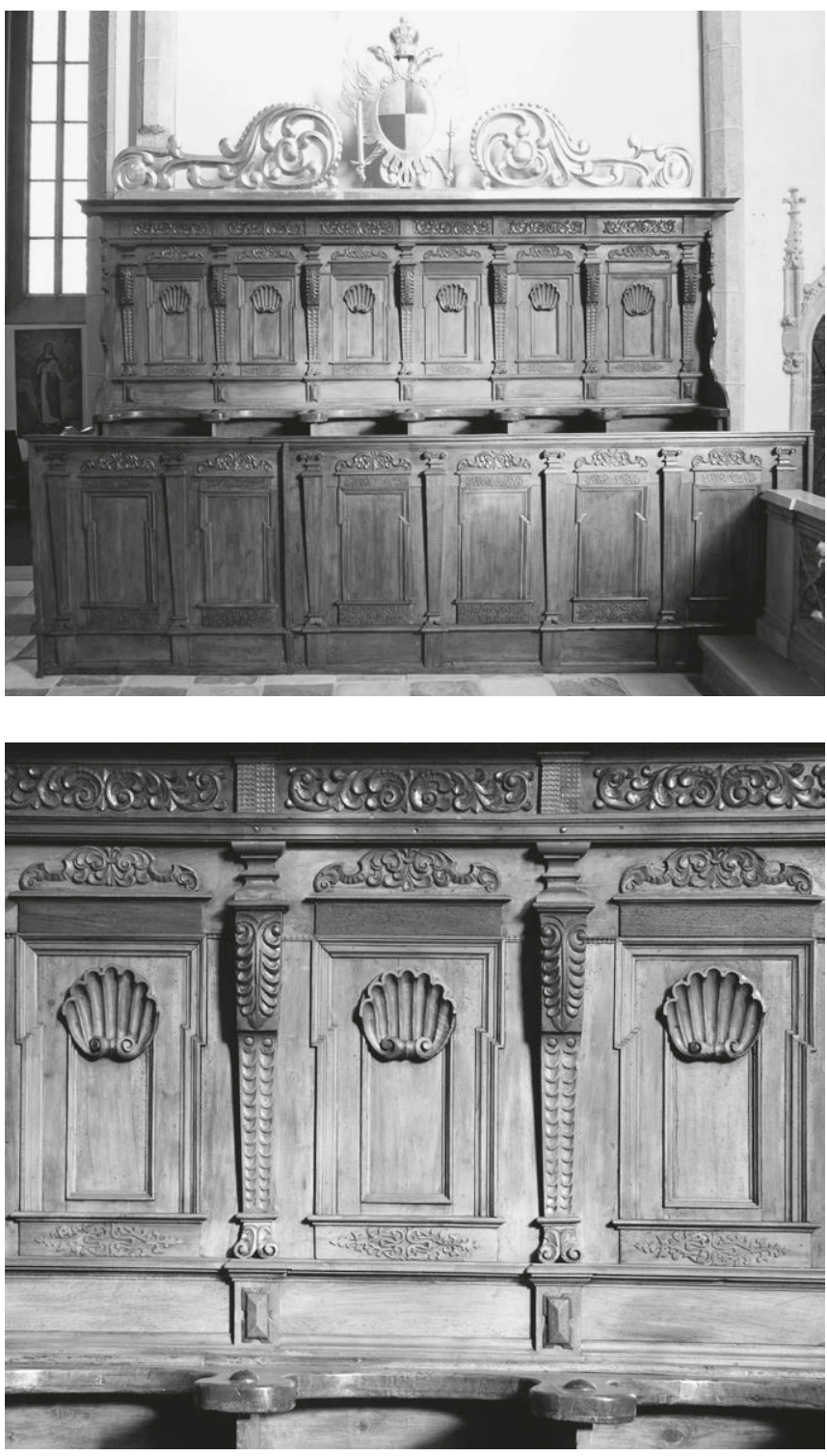

69 Chorraum, Chorgestühl. Völkermarkt, I640/6o, der Schnitzaufsatz mit dem Wappen des österreichischen Kaisertums I 9./20. Jh.
Chorraum, Chorgestühl (Detail). Völkermarkt, I640/60

Felder kürzer, die Vorderkante der einstigen Außenwange, die nicht entfernt, sondern in den Bestand integriert wurde, ist gut zu erkennen (Abb. 72). Dabei stimmen nicht nur Großform und Ziermotive des angesetzten Stücks mit den restlichen vier Feldern überein, sondern auch die Struktur des Holzes und die Farbe der Oberfläche, was auf eine nahezu gleichzeitige Entstehung der beiden Möbelsegmente schließen lässt. 


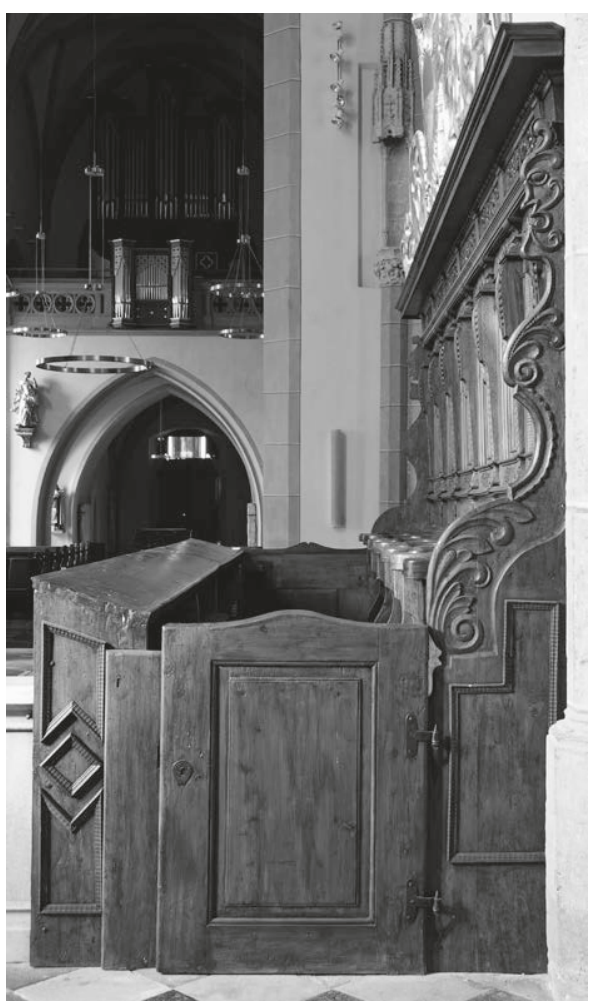

7 I Chorraum, Chorgestühl (Seitenansicht). Völkermarkt, I640/6o

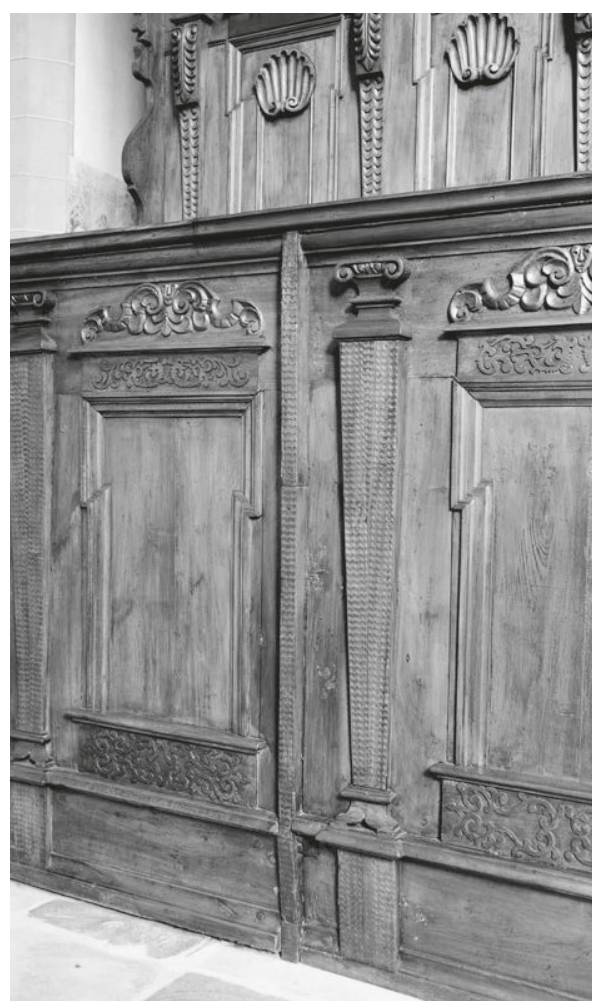

72 Chorraum, Chorgestühl (Detail der Brüstung). Völkermarkt, I640/6o

Die geraden, vorn leicht überstehenden Kanten der Außenwangen flankieren die mit ionischen Keilpilastern versehene Brustwand. Die Tischler interpretierten die geohrten und mit Flachschnitzereien dekorierten Füllungen als welsche Fenster. Die Pilaster, Postamente und Dockenvorderkanten sind quergeriffelt und damit auf eine Art verziert, die als Vorstufe von Flammleisten bezeichnet werden könnte.

Türen verschließen die Eingänge zu den Gestühlsreihen. Während die Außenwangen der Brüstung als hochrechteckige Baluster ausgearbeitet und mit einer Raute verziert sind, konzipierte man die der Stallen als Hochwangen, die weite Bögen nach oben führen. Sie enden mit einer Groteskmaske, auf der das Gebälk aufliegt. Wie die Brüstung umfasst auch das Dorsale sechs Achsen, besaß aber von Anfang an die heutige Länge. Hier bezeichnen Ädikulä mit Muschelnischen die Füllungen. Mit Schuppenfries und stilisiertem Blattwerk ornamentierte Volutenpilaster stehen vor den senkrechten Stollen und stützen das Gebälk. Geometrische Ornamentmotive sowie 
kleinteiliges Laub schmücken die Rückwandfelder und den Gebälkfries, den geriffelte Konsolen schmücken.

Schnitzaufsätze, die nicht zum Originalbestand gehören, setzen sich aus barockartigen Ornamentformen und Wappenschildern zusammen. Auf der Nordseite handelt es sich um das Wappen des österreichischen Kaisertums, auf der Südseite um ein Bischofswappen. Zum Bau der Brüstung, der Accoudoirs und der Rückwand wurde massives Nussholz und aufgedoppeltes Nussholz verwendet, dagegen bestehen die Sitzbretter und die Lehne hinter den Sitzen aus Nadelholz. Die Voluten an der Rückwand und die Felder über den Ädikulä wurden dunkelbraun gebeizt, der Aufsatz ist vergoldet und polychrom gefasst. Eduard Mahlknecht datierte das Gestühl zunächst auf den Beginn des i 8. Jahrhunderts, später auf das Jahr i675. Dieser Datierung schlossen sich die Autoren des Dehio-Bandes an. An Ornamentmotiven finden sich am Gestühl, nicht am Aufsatz, neben Schweifwerkformationen ausschließlich manieristische und frühbarocke Motive. Ausgehend davon könnte das Gestühl auf die Zeit um r640 datiert werden, doch belegt das nachfolgend beschriebene Möbel von I655, dem das Gestühl im Chorraum ähnelt, die lange Verwendung solcher Zierformen in dieser Kunstregion.

\section{Nördliches Seitenschiff}

Gestühl im Westen

Völkermarkt, I 655

HS I0,5 cm

$\mathrm{H} 205 \mathrm{~cm}(+\mathrm{IO}, 5 \mathrm{~cm}) \times \mathrm{L} 625 \mathrm{~cm}$

\section{Gestühl im Osten}

Völkermarkt, um I650/60

HS Io, $5 \mathrm{~cm}$

$\mathrm{H} 207 \mathrm{~cm}(+\mathrm{IO}, 5 \mathrm{~cm}) \times \mathrm{L} 655 \mathrm{~cm}$

Nadelholz, nussfarben gebeizt

Die beiden Gestühlsreihen stehen vor der Außenwand des nördlichen Seitenschiffs. ${ }^{128}$ Einige Bänke, Teile der Brüstung sowie die Laufpodeste sind Neuanfertigungen, andere Möbelteile gehören zwar dem i 8. Jahrhundert an, wurden aber als Spolien hinzugefügt.

Die Rückwände der beiden Möbel variieren in ihrem Aussehen. Am Dorsale des westlichen Möbels (Abb. 73) besitzen die als Hochwangen geformten Außendocken

I 8 Mahlknecht, Völkermarkt (I 993); ders., Stadtpfarrkirche (I 998), ebd.; Dehio, ebd. 


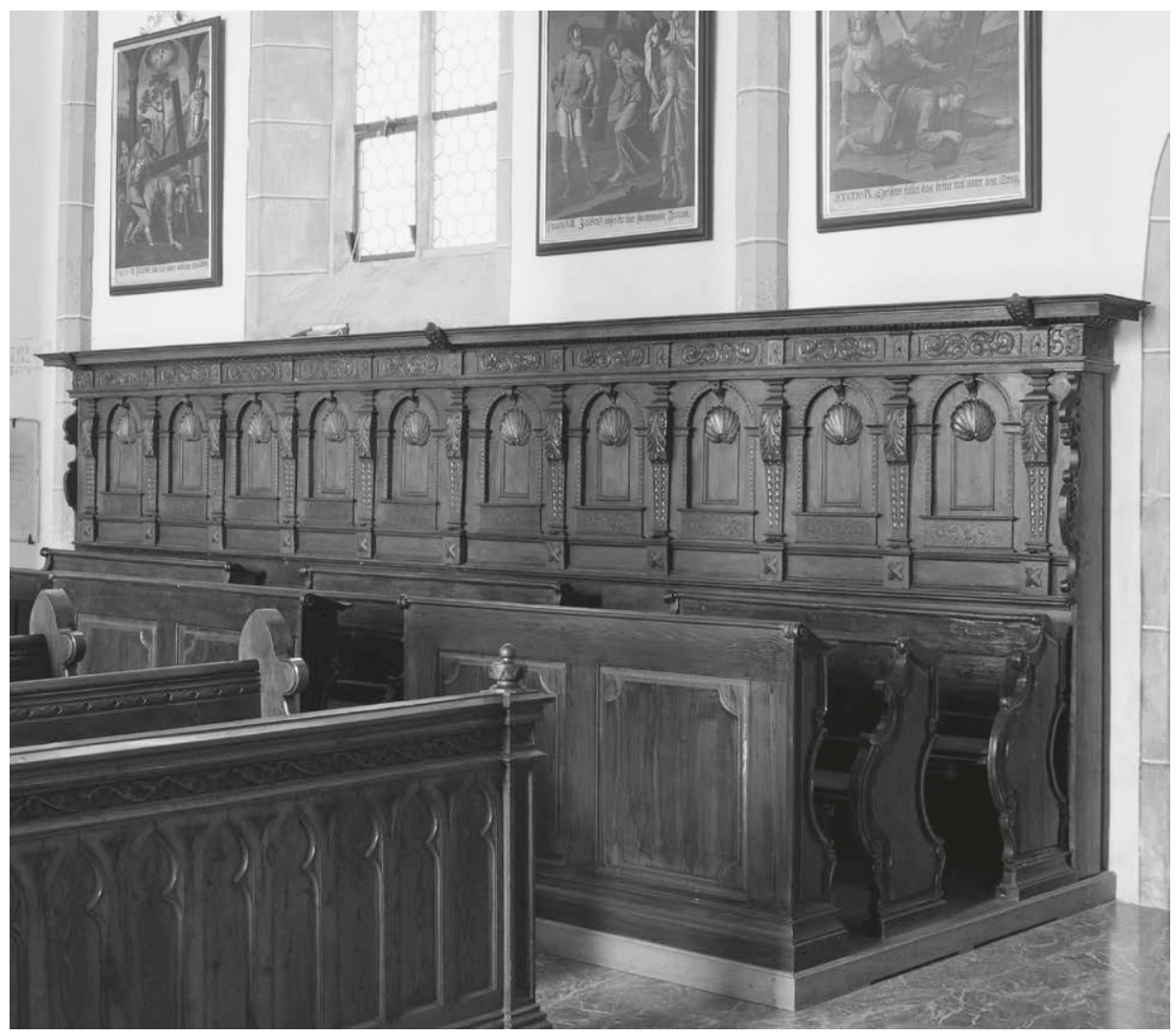

73 Nördliches Seitenschiff, westlicher Teil des Gestühls. Völkermarkt, I655. Bankwangen und Brüstung sind spätere Ergänzungen.

in der oberen Hälfte Zierbögen, die unter dem Gebälk die Form von Blattmasken annehmen. In der Seitenansicht sind sie gut zu erkennen. Die Volutenpilaster der Rückwand besitzen Blockkapitelle und »geteilte Füße«, mit Akanthus sind die Voluten, mit Schuppenfriesen die Pilasterschäfte dekoriert. Rundbogige Muschelarkaden auf hohen, mit Flachschnitzereien versehenen Konsolenplatten nehmen die Felder dazwischen ein. Gesimse tragen die Bögen, deren Keilsteine zusammen mit den Pilastern das Abschlussgebälk stützen. Flache, mit lilienartigen Gebilden verzierte Konsolen und frühbarocke Blattvoluten vervollständigen den auf das Jahr ${ }_{1655}$ datierten Gebälkfries. Ein Zahnschnittfries und mit nagelkopfartigen Gebilden verzierte Schlaufenkonsolen bereichern das Gesims.

An der östlichen Gestühlsrückwand (Abb. 74) sind die Bögen der Außenwangen bis unter das Gebälk nach oben gezogen, Blattmasken kommen nicht vor. Auch hier 


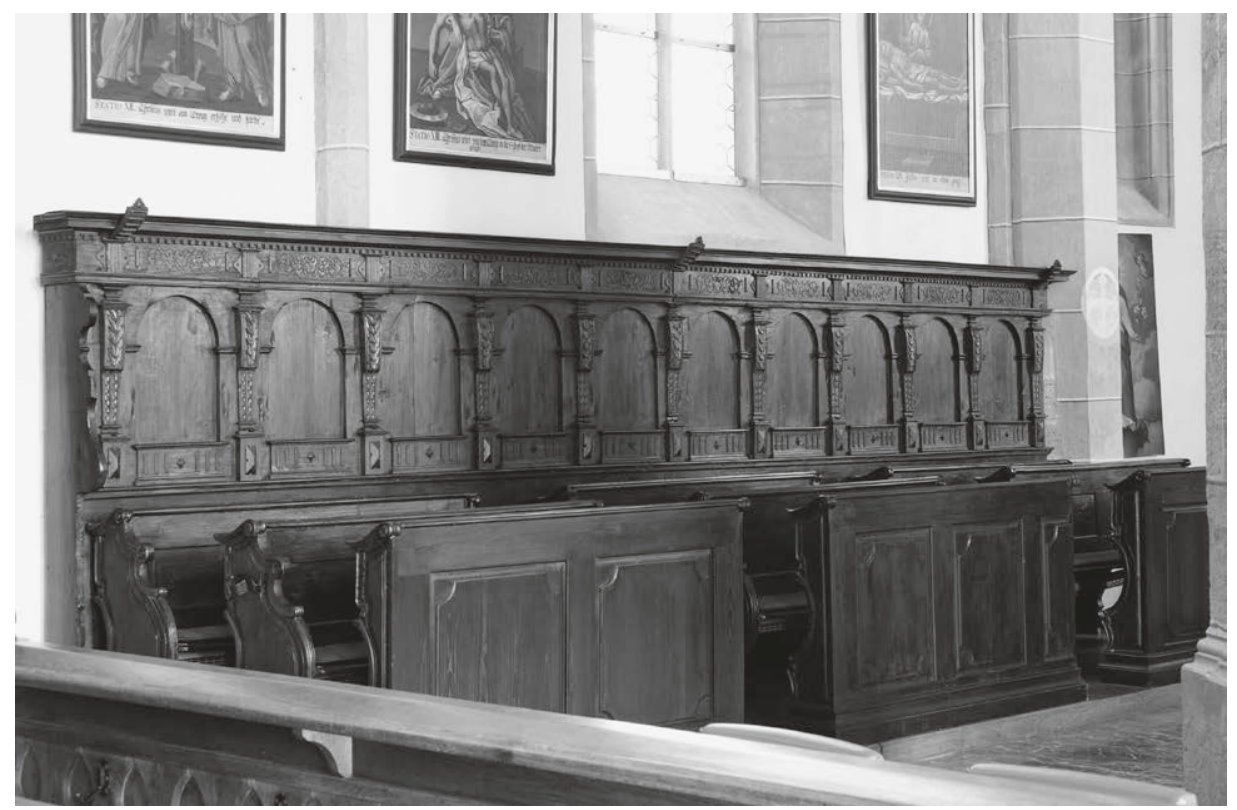

74 Nördliches Seitenschiff, östlicher Teil des Gestühls. Völkermarkt, um I65o/60. Die Bankwangen und die Brüstung sind spätere Ergänzungen.

flankieren geschuppte Pilaster die Joche der Rückwand, schlichte Arkaden bilden die Zwischenräume. Triglyphenfelder und Flachschnitzereien vervollständigen den Gebälkfries, vor dem Gesims reichen vereinzelte, mit Querstäben geschmückte Schlaufenkonsolen in die Höhe. Das westliche Ende des Gebälks wurde beschnitten, während man am östlichen Ende ein kurzes Teilstück ansetzte, das Dorsale stand folglich einstmals in einem anderen Raumzusammenhang. Die Stallen und die Wangen beider Möbel wurden entfernt. 
III.

\section{Sakralbauten in Salzburg/Stadt und Land}

\section{Maria Plain, Wallfahrtskirche Maria Plain (Maria Himmelfahrt)}

I 652 wurde ein Gnadenbild der Muttergottes nach Plain transloziert und zunächst an einem Ort aufgestellt, an dem sich bereits eine Gebetsstätte befunden hatte. ${ }^{129}$ I 655 und r 657 errichtete man für das Bild sowie für eine Kopie zwei Kapellen, die sich bald als zu klein für die zunehmende Zahl an Pilgern erwiesen, weshalb der Salzburger Erzbischof Guidobald Thun (reg. I 654-I 668) Planungen für eine größere Wallfahrtskirche veranlasste. Die Grundsteinlegung erfolgte durch seinen Nachfolger, Max Gandolph Graf von Kuenburg (reg. I668-r687). Er beauftragte den Salzburger Architekten Giovanni Antonio Dario († I702) mit der Ausarbeitung der Pläne für die Kirche und ein Kloster, das Kuenburg dem Benediktinerorden überließ. Die Errichtung der Anlage fällt in die Jahre I67 I bis I673/74. Bei der Konzeption der doppeltürmigen Fassade übernahm der Architekt wichtige Charakteristika der Gestaltung des Salzburger Doms. Die genordete Kirche ist einschiffig, sie besitzt zwei vollständige Joche und je ein Halbjoch im Norden und Süden, sie verfügt über Seitenkapellen, Emporen und einen einspringenden Chor, den ein Eisengitter vom Langhaus abgrenzt. Erzbischof Max Gandolph ließ sich mit seinem Wappen am Giebel über dem Hauptportal verewigen. Bis I 8 Io gehörte die prachtvoll ausgestattete Kirche zur Benediktineruniversität in Salzburg, seit I 824 wird sie vom Stift St. Peter betreut.

\section{Kirchenbänke}

Salzburg, um I690/ I700

HS $10,5 \mathrm{~cm}$

$\mathrm{H} 93,5 \mathrm{~cm}(+\mathrm{IO}, 5 \mathrm{~cm}) \times \mathrm{L}_{33} \mathrm{I} \mathrm{cm}$

Nadelholz, massiv und geschnitzt, gefasst. Messingblech

I 29 Zur Geschichte der Kirche und ihrer Beschreibung vgl. ÖKT, Salzburg-Land, 2 (I9I6), 344-37I; Schellhorn, Maria Plain [r 195 I]; Hootz, Kunstdenkmäler (I 965-1968), Bd. I (r965), 2 I 8, 21 19, 340; Hahnl, Kunstgeschichte (1974); Hermann, Geschichte (I 974); Ebhardt, Barockkirchen (1975), 52 57; Dehio, Salzburg (1 986), 22 5-228; Eltz-Hoffmann/Anrather, Kirchen Salzburgs (I 993), I 23-I 30 ; Hermann, Maria Plain (1998); Hermann, Maria Plain (200I); Hahnl/Bachler, Wallfahrtsbasilika (2009). 


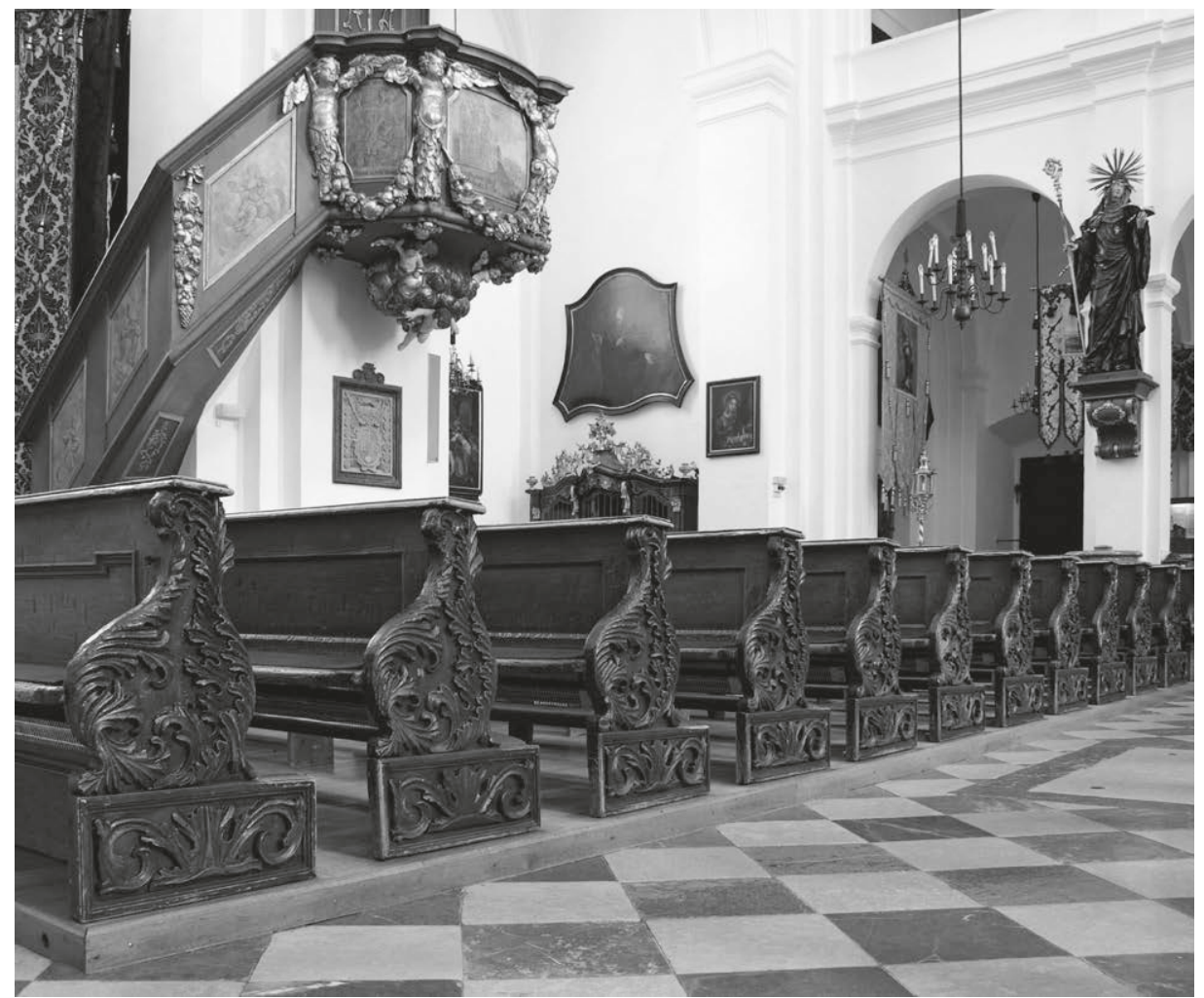

75 Kirchenbänke. Salzburg, um I690/I 700

Die seitlich der Kirchenmittelachse aufgereihten 24 Bänke kommen ohne Vorderbrüstungen aus (Abb. 75, 76). ${ }^{130}$ Die Docken bestehen aus einem Sockel, der auf der Seite des Mitteldurchgangs leicht abgeschrägt ist, und einem Aufsatz in Form einer asymmetrischen dickbauchigen Vase mit schmalem Hals und verbreitertem Ausguss. Akanthusvoluten und Rauten zieren die Sockel, weiteres Laubwerk bedeckt den oberen Wangenbereich. Eine dunkelbraune Malschicht überzieht die aus Nadelholz gefertigten Möbel, Messingblech schützt die Abschlussleisten auf den Rückenlehnen. Zahlreiche, durch Kerzen verursachte Brandflecken an den Bänken vieler anderer Kirchen (Abb. I 93, 20I) zeugen von der Sinnhaftigkeit dieser Vorsichtsmaßnahme.

Die Verfasser der ÖKT datieren die Möbel um I675, was zwar mit der Bauchronologie übereinstimmen würde, sich aus stilistischen Gründen aber nicht halten lässt. Stattdessen ist mit einer Herstellungszeit um die Wende vom i 7. zum i 8. Jahrhundert

I30 ÖKT, ebd., 362 ; Dehio, ebd., 228 ; Hermann, Maria Plain (1998), 8 ; Hahnl/Bachler, ebd., 9. 


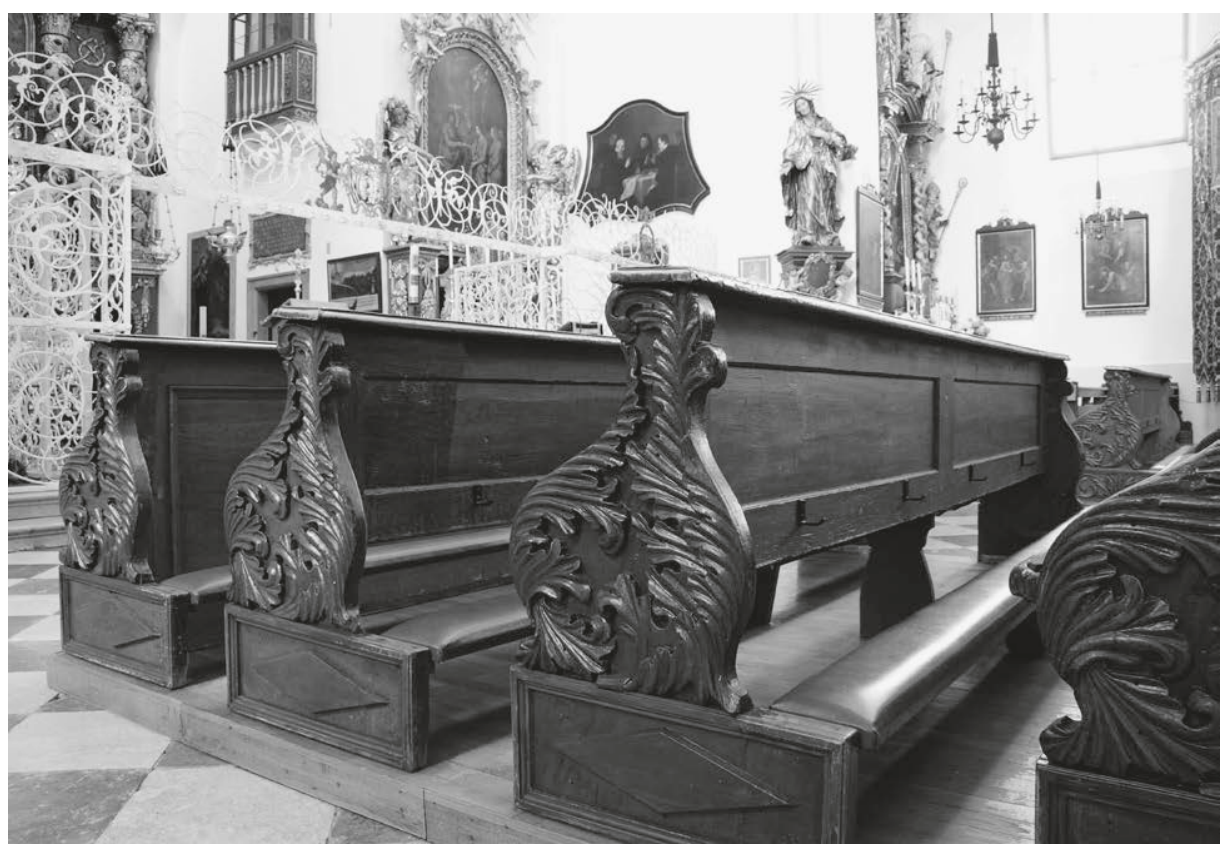

76 Kirchenbänke (Wandseite). Salzburg, um I690/I 700

zu rechnen. Überraschend sind die großen formalen Übereinstimmungen zwischen diesen Bänken und dem Gestühl in St. Markus (Abb. I 3 I, I 32). Die Möbelgarnituren in den beiden Kirchen sind dermaßen ähnlich, dass die These ihrer Herstellung in ein und demselben Bildhaueratelier berechtigt erscheint.

\section{Beichtstühle}

Verm. Hoftischler Simon Thaddäus Baldauf und Bildschnitzer Johann Georg Hitzl, um I 760 HS I $2,5 \mathrm{~cm}$

Gesimshöhe 2 IO cm $(+\mathrm{I} 2,5 \mathrm{~cm}) \times \mathrm{B} 265 \mathrm{~cm} \times \mathrm{T} 93 \mathrm{~cm} / \mathrm{I} 38 \mathrm{~cm}$

Nuss, Nussmaser, Zwetschke, Ahorn, Nadelholz, Holz geschwärzt, Holz vergoldet, Lüsterfarben. Messing

In den Seitenkapellen der Kirche befinden sich vier Beichtstühle, die vermutlich in der Werkstatt des Salzburger Hoftischlers Simon Thaddäus Baldauf (r677-1 753) gefertigt wurden (Abb. 77, 78). ${ }^{131} \mathrm{Im}$ Grundriss der geschweiften Sockel, die zugleich

I3 I ÖKT, ebd., 362; Schellhorn, Maria Plain [r95 I], 29; Hahnl, Kunstgeschichte (1974), 201, 204, 2 I 2 ; 


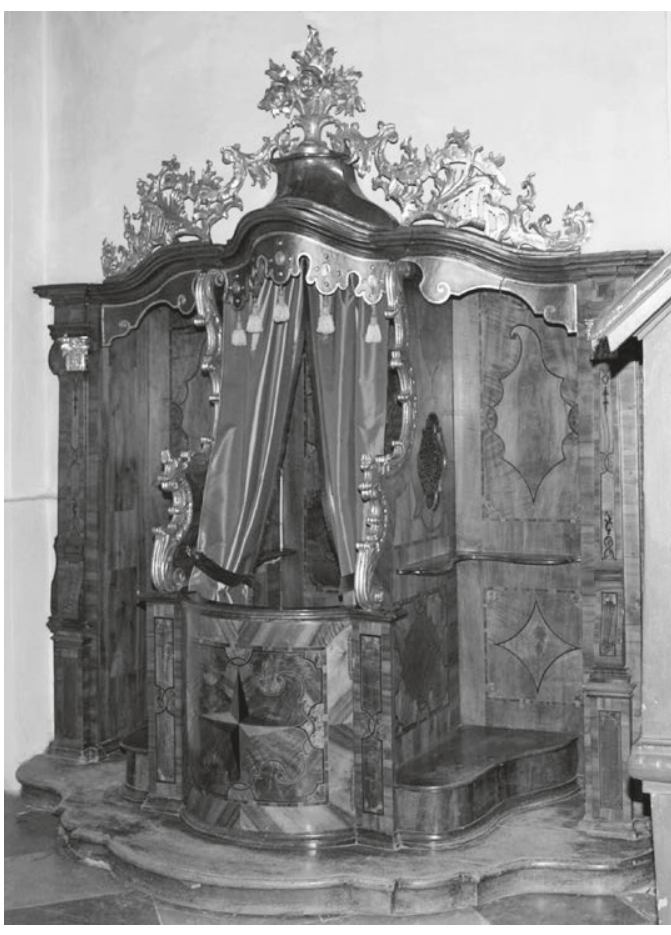

77 Beichtstuhl. Verm. Hoftischler Simon Thaddäus Baldauf, Bildschnitzer Johann Georg Hitzl, um I760

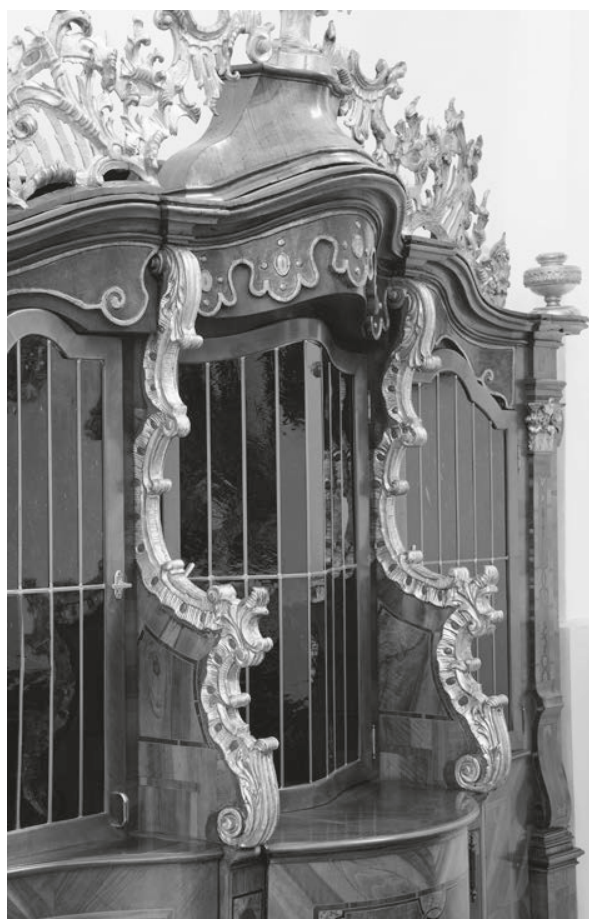

78 Beichtstuhl (Detail). Verm. Hoftischler Simon Thaddäus Baldauf, Bildschnitzer Johann Georg Hitzl, um r760. Die seitlichen Türen und die Verglasung sind moderne Ergänzungen.

die Böden der Möbel bilden, spiegelt sich die Großform der Beichtstühle wider. Die bewegte Mittelachse wölbt sich mit einem Segmentbogen weit in den Raum, während die beiden Schmalseiten von der Rückwand aus kaum über die halbe Möbeltiefe hinausreichen. Die seitlichen Gehäuse sind offen, die Kniebänke der Pönitenten reichen bis zur Fassade nach vorn. Volutenpilaster vor den Außenkanten rahmen das Möbel, Baluster und Scheidewände mit stark bewegten Vorderkanten flankieren die Zelle des Geistlichen. Während die Handwerker Architrav und Fries auf die kurzen Abschnitte über den Pilastern reduzierten, zogen sie das wellenförmige Gesims über die gesamte Breite des Möbels durch. Es trägt einen schlanken Auszug mit einer Blumenvase, die

Oberhofer/Hahnl, Handwerk (1 978), 78; Dehio, ebd., 2 28; Hermann, ebd., 29; Hermann, Maria Plain (200I), I $2 ;$ Hahnl/Bachler, ebd., I 9. 
geschnitzte und à jour gearbeitete Rokokoornamente begleiten. Die Beichtstuhlbekrönung besitzt eine Höhe von etwa $65 \mathrm{~cm}$.

Gestreiftes Furnier überzieht die Innen- und Außenseiten der Möbel, Zwetschkenadern sowie Bänder aus geschwärztem Holz säumen die mit Maserholz dekorierten Füllungsfelder, in die geometrische Motive eingelegt sind. Ein Stern vervollständigt die Türen. Der angenehme braune Farbton des Holzes, der zwischen hellen und dunklen Furnieren changiert, kontrastiert mit den vergoldeten Schnitzarbeiten und der mit roten Lüsterfarben bemalten Schabracke unter dem Abschlussgesims. Was diese Möbel von vielen andern Confessionalen unterscheidet, ist die auffallend lockere optische Verbindung zwischen der Front und den seitlichen Außenwänden, die im Grunde nur als Stützen für das Dach benötigt werden. Damit erinnern die Möbel an die Exemplare in der Salzburger Domkirche (Abb. I 23), deren seitliche Zellen ursprünglich weitgehend offen standen. Drei der Beichtstühle in Maria Plain wurden in jüngerer Vergangenheit mit verglasten Türen versehen. Maurus Schellhorn ist der Ansicht, die Garnitur sei für ein bayrisches Kloster gefertigt und »später, wohl nach dessen Aufhebung«, nach Maria Plain verbracht worden. ${ }^{132}$ Belege dafür liefert er nicht, in der Literatur wird diese Angabe auch nicht wiederholt.

\section{Sakristei}

Seitlich des Chors liegen zwei Sakristeien, das Portal eines der beiden Räume trägt die Jahreszahl I674. Für uns besitzt die Einrichtung der Westsakristei besondere Bedeutung. Das Mobiliar besteht dort aus einer Aufsatzkredenz und zwei Paramentenkästen. Hier interessieren der Aufsatzschrank sowie der größere und qualitativ bessere der beiden Kleiderschränke. ${ }^{133}$

\section{Aufsatzkredenz}

Salzburg, um I675

Fußhöhe $7 \mathrm{~cm}$

$\mathrm{H}_{21} \mathrm{I}_{4}, 5 \mathrm{~cm}(+7 \mathrm{~cm}) \times \mathrm{L}_{535} \mathrm{~cm} \times \mathrm{T} 100 \mathrm{~cm}$

Zirbelkiefer. Eisen, verzinnt

Die Kredenz entspricht dem Aussehen vieler Kelchschränke aus dem fortgeschrittenen I7. Jahrhundert (Abb. 79). Ein ähnliches Möbel von I646 wird beispielsweise in

I32 Schellhorn, ebd.

I33 ÖKT, Salzburg-Land, 2 (I 9r6), 354; Dehio, Salzburg (I 986), 225, 228. 


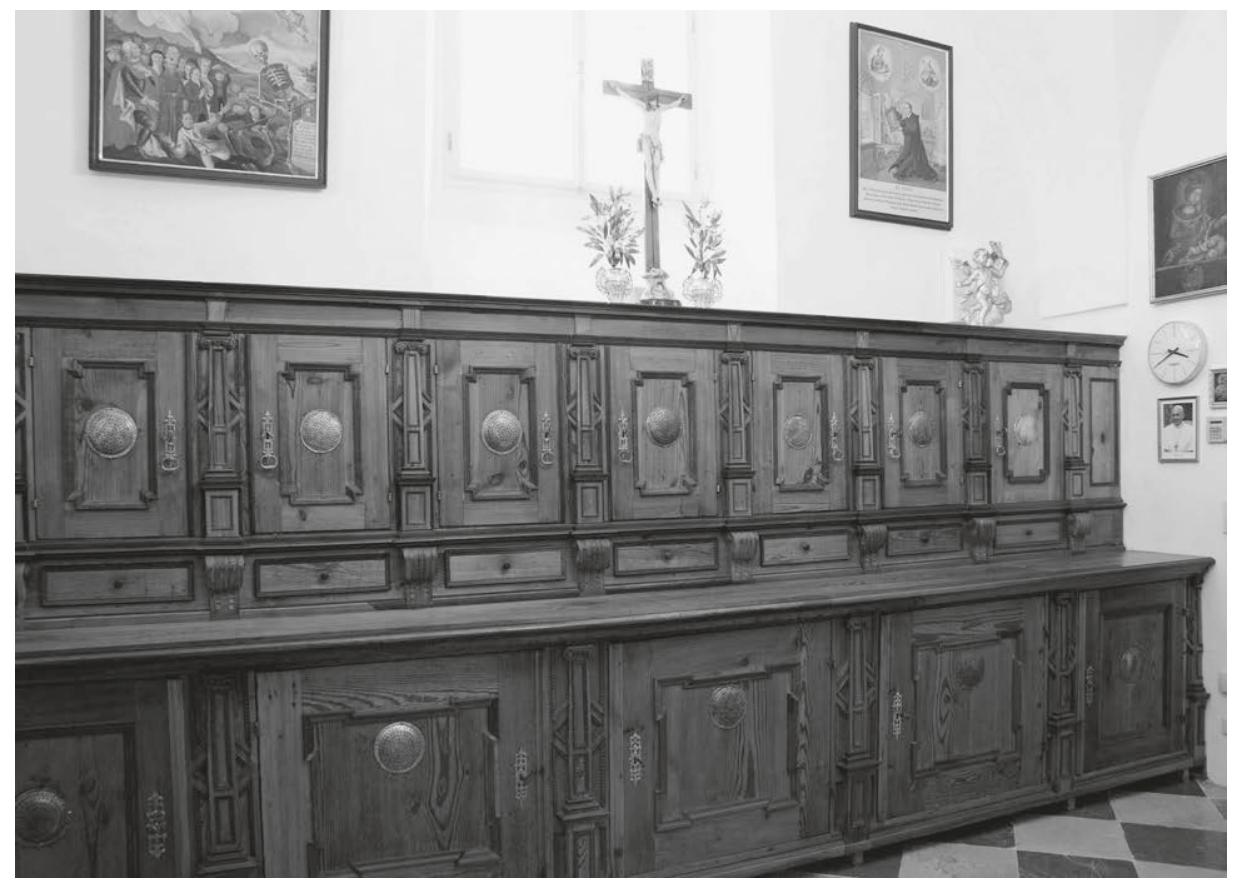

79 Sakristei, Aufsatzkredenz. Salzburg, um I675

der Schatzkammer von Lilienfeld aufbewahrt. ${ }^{134}$ Über einem tiefen, mit großen Türen versehenen Unterbau folgt der unmittelbar auf der Platte aufsitzende Oberschrank. Wie beim Möbel in Lilienfeld laufen auch in dessen Sockelbereich flache Schubladen, ein Gesims scheidet sie vom Hauptteil mit den Kelchkästen. Das Möbel schließt mit einem leichten Gebälk.

Ionische Pilaster gliedern die Möbelfassade. Unten stehen sie auf hohen Piedestalen, oben auf Rollvoluten und Sockeln, ohne aufeinander bezogen zu sein. Verkröpfte Rahmen mit nach außen tretenden bzw. eingezogenen Ecken fassen die Türfüllungen ein. Geflammte Profilstäbe säumen an Pilastern und Piedestalen Scheinfüllungen, ebenfalls von geflammten Leisten gebildete Keilstäbe liegen hinter den Stützen. Die Türfüllungen sind mit Belüftungsöffnungen versehen, perforierte Metallscheiben schützen den Inhalt. Beschläge und Metallblenden wurden verzinnt.

Das Möbel wurde bei einer Restaurierung um etwa I05 cm vergrößert, seine Länge betrug ursprünglich also ca. 4,30 m. Unten fügte der Tischler den letzten Schrank auf

I34 Bohr, Sakralmöbel (2017), Abb. I95. 
der rechten Seite hinzu, oben setzte er links eine halbe Achse, rechts eineinhalb Achsen an. Durch Farbunterschiede und einen anderen Verlauf der um die Füllungen gelegten Profile sind die modernen Teilstücke auf den Abbildungen gut zu erkennen. Neu sind außerdem die Füße, wahrscheinlich stand das Möbel einst auf einem Sockel.

\section{Paramentenschrank}

Salzburg, um I675

$\mathrm{H} 233,5 \mathrm{~cm} \times \mathrm{L} 322 \mathrm{~cm} \times \mathrm{T} 84 \mathrm{~cm}$

Zirbelkiefer. Eisen, verzinnt

Die Kredenz und der Schrank wurden als Garnitur konzipiert. Entsprechend einem Großteil der Schränke jener Epoche ist der dreitürige Paramentenkasten in Sockel, Hauptteil

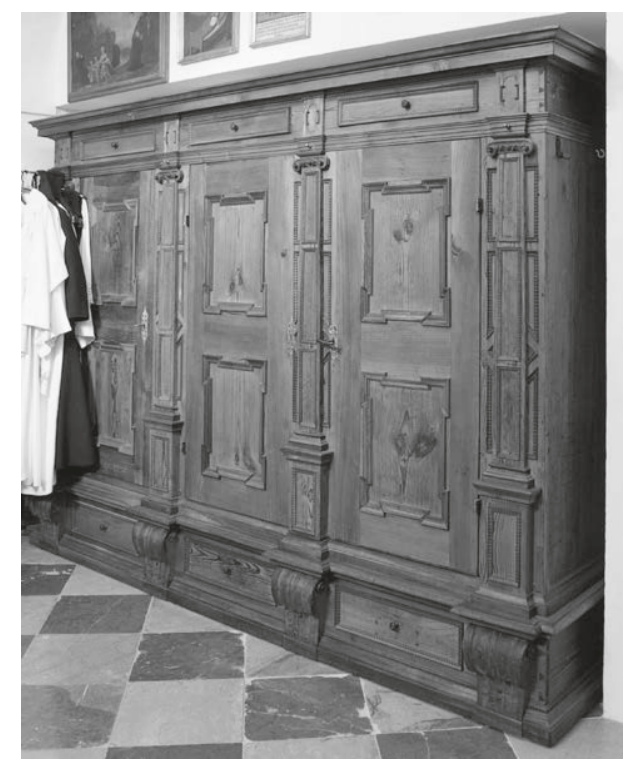

80 Sakristei, Paramentenschrank. Salzburg, um 1675 und Gebälk geschieden (Abb. 80). Stehvoluten im Sockelbereich, Piedestale und ionische Pilaster im Hauptbereich sowie ein vollständiges Gebälk verleihen dem Möbel den obligatorischen architektonischen Aufbau. Ein Charakteristikum von Schränken aus Salzburg und dem Salzburger Umland ist die Tatsache, dass Schubladen nicht nur im Sockel, sondern auch im Möbelhut laufen. Seine Konstruktion musste deshalb komplexer ausfallen, als dies sonst der Fall war. Die Türfüllungen sind verkröpft, erneut umschreiben Flammleisten Scheinfüllungen an Pilastern und Sockeln.

\section{Mattsee, Kollegiatstift}

\section{Stifts- und Pfarrkirche hl. Michael}

Zur Frühzeit des Klosters macht die relevante Literatur unterschiedliche Angaben, doch deuten Grabungsbefunde und Archivalien darauf hin, dass Herzog Tassilo III. um 760 in Mattsee ein Benediktinerkloster gründete, zehn Jahre später ist dort in Schriftquellen ein erster Abt fassbar. ${ }^{135}$ Die alte Abtei wurde wahrscheinlich Mitte

I35 In der Literatur wird verschiedentlich auch Herzog Tassilo II. genannt, das dürfte falsch sein. Vgl. all- 


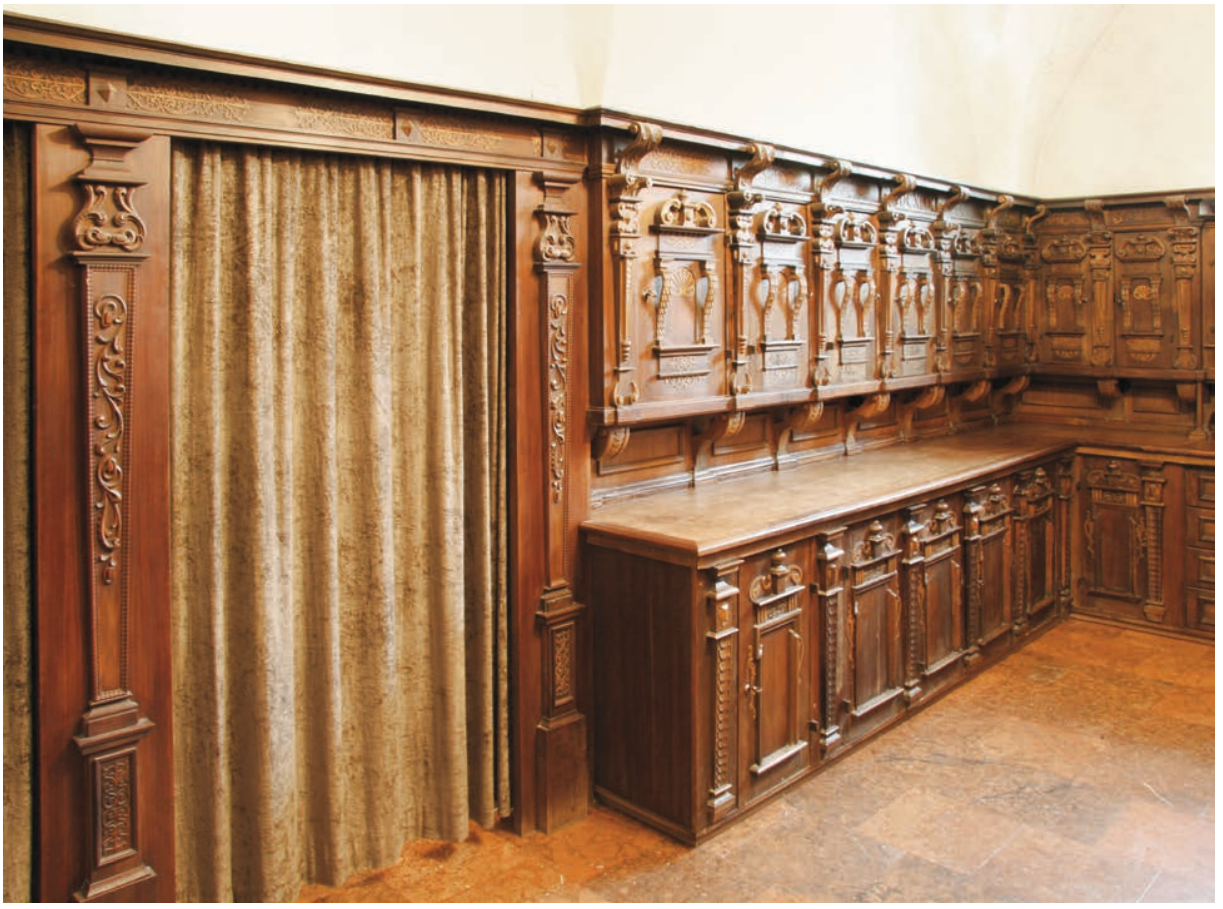

Farbtafel ıo Sakristei, Kelchschränke und Teilansicht des früheren Beichtstuhls. Tischlermeister Matthäus Steinle, r649

des Ir. Jahrhunderts in ein weltpriesterliches Kollegiatstift umgewandelt. Für das I2. Jahrhundert ist die Neuerrichtung der Kirche überliefert, die ein verheerender Brand I 276 einäscherte. Der Nachfolgebau, eine dreischiffige Pfeilerbasilika mit fünfjochigem Langhaus, dreijochigem Querschiff und zweijochigem Chor, wurde im 18. Jahrhundert auf Betreiben der Dekane Johann Sebastian Wisinger (reg. I680I713) und Franz Sebastian Wisinger (I73I-I774) barockisiert. Der Chor weist die gleiche Breite und Höhe wie das Mittelschiff auf, das Querhaus etwa die doppelte Tiefe der Seitenschiffe. Der einstige Kreuzgang lehnt sich an das nördliche Seitenschiff, was in unserem Kunstraum selten, aber doch gelegentlich vorkommt. ${ }^{136}$

gemein zum Stift ÖKT, Salzburg-Land, I (I 9 I 3), bes. 265-306; Hootz, Kunstdenkmäler (I 965-1968), Bd. I (1965), I36, 328; Röhrig, Alte Stifte (1967), 34-35; Spatzenegger, Geschichte (1977); Wagner, Mattsee (I 982); Dehio, Salzburg (1986), 230-234; Wagner, Mattsee (1 997); Hermann, Mattsee (2001); Kerschbaum, Mattsee (2010), 4-33.

I36 Kloster Stams wäre ein Beispiel hierfür, St. Peter in Salzburg ein weiteres.Vgl. hierzu die entsprechenden Abschnitte im vorliegenden Katalog. 


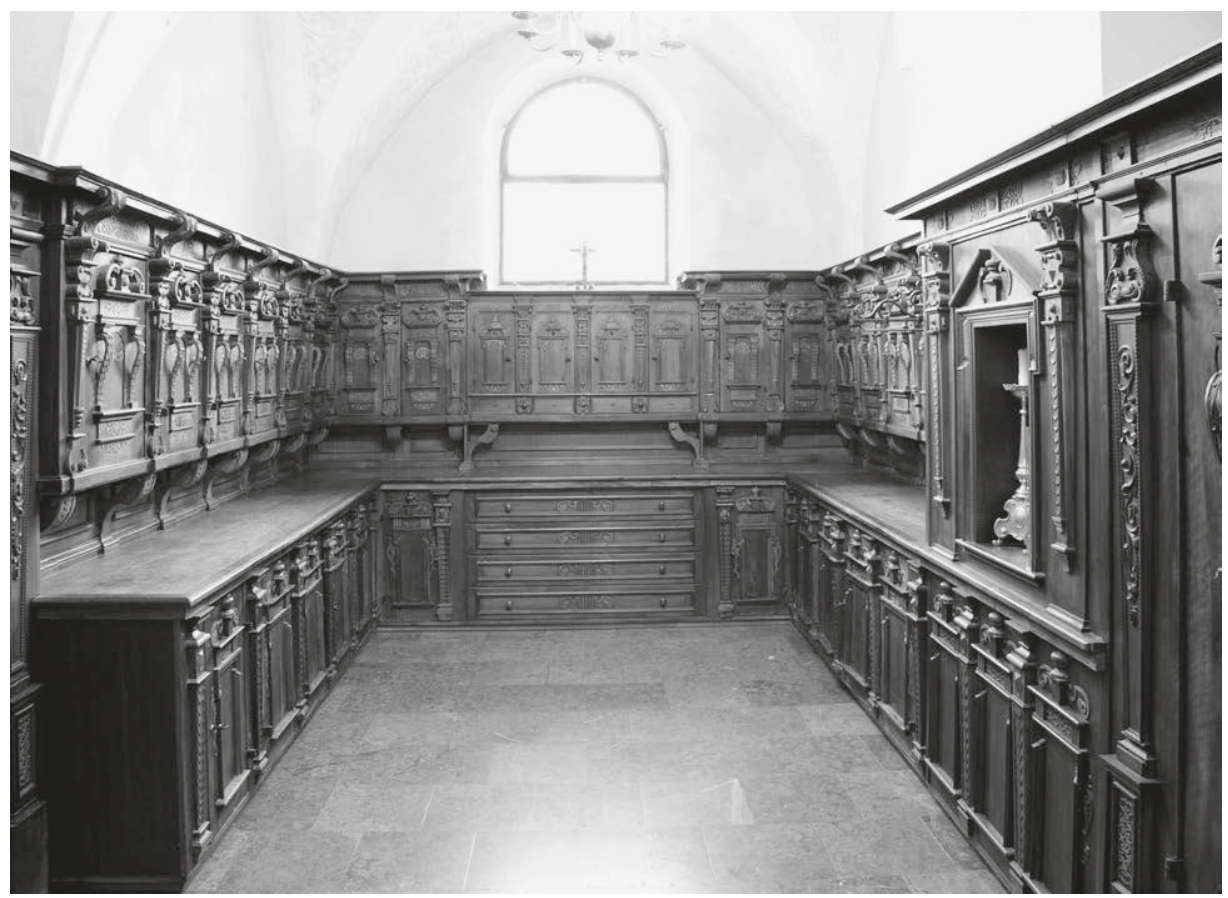

8I Sakristei, Kelchschränke. Tischlermeister Matthäus Steinle, r649. Der Unterschrank mit den Laden sowie der Aufsatz mit der Nische sind moderne Ergänzungen.

\section{Sakristei}

\section{Sakristeiausstattung}

Tischlermeister Matthäus Steinle, Schlosser Georg Clain, r649

Gesimshöhe 22I cm

Raummaße etwa L 6,80 m × B 4,00 m

Nuss, aufgedoppelt, geschnitzt. Eisen geschwärzt, ziseliert

Die mit einem zweijochigen Kreuzgratgewölbe überspannte Sakristei wird vom nördlichen Querhausflügel aus betreten. ${ }^{137}$ Durch ein Fenster in der Ostwand fällt Licht in den kleinen Raum, dessen Wände mit Sakristeischränken und einem Beichtstuhl verbaut sind.

I 37 ÖKT, Salzburg-Land, I (I913), bes. 267, 282, 284; Dehio, Salzburg (I986), 233; Wagner, Mattsee (1997), г8. 


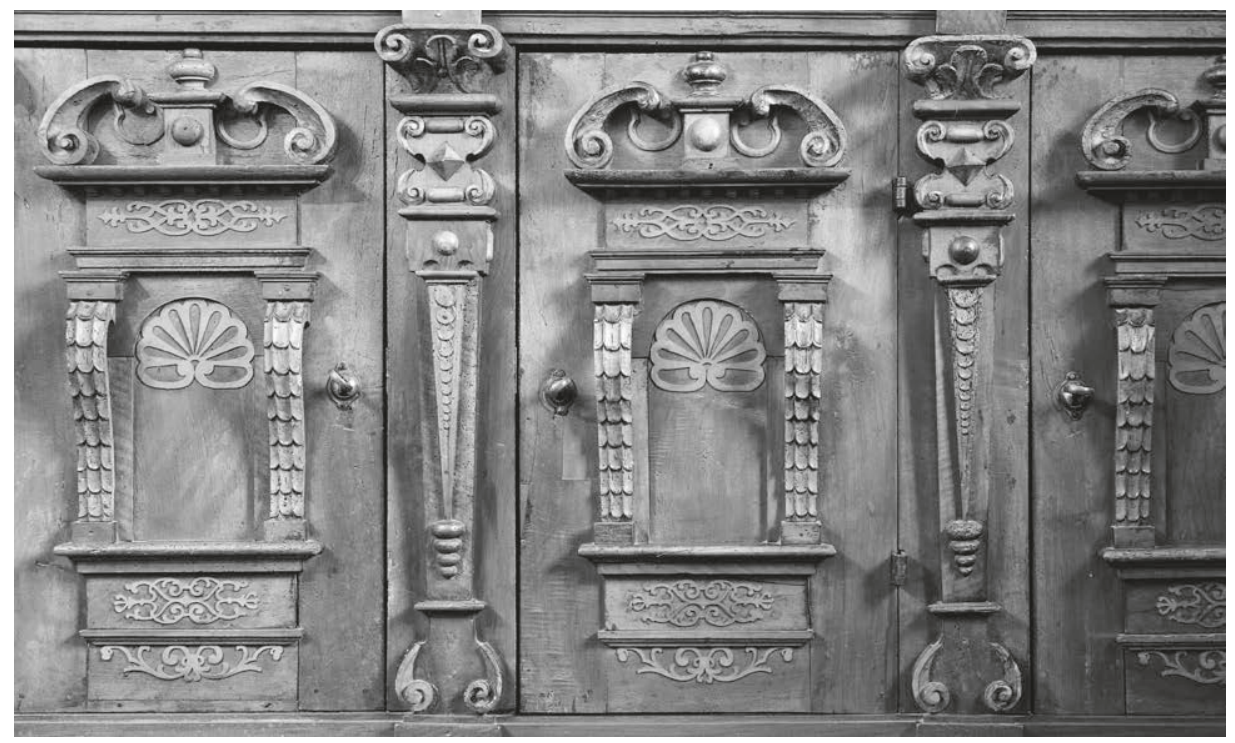

82 Sakristei, Kelchschränke (Detail). Tischlermeister Matthäus Steinle, r 649

Das Interieur besteht aus einer tiefen Substruktion und weit nach hinten tretenden Oberschränken, die auf Volutenkonsolen lasten (Farbtaf. ıо; Abb. 81, 82). Dorische und ionische Keilpilaster rhythmisieren die Fassade der Möbel, Schuppenmuster, kleine Schnörkel und »Nagelköpfe« zieren die Stützen, Ädikulä dienen als Türfüllungen. Unten besitzen sie geohrte und von Schweifwerkornamenten gesäumte Rahmen mit Volutengiebeln, in die je ein Postament mit einem Kegel eingestellt ist. Oben präsentieren sie sich mit einer aufwendigeren Gestaltung: Flankiert von Henkelpilastern, ruhen sie dort auf einem hohen Sockel und tragen ein Gebälk mit Sprenggiebel. Sägeornamente schmücken die zwischen die Stützen eingestellten Arkaden und zieren die Sockel und Giebelfelder der welschen Fenster. Über den Kapitellen folgt ein hohes, mit weitausladenden Agraffen gegliedertes Gebälk, das mit der römischen Jahreszahl MDCXLIX datiert ist. An die Möbel vor der Nordwand grenzt ein mit Vorhängen geschlossenes Segment, das einst als Beichtstuhl diente, auf der anderen Raumseite befindet sich ein Paramentenschrank. Die Möbel bestehen aus Nussholz, die Schnitzornamente und aufgelegten Sägemotive aus hellem Splintholz, ebenfalls aus Nuss.

Laut einem Zahlungsnachweis von I650 erhielt der Tischler Matthäus Steinle (Steinl) aus Mattsee, der in die Sakristey einen Kelchkasten auf der einen Seite gemacht, dann auf der andern Seiten gegenüber den andern dergleichen, ferner einen Beichtstubl und 
einen Messkleiderkasten gemacht hat, $70 \mathrm{fl}$ ausbezahlt. Die Beschläge lieferte der Schlosser Georg Clain aus Salzburg für 2 I fl. ${ }^{138}$

Das Möbelensemble wurde in den I96oer-Jahren bei einer Restaurierung überformt. Der mit einer Nischenarchitektur austaffierte Schrank, das Möbelsegment mit den breiten Schubladen unter dem Fenster und die Platte auf den Unterschränken sind modern. Zudem überzog man die Teilstücke zwischen den Konsolen mit neuem Furnier.

\section{Kirchenraum}

\section{Sakristeitür}

Tischlermeister Matthäus Steinle (?), um I649

Lichte Maße H I $82 \mathrm{~cm} \times \mathrm{B} 90 \mathrm{~cm}$

Eiche, massiv und aufgedoppelt, geschnitzt. Eisen

Das auf der Sakristeiinnenseite eher einfach gehaltene Portal präsentiert sich auf der Seite des Kirchenquerhauses reich verziert (Abb. 83). Eine querrechteckige verkröpfte Füllung nimmt sein unteres Drittel ein, darüber folgt eine hohe Ädikula. Zweifach nach außen gewölbte Henkelpilaster auf Piedestalen stützen ein hohes Gebälk mit Sprenggiebel und eingestelltem Postament mit Kegel. Blattwerk und Schuppen schmücken die Pilaster, Perlreihen und Profilstäbe runden das Bild ab. In der sparsamen Verwendung der geflammt gezogenen Profile zeigt sich an der Tür, übrigens auch an den Sakristeimöbeln, ein gravierender Unterschied zu vielen anderen Tischlerarbeiten unseres Kunstraums, an denen solche Profile in jener Zeit recht häufig vorkommen. Der Türgriff besitzt die Form eines Delphins.

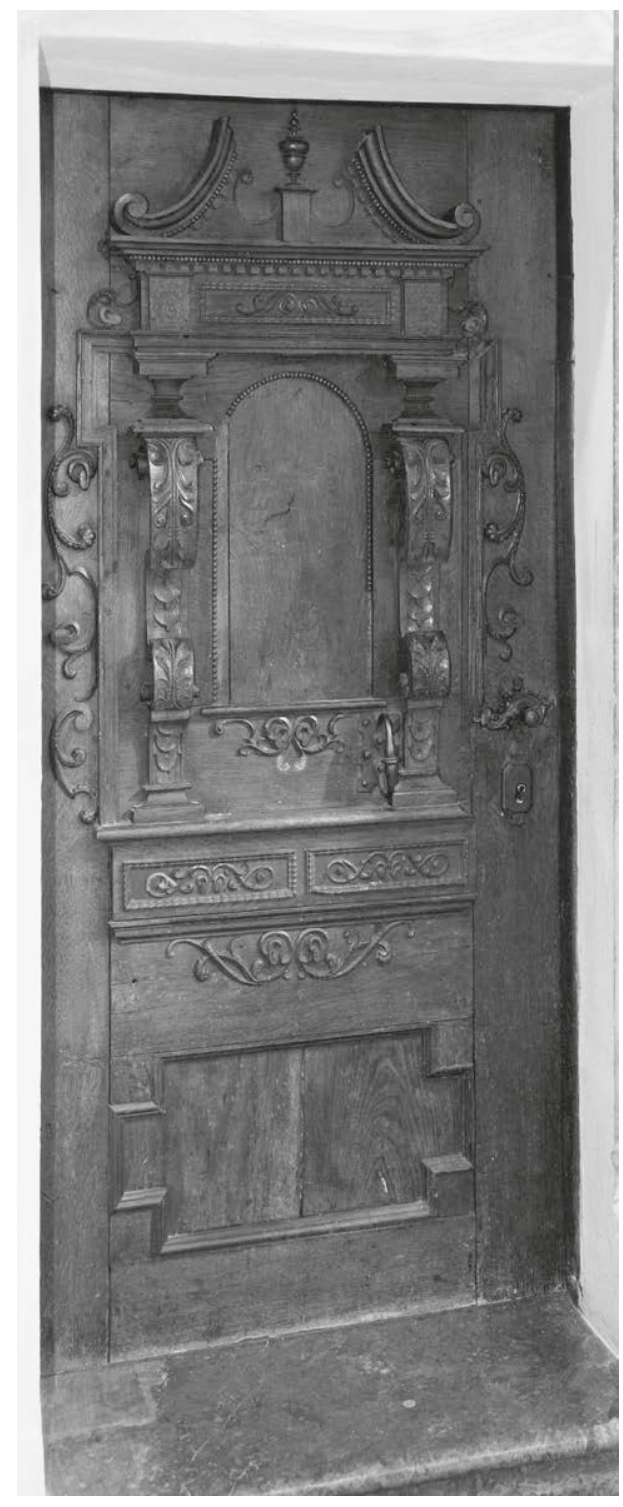

83 Sakristeitür. Tischlermeister Matthäus Steinle (?), um I 649

I38 Angaben und Zitat nach der ÖKT, Salzburg-Land, I (I9I3), 267. Matthäus Steinle war der Vater von Matthias Steinl (I643/44-1727), der gegen Ende des I7. Jahrhunderts in Wien als Kunsttischler, Elfenbeinstecher und »Kunstintendant« reüssieren sollte. Pühringer-Zwanowetz, Steinl ( I 966), 9-го. 


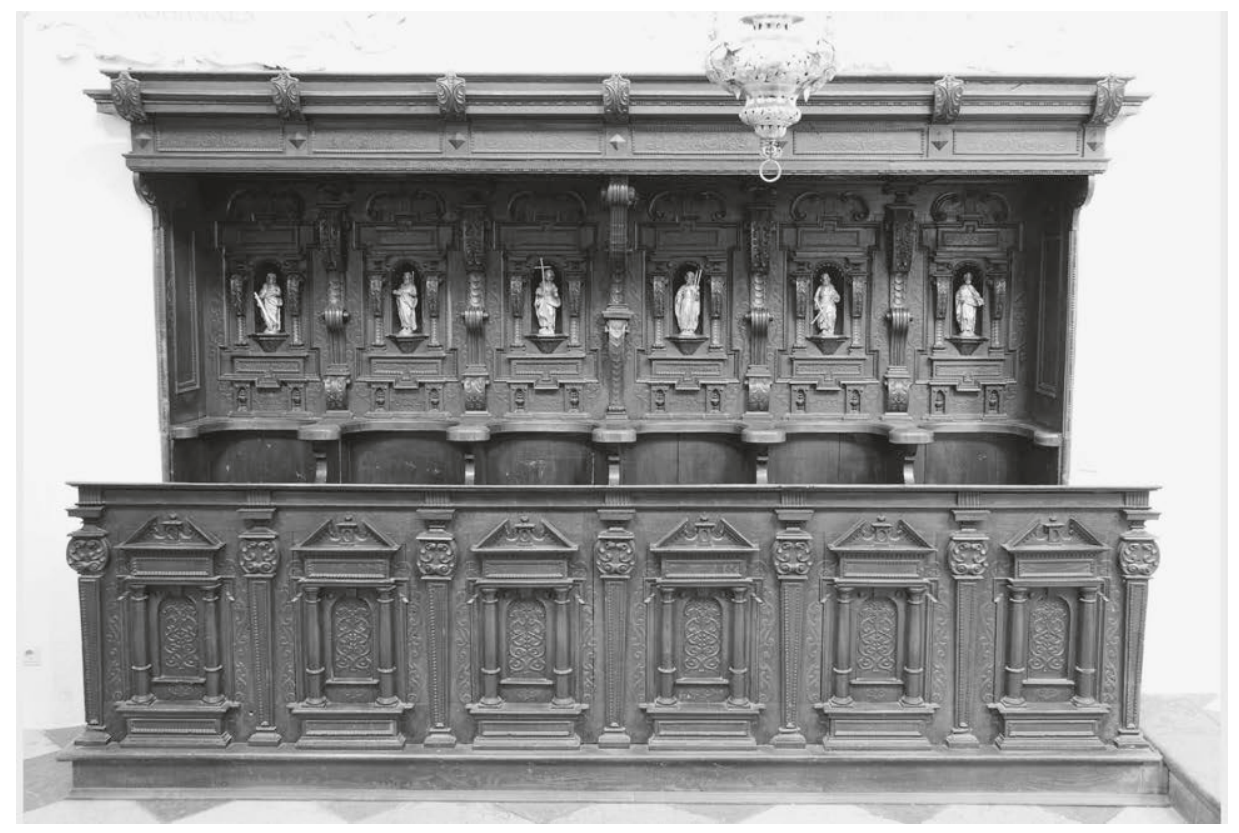

84 Chorgestühl. Tischler Matthäus Steinle (?), um I650

\section{Chorgestühl}

Tischler Matthäus Steinle (?), um I65o

HS I $7 \mathrm{~cm}$

$\mathrm{H} 240 \mathrm{~cm}(+\mathrm{I} 7 \mathrm{~cm}) \times \mathrm{L}_{392} \mathrm{~cm}$

Eiche, Nadelholz, massiv und aufgedoppelt, geschnitzt, dunkel gebeizt, Holz vergoldet

Das Gestühl zählt auf beiden Seiten des Chorraums sechs Stallen (Abb. 84, 85). ${ }^{139}$ Keilpilaster unterteilen die Brüstung. Die Stützen besitzen ein Schulterstück sowie ein manieristisches Kapitell mit dem charakteristischen schmalen Hüftstück zwischen einem breiten Anlauf und dem ebenso breiten Abakus. Ädikulä, die sich aus massiven Sockeln, Säulen und Giebeln zusammensetzen, füllen die Achsen zwischen den Pilastern. In die Interkolumnien sind rundbogige Arkaden eingestellt.

Eine wesentlich reichere Gestaltung zeichnet die Rückwand aus. Nun basiert die Gliederung der Großform auf zweifach geschwungenen Volutenpilastern über ebenfalls gebauchten Konsolen. Wieder sind welsche Fenster eingefügt. Sie rahmen $\mathrm{Mu}-$

I39 ÖKT, ebd., bes. 284; Dehio, Salzburg (I 986), 233; Wagner, Mattsee (1997), I 8 ; Kerschbaum, Mattsee (2010), I7. 


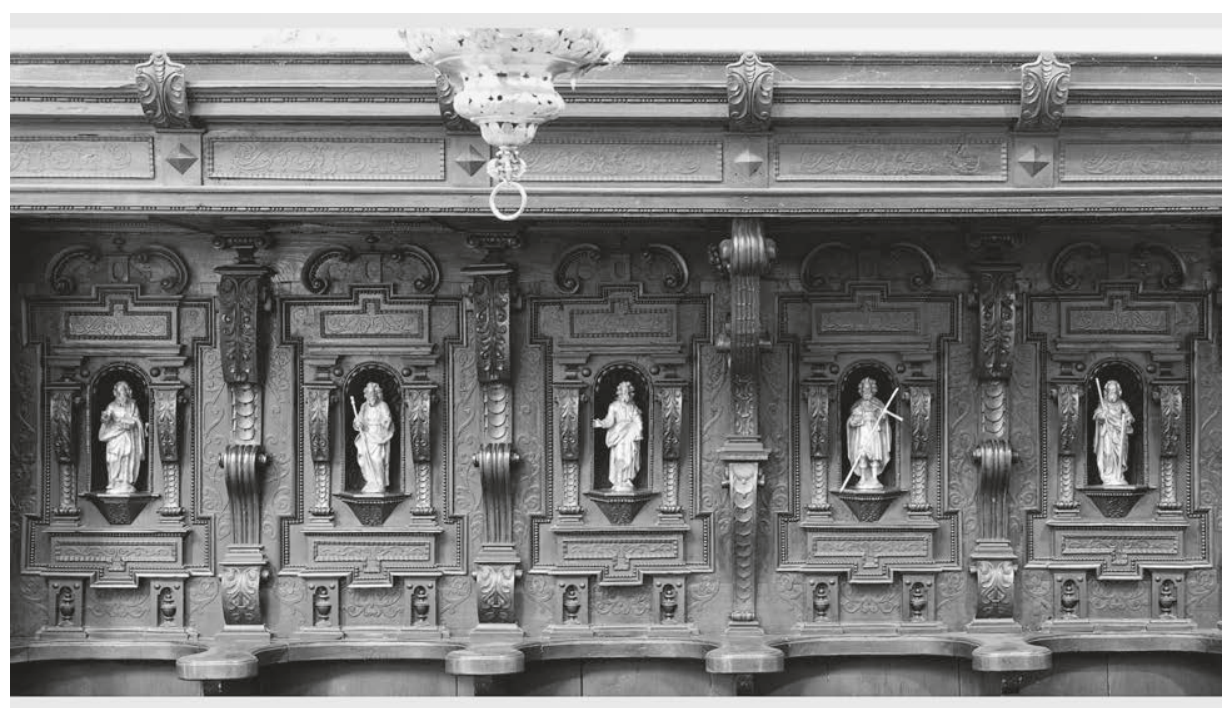

85 Chorgestühl (Detail). Tischler Matthäus Steinle (?), um I650

schelnischen mit Apostelfiguren zwischen weiteren Stützen, Sprenggiebel überragen die Binnenfelder. Als Plinthen dienen Konsolen über einem Sockelband, das seinerseits von Piedestalen getragen wird. Nischen mit kleinen Vasen vervollständigen die Postamente. Seitliche Hochwangen tragen zusammen mit einer kräftigen Mittelkonsole das einen tiefen Baldachin formende Gebälk. Die hohen Außenwangen des Gestühls, das in eine Wandnische eingepasst ist, schließen das Möbel zum Mauerwerk hin ab und sorgen so für einen isolierenden Schutz gegen Zugluft.

Schuppenmuster, Laubwerkornamente, Flammleisten, Perlreihen und ausgesägte Schweifwerkmotive zieren das Möbel selbst auf den Innenseiten der Hochwangen und auf der Unterseite des Baldachins. Die Skulpturen sind vergoldet, zur Herstellung der Stallen und der Rückwand hinter den Sitzen wählten die Tischler dunkel gebeiztes Nadelholz. Werkstoff aller anderen Möbelteile ist dunkelbraune Eiche. In der ÖKT wird das Gestühl dem Mattseer Tischler Matthäus Steinle zugeschrieben. Belege dafür liegen nicht vor, doch ist die hohe handwerkliche und künstlerische Qualität von Sakristeimöbeln und Chorgestühl durchaus vergleichbar. Die Statuetten sind Kopien, die Originale werden heute im Stiftsmuseum aufbewahrt. ${ }^{140}$

I 40 Kerschbaum, ebd. 


\section{Michaelbeuern, Benediktinerstift}

Ein gesichertes Gründungsdatum für das Kloster ist nicht überliefert. ${ }^{141}$ In einer Urkunde von 977 wird die Abtei erstmals erwähnt, möglicherweise reichen die Anfänge der Mönchsgemeinschaft jedoch auf das achte Jahrhundert zurück. Als typisch für die Salzburger Gegend jener Epoche gilt ein kleiner, aus einer Kirche und einer vierflügeligen Klosteranlage bestehender Architekturkomplex mit hölzernen Gebäuden. ${ }^{142}$ Für I072 ist die Weihe einer Kirche verbürgt, wahrscheinlich handelte es sich um einen Neubau oder tiefgreifenden Umbau der ursprünglichen Sakralarchitektur. I 266 wurde die Abtei durch bayrische Truppen geplündert, zu weiteren Zerstörungen kam es I 364 während des bayrisch-österreichischen Kriegs. Abt Ulrich IV. Hofbauer (reg. I6 I4I626) veranlasste die barocke Überformung der Anlage. Auf die Jahre um I692 datiert die Aufstellung des Hochaltars, den die Tischler Georg Wendtner und Matthias Steinl (I643/44-I 727), der Bildhauer Meinrad Guggenbichler (I649-1723) sowie der Fassmaler und Vergolder Johann Martin Schaumberger († I 7 I 2) geschaffen hatten. Das Altarblatt kam aus dem Atelier Johann Michael Rottmayrs (I654-I730). ${ }^{143}$ In den r93oer-Jahren ließ Abt Maurus Riha (reg. I933-r 969) das barocke Gewölbe in der Kirche entfernen, um sie zwischen r 947 und r 950 zu reromanisieren. ${ }^{144}$

Heute präsentiert sich der Sakralbau als südlicher Abschluss eines mit mehreren Innenhöfen ausgestatteten Areals, das sich trapezförmig nach Norden hin ausdehnt. Die Kirche ist dreischiffig, das Langhaus umfasst sieben Joche. Statt eines Gewölbes liegen moderne Holzbalkendecken über Mittelschiff und Seitenschiffen.

\section{Chorkapelle}

Die r 948 umgebaute dreischiffige Chorkapelle lehnt sich im Obergeschoss an die Nordseite der Apsis an. ${ }^{145}$ Kassetten überspannen die gewölbte Mittelachse, seitlich

\footnotetext{
I4I ÖKT, Salzburg-Land, I (г913), bes. 477-556; Mayr, Michaelbeuern (1958); Hootz, Kunstdenkmäler (1965-1968), Bd. I (I965), I39-I4I, 328-329; Röhrig, Alte Stifte (1967), 40-42; Stenzel, Stift (1977), I48-I5 I Dehio, Salzburg (1986), 248-253; Haidenthaler, Michaelbeuern (2001); Dopsch/ Hahnl/Koll, Michaelbeuern (200I), bes. 655-693. Vgl. außerdem die relevanten Beiträge in Wagner, Benediktinerabtei Michaelbeuern (I985).

I42 Zur Gestaltung der frühen Klosteranlagen vgl. Dopsch/Hahnl/Koll, ebd., 728.

I43 ÖKT, Salzburg-Land, I (I9I 3), 48 I, 482; Dehio, Salzburg (I 986), 249. Zu Matthias Steinl vgl. allgemein Pühringer-Zwanowetz, Steinl (1966).

I44 Ein Foto aus dem frühen I9. Jahrhundert (ÖKT, ebd., 490) zeigt das Kircheninnere noch mit der barocken Einwölbung; Dehio, ebd., 248; Dopsch/Hahn1/Koll, Michaelbeuern (200I), 74I-742.

I45 Zu Raum und Ausstattung ÖKT, ebd., 48 I, 522 ; Mayr, Michaelbeuern (I958), I2; Dehio, ebd., 25 I; Dopsch/Hahn1/Koll, ebd., 736; Haidenthaler, Michaelbeuern (200I), I 8.
} 


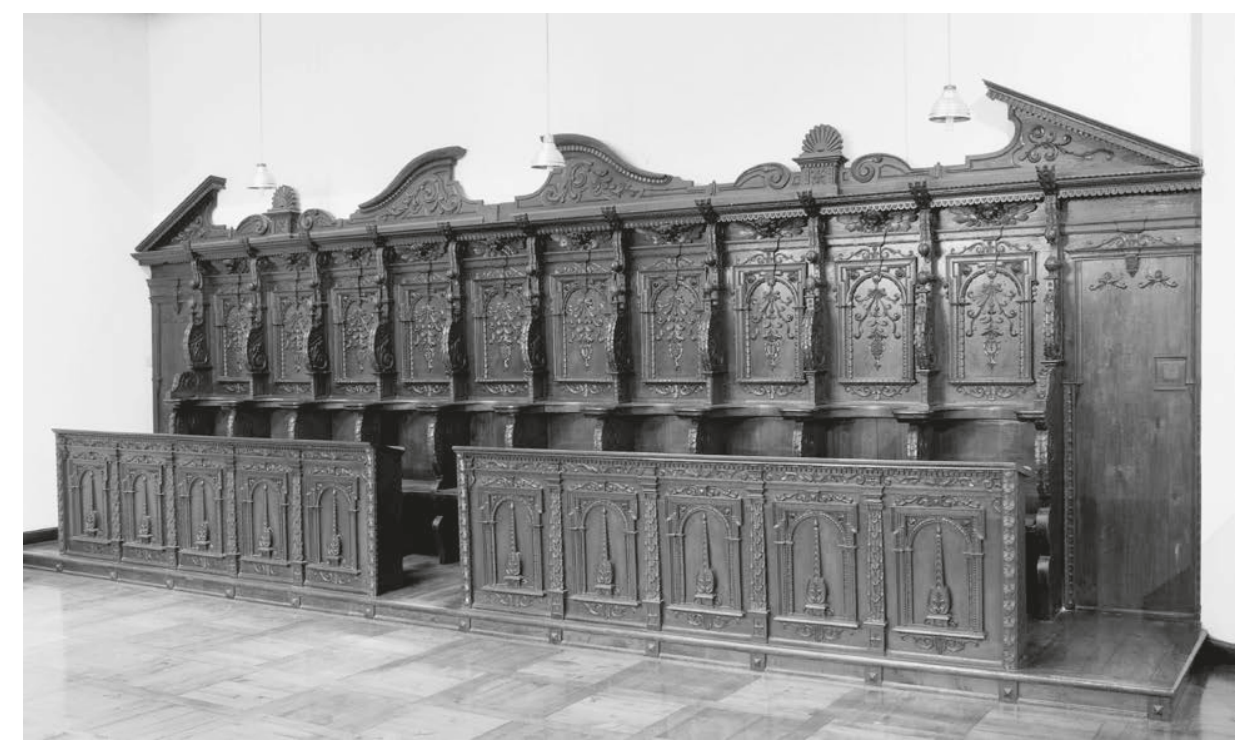

86 Chorkapelle, Chorgestühl. Matthäus Steinle (?), um I640/50

tragen Balken eine gerade Decke. Das Gestühl steht vor den Längswänden des Raums, die Abtstalle vor einer Stirnseite.

\section{Chorgestühl}

$\mathrm{HS}_{\mathrm{I}} 3,5 \mathrm{~cm}$

$\mathrm{H}_{282,5} \mathrm{~cm}(+\mathrm{I} 3,5 \mathrm{~cm}) \times$ gesamte $\mathrm{L} 805 \mathrm{~cm}$

\section{Abtstubl}

HS I $3,5 \mathrm{~cm}$

$\mathrm{H}_{3} 05 \mathrm{~cm}\left(+\mathrm{I}_{3}, 5 \mathrm{~cm}\right) \times \mathrm{B} \mathrm{I} 67 \mathrm{~cm}$

\section{Türen}

Türflügel $\mathrm{H} 200 \mathrm{~cm} \times \mathrm{B}$ 100 cm

Matthäus Steinle (?), um I640/50

Eiche, massiv, dunkelbraun lasiert und gefasst. Eisen, ziseliert, verzinnt

Das Gestühl besteht aus zwei Sitzreihen mit je zehn Stallen, die von seitlichen Wandpaneelen flankiert werden (Abb. 86-88). Sich verjüngende ionische Pilaster gliedern die 


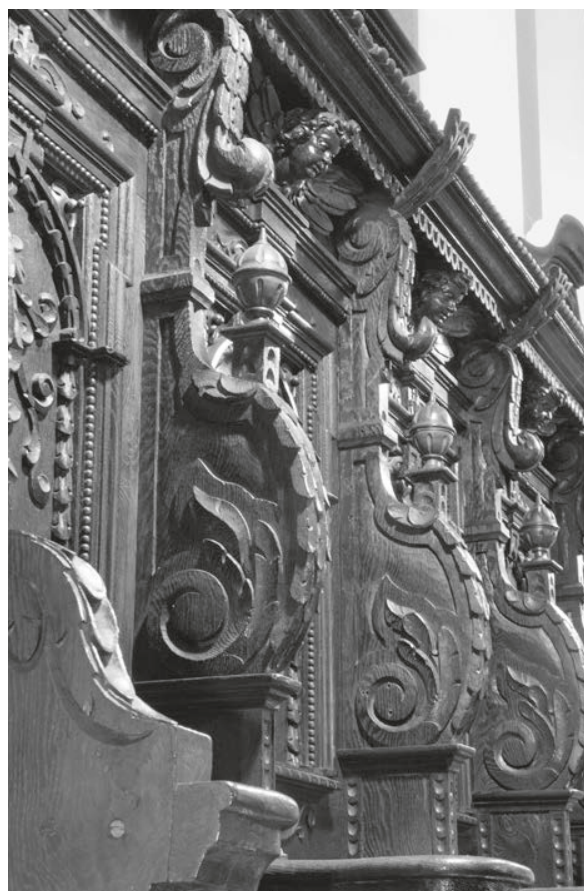

87 Chorgestühl (Schrägansicht der Rückwand). Matthäus Steinle (?), um I640/50

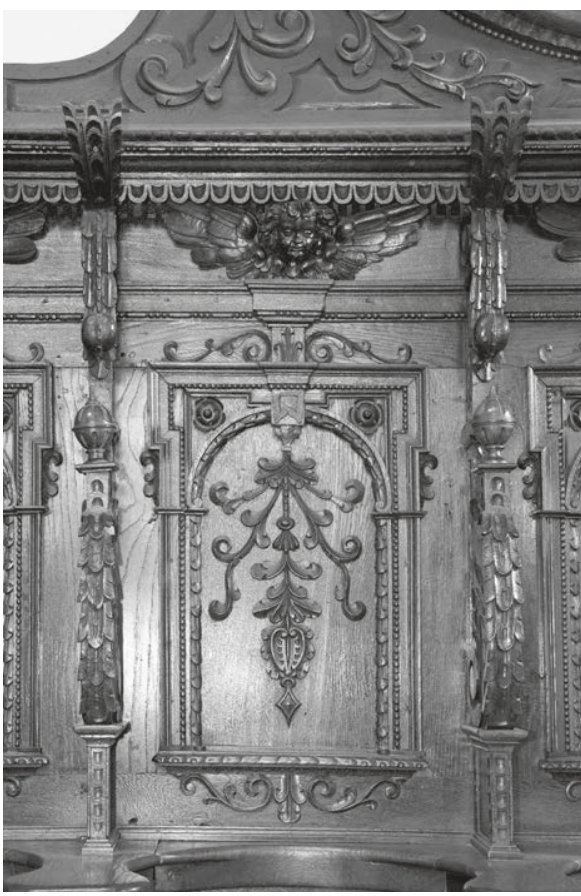

88 Chorgestühl (Rückwanddetail). Matthäus Steinle (?), um I640/50

Brüstung, Ädikulä mit Rundarkaden und eingestellten Obelisken bilden die Füllungen. Das Brüstungsgebälk ist verkröpft, die Frieszone mit vegetabilen Ranken verziert. Ähnliche Ornamentmotive liegen auf den welschen Fenstern, die von Perlleisten eingefasst werden.

Die geschweiften Wangen der Sitzreihe setzen sich als Hochwangen bis zum Dorsalegebälk fort, schuppenartiges Blattwerk bereichert ihre Vorderkanten. In mittlerer Höhe formen sie große halbrunde Gebilde mit Postamenten für Kegel aus. Die Docken enden mit Konsolen, die sich über den Architrav und Fries legen, um das Abschlussgesims zu stützen. ${ }^{146}$ Cherubim zieren den Gebälkfries. Zu Ädikulä wurden auch die Dorsalefüllungen umgedeutet, an Schnüren hängende vegetabile Ornamente schmücken die Binnenfelder. Der flache Dorsaleaufsatz schließt die seitlichen Vertäfelungsstreifen mit ein, Giebel bekrönen das Möbel. ${ }^{147}$ Den Raum dazwischen füllen Liegevoluten und Postamente mit Palmettenmotiven.

I46 Nicht zuletzt durch die Gestaltung der Hochwangen ähnelt das Gestühl jenem in Seitenstetten von I652. Bohr, Sakralmöbel (2017), 453-455.

I47 Dass der Giebel nicht mittig über dem Gestühl positioniert werden konnte, ist der Form des nicht 


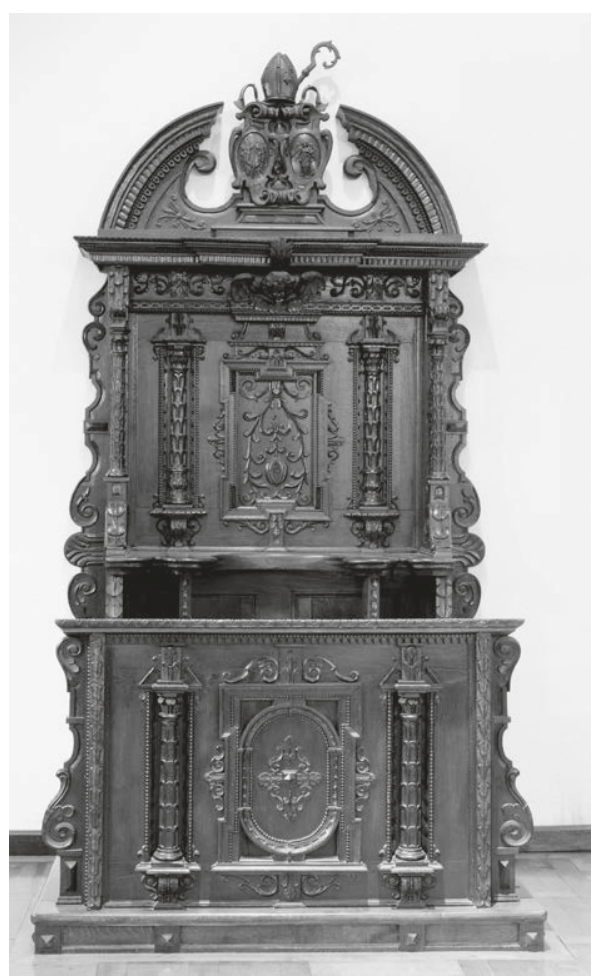

89 Chorkapelle, Abtthron. Matthäus Steinle (?), um I 640/50

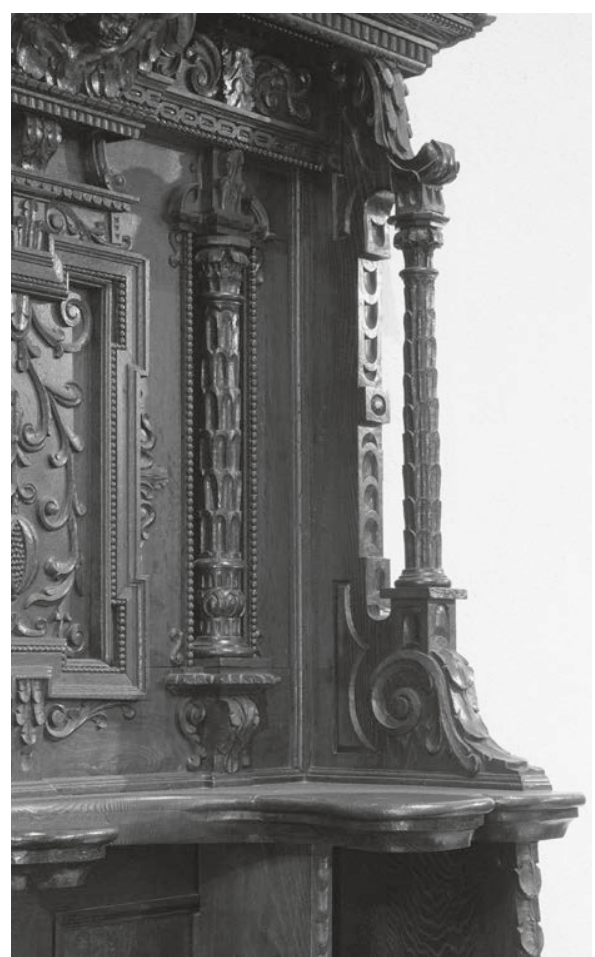

90 Abtthron (Detail). Matthäus Steinle (?), um I $640 / 50$

Aufwendiger als die Hauptreihen des Gestühls gestalteten die Tischler die Sessio des Abtes, deren Brüstung schmale Lisenen und geschweift gesägte Rahmen flankieren (Abb. 89, 90). Seitlich einer großen Ädikula mit zentralem Hochoval ergänzen von Nischen hinterfangene Säulen die Füllung, Perlreihen, Blattwerk und gebrochene Bögen zieren die Architekturmotive.

Hochwangen schließen die Stalle zu den Seiten hin. Über der Schulterstütze treten sie in der Tiefe zurück, tragen aber zusammen mit vorgestellten Säulen das Gebälk und einen hohen Sprenggiebel, den die Wappen des Stiftes und des Abtes Michael Trometer (reg. I637-I676) vervollständigen. ${ }^{148}$ Das Dorsale ist ähnlich wie die Brüs-

ganz symmetrischen Gewölbes im Sommerkonventchor geschuldet, in dem das Gestühl zuvor gestanden hatte. Mündlicher Hinweis von Abt Johannes Perkmann.

I 48 Das Stiftswappen zeigt zwei nebeneinander gestellte Flügel, das Wappen des Abtes einen Engel mit einer Fanfare. 


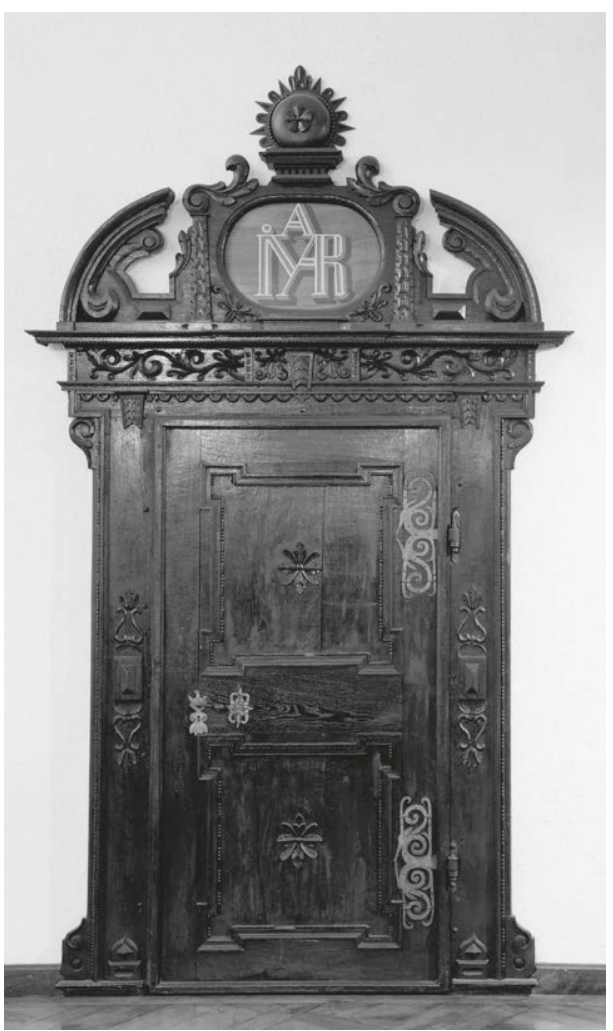

9I Chorkapelle, Tür. Matthäus Steinle (?), um I640/50 tungsvorderseite konzipiert. Wieder rahmen geschuppte Säulen eine Interkolumnie mit hochrechteckigem Feld, das jedoch nur noch entfernt an eine Ädikula erinnert. Die Füllung trägt eine Art von Giebel, über dem das $\mathrm{Ab}$ schlussgebälk der Rückwand mit einem Cherub verziert ist.

Große Zapfenlöcher bezeugen, dass das Gestühl ursprünglich mit vier drehbaren Lesepulten ausgestattet war, die Brüstung des Abtstuhls trug ein fünftes. Eines davon beließ man in der nördlichen Gestühlsreihe, die restlichen Exemplare haben sich in einem Depotraum des Stiftes erhalten. ${ }^{149}$ Sie bestehen aus einem kräftigen Rundstab und dem dachförmigen Pult.

Die Wappen belegen, dass das Gestühl von Abt Trometer in Auftrag gegeben wurde, die Ornamentmotive lassen den Schluss zu, dass dies bald nach seinem Regierungsantritt geschah. Flammleisten fehlten seit den späten I62oer- oder den 3oer-Jahren bis weit in das letzte Jahrhundertdrittel hinein als Ziermotiv an kaum einem Möbel aus jener Kunstlandschaft. Hier kommen sie noch nicht vor. Au-

ßerdem sucht man vergebens nach jenen knorpeligen Verdickungen, die beispielsweise die I657/58 entstandene Sakristeiausstattung von St. Lambrecht charakterisieren (Abb. 267). Stattdessen übernehmen die in Michaelbeuern verwendeten delikaten Formen Beschlagwerkornamente aus der Zeit um und nach I6oo. Das Gestühl vertritt eine Stilstufe, in der sich das Knorpelwerk noch kaum entfaltet hatte, das Ensemble erinnert an die Ausgestaltung der r 648 aufgestellten Möbel in der Innsbrucker Jesuitenkirche (Abb. 306-309). Der Datierungsvorschlag in der Literatur, um r66o, ist folglich zu korrigieren. ${ }^{150}$ Die Vermutung, dass Matthäus Steinle der Urheber des Gestühls war, könnte aber zutreffen. ${ }^{151}$

I 49 Freundlicher Hinweis von Johannes Perkmann.

I 5 O ÖKT, Salzburg-Land, I (I9I3), 522.

I 5 I Dopsch/Hahnl/Koll, Michaelbeuern (2001), 736. 
Aus der Zeit des Chorgestühls stammen ebenfalls die beiden Türen in der Nord- und Ostwand der Kapelle (Abb. 9r). Konsolen am Portalrahmen stützen das Gebälk, den Giebel und den hohen Auszug, der die Türen überragt. Neubemalte Kartuschen im Giebelfeld tragen die Zeichen Christi sowie den Namen Mariens. Die Türblätter sind in zwei nahezu quadratische Füllungen mit verkröpften Ecken unterteilt. Breite Hohlkehlprofile und Perlreihen fassen die Binnenfelder ein, ansonsten ist das Portal mit ähnlichen Ziermotiven wie das Gestühl geschmückt. Schwere Schlösser aus graviertem und verzinntem Eisen verriegeln die Türen.

\section{Gästerefektorium}

Im Refektorium, einem auf zwei Seiten durchfensterten Longitudinalraum mit flacher stuckverzierter Decke, haben sich Türen und drei Tische aus der Barockzeit erhalten. Die

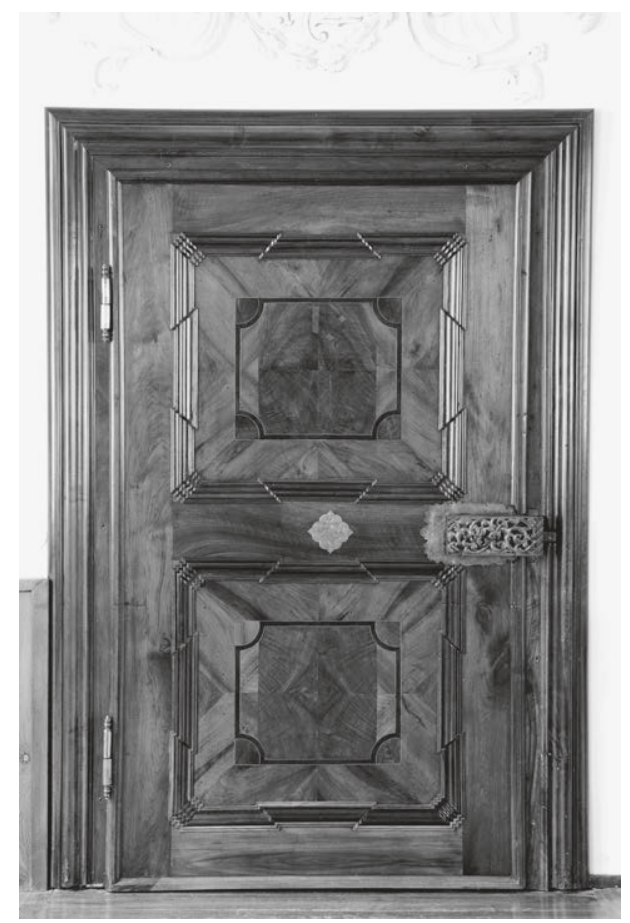

92 Refektorium, Tür. Michaelbeuern, um I $720 / 25$ Stuckverzierung ist I722 datiert, ein Datum, das auch für die Ausstattung zutreffen dürfte.

\section{Türen}

Michaelbeuern, um I $720 / 25$

$\mathrm{H}_{2}$ I $4 \mathrm{~cm} \times \mathrm{B}$ I $24,5 \mathrm{~cm}$ (Türblatt)

Nuss und Nussmaser, massiv und furniert auf Nadelholz. Eisen, geschwärzt, Zinn- und Messingblech

Ein profilierter Rahmen fasst die in Rahmenbauweise konstruierten Türen ein (Abb. 92). Die Profilleisten, die die Füllungen halten, sind mit großer Perfektion gefertigt, die komplizierten Verkröpfungen an ihren Ecken formen ein ausgefallenes Zick-Zack-Muster. Ein breiter, vierfach gestürzter Fries säumt die mit einer zusätzlichen Ader eingefassten Mittelfelder. Als Furnier wurde für die Binnenfelder Maserholz aus Nussbaum gewählt. 
Geschweift geschnittenes und graviertes Zinnblech umgibt die Kastenschlösser, die eine durchbrochene Platte aus getriebenem Messingblech bereichert. Distelähnliches Blattwerk, wie es etwa von Johann Indau ( I 65 I-I690) um I 686 in das österreichische Formenvokabular übernommen wurde, gibt die Ornamentmotive vor. ${ }^{152}$ Die Marketerien selbst entbehren jener Laub- und Bandlwerkmotive, die für das frühe I 8. Jahrhundert charakteristisch waren.

Zusammen mit den Türen entstanden die Lesekanzel und die Refektoriumstische. Bei unterschiedlichen Maßen, aber weitgehend übereinstimmendem Aussehen bestehen die Tische vorwiegend aus massiv verarbeitetem Nussbaum.

\section{Tisch der Klostervorsteher}

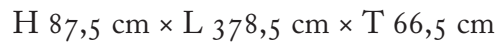

\section{Tische}

$\mathrm{H} 85 \mathrm{~cm} / 88 \mathrm{~cm} \times \mathrm{L} 235,5 \mathrm{~cm} / 392 \mathrm{~cm} \times \mathrm{T} 63 \mathrm{~cm}$ Michaelbeuern, um I720/25

Nussholz, Zwetschke, Ahorn (?), Eiche, massiv und furniert, Nadelholz

Der Tisch der Klostervorsteher ist mit Pilastern architektonisch instrumentiert (Abb. 93). Die Basen und Blockkapitelle liegen auf einer Höhe mit der verkröpften Sockelleiste und dem ebenfalls verkröpften Gesims. Wie an der beschriebenen Tür präsentieren sich die Profile um die Füllungen handwerklich perfekt ausgearbeitet. Und wieder rahmt ein Fries aus diagonal aufgelegtem Nussfurnier eine breite Ader und ein Zentrum mit gespiegeltem Nussholz. Einfacher sind die Seitenwangen, an denen Massivholzrahmen ein Mittelfeld mit schlichter Maserung säumen. Die kaum überstehende Platte ist aufgelegt, die Kante abgerundet.

Hinsichtlich ihrer Großform korrelieren die beiden anderen Tische mit dem der Klostervorsteher, doch wurde nun auf eine Pilastergliederung sowie auf Marketerien verzichtet. Zudem sind die Verkröpfungen um die zentralen Kompartimente schlichter. Bezeichnend für die Refektoriumstische der alten Orden in Österreich ist der Umstand, dass sie nicht wie die Möbel der Franziskaner auf Schragen oder "gewöhn-

I 52 Berliner/Egger, Vorlageblätter (I98 I), Bd. I, 88, Bd. 3, Abb. I o6o-Io62. Als weitere Ornamentstecher mit vergleichbaren Motiven aus der Zeit um r680 bis I 700 wären vor allem Matthias Echter aus Weiz (r653-r701/o3, in Graz nachweisbar), Johannes Unselt (I68 I Meister in Augsburg, letztes Datum I696) und Leonard Heckenauer d.J. (Stichdaten zwischen I679 und I 704) zu nennen. Berliner/Egger, ebd., Bd. I, S. 87-89, Bd. 3, Abb. 1054, 1063, 1068, 1069 


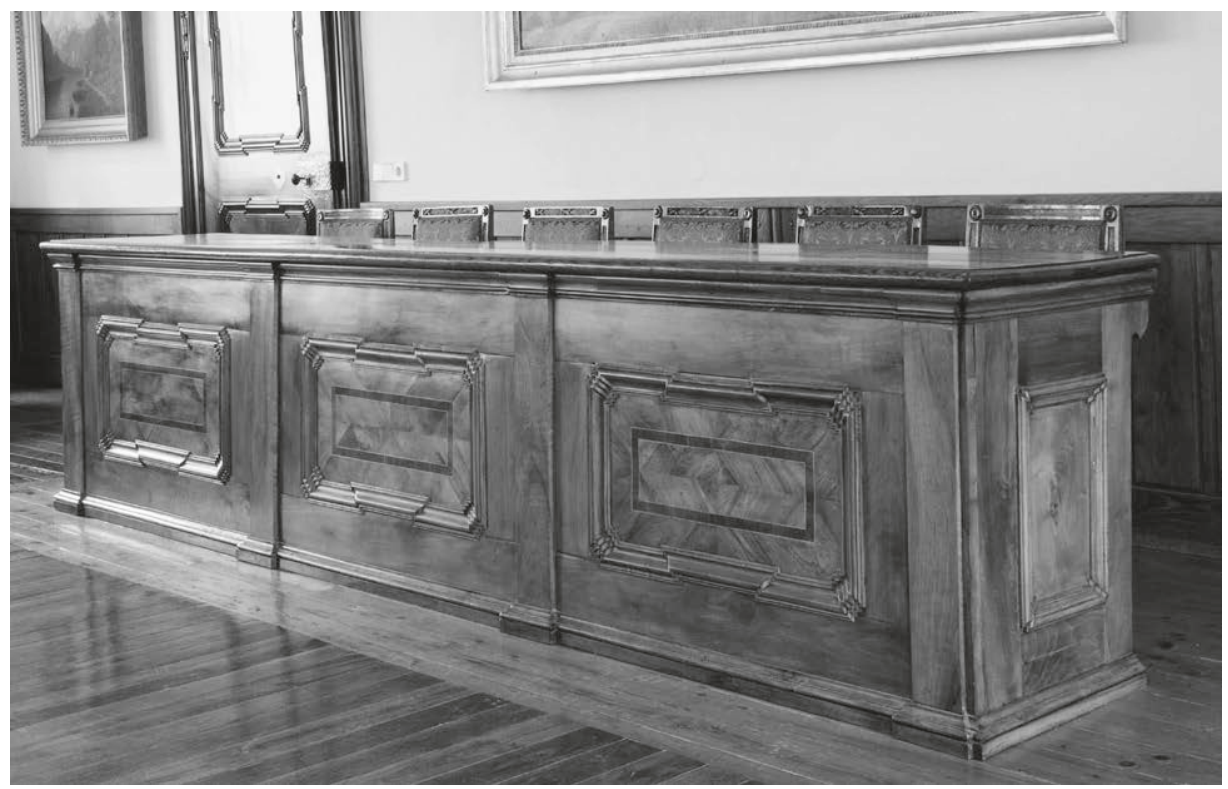

93 Refektorium, Tisch der Klostervorsteher. Michaelbeuern, um I 720/25

lichen« Tischgestellen stehen (Abb. o9), sondern vorn und seitlich geschlossen sind. Manchmal besitzen sie wie die Möbel in Michaelbeuern auch noch eine Bodenplatte, die einige Zentimeter über dem Fußboden in den Rahmen des Möbels eingepasst ist.

\section{Lesekanzel}

Michaelbeuern, um I720/25

Fußhöhe ca. $10 \mathrm{~cm}$

H I4I, $5 \mathrm{~cm}(+$ IO $\mathrm{cm}) \times$ B I I I cm $\times$ T I $30 \mathrm{~cm}$

Nussbaum, Nussbaummaser, Eibe, Ahorn (?), furniert auf Nadelholz. Eisen, graviert, geschwärzt

Pilasterartige Lisenen vor den diagonalen Außenkanten verleihen dem kubusförmigen Möbel eine tektonische Struktur (Abb. 94). Sockel und Gebälk sind verkröpft, die Rahmen schräg furniert, die Füllungen mit kompliziert gehobelten Profilstäben konturiert. Das Möbel ist zum größten Teil mit gestreiftem Nussbaum überzogen, Maserholz füllt die Kompartimente von Sockel, Gebälkfries und Lisenen, die Adern, die die Binnenfelder rahmen, bestehen aus Eibenholz. Die nur partiell mit Furnier dekorierte Rückseite des Möbels dokumentiert, dass es für den Platz vor einer Wand bestimmt war. Die Innenseite der Lesekanzel trägt einen eierschalenfarbenen Anstrich. 


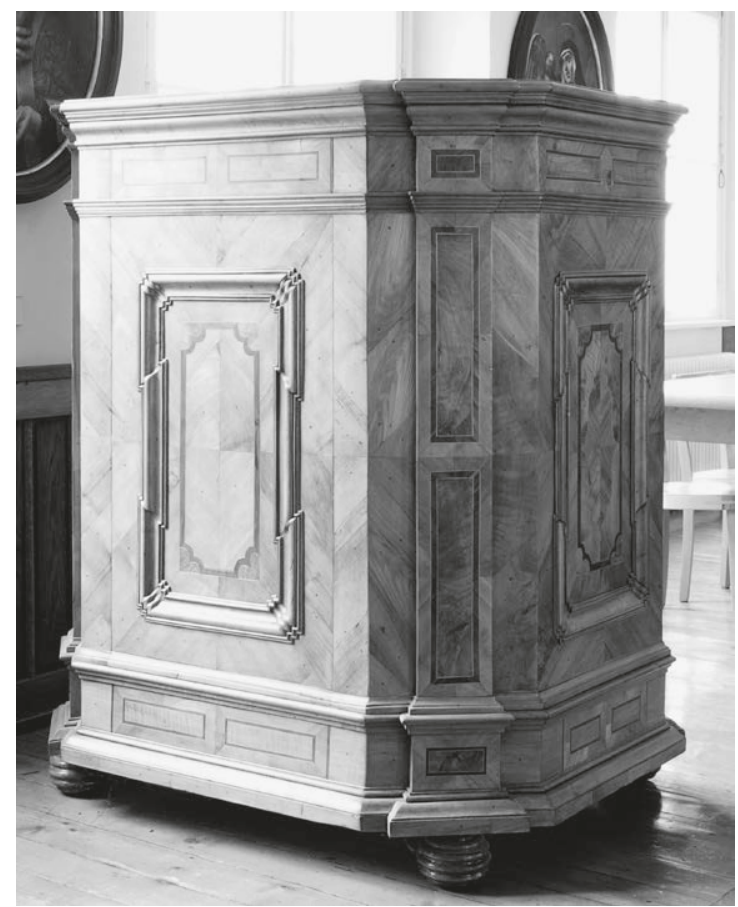

94 Refektorium, Lesekanzel.

Michaelbeuern, um I 720/25

Dass die Kanzel zusammen mit den anderen beschriebenen Ausstattungsstücken als originärer Bestandteil des Ensembles gebaut wurde, erscheint als unmittelbar einsichtig. Auffallend ist die formale Ähnlichkeit des Möbels mit dem Exemplar im Refektorium von St. Peter zu Salzburg (Abb. I03). Das Salzburger Möbel entstand zwei Dezennien später, seine Proportionen sind etwas gestreckter, die Marketerien anspruchsvoller, dennoch stellt sich die Frage, ob die Lesekanzel in Michaelbeuern dem Salzburger Inventarstück nicht als Vorlage gedient haben könnte. Zukünftige lokale Forschungen werden eventuell dazu beitragen, eine Antwort auf diese Frage zu finden.

\section{Stiftskirche}

Laiengestühl

Bildhauer Johann Kapfer, Trostberg (Bayern), um I 770

HS $9,5 \mathrm{~cm}$

H IOI $\mathrm{cm}(+9,5 \mathrm{~cm}) \times \mathrm{L}_{305} \mathrm{~cm}$

Eiche, massiv, Nadelholz 


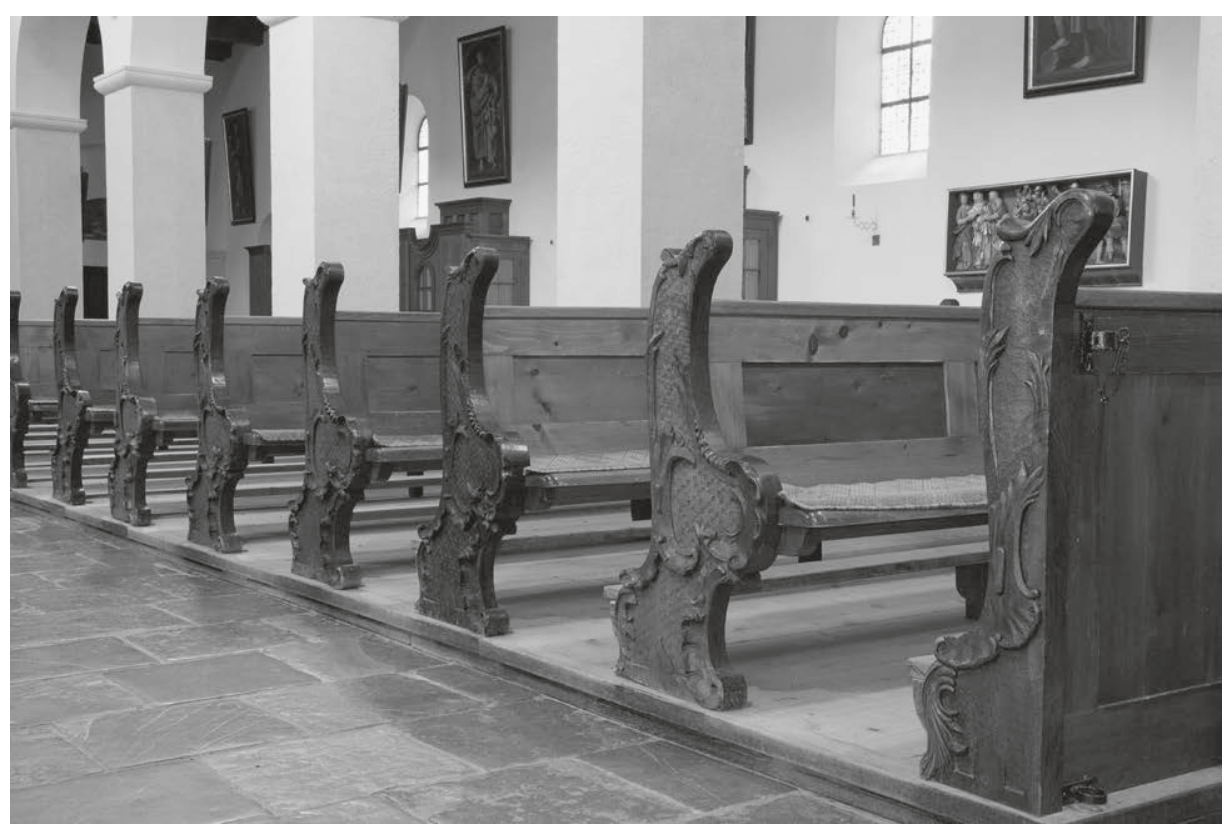

95 Stiftskirche, Laiengestühl. Bildhauer Johann Kapfer, Trostberg (Bayern), um I 770

96 Bankwange. Bildhauer Johann Kapfer, Trostberg (Bayern), um I 770

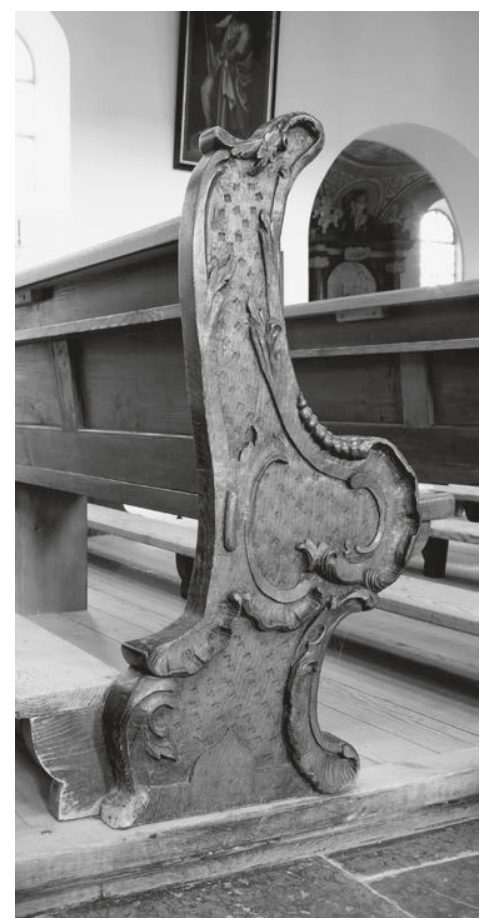


Das Laiengestühl der Kirche besteht aus zwei Blöcken mit je 23 Bankreihen, hinzu kommen die beiden Vorderbrüstungen (Abb. 95, 96). ${ }^{153}$ Wenige große Schwünge formen die Außenkanten der schmalen Wangen, lange lanzettförmige Blätter, schlichtes Muschelwerk und knorpelige Verdickungen folgen der Kontur. Die Binnenfelder liegen vertieft, locker gesetzte Punzen beleben die ansonsten glatte Oberfläche. Die Bankwangen sind ein Werk des Bildhauers Johann Kapfer aus dem bayrischen Trostberg, das etwa $40 \mathrm{~km}$ westlich von Michaelbeuern liegt. Abt Anton Moser (reg. I765I783) vergütete die Arbeit des Bildhauers an den Bänken laut einer Schriftquelle von I 770 mit insgesamt 7o fl. ${ }^{154}$ Das Gestühl steht zeitlich auf einer Stufe mit den Möbeln im Refektorium von Kremsmünster und den Bänken von Fiecht (Abb. 340, 34I ). ${ }^{155}$ Wie in Kremsmünster wurde in Michaelbeuern eine zurückhaltende und schlichte Art des Spätbarocks gewählt, wobei die für Salzburg und das Umland der Stadt typische Form der Wangen aufgegeben wurde.

Die Vorderbrüstungen und letzten Bankreihen sind beidseitig mit barocken Wangen aus Eichenholz versehen, sonst stehen alte Docken nur zum Mittelgang hin. Dagegen wurde bei der Erzeugung der modernen Außenwangen sowie der ebenfalls neuen Rückenlehnen, Sitz- und Kniebänke Nadelholz verwendet.

\section{Salzburg, Benediktiner-Erzabtei St. Peter}

\section{Stiftskirche St. Peter}

Die These, der hl. Rupert (um 650-7 I 8) habe die Abtei gegen Ende des siebten Jahrhunderts gegründet, ist in der Fachliteratur nicht unumstritten ${ }^{156}$, doch wird das Faktum allgemein akzeptiert, dass sich St. Peter als das älteste niemals aufgehobene Kloster des deutschsprachigen Raums bezeichnen darf. Der aus Worms stammende Bischof Rupert leitete die Missionierung der südöstlichen Regionen des Stammesherzogtums Bayern und war damit in Landschaften tätig, die große Teile des heutigen österreichischen Staatsgebietes umfassen. Zu seinem Bischofssitz hatte er das verwüstete römische Iuvavum, das spätere Salzburg bestimmt. Vermutlich ließ er antike Ruinen am Fuße des Mönchsbergs wiederherstellen und nahebei eine erste, dem hl. Peter geweihte Kirche errichten. ${ }^{157} 987$ beschloss Friedrich I. († 991), Erzbischof von Salzburg

I 53 Zu den Bänken ÖKT, Salzburg-Land, I (I913), 496.

I 54 ÖKT, ebd., 43,484 .

I 55 Zu Kremsmünster vgl. Bohr, Sakralmöbel (20 I 7), 53 I-534.

I 56 Möglicherweise gründete Rupert keine Mönchsgemeinschaft ex novo, sondern übernahm die Baulichkeiten einer bereits bestehenden Kommunität. Dopsch, Klöster (1 983), bes. I007-1009.

I 57 ÖKT, St. Peter (I 1 I 3), bes. XI-CXCIV; Martin, St. Peter (I 927); ders., St. Peter (I 94I); Hermann, 
und Abt von St. Peter, die Aufhebung der Personalunion von Abt und Bischof, womit er die Abtei vom Bistum bzw. Erzbistum löste. ${ }^{158}$

Die Frühzeit der Klosterbaugeschichte liegt im Dunkeln. ${ }^{159}$ Anfangs soll sich die Klosteranlage südlich der Kirche befunden haben. Um oder nach i I I o wurde sie in den Norden verlegt, nachdem die Abtei in den Besitz von Gebäuden gekommen war, die zuvor zur erzbischöflichen Residenz gehört hatten. Die noch bestehende Basilika geht im Wesentlichen auf einen I 43 geweihten Erweiterungsbau der ursprünglichen Kirche zurück. Zwischen dem I 5. und I 7. Jahrhundert ließ der Konvent die Kirche durch den Anbau von Kapellen an der Südflanke vergrößern. Der heutigen architektonischen Form der Klosteranlage liegen in erster Linie Bauvorhaben der Äbte Amand Pachler (reg. I657-1673), Edmund Sinhuber (reg. I673-1702) und Placidus Mayrhauser (reg. I704-I74I) zugrunde, Abt Beda Seeauer (reg. I753-I785) erteilte den Auftrag zur Barockisierung der dreischiffigen und kreuzgratgewölbten Kirche. ${ }^{160}$ Die zarte Stuckausstattung von I 760/66 lässt die romanische Baustruktur noch deutlich erkennen. Johann Weiß (I738-1776) schuf die Deckenfresken im Langhaus kurz vor der Fertigstellung des Stuckzierrats. Wie in den Klöstern Stams, Michaelbeuern, Mattsee und Viktorsberg befindet sich der Kreuzgang auch hier an der Kirchennordseite. $^{161}$

\section{Stiftskirche}

Eingangsportal

Bildschnitzer Lorenz Härmler, Hofschlosser Philipp Hinterseer, Glasermeister Lorenz Pauer, I $765 / 67$

Lichte Maße H $435 \mathrm{~cm} \times \mathrm{B} 202,5 \mathrm{~cm}$

Gesimshöhe der Tür $324 \mathrm{~cm}$

Eiche, dunkelbraun lasiert. Messing, Eisen, geschwärzt, teilvergoldet

Die beiden Türflügel hängen im Gewände eines mittelalterlichen Trichterportals, dessen rundbogigen Durchgang sie zusammen mit einem verglasten Gitter schließen

St. Peter (I 96 I); Hootz, Kunstdenkmäler (I 965-I 968), Bd. I (I965), I 94-201, 335-336; Röhrig, Alte Stifte (r 967), 36-40; Stenzel, Stift (r 977), r 40-I 43; Fuhrmann, Baugeschichte ( 1982 ); Hahnl, St. Peter (I982); Dehio, Salzburg (I 986), 532-550; Eltz-Hoffmann/Anrather, Kirchen Salzburgs (1993), 20-32; Hermann, Geschichte (1996); Hermann/Hahnl, St. Peter (2002), 263-408.

I 58 Hermann, Trennung ( 1982 ). Das Bistum wurde 798 zum Erzbistum erhoben.

I59 Fuhrmann, Baugeschichte (1982); Hermann/Hahnl, St. Peter (2002), 390-399. Vgl. hierzu außerdem die verschiedenen Beiträge in: Kolb/Angermüller, Festschrift St. Peter (1982).

I6o Dehio, Salzburg ( I 986), 535 ; Hermann/Hahnl, ebd., 397-398.

I6I Zur Beschreibung der Gesamtanlage s. ÖKT, St. Peter (I9I3), I-I 98; Dehio, ebd., 534-550. 


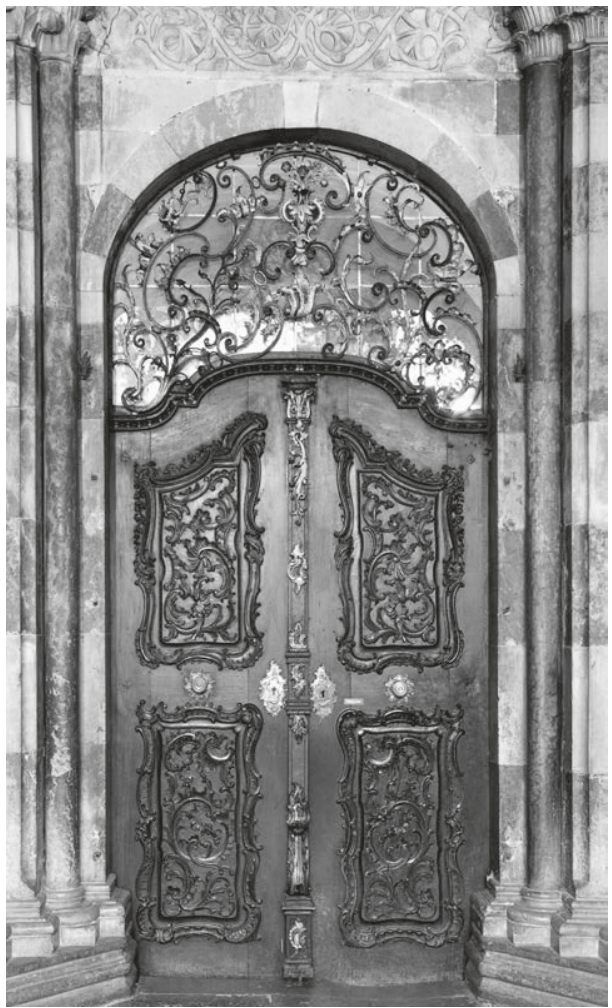

97 Eingangsportal zur Stiftskirche. Bildschnitzer Lorenz Härmler, I $765 / 67$
(Abb. 97). ${ }^{162}$ Ein schlanker Pilaster verdeckt als Schlagleiste die Fuge zwischen den aus Rahmen und Füllungen konstruierten Türblättern. Den unteren hochrechteckigen Binnenfeldern stehen oben Kompartimente gegenüber, die zur Mitte zu in die Höhe schwingen. Damit folgen sie dem Verlauf des Karniesbogens, der die Türblätter bekrönt. Von Blattlaub, Muschelwerk und Rosenblüten unterbrochene Profile begleiten die bossierten Füllungen. Schnitzarbeiten mit dicht gesetzten Rocaillemotiven und vegetabilen Formen überziehen den Oberflächenspiegel der Mittelfelder, Beschläge aus Goldbronze vervollständigen die Tür.

Dank erhaltener Rechnungen sind wir über die Handwerker unterrichtet, die an der Fertigung des Portals beteiligt waren: I765, I766 und I767 erhielten der Bildhauer Lorenz Härmler (Härmbler), der Schlossermeister Hinterseher († I 780) und der Glasermeister Lorenz Pauer für ihren Beitrag an der Herstellung der Tür den ihnen zustehenden Lohn. ${ }^{163}$

\section{Kirchenbänke}

Bank im Querschiff

Salzburg, um I 7 I 5

HS ro $\mathrm{cm}$

$\mathrm{H}_{92,5} \mathrm{~cm}\left(+\right.$ IO cm) $\times \mathrm{L}_{2} \mathrm{I} 7,5 \mathrm{~cm}$

Nussbaum, massiv, Nadelholz

I62 ÖKT, ebd., CLXXVIII, 3-5; Hermann, St. Peter (196I), 7; Feuchtmüller, Umgestaltung (I 982), 659; Dehio, ebd., 534-535.

I63 ÖKT, ebd., CLVI. 


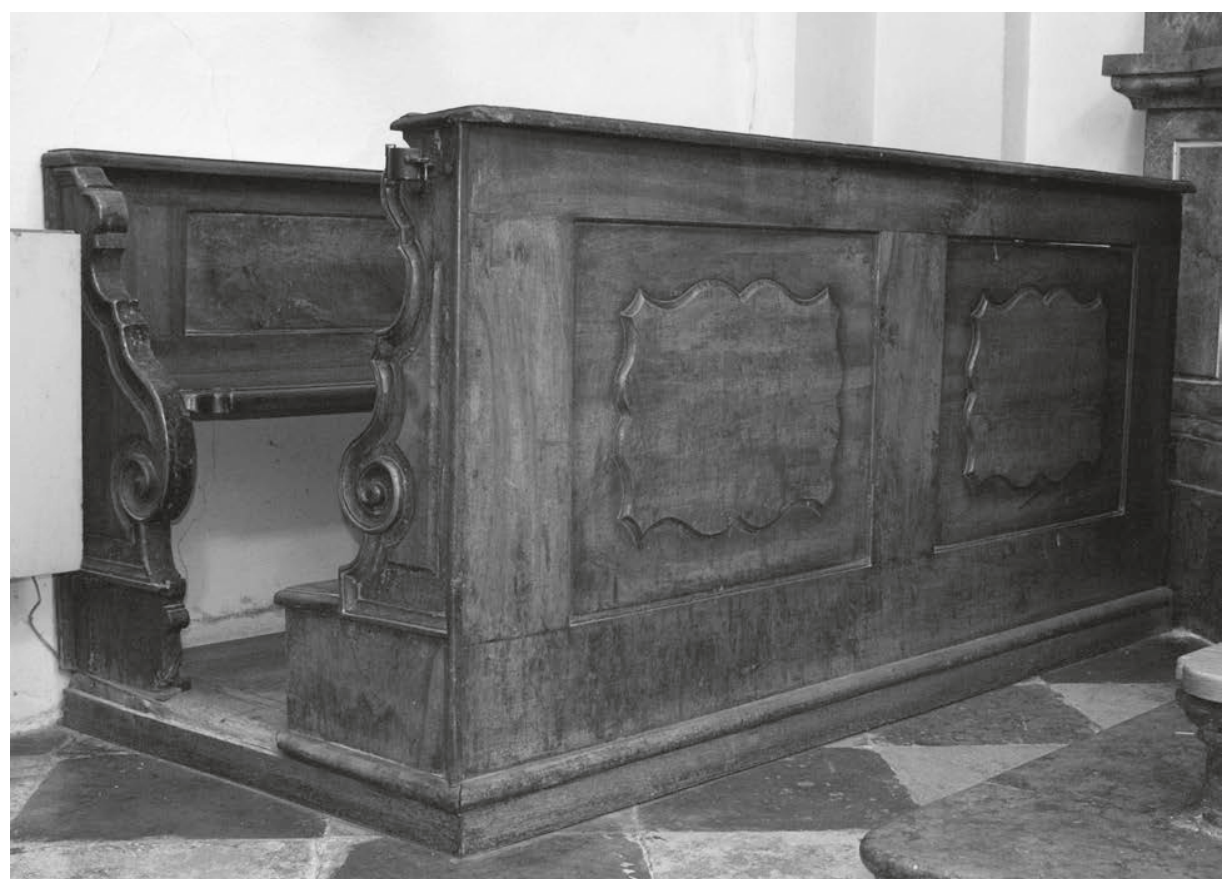

98 Altarraum, Bank. Salzburg, um I 7 I 5

\section{3o Bänke im Mittelschiff}

Tischlermeister Simon Mathias Wessicken (?), I 78 I/82

HS I I $\mathrm{cm}$

$\mathrm{HW} 98 \mathrm{~cm}\left(+\right.$ I I cm) $\times \mathrm{L}_{4} 62 \mathrm{~cm}$

Nussbaum, Eiche, Nadelholz

In der Stiftskirche haben sich verschiedene Arten von Bänken erhalten. ${ }^{164}$ Eine einzelne Sitzbank wird im nördlichen Querschiff aufbewahrt (Abb. 98). Die schlichten Rahmen des Pultes fassen zwei große Füllungen mit leicht erhabenen und geschweiften Spiegelfeldern ein. Die Brüstungswangen bestehen aus einem Sockel und einem hochaufragenden schmalen Teilstück, das vorn bündig mit der Pultfront abschließt, während die hintere Kante in Bögen verläuft. Ein kräftiges Profil akzentuiert die Außenkanten. Eine vergleichbare Gestaltung weisen die Docken der Sitzbank auf. Wie die Brüstungsfront ist die Rückwand in Rahmenbauweise konstruiert.

r64 ÖKT, ebd., 25; Oberhofer/Hahnl, Handwerk (r 978), 35, 38; Dehio, Salzburg (1986), 537. 


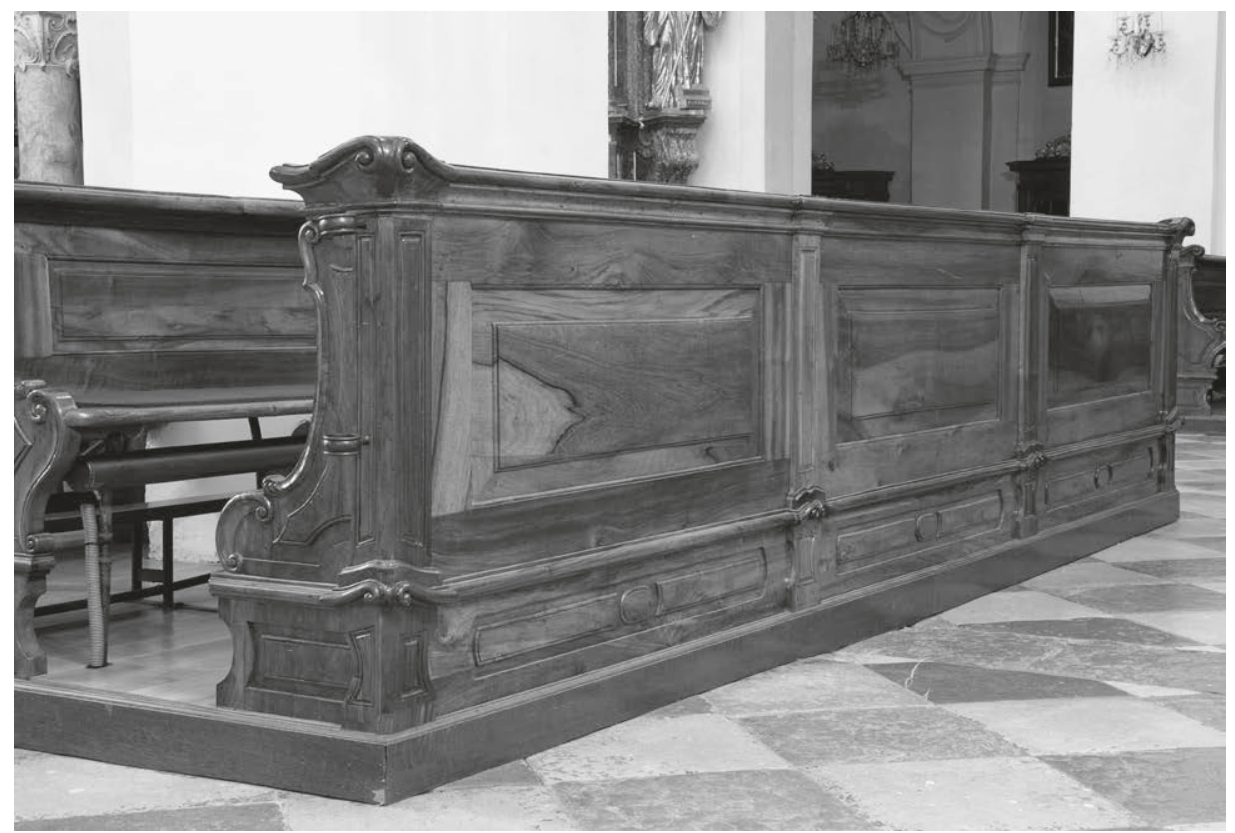

99 Laiengestühl. Tischler Simon Mathias Wessicken (?), I 78 I/82

Im Mittelschiff befinden sich auf sechs Laufböden insgesamt 36 Bänke. Die mittleren sechs Bänke $(2 \times 3)$ wurden vermutlich im I 9 . oder beginnenden 20 . Jahrhundert hinzugefügt. Ihre Form entspricht der der anderen Exemplare, doch wählte man bei ihrer Herstellung mit massiver Eiche eine andere Holzart. Die Kunsttopographie nennt die sechs Reihen zwar nicht, doch sind sie auf alten Abbildungen zu erkennen. ${ }^{165}$

Beim Entwurf der 30 spätbarocken Sitzreihen und vier Brüstungen orientierte man sich an Möbeln aus dem Salzburger Raum sowie an Exemplaren aus anderen Landesteilen Österreichs, wodurch diese Bänke eine Art von Zwitterstellung einnehmen (Abb. 99, roo). Von früheren Salzburger Möbeln wurde die Idee eines vom Aufsatz getrennten Sockels übernommen. Im Unterschied zu diesen Stücken oder auch zur Bank im Querschiff (Abb. 76, 98) ist der Aufsatz hier jedoch nicht schmaler als der Sockel, sondern ebenso breit. ${ }^{166}$ Abgesehen von der Zweiteilung gleichen die Docken deshalb zeitgenössischen Exemplaren aus den übrigen österreichischen Regionen. Als gutes Beispiel könnte auf die in den I 77oer-Jahren von Lorenz Horeß geschaffenen Möbel

I65 ÖKT, ebd., Taf. III, Abb. 20, 22.

I66 Die Bänke in der Salzburger Dreifaltigkeitskirche (Abb. I08), die eine vergleichbare Großform besitzen, sind eine Ausnahme. 


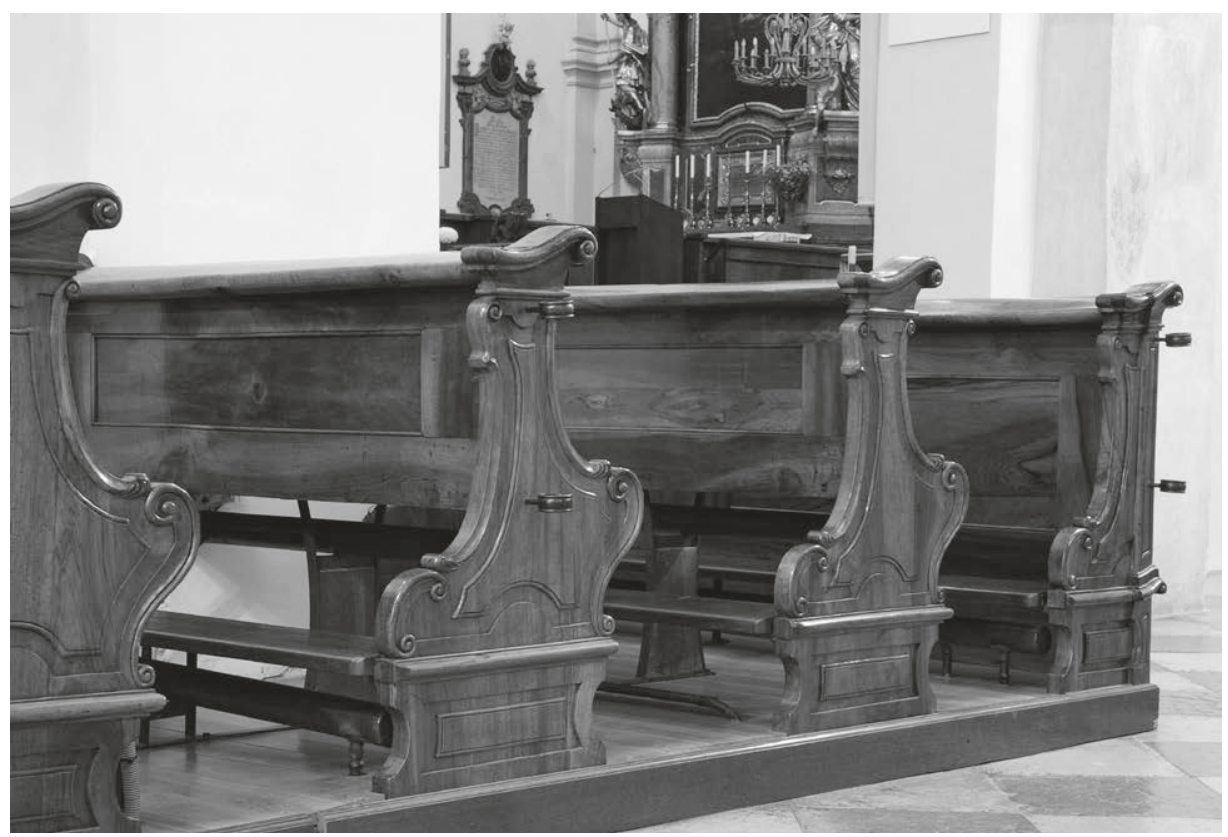

Ioo Laiengestühl, Seitenwangen. Tischler Simon Mathias Wessicken (?), I 78 I/82

im Stift Herzogenburg verwiesen werden. ${ }^{167}$ Das Laiengestühl in St. Peter wurde also dem Aussehen von Bankgarnituren in den anderen Landesteilen angeglichen, ohne jedoch jenes Charakteristikum ganz aufzugeben, das als Wesensmerkmal der Salzburger Kirchenbänke des späten I 7. und frühen I 8. Jahrhunderts bestimmt werden konnte.

Im Vergleich mit der älteren Bank verrät die Gestaltung der Exemplare im Mittelschiff eine modernere Formensprache: Die Kontur der über dem Sockelbereich mit gegenläufigen Schwüngen nach oben gezogenen Brüstungswangen ist weniger kleinteilig, vielmehr weich und fließend. Zudem verdecken die S-förmigen Wangenbekrönungen nun auch die Stirnseiten der Gebetbuchablagen. Als Werkmaterial diente massives Nussholz, nur die Knie- und Sitzbänke bestehen aus Eichen- und Nadelholz.

Die Möbel waren nicht die erste Garnitur für die Stiftskirche. Wie Adolf Hahnl anhand von Archivalien ermittelte, lieferte der bürgerliche Hoftischlermeister Lorenz Windpichler (um I65 I-I724) bereits 1683 ein Gestühl für die Kirche. ${ }^{168}$ Schon um I 7 I 4 gab Abt Mayrhauser jedoch neue Bänke in Auftrag, wie aus einer Auflistung der

I67 Bohr, Sakralmöbel (2017), 346-347.

I68 Oberhofer/Hahnl, Handwerk ( I978), 29. 
in seiner Regierungszeit angeschafften Ausstattungsstücke hervorgeht. ${ }^{169}$ Vermutlich ist die Bank im Querschiff ein Relikt jener Jahre. Sechs Dezennien später genügte auch Mayrhausers Ausstattung offenbar nicht mehr den ästhetischen Ansprüchen und Abt Beda Seeauer ließ eine dritte Garnitur von Laienbänken fertigen, die I 78 I erstmals in einem Rechnungsbuch genannt werden: den I7. July bezalle ich dem TischlerMr. pr. Abschlag der 34 neuen Kirchen-Stuell v. harten Holz nach dem Accord jeden à $28 \mathrm{f}$. zusamen $952 f$. dermablen ${ }_{5} 2 f .{ }^{170}$ Der Eintrag bezieht sich auf die 30 Bänke und die vier zugehörigen Brüstungen. Weitere Zahlungen an den Tischler erfolgen im Herbst I78 I und im Frühjahr des Folgejahres. ${ }^{171}$ Des Tischlermeisters Name geht aus den genannten Schriftquellen nicht hervor, konnte jedoch dank schriftlicher Nachrichten erschlossen werden: Es handelte sich höchstwahrscheinlich um Simon Mathias Wessicken (I740-I 8 I 5) aus Salzburg-Mülln, der seit den späten I77oer-Jahren mit seinen Gesellen für den Konvent von St. Peter tätig war. ${ }^{172}$

\section{Psallierchor}

Der um I705/06 über dem nördlichen Seitenschiff der Stiftskirche errichtete Psallierchor öffnet sich mit Fenstern zum Konventhof hin, weitere weisen zum Mittelschiff der Kirche und zum Querhaus. ${ }^{173}$ Die Einrichtung besteht aus einem Altar im Osten, einer Abtstalle im Westen und einem Gestühl vor der Nordwand.

\section{Gestübl}

Abtstalle

$\mathrm{HS} 23 \mathrm{~cm}$

$\mathrm{H} 370 \mathrm{~cm}(+23 \mathrm{~cm}) \times \mathrm{B} 262 \mathrm{~cm}$

I69 ÖKT, St. Peter ( (1913), CXX und CXXIII.

I70 Zitiert nach ÖKT, ebd., CLXIX.

I7 I Am 22. November I78I sowie am 29. Januar, I4. März und 20. April I782. ÖKT, ebd., CLXIX.

I72 Oberhofer/Hahnl, Handwerk (1978), 38. Ebd., auf S. 35, wird allerdings ein Meister namens Johann Bernhard Grim erwähnt, der das Laiengestühl geschaffen hätte. Dieser Widerspruch konnte bislang nicht geklärt werden. Zu Wessicken vgl. Malle, Wessicken (201 2), bes. I 7-1 8, 66-74, I 33 .

I 73 ÖKT St. Peter (1913), I30-I3 I ; Dehio, Salzburg (I 986), 542. 


\section{Hauptreiben}

$\mathrm{HS} 37,5 \mathrm{~cm}$

$\mathrm{H}$ I $4 \mathrm{I} \mathrm{cm}(+37,5 \mathrm{~cm}) \times \mathrm{L} 95 \mathrm{I} \mathrm{cm}$

Salzburg, um i 7 io und i 9 . Jh.

Nussbaum, massiv und furniert, dunkelbraun lasiert, Eiche, Nadelholz. Eisen

Die Abtstalle besitzt die ungewöhnliche Form einer großen Arkade (Farbtaf. I I). Korinthische Säulen vor quergehobelten Pilastern flankieren das Dorsale und tragen zusammen mit dem hohen Arkadenbogen und seitlichen Voluten eine Plinthe für eine Muttergottesstatue aus der Mitte des I 7. Jahrhunderts. ${ }^{174}$ Vor dem Bogenfeld liegt eine Muschel, darunter füllt ein großes, mit einem Kielbogen schließendes Mittelfeld die Rückwand. Es wirkt wie eine Folie hinter dem Prälatenstuhl, der als eine aus geschweiften Seitenwangen, Sitz und Schulterlehne bestehende autonome Einheit konzipiert ist. Zwei Volutenpilaster rahmen die Brüstungsvorderseite. Dazwischen zeigt ein Oval das Stiftswappen und das des Abtes Placidus Mayrhauser. ${ }^{175}$ Krautige Akanthus-

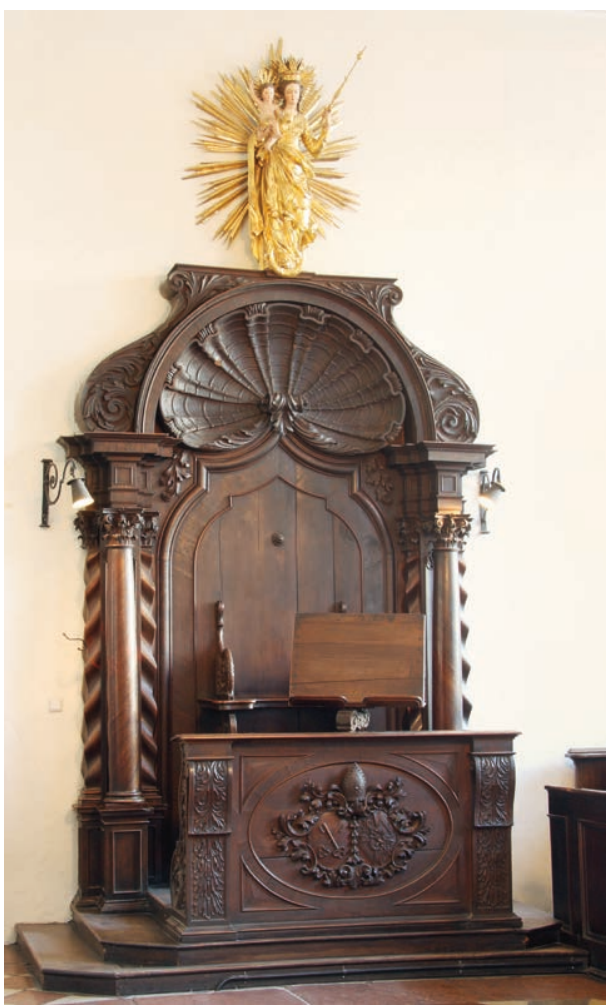

Farbtafel i I Psallierchor, Abtsessio. Salzburg, um I 7 IO blätter und quergeriffelte Bänder umgeben die Wappenkartuschen, ein Abthut überragt die Darstellung. Weiteres Laubwerk ziert Docken und Pilaster.

Das dreireihige Chorgestühl ist in zwei Einheiten geteilt (Abb. Ior). Jede Reihe des Gestühls verfügt über sechs Sitze, sodass insgesamt 36 Plätze vorhanden sind. Ursprünglich war das Inventarstück allerdings zweireihig, die vorderen Stallen kamen wahrscheinlich im I9. Jahrhundert hinzu. Im Gegensatz zu den betont schlicht gehaltenen Brüstungsvorderseiten präsentieren sich die Seitenwangen der Brustwände aufwendig mit Akanthusranken veredelt. Wie üblich in dieser Kunstlandschaft bestehen die Wangen aus einem niedrigen Sockelbrett, das die Kniebank trägt, und einem schmalen hohen Segment. Hier besitzt es eine geschweifte Hinterkante sowie eine

I74 ÖKT, ebd., I3 I ; Dehio, ebd., 542.

I75 Das Stiftswappen zeigt die gekreuzten Schlüssel Petri, das Wappen des Abtes mit Bändern umwundene Pfeile im gevierteilten Schild mit steigendem Löwen im Herzschild. 

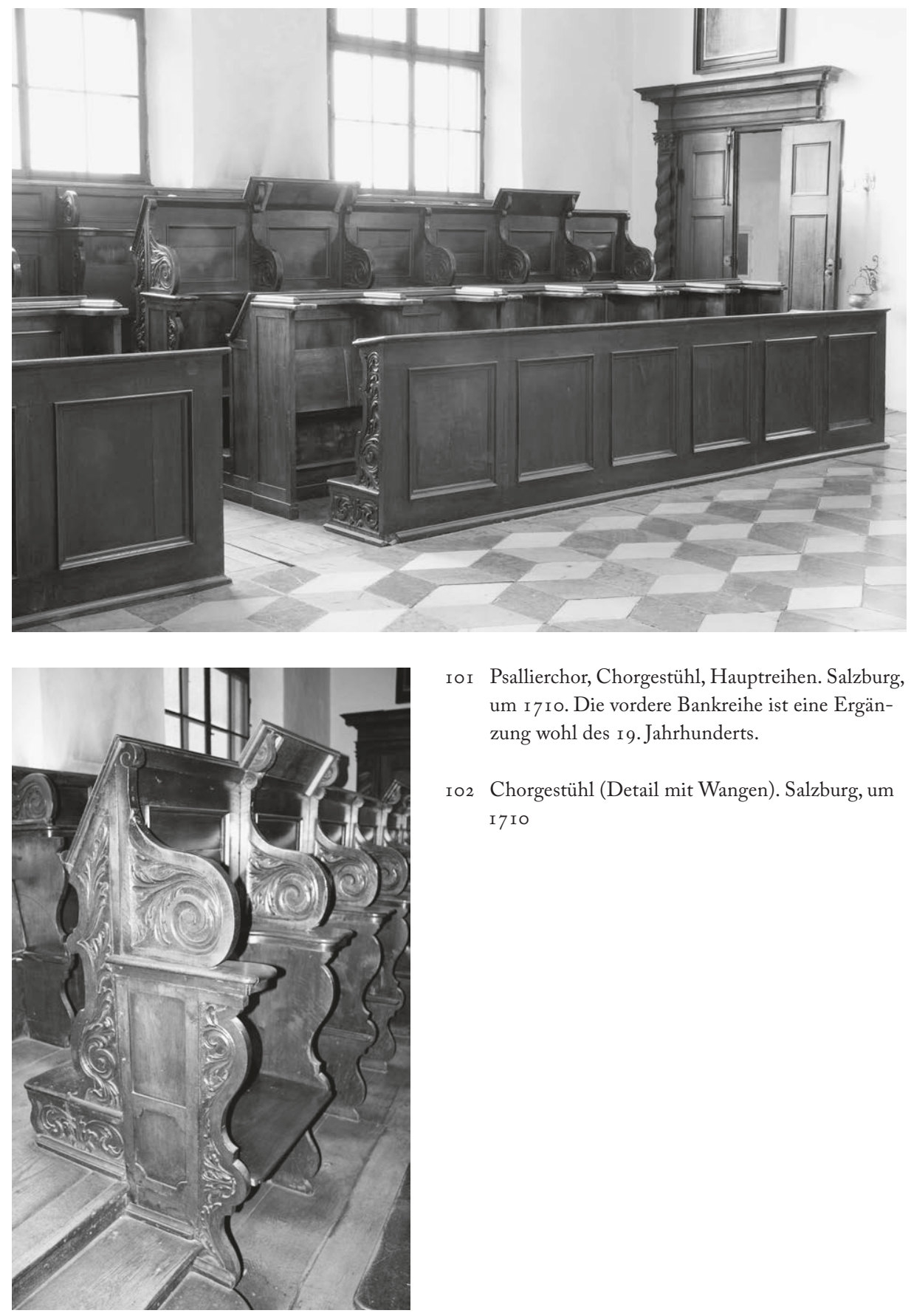

Io I Psallierchor, Chorgestühl, Hauptreihen. Salzburg, um I 7 I o. Die vordere Bankreihe ist eine Ergänzung wohl des I 9. Jahrhunderts.

IO2 Chorgestühl (Detail mit Wangen). Salzburg, um I 7 IO 
schräge Oberkante, auf der die Gebetbuchablage befestigt ist. Gekurvte Zwischenwangen unterteilen die Innenseite der Brüstung. Sie stützen nicht nur das Abschlussbrett, sondern auch Zwischenböden, unter denen einige Schubladen laufen. Weitere Schubladen hat man über den Kniebänken eingefügt. ${ }^{176}$ Die Außenwangen der hinteren Sitzreihen setzen sich aus einer hochrechteckigen Rahmenkonstruktion mit glatten Füllungen sowie aus geschweiften Tableaus zusammen, die mit geschnitzten Blattranken verziert sind (Abb. I02). Voluten über den Accoudoirs stützen die hohe Rückwand und die Lesepulte der hinteren Sitze.

Charakteristika wie die geriffelten Spangen an der Abtstalle und die Akanthusranken weisen auf eine Entstehungszeit des Gestühls im ersten oder spätestens zweiten Jahrzehnt des I 8. Jahrhunderts. Es steht auf einer Entwicklungsstufe mit Möbeln, die zwischen I707 und I7I I für die Stifte Kremsmünster und Lambach angekauft wurden. ${ }^{177}$ Hinzu kommt, dass der oben erwähnte Altar auf das Jahr I 706 datiert ist, auf das Jahr also, in dem der

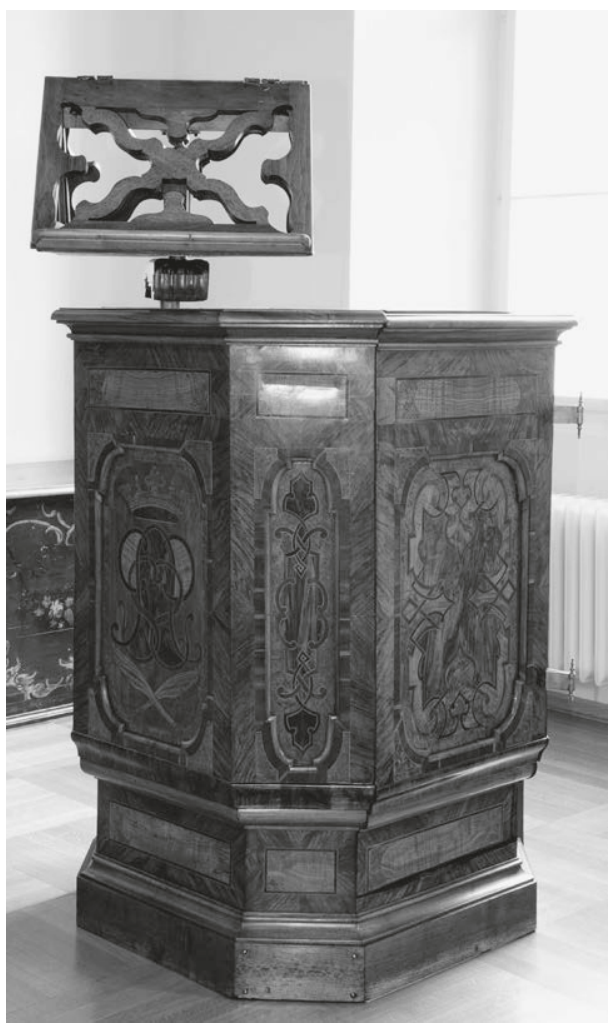

I03 Refektorium, Lesekanzel. Salzburg, um I $730 / 40$

Psallierchor als Raum fertiggestellt wurde. Einen sicheren Terminus post bzw. Terminus ante quem liefert Abt Placidus mit seiner Sumarische[n] Beschreibung der vornemeren Gebey Sachen, so von ao I7O4 bis I7 I 4 sein gemacht worden. Dort ist das Chorgestühl aufgeführt. ${ }^{178}$

I76 Sonst kennen wir Laden in den Brustwänden von Gestühlen der Zisterzienser, doch sind die Laden dort in der Regel unter den Kniebänken eingefügt.

I77 Bohr, Sakralmöbel (2017), 528-53 I, 543-545.

I78 Zitiert nach ÖKT, St. Peter (I9I3), CXX-CXXI. 


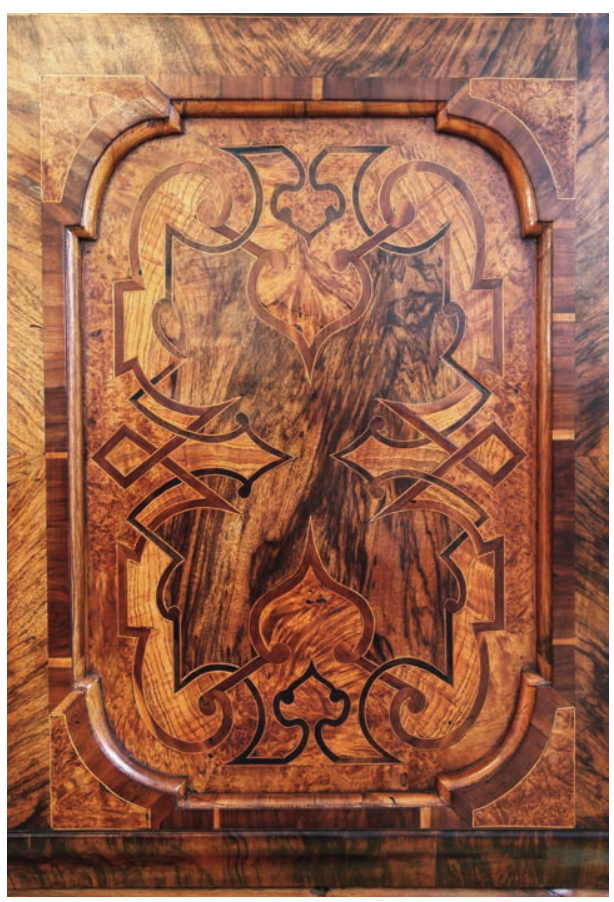

Farbtafel I 2 Lesekanzel, Füllung. Salzburg, um $\mathrm{I} 730 / 40$

\section{Refektorium}

Die freskierte Decke des längsrechteckigen Raumes trägt eine Darstellung des Letzten Abendmahls sowie Szenen aus dem Leben des hl. Benedikt. Schriftquellen zufolge führte der Maler Melchior Steidl († I 727) die Gemälde I705 aus. ${ }^{179}$

\section{Lesekanzel}

Salzburg, um I $730 / 40$

H I 8 I, $5 \mathrm{~cm} /$ I $36,5_{5} \mathrm{~cm}$ B I09 $\mathrm{cm} \times$ T I05 $\mathrm{cm}$ Nussbaum, Nussmaser, Ahorn, geschwärztes Nussholz, Pappelmaser, Esche, Zwetschke, Buchs (?), graviert und geschwärzt, furniert auf Nadelholz. Eisen

Die Kanzel erhebt sich über den Seiten eines ungleichmäßigen Polygons (Farbtaf. I 2; Abb. I03, I04). ${ }^{180}$ Drei der breiten Seiten und die vier Schrägen sind mit Marketerien überzogen, die Rückseite blieb undekoriert. ${ }^{181} \mathrm{Da}$ mit wurde das Möbel für den Standplatz vor einer Wand konzipiert. Der Fuß besteht aus einer (wohl erneuerten) Sockelleiste und einem eingezogenen Teilstück. Ihm folgt der etwas breitere und tiefere, gerade nach oben gezogene Kanzelkorb. Ein flaches Abschlussgesims, über dem ein drehbares Lesepult aufragt, bildet den oberen Rand des Inventarstücks. Eine Seite kann geöffnet werden und dient so als Einstieg.

Der Kanzelkorb ist in Rahmenbauweise konstruiert, vertieft liegende Füllungen mit abgerundeten und verkröpften Ecken sind eingesetzt. Geschweifte und miteinander verkettete Adern zieren die Kompartimente. Zum Teil geben die eingelegten Motive relativ einfache geometrische Formationen wieder, zum Teil bilden sie aber auch mit Spitzen, scharfen Brechungen und Zwiebelmotiven kompliziert gestaltete Ornamente. Das Marketeriebild der Vorderseite stellt über gekreuzten Palmzweigen ein bekröntes Spiegelmonogramm dar. Nach einer These Adolf Hahnls ist das Mo-

I79 Zum Raum und seiner Einrichtung s. ÖKT, ebd., I 3 I-I 32 ; Dehio, Salzburg (I 986), 543.

I 80 Oberhofer/Hahnl, Handwerk ( 1978 ), 78.

I8 I Oberhofer/Hahnl, ebd. 
nogramm als Buchstabenfolge C.A.S.P. zu deuten, womit das Möbel unter dem kurzen Abbatiat von Carl Schrenk von Notzing (reg. I 702-I704) entstanden wäre. ${ }^{182}$ Aus Gründen der Stilkritik muss diese Vermutung jedoch verworfen werden. Die Großform der Kanzel, die Gestaltung des Bandlwerks und das Fehlen von Akanthusranken sprechen klar gegen ihre Entstehung in jenen Jahren. Die Kunsttopographie datiert die Kanzel dagegen auf das vierte Jahrzehnt des I 8. Jahrhunderts. ${ }^{183}$ Abt war damals Placidus Mayrhauser. Die ineinander geschriebenen und gespiegelten Buchstaben wären dann als A.P.M. zu lesen, auch das scheint möglich. Dabei überfängt statt des Abthutes eine Krone das Monogramm. Sie ist nicht heraldisch, sondern als Dekormotiv zu verstehen. ${ }^{184}$

Durch das handverlesene Furnier unterscheidet sich die Kanzel deutlich von den anderen Möbeln in der Abtei. Rahmende Friese sind aus gemasertem Nussbaumholz

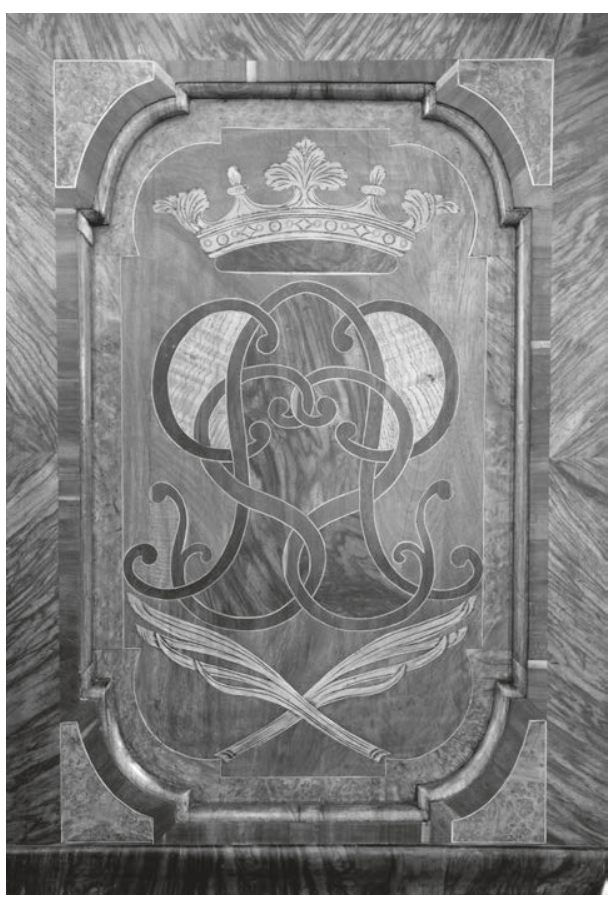

I04 Lesekanzel, Füllung. Salzburg, um I $730 / 40$ geschnitten, Adern aus Zwetschkenholz und geschwärztem Nussholz, Binnenflächen aus Nussmaser, Pappelmaser und Esche. Die Verarbeitung des Möbels ist von solch hoher Qualität, dass es nur von einem der führenden Meister in Salzburg geschaffen worden sein kann. An erster Stelle denkt man sicher an den Hoftischler Simon Thaddäus Baldauf ( $1677^{-1}$ 753), dessen Arbeiten in jeder Hinsicht mit der höfischen Luxusware aus Wien oder München gleichrangig waren. Doch ist sein Kunstschaffen bisher nur ansatzweise erforscht ${ }^{185}$, eine Zuschreibung an ihn wäre mithin rein spekulativ. Andererseits wurde 1733 M. Johann Zengerle, Bürger und Tischler wegen in das Refectorium gemachte Arbeit [mit] 67 fl. $30 \mathrm{kr}$. entlohnt. ${ }^{186}$ Sollte er das Möbel geliefert haben? Leider geben die bisher erschlossenen Quellen hierüber keine Auskunft.

I82 Ebd.

I 83 ÖKT, St. Peter (1913), r 32 .

I84 Ähnliches ist auch an Archivschränken im Stift Göttweig zu beobachten, die um I737 unter Abt Gottfried Bessel (reg. I 7 I4-1 749) angeschafft wurden. Bohr, Göttweig (2009), Abb. 3.

I 85 Wagner, Baldauf (1 978).

I 86 Zitat nach ÖKT, St. Peter (1913), CXLV. 


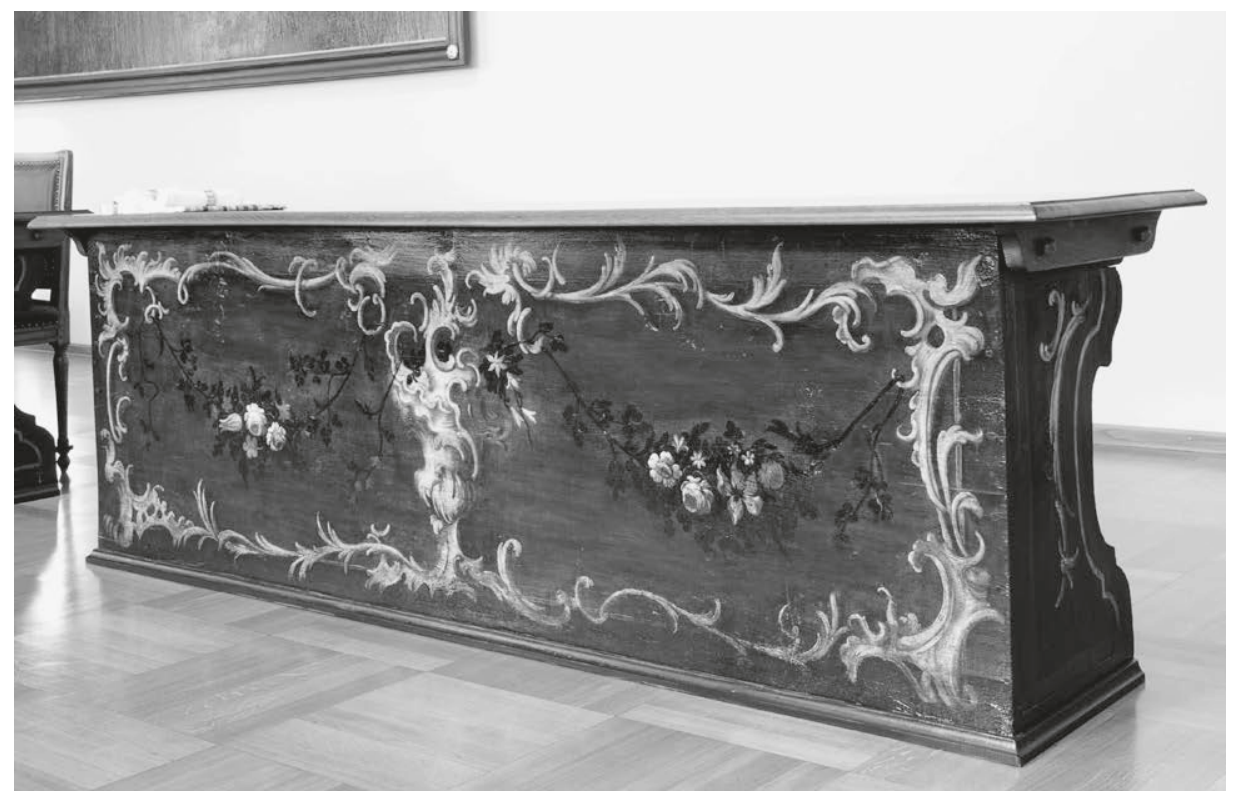

I05 Refektorium, Tisch. Johann Georg Zängerl, I 758

\section{I4 Tische}

Tischler Johann Georg Zängerl, I 758

$\mathrm{H} 78,5 \mathrm{~cm} \times \mathrm{B} 2 \mathrm{I} 5 \mathrm{~cm} \times \mathrm{T} 64 \mathrm{~cm}$

Nadelholz, polychrom bemalt

Die Speisetische des Refektoriums (Abb. I05) entsprechen dem bei den Benediktinern gängigen Typus: Sie besitzen keine Tischgestelle, sondern sind vorn und seitlich geschlossen, wobei hier die Stirnseiten geschweifte Konturen aufweisen. Die dunkelbraun lasierten und bemalten Möbel wurden in Brettbauweise hergestellt. Gelblichweiße, teils auch ockerfarbene Rocaillen und vegetabile Ziermotive säumen große querrechteckige Felder mit Blütengirlanden, die die Rahmenstrukturen optisch miteinander verbinden. Das Blattwerk ist fast schwarz wiedergegeben; vor dem Hintergrund heben sich hellfarbene, weiße, blaue und rote Blüten kontrastreich ab. Nach Recherchen von Adolf Hahnl gehen die Möbel auf den Tischler Johann Georg Zängerl zurück, vermutlich ein Sohn des oben genannten Johann Zengerle. Zängerl legte 1758 die Meisterprüfung ab, die Arbeiten für das Refektorium führte er im gleichen Jahr aus. ${ }^{187}$

I $87 \mathrm{Zu}$ Zängerl und den Refektoriumsmöbeln vgl. Oberhofer/Hahnl, Handwerk (I 978), 37. 
Io6 Kircheninneres, Blick nach Südwest. Architektur und Einrichtung (?) nach einem Entwurf von Johann Bernhard Fischer von Erlach, um I 694/I 702. Die vorderen Bänke und Kniebänke sind modern.

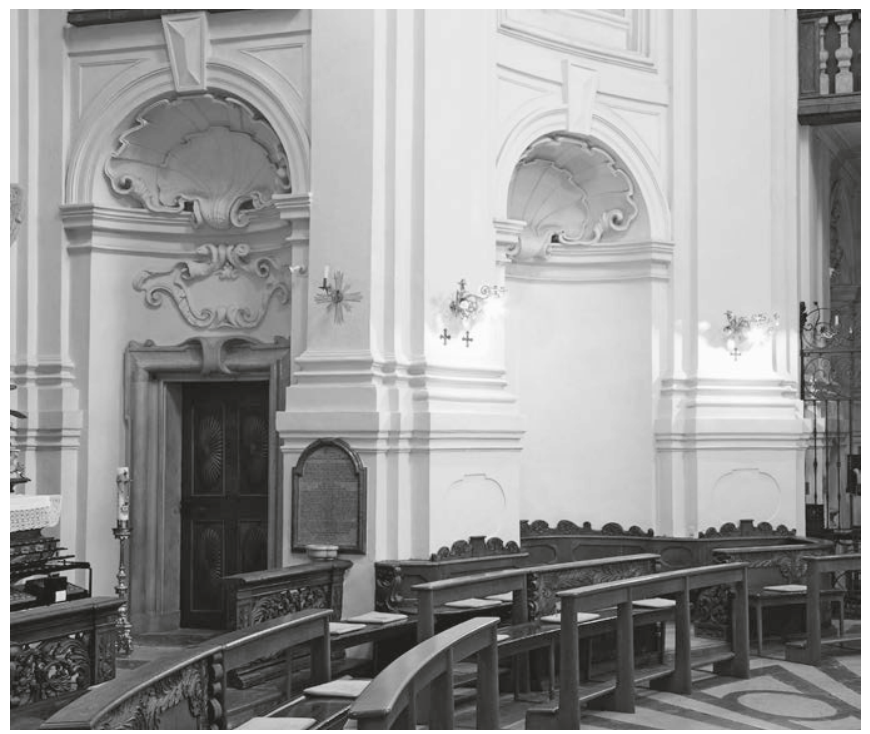

\section{SAlzburg, Dreifaltigkeitskirche}

Priesterhaus, Knabenkolleg und Kirche gehen auf eine Stiftung durch Erzbischof Johann Ernst Graf von Thun-Hohenstein (reg. I687-I 709) zurück. ${ }^{188}$ Errichtet wurde die Kirche zwischen 1694 und 1702 unter der Leitung von Johann Bernhard Fischer von Erlach (1656-I723), bei der Planung hatte er sich der Fachliteratur zufolge Sant'Agnese in Rom von Francesco Borromini (1599-1667) zum Vorbild genommen. Die 1702 geweihte Dreifaltigkeitskirche, ein längsovaler Zentralbau mit vier tonnengewölbten Kreuzarmen und Tambourkuppel, bildet das Zentrum einer ausgedehnten Vierflügelanlage, deren Gebäude sich um große Innenhöfe gruppieren. Die von zwei Türmen flankierte und konkav eingezogene Front mit der dahinter aufragenden hohen Kuppel bestimmen die Hauptansicht des Sakralbaus. Die Stuckarbeiten im Innern gehen vermutlich auf Diego Francesco Carlone (I674-1750) zurück, das Kuppelfresko wurde von Johann Michael Rottmayr (I654-I730) ausgeführt. Fischer von Erlach entwarf den Hochaltar der Kirche, in der Krypta befindet sich ein von Fischer projektierter Marmorsarkophag. Wie Studien ausweisen, war die Werkstatt des Hoftischlers

I 88 ÖKT, Salzburg (I9I 2), bes. I60-I72; Hootz, Kunstdenkmäler (I965-1968), Bd. I (I965), 209, 2 Io, 337-338; Ebhardt, Barockkirchen ( 1975), 83-95; Sedlmayr, Fischer von Erlach (1 976), ro4, I05, 256, 257; Dehio, Salzburg ( I 986), 6 6 3 -6 I 5 ; Eltz-Hoffmann/Anrather, Kirchen Salzburgs ( I 993), I I o-I I 3 ; Sedlmayr, Fischer von Erlach (1997), I 77-г 85; Neuhardt, Dreifaltigkeitskirche (I 998); Kreul, Fischer von Erlach (2006), I 90-1 94 . 


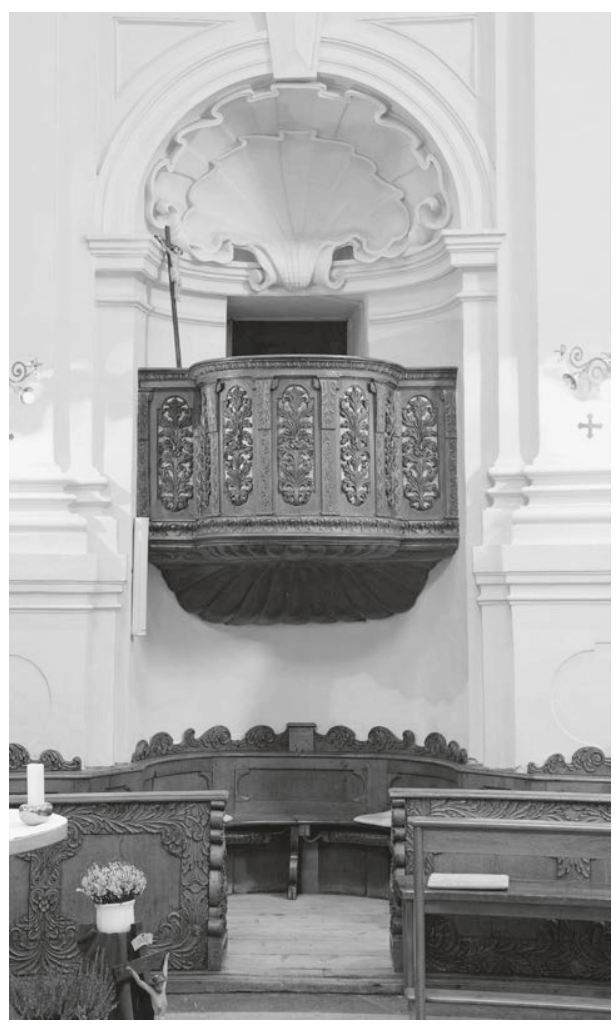

107 Kircheninneres. Bank und Kanzel in einer der Nischen. Entwurf verm. von Johann Bernhard Fischer von Erlach, um 1702

Balthasar Köbl (Kölbl; r645-I7 I I), der auch Kirchenbänke für die Domkirche zu Salzburg (Farbtaf. I4; Abb. I 27-I 29) gefertigt haben soll, für einige der nachfolgend beschriebenen Tischlerarbeiten zuständig. ${ }^{189}$

\section{Kirchenbänke}

Hoftischler Balthasar Köbl (?), Entwurf Johann Bernhard Fischer von Erlach (?), um I 702 HS $9,5 \mathrm{~cm}$ $\mathrm{H}$ 9 I cm $(+9,5 \mathrm{~cm}) \times$ gesamte $\mathrm{L}$ ca. $25 \mathrm{~m}$ Eiche, massiv

Anders als sonst steht das Gestühl nicht frontal zum Hauptaltar, sondern in den Raumdiagonalen, wo es der Rundung der Wände angepasst und in tiefe Nischen eingefügt ist (Abb. ro6-r Io). ${ }^{190}$ Seinen Verlauf unterbrechen lediglich die Speisgitter vor den Altären und der Eingangsbereich unter der Westempore. Die Brustwände sind in der vertikalen Ausrichtung gerade, in der horizontalen aber dem Grundrissverlauf entsprechend ausgerichtet, zu den Altären hin schließen sie mit Außenwangen ab. Die Brüstungen setzen sich aus Rahmen und Füllungen zusammen, wobei breite, mit Schnitzarbeiten verzierte Friese große ebene Flächen säumen. Die Schnitzarbeiten zeigen im Fischgratmuster angeordnetes Laubwerk, das an den vertikalen Stollen in amorphen, noch an Knorpelwerkmotive erinnernden Gebilden endet.

Wie üblich in Salzburg wird an den Wangen zwischen dem Sockelbereich und dem oberen Wangensegment unterschieden, wobei hier ausnahmsweise die Breite des obe-

I 89 Darüber hinaus erwarb Thun-Hohenstein I 702 von Köbl einen Schrank, der im Priesterhaus aufgestellt wurde, kurz danach schrieb der Handwerker einen Kostenvoranschlag zur Anfertigung eines Reliquienschreins. ÖKT, ebd., I6 I.

I90 Vgl. zu den Möbeln ÖKT, ebd., r68; Dehio, Salzburg ( 1986), 6 I 5 ; Neuhardt, Dreifaltigkeitskirche ( I998), ıо. Einst befanden sich weitere Bänke im Schiff, die in der ÖKT als »einfach« und »aus dunkelbraunem Holze« beschrieben werden. Abb. etwa in Aurenhammer, Fischer (1973), 64. 

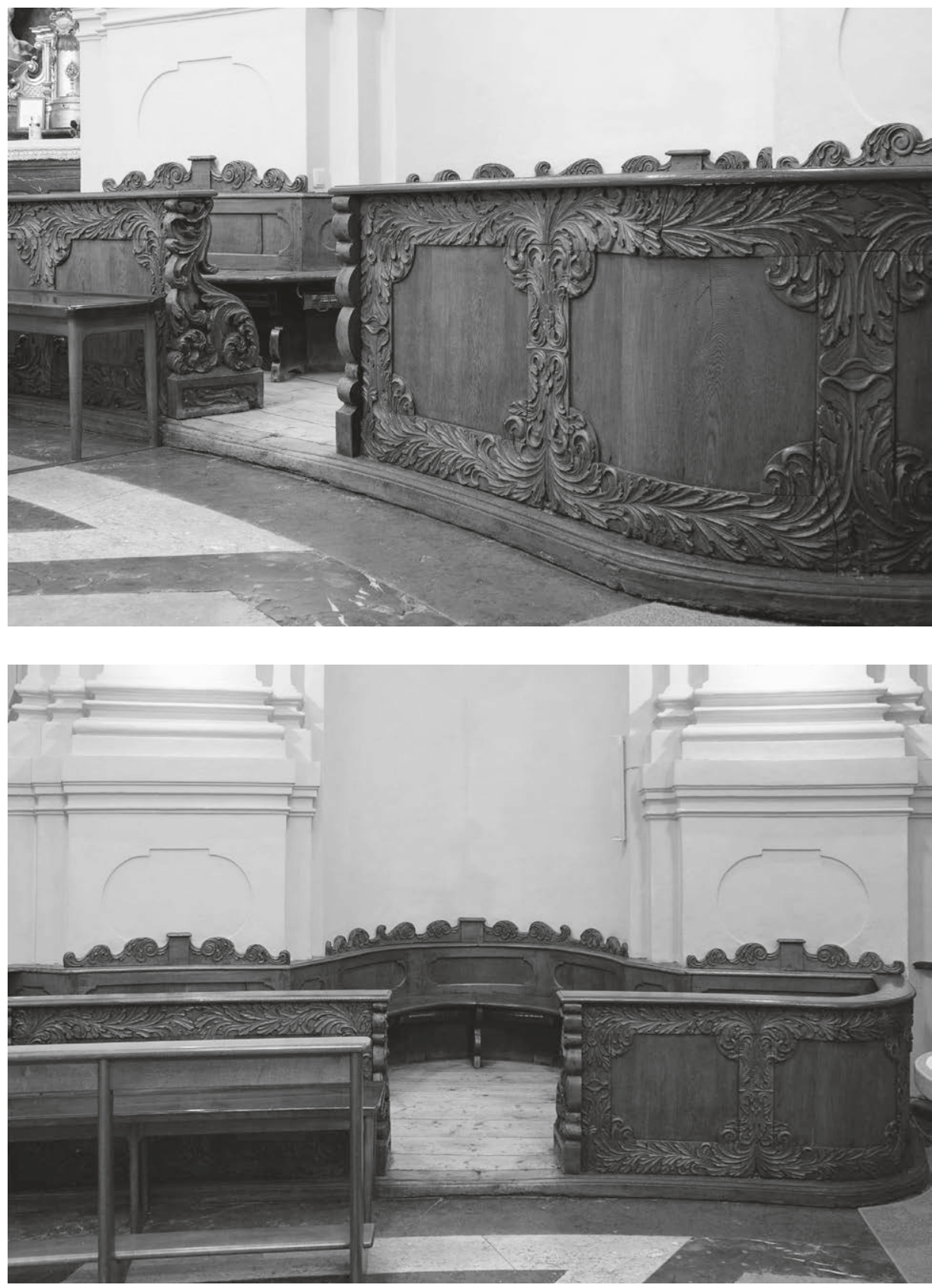

I08, I09 Teilansicht des Gestühls. Hoftischler Balthasar Köbl (?) verm. nach einem Entwurf von Johann Bernhard Fischer von Erlach, um 1702 


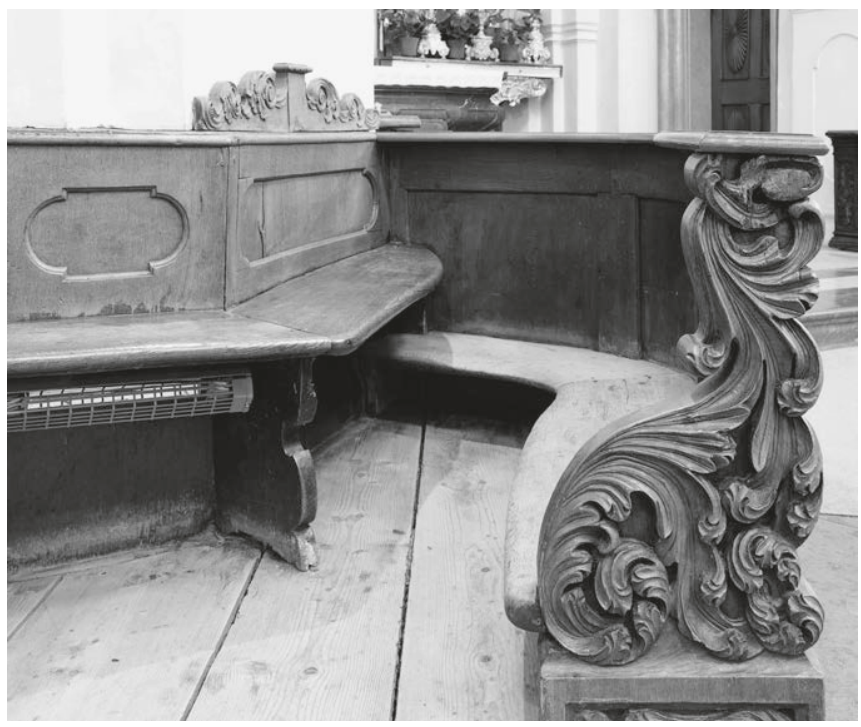

I Io Teilansicht des Gestühls. Hoftischler Balthasar Köbl (?) verm. nach einem Entwurf von Johann Bernhard Fischer von Erlach, um I 702

ren Segments mit der des Sockels übereinstimmt. Diese Art der Gestaltung kommt sonst in jener Zeit nicht vor. Der Sockel besteht aus einem breiten glatten Rahmen um ein mit schlichtem Laubwerk ornamentiertes Feld. Dagegen formen große Akanthusblätter den oberen Teil. Sie legen sich in kraftvoll gearbeiteten Wirbeln über die Fläche und unterscheiden sich dadurch vom Laubwerk der Vorderseiten.

Mit dem deutlichen Kontrast zwischen dem dichten Oberflächenrelief der Rahmen und den großen glatten Flächen der Füllungen erinnern die Möbel an verschiedene Bänke in der Salzburger Metropolitankirche (Abb. I26). Und hinsichtlich des Schnitzaufsatzes korrelieren die Rückenlehnen der Bänke in der Dreifaltigkeitskirche mit jenen vor den Wandpfeilern, die das Mittelschiff des Doms von den Seitenkapellen trennen (Abb. I 28). Die ausgefallene Form der Möbel in der Dreifaltigkeitskirche, ihre ungewöhnliche Positionierung und die bedeutenden Übereinstimmungen mit den Bankgarnituren in der Domkirche sind es denn auch, die an Fischer von Erlach als den Entwerfer und Balthasar Köbl als ausführenden Tischlermeister denken lassen. Hinzu kommt die Tatsache, dass Fischer auch als Inventor der nachfolgend beschriebenen Tischlerarbeiten in der Dreifaltigkeitskirche zu gelten hat.

\section{Chorschranken}

Hoftischler Balthasar Köbl (?), Entwurf Johann Bernhard Fischer von Erlach (?), um I 702 $\mathrm{H} 7 \mathrm{I}, 5 \mathrm{~cm} \times \mathrm{L} \mathrm{I} 65,5 \mathrm{~cm} / \mathrm{I}_{3} 8 \mathrm{~cm}$

Eiche massiv, geschnitzt 


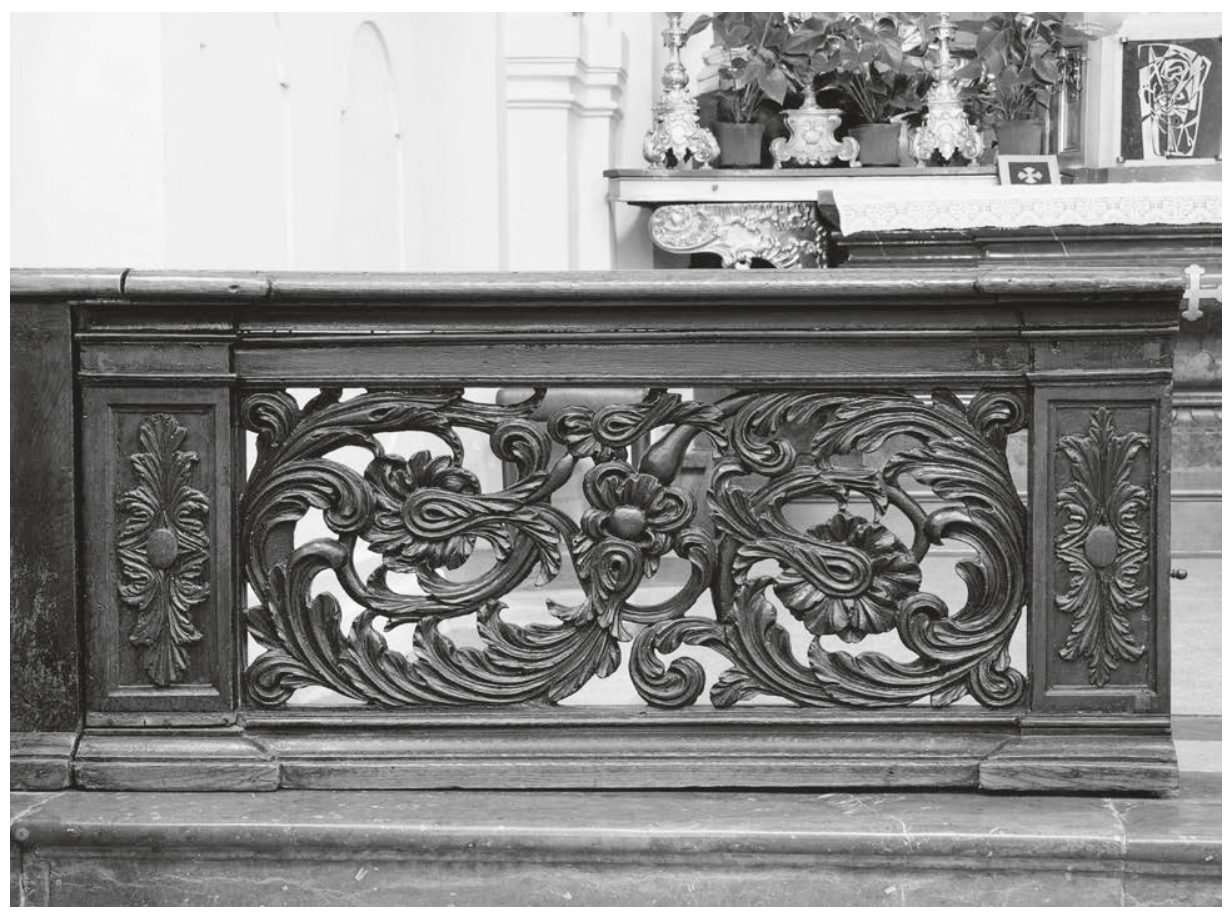

I I I Chorschranke. Hoftischler Balthasar Köbl (?) verm. nach einem Entwurf von Johann Bernhard Fischer von Erlach, um 1702

Kommunionbänke unterschiedlicher Länge trennen den Laienraum von den Altären (Abb. I I I) ${ }^{191}$ Niedrige pilasterartige Baluster unterteilen die Schranken. Rautenförmig ausgebreitetes Blattwerk ziert die Stützen, während kräftiger Akanthus die querrechteckigen Binnenfelder zwischen den Balustern füllt. Er besteht aus einem diagonal angeordneten Mittelmotiv, von dem zwei in Blüten endende Akanthusspiralen ausgehen. Zwischen diesen Brüstungen und jenen der Salzburger Markuskirche (Farbtaf. I 5), für deren Entwurf ebenfalls Fischer von Erlach zuständig gewesen sein soll, bestehen erstaunliche Parallelen, wie die Fachliteratur schon mehrfach betonte. ${ }^{192}$

I9I Vgl. zu den Arbeiten ÖKT, ebd., r67; Oberhofer/Hahnl, Handwerk (1978), 77; Dehio, ebd., 615; Neuhardt, ebd.

I92 Vgl. hierzu den Beitrag zu St. Markus. 


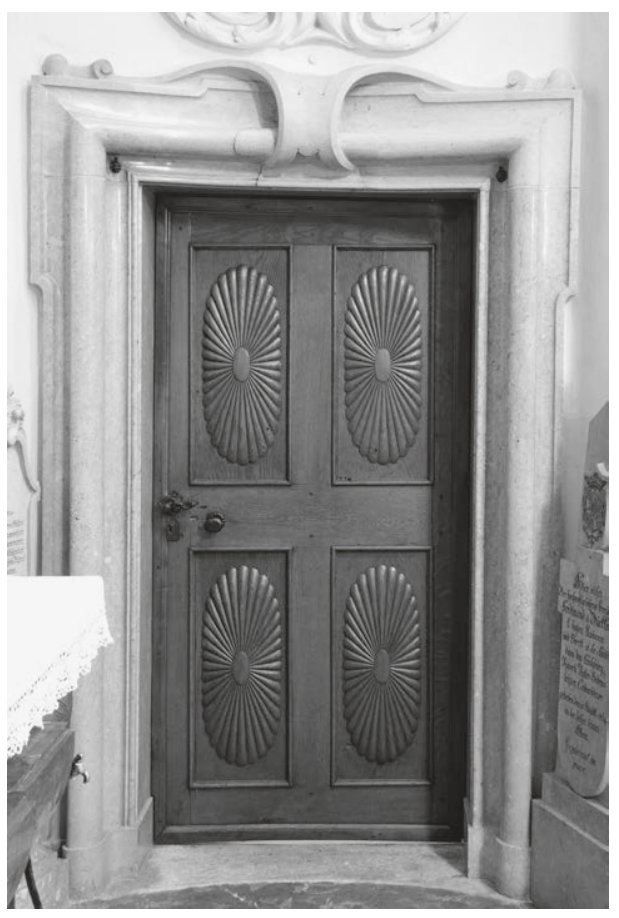

I I 2 Seitenkapelle, Tür. Entwurf verm. Johann Bernhard Fischer von Erlach, um I 702

Türen

Entwurf Johann Bernhard Fischer von Erlach (?), um I 702

Lichtes Maß H $208 \mathrm{~cm} \times$ B $100 \mathrm{~cm}$

Eiche massiv. Eisen, geschmiedet, ziseliert, geschwärzt

Die Türen, die die Seitenkapellen zu Annexräumen hin öffnen, sind jeweils aus einem einzigen Türblatt konstruiert, das ein kreuzförmiger Rahmen vierteilt (Abb. I I 2). Ein aus Godronen bestehendes Hochoval, das an ein antikes Velum oder ein stilisiertes Muschelornament erinnert, liegt auf jeder Füllung. Vergleichbarer, aber ins Monumentale gesteigerter Dekor kehrt an der Unterseite der Kanzel (Abb. I07) in der Dreifaltigkeitskirche wieder.

Schon im ersten Band der Untersuchung wird darauf hingewiesen, dass um die Jahrhundertwende relativ breite und niedrige Türen, die ein Horizontalrahmen teilte, der althergebrachten österreichischen Form entsprachen. Seit etwa I 7o I existierten allerdings auch Türen nach französischem Muster, die aus zwei schmalen Türblättern mit je drei Füllungen bestanden. Eingeführt wurden sie beim Bau der Sommersakristei des Klosters Melk. ${ }^{193}$ In Salzburg findet sich nun als dritter Typus eine Verschmelzung der österreichischen mit der französischen Türform. Wie bei den französischen Exemplaren ist auch hier die vertikale Ausrichtung akzentuiert, doch ist sie weniger konsequent durchformt. Nahezu identische Türen verschließen den Zugang zur Kapelle im Bergschloss Frain sowie den der Salzburger Johannesspitalskirche, die Fischer um die Wende vom I7. zum i 8. Jahrhundert, also etwa gleichzeitig mit der Dreifaltigkeitskirche, errichtete. ${ }^{194}$ Vielleicht nahmen diese Portale die in Melk vorweg, wo übrigens

I93 Bohr, Sakralmöbel (2017), bes. 63-64, 4I4-4I5. Wie im ersten Band dargelegt, gehen die französischen Türen ihrerseits vermutlich auf italienische Vorbilder zurück.

I94 ÖKT, Salzburg (I9I 2), Abb. 299, 30 I ; Tremmel-Endres, Denkmalarchitektur (1996), Abb. A I I 5, A I $47, \mathrm{~A}$ I 48 . 
auch traditionelle, aber mit Vela verzierte Türen zu finden sind. ${ }^{195}$ Das Kloster Melk wurde zunächst unter Federführung des Baumeisters Jakob Prandtauer (I660-I726), ab I7I9 wohl auch des Theateringenieurs Antonio Maria Niccolò Beduzzi (1675I735) erbaut, der Verdacht liegt nahe, dass die beiden Künstler Kenntnis von den Ausstattungen der Salzburger Kirchen besaßen.

Es ist vor allem die dichotome Formensprache, die das Mobiliar in der Dreifaltigkeitskirche auszeichnet. Als Dekormotiv wurde für die Bänke und Speisgitter kraftvoll modellierter Akanthus gewählt, während an den Türen das klassisch strenge Velummotiv als alleiniges Ornament vorkommt. Die im vorliegenden Katalog nicht beschriebene Kanzel (Abb. IO7) ist als Zwitter mit beiden Zierformen gestaltet. Fischer von Erlach stand am Beginn seiner Karriere noch unter dem massiven Einfluss italienischer Kunst, die auch das etwa zeitgleich entstandene Laiengestühl des Salzburger Domes (Abb. I 25-I29) dominierte. Man hat den Eindruck, dass er sich auf der Suche nach eigenständigen Formen vorantastete, um schließlich das Formenvokabular zu finden, das die Türen der Dreifaltigkeitskirche charakterisiert - falls er für den Entwurf der Tischlerausstattung des Sakralbaus zuständig war, was wahrscheinlich ist, aus den relevanten Schriftquellen aber nicht hervorgeht. ${ }^{196}$

\section{Sakristei}

Die nordöstlich an die Kirche angebaute Sakristei erhebt sich über unregelmäßigem Grundriss. ${ }^{197}$ Bei der Einrichtung des Raumes wurde auf die üblichen Aufsatzmöbel mit Kelchfächern verzichtet, stattdessen besteht das barocke Interieur aus drei Paramentenschränken, von denen zwei ein Paar bilden, einem Aufsatzschrank und einer Kredenz.

\section{Paar Paramentenschränke}

Salzburg, um I680/ I700

$\mathrm{H} 235 \mathrm{~cm} \times \mathrm{B} \mathrm{I} 73,5 \mathrm{~cm} \times \mathrm{T} 79,5 \mathrm{~cm}$

Nuss, massiv, Weichholz, dunkelbraun lasiert. Eisen, teilweise gemeißelt und verzinnt

Die Möbel besitzen mit Sockel, Hauptgeschoss und Hut den dreigliedrigen Aufbau barocker Kleiderschränke (Abb. I I3). Quadratische und querrechteckige Felder rhythmisieren Sockel und Gebälk, wobei die quergelagerten Segmente die Vorderstü-

I95 Bohr, Sakralmöbel (2017), bes. $43 \mathrm{I}-432$.

I 96 Vgl. hierzu Teil 2, Kap. III: Entwürfe und Modelle von Architekten und Baumeistern.

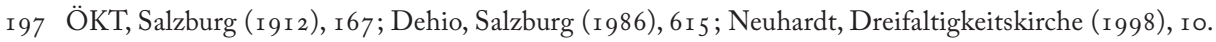




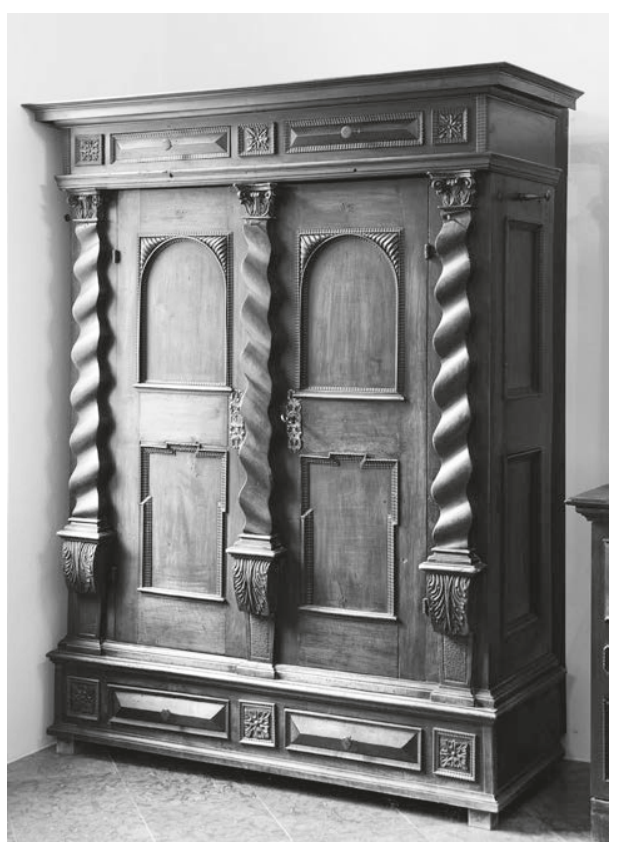

I 3 Sakristei, Paramentenschrank. Salzburg, um I680/I 700

cke von Schubladen markieren. Die Vertikalgliederung des Hauptgeschosses erfolgt durch Pilaster auf Stehvoluten. Je zwei Füllungen strukturieren die Schmalseiten und die Türen. Seitlich besitzen sie eine schlichte hochrechteckige Form, wohingegen die Binnenfelder der Front als reduzierte Ädikulä auf Sockelleisten aufsitzen. Die Tischler formten sie oben als Rundarkaden, unten versahen sie sie mit geohrten Rahmen. Geflammte Profilleisten und godronierte Dreiecke bereichern die Füllungen. Stilisierte Blüten zieren die Quadrate im Sockel und im Fries, Diamantbossen die Schubladenvorderseiten. Als Werkstoff diente beim Bau der Möbel massives Nussholz. Im hinteren Möbelbereich wurden Weichholzbretter angefügt, um die Tiefe der Schränke zu verändern, die offenbar zum Hängen der Paramente nicht ausreichte. Auf eine spätere Überarbeitung gehen ebenfalls die würfelartigen Füße zurück, einstmals standen die Möbel wahrscheinlich auf einem flachen Sockel oder auf Kugelfüßen.

\section{Aufsatzschrank}

Salzburg, um I 680/ I 700

$\mathrm{H} 240 \mathrm{~cm} \times \mathrm{B} \mathrm{I} 85,5 \mathrm{~cm} \times \mathrm{T} 8 \mathrm{I} \mathrm{cm}$

Nuss, massiv, Weichholz, dunkelbraun lasiert. Eisen, teilweise gemeißelt und verzinnt

Konstruktion und Ausgestaltung des Ober- und Unterschranks mit unterschiedlichen Ziermotiven belegen, dass die beiden Teile der Aufsatzkredenz ursprünglich kein zusammengehörendes Möbelstück formten (Abb. II4). Auf den breiten seitlichen Stollen des Unterschranks umschreiben aufgeleimte Profile polygonale Zierfelder, die Türrahmen sind zur Mitte zu entsprechend dekoriert, eine schmale Schlagleiste ist aufgesetzt. Äußere Profilleisten, die ein rechteckiges Feld einfassen, und innere Friese mit abgeschrägten Ecken säumen die vertieft liegenden Füllungen, pyramidale Gebilde dekorieren die Zwickel. Eine heute fehlende Leiste setzte den Sockel des Möbels einst vom Hauptteil optisch ab. Vier fragile Kegel tragen den Aufsatz, der im Prinzip 
ein verkleinertes Gegenstück der beschriebenen Schränke darstellt. Die Möbel dürften innerhalb eines kurzen Zeitraums im Umfeld ein und derselben Werkstatt entstanden sein. Auch hier bilden Flammleisten Keilstäbe, die nun jedoch hinter die Pilaster gelegt zu sein scheinen. Blattgirlanden schmücken den Fries. Die Front des Aufsatzes ist um etwa sieben cm breiter als der dahinter liegende Kasten, dessen Seiten zudem schräg zulaufen. Das Möbel war einmal als Wandschrank in eine Aussparung im Mauerwerk eingesetzt.

\section{Kredenz}

Salzburg, um I680/ I700

$\mathrm{H}$ 105,5 $\mathrm{cm} \times$ B I9I, $5 \mathrm{~cm} \times \mathrm{T} 73 \mathrm{~cm}$

Nuss, massiv, Weichholz, dunkelbraun lasiert.

Eisen, teilweise gemeißelt und verzinnt

Hinsichtlich des Aussehens und der Konst-

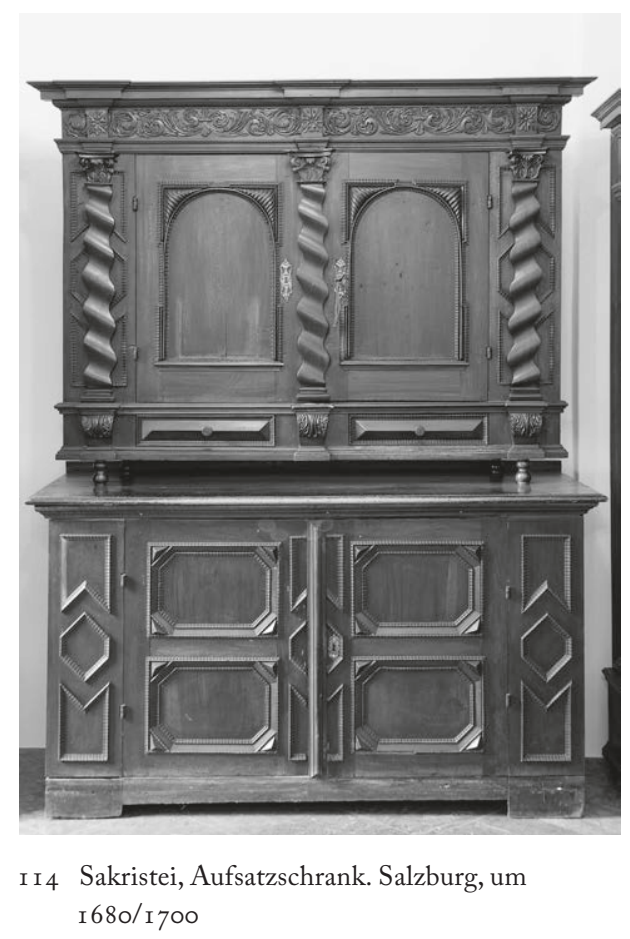
ruktion entspricht die Kredenz (Abb. I I 5) dem vorhergehend beschriebenen Unterschrank.

\section{Paramentenschrank}

Salzburg, um I680/ I 700

$\mathrm{H} 222 \mathrm{~cm} \times \mathrm{B} \mathrm{I} 85 \mathrm{~cm} \times \mathrm{T} 62 \mathrm{~cm}$

Nuss, massiv, geschwärztes Holz, Weichholz, dunkelbraun lasiert. Eisen, teilweise gemeißelt und verzinnt

Der Paramentenschrank übernimmt mit seinem dreigliedrigen vertikalen Aufbau das gewöhnliche Schema (Abb. I 6 ). Im Hut und Sockelkasten laufen Schubladen, Türen, die an breiten Außenstollen hängen, verschließen den Hauptteil. Seitlich fassen Flammleisten polygonale Felder ein, verkröpfte Füllungen strukturieren die Türblätter. Geschnitztes Blattwerk, das groteske Masken formt, bekrönt die oberen Binnenfelder.

Die Füße des Schranks besitzen eine Form, die sich häufig an Biedermeiermöbeln findet. Wahrscheinlich stand das Inventarstück ursprünglich ebenfalls auf einem Sockel oder flachen Kugeln und erhielt hohe Füße, um es vor der aufsteigenden Bo- 

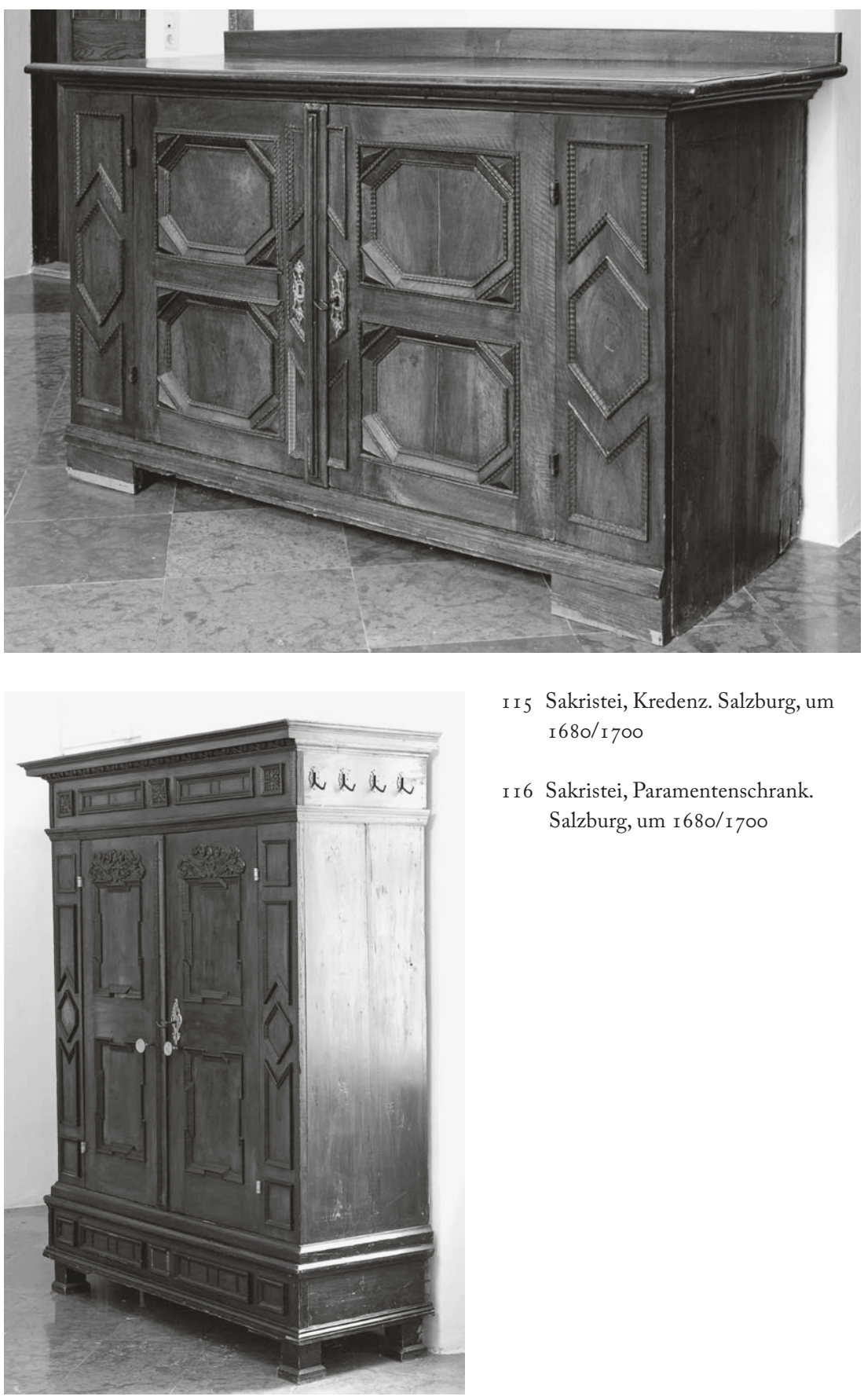

I 5 Sakristei, Kredenz. Salzburg, um I $680 /$ I 700

I 6 Sakristei, Paramentenschrank.

Salzburg, um I680/I 700 
denfeuchtigkeit zu schützen. Als Werkmaterial für seine Fassade fand Nussholz Verwendung, für die Seiten Nadelholz. Das Möbel wurde mit einer dunkelbraunen Lasur eingelassen, die Schnitzarbeiten und Profile hat man geschwärzt, Möbelbeschläge und Schlösser bestehen aus teilverzinntem Eisen.

\section{Salzburg, Metropolitankirche hll. Rupert und Virgil}

Bischof Virgil (745-784) errichtete einen ersten Vorgängerbau der Domkirche, geweiht wurde er 774. I 598 legte eine Brandkatastrophe die Sakralarchitektur in Schutt und Asche, woraufhin Erzbischof Wolf Dietrich von Raitenau (reg. I587-I6 I 2) Planungen für einen Neubau in Auftrag gab. Ein erstes Projekt fiel in die Zeit um r6or, Vincenzo Scamozzi (I 552-I6I6) entwarf einige Jahre später ein zweites, zur Realisierung eines dritten Projekts wurde I6 I I der Grundstein gelegt, doch kam es nach dem Sturz des Erzbischofs I 6 г zu einem vorläufigen Ende der Arbeiten. Danach lieferte der Baumeister Santino Solari (I576-I646) weitere Entwürfe, die während der Regierungszeiten der Erzbischöfe Markus Sittikus von Hohenems (reg. I6 1 2-I6r 9) und Paris Graf von Lodron (reg. I6I9-I653) zwischen I6 I4 und I628 umgesetzt werden konnten. Die Weihe des neuen Doms, einem der frühesten barocken Sakralarchitekturen nördlich der Alpen ${ }^{198}$, erfolgte noch in jenem Jahr, knapp drei Jahrzehnte später wurde die Westfassade unter Erzbischof Guidobald Graf Thun (reg. 1654-I668) vollendet. An das vierjochige Mittelschiff grenzen zwei aus der Westfassade vortretende, durch eine Vorhalle und ein zusätzliches Emporenjoch verbundene Türme sowie eine Reihe von Seitenkapellen und Oratorien. Eine Tambourkuppel mit Laterne überwölbt die Vierung, die Querhausarme laufen ebenso wie der Chor in großen Konchen aus. Mit der Doppelturmfassade und der hohen Kuppel beherrscht die in ihren Maßen beeindruckende Domkirche die Silhouette der Stadt. Am r6. Oktober I 944 wurde der östliche Teil des Baus bei einem Bombenangriff der Alliierten schwer beschädigt, was unter anderem zum Einsturz der Kuppel und angrenzender Gewölbeteile führte. Die Wiederherstellungs- und Renovierungsarbeiten dauerten von I 947 bis I $959 .{ }^{199}$

I 98 Etwa gleichzeitig entstand in Krems die Pfarrkirche St. Veit. Bohr, Sakralmöbel (2017), 380-386.

I99 ÖKT, Salzburg (г91 2), bes. I-4I; Mühlmann, Dom (1925); Dom von Salzburg (I928); Fuhrmann, Romanische Dome (1959); Hoppe, Wiederaufbau (1959); König, Geschicke (1959); Zacherl, Wiederaufbau (I 959); Hootz, Kunstdenkmäler (I 965-1 968), Bd. I (I 965), I 84-I89, 334-335; Fuhrmann, Dom (I 974); Pagitz, Mittelalterliche Dome (I 974); Ebhardt, Barockkirchen (I 975), bes. 20-5 I ; Neuhardt, Dom (I 980 ); Dehio, Salzburg (I 986), 526-532; Eltz-Hoffmann/Anrather, Kirchen Salzburgs (1 993), 9-19; Neuhardt, Dom (1 998); Fuhrmann, Dom (1999); Lippmann, Salzburger Dom (1 999); Winkler/Krassnig/Brandes, Salzburg (2005); Erker, Chronologie (2009). 


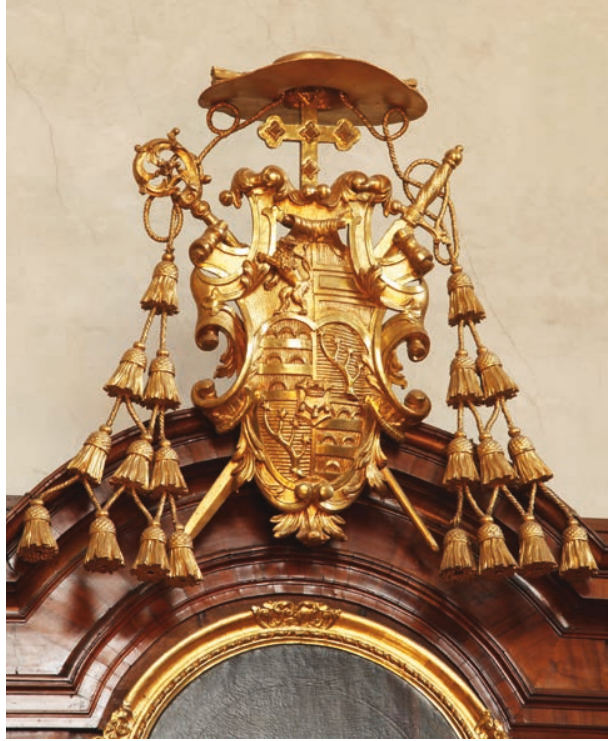

Farbtafel I 3 Domherrensakristei, Wappen des Erzbischofs Leopold Anton Freiherr von Firmian

\section{Domberren-oder Sommersakristei}

Die Sommersakristei lehnt sich an die Südseite des Chorraums. ${ }^{200}$ Zugänge im Westen und Norden verbinden die Sakristei mit dem Querschiff und dem Presbyterium. ${ }^{201}$ Im Osten schließen sich an die Sakristei zwei kleine Nebenräume an. Das im Krieg beschädigte Interieur musste umfassend restauriert wer$\operatorname{den}^{202}$, außerdem versah man einige Möbel mit einem neuen Inneren und vervollständigte die Wandvertäfelung in der Südwestecke des Raumes. ${ }^{203}$ In diesem Bereich stand früher ein Ofen, weshalb man dort auf ein hölzernes Getäfel verzichtet hatte. In der Raummitte befindet sich heute ein großer gemauerter $\mathrm{Ku}$ bus, der die moderne Raumheizung birgt, als Ablage dient und einen barocken Kastentisch ersetzt. $^{204}$

\section{Sakristeiinterieur}

Hoftischler Simon Thaddäus Baldauf, I733/36

$\mathrm{H}$ des umlaufenden Gebälks ca. 5,50 m

Raummaße ca. Io,00 m × I0,00 m

Nuss, Pappelmaser, Mooreiche, Ebenholz, Zwetschke, auf Nadelholz furniert, innen rotbraun gestrichen. Eisen, Messing, teilvergoldet

Das Mauerwerk in der Sakristei ist mit zweigeschossigen Vertäfelungselementen und Schränken verbaut (Farbtaf. I3; Abb. I I 7- I 20). Ein von Kolossalpilastern flankiertes Portal, dessen an einen Triumphbogen erinnernde Großform deutlich aus dem Wand-

200 ÖKT, ebd., bes. 25-26; Dom von Salzburg (1928), I97; Wagner, Baldauf (1978); Neuhardt, Dom (I 980), 28; Dehio, ebd., 532 ; Neuhardt, Dom (I 998), 32.

20I Der heutige Zugang zum Presbyterium geht auf die Wiederherstellung der Domkirche nach dem Krieg zurück. Erker, Chronologie (2009), I 8.

202 Ebd.

203 AES, Konsistorialarchiv Salzburg, i /87, Wiederaufbau des Domes, Rechnungen 1958-59, o5. Mai I 959 .

204 ÖKT, Salzburg (I 9 I 2), Fig. 34. 


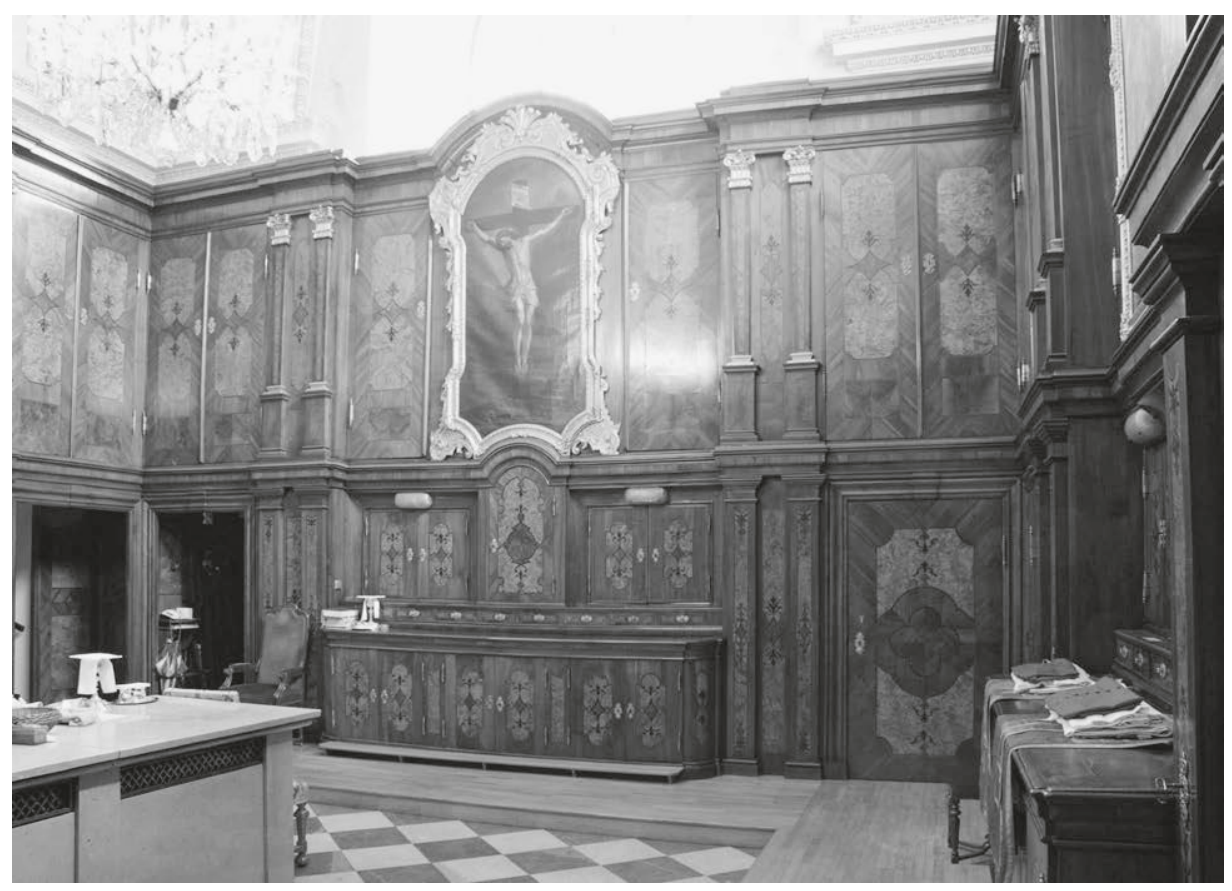

I 7 Domherrensakristei, Ostseite, Paramenten- und Schatzkammerschränke. Hoftischler Simon Thaddäus Baldauf, $1733 / 36$

I 8 Domherrensakristei, Interieur von Hoftischler Simon Thaddäus Baldauf, I $733 / 36$

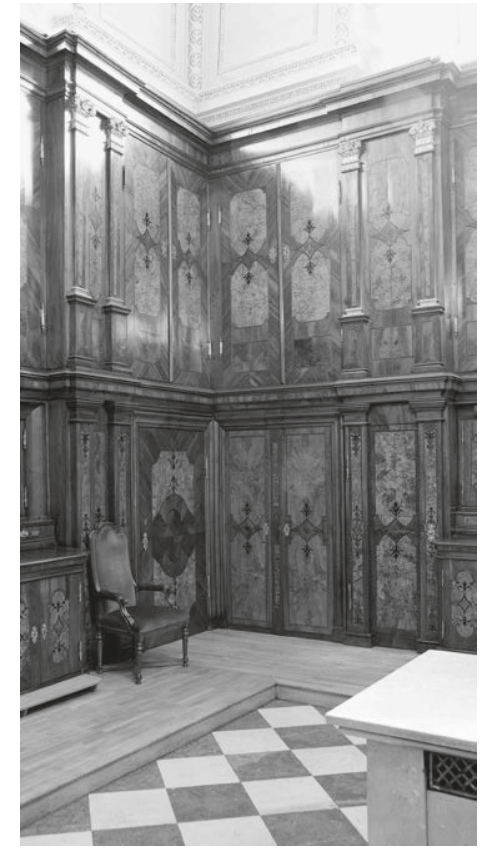




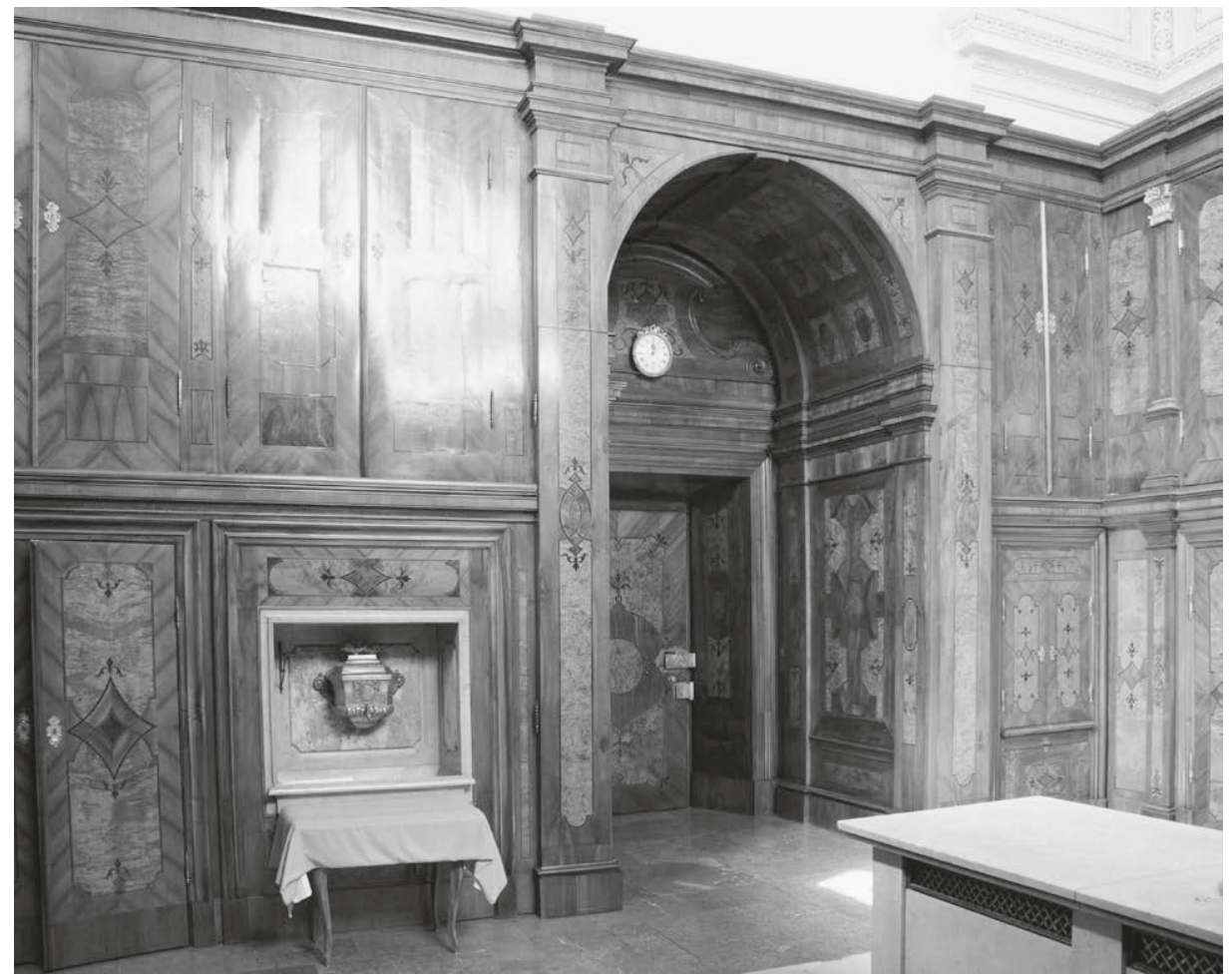

I 9 Domherrensakristei, Westseite, Portal und Lavabo. Hoftischler Simon Thaddäus Baldauf, I 733/36

aufriss des Kirchenraums heraus entwickelt wurde, dominiert die Westseite des Raums. Marketerien an der Bogenunterseite täuschen eine Kassettierung vor, ein Motiv, das wir von den Gewölben vieler antiker sowie renaissancezeitlicher und barocker Bauwerke her kennen. Die Riesenpilaster lassen sich öffnen, die Hohlräume dienen der Aufbewahrung von Stangen für Fahnen oder Baldachine. Ansonsten gliedern gekuppelte dorische und ionische Pilaster die Wandflächen. Links des Portals befindet sich ein Lavabo, rechts ein Schrank für die in der Messfeier benötigten Gefäße. Seitlich davon bieten weitere Kästen den benötigten Stauraum.

Während ebene Flächen die Westseite charakterisieren, bewirken an den anderen Raumseiten kräftige Vor- und Rücksprünge eine etwas unruhig anmutende Vielschichtigkeit. In breite Nischen, die jeweils die Mittelachse der drei Seiten akzentuieren, passten die Tischler Kredenzen ein, die aus einem tiefen Unterschrank und einem weit nach hinten versetzten Aufsatz mit Kelchfächern bestehen. Ein tabernakelähnlicher Schrank hebt die Ostwand optisch hervor. Über dem Möbel vergegenwärtigt ein Ölbild in aufwendig verziertem Rahmen den Gekreuzigten. Leinwandgemälde mit 
der Taufe des Herzogs Theodor von Bayern und der Übergabe des Dombauplans an den hl. Virgil hängen vor der Nord- und Südwand, skulptierte Wappen des Erzbischofs Leopold Anton Eleutherius Freiherr von Firmian (reg. I727-1744), dem Auftraggeber der Einrichtung, bekrönen die beiden Gemälde.

Die Flächenaufteilung der Möbel entspricht dem üblichen Muster mit Rahmen und Füllungen. Der Hoftischler Simon Thaddäus Baldauf (I677-I753) leimte das gestreifte Nussfurnier teils diagonal, teils horizontal auf die Rahmen auf, während er die Füllungen mit Nuss- und Pappelmaser auslegte. Einen Großteil der Binnenfelder dekorierte er mit Rauten, Vierpässen und vegetabilen Ornamenten, das Zentrum des "Tabernakels« mit einem Hochoval. Feine Adern aus verschiedenen Holzarten umgeben die Füllungen und zentralen Ornamentmotive. Die Beschläge bestehen aus vergoldetem Messing und tragen Motive aus dem Wappen Firmians. Basen und Kapitelle der Obergeschossordnung sind ebenso wie die Gemälderahmen und Wappenschilde vergoldet. I733 schloss Erzbischof Firmian mit Simon Thaddäus Baldauf den Vertrag über die

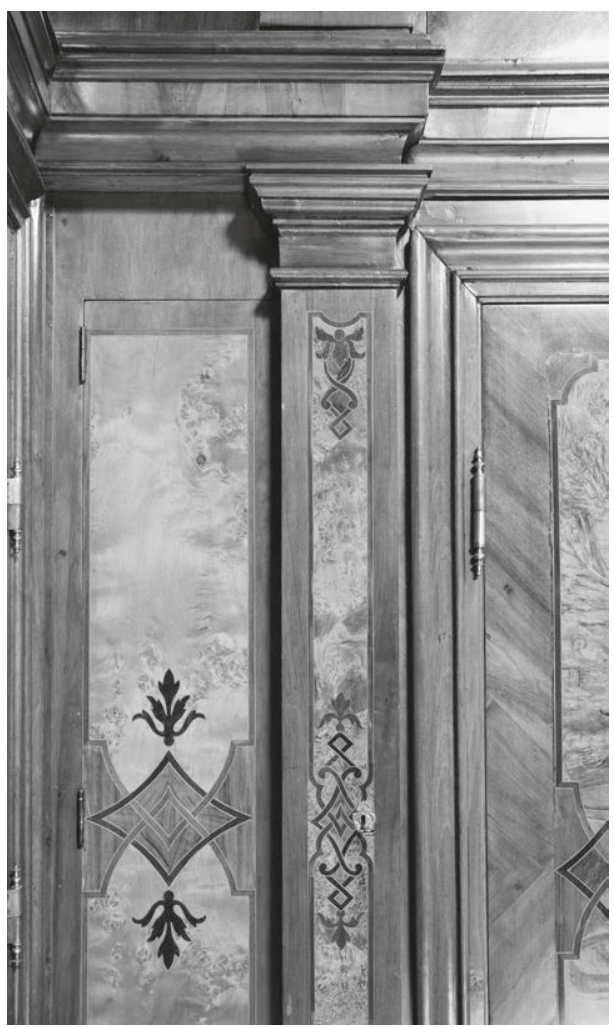

I 20 Domherrensakristei, Detailansicht mit einem Schrank in einem Wandfeld und einem Pilaster. Hoftischler Simon Thaddäus Baldauf, I 733/36 Herstellung der Einrichtung, der Hoftischler verpflichtete sich, das Interieur innerhalb eines Zeitraums von dreieinhalb Jahren zu vollenden. Baldauf zeichnete den notwendigen Riss der Ausstattung und reichte einen Kostenvoranschlag über $5.450 \mathrm{fl}$ ein, den er jedoch auf $4.000 \mathrm{fl}$ reduzieren musste. Die Summe umfasste neben dem Arbeitslohn auch den Kauf der erforderlichen Werkstoffe. ${ }^{205}$ Dabei spricht nicht zuletzt die Verwendung von Mooreiche, Ebenholz und vergoldeten Beschlägen dafür, dass der Erzbischof von seinem Handwerker eine Arbeit auf höchstem technischem und künstlerischem Niveau einforderte.

205 Wagner, Baldauf (1 978), 21, 27. Vgl. zu Baldauf auch Haslinger/Mittermayr, Kulturlexikon (200I), 69. 


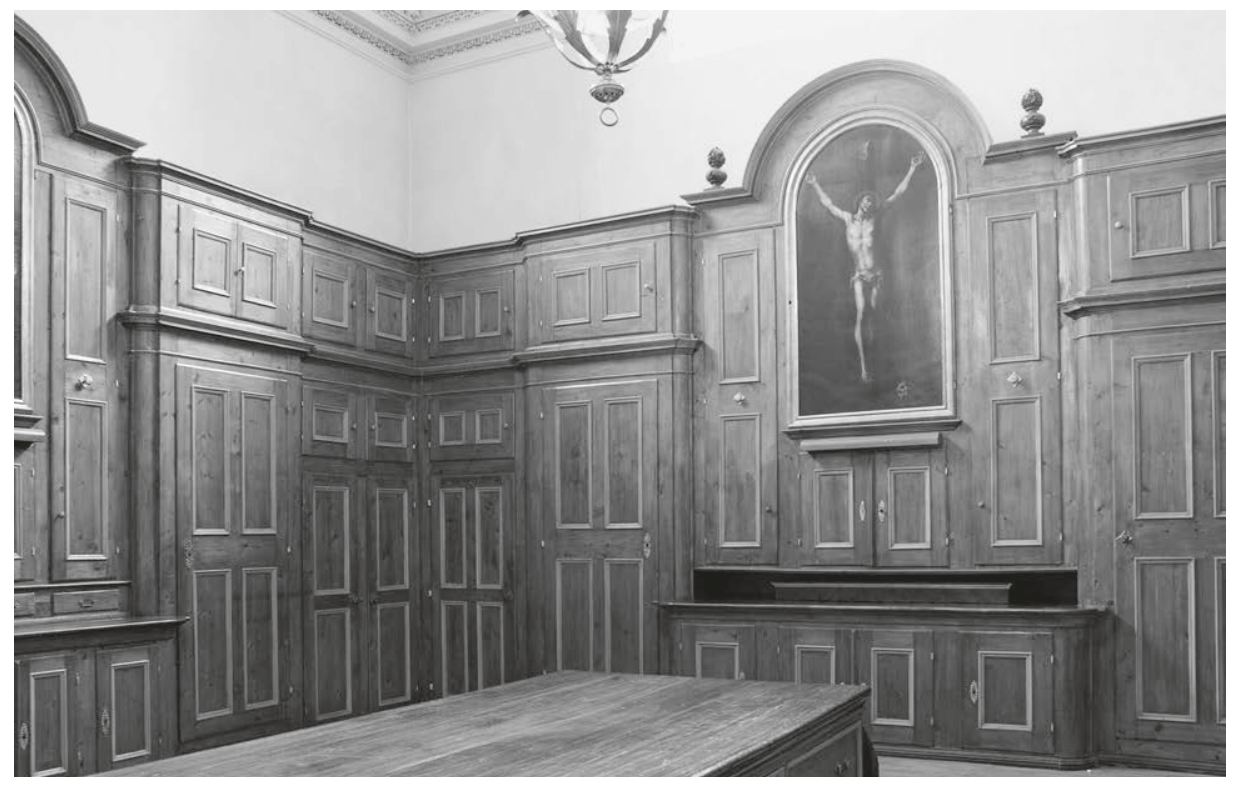

I 2 I Teilansicht der Chorherrensakristei. Salzburg, um I 730/40

\section{Pfarr-, Winter-oder Chorherrensakristei}

Salzburg, um I $730 / 40$

Gesimshöhe ca. 4,00 m

Raummaße etwa Io,o0 $\mathrm{m} \times 10,00 \mathrm{~m}$

Nadelholz, gebeizt und gefasst. Eisen verzinnt

Mit den typischen Sakristeimöbeln, die aus Unterschränken und Aufsätzen mit Kelchkästen bestehen, hat auch die Ausstattung der vor der Nordseite des Chorraums verorteten Chorherrensakristei kaum etwas gemein (Abb. I 2 I). ${ }^{206}$ Die Wandvertäfelungen und Schränke stehen entlang der Nord-, Ost- und Südseite, die Massengliederung der Möbel erinnert an jene der Sommersakristei. Erneut rhythmisieren Risalite die Tischlerarbeiten, nun folgt allerdings über einem hohen Hauptgeschoss eine Art von Attika. Wieder flankieren vorstehende Segmente drei Nischen mit tiefen Substruktionen und nach hinten gerückten Aufsätzen, die aus schmalen Schränken, großen Leinwandgemälden und hohen Rundgiebeln bestehen. Eine akzentuierte Kassettierung kennzeichnet die Möbel und das Getäfel, dabei liegen die rechteckigen Füllungen anders als die

206 ÖKT, Salzburg (191 2), 27-28; Dom von Salzburg (1928), I 97; Dehio, Salzburg (1986), 53 I. 


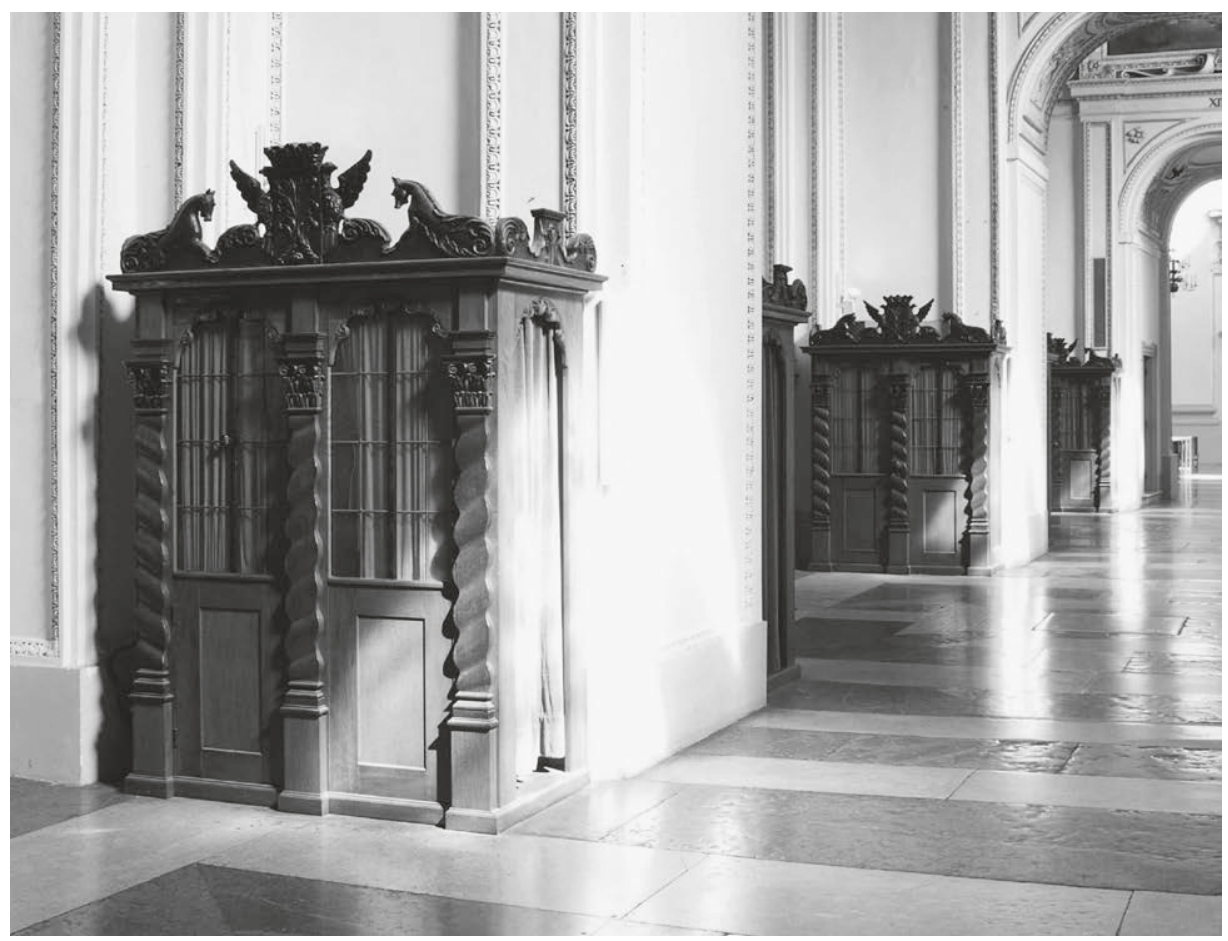

I 22 Südliches Seitenschiff. Blick nach Osten mit rekonstruierten Beichtstühlen und Schränken vor den Kirchenpfeilern

der Schränke in der Sommersakristei leicht vertieft in den Rahmen. Die Tischler fertigten die Möbel aus hellbraun gebeiztem Nadelholz, ockerfarben gefasste Profile säumen die Binnenfelder. Als Werkmaterial für die Beschläge wurde verzinntes Eisen gewählt.

\section{Kirchenraum}

\section{Beichtstüble und 7 Schränke}

Salzburg, um I 700 (mit Rekonstruktionen und Abänderungen)

$\mathrm{H} 270 \mathrm{~cm} \times \mathrm{B}$ I $75 \mathrm{~cm} \times \mathrm{T} 92,5 \mathrm{~cm}$

Eiche, massiv, teilweise geschnitzt. Glas, Eisen

Auch die Beichtstühle und Schränke (Abb. I 22-I24) wurden bei Bombenangriffen stark beschädigt. Fotografien, die nach der Zerstörung des Domes aufgenommen wurden, lassen erahnen, wie sehr bei der Restaurierung der Möbel in den originalen Bestand eingegriffen werden musste. Eigentlich war es eine Auflage des BDA, die Fas- 


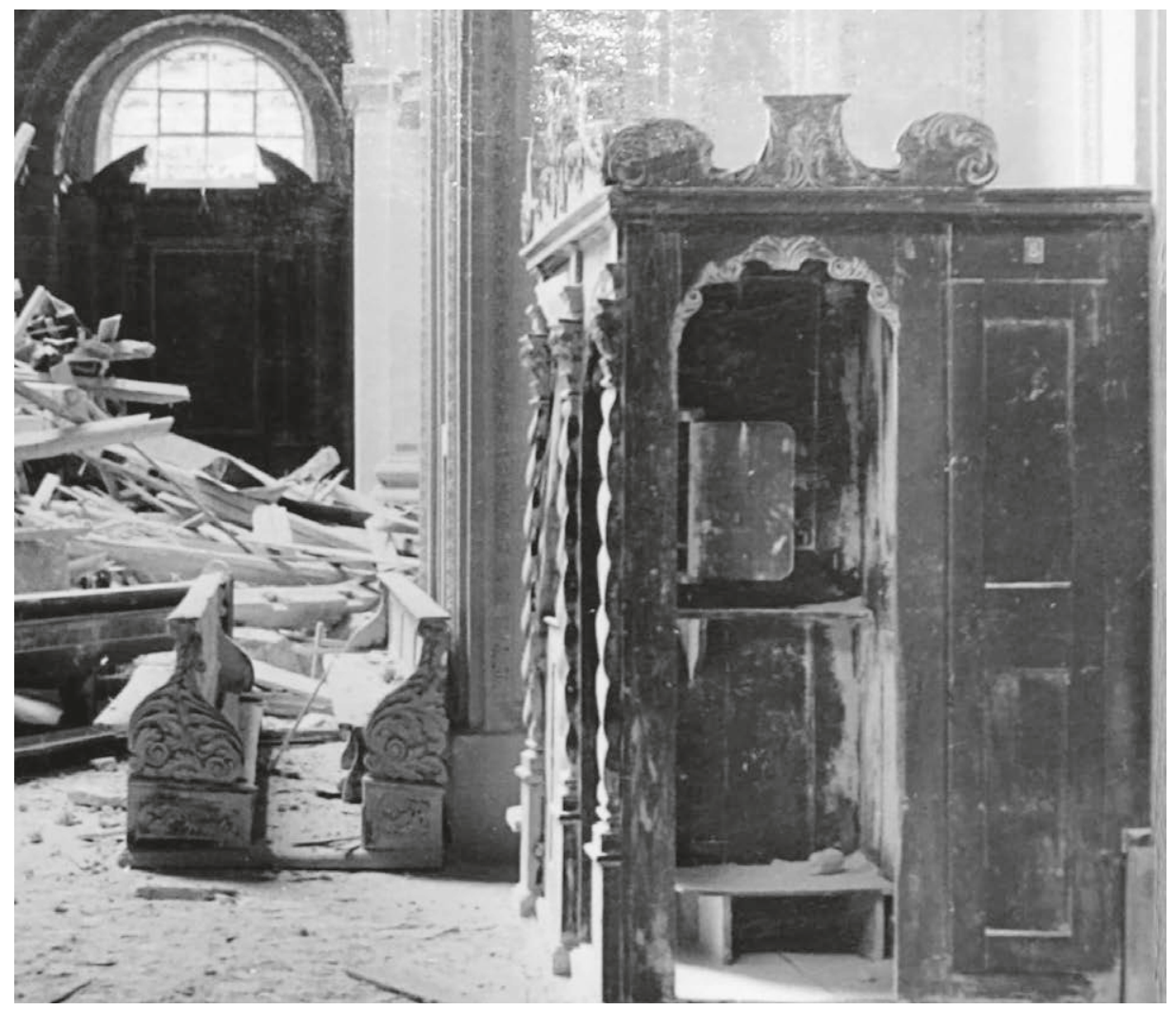

I23 Aufnahme nach dem I6.10.1944, Schutt der eingestürzten Kuppel. Kirchenbänke und Beichtstuhl mit vermutlich nachträglich angefügtem Schrank. Salzburg, um I 700

saden möglichst zu erhalten, während Seitenteile und Inneres erneuert werden konnten. ${ }^{207}$ Allerdings folgte die beauftragte Tischlerei dieser Vorgabe nur bedingt, da sie die Möbel umbaute und neuangefertigte Teilstücke in die Möbelfronten einfügte. Im März I 958 beendete sie ihre Arbeiten. ${ }^{208}$

207 Freundlicher Hinweis des Apostolischen Protonotars Prälat Johannes Neuhardt.

208 Erker, Chronologie (2009), I 8. AES, Konsistorialarchiv Salzburg, Finanzkammer Direktion I67, Kostenaufstellung vom 20. Mai 1958. AES, Konsistorialarchiv Salzburg, i/86 Domwiederaufbau, Sitzungsprotokolle des Dombaukomitees, Sitzung vom I8. März 1958; ebd., I/87, Wiederaufbau des Domes, Rechnungen I958-59. Die Rechnungen datieren zwischen 1957 und 1959. 
Die Beichtstühle und Schränke lehnen sich an die Pfeiler der Bogendurchgänge zwischen den Seitenkapellen. ${ }^{209}$ Die Beichtstühle entsprechen dem zweizelligen Typus. Schräg gehobelte Pilaster strukturieren die Fassade und tragen ein Gebälk, in das mit Rollvoluten und Akanthuslaubwerk verzierte Rundarkaden einschneiden. Die Möbel schließen mit einem Schnitzaufsatz, dessen Mitte ein mit Blattwerk dekoriertes und bekröntes Feld einnimmt. Adler, ein dezenter Hinweis auf das Thun'sche Wappen, flankieren das Zentrum, Hippokampen akzentuieren die Außenkanten. Voluten und ein reliefiertes Hochrechteck über dem Gebälk lassen auch die Schmalseiten optisch leichter erscheinen.

Die obligatorische halbhohe Tür und ein schwerer Vorhang schützten einst die Priesterstalle, während das Gehäuse der Beichtenden vorn und seitlich offenstand. Die Verglasung der Beichtstuhlfassaden stammt aus der Zeit nach dem Krieg. Das auf der Abb. I 23 ge-

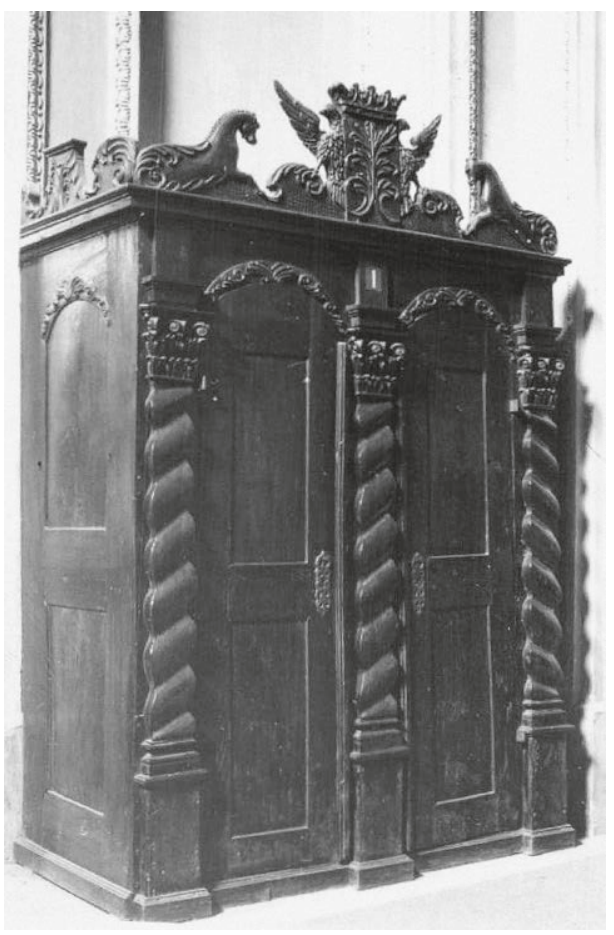

I 24 Historische Aufnahme, Schrank in einem Seitenschiff. Salzburg, um I 700 zeigte Exemplar war im hinteren Bereich mit einem zusätzlichen Schrank versehen, doch entsprach dieser Befund vermutlich nicht dem originalen Zustand. Die asymmetrische Konzeption der Schmalseite und der zu kurze Aufsatz sprechen dagegen. Falls unsere Interpretation der Aufnahme von 1944 zutrifft, war die frühere Konstruktion der Pönitentenzellen absolut ungewöhnlich. Ein Pilaster und der dahinter liegende Stollen markierten auf der Seite der Beichtenden die vordere Außenkante des Möbels, eine gestalterische Lösung, die die Bauform von Loggien aufgreift. Damit nahmen diese Beichtstühle eine aparte Stellung zwischen den kastenförmigen Exemplaren und jenen Möbeln ein, die lediglich ein geschlossenes Gehäuse für die Priester besaßen, während vorn und seitlich auf Wände verzichtet wurde. Für beide Möbeltypen liefert der Katalog Beispiele (Abb. 77, I7 I, I 72, 205). Hinsichtlich der Großform ähneln sich heute Beichtstühle und Schränke, denn bei

209 ÖKT, Salzburg (I9I2), 36; Dom von Salzburg (1928), I89; Dehio, Salzburg (1986), 53 I ; Fuhrmann, Dom (I 999), 4. 


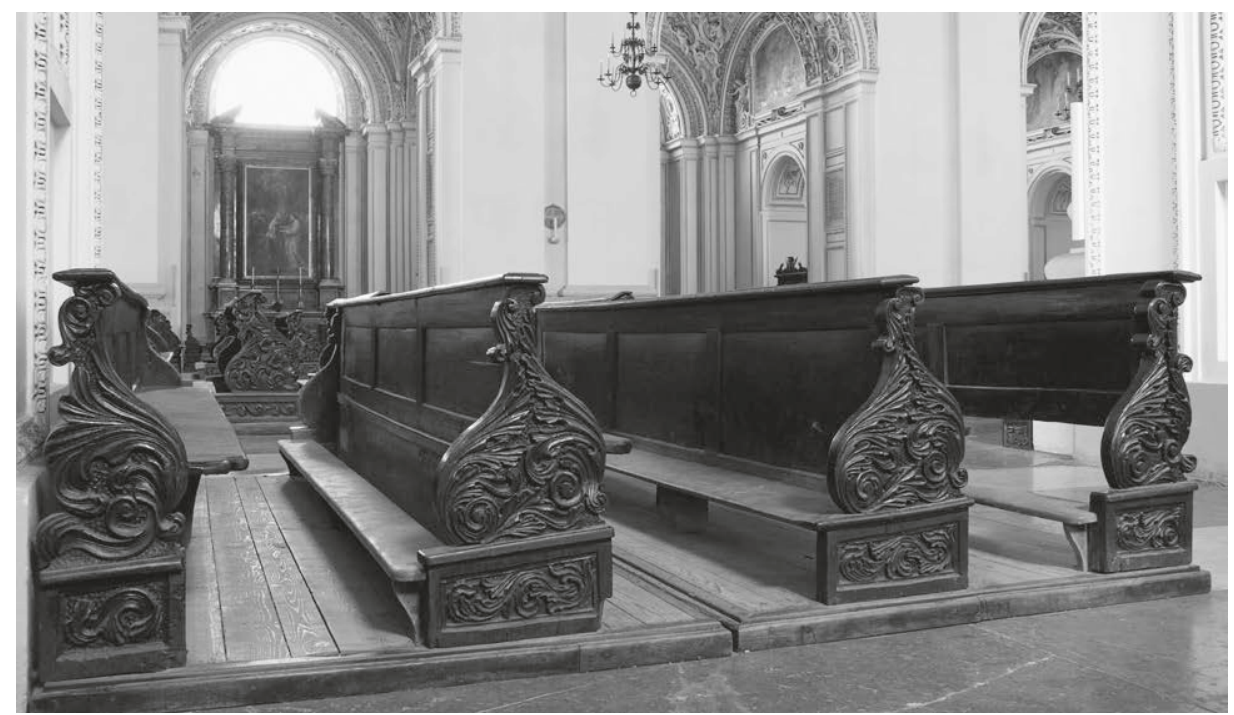

I25 Bankreihen unter den Mittelschiffarkaden. Salzburg, um I 700

den Restaurierungsarbeiten wurden auch deren Fassaden verglast, früher besaßen sie die für Schränke üblichen geschlossenen Holzfüllungen.

\section{I2 Bänke unter den Arkaden}

HS $10,5 \mathrm{~cm}$

$\mathrm{H} 84 \mathrm{~cm}(+\mathrm{IO}, 5 \mathrm{~cm}) \times \mathrm{L} 340 \mathrm{~cm}$

\section{Bänke vor den Wandpfeilern}

$\mathrm{H}$ I $22 \mathrm{~cm} \times \mathrm{L} 475 \mathrm{~cm}$

Salzburg, um I 700

Nussbaum, Eiche massiv, Nadelholz

Unter den Mittelschiffarkaden werden zwölf Bänke aufbewahrt (Abb. I 25). Fünf weitere Exemplare befinden sich vor den Wandpfeilern des Langhauses, allerdings wurden sie wie die Möbel in der Dreifaltigkeitskirche (Abb. ro9) mit einem geschweiften Abschluss über der Rückenlehne versehen, zudem sind sie wesentlich länger. ${ }^{210}$ Auch

2 10 ÖKT, ebd. 
diese Inventarstücke mussten nach dem Krieg teilweise erneuert werden. ${ }^{211}$ Die zwölf Möbel stehen quer zur Längsrichtung des Raums auf mobilen Podesten, die anderen direkt auf dem Boden und parallel zur Kirchenlängsachse.

Die schlichten Brüstungen der Bänke unter den Arkaden erscheinen als waagrechte, zwischen den Seitenwangen aufgespannte Wände, wie das beispielsweise auch an den Möbeln in St. Markus vorkommt (Abb. I3r). Ansonsten kennen wir diese Art der Konstruktion vor allem von Inventarstücken aus dem Süden Österreichs (Abb. 56). Der abgeschrägte Sockelbereich der Docken besitzt ein querliegendes, mit Laubwerkschnitzereien geschmücktes Binnenfeld. Darüber erhebt sich der Aufsatz, der Rückenlehne und Sitzbank trägt. Akanthus schmückt auch diese Bereiche der Seitenwangen. Hier formt er im unteren Bereich große Wirbel, denen das Laub entsprießt. Den Abschluss bildet ein mit Eckvoluten versehener Abakus, auf dem eine schmale Buchablage befestigt ist. Die Möbel vor den Pfeilern und die Exemplare unter den Arkaden entstanden um die Wende vom 17. zum i 8. Jahrhundert, die Podeste sind modern.

\section{Bänke im Mittelschiff}

Salzburg, um r670/80 und Hoftischler Balthasar Köbl (?), um I 700

HS $9,5 \mathrm{~cm}$

H IOI $\mathrm{cm}(+9,5 \mathrm{~cm}) \times \mathrm{L}_{312} \mathrm{~cm}$

Eiche massiv, Nadelholz

Die vermutlich von Balthasar Köbl (I645-I7I I) gefertigte Möbelgarnitur wurde in den I95oer-Jahren im Hauptschiff der Domkirche in vier große Blöcke $(2 \times$ I 2 und $2 \times$ I6 Bänke) eingeteilt (Farbtaf. I4; Abb. I26-I 29). ${ }^{212}$ Dagegen geben alte Fotografien sechs, wenn nicht acht kleinere Einheiten zu erkennen, die Aufstellung der Bankreihen war ehemals folglich eine andere. ${ }^{213}$ Etliche dieser Möbel wurden ebenfalls während der Kriegshandlungen zerstört. Eine bei der Restaurierung von Kirche und Ausstattung angefertigte Skizze dokumentiert den Standort der Reproduktionen,

2 I I AES, Konsistorialarchiv Salzburg, I / 87 Dombau Korrespondenz 1959, Schreiben vom 29. Juni 1959.

2 I 2 ÖKT, Salzburg (I9I 2), 36 ; Dom von Salzburg (I 928), I 2 I, I 89; Zacherl, Wiederaufbau (I959), I I I ; Neuhardt, Dom (1980), 32 ; Dehio, Salzburg (1986), 53 I ; Fuhrmann, Dom (1996), 4 ; Neuhardt, Dom (1998), 33. Köbl wurde am 5. Juni r7I r beigesetzt. Salzburg Dompfarre, Sterbebuch r67I-I7I4, fol. 682, STB II, 03-Tod_o682, https://data.matricula-online.eu/de/oesterreich/salzburg. Köbl wird dort als »hochfürstlicher « Tischlermeister bezeichnet [Zugriff Oktober 2020].

2 I 3 Mühlmann, Dom (r 925), Abb. 7 I ; Dom von Salzburg (I 928), 73, I 2 I ; Fuhrmann, Kirchen (I 949), Taf. 25 . 


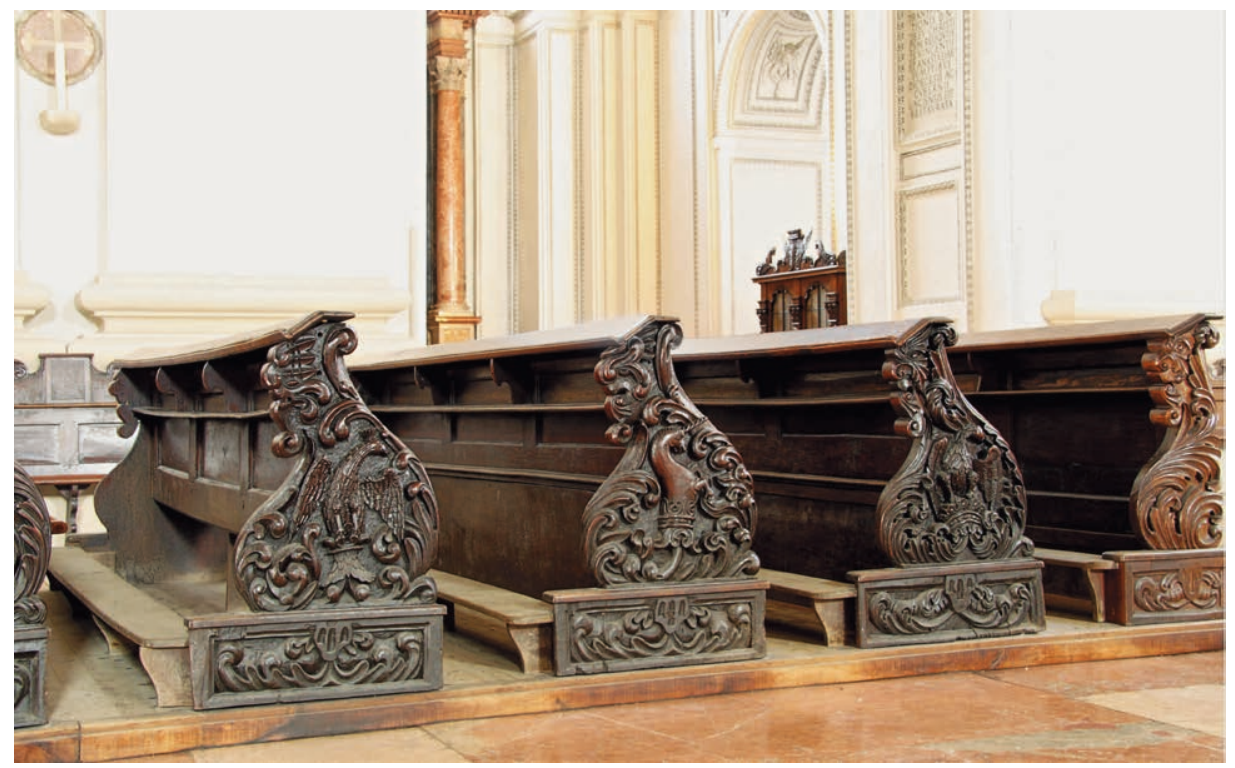

Farbtafel I4 Mittelschiff, Laiengestühl, Bankwangen. Hoftischler Balthasar Köbl (?), um I 700. Rechts im Bild eine neue Brüstungswange.

mit denen die devastierten Inventarstücke ersetzt wurden. ${ }^{214}$ Bei den beiden vorderen Blöcken hat man demnach mit weitgehend oder komplett erneuerten Sitzmöbeln zu rechnen, während sich die hinteren Bänke bis auf die teilweise ausgetauschten Brustwände als zum originalen Bestand gehörende Möbel erweisen. Die Reproduktionen können durch eine etwas hellere Holzfarbe und das Fehlen der üblichen Altersschäden von den barocken Stücken recht gut unterschieden werden (Farbtaf. I4), wobei diese Merkmale freilich auch für stark restaurierte Objekte charakteristisch sind. Stilistisch lassen sich zwischen alten und neuen Bänken so gut wie keine Differenzen erkennen, es handelt sich bei Letzteren um originalgetreue Nachbildungen. Die Aufstellung des Möbelensembles erfolgte im März 1959. ${ }^{215}$

Die Brustwände zeigen den üblichen Aufbau in Rahmen und Füllungen, wobei einige mit einer ungewöhnlichen Gestaltung aufwarten: Sie sind als durchgehende Einheiten konzipiert, die aus einem breiten Rahmen und einem einzigen großen Binnenfeld bestehen (Abb. I 27). Akanthuskraut überwuchert die Brüstungen, Akan-

2 I 4 AES, Konsistorialarchiv Salzburg, I/87 Dombau Korrespondenz 1959.

2I 5 Zacherl, Wiederaufbau (I 959), i I I, I 24, 250; Erker, Chronologie (2009), i 8. S. außerdem AES, Konsistorialarchiv Salzburg, Finanzkammer Direktion I68, Kostenaufstellung vom 27. Jänner 1959. 


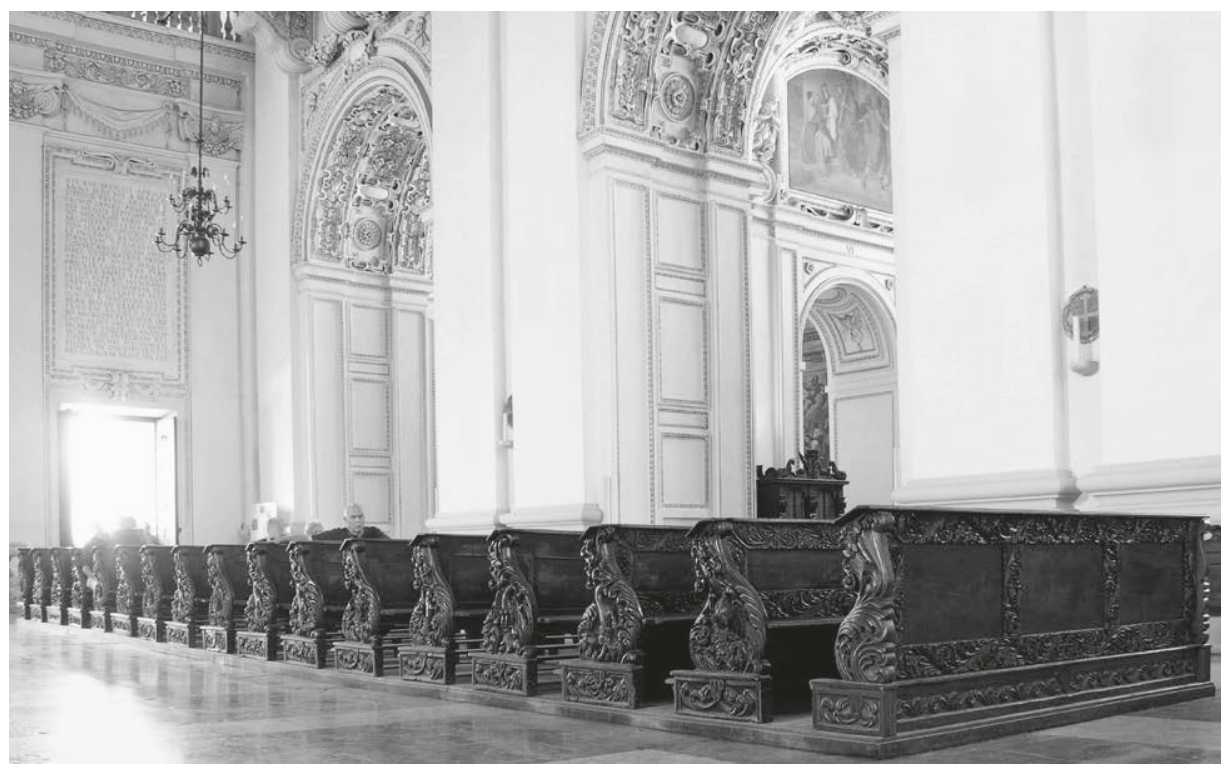

I26 Mittelschiff, Laiengestühl. Hoftischler Balthasar Köbl (?), um I 70o

thusblüten akzentuieren die oberen Ecken der zentralen Felder. Zwei große Wappenkartuschen zeigen das Doppelwappen des Landes Salzburg und des Fürsterzbischofs Johann Ernst Graf Thun und Hohenstein (reg. in Salzburg 1687-1 709), der den Auftrag zur Fertigung des Gestühls erteilte. Ein Bischofshut bekrönt die Wappen, seitlich hängen Quasten herab.

Der Aufbau der Wangen mit Sockel und Aufsatz entspricht jenem der Möbel unter den Arkadenbögen. An den zu den Seitenschiffen weisenden Wangen besteht der Schmuck aus grotesken Blattmasken und Laubwerk (Abb. I 29), an den inneren Wangen aus Akanthus, der einen Adler oder ein Einhorn umrahmt (Abb. I28). ${ }^{216}$ Auffallend sind die stilistischen Unterschiede zwischen den vegetabilen Motiven an den Brüstungen und den an den Docken. Während distelartiges Blattwerk, das an Vorlagen von Künstlern wie Johann Conrad Reuttimann (nachgew. I676-I69I), Matthias Echter ( $1653-\mathrm{I} 70 \mathrm{I} / 03)$, Johann Indau (I $65 \mathrm{I}-\mathrm{I} 690$ ) oder Georg Caspar Erasmus (wohl I620/30-nach I695) aus dem ausgehenden I7. Jahrhundert denken lässt, die Brustwände bedeckt, favorisierte der Bildschnitzer bei der Herstellung der Wangen

2 I6 Der Steinbock aus dem Wappen des Erzbischofs Markus Sittikus, der die Planungen durch Santino Solari veranlasste, ist vermutlich nicht gemeint. 

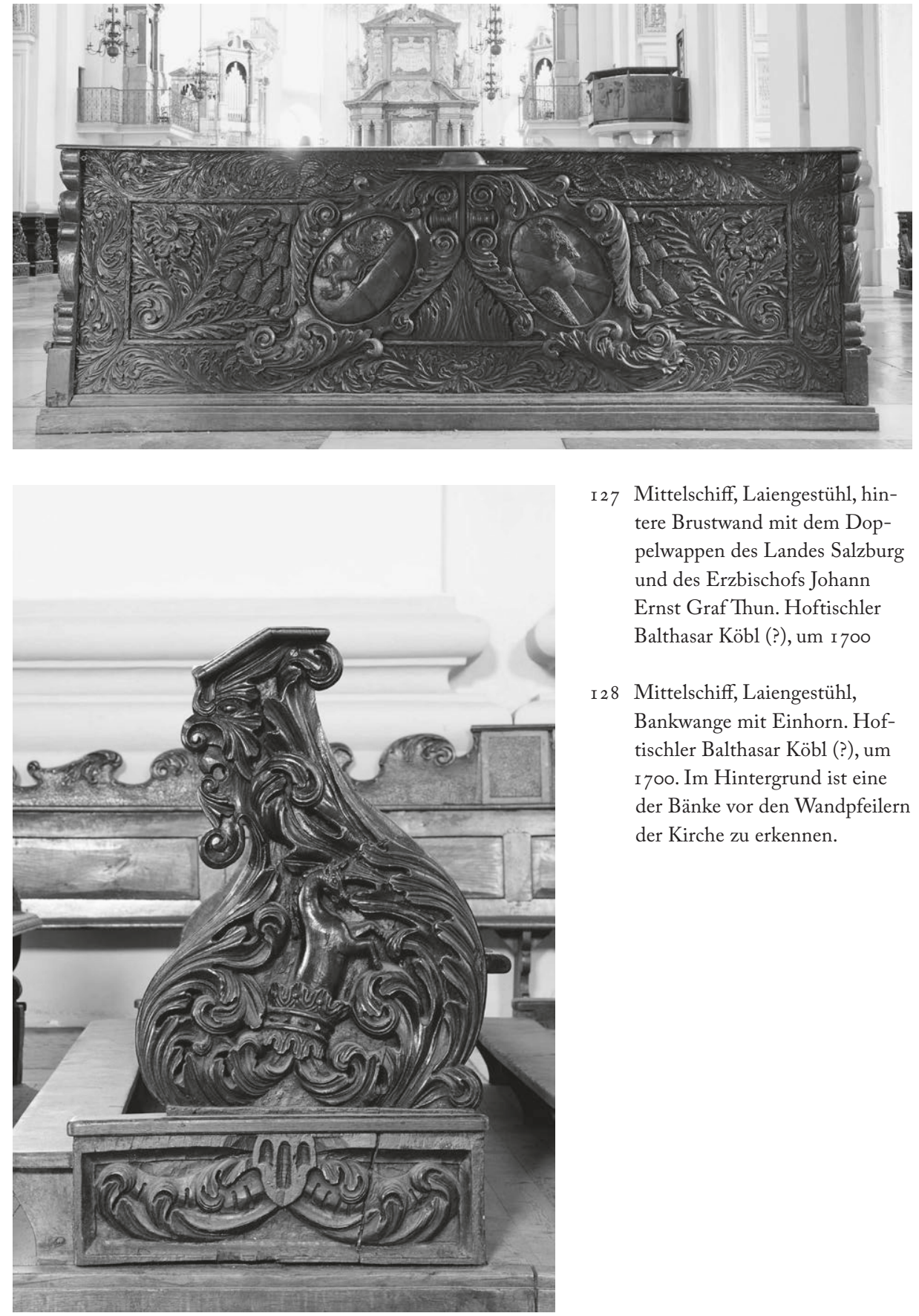

I 7 Mittelschiff, Laiengestühl, hintere Brustwand mit dem Doppelwappen des Landes Salzburg und des Erzbischofs Johann Ernst Graf Thun. Hoftischler Balthasar Köbl (?), um I 7oo

I 8 Mittelschiff, Laiengestühl, Bankwange mit Einhorn. Hoftischler Balthasar Köbl (?), um I 70o. Im Hintergrund ist eine der Bänke vor den Wandpfeilern der Kirche zu erkennen. 
zum Mittelgang hin großblättriges, fleischiges und stark reliefiertes Laubwerk, das detailreich ausgearbeitet ist. ${ }^{217}$ Die Brüstungen und diese Wangen lassen sich gut ins ausgehende I 7. Jahrhundert datieren. Nicht so die äußeren Wangen, deren stilisiertes Laubwerk noch mit frühbarocken Schnörkeln endigt und manieristische Masken einschließt. Und verschiedene Abschlusswangen zeigen überhaupt nur knorpelige Bögen. Schnitzereien, die um die Jahrhundertwende auf der Höhe der Zeit waren, stehen folglich neben Arbeiten, die einige Jahrzehnte früher entstanden sein dürften. Mit großer Wahrscheinlichkeit wurden hier Teile einer älteren Bankgarnitur in Zweitverwendung eingesetzt.

Schnitzarbeiten zieren überdies die Rahmen einiger Rückenlehnen. Das kommt zwar auch an Möbeln in Tirol vor, etwa an den Bänken in der Jesuitenkirche zu Innsbruck (Abb. 303, 304), doch dürfte es sich bei den Exemplaren in der Domkirche um pasticci handeln. Wie erwähnt, war das Gestühl ursprünglich auf sechs oder sogar acht Blöcke verteilt, es wird also auch eine entsprechende

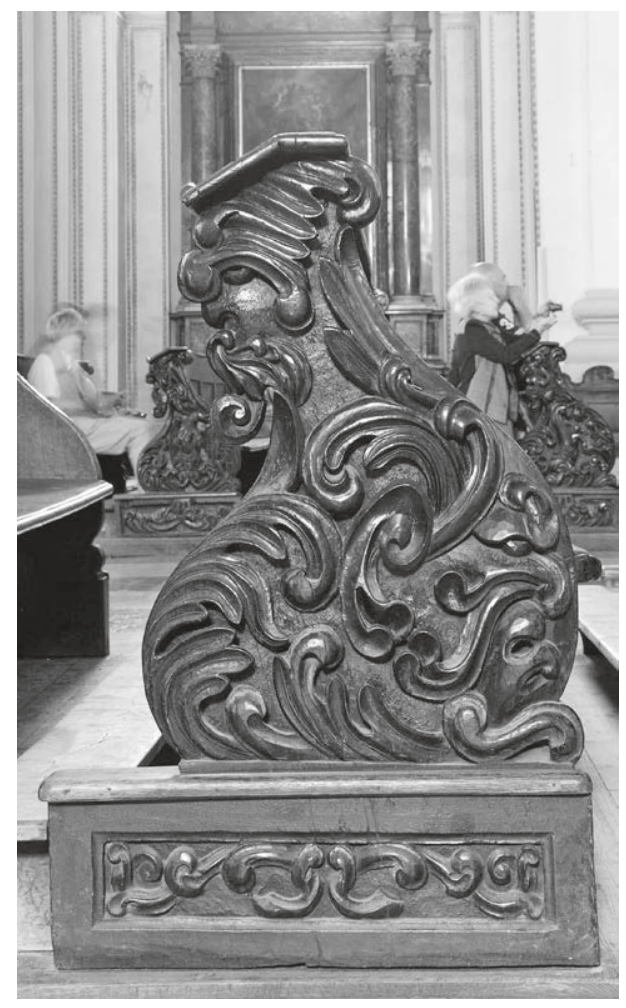

I 29 Mittelschiff, Laiengestühl, Bankwange auf der südlichen Außenseite. Salzburg, um I $670 / 80$ Anzahl von Brüstungen existiert haben. Vermutlich funktionierte man die überzähligen Brustwände bei der Neuaufteilung des Bankensembles zu Lehnen um und ersetzte die originalen und nicht weiter verzierten Stücke. Die Möbel bestehen aus dunkelbraun gebeiztem Eichenholz, das durch seinen angenehmen Farbton dem Aussehen alten Nussholzes entspricht. Die neuen Laufböden wurden aus Nadelholz gefertigt. ${ }^{218}$

2 I $7 \mathrm{Zu}$ Reuttimann, Echter und Indau vgl. Berliner/Egger, Vorlageblätter (г98 г), Bd. I, 87-88, Bd. 3, Abb. ro43-1062, zu Erasmus s. Thornton, Form (1998), Taf. 2 I5. Weitere für die Verbreitung des Laubwerks wichtige Ornamentstecher waren Leonhard Heckenauer d.J. ( $679-$ I 704), Johannes Unselt (nachgew. I68I-r696) und Ägidius Bichel (nachgew. I698). Berliner/Egger, ebd., Bd. I, 88-89, Bd. 3, Abb. 1063-1075.

2 I 8 In der Fachliteratur werden die Entwürfe zum Kirchengestühl und zu den Beichtstühlen bisweilen Johann Bernhard Fischer von Erlach (I656-I 723) zugeschrieben. Diese These wird jedoch durch keine Schriftquellen oder stilistischen Vergleiche gestützt. 


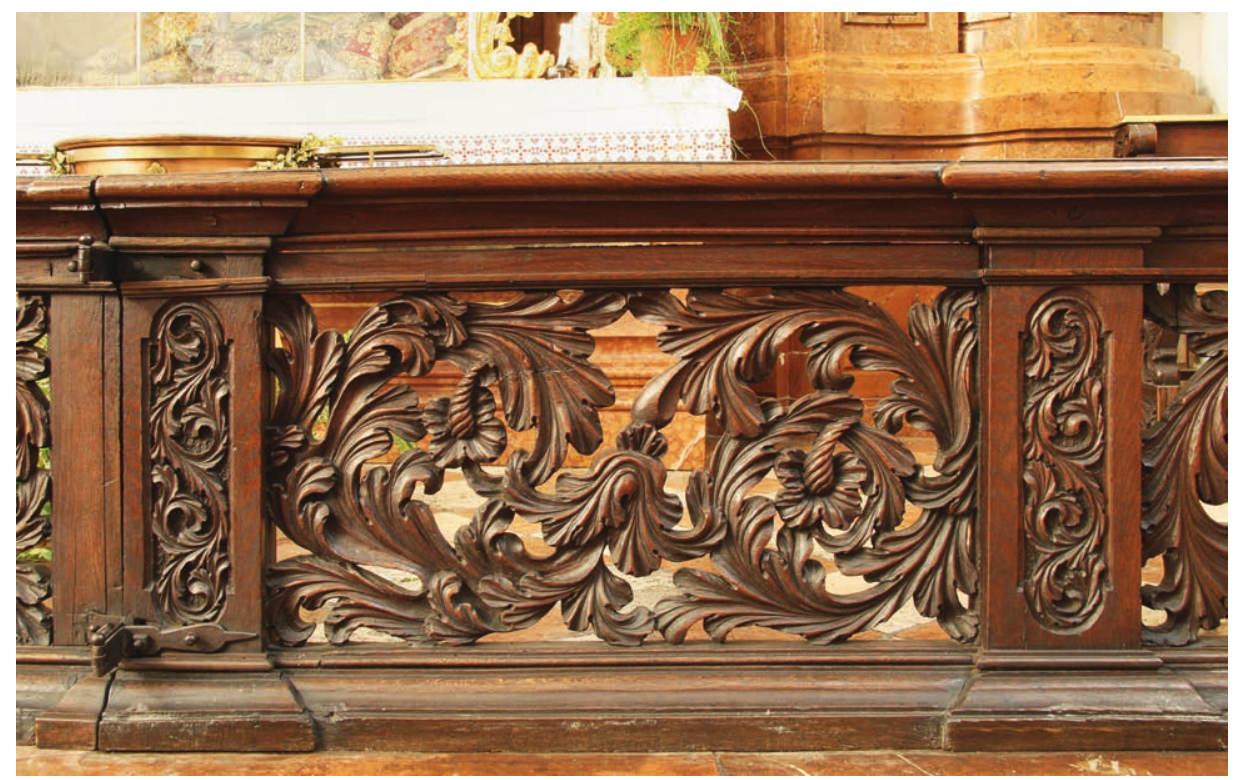

Farbtafel I 5 St. Markus, Teilansicht einer Chorschranke. Hoftischler Balthasar Köbl (?), verm. nach einem Entwurf von Johann Bernhard Fischer von Erlach, um I 704

\section{Salzburg, St. Markus}

\section{Ehemaliges Ursulinenkloster}

Eine im frühen I7. Jahrhundert am Fuße des Mönchsbergs errichtete Vorgängeranlage wurde 1669 durch einen Bergsturz zerstört. ${ }^{219}$ Ursulinen, die der Erzbischof Johann Ernst Graf von Thun-Hohenstein (reg. I687-r 709) I695 nach Salzburg berief, bauten Kloster und Kirche zwischen I 699 und I705 wieder auf. Architekt war Johann Bernhard Fischer von Erlach (I656-I723). Die Klosteranlage wird von zwei Straßenzügen begrenzt, sie besitzt eine sich nach Osten erweiternde Keilform, der schmalen Westfassade mit dem Eingang zur Kirche ist ein kleiner Platz vorgelagert. Der Grundriss des Sakralbaus gibt die Form eines griechischen Kreuzes mit Kuppel und kurzen Querarmen wieder, die zwei Seitenaltären Platz bieten. Die Stuckateure arbeiteten unter der Leitung von Diego Francesco Carlone (I674-I750). Die relevante Literatur schreibt die Entwürfe zur Ausstattung der Kirche ebenfalls dem Architekten zu, mög-

2 I9 ÖKT, Salzburg (I9I 2), bes. 27 I-280; Ebhardt, Barockkirchen (I 975), I3 I-I 38 ; Sedlmayr, Fischer von Erlach (1976), I07, 268-269; Dehio, Salzburg (1986), 571-572; Eltz-Hoffmann/Anrather, Kirchen Salzburgs (1993), I I4-I r6; Sedlmayr, Fischer von Erlach (1997), I 94-1 97, 388; Bogner, Ursulinerinnen (I 999); ders., St. Markus (2003); Kreul, Fischer von Erlach (2006), $230-232$. 


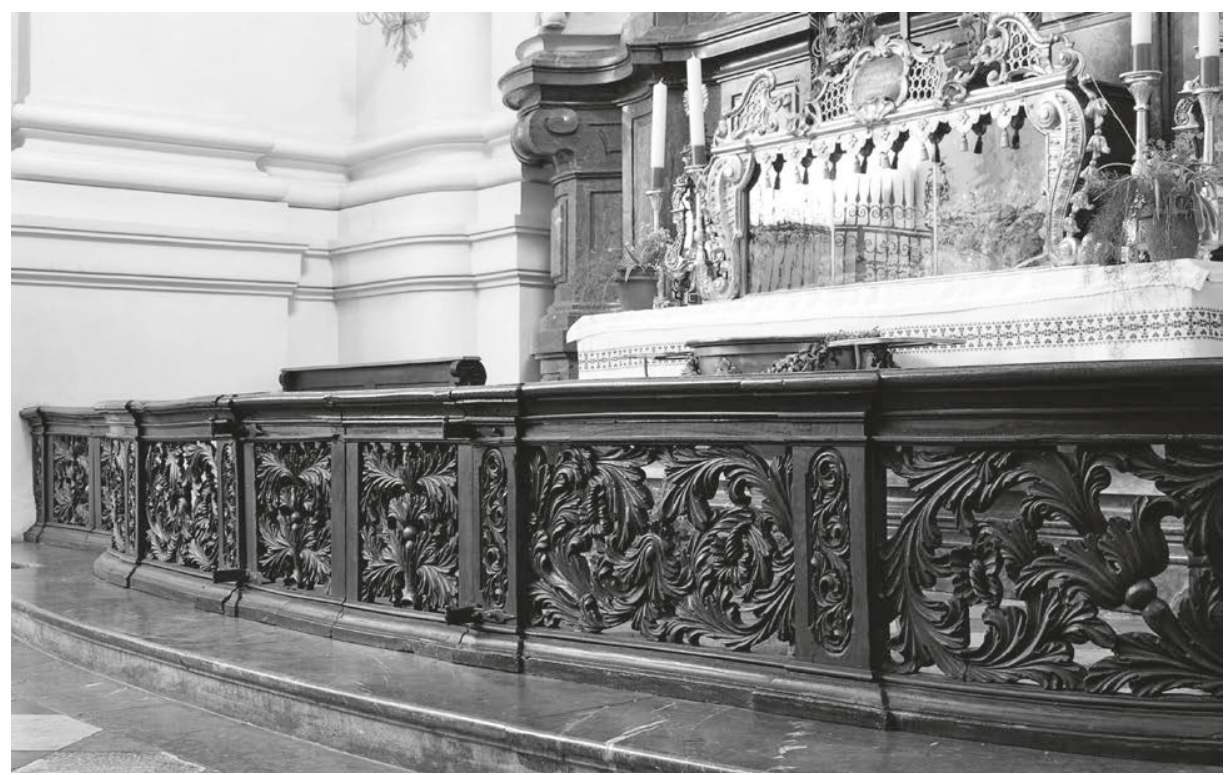

I30 Schranke vor einem Seitenaltar. Hoftischler Balthasar Köbl (?), verm. nach einem Entwurf von Johann Bernhard Fischer von Erlach, um I 704

licherweise war Balthasar Köbl (I645-I7 I I) für die Ausführung der Tischlerarbeiten verantwortlich. ${ }^{220}$ Seit 1999 wird der Bau von der ukrainischen griechisch-orthodoxen Gemeinde in Salzburg genutzt.

\section{Chorschranken vor Altarraum und Seitenaltären}

Hoftischler Balthasar Köbl (?), Entwurf Johann Bernhard Fischer von Erlach (?), um I 704 $\mathrm{H} 86,5 \mathrm{~cm}(+\mathrm{r} 6 \mathrm{~cm}) \times \mathrm{L}$ (vor den drei Altären) ca. 9,50 m Eiche, massiv, dunkelbraun lasiert

Von Pilastern in regelmäßige Abschnitte unterteilte Chorschranken grenzen den Raum vor den Altären vom Laienraum der Kirche ab, in den die Balustraden mit ihrem geschwungenen Grundriss hineinstoßen (Farbtaf. I 5 ; Abb. I 30 ). ${ }^{221}$ Sockelleiste und Gesims sind profiliert, das Feld dazwischen füllen reiche Akanthusschnitzereien. An den Türen basiert die Komposition auf einem senkrecht angeordneten Strunk, von dem aus sich die kräftigen und mit dicken Rippen versehenen Akanthusblätter zu den

220 Bogner, St. Markus (2003), 8.

22 I Oberhofer/Hahnl, Handwerk (I 978), 77; Dehio, Salzburg (I 986), 572; Bogner, ebd., 8, I I, I 2. 
Seiten hin ausbreiten. Dagegen gehen in den anderen Feldern von einem diagonal angeordneten Mittelstück große Blattspiralen aus, die mit Blüten und Fruchtständen enden. Im Jahr 2000 wurde die Kommunionbank vor dem Hauptaltar um eine Ikonostase erweitert, nachdem man die Kirche der orthodoxen Glaubensgemeinschaft überlassen hatte. Durch ihre Aufteilung, die derjenigen der Balustrade entspricht, und den à jour gearbeiteten Akanthusschmuck passt sie sich dem originalen Bestand recht gut an.

Wie Experten vermuten, entwarf Fischer von Erlach nicht nur den Baukörper, sondern auch die Einrichtung und damit die Balustraden vor den Altären. ${ }^{22}$ In der Salzburger Dreifaltigkeitskirche, die zwischen r694 und I 702 und damit kurz vor der Ursulinenkirche nach Plänen Fischers entstand, wurden sie in ähnlicher Weise, aber mit nicht ganz so überragender Qualität vorweggenommen (Abb. I I I). ${ }^{223}$ Hier wie dort teilt ein auffallender Rundstab das Gesims horizontal in Hälften. In der Profilierung des Gebälks über den Riesenpilastern der Ursulinenkirche wiederholt sich dieses ungewöhnliche Motiv, wenn auch nicht als Rundstab, sondern als Hohlkehlprofil, ein weiteres Indiz dafür, dass die Vorlagen zu den Tischlerarbeiten aus der Hand Fischers stammten. I704 bezahlte der Konvent für die Anfertigung von Chorschranken und Laiengestühl I 50 Gulden. ${ }^{224}$

\section{Kirchenbänke}

Hoftischler Balthasar Köbl (?), um I 704

HS $12 \mathrm{~cm}$

$\mathrm{H}$ 9I, $5 \mathrm{~cm}(+\mathrm{I} 2 \mathrm{~cm}) \times \mathrm{L} \mathrm{I} 93 \mathrm{~cm} / 2 \mathrm{I} 3,5 \mathrm{~cm}$

Ahorn (?), Nadelholz, dunkelbraun, fast schwarz gebeizt. Messing

Das Gestühl zählt zehn Bankreihen, sieben davon im Langhaus bzw. im Kuppelraum, drei unter der Empore, hinzu kommen vier Brüstungen (Abb. I 3 I, I 32). ${ }^{225}$ Weitere vier Bänke stehen in den Seitenkapellen. Nach der Umwandlung der Kirche in einen orthodoxen Sakralraum mussten letztere aus Platzgründen von ihrem ursprünglichen Standort weichen.

222 Oberhofer/Hahnl, ebd.; Bogner, Ursulinerinnen (1999), 20, 58. Archivalien, die diese These stützen würden, wurden bisher leider nicht erschlossen.

223 Auf Übereinstimmungen in den Ausstattungen verschiedener Salzburger Kirchen Fischers wurde in der Literatur bereits hingewiesen. Sedlmayr, Fischer von Erlach (1976), 268, 269 und Abb. 74, 75; Sedlmayr, Fischer von Erlach (r 997), 388; Bogner, ebd.; ders., St. Markus (2003), 8.

224 Bogner, Ursulinerinnen (I 999), 58.

225 Zu den Bänken ÖKT, Salzburg (r 91 2), 278 ; Dehio, Salzburg (I 986), 572 ; Bogner, ebd.; ders., St. Markus (2003), 8. 


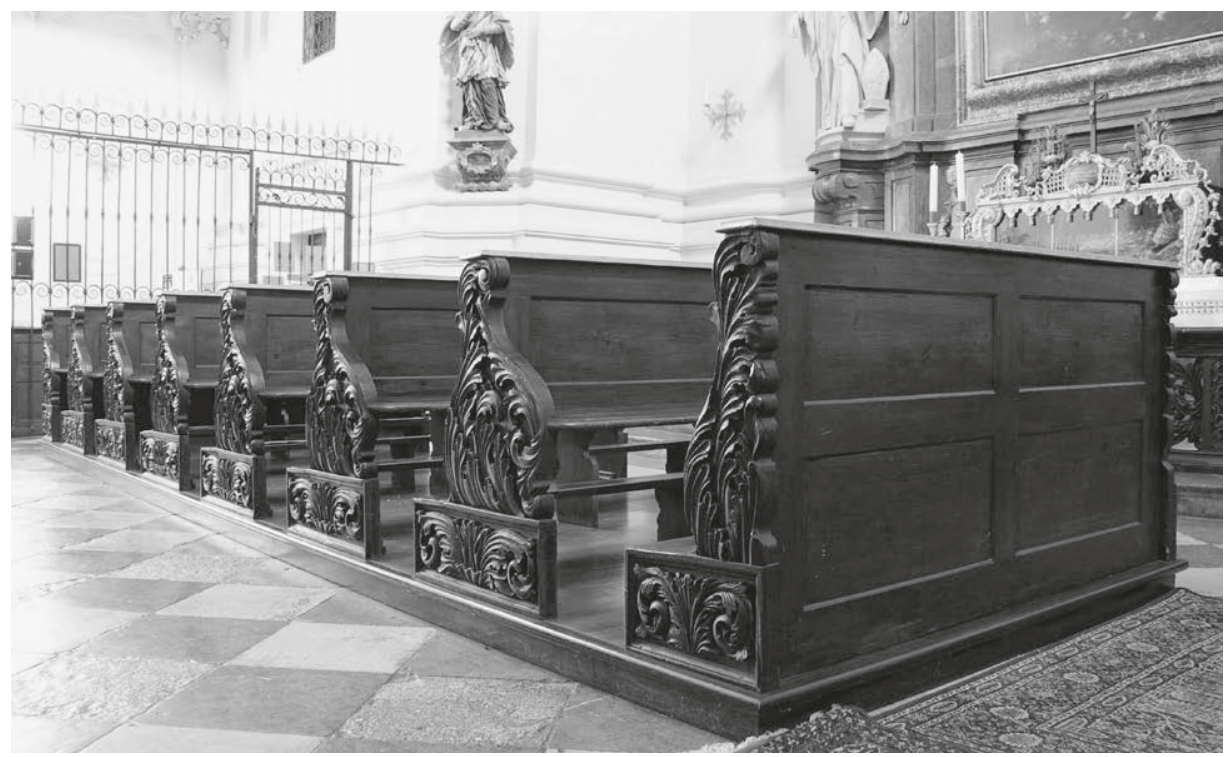

I3 I Kirchenbänke. Hoftischler Balthasar Köbl (?), um I 704

I32 Bankwange. Hoftischler Balthasar Köbl (?), um 1704

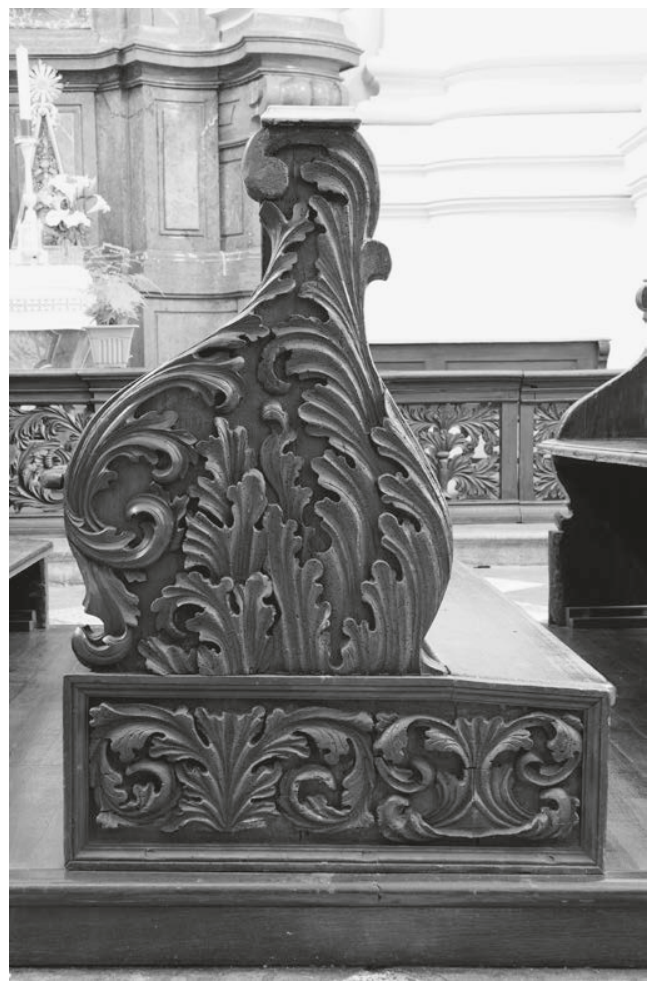


Bei der Gestaltung der Brüstungen entschied man sich für eine relativ schlichte Formgebung: Sie bestehen aus einer glatten geschlossenen Fläche, deren einziger Schmuck in ihrer Aufteilung in breite Rahmenelemente und leicht vertieft liegende Füllungen besteht. Wie das vor allem im Westen und Süden Österreichs immer wieder zu beobachten ist, verschmelzen die Vorderkanten der Wangen nicht mit der Front der Brustwände, sondern ragen einige Zentimeter nach vorn. Diese Art der Konstruktion sorgt für eine klare optische Scheidung der einzelnen Möbelsegmente.

Auch hier setzen sich die Docken aus einem Sockelteil und einem Aufsatz zusammen. Er erinnert durch sein Aussehen an dickbauchige Keulen oder Vasen mit schlankem Hals und nur unwesentlich breiterem Ausguss, eine Form, die sich an den Wangen der Kirche Maria Plain und der Augustinerkirche in Salzburg-Mülln (Abb. 75, 76, I 36, I 37) wiederfindet. In mehreren Schichten übereinander gelegter Akanthus ziert die Wangen.

Die Möbel bestehen vornehmlich aus Nadelholz, für die Schnitzarbeiten wurde offenbar Ahorn verwendet. Untereinander weisen die Schnitzereien zum Teil große formale Differenzen auf, was darauf hindeuten könnte, dass sie von verschiedenen Handwerkern ausgeführt wurden. Dabei erstaunen die Analogien einiger Wangen mit jenen der Bänke in der Wallfahrtskirche Maria Plain. Etliche Docken in den beiden Kirchen sind nahezu identisch, weshalb angenommen wird, dass für ihre Herstellung ein und dasselbe Atelier verantwortlich war. Bemerkenswert ist auch hier der formalästhetische Gegensatz zwischen den schlichten, weil glatten Flächen der Brustwände mit dem Ordnungssystem aus Waagrechten und Senkrechten und den Docken mit ihren kräftigen Schnitzarbeiten, die die Oberfläche in Spannung und Bewegung versetzen und klare Strukturen verunklären. Das Holz ist dunkelbraun, fast schwarz gebeizt, Messingblech schützt die Buchablage, die Laufböden sind neu.

\section{Salzburg-Mülln, Stadtpfarririreme Zu Unserer Lieben Frau Mariae} HiMMELFAHRT

\section{Ehemaliges Augustinerkloster}

Die spätgotische Wandpfeilerkirche erhebt sich über einem früheren, seit I I 48 fassbaren Sakralbau. ${ }^{226}$ Sie ist vierjochig, besitzt Kapellen an den Längsseiten, der Chor

226 ÖKT, Salzburg ( ( 9 I 2), bes. г 90-2 г6; Hootz, Kunstdenkmäler (г 965-1 968), Bd. I (I 965), 220, 340; Buchwinkler, Salzburg-Mülln (ı 968); König, Mülln (ı 968); Dehio, Salzburg (ı 986), 644-647; EltzHoffmann/Anrather, Kirchen Salzburgs (1993), 69-72; Dopsch, Weihe (r 998); Hahnl, Mülln (I 998); Mund, Stadtpfarrkirche (2004). 
endet mit einem 3/8-Schluss. Baumeister der Kirche waren einer Quelle von I439 zufolge Ulrich Dankl und Heinrich Murauer, die Weihe fiel in das Jahr I 453. Ein zwischen 1707 und I709 errichteter Sakristeiflügel grenzt an die Südflanke der Kirche, der Zugang zur Sakristei öffnet sich deshalb nicht vom Altarraum, sondern vom Westjoch des Längsschiffs aus. Die Barockisierung des Kircheninnern wurde in den Jahren I 735 bis 1738 bewerkstelligt. Johann Georg Hitzl (um I706-I 78I) schuf I 738 die mit Bandlwerk und Rosengittern verzierte Kanzel, auf jenes Jahr gehen zudem ähnlich dekorierte Stuckarbeiten am Gewölbe von Christof Fenninger (nachgew. um I 735 und I758) zurück. Als Filialkirche der Dompfarre betreuten seit I I 39 zunächst Augustiner-Chorherren die Kirche. I46I wurde sie von der Domkirche gelöst, einige Jahre später richtete man in Mülln ein Kollegiatstift ein, I 835 übernahmen Benediktiner aus Michaelbeuern die Seelsorge.

\section{Sakristei}

Der Raum liegt in Nord-Süd-Richtung. ${ }^{27}$ Vor der Ostwand befindet sich unter Fensteröffnungen ein langer Aufsatzschrank, den zwei hohe Kleiderschränke flankieren. Gegenüber stehen weitere Möbel. Eine Tür in der Nordwand führt zu einem kurzen Gang, der die Verbindung zum Kirchenschiff herstellt.

\section{Aufsatzschrank mit Kelchkästen}

HS $12 \mathrm{~cm}$

$\mathrm{H}_{205,5} \mathrm{~cm}(+\mathrm{I} 2 \mathrm{~cm}) \times \mathrm{L} 865 \mathrm{~cm} \times \mathrm{T} 93 \mathrm{~cm}$

\section{Paramentenschränke}

$\mathrm{H} 287 \mathrm{~cm} \times \mathrm{B} \mathrm{I} 46 \mathrm{~cm} / \mathrm{I} 56 \mathrm{~cm} \times \mathrm{T} 88 \mathrm{~cm}$

\section{Vierteiliger Schrank und Schrank in der Raumecke}

$\mathrm{H} 286 \mathrm{~cm} \times \mathrm{L} 634 \mathrm{~cm} \times \mathrm{T} 96 \mathrm{~cm}$

$\mathrm{H} 288 \mathrm{~cm} \times \mathrm{B} \mathrm{I} 40 \mathrm{~cm} \times \mathrm{T} 89 \mathrm{~cm}$

Tischlermeister Ruep Schaider, um I 708/1709

Eiche massiv, Nuss, furniert und geschnitzt, Buche. Eisen, verzinnt

227 ÖKT, ebd., I 93, 205; König, ebd., I8; Dehio, ebd., 646; Hahnl, ebd., I3; Mund, ebd., 73-74. 


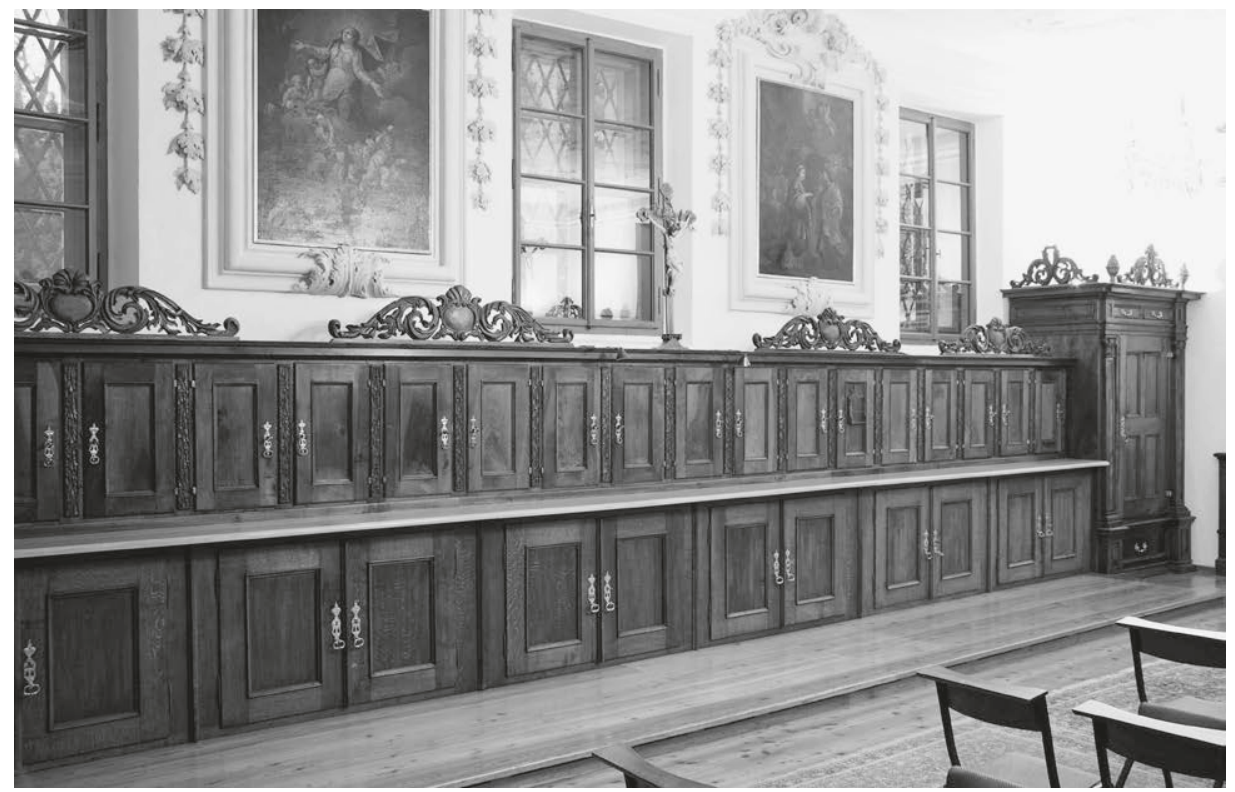

I33 Sakristei, Kelchkästen und Paramentenschrank. Mülln und Tischlermeister Ruep Schaider, um I $708 / 1709$

Der Aufsatzschrank setzt sich aus einer mit zwölf Türen versehenen Substruktion und einem Aufsatz mit I 8 Kelchfächern zusammen (Abb. I33). Schmale Profile dienen am Unterschrank als Trennelemente zwischen den einzelnen Schrankteilen, oben bezeichnen mit Blattwerkschnitzereien verzierte Lisenen die Stollen zwischen den Kästen. Die Füllungen liegen in den hochrechteckigen Türen leicht vertieft. Über dem Abschlussgesims ragt in der Mitte ein großes Kreuz auf, das ornamentale Durchbrucharbeiten flankieren. Sie zeigen zu Liegevoluten eingedrehten Akanthus sowie Kartuschen, die an das Flammenherz des hl. Augustinus gemahnen. Wie das häufig der Fall ist, verschließen die Türen des Aufsatzes zusammen mit den Fächern auch Schubladen. Der Unterschrank besteht aus massiver Eiche, der Aufsatz aus Nadelholz, das mit dickem Nussfurnier überzogen ist. Die aus Buche gefertigte Platte der Substruktion ist eine moderne Ergänzung, Beschläge und Schlösser sind aus verzinntem Eisen.

Das Möbel grenzt an zwei Kleiderschränke, der linke ist zweitürig, der rechte eintürig. Pilaster mit stilisierten ionischen Kapitellen stützen ein hohes Gebälk und einen Schnitzaufsatz aus Akanthus, stilisierte Flammenvasen betonen die äußeren Achsen. In den Sockel der beiden Inventarstücke ist jeweils eine Schublade eingeschoben, im Gebälk laufen weitere - eine der Charakteristika von Schränken aus dem Salzburger Land. Das Türblatt des rechten Möbels wird durch einen massiven kreuzförmigen 


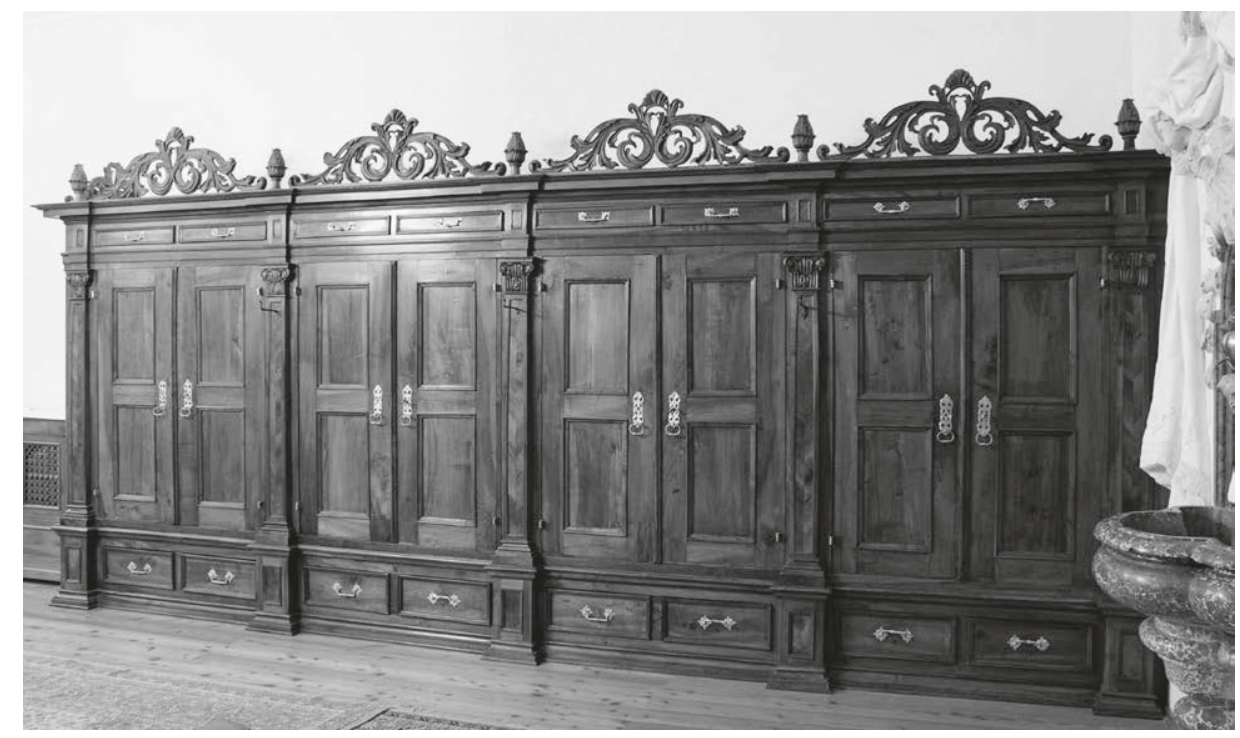

I34 Paramentenschrank. Mülln und Tischlermeister Ruep Schaider, um I708/I 709

I35 Paramentenschrank, Beschlag und Zugring. Mülln, um I708/I 709

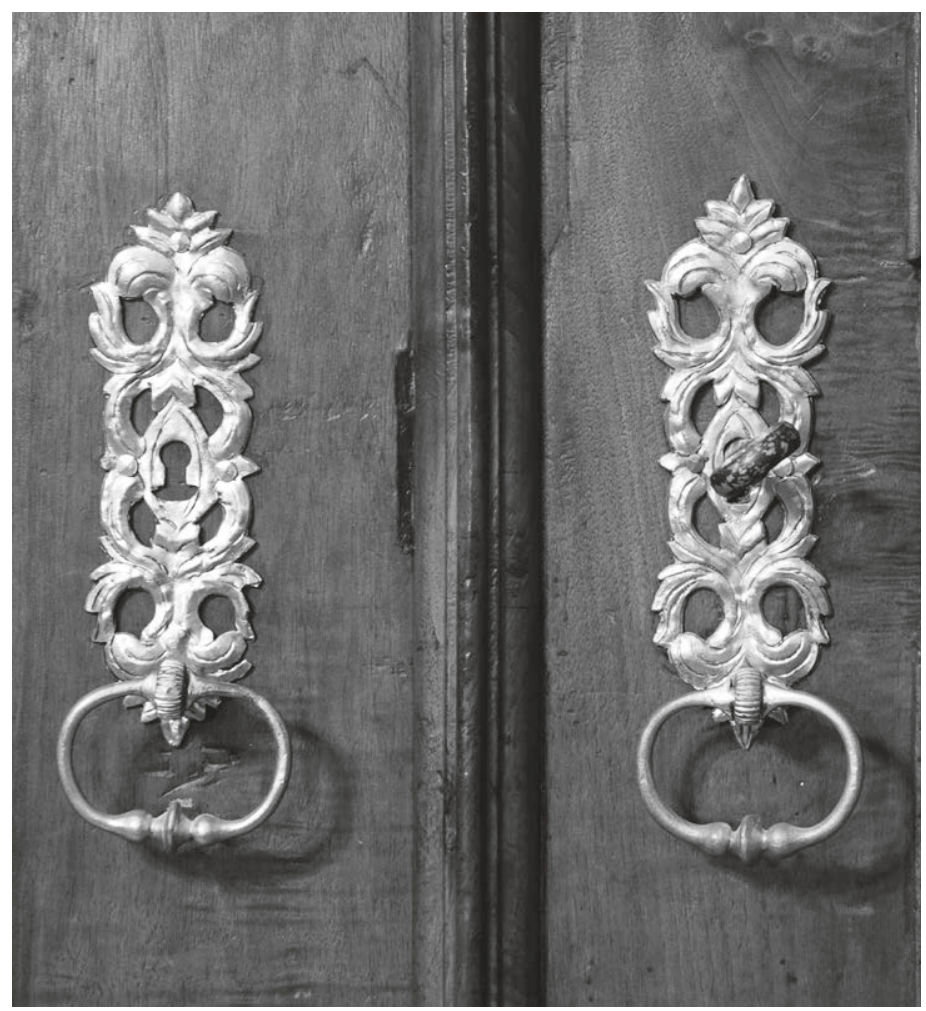


Rahmen in vier Füllungen unterteilt, was die schwere optische Wirkung hervorruft, die für das Inventarstück bezeichnend ist.

Mit einer vergleichbaren Gestaltung präsentieren sich die Möbel vor der gegenüberliegenden Raumseite (Abb. I34, I35). Es handelt sich dabei um einen langen, aus vier Segmenten bestehenden Kleiderschrank, den acht Türen verschließen, sowie um ein eintüriges Möbel. Auch diese Schränke besitzen Schübe im Sockel und im Gebälkbereich, Werkmaterial ist Nussfurnier.

Die ÖKT zitiert einen Rechnungsbeleg von I 708: M. Ruep Schaider Tischler à Conto der angefriemten Kasten $80 f t{ }^{228}$ Insgesamt müsste Schaider etwa 300 Gulden für seine Arbeiten in der Sakristei erhalten haben. ${ }^{229}$ Auf welche Möbel sich die Abschlagszahlung bezieht, ist nicht klar, doch entstammt die gesamte Einrichtung der Sakristei dem frühen I 8. Jahrhundert. Nach Hinweisen im Dehio befanden sich in dem Raum neben den beschriebenen Möbeln Inventarstücke aus dem frühen I7. Jahrhundert. Sie sind heute nicht mehr nachweisbar.

\section{Kirchenraum}

\section{Laiengestühl}

Tischlermeister Johann Zengerle, um I 735

HS I $2,5 \mathrm{~cm}$

$\mathrm{H} 88 \mathrm{~cm}(+\mathrm{I} 2,5 \mathrm{~cm}) \times \mathrm{L} 79 / \mathrm{I} 26 / \mathrm{I} 29 / 267 / 3 \mathrm{I} 9 \mathrm{~cm}$

Eiche, massiv, geschnitzt, Nadelholz

Die seitlich des Mitteldurchgangs situierten Möbelgarnituren zählen 28 Sitzreihen (Abb. I36). ${ }^{230}$ Die vorderen Einheiten umfassen acht Bänke, die hinteren sechs. Auf Vorderwände mit Kniebänken wurde verzichtet.

Die Wangen bestehen aus einem quergelagerten Sockel und einem optisch davon getrennten Aufsatz. Auf dem unteren Möbelsegment, das seitliche Voluten begrenzen, liegt die Kniebank, deren Stirnseite zu einem kräftigen Gesims verlängert wurde, das sich zwischen Sockelzone und Aufsatz schiebt. Durch seine Form ähnelt er einer dickbauchigen asymmetrischen Flasche mit dünnem Hals und weitem Ausguss. Entsprechend der Gestaltung des Sockels fassen breite Rahmen die Außenkanten des Aufsatzes ein. Über das Binnenfeld legt sich Bandlwerk, das in Höhe des Halses mit einem Flammenherz endet. Der Grund ist aufgeraut, die Schnitzarbeiten sind geglättet. Die Buchablage wurde von oben auf den Docken befestigt.

228 ÖKT, ebd., I 93 .

229 Mund, Stadtpfarrkirche (2004), 74.

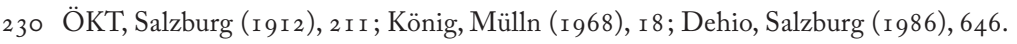




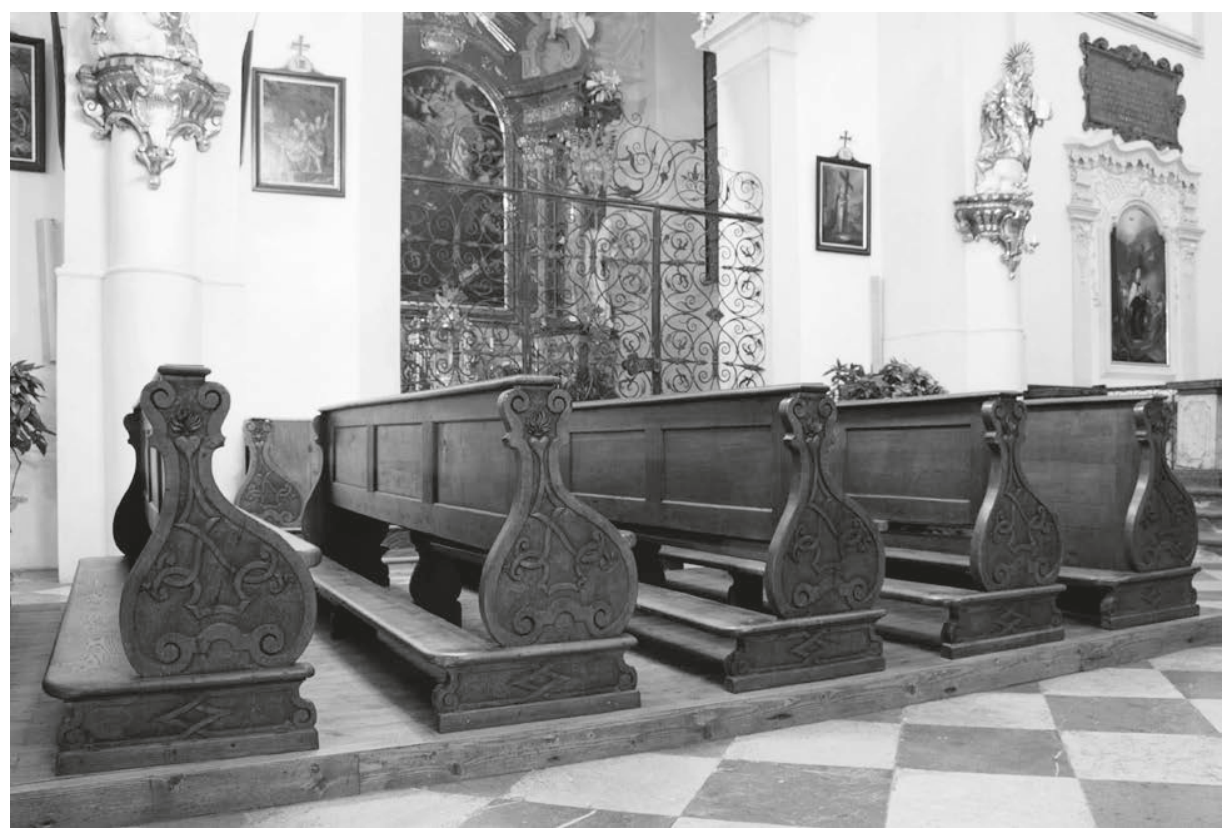

I36 Kirchenraum, Laiengestühl. Tischlermeister Johann Zengerle, um I 735

Vor den Seitenwänden der Kirche stehen weitere Garnituren dieses Typs (Abb. 137), sie ersetzen Bankreihen, die sich schon im frühen I7. Jahrhundert an gleicher Stelle befanden. ${ }^{231}$ Einige Möbelensembles besitzen Brüstungen, andere nicht, verschiedene Bänke sind außerdem mit Türen gesichert. Wie etliche Beispiele (Farbtaf. I8, I9; Abb. 209) im vorliegenden Katalog dokumentieren, kam das an Möbeln des I 8. Jahrhunderts nicht selten vor, doch wurden die Türen im Laufe der Zeit meist entfernt. Die Bänke vor den Wänden stehen wie das Gestühl im Mittelschiff quer zur Kirchenlängsachse. Bei unterschiedlichen Maßen stimmen die Möbel in ihrem Aussehen mit den beschriebenen Bänken überein. Die dem Mauerwerk zugewandte Seite kommt ohne Schnitzarbeiten aus, was belegt, dass die Möbel von Anbeginn an für ihren jetzigen Aufstellungsort bestimmt waren. Offensichtlich zitierten die Tischler beim Bau der Möbel die Großform der Bankensembles in Maria Plain und in der Markuskirche (Abb. 75, 76, I3 I, I 32), verschieden ist dagegen die Auszier, die am Gestühl in Mülln dem im Ursprung französischen Bandlwerk, an den Einrichtungen der beiden anderen Kirchen dagegen italienischem Akanthus verpflichtet ist. Die Bankgarnitur besteht

23I ÖKT, ebd., Fig. 228; Buchwinkler, Salzburg-Mülln (r 968), 5 ; Hahnl/Lebesmühlbacher, Mülln (I 998), 34 . 


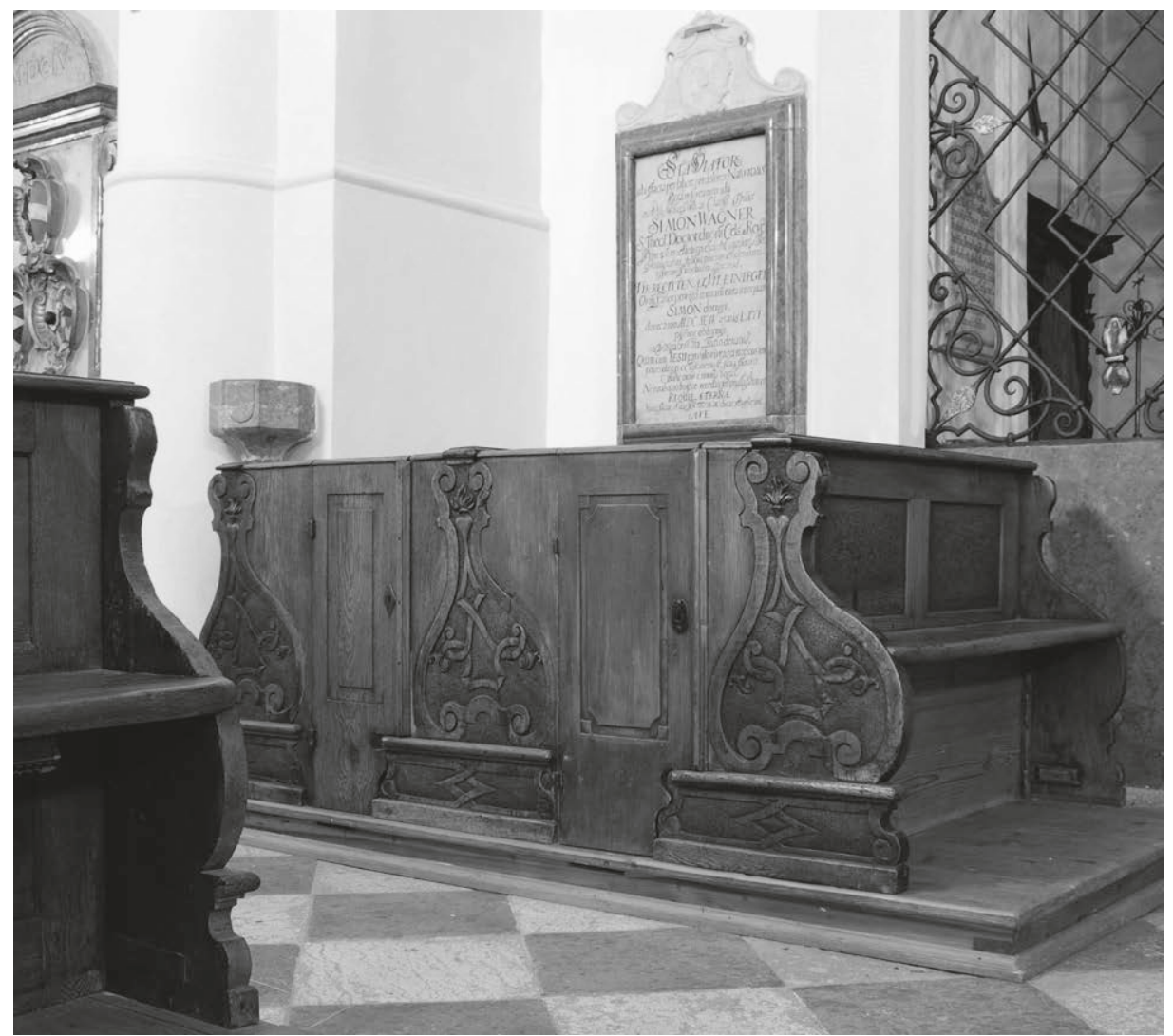

I37 Laiengestühl. Tischlermeister Johann Zengerle, um I735

aus Eiche, die neuen Podeste sind aus Nadelholz. I735 erhielt der Tischlermeister Johann Zengerle, der uns bereits in Verbindung mit Arbeiten für St. Peter begegnete, für den Bau des Gestühls sowie für die Anfertigung zweier Schränke laut einer in der ÖKT wiedergegebenen Nachricht 250 Gulden. ${ }^{232}$

232 ÖKT, ebd., 194. 
IV.

\section{Sakralbauten in der Steiermark}

\section{Frauenberg, Pfarr- und Wallfahrtskirche Mariä Opferung}

Die Konsekration der im frühen I 5. Jahrhundert errichteten Wallfahrtskirche ist für das Jahr 1423 verbürgt. ${ }^{233}$ Schon bald nach der Eröffnung war das Raumangebot für die große Zahl an Pilgern nicht mehr ausreichend, sodass man den zwischenzeitlich zur Pfarrkirche erhobenen Bau erweiterte und 4447 erneut weihte. Abt Urban Weber von Admont (reg. 1628-1659), von dessen Abtei die Kirche damals betreut wurde und heute noch immer betreut wird, verfügte ihre Barockisierung und bestellte in Verbindung damit 1648 bei dem Neumarkter Tischler und Bildhauer Christoph Paumgartner einen Altar nach dem Muster des nach St. Lambrecht gelieferten Exemplars. ${ }^{234}$ Abt Adalbert Heuffler von Rasen und Hohenbühel (reg. 1675-1696) ließ die Kirche zwischen 1683 und 1687 umbauen und vergrößern, Architekt war wahrscheinlich Carlo Antonio Carlone (um r635-1708).

Der Bau weist ein einschiffiges und vierjochiges Langhaus auf, komposite Pilaster tragen die Stichkappentonne. An die Langhausjoche schließen sich Seitenkapellen an, seitlich des Chors liegen zwei Sakristeien. Die Deckenfresken mit Szenen aus dem Leben Mariens schuf um 1695 vermutlich Anton Maderno, Giovanni Battista Carlone (um r642-I 72 I) dekorierte die Kirche zwischen I690 und I 695 mit reichen, zum Teil auch figürlichen Stuckarbeiten. Der Hauptaltar dürfte um I690 im Atelier von Martin Neuberg entstanden sein.

233 Scherf, Frauenberg (1904); Waagen, Frauenberg (1931); Krause, Frauenberg [1 949]; Hootz, Kunstdenkmäler (I 965-1968), Bd. 2 (I 966), 202-204, 366; Krause, Frauenberg (1978); Rabl, Ausstattungsgeschichte (1998); Dehio, Steiermark (2006), ro6-107.

234 Ein in Neumarkt ansässiger Bürger dieses Namens wurde am or.Io.r 709 begraben. Es handelte sich bei dem Toten vermutlich um einen Sohn oder Neffen des Künstlers. Leider wird im betreffenden Sterbebuch das Alter des Verstorbenen nicht erwähnt. Außerdem sind dort die Berufe nicht aufgeführt. Pfarre Neumarkt in Steiermark, Sterbebuch A I690-1727, fol. 298 [https://data.matricula-online.eu/ de/oesterreich/graz-seckau/neumarkt-in-steiermark; Zugriff Juni 2020]. 


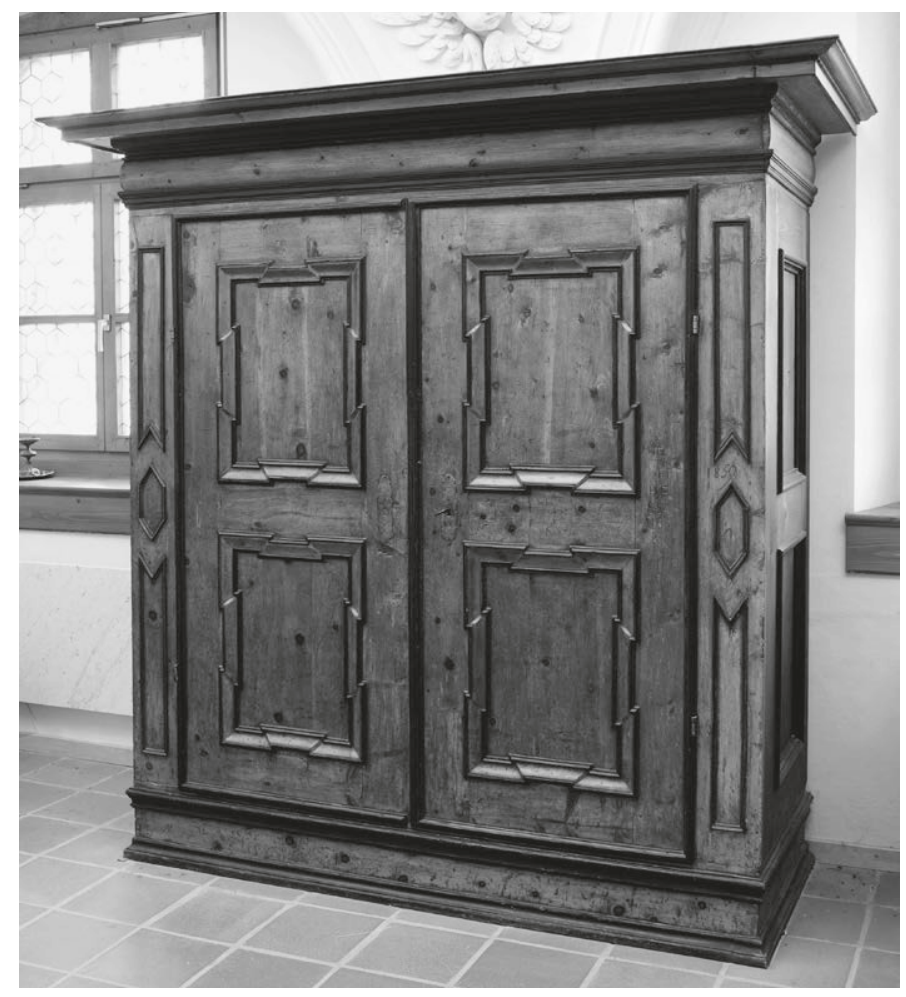

I38 Sakristei, Paramentenschrank. Frauenberg, um I $685 /$ I 700

\section{Sakristei}

Paramentenschrank

Frauenberg, um I685/1700

$\mathrm{H} 227 \mathrm{~cm} \times \mathrm{B}_{23} 3 \mathrm{~cm} \times \mathrm{T} 98,5 \mathrm{~cm}$

Zirbelkiefer. Eisen, graviert

Die Sakristei wurde vor nicht allzu langer Zeit renoviert, wobei man das alte Mobiliar durch modernes ersetzte. ${ }^{235}$ Als einziges barockes Inventarstück befindet sich dort heute ein Paramentenschrank (Abb. I38). Die neuen Schmalseiten und das ergänzte seitliche Abschlussgebälk lassen vermuten, dass er ursprünglich als Wandschrank seine Dienste tat.

235 Im Dehio, Steiermark (2006), I07, wird noch von einer einfachen Sakristeieinrichtung aus dem Ende des I7. Jahrhunderts berichtet. 
Das Inventarstück besitzt den für diese Art von Möbeln typischen dreiteiligen Aufbau, der aus einem Sockel, einem Hauptgeschoss mit den beiden Türen und einem Gebälk mit weit in den Raum ragendem Gesims besteht. Die einzelnen Schranksegmente sind mit profilierten Gesimsen voneinander abgesetzt. Kräftige Rundprofile folgen der Kontur der Türen, eine unübliche Art der Gestaltung, die wie an der Sakristeitür in Frauenberg (Abb. 139) jedoch bisweilen gewählt wurde. ${ }^{236}$ Die Türfüllungen sind verkröpft, Keilstäbe zieren die Stollen, ein abgerundeter Fries das Gebälk. Er erzeugt eine Art innerer Spannung und lässt das Gebälk weniger steif und »trocken" als ein gerade verlaufender Fries erscheinen. ${ }^{237}$ Das Möbel besteht aus Zirbelkiefer, die glatt ausgehobelten Profile sind geschwärzt. In der

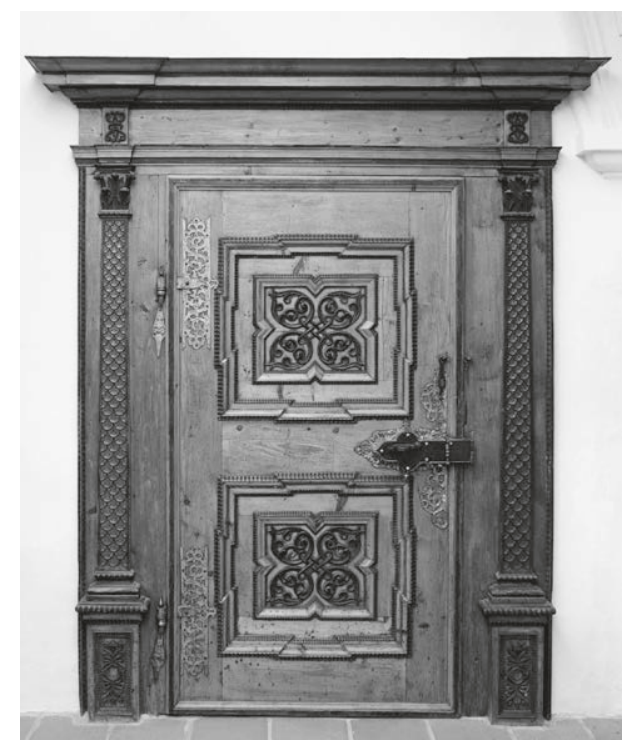

I39 Sakristei, Tür zu Seitenkapelle. Frauenberg, um $1650 / 60$ Fassade haben sich mindestens seit dem frühen I 9. Jahrhundert Personen mit Namen und Jahresangaben verewigt. Verdienstvollerweise hat man die eingravierten biographischen Daten bei der Restaurierung als Teil der Geschichte des Möbels erhalten.

\section{Tür zur Seitenkapelle}

Frauenberg, um $1650 / 60$

Maße des Türrahmens: $\mathrm{H} 258 \mathrm{~cm} \times \mathrm{B} 220 \mathrm{~cm}$

Zirbelkiefer. Eisen, grau, verzinnt, geschwärzt

Das tektonisch aufgebaute Portal verbindet die Sakristei mit einer Seitenkapelle (Abb. I39). Schuppenmuster zieren die Pilasterschäfte, vegetabile Ornamente die Piedestalli. Die beiden Füllungen des Türblatts setzen sich aus Friesen und zentralen Binnenfeldern zusammen. Die Füllungen sind verkröpft, die Profile, die die Felder

${ }_{23} 6$ Vgl. hierzu auch Beichtstühle in der Stiftskirche zu Kremsmünster aus der Zeit um r67o/8o. Bohr, Sakralmöbel (2017), 5 I4-5 I 5 .

237 Abgerundete Friese kommen bereits im I 537 publizierten vierten Architekturbuch und im I 540 veröffentlichten dritten Buch Sebastiano Serlios (I 475 -ca. I 554 ) vor. Serlio, Architettura (I 584 ), beispielsweise auf pp. 64r, 87v, 98v, Ioov, I6 IV, I $82 \mathrm{v}$. 


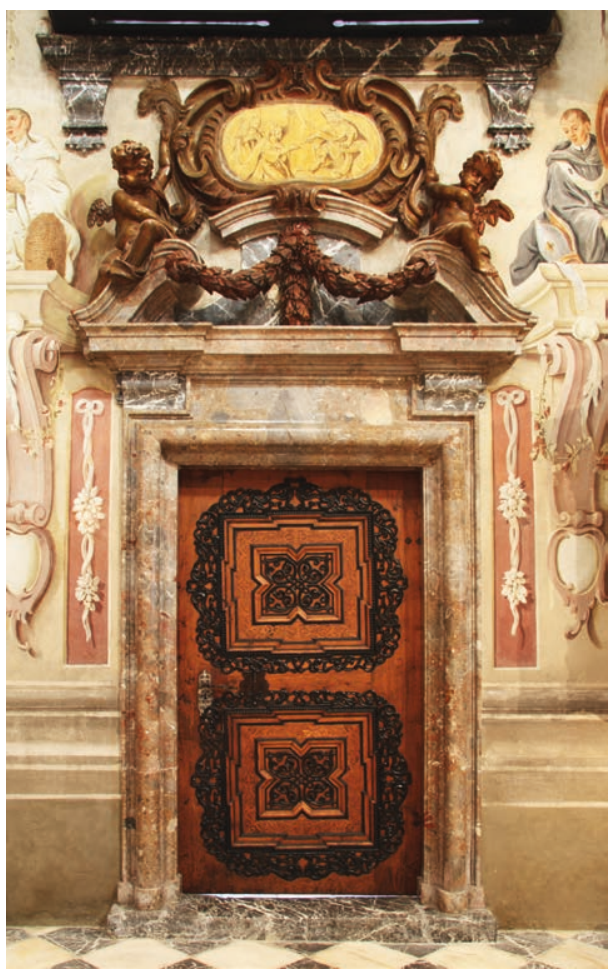

Farbtafel I6 Chorraum, Sakristeitür. Frauenberg, um $1650 / 60$

säumen, zum Teil mit Flammleisten vollendet. Langgezogene und miteinander verknüpfte Ringe verbinden außergewöhnliche zentrale Motive, die aus diagonal angeordneten zwiebelartigen Mustern bestehen. Ähnlich wie am Schrank fasst auch hier eine Leiste die Tür ein. Schnitzarbeiten, Profile und das schwere Schloss sind geschwärzt, während man die aufwendig gearbeiteten Bänder und Beschläge verzinnte. Die frühbarocken Ziermotive dokumentieren, dass die Tür noch in der ersten Barockisierungsphase der Kirche gefertigt wurde. ${ }^{238}$

\section{Chorraum}

\section{Sakristeitür}

Frauenberg, um I650/60

Lichte Maße H $228 \mathrm{~cm} \times$ B I $28,5 \mathrm{~cm}$

Zirbelkiefer, teilweise geschwärzt

Ein schwerer Marmorrahmen mit Volutengiebel formt das Gewände (Farbtaf. I6; Abb. I40). ${ }^{239}$ Hinsichtlich der Großform entspricht die zum Kircheninnern weisende Türseite dem beschriebenen Portal zwischen der Sakristei und der Seitenkapelle. Die Füllungen sind auch hier verkröpft, erneut kommt das charakteristische Zwiebelmuster vor. Nun zieren allerdings an Schweifwerk erinnernde Flachschnitzereien den um das Zentrum der Füllungen gelegten Fries, während verschnörkelte und kleinteilige frühbarocke Motive die von Flammleisten gehaltenen Binnenfelder säumen. ${ }^{240}$ Die Flachschnitzereien wurden naturbelassen, die anderen Schnitzarbeiten sowie die Flammleisten geschwärzt. ${ }^{241}$

238 Die Abbildung zeigt die Tür auf der Seite der Sakristei. Die Außenseite zur Kapelle ist weniger aufwendig ausgeführt.

239 Dehio, Steiermark (2006), ro6.

$240 \mathrm{Zu}$ diesem Ornamentmotiv vgl. Kap. VI der Einleitung.

24I In der Kirche und Annexräumen existieren mehrere Exemplare der beschriebenen Türen. 


\section{Kirchenraum}

4 Beichtstüble

Frauenberg, um $1665 / 75$

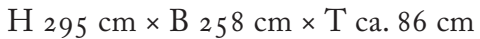

Nadelholz, braun lasiert, teilweise geschwärzt

Die dreiteiligen Beichtstühle füllen Mauernischen unter der Westempore, zwei hat man in die Westwand eingesetzt, zwei in die seitlichen Außenwände (Abb. I4I, I 42). ${ }^{242}$ Von Keilpilastern flankierte Arkaden gestatten den $\mathrm{Zu}^{-}$ tritt zu den Möbeln. Die Stützen, die ein verkröpftes und mit Konsolen bestücktes Gebälk tragen, weisen volutenförmige Basen, Schulterstücke und Blockkapitelle auf, ein Fries ziert die Schäfte. Stilisiertes Laubwerk und knorpelige Motive bereichern die Möbel, in der Gebälkmitte prangt ein gewölbtes ovales Feld. ${ }^{243}$ Die vier Beichtstühle besitzen ein nahezu identisches Äußeres, Unterschiede ergeben sich al-

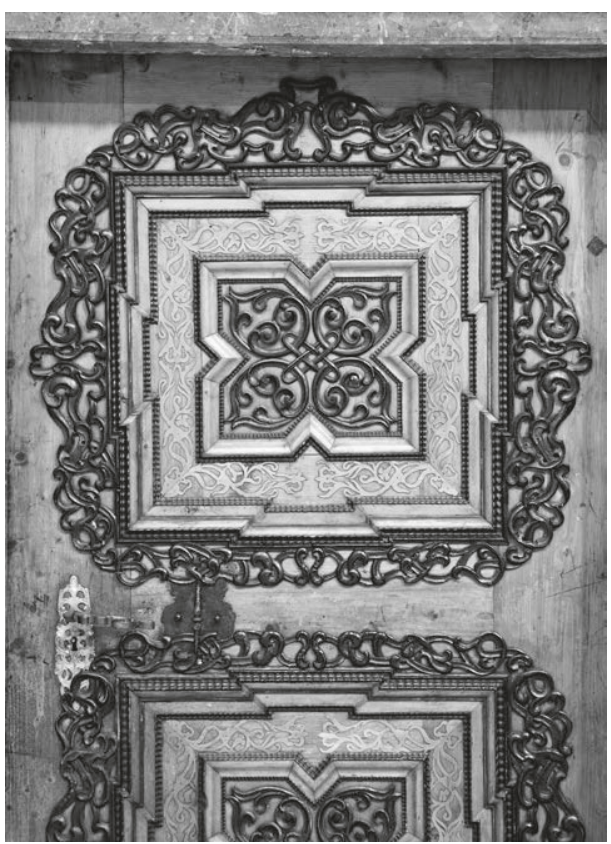

I 40 Sakristeitür, Füllungen. Frauenberg, um I $650 / 60$ lerdings durch die Schnitzaufsätze. Je eine Kartusche mit dem Monogramm Christi bekrönt die beiden Exemplare vor der südlichen und nördlichen Außenmauer, dagegen lassen die beiden Möbel vor der Westwand Groteskmasken im Zentrum der Schnitzereien erkennen. Auffallend ist die formale Diskrepanz zwischen den Auszügen untereinander sowie zwischen den Auszügen und den Möbelfassaden. Die Aufsätze mit dem IHS-Symbol zeigen weite Bögen, über die sich krause Schnörkel legen. Obgleich sie sich im Hinblick auf die stilistische Entwicklung gut zu den Möbelvorderseiten mit den flach anliegenden und frühbarocken Motiven fügen, heben sie sich doch durch scharfe Bögen, Brechungen und Durchdringungen vom Fassadenzierrat der Beichtstühle ab. Dennoch können sie zum originalen Bestand gehören, da sich vergleichbare Kontraste am Laiengestühl der Kirche wiederholen. Einen markanten Gegensatz dazu bilden die Möbel seitlich des Eingangsportals. Die Aufsätze charakterisiert schweres Knorpelwerk, das an den Beichtstühlen sonst nicht vorkommt. Zudem wäre an dieser Stelle das Monogramm Mariens zu erwarten, die Masken sind hier fehl am Platz. Schließlich

242 Dehio, Steiermark (2006), I07.

$243 \mathrm{Zu}$ diesem Motiv vgl. Teil 2, Kap. V1. 


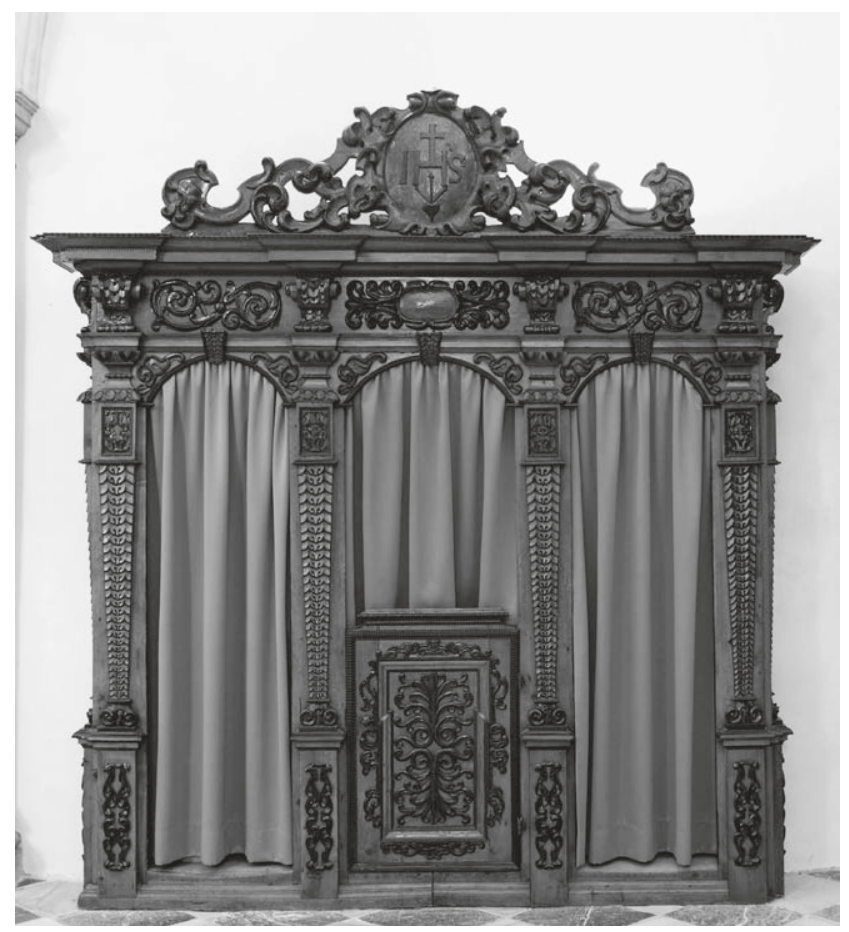

I4 I Beichtstuhl. Frauenberg, um $\mathrm{r} 665 / 75$

I42 Beichtstuhl (Detail). Frauenberg, um I665/75

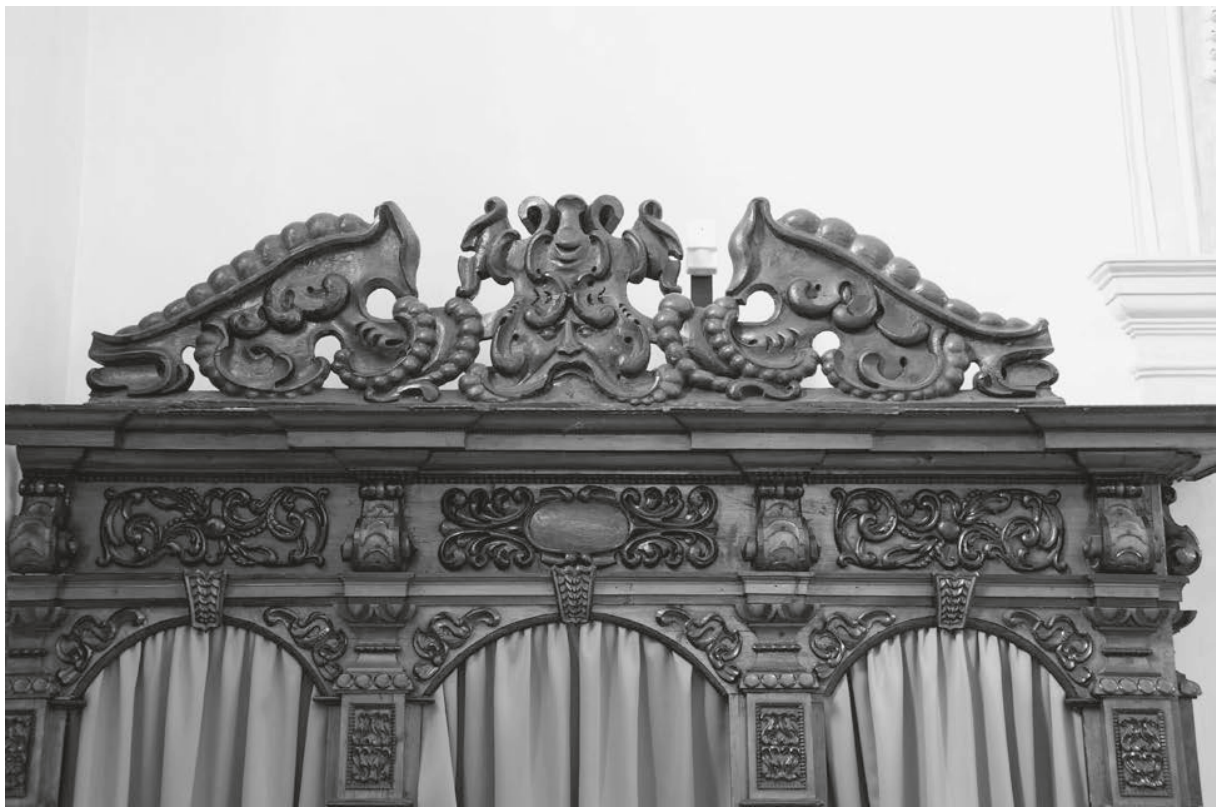




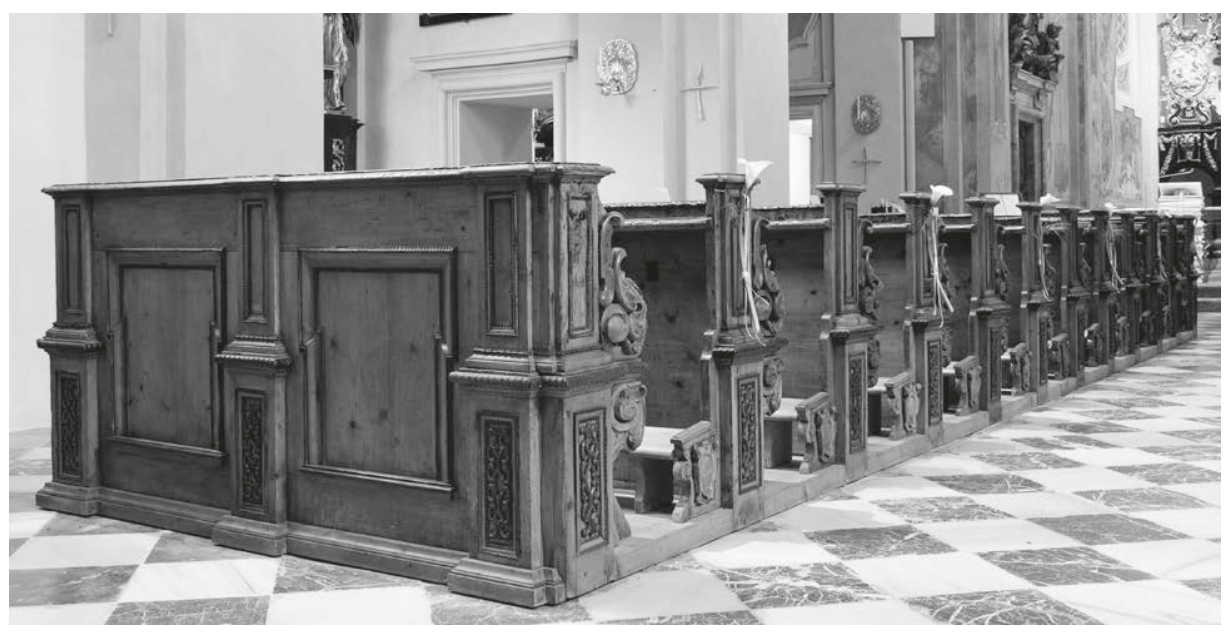

I43 Laiengestühl. Hoftischler Hans Seltenreich aus Admont, um r665/75

vermitteln die Aufsätze den Eindruck, dass sie seitlich beschnitten wurden. Falls man sie nicht einst als Bekrönung anderer Möbelstücke schuf, werden sie ursprünglich von Flammenvasen oder ähnlichem Zierrat begleitet worden sein, Beichtstühle in Graz oder Rein (Abb. I 54, I7I , 242) bieten gute Beispiele für entsprechende Lösungen.

Eines der Möbel wurde zu einem Aussprachezimmer umgebaut. Man verschloss die Arkaden mit Türen, eine Trennwand wurde entfernt, die andere in die Möbelmitte versetzt, sodass jetzt innen zwei etwa gleich große Räume für den Pönitentiar und den Pönitenten vorhanden sind. Zum Schutz der Oberfläche wurden die Möbel leicht lackiert.

\section{Laiengestübl}

Tischlermeister Hans Seltenreich aus Admont, um r 665/75

HS $8 \mathrm{~cm}$

$\mathrm{H}$ I IO cm/ I04,5 cm $\times \mathrm{L} 225 \mathrm{~cm}$

Nadelholz, Linde (?), teilweise geschwärzt

Die Bankgarnituren sind auf vier Blöcke verteilt, vorn stehen auf jeder Seite elf Reihen, hinten sind es vier, hinzu kommen die jeweiligen Brüstungen (Farbtaf. I7; Abb. 143). ${ }^{244}$ Die Möbel besitzen ein Äußeres, wie wir es bisher noch nicht beobachtet haben. Drei Stützen, die aus Sockeln und Balustern gleicher Höhe bestehen,

244 Krause, Frauenberg (1 978), 25; Dehio, Steiermark (2006), ro7. 


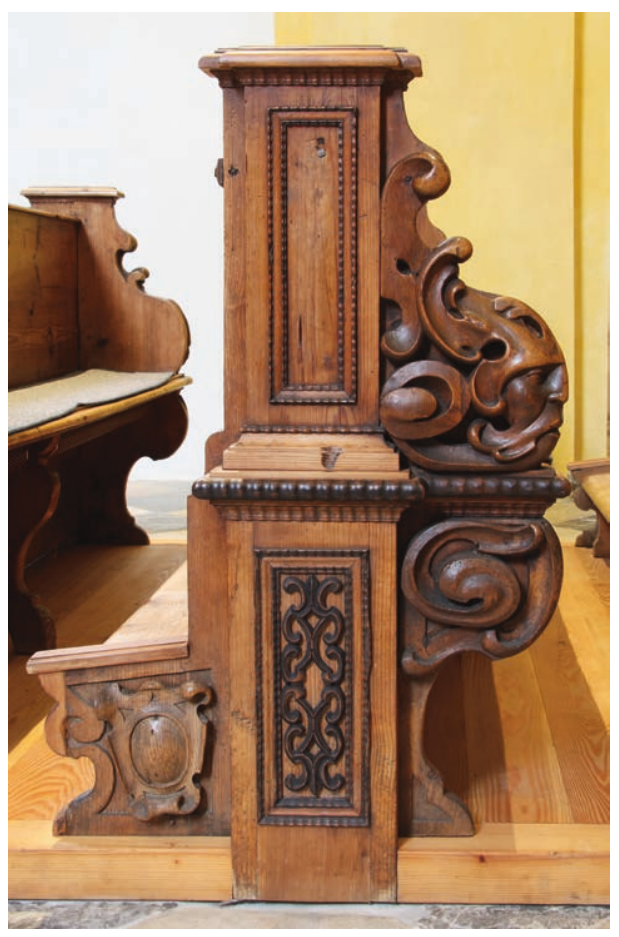

Farbtafel i7 Bankwange. Hoftischler Hans Seltenreich aus Admont, um r665/75

gliedern die Brüstungen, die Füllungen geben sich als schlichte Ädikulä zu erkennen. Geschwärzte Flammleisten säumen die welschen Fenster sowie die Binnenfelder an den Stützen. Kleinteiliger Schnitzzierrat, wie er ähnlich an den Türen und Beichtstühlen vorkommt, vervollständigt die Sockel, während sich die übrigen zentralen Kompartimente als leere Flächen präsentieren.

Postamente und Baluster, deren Aussehen dem der Brüstungsstützen entspricht, bilden als massive vertikale Achsen nicht nur konstruktiv, sondern auch formal einen wesentlichen Teil der Bankwangen. Rückseitig ist jeweils eine Konsole angesetzt, hinter der sich die Kniebank verbirgt, während vorn zwei Schleierbretter, die Profile voneinander trennen, einen kräftigen Bauch mit schweren Knorpelschnitzereien hervorbringen. Als Dekormotive sind an den Wangen einerseits sich verdickende und unrunde Voluten, C-Bögen sowie Blattmasken zu erkennen, andererseits aber auch wieder jene filigranen Ornamente, von denen bereits die Rede war. Auch am Laiengestühl kann also diese merkwürdige Dichotomie in der Formensprache konstatiert werden.

Die Wangen der hinteren vier Bankreihen wurden lediglich zur Kirchenmitte hin mit Schnitzarbeiten versehen, während außen auf eine Verzierung weitgehend verzichtet wurde. Das ist vermutlich ein Hinweis darauf, dass einige Bänke nachträglich hinzugefügt und Docken, die zuvor auf der Außenseite angeordnet waren, nach innen versetzt wurden. Die stilistischen Charakteristika sprechen für eine Datierung der Möbel vor dem letzten Viertel des I7. Jahrhunderts. Sie entstanden vermutlich etwa zeitgleich mit den Bänken in Gröbming und Pürgg in den I66oer- oder 7oer-Jahren (Abb. 194, I96, 232), wirken allerdings durch das Motiv der klassisch-strengen Stützen fast noch renaissancehaft. Offensichtlich waren die Möbel in Frauenberg schon vorhanden, als die Kirche erweitert und mit Stuck und Fresken dekoriert wurde. Der relevanten Literatur zufolge war für ihre Herstellung der Hoftischler Hans Seltenreich (I643-1715) aus Admont verantwortlich. ${ }^{245}$ Die Kniebänke und Podeste sind Neuanfertigungen.

245 Krause, ebd., 25. Zum Geburtsdatum von Seltenreich am i6.I 2.I643 vgl. Pfarre Admont, Taufbuch 


\section{Graz, Barmherzige Brüder, Kloster und Spital}

\section{Barmherzigenkirche/Kirche Mariä Verkündigung/Garnisonskirche}

Der Portugiese Johannes von Gott (I495-I 550) richtete in Granada ein erstes Spital ein, das Kranke ohne Unterschied ihres Standes aufnahm. I 586 wurde die Gemeinschaft des »Ordens der Barmherzigen Brüder« als geistlicher Orden anerkannt, sein Emblem ist der mit einem Kreuz bekrönte Granatapfel. I604 übernahm die Kongregation ein Hospital in Valtice (Feldsberg, Südmähren), r6 I 4 gründete der Orden eine Niederlassung und ein Krankenhaus in Wien, im Jahr darauf berief Erzherzog Ferdinand (I 578-I637) Barmherzige Brüder nach Graz. ${ }^{246}$ Zunächst diente ihnen eine kleine Kapelle als Gotteshaus, dann ermöglichten Stiftungen den Bau einer ersten Kirche, deren Grundsteinlegung I632 erfolgte. Wegen diverser Baumängel musste die Kirche im folgenden Jahrhundert abgetragen werden, die Wiedererrichtung fiel in die Jahre zwischen I735 und I738. Verantwortlicher Bauführer war der Grazer Hofmaurermeister Johann Georg Stengg (I689-I753). Auf die I740er- und 5oer-Jahre datieren Altäre und Fresken, auf I739 die von Matthias Leitner († I763) geschaffene Kanzel. In den eigenen Werkstätten besaß das Ordenshaus wenige Jahrzehnte später mit dem I737 im westfälischen Felgen geborenen Sophronius Siegenbrock einen außergewöhnlich talentierten Mitarbeiter. Der Tischler legte am 25. November I 766 in Wien die Profess ab und starb am 29. August I 802 im mährischen Letovice (Lettowitz). Nach den Angaben in der Fachliteratur dürfte er anfangs für die Barmherzigen Brüder in Wien tätig gewesen sein, dann erst in Graz. ${ }^{247}$ Nach I 838 fand die Grazer Kirche, bei der es sich um einen einschiffigen und vierjochigen Longitudinalbau mit Seitenkapellen, Emporen und eingezogenem Chor handelt, für ein Jahrhundert auch als Garnisonskirche Verwendung. Eine umfassende Restaurierung des Sakralbaus wurde von 1978 bis I 990 vorgenommen, überarbeitet wurden überdies die mit einem hochglänzenden Lacküberzug versehenen Tischlerarbeiten.

I, I632-I643, fol. I 90 . Hans (Johannes) war der legitime Sohn des Jacobus Seltenreich, auch er war Tischler. Beerdigt wurde Hans am 06.05.I7 I 5. Pfarre Admont, Sterbebuch 3, I699-1768, p. 547. Bezeichnet wird er dort als hoftischler und burger allhir. Zu Tauf- und Sterbebuch vgl. die relevanten Einträge unter https://data.matricula-online.eu/de/oesterreich/graz-seckau/admont [Zugriff Juni 2020].

246 Hierzu und zum folgenden Abschnitt besonders Kohlbach, Barocke Kirchen [195 I], I I 7-I 28 ; Schmid, Klosterkirche [1965]; Dehio, Graz (I 979), I47-I 52 ; Attems/Koren, Kirchen (I 988), 22-23; Schweigert, Barmherzigenkirche (I 999); Kölb1/Resch, Wege (2002), I 48-I 5 I Rust, Stengg (2009), bes. 89II I, I $82-$ I 85 .

247 Schmid, Klosterkirche Wien (1976); Dehio, Wien (1993), 5; Laschalt, Sakristeischränke (201 2), 27, I36-I 42. Auch in Wien soll Siegenbrock Kirchenmobiliar gefertigt haben. 


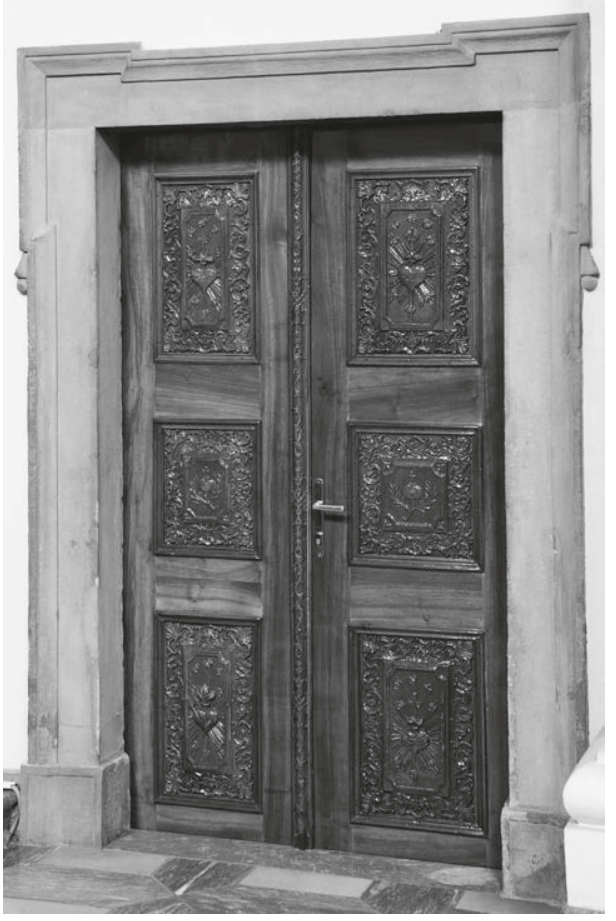

I44 Chorraum, Sakristeitür. Graz, um I 740

\section{Kirchenraum}

Sakristeitür

Graz, um I 740

Lichte Maße H 2I $8 \mathrm{~cm} \times$ B I $29 \mathrm{~cm}$

Nuss, massiv. Messing, Eisen

Schnitzarbeiten vervollständigen die bossierten Füllungen und die Schlagleiste, während der Rahmen nicht dekoriert ist (Abb. I 44). ${ }^{248}$ Die Spiegel der mittleren Füllungen zeigen Granatäpfel und Blattzweige, die anderen Binnenfelder Flammenherzen im Strahlenkranz sowie Herzen, die mit einem Kreuz, einem aus Dornen gewundenen Gürtel und einem Dolch versehen sind. Das Herz oben rechts trägt die Beschriftung CAR/DAS (Caritas). Blütengirlanden sowie Laub- und Bandlwerk zieren die Schlagleiste, kleinteilige Schnörkel die Friese um die Bossen. Palmettenmotive akzentuieren die Ecken der oberen und unteren Füllungen.

\section{Beichtstüble}

Graz, um I 750/60

HS $\mathrm{I} 2 \mathrm{~cm}$

$\mathrm{H} 228 \mathrm{~cm}(+\mathrm{I} 2 \mathrm{~cm}) \times \mathrm{B} 225 \mathrm{~cm} \times \mathrm{T} \mathrm{I} 20 \mathrm{~cm}$

Nussbaum, Nussmaser, Zwetschke, Esche (?), furniert auf Nadelholz, vergoldetes Holz. Messing, Eisen

Die Beichtstühle stehen auf einem ausladenden Podest, das als Trittstufe dient (Abb. I 45). ${ }^{249}$ Während die alten, vermutlich aber nicht originalen Postamente allseits sanft geschwungene Seiten besitzen, kennzeichnen den Grundriss der Beichtstühle gerade verlaufende Schmalseiten und eine konkav-konvex-konkav gekurvte Vorderseite. Schlanke Pilaster auf hohen Piedestalen gliedern Seiten und Fassaden. Analog zum Schwung der Vorderseite

248 Zur Tür vgl. Dehio, Graz (1979), I 5 I.

249 Schmid, Klosterkirche [1 965], ro; Dehio, ebd., I50; Schweigert, Barmherzigenkirche (I999), I 7. 
I45 Beichtstuhl. Graz, um I $750 / 60$

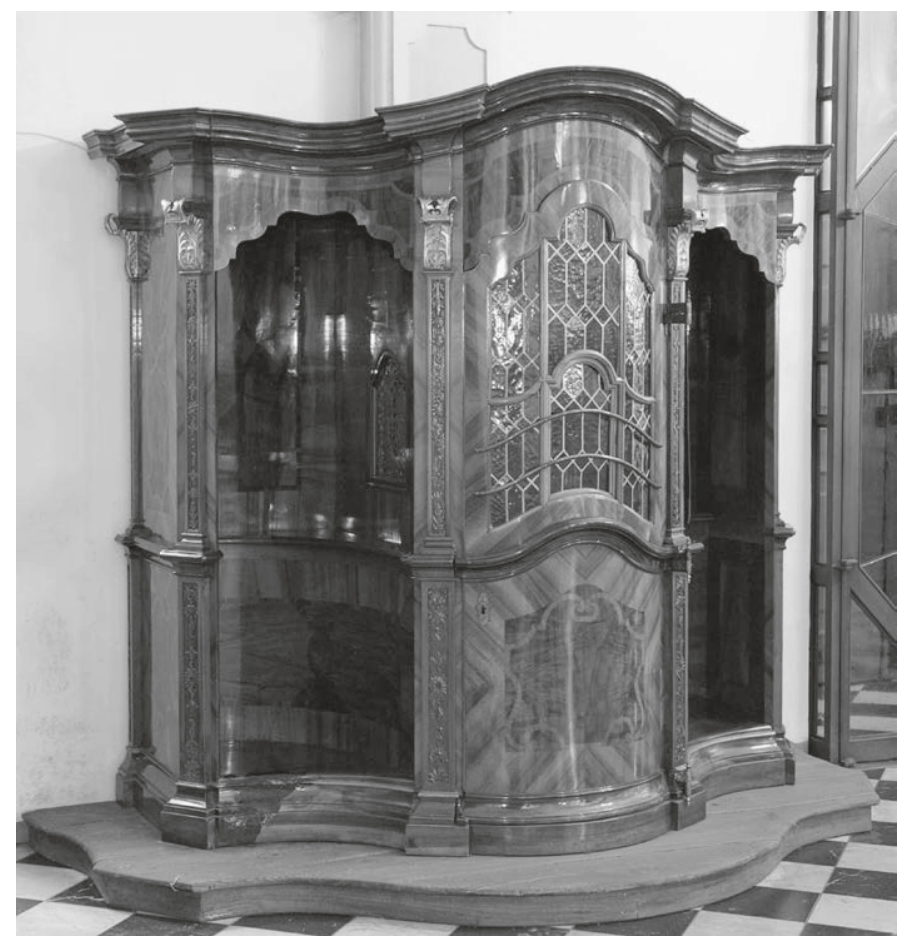

sind die vorderen Stützen schräg gestellt, was den Eindruck erweckt, dass sie von der wuchtigen Masse des Mittelteils nach außen gedrückt werden. Architrav und Fries des reduzierten Gebälks sind auf die schmale Zone über den Stützen beschränkt. Verkröpfungen lassen das profilierte Abschlussgesims über den Pilastern weit nach vorn treten, zur Mitte zu ist es als Segmentbogen nach oben geführt. Geschweifte Bögen überfangen die sich zu den Gehäusen öffnenden Arkaden, eine Tür verschließt die Stalle des Priesters. Ursprünglich war sie halbhoch, der verglaste Teil ist modern.

Die Tatsache, dass die Tischler auch die Innenseiten der Möbel furnierten, unterstreicht die hohe Qualität der Beichtstühle. Die Furniere bestehen aus gestreiftem Nussholz und Nussbaummaser, Adern aus Zwetschke und Esche (?), die Sprechgitter aus Messing. Geschnitztes Muschelwerk und vegetabile Ornamente schmücken die Pilasterschäfte, vergoldete Akanthuskonsolen treten an die Stelle der Kapitelle, Agraffen legen sich über den Architrav. Der Fachliteratur zufolge sollen die beiden Inventarstücke unter der Leitung von Sophronius Siegenbrock um I770 gefertigt worden sein, allerdings deuten Gründe der Stilkritik auf ein früheres Datum, was zu Zweifeln an einer Mitarbeit Siegenbrocks bei der Herstellung der Möbel führt. Fragen werfen 


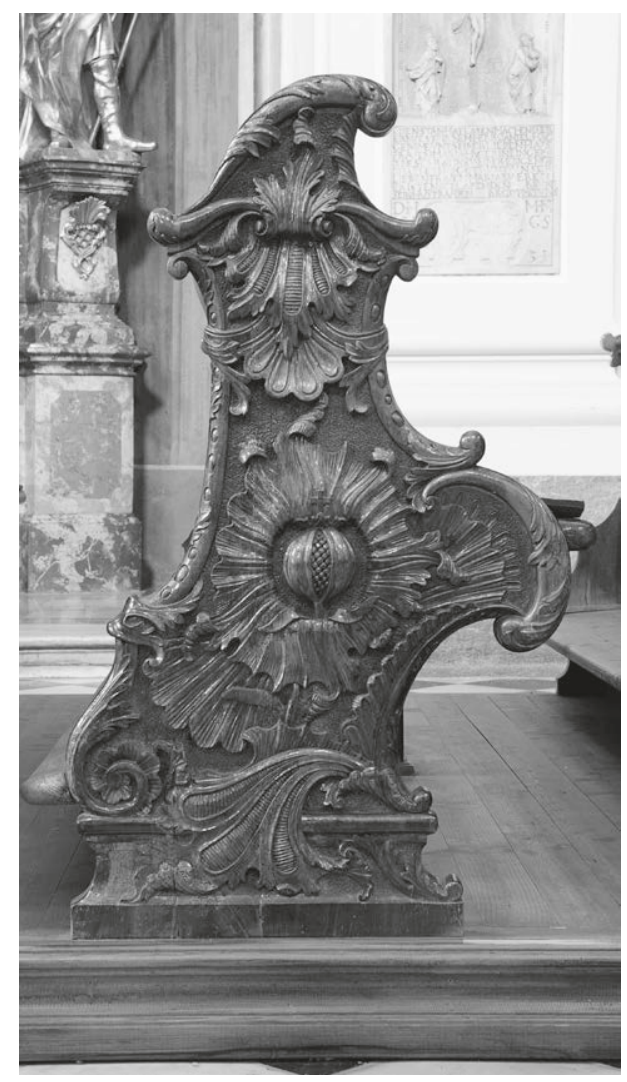

I 46 Bankwange. Fr. Sophronius Siegenbrock, um $\mathrm{I} 770 / 75$

vor allem die gravierenden Differenzen in der Formensprache der geschnitzten Ornamentmuster an den Möbelgarnituren auf. An den Kirchenbänken, die im Anschluss beschrieben werden, sind schwere Rocaillemotive das vorherrschende Ziermotiv, während sie an den Beichtstühlen noch sehr verhalten und lediglich in Verbindung mit älteren Formen vorkommen. Darüber hinaus ist der Duktus der Schnitzornamente ein völlig anderer. Es spricht folglich vieles gegen eine Anfertigung der Beichtstühle durch Siegenbrock um I770, zeitlich sind die Möbel um die Jahrhundertmitte anzusetzen.

\section{Kirchengestübl}

Fr. Sophronius Siegenbrock, um I770/75

$\mathrm{HS}$ i $5 \mathrm{~cm}$

H I IO cm $(+\mathrm{I} 5 \mathrm{~cm}) \times \mathrm{L} 28 \mathrm{I} \mathrm{cm}$

Nuss, Nussmaser, Esche, Nadelholz

Die 26 Bänke ruhen zusammen mit den Brüstungen seitlich der Längsachse des Kirchenschiffs auf zwei Laufböden, deren profilierte Kanten wie eine zusätzliche Postamentzone wirken (Farbtaf. ı 8; Abb. г46, I47) ${ }^{250}$ Baluster gliedern die Brustwände, die über dem Podest aus einem weiteren Sockel, einem hohen Mittelteil und einem abschließenden Gesims bestehen. Halbrunde und gekehlte Profile formen die Sockel- und Gesimsbänder, dazwischen spannen sich ebene Bereiche aus diagonal furnierten Nussholzrahmen und geschweiften Binnenfeldern aus Maserholz.

$\mathrm{Zu}$ den glatten Profilen und Flächen bilden die mit kräftigen Schnitzarbeiten dekorierten Bankwangen einen scharfen Kontrast. Ihre Großform entspricht einem flachen S-Bogen über einem mäßig hohen Sockel. Dabei fallen die abgerundeten vorderen Docken, die die Seiten mit den Fassaden der Brüstungen verbinden, wegen ihrer ungewöhnlichen Form besonders ins Auge. Blattwerk, Godrone und kleine ovale Ver-

\footnotetext{
250 Kohlbach, Barocke Kirchen [195 I], I 28 ; Schmid, ebd.; Dehio, ebd.; Schweigert, ebd., I7.
} 


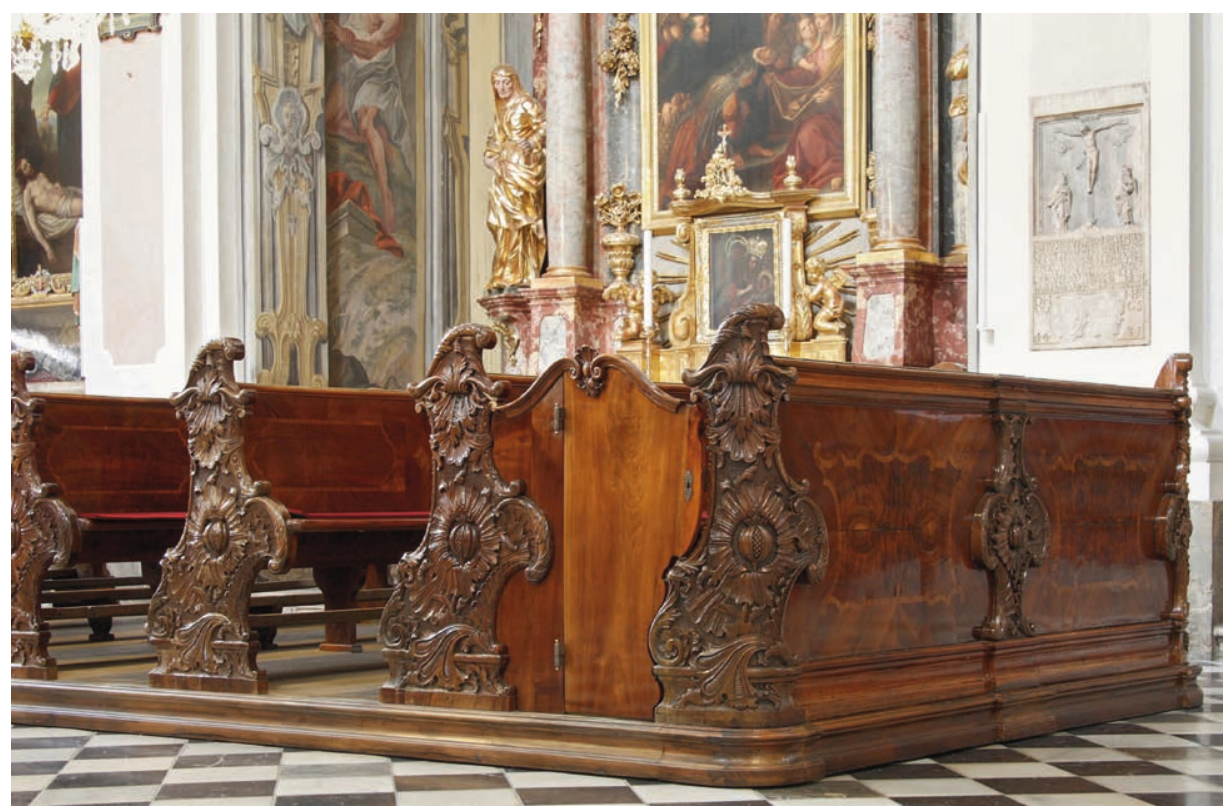

Farbtafel I 8 Kirchenbänke. Fr. Sophronius

Siegenbrock, um $1770 / 75$

I47 Bankwange, Detail mit Granatapfel und Kreuz, dem Emblem des Ordens der Barmherzigen Brüder. Fr. Sophronius Siegenbrock, um I770/75

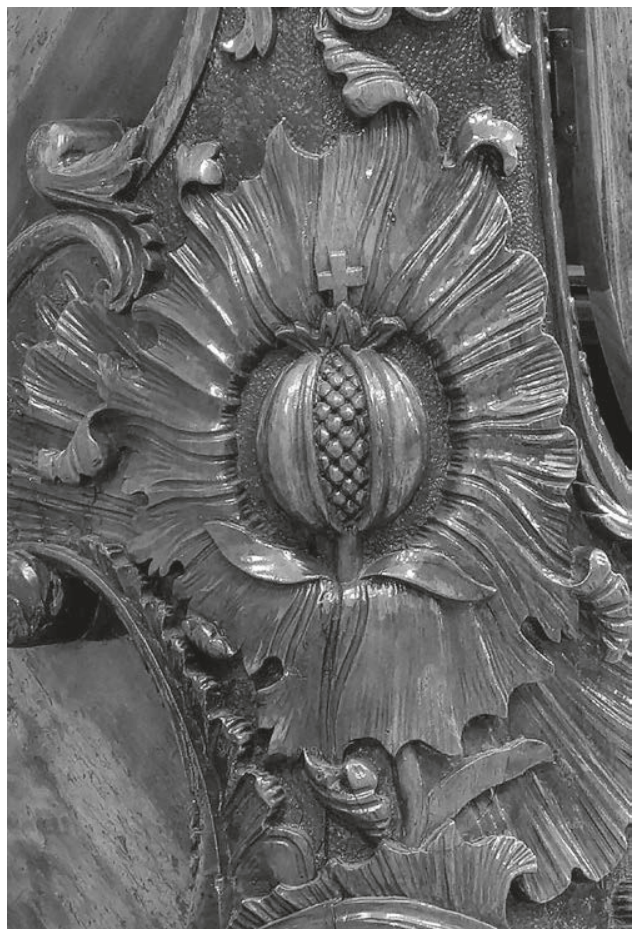


tiefungen zieren die wulstartigen, in C-Spangen aufgelösten Konturen der Docken, die mit einem wellenförmigen Schnitzaufsatz enden. Ein Granatapfel und eine große mehrschichtige Rocaille füllen das ausladende Mittelfeld der Wangen, eine Palmette legt sich über den Sockel, Muscheln stützen zusammen mit einem Akanthusblatt eine Art von Giebel. Dicht gesetzte Punzen zwischen den Ornamenten verursachen einen unebenen Grund, auf dem Glanzlichter und Schatten für reizvolle Lichteffekte sorgen.

Die Spannung, die der formale Unterschied zwischen ebenen und furnierten Flächen auf der einen Seite und den im schweren Hochrelief aus dem Vollholz herausgearbeiteten Wangen auf der anderen erzeugt, tritt an diesen Möbeln deutlich zutage. Ähnliches kommt an Kirchenbänken in der Steiermark und in Kärnten häufiger vor, im vorliegenden Katalog wird mehrfach darauf hingewiesen (etwa Farbtaf. o7; Abb. 240, 24I). In diesem speziellen Fall sind die Schnitzarbeiten allerdings besonders eindrucksvoll. Als Vorlagen könnten Augsburger Stiche aus der Jahrhundertmitte gedient haben, wie sie beispielsweise von Jeremias Wachsmuth (I 7 I 2-I 779) und Caspar Gottlieb Eissler überliefert sind. ${ }^{251}$

\section{Sakristei}

Der 1738 vollendete dreijochige Raum grenzt an die Südseite des Presbyteriums. ${ }^{252}$ Er ist gewölbt, hohe Fenster in der Süd- und Westwand schneiden in das Gewölbe ein. Die oben beschriebene Tür und ein großes Fenster verbinden die Sakristei mit dem Chor und dem Altarraum (Abb. I50). Den im Spital betreuten Patienten, denen in der Sakristei wie heute vermutlich auch früher schon Sitzmöbel zur Verfügung standen, wurde so die Teilnahme an der Eucharistiefeier ermöglicht. ${ }^{253}$ Eine zweite Tür führt in den Klosterbereich und in den Hospitalstrakt. Die Wände des Raumes sind mit Schränken verbaut und mit Holzpaneelen vertäfelt, unter dem Fenster zur Kirche sowie seitlich davon befinden sich Kniebänke.

\section{Sakristeiausstattung}

Fr. Sophronius Siegenbrock (?), um I765/75

Raummaße: ca. I 2,20 m × 7,20 m

Nuss massiv, Nadelholz. Messing, vergoldet

25 I Berliner/Egger, Vorlageblätter (I 98 I), Bd. I, го9-г 1о, Bd. 3, Abb. I368-I369, I382-I 383.

252 Zur Sakristei und ihrer Ausstattung vgl. Schmid, Klosterkirche [1 965], 25-26; Dehio, Graz (I 979), I 5 O-I 5 I; Schweigert, Barmherzigenkirche (I 999), I 8.

253 Eine ähnliche bauliche Situation liegt in Kramsach vor, doch werden dort solche Überlegungen vermutlich keine Rolle gespielt haben. 


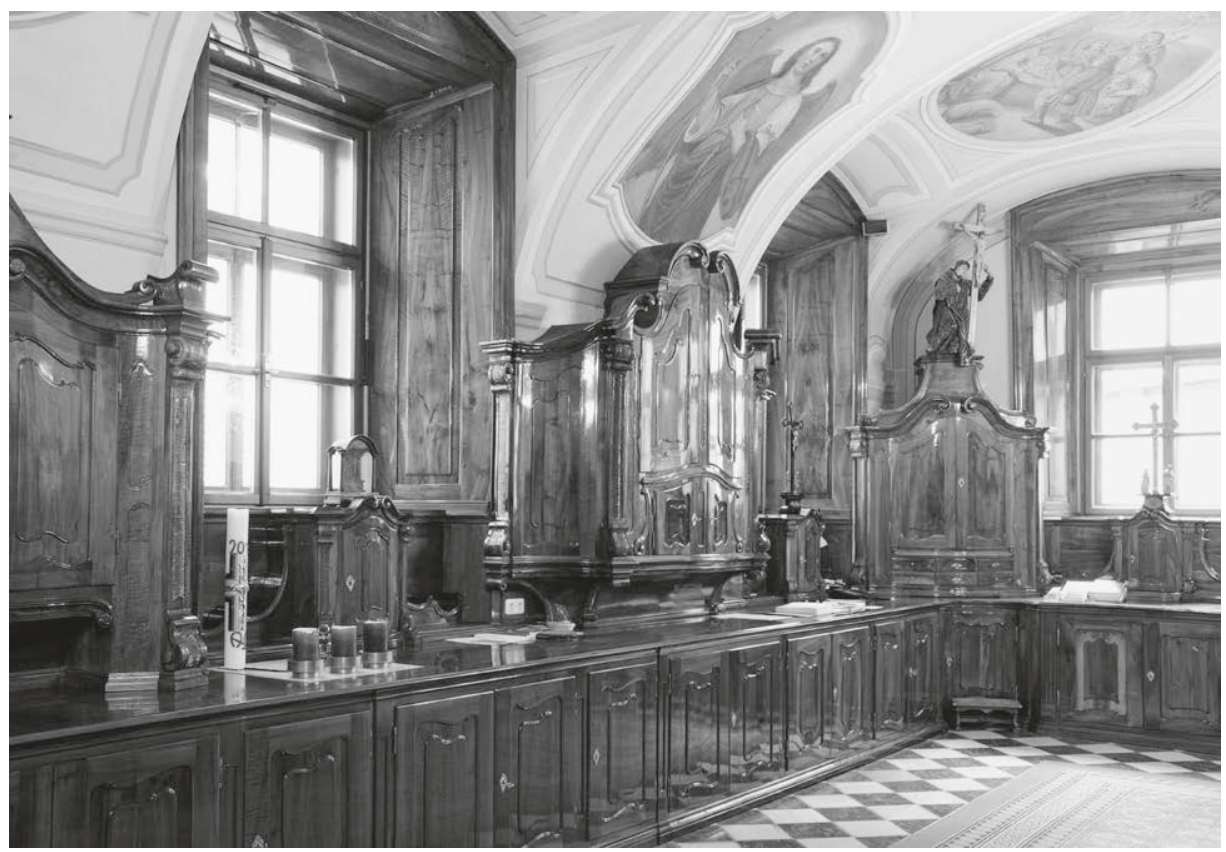

I48 Sakristei, Südseite. Ausstattung verm. Fr. Sophronius Siegenbrock, um I $765 / 75$

I49 Sakristei, Aufsatzkredenz vor der Südwand. Verm. Fr. Sophronius Siegenbrock, um I $765 / 75$

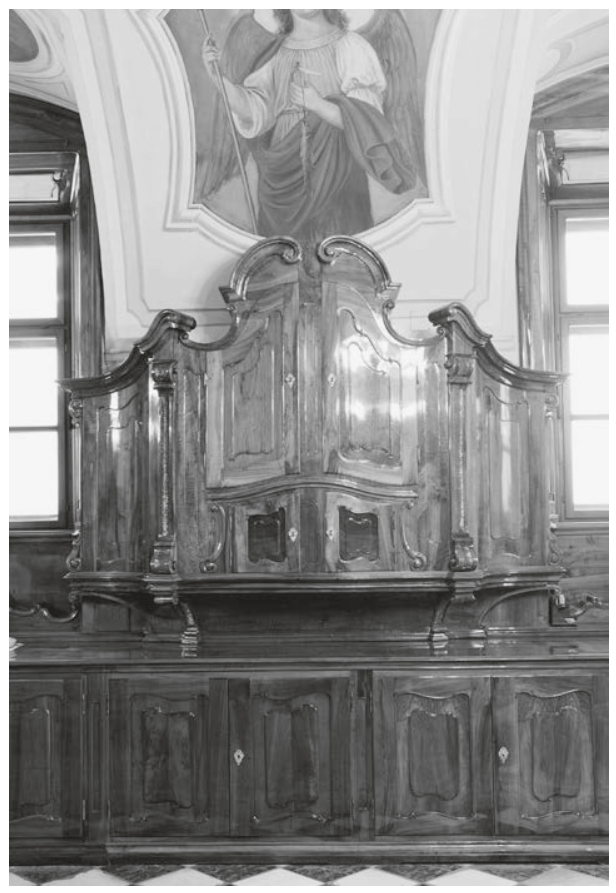




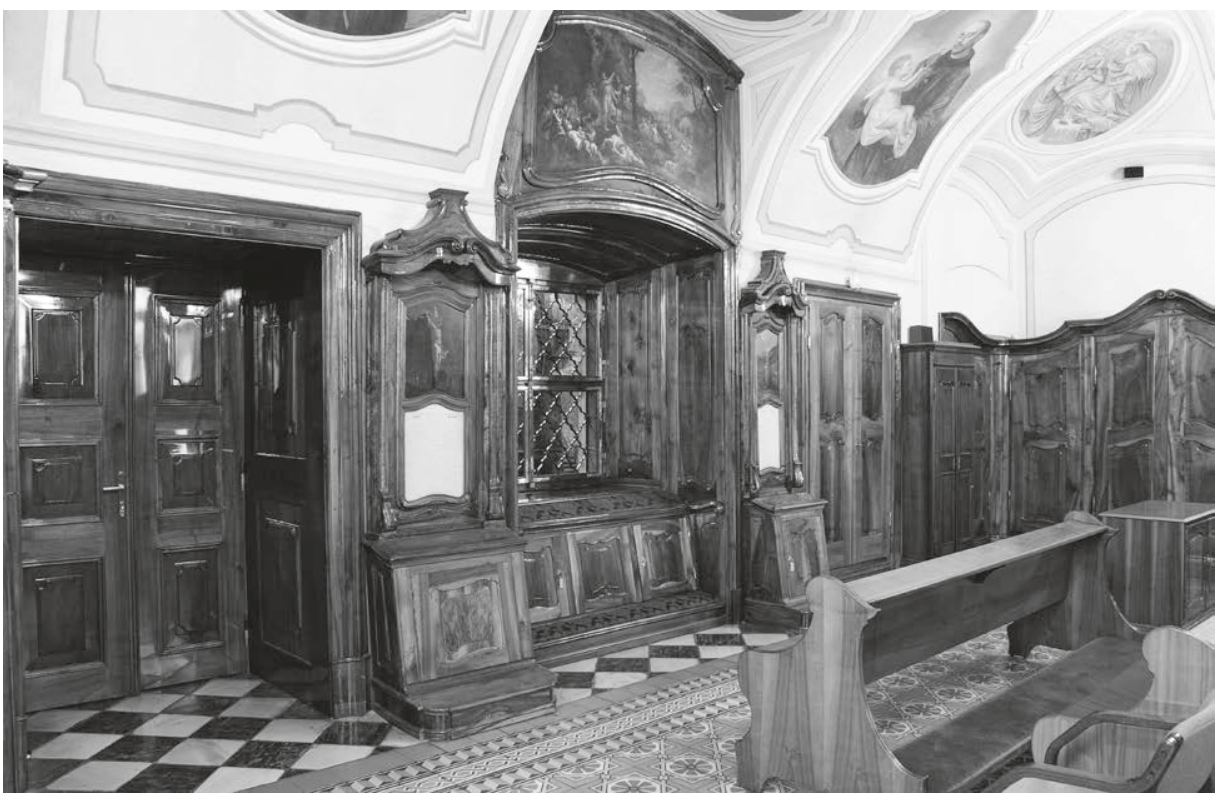

I50 Sakristei, Nordseite. Kniebänke sowie Tür und Fenster zum Chor- und Altarraum der Kirche. Verm. Sophronius Siegenbrock, um I 765/75

Während die Form der Möbel vor der Ost-, teilweise auch vor der Nordwand das Aussehen profaner Kleiderschränke aufgreift, entsprechen die Exemplare vor den beiden anderen Raumseiten Aufsatzmöbeln, wie sie in vielen Sakristeien vorkommen (Abb. I48-r 5 I). Sie setzen sich aus einem langen Unterschrank und mehreren Oberschränken vor den Fensterpfeilern zusammen. Die Aufsatzschränke weisen unterschiedliche Maße auf, das höchste Segment erreicht eine Gesamthöhe von etwa 3,20 m. In den Fensternischen finden sich außerdem vier tabernakelförmige Kästen.

Der Unterschrank, der große leere Fächer und Schubladen beinhaltet, besitzt eine relativ schlichte Fassade, die kaum in Erscheinung tretende pilasterartige Bänder mit Blockkapitellen strukturieren. Sehr viel aufwendiger ist die Gestaltung der Oberschränke, die keiner gemeinsamen Formensprache folgt. Einen Typus vertritt der linke Schrank vor der Südwand. Hier nehmen zwei Kästen, die von den Stirnseiten des Möbels her zu öffnen sind, ein breites Segment mit Fronttüren in ihre Mitte. Während die seitlichen Kästen direkt auf der Platte aufsetzen, steht das mittlere Teilstück erhaben über dem Unterschrank. Den zweiten Typus vertritt das diagonal gestellte Möbel in einer Raumecke. Es ruht mit dem gesamten Korpus auf der Platte, seine Fassade ist konvex geschwungen, Stützen tragen einen Volutengiebel mit hohem Postament, das einer Statue des Ordensgründers als Standfläche dient. In den unteren Korpusbereich 


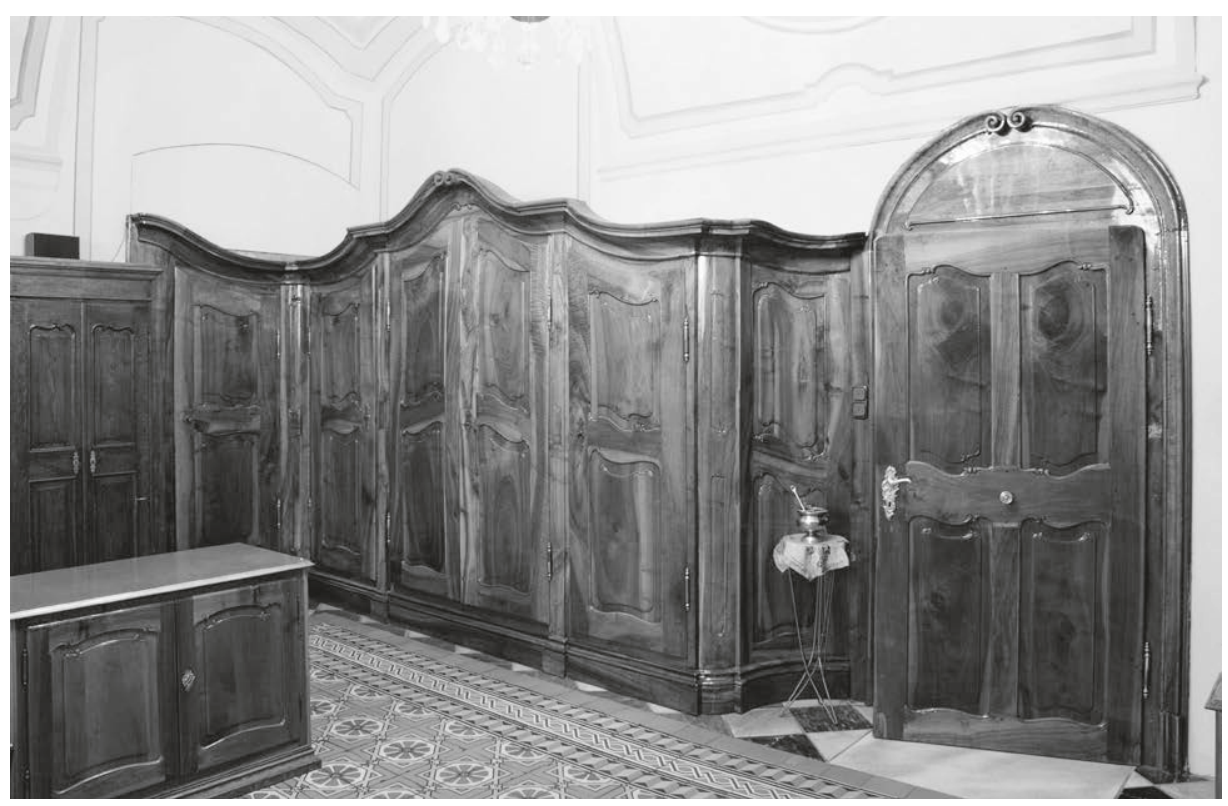

I 5 I Sakristei, Nord- und Ostwand mit Schränken und einer Tür. Verm. Fr. Sophronius Siegenbrock, um I 765/75. Die Kredenz in der Raummitte ist eine Neuanfertigung

sind Schubladen eingeführt, darüber verschließen Türen das Inventarstück. Eine dritte Gestaltungsmöglichkeit zeigen zwei Möbel vor der Süd- und Westwand. Sie schweben sozusagen über der Substruktion, da sie auf einem sich nach unten stark verjüngenden Segment lasten, dessen Kanten auf die Rückwand zulaufen. Die Schmalseiten beider Aufsatzschränke sind konkav eingezogen, die Rückwand ist um einiges breiter als die Fassade. Das Exemplar vor der Westwand ist eintürig, das vor der Südwand zweitürig, ein Kelchfach resp. zwei Kelchfächer sind eingepasst.

Schließlich wäre noch auf die tabernakelförmigen Möbel in den Fensternischen aufmerksam zu machen. Ihre Rückwand ist mit seitlichen Blenden nach außen gezogen, zwei Volutenpilaster flankieren die gebauchte Vorderseite, die ein Sprenggiebel überfängt.

Die Gestaltung der Kniebänke (Abb. I50), die den Geistlichen für Akzess- und Rezessgebete zur Verfügung stehen, rekurriert auf Möbel, die namentlich in Kärnten (Abb. 44) häufig vorkommen, ursprünglich aber auf italienische Modelle zurückgehen. Die Möbel setzen sich aus einem flachen Unterbau und einem niedrigen Schrank zusammen. Darüber folgt in der Barmherzigenkirche ein hoher und schlanker Rahmen mit einem baldachinförmigen Giebel. Die hölzerne Struktur fasst Gebetstafeln sowie Gemälde des Gekreuzigten und der Schmerzensmutter ein, eine entsprechend 
gestaltete, aber breitere Kniebank befindet sich unter dem Fenster, selbstverständlich ohne Aufsatz.

Das Möbelensemble besteht aus massivem Nussholz, von der geglätteten Oberfläche heben sich nur die quergeriffelten Stützen mit ihrer bewegten Oberflächenstruktur ab. Die Garnitur besitzt geschweift gesägte Horizontalrahmen und bossierte Füllungen. Von den vergoldeten Messingbeschlägen abgesehen, bestimmt einzig und allein die ansprechende Maserung des ausgewählten Holzes das Aussehen der Tischlerarbeiten. Die Ausstattung wurde in einem bodenständigen spätbarocken Stil gefertigt, mit französischen Rokokoformen hat er kaum etwas gemein hat. Dadurch unterscheidet sie sich deutlich vom Laiengestühl.

\section{Graz, Dom- und Pfarrkirche St. Ägidius}

St. Ägidius, seit I I74 in Urkunden genannt, geht wahrscheinlich auf eine frühere Eigenkirche zurück. ${ }^{254}$ Auf Veranlassung Kaiser Friedrichs III. (I 4I5-I 493) hin erfolgte zwischen I 438 und I462/64 die Neuerrichtung der in Schriftquellen schon lange zuvor als Pfarrkirche und Basilika bezeichneten Architektur. I 564 wurde St. Ägidius zur Hofkirche, I 573 zur Stadtpfarrkirche erhoben, I577 überließ man sie Jesuiten als Ordenskirche. Nach ersten architektonischen Eingriffen im I7. Jahrhundert, dem Bau einer neuen Sakristei und mehrerer Kapellen, gab die Gesellschaft Jesu zwischen I730 und I733 einen neuen Hochaltar nach einem Entwurf des Ordensangehörigen Georg Kraxner (Kräxner; r 688-I755) in Auftrag. ${ }^{255}$ Der Altar zeichnet sich durch ein komplexes ikonographisches Programm aus und besticht durch die Verwendung besonderer Werkmaterialien, zu denen verschiedene italienische Marmorarten gehören. Bei der Kirche handelt es sich um eine dreischiffige gestaffelte Hallenkirche, das Langhaus umfasst fünf, das schmalere Presbyterium vier Joche. Im Zuge der Neuordnung der österreichischen Bistümer in den I 780er-Jahren wurde die Kirche zur Domkirche bestimmt.

254 Kohlbach, Dom (1948); ders., Gotische Kirchen (1950), 39-56; Woisetschläger/Krenn, Steirische Herrlichkeiten (1973), 38, 82-83, Taf. 60, I89; Hootz, Kunstdenkmäler (1965-1968), Bd. 2 (I966), 207, 367; Schnell, Dom (1969); Schweigert, Stadtpfarrkirche (1974); Dehio, Graz (1979), I3 3 -23; Attems/Koren, Kirchen (I988), го-13; Steinböck, Domkirche (1989), 6-59; Kölbl/Resch, Wege (2002), $70-86$.

255 In der Literatur herrscht Uneinigkeit darüber, ob Georg Kraxner zugleich auch Baumeister war und gelegentlich anders geschrieben wurde, oder ob es sich bei Kraxner und Kräxner um verschiedene Personen handelte. Es spricht aber einiges dafür, von einer einzigen Person auszugehen. Kohlbach, Dom (I948), I $22-$ I 24. 


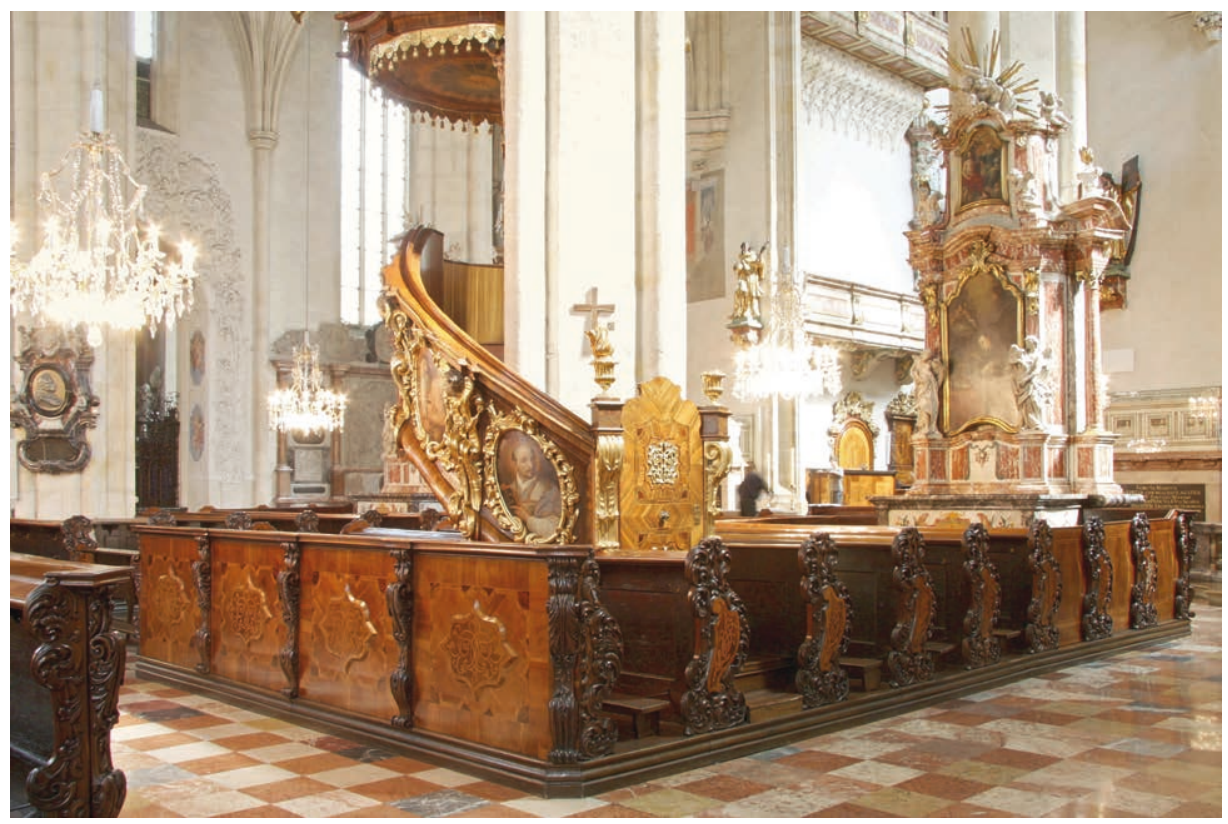

Farbtafel I 9 Laiengestühl. Ordenstischlerei der Jesuiten mit Chrysostomus Lindemayr, Franz Kienast, Adam Kössler, Johann Lantscher, Peter Walden nach einem Entwurf von C. Lindemayr, I 706/o9

\section{Tischler und Bildhauer}

Neben dem prachtvollen Hochaltar und anderen kulturhistorisch bedeutenden Kunstwerken besitzt die Domkirche eine erlesene Tischlerausstattung aus der ersten Hälfte des I 8. Jahrhunderts. Der Jesuitenorden verfügte damals in Graz über eine eigene Tischlerei, der Chrysostomus (Georg) Lindemayr mit Unterbrechungen vorstand. Der vielseitige Handwerker, 1678 in Wilten (Tirol) geboren, trat nach der Absolvierung einer Tischlerlehre I702 dem Jesuitenorden bei. I706 arbeitete er in Wien für die Gesellschaft Jesu als Unterkoch, 1707 in Zagreb als Koch und Tischler. In Graz übte er von 1708 bis I 7 I I sowie von I7I 3 bis I7 I 7 die gleichen Berufe aus, von I7 I 9 bis I 727 leitet er dort als »Präfekt« die Tischlerei. I 7 I 2 wird er in Passau als Pförtner und Schuster beschäftigt, I 718 in Tyrnau als Tischler und Kredenziar, 1728 als Tischler und Pförtner im ungarischen Güns (Kőszeg). I 729 bis I 739 ist er wieder im Wiener Professhaus fassbar, nun als Begleiter bei Ausgängen der Patres. Lindemayr verstarb am 21. Januar 1739. ${ }^{256}$ Den Klosterangehörigen eines alten Ordens wäre solch ein

256 Die biographischen Daten nach freundlicher Mitteilung von Martina Lehner, Jesuitenarchiv in Wien.

Vgl. dazu außerdem Kohlbach, Dom (1 948), 95. 
häufiger Standortwechsel nicht gestattet worden ${ }^{257}$, dagegen sprachen im Falle Lindemayrs die Ordensregeln nicht gegen die Umzüge, da sich Jesuiten durch ihr Gelübde an den Orden, nicht aber an ein bestimmtes Haus banden. Vermutlich fiel nicht nur die Erzeugung des Mobiliars in den Verantwortungsbereich Lindemayrs, sondern er dürfte auch die nötigen Entwürfe und Risse gezeichnet haben. I708 und r 709 nennt das Rechnungsbuch der Kommunität namentlich die Tischler Franz Kienast, Adam Kössler, Johann Lantscher und Peter Walden. ${ }^{258}$ Andreas Trarer, ein Tischler aus dem steiermärkischen Weiz, belieferte die ordensinterne Werkstatt mit Nussbaumholz, zudem erhielt sie Lieferungen mit Olivenholz aus Triest und Laibach. ${ }^{259}$

Nach I736 wird Philipp Jakob Straub ( I706-1 774) immer wieder für die Grazer Jesuiten tätig. ${ }^{260}$ Der in Württemberg gebürtige Bildschnitzer arbeitete seit I 730 zunächst zusammen mit seinem Bruder Johann Baptist ( I704-I784) in Wien. Gegen Ende I734 oder Anfang I 735 verließ Philipp Jakob die österreichische Residenzstadt und suchte sein Glück in Graz. Für die damalige Jesuiten- und heutige Domkirche schuf er unter anderem die Kanzel, ein Oratorium, die Bekrönung der Sakristeimöbel sowie vermutlich auch die Schnitzaufsätze des Chorgestühls und zweier Türen. Wie groß der Einfluss war, den die Tischler- und Bildhauerarbeiten der Domkirche in stilistischer Hinsicht zumindest regional ausübten, zeigen Möbelgarnituren etlicher Sakralbauten in Graz selbst und in der Umgebung der Stadt. Sie finden in den nächsten Abschnitten der Arbeit Erwähnung.

\section{Kirchenraum}

\section{Laiengestühl}

Tischler Chrysostomus Lindemayr, Franz Kienast, Adam Kössler, Johann Lantscher und Peter Walden; Entwurf Chrysostomus Lindemayr, I 706/o9

HS $\mathrm{I} 7 \mathrm{~cm}$

$\mathrm{H}$ i I $\mathrm{cm}(+\mathrm{I} 7 \mathrm{~cm}) \times \mathrm{L} 550 \mathrm{~cm}$

Nuss, Nussmaser, Olive (?), Ahorn, furniert auf Nadelholz

257 Eine Ausnahme stellt Frater Kaspar Schrezenmayer (I693-1782) aus dem Zisterzienserstift Heiligenkreuz dar, der 1734 in das ungarische Kloster St. Gotthard (Szentgotthárd) wechselte, nachdem er zehn Jahre im niederösterreichischen Stift als Tischler gearbeitet hatte. Bohr, Sakralmöbel (2017), 3738, 333-334. Tatsächlich hatten Zisterzienserklöster offenbar die Möglichkeit, ihre Konversen anderen Abteien des Ordens zu vermitteln. Schwaiger, Mönchtum (2003), 459. In Verbindung mit Tischlern scheint das allerdings nur selten vorgekommen zu sein.

258 Diözesanarchiv Graz, XX-C-ro, Gebundene Quellen, Rechnungsbuch Jesuiten Bd. 2, Stichwort $» \mathrm{Fab}[\mathrm{ro}] \ll ;$ Kohlbach, Dom ( 1948$), 92$.

259 Kohlbach, ebd., 92, 242.

260 Kohlbach, ebd., I 22. Zu Straub vgl. zudem Schweigert, Studien (2017), 309-329, mit dem Neudruck eines 1992 erschienenen Beitrags. 


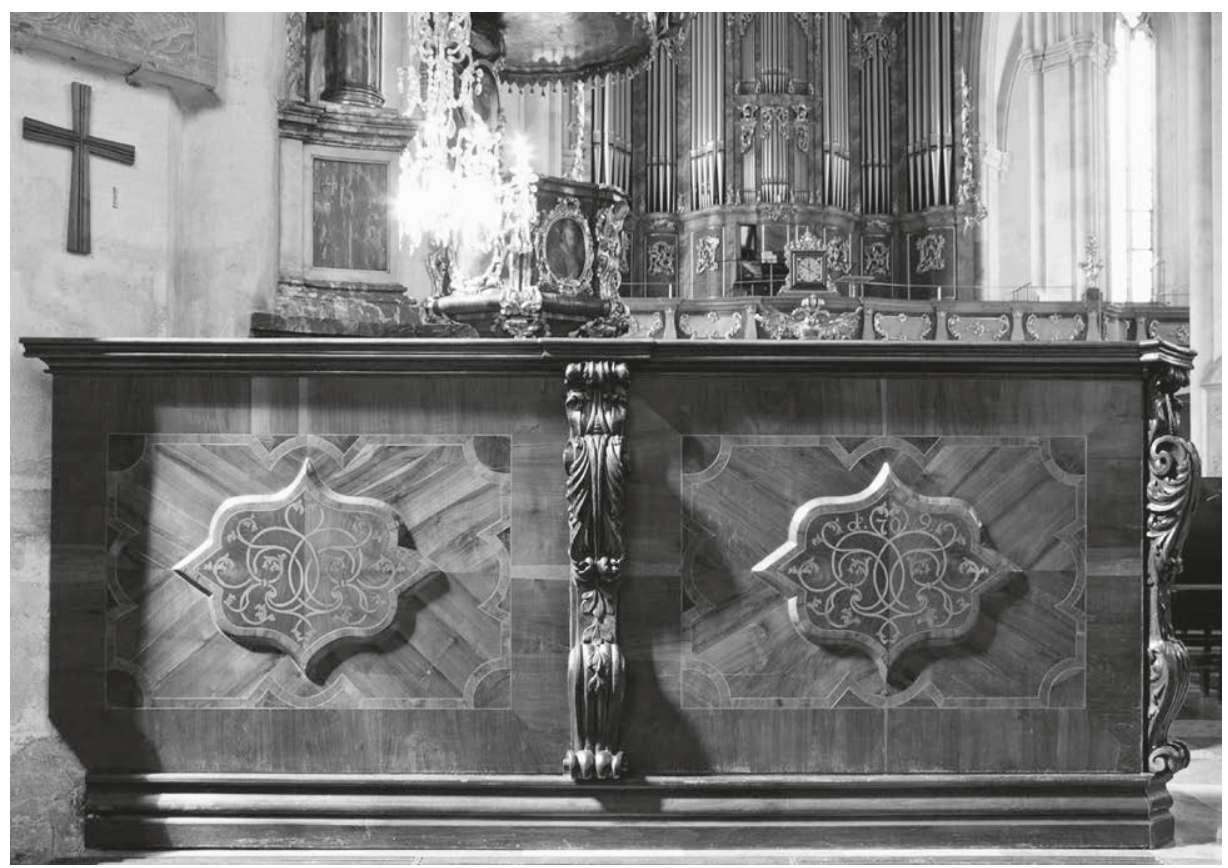

I 52 Laiengestühl, Brustwand. Ordenstischlerei, I706/o9

Das Gestühl setzt sich aus vier Blöcken mit 36 Bänken zusammen, eine weitere Bank wird in einer Seitenkapelle aufbewahrt (Farbtaf. I9; Abb. I 52, I 53). ${ }^{261}$ Der mit profilierten Kanten ausgestattete Laufboden bildet bei diesen Möbeln die Sockelzone, Baluster gliedern die Brüstungen. Akanthus und eine Blattgirlande schmücken die Stützen, die aus Voluten bestehen und mit ihrer plastischen Ausbildung überraschen. Rahmen und Füllungen schließen die zwischen den Stützen, dem Sockel und dem Abschlussgesims liegenden Flächen. Die Holzstruktur des Furniers verläuft auf den Rahmensegmenten in horizontaler und vertikaler Richtung, während in den Rechteckfüllungen geschweifte Adern Flächen voneinander scheiden, die mit Maserholz und diagonal aufgelegtem Nussholz dekoriert sind. Bossen, die die Füllungen mehrschichtig und spannungsreich erscheinen lassen, erinnern mit abgerundeten Ecken und nach außen gerichteten Spitzen an gotische Zierornamente. Die Tafeln tragen gestürztes und gespiegeltes Nussholz, auffallend filigrane Adern kreuzen sich und laufen in feinen Blättern aus.

26I Kohlbach, ebd., 92, 96, 242; Schnell, Dom (r 969), I 2; Dehio, Graz (1 979), 22 ; Steinböck, Domkirche (I 989), 46. Weitere Bänke, die hier jedoch keine Relevanz besitzen, befinden sich im Mitteldurchgang. 


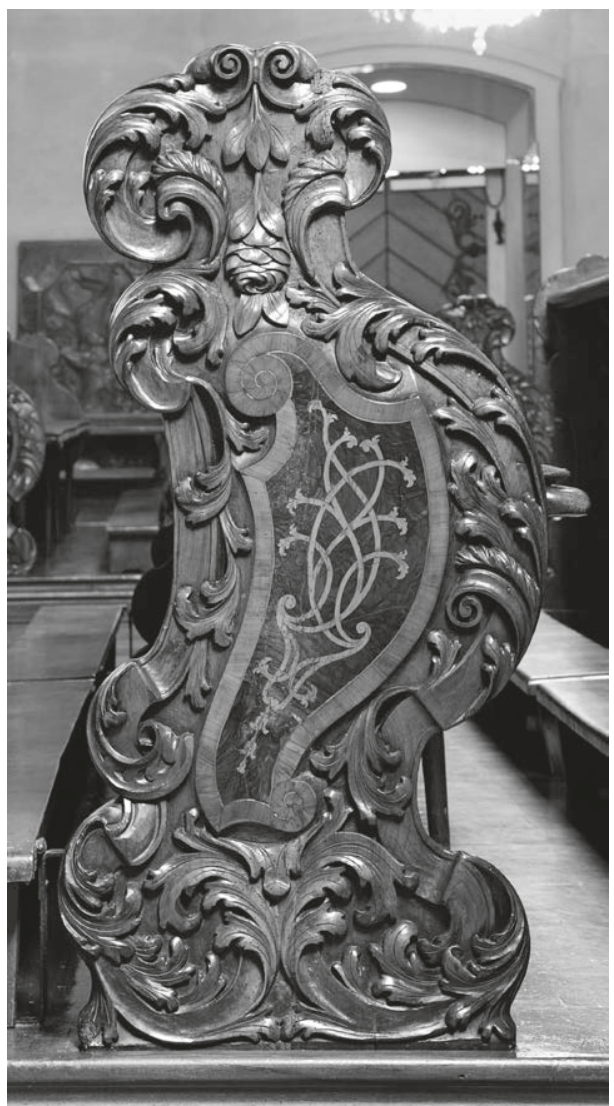

I53 Bankwange. Ordenstischlerei, I 706/o9

Ein anderes Gepräge charakterisiert die Bankwangen. Ihre Grundform entspricht einem nach vorn gerichteten C-Bogen, an den sich oben und unten geschweifte $\mathrm{S}-\mathrm{Schwünge}$ anschließen. Akanthusvoluten vervollständigen die Basis, von ihnen ausgehend zieht sich schweres Laub- und Bandlwerk in die Höhe. Den Wangenabschluss bilden kleine Voluten, von denen Blätter und Feldfrüchte herabhängen. Die kräftigen Schnitzarbeiten kontrastieren mit den glatten und intarsierten Flächen im Zentrum. Ein Fries umgibt dort ein maserholzfurniertes Feld mit eingelegten Adern und vegetabilen Ornamenten. Türen verschließen einige Bankreihen. Sie passen sich der Wangenform an, weisen ansonsten aber eine schlichte Gestaltung auf.

Das bei der Herstellung des Laiengestühls gewählte Formenvokabular verbindet italienischen Akanthus mit französischem Bandlwerk. Damit ist es wesentlich moderner als beispielsweise die gleichzeitig gefertigten Bibliotheks- und Refektoriumsmöbel in den Abteien Kremsmünster und Lambach. ${ }^{262}$ Von Rochus Kohlbach erschlossene Schriftquellen erteilen darüber Auskunft, dass I706 Lärchenholz zum Bau des Laufbodens angekauft wurde. Unter der Leitung von Chrysostomus Lindemayr stellten die Tischler das Gestühl danach in der Kirche auf, möglicherweise vollendeten sie es abschnittsweise. ${ }^{263}$ Die hier gezeigte Brustwand ist auf das Jahr 1709 datiert.

262 Bohr, Sakralmöbel (2017), 528-53 I, 543-545.

263 Diözesanarchiv Graz, Kloster und Stifte Jesuiten, 54-f-I/I, Rechnungen Großformat I602-I7I I, XIX-C-29/ז, Nr. 284, Juli I709; außerdem XX-C-1o, Gebundene Quellen, Rechnungsbuch Jesuiten Bd. 2, unter »Fab[ro]«, I708. Vgl. auch Kohlbach, Dom (1948), 92, 242. 
I 54 Reihenbeichtstuhl.

Ordenstischlerei und

Chrysostomus Lindemayr, I 707 / I 7 I 9

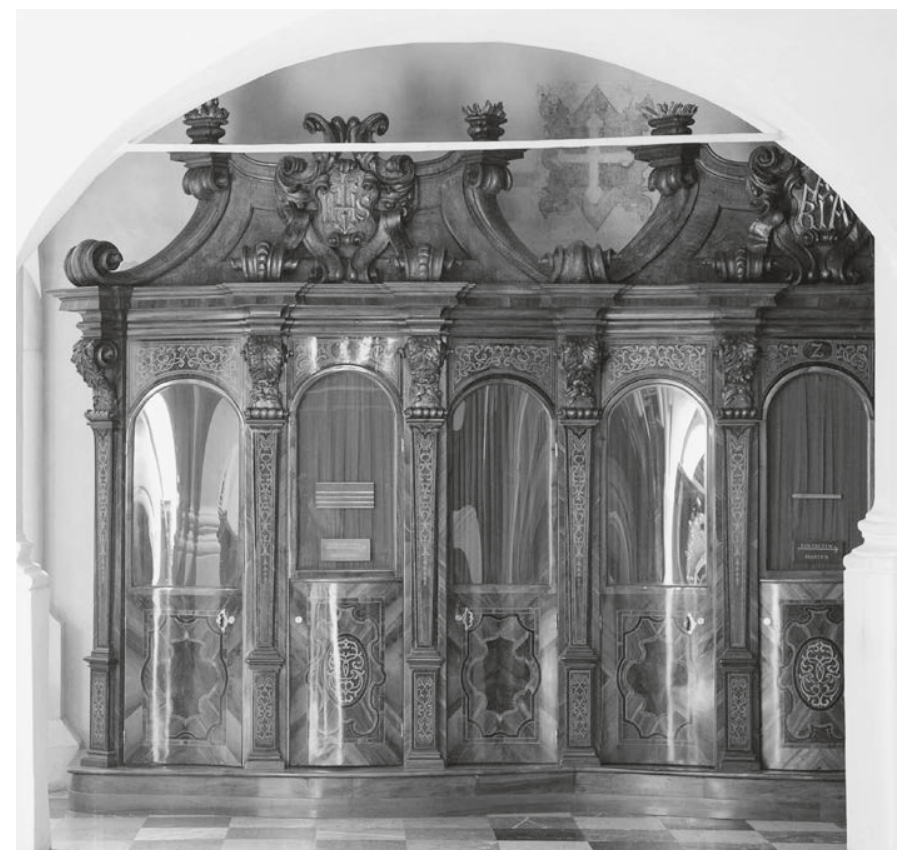

\section{${ }_{4}$ Reihenbeichtstüble und 4 Einzelbeichtstüble}

Verm. Franz Kienast, Adam Kössler, Johann Lantscher und Peter Walden unter der Leitung und nach einem Entwurf von Chrysostomus Lindemayr, i 707/r 7 i 9

HS I $8 \mathrm{~cm} / 22 \mathrm{~cm}$

Gesimshöhe $230 \mathrm{~cm}(+\mathrm{I} 8 \mathrm{~cm}) / 235 \mathrm{~cm}(+22 \mathrm{~cm}) \times \mathrm{L} 250 \mathrm{~cm} / 500 \mathrm{~cm} / 600 \mathrm{~cm} / 755 \mathrm{~cm} \times$ T $105 \mathrm{~cm} / \mathrm{I} 20 \mathrm{~cm}$

Nuss, Nussmaser, Olive, Holz geschwärzt, furniert auf Nadelholz, Nadelholz, gefasst und bemalt

Unter der Westempore stehen vier Reihenbeichtstühle - drei Möbel für zwei Geistliche und eines für drei (Abb. I 54). ${ }^{264}$ Hochgesockelte Keilpilaster mit Volutenkapitellen verleihen den geschwungenen Möbelfronten die gewünschte architektonische Struktur, rundbogige Arkaden öffnen sich zu den Kammern der Beichtväter und Pönitenten. Ursprünglich waren lediglich die mittleren Stallen durch Türen verschlossen. ${ }^{265}$

${ }_{264} \mathrm{Zu}$ den Beichtstühlen vgl. Kohlbach, ebd., 91-92, 95-96, 98, 242; Schnell, Dom (r969), I 2; Dehio, Graz (1979), 22; Steinböck, Domkirche (1989), 46.

265 Das frühere Aussehen dürften die Beichtstühle in der Kirche Mariatrost recht gut wiedergeben (Abb. I 7 I). Eventuell geht die Überarbeitung der Möbel auf eine Restaurierung zurück, die nach den Angaben des Dehio-Handbuchs I 963 durchgeführt wurde. Dehio, ebd. 


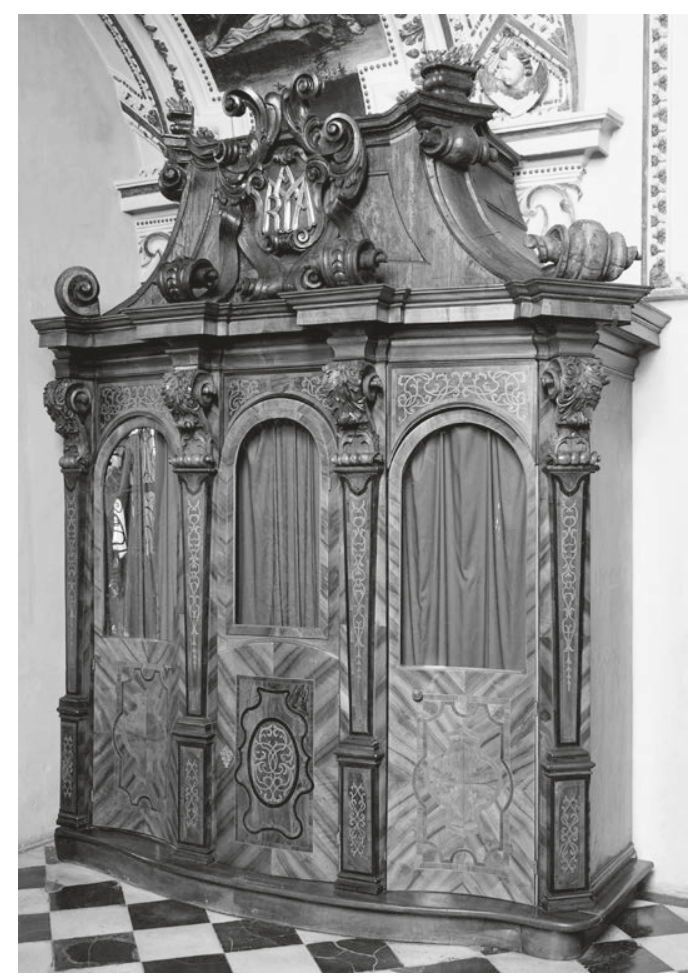

I 55 Beichtstuhl. Ordenstischlerei und Chrysostomus Lindemayr, I 707/I 7 I 9

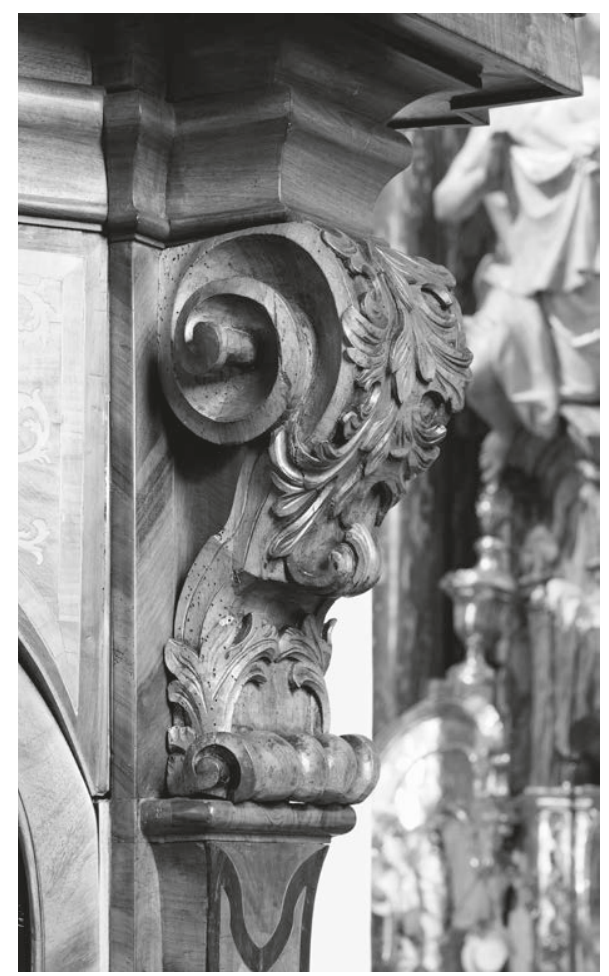

I 56 Beichtstuhl, Detail eines Pilasterkapitells. Ordenstischlerei und Chrysostomus Lindemayr, I 707 / I 7 I 9

Miteinander verschlungene Adern in den Flächen über den Arkaden, in den barocken Türen sowie in den Pilasterschäften ähneln den Ornamentmotiven an den Bänken, vermutlich entstanden die Möbel in der Ordenstischlerei unter der Federführung derselben Handwerker. Die Beichtstühle enden mit einem mächtigen Auszug, den schräg nach außen gerichtete Spangen begrenzen. Flammenvasen stehen dort auf Gesimsen, Blatt- und Bandlwerk säumt Kartuschen, von denen zwei kräftige Bänder nach unten fallen. Die Inschriftentafeln tragen das Monogramm Christi zusammen mit einem Kreuz und drei Nägeln sowie die ineinander geschriebenen Buchstaben der Namen Joseph und Maria. ${ }^{266}$ Anders als die furnierten Möbelgehäuse bestehen die Auszüge nur zum Teil aus Nuss, zum Teil aber auch aus dunkelgefasstem Nadelholz mit aufgemalter

266 Die Jesuiten übernahmen die Buchstabenkombination IHS in der Umdeutung zu Jesum Habemus Socium, Jesus haben wir zum Verbündeten. Kölb1/Resch, Wege (2002), 83. 
Maserung. In den Seitenkapellen befinden sich weitere fünf Beichtstühle (Abb. I55, I 56). Sie sind dreiachsig, ansonsten entspricht ihr Aussehen dem der Inventarstücke unter der Empore.

Ein Rechnungsbuch der Jesuiten informiert darüber, dass am 15. Oktober I699 ein erster Beichtstuhl geliefert wurde, am 9. Januar I 707 folgte ein zweiter, I7 I kamen neun Exemplare hinzu, I7 9 noch einmal zwei. ${ }^{267}$ Den Schriftquellen zufolge stellte man in jenen Jahren also I3 Beichtstühle in der Kirche auf, I 948 waren noch elf Exemplare vorhanden. ${ }^{268}$ Das Exemplar von 1699 existiert nicht mehr, denn aus stilistischen Gründen kann keines der Möbel so früh datiert werden. Von den anderen zwölf wurde eines deponiert, zwei sind verschollen, Teile eines Beichtstuhlaufsatzes wurden zu Volksaltar und Ambo umgebaut. ${ }^{269}$ Die geringen Differenzen zwischen den erhaltenen Möbeln geben Anlass zur Vermutung, dass sie auf die Lieferung von I 7 I I zurückgehen.

\section{Opfergangsportale}

Ordenstischlerei, Entwurf verm. Georg Kraxner, I 733

$\mathrm{H} 230 \mathrm{~cm} \times \mathrm{B}$ Io7 $\mathrm{cm}$ (lichte Maße)

Nuss, Nussmaser, Olive, Ebenholz, Buchs (?), Ahorn, weitere Holzarten, furniert auf Nadelholz. Eisen, Messing, graviert

Die beiden rundbogigen Türen sind in eine Portalarchitektur aus Marmor eingefügt, vom Gewicht des Materials und der Wucht der von Steinmetzen geschaffen schweren Formen werden sie optisch nahezu erdrückt (Farbtaf. 20). ${ }^{270}$ Eine schlichte Basis, deren ungewöhnliche Höhe der des seitlichen Marmorsockels entspricht, trägt die mit einem breiten Fries gerahmte Füllung. Zwischen geometrischen Motiven bereichern Darstellungen von Flammenvasen, Papageien, einem Blumenarrangement, einer Heiligenbüste und einer Maske das zentrale Feld. Typisch für eine groteske Illustration der Zeit, kommt das Furnierbild ohne die dritte Dimension aus. Es ist flach und benötigt weder eine räumliche Ausdifferenzierung noch einen logischen Aufbau, die Positionierung der Gegenstände im Raum bleibt völlig unklar. Der Komposition dürfte ein Ent-

267 Diözesanarchiv Graz, XX-C-ıo, Gebundene Quellen, Rechnungsbuch Jesuiten Bd. 2, Stichwort »Fab[ro]«; Kohlbach, Dom (1948), 91-92, 96, 98.

268 Kohlbach, ebd., 96, zählt fünf »einschichtige«, vier doppelte und zwei dreiteilige Möbel.

269 Prälat Schnuderl wies mich freundlicherweise auf das deponierte Möbel hin. Schnell, Dom ( I 969), 8; Dehio, Graz (1979), I8.

270 Kohlbach, Dom (1 948), 226; Dehio, ebd., I7-18. 


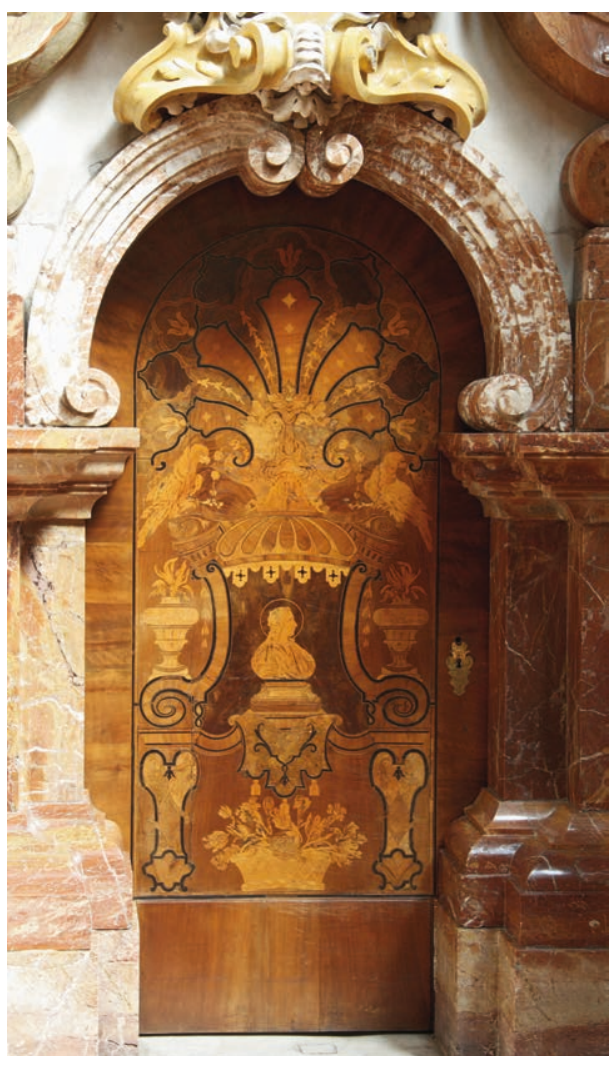

Farbtafel 20 Opfergangsportal. Ordenstischlerei verm. nach einem Entwurf von Georg Kraxner, I733 wurf von Georg Kraxner zugrunde liegen, wie Rochus Kohlbach vermutete. ${ }^{271}$ Man muss ihm beipflichten, wenn er an einen süddeutschen oder österreichischen Künstler denkt, da die Marketerie definitiv unfranzösisch wirkt. Und dennoch ist sie letztendlich auf Ornamententwürfe Jean Bérains d. Ä. ( I637-I 7 I I) aus der Zeit um I 700 zurückzuführen, in dessen Stichen sich ähnliche Ornamentmotive finden. ${ }^{272}$ Die Marketerien unterscheiden die Türen jedenfalls deutlich von den anderen Tischlererzeugnissen in der Kirche und auch sonst lässt sich eine vergleichbare Arbeit in österreichischen Sakralbauten kein weiteres Mal nachweisen.

In einer Schriftquelle wird das Ende der Arbeiten an den beiden Türen indirekt erwähnt. I733 werden neun Gulden für $I \frac{1}{2}$ Mass Spanische Fierneis vor die Zwey Tirn bey den Altar zu fierneissen verrechnet. ${ }^{273}$ Sie waren damals weitgehend fertiggestellt und erhielten einen mattglänzenden Überzug, der das Holz vor Staub und Feuchtigkeit schützte und zugleich seine Struktur und Farbe stärker in Erscheinung treten ließ.

\section{Türen im Chorraum}

Ordenstischlerei, Schnitzaufsatz verm. Philipp Jakob Straub, um I 735/40 $\mathrm{H} 237 \mathrm{~cm} \times \mathrm{B}$ I $33 \mathrm{~cm}$ (Türblatt)

Nussbaum, Nussmaser, Olive, Palisander, weitere Holzarten, furniert auf Nadelholz, Holz vergoldet. Eisen, graviert und verzinnt

27 I Kohlbach, ebd.

272 Berliner/Egger, Vorlageblätter (I98 I), Bd. I, 93-94, Bd. 3, etwa Abb. I I 35-I I 37, I I 42.

273 Kohlbach, Dom (I 948), 226. Spanischer Firnis bestand aus einer Mischung aus Weingeist, Spicköl, Sandarak und Schellack. Zedler, Universal-Lexicon (I 732 ff), Bd. 38 (I 743), Sp. I I66-i r 68. 


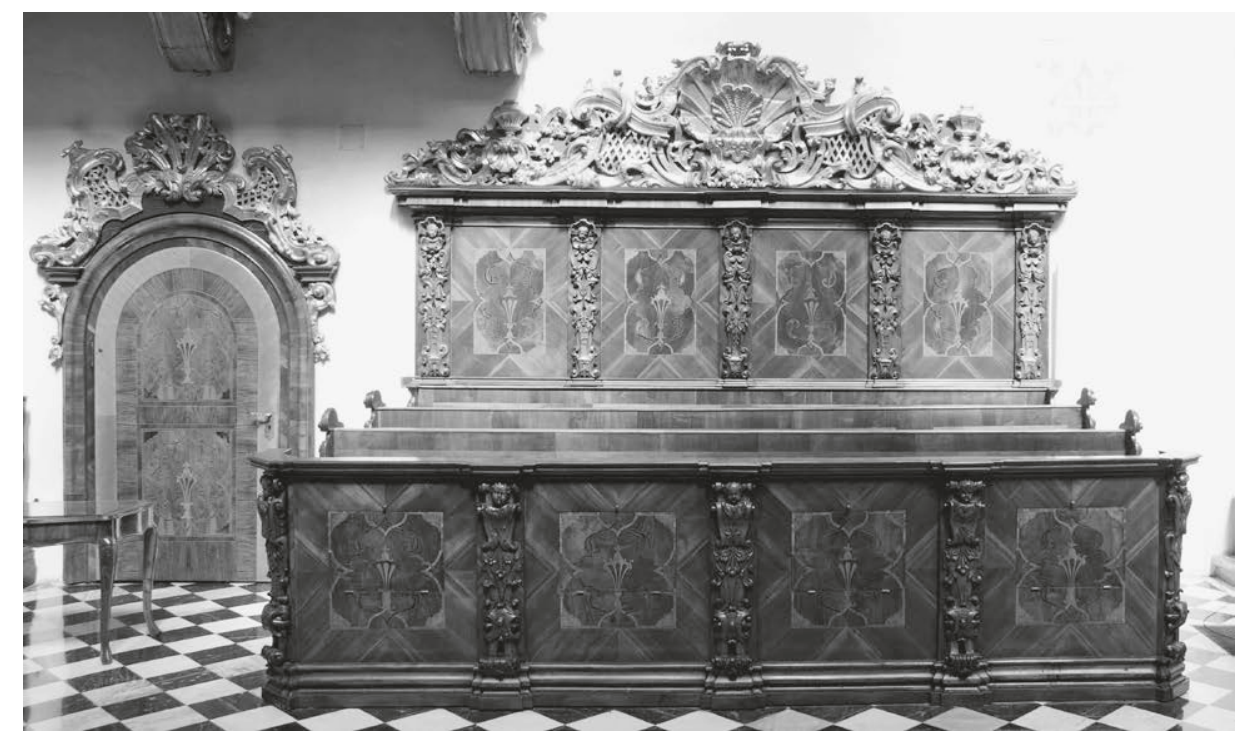

I 57 Domherrengestühl. Ordenstischlerei, der Schnitzaufsatz verm. von Philipp Jakob Straub, I738. Im Hintergrund die Tür zur Barbarakapelle.

Von vergoldeten Schnitzarbeiten bekrönte Türen im zweiten Chorraumjoch führen zur Sakristei bzw. zur Barbarakapelle (Abb. 157) ${ }^{274}$ Friese wahrscheinlich aus Obstund Olivenholz sowie eine breite Palisanderader rahmen die Füllungen, in denen geschwungene Adern schlanke Pokale säumen. Ihre außergewöhnliche Gestaltung basiert ebenfalls auf Ornamententwürfen Bérains. ${ }^{275}$ Fuß und Anlauf setzen sich aus Blütenkelchen zusammen, die sich nach unten bzw. nach oben hin öffnen. Der obere legt sich als Manschette um ein aus langgezogenen Godronen bestehendes Gebilde, den Abschluss formt eine weitere Blüte.

In Schriftquellen können die Türen zwar nicht sicher nachgewiesen werden, doch deuten Gründe der Stilkritik auf eine Entstehung um I738, da die Marketerien der Füllungen mit jenen des im Anschluss besprochenen Chorgestühls übereinstimmen. Offensichtlich wurden sie nach einer einzigen Vorlage geschaffen. Die Autoren des Dehio-Handbuchs gehen davon aus, dass der Schnitzaufsatz über den Türen von Philipp Jakob Straub stammte. Falls Straub, wie angenommen wird, jenen des Chorgestühls verfertigte, dürfte der Bildhauer tatsächlich auch für die Herstellung der Türbekrönungen verantwortlich gewesen sein.

274 Dehio, Graz (1979), i 8.

275 Berliner/Egger, Vorlageblätter ( 98 I), Bd. I, 93-94, Bd. 3, Abb. I I 37. Das Blatt entstand um I 700. 

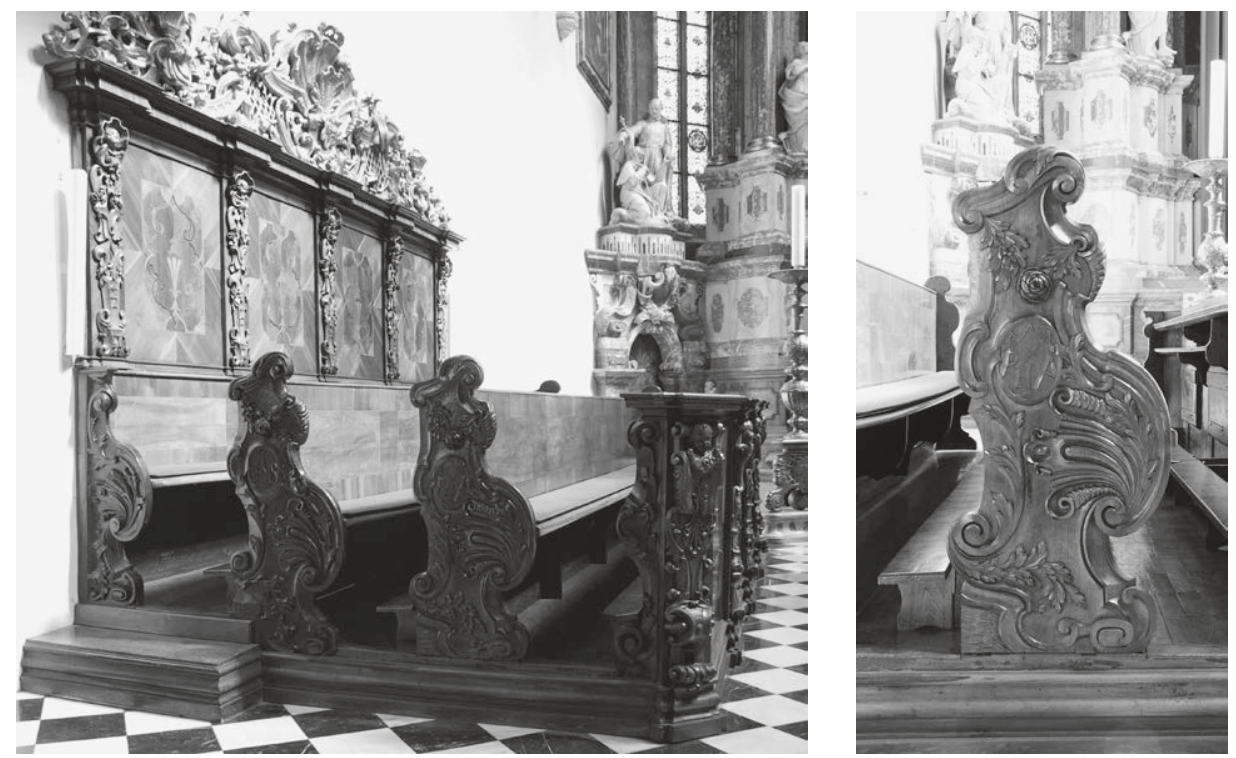

I 58 Domherrengestühl, Seitenansicht. Ordenstischlerei, I 738

I59 Domherrengestühl, Bankwange. Ordenstischlerei, I 738

\section{Domberrengestühl}

Ordenstischlerei und Bildschnitzer Philipp Jakob Straub (?), Vergolder Franz Anton Ramschüssl, I 738

HS I $5 \mathrm{~cm} / 24 \mathrm{~cm}$

$\mathrm{H}$ gesamt $325 \mathrm{~cm}(+24 \mathrm{~cm}) \times \mathrm{L} 460 \mathrm{~cm}$

Nuss, Nussmaser, Nuss geschwärzt, Olive, Ahorn, graviert, weitere Holzarten, Nadelholz, Eiche, Holz vergoldet

Das Gestühl umfasst insgesamt sechs Bankreihen (Abb. I 57-I59). ${ }^{276}$ Beim Bau der Vorderwände, in denen einige Resevesitze verborgen sind, rezipierten die Tischler die Großform des Laiengestühls. Wieder flankierten sie die Füllungen mit Stützen, erneut ordneten sie die äußeren diagonal an. Allerdings sind die Stützen nun mit Bögen und Voluten stärker nuanciert. Den Abschluss bildet jeweils ein Cherubskopf, der sich zusammen mit seitlichen Schnecken zu einem stilisierten ionischen Kapitell fügt. Eine

276 Kohlbach, Dom (r 948), 22 2; Schnell, Dom (r 969), 8; Dehio, Graz (r 979), I 8; Steinböck, Domkirche (1989), 47. 


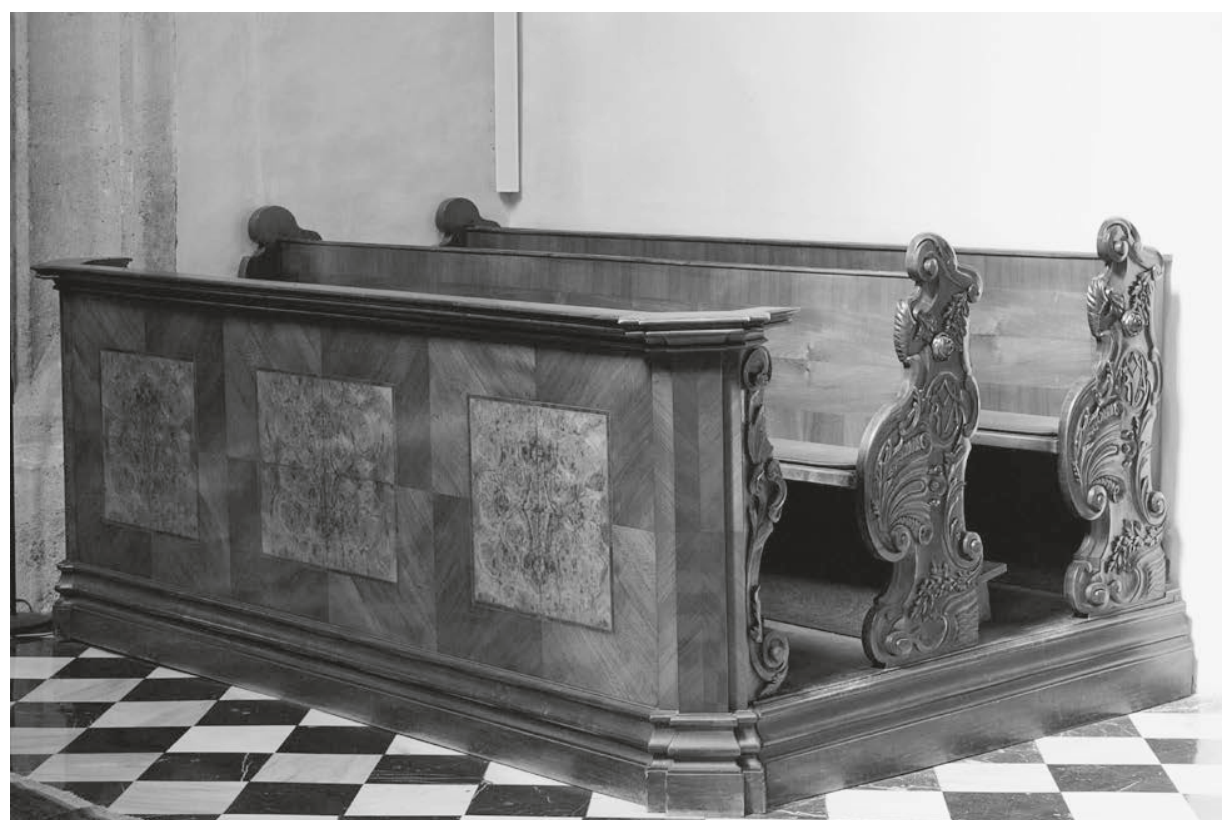

I6o Gestühl. Ordenstischlerei, um 1738

ähnliche, aber weniger detailreiche Ausführung begegnet am Chorgestühl des Stiftes Rein ein zweites Mal (Abb. 237-239).

Deutlich unterscheiden sich dagegen die Wangen des Domherrengestühls von jenen der Kirchenbänke. Die Konturen der Docken des Domherrengestühls sind akzentuierter und weniger verschliffen, die Bögen markanter und stärker gegeneinander abgesetzt. Schnitzarbeiten schmücken auch diese Wangen. Sich an den Enden einrollende Bänder säumen die Kanten, während ein großflächiges Palmetten- oder Muschelmotiv den Bauch bedeckt. Darüber ist ein Hochoval mit den Monogrammen Christi und Mariens ausgespart, außerdem zieren Blütenfestons die Docken.

In Ornamentmotive aufgelöste und mit Cherubsköpfchen endende Stützen rastern zusammen mit Sockelleiste und reduziertem Gebälk auch die Gestühlsrückwand. Furnierte Flächen liegen zwischen den Pilastern, Marketerien, die denen an den Türen des Chorraums gleichen, zieren das Zentrum. Ein aufwendig geschnitzter Auszug bekrönt die Möbel. Er besteht aus übereinander geschichteten Bändern, aus Blütengirlanden, Akanthusblättern und Gitterwerk. Ein großes Muschelmotiv betont das Zentrum. Die hohe künstlerische und handwerkliche Qualität des Aufsatzes belegt, dass ein Bildschnitzer ersten Ranges mit seiner Herstellung beauftragt war, vermutlich handelte es sich um Philipp Jakob Straub. Nach den Recherchen von Rochus Kohlbach wurde das 


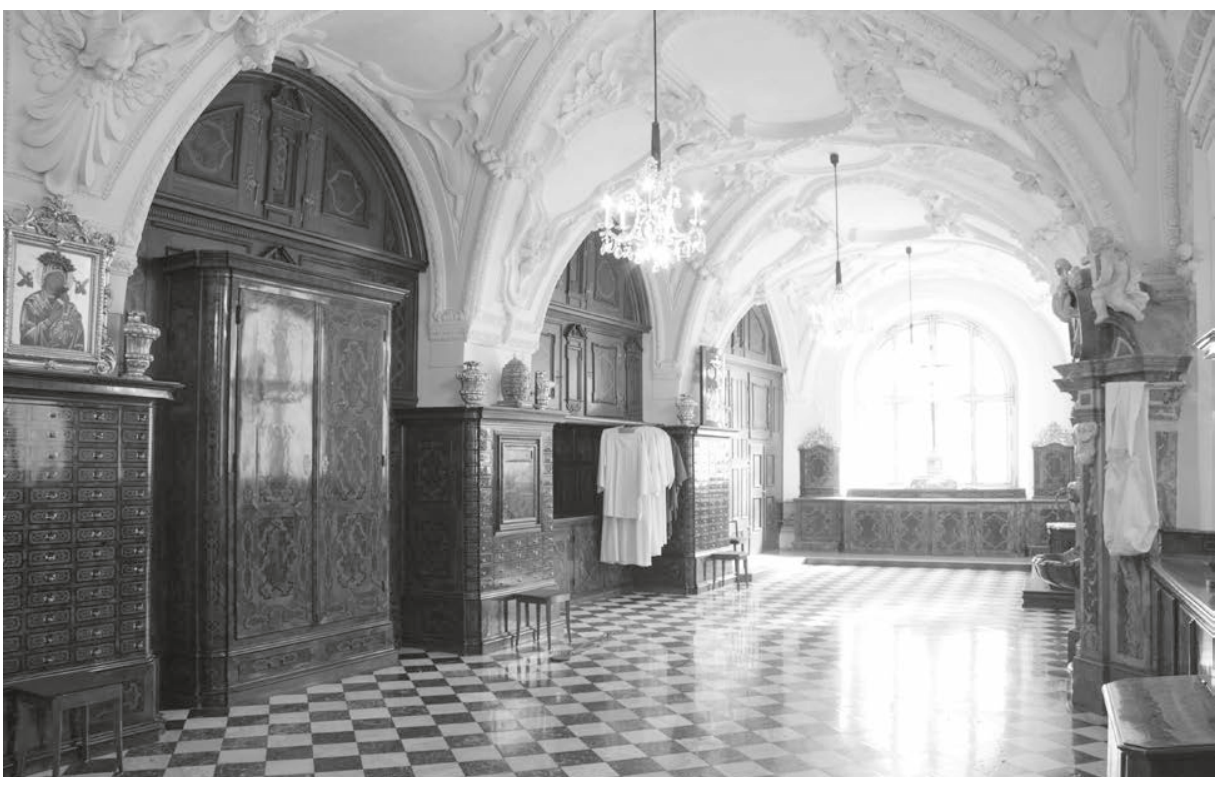

I6 I Sakristei, Blick nach Osten

Chorgestühl I 738 geliefert, der Bildhauer, also wohl Straub, erhielt für seine Arbeit 440 fl. Die Vergoldung übernahm Franz Anton Ramschüssl um 8 o fl. ${ }^{277}$ Der Laufboden besteht aus Eiche, die Sitzbänke fertigte man aus Nuss.

Zusammen mit dem Gestühl wurden einige Bankreihen geschaffen, die am Westende des Chorraums stehen (Abb. I6o). Ein Dorsale fehlt, die Brüstungen sind wesentlich einfacher, doch sind sie mit Wangen ausgerüstet, die jenen des Domherrengestühls entsprechen.

\section{Sakristei}

Die vierjochige Sakristei ist von der Südseite des Chors aus zu betreten. ${ }^{278}$ Dem nach I6 I4/I 5 mit einer Länge von gut I 8, o0 m errichteten Trakt dürfte ein Entwurf Giovanni Pietro de Pomis ( $569-$ r633) zugrunde liegen. Licht fällt durch große Fenster in der Süd- und Ostseite, kräftige Stuckarbeiten, die vermutlich Mattias Camin († I 673) um r66o schuf, zieren das Tonnengewölbe. Eine Tür im ersten westlichen Joch der

277 Kohlbach, ebd.; Steinböck, ebd.

278 Kohlbach, ebd., 54-58; Schnell, Dom (1969), I2; Dehio, Graz (1979), 23; Steinböck, ebd., 33-34. Ursprünglich lag die Sakristei nördlich des Chors, der Raum wurde zur Barbarakapelle umgestaltet. 
Nordseite verbindet die Sakristei mit dem Chorraum, zwischen die Pfeiler der anderen drei Travéen fügten die Tischler Schränke ein, von denen nur der östliche vollständig erhalten ist (Abb. I6I, I62). Ein Großteil der Füllungen dieses Möbels besitzt schlichte Rechteckform, einige sind mit ausspringenden Ecken versehen, eine kleine Ädikula schmückt das Bogenfeld. Die ausschließlich dem Formenschatz des Beschlagwerks entlehnten Ornamentformen, die das welsche Fenster bereichern, sowie die an der Möbelfassade angebrachten metallenen Beschläge lassen an eine Datierung der Wandschränke bald nach der Errichtung der Sakristei denken. Um I 720 wurden sie gefasst, aufgemalte Adern imitieren eingelegte Bandlwerkstrukturen.

Etwa gleichzeitig mit der Arbeit der Fassmaler erhielt die Sakristei neues, überaus reizvolles Mobiliar. Die nördlichen Wandpfeiler ummantelte man mit niedrigen Schränken (Abb. I6I, I64), im zweiten Joch stellte man

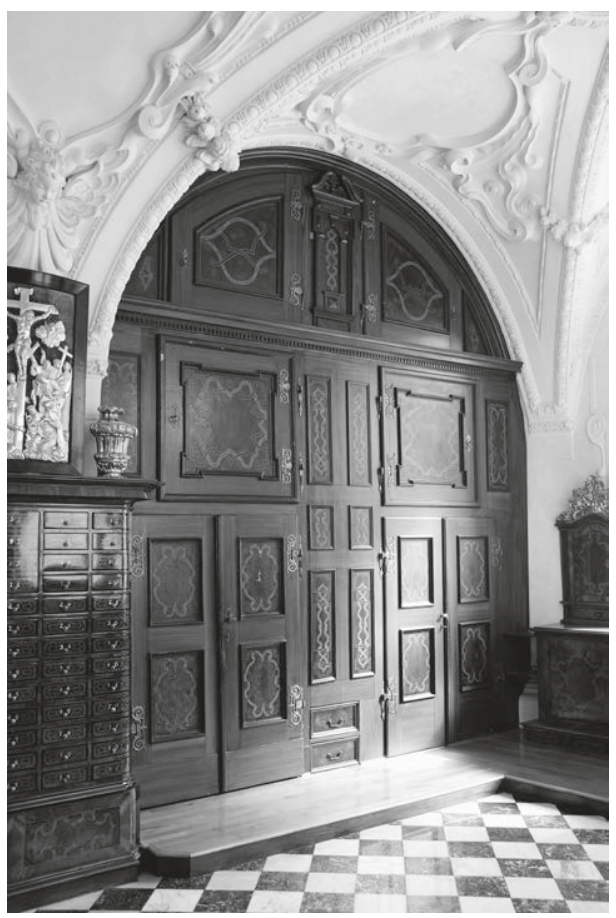

I62 Sakristei, Paramenten- und Schatzkammerschrank. Graz, um I620/30 einen großen Schatzkammerschrank auf(Abb. I63), im dritten eine Aufsatzkredenz mit Kelchfächern und einer tiefen Nische zum Auslegen von Paramenten. Halbschränke, die einige Kelchkästen und einen flachen Aufsatz mit Schubladen tragen, füllen die Fensternischen, vor den Fensterpfeilern befinden sich Kniebänke (Abb. I6 I, I65).

\section{Schatzkammer-oder Paramentenschrank vor der Nordwand}

H ca. $299 \mathrm{~cm} \times$ B I 8 I cm

3 niedrige Schränke vor den Pfeilern der Nordwand

$\mathrm{H}_{2} \mathrm{I} 5 \mathrm{~cm} \times \mathrm{B}$ I $45 \mathrm{~cm} \times \mathrm{T} 79 \mathrm{~cm}$

Aufsatzkredenz vor der Nordwand

$\mathrm{H}_{2} \mathrm{I}_{5} \mathrm{~cm} \times \mathrm{B}_{3} \mathrm{I}_{4} \mathrm{~cm} \times \mathrm{T} 63,5_{3} \mathrm{~cm}$ 


\section{Halbschrank mit Aufsatz vor der Ostwand}

HS I I, $5 \mathrm{~cm}$

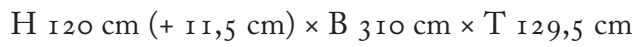

\section{Kniebänke vor der Ostwand}

HS I I, $5 \mathrm{~cm}$

$\mathrm{H} 2 \mathrm{I} 8 \mathrm{~cm}(+\mathrm{II}, 5 \mathrm{~cm}) \times \mathrm{B} 76 \mathrm{~cm} \times \mathrm{T} 68 \mathrm{~cm}$

\section{Halbschränke mit Aufsatz vor der Südwand}

$\mathrm{H}$ I $22 \mathrm{~cm} / \mathrm{I}_{32,5} \mathrm{~cm} \times \mathrm{B} 278 \mathrm{~cm} \times \mathrm{T} 97,5 \mathrm{~cm}$

\section{Kniebank vor der Südwand}

$\mathrm{HS} 20 \mathrm{~cm}$

$\mathrm{H} 250 \mathrm{~cm}(+20 \mathrm{~cm}) \times \mathrm{B}$ 106 cm

Ordenstischlerei, um I 720/23, Bildschnitzer Philipp Jakob Straub, I746/47

Nuss, Nussmaser, Olive, geschwärztes Holz, Ebenholz, furniert auf Nadelholz, Holz vergoldet und gefasst. Messing, vergoldet, Elfenbein, Perlmutt, Eisen geschwärzt

Die Großformen der Möbel sind relativ schlicht, auf Säulen, Pilaster oder andere tektonischen Strukturelemente wurde verzichtet. Die Konstruktion des hohen Schatzkammerschranks (Abb. I63) entspricht der eines profanen Kleiderschranks, während die niedrigeren Möbel (Abb. I6r) vor der Wand zur Kirche eine Mischung aus Schrank und Schubladenkasten darstellen. An den Fassaden dieser Möbel sorgen Furnierbild und Messingknöpfe für die irreführende Annahme, dass die Kästen ausschließlich Schubladen bergen. Stattdessen verschließen auch kaum in Erscheinung tretende Türen die Möbel. ${ }^{279}$ Nur am mittleren Exemplar (Abb. I 64) hoben die Tischler eine große Schranktür optisch hervor. Mit ihrer Beschriftung und den Vorbohrungen zum Einstecken kleiner Knöpfe diente sie einst als Hinweistafel für die Geistlichen zum Organisieren der Gottesdienste. Die Möbel schließen mit einem kräftigen Gesims. Front und Stirnseiten der Kästen verlaufen gerade, lediglich die nach innen verkröpften und abgerundeten senkrechten Außenkanten bringen etwas Bewegung in die statisch komponierten Fassaden.

279 Dies geht möglicherweise auf eine moderne Umgestaltung der Möbel zurück. Kohlbach, ebd., 5 8, berichtet lediglich von I68 »Lädchen« für die Kelchwäsche der Zelebranten. Türen und größere Fächer erwähnt er nicht. 


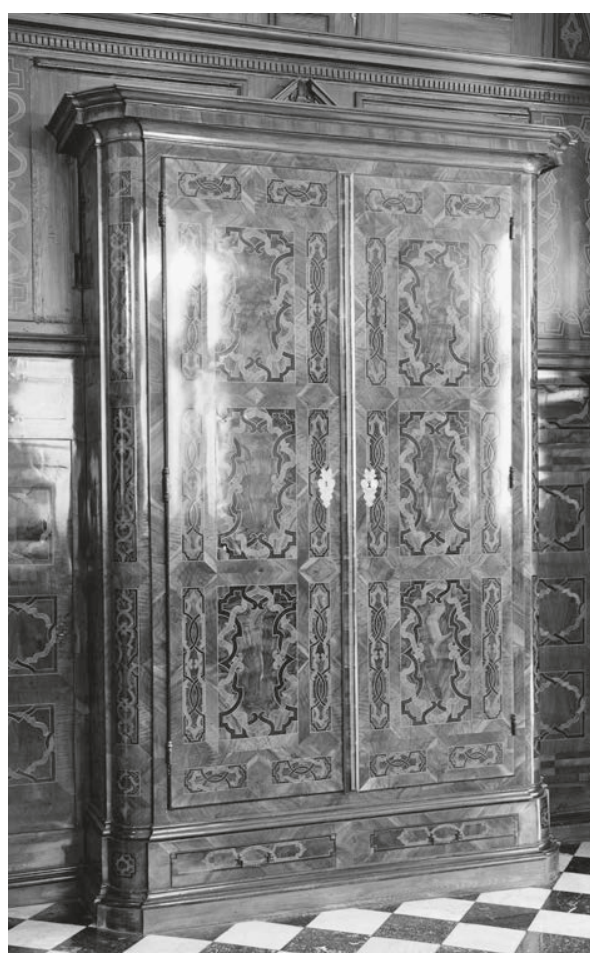

I63 Paramentenschrank. Ordenstischlerei, I $720 / 23$
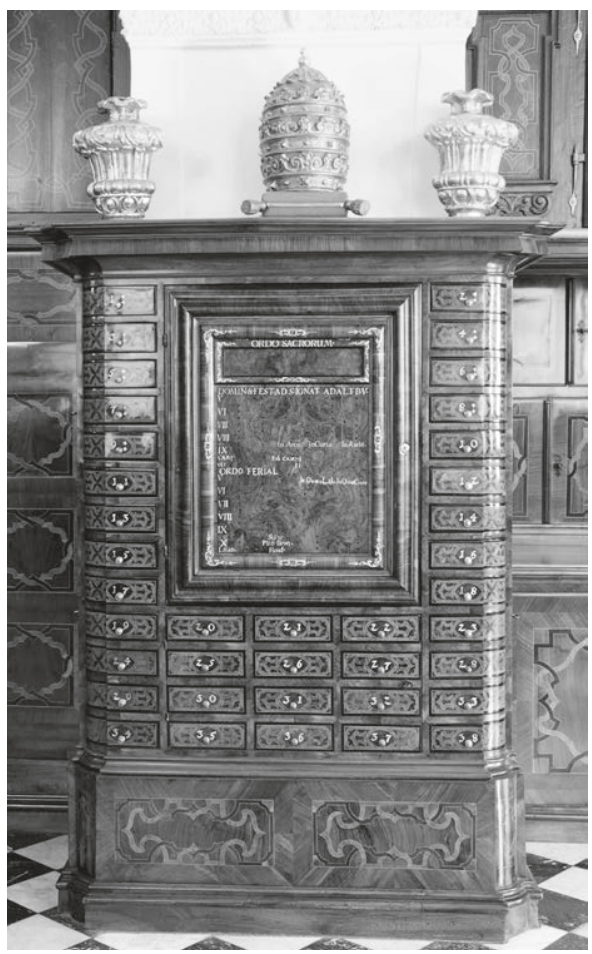

I64 Sakristeimöbel. Ordenstischlerei, I $720 / 23$

Während eine ähnliche Gestaltung die Möbel in den Fensternischen und den Schatzkammerschrank charakterisiert, zeigt sich die Gesamtdisposition der Kniebänke belebter (Abb. I 65). Ein tiefer Sockel trägt dort jeweils eine Kredenz sowie einen flachen Schrank bzw. einen Rahmen mit einem Andachtsbild, Auszüge bekrönen die Möbelstücke.

Den vergoldeten und zum Teil grau gefassten Schnitzarbeiten stehen die nussbaumfurnierten Kastenmöbel mit ihren erlesenen Marketerien gegenüber. Das Furnierbild zeigt verschiedenfarbiges und miteinander verkettetes Bandlwerk. Dabei ist die Aufteilung der Türblätter des Schatzkammerschranks bemerkenswert, da sie noch Füllungen gleicher Größe besitzen, was eigentlich für frühe Türen mit einer dreigeteilten vertikalen Aufteilung kennzeichnend ist. ${ }^{280}$ Die Verwendung kostbarer Werkstoffe wertet

280 Im ersten Band der Studie wurde bereits auf diese Besonderheit hingewiesen. Bohr, Sakralmöbel (2017), 63-64. Der entsprechende Abschnitt bezieht sich auf Zimmertüren, trifft vermutlich aber ebenso auf die Gestaltung von Schranktüren zu. 


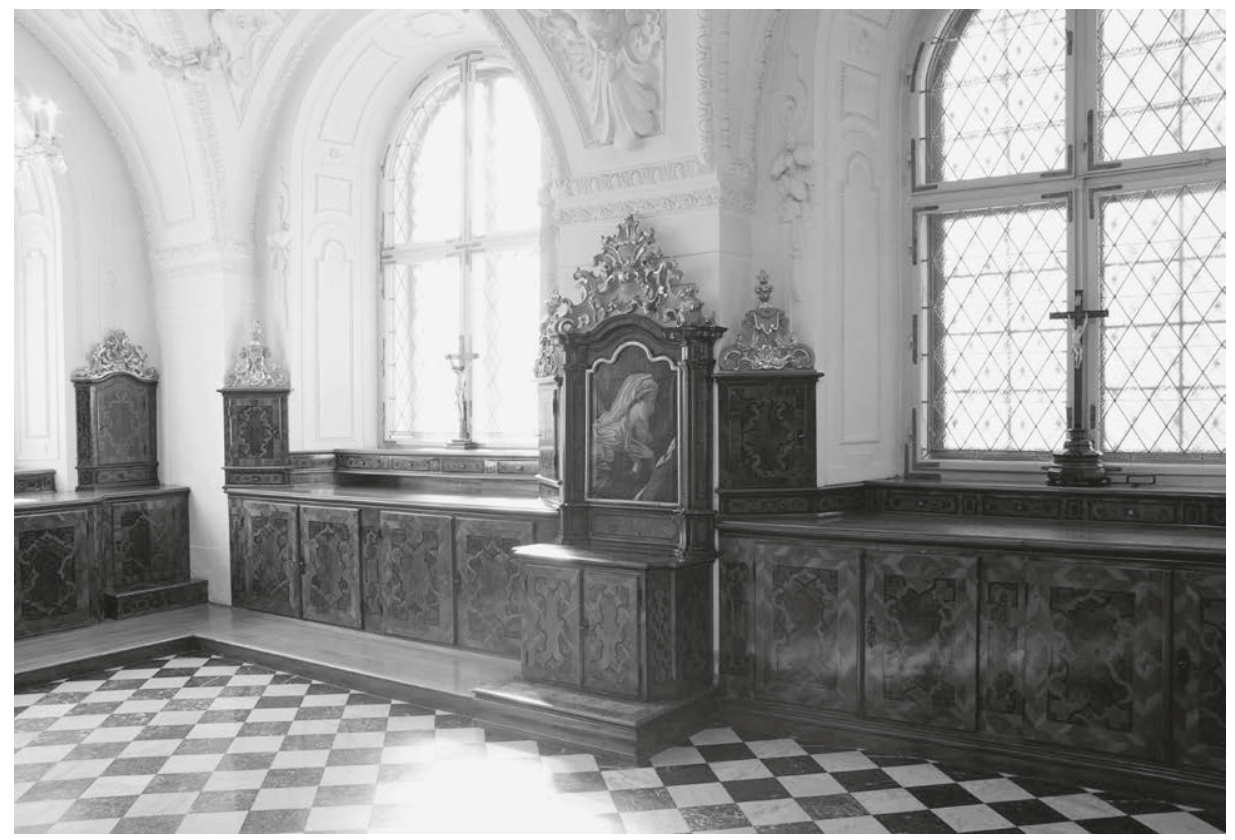

I65 Sakristei, Ausstattung, Ordenstischlerei, I720/23, die Schnitzaufsätze von Philipp Jakob Straub I $746 / 47$

die Möbel zusätzlich auf: In die Fassaden der niedrigen Möbel vor der Nordwand sind als exotische Materialien Perlmutt und Elfenbein eingelegt, die Beschläge bestehen aus vergoldetem Messing und geschwärztem Eisen.

Während Mobiliar jener Zeit häufig geschwungene Vorderseiten besitzt, zeichnen sich diese Stücke durch weitgehend gerade verlaufende Fassaden und plane Oberflächen aus. Etwas jüngere Möbel in Wien, das Mobiliar der Domherrensakristei von St. Stephan etwa oder das der Prälatensakristei des Schottenstiftes, weisen ähnliche Charakteristika auf. ${ }^{281}$ Tatsächlich fiel in jene Zeit eine kurze Periode, in der man strengen Großformen den Vorzug gab. Die Fronten späterer Möbel wurden normalerweise wieder in Schwingung versetzt.

Dank verschiedener Einträge in den von den Jesuiten geführten Rechnungsbüchern kann die Anfertigung der Möbelausstattung nachverfolgt werden. Am I6. März I72 I wurden den arcularijs domesticis pro constructione armarium sacristia $\mathrm{I}_{4}$ Gulden und 34 Kreuzer ausgehändigt. Die festangestellten Tischler der Gesellschaft Jesu erhielten einen Grundlohn, zu dem offensichtlich eine Vergütung für die von ihnen durchge-

28 I Bohr, ebd., 232-235, 242-245. 
führten Arbeiten hinzukam. ${ }^{282}$ Und am 9. Mai ${ }^{1} 723$ waren für 168 nodis ex auricale chonauratis ad nova armaria sacristia 33 Gulden und 36 Kreuzer zu entrichten. ${ }^{283}$ Die Möbel müssen damals vollendet worden sein, gebaut hatten sie die in der Haustischlerei beschäftigten Handwerker. Außerdem finden die Schnitzaufsätze in den Schriftquellen Erwähnung. Sie stammen aus dem Atelier Philipp Jakob Straubs, der die Bildhauerarbeiten für die Kniebänke um I 746 und für die Kelchkästen im folgenden Jahr fertigte. ${ }^{284}$ Der Zierrat zeigt nur wenige Rocaillen, vor allem Bögen, Voluten, einige Blattformationen, außerdem Schabracken und Flammenvasen. Im Gegensatz zu vielen Schnitzarbeiten der Zeit sind diejenigen Straubs kaum durchbrochen, stattdessen ließ er die Räume zwischen den Ornamenten als geschlossene Flächen bestehen. Vergoldungen hellen besondere Stellen der grau gefassten Auszüge auf. Auch das unterscheidet sie von etlichen zeitgleichen Arbeiten.

Das Sakristeimobiliar wurde Anfang des 2 I. Jahrhunderts restauriert, vor einigen Jahren erneuerte man die Inneinrichtung des Möbels in der südöstlichen Fensternische. ${ }^{285}$

\section{Graz, Franziskanerkloster}

\section{Kloster- und Pfarrkirche Mariä Himmelfahrt}

Seit I239, dem Gründungsdatum des Klosters, findet die Präsenz der Franziskaner in Graz ihren Niederschlag in Archivalien. ${ }^{286}$ Die Errichtung der Architekturanlage bei einer Murbrücke am Stadtrand ging rasch vonstatten, denn bereits Anfang der vierziger Jahre war das Kloster Gastgeber eines Provinzialkapitels der österreichischen Minoriten. Der erste Kirchenbau wurde im fortgeschrittenen I3. Jahrhundert ausgeführt, im folgenden Säkulum errichtete man den Anbau des Langchores. Für das frühe I6. Jahrhundert ist die Umgestaltung des Langhauses in eine dreischiffige Hallenkirche nachgewiesen, weitere, weniger schwerwiegende Eingriffe in den architektonischen Bestand kamen auch in jüngerer Zeit immer wieder vor. 1783 wurde die Kirche zur Pfarrkirche bestimmt. In die Jahre zwischen I 86 I und I 886 fiel die Regotisierung eines Teils der Kirchenausstattung.

282 Da entsprechende weitere Einträge fehlen, handelte es sich bei dem Betrag wahrscheinlich nicht um einen Teilbetrag.

283 Diözesanarchiv Graz, XX-C-1o, Gebundene Quellen, Rechnungsbuch Jesuiten Bd. 2, unter dem Stichwort »Fab[ro]«.

284 Dehio, Graz (1979), 23.

285 Freundlicher Hinweis von Prälat Heinrich Schnuderl.

286 Kohlbach, Gotische Kirchen (I950), 91-I 18; Dehio, Graz (1979), 33-39; Attems/Koren, Kirchen ( I 988), 20-2 I ; Kölb1/Resch, Wege (2002), 96-ıо ; Zündel, Franziskanerkirche (2005). 

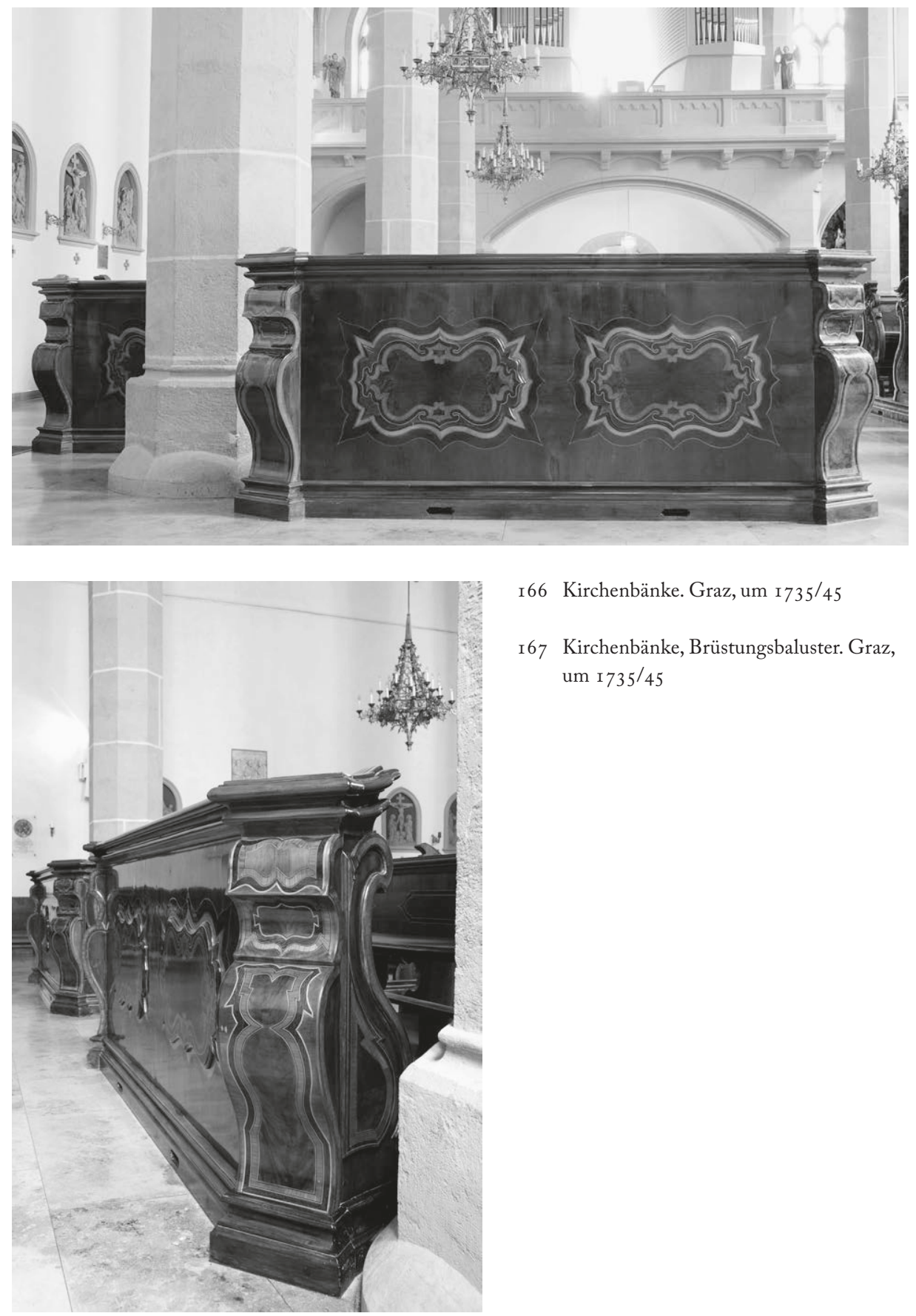

I66 Kirchenbänke. Graz, um 1735/45

I67 Kirchenbänke, Brüstungsbaluster. Graz, um $1735 / 45$ 
Kirche

Laiengestübl

Graz, um I 735/45

HS $16,5 \mathrm{~cm}$

$\mathrm{H}$ io6, $5 \mathrm{~cm}(+\mathrm{r} 6,5 \mathrm{~cm}) \times \mathrm{L} 470 \mathrm{~cm}$

Nuss, Nussmaser, Palisander, Ahorn, Kirschbaum, Eibe, geschwärztes Holz, Nadelholz

Die Bestuhlung der Franziskanerkirche ruht auf vier Podesten und reicht vom Mittelschiff bis in die Seitenschiffe (Abb. I66, I67). ${ }^{287}$ Hinten stehen I 4, vorn I6 Bänke, hinzu kommen die zugehörigen Brüstungen. Die beiden östlichen Bankreihen grenzen an Kirchenpfeiler und sind daher kürzer als die anderen Möbel, erst die dritte Reihe besitzt die volle Länge. Schräg angeordnete, massive Eckstützen säumen die Brustwände. Eine durchgehende Fläche, die Bossen auflockern, füllt den Zwischenraum. Wie dies an den um drei Jahrzehnte älteren Bänken der Grazer Domkirche (Abb. I 52 ) zu beobachten ist, besitzen die Bossen auch hier gotisierende Formen. Die aufgesetzten Spiegel gleichen querrechteckigen Vierpässen mit nach außen weisenden Zacken. Die Tischler furnierten sie mit Nussbaummaser und Friesen aus verschiedenen Holzarten. Dagegen zeigt das eher schlichte Nussholzfurnier auf den Rahmen vertikale und horizontale Maserrichtung, wobei die Verbindungsstellen auf Gehrung geschnitten sind. Es entspricht der hohen Qualität der Bänke, dass die Tischler auch die Rückenlehnen aufwendig furnierten.

Ungewöhnliche Gestaltung weisen überdies die Bankwangen auf (Abb. I68). Sie besitzen zwar die in jener Zeit häufig anzutreffende Grundform, doch enden die Konturen mit nach außen weisenden nasenförmigen Gebilden, die wir sonst andeutungsweise nur an den Bankwangen des Gestühls im Gurker Dom von I 735/45 beobachten können (Abb. 36). Die Bänke schließen mit einem verkröpften Gesims, dessen höheres Ende wie üblich nach Osten zum Altar weist. Wie die Brüstungen besitzen die Docken einen zweischichtigen Aufbau. Ein erhabener Fries konturiert die Wangen, die im Mittelfeld ebenfalls eine Bosse tragen. Adern aus dunklem und hellem Holz säumen ein zentrales Feld aus Nuss. Die Gestaltung der Wangen mag ebenfalls auf das Laiengestühl in der Domkirche zurückzuführen sein, doch ist hier die Physiognomie sehr viel weicher angelegt, der Duktus ist ein anderer. Auch damit erinnern die Möbel an die Exemplare aus Gurk.

Kirchenbänke wurden normalerweise in der unmittelbaren Umgebung ihres späteren Standortes angefertigt, da längere Transportwege schon wegen der anfallenden

287 Dehio, ebd., 35 . 


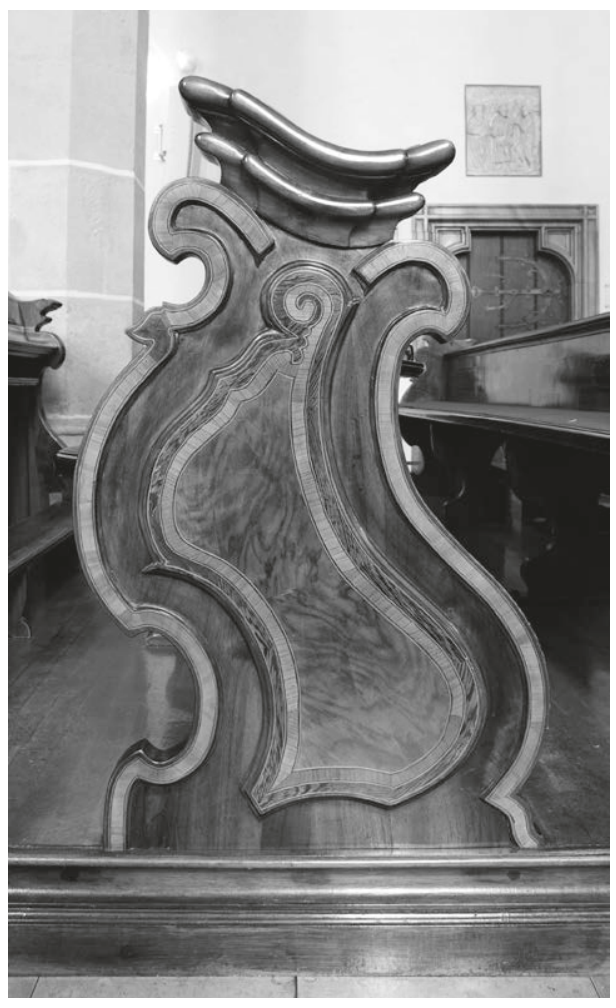

I68 Bankwange. Graz, um I 735/45

Kosten wenig sinnvoll gewesen wären. Tatsächlich verfügte das Kloster zumindest im frühen I8. Jahrhundert über eine eigene Tischlerei, denn Einträge in der Ordenschronik von I7r 8 und I7I9 erwähnen Tischler namens Lazarus, Sydinius und Laurentius. ${ }^{288}$ Das Gestühl wurde 1972 und I982/83 restauriert. ${ }^{289}$ Vermutlich erneuerte man dabei nicht nur die Laufböden, sondern nahm die zum Teil sehr großfächigen Furnierergänzungen vor. Außerdem erhielten die Bänke damals wohl die hochglänzende Lackoberfläche.

\section{Graz, Pfarr- und Wallfahrtskirche Mariatrost}

\section{Ehemaliges Kloster der Pauliner-Eremiten und der Franziskaner}

I669 erwarb Franz Caspar Conduzi von Heldtenfeld auf dem Burgberg (Purberg) das sogenannte Purbergschlössl nebst einer Kapelle, zu der nach einer Wunderheilung eine Marienwallfahrt einsetzte..$^{290} \mathrm{Um}$ I708/o9 übernahm der Orden der Pauliner-Eremiten das Anwesen, das wenige Jahre später die offizielle Anerkennung als Wallfahrtsort erhielt. In der Folge entschloss man sich zum Neubau der Kirche, die Baupläne gehen vermutlich auf Andreas Stengg (I660-I74I) und seinen Sohn Johann Georg (I689-I753) zurück. I7I4 war die Grundsteinlegung, I719 wurde die Kirche nach der provisorischen Aufstellung eines Hochaltars für Eucharistiefeiern geöffnet. I723 konnte die Messe an sieben Altären gelesen werden, I724 war

288 Zündel, Franziskanerkirche (2005), 45, 46.

289 Zündel, ebd., 50. Zur Restaurierung von r 972 vgl. Dehio, Graz ( I 979), 35 .

290 Kohlbach, Barocke Kirchen [I95I], I83-202; Rohrer, Maria Trost (I962); Hootz, Kunstdenkmäler (I965-1968), Bd. 2 (I966), 228-229, 371-372; Woisetschläger/Krenn, Steirische Herrlichkeiten (r 973), 75, Taf. r68; Dehio, Graz (r 979), 220-2 25; Attems/Koren, Kirchen (I 988), 36-38; Berthold, Maria Trost [ca. I 996]; Ruhri, Ursprünge (2000); Thaller, Mariatrost (2000); Kölbl/Resch, Wege (2002), I 89-I 92; Bierbauer, Mariatrost (2005); Rust, Stengg (2009), bes. I47-I63; Bierbauer, Mariatrost (2OII). 
der Rohbau der Sakralarchitektur abgeschlossen. Im Zuge der josephinischen Reformen kam es zur Aufhebung des Klosters, die Kirche ist seitdem selbständige Pfarrkirche. I 846 übernahm der Franziskanerorden die Obhut über die Anlage, seit 1996 befinden sich Pfarr- und Wallfahrtsseelsorge erneut in den Händen der Diözese und weltlicher Priester, 999 wurde die Kirche zur Basilika minor erhoben.

Die eindrucksvolle Doppelturmfassade der Kirche, um die sich auf drei Seiten Klostergebäude gruppieren, ist auf eine grandiose Fernwirkung hin ausgelegt. Dem Sakralbau liegt ein kreuzförmiger Grundriss zugrunde, sechs Seitenkapellen begleiten das einschiffige Langhaus, eine Kuppel überfängt die Vierung, ihr folgt ein langer, halbrund schließender Chor. Seitlich liegen zweigeschossige Anbauten, von denen der südliche als Sakristei, der nördliche als Pauluskapelle Verwendung finden. Die Gewölbefresken gelangten in den I 73oer- und 5oer-Jahren zur Ausführung. Die Entwürfe für den Hochaltar und die beiden Querschiffaltäre zeichnete 1736/37 Lukas von Schram (I702-I 765), der Bau des Hochaltars unter der Leitung des Grazer Bildhauers Joseph Schokotnigg ( $1700-1755)$ fiel in die Jahre I74I bis I752. Wie so oft bei vergleichbaren Bauvorhaben haben sich keine Archivalien erhalten, aus denen die Namen der verantwortlichen Tischler hervorgehen würden. Wahrscheinlich wurden die Arbeiten zumindest teilweise von einer Ordenstischlerei übernommen, andere Aufträge werden an Tischler in der näheren Umgebung, vielleicht auch in der Stadt Graz vergeben worden sein.

\section{Kirchenraum}

4 Türen

Graz, um I $730 / 40$

Lichte Maße H $274 \mathrm{~cm} \times$ B I 5 r cm

Nussbaum, Nussmaser, Ahorn, Mahagoni, furniert auf Nadelholz. Messing

Vier Türen im Chorraum und in den Querhausarmen führen in die Sakristei und in den nördlichen Andachtsraum (Abb. I69, I70). ${ }^{291}$ Joseph Schwath fertigte 1737 die mit Rundprofilen verzierten Marmorumrahmungen, eine Arbeit, für die er mit $320 \mathrm{fl}$ entlohnt wurde. ${ }^{292}$ In der Literatur wird die These vertreten, dass die Tischlerarbeiten etwa gleichzeitig entstanden seien, das trifft vermutlich zu.

Die Aufteilung der beiden Türblätter in Rahmen und drei Füllungen entspricht der seit der Jahrhundertwende üblichen Gesamtdisposition. Allerdings besitzen die

29 I Dehio, ebd., 222.

292 Kohlbach, Barocke Kirchen [195 I], I96. 

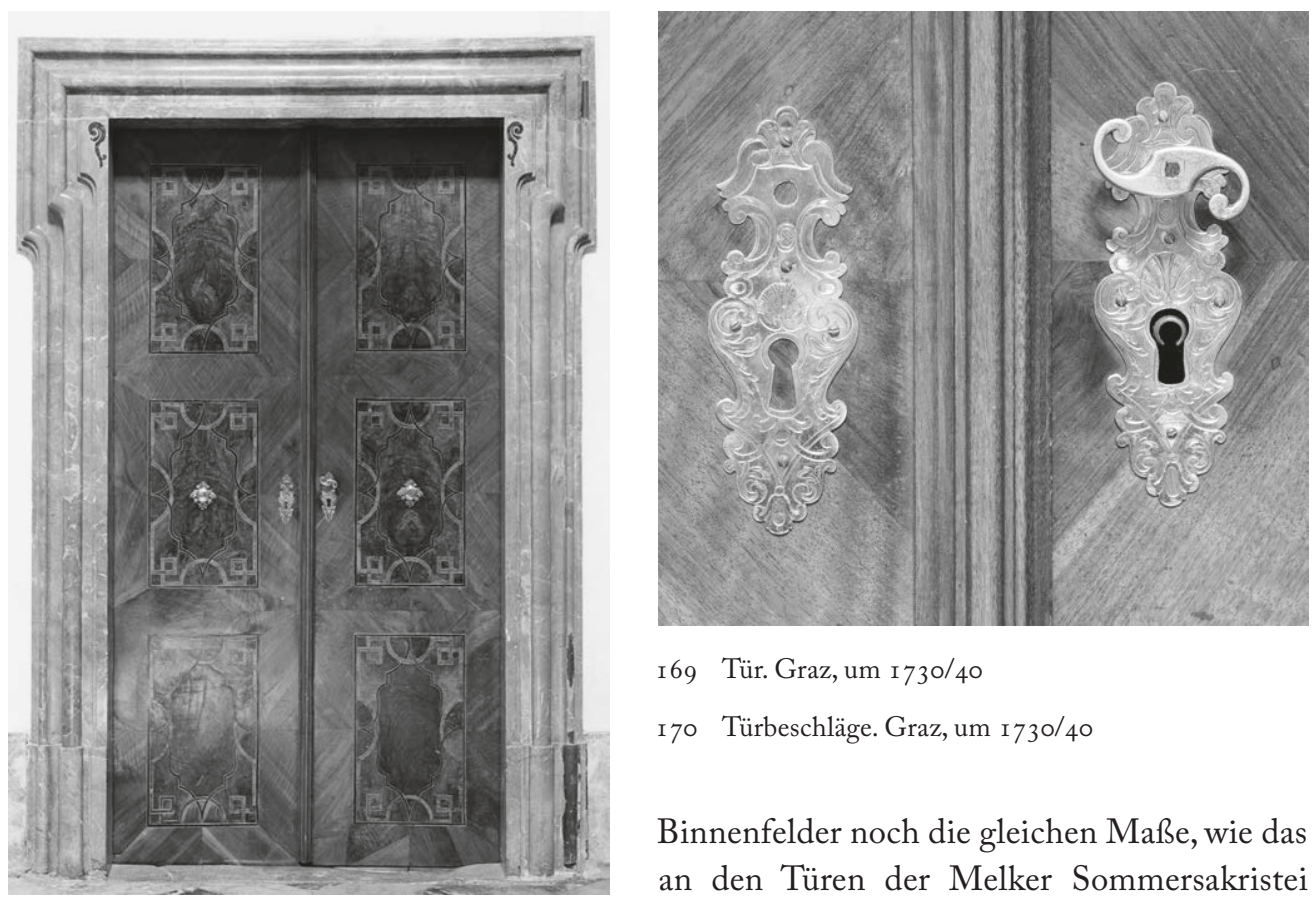

I69 Tür. Graz, um I730/40

I 70 Türbeschläge. Graz, um I $730 / 40$

Binnenfelder noch die gleichen Maße, wie das an den Türen der Melker Sommersakristei von r7or und des Refektoriums im Stift Heiligenkreuz von I 7 I 2 zu beobachten ist. Die jüngere rhythmisierte Form mit Füllungen unterschiedlicher Größe kommt dagegen bereits um I 7 I 9 ebenfalls in Heiligenkreuz vor. ${ }^{293}$ Damit folgt die Gestaltung der Portale in Mariatrost ästhetischen Vorstellungen, die 1737 antiquiert waren. Ein weiterer Punkt, der zu denken gibt, betrifft die Intarsien, denn die mit Einzügen und rechtwinkligen Brechungen versehenen Adern lassen an die Verwendung von Ornamentvorlagen aus dem frühen i 8. Jahrhundert von Jean Bérain d.Ä. (ı637-I7 I I), Paul Decker d.Ä. (ı677-17 I3) oder Johann Conrad Reiff ( $\dagger_{\mathrm{I}}$ 726) denken, in den späten 3 oer-Jahren waren sie nicht mehr modern. ${ }^{294}$ Wie oben erwähnt, war die Kirche seit I 7 I 9 wieder für Besucher geöffnet, die Sakristei muss deshalb verschließbar gewesen sein. Wahrscheinlich wurden Türen damals zunächst nur provisorisch eingesetzt, denn die mit elegantem Laub- und Bandlwerk sowie mit einem frühen Palmettenmotiv dekorierten Messingbeschläge der erhaltenen Sakristeitüren deuten eher auf ein Entstehungsdatum in den I73oer-Jahren. Sie

293 Bohr, Sakralmöbel (2017), 63-64. Zu den Türen in Heiligenkreuz und Melk vgl. ebd., 33 I-334, 4I 44I 5 .

294 Berliner/Egger, Vorlageblätter (I 98 I ), Bd. I, 93-94, 99-I Ioo, Bd. 3, Abb. I I 37, I I 38, I 2 I 2-I 2 I 4 , I 22 I, I 224, I 225 , mit Stichen von Bérain, Decker und Reiff aus der Zeit um I 700-I720. 
lassen sich gut mit den nachfolgend beschriebenen Wangen des Laiengestühls vergleichen (Abb. I74). Die Tischler furnierten die Rahmen mit gestreiftem Nussholz, die Binnenfelder mit Maserholz. Helle Adern begleiten die Füllungen, geschweifte dunkle Bänder verlaufen im Zentrum. ${ }^{295}$

\section{Beichtstüble unter der Empore}

Graz, um I720/30

$\mathrm{HS} 2 \mathrm{I} \mathrm{cm}$

Gesamthöhe ca. $380 \mathrm{~cm}(+2 \mathrm{I} \mathrm{cm}) \times \mathrm{B} 246 \mathrm{~cm} \times$ T $107 \mathrm{~cm}$

Nussbaum, Nussmaser, Zwetschke, geschwärztes Holz, Zinneinlagen, furniert auf Nadelholz, Nadelholz vergoldet und bemalt. Messing

Die Möbel stehen auf einem Sockel, der sich zusammen mit der Fassade der Gehäuse zwi-

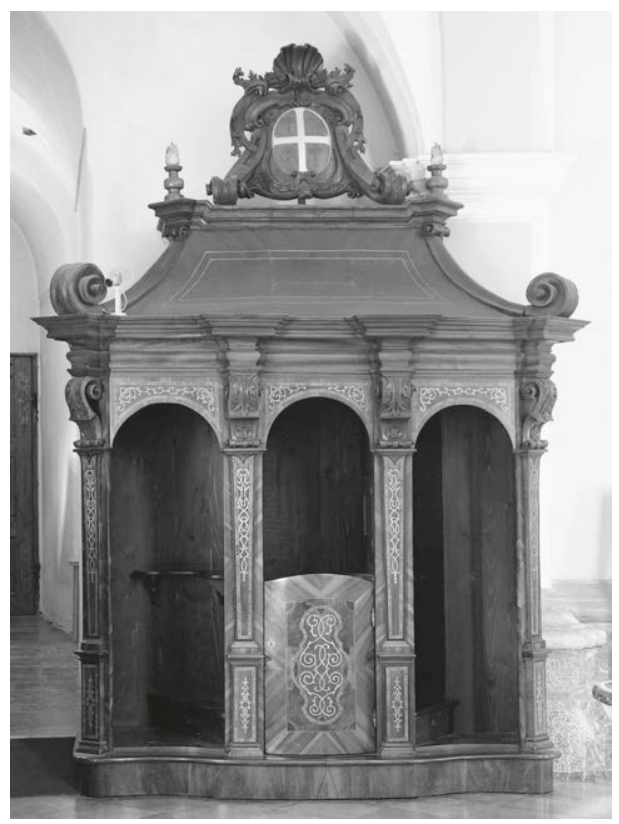

I 7 I Beichtstuhl. Graz, um I720/30 schen zwei flachen konkaven Schwüngen nach vorn in den Raum wölbt (Abb. I 7 I). ${ }^{296}$ Pilaster gliedern die Front, die äußeren Stützen sind schräg angeordnet, Öffnungen mit halbrundem Abschluss gestatten den Zutritt zu den Zellen. Volutenkapitelle tragen ein verkröpftes und reichprofiliertes Gebälk sowie einen hohen Aufsatz, der im Aufriss die Gestalt eines Dreiecks annimmt. Er besteht aus einem unteren trapezförmigen Teil, was den Exemplaren in der Domkirche entspricht, schließt aber mit einer spitz zulaufenden, skulptierten Kartusche. Schwere Liegevoluten, Flammenvasen, sich einrollende Bänder, Laubwerk und eine bekrönende Muschel bilden die Zierelemente des Auszugs.

Entsprechend der Verzierungen an den Möbeln im Dom legten die Tischler in die Flächen über den Arkadenöffnungen, in die Schäfte der Stützen sowie in die Türen auffallend feine und miteinander verkettete Adern ein, denen zarte Blätter entsprießen. Doch anders als in der Metropolitankirche handelt es sich in Mariatrost um Zinnintarsien. Wie das im Kunstraum auf der Alpensüdseite meist der Fall ist, sind die Binnenfelder mit Nussbaummaserholz furniert, die Rahmen mit gestreiftem

295 Vgl. zu den Türen auch die Beschreibung der Tür in der Chorkapelle von Mariatrost (Abb. I77) sowie des Exemplars in St. Andrä (Abb. I8I).

296 Rohrer, Maria Trost (1962), i6; Dehio, Graz (1979), 224. 
Nussholz. Der Aufsatz besteht aus Nussbaum und gefasstem Nadelholz, die zentralen Kartuschen zweier Möbel tragen ein aufgemaltes Kreuz, die beiden anderen das Monogramm Mariens. Im Dehio werden die Schnitzaufsätze mit Vorbehalt Joseph Schokotnigg zugeschrieben. Das ist möglich, da das Kloster den Bildhauer in jener Zeit immer wieder mit Aufträgen bedachte. Mit Schriftquellen belegen lässt sich die Vermutung allerdings nicht. ${ }^{297}$

Die Übereinstimmungen zwischen diesen Möbeln und den Beichtstühlen in der Grazer Domkirche (Abb. I 55) sind frappierend. Die Inventarstücke im Dom entstanden zwischen I707 und I7r9, während in Verbindung mit der Bauchronologie von Mariatrost eine Anfertigung der in der Wallfahrtskirche erhaltenen Exemplare um I 720/30 wahrscheinlich ist. Dabei fällt die Verwendung der Zinneinlagen auf, die sonst an Grazer Möbeln jener Epoche nicht vorkommen. Wahrscheinlich arbeitete damals ein in jener Technik versierter Intarsienkünstler in der ordensinternen Tischlerei.

\section{Beichtstüble in Querschiff}

Graz, um $1735 / 45$

HS I $8,5 \mathrm{~cm}$

$\mathrm{H} 249 \mathrm{~cm}(+\mathrm{I} 8,5 \mathrm{~cm}) \times \mathrm{B} 265 \mathrm{~cm} \times \mathrm{T}$ i $10 \mathrm{~cm}$

Nuss, Nussmaser, Zwetschke, Ahorn, Buchs (?), Holz geschwärzt, furniert auf Nadelholz. Eisen

Unter den leicht gebauchten Pilastern, die die Vorderseite der Beichtstühle strukturieren, wölbt sich der konkav-konvex-konkav geschweifte Sockel nach vorn und unterstreicht so den Grundriss der Möbel (Abb. I 72). ${ }^{298}$ Zugleich lassen diese Wölbungen die Front dynamischer erscheinen, als dies bei Beichtstühlen sonst der Fall zu sein pflegt.

Arkaden öffnen die Vorderseite der Möbel, Wandstreifen mit Keilpilastern definieren ihre Tiefe. Die Arkaden und das verkröpfte Gebälk sind analog zum Sockel in der Tiefe geschwungen, dabei verläuft der Architrav gerade, während das auffallend profilierte Gesims zur Mitte ansteigt, um über der Priesterstalle in einen Segmentbogen überzugehen. Im Gegensatz zu den vorn offenen Gehäusen der Pönitenten schließt eine Tür die Zelle des Geistlichen. Oben enden die arkadenförmigen Eintritte mit geschweiften Bögen, deren mittlerer in der Mitte durchhängt.

Die beiden Möbel sind mit ausgewähltem Nussholz furniert, feine bandartige Adern folgen dem Verlauf der Kanten. Die Tischler legten in die geschlossenen Felder

297 In den Seitenkapellen befinden sich sechs weitere Beichtstühle, die ähnlich konstruiert, jedoch nicht mit einem Aufsatz versehen sind. Vermutlich wurden sie erst im I9. Jahrhundert nach dem Vorbild der Möbel unter der Westempore gebaut.

298 Dehio, Graz (1979), 224. 
I72 Beichtstuhl. Graz, um I $735 / 45$

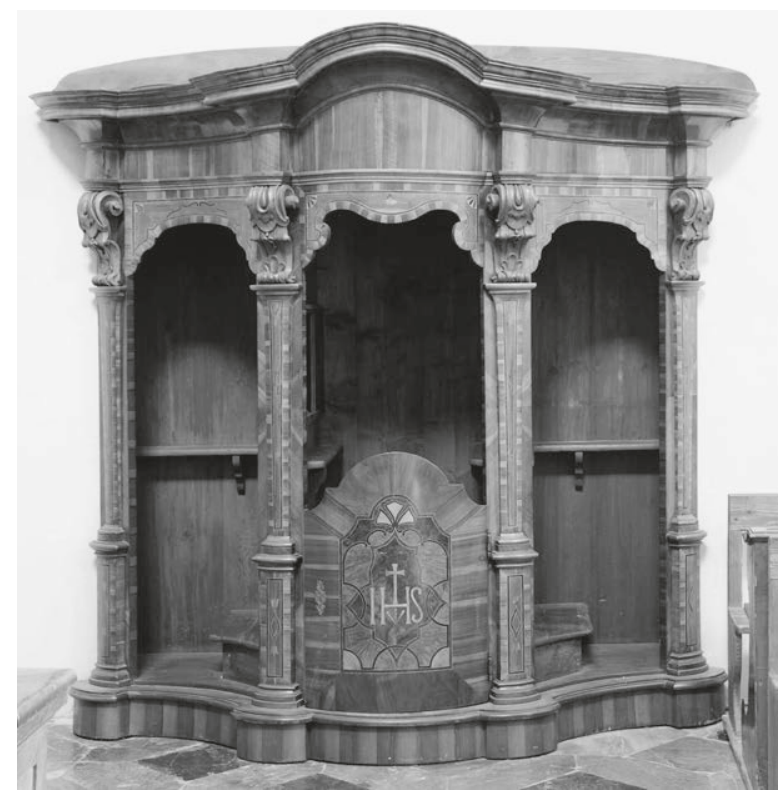

über den Gehäusen sowie in die Pilasterschäfte geometrische Ornamente ein, unter denen fächerartige Motive in den Ecken über den Arkaden hervorstechen. An den Türen kommen miteinander verkettete Bandlwerkstrukturen vor, die an einem Möbel das Christusmonogramm mit Kreuz und Nägeln säumen, am anderen die Buchstabenkombination des Namens Maria. Die Inventarstücke sind in Wandnischen eingesetzt, deren Oberkanten mit einigem Abstand über den Beichtstühlen enden. Blenden aus dunkelgebeiztem Nadelholz verdecken jeweils den Spalt zwischen Möbel und Mauerwerk. Breite Aussparungen im Hut der Beichtstühle deuten darauf hin, dass sie einst mit Auszügen wie die Exemplare unter der Empore oder mit Schnitzaufsätzen wie die nachfolgend beschriebenen Sakristeimöbel versehen waren. Eine ähnliche Konstruktion weist der Doppelbeichtstuhl in der Abtei Rein auf (Abb. 242). Die Holzverschalung der Nische verbirgt sich dort größtenteils hinter dem Schnitzwerk und ist überdies mit Wandfarbe gestrichen.

\section{Laiengestübl}

Graz, um I $730 / 40$

$\mathrm{HS}$ I $6,5 \mathrm{~cm}$

$\mathrm{H}$ IO7 $\mathrm{cm}(+\mathrm{I} 6,5 \mathrm{~cm}) \times \mathrm{L} 293 \mathrm{~cm}$

Nuss massiv, Nussbaum, Nussmaser, Pappelmaser, geschwärztes Holz, Ahorn, furniert auf Nadelholz 


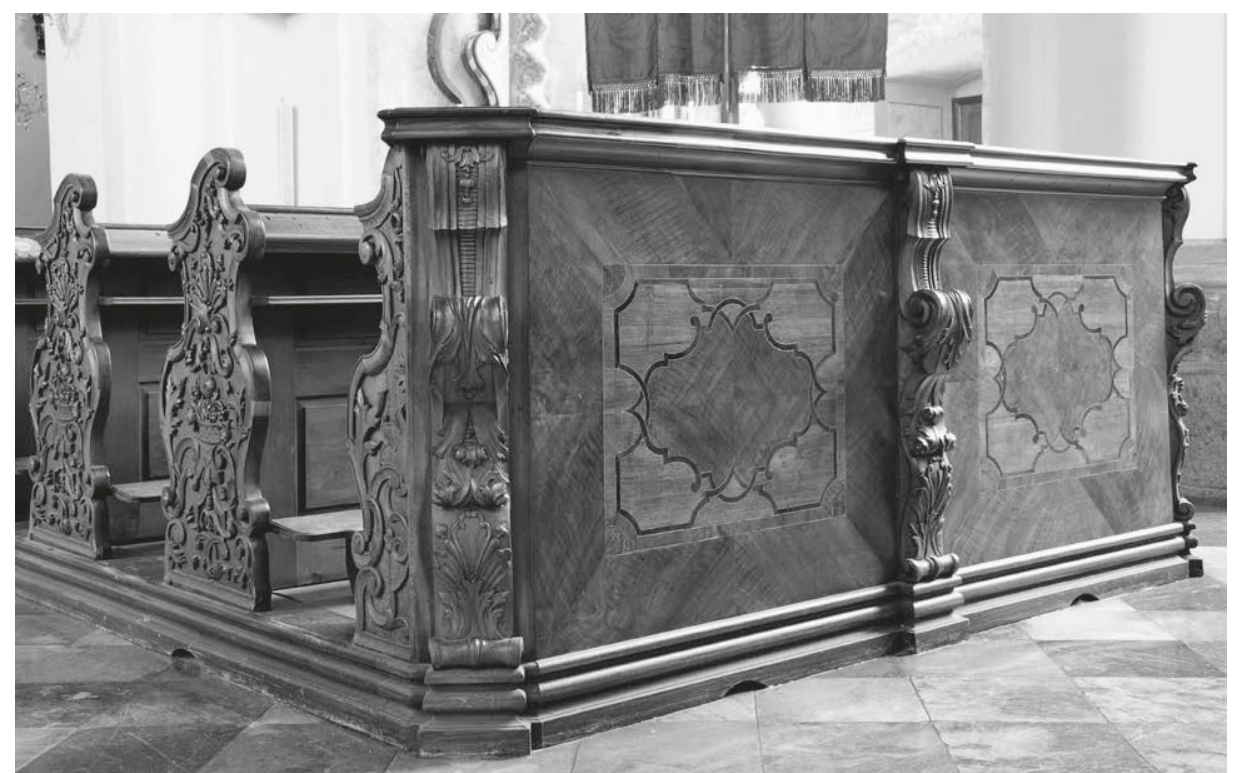

I73 Kirchenbänke. Graz, um I730/40

Die Bänke stehen auf vier mit Halbrundstäben profilierten Postamenten (Abb. I73, I 74). ${ }^{299}$ Vorne befinden sich auf den Laufböden fünf Exemplare, hinten acht. Zu den 26 Sitzreihen kommen noch die vier Vorderbrüstungen.

Massive schrägstehende Baluster flankieren die Brustwände, Vergleichbares lässt sich im Südosten Österreichs häufig beobachten. Ein dritter Baluster, den ebenso wie die anderen starke Schwellungen und Einzüge charakterisieren, teilt die Brüstungen in zwei Travéen. Die Enden der Stützen rollen sich zu Voluten ein, eine weitere, kräftigere formt eine Art von Schulterstück. Reicher Schnitzzierrat legt sich über die Baluster. Oben ist es eine kleine Blütengirlande vor profiliertem und quergeriffeltem Grund, am Schulterstück und darunter sind es Akanthusblätter und abgewandelte Palmettenmotive. Glatte Rahmen und Füllungen schließen die Räume zwischen den Stützen, Furniere aus gestreiftem Nussholz und Nussmaserholz überziehen die Kompartimente. Dunkle Adern, die markant hervorstechen, wurden eingelegt.

Bei stark bewegter Kontur besitzen die Bankwangen einen annähernd symmetrischen Aufbau. Lediglich der obere Abschluss, der aus einem S-Bogen über zwei Voluten besteht, hebt die Symmetrie auf. Kräftige Schnitzarbeiten schmücken die Wangen.

299 Dehio, ebd. 
Entlang der Außenkanten verlaufen breite Profile, dagegen veredeln Bandlwerk, vegetabile Ornamente, Palmettenmotive und Lambrequins die Fläche. Ein Korb mit einem Blumenarrangement nimmt das Zentrum jeder Wange ein. Wie bei vielen grotesken Darstellungen Jean Bérains d.Ä. wird der Korb nicht von einem festen Sockel gestützt, sondern scheint im Raum zu schweben. ${ }^{300}$ Punzen rauen die Grundfläche zwischen den Darstellungen auf, Stoffbehänge und Blumenkörbe sind mit einer Riffelung versehen. Ansonsten besitzen die Schnitzarbeiten eine geglättete Oberfläche, die zwischen hellen, das Licht widerspiegelnden Partien und im Schatten liegenden Segmenten changiert. Stilistisch stehen die Wangen auf einer Stufe mit jenen des Chorgestühls in Stams, das um I 735 entstand.

\section{Sakristei}

Vor der Nordwand der längsrechteckigen Sa-

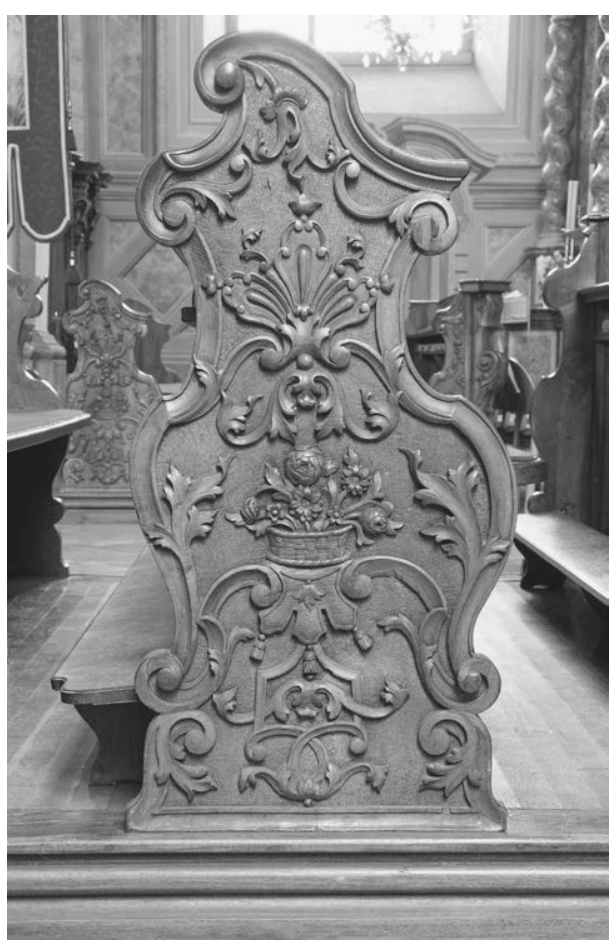

I74 Bankwange. Graz, um I730/40 kristei steht ein langes Aufsatzmöbel, seitlich davon befinden sich zwei neobarocke Kniebänke mit Andachtsbildern (Abb. I 75). ${ }^{301}$ Schmale Schränke vor Fensterpfeilern geben mit Aufbau und Proportion die Rezeption der Gestaltung von Standuhren deutlich zu erkennen (Abb. I76). Die Möbel tragen einen Spiegel in einem geschnitzten Rahmen. Hier im Zusammenhang ist das Aufsatzmöbel von besonderem Interesse.

300 Berliner/Egger, Vorlageblätter (I98 I), Bd. I, 93-94, Bd. 3, etwa Abb. I I 35, I I 37. Die beiden Blätter entstanden um I69o bzw. um I700.

30 I Zu Raum und Ausstattung vgl. Kohlbach, Barocke Kirchen [195 I], r95; Dehio, Graz (1979), 224; Berthold, Mariatrost (20 I I), o. S. Die seitlichen Möbel ähneln dem Kelchkasten, doch sind bei genauer Untersuchung Unterschiede in den Marketerien zu erkennen. Im Dehio werden die Gemälde über den Kniebänken zwar ins I 9. Jahrhundert datiert, die Möbel aber fälschlicherweise ins I 8. Eines der Möbel trägt die Jahreszahl der Fertigung: I 86 I. 


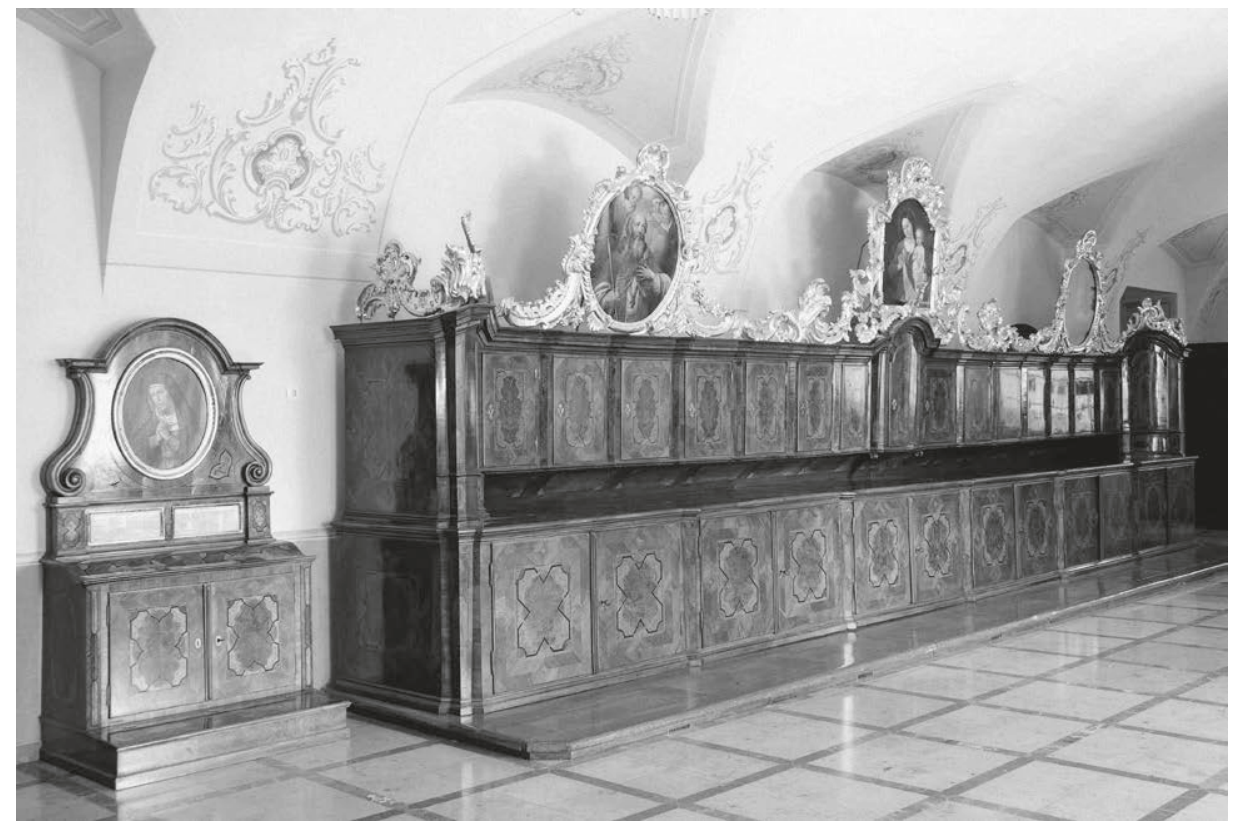

I75 Sakristei, Ankleidekredenz. Graz, I748 und Bildhauer Joseph Schokotnigg

\section{Ankleidekredenz}

Graz, I 748, Bildhauer Joseph Schokotnigg

HS $9,5 \mathrm{~cm}$

$\mathrm{H}_{35} \mathrm{I}, 5 \mathrm{~cm}(+9,5 \mathrm{~cm}) \times \mathrm{L} 990 \mathrm{~cm} \times \mathrm{T}$ i $15 \mathrm{~cm}$

Nuss, Nussmaser, Pappelmaser, Ahorn, Holz geschwärzt, Nadelholz, Holz vergoldet. Messing.

Laufboden aus Eiche

Als Substruktion des Aufsatzmöbels dient eine gleichförmige Reihe zweitüriger Schränke, die keilförmige Baluster über dreieckigem Grundriss voneinander trennen (Abb. I 75). Die Außenkanten des Unterschranks sind abgeschrägt, ihnen sind weitere Stützen vorgelegt. Der außergewöhnliche Rhythmus der Flächen und die eigenartige Form der Baluster wiederholen sich am Aufsatz. Und noch eine Besonderheit charakterisiert das Möbel: Die beiden äußeren Achsen des Oberschranks sind so weit nach vorn geführt, dass seine Stirnseiten nur unwesentlich schmaler als jene der Substruktion sind. Unter den schräg angeordneten und konkav eingezogenen Türen der äußeren Joche liegt ein Sockelgeschoss mit einer Schublade, während die Fächer dazwischen erhöht über der Platte des Unterschrankes ansetzen, eine in jener Zeit übliche Konstruktion. Rundgiebel bekrönen die äußeren Schranksegmente sowie ein tabernakelarti- 
ges Fach in der Mitte des Möbels. Ansonsten verläuft das Abschlussgesims in der Horizontalen gerade, weist aber wegen der dreieckigen Stollen Vor- und Rücksprünge in der Tiefe auf. Verstärkt wird die Tiefenbewegung durch das Faktum, dass der Grundriss der Aufsatzfront mit langen an- und abschwellenden Bögen einer wellenartigen Kurve folgt.

Die hohe Qualität des Möbels zeigt sich nicht zuletzt in den sauber verarbeiteten Marketerien. Die gestreifte Zeichnung des Furniers formt an den Rahmen ein Fischgratmuster, dagegen zieht sich Maserholz über die Füllungen. Das eingelegte Bandlwerk präsentiert auch hier die an österreichischen und süddeutschen Möbeln häufig anzutreffende schlichte Grundform. Insgesamt erinnert das Möbel durch die flächige Gestaltung in Verbindung mit dem Furnierbild an Sakristeimöbel aus den I73oer-Jahren, etwa an jene im Wiener Schottenkloster oder in der Unteren Sakristei des Stephandoms. ${ }^{302}$ In drastischem Gegensatz zum Möbel selbst steht der detailreich geschnitzte und vergoldete Aufsatz. Dort fassen Rahmen drei große Bilder ein, die Maria mit dem Kind sowie die Heiligen Augustinus und Paulus den Einsiedler vergegenwärtigen. Auf Letzteren berufen sich die Pauliner-Eremiten, die das Kloster lange Zeit leiteten, in ihrem Namen. Weite Bögen verbinden die Gemälde untereinander, als Zierelemente kommen Rocaillen, Blütengirlanden, Palmettenmotive und Blattwerk vor. Joseph Schokotnigg schuf den Schnitzaufsatz i748. Weil der Grazer Bildhauer an Rokokoformen anknüpfte, die un-

302 Bohr, Sakralmöbel (201 7), 232-235, 242-245.

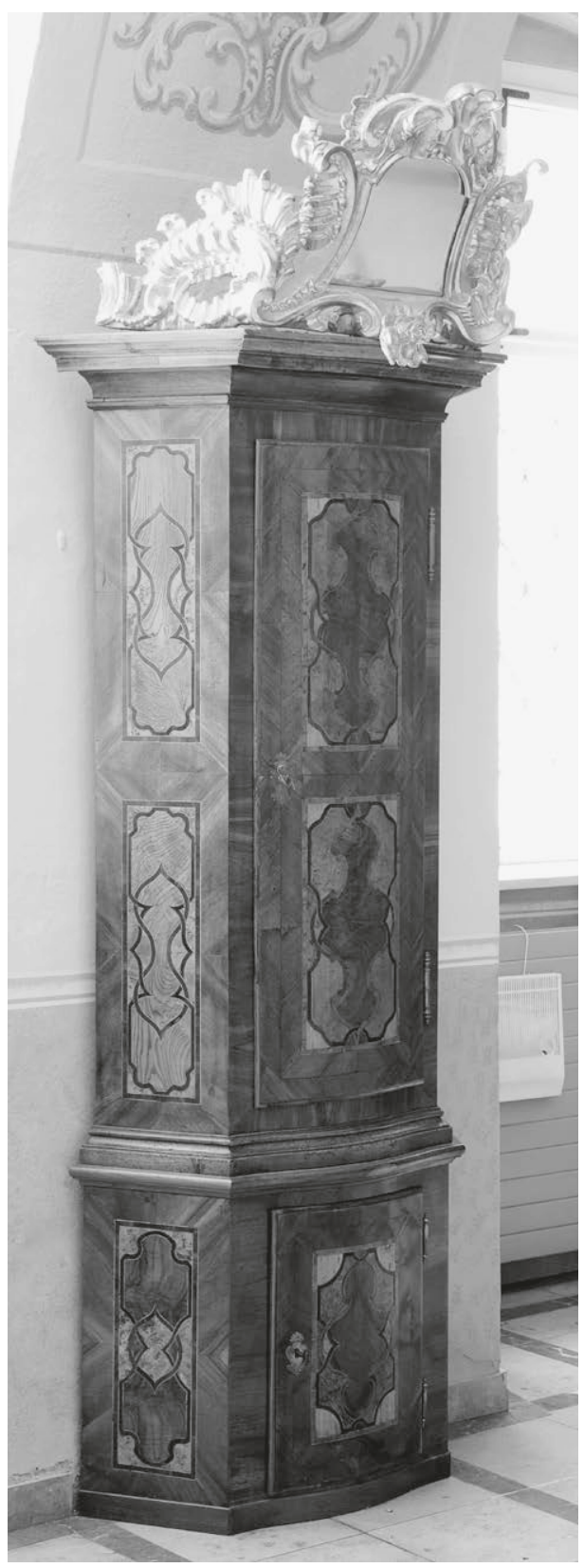

I76 Schmaler Sakristeischrank. Graz, I 748, der Schnitzaufsatz von Bildhauer Joseph Schokotnigg 


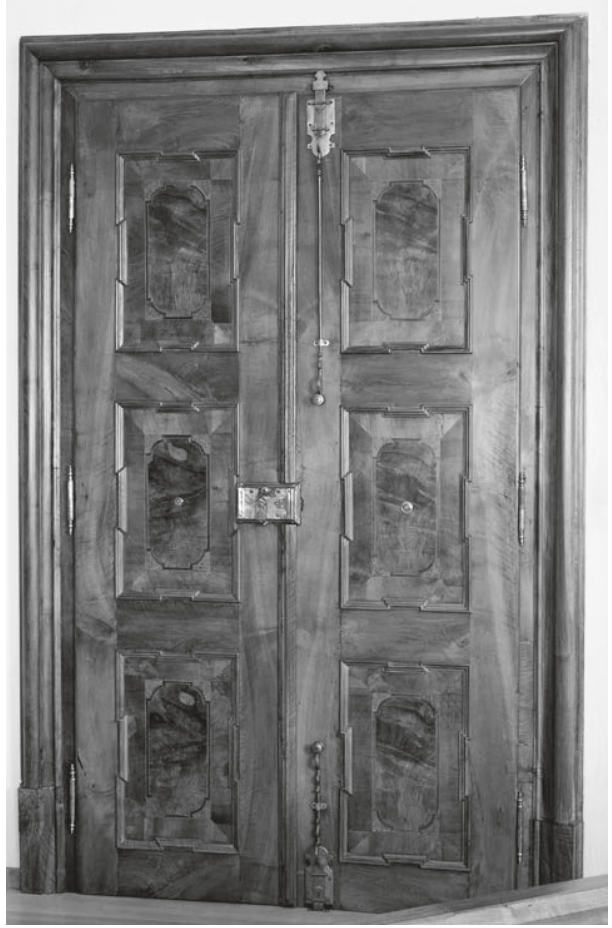

I77 Chorkapelle, Tür. Graz, um I $720 / 30$ bekannten Tischler dagegen an Gestaltungsmerkmale des österreichischen Spätbarocks, bestimmt eine auffallende Diskrepanz zwischen fortschrittlichen und konservativen Stilmerkmalen das Gesamterscheinungsbild des Sakristeimöbels. Dabei scheinen Teile der Bekrönung verloren zu sein, denn Schokotnigg legte die Rechnung u.a. für Adler, die den Aufsatz bereicherten. ${ }^{303}$

\section{Chorkapelle/Betraum}

Über der Sakristei liegt der sogenannte »Betraum«, andernorts als Winterchor oder Chorkapelle bezeichnet. ${ }^{304}$ Er wird wie die Sakristei durch Fenster in der Südwand beleuchtet, zwei Türen stellen die Kommunikation zu angrenzenden Konventräumen her. Wanddurchbrüche gestatten den Blick auf Querschiff, Langhaus und Presbyterium.

Tür

Graz, um $1720 / 30$

Maße des Türrahmens: $\mathrm{H} 300 \mathrm{~cm} \times \mathrm{B} 200 \mathrm{~cm}$

Nussbaum, Nussbaummaser. Messing, Eisen

Die mit zwei Flügeln ausgestattete Tür entspricht dem modernen französischen Typus, dabei ist jedoch die Gestaltung der Füllungen, die nicht rhythmisiert sind, stilkonservativ (Abb. I77). Breite Rahmen und feine Profile halten die verkröpften Binnenfelder. Sie bestehen aus Friesen, die mit gestreiftem Nussholz furniert sind, sowie aus maserholzfurnierten zentralen Flächen. Die Binnenfelder liegen vertieft in den Rahmen und werden von schmalen, verkröpften Profilen gehalten. Das lässt darauf schließen, dass die Tür vor den oben beschriebenen Exemplaren hergestellt wurde.

303 Kohlbach, Kirchenrechnungen [ca. I946], 2 I I ; Kohlbach, Barocke Kirchen [I 95 I], I 95.

304 Dehio, Graz (I 979), 224. 


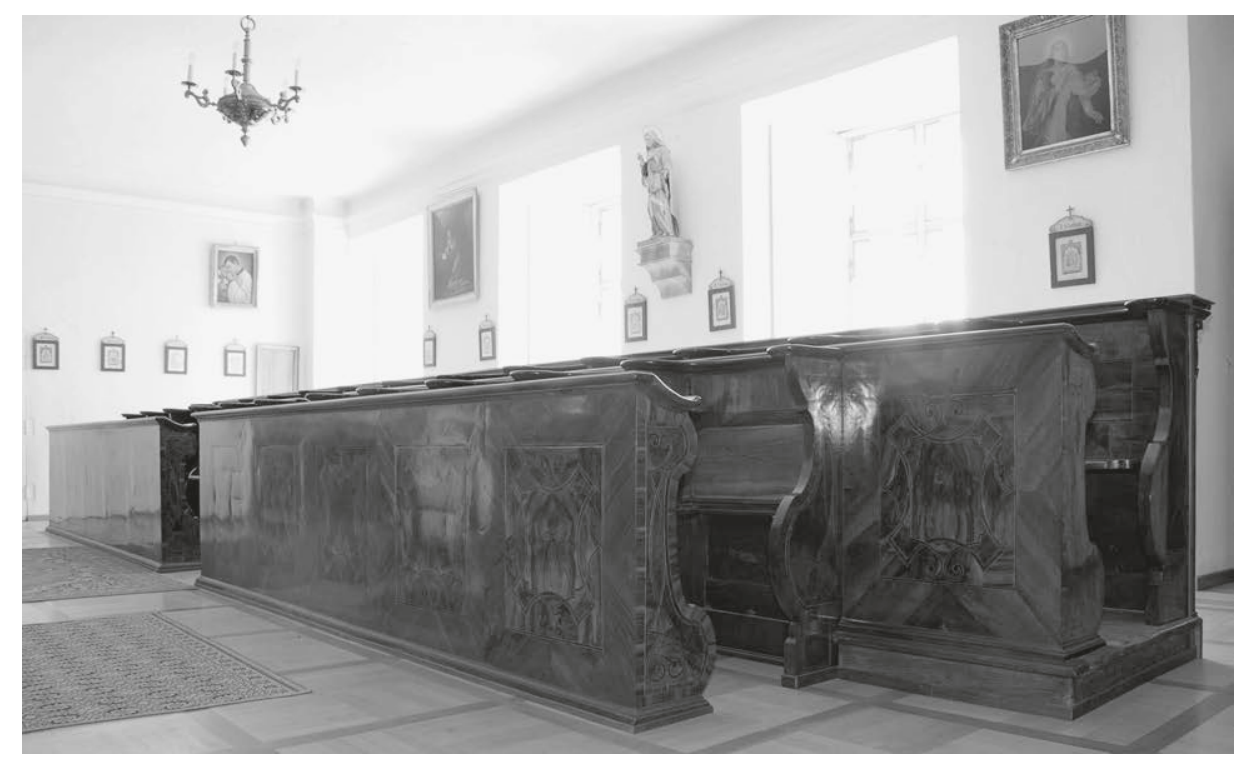

I78 Chorgestühl. Graz, um I735/45

\section{Chorgestübl}

Graz, um I 735/45

HS I $6 \mathrm{~cm}$

H I I $2,5 \mathrm{~cm}(+\mathrm{I} 6 \mathrm{~cm}) \times \mathrm{L} 988 \mathrm{~cm} / 83$ I cm

Nussbaum, Nussbaummaser, Nuss geschwärzt, Pappelmaser, Eibe, Zwetschke, Ahorn, furniert auf Nadelholz

Die hintere Stallenreihe umfasst I 3 Plätze, die vordere zehn (Abb. I78-г 80). Brüstung und vordere Sitzreihe sind geteilt, um den Einstieg in das Gestühl zu erleichtern. Anders als die Brustwände des Laiengestühls in der Kirche bildet die Brüstung im Betraum eine durchgehende Fläche. Die Füllungen liegen mit den Rahmen auf einer Ebene, auf Pilaster oder andere architektonische Gliederungselemente wurde bei der Fertigung der Brustwand verzichtet. Die Friese sind mit "gewöhnlichem« Nussbaumholz dekoriert, die zentralen Felder mit Maserholz aus Nuss und die anmutig geschwungenen Adern aus verschiedenen Holzarten. Passend dazu präsentieren sich die Außenwangen der Brüstung, die aus einem mittleren konkaven Bogen zwischen konvexen Auswölbungen bestehen. Auch hier wurden die Formen bewusst einfach gehalten, wobei an Front und Docken das ausgewählte Furnier und der elegante Aderverlauf bestechen. Die schlichte Form übernehmen überdies die Außen- und Zwi- 


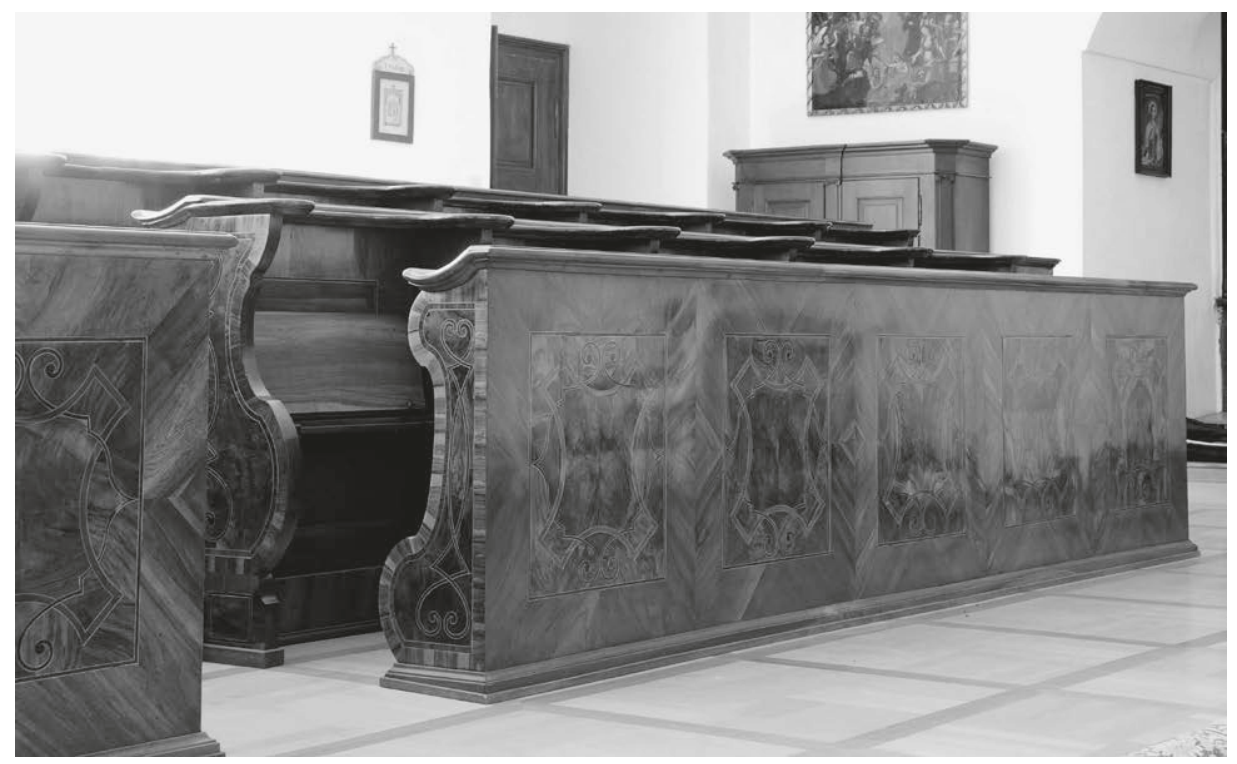

I79 Chorgestühl. Graz, um I 735/45

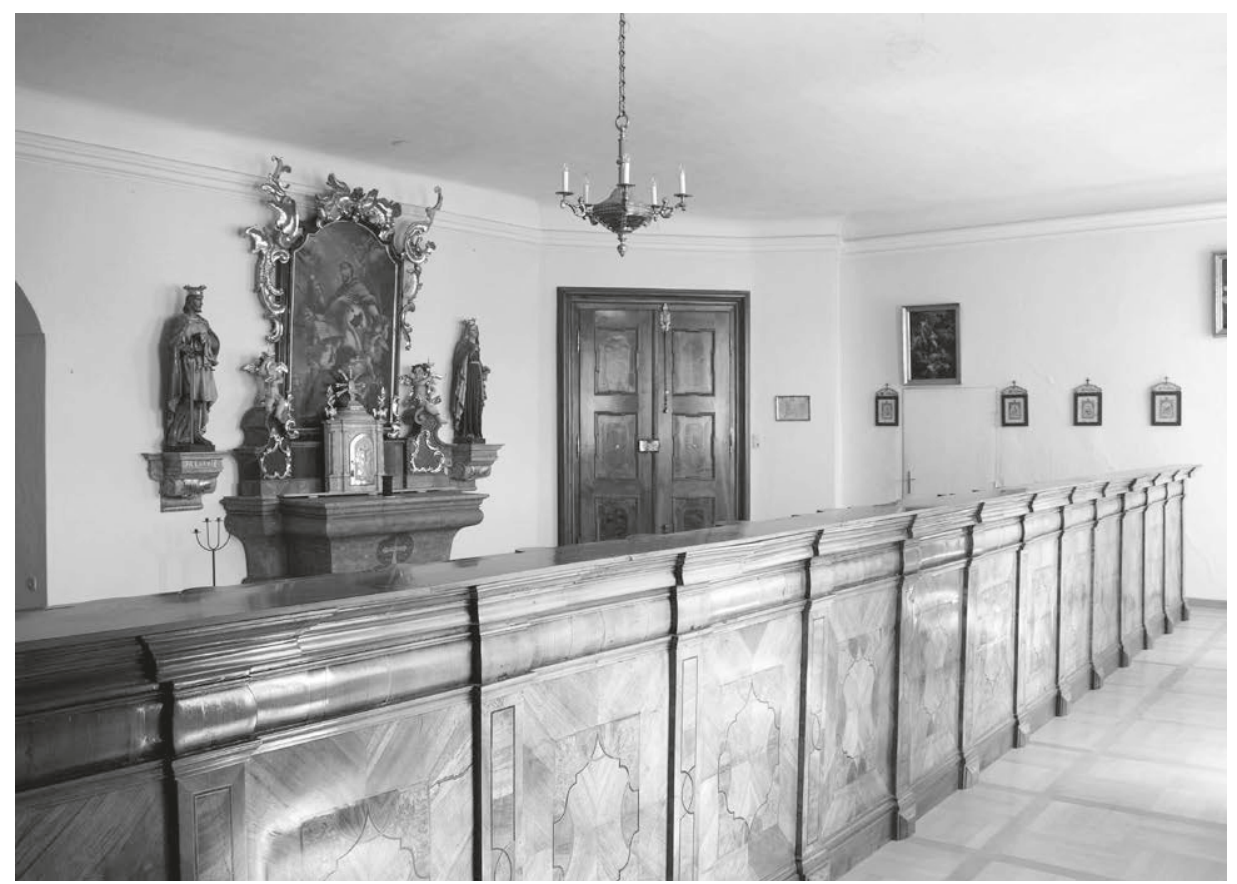

I 80 Chorgestühl, Ansicht der furnierten Rückseite. Graz, um I 735/45 
schendocken der Sitzreihen. Das Gestühl steht frei im Raum, weshalb man die Rückseite ebenfalls als Schauseite ausarbeitete. Im Gegensatz zur Vorderbrüstung gliedern nun allerdings pilasterartige Stützen die Fläche. In den Marketerien der Rückwand kommt Pappelmaser vor, ein weiterer Unterschied zur vorderen Brustwand.

\section{Graz, Pfarrkirche St. Andrä}

\section{Ehemaliges Dominikanerkloster}

Die erste archivalische Nennung der Kirche geht dem Anschein nach auf das Jahr I 270 zurück. ${ }^{305}$ Ursprünglich dürfte es sich bei dem Sakralbau um eine Kapelle gehandelt haben, die im I 4. Jahrhundert zur Pfarrkirche erhoben wurde. I 586 gelangte sie zusammen mit umliegenden Gebäuden in den Besitz des Dominikanerordens, der sie zur Klosterkirche umwidmete und sich einige Jahrzehnte später zum Neubau der Anlage entschloss. I6 6 erfolgte die Grundsteinlegung, I627 war der Bau vollendet, I635 konnte die Weihe gefeiert werden. Der Architekt Archangelo Carlone († I 635) wurde mit der Planung und Überwachung der Baumaßnahmen beauftragt. I786 säkularisierten die kaiserlichen Behörden das Kloster, woraufhin die Klosterkirche erneut die Bestimmung als Pfarrkirche erhielt. Carlone wählte für den dreischiffigen und fünfjochigen Bau den spätgotischen Staffelkirchen-Typus. Der abgesetzte zweijochige Chor reicht in den Nordtrakt des früheren Dominikanerklosters hinein. Die Ausstattung der Kirche entstand wie der Hochaltar um oder bald nach I 735 .

\section{Türen}

Graz, um I $730 / 40$

Lichte Maße $\mathrm{H}_{23}$ I $\mathrm{cm} \times \mathrm{B}$ i 2 I cm

Nussbaum, Nussbaummaser, Ahorn (?), weitere Hölzer, furniert auf Nadelholz. Eisen, getrieben, ziseliert, verzinnt

Die beiden in einer profilierten Umfassung hängenden Türen, die das Presbyterium mit der Sakristei und einem weiteren Annexraum verbinden, entsprechen der in unserem Kulturkreis vorherrschenden traditionellen Form: Einflügelig konzipiert, bestehen sie aus einem breiten Rahmengerüst und zwei gleich großen Füllungen (Abb. I 8 I). Anders als die in französischer Manier konstruierten Türen in Mariatrost (Abb. I69, I77)

$305 \mathrm{Zu}$ Kirche und Kloster vgl. Kohlbach, Gotische Kirchen (I950), I I9-I 22 ; Dehio, Graz (1979), I76I79; Kölbl/Resch, Wege (2002), I 54-I55. Die Datierung der Quelle wird in der relevanten Literatur kontrovers diskutiert. 


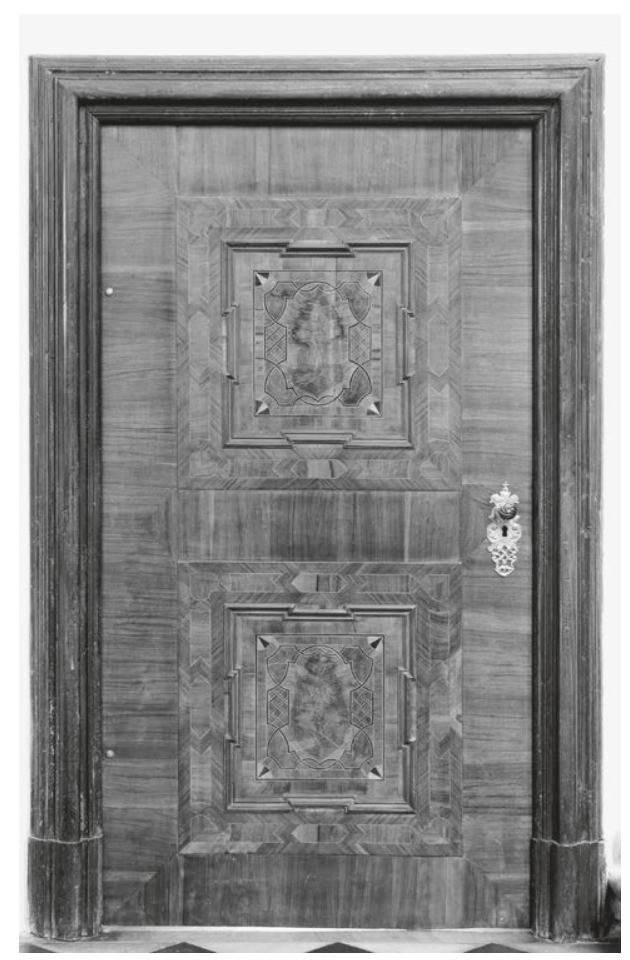

I8 I Tür. Graz, um I730/40

wirken die herkömmlichen Exemplare eher etwas altväterisch. Sie betonen nicht die Vertikale, sie wirken optisch weniger leicht und elegant. Dabei achteten die Tischler bei der Herstellung der Tür in St. Andrä durchaus auf künstlerische und handwerkliche Qualität. Als Besonderheit isoliert hier ein leicht erhabener Fries die Binnenfelder von den Rahmensegmenten. Während die Holzmaserung außen quer zur Längsrichtung des Blindholzes horizontal bzw. vertikal verläuft, dekorierten die Tischler den Fries mit diagonal aufgeleimtem, gespiegeltem und gestürztem Furnier. Außerdem legten sie Keilstäbe ein, in die Ecken auch herzförmige Motive. Feine, verkröpfte Profile halten die vertieft in die Rahmen eingesetzten Füllungen. Kantenparallele hell-dunkel-helle Adern säumen je ein Hochrechteck mit fächerartigen Ornamenten, wie sie uns bereits am Beichtstuhl in Mariatrost (Abb. I72) begegnet sind. Geschwungene Bänder umgeben das Zentrum der Mittelfelder und zwei seitliche vergitterte Flächen. Solche Gitterstrukturen zählen zu jenen Ornamentmotiven, die an Kirchenmöbeln in Reliefform häufig vorkommen, nur selten jedoch als Teil von Marketerien. Furniere aus gestreiftem Nussbaum überwiegen an den beiden Türen, für die Mitte wählten die Tischler Maserholz. Das Schlüsselschild zeigt als Dekor Gitterwerk, Laubwerk und eine Krone mit kleinem Kreuz.

\section{Kirchenbänke}

Graz, um I $745 / 60$

HS $13,5 \mathrm{~cm}$

$\mathrm{HB}$ i I $\mathrm{cm}(+\mathrm{I} 3,5 \mathrm{~cm}) \times \mathrm{L}_{45}$ o cm

Nussbaum, massiv und furniert, Nussbaummaser, Ahorn oder Buchs, graviert und geschwärzt, Holz geschwärzt, furniert auf Nadelholz, Eiche 


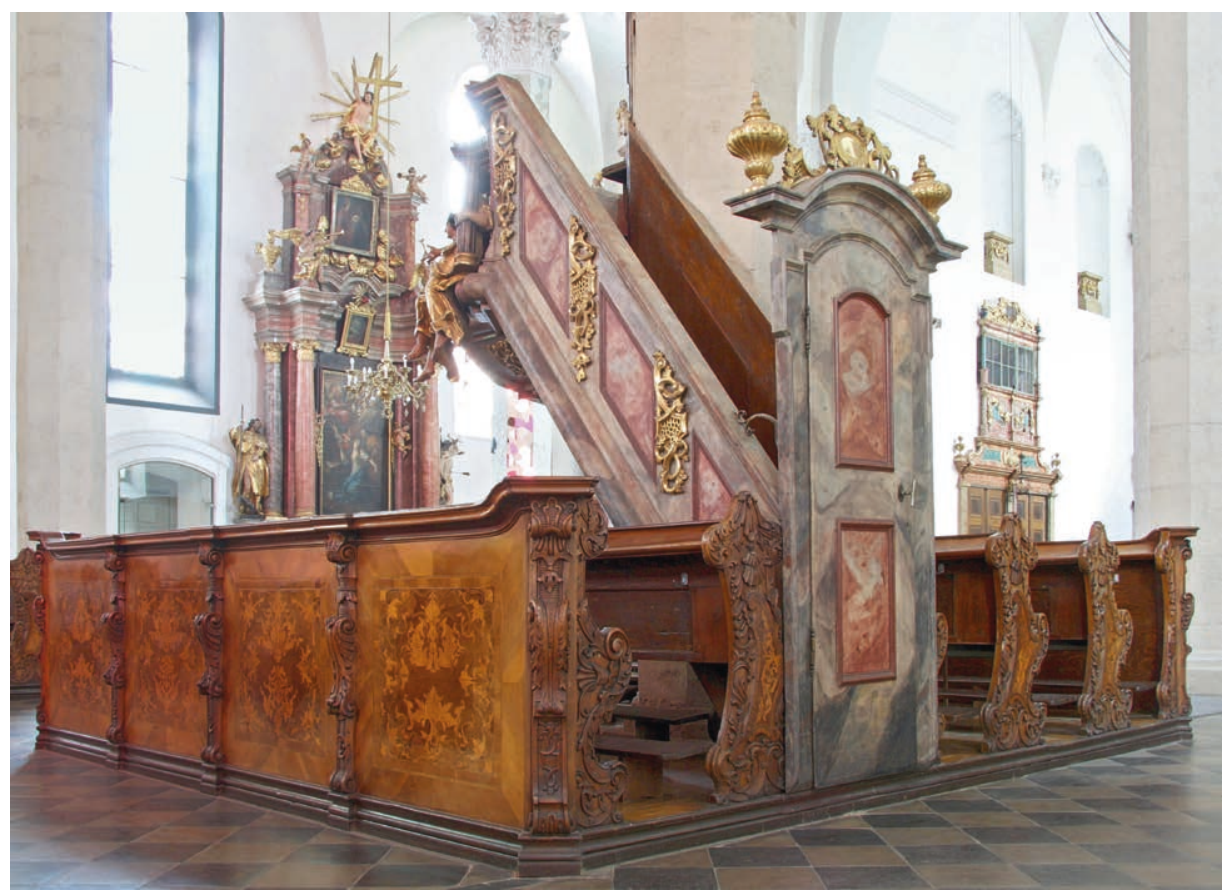

Farbtafel 2 I Kirchenbänke. Graz, um I 745/6o

Die Bankgarnitur steht auf vier Postamenten, die vom Mittelschiff aus in die Seitenschiffe hineinreichen (Farbtaf. 2 I ; Abb. I 82-I 84). ${ }^{306}$ Hinten befinden sich beidseitig zehn Sitzreihen, vorn fünf, sodass den Besuchern insgesamt 30 Bänke zur Verfügung stehen. Hinzu kommen vier Vorderbrüstungen.

Mehrschichtig aufgebaute und bewegte Baluster unterteilen die Brustwände, wie das ähnlich auch an der Bestuhlung anderer Kirchen in der Steiermark und in Kärnten zu beobachten ist (Abb. 57, I 52). Eine große Akanthusvolute ziert jeweils die Balustermitte, über und unter ihr säumen glatte Stege tiefliegende, zum Teil quergeriffelte Binnenfelder. Einige Stützen sind im unteren Bereich mit einer Blüte, andere mit Bandlwerk verziert, an verschiedenen Exemplaren schnürt oben ein Band die seitlichen Stege und das Mittelfeld kraftvoll ein. Die Baluster enden nicht mit Kapitellen, sondern mit Voluten, über die sich Muscheln und stilisierte Palmetten legen.

Glatte Flächen füllen die Zwischenräume, Rahmen und Füllungen befinden sich auf einer Ebene. Im Unterschied zur Vorgehensweise an den beschriebenen Türen, furnierten die Tischler die Rahmen der Brustwände diagonal mit gestreiftem Nuss-

306 Dehio, ebd., 178. 


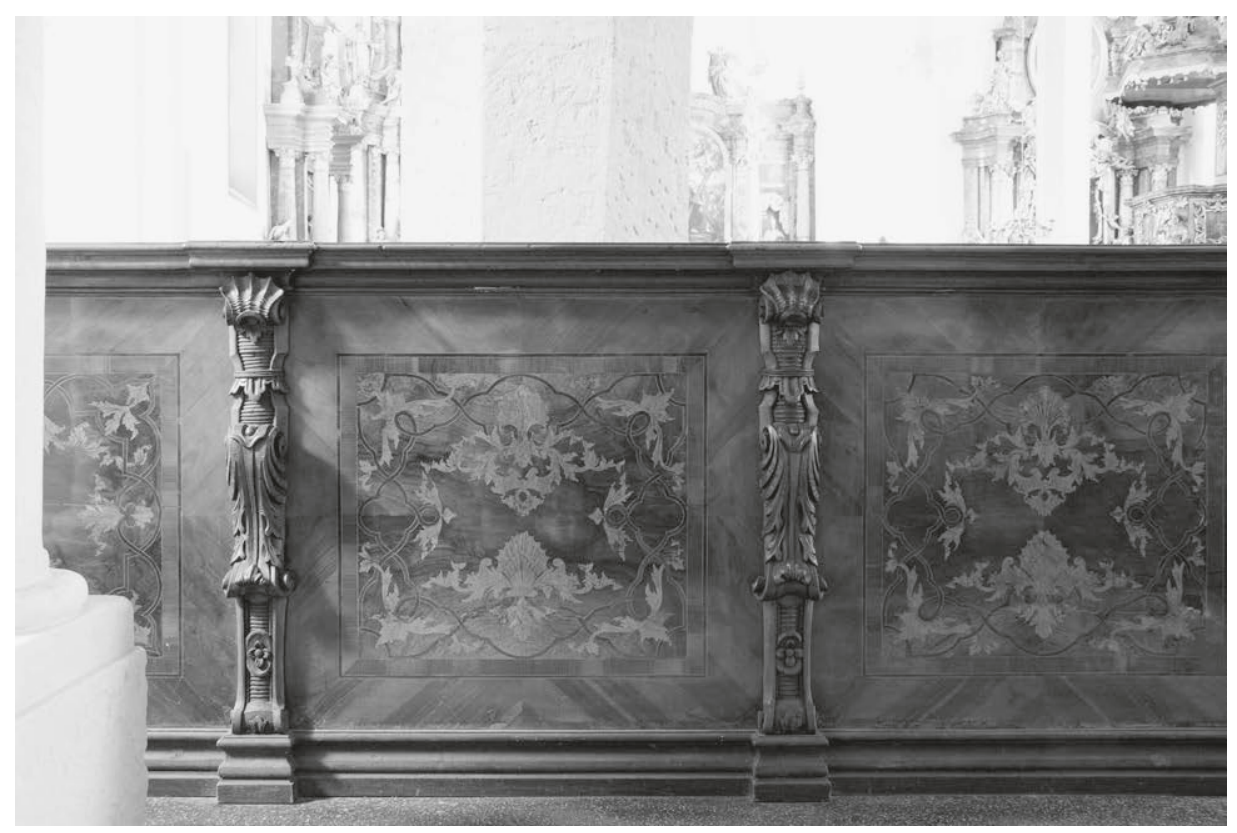

I82 Kirchenbank, Brustwand. Graz, um I745/60

holz, während sie die Binnenfelder wieder mit Maserfurnieren überzogen. Ein breiter Fries begrenzt die Kompartimente, geschwungene, durch eine Reihe von Schlaufen und harten Brüchen gekennzeichnete Adern sind intarsiert. Auffallender als der Aderverlauf ist das eingelegte Blatt- und Muschelwerk aus Ahorn oder Buchs. Graviert und schattiert, vervollständigt es detailreich die Binnenfelder. Als Abschluss tragen die Brustwände ein verkröpftes, über den Außenbalustern in die Höhe gezogenes Gesims.

Die Außenwangen der Bänke (Abb. I 84) geben deutlich zu erkennen, dass man sich bei ihrer Herstellung am Gestühl in der Grazer Domkirche orientierte (Abb. 153). Als Relief gearbeitetes Laub- und Bandlwerk begleitet die Wangenaußenkanten, unter dem bekrönenden Zierelement, einem glockenförmigen Gebilde, hängen muschelartige Motive. Das Zentrum der Wangen nimmt eine große asymmetrisch gestaltete Kartusche ein. Friese und Adern rahmen dort ein Mittelfeld mit kleinteiligen Intarsien. Wie an den Möbeln im Dom wird auch an den Exemplaren in St. Andrä mit dem optischen Gegensatz gespielt, der aus dem glatten, furnierten Binnenfeld und den kräftigen seitlichen Schnitzereien resultiert. 


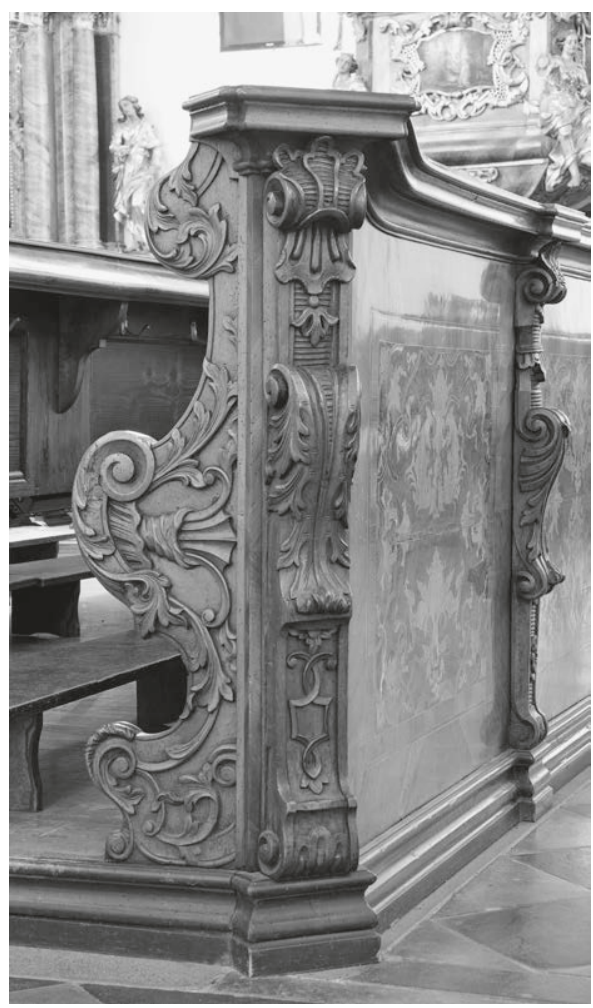

I 83 Kirchenbank, Schrägansicht. Graz, um I $745 / 60$

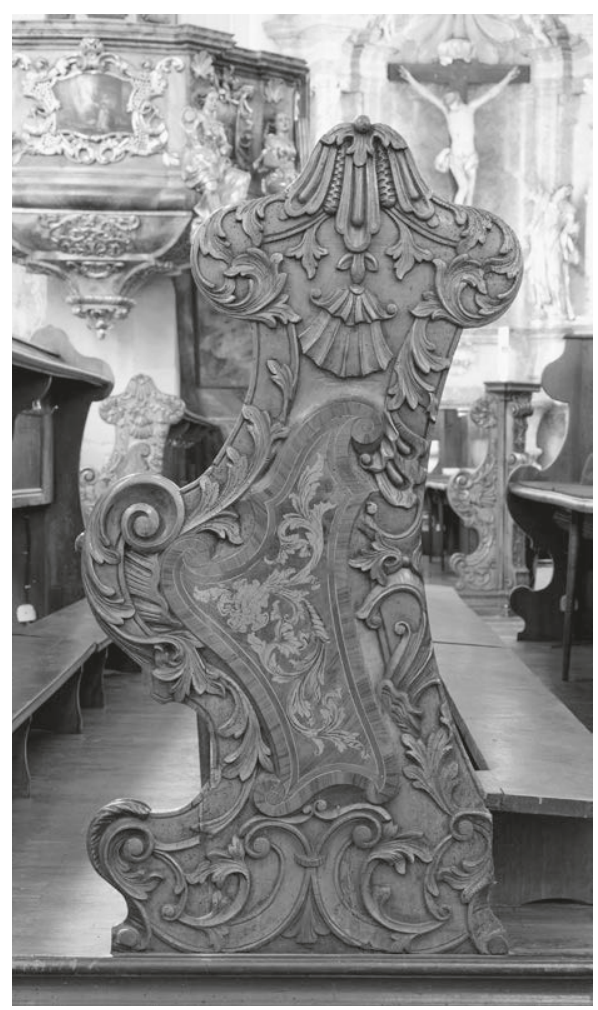

I 84 Bankwange. Graz, um I745/6o

Die Sitzbänke fertigte man aus Nuss, die Kniebänke aus Nadelholz, die Laufböden aus Eiche. Im Dehio wird eine Anfertigung der Bänke um I $730 / 35$ vermutet $^{307}$, damit sind sie zeitlich etwas zu früh angesetzt. Kniebänke und Podeste sind modern.

Graz, Welsche Kirche/Kirche hl. Franz de Paula

Ehemalige Bruderschaft des hl. Franz de Paula

Die Gründung der Welschen Kirche erfolgte auf Wunsch der Bruderschaft des hl. Franz de Paula (I4I6-I 507), deren Mitglieder sich in erster Linie aus der Grazer

307 Dehio, ebd. 
Kommunität italienischer Künstler und Handwerker rekrutierten. ${ }^{308}$ Außerdem traten der Bruderschaft einige steirische Adlige bei, sodass im I 8. Jahrhundert nicht weniger als I 68 Familien in ihr vertreten waren. I 7 I 7 ist der Ankauf zweier Häuser durch die Konfraternität dokumentiert, I 72 I erhielt sie die Genehmigung zum Bau der kleinen Kirche, die Weihe fand schon im folgenden Jahr statt. Als Architekt und Baumeister wird Leopold Joseph Carlone (I678-I739) vermutet. Die Arbeiten an der Fassade zogen sich noch zwei Jahrzehnte hin, Carlones Nachfolger, Joseph Hueber ( $†$ I 787 ), führte sie I 745/46 auf.

Die einschiffige und vierjochige Kirche ist in den Häuserverband des Griesplatzes in Graz eingebettet. Carlo Federico Formentini (um r662-I 742 ?) und Johann Peter Zaar († I 726) schufen wahrscheinlich die Stuckarbeiten zwischen I722 und I725. Als Maler der Fresken konnte Johann Chrysostomos Vogl (I679-I 748) nachgewiesen werden, er vollendete sie I 726. Die Gemälde vergegenwärtigen unter anderem Szenen aus dem Leben Franz de Paulas.

\section{Kirche}

\section{Laiengestühl}

Graz, 1738

HS I I, $5 \mathrm{~cm}$

$\mathrm{H}_{105} \mathrm{~cm}(+\mathrm{II}, 5 \mathrm{~cm}) \times \mathrm{L}_{2} 46 \mathrm{~cm}$

Nussbaum, massiv und furniert, Nussmaser, Eibe, Ahorn, Pappelmaser (?), Ahorn, graviert und geschwärzt, geschwärztes Holz, Nadelholz

Das Möbelensemble umfasst I 8 Sitzreihen und zwei Vorderbrüstungen (Abb. I 85 , I 86). ${ }^{309}$ Auch an diesen Bänken ist der Einfluss des Gestühls der Grazer Domkirche (Abb. I 52, I 53) evident. Schrägstehende Eckbaluster flankieren die Brüstung, die eine weitere Stütze in zwei Achsen unterteilt. Eine große Stehvolute nimmt die untere Hälfte der Stützen ein, darüber folgen, geschmückt mit einer Blütengirlande, ein flacher Bogen und eine weitere Volute. Ebene Flächen bilden die Zwischenräume. Mit gespiegeltem Nussholz furnierte Rahmen umgeben quadratische Binnenfelder, in denen Adern ein Achteck einfassen. Im Oktogon ist gestreiftes Furnier an den Mittelfugen gestürzt und gespiegelt, wohingegen man die Zwickelfelder vermutlich mit

308 Zur Kirche, ihrer Geschichte und zur Fraternität vgl. Moser, Welsche Kirche (1928); Mandl, Geschichte (I 934); Kohlbach, Barocke Kirchen [195 I], 205-2 10; Dehio, Graz (1979), I 84-I86; Attems/ Koren, Kirchen ( 1988), 28-29; Kölbl/Resch, Wege (2002), I 5 8-160.

309 Zum Gestühl vgl. Dehio, ebd., I 85. 


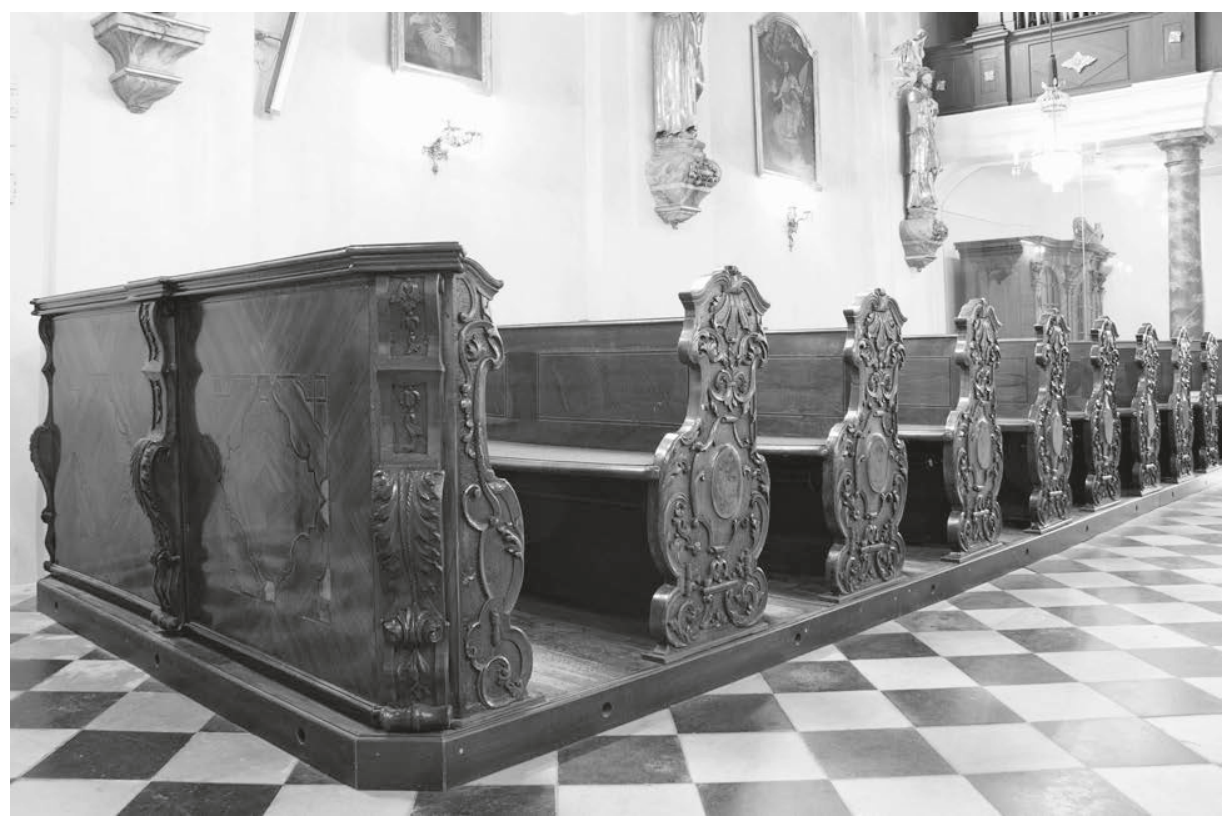

I 85 Kirchenbänke. Graz, um 1738

I 86 Bankwange. Graz, um 1738

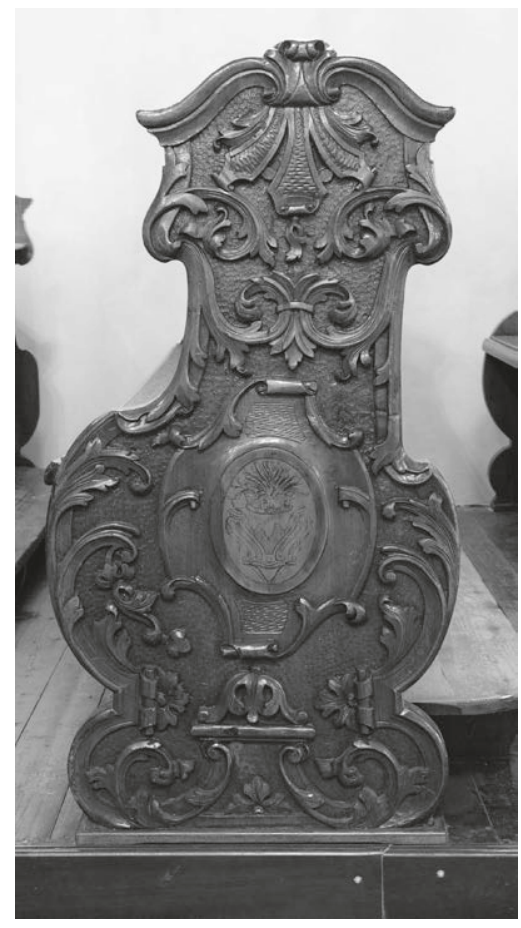


Pappelmaser dekorierte. Die hinteren Brustwände tragen im Zentrum jeweils Wappenschilde mit drei Glocken.

Beim Bau der etwas steif wirkenden Seitenwangen rezipierten die Tischler ebenfalls das Mobiliar der Domkirche. Laub- und Bandlwerk begleiten die Außenkanten der nur leicht asymmetrischen Docken und greifen auf die mit Punzen aufgeraute Fläche über. Unter dem Volutengiebel hängt ein großes Palmettenmotiv, eine mit vegetabilen Ornamenten und Rollwerk geschmückte Kartusche nimmt die Wangenmitte ein. In ihrem Zentrum befindet sich ein Hochoval aus hellem Ahornfurnier, das einen reizvollen Kontrast zum geschnitzten und dunkelbraunen Nussbaumholz erzeugt. Das Oval trägt gravierte und geschwärzte, teilweise auch gefärbte Darstellungen, die alternierend Flammenvasen und Konsoltische mit je einem Blumengebinde in einem Korb zum Inhalt haben. Hinweisen in der Literatur zufolge stiftete ein gewisser Donatus Johannes Baptist Vanustele die Bänke I 738 der Bruderschaft und ihrer Kirche. ${ }^{310}$ An den Schnitzarbeiten fällt namentlich die Verwendung von Rollwerkmotiven auf. Solche Ornamente, die auf die Formensprache des i6. Jahrhunderts rekurrieren, finden sich zwar mitunter auf süddeutschen Stichen von Paul Decker d. ̈̈. (I677-I7 I3), Johann Jacob Baumgartner ( I 694-I 744) oder Abraham Drentwett d.J. (I696-I 735) aus dem ersten Drittel des I 8. Jahrhunderts, können aber nur selten an österreichischen Möbeln der Zeit nachgewiesen werden. ${ }^{311}$

\section{Gröbming, Pfarrkirche Mariä Himmelfahrt}

In Schriftquellen ist ein Vorgängerbau seit I I 7o fassbar. Die heutige Kirche stammt aus dem Ende des I 5. Jahrhunderts, errichtet wurde sie vermutlich von einem Salzburger oder Braunauer Meister. ${ }^{312}$ Der Baukörper besteht aus einem vierjochigen Langhaus und einem zweijochigen, mit den fünf Seiten eines Achtecks schließenden Chor, den ein Triumphbogen vom Schiff trennt. Die Kirche ist mit einem Netzrippengewölbe versehen, im Chor ist es als geknickte Reihung konzipiert. Die Pfarre Gröbming ist dem Stift Admont unterstellt, wird aber sowohl von Benediktinern als auch von weltlichen Geistlichen betreut.

3 ro Moser, Welsche Kirche (I 928), I6; Mandl, Geschichte (I934), го.

3 I I Berliner/Egger, Vorlageblätter (I98 I), Bd. I, 99-ıо I, Bd. 3, etwa Abb. I 2 I I, I 220, I 239, I 240, I 245.

3 I 2 Zur Kirche und ihrer Geschichte vgl. Hootz, Kunstdenkmäler (I 965-1 968), Bd. 2 (I 966), 230, 372; Attems/Koren, Kirchen (1988), I 22 ; Tomaschek, Gröbming (200I); Dehio, Steiermark (2006), I 46 I 48. 


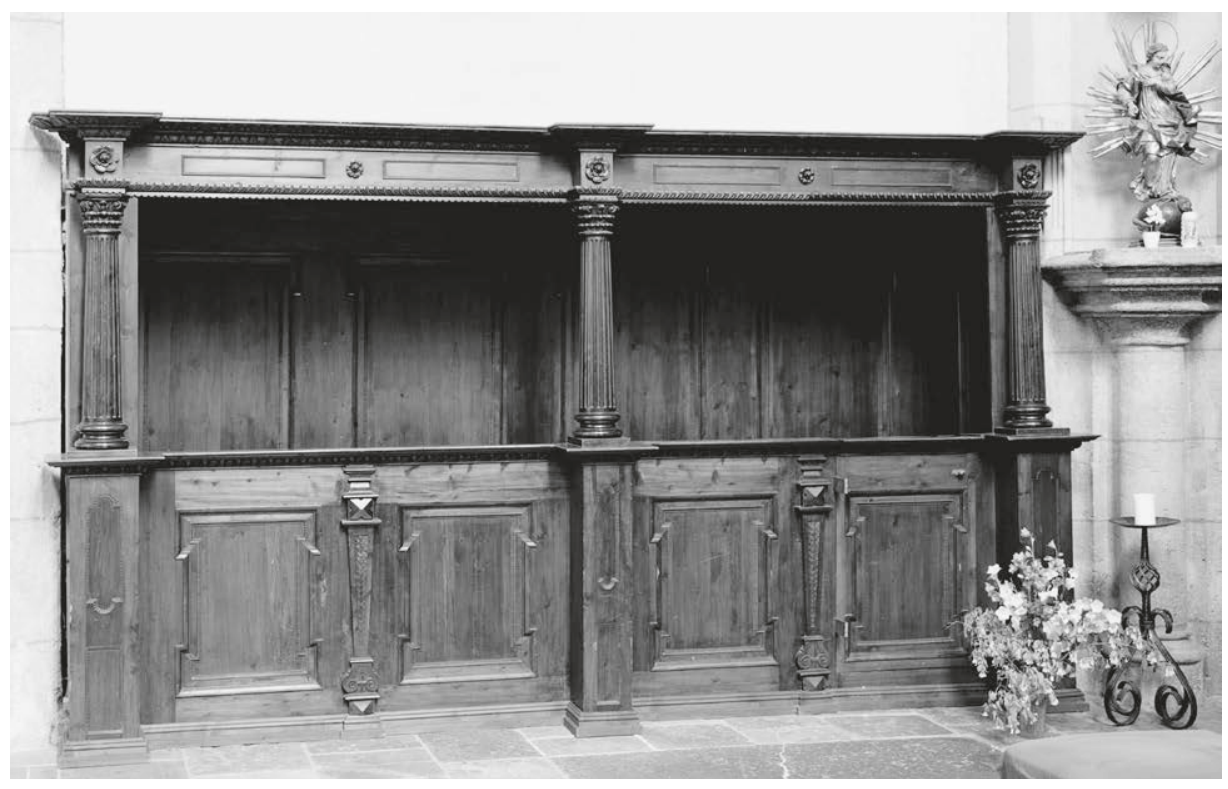

I 87 Gestühl. Gröbming, um r66o/80

\section{Chorraum}

\section{Gestübl}

Tischlermeister Martin Knöpl (?), um r66o/8o und I 676 $\mathrm{H} 240 \mathrm{~cm}$ (Gesimshöhe) $\times \mathrm{L} 435 \mathrm{~cm} \times \mathrm{T} \mathrm{I} 26 \mathrm{~cm} / \mathrm{I} 45 \mathrm{~cm}$

Nuss, Linde, Nadelholz, geschnitzt, nussfarben gebeizt, polychrome Fassung, Reste einer Vergoldung. Eisen

Die seitlich des Hauptaltars platzierten Bänke stehen in zwei tiefen Gehäusen, deren Großform an ein Chorgestühl mit weit nach vorn gezogenem Baldachin erinnert (Farbtaf. 22; Abb. I 87, I 88). ${ }^{313}$ Trotz der unterschiedlichen Werkstoffe, denen man bei der Herstellung der Möbel den Vorzug gab, ist ihr Aussehen nahezu identisch. Die Brustwände nehmen etwa die halbe Höhe der Möbel ein. Schlanke Postamente, die die gleiche Höhe wie die Brüstungen besitzen, tragen Säulen, auf denen der Himmel ruht. Hochrechteckige Füllungen mit Ohren und Füßen schließen die Räume zwischen den Sockeln. Das Gebälk ist verkröpft, Querrechtecke und Blütenmedaillons lo-

3 I 3 Attems/Koren, ebd.; Tomaschek, ebd., I4; Dehio, ebd., I 48. 


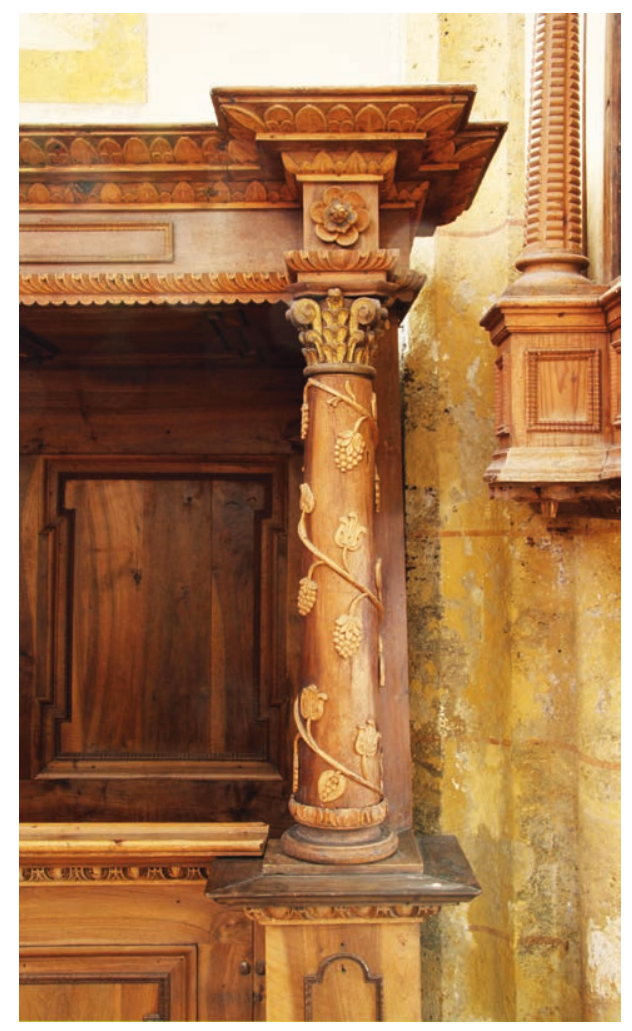

Farbtafel 22 Detail des Gestühls aus Abb. ı 88. Gröbming, r676

ckern den Fries auf, Leisten mit Zahnschnittund Ochsenaugenmotiven zieren Architrav und Gesims.

Das etwas kleinere Möbel auf der Evangelienseite wurde um I660/80 aus dunkelbraun gebeiztem Nadelholz gefertigt (Abb. I 87). Konisch zulaufende Pilaster auf Diamantquadern trennen die Brüstungsfüllungen voneinander. Die Stützen besitzen Basen in Form zweier Stehvoluten, Schäfte mit Scheibenfriesen, diamantförmige Schulterstücke und profilierte Blockkapitelle. Geflammt gehobelte Leisten halten die Füllungen. Der östliche Brustwandabschnitt kann als Tür geöffnet werden und gestattet so den Zutritt zum Gestühl. Die das Gebälk tragenden kannelierten Säulen ruhen auf Basen, deren Form von attischen Vorbildern abgeleitet ist, und besitzen mit Blattkränzen und kleinen Voluten vervollkommnete Kapitelle.

Im Gegensatz dazu verwendeten die Tischler beim Bau des Exemplars auf der Epistelseite Nussbaumholz (Abb. I 88). Der Tischler setzte hier die Tür im westlichen Brüstungssegment ein. Wieder strukturieren Pilaster die Brustwand, doch sind sie schlichter als die des anderen Möbels. Statt eines Frieses zieren wie am Beichtstuhl in Wilten (Abb. 376) Blütengehänge die Pilasterschäfte, ferner sind die Schulterstücke als einfache Kuben und nicht als Diamantsteine ausgebildet. Darüber hinaus verschieben sich an diesem Möbel im Vergleich mit dem anderen die Größenverhältnisse zwischen Rahmen und Füllungen. Und schließlich ist hier lediglich die mittlere Säule kanneliert, zudem ist sie mit Perlreihen verziert, womit sie an die Stützen der Sakristeimöbel in St. Lambrecht von I657/58 erinnert (Abb. 265). Um die glatte Oberfläche der seitlichen Stützen windet sich dagegen locker angeordnetes Weinlaub, ein Motiv, das von vielen Altären der Zeit her bekannt ist. Ein am Gebälk angebrachtes polychromes Allianzwappen trägt die Inschrift Thanngg Zuegehorig/ I676. Die Schnitzarbeiten bestehen zum Teil aus Lindenholz, Reste einer Vergoldung sind erkennbar. Johann Tomaschek geht von der Entstehung des Möbels 


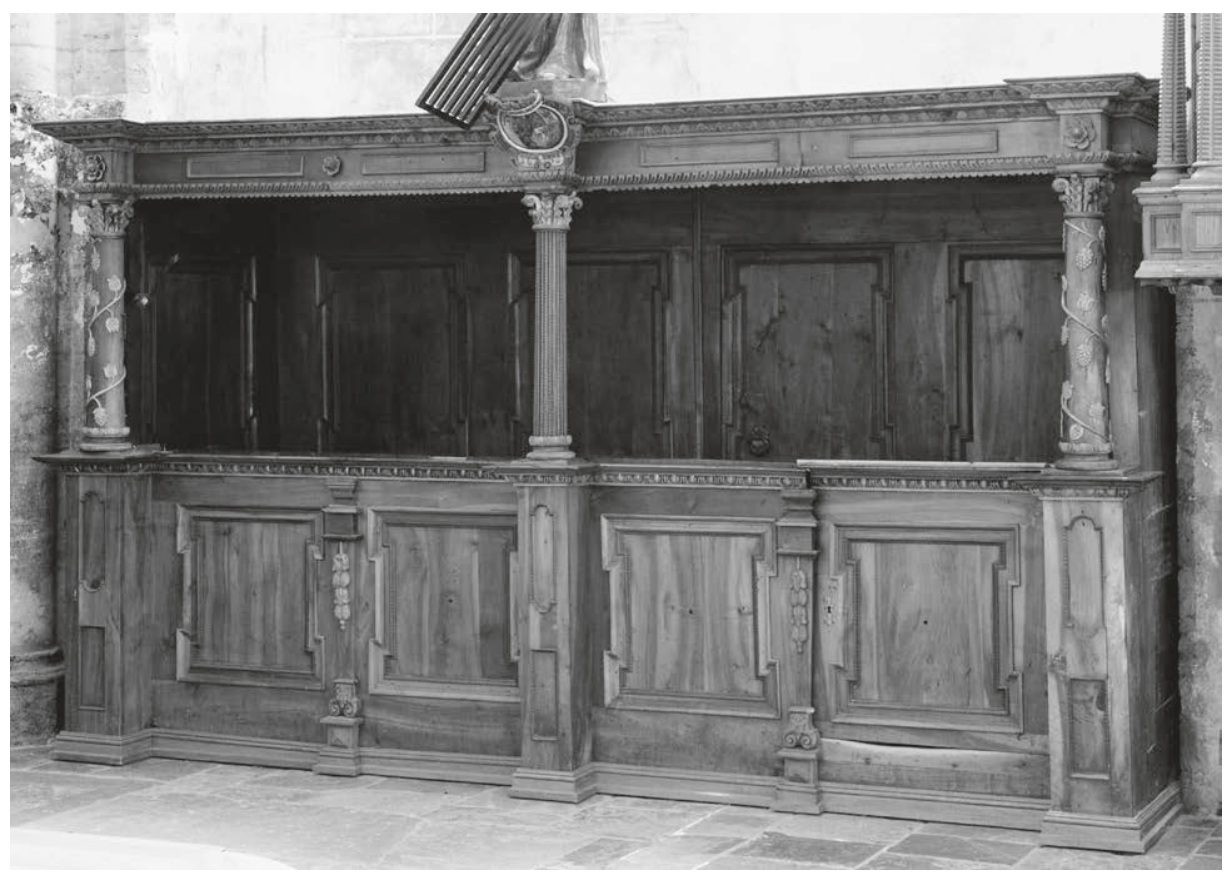

I 88 Gestühl. Gröbming, I 676

in der Werkstatt des Gröbminger Tischlers Martin Knöpl aus. ${ }^{314}$ Das ist denkbar, kann aber anhand des erhaltenen Quellenmaterials nicht verifiziert werden.

\section{Chorraum}

\section{Empore}

Tischler Martin Knöpl (?), um I 660/70

$\mathrm{H} \mathrm{I} 27 \mathrm{~cm} \times \mathrm{L} 68 \mathrm{I} \mathrm{cm}$

Nadelholz

Eine steile Treppe führt zu einer Empore hinauf, die an der epistelseitigen Außenwand des Chorraums angebracht wurde (Abb. I 89). ${ }^{315}$ Die Vorderseite der Brüstung setzt sich aus klar voneinander geschiedenen waagrechten Registern zusammen - einem hohen Sockel, einer Hauptzone und einem schweren verkröpften Gebälk. Es wird von schlanken Säulen gestützt, denen feine querovale, an Schmucksteine erinnernde

3 I 4 Tomaschek, ebd.

3 I 5 Tomaschek, ebd.; Dehio, Steiermark (2006), I 48. 


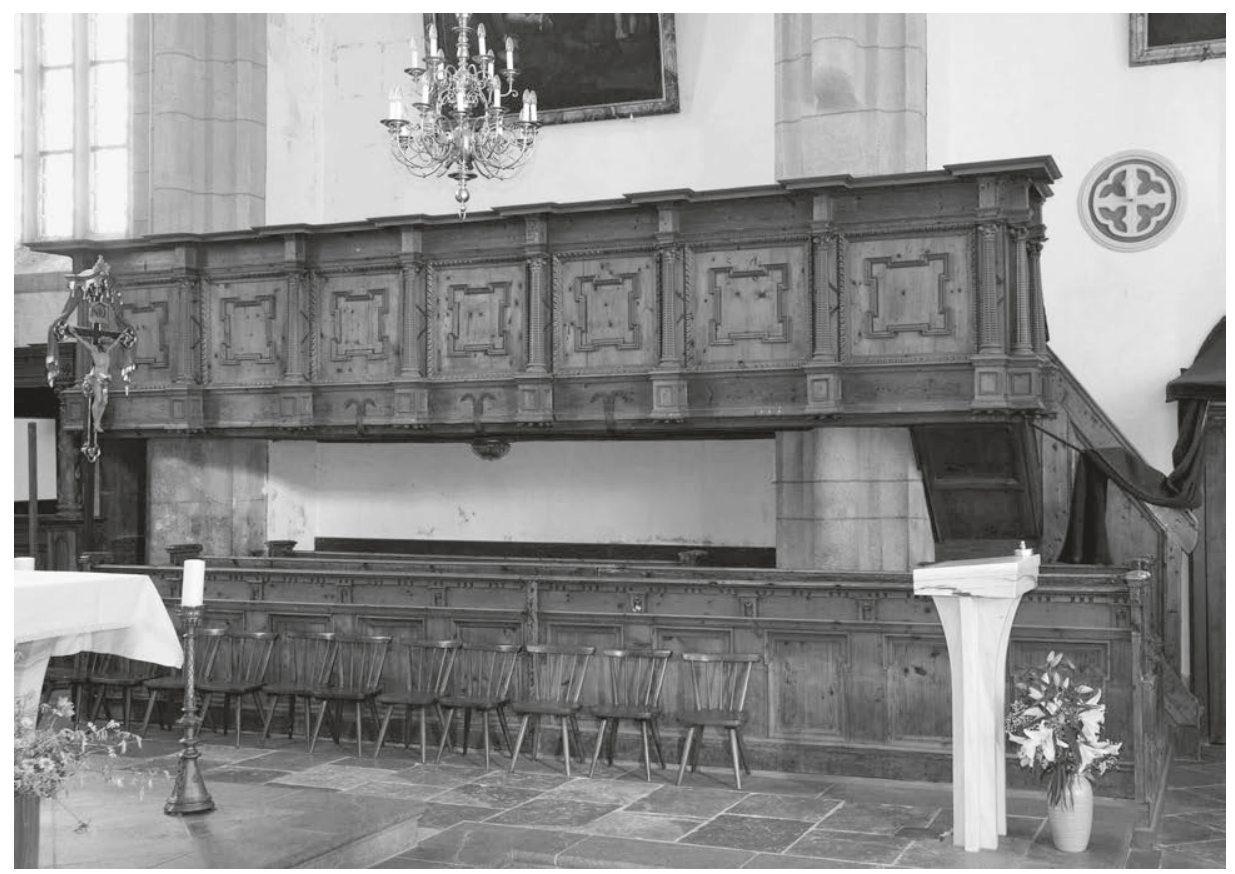

I 89 Chorraum, Empore und Bänke. Gröbming, um I660/70

Gebilde ein gerastertes Erscheinungsbild verleihen (Farbtaf. 22). Mit Scheinfüllungen dekorierte Felder bilden die Interkolumnien. Sie werden von Rahmen eingefasst, die mit einem Zahnschnitt verziert sind. Wahrscheinlich geht die Empore auf Martin Knöpl zurück, der in jener Zeit wiederholt im Auftrag der Gröbminger Pfarrei arbeitete. ${ }^{316}$ Laufboden, Stiegen und die Gebetbuchablage der Empore wurden bei einer Restaurierung erneuert.

\section{Chorraum}

\section{Bankreihen}

Gröbming, um I 660/70

$\mathrm{HS} 20 \mathrm{~cm}$

H IOO cm $(+20 \mathrm{~cm}) \times \mathrm{L} \mathrm{6I} 2 \mathrm{~cm}$

Nadelholz

316 Tomaschek, ebd. 


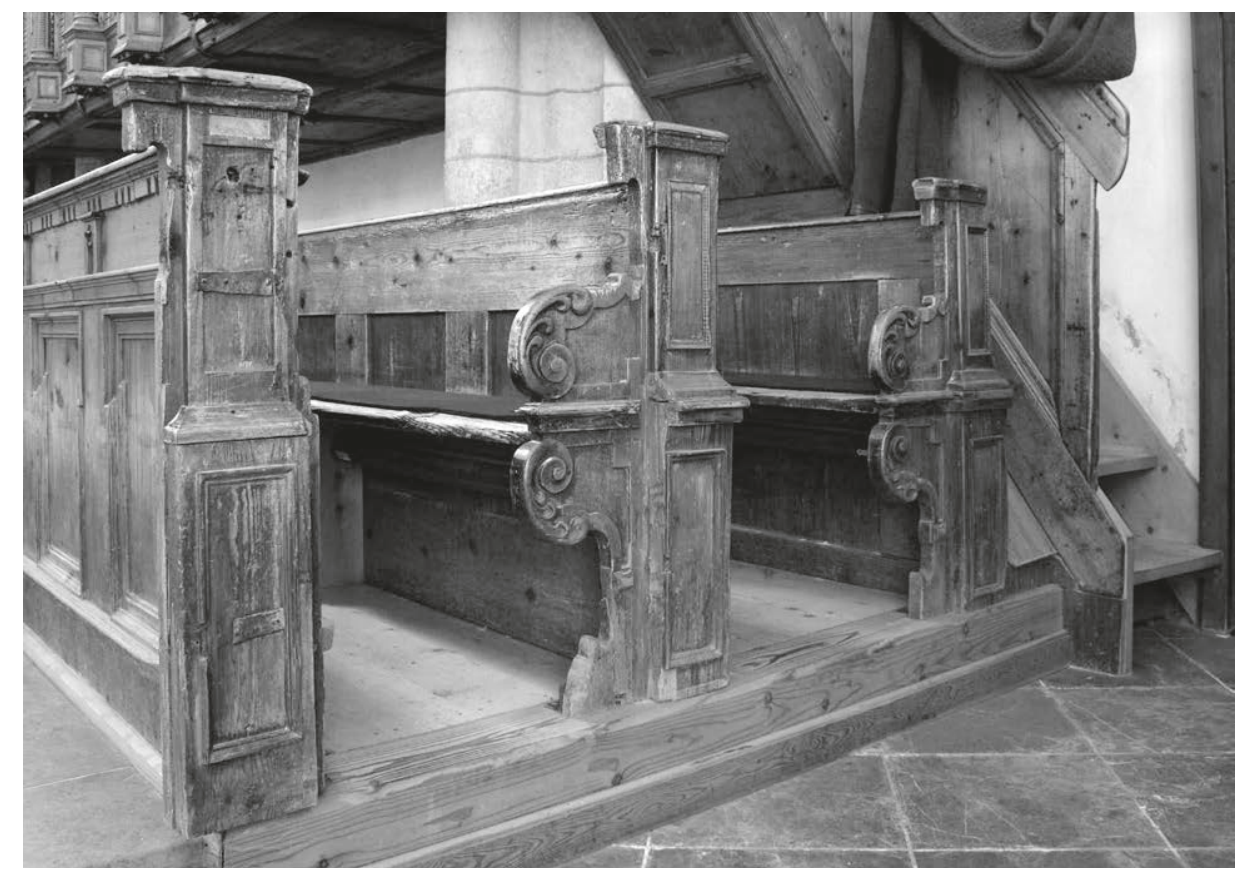

I90 Chorraum, Bankwangen. Gröbming, um I660/70

Unter der Empore befinden sich drei Bankreihen, von denen an dieser Stelle lediglich die beiden vorderen von Interesse sind (Abb. I89, I90). Die hintere Bank wurde nachträglich hinzugefügt.

Die Bänke besitzen aus schlanken Hochrechtecken bestehende balusterförmige Wangen, weit ausladende und gegeneinander gerichtete Voluten stützen das Sitzbrett. Ein kräftiges Gesims scheidet die in Rahmen und Füllungen aufgelösten Hochrechtecke voneinander. Profilleisten säumen die zentralen Felder, frühbarocke Bögen legen sich über die Voluten. Durch ihre besondere Form erinnern die Bankwangen an das im nächsten Abschnitt beschriebene Laiengestühl, aber auch an die Gestühle in Frauenberg und Pürgg, den Möbeln dürfte eine gemeinsame Vorlage zugrunde liegen (Abb. I 43, I94, I96, 232). Handwerklich korrekt setzt sich die Brüstung aus Rahmen und Füllungen zusammen, die hier geohrt sind. Darüber folgt ein Gebälk mit Konsolen, deren Umriss an ein auf dem Kopf stehendes und mit einem Diamantquader veredeltes U denken lässt. Solche Konsolen werden uns am nächsten Ausstattungsstück erneut begegnen. Stilistisch stehen die Bänke auf einer jüngeren Stufe als das um I640/43 gefertigte Laiengestühl in St. Lambrecht (Abb. 26r). Allerdings kommen auch in Gröbming noch jene merkwürdigen leder- oder metallartigen Bänder 


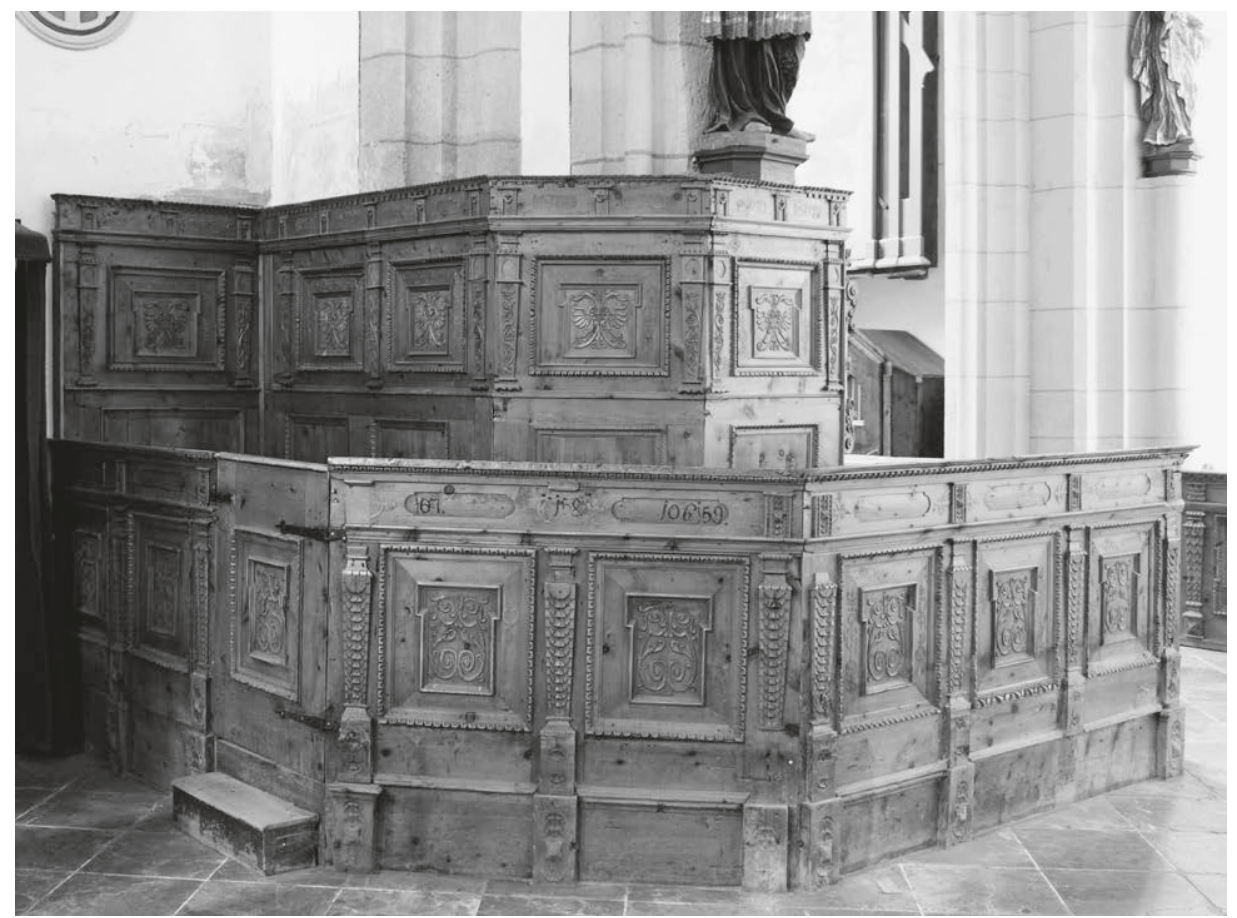

I9I Bank am Triumphbogenpfeiler. Gröbming, I665

vor, die an Beschlagwerkformationen erinnern und die Konturen der Schweifungen nachzeichnen.

\section{Triumphbogenpfeiler}

Bank

Gröbming, I 665

$\mathrm{HS} 28 \mathrm{~cm}$

$\mathrm{H}_{2} \mathrm{I} 2 \mathrm{~cm}(+28 \mathrm{~cm})$

Zirbelholz. Eisen

Ein aus Brüstung, Bank und hoher Rückwand bestehendes polygonales Gestühl umgibt den südlichen Triumphbogenpfeiler (Abb. I9 I). Es erhebt sich über einem hohen Postament, darüber folgt mit Sockel, Hauptzone und Gebälk die in der Frühen Neuzeit häufig vorkommende Dreiteilung der Brüstung. Mit einem ausgefallenen Schuppenmuster ornamentierte Keilpilaster gliedern die Hauptzone, dazwischen sind auf 
Gehrung geschnittene rahmende Friese und geohrte Füllungsfelder eingesetzt. Aus feinen Bögen bestehende Ornamente zieren die mittleren Kompartimente. Konsolen sowie querrechteckige, mit halbrunden Enden versehene Abschnitte strukturieren das Gebälk. Türen in der West- und Ostseite gestatten den Zutritt.

Die Rückwand ist in zwei Registern angelegt. Das obere erinnert durch seine architektonische Strukturierung an das Dorsale eines Chorgestühls. Einfache Rechteckfüllungen vervollständigen die untere Zone, oben sind es verkröpfte Binnenfelder mit doppelköpfigen Adlern. Das Gebälk trägt die Jahreszahl r 665, es ist mit Friesen und Konsolen dekoriert, Letztere gleichen den Konsolen am Gestühl unter der Empore. Über dem Fries fehlt heute ein abschließendes Gesims.

\section{Kirchenschiff \\ Laiengestübl}

Tischler Martin Knöpl, r674

HS I I cm

$\mathrm{H} 97 \mathrm{~cm}(+\mathrm{II} \mathrm{cm}) \times \mathrm{L} \mathrm{I} 90 \mathrm{~cm} / 237,5 \mathrm{~cm}$

Nadelholz

Auf der Evangelienseite der Kirche befinden sich vor dem Chorraum sieben Bänke (Abb. 192-I 94) ${ }^{317}$ Wegen der Kanzel sind die vorderen Sitzreihen kürzer als die hinteren, außerdem differiert die Wangenhöhe um einige Zentimeter. Die Vorderbrüstung besitzt den Aufbau, den wir an den anderen Möbeln in der Pfarrkirche bereits kennengelernt haben. Dabei werden die Füllungen allerdings von einem gerade verlaufenden äußeren Profil gehalten, das mit einer Art von Kyma verziert ist, sowie von einem inneren, glatt ausgehobelten, das Verkröpfungen aufweist. Auf den Binnenfeldern waren einmal Tondi befestigt, wie im Streiflicht zu erkennen ist. Sich verjüngende Pilaster tragen die Reste eines mit Konsolsteinen verzierten Querbretts. Der Erhaltungszustand der Brüstung lässt zu wünschen übrig, etliche Stücke fehlen, andere sind beschädigt.

Die Rückwand der letzten Bankreihe besitzt ein völlig anderes Aussehen: Vegetabile Ranken schmücken die hochgesockelten Pilaster, die mit den typisch manieristischen Kapitellen versehen sind; im vorliegenden Katalog kommen sie recht häufig vor. Die Füllungen bestehen aus Friesen mit aufgeleimten Sägeornamenten sowie aus geohrten Binnenfeldern mit doppelköpfigen Adlern. Unten brachte man Ziersteine an, oben das Buchstabenpaar A und $\mathrm{O}$ sowie die Jahreszahl I674, was erstaunt, da die

3I7 Gerlach, Chorgestühl (I93 I), 37; Tomaschek, ebd.; Dehio, Steiermark (2006), I 48. 


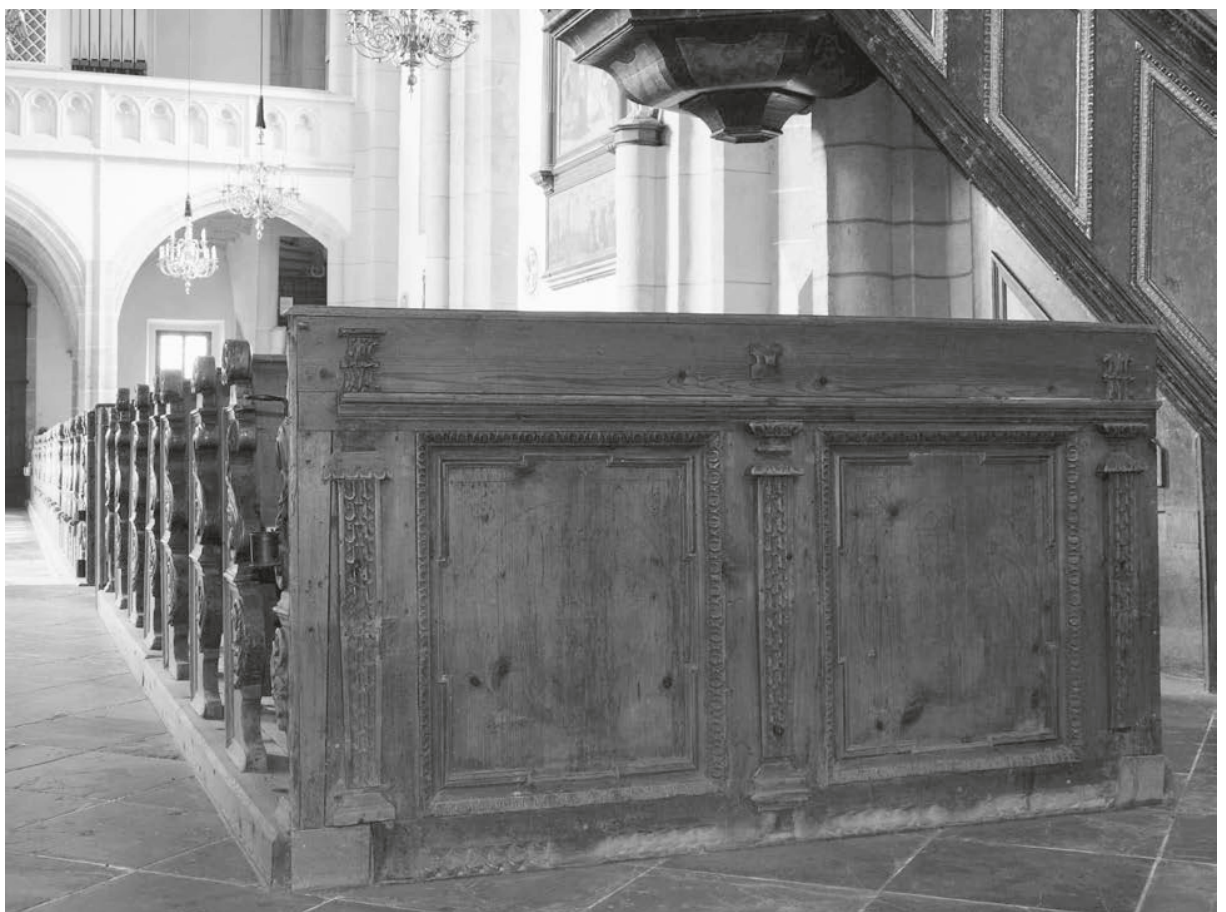

I 92 Kirchengestühl, Brüstung. Tischler Martin Knöpl, I674

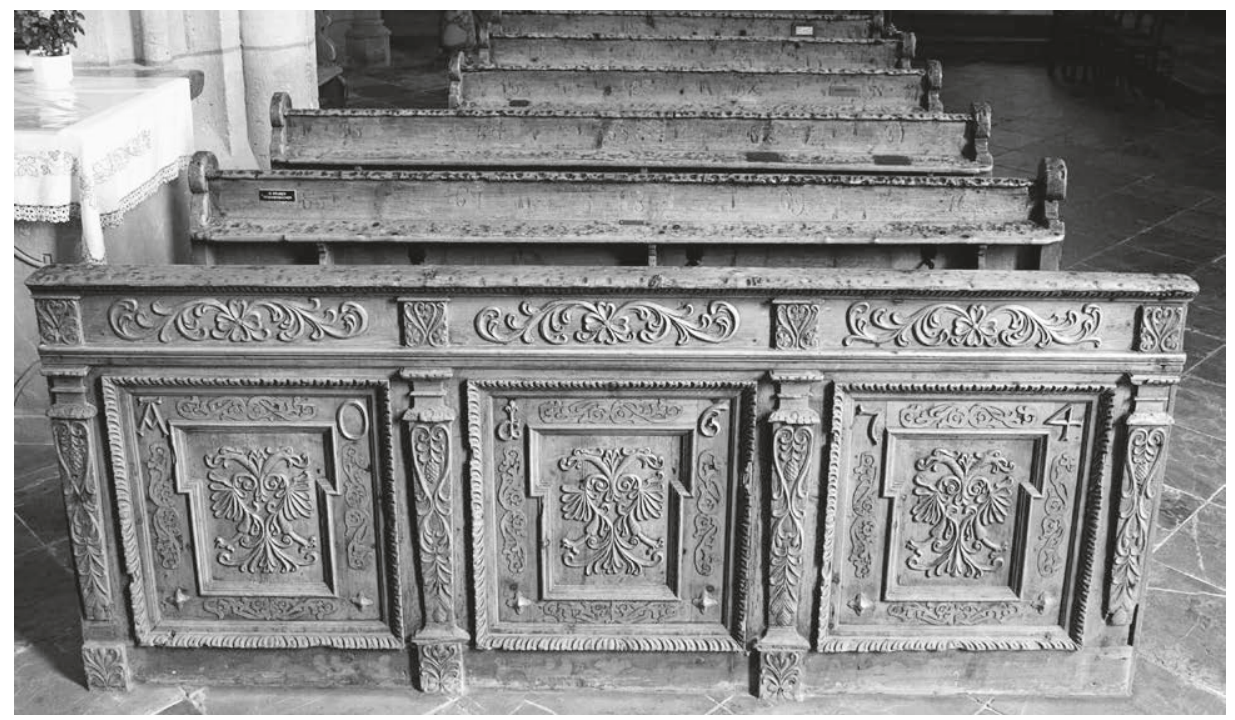

I93 Kirchengestühl, hintere Brustwand. Tischler Martin Knöpl, I674 


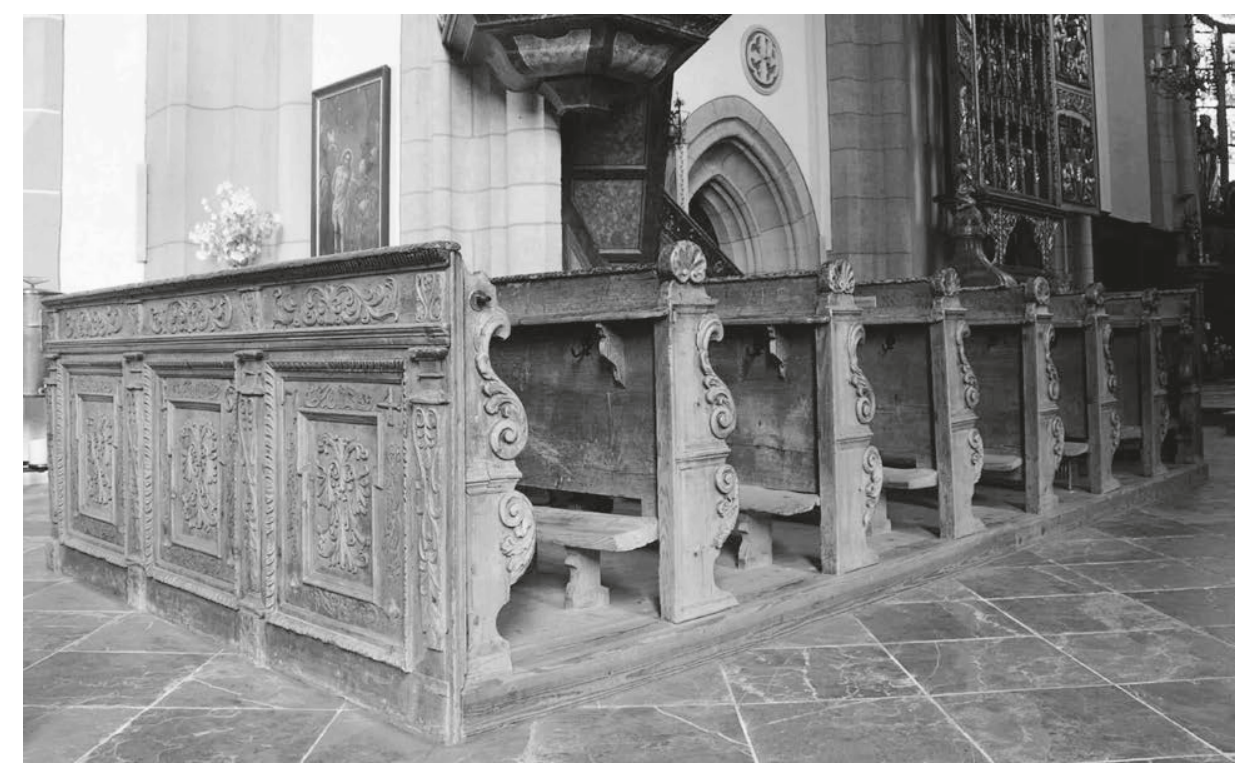

I 94 Kirchengestühl, Schrägansicht und Bankwangen. Tischler Martin Knöpl, ı674

Ornamentmuster auf ein früheres Herstellungsdatum zu deuten scheinen. Die Bänke bieten ein gutes Beispiel dafür, dass in ländlichen Gegenden stets mit Stilverschleppungen zu rechnen ist.

Die Wangen erinnern an die Sitzreihen unter der Empore. Nun setzen sie sich jedoch aus zwei schlanken Hochrechtecken mit geraden rückwärtigen und stark konturierten vorderen Kanten zusammen, die von Voluten, Schwüngen und Blattwerk begleitet werden. Die Docken enden mit einem Muschelmotiv. Verzierungen tragen lediglich die Wangen in der Mitte des Kirchenschiffs, während die äußeren zwar entsprechend konturiert, aber nicht weiter geschmückt sind. Eine schlichte Leiste dient als Abschluss der Rückenlehnen, die Gebetbuchablage ist ein gutes Stück darunter angeordnet.

Der Literatur zufolge wurden die Möbel von Martin Knöpl verfertigt. An den Bänken fällt vor allem der Kontrast zwischen den feinen und konservativen Schnitzmotiven der hinteren Brustwand und den kräftigen, um r670 noch modernen Ornamentformen der Wangen auf. Der Sockel gibt die Konstruktion der Laufböden deutlich zu erkennen. Er besteht aus einem massiven Balkengerüst und dazwischen verlegten Brettern. Sonst befestigte man die Dielen meist auf den Balken und verbarg das Gerüst hinter hohen Sockelleisten. 


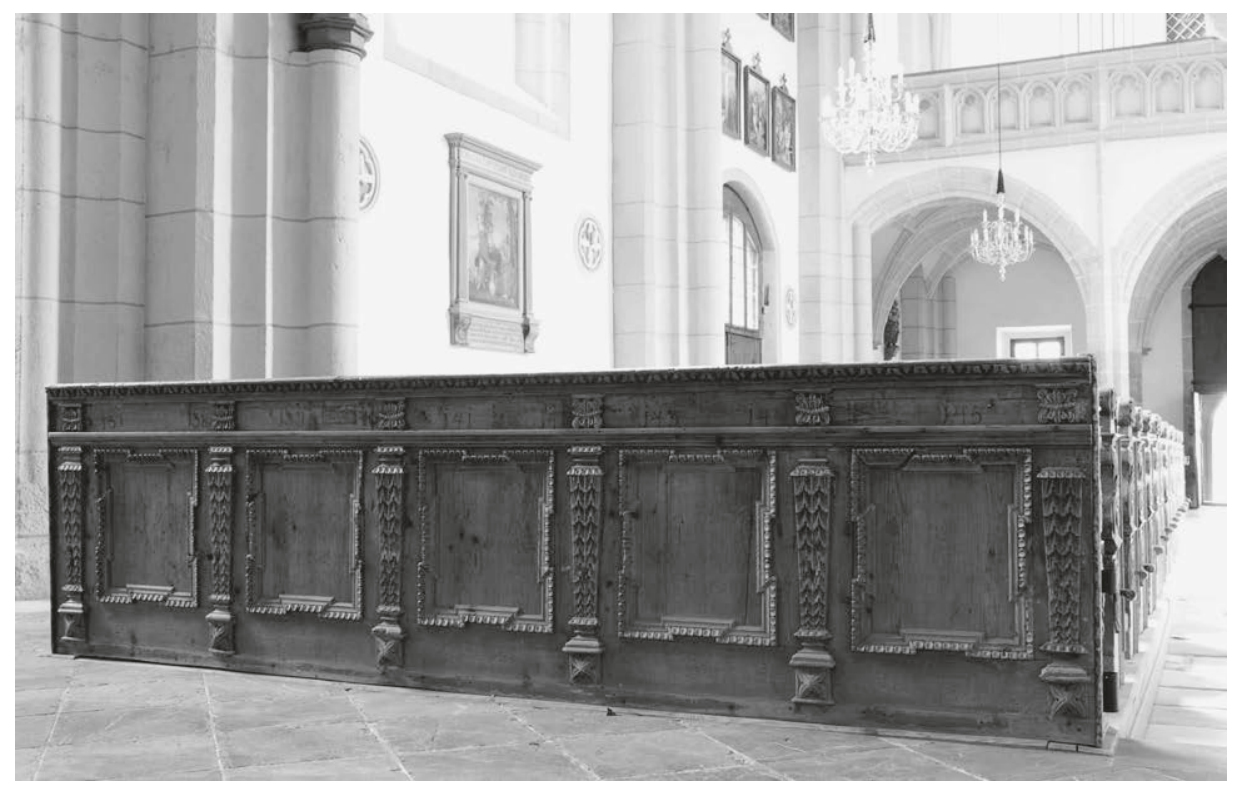

I95 Kirchengestühl. Verm. Tischler Martin Knöpl, um r66o/80

\section{Laiengestühl}

Tischler Martin Knöpl (?), um r66o/8o

$\mathrm{HS} 22 \mathrm{~cm}$

$\mathrm{H}_{105}, 5 \mathrm{~cm}(+22 \mathrm{~cm}) \times \mathrm{L}_{395} \mathrm{~cm}$

Nadelholz

Im Langhaus befinden sich weitere Bänke eines ähnlichen Typs: Auf der rechten Seite sind es I 3 Reihen, links I 9, hinzu kommen die Brüstungen (Abb. I95, I 96).

Die Bankwangen entsprechen weitgehend den vorhergehend beschriebenen. Ein wichtiger konstruktiver und formaler Unterschied besteht allerdings in der Tatsache, dass hier jeweils eine Strebe unter den Sitzbänken für eine Versteifung der Konstruktion sorgt. Die eingerollten Enden der Traversen sind durch die Wangen gesteckt und stehen seitlich heraus. Ein weiteres Beispiel für solch eine Art der Konstruktion ist aus Österreich bislang nicht bekannt.

Größere Differenzen ergeben sich jedoch aus der Gestaltung der Brüstungen. Man verzichtete auch hier auf einen klaren horizontalen Aufbau und deutete die Sockelzone lediglich an. Geschuppte Pilaster erheben sich über vegetabil geschmückten Postamenten, die wegen der fehlenden Bodenleiste zu schweben scheinen, schwere, mit 
einer Art von Traubenfries versehene Profile säumen die verkröpften Füllungen. Den Gebälkfries unterteilen Konsolen. Ihre ungewöhnliche Form besteht aus amorphen Gebilden, die ein gezacktes Band zusammenschnürt. Ein Kyma ziert das Abschlussgesims. Die hinteren Brustwände sind schlichter. Sie wurden nicht weiter dekoriert, aufgesetzte Profile täuschen dort die Füllungen lediglich vor. Wegen der stilistischen Übereinstimmungen mit den vorhergehend beschriebenen Möbeln liegt die Vermutung nahe, auch diese Bänke könnten von Martin Knöpl gebaut worden sein. Etliche Bänke tragen Nummern auf den Rückwänden und den Rückenlehnen, teilweise auch auf den Vorderseiten der Brüstungen. Einige Nummern wurden eingraviert, zum Teil mit dunkler Farbe nachgezogen. Darüber hinaus bezeichnen Namensschilder die Inhaber einer Reihe von Sitzplätzen. ${ }^{318}$

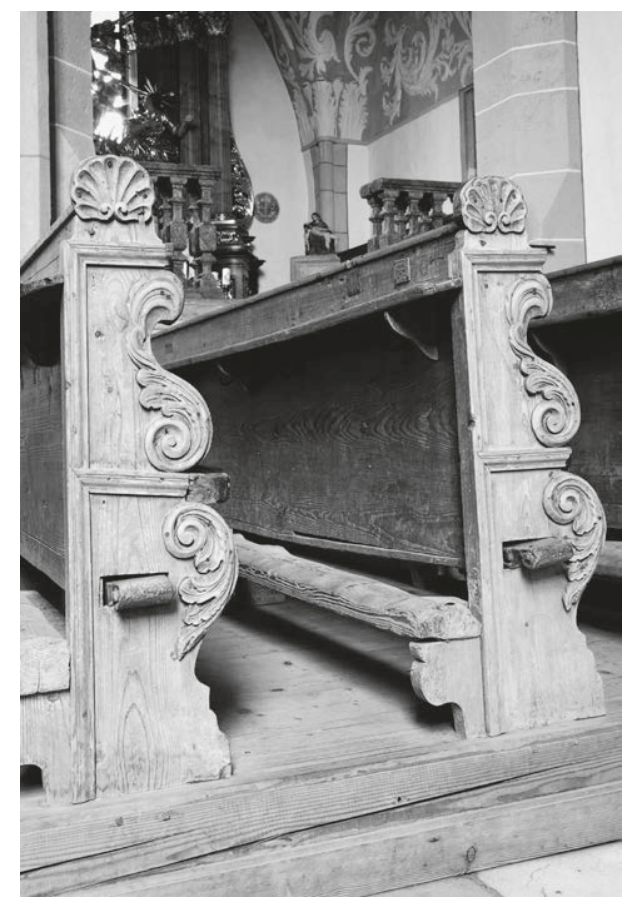

I96 Kirchengestühl, Docken. Verm. Tischler Martin Knöpl, um r66o/8o

Mariahof, Pfarrkirche hl. Maria

Ein gotischer Bau ersetzte im I 5. Jahrhundert eine seit ro66 dokumentierte und seit I I 03 dem Stift St. Lambrecht inkorporierte Vorgängerkirche. ${ }^{319}$ Mitte des I2. Jahrhunderts errichtete der Konvent in Mariahof ein Priorat für I 2 Geistliche, das in der Frühen Neuzeit aufgegeben worden zu sein scheint. Um I 482 verwüsteten ungarische und türkische Heere die hochgotische Architektur, was ihren Wiederaufbau und eine neue Weihe erforderlich werden ließ. Die auf einer Hügelkuppe liegende Pfarrkirche zählt mit dem dazu gehörenden Pfarrhof zu den größten kirchlichen Wehranlagen der Steiermark. Bei einer I679 bis 168 I erfolgten Barockisierung, für die der relevanten Literatur nach der Stiftsbaumeister von St. Lambrecht, Domenico Sciassia (I 599/ı603-I679), verantwortlich zeichnete, erhielt der spätmittelalter-

31 8 Bohr, Sakralmöbel (2017), 96-97.

3 9 Zum Gebäude und seiner Geschichte vgl. Schlacher, Vergangenheit (I 966); Plank, Mariahof (I 995);

Dehio, Steiermark (2006), 277-279. 


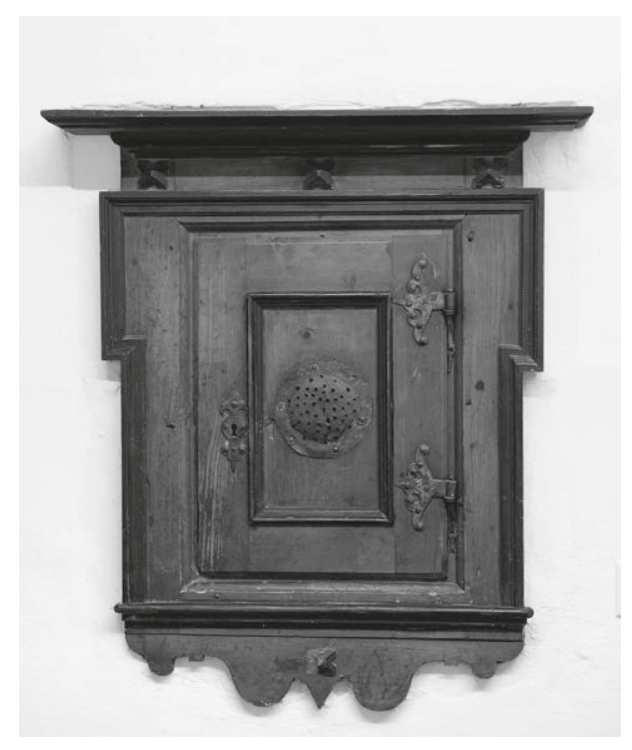

I 97 Sakristei, Wandschrank. Mariahof, 3. D. I7. Jh. liche dreijochige Baukörper Wandpfeiler und ein Kreuzgratgewölbe. Der eingezogene und durch einen Triumphbogen abgegrenzte Chor ist zweijochig, trägt ein Netzrippengewölbe und endet mit einem 5/8-Schluss. Den Hochaltar schuf nach ${ }_{16} 67$ Christoph Paumgartner, ein Tischler und Bildschnitzer aus dem nahe gelegenen Neumarkt.

\section{Sakristei}

Der sternrippengewölbte Raum liegt nördlich des Chors. ${ }^{320}$ Die barocke Einrichtung besteht aus drei Möbeln, von denen zwei an dieser Stelle interessieren: ein großer Aufsatzschrank sowie ein kleiner Wandschrank.

\section{Wandschrank}

Mariahof, 3. D. 17.Jh.

$\mathrm{H} 90 \mathrm{~cm} \times \mathrm{B} 79 \mathrm{~cm}$

Nadelholz, teilweise geschwärzt. Eisen, verzinnt

Der Kasten ist in eine Nische in der Südwand der Sakristei eingelassen (Abb. 197). Seine Fassade besitzt die Form einer Ädikula, die über einem geschweiften Sockelbrett ansetzt und mit einem markanten Gebälk endet. Am Möbel angebrachte diamantförmige Zierköpfe gehören noch zum Formenvokabular des Beschlagwerks und sind zusammen mit den Profilen, die die Kontur des Kastens nachzeichnen und die Türfüllung rahmen, geschwärzt. Ein perforiertes Blech deckt eine Öffnung ab, die zur Belüftung des Möbelinneren aus dem Türchen ausgeschnitten wurde. Vermutlich bewahrte man in dem Wandschrank einst das Allerheiligste auf.

320 Plank, ebd., 5; Dehio, ebd., 278. 


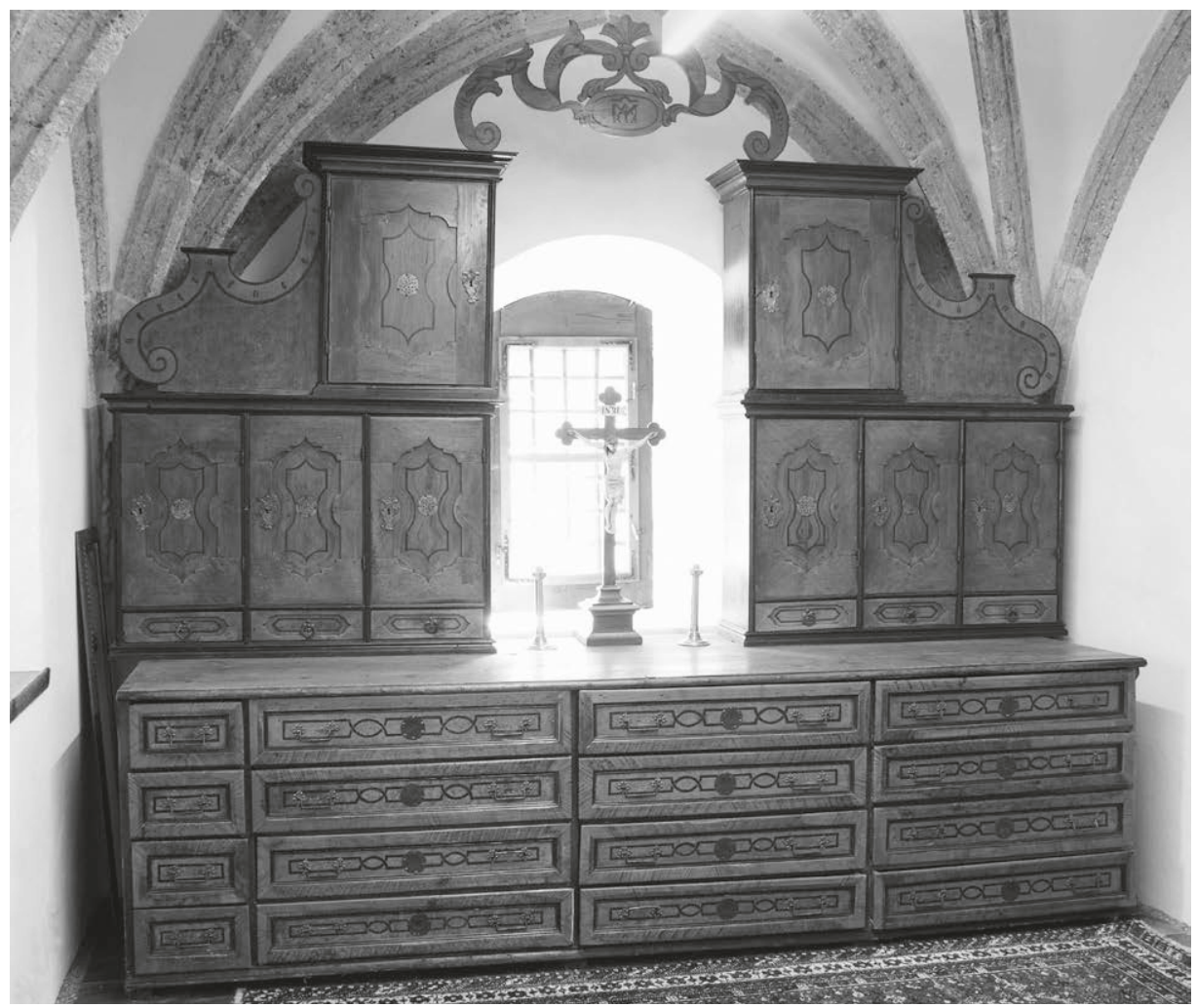

I98 Ankleidekredenz. Mariahof (?), um I730/40

\section{Ankleidekredenz}

Mariahof (?), um I $730 / 40$

Höhe der Füße $5 \mathrm{~cm}$

Gesimshöhe $270 \mathrm{~cm}(+5 \mathrm{~cm}) \times \mathrm{B} 34 \mathrm{I} \mathrm{cm} \times \mathrm{T}$ Iog $\mathrm{cm}$

Weichholz, bemalt. Eisen, teilverzinnt

Der vertikale Aufbau der vor der Ostwand des Raumes befindlichen Aufsatzkredenz besteht aus einer Substruktion, zwei Oberschränken und einem abschließenden Schnitzaufsatz (Abb. I98). Das Möbel lastet auf neuen Füßen, dürfte ursprünglich aber wie üblich auf einem Podest gestanden haben. ${ }^{321}$ Die Substruktion enthält Schub-

32 I Bei den wenigen mit Füßen versehenen Sakristeischränken, die im ersten Band unserer Studie vorgestellt werden, handelt es sich um Einzelfälle. Vgl. hierzu die Sakristeimöbel in Geras und Dürnstein. Bohr, Sakralmöbel (2017), 267-270, 291-294. 
laden, breite Leisten umrahmen ihre Vorderstücke. Eine in der Höhenausdehnung L-förmige Gestaltung ist den beiden Aufsatzschränken, die aus einem flachen Sockel, einer Reihe mit Kelchfächern und einem hohen Oberschrank bestehen, zu eigen. Am Aufsatz sind die Füllungen von den Rahmen auf eine ungewöhnliche Art geschieden, denn die mit kleinteiligen Schweifungen und rechtwinkligen Brüchen versehenen breiten Rahmensegmente vermitteln den Eindruck, wie eine zweite Schicht auf eine Grundfläche aufgebracht worden zu sein, da keine Profilleisten die Füllungen begleiten und die Kanten auch nicht abgeschrägt sind. ${ }^{322}$ Blenden füllen die Zwickel seitlich der oberen Möbelsegmente, ausgesägte Bögen, die sich der spitzbogigen Raumwölbung anpassen, verbinden die beiden Schränke über die Fensternische hinweg. Die mit Blattwerk ergänzten Spangen der Bekrönung stützen eine Kartusche mit dem Monogramm Mariens.

Die Kredenz ist hellbraun gefasst, Maserung und Adern sind aufgemalt, die Profile geschwärzt, Beschläge teilweise verzinnt. Die Zuggriffe der Schubladen des Unterschranks besitzen die Form eines flachen und breiten U, eine Form mithin, die im fortgeschrittenen I7. sowie im I8. Jahrhundert häufig gewählt wurde. Die Sakristeischränke der Stifte Seitenstetten und St. Paul bieten hierfür gute Beispiele (Farbtaf. o9; Abb. 6r I) das Gleiche gilt für die Adern, die die Laden zieren. Sie zeichnen unprätentiöse Muster nach, wie wir sie aus dem zweiten Viertel des I 8. Jahrhunderts ähnlich von den Schränken in St. Paul oder von Möbeln in St. Stephan zu Wien her kennen. ${ }^{324}$

Der Unterschrank präsentiert sich mit einer asymmetrischen Formgebung. Weiter fällt auf, dass die oberen Schrankteile seitlich etwa eine Handbreit über die Platte des Unterschrankes überstehen, während ihre Innenseiten in die Fensternische hineinragen. Möglicherweise war der Oberschrank also einmal Teil eines anderen Möbels. Oder Substruktion und Aufsatz gehören zwar zusammen, sind aber einst für den Standplatz in einer größeren Sakristei gefertigt worden, weshalb der Unterschrank bei der (angenommenen) Translokation gekürzt werden musste.

\section{Kirchenraum}

\section{Zweisitz}

Mariahof, 2. H. I7. Jh.

$\mathrm{HS} 7 \mathrm{~cm}$

$\mathrm{H} \mathrm{I} 37,5 \mathrm{~cm}(+7 \mathrm{~cm}) \times \mathrm{B}_{\mathrm{I}} 25 \mathrm{~cm}$

Nadelholz

322 Eine vergleichbare Gestaltung ist vor allem von Möbeln aus der Mitte des I 9. Jahrhunderts bekannt.

$323 \mathrm{Zu}$ Seitenstetten vgl. Bohr, Sakralmöbel (20 I 7), 458-46r.

324 Bohr, ebd., 23 I-232. 
Analog zur Situation in etlichen anderen Kirchen (Abb. I 8, 228) steht der Zweisitz neben dem Sakristeieingang (Abb. I99). Wie viele Möbel aus dem Alpenraum kennzeichnet auch ihn ein recht einfacher Aufbau. Auf die Seitenwangen aufgenagelte Bretter bilden die Brustwand, die an der Vorderseite befestigten Profile fassen eine Scheinfüllung ein. Schweifungen bestimmen das Design der schmalen Wangen von Brüstung, Sitzbank und Rückenlehne, deren Oberkante ebenfalls eine Reihe von Bögen aufweist. Aufgeleimte Lettern formen an der Lehne das Monogramm Christi sowie zwei unlesbare Buchstabenpaare, Farbreste bezeugen eine frühere Fassung des heute holzsichtigen Möbels.

\section{Laiengestübl}

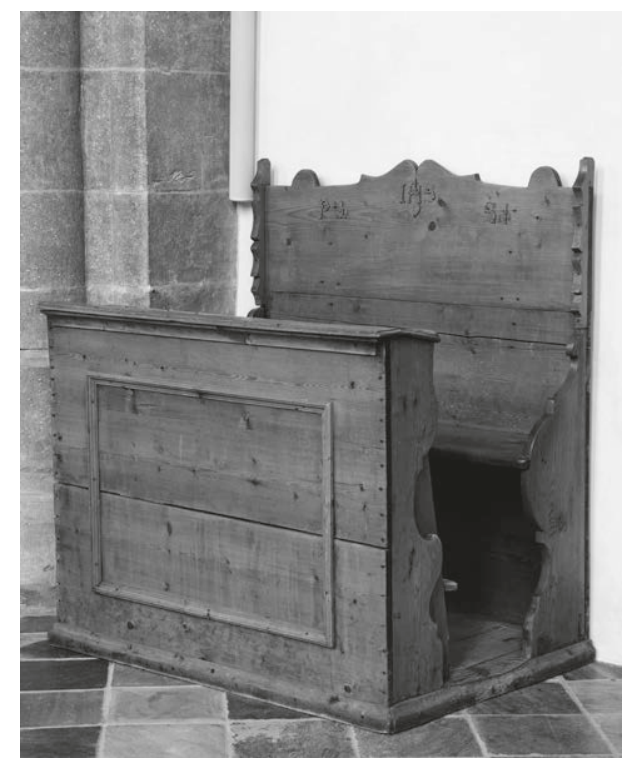

I99 Chorraum, Zweisitz. Mariahof, 2. H. I7. Jh.

Christoph Paumgartner (?), um I640/50

HS $22 \mathrm{~cm}$

$\mathrm{H} \mathrm{IO} 4 \mathrm{~cm}(+\mathrm{I} 2 \mathrm{~cm}) \times \mathrm{L}_{32} 6 \mathrm{~cm}$

Zirbelholz, Lärche

Seitlich des Mitteldurchgangs verteilen sich 32 Kirchenbänke mit den zugehörigen Brüstungen auf zwei Podeste (Abb. 200-202). ${ }^{325}$ Die Brustwände bestehen aus langen horizontalen Bohlen, in die die senkrechten Stollen eingezapft wurden. Von profilierten Rahmen gehaltene Rechteckfüllungen schließen die Konstruktion. Zusammen mit dem Abschlussgesims vermittelt ein über den Binnenfeldern angebrachter Profilstab die Illusion eines Gebälkes.

Die Brüstungswangen sind auffallend schmal und bis auf das obere Endstück gerade von oben nach unten geführt. Dem entspricht eine gerade Vorderkante an den Docken der ersten Reihen, offensichtlich waren hier einst Türen eingesetzt. Ansonsten bilden die Bankwangen einen angedeuteten C-Bogen mit geschweiften Konturen, die breite Profile zusätzlich betonen. Ein Hochoval in der Mitte jeder Docke trägt an den südseitigen Gestühlsreihen das Monogramm Christi, gegenüber das Marienmono-

325 Gerlach, Chorgestühl (r 93 I), 34; Plank, Mariahof (r 995), I 3; Dehio, Steiermark (2006), 279. 


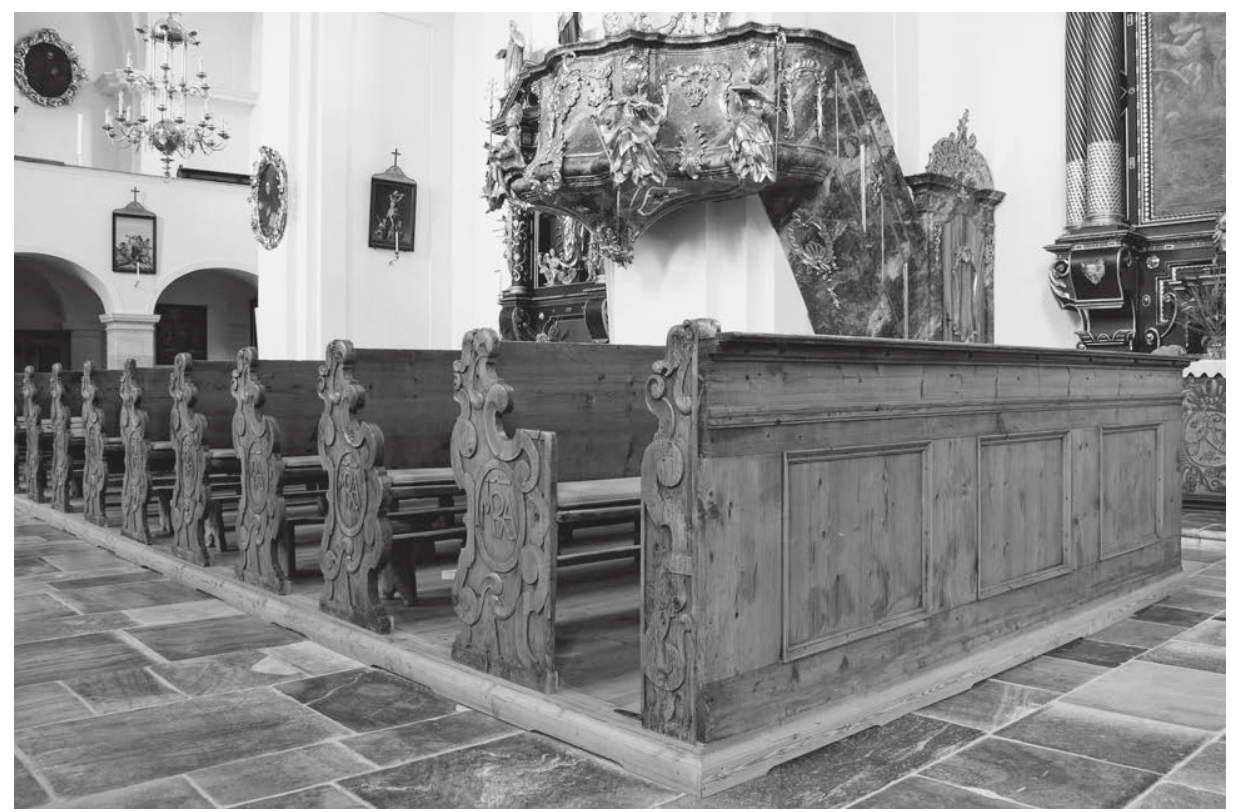

200 Kirchengestühl. Christoph Paumgartner (?), um I640/50

gramm. Der Kopf eines grotesken Raubvogels formt das Wangenende. Augen und gekrümmter Schnabel sind gut zu erkennen, mit dem Hohleisen geschnitztes Blattwerk deutet das Federkleid an. Zusammen mit diesen manieristischen oder frühbarocken Formen kommen Beschlagwerkmotive vor: ein Obelisk über der Sockelleiste, ein diamantförmiger »Nagelkopf « in mittlerer Höhe über der Kniebank sowie abgeflachte Profile, die an aufgelegte Leder- oder Metallbänder erinnern.

Die Möbel auf der Südseite besitzen schräge Gebetbuchablagen, die jeweils auf der Rückenlehne der Bank aufliegen, während die Buchablagen gegenüber etwa $15 \mathrm{~cm}$ unterhalb der Oberkante des Rückenbretts angebracht sind. Für eine ähnliche Konstruktion entschied man sich um die Mitte des I7. Jahrhunderts bei der Fertigung der Gestühlsgarnituren für die Pfarrkirche zu Steirisch Laßnitz und die Stiftskirche zu St. Lambrecht (Abb. 260, 26r). Den Grund hierfür kennen wir nicht, doch liegen die Sakralbauten nur wenige Kilometer voneinander entfernt, selbstverständlich kannte man die Ausstattungen der jeweils anderen Kirchen. Die Möbelgarnituren in Mariahof und St. Lambrecht sind nahezu identisch, das Gestühl in Laßnitz ist etwas einfacher. Allerdings verrät auch dessen Erscheinungsbild die Entstehung in diesem Zusammenhang. Georg Gerlach nimmt die Herkunft der Mariahofer Möbel aus der Werkstatt Christoph Paumgartners an, der I640/43 nachweislich die Bänke für 


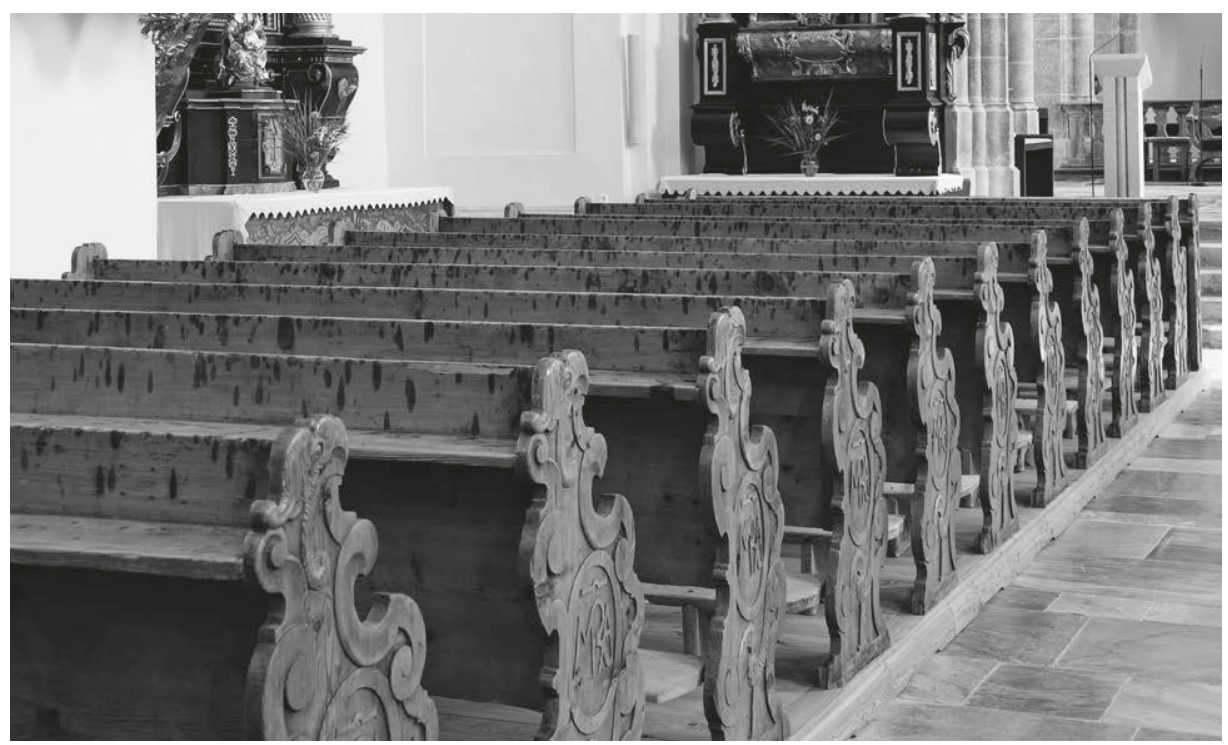

201, 202 Kirchengestühl. Christoph Paumgartner (?), um I640/50

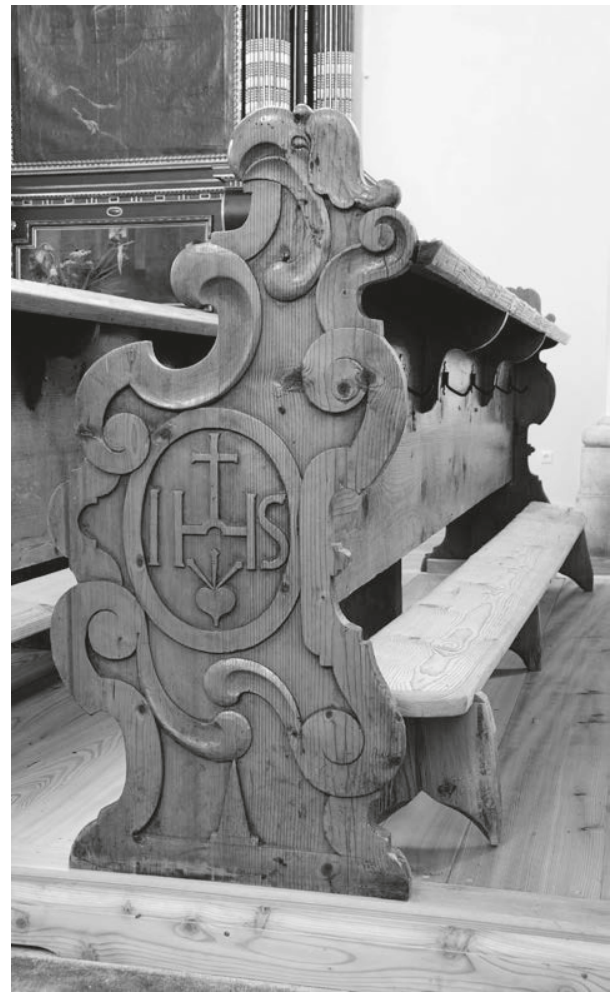


St. Lambrecht fertigte, die Vermutung Gerlachs dürfte zutreffen. ${ }^{326}$ Die Kniebänke und Laufpodeste des Möbelensembles in Mariahof sind modern, dagegen wurden die Lehnen und Gebetbuchablagen trotz der vielen Brandflecken bei der Überarbeitung der Möbel verdienstvollerweise nicht erneuert. Die Schäden sind ein wichtiger Teil der Geschichte dieser Inventarstücke.

\section{Laiengestübl}

Mariahof, um I650/60

HS $13,5 \mathrm{~cm}$

H I I cm $(+\mathrm{I} 3,5 \mathrm{~cm}) \times \mathrm{L} 226 \mathrm{~cm} / 232 \mathrm{~cm}$

Nadelholz, teilweise geschwärzt

Die Bankreihen stehen seit einigen Jahren auf der Empore der Kirche, zuvor befanden sie sich im Chorraum (Abb. 203, 204) ${ }^{327}$ Erhalten haben sich in Mariahof sechs Exemplare dieses Typs und zwei Brüstungen. Die Bänke der Evangelienseite sind um einige Zentimeter länger als die der Epistelseite.

Korinthische Keilpilaster auf hohen Postamenten gliedern die Brüstungen, über den Pilastern zieren Konsolen das Gebälk. Große Füllungen mit spitz nach innen gerichteten Seiten schließen die Zwischenräume. Geflammt gehobelte Profilleisten rahmen die Binnenfelder, Knorpelwerk und Scheibenfriese vervollständigen die Pilasterschäfte, Postamente und Konsolen.

Kleinteilige Bögen, wie sie als typisch für das I7. Jahrhundert gelten, schrägen die Bankwangen im oberen Drittel ab, darunter hobelten die Tischler die Außenkanten gerade aus. Ohrrahmen und ein gesprengter Giebel formen eine Ädikula als Scheinfüllung. Knorpelige Spangen folgen der geschweiften Kontur und säumen das welsche Fenster. Durch ihre Großform erinnern die stelenartigen Docken an ähnliche Exemplare im steiermärkischen Neuberg oder im burgenländischen Maria Loretto (Farbtaf. o2; Abb. 209).

\section{Beichtstüble}

Vor der Westwand der Kirche stehen unter der Empore zwei kastenförmige, mit Türen verschlossene Beichtstühle. ${ }^{328}$

326 Gerlach, ebd.

327 Dehio, Steiermark (2006), 279.

328 Plank, Mariahof (r 995), I 2 ; Dehio, ebd. 


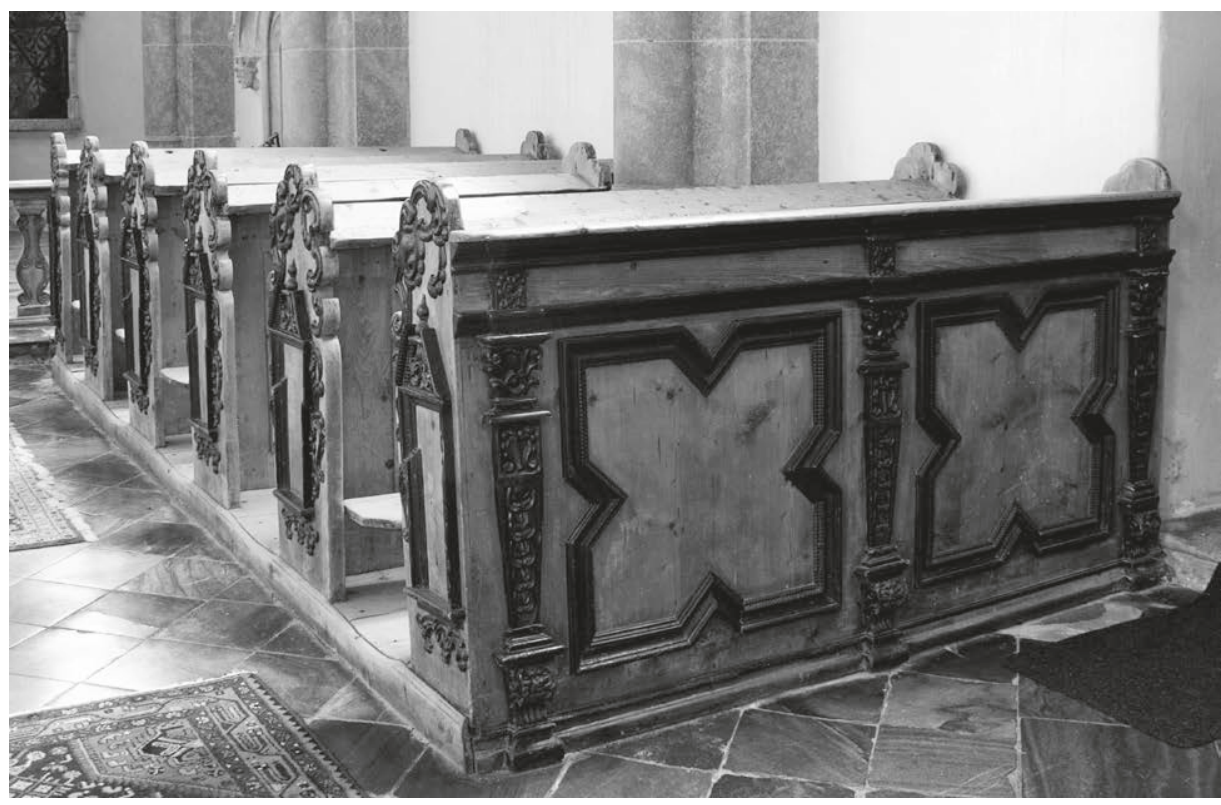

203 Kirchengestühl. Mariahof, um I650/60. Die Aufnahme entstand 2009, die Bänke befanden sich damals noch im Chorraum der Kirche.

204 Kirchengestühl, Bankwange. Mariahof, um r650/60

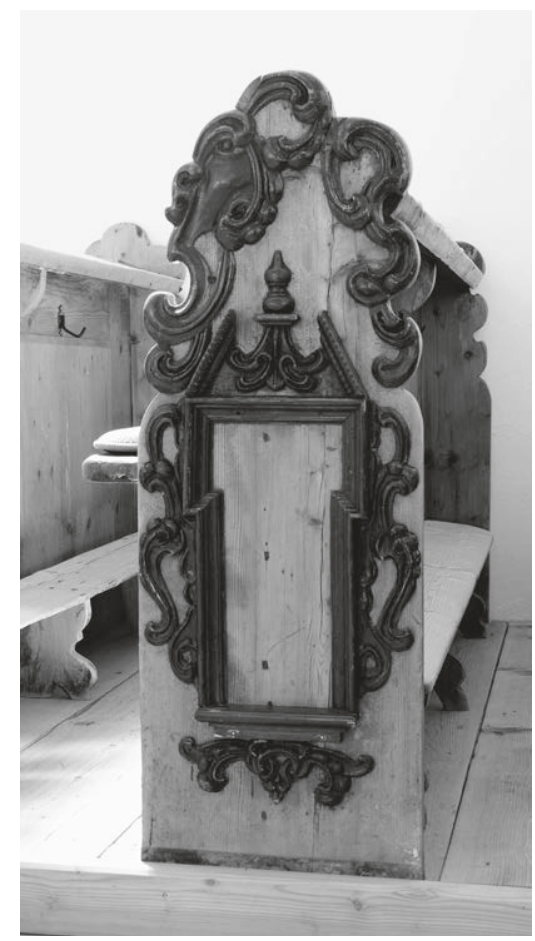




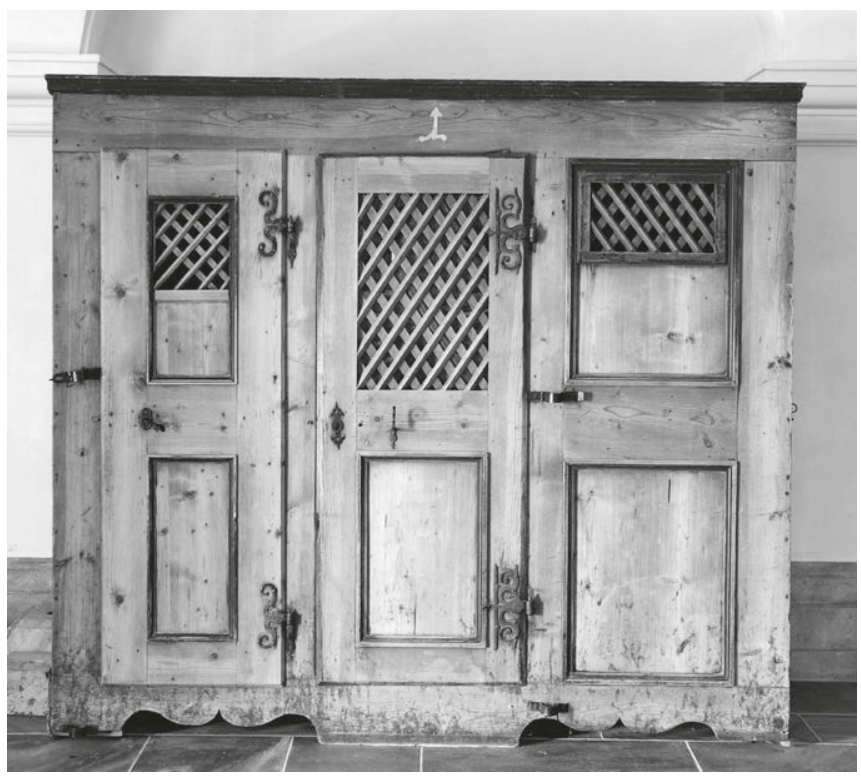

205 Beichtstuhl. Mariahof, 3. D. I7. Jh.

\section{Beichtstubl}

Mariahof, 3. D. I7. Jh.

$\mathrm{H} 2 \mathrm{I} 6 \mathrm{~cm} \times \mathrm{B} 242 \mathrm{~cm} \times \mathrm{T} 94 \mathrm{~cm}$

Nadelholz, teilweise geschwärzt. Eisen

\section{Beichtstuhl}

Mariahof, 3. D. I7. Jh.

$\mathrm{H}_{2} \mathrm{I} 3 \mathrm{~cm} \times \mathrm{B} 27 \mathrm{I} \mathrm{cm} \times \mathrm{T} 88 \mathrm{~cm}$

Nadelholz, Nuss. Eisen

Die Fassade des mit der Ziffer » « « bezeichneten Exemplars besitzt einen asymmetrischen Aufbau (Abb. 205). Die Front des rechten Fachs ist nicht mit einer Tür versehen, Pönitenten können es nur von der Schmalseite her betreten. Zwar ist auch auf dieser Seite ein Sprechgitter in die Trennwand zur Stalle des Priesters eingesetzt, doch wird es sich ursprünglich rechts um einen Schrank gehandelt haben, wie das bei solchen Möbeln häufiger zu beobachten ist. Das Confessarium wäre dann also später eingefügt worden. Sollte diese Vermutung zutreffen, hätte den Beichtenden lediglich das linke Gehäuse zur Verfügung gestanden. Das würde auch erklären, weshalb man das Füllungsgitter der rechten Zelle nachträglich hinzufügte, es wurde mit einem zusätzlichen Rahmen von außen an der Fassade befestigt. Nur so konnte auch diese Zelle von Pönitenten genutzt werden. 


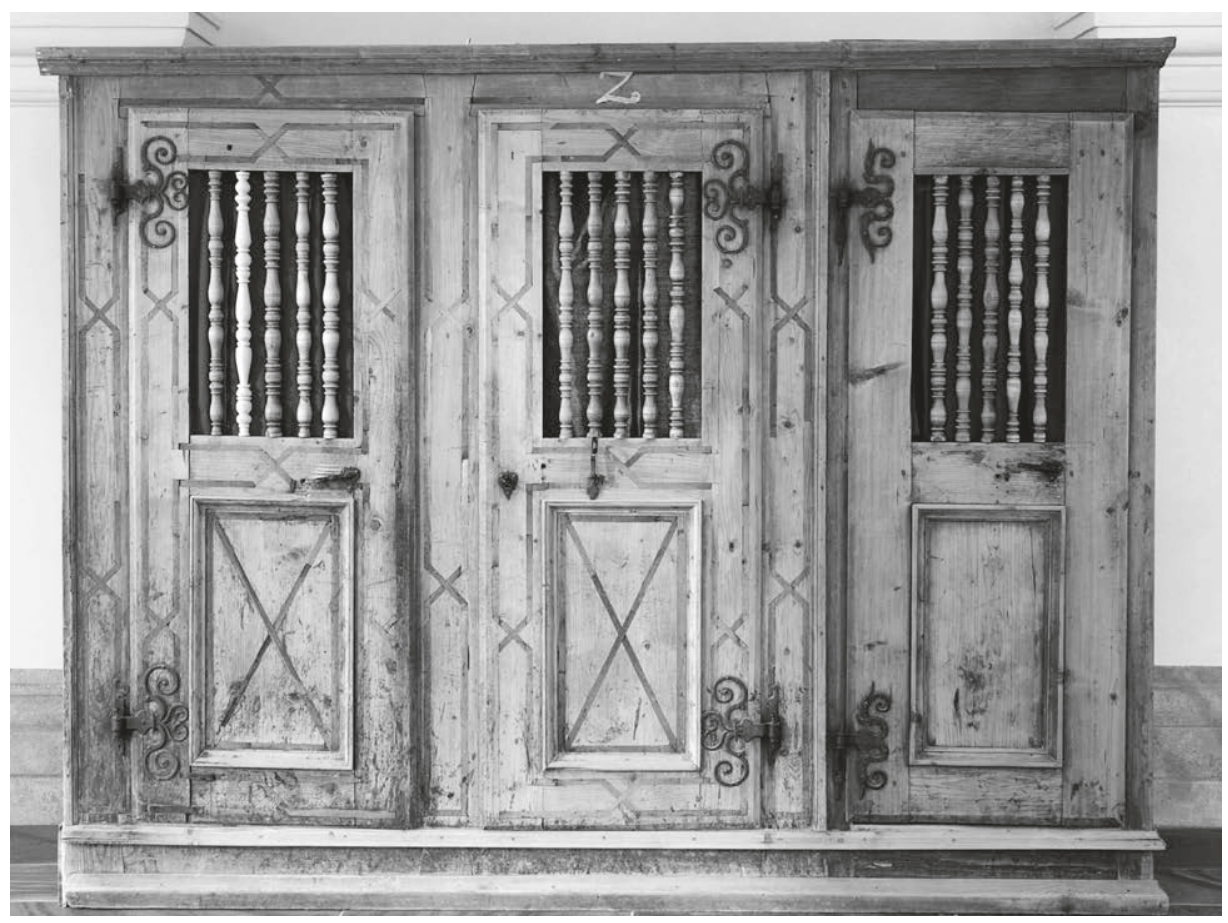

206 Beichtstuhl. Mariahof, 3. D. I7. Jh.

Exemplar Nr. 2 war ursprünglich ebenfalls ein Vertreter des zweizelligen Typus, das rechte Gehäuse kam später hinzu (Abb. 206). Links schmücken Zieradern die Fassade, rechts fehlen sie. Weiter verlängerte man das Abschlussgesims auf der rechten Seite und veränderte den Sockel. Und schließlich besitzen die Bänder auf der linken Seite eine andere Gestaltung als die etwas grober geschmiedeten rechts.

Neuberg an der Mürz, Pfarrkirche Maria Himmelfahrt

\section{Ehemaliges Zisterzienserstift}

Herzog Otto der Fröhliche gründete 1327 das Zisterzienserkloster, ließ es durch Mönche aus Heiligenkreuz besiedeln und bestiftete es mit reichen Ländereien und anderen gewinnbringenden Einnahmequellen. ${ }^{329}$ Zwar wurden 1336 bereits die Sa-

329 Pichler, Neuberg (1884); Kohlbach, Stifte (1953), 2 19-246; Mayer, Neuberg (I 953); Hootz, Kunstdenkmäler (I 965-1 968), Bd. 2 (1966), 262-265, 377-378; Fink, Neuberg (1967); Woisetschläger/ Krenn, Steirische Herrlichkeiten (I 973), 22-23, 64-65, Taf. 20, 22, 24, I33; Dehio, Steiermark (I 982 ), 
kristei und etwas später auch der Kapitelsaal geweiht, doch konnten die Bauarbeiten nach einem verheerenden Brand und einer Planänderung erst I 496 zum Abschluss gebracht werden. Nach der Aufhebung des Klosters am Ende des i 8. Jahrhunderts fiel dessen Vermögen dem steirischen Religionsfonds zu, seit I 800 befindet sich die Anlage in Staatsbesitz.

Die Kirche weist im Innern einen im Grunde nur angedeuteten kreuzförmigen Grundriss auf, der leicht erhöhte Chorraum ist mit einem Umgangschor versehen. Konvent und staatliche Stellen griffen in den vergangenen Jahrhunderten nur sehr zurückhaltend in den Bestand ein, sodass das charakteristische Erscheinungsbild einer spätmittelalterlichen Zisterzienserabtei noch heute das Aussehen der Anlage prägt. Am Interieur ist sehr gut ablesbar, dass die Ausstattung in verschiedenen Epochen erfolgte. Gotische Wandmalereien haben sich ebenso erhalten wie barocke Fresken, mittelalterliche Skulpturen ebenso wie frühneuzeitliche Altarwerke und verschiedene Bankgarnituren aus dem i 7. und I 8. Jahrhundert. Dabei wurden trotz großer Qualitätsunterschiede bereits existierende Möbel nicht ausgetauscht, sondern neue Exemplare jeweils in den alten Bestand integriert, was im Laufe der Zeit zu einem pittoresk anmutenden Erscheinungsbild führte.

\section{Tischlerwerkstätten}

In der vorbürgerlichen Epoche unterhielt das Stift Neuberg eine eigene Tischlerei, in denen Laienbrüder zusammen mit Handwerkern arbeiteten, die keine Ordensangehörigen waren. Archivalien listen im späten I8. Jahrhundert in der Tischlerwerkstatt der Abtei drei Hobelbänke und eine große Anzahl von Werkzeugen auf, außerdem standen dort zwei Betten und ein Schrank. Besaßen die ortsfremden Handwerker in der Nähe des Stiftes keine eigene Unterkunft, schliefen sie offenbar an ihrer Arbeitsstelle. Waren die Konventbetriebe mit Aufträgen ausgelastet, wandten sich die Klostervorsteher an externe Meister, um ihnen die nötigen Arbeiten zu übertragen. Mithilfe von Schriftquellen konnte der frühere Grazer Domkapitular Rochus Kohlbach eine ganze Reihe von Künstlern und Handwerkern nachweisen, die für den Konvent tätig waren. Dabei sind Nachrichten aus dem Stiftsarchiv weniger aufschlussreich als die Pfarrmatrikel der Gemeinde von Neuberg.

Der neuzeitliche Hochaltar der Stiftskirche, der in der Steiermark den Beginn der Entwicklung einer bestimmten Art barocker Altäre markiert, wurde I6II/I 2

31 5-320; Attems/Koren, Kirchen (I 988), 53-55; Pickl, Geschichte (1 996); Pick1/Kanzler, Geschichte (1996), bes. 39-170; Linhardt, Neuberg (2003). Zu weiteren Literaturhinweisen, zu Quellen und zur Forschungslage vgl. Taubinger, Refektorium (20 10), го-I6. 
von Stiftsbildhauer Hans Georg Mader aus Überlingen zusammen mit verschiedenen Kollegen geschaffen. Das Schreinwerk verfertigte Hans Schmid, genannt auch Hans Faber, den Archivalien nicht als Stiftstischler, sondern als ortsansässigen Hoftischler vermerkt haben. I620 wird er in einer Schriftquelle erneut erwähnt. ${ }^{330}$ Seine Tochter heiratete r63 I den Hoftischler Adam Beer, womit Beer den Zunftordnungen zufolge Schmids Tischlerei übernehmen konnte. ${ }^{331}$ Ab I657 war Martin Schött in der Umgebung des Stiftes tätig. Zunächst fand er als Architectus, dann als Faber lignarius Eingang in das Quellenmaterial. Er übte also die Berufe des Architekten und Zimmermanns oder Tischlers aus. I 686 berichten die Matrikel von einem Tischler namens Valentin Olm (I666-I720), I72I starb in Neuberg der Hofschreiner Wolfgang Supacher, I744 Anton Helmich (ca. I 7 I 9-I 744), einer seiner Nachfolger. ${ }^{332}$ I 755 baute Tischler Philipp Primbsch aus Neuberg eine Kanzel für die Kirche zu Stanz im Mürztal; der Handwerker verstarb I772. ${ }^{333}$ In der Gemeinde fanden also nicht nur kleine Landtischlereien ihr Auskommen, sondern auch Betriebe, die von Hoftischlern geleitet wurden. Mehrere dieser Handwerker kamen den Unterlagen zufolge aus weit entfernten Gegenden, aus dem Bodenseeraum etwa, aus Böhmen, Adam Beer sogar aus dem an der Masurischen Seenplatte gelegenen Węgorzewo (Angerburg) im damaligen Ostpreußen. Die Aufträge des Klosters müssen entsprechend anspruchsvoll und umfangreich gewesen sein.

\section{Empore}

Die dreiachsige Empore entstand während des Abbatiats von Johann Ludwig Holtz (reg. 1663-r671 $)^{334}$, ein Korridor über dem Kreuzgang verbindet sie mit dem ehemaligen Dormitorium. Depoträume in den äußeren Emporentravéen flankieren das Mittelschiffsjoch mit der Orgel und dem Chorgestühl. Standort des Instruments war ursprünglich eine Orgeltribüne am linken Seitenschiff der Kirche. I8 I4 wurde die

330 Kohlbach, ebd., 242.

33 I https://data.matricula-online.eu/de/oesterreich/graz-seckau/neuberg-an-der-muerz/9342/?pg= I [Zugriff Juni 2020]; Trauungsbuch IA I622-I653, 9342, p. I3, 31. August I63 I.

$332 \mathrm{Zu}$ Supacher:https://data.matricula-online.eu/de/oesterreich/graz-seckau/neuberg-an-der-muerz/9340/ [Zugriff Juni 2020]. Neuberg an der Mürz Sterbebuch I B, I689-I740, 9340, p. 90, 8. Januar I72 I. Zu Olm, ebd., p. 89, 2. Juni I 720. Zu Helmich, ebd., p. I33, 27. Juni I 744.

333 http://data.matricula-online.eu/de/oesterreich/graz-seckau/neuberg-an-der-muerz/9339/?pg=I 4 [Zugriff Juni 2020]; Sterbebuch 2, I 749-I784, 9339, p. 26, 20. Oktober I772. Vgl. zu den vorhergehenden Angaben auch Kohlbach, Stifte (1953), 242.

334 Pickl, Geschichte (I 996), 349. 


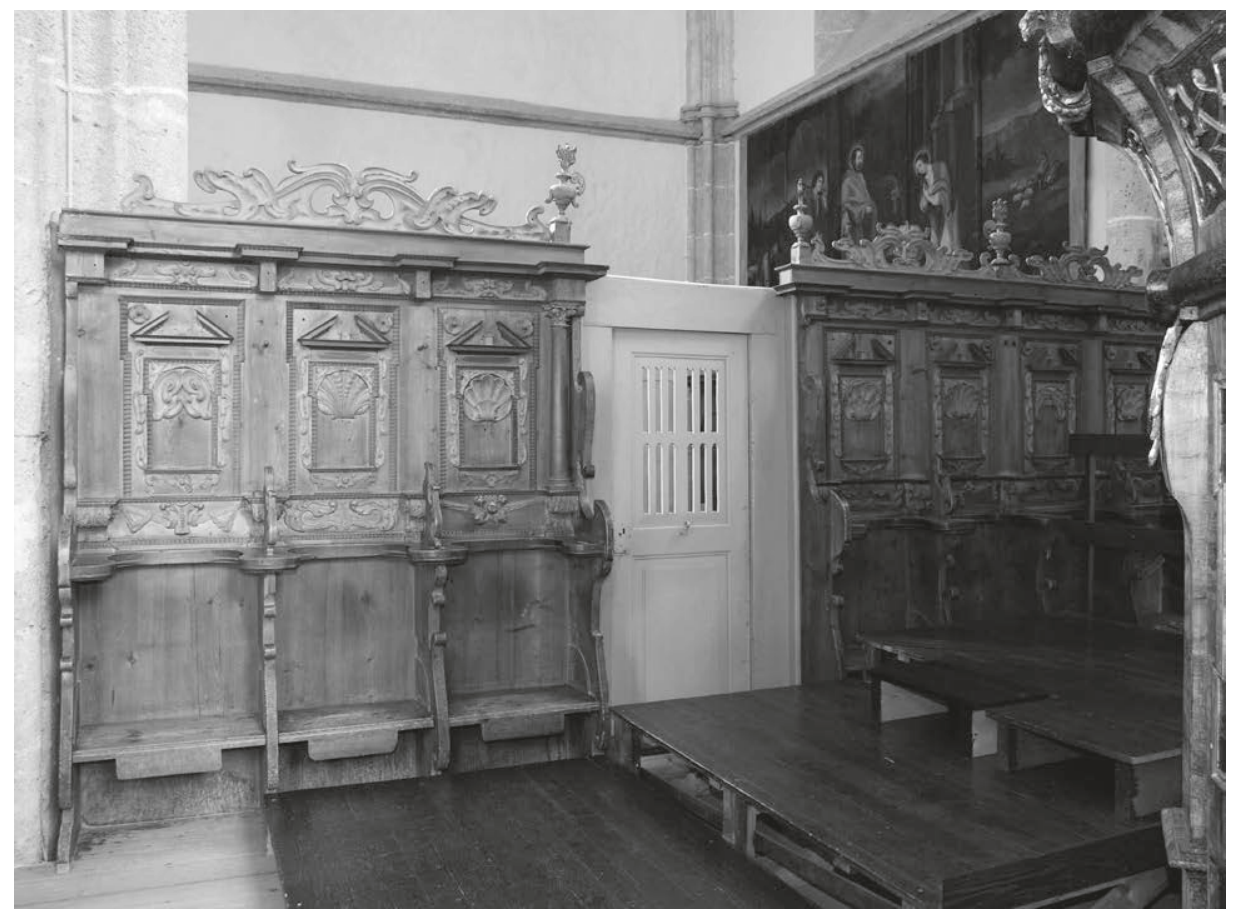

207 Empore, Chorgestühl. Neuberg, um I660/75

Orgel auf die Westempore verbracht und in einigem Abstand vor der Außenwand aufgerichtet. ${ }^{335}$

\section{Chorgestühl}

Neuberg, um r660/75

Gesamthöhe ca. $300 \mathrm{~cm} \times \mathrm{L} 2$ I $2,5 \mathrm{~cm} / 32 \mathrm{I} \mathrm{cm}$

Nadelholz, Linde

Das vierteilige Gestühl, das im heutigen Zustand I 4 Stallen umfasst, steht seitlich der Orgel (Abb. 207, 208). ${ }^{336}$ Vergleichbar mit dem Exemplar auf der Empore des Stiftes Rein (Abb. 243-248), erhob es sich einst vermutlich über U-förmigem Grundriss. Der querstehende Teil ist zwar verloren, doch bezeugt eine auf Gehrung geschnittene Schulterlehne am Ende der südlichen Stallenreihe, dass sich das Gestühl ursprünglich

335 Linhardt, Neuberg (2003), 26.

336 Vgl. zum Möbel Gerlach, Chorgestühl (I93 I), 38; Dehio, Steiermark (I 982), 3 I 8. 


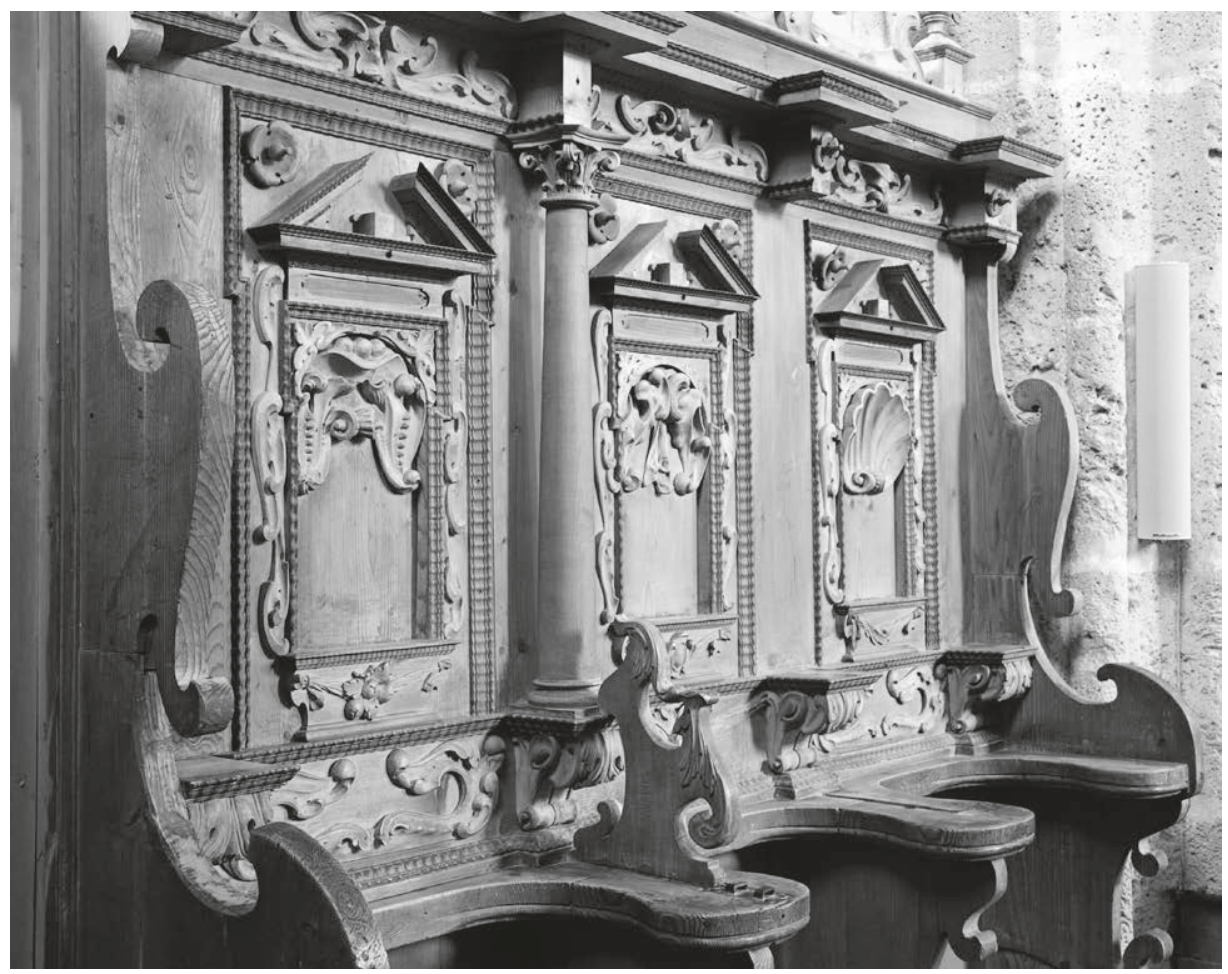

208 Chorgestühl, Schrägansicht der Rückwand. Neuberg, um I66o/75

vor der Westwand fortsetzte. Die Umgestaltung des Möbels könnte in Verbindung mit der Versetzung der Orgel vorgenommen worden sein.

Sitzbretter und Accoudoirs lasten auf geschweiften Docken, die außen zu Hochwangen verlängert sind. Korinthische Säulen auf Voluten sowie Ädikulä, die von Konsolen getragen und von gesprengten Dreiecksgiebeln bekrönt werden, sorgen für die notwendige architektonische Instrumentierung der Rückwand. Große Muscheln, Blüten, Girlanden, Knorpelschnitzereien und Flammleisten schmücken das Gestühl. Es endet über dem verkröpften Gebälk mit hochbarocken Schnitzornamenten und Flammenvasen.

Georg Gerlach nahm das Gestühl I93 I mit folgendem Eintrag in seine Arbeit auf: »[...] Neuberg, ehemalige Stiftskirche, Chorgestühl jetzt auf der Musikempore aufgestellt. ${ }^{337}$ Ist das so zu verstehen, dass das Chorgestühl vor I 93 I im Chor oder im Mittelschiff der Kirche platziert war? Leider macht Gerlach dazu keine weiteren Angaben und in der relevanten Literatur gibt es keine Hinweise, die zur Klärung die-

337 Gerlach, ebd. 


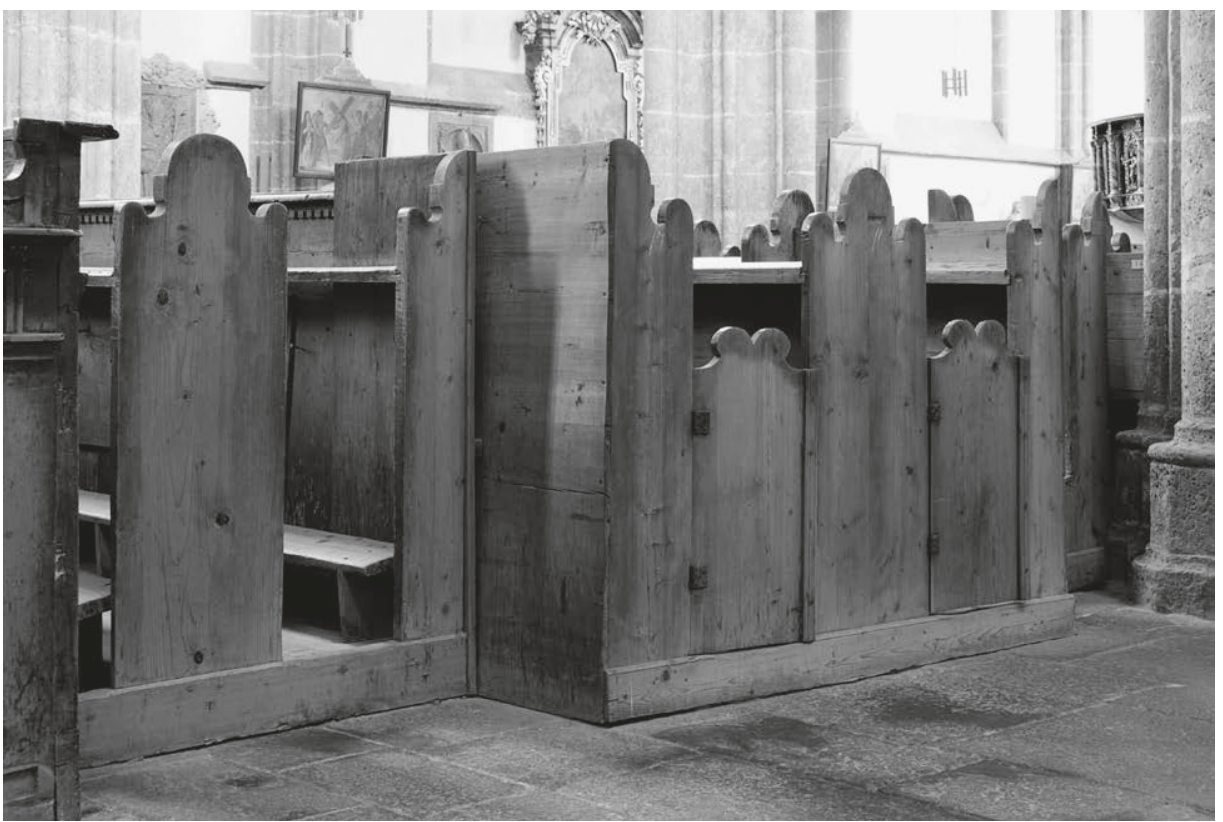

209 Laiengestühl. Neuberg, 2. D. I7. Jh. Im Bild sind Bänke zu erkennen, aber auch Einzel- oder Zweiersitze.

ser Frage beitragen könnten. Befand sich das Gestühl zuvor tatsächlich im Chorraum, könnte man bei seiner Translozierung auch die Brüstung entfernt haben - wenn sie denn jemals existierte. ${ }^{338}$ Falls man das Möbel jedoch speziell für den Standort auf der Empore konzipiert hatte, war vielleicht aus Platzgründen die Umgestaltung notwendig, als die Orgel I 8 I 4 auf der Westempore errichtet wurde. Der Korpus des Gestühls besteht aus Nadelholz, der Schnitzzierrat aus Linde.

\section{Kirchenraum}

\section{Laiengestühl}

Neuberg, 2. D. I7. Jh.

HS $15 \mathrm{~cm}$

$\mathrm{H} \mathrm{I} 20 \mathrm{~cm} / \mathrm{II} 5 \mathrm{~cm} / \mathrm{IO} 5 \mathrm{~cm}(+\mathrm{I} 5 \mathrm{~cm}) \times \mathrm{L} 63 \mathrm{~cm} / 79 \mathrm{~cm} / 266 \mathrm{~cm} / 354 \mathrm{~cm} / 402 \mathrm{~cm}$

Zirbelkiefer

338 Nach Recherchen von Sybe Wartena besaßen Gestühle der Zisterzienser in Süddeutschland generell keine Brüstungen. Wartena, Süddeutsche Chorgestühle (2008), 36. Vgl. hierzu auch Bohr, Sakralmöbel (2017), 85-86. 


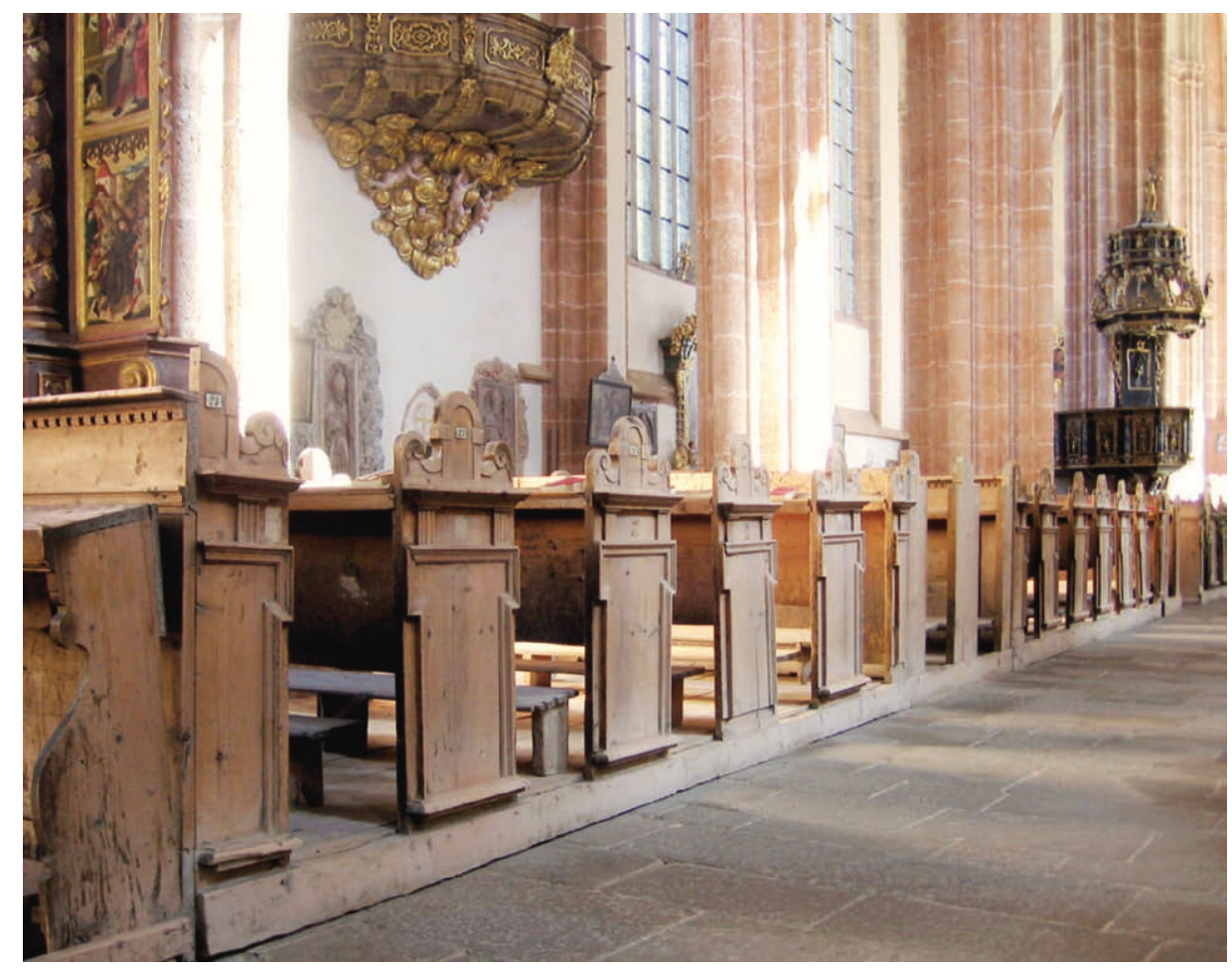

Farbtafel 23 Laiengestühl. Neuberg, 2. D. 17. Jh.

Die 56 Bänke und Brüstungen verteilen sich auf vier Postamente, die zum Teil vom Mittelschiff aus in die Seitenschiffe hineinragen. ${ }^{339}$ Einige Möbel wurden als Einzeloder Zweiersitze gebaut (Abb. 209) und an längere Bänke angefügt. Daneben unterscheiden sich die Inventarstücke aber auch durch ihr Aussehen voneinander, sie entstanden zu verschiedenen Gelegenheiten. Hier liegt der seltene Glücksfall vor, dass das Kircheninterieur im historisch gewachsenen Zustand belassen und nicht erneuert wurde. Wegen ihrer Gestaltung interessieren im Kontext namentlich zwei Banktypen.

Die Wangen des ersten Typs (Farbtaf. 23) präsentieren sich als Hochrechteck mit oberer Schmalseite, die aus einem mittleren arkadenförmigen Segment und zwei niedrigen Voluten besteht. Breite Bänder unterstreichen am Auszug die Außenkanten und heben das Mittelstück hervor. Mit dieser Formensprache erinnern die Möbel an das I 640/43 geschaffene Gestühl in St. Lambrecht sowie an das um I640/50 entstandene in Mariahof (Abb. 202, 26r). Unter dem Auszug blendeten die Tischler den Wan-

339 Dehio, Steiermark (1982), 3 I 8. 
gen eine schlichte Ädikula vor. Das kommt vergleichbar an einer Bankgarnitur in der Stadtpfarrkirche zu Oberwölz von i 647 vor. ${ }^{340}$

Eine andere Form wählte man für eine zweite Gruppe von Sitzmöbeln, bei deren Bau der künstlerische und handwerkliche Aufwand weiter reduziert wurde (Abb. 209). Die Grundform der Wangen, hohe Stelen mit dreigliedrigem Abschluss, entspricht dem Erscheinungsbild der beschriebenen Exemplare, doch verzichtete man nun auf jegliche weitere Verzierung. Die Gestaltung der Docken ist vermutlich als Weiterentwicklung spätmittelalterlicher Exemplare anzusehen, wie sie sich beispielsweise in Gröbming erhalten haben. Die I 5 I 4 datierten Möbel zeichnen stelenförmige, im oberen Bereich eingezogene und abgerundete Wangen aus, sie sind allerdings mit Flachschnitzereien verziert und polychrom gefasst. ${ }^{341}$ Den Zugang zu den Bänken in Neuberg verschließen niedrige Türen. Die Brüstungen ähneln jenen in der Stiftskirche zu St. Lambrecht (Abb. 260), die Konstruktion aus breiten Rahmen und großen Rechteckfüllungen wiederholt sich an etlichen Bankensembles aus jener Zeit. ${ }^{342}$

\section{Abtsedile}

Neuberg, um I730

$\mathrm{H}$ ca. $300 \mathrm{~cm} \times \mathrm{B} 356 \mathrm{~cm} \times \mathrm{T} \mathrm{I} 80 \mathrm{~cm}$

Nussbaum, Nuss (?) geschwärzt, Pappelmaser, Ahorn, Nadelholz

Die über einem segmentbogenförmigen Grundriss errichtete Sedilie stand I 884 am ersten Pfeiler rechts des Hochaltars, an dieser Stelle zeigt sie noch ein Aquarell von I9 $6 .{ }^{343}$ Heute ist sie gegenüber der Kanzel vor der südlichen Außenwand platziert (Abb. 2 Iо, 2 I I). Seitenwände verbinden Brüstung und Rückwand, sodass sich insgesamt eine trapezähnliche Form mit abgerundeter Vorderseite ergibt. Allerdings weist das Möbel keine Achsensymmetrie auf, vielmehr verläuft die linke Seite, die den Zugang zur Sitzbank gestattet, beinahe im rechten Winkel von der Rückwand nach vorn, wohingegen die rechte Seite mit einem stumpfen Winkel nach außen geführt ist. Die Form des Inventarstücks ist ausgefallen, doch lassen sich nicht nur in der Steiermark, sondern auch in anderen Regionen ähnliche Bänke vor einem Vierungs- oder

$340 \mathrm{Zu}$ den Bänken in Oberwölz s. Woisetschläger/Krenn, Steirische Herrlichkeiten (1973), 68-69, Taf. I47.

34I Attems/Koren, Kirchen (I988), I 22 ; Tomaschek, Gröbming (200I), I4; Dehio, Steiermark (2006), I 48.

342 Vgl. hierzu auch die ehemaligen Bänke in der Domkirche zu Wien. Kuba-Hauk/Saliger, Diözesanmuseum (1987), 290-292, Abb. 364. Ähnliche Möbel müssen sich überdies in der Kirche in SalzburgMülln befunden haben. ÖKT, Salzburg (I 9 I 2), I 96.

343 Pichler, Neuberg (1884), 24; Gerlach, Chorgestühl (1931), 40; Dehio, Steiermark (1982), 318; Linhardt, Neuberg (2003), 23-24; Dorotheum Wien, Versteigerung am 30.09.2015, Lot 258. 


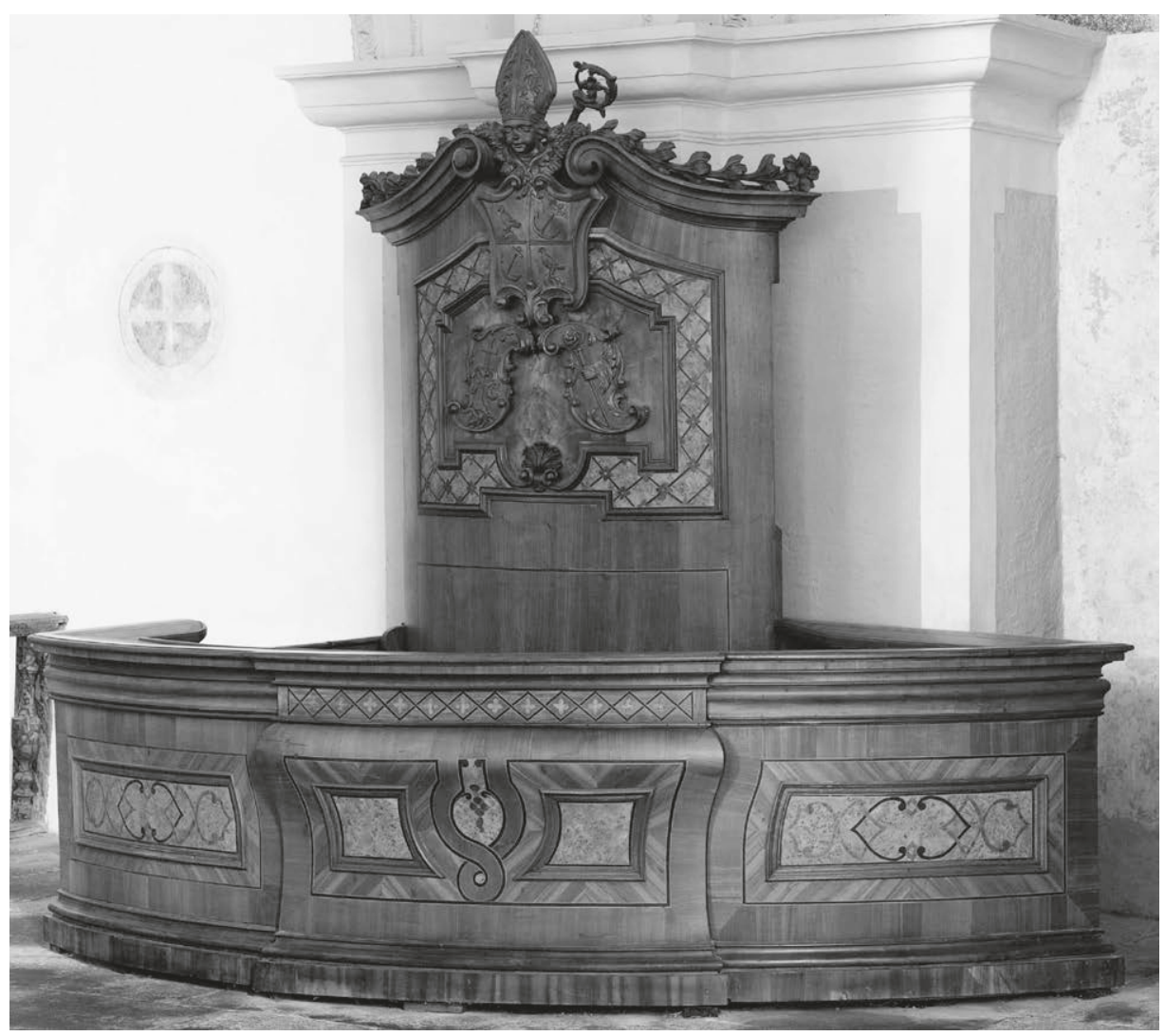

2 Io Kirchenraum, Abtsedile. Neuberg, um 1730

2 I I Abtsedile (Rückwanddetail). Neuberg, um 1730

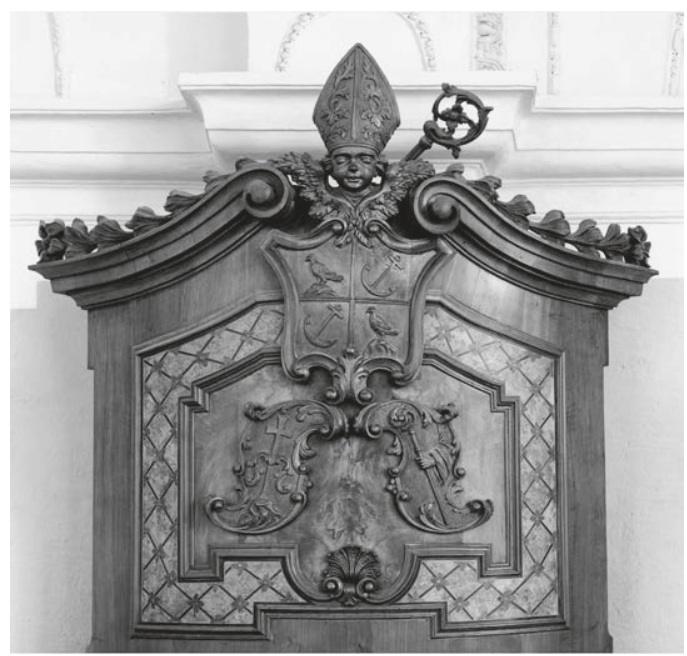


Chorbogenpfeiler nachweisen. Das Möbel in der Pfarrkirche Mariä Himmelfahrt zu Gröbming (Abb. I9I) ist dafür ein Beispiel, weitere Exemplare befinden sich in der Stadtpfarrkirche zu Murau. Sie stehen vor den westlichen Vierungspfeilern und weisen diagonal in das Vierungsquadrat. ${ }^{344}$ Zwei Möbel mit analoger Positionierung im Kirchenschiff aus dem oberösterreichischen Baumgartenberg werden im ersten Band der Untersuchung vorgestellt, auf weitere wird in Verbindung mit der Beschreibung des Mobiliars von St. Paul im Lavanttal (Kärnten) aufmerksam gemacht. ${ }^{345}$ Und I 7 I 2 baute der Wiener Hoftischler Matthias Rueff (I658-ı7 18) solch ein Möbel zur Aufstellung in der Stiftskirche Heiligenkreuz in Niederösterreich. ${ }^{346}$

Die Brüstung der Sedilie ist dreigeteilt, die Mittelachse ähnlich einem Postament ausgearbeitet und verkröpft, das Schulterstück unter dem gebälkartigen Abschluss gebaucht. Dagegen sind die seitlichen Bahnen in der vertikalen Ausrichtung als gerade Flächen angelegt, wobei sich ihr Abschluss von dem des mittleren Jochs unterscheidet: Ein intarsiertes Rautenmuster in der Mitte steht seitlichen wellenartigen Profilen gegenüber.

Einem konvexen Bogen folgt auch die hohe, mit einem gesprengten Volutengiebel endende Rückwand. Über dem Sockelbereich erhebt sich das Hauptfeld, dessen Oberseite parallel zur Kontur des Giebels verläuft. Unter dem Giebel prangt das geschnitzte Wappen des Abtes Gottfried Haller (reg. I723-I730), ein geflügelter Engelskopf mit Mitra und Krummstab bekrönt das Möbel. Zwei weitere Kartuschen schmücken die Füllung. In einer erkennt man eine Hand mit einer Abt- oder Bischofskrumme, in der anderen ein M mit Kreuz, ein Hinweis auf den Umstand, dass der Zisterzienserorden seine Stiftskirchen der Muttergottes weihte.

Das Furnier wurde an Rahmen und Friesen der Brüstung mit senkrechtem, waagrechtem und diagonalem Maserverlauf aufgeleimt, Maserholz liegt auf den Füllungen. Miteinander verkettete Bänder, in der Mitte auch Blüten, zieren die Binnenfelder. Dagegen ist die Rückwand mit den erwähnten Schnitzarbeiten und einem intarsierten Rosengitter bereichert.

\section{Beichtstüble}

Neuberg, um I $735 / 40$

$\mathrm{H} 222 \mathrm{~cm} \times \mathrm{B} 286 \mathrm{~cm} \times \mathrm{T} 100 \mathrm{~cm}$

Nussbaum, Nussbaummaser, Pappelmaser, Zwetschke und andere Holzarten auf Nadelholz furniert. Eisen, geschwärzt

344 Woisetschläger/Krenn, Steirische Herrlichkeiten (I 973), I 9-20, Taf. I 5.

345 Zu den Möbeln in Baumgartenberg vgl. Bohr, Sakralmöbel (2017), 505-506, zu den Exemplaren in St.

Paul s. den relevanten Abschnitt in vorliegender Arbeit.

346 ÖKT, Heiligenkreuz (1926), 8 o. 

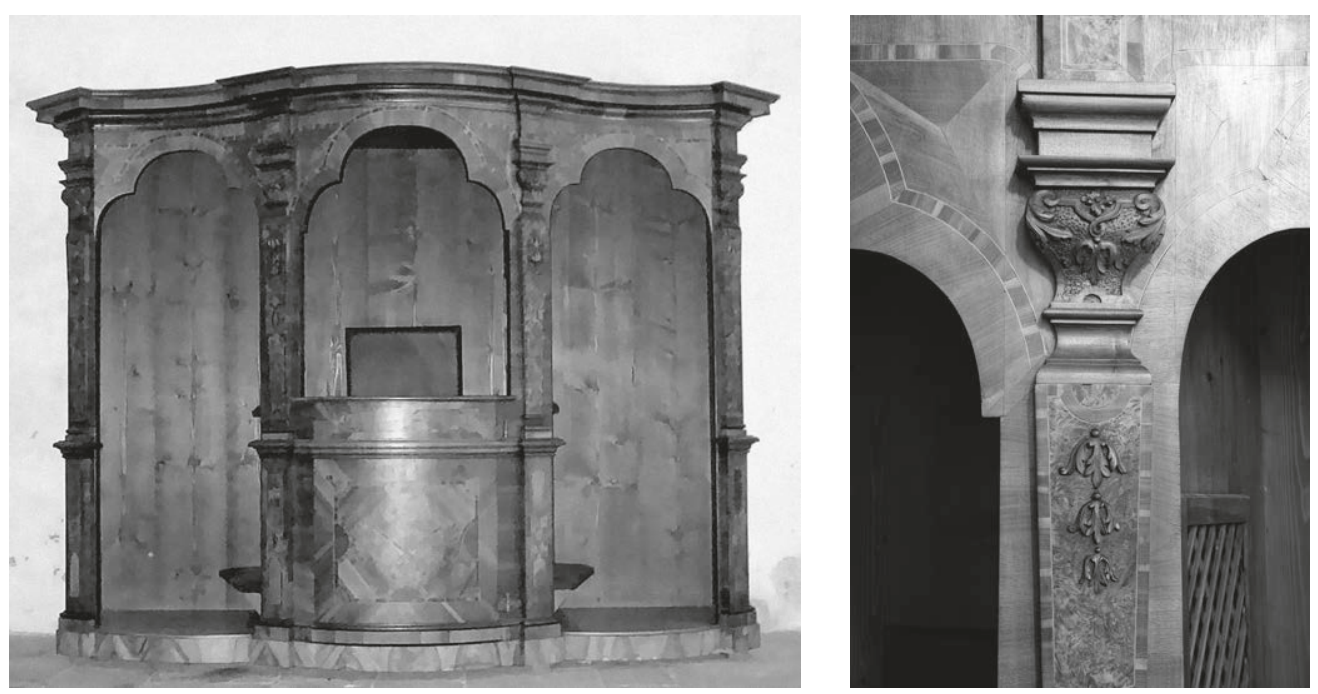

2 I 2 Beichtstuhl. Neuberg, um I 735/40

2 I 3 Beichtstuhl, Pilasterdetail. Neuberg, um I 735/40

Zwei Beichtstühle befinden sich unter der Empore, zwei weitere in einer Seitenkapelle (Abb. 2 I 2, 2 I 3) ${ }^{347}$ Den Sockelbereich der dreiachsigen Möbel kennzeichnen konvexe Bögen, wobei der mittlere weiter nach vorn reicht als die seitlichen. Von hohen Balustern aufsteigende Keilpilaster flankieren die arkadenförmigen und mit Kleeblattbögen schließenden Eintritte in die Möbel. Während das Gebälk im mittleren Joch den Grundrissverlauf des Sockels widerspiegelt, ist es seitlich in einer Gegenbewegung eingezogen.

Marketerien schmücken die Beichtstühle. Adern verlaufen teils kantenparallel, teils winden sie sich nach innen und bilden geschweifte geometrische Ornamentmotive. Füllungen mit eingelegten Sternen lösen die Schmalseiten der Möbel auf. Geschnitztes Bandl- und Laubwerk ziert die Kapitelle, Blütengirlanden vervollständigen den oberen Bereich der Pilasterschäfte.

\section{Sakristei}

Die Lage der mit einem Kreuzrippengewölbe versehenen Sakristei zwischen Kapitelhaus und Chorraum der Kirche entspricht dem klassischen Plan von Zisterzienserab-

347 Dehio, Steiermark (1982), 318; Linhardt, Neuberg (2003), 24. 


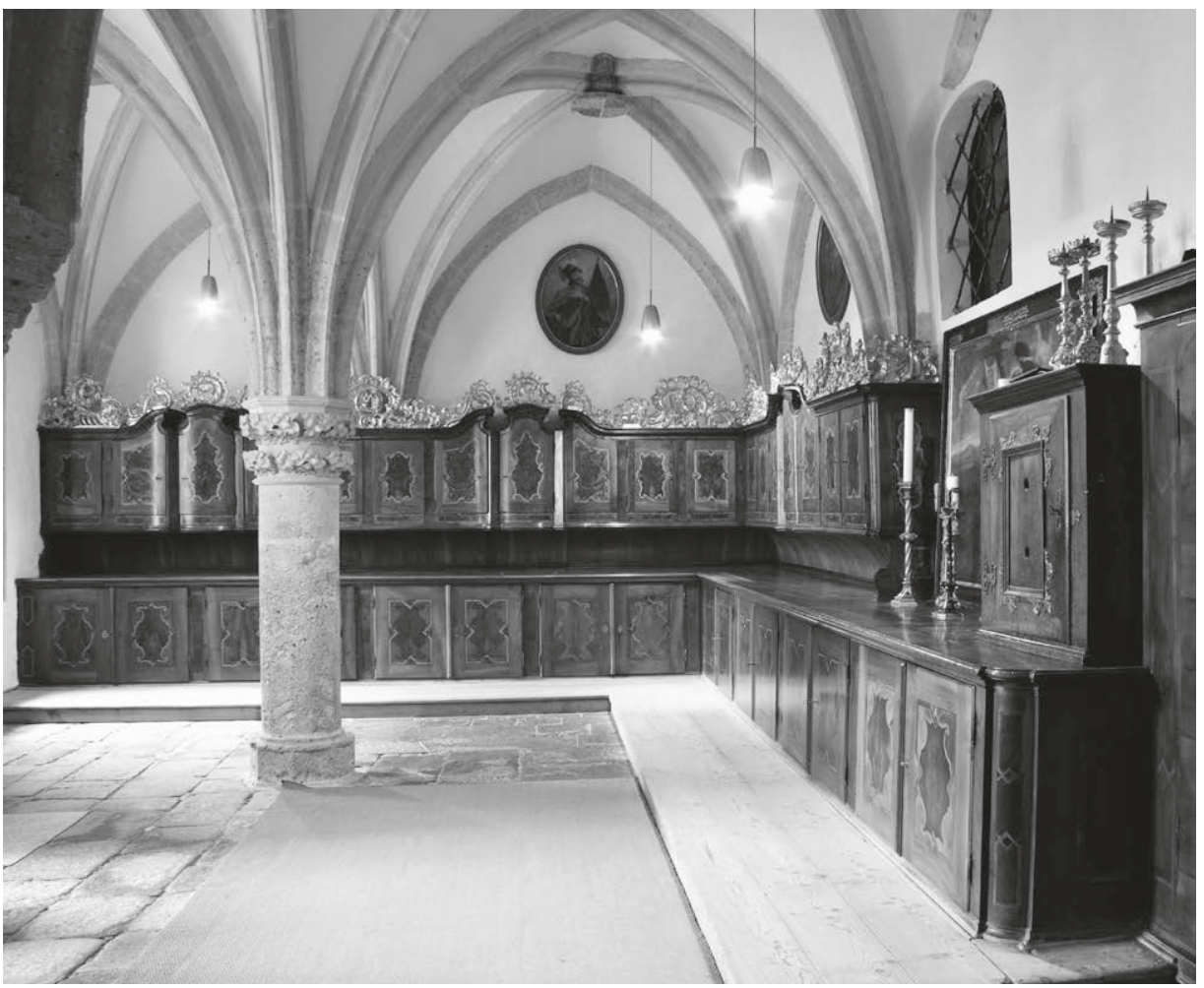

2 I 4 Sakristei, Ankleidekredenz. Neuberg, um I 755/65

teien. ${ }^{348}$ Durch Fensteröffnungen in der Ostwand strömt Licht in den Raum. Zwischen den Fenstern befindet sich ein Lavabo aus den r63oer-Jahren, vor der Süd- und Westwand stehen Schränke, die die Mönchskommunität bald nach der Mitte des I 8. Jahrhunderts anfertigen ließ. I 975 wurden sie restauriert.

\section{Ankleidekredenz}

Neuberg, um I 755/65

$\mathrm{HS} \mathrm{I}_{3} \mathrm{~cm}$

$\mathrm{H} 280 \mathrm{~cm}(+\mathrm{I} 3 \mathrm{~cm}) \times$ Gesamtlänge ca. I 3, Io m $\times \mathrm{T} 97 \mathrm{~cm}$

Nuss, Nussmaser, massiv und furniert, Zwetschke, Esche. Messingbeschläge, Eisen

348 Zu Raum und Einrichtung vgl. Kohlbach, Stifte (1953), 222, 243; Mayer, Neuberg (1953), 80; Fink, Neuberg (1967), I ; ; Dehio, ebd., 31 9 ; Linhardt, ebd. 


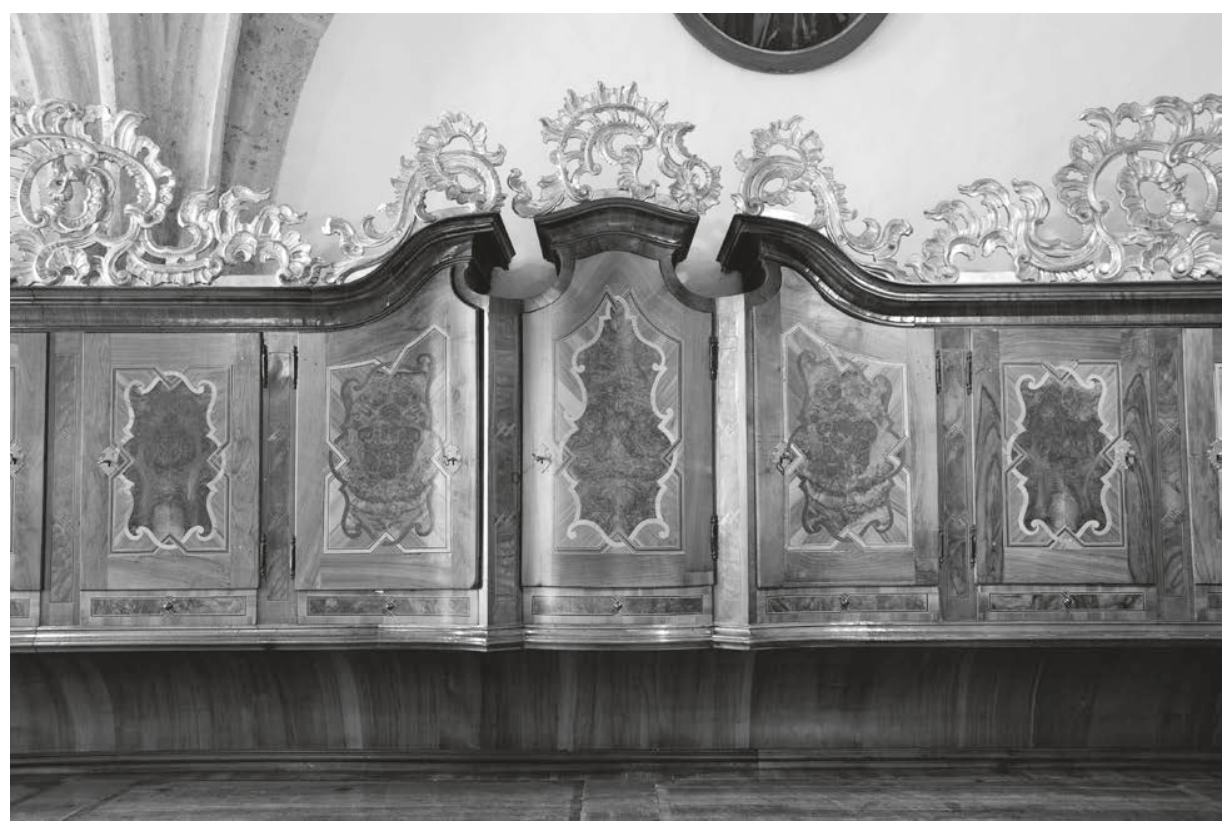

215 Ankleidekredenz, Teilansicht. Neuberg, um I755/65

Das über L-förmigem Grundriss errichtete Inventarstück reicht mit seiner Höhe bis zum Gewölbeansatz (Abb. 2 I 4, 2 I 5). Die freistehende vertikale Vorderkante der Substruktion wurde nach innen verkröpft und abgerundet, ansonsten bestimmen die flächig gearbeiteten Schranktüren das Erscheinungsbild des Unterschranks, der gut zwei Meter länger als der Aufsatz ist. Getragen von der Rückwand sowie von Konsolen unter den äußeren Enden, besteht er aus einer langen Abfolge von Kelchkästen, unter denen sich zusätzlich flache Schubkästen befinden. Bis auf drei mehrachsige und mit Sprenggiebeln versehene Teilstücke ist der Aufsatz gerade geführt.

Wie üblich trennen Adern die Rahmen von den Füllungen, doch setzt sich ein Teil der Adern aus fünf feinen Bändern zusammen. Dieser Umstand sowie die Tatsache, dass das Gesims quer zur Längsrichtung des Blindholzes mit senkrechtem Furnier überzogen ist, unterstreicht die hohe Qualität des Möbels. Als Werkmaterial wählten die Tischler handverlesenes Nussholz, dessen starke Maserung teilweise an die von Olivenholz erinnert. Aus luftigen Rocaillen bestehende, vergoldete und à jour ausgeführte Schnitzarbeiten bekrönen das Möbel. Die Beschläge sind modern.

Die Literatur nennt zwei verschiedene Herstellungsdaten. Rochus Kohlbach gibt an, das Möbel sei mit der Jahreszahl I 750 versehen, sie ist nicht mehr (?) zu finden. In der Folge ging Anton Fink von einer Herstellung der Möbel um die Mitte des I 8. Jahr- 


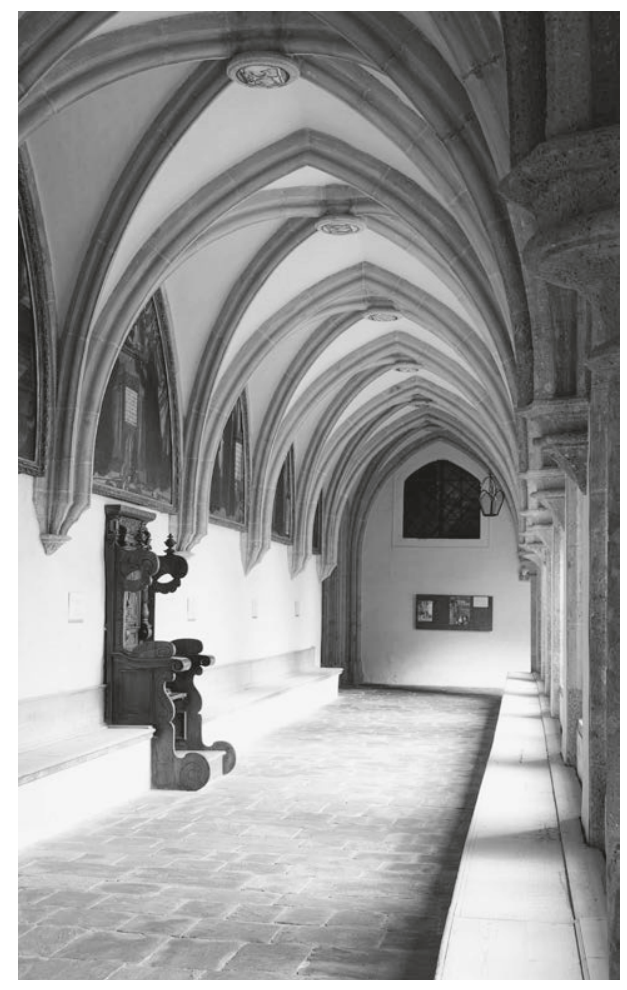

2 I 6 Kreuzgang, Kollationsgang mit Abtstuhl. Neuberg, I630 hunderts aus, während die Autoren des Dehio den Kelchschrank auf das Jahr I757 datierten. ${ }^{349}$ Auch diese Angabe ließ sich nicht verifizieren. Aus stilistischen Gründen darf aber ein Entstehungsdatum der Möbel etwa um I 755 bis I 765 als sicher gelten, eventuell gehen sie auf den eingangs erwähnten Tischler Philipp Primbsch zurück, der nach den Angaben in einer Schriftquelle für den Konvent arbeitete.

\section{Kreuzgang}

Abtstubl

\section{Neuberg, I6 630}

$\mathrm{H} 256 \mathrm{~cm} \times \mathrm{B} \mathrm{I} 25,5 \mathrm{~cm} \times \mathrm{T}$ ca. $100 \mathrm{~cm}$

Eiche, Nuss, Nadelholz, dunkel gebeizt

Wie in anderen Zisterzienserklöstern wurde in Neuberg der sich an das Kirchenschiff anlehnende Nordflügel des Kreuzgangs als Kollationsgang verwendet (Abb. 2 I6). ${ }^{350}$ Die etwa 23 bzw. $20 \mathrm{~m}$ langen Steinbänke vor den Mauern erhielten zu einem unbekannten

Zeitpunkt Auflagen aus Holzplanken, die Sessio des Abtes befindet sich auf der Nordseite (Abb. 217, 21 8). ${ }^{351}$ Zwischen zwei Voluten, die direkt auf dem Steinfußboden ansetzen, betritt man das Möbel über eine tiefe Stufe. Das Sitzbrett ist weit über den seitlichen Bänken angeordnet, sodass der Abt gegenüber seinen Mitbrüdern erhöht saß, um seine besondere hierarchische Stellung zu unterstreichen. Durch ihre auffallende Breite gemahnen die geschwungenen Armlehnen an analog geformte Lehnen südländischer Sitzmöbel. Als Besonderheit stützen hier zusätzlich Liegenvoluten die Arme des Prälaten auch zu den Seiten hin ab, darüber folgen Hochwangen mit nach vorn reichenden Blenden. ${ }^{352}$ Wie die Rückwände vieler Chorgestühle ist das Dorsale architektonisch strukturiert. Den Raum zwischen korinthischen Dreiviertel-

349 Kohlbach, ebd., 243; Fink, ebd.; Dehio, ebd.

350 Eine Analyse der Architektur des Kreuzgangs bei Mayer, Neuberg (I 953), $70-75$.

35 I Gerlach, Chorgestühl (I 93 I), 34.

352 Liegevoluten und Blenden dienten vermutlich auch als Schutz vor kalter Zugluft. 


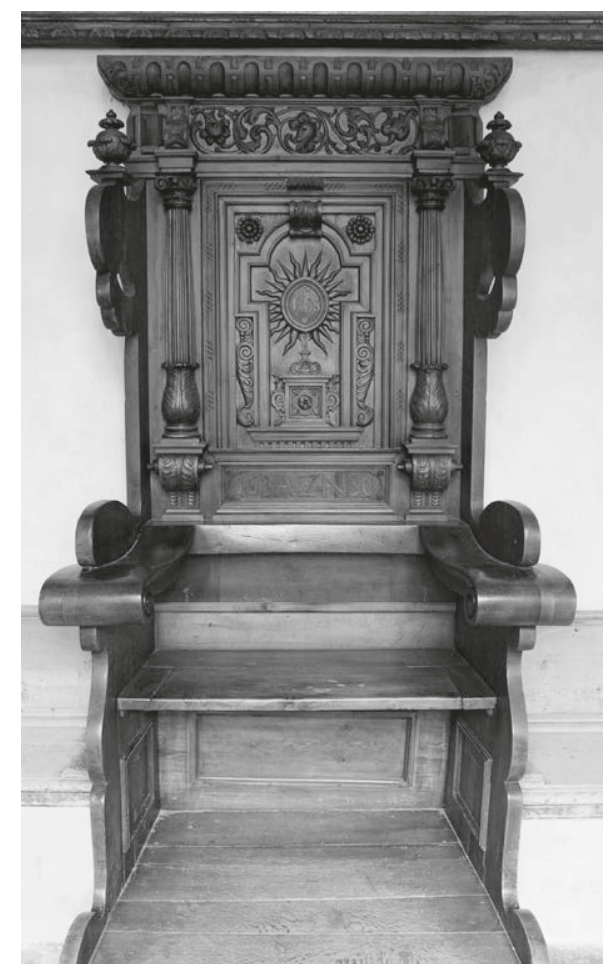

2 I 7 Abtstuhl. Neuberg, I630

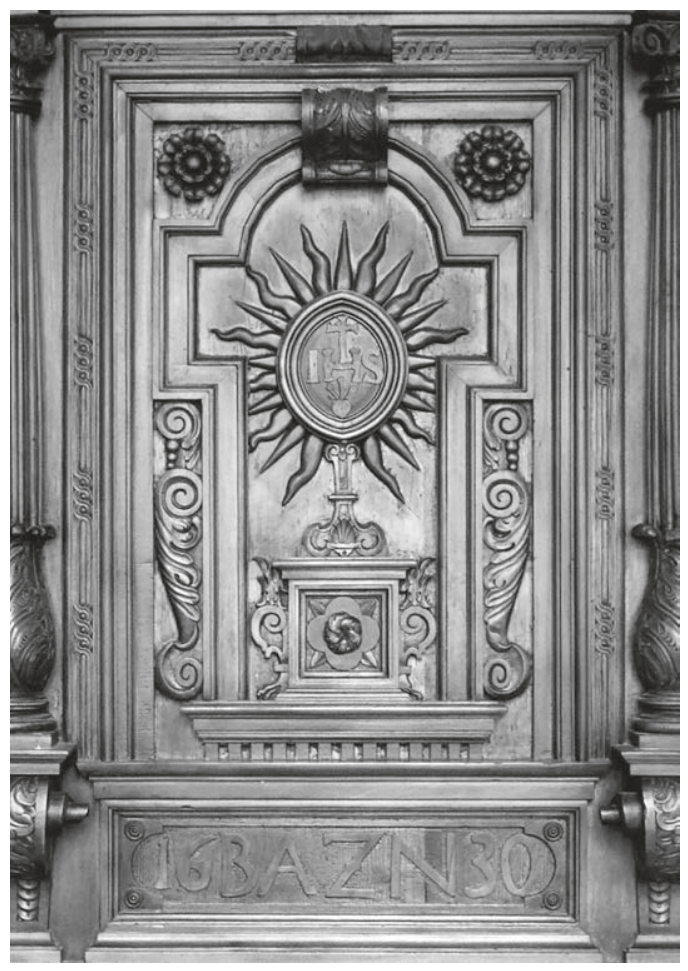

2 I 8 Detail aus Abb. 2 I7

säulen schließt ein querrechteckiges Kompartiment, das mit der Jahreszahl I 630 und dem Monogramm BAZN des Abtes Balthasar (reg. I626-r663) bezeichnet ist. Der darüber angeordneten Füllung wurde ein Binnenfeld in Kreuzesform vorgeblendet, das ein Postament mit einer Strahlenmonstranz vervollständigt. Knorpelige Schnitzereien und Blütenrosetten säumen das Kreuz, ein Flechtband rahmt das Zentrum. Die Rückwandfüllungen bestehen aus dunkel gebeiztem Nadelholz, Schnitzornamente aus Nussbaum, Eichenholz wurde für die Armstützen und das Podest gewählt.

Pöllau, Pfarrkirche St. Veit

\section{Ehemaliges Augustiner-Chorherrenstift}

Schriftquellen erwähnen die dem hl. Veit geweihte Kirche erstmals ir63, sie war damals Teil einer Burganlage. ${ }^{353}$ I 459 erwarb Heinrich von Neuberg das Anwesen

353 Kohlbach, Stifte (1953), 267-286; Hootz, Kunstdenkmäler (1 965-1 968), Bd. 2 (I 966), 270-27 1, 379; 
und die dazu gehörende Herrschaft, sein Sohn Hans verfügte I 482 testamentarisch, dass dieser Teil seines Erbes zur Gründung eines Augustiner-Chorherrenstiftes verwendet werden sollte. Das Testament gilt als Stiftungsbrief von Pöllau. I 504 wurde die zur Abtei umfunktionierte Veste vom Kloster Vorau aus besiedelt, jenes Jahr wird als das eigentliche Gründungsjahr der Abtei bezeichnet. Propst Michael I. Maister (reg. I669-I696) ließ die mittelalterliche Burg schleifen und begann in den I69oerJahren mit dem Bau neuer Klostergebäude. Stilistische Gründe sprechen dafür, erste Planungen Domenico Sciassa (I 599/r603-r679) zuzuschreiben, dem Carlo Antonio Carlone (um I635-I7I3) und seit I7or Joachim Carlone (1653-1713) aus Graz als Baumeister folgten. ${ }^{354}$ I 7 I 2, während der Regierungszeit von Propst Johann E. Ortenhofen (reg. I697-1743), wurden die Bauarbeiten am Kloster und an der Kirche, etwa ro Jahre später auch die an der neuen Sakristei beendet. Joachim Carlone inspizierte die Baustelle jedes Jahr einige Male, vor Ort überwachten zwei Poliere oder Baumeister die Arbeiten. Einer von ihnen war ein Schüler Matthias Steinls (I643/44-I727), Remigius Horner (I670-I750), der als Tischler wiederholt für das Stift tätig war. ${ }^{355}$ Schriftstücke unterzeichnete er als Remigius Horner burger tischler und maurer maister zu Pöllau. ${ }^{356}$

Bei der Klosterkirche zu Pöllau, einem der größten barocken Kirchenräume der Steiermark ${ }^{357}$, handelt es sich um eine Kreuzkuppelkirche mit einer Dreikonchenanlage. An das Langhaus, zu dem im Westen eine zweijochige Vorhalle und die Orgelempore überleiten, lehnen sich auf beiden Seiten je drei Kapellen mit Emporen, auf denen der Konvent weitere Altäre errichtete. Über das Langhaus spannt sich ein gurtenloses, von Riesenpilastern getragenes Tonnengewölbe. Der Pöllauer Stiftsmaler Matthias von Görz (um r670-I73I) führte die Fresken in der Kirche zwischen I 7 I 2 und I 7 I 8 aus, die Malereien in der Sakristei I 723. I 785 hoben kaiserliche Beamte das Kloster auf, das nach mehrfachem Besitzerwechsel r 938 in das Eigentum der Marktgemeinde Pöllau überging.

Woisetschläger/Krenn, Steirische Herrlichkeiten (1973), 74-75, 78-79, Taf. I67, I78; Stenzel, Stift (1977), 98; ÖKM, Oststeiermark (1987), 21 9-223; Attems/Koren, Kirchen (1988), 50-52; Allmer, Pöllau (1993), bes. 95-123; ders., St. Veit (2003); Hutz, Pöllau (2005); Dehio, Steiermark (2006), 364-368.

354 Die ÖKM, ebd., 2 I 9, nennt als möglichen Baumeister Jakob Schmerlaib aus Leibnitz.

355 Hutz, Pöllau (2005), 230-23 I. Horner verstarb am I 8. November I750. https://data.matricula-online. eu/de/oesterreich/graz-seckau/poellau [Zugriff Juni 2020], Sterbebuch I, I74I-I 770, 7365, p. 52. Zu

Remigius Horner vgl. auch Allmer, Pöllau (r993), го I, 20I-203.

356 Allmer, ebd., 202.

357 ÖKM, Oststeiermark (I987), 2 I 9. 


\section{Ehem. Bibliothek \\ Portal}

Stiftstischler Remigius Horner (zugeschr.), um I 700

Lichte Maße H $276 \mathrm{~cm} \times$ B I $78 \mathrm{~cm}$

Nuss, Nussmaser, Pappelmaser, Ahorn, Mooreiche (?), Rüster (?), Kirschbaum, Holz, geschnitzt, vergoldet. Eisen, Zinn, Messing, vergoldet

Der Klostertrakt mit der Bibliothek wurde in den späten r6goer-Jahren erbaut, Anton Maderno (Antonio Maderni) führte die Deckenfresken 1699 aus. Ein I 785 bei der Aufhebung des Klosters erstelltes Inventar listet furnierte Bücherschränke auf, die mit vergoldeten Schnitzarbeiten und Kirchen Lehrer[n], wohl Büsten wie in Heiligenkreuz, geschmückt waren. ${ }^{358}$ Das Möbelensemble der Bibliothek ist verloren, leider besitzen wir auch keinerlei Informationen über den Buchbestand, der dort vorhanden war. ${ }^{359}$ Falls die Möbel eine ähnlich hohe Qualität wie das Eingangsportal besaßen, müssen sie überaus prachtvoll gewesen sein.

Auf der Gangseite flankieren korinthische Vollsäulen die als Portalarchitektur gestaltete Bibliothekstür, das tiefe Gewände ist wie die Türflügel mit kompliziert konstruierten Binnenfeldern versehen (Abb. 219, 220). Das weit nach vorn ragende, schwere Gebälk trägt

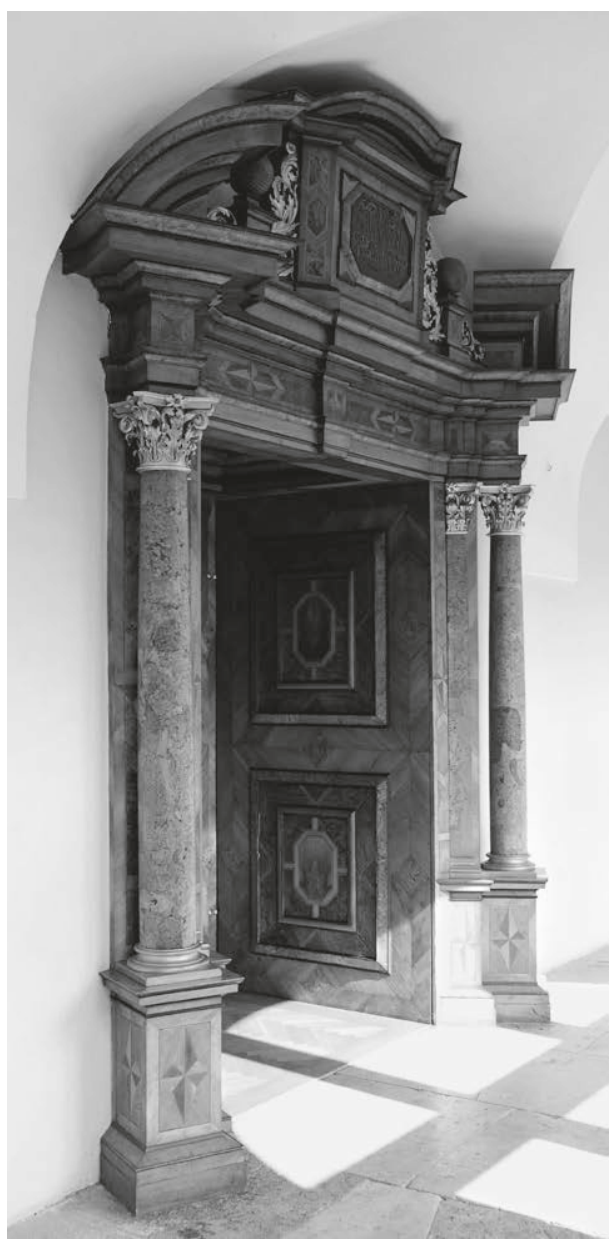

2 I 9 Korridor, Portal zur ehem. Bibliothek. Verm. Stiftstischler Remigius Horner, um I700 einen Sprenggiebel und einen Auszug mit der Inschrift: Ad/sciendam/sapienTIAM/ET/DisCiPLINAM/PRO VERA I AP. Feine Akanthusranken zieren das Binnen-

358 Zur Bibliothek in Heiligenkreuz vgl. Bohr, Sakralmöbel (2017), 3 I6-320.

359 Die vorhergehenden Angaben nach Hutz, Pöllau (2005), 227. ÖKM, Oststeiermark (I 987), 222, mit Hinweisen zum ikonographischen Programm. Vgl. außerdem Allmer, Pöllau (I993), I 20-I 22 ; Lehmann, Bibliotheksräume (I996), Bd. I, 39, Bd. 2, 496; Allmer, St. Veit (2003), 22; Dehio, Steiermark (2006), 368 . 


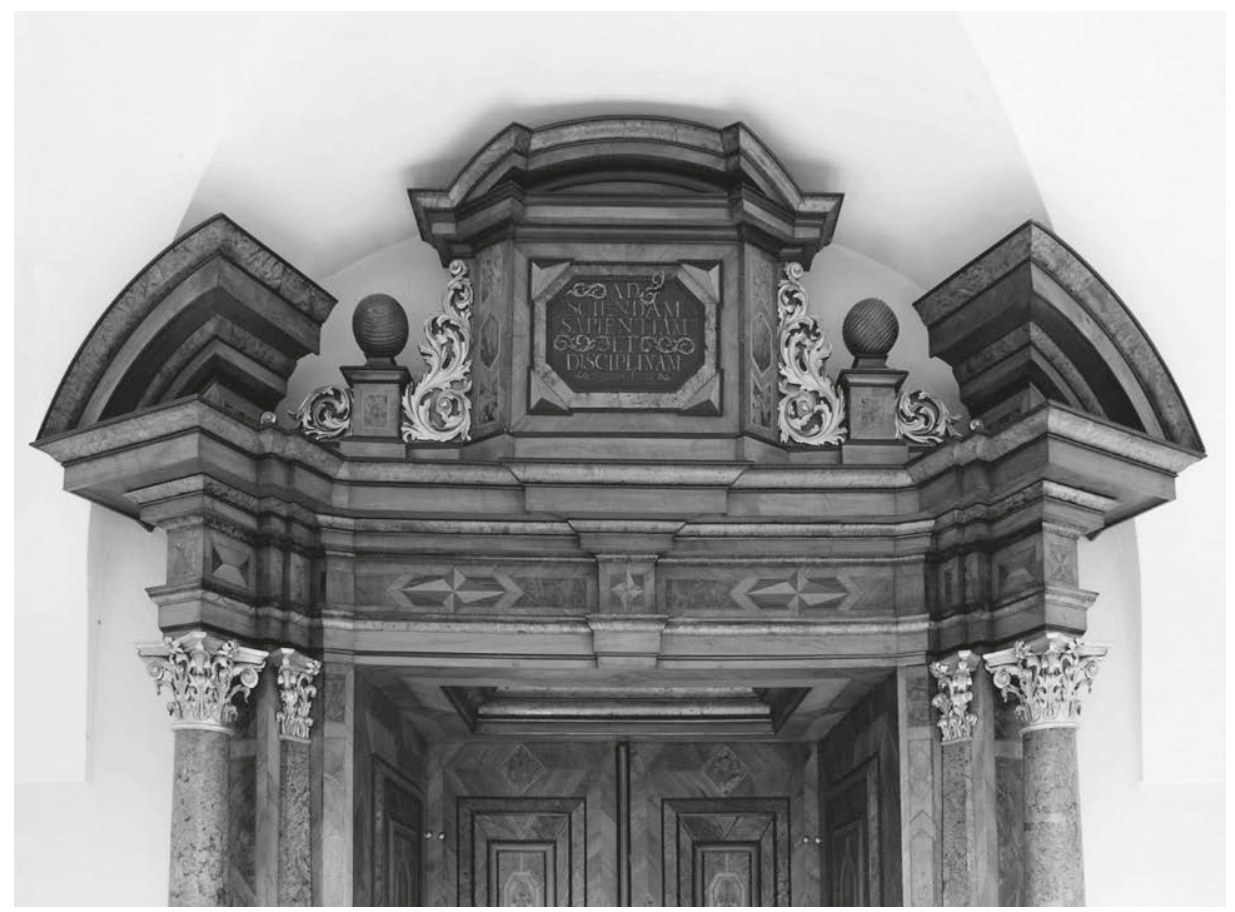

220 Korridor, Portal zur ehem. Bibliothek, Teilansicht. Verm. Stiftstischler Remigius Horner, um I 700

feld des Auszugs, den geschnitztes Laubwerk von den Seiten her optisch stützt. Die Tischler furnierten die Türrahmen teils diagonal, teils im Fischgratmuster, Sterne und geometrische Figuren verschönern die Füllungen.

Auf der Seite der früheren Bibliothek besitzt das Portal eine vergleichbare Großform, ist aber mit tordiert gedrehten Säulen vor Pilastern aufwendiger gestaltet (Farbtaf. 24; Abb. 22 I, 222). Die Stützen tragen ein Gebälk mit bogenförmigem Fries und hochaufragendem Volutengiebel. Stehvoluten leiten zu einem Auszug mit Segmentgiebel und flacher Kuppel über, ein hochovales Gemälde, das vermutlich den hl. Markus vergegenwärtigt, ist vorgeblendet. Breite, abgerundete Profile, die den Höhenunterschied zwischen Rahmen und zurückliegenden Binnenfeldern ausgleichen, halten die Füllungen. Ihr Zentrum besteht aus einem Fries und einem achteckigen Binnenfeld, in das ein weiteres Kompartiment mit einem vielgliedrigen Stern eingelegt ist. Eine feine Zinnader fasst ihn ein.

Beim Bau des Portals fanden als Furniere feingestreifte Nusshölzer sowie Maserhölzer aus dunklem Nuss- und hellem Pappelholz Verwendung. Die Fachliteratur da- 
Farbtafel 24 Bibliothek, Portal. Verm. Stiftstischler Remigius Horner, um I 700

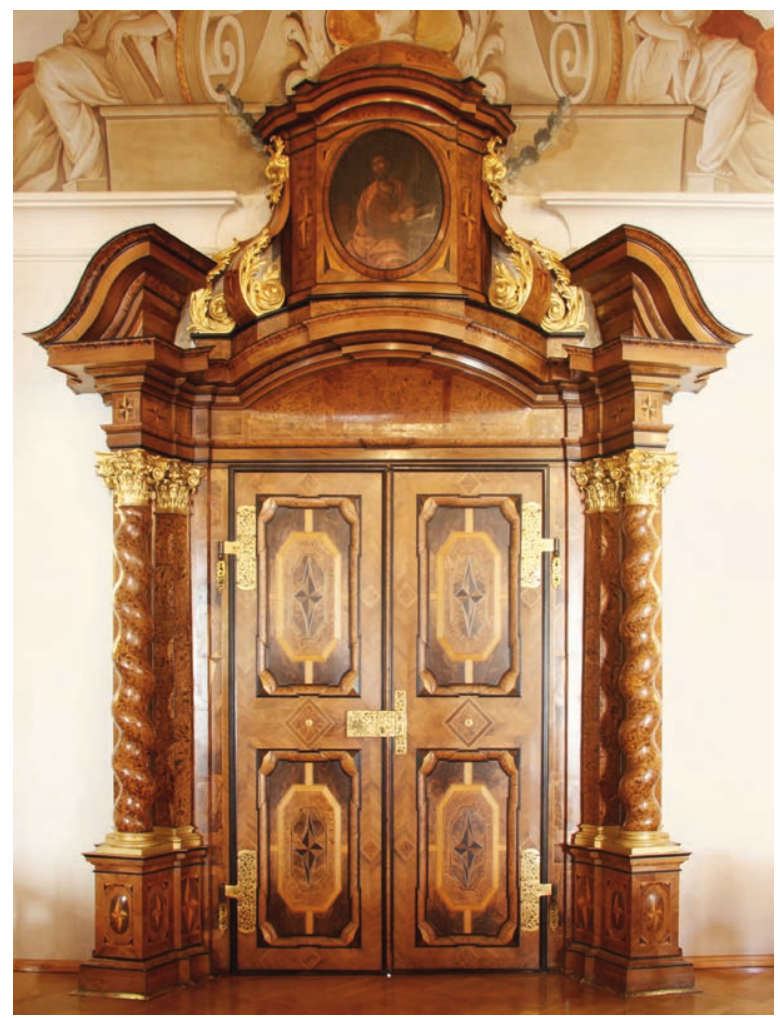

tiert das Portal bisweilen etwas zu spät um I $720 .{ }^{360} \mathrm{~W}$ ie berichtet gehen die Fresken in der Bibliothek auf das Jahr I699 zurück. Die Arbeiten in dem Raum waren damals so weit gediehen, dass er mit Mobiliar eingerichtet werden konnte. Um die Jahrhundertwende wird man auch das Portal gebaut haben. Neben der Bauchronologie sprechen Gründe der Stilkritik für eine frühe Herstellungszeit der Tischlerarbeit. Zu nennen ist etwa die Aufteilung der Türflügel und Gewände in zwei und nicht in drei Füllungen, weiter erinnert die Form des Akanthusblattwerks an Vorlagenstiche von Johann Indau (I65 I-I690) oder Leonard Heckenauer d.J. (I669-I704) aus dem späten I7. Jahrhundert und schließlich lassen sich intarsierte Sterne in den Jahren um I 7oo besonders häufig an Tischlerarbeiten nachweisen. ${ }^{361}$ Konservativ ist das Motiv der Stege, die die Binnenfelder mit den Rahmen verbinden. Anders als bei den um r66o/80 gebauten

360 Allmer, Pöllau (r 993), r 20-I 2 I.

36 I Zu Indau und Heckenauer vgl. Berliner/Egger, Vorlageblätter (198I), Bd. I, 88, Bd. 3, Abb. Io6oI063, mit Stichen aus der Zeit um r686 und um i70o. Zu den Großformen von Türen vgl. Bohr, Sakralmöbel (2017), 63-64. 


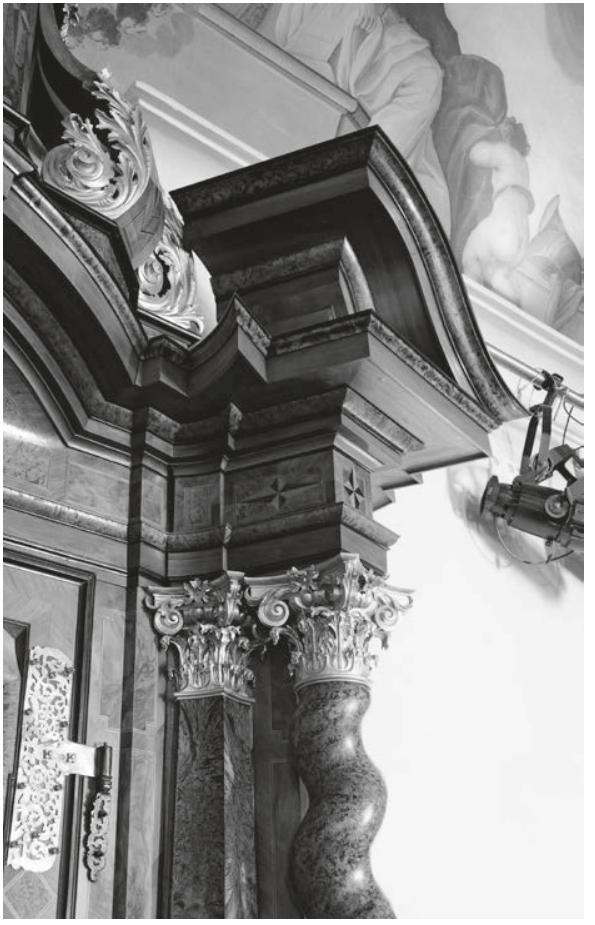

22 I Bibliothek, Portal (Detail). Verm. Stiftstischler Remigius Horner, um 1700

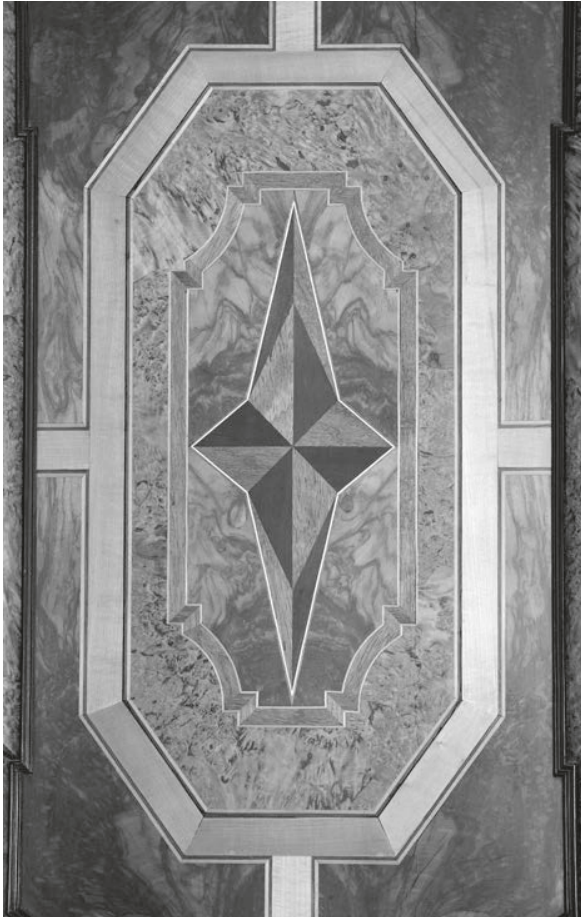

222 Bibliothek, Portal, Türfüllung. Verm. Stiftstischler Remigius Horner, um I 700

Bänken in Pürgg (Abb. 228, 230, 232) ist dieses Motiv, das in Italien in der Renaissance aufkam, eigentlich um I 700 nicht mehr zu erwarten.

\section{Sakristei}

Die weiträumige, zwischen I720 und I723 gebaute Sakristei lehnt sich an Chor und Querhaus der Kirchennordseite an. ${ }^{362}$ Sie erstreckt sich in Nord-Süd-Richtung, die östliche Längswand ist für Fenster geöffnet. Die Sakristeieinrichtung besteht aus einer großen Kredenz mit Kelchkästen vor der Nordwand, Paramentenschränken vor der West- und Südwand, niedrigen Halbschränken in den Fensternischen, einem schmalen

362 Kohlbach, Stifte (1953), 280; Woisetschläger/Krenn, Steirische Herrlichkeiten (I 973), 78-79, Taf. I78; ÖKM, Oststeiermark ( I 987), 222 ; Allmer, Pöllau ( ( 993), г I 2-I I 3; Betz, Bildprogramme (2000), bes. 76-г ro; Allmer, St. Veit (2003), 20-22 ; Hutz, Pöllau (2005), 23 I ; Dehio, Steiermark (2006), 368; Gierse, Bildprogramme (2010), 423-450. 


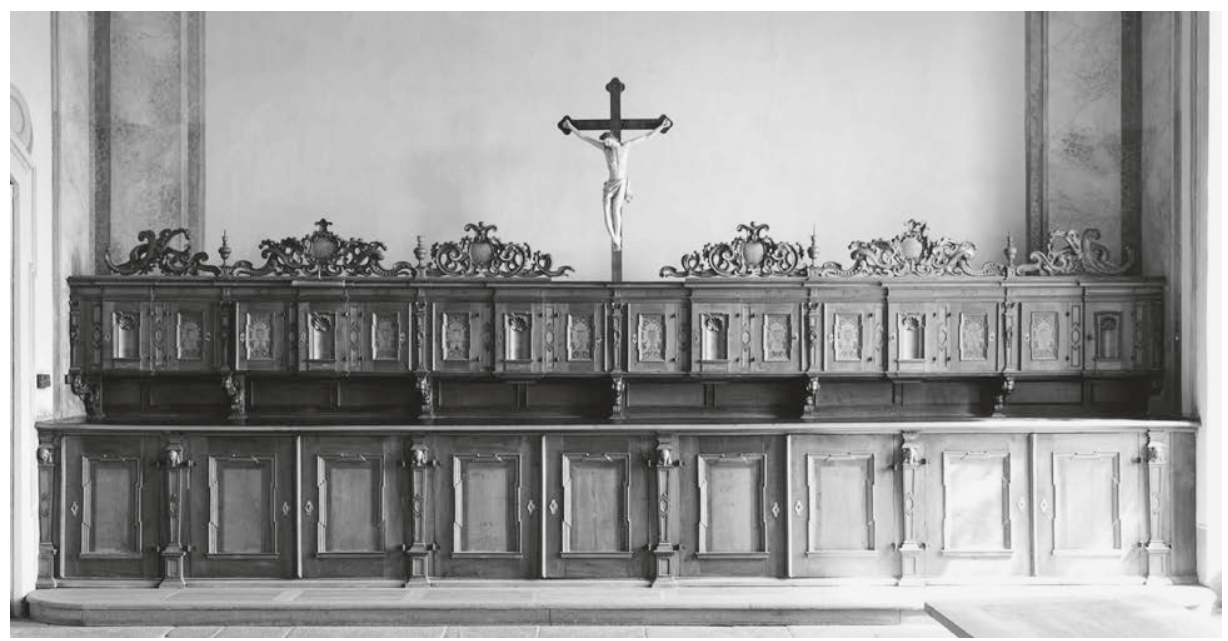

223 Sakristei, Ankleidekredenz mit Kelchfächern. Pöllau, um I660/70

Schubladenschrank vor einem Fensterpfeiler und einem großen Tisch in der Raummitte. Hier im Kontext interessieren besonders der Aufsatzschrank sowie der Ladenschrank.

\section{Kredenz mit Kelchkästen}

Pöllau, um I660/70

HS I $3,5 \mathrm{~cm}$

$\mathrm{H} 236 \mathrm{~cm}$ (einschl. Schnitzaufsatz; + I $3,5 \mathrm{~cm}$ ) $\times \mathrm{L} 745 \mathrm{~cm} \times \mathrm{T}$ Iо $3 \mathrm{~cm}$

Nuss, Nussmaser, Ahorn, Linde, Nadelholz. Eisen, teilverzinnt, Wachsleinwand

Die auf einem Podest ruhende und die gesamte Raumbreite einnehmende Kredenz besteht aus einem schweren Unterschrank und dem optisch sehr viel leichteren Aufsatz (Abb. 223, 224). Den Unterschrank verschließen Türen mit verkröpften Füllungen auf Konsolleisten wie sie im fortgeschrittenen I7. Jahrhundert recht häufig vorkommen. Konische Pilaster mit Frauenköpfen und Blockkapitellen flankieren die Türen.

Rückwand und Konsolen stützen den Aufsatz, Pilaster nehmen Gruppen von zwei bzw. drei Türen in ihre Mitte. An einigen Füllungen rahmen ausgesägte und aufgeleimte Ornamente jeweils einen intarsierten Kelch mit dem IHS-Zeichen im Strahlenkreis, während welsche Fenster mit Muschelnischen und eingelegten Rauten andere Binnenfelder schmücken. Die Travéen mit den Ädikulä treten aus der Grundebene leicht als Risalite nach vorn. Flammleisten säumen die Füllungen, markieren geometrische Felder und zieren das Gebälk, dessen Abschlussgesims mit jenem markanten V-förmigen Pro- 


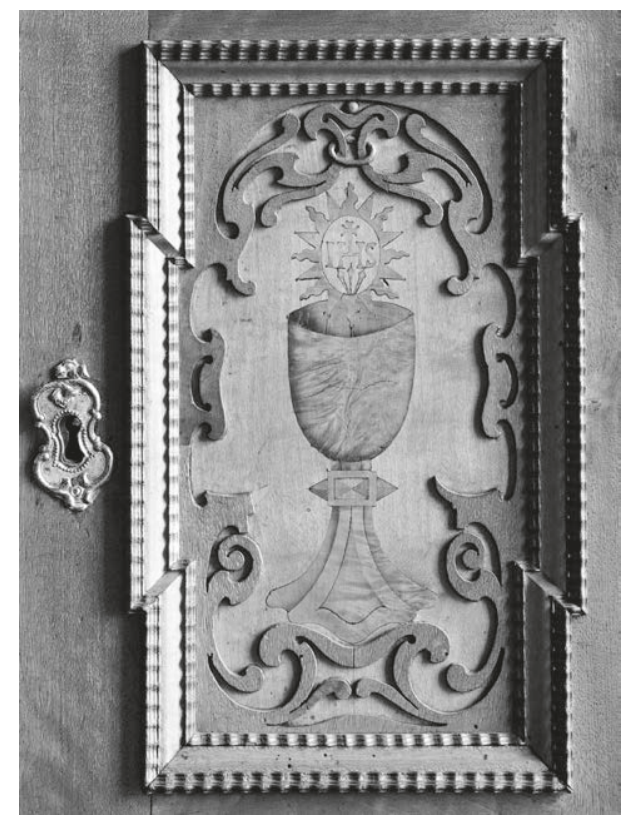

224 Türfüllung eines Kelchfachs. Pöllau, um I $660 / 70$

fil schließt, das wir auch schon an oberösterreichischen Möbeln beobachten konnten. ${ }^{363}$ Das Möbel endet mit einer Reihe durchbrochener Schnitzaufsätze, einige von ihnen halten einen wappenförmigen Schild. Ein hochaufragendes Kruzifix akzentuiert die Mitte.

An der Aufsatzkredenz überwiegt Nussbaumholz, für helle Flächen wurde Ahorn, für Schnitzarbeiten Linde verwendet. Bänder und Beschläge bestehen aus geschwärztem und teilverzinntem Eisen. Ursprünglich war die Platte der Unterschränke mit Leder bezogen, die heutige Auflage aus Wachsleinwand geht auf eine Restaurierung im Jahr I 988 zurück. ${ }^{364}$

Gottfried Allmer sowie die Autoren des Dehio nehmen eine Entstehung des Sakristeischranks um I720 unter Verwendung von Überresten eines Möbels aus der zweiten Hälfte des I 7. Jahrhunderts an. ${ }^{365}$ Tatsächlich ist das Inventarstück älter als die Sakristei, es musste in den zur Verfügung stehenden Raum eingepasst werden. Namentlich der Unterschrank, an dem die Aufteilung der Fassade in Türen und Pilaster nicht ganz stimmig ist, belegt, dass die Kredenz umgebaut wurde. Nagellöcher und Beschädigungen der Holzoberfläche verraten zudem, dass die Schlossbeschläge ausgetauscht wurden; die originalen waren etwas größer als die heutigen. Mithin führt es in die Irre, von einer Fertigung des Inventarstücks etwa zeitgleich mit dem Bau der Sakristei auszugehen.

Flammleisten, die seit den I62oer-Jahren vermehrt vorkommen, rahmen die Füllungen. Frauenköpfe mit Kopftuch, ein Motiv, das in der Renaissance entwickelt wurde und in der Ornamentik zumindest bis ins späte I 7. Jahrhundert hinein eine wichtige Rolle spielte, zieren die Pilaster des Unterschrankes. ${ }^{366}$ Daneben wurden für die Schnitzarbeiten mit amorphen Gebilden und schotenartigen Verdickungen hochbarocke Motive gewählt. In ihrer Gesamtheit lassen die Dekorformen eine Fertigung des Möbels im

363 Etwa an den Sakristeimöbeln der Karmelitenkirche zu Linz. Bohr, Sakralmöbel (2017), 567-570.

364 Betz, Bildprogramme (2000), 77, I28, Qu. I 2.

365 Allmer, Pöllau (I 993), I I 2 ; Dehio, Steiermark (2006), 368.

366 Zum Motiv des Frauenkopfes mit Kopftuch vgl. Berliner/Egger, Vorlageblätter (I98I), Bd. I, 37, Bd. 2, Abb. I 59, mit einem Entwurf von Augustin Hirschvogel (1 $503-1553$ ) von I 543 . Und ebd., Bd. I, 92, Bd. 3 , Abb. I I 7 , mit einem Vorlagenstich von Jean Lepautre (I6I8-I682) von I675. 
fortgeschrittenen dritten Viertel des I 7. Jahrhunderts wahrscheinlich werden.

\section{Ladenschrank}

Pöllau, um I690/I 720

$\mathrm{H} 250 \mathrm{~cm} \times \mathrm{B}$ i Io $\mathrm{cm} \times \mathrm{T} 49 \mathrm{~cm}$

Nadelholz, polychrom gefasst

Das Möbel vor dem Fensterpfeiler ist denkbar einfach konstruiert (Abb. 22 5 ): Über einer Bodenleiste folgt ein Sockelgeschoss mit breiten Schüben, dann über einem Gesims ein hoher Schrankteil mit drei Reihen kleiner Laden. Ein gebogener Fries zieht das Abschlussgesims nach außen. Es trägt einen gesprengten Volutengiebel sowie eine hochovale Kartusche, die ornamentale Schnitzarbeiten umgeben. Ausgesägte geometrische Ornamente liegen auf dem Fries, Profilleisten fassen die Laden ein, die mit gedrehten Zugknöpfen bewegt werden können. Den Schmalseiten wurden großflächige Schollen aufgedoppelt. Das Möbel ist gefasst: Binnenfelder an den Schubladen und die Kartusche im Auszug sind hellbraun gestrichen, alles andere dunkelbraun, rotbraune und schwarze Linien deuten Adern an. Mit der Vielzahl kleiner Schubladen erinnert das Inventarstück an die Schränke in der Sakristei der Grazer Domkirche (Abb. I6 I, I64), weitere Beispiele vergleichbarer Möbel konnten im sakralen Ambiente bislang nicht nachgewiesen werden. Allgemein dienten solche

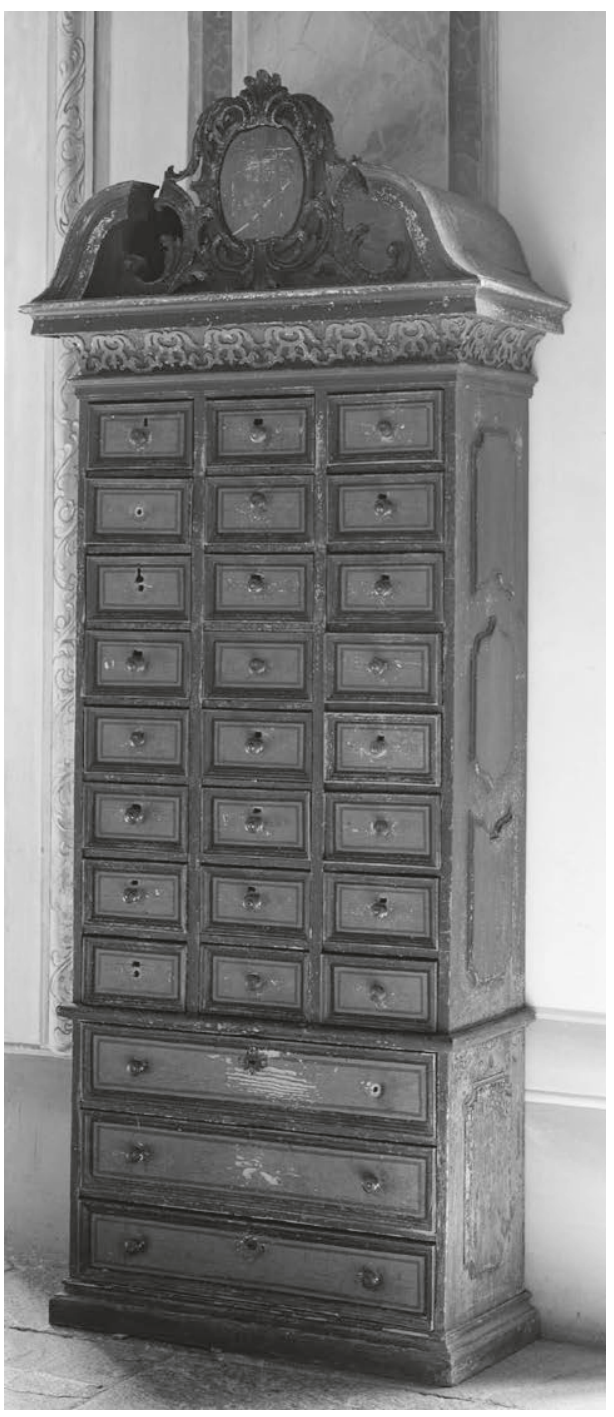

225 Sakristei, Ladenschrank. Pöllau, um I690/I 720

Schubladkästen zur Aufbewahrung von Altarwäsche oder wichtiger Dokumente. ${ }^{367}$

367 Im früheren Kloster Rottenmann bewahrte man I 545 Urkunden in Ladln auf. Naschenweng, Rottenmann (2005), 3 I 7. Und I63 I lieferte ein Tischler in das Kanzleiarchiv von St. Peter zu Salzburg einen Schrank mit I 6 Schubladen. ÖKT, St. Peter ( г 9 13), LVIII. Vgl. auch Kreisel/Himmelheber, Deutsche Möbel (I98I-I983), Bd. I, Abb. Io I und Bd. 2, Abb. 306, 307. Die bei Kreisel/Himmelheber vorge- 


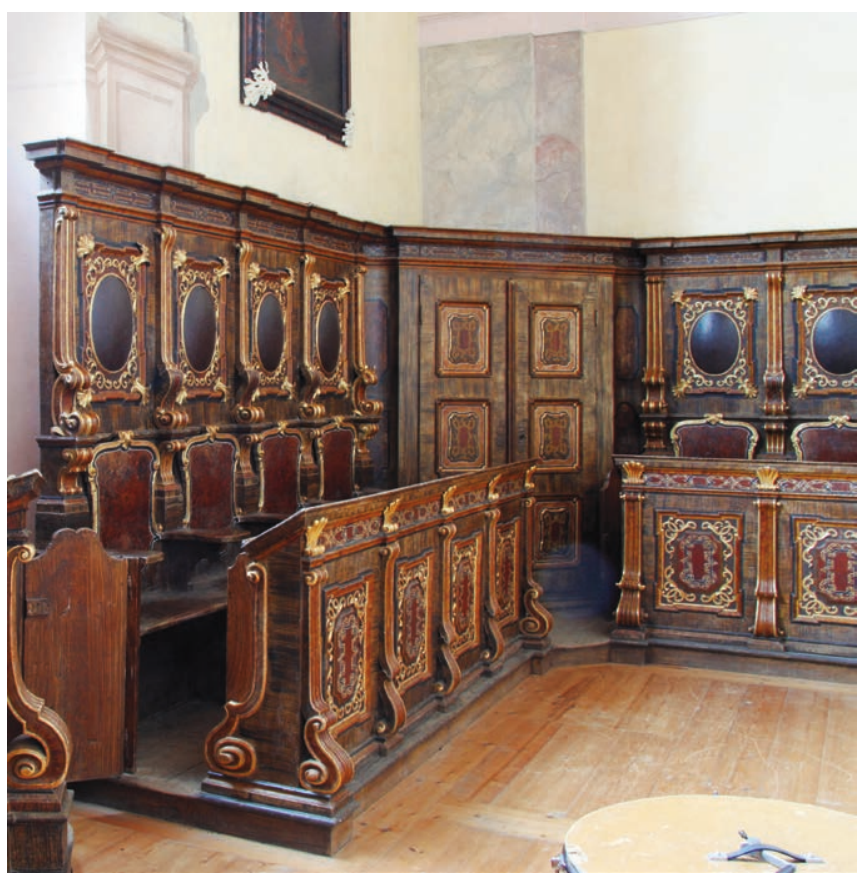

Farbtafel 25 Westempore, Chorgestühl. Pöllau, um I 739

\section{Kirchenraum}

\section{Empore, Chorgestühl}

$\mathrm{HS}{ }_{4} \mathrm{~cm}$

$\mathrm{H}_{25} \mathrm{ocm}(+\mathrm{I} 4 \mathrm{~cm}) \times \mathrm{L}$ ca. I $4,70 \mathrm{~m}$

\section{Abtstubl}

\section{HS $33,5 \mathrm{~cm}$}

Gesimshöhe $275 \mathrm{~cm}(+33,5 \mathrm{~cm}) \times \mathrm{B} 290 \mathrm{~cm}$

\section{Eckschränke}

$\mathrm{HS}{ }_{4} \mathrm{~cm}$

$\mathrm{H} 250 \mathrm{~cm}(+\mathrm{I} 4 \mathrm{~cm}) \times \mathrm{B}$ I $85 \mathrm{~cm}$

Pöllau, um 1739

Nadelholz, polychrom gefasst, vergoldet

stellten Möbel stammen aus dem Basler Domstift sowie aus dem Kloster Ottobeuren und wurden 5 I 8 bzw. um I 730 gefertigt. Vgl. hierzu auch Bohr, Sakralmöbel (2017), го4. 


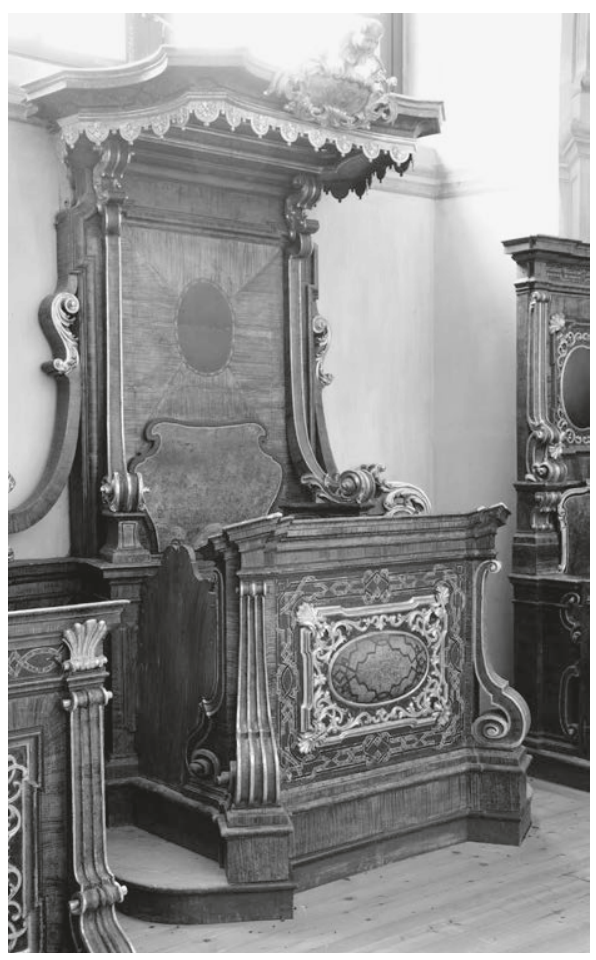

226 Chorgestühl, Abtstuhl. Pöllau, um I739

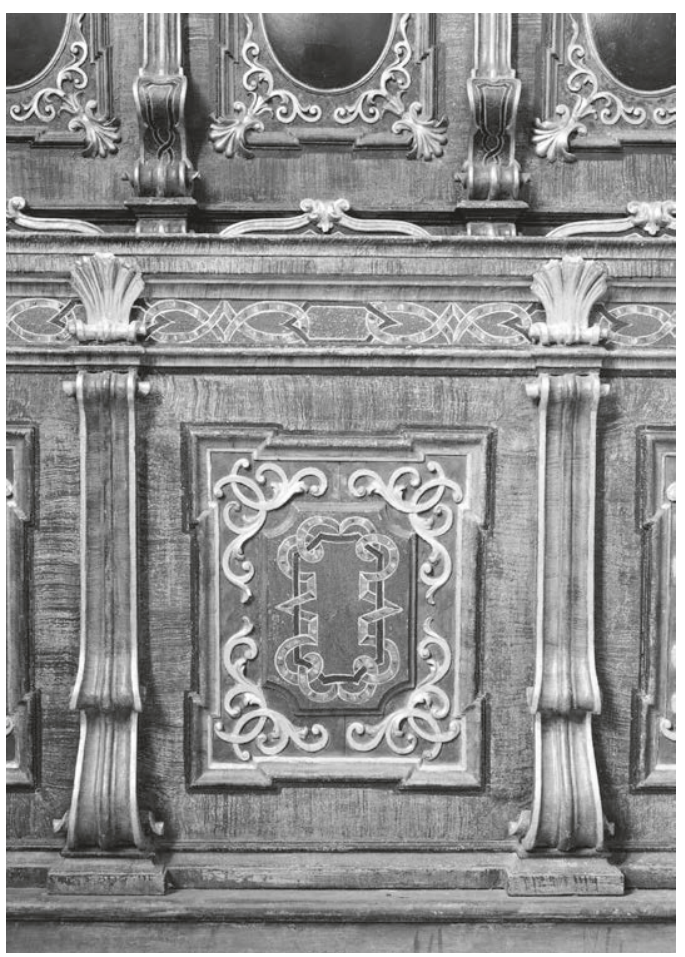

227 Chorgestühl (Detail). Pöllau, um I 739

Einst gab es in Pöllau zwei Chorgestühle: eines im ehemaligen Winterchor bzw. Kapitelsaal, der über der Sakristei lag, und eines auf der Westempore hinter der Orgel. ${ }^{368}$ Erhalten hat sich lediglich das über U-förmigem Grundriss errichtete Exemplar auf der Empore (Farbtaf. 25; Abb. 226, 227). ${ }^{369}$ Vor der Westwand steht die Sessio des Propstes als Einzelmöbel, seitlich davon finden acht, vor der Nord- und Südwand zehn Stallen Platz. Diagonal angeordnete Eckschränke vermitteln zwischen den Stallenreihen. Der Orgelkasten öffnet sich mit einer großen Arkade, um von der Empore aus das Geschehen am Hochaltar verfolgen zu können.

Die Einzelstalle ist höher und breiter als die Sitze der anderen Herren. Schräg gestellte Volutenpilaster vor breiten Rücklagen akzentuieren die Außenkanten. Die Vorderwand trägt eine verkröpfte Füllung, ein medaillonartiges, nach vorn gewölbtes Bin-

368 Allmer, Pöllau ( ( 993), I 20.

369 ÖKM, Oststeiermark (I 987), 22 I ; Allmer, ebd., I Io-I I 2 ; ders., St. Veit (2003), I 8-I 9; Dehio, Steiermark (2006), 367 . 
nenfeld ist aufgesetzt. Dieses Motiv haben wir bereits an Möbeln aus Oberösterreich, dem Burgenland und Kärnten kennengelernt (Abb. I6, г 8). ${ }^{370}$ Muschelartige Ornamente zieren die Ecken des Feldes, Laub- und Bandlwerk die verbleibende Fläche.

Die Rückwand setzt sich aus einem mit seitlichen Blenden versehenen Sockel und einem hohen Aufsatz zusammen, den ein geschweifter Baldachin überfängt. Baluster flankieren den Sitz des Prälaten, sie tragen schlanke Voluten, die bis zum Abschlussgebälk emporragen. Zwei seitliche Bögen vor der Außenmauer stützen die Konstruktion. Blattwerk liegt auf den Voluten, unter dem Baldachin hängt ein Lambrequin, in der Mitte des Gebälks ist eine mit einem Putto bekrönte Inschriftentafel mit dem Monogramm des Propstes Johann Ernst von Ortenhofen (reg. I697-I743) angebracht. Eine geschweifte Tür verschließt die Stalle.

Die Sitze der übrigen Konventmitglieder weisen eine ähnliche, aber nicht ganz so aufwendige Ausgestaltung auf. Henkelpilaster unterteilen die Brüstung, deren Füllungen verkröpfte Ecken besitzen, hochrechteckige Spiegel mit konkav gerundeten Ecken sind als Binnenfelder aufgedoppelt. Hier säumen miteinander verkettete Bögen die zentralen Felder, Muscheln ergänzen das Gebälk der Brustwände.

Auch am Dorsale übernehmen Volutenpilaster die tektonische Strukturierung. Nun tragen die Rückwandfüllungen ovale, nach vorn gewölbte Binnenfelder. Das Möbel kennzeichnet insofern eine außergewöhnliche Konstruktion, als die Chorherren nicht auf Einzelstallen, sondern auf einer Sitzbank Platz nahmen. Allerdings definieren die hohen und geschweiften Rückenlehnen sowie kurze Zwischenwangen und Armlehnen die einzelnen Sitzplätze. Unverkennbar wird hier an das Aussehen profaner Armlehnssessel angeknüpft, eine vergleichbare Konstruktion kommt an den für die Studie untersuchten Möbeln kein zweites Mal vor.

Bei Gestühlen über U-förmigem Grundriss stellen die Endstücke, an denen die Gestühlsreihen rechtwinklig aufeinandertreffen, stets nicht nur eine ästhetische, sondern auch eine räumliche Problemzone dar, denn es ist kaum möglich, die Stallen so anzuordnen, dass den Konventmitgliedern ein angenehmes Sitzen ermöglicht wird (Farbtaf. o I Abb. 02, 254). In Pöllau wurde auf diese gestalterische Herausforderung überzeugend reagiert, indem man die Gestühlsreihen mit diagonal gestellten Schränken miteinander verband. Die beiden zweitürigen Möbel besitzen die gleiche Höhe wie das Dorsale, ihr Gebälk setzt sich ohne Unterbrechung seitlich fort. Neben den Schränken und den außergewöhnlichen Sitzen muss noch auf eine weitere Besonderheit hingewiesen werden: In diesem Fall wurde das Gestühl zusammen mit der Orgel geplant und um I 739 verfertigt. Die Entwürfe stammen aus einer Hand, und

370 Beispielsweise an den Sakristeimöbeln des Linzer Karmelitenklosters. Vgl. hierzu Bohr, Sakralmöbel (2017), 567-570. 
möglicherweise waren es auch dieselben Handwerker, die Stallen und Orgelgehäuse bauten. Das Mobiliar besteht aus gefasstem Nadelholz, Holzmaserung und Adern sind aufgemalt, Schnitzornamente vergoldet.

\section{Pürgg, Pfarrkirche St. Georg}

Die Weihe der bei einer Burg errichteten romanischen Pfeilerbasilika erfolgte um I $130 / 35 \cdot{ }^{371} \mathrm{Im}$ Hochmittelalter war sie zunächst Eigenkirche, wurde dann den Chorherren in Wiener Neustadt zugesprochen, später dem St.-Georgs-Ritterorden in Millstatt, I 599 schließlich dem Jesuitenorden. Heute ist St. Georg eine eigenständige Pfarrkirche.

Der vorletzte von mehreren Umbauten der Architektur ist für das I 5. Jahrhundert verbürgt, als die Seitenschiffe ein Kreuzgrat- und das Hauptschiff ein Netzrippengewölbe auf kräftigen Wandpfeilern erhielten. In der zweiten Hälfte des I7. Jahrhunderts, der letzten Renovierungsphase, wurden nur noch kleinere Eingriffe in den Baukörper vorgenommen. Das Mittelschiff erstreckt sich über drei Joche, im Westen schließt sich die Halle des eingestellten Turms an, im Osten nach dem eingeschnürten Fronbogen das Chorquadrat und ein $5 / 8$-Schluss. Das nördliche Seitenschiff zählt fünf Travéen, das südliche vier, da sich an seinem Westende ein jochgroßer Raum befindet, der in der Frühzeit der Kirche als Sakristei diente. Sie wurde vor I 324 in einen neuerrichteten Raum nördlich des Chors übertragen.

\section{Chorraum}

\section{Zweisitz}

Pürgg, 3. V. I 7. Jh.

HS 5 cm

$\mathrm{H}$ I $17 \mathrm{~cm}(+\mathrm{I} 5 \mathrm{~cm}) \times \mathrm{B}$ I $89 \mathrm{~cm}$

Nadelholz, grau und ocker gefasst

Vergleichbar mit der Situation in Mariahof (Abb. I 99) steht auch hier seitlich des Sakristeieingangs ein Zelebrantensitz (Abb. 228). Die Brüstung des Möbels entspricht im Wesentlichen den Brustwänden der Kirchenbänke, auf die nachfolgend eingegangen wird. Sitzbank, Lehne und Docken besitzen einen schlichten formalen Aufbau. Die jeweils freistehende Kante der stelenförmigen Wangen ist leicht geschweift, breite

37I Attems/Koren, Kirchen (1988), I24-I25; Rabensteiner/Hensle-Wlasak, Pürgg (2003), bes. 2-I I; Dehio, Steiermark (2006), 379-38I ; Deuer, Kunstgeschichte (201 3), bes. 449-47 I ; Naschenweng, Geschichte (2013). 


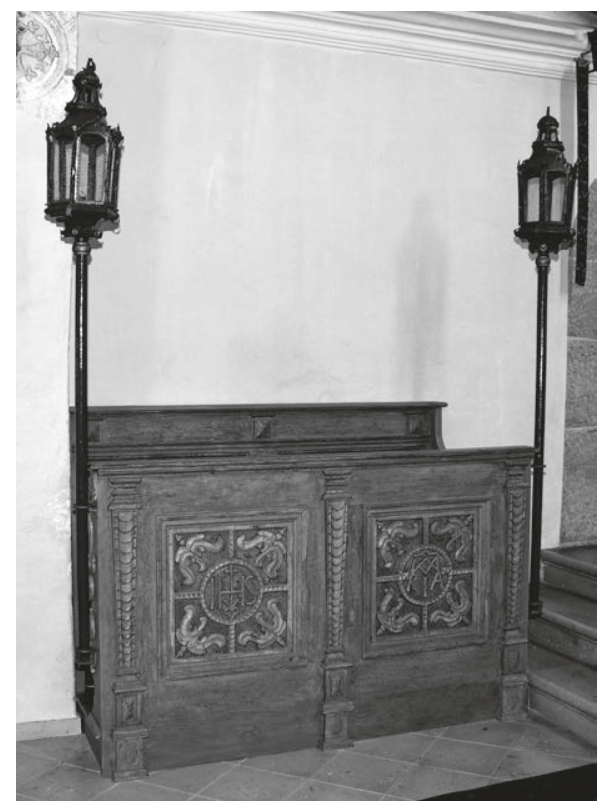

228 Chorraum, Zweisitz. Pürgg, 3. V. I7. Jh.

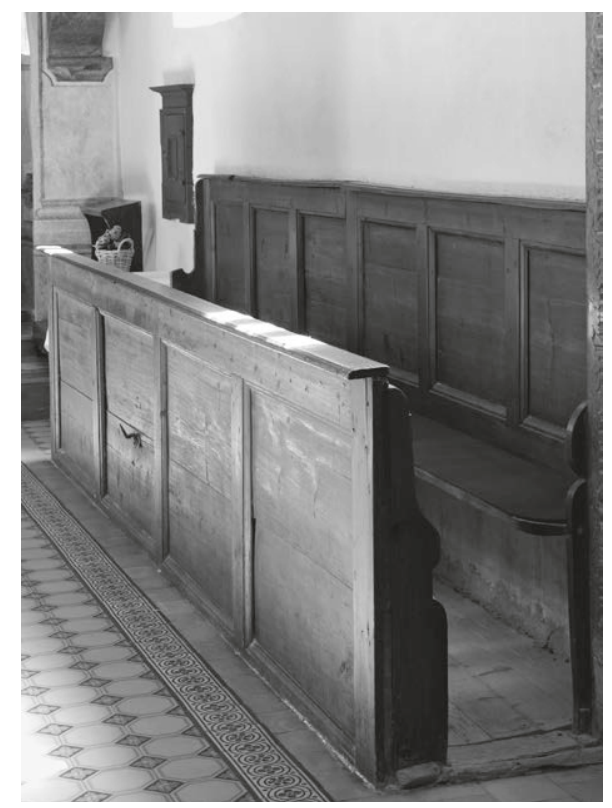

229 Südl. Seitenschiff, Bank. Pürgg. 3. V. I 7. Jh. (die Brüstung ist nicht original)

Rahmen und große Füllungen formen die mit einem Gebälk schließende Lehne. Den Fries zieren diamantförmige Konsolen.

\section{Bänke}

Pürgg, 3.V. 17.Jh.

$\mathrm{HS}_{3,5} \mathrm{~cm}$

$\mathrm{H} \mathrm{I} 24,5 \mathrm{~cm}(+3,5 \mathrm{~cm}) \times \mathrm{L}_{46} \mathrm{I} \mathrm{cm}$

Nadelholz

Wie in etlichen steirischen Sakralbauten befinden sich in Pürgg Bänke in den Seitenschiffen längs der Außenwände (Abb. 229). Ihre Konstruktion setzt sich aus profilierten Rahmen, vertieft liegenden Füllungen und schmalen, leicht geschweiften Wangen zusammen. Nach den Angaben von Wilhelm Deuer ist das hier gezeigte Möbel allerdings nicht im Originalzustand überliefert, da man die barocke Brustwand, die den Vorderstücken des Zweisitzes und der Bankreihen (Abb. 228, 230) ähnelte, zum Bau von Ambo und Volksaltar verwendete. ${ }^{372}$

372 Deuer, ebd., 464. 


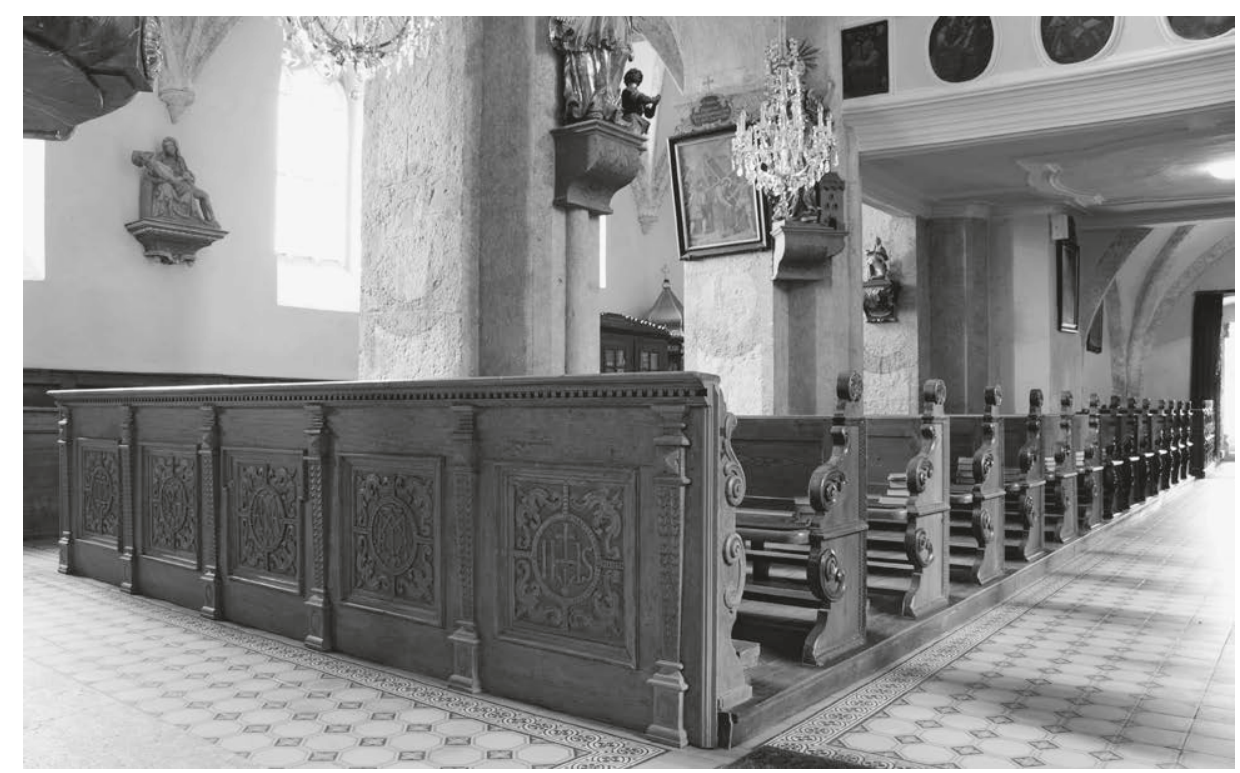

230 Laiengestühl. Tischlerei in Pürgg oder Martin Knöpl aus Gröbming, um r66o/8o

\section{Laiengestübl}

Tischlerei in Pürgg oder Martin Knöpl aus Gröbming, um r66o/8o

HS I I cm

$\mathrm{H}$ 96,5 cm/ ro3 $\mathrm{cm}$ (jeweils + I I cm) $\times \mathrm{L} \mathrm{I} 77 \mathrm{~cm} / 458 \mathrm{~cm}$

Nadelholz, grau und ocker gefasst, teilweise nussfarben lasiert

Die beiden östlichen Bankgarnituren umfassen insgesamt 26, die beiden westlichen acht Reihen, hinzu kommen die Brüstungen (Abb. 230-232). ${ }^{373}$ Die Möbel der vorderen Blöcke wurden umgebaut: Die Brustwände sowie die Schnitzarbeiten an den Wangen entstammen noch der Barockzeit, alles andere hat man größtenteils oder vollständig erneuert. Im historischen Zustand haben sich jedoch die Bänke im hinteren Bereich der Kirche erhalten, dort wurden - ein Glücksfall - sogar die abgetretenen Balken belassen, auf denen die Wangen wie auf Kufen befestigt sind. Ein spezielles Podest ist nicht vorhanden.

Keilpilaster mit blockförmigen Basen, Kapitellen und geschuppten Schäften unterteilen die Brustwände, auf den Stützen liegt ein Gesims, das mit einem Zahnschnittfries verziert ist. Kräftige Rahmen fassen die nahezu quadratischen Füllungen ein.

373 Rabensteiner/Hensle-Wlasak, Pürgg (2003), 7; Dehio, Steiermark (2006), 38 r ; Deuer, ebd. 


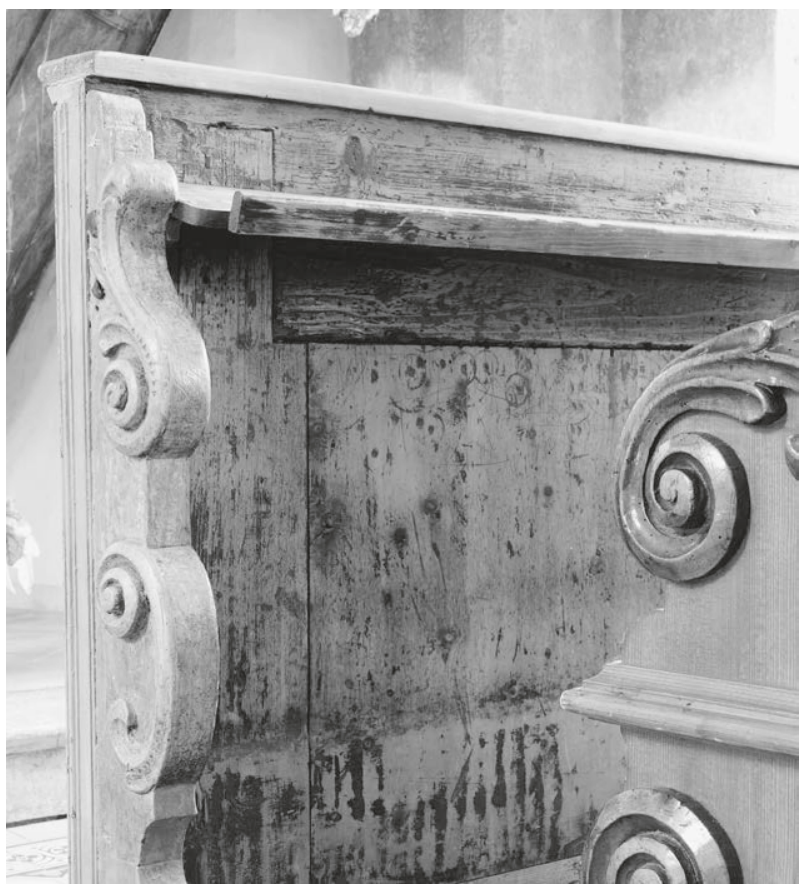

23 I Laiengestühl, Innenseite der Brüstung. Tischlerei in Pürgg oder Martin Knöpl aus Gröbming, um I66o/8o. Die komplizierte Zapfenverbindung ist gut zu erkennen. Gebrauchsspuren wurden als Teil der Geschichte der Möbelgarnitur bei der Restaurierung belassen. Rechts neue Bankwange mit alter Schnitzarbeit.

232 Hintere Bankreihen. Tischlerei in Pürgg oder Martin Knöpl aus Gröbming, um I66o/8o. Die Bänke stehen noch auf den alten kufenartigen Balken, ein Podest ist nicht vorhanden.

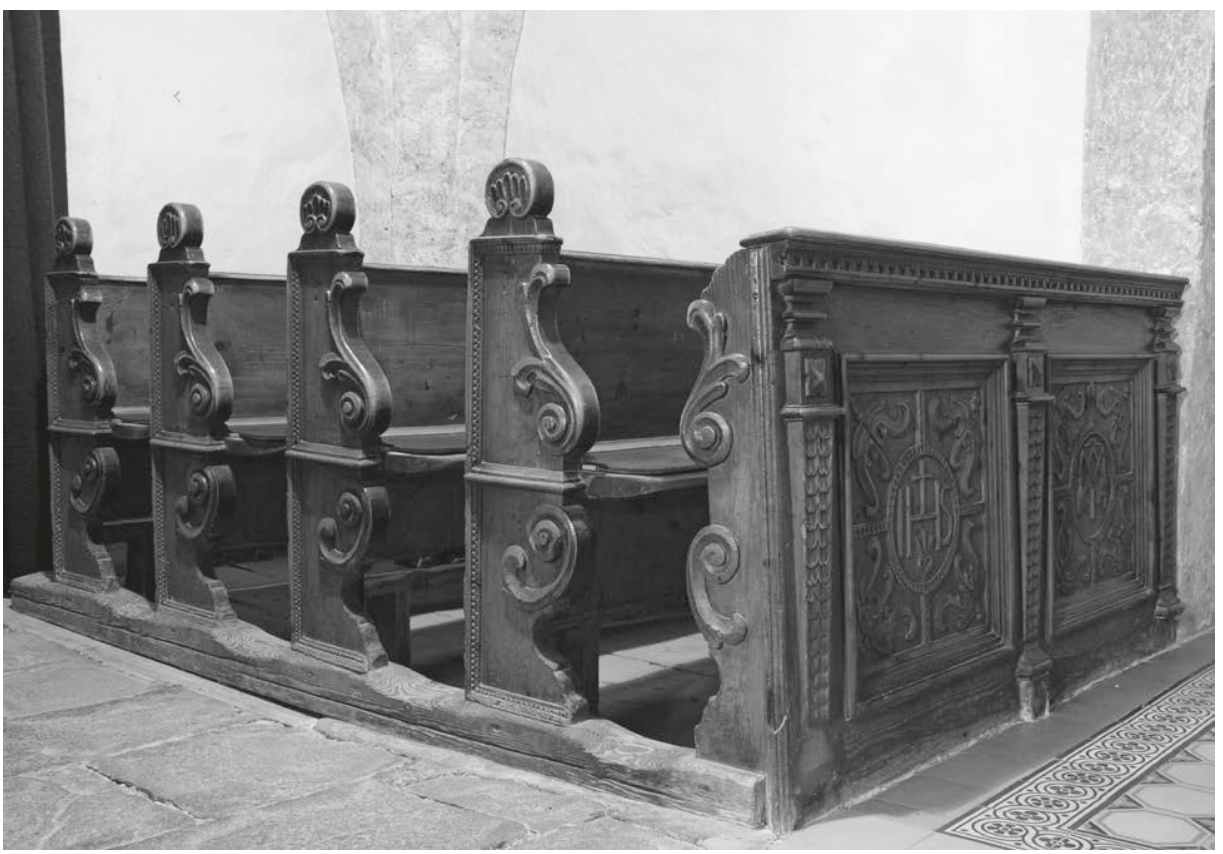


Tondi, die Stege mit den Randprofilen verbinden, umfangen dort die Monogramme Christi, Mariens, Josephs, Annas und Johannes'. Stilisierte Blüten schmücken die Zwickel, Kreuz, Herz und Nägel das IHS-Symbol. Der äußere Rahmen besitzt eine glatte Oberfläche, während mit dem Geißfuß ausgehobene Schuppenmuster die Stege und Kreise vervollständigen. Unregelmäßig gesetzte Punzenschläge mattieren den Grund.

Mittig angebrachte Gesimse teilen die Bankwangen in je zwei gleich hohe Segmente. Bei geschwungenen Vorderseiten verläuft die Wangenrückseite gerade. Ein Rundbogenfries vervollkommnet ein Profil, das den Schmalseiten und der hinteren Kante folgt, wohingegen sich über die Vorderkanten Spangen und stilisiertes Blattwerk legen. Die Docken schließen mit einem gedrückten Kreisbogen, der schmale lanzettförmige Gebilde umgibt. Bemerkenswert ist der Umstand, dass die Wangen dieser Möbel im Detail etwas aufwendiger, sonst aber fast baugleich mit den auf r 674 datierten Exemplaren von Martin Knöpl im etwa 20 km entfernten Gröbming sind (Abb. 194). Es würde nicht überraschen, falls sich mithilfe zukünftiger Archivfunde nachweisen ließe, dass die Möbel in ein und derselben Tischlerei gefertigt wurden.

In alpinen Regionen war Nadelholz das für den Bau von Möbeln bevorzugte Werkmaterial, so auch hier. Die hinteren Bänke wurden braun gebeizt, doch beließ man sie holzsichtig, was dem ursprünglichen Zustand entsprechen dürfte. Dagegen wurden die Brüstungen der vorderen Bankblöcke marmoriert, die Schnitzarbeiten zum Teil ockerfarben gefasst. Die Autoren des Dehio geben als Entstehungsdatum des Gestühls die Jahre um I 700 an. Das ist korrekturbedürftig, denn das Möbelensemble zeigt ausschließlich das für den Frühbarock typische Formenvokabular. Selbst wenn man wegen der ländlichen Lage der Kirche eine Stilverschleppung von ein bis zwei Jahrzehnten unterstellen würde, wären um die Wende von I7. zum I8. Jahrhundert doch Akanthusformationen als Zierelemente zu erwarten.

\section{Taufbeckenaufsatz}

Pürgg, um r640/60

$\mathrm{H}$ des Taufbeckens $106 \mathrm{~cm}$

$\mathrm{H}$ des Aufsatzes ca. 203,5 cm

Durchmesser des Aufsatzes ca. $94 \mathrm{~cm}$

Nadelholz, gefasst, teilvergoldet. Eisen

Der mit zwei Türen verschlossene Taufbeckenaufsatz steht im südlichen Seitenschiff auf einer ${ }^{4} 483$ datierten Marmorsäule (Farbtaf. 26; Abb. 233). ${ }^{374}$ Durch seine Form erin-

374 Rabensteiner/Hensle-Wlasak, ebd., 8; Dehio, ebd.; Deuer, ebd., 46o-462. 


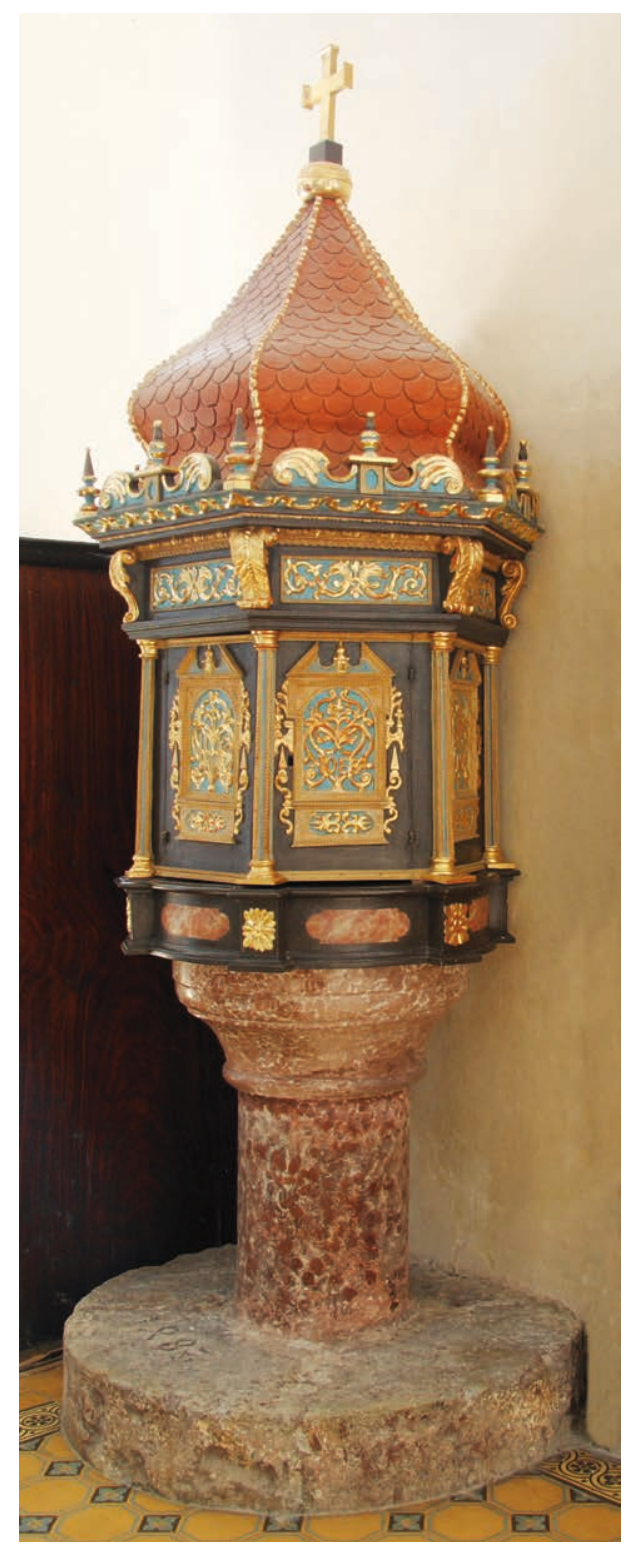

Farbtafel 26 Taufbeckengehäuse. Pürgg, um I640/60 nert er an einen Tempietto mit Zwiebelhaube und abschließendem Kreuz. Über einem runden, von Piedestalen unterbrochenen Sockelgeschoss erhebt sich der sechseckige Korpus des Möbels. Schlanke dorische Dreiviertelsäulen begrenzen die vertikalen Kanten der Kompartimente. Die Stützen tragen ein schweres Gebälk mit Akanthusvoluten und tiefem Gesims. Eine hohe, mit einem Kranz aus Piedestalen, Kegeln und Liegevoluten eingefasste Haube dient als Dach. Die als Ädikulä ausgeführten Füllungen an Türen und Seiten sind wie die Bankbrüstungen mit den Monogrammen Jesu, Mariä, Josephs, Annas und Johannes' bezeichnet. Frühbarocke Ornamente sowie Motive aus dem Formenschatz des Beschlag- und Schweifwerks (feine, elegant geschwungene Bögen, Obelisken, hornartige Auswüchse, Kegel) zieren das Gehäuse zusammen mit Flammleisten und stilisiertem Laubwerk. Der Sockel ist mit schwarzer Farbe gestrichen, der mittlere Teil mit einem dunklen Grau, das geschuppte Dach mit einer Ziegelfarbe. Die Füllungen sind hellblau, die Schnitzarbeiten vergoldet. Die Bänder bestehen aus Eisen. Ein ähnliches Möbel wird im Stift St. Paul aufbewahrt (Farbtaf. o8). Im bezüglichen Katalogabschnitt finden sich weitere Hinweise zur ausgefallenen Form des Inventarstücks. ${ }^{375}$

Wilhelm Deuer informierte darüber, dass die Gesellschaft Jesu, die die Kirche I599 erhielt, nach der Mitte des I7. Jahrhunderts solche Aufsätze häufiger in Auftrag gegeben hätte und datierte die Tischlerarbeit um I660/70. ${ }^{376}$ Das Fehlen hochbarocker Formen lässt jedoch eine etwas frühere Entstehung der

375 Vgl. hierzu außerdem Teil 2, Kap. VI der vorliegenden Arbeit.

376 Deuer, Kunstgeschichte (2013), 462. 
Arbeit wahrscheinlich werden. Dagegen sprechen auch nicht die Akanthusvoluten am Gebälkfries. Zwar sollte der eigentliche Durchbruch des Akanthusstils erst gegen Ende des Säkulums erfolgen, doch sind Blattvoluten auch vorher schon möglich. Als Belege hierfür mögen die Volutenpilaster an den Gestühlen in Friesach und Völkermarkt aus dem zweiten Viertel des I 7. Jahrhunderts oder die mit langgezogenen Akanthusblättern verzierten Pilaster am Beichtstuhl in der I657/58 eingerichteten Sakristei von St. Lambrecht ausreichen (Abb. 20, 73, 264). Neueren Datums ist das große Kreuz auf der Kuppel des Taufbeckens.

Rein, Zisterzienserstift

\section{Stiftskirche und Basilika Minor Mariä Himmelfahrt}

Markgraf Leopold I. von Steyer gründete die

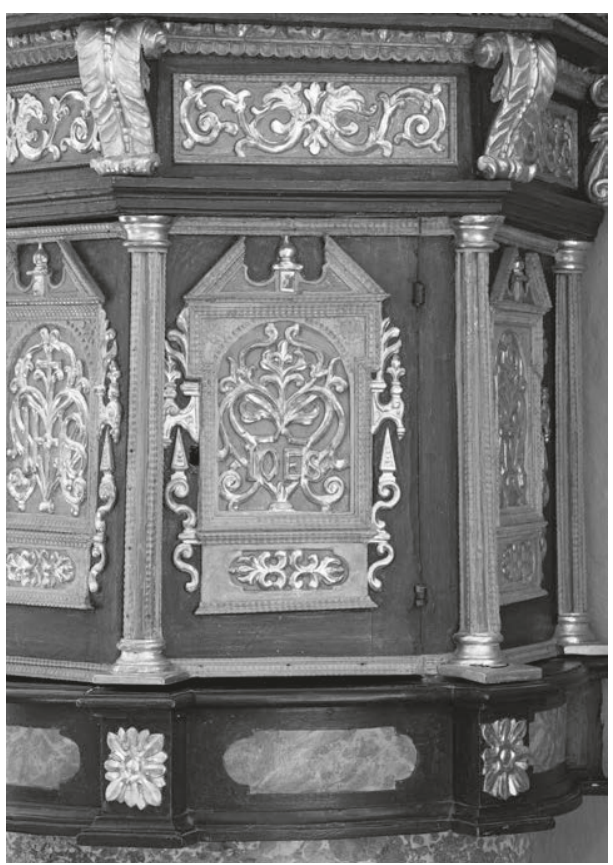

233 Taufbecken, Detail mit Monogramm des Johannes. Pürgg, um I 640/6o

Abtei I I 29, das bayrische Kloster Ebrach, eine Tochter von Morimond, besiedelte sie. ${ }^{377}$ Die Weihe der romanischen Basilika geht auf das Jahr I I 40 zurück. Nachdem die Klosteranlage im frühen I 7. Jahrhundert erweitert worden war, begann Abt Placidus Mally (reg. I7 I0-I 745) in den I730er-Jahren mit der Barockisierung der Stiftskirche. Als planenden Architekten wählte Mally den Grazer Hofbaumeister Johann Georg Stengg (1689-1753), der in dieser Kunstlandschaft etliche Um- und Neubauten ausführte. I 738/39 wurde die westliche Hälfte der Kirche teilweise abgetragen und anstelle des Westchores ein neues Presbyterium errichtet. ${ }^{378}$ Der Sakralraum ist folglich gewestet, zu betreten ist er durch ein Portal im Osten. I742 wurde die Kirche benediziert, ihre Neuweihe fand fünf Jahre später während des Abbatiats von Abt Marian Pittreich (reg.

377 Kohlbach, Stifte (1953), ıог-132; Hootz, Kunstdenkmäler (I965-1968), Bd. 2 (1966), 280-282, 381-382; Röhrig, Alte Stifte (1967), 26-27; Hahnl, Rein (1973); Woisetschläger/Krenn, Steirische Herrlichkeiten (1973), 75-76, Taf. I69, I98; Stenzel, Stift (1977), ro3-105; Amon, Geschichte (1979); Müller, Abriß (I 979); Attems/Koren, Kirchen (I 988), 40-42; Dehio, Steiermark (2006), 392-398; Rust, Stengg (2009), bes. I I 2-1 33, I65-1 82; Brenner, Himmel (2014); Müller, Basilika (201 8); ders., Gründungsgeschichte (2018).

378 Kohlbach, ebd., I 27. 

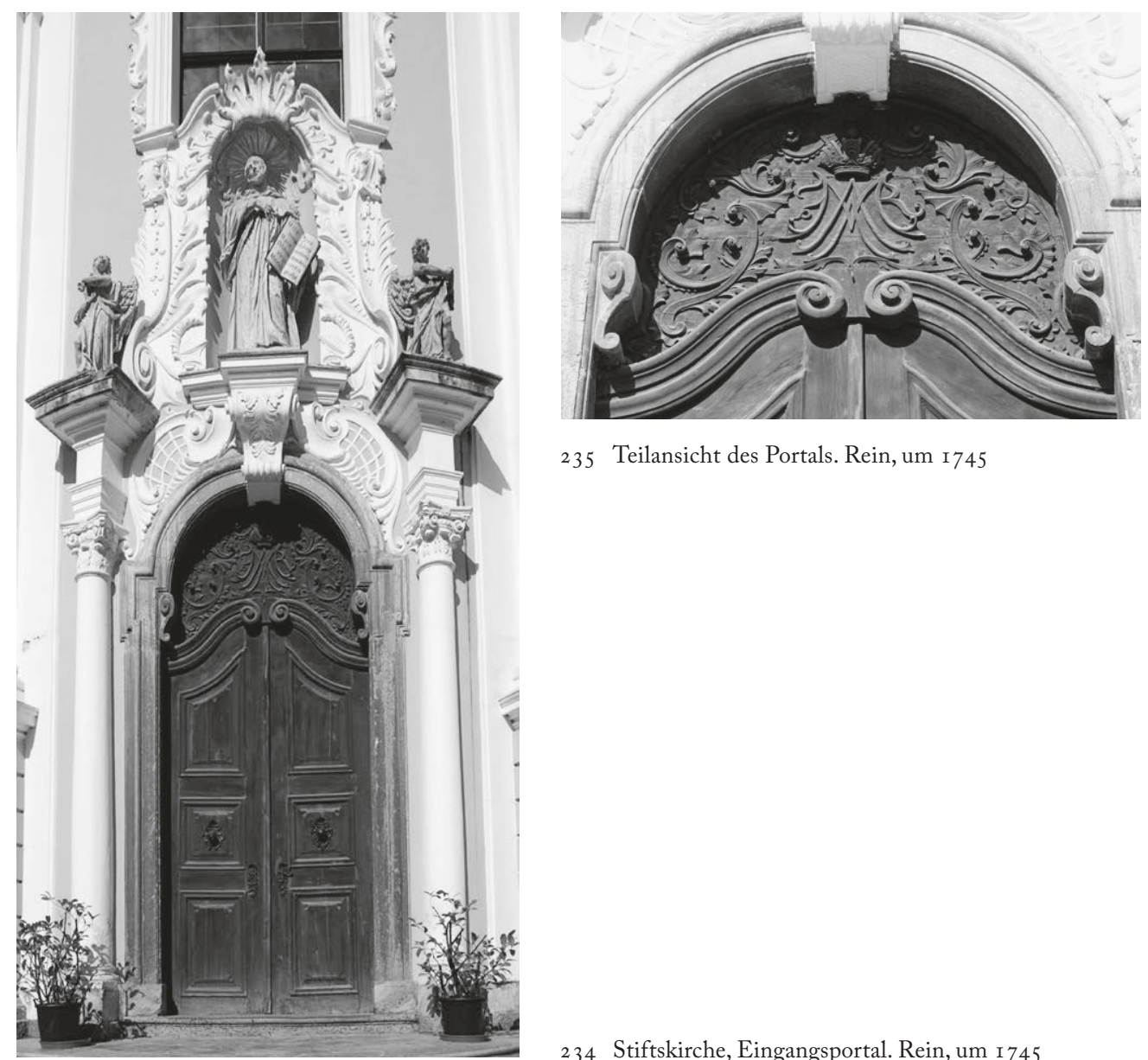

235 Teilansicht des Portals. Rein, um I 745

234 Stiftskirche, Eingangsportal. Rein, um I745

I745-I77I) statt. I766 staffierte Josef Adam Mölck (um I7 I4-I794) den Innenraum mit Fresken aus, der Hochaltar entstand I 768, er geht ebenso wie die anderen Altäre auf Entwürfe Stenggs zurück. Als Bildschnitzer arbeitete seit I743 Johann Matthias Leitner $\left(\dagger_{\mathrm{I}} 76_{3}\right)$ für das Stift.

\section{Stiftskirche}

Eingangsportal

Rein, um I 745

Gesamthöhe ca. $550 \mathrm{~cm} \times \mathrm{B} 237 \mathrm{~cm}$

Eichenholz, dunkelbraun lasiert. Eisen, graviert, geschwärzt 
Der von einer Säulenstellung flankierte Haupteingang der Kirche wurde zwischen I 742 und I 747 nach Plänen Johann Georg Stenggs errichtet (Abb. 234, 235). ${ }^{379}$ Über dem Rundbogenportal schafft eine tiefe Nische Raum für eine von Johann Matthias Leitner I743 gefertigte Statue des hl. Bernhard. Ein Volutengiebel bekrönt die beiden Türflügel des Portals. Kantenparallel geformte Kompartimente mit erhabenen Spiegeln bilden die Füllungen. Über den Türblättern liegt ein mit Schnitzarbeiten veredeltes halbrundes Feld. In der Mitte trägt es unter einer Krone die ineinander geschriebenen Buchstaben des Namens Maria, seitlich davon mit Muschelmotiven und Blattwerk ergänzte Bandlwerkornamente sowie mit Bogenfriesen verzierte Spangen. Die am Portal vorkommenden Dekormotive werden uns in den nachfolgenden Abschnitten noch mehrfach begegnen.

\section{Kirchenraum}

Chorgestühl

Tischler und Bildschnitzer Thomas Schiffer, Vergolder Joseph Anton Rogg, I 743/44 $\mathrm{HS}$ i $8,5 \mathrm{~cm}$

$\mathrm{H} 400 \mathrm{~cm}(+\mathrm{r} 8,5 \mathrm{~cm}) \times \mathrm{L} 700 \mathrm{~cm}$

Nussbaum, massiv, geschnitzt, furniert, Nussbaummaser, geschwärztes Nussbaumholz, Pappelmaser, Zwetschke, Ahorn, Buchs (?), graviert und geschwärzt, Nadelholz, Holz, vergoldet, bronziert. Eisen, verzinnt

Das im Chorraum platzierte Gestühl bietet 20 Konventualen Platz (Abb. 236-239). ${ }^{380}$ Über einer verkröpften Sockelleiste vervollständigen stilisierte Pilaster die Brüstung. Gegenläufige Bögen ergänzen die geschnitzten Schäfte, darüber folgen vor einer Muschel geflügelte Engelsköpfe, die die Kapitelle tragen. Letztere setzen sich seitlich als Gesims fort und bilden so die Vorderkante des Lesepults. Bastionsfüllungen schließen die Räume zwischen den Pilastern. In die Zwickel legten die Tischler Rocaillen und Blattwerk ein.

Geschweift gesägte Hochwangen schließen die Sitzreihen nach außen hin ab, während die ebenfalls geschweiften Zwischenwangen unter den Accoudoirs enden. Wangen und Stallen bestehen aus massivem Nussbaumholz.

Die Rückwandstützen besitzen geschwungene Basen und Schäfte, auf denen mehrschichtig aufgebaute Rollvoluten mit Engelsköpfen aufliegen. Die marketierten Füllungen ruhen auf einem Sockel, den Schnitzarbeiten bereichern. Große bronzierte

379 Dehio, Steiermark (2006), 393.

380 Zum Gestühl im Chorraum s. Gigler, Umbauten (I 924), 40-4I ; Kohlbach, Stifte (I 953), I 29 ; Woisetschläger, Kunstschaffen (1979), 83 ; Dehio, ebd. 394; Wagner, Heiligenkreuz (2007), r 49-1 50; Brenner, Himmel (2014), I 40; Kopp, Chorgestühl (2014). 


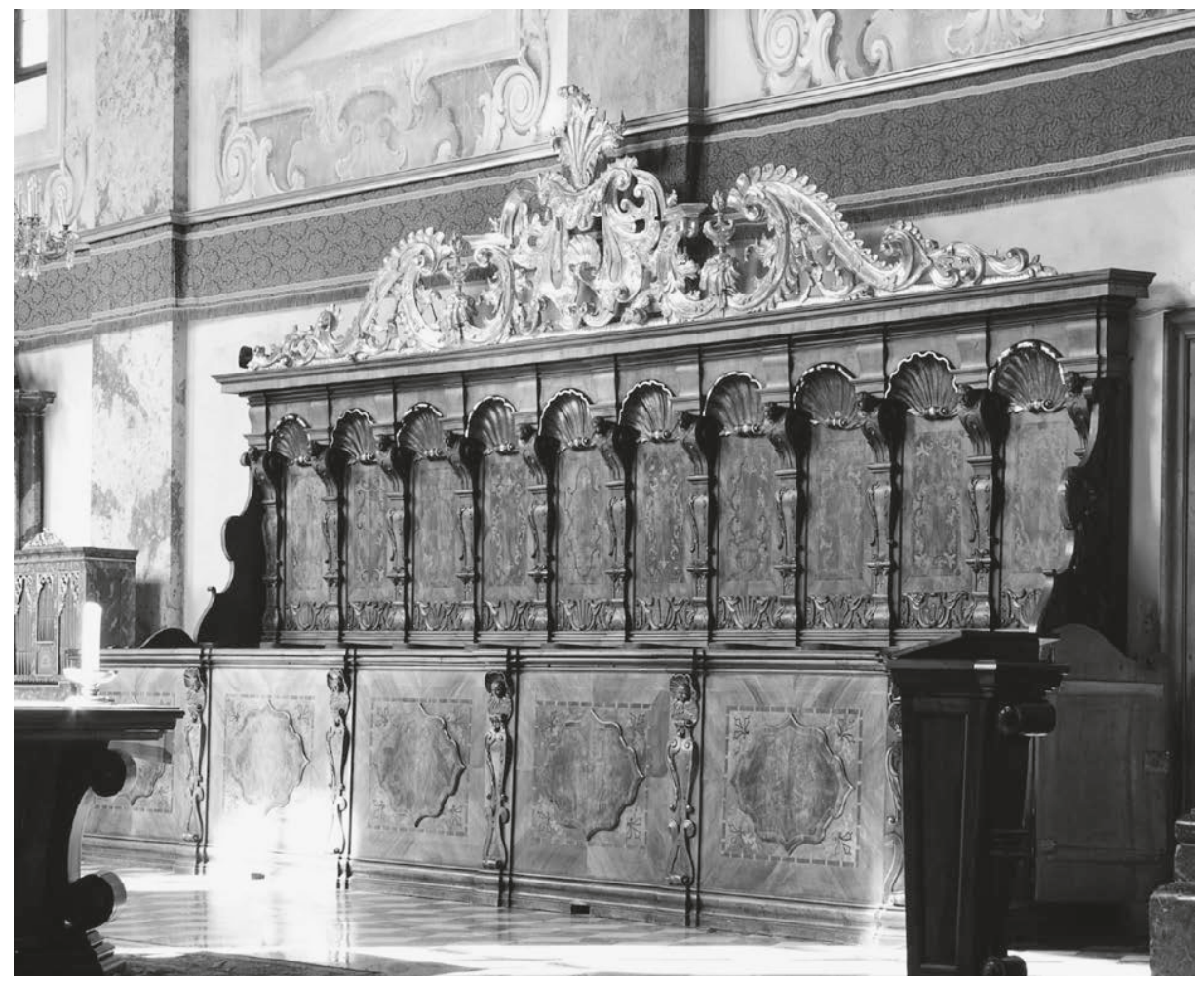

236 Chorraum, Epistelseite, Chorgestühl. Thomas Schiffer, I 743/44

Muscheln bekrönen die Mittelfelder, zusammen mit dem Gebälk formen sie einen flachen Baldachin. Ein unbekannter Bildhauer schuf den skulptierten Aufsatz, der sich aus Flammenvasen, Rocaillen, Lambrequins, Laub- und Blattwerk sowie C- und SBögen zusammensetzt. Sie sind mit jenem eigenartigen Fries ornamentiert, auf den bereits in Verbindung mit dem Portal hingewiesen wurde. Palmetten, Muschelornamente sowie bandartige und vegetabile Motive bereichern überdies die reliefierten Stirnseiten des Möbels. Auch aus der Zusammenstellung dieser Ornamentformen spricht ein besonderes ästhetisches Empfinden. Möglicherweise rezipierten die Bildschnitzer graphische Vorlagen von Johann Georg Stengg, während die Einzelmotive auf der Formensprache von Ornamentisten wie Johannes Rumpp (I702-I755) aus Augsburg basiert haben dürften. ${ }^{381}$ Ähnliche Zierformen finden sich allerdings auch in den Stuckarbeiten, die die Kirchenfassade über dem Eingangsportal ausschmücken.

38 I Etwa auf der um 1740 erschienenen Serie »Tischler oder Schreiner Riße inventiert und gezeichnet 


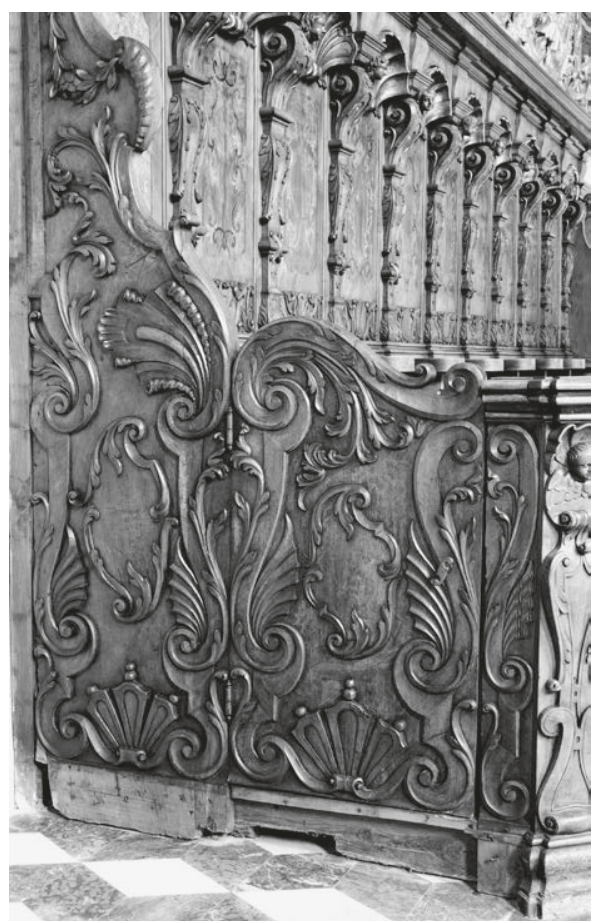

237 Chorgestühl, Tür und Außenwange. Thomas Schiffer, I 743/44

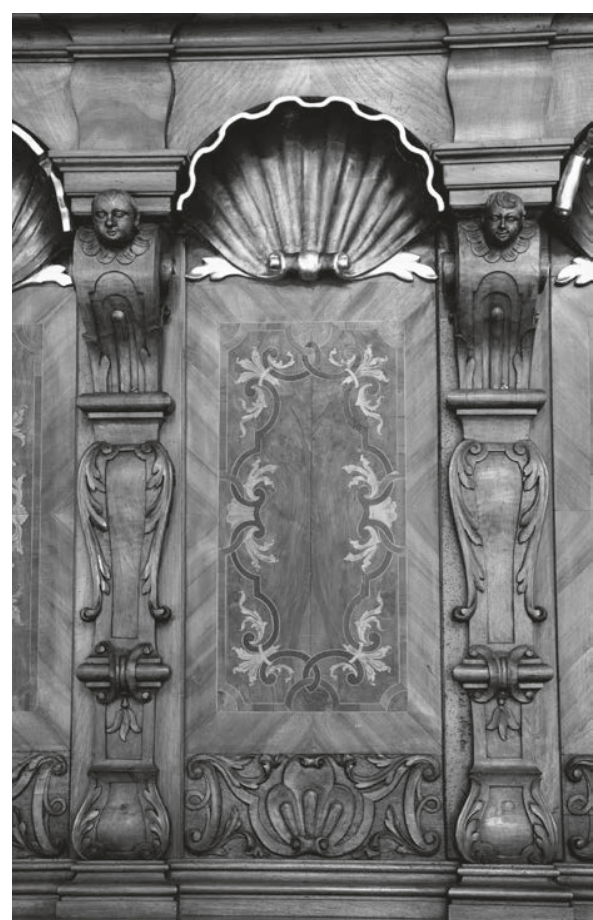

238 Chorgestühl, Rückwand (Detail). Thomas Schiffer, I 743/44

Der Vertrag über die Anfertigung des Gestühls hat sich im Klosterarchiv erhalten. ${ }^{382} \mathrm{Er}$ datiert vom 28. April I 743 und ist im ersten einleitenden Kapitel des Buchs wiedergegeben. Der Quelle zufolge beauftragte Abt Placidus Mally den Tischlergesellen Thomas Schiffer mit dem Bau des Gestühls. Bis auf den Aufsatz, für dessen Erzeugung Mally einen weiteren Künstler verpflichtete ${ }^{383}$, sollte Schiffer auch die Schnitzarbeiten am Gestühl verfertigen. Für die benötigten Werkstoffe hatte der Handwerker selbst Sorge zu tragen.

Daneben bewahrt das Stiftsarchiv noch einen Vertrag mit Joseph Anton Rogg auf, der im Mai I 744 angewiesen wurde, den Schnitzaufsatz zu vergolden. ${ }^{384}$ Der fertigge-

von Johannes Rumpp [...]«. Vgl. https://sammlung.mak.at [Zugriff August 2020]. Außerdem Berliner/ Egger, Vorlageblätter (198 I), Bd. I, I07-108, Bd. 3, Abb. I339, I340.

382 StAR, Lade M/XXXV: Tischler und Tapezierer. Vgl. dazu auch Gigler, Umbauten (r 924), 65 (Quellenanhang).

$383 \mathrm{Zu}$ Bildschnitzern, die für Rein arbeiteten, s. Schweigert, Plastik ( ( 979), bes. 455-459.

384 Die Vertragsunterzeichnung erfolgte am I r. Mai I 744. Gigler, Umbauten (I 924), 3 I (Quellenanhang); Woisetschläger, Kunstschaffen (1979), 83. 


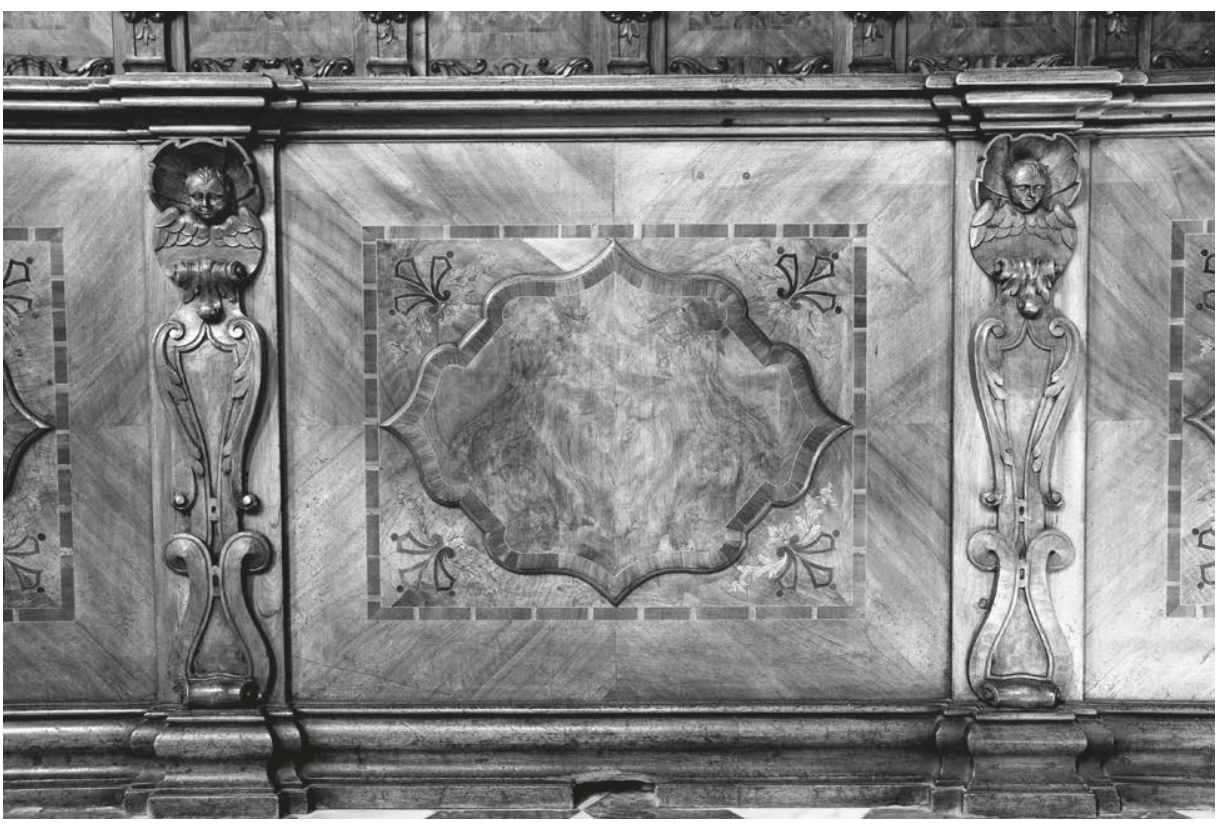

239 Chorgestühl, Brüstung (Detail). Thomas Schiffer, I743/44

stellte Auszug konnte damals zur Vervollständigung an den Vergolder weitergegeben werden, vom Konvent erhielt er das benötigte Blattgold. Der letzte Arbeitsgang an dem Inventarstück wurde damit in Angriff genommen.

In jenen Jahren verfügte die Abtei Rein über eine stiftsinterne Tischlerei, sie stand unter der Leitung des Laienbruders Mauritius Tauffer (I692-I 776). ${ }^{385}$ Die mündliche Überlieferung des Klosters berichtet von einer Inschrift an der Rückwand des Chorgestühls, die Tauffer als den verantwortlichen Tischler des Inventarstücks ausweise. ${ }^{386}$ Allerdings wurde das Gestühl vor einigen Jahren restauriert, nach Aussagen der Restauratoren war dort keine derartige Inschrift zu erkennen. ${ }^{387}$ Zudem sahen Fachexperten Einträge in die Stiftschronik und in das Totenbuch der Abtei als Bestätigung dafür an, dass Tauffer das Gestühl verfertigt hätte. ${ }^{388}$ Auch diese Überlegungen sind aber

385 Zumindest im Mittelalter existierten in Rein überdies eine Bildhauerwerkstatt und ein Maleratelier. Schweigert, Plastik (1979), 455 ; Woisetschläger, Kunstschaffen (I 979), 89. Genannt sind in der Frühen Neuzeit zudem eine Bäckerei und eine Mühle. Woisetschläger, ebd., 85 .

386 Freundliche Mitteilung von Norbert Müller.

387 Freundlicher Hinweis von Peter Kopp, dem verantwortlichen Restaurator.

388 Vgl. zu den Einträgen den nachfolgenden Text. Zur Zuschreibung des Gestühls an Tauffer vgl. bes. Pater, Baugeschichte (I915), 280; Mausser, Stift Rein (1949), I99; Kohlbach, Stifte (1953), r 29. 
mit Thomas Schiffers Arbeitsauftrag kaum in Einklang zu bringen, wenn man nicht wie Rochus Kohlbach von der Annahme ausgeht, dass Schiffer ein Mitarbeiter Tauffers gewesen sei. ${ }^{389}$ Jedoch muss Kohlbachs These ebenfalls verworfen werden, denn zum einen beruhten die Aufträge von Stiftswerkstätten auf mündlichen Absprachen, vertragliche Regelungen des Konvents mit der Stiftstischlerei waren folglich nicht notwendig. Zum andern handelten Auftraggeber mit den Leitern von Werkstätten die Verträge aus, nicht mit deren Gehilfen, Schiffer wäre daher der falsche Ansprechpartner gewesen. Und schließlich trug der Handwerker wie erwähnt für die Verwendung adäquaten Werkmaterials die Verantwortung, auch das belegt die selbständige Tätigkeit des Gesellen. Schiffer, über den sonst leider nichts bekannt ist, besaß offenbar eine eigene Werkstatt in der Nähe der Abtei. Das Gestühl muss ihm zugeschrieben werden, doch könnten Teile davon in der Stiftstischlerei angefertigt worden sein. Im nächsten Abschnitt wird die Auftragserteilung zur Herstellung des Laiengestühls analysiert. Die daraus resultierenden Erkenntnisse deuten darauf hin, dass die beiden Handwerker bei der Ausführung ihrer Arbeiten tatsächlich zusammenarbeiteten.

Vorbilder für Details am Gestühl lassen sich in der Ausstattung der Domkirche zu Graz finden. So ruht das Dorsalegebälk des I 738 gefertigten Domherrrengestühls auf Engelsköpfchen vor Muscheln (Abb. 157, 158), ein Motiv, das in den Kapitellen der Reiner Stallenbrüstung wiederkehrt. Und die Brüstungen des Gestühls in Rein sowie jene der Kirchenbänke in Graz (Farbtaf. I 9; Abb. I 52) sind mit Füllungen ausstaffiert, die aufgedoppelte Mittelfelder tragen. Dass bei der Herstellung der klösterlichen Möbel die Einrichtung in der Domkirche als Muster diente, vermag freilich nicht zu verwundern, liegen die beiden Sakralbauten doch nur etwa $20 \mathrm{~km}$ voneinander entfernt. Offensichtlich hatte der für den Entwurf des Reiner Mobiliars zuständige Künstler das Interieur in Graz sehr genau studiert.

\section{Laiengestübl}

Stiftstischlerei unter der Leitung von Mauritius Tauffer (?) sowie Thomas Schiffer, I 744 HS I $8 \mathrm{~cm}$ $\mathrm{H}$ I05,5 cm $(+\mathrm{I} 8 \mathrm{~cm}) \times \mathrm{L} 320 \mathrm{~cm}$

Nussbaumholz, massiv und furniert, Nussbaummaser, Nadelholz

Das Kirchengestühl besteht aus sechs Einheiten mit je sechs Bänken und den notwendigen Vorderbrüstungen (Abb. 24O, 24I). ${ }^{390}$ Pilaster, die weitgehend den Stützen am

389 Kohlbach, ebd.

390 Woisetschläger, Kunstschaffen (1979), 83; Dehio, Steiermark (2006), 394; Zimmermann, Kirchenbänke (2014). 


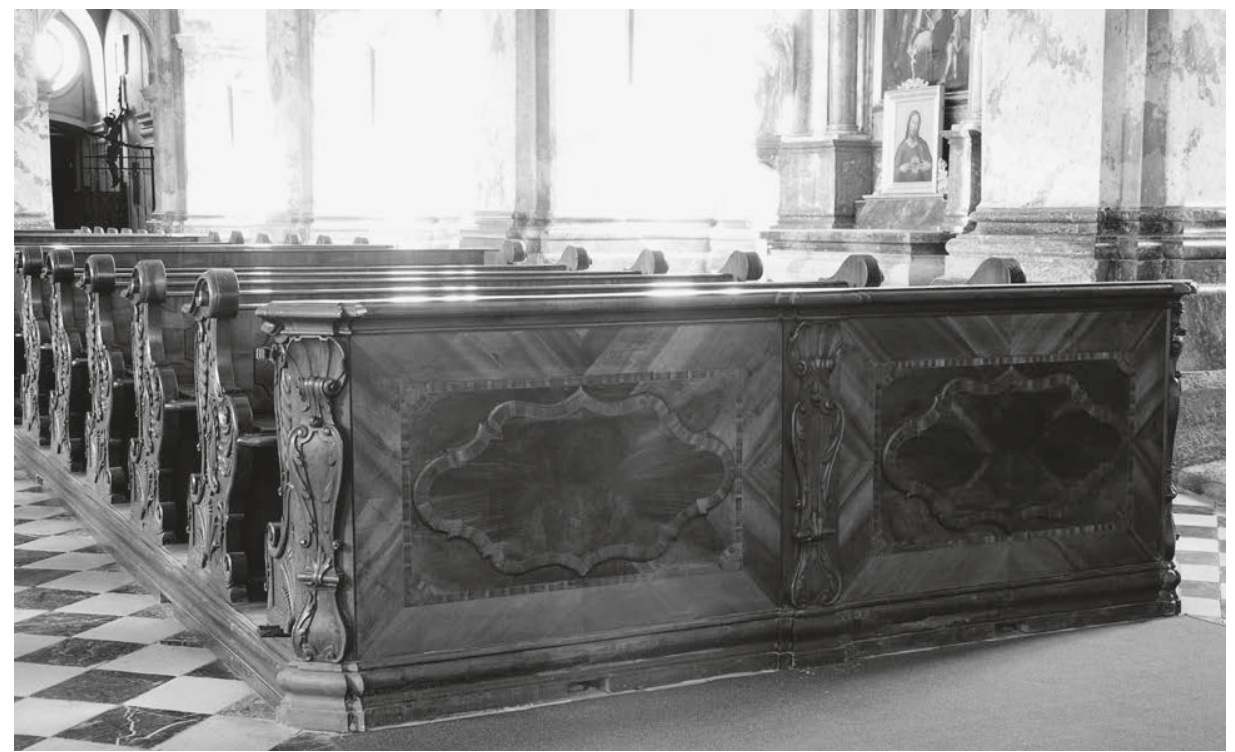

240 Kirchenbänke. Stiftstischlerei unter der Leitung von Mauritius Tauffer (?) sowie Thomas Schiffer, I 744

Chorgestühl entsprechen, unterteilen die Brüstungswände in zwei Achsen. Auch hier erinnern die Basen an Blütenkelche, die sich nach oben öffnen, während Muscheln die verkröpften Abschlussleisten tragen. Die diagonal furnierten Rahmen fassen rechteckige Bastionsfüllungen ein, zu deren Herstellung Nussbaummaserfurnier verwendet wurde.

Für die Seitendocken wurde eine asymmetrische Form gewählt. Dem markanten, aus einem S-Schwung entwickelten Wangenbauch steht auf der Kniebankseite ein ähnlicher Bogen gegenüber, eine Liegevolute bildet den oberen Abschluss. Sich an den Enden einrollende Bänder konturieren die Wangen. Während einfaches Blattwerk die Außenkanten schmückt, vollenden großfl̈̈chige Muschelornamente die vertieft liegenden Innenflächen. Der Grund ist nicht gekörnt, wie das an vielen anderen Gestühlen beobachtet werden kann, sondern mit dem Schnitzeisen nur grob bearbeitet, was eine leichte Struktur hervorruft, die die Oberfläche optisch belebt.

Der Vertrag über die Herstellung der Bänke wurde im August I 744 unterzeichnet:

Contract. Anheündt zu endt geßezten dato ist zwischen dem fürstlichen stüfft Rhein an ainem, dan Thomas Schüffer bestelten tischler gesellen albier, andern thaills folgender contract aufgericht, und beschlossen worden. 
Erstlichen verspricht, und verobligiert sich ernenter Thomas Schüffer die in dem neüen gottshauß zu Rhein zu denen kürchen stüellen zu machen seyende 48 ganze, und 24 halb dokhen, zusamben also 60 ganze dokhen, dan 36 cordellen dergestalten sauber, zierlich, und formlich /: iedoch obne deren requisiten, welche vom löblichen stüft auß beygeschaffet werden sollen:I von schneidtarbeith zuverfertigen, das ein löbliches stüfft hieran keine außstöllung zu machen haben, sondern mit selbiger seiner außgeschnitnen arbeith bestens contentiert, und zufriden sein solle.

Dabingegen und/andertens hat mehrgedacht löbliches stüfft Rhein vor obbemeblte obne außstöllung verfertigte schneidtarbeith gedachten Thomas Schüffer, nebst seiner gewöhnlichen cost, und trunkb vor ain ganze dokhen 48 kreüzer, dan vor ain cordellen 27 kreüzer in gnaden zubezablen versprochen. Actum stüfft Rhein, den 3o. August 1744 Placidus abbten

Und als Nachsatz: Den I 6 Jener I 745 habe ich diße verackorddirde arbeith völlich zalt mit $64 \mathrm{fl}$

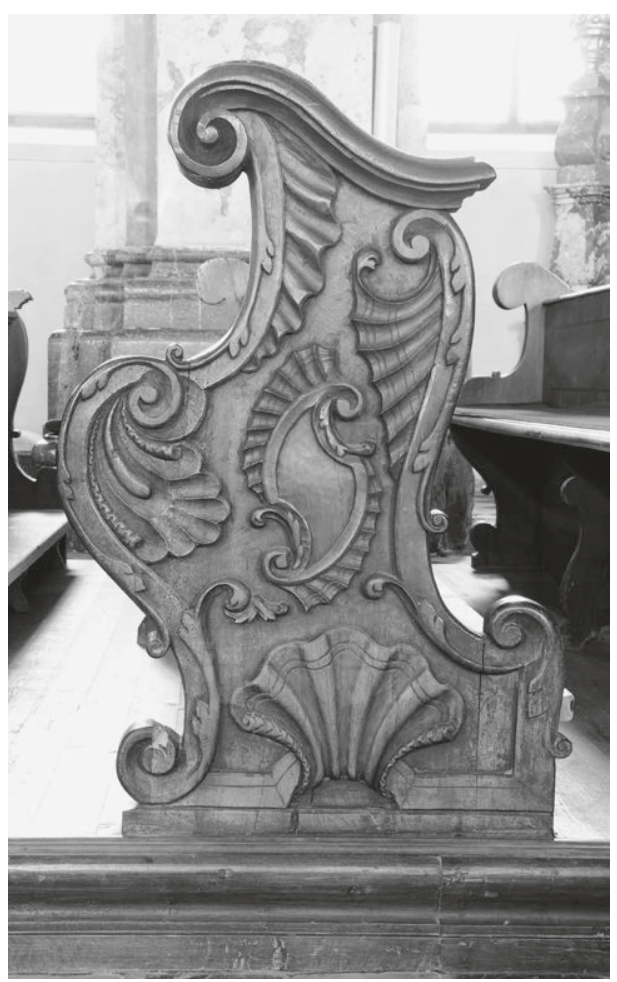

24I Bankwange. Thomas Schiffer, I 744 I 2 xr/f. Mauritius. ${ }^{391}$

Nach der Fertigung des Chorgestühls sollte Schiffer folglich die Docken der Kirchenbänke schnitzen, während die Bänke selbst im Vertrag nicht erwähnt werden; möglicherweise war die Stiftstischlerei für ihre Herstellung zuständig. ${ }^{392}$ Wegen des erheblichen Arbeitsaufwandes erstaunt der knappe Zeitraum, in dem das Laiengestühl verfertigt wurde, denn Schiffer erledigte seinen Auftrag in nur viereinhalb Monaten. 24 »halbe« Docken wurden für die vorderen und hinteren Brustwände der sechs Blöcke mit Bankreihen benötigt, das entspricht dem heutigen Befund. Mit den 36 cordellen dürften die Stützen gemeint sein, auch das stimmt mit der heutigen Anzahl überein. Differenzen ergeben sich jedoch bei der Anzahl der "ganzen« Docken, da wir heute pro Block zehn, insgesamt also 60 "ganze« Wangen vorfinden. Offenbar wurde der Auftrag an den Tischler nachträglich um sechs Bänke erweitert, obgleich Schif-

39I StAR, Lade M/XXXV.

392 Das vermutet auch die relevante Literatur. Kohlbach, Kirchenrechnungen [ca. I 946], Bd. 2, 965. 
fers Lohn, den Mauritius Tauffer ausbezahlte, die ursprünglich ausgehandelte Summe nicht überstieg. Darüber hinaus fallen die Unterschiede im Duktus der Schnitzarbeiten von Chor- und Laiengestühl auf. Gab Schiffer am Chorgestühl scharfkantigen, feinen und detailreichen Motiven den Vorzug, präsentieren sich die Schnitzereien an den Kirchenbänken als weniger delikat, die Formen sind breiter angelegt und leicht miteinander verschliffen. Möglicherweise ist das der unterschiedlichen Wertigkeit der Möbel geschuldet, die ihnen aufgrund ihrer Funktion und ihres Standortes innerhalb des Raumgefüges der Kirche zukommt. Dem würde auch das etwas rustikal anmutende non finito des Laiengestühls entsprechen. ${ }^{393}$

\section{Doppelbeichtstuhl}

Stiftstischlerei unter der Leitung von Mauritius Tauffer (?), um I 740/45, Maler und Vergolder Franz Josef Schlögl, I 753

HS $5 \mathrm{~cm}$

$\mathrm{H}_{33} \mathrm{~cm}\left(+\mathrm{I}_{5} \mathrm{~cm}\right) \times \mathrm{B} 400 \mathrm{~cm} \times \mathrm{T}$ ca. I Io $\mathrm{cm}$

Nussbaum, Nussmaser, Nuss geschwärzt, Buchs, graviert, geschwärzt, Nadelholz, Holz vergoldet und versilbert. Eisen geschwärzt

Der Doppelbeichtstuhl füllt eine Mauernische unter der Orgelempore (Abb. 242). ${ }^{394}$ Rundarkaden öffnen seine Fassade, nur in die Gehäuse der Geistlichen setzten die Tischler halbhohe Türen ein. Pilaster mit Volutenkapitellen stützen ein verkröpftes Gebälk und hochovale Gemälde mit Darstellungen der Heiligen Maria Magdalena und Petrus. Zwischen den Bildern ist auf dem Buch mit sieben Siegeln das apokalyptische Lamm Gottes im Strahlenkranz vergegenwärtigt, eine Thematik, die als Hinweis auf den Opfertod Christi und das Jüngste Gericht zu verstehen ist. Kirchenbesucher sollten so im Sinne der Gegenreformation zu Reue, Sühne und einem gottgefälligen Lebenswandel veranlasst werden. In der vorliegenden Studie wird mehrfach auf entsprechende ikonographische Programme an Beichtstühlen verwiesen. ${ }^{395}$ Ornamentale Schnitzmotive vervollständigen den Auszug. Das Lamm Gottes ist versilbert, während der Konvent die anderen Schnitzereien vergolden ließ. Die Tischler furnierten das Gerüst des Möbels mit gestreiftem Nussholz, die Füllungen mit Nussbaummaser. In Schlaufen gelegte und miteinander verkettete Adern sowie feines Blattwerk schmücken die Binnenfelder.

393 Bohr, Sakralmöbel (2017), I 27-I 29, sowie Teil 2, Kap. IV der vorliegenden Untersuchung.

394 Zum Beichtstuhl Dehio, Steiermark (2006), 394; Brenner, Himmel (2014), 68-73; Kopp, Beichtstühle (20I4).

395 Vgl. etwa die Hinweise zu den Beichtstühlen in der Stiftskirche von St. Georgenberg. 


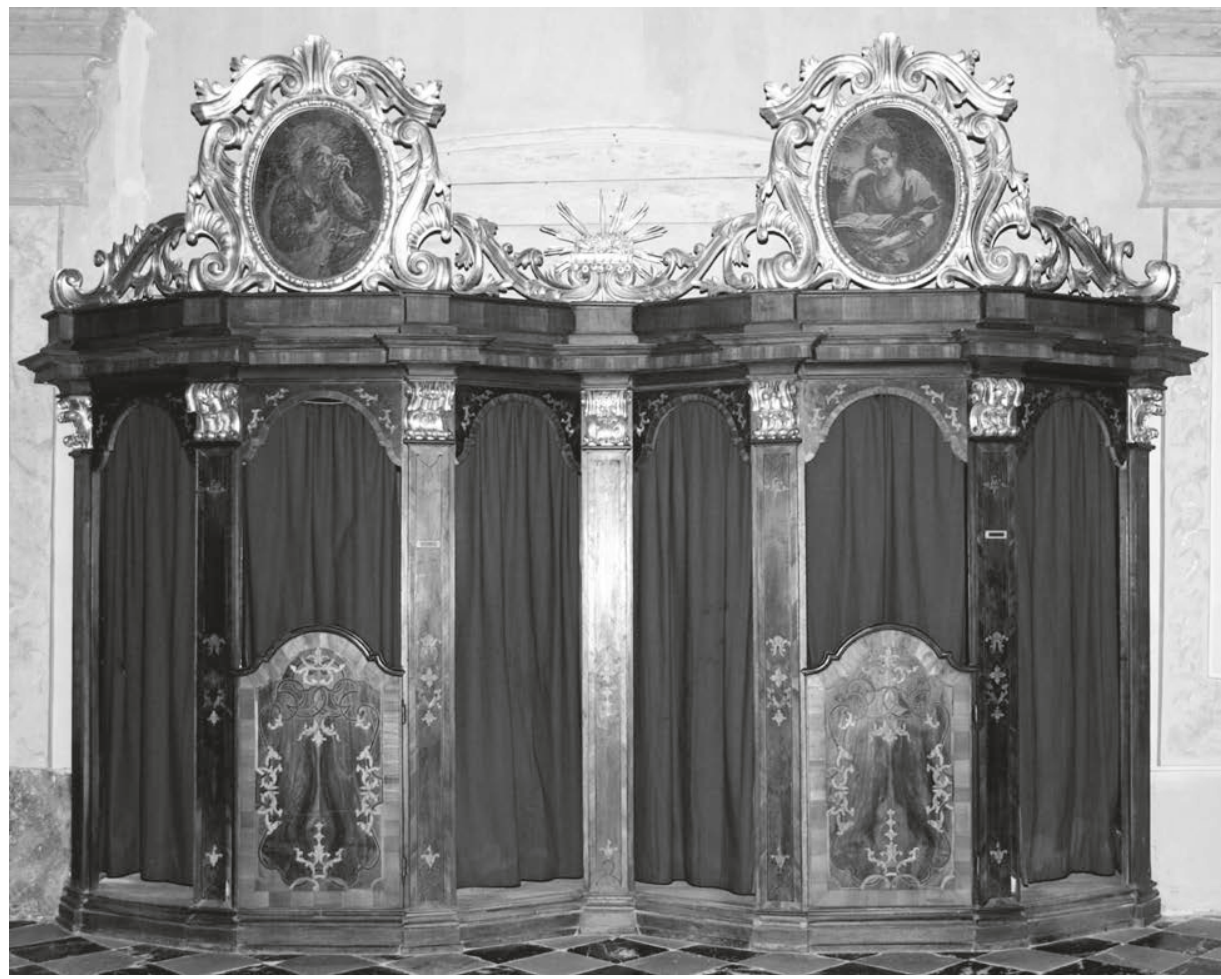

242 Doppelbeichtstuhl. Stiftstischlerei unter der Leitung von Mauritius Tauffer (?), um I 740/45, Vergolder Franz Josef Schlögl, I753

Das Reiner Stiftsarchiv verwahrt den Vertrag mit Franz Josef Schlögl, der den Schnitzaufsatz zu vergolden hatte. Das Schriftstück wurde am 4. April r 753 unterzeichnet. ${ }^{396}$ Zwar legt dieser Umstand eine Herstellung des Beichtstuhls in jenem Jahr oder kurz zuvor nahe, doch deutet der noch ohne Rocaillen auskommende Dekor auf eine frühere Herstellung des Möbels. Aufschlussreich ist ein Vergleich mit dem I 747/49 entstandenen Gestühl auf der Empore der Stiftskirche (Abb. 244), das bereits wesentlich moderneren Geschmacksvorstellungen folgt. In Verbindung mit der Bauchronologie scheint überdies eine Datierung auf die Jahre um I 740/45 wahrscheinlicher. Wie beispielsweise die Beichtstühle in Dürnstein oder die Sakristeimöbel im Grazer Dom belegen (Abb. I65), konnten zwischen der Herstellung von Möbeln und deren Vollendung durch Schnitzaufsätze und Vergoldungen durchaus einige Jahre liegen. ${ }^{397}$

396 Gigler, Umbauten (I 924), 33 (Quellenanhang).

397 Zu Dürnstein vgl. Bohr, Sakralmöbel (2017), 279-282. 


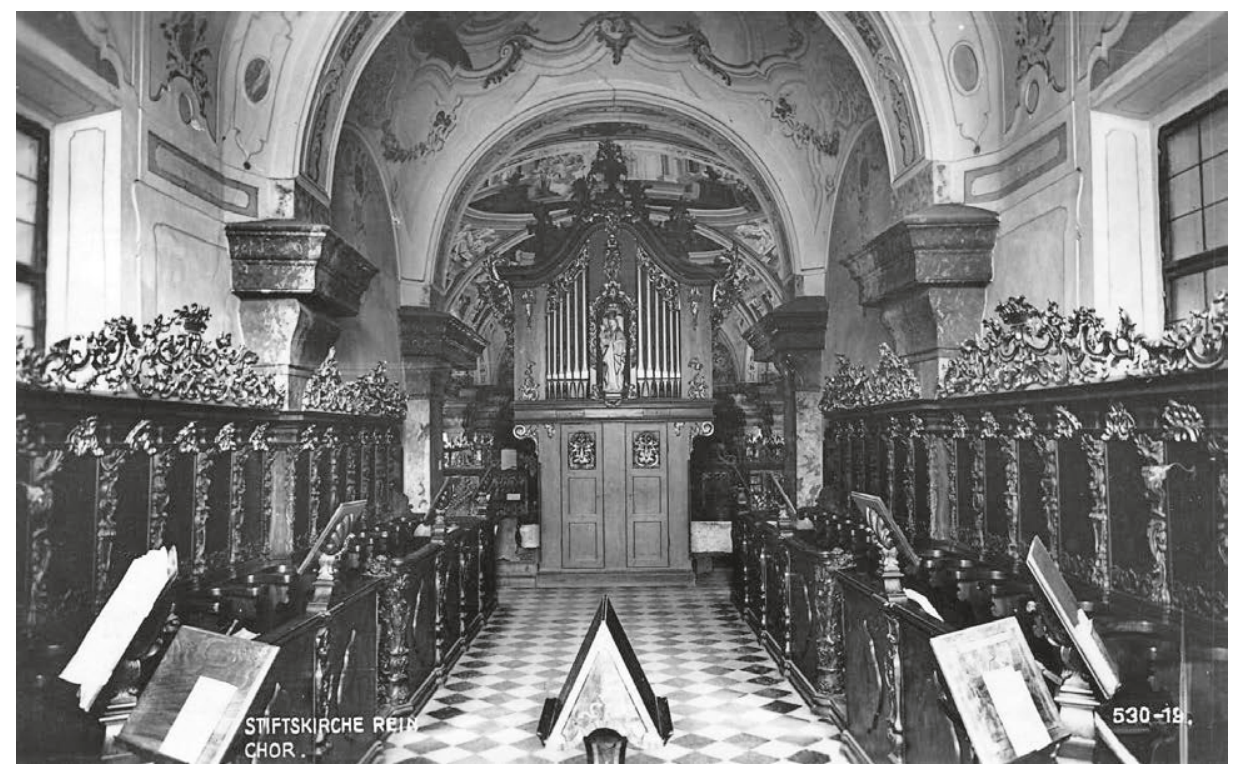

243 Orgelempore, historische Aufnahme. Inzwischen wurde die Orgel umgebaut, sodass der Blick auf den Hauptaltar frei ist.

\section{Gestübl auf der Empore}

Stiftstischlerei und Fr. Mauritius Tauffer, I 747/49

HS I $9 \mathrm{~cm}$

Höhe $350 \mathrm{~cm}(+\mathrm{I} 9 \mathrm{~cm}) \times$ Gesamtlänge ca. $25 \mathrm{~m}$

Nussbaum, massiv und furniert, Nussbaummaser, geschwärztes Nussbaumholz, Pappelmaser, Buchs, graviert und geschwärzt, Nadelholz, Linde, geschnitzt, vergoldet und versilbert. Eisen

Das Gestühl besteht aus 38 Stallen (Abb. 243-248). ${ }^{398}$ Die hier wiedergegebene historische Aufnahme zeigt einen Raum, den zum Kirchenschiff hin die Orgel begrenzt. Das Instrument wurde längst umgebaut und in der Mitte geöffnet, der Blick auf den Hauptaltar ist von der Empore aus seitdem möglich. Ein hohes Fenster in der Kirchenfassade teilt das U-förmige Gestühl, unter dem Fenster verbindet eine Wandvertäfelung die beiden Hälften. Wieder sorgen pilasterähnliche Stützen für die notwendige architektonische Instrumentierung der Brüstung, erneut hat man die Stützen als Schnitzarbeit gefertigt und mit einer Fantasieordnung versehen. Die Form der Binnenfelder ähnelt jener des Gestühls im Chorraum, fast identisch sind die Marketerien der Zwickel, doch vervollständigen

398 Gigler, Umbauten (I 924), 55-56; Hahnl, Stift Rein (1973), 21 ; Woisetschläger, Kunstschaffen (1979), 83; Dehio, Steiermark (2006), 394; Brenner, Himmel (2014), r48-I 49; Müller, Basilika (201 8), 54. 


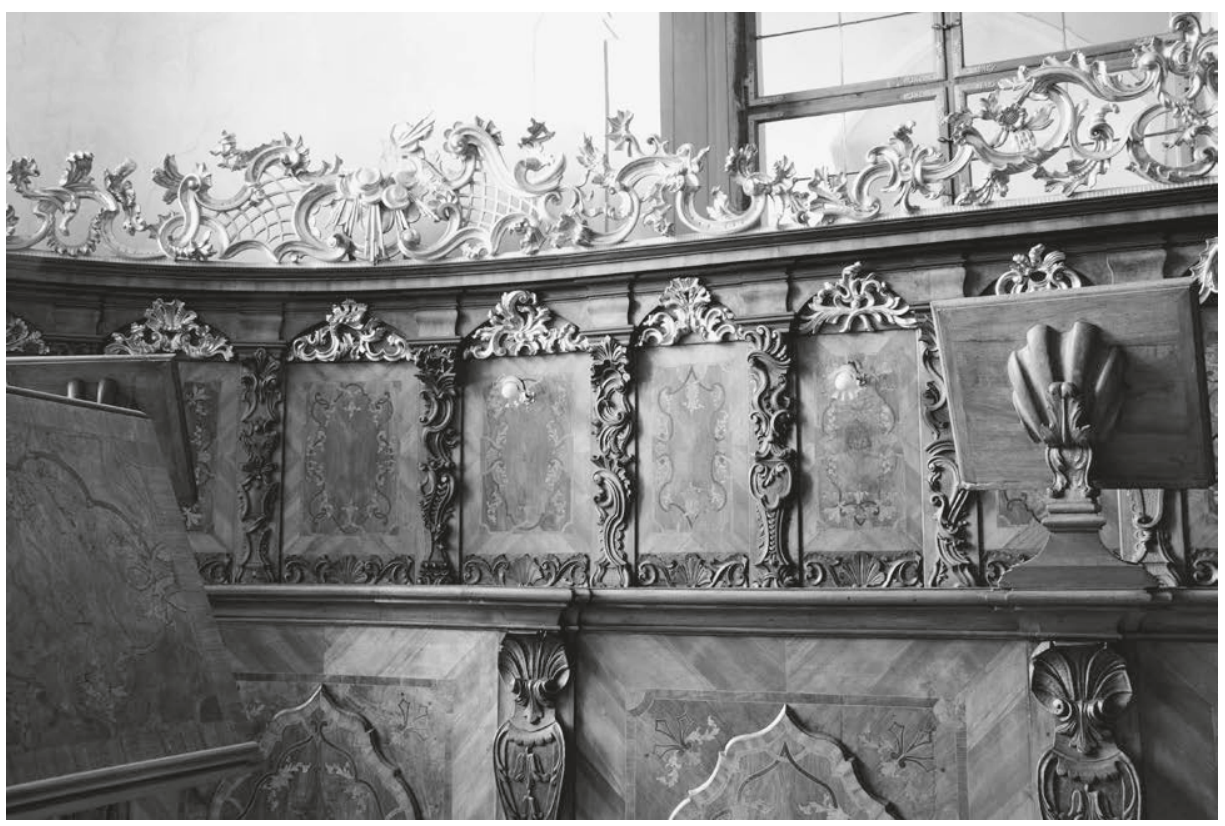

244 Empore, Chorgestühl (Detail). Fr. Mauritius Tauffer, $1747 / 49$

245 Empore, Teilansicht mit Abtstalle. Fr. Mauritius Tauffer, $\mathrm{I} 747 / 49$

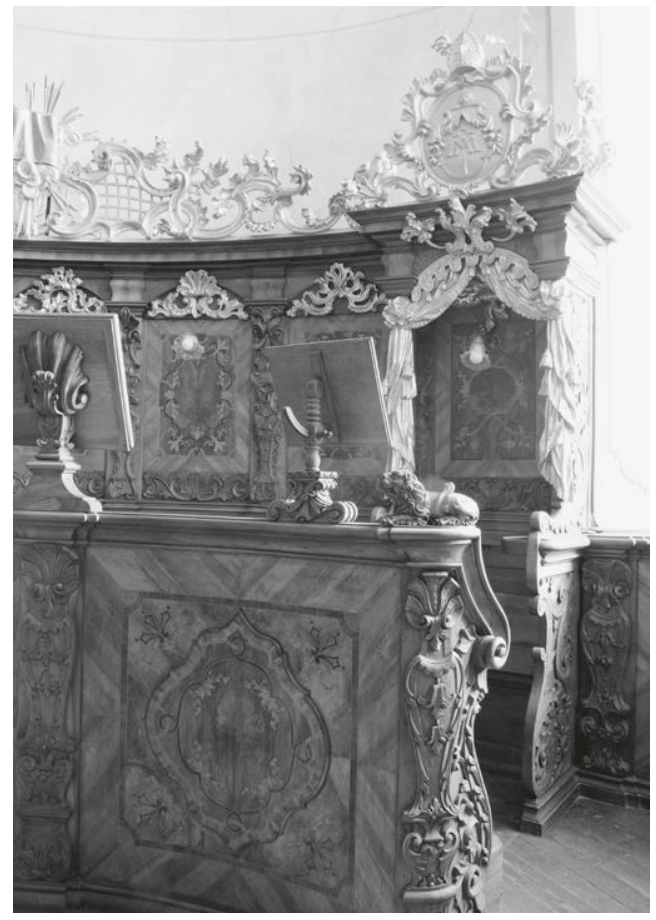




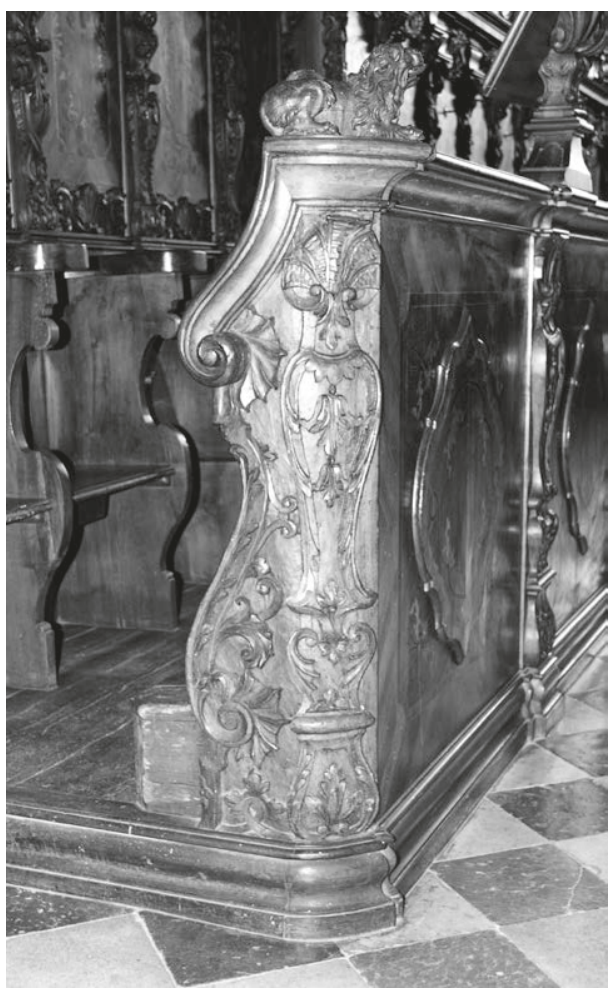

246 Empore, Brüstung (Detail). Fr. Mauritius Tauffer, $\mathrm{I} 747 / 49$

Intarsien nun auch die aufgedoppelten Platten. Die Brustwand trägt Lesepulte, auf den Wangen kauern Löwen und die Brüstungsinnenseite ist mit zusätzlichen Ablagen und schwenkbaren Kerzenhaltern bestückt. Auch das spricht für die hohe Qualität des Gestühls.

Die beiden mit Hochwangen eingefassten Stallen der Klostervorsteher befinden sich seitlich des Kirchenfensters. Das Gebälk formt über den Sitzen einen Baldachin, von dem ein mit kräftigen Faltenwürfen zur Seite gezogener, geschnitzter Vorhang herabhängt. Abgesehen von den Sitzen der Klostervorsteher entspricht die Konzeption des Ensembles jener des Gestühls im Chorraum, doch geben sich im stark geschwungenen und asymmetrischen Dekor der Dorsalestützen modernere Formen zu erkennen. Jüngere Ornamente präferierte man außerdem für den Schnitzaufsatz, wo mit Gitterwerk dekorierte Felder und flammenartig züngelndes Blattwerk vorkommen. Über der Sessio des Abtes gibt ein Schild mit dem Monogramm Mariens, dem Zeichen der Trinität sowie mit betenden Händen, Fruchtgehängen und einem Anker heraldische Motive wieder, die Abt Marian für sein Wappen gewählt hatte.

Selbstverständlich können die Analogien zwischen den Gestühlen auf der Empore und im Chorraum nicht überraschen, bemerkenswerter sind die Differenzen. Die beschriebenen Einzelformen verdeutlichen, dass der Umbruch vom Spätbarock hin zum Rokoko bei der Fertigung des Gestühls vollzogen war. Gleichwohl ist aber auch zu erkennen, dass die Möbelgarnituren im Abstand von nur wenigen Jahren entstanden. Das Gestühl auf der Empore ist qualitätvoller als das im Chorraum, die Marketerien sind vielfältiger, die Schnitzarbeiten detailreicher. Zudem nehmen Abt und Prior hier auf Stallen Platz, die durch ihr besonderes Aussehen hervorgehoben sind, während sich ihre Sitze im Chorraum nicht von denen der anderen Konventualen unterscheiden. Vermutlich muss dies als ein gesteigertes Maß an Selbstinszenierung Marians gedeutet werden, der sich gemäß der Zeit als angesehenen Barockprälat und den Prior als seinen Stellvertreter feiern ließ. Die Tatsache, dass das Gestühl vom Laienbereich der Kirche aus nicht zu sehen war, besaß in diesem Kontext keinerlei Bedeutung. 


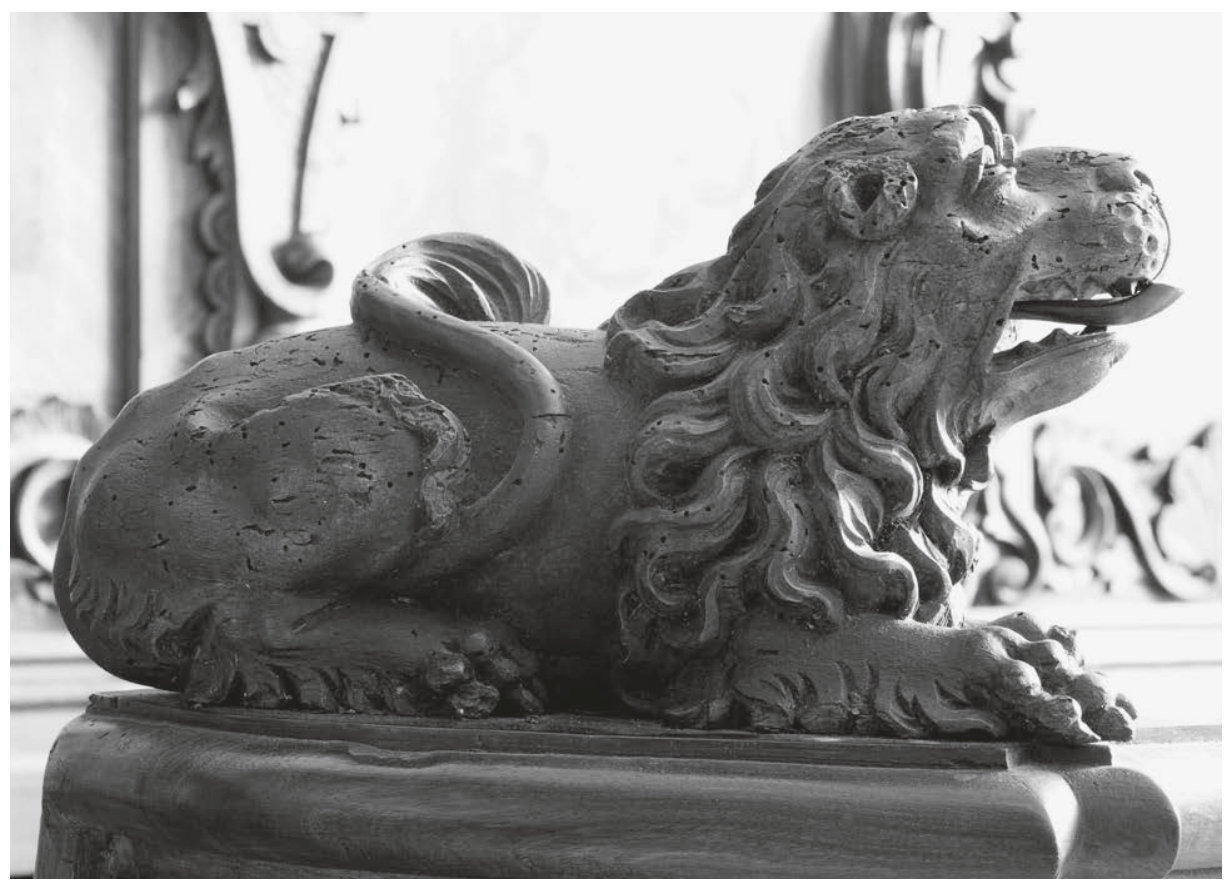

247 Empore, auf der Brüstung kauernder Löwe. I 747/49

In Bezug auf den verantwortlichen Tischler bzw. Bildhauer und die Datierung des Gestühls liefert die von Pater Alanus Lehr († I 775) verfasste Stiftschronik wichtige Hinweise. Der nachträglich erfolgten Schilderung nach soll Tauffer das Möbel zusammen mit dem Orgelgehäuse bis Ende August I 749 geschaffen haben:

Chorus novus perfectus fuit. Sedilia seu flexoria in Ecclesia et Stalla in choro, quae unacum Organo veteri in fine Augusti erecta I749, elaboravit praeter sculptilia fr. Mauritius Taufferer converses et Runae Professus. ${ }^{399}$

Wie oben erwähnt, wurde diese Nachricht in der Vergangenheit mit dem Gestühl im Chorraum der Kirche in Verbindung gebracht, doch führen zwischen dem Gestühl und der Orgel Türen zu Nebenräumen, eine trägt in der Schnitzbekrönung die Jahreszahl i 749. Dementsprechend liegt es nahe, die Schriftquelle auf das Gestühl auf

399 Lehr, Collectaneum, StAR, Hs I07, Bd. I, I05-107. Die Quelle ist wiedergegeben bei Gigler, ebd., 3 (Quellenanhang). 


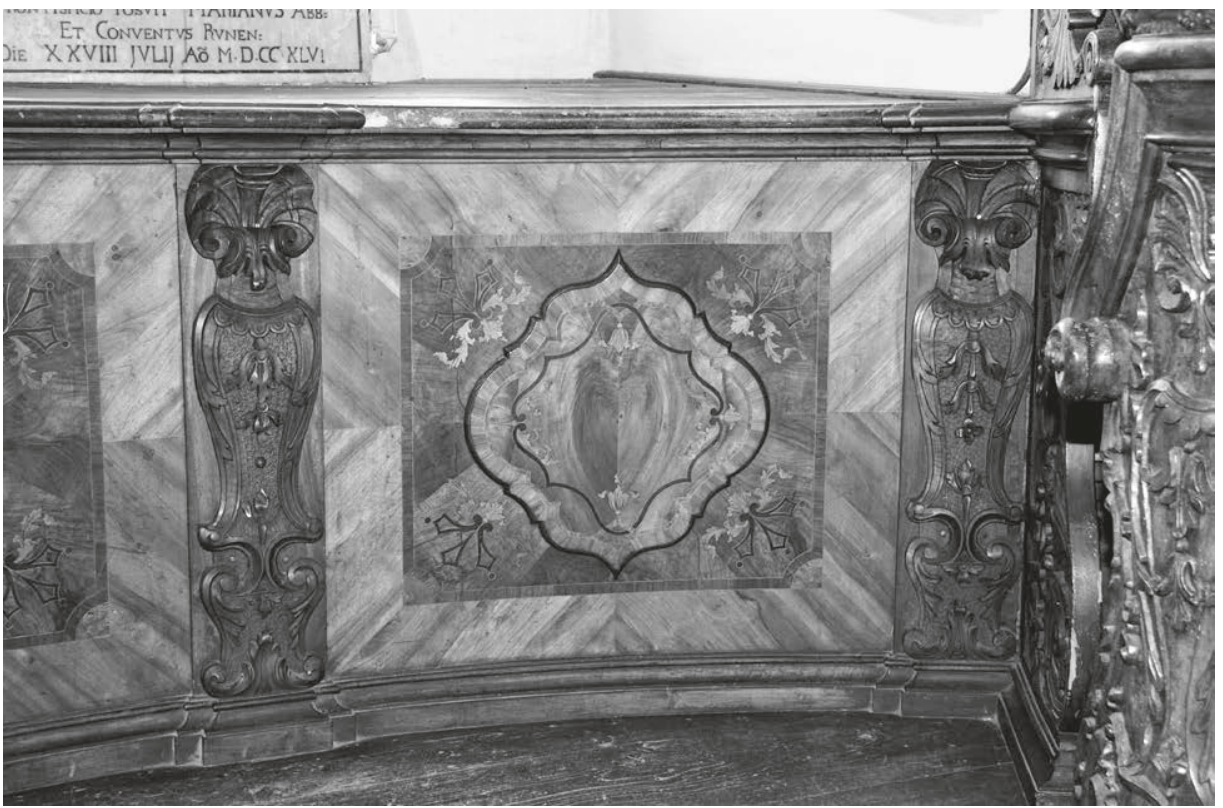

248 Empore, Wandverkleidung unter dem Außenfenster (Detail). Fr. Mauritius Tauffer, I747/49

der Empore zu beziehen. ${ }^{400}$ Die Stallen selbst könnten dem Eintrag zu Tauffer im Totenbuch des Stiftes zufolge etwas früher entstanden sein:

Fr. conv. Mauritus Tauffer (Taufferer). Aus Mainz/Deutschland, geb. am I7.9. I692. Aufgenommen von Abt Placidus, Profess am 2.I I.I727. Er war von Beruf Schreiner. 1747 hat er das Chorgestübl für die neue Stiftskirche geschaffen und sich damit ein Denkmal seiner Kunst und seiner Frömmigkeit gesetzt - Er war ferner Granarius, Excitator, Tischdiener und Refektorar. Er starb, reich an Jahren und Verdiensten, am 22. $10.1776 .^{401}$

Anders als in der Literatur gelegentlich vermutet, lassen Gründe der Stil- und Quellenkritik darauf schließen, dass die schriftlichen Nachrichten das Gestühl auf der Empore meinen. ${ }^{402}$ Tauffer dürfte es bereits I 747 geschaffen haben. Obgleich bis zur Auf-

400 Dem widerspricht auch nicht die Angabe in choro. Existiert ein Gestühl auf der Westempore oder in einem Zimmer, das an den eigentlichen Kirchenraum angrenzt, wird häufig von einem Winter- und Sommerchor oder einem Betchor berichtet.

40I Wild, Totenbuch, Bd. I3, I 2 I, sowie Bd. Io unter dem Sterbedatum.

402 Verschiedentlich wurde dieser Eintrag ebenfalls auf das Gestühl im Presbyterium bezogen. Hahnl, Stift Rein (1973), 2 I, nennt im Zusammenhang mit dem Bau des Gestühls auf der Empore auch 
findung weiterer Quellen nicht alle Zweifel ausgeräumt und keine wirklich sicheren Antworten auf die Fragen nach den Entstehungsprozessen der Möbelensembles in der Abteikirche geliefert werden können, scheinen die hier vorgeschlagenen Lösungsansätze doch in die korrekte Richtung zu weisen. Erhellende Resultate zeitigt überdies ein Vergleich des Gestühls mit dem gleichzeitig entstandenen im Stift Vorau. Im bezüglichen Abschnitt der Studie gehen wir auf diese Gegenüberstellung genauer ein.

\section{Rottenmann, Stadtpfarrkirche St. Nikolaus}

\section{Ehemaliges Augustiner-Chorherrenkloster}

Die Gründung des ehemaligen Augustiner-Chorherrenklosters in Rottenmann geht auf die I 45 oer-Jahre zurück, besiedelt wurde es von der Wiener Abtei St. Dorothea. ${ }^{403} \mathrm{Zu}$ nächst zelebrierten die Chorherren die Eucharistiefeier in der Marienkirche außerhalb der Stadtmauer. Nachdem das Kloster aber 1480/8 I wegen der drohenden Gefahr durch anrückende osmanische Heere in die Stadt verlegt worden war, sprach man den Herren die hochgotische Stadtpfarre St. Nikolaus als Abteikirche zu, die damals renoviert wurde. I 509 konnten die Umbaumaßnahmen beendet werden, die Weihe der Kirche erfolgte I 5 I 2. I 675 erweiterte der Konvent das Ostjoch des Schiffs im Norden und Süden um je zwei Seitenkapellen, etwa zeitgleich ließ er überdies die Westempore errichten. Bei dem Sakralbau handelt es sich um eine Hallenkirche. An das dreijochige und dreischiffige Langhaus schließt sich ein eingezogener zweijochiger, aber ebenfalls dreischiffiger Chor an. 1785 wurde die Abtei aufgehoben. Vertäfelungen an der Nordwand des Chorraums werden ursprünglich einmal die Rückwände von Stallen oder Sitzbänken gewesen sein, während sich vor der Südseite ein vollständiges Gestühl befindet.

\section{Getäfel im westlichen Joch der Chornordseite}

Rottenmann, um I630/40

$\mathrm{H} 246 \mathrm{~cm} \times \mathrm{L} 764 \mathrm{~cm}$

Nuss, Ahorn (?), dunkelbraun gebeizt

Die untere der beiden Sockelzonen ist nicht weiter verziert, während in der oberen Adern geometrische Motive nachzeichnen (Abb. 249, 250). Die untere Zone ist mo-

Thomas Schiffer, der jedoch in diesem Zusammenhang durch Quellen nicht belegt ist.

403 Kohlbach, Stifte (I 953), 247-266; Hootz, Kunstdenkmäler (I 965-1968), Bd. 2 ( 1966 ), 285, 383 ; Attems/Koren, Kirchen (1988), 66-67; Schwarzkogler, Bankrott (1992); Naschenweng, Rottenmann (2005); Dehio, Steiermark (2006), 406-409. 

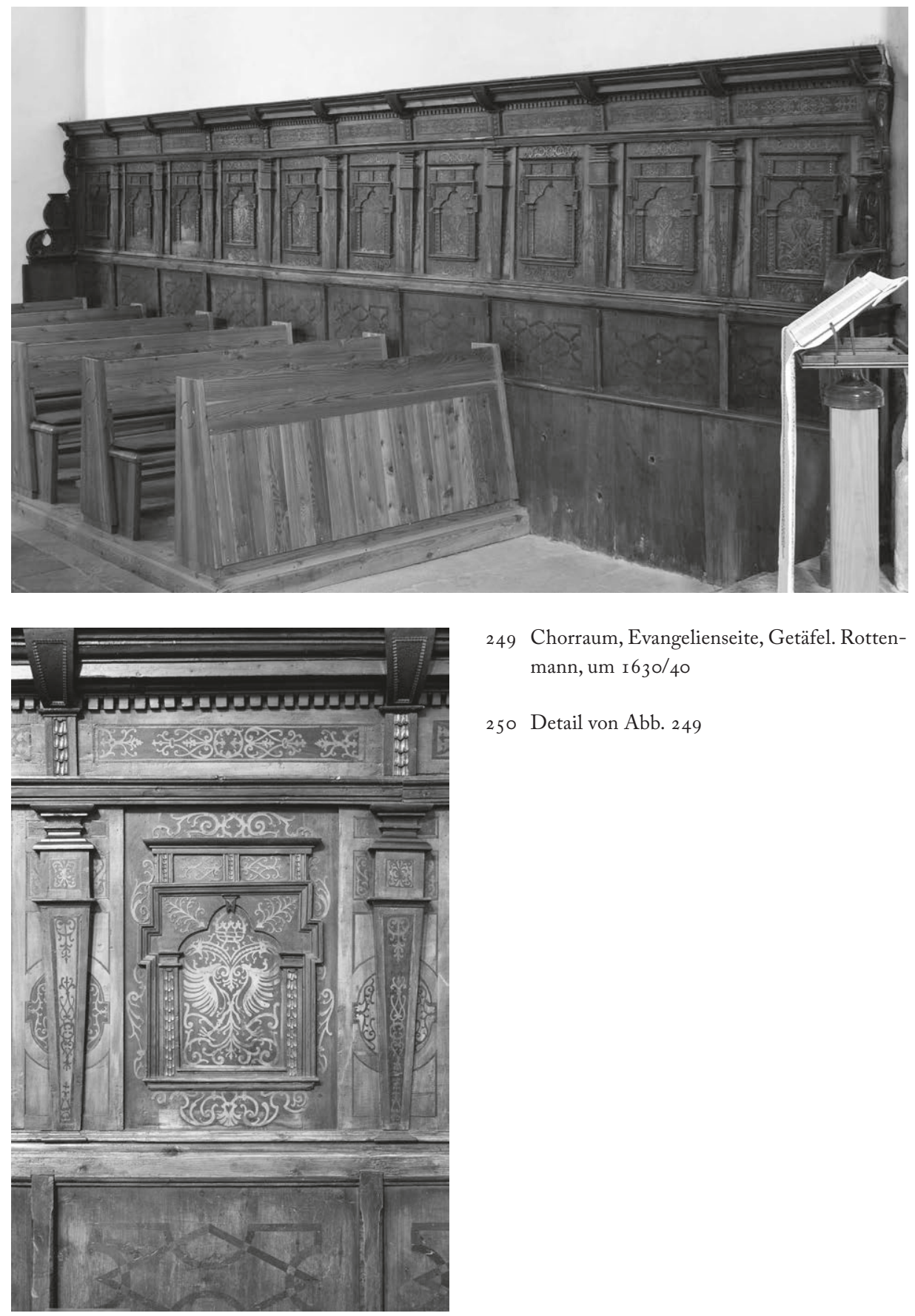

249 Chorraum, Evangelienseite, Getäfel. Rottenmann, um $1630 / 40$

250 Detail von Abb. 249 
dern, die obere geht auf das I7. Jahrhundert zurück. Senkrechte Leisten, möglicherweise die Reste von Zwischenwangen eines Gestühls, zergliedern sie.

Keilpilaster vor breiten Rücklagen unterteilen die Hauptzone der Vertäfelung, die Tischler gestalteten die dazwischen liegenden Füllungsfelder als Ädikulä mit eingestellten Arkaden. Das Getäfel schließt mit einem Gebälk, das hochrechteckige Platten und Schlaufenkonsolen strukturieren. Geschnitzte Schuppenfriese beleben die Platten sowie die Stützen der Arkaden, ausgesägte Ornamente säumen die welschen Fenster. Darüber hinaus bereichern qualitätvolle Marketerien die Tischlerarbeit: Bekrönte Doppeladler schmücken die Arkaden, Schweifwerkmotive und Ornamente aus dem Formenvokabular des beginnenden Frühbarocks die übrigen Flächen. Dabei wechseln dunkle Ornamente in hellem Grund mit Einlegearbeiten im Gegensinn. Die Intarsien des Getäfels stehen auf einer Stilstufe mit den Furnierarbeiten der vor 1620 gebauten Paramentenschränke in der oberösterreichischen Abtei Kremsmünster, geschnitzte Schuppenfriese kommen seit den fortgeschrittenen I62oer-Jahren vor, die für die Barockzeit typischen Knorpelmotive fehlen. ${ }^{404}$ Eine im Universalmuseum Joanneum zu Graz aufbewahrte steirische Truhe mit ähnlichen Ziermotiven wird auf das zweite Viertel des I7. Jahrhunderts datiert. ${ }^{405}$ Diese Datierung trifft auch auf die Wandverkleidung zu.

\section{Getäfel im östlichen Joch der Chornordseite}

Rottenmann (?), um I635/50

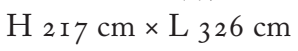

Nuss, Ahorn (?), dunkelbraun gebeizt

Erneut ist der Sockel zweizonig (Abb. 25 r). Lisenen und Scheinfüllungen schmücken das untere moderne Register, das negative Beizbild des dunkel gefärbten Holzes ist deutlich zu erkennen. Dagegen gehört die zweite Zone vermutlich zum historischen Bestand. Das darüber angeordnete und architektonisch interpretierte Hauptgeschoss weist überraschende Analogien zum Dorsale des nachfolgend beschriebenen Chorgestühls auf. Vor der Hauptzone stehen mit Schulterstücken und Blockkapitellen ausgestattete Keilpilaster auf hohen Sockeln. Quer- und Hochrechtecke rastern die Zwischenräume, nun setzte man die großen Füllungen aus einem Binnenfeld und zwei Friesen zusammen. Flache Sägeornamente zieren den äußeren Fries, die querrechteckigen Felder und die Kapitellzone, mit dem Schnitzmesser geformte vegetabile Schmuckmotive die Pilasterschäfte und zentralen Kompartimente. Den Abschluss bildet ein

$404 \mathrm{Zu}$ Kremsmünster vgl. Bohr, Sakralmöbel (2017), 5 1 7-522.

405 Kreisel/Himmelheber, Deutsche Möbel (I98I-I983), Bd. I (I98I), Abb. 45 o. 


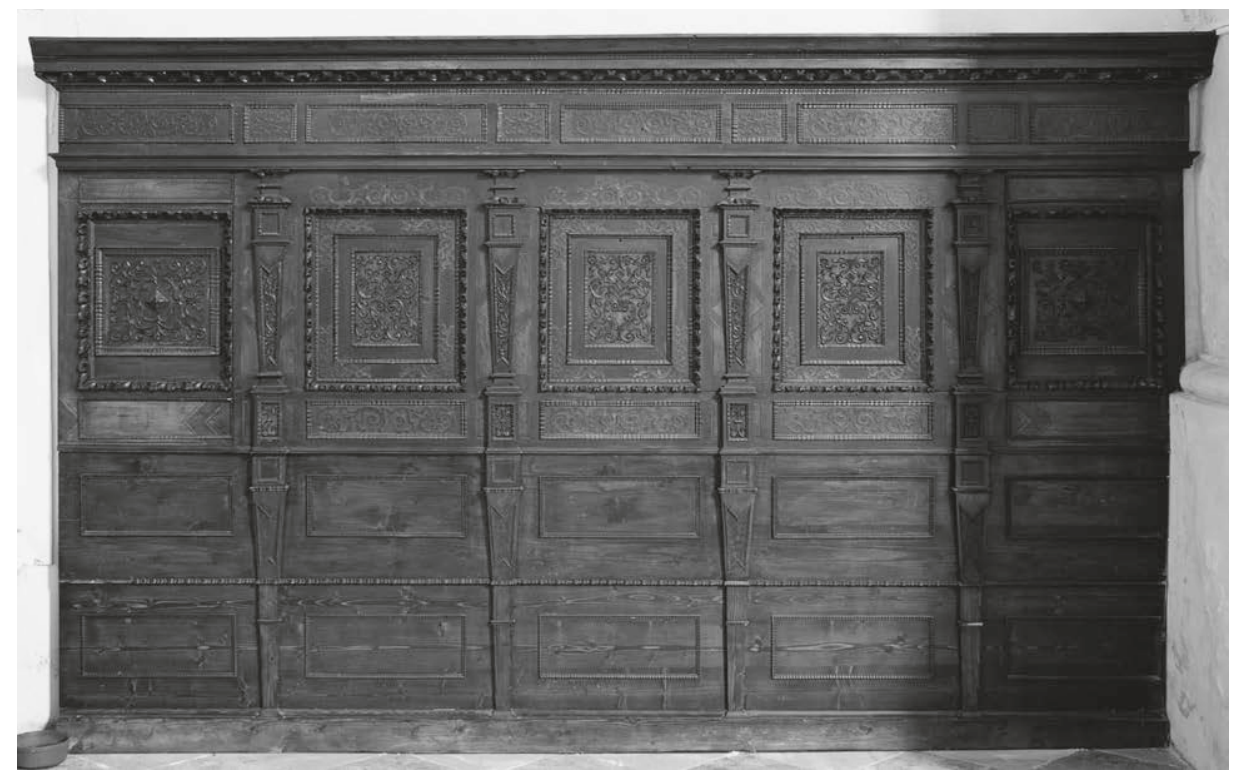

25 I Chorraum, Evangelienseite, Getäfel. Rottenmann, um I635/50

Gebälk, das ursprünglich in anderer Weise auf der Hauptzone montiert war, weshalb die Aufteilung des Frieses mit der des Dorsalebereichs nicht übereinstimmt. Und auch die beiden äußeren Achsen der Hauptzone gehören nicht zum Originalbestand, wie die spezielle Form der Binnenfelder, die anders gestalteten Profilleisten sowie die Furnierarbeiten über und unter den Füllungen dokumentieren. Offenbar wurde die Rückwand eines ursprünglich dreiachsigen Gestühls verlängert, um sie hier einzupassen.

\section{Chorgestübl auf der Südseite}

Rottenmann, um I645/55

HS $16 \mathrm{~cm}$

$\mathrm{H}$ I $96 \mathrm{~cm}(+\mathrm{I} 6 \mathrm{~cm}) \times \mathrm{L} 277 \mathrm{~cm}$

Nuss, dunkel gebeizt, Ahorn (?), Nadelholz

Mit Diamantquadern verzierte Piedestale wurden vor der Sockelzone der Brustwand angebracht (Abb. 252, 253). ${ }^{406}$ Auf ihnen lastende Keilpilaster mit Blockkapitellen und geschuppten Schäften tragen ein hohes, mit einem Eierstab verziertes Gebälk.

406 Naschenweng, Rottenmann (2005), 3 I 9 ; Dehio, Steiermark (2006), 409. 
252 Chorraum, Epistelseite, Chorgestühl. Rottenmann, um I 645/55

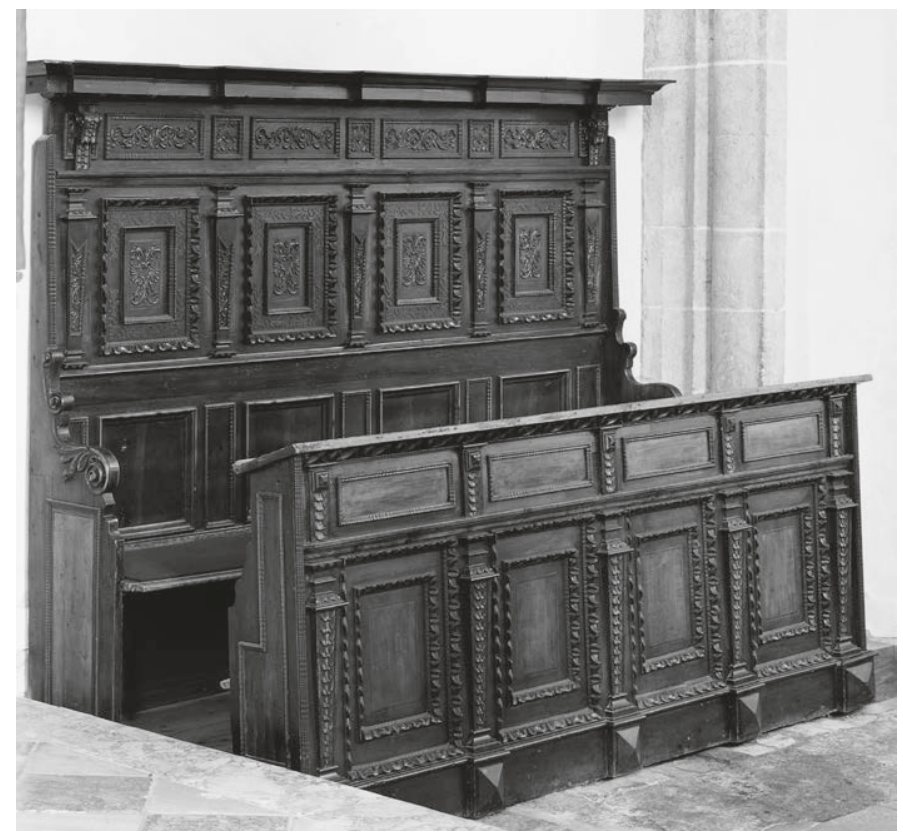

253 Chorraum, Epistelseite, Chorgestühl, Rückwand (Detail). Rottenmann, um I $645 / 55$

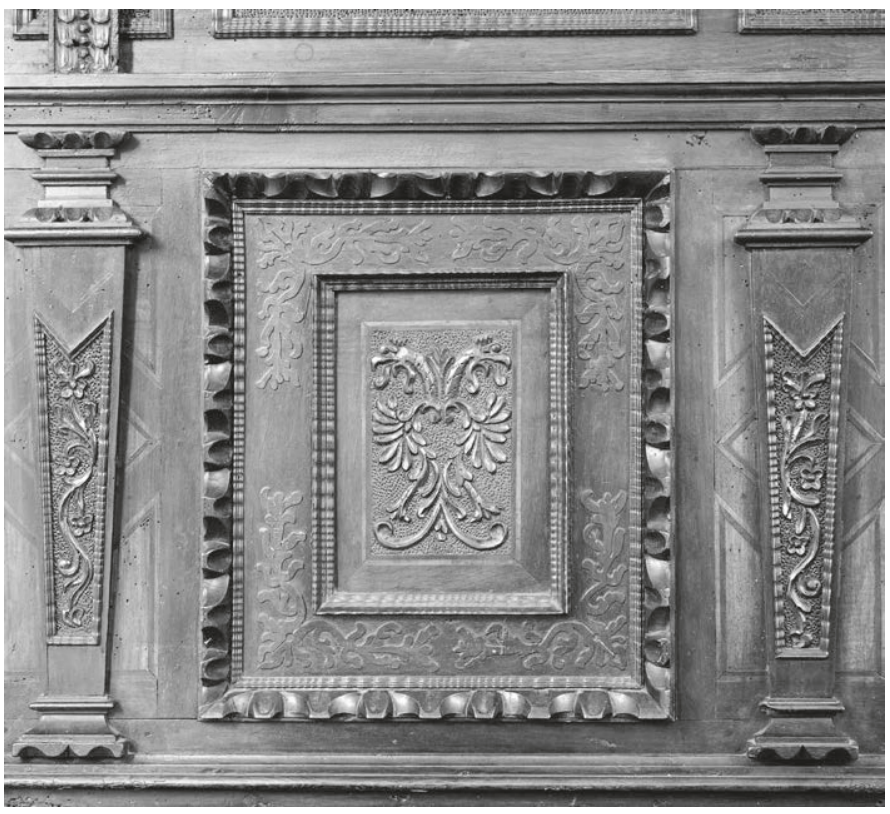


Kräftige Profile fassen zwischen den Stützen einen äußeren Fries und ein inneres Hochrechteck ein. Das Furnier der Frieszone besteht aus Nussbaum, das des zentralen Feldes aus hellem Ahorn mit eingelegten kantenparallelen Adern. Die Brüstungswangen, an deren Vorderkanten Flammleisten befestigt sind, stehen leicht vorn über, Ähnliches haben wir bereits am etwa gleichzeitig gefertigten Gestühl in der Stadtpfarrkirche in Völkermarkt beobachtet (Abb. 69). Die obere Hälfte der Wangenrückseite ist geschwungen, als Binnenfeld trägt die Docke ein L-förmiges Gebilde.

Die Bankwangen wurden im unteren Bereich gerade ausgehobelt, in mittlerer Höhe dient eine Akanthusvolute als Armstütze, darüber setzt sich die Wange bis zum Gebälk hin fort. Pilaster strukturieren ebenfalls das Dorsale. Auch die Füllungen sind zweifach gerahmt, wobei das innere Profil aus einer Flammleiste geschnitten wurde und deshalb optisch leichter als das entsprechende Gegenstück an der Brüstung ausfällt. Quadrate und Querrechtecke, deren Größe und Anordnung sich nach den Dorsalefeldern richten, rhythmisieren den Gebälkfries, Vorsprünge unterbrechen das Gesims in regelmäßigen Abständen. Blütenranken zieren die Pilaster, vegetabile Sägeornamente säumen die Füllungen. Als Flachreliefs ausgeführte Doppeladler heben sich von den zentralen Feldern ab, die mit einem gekörnten Grund versehen sind. Den Fries schmücken vegetabile Ornamente. Nach den Recherchen von Hannes P. Naschenweng gab Propst Bartholomäus Ferdinand Judex (reg. I645-1672) das Chorgestühl in Auftrag. ${ }^{407}$ Die Stilmerkmale deuten darauf hin, dass das bald nach seiner Inthronisation geschah.

\section{St. Lambrecht, Benediktinerabtei}

\section{Stifts- und Pfarrkirche St. Lambrecht}

Graf Markward von Eppenstein ( $\dagger$ Io76) und sein Sohn Herzog Heinrich III. († I I 22) errichteten um ro66 die Abtei als Eigenkloster und ließen sie von Mönchen aus St. Blasien im Schwarzwald besiedeln. ${ }^{408}$ I 262 wurde die Stiftskirche ein Raub der Flammen, 65 Jahre später stürzte die neurenovierte Kirche ein, die daraufhin bis I 42 I wieder aufgebaut wurde. Abt Benedikt Pierin (reg. I638-I662) begann mit der Barockisierung der Stiftsanlage durch Baumeister Domenico Sciassia (I 599/r6o3-r679).

407 Naschenweng, ebd.

408 Zur Geschichte der Abtei vgl. ÖKT, St. Lambrecht (195 I), I5-58; Kohlbach, Stifte Steiermarks (r 953), 67-ı oo; Hootz, Kunstdenkmäler (I965-I 968), Bd. 2 (I 966), 29 I-296, 384-385; Röhrig, Alte Stifte (I 967), I 9-2 I ; Woisetschläger/Krenn, Steirische Herrlichkeiten (I 973), 65-66, Taf. I 37; Stenzel, Stift (1977), го6-го9; Plank, Geschichte (г978); Attems/Koren, Kirchen (1 988), 63-65; Plank, St. Lambrecht (I99I); ders., St. Lambrecht (200I), 3 I 8-332; Plank/Romirer, St. Lambrecht (2002); Dehio, Steiermark (2006), 445-45 I. 
Um r640 ließ er die Westempore einfügen und zugleich den Lettner abbrechen, auf dem Altäre, eine Orgel und sogar ein Chorgestühl gestanden haben sollen. ${ }^{409}$ Der Sakralbau präsentiert sich heute als zwölfjochige Hallenkirche mit drei Schiffen gleicher Höhe, aber unterschiedlicher Breite, einem Chorumgang und zwei Westtürmen. Seine Ausstattung mit Barockaltären geht auf die Jahre I 632 bis r 644 zurück. ${ }^{410}$ Einige Altäre stammen von Christoph Paumgartner, einem Tischler und Bildschnitzer aus Neumarkt, der im vorliegenden Katalog mehrfach Erwähnung findet. ${ }^{411}$ Wie nachfolgend berichtet wird, fertigte er auch Kirchenmobiliar für St. Lambrecht an.

\section{Westempore \\ Chorgestühl \\ Abtstalle}

HS $37 \mathrm{~cm}$

$\mathrm{H} 340 \mathrm{~cm}(+37 \mathrm{~cm}) \times \mathrm{B}$ I $88 \mathrm{~cm}$

\section{Gestübl}

HS $52 \mathrm{~cm}$

Gesimshöhe ca. $360 \mathrm{~cm}(+52 \mathrm{~cm}) \times \mathrm{L}$ ca. I $3,20 \mathrm{~m}$

\section{2 seitliche Bänke}

Tischler und Bildhauer Christoph Paumgartner aus Neumarkt, I640/43

$\mathrm{HS} 26 \mathrm{~cm}$

H ca. $100 \mathrm{~cm}(+26 \mathrm{~cm}) \times \mathrm{B}$ I $78 \mathrm{~cm}$

Nussbaum, massiv, Nadelholz. Eisen

Die Kirchtürme nehmen beidseitig die Grundfläche der ersten Seitenschifftravée ein, weshalb die Empore, deren Tiefe sich über zwei Joche erstreckt, einen T-förmigen Grundriss besitzt. Das Gestühl wurde auf dem Geviert zwischen der Westfassade und den Türmen errichtet (Farbtaf. 27; Abb. 254-259). ${ }^{412}$ Vor der Außenwand befindet

409 Plank, St. Lambrecht (200I), 354.

4Io Plank, ebd., 356-357.

4I I Plank, ebd., 357 .

4I 2 Zum Gestühl: Riesenhuber, Barockkunst (I 924), Taf. 99; Gerlach, Chorgestühl (I93 I), I 7-I 8, 34-35; ÖKT, St. Lambrecht (1951), 78-79, Abb. 55-57; RDK, Bd. 3 (1954), Sp. 549-550, Abb. 3; Plank, Geschichte (I 978), 70 ; Schindler, Chorgestühle (I983), 56, Abb. 50, 5 I ; Plank, St. Lambrecht (199I), 7; ders., St. Lambrecht (2001), 357; Dehio, Steiermark (2006), 449. 


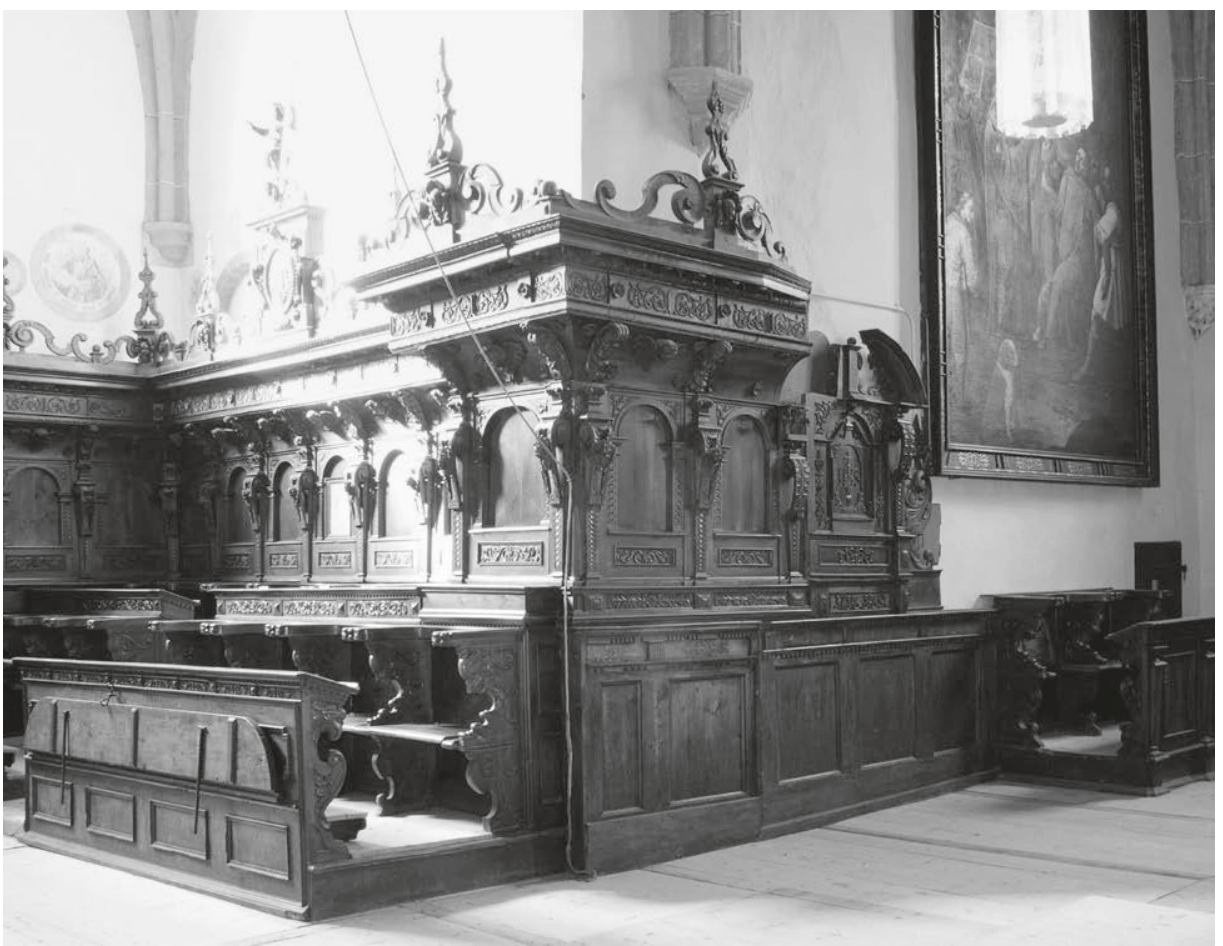

254 Empore, Nordseite des Chorgestühls mit Wandverkleidung und Zweisitz. Christoph Paumgartner, I $640 / 43$

sich der Einzelsitz des Abtes, die Plätze der Mönche stehen rechtwinklig dazu. Getäfel verbindet die seitlichen Hauptreihen mit der Abtstalle.

Massive Docken begrenzen die gedrungene Sedilie des Abtes. Akanthusblattwerk, geometrische Motive und mit Tüchern umwundene Köpfe, die ähnlich schon bei Ornamentstechern wie Jacques Androuet Ducerceau d. A. (um I 5 Io-nach I 584) vorkommen, schmücken die Wangen. ${ }^{413}$ Volutenpilaster und vollrunde Säulen vor $\mathrm{Mu}$ schelnischen flankieren am Dorsale über der Sessio des Abtes eine Arkade. Sie tragen einen Sprenggiebel und ein I643 datiertes Postament, auf dem das Wappen des Abtes Benedikt Pierin (ein Birnenzweig) kombiniert mit dem Stiftswappen (gekreuzten Hirtenstäben und einem L) aufsitzt. An der Stallenrückwand angebrachte Blenden, die vom Sockel bis zum Gebälk reichen, fassen Sitz und Dorsale zusammen.

4I3 Berliner/Egger, Vorlageblätter (I98I), Bd. I, 58-59, Bd. 2, Abb. 459, 46I, mit zwei Stichen aus der Mitte des i6. Jahrhunderts. 


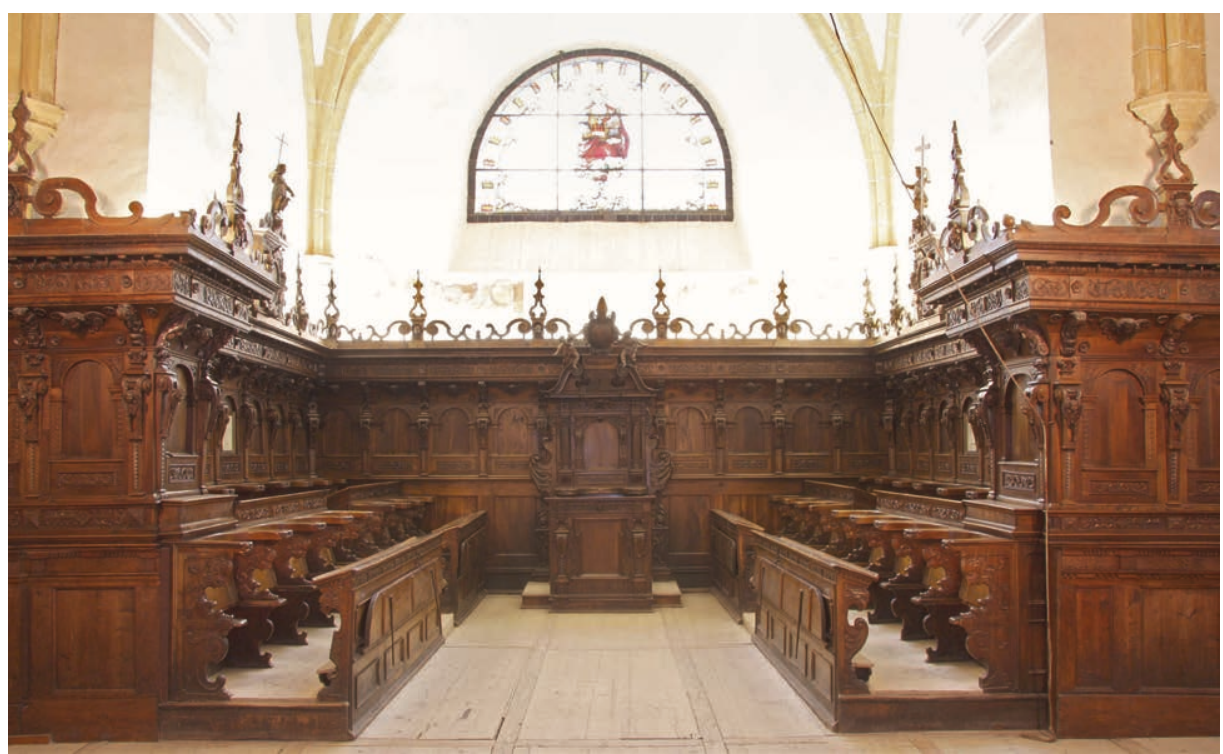

Farbtafel 27 Empore, Chorgestühl. Tischlermeister Christoph Paumgartner aus Neumarkt, I640/43

Über querrechteckigen Füllungen schließen die mit zusätzlichen Bänken versehenen Brustwände der Hauptreihen mit einem Gesims, dem Laubwerk, Diamantquader und ein Konsolfries aufgelegt sind. Die geschweiften Seitenwangen der Pulte zeigen einen nach unten geneigten Adlerkopf, C-Bögen formen die Federn. Mit anderer Gestaltung präsentieren sich die Docken der Sitzreihen: Ein breites Band, von dem Blattwerk ausgeht, begleitet die Vorderkanten des unteren Bereichs, während die oberen Wangenhälften als Blattmasken über einem flachen Delphinkopf ausgearbeitet sind. Blätter und Früchte vervollständigen die Vorderkanten der Accoudoirs.

Engelsköpfe, Rollvoluten und Schuppenfriese zieren die Pilasterschäfte vor der Rückwand. An der tiefen Hohlkehle, die das Dorsalegebälk weit nach vorn in den Raum zieht, wechseln groteske Maskenkonsolen und Cherubim einander ab. Den Gebälkfries schmücken Medaillons und vegetabile Ranken. Große Arkaden zwischen den Pilastern blieben unverziert, während in den seitlichen Zwickelfeldern Birnenzweige aus dem Wappen Pierins zu erkennen sind. Ein hoher Aufsatz bekrönt das Gebälk. Auf der Evangelienseite trägt es ein Postament mit der Statue des Christuskindes, gegenüber eine Skulptur Johannes des Täufers. Seitlich davon stehen Sockel mit hohen geschweiften Spitzen zwischen ornamentalen Gebilden, die ohne inneren Zusammenhang mit dem Gestühl auf dem Gebälk befestigt sind.

Eine Wandverkleidung führt das Dorsale an der Ostseite der Türme weiter, danach folgen Teilstücke von Möbeln, die nicht zum originalen Bestand gehören. Der Sockel- 


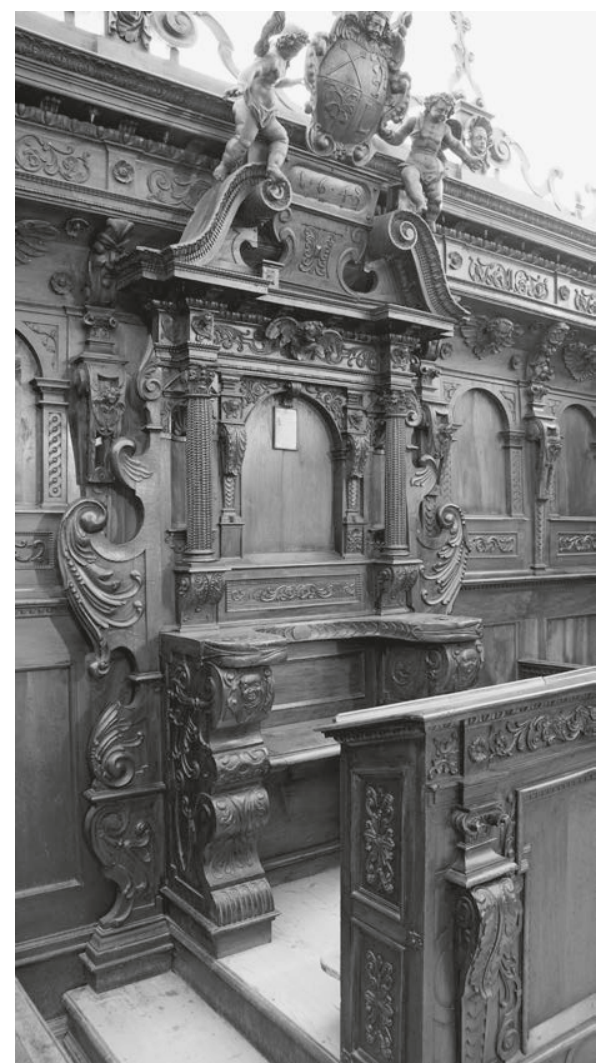

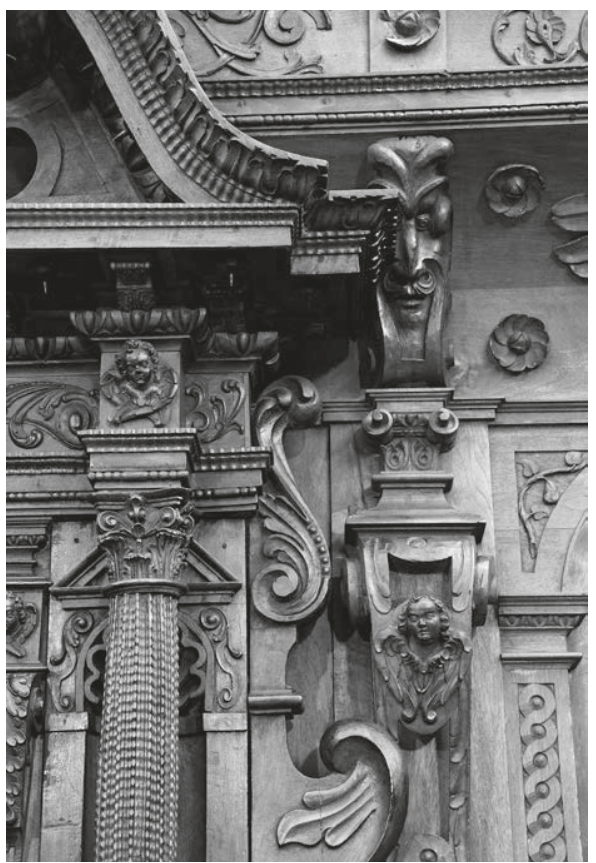

256 Empore, Detail des Abtstuhls. Christoph Paumgartner, $1640 / 43$

255 Empore, Abtstuhl. Christoph Paumgartner, I $640 / 43$

bereich wurde vermutlich aus Resten des Laiengestühls der Kirche zusammengefügt (Abb. 254). Die Vertäfelung endet mit zwei Stallenpaaren, die etwa gleichzeitig mit dem Chorgestühl gefertigt wurden, sich aber dennoch von ihm unterscheiden. Möglicherweise standen sie einst an einem anderen Ort, vielleicht vor den Vierungspfeilern, so wie das in anderen Sakralbauten noch immer der Fall ist. ${ }^{414}$

Vier große, mit Cherubim bereicherte Lesepulte vervollständigten einst das Gestühl, sie haben sich in der Kunstsammlung des Stiftes erhalten. Alte Abbildungen zeigen noch ihre frühere Anordnung. ${ }^{415}$ Das Gestühl besteht aus massivem Nussbaumholz. Aus Nadelholz fertigte man die erneuerten Laufböden und die modernen Auflagen der

4I4 S. hierzu den Beitrag über die Abtsedilie im ehemaligen Zisterzienserstift Neuberg (Abb. 2 IO, 2 I I).

4I 5 Riesenhuber, Barockkunst (1 924), Taf. 99; RDK, Bd. 3 ( 1954 ), Sp. 549-550, Abb. 3 ; ÖKT, St. Lambrecht (195 I), Abb. 57 . 


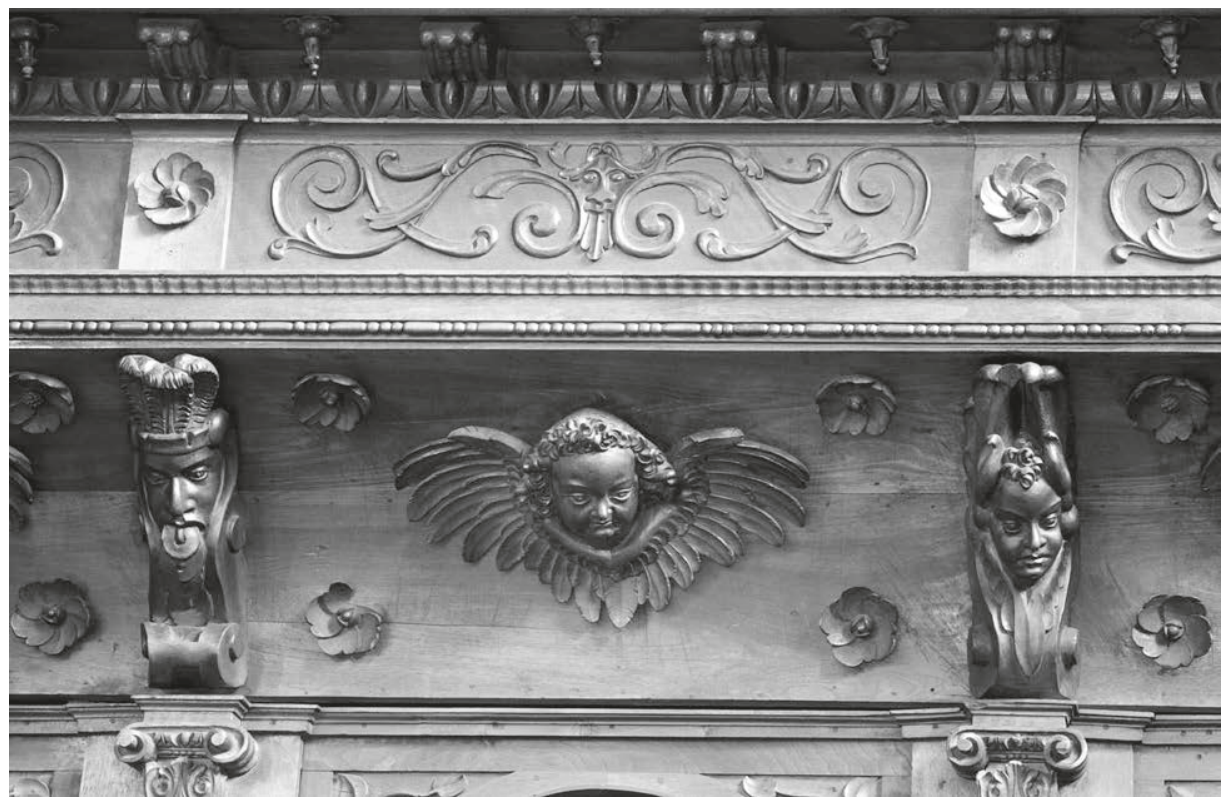

257 Empore, Chorgestühl, Detail des Baldachins über der Hauptreihe mit Cherubim und Groteskmasken. Christoph Paumgartner, I640/43

Kniebänke, deren geschweifte Kufen wohl noch dem I 7. Jahrhundert angehören. Aus Eisen sind die Beschläge, die die Sitze halten.

Christoph Paumgartner, ein Bildhauer und Tischler, der im nur wenige Kilometer entfernten Neumarkt eine Werkstatt besaß und wiederholt vom Konvent mit wichtigen Arbeiten bedacht wurde, baute das Gestühl. Der mit ihm ausgehandelte Kontrakt unterrichtet über die Auftragsvergabe und das Entstehungsdatum des Ensembles:

An heut dato den I8. februarii I 640 ist zwischen ibr Hochw. und Gnaden herrn herrn Benedict abbten des fürstl. stüfts St. Lamprecht an einem, dan maister Christoffen Paumbgartner andersteils wegen machung des gestüel und podn auf den newen chor in die hofkirchen zu St. Lamprecht nachvolgender contract aufgericht und beschlossen worden.

Erstlichen solle meister Christoff Paumbgarttner auf den newen chor einen fueßpoden von feuchten tafel und lerchen füessen eingefast machen.

Mehr das gestüel auf den newen chor von nußpaumben holz nach der visierung gemacht werden für die herrn Patribus 28 ständ, was die ruckwand jänisch krackstein tärmis auch englknöpf (!) darauf, auch auf der ausladung auf den kappetel mit frazengesichter oder schnaggenköpf geschnitten werden. Zwischen aber englsköpf mit ausgeschlagenen flüegl in den haubtfrieß mit einer schrift, wie man ihms wirdfürschreiben, die archentrag (!) geflambtgelt, aufdas haubtgesimbs der carnißgeschnitten oder aber 


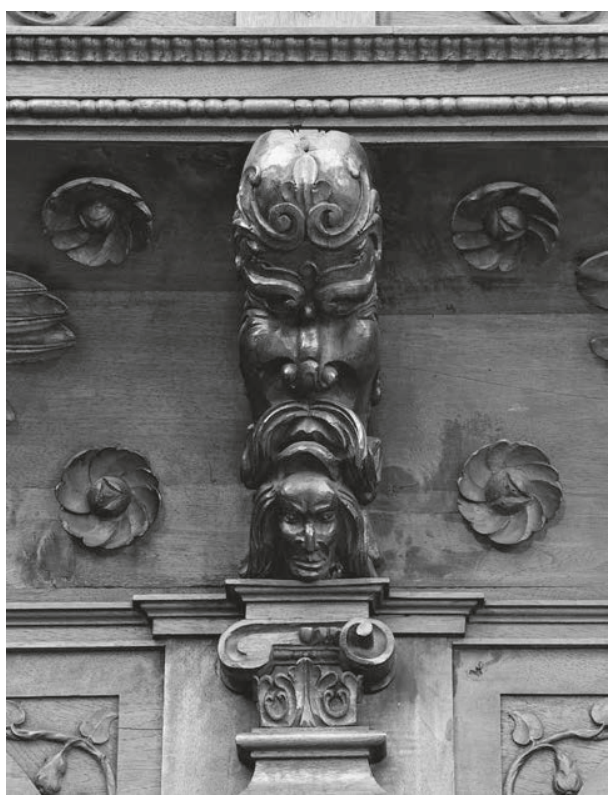

258 Empore, Chorgestühl, Detail des Baldachins mit Groteskmaske und Selbstporträt des Künstlers (?). Christoph Paumgartner, $1640 / 43$ geflambtgelt unter der platten mit schön geschnittnen krackstein zwischen geschnittene rößlen, der auszug soll mit einer zerbrochnen dachung mit schniegln, darauf zwey sizende kindlen, die ein schild oder das wappen halten, oben darauf ein schönes haubtgesimbs, darauf einen zerbrochenen auszug, zwischen ein postement, darauf ein pild, wie mans ibme wird angeben, nebens zween durchgebrochene auszug, darzwischen auch ein postement, darauf zween geschnittene pyrämnus ${ }^{416}$ oder pilder, wie man ibms wird angeben.

Ihr Gn. stuel solle mit mehrerem fleiß gemacht werden, vorn an dem pult oder lain mit einem jänischen krackstein auf das zierlichist gemacht, darzwischen ein wälsches fenster mit zieraten und geflambten kellstoßen geziert werden, oben auf das pult mit zween liegunden löwen, die rüglain solle mit carinthischen sailen und geflambgelt werden, hinder den sailen mit muscheln zwischen ein schöne verdüefte rundung, der auszug und haubtgesimbs, der solt nach der visierung auf das fleissigist sambt den wappen und andern zieren gemacht werden.

Mehr zway pult auf zwo gedräten sailen oder sonsten auf zwo schöne gestöll, darunter zwey dreyeggete postementer, auf ein ieden egg ein schön krackstein oder plindflüegl, oben darauf ein schönes kindl mit einem fliehenden gwäntl. Mebr vorn herauf den newen chor auf den steinenen haubtgesimbs ein gätter mit schubern, darauf ein schönes haubtgesimbs, inwendig ein eingefastes brusttäfel mit sambt einem knieschämbl.

Darzu ibr Gn. alle notwendigkeit von holz, laimb, nägl, kerzen und dergleichen selbsten geben lassen und inen darmit versehen werden. [...] Beschehen in der abbteilichen residenz St. Lamprecht, die et anno quo supra. ${ }^{417}$

Paumgartner erhielt somit den Auftrag, auf der Empore einen Boden aus Fichtenund Lerchenholz zu verlegen. Das Gestühl selbst sollte er aus Nussbaumholz fertigen, Maße und Aussehen einer heute verschollenen Zeichnung entnehmen. Einige Details werden im Vertrag trotzdem angesprochen: Unter anderem wird festgehalten, dass der

4I6 Der Begriff pyrämnus ist eventuell als Verballhornung des lateinischen Wortes "pyramis« oder des deutschen Wortes »Pyramide« zu verstehen. Wahrscheinlich sind damit die weit in die Höhe ragenden Spitzen gemeint, wie sie in der Sakristeiausstattung auf Postamenten vorkommen (Abb. 263).

4I7 Zitiert nach ÖKT, ebd., I 96-I97, Reg. 22 I. 
Fries mit einer Inschrift verziert werden sollte. Das wäre ungewöhnlich gewesen und wurde offenbar auch nicht ausgeführt. Danach geht der Kontrakt genauer auf die Stalle des Abtes ein. Zwischen ionischen Pilastern sollte am Pult ein wälsches fenster eingesetzt werden, das der Handwerker mit Schnitzwerk zu säumen hatte. Zwei Löwen sollten das Pult flankieren, sie fehlen heute. Der abschließende Satz des vorletzten Passus bezieht sich vermutlich auf eine Verkleidung der Emporenbrüstung. Die Verkleidung ist nicht erhalten, doch zeigen Arbeiten im burgenländischen Frauenkirchen (Abb. 07) sowie in der Priesterseminarkirche zu Linz, wie wir sie uns etwa vorzustellen haben. ${ }^{418}$ Der Vertrag endet mit der Selbstverpflichtung des Abtes, die von Paumgartner benötigten Werkmaterialien zu stellen. Dieser Passus wurde nachträglich abgeändert, denn aus einer anderen Quelle geht hervor, dass der Tischler bei der Herstellung der Abtstalle sein eigenes Holz verarbeitete. ${ }^{419}$ Solange er mit der

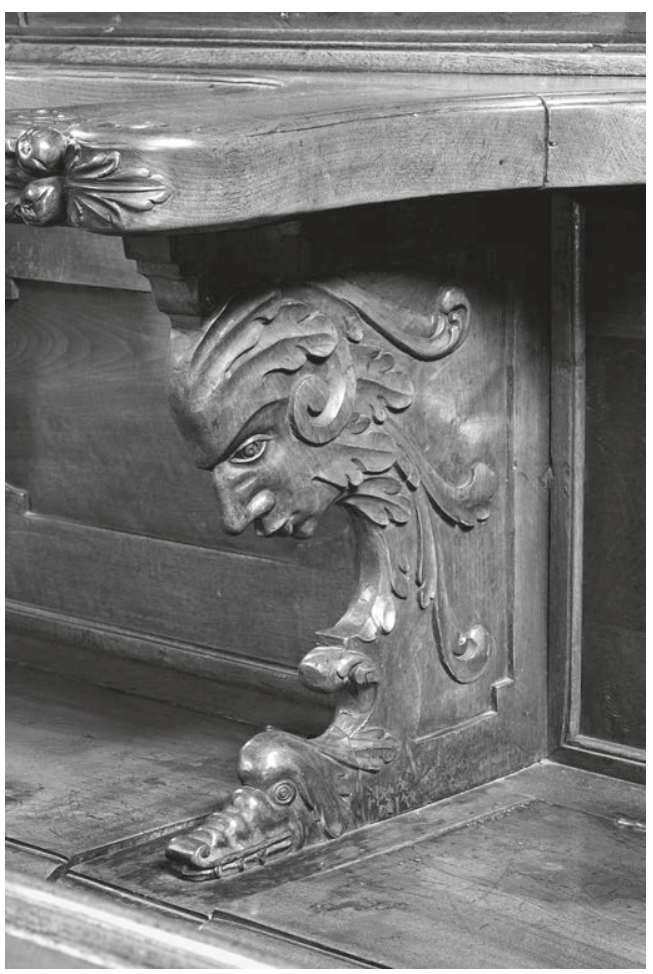

259 Empore, Chorgestühl, Zwischenwange mit Delphinkopf und Blattmaske. Christoph Paumgartner, I640/43

Fertigung des Gestühls beschäftigt war, wurde er im Kloster an der Offizierstafel verköstigt, während die Gesellen zusammen mit den anderen Handwerkern an der Gesindetafel speisten. Als Verdienst wurden 500 Gulden und I 5 Gulden Leihkauf vereinbart. ${ }^{420}$

\section{Kirchenbänke}

Tischler Christoph Paumgartner, Neumarkt, I640/43

HS ${ }_{15}, 5 \mathrm{~cm}$

$\mathrm{H}$ Io6 $\mathrm{cm}\left(+\mathrm{I}_{5}, 5 \mathrm{~cm}\right) \times \mathrm{L}_{45} 2 \mathrm{~cm}$

Zirbelkiefer, Fichte

4I 8 Zur Brüstung in Linz vgl. Bohr, Sakralmöbel (2017), 575-576.

4I9 ÖKT, St. Lambrecht (I95 I), 205, Reg. 24I.

420 ÖKT, ebd., I 97 . 


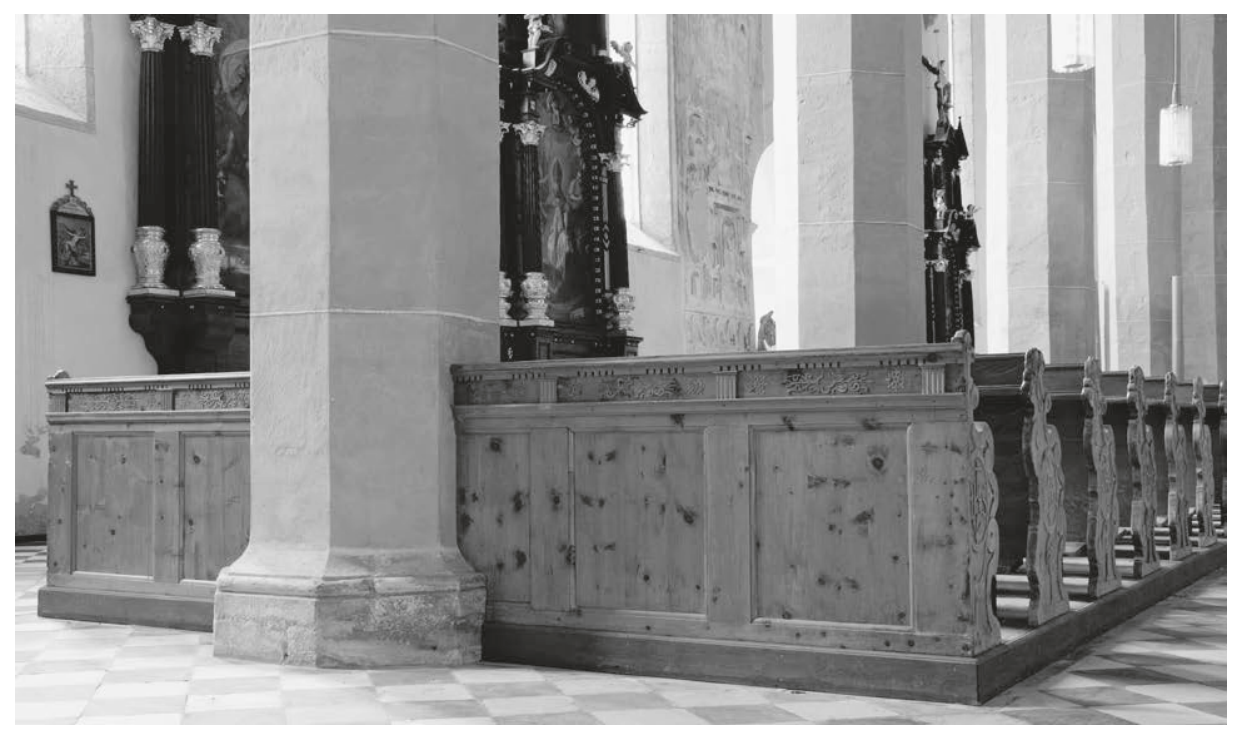

260 Laiengestühl. Christoph Paumgartner aus Neumarkt, I640/43

Paumgartner konnte unmöglich die Arbeit am Chorgestühl vollendet haben, als keine sechs Monate nach dem ersten Vertrag ein weiterer Kontrakt zwischen dem Abt und dem Tischler aufgesetzt wurde. Er datiert vom 24. Juli I 640 und beinhaltet die Lieferung des Laiengestühls für die Stiftskirche und den Bau der entsprechenden Laufböden (Abb. 26o, 26I). Der Handwerker hatte in der mitten zwischen der pfäler söchs pöden, auch an baiden seiten nach der leng hinauf, auf die vier pöden ... außerhalb was Ir Gnaden etwan mehrers von nußpämben holz für herrn hofrichter oder andere stüel machen lassen wirdet anzufertigen. ${ }^{421} \mathrm{Abt}$ Benedikt versprach, das zur Herstellung der Bankgarnitur benötigte Holz beizusteuern. ${ }^{422}$

Der Schriftquelle zufolge sollte Paumgartner sechs Sockel für die Bänke zimmern, die wie üblich quer zur Kirchenlängsachse ausgerichtet waren, ferner vier Sockel für einen Platz in den Seitenschiffen vor den Außenwänden, also parallel zur Längsachse. In der Steiermark und in Kärnten finden sich für diese Art der Aufstellung mehrere Beispiele (Abb. 56, 73, 74, 229). Außerdem deutete der Abt an, möglicherweise weitere Bänke für Honoratioren in Auftrag zu geben.

Ursprünglich standen auch in St. Lambrecht die Seitenaltäre vor den Kirchenpfeilern, die Altäre wurden in den sechziger Jahren des i 9. Jahrhunderts vor die Außen-

42 I Zitiert nach ÖKT, ebd., Reg. 223. Vgl. zu den Kirchenbänken auch Gerlach, Chorgestühl (I93 I), 33;

Plank, St. Lambrecht (I 99I), 7 ; Dehio, Steiermark (2006), 449.

422 ÖKT, ebd. 
mauern des Sakralbaus versetzt. ${ }^{423}$ So ergab sich die Möglichkeit, die Länge der Bänke zu vereinheitlichen und zusätzliche Sitzplätze zu schaffen. Schon damals wird eine erste Umgestaltung zahlreicher Möbel erfolgt sein, doch wurde historischen Aufnahmen zufolge die ursprüngliche Aufteilung der Bankreihen auf sechs Postamentblöcke beibehalten. ${ }^{424}$

In der zweiten Hälfte des 20. Jahrhunderts wurden die alten Sockel durch neue ersetzt und die Sitzmöbel dabei zu vier großen Blöcken zusammengefasst. Die beiden vorderen zählen jeweils I 3, die hinteren I7 Sitzreihen. In Verbindung damit baute man auch die restlichen (oder alle?) Bänke um: Die Brüstungen gehören zum originalen Bestand, wobei jene Brustwände, die bei der Neuaufstellung der Bankreihen überflüssig geworden waren, wie erwähnt vermutlich als Wandverkleidung auf der Empore Verwendung fanden. Alt sind weiterhin die zur Mitte des Kirchenschiffs weisenden geschnitzten Wangen, während sich die Außenwangen größtenteils als Neuanfertigungen erweisen. Das Gleiche gilt für die Sitz- und Kniebänke.

Von den alten Wangen existieren zwei

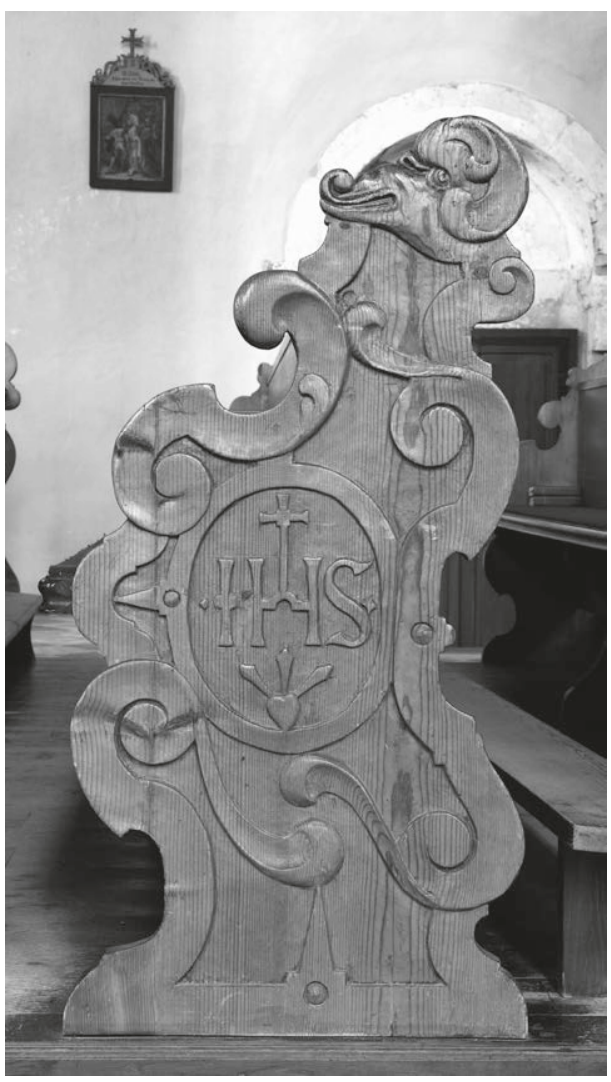

26 I Seitenwange des Gestühls mit Christusmonogramm. Christoph Paumgartner, $\mathrm{I} 640 / 43$ verschiedene Typen: Eine Garnitur trägt in einem Oval das Monogramm IHS mit Kreuz und Herz, die andere die ineinander geschriebenen Buchstaben MRA. Die Konturen der Docken zeichnen konkave und konvexe Bögen nach, entlang der Außenkanten verlaufen breite, zum Teil auch gekehlte Bänder, die mit Delphin- bzw. Adlerköpfen enden. Im Gegensatz zu vielen anderen im Katalog vorgestellten Bankwangen aus dem I 7. Jahrhundert sind die Exemplare in St. Lambrecht asymmetrisch konstruiert. Ähnliche Kirchenbänke befinden sich in den Pfarrkirchen von Mariahof (Abb. 200-202) und Steirisch Laßnitz, die dem Stift inkorporiert sind. Die Brustwände der Möbel in St. Lambrecht sind mit

423 Plank, St. Lambrecht (2001), 360.

424 ÖKT, St. Lambrecht ( 95 I), Abb. 40, 4I. 
schlichten Rahmen, großen Rechteckfüllungen und gebälkartigen Gesimsen versehen. An Schweifwerkmotive erinnernde frühbarocke Sägeornamente schmücken die Frieszone, Triglyphenfelder weisen die Brüstungen der ionischen Ordnung zu. ${ }^{425} \mathrm{Wie}$ in Mariahof sollen die Bänke mit den Mariensymbolen einst auf der Frauenseite der Kirche, die übrigen auf der Männerseite gestanden haben. ${ }^{426}$

Eine Rechnungsaufstellung Paumgartners von r643 endet mit dem Hinweis, dass der Tischler das Laiengestühl nussbaumfarben gebeizt, mit Leim getränkt und mit einem schützenden Firnis überzogen hatte. ${ }^{427}$ Um beim Umbau der Bänke eine homogene Gesamterscheinung zu erzielen, wurde die originale Patina von den Möbeln entfernt.

\section{Beichtstüble}

St. Lambrecht, um I 700/ I 5

$\mathrm{H} 233 \mathrm{~cm} \times \mathrm{B}_{3} \mathrm{IO} \mathrm{cm} \times \mathrm{T} 106 \mathrm{~cm}$

Nuss, Ahorn, geschwärztes Holz, Zirbelkiefer. Metall

Die dreiachsigen Beichtstühle erheben sich über rechteckigem Grundriss mit abgeschrägten Ecken, korinthische Pilaster tragen ein schweres Gebälk, Türen verschließen den Korpus (Abb. 262). ${ }^{428}$ In der unteren Hälfte setzten die Tischler geschlossene Füllungen in die Rahmen ein, oben treten hochrechteckige Öffnungen mit Rundhölzern und Schnitzarbeiten an die Stelle der zentralen Felder. Am hier abgebildeten Beichtstuhl zeigen die Schnitzereien ein von glockenförmigen Blüten umgebenes Hochoval mit Blütenrosette, am anderen ein kreisförmiges Segment, von dem aus sich krautiges Akanthusblattwerk nach den Seiten hin ausbreitet. Den Schnitzarbeiten stehen Marketerien mit Keilstäben und Sternen in geschweiften Hochovalen gegenüber.

Die Autoren des Dehio-Handbuchs nehmen eine Anfertigung der Beichtstühle um I700 an, obgleich der damals noch vorherrschende Akanthusdekor weitgehend fehlt. Andererseits lassen sich Blüten und Intarsienbilder tatsächlich sehr gut auf den Jahrhundertwechsel oder auf das frühe i8. Jahrhundert datieren. Für eine Anfertigung in jener Zeit sprechen überdies die architektonischen Zierelemente und die ab-

425 Möbel mit ähnlichen Brüstungen sind übrigens auf einem Kupferstich von Johann Jakob Kraus II. (I642-I70I) von I680 zu erkennen. Der Stich zeigt die Ausstattung der Heiligkreuzkirche in Augsburg. Egg, Hofkirche (1 974), Abb. I 9.

426 Freundlicher Hinweis von Abt Benedikt Plank.

427 ÖKT, St. Lambrecht (I95 I), 205, Reg. 24I.

428 Dehio, St. Lambrecht (I95 I), 449. Ursprünglich müssen es fünf Exemplare gewesen sein, wie das in einem der folgenden Abschnitte wiedergegebene Zitat belegt. 
262 Beichtstuhl. St. Lambrecht, um I $700 /$ I 5

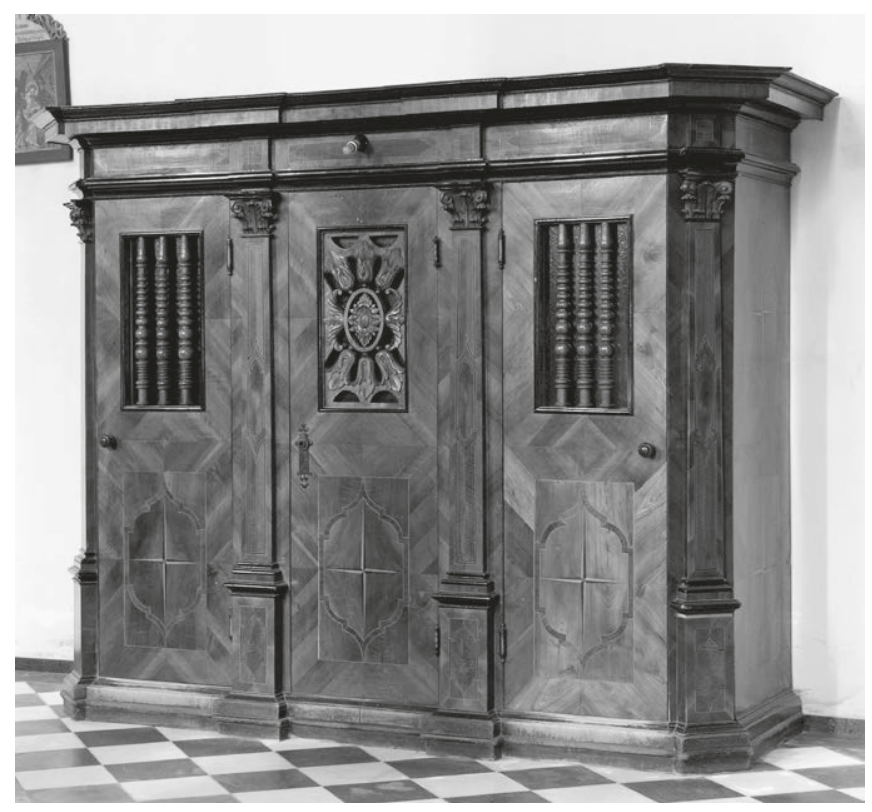

geschrägten äußeren Vertikalkanten, die den Blick des Betrachters von der Fassade zu den Schmalseiten führen. Zuvor waren Möbel auf eine reine Frontalsicht hin angelegt.

\section{Sakristei \\ Sakristeiausstattung}

Hoftischler Gregor Perchtoldt aus Piber, Schlosser Blasius Lackner, r 657/58

Höhe des Unterschrankes und der Wandverkleidung $94 \mathrm{~cm}$

Gesamthöhe ca. 5 Io cm

Nussbaum, massiv und furniert auf Zirbelkiefer und Fichte. Eisen, gebläut und graviert, Zinn

Der mit einer Stichkappentonne überwölbte Raum wurde r657 von Johann Baptist Cherubin († I 696) mit Stuckarbeiten vollendet (Abb. 263-269). ${ }^{429}$ Zutritt zur Sakristei gewährt ein Portal am westlichen Ende der Nordwand, ein zweites Portal ihm gegenüber führt zu Paramentenkammern. Wandschränke stehen vor den beiden Längswänden, vor der westlichen Schmalseite befindet sich ein Möbel mit einem Lavabo, im Osten ein Scheinaltar. Im Nordosten schließt sich ein kleiner Annexraum an, in dem

429 Zu Raum und Mobiliar vgl. Riesenhuber, Barockkunst (I924), I44; ÖKT, St. Lambrecht (I95 I), 83-84; Wagner, Kunsthandwerk (1 999), 574-575; Plank, St. Lambrecht (200I), 358; Plank/Romirer, St. Lambrecht (2002), 25 ; Dehio, ebd.; Stephan, Sakristeien (2007). 


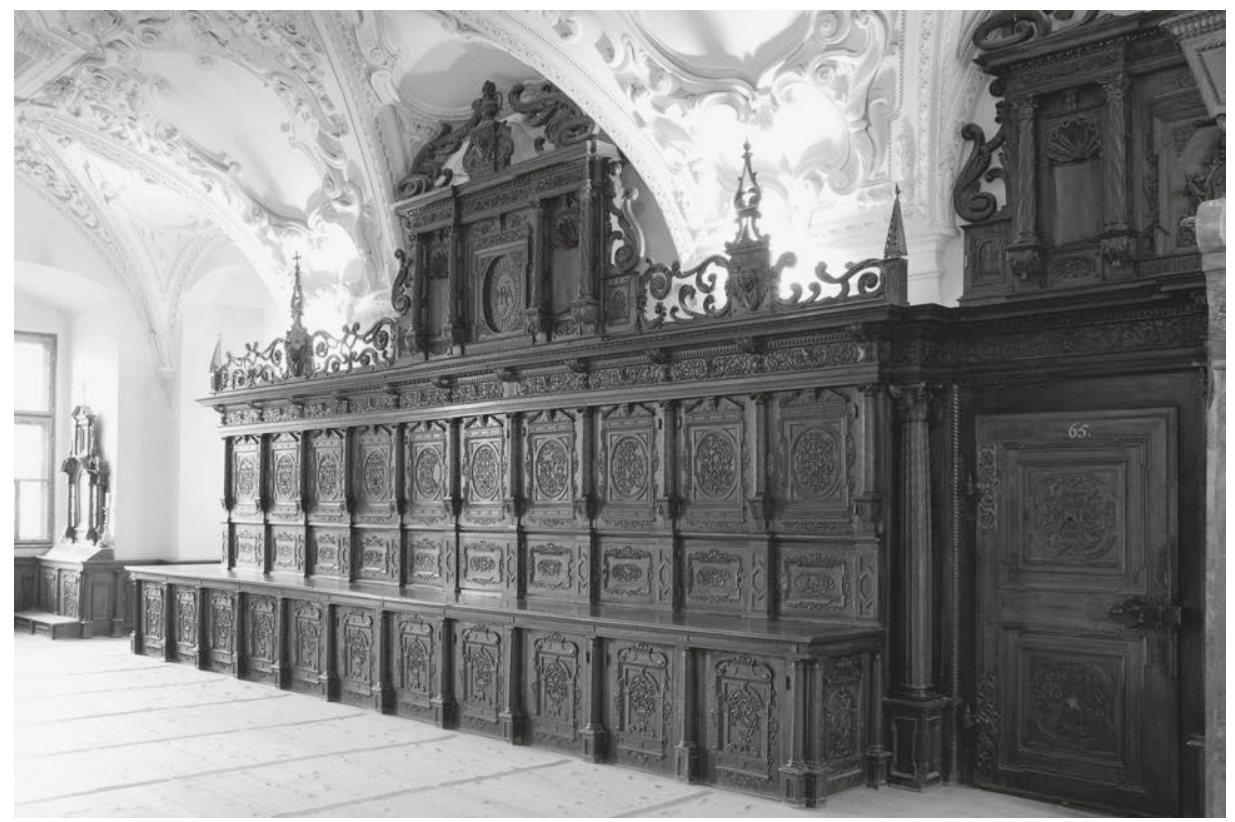

263 Sakristeischränke. Hoftischler Gregor Perchtoldt, I657/58

sich die Tischlerausstattung mit einem Beichtstuhl fortsetzt. Die Möblierung der Sakristei zeichnet sich nicht nur durch die außergewöhnlich hohe Qualität aus, sondern ebenso durch den Umstand, dass es sich bei ihr um ein frühes wandfestes Möbelensemble handelt, dessen Großformen durch die Gestaltung des Raumes maßgeblich bestimmt werden. Als älteres österreichisches Beispiel konnte bisher nur das aus der Sakristei des Stiftes Schlägl identifiziert werden, das I6 54 entstand. ${ }^{430}$

Die vertikale Gliederung der Möbel vor den Längswänden im Norden und Süden erfolgt durch Unterschränke und in der Tiefe zurückversetzte Oberschränke, in denen nicht nur Kelchkästen und Schubladen untergebracht sind, sondern auch ausziehbare Pulte, die das Hantieren mit den Sakralgerätschaften wesentlich erleichtern. Eine vergleichbare Konstruktion konnte bisher bei keiner anderen Sakristeiausstattung nachgewiesen werden.

Die architektonische Instrumentierung der Aufsatzschränke geschieht mittels dorischer und ionischer Dreiviertelsäulen und lisenenartiger Bänder. Die Stützen unterteilen

430 Bohr, Sakralmöbel (2017), 6r г-6r3. Vgl. hierzu auch Teil 2, Kap. IV, Abschnitt »Sakristeimöbel«. Nach den Studien von Renz-Krebber, Sakristeischränke (I998), 45, befindet sich in der Stiftskirche St. Zeno in Bad Reichenhall das älteste bekannte Beispiel einer wandfesten Sakristeiausstattung in Süddeutschland. Das Möbelensemble in St. Zeno entstand nach I640. 


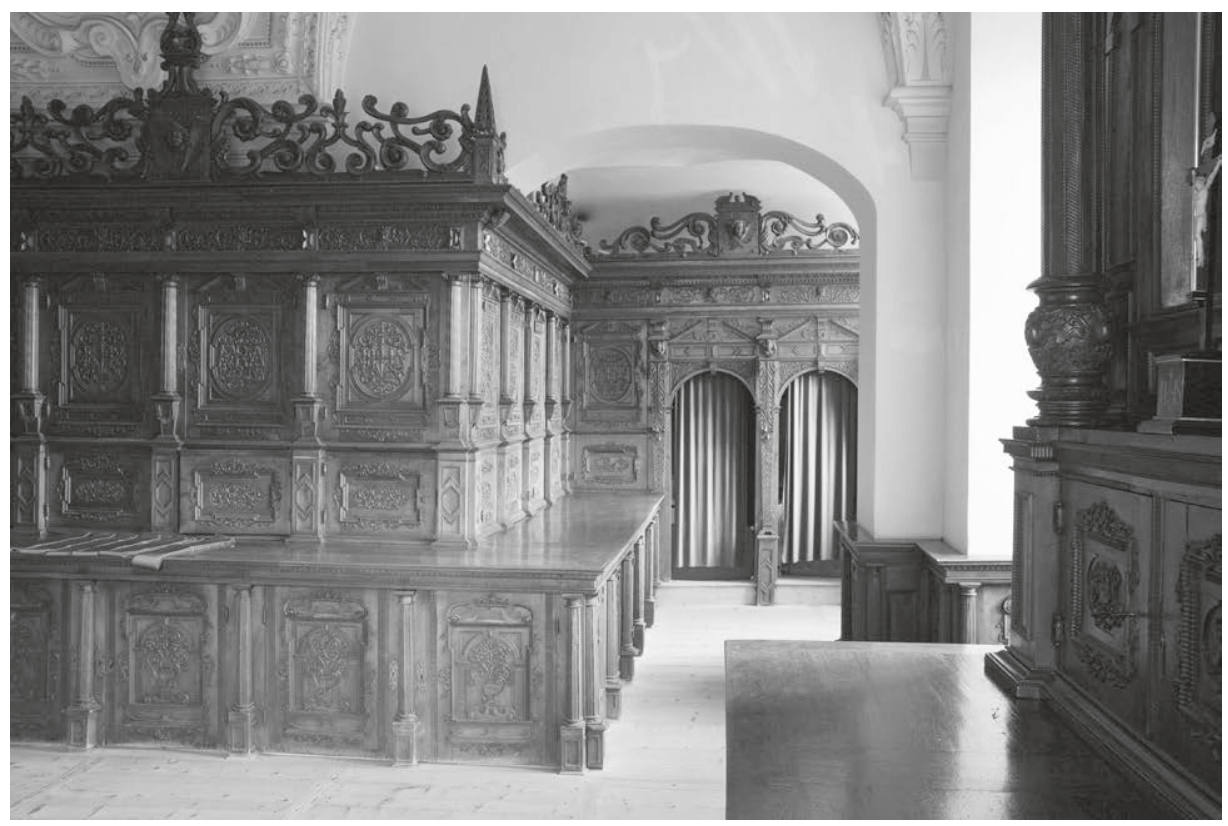

264 Sakristeischränke und Beichtstuhl. Gregor Perchtoldt, I6 57/58

die Möbel in eine monotone Abfolge gleichförmiger Achsen, lediglich das in die Stichkappe des Gewölbes hineinreichende schwere Attikageschoss sorgt für eine gewisse Akzentuierung. Am Auszug treten als weitere Architekturelemente vollrunde korinthische Säulenpaare und ein verkröpftes Gebälk hinzu.

Im Sockelgeschoss des Oberschranks besitzen die Füllungen die Form verkröpfter Rechteckfelder, im Unterschrank sowie im Hauptgeschoss des Oberschranks gibt ihre Gestaltung dagegen diejenige von Ädikulä wieder. Unten zieren Arkaden mit Blumenvasen die welschen Fenster, oben kreisförmige Flächen mit reliefierten Schnörkeln, die abwechselnd die Buchstabenkombinationen IHS und MRA nachzeichnen. Die Säulen sind geflammt gehobelt und mit Perlschnüren versehen, Flammleisten rahmen die Binnenfelder. Schnitzarbeiten mit vegetabilen Ranken, in die sich Beschlagwerkornamente und manieristische Tierköpfe mischen, säumen die Füllungen und bereichern den Gebälkfries. Vergleichbar ist das Attikageschoss dekoriert. Hier stehen die Säulenpaare allerdings seitlich von Nischenarchitekturen, in deren Mitte sich ein Kompartiment befindet, das im Norden mit dem Christusmonogramm versehen ist, gegenüber mit dem Monogramm Mariens. Frühbarocke »gedärmartige« Schnitzereien, die eine giebelähnliche Struktur formen, legen sich über die Auszüge. Wie am Chorgestühl bilden auch hier Postamente mit Engelsköpfen zwischen ornamentalen 


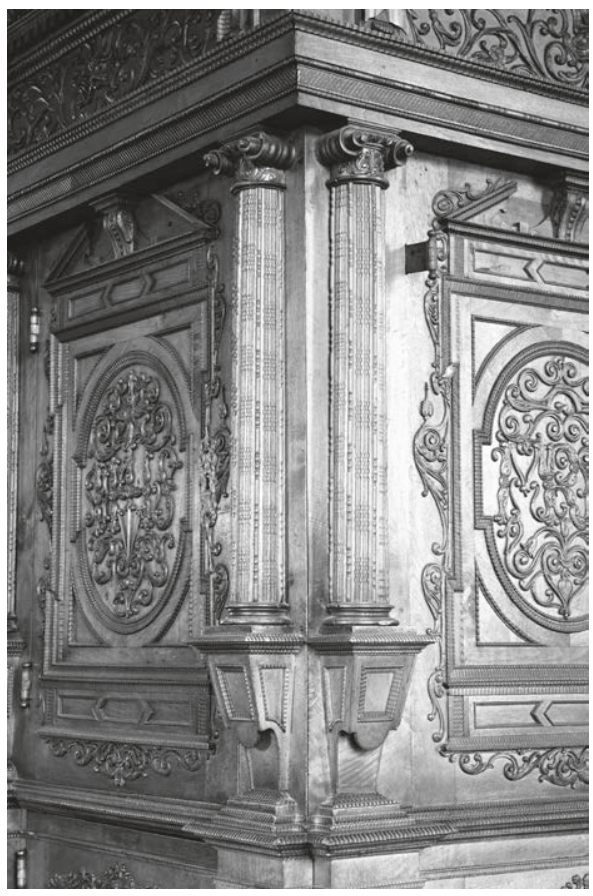

265 Detail einer Eckverbindung. Mit Perlreihen verzierte Säulen. Gregor Perchtoldt, $1657 / 58$

266 Sakristei, Türen zu Annexräumen. Gregor Perchtoldt, $1657 / 58$

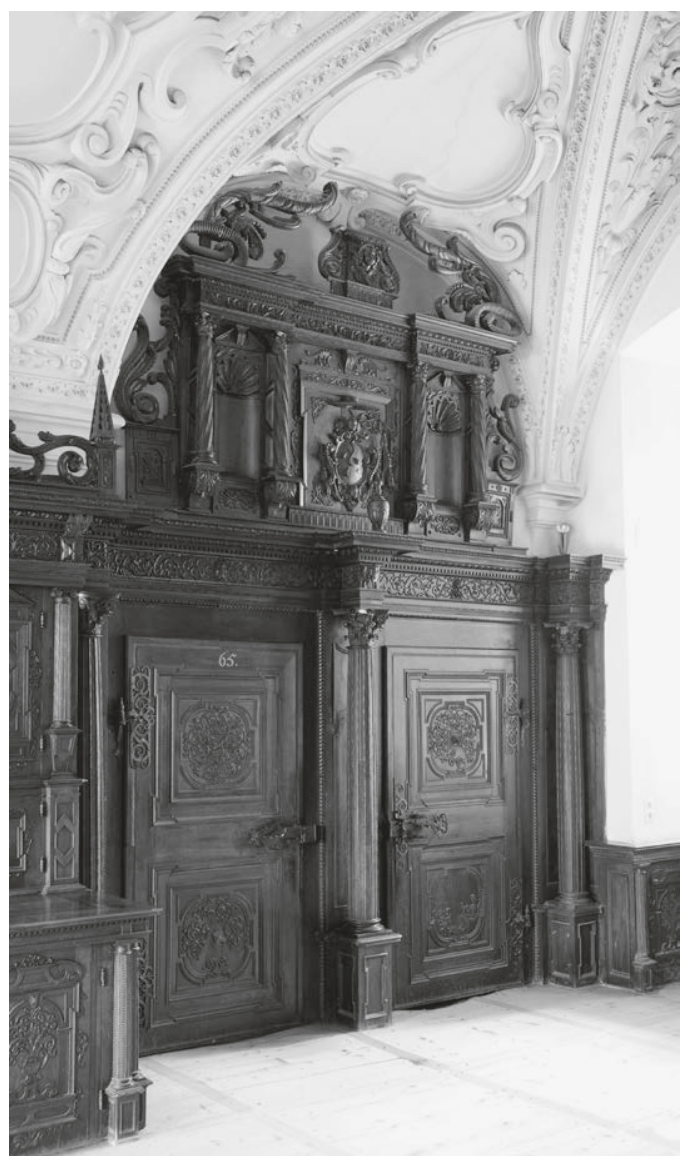

Motiven den Aufsatz. Sind die zartgliedrigen und fragil erscheinenden Schnitzereien noch späte Reflexe auf die Formensprache des Schweifwerks, zeigen die kraftvollen Schnitzarbeiten des Aufsatzes die Übernahme früh- und hochbarocker Gestaltungsmerkmale. Die Schränke bestehen aus eintürigen und zweitürigen Einheiten, Säulen dienen als Schlagleisten.

Bis auf die Türöffnungen sind die Sakristeiwände mit Möbeln verbaut, selbst in den Fenstergewänden finden sich Schränke. Nur dort, wo das Platzangebot für Kästen nicht ausreichte, wurde das Mauerwerk mit Vertäfelungen verkleidet. In ständiger Repetition übernehmen sie die architektonischen Strukturen und ornamentalen Formen des Mobiliars. Die Möbel bestehen aus Nussbaumholz, das teils als dickes Furnier, teils aber auch massiv verarbeitet wurde. Werkmaterial der Schlösser und Beschläge ist gebläutes und graviertes Eisen. Ein Schloss trägt den Doppeladler, ein weiteres die Jahreszahl I65 8 so- 


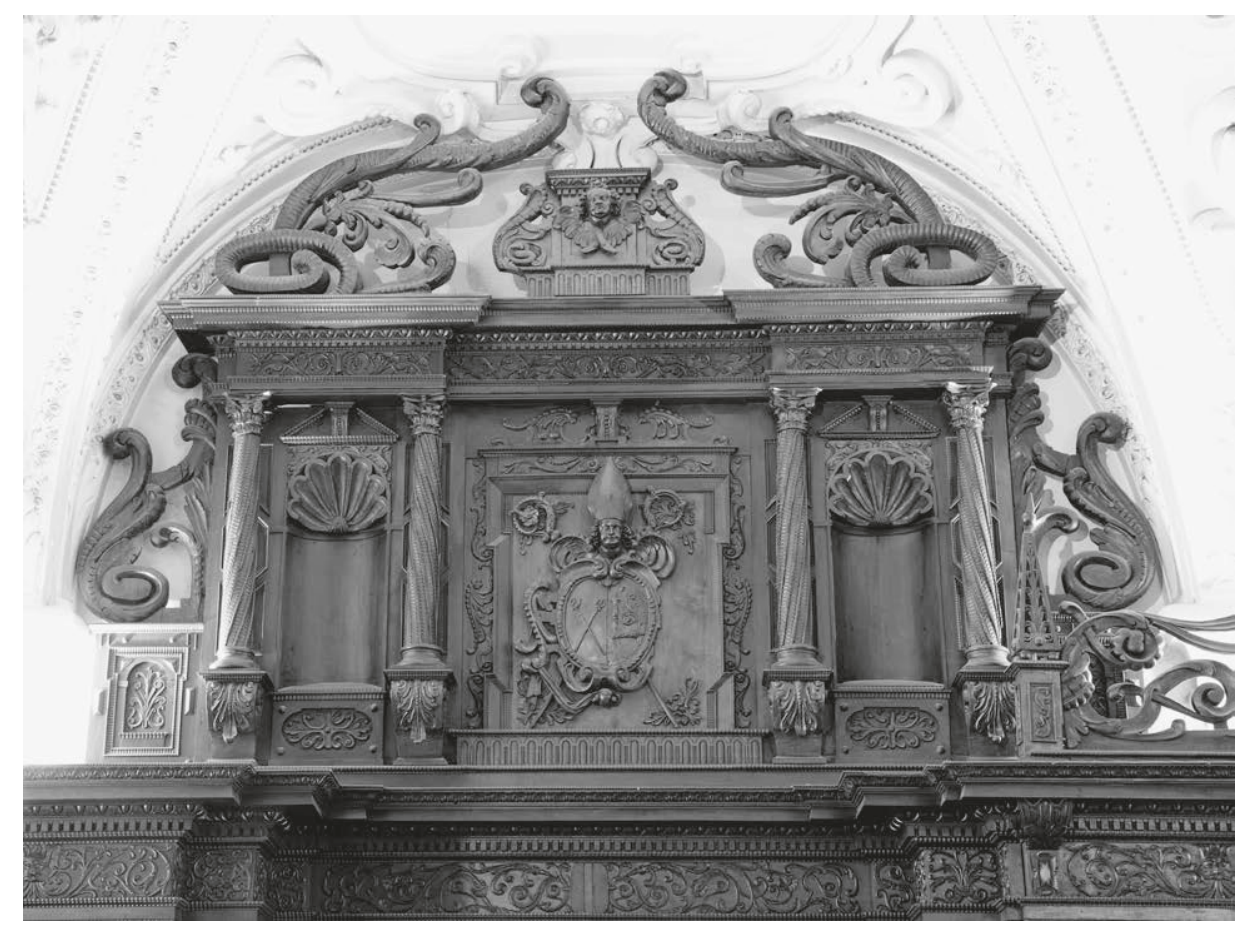

267 Sakristei, Schnitzauszug über einer Tür. Gregor Perchtoldt, I6 $57 / 58$

wie die Buchstabenkombination WASL, vermutlich eine Verschreibung für BASL (Benedictus Abbas Sancti Lamberti).

Eine posthume Auflistung der vom Hoftischler Gregor Perchtoldt († I659) ausgeführten Arbeiten belegt, dass die Sakristeiausstattung in seiner Werkstatt gefertigt wurde. Das Verzeichnis wurde von des Meisters Witwe zusammengestellt:

[...] Den 27. und 28. octobris ${ }_{16} 68$ aus bevelch Ir Gn. zu den zwen saagmaistern auf St. Salvator und Hiettenberg gehen miessen wegen bestellung nußpämben holz, hab ich verzört-4-. Was die arbait in der sacristey belangt, wie zu sechen, als die kästen sambt den auszigen, türgerichter, beichtstuell sambt den fueßpoden (außer des täflwerch) werden sich Iro Hochwürden und Gn. zu entsinen wissen, daß mein hauswiert seelig zu vergangnen pfingsten des verloffenen I657zigisten jabr angefangen und hernach im februari und märti anno ${ }_{1} 658$ sich ganz übl aufbefunden, als hat er in diser seiner krankheit zum öftern betracht und vermelt, wan er solche arbeit bei seiner lebzeit nit verfertigen kinte, damit Iro Hochw. und Gn. oder seiner hinterlassnen armen wittib und klainen unerzognen kindern kainem unrecht geschehen solte, wurde das peste mitl sein, wan man solche arbait nach den tagwerch ausraiten tete. Wie wollen er die maiste zeit selbachter gewöst, so woll man aber zu dieser arbait 


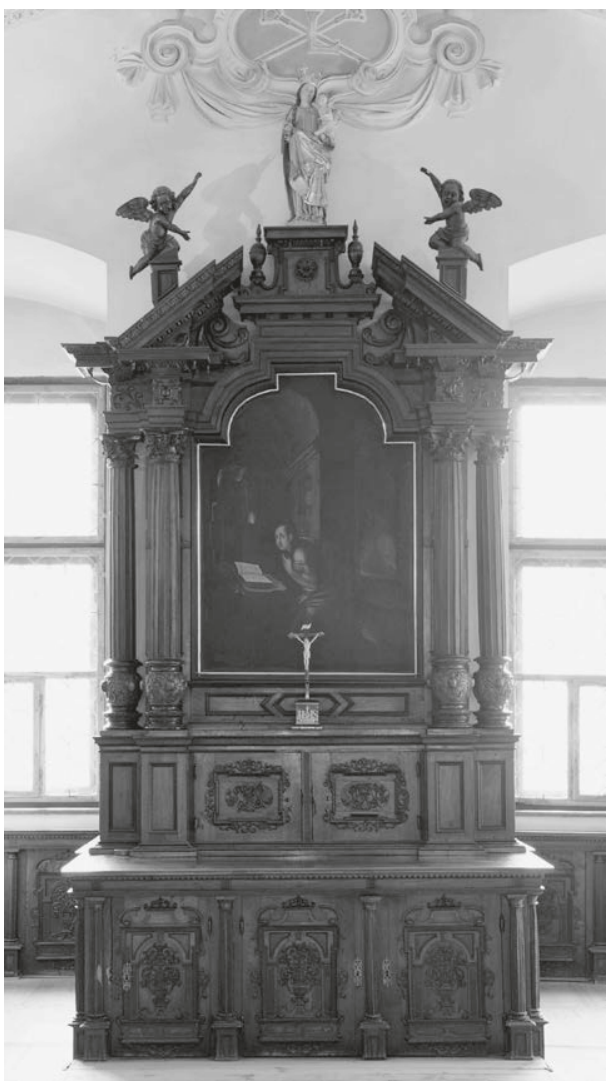

268 Sakristei, Scheinaltar. Gregor Perchtoldt, $1657 / 58$ nuer vier gesöllen sambt den maister raitten, wie dan noch 3 gesöllen verhanden und dessen zeugnus geben kinten, für ain gesöllen die wochen für kost und lohn per I f $6 \beta$ bringt von zwai jabren und 18 wochen für vier gesöllen per $1004 \mathrm{fl}$. Item für den maister, weillen er die kost $z$ u hof gehabt, ain wochen per $2 \mathrm{fl}$ bringt von 122 wochen $244 f[\ldots] .{ }^{431}$

Abt Pierin beauftragte demnach Ende Oktober I 658 Perchtoldts Ehefrau, in zwei Sägewerken Nussbaumholz zu beschaffen. Der Verdacht liegt nahe, dass es für die Fertigstellung der Sakristeiausstattung benötig wurde, da der Meister der Quelle zufolge bereits an Pfingsten (20. Mai) I657 mit den Arbeiten für die Sakristei begonnen hatte. Danach litt Perchtoldt unter einer schweren Erkrankung, sodass er dem Konvent den Vorschlag unterbreitete, seine Leistung nicht pauschal, sondern nach Tagwerken zu verrechnen. Aus dem Schriftstück geht weiter hervor, dass der Meister mit vier Gesellen an der Möbelgarnitur arbeitete, dass er zwar verköstigt wurde, seinen Gesellen aber die Kost zu stellen hatte. Nach Angaben des Stiftsnekrologs verstarb Perchtoldt am 9. Januar i659. Zwei Tage später wurde er in Piber, das zur Grundherrschaft des Stiftes gehörte, beigesetzt. ${ }^{432}$

Gregor Perchtoldt war seit dem September I649 zunächst als Geselle für das Stift tätig. ${ }^{433}$ Abt Pierin muss seine Fähigkeiten bald erkannt haben, denn er band ihn an das Kloster, indem er ihn zum Hoftischler ernannte. Allerdings gab Perchtoldt seine eigene Werkstatt niemals auf, nach seinem Tod übernahm sie seine Witwe. ${ }^{434}$ Eventuell führte sie noch letzte Arbeiten an den Sakristeimöbeln für St. Lambrecht aus, um einige Jahre später mit vorbereitenden Arbeiten für fast identische Möbel in den

43 I Zitiert nach ÖKT, St. Lambrecht (195 I), 229-23I, Reg. 309, hier 230. Die Quelle wurde ebenfalls veröffentlicht von Stephan, Sakristeien (2007), $236-237$.

432 Zitat nach Stephan, ebd., 237. Zu Piber vgl. Koren/Attems, Schlösser (1 986), г05-1o6.

433 Stephan, ebd., 220.

$434 \mathrm{Zu}$ Perchtoldts Testament und seinem Nachlassinventar vgl. Wagner, Testament (2007). 
Sakristeien der Wallfahrtskirche zu Mariazell zu beginnen. ${ }^{435}$

\section{Stiftssammlung}

\section{Beichtstubl}

St. Lambrecht, um I 735/40

$\mathrm{H}_{32} 8 \mathrm{~cm} \times \mathrm{B}_{2} 80 \mathrm{~cm} \times \mathrm{T} 100 \mathrm{~cm}$

Nadelholz, bemalt. Metallgitter

In der Stiftssammlung wird ein Beichtstuhl aufbewahrt, der ursprünglich zur Einrichtung der Priestergruft zählte (Abb. 27o). Das ikonographische Programm der vom Chor der Stiftskirche aus zu erreichenden Krypta gemahnt an die ungewisse Todesstunde, an das Sterben selbst sowie an die Verheißung jenseitigen Glücks. Am Eingang des etwas bizarren Ambientes befindet sich in einer Marmornische eine Weihwasserschale in Form eines Totenkopfes, daneben stand ursprünglich das Möbelstück. ${ }^{436}$ Zusammen mit den Exemplaren im Laienraum der Kirche erwähnte ihn

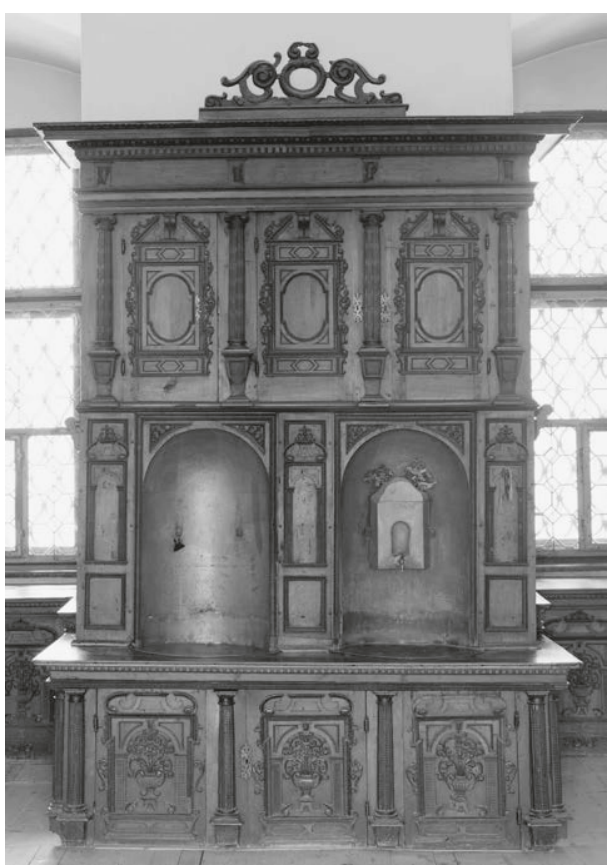

269 Sakristei, Buffet mit Waschbecken. Gregor Perchtoldt, I657/58. Der Schnitzaufsatz ist vermutlich nicht original. Abt Eugen Graf Inzaghi (reg. I737-1760) I 740 anlässlich einer Visitation: Confessionalia in ecclesia abbatiali habentur 5, habetur et confessionale in crypta. ${ }^{437}$ Auf die übliche Art konstruiert ist lediglich die Priesterstalle des über einem dreipassigen Grundriss errichteten Möbels, wohingegen die beiden seitlichen Plätze ein ungewöhnliches Erscheinungsbild aufweisen. Kniet sich der Pönitent in den Beichtstuhl, bietet zum Raum hin eine breite Lisene Sichtschutz und schließt sich hinter ihm eine gebauchte Tür. Das Abschlussgesims spiegelt in der Mitteltravée den Grundrissverlauf wider, während es seitlich mit einem konkaven Schwung zur Rückwand geführt ist, die von einer Stehvolute gebildet wird. Über dem Gesims folgt ein mit Volutengiebel und Krone endender Auszug.

435 Sie gleichen selbst in Details den Paramentschränken von St. Lambrecht. Die Mariazeller Ausstattung stammt aus der Mitte der r66oer Jahre, wurde also erst nach Perchtoldts Tode gefertigt. Stephan, Sakristeien (2007), bes. 223.

436 ÖKT, St. Lambrecht ( I 95 I), 82-83.

437 ÖKT, ebd., 265-267, Reg. 427, hier 266. 


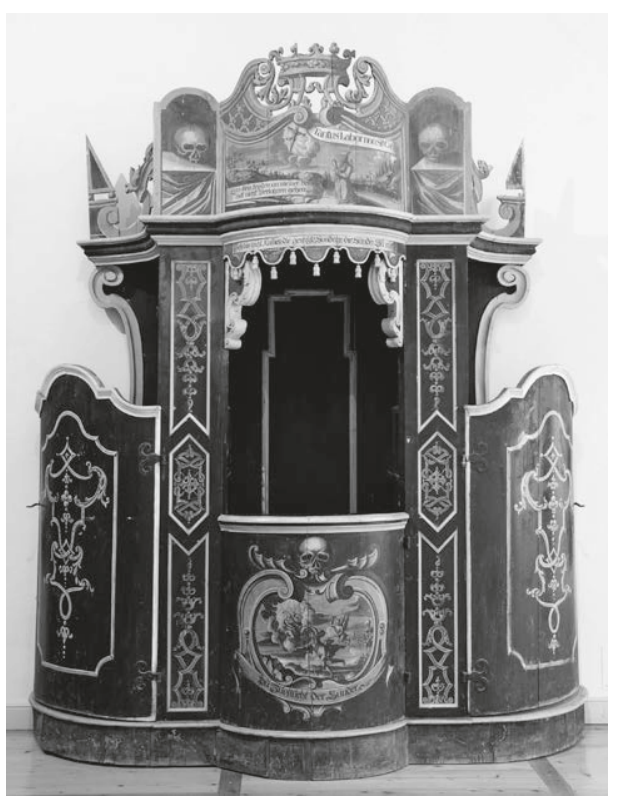

270 Stiftssammlung, Beichtstuhl. St. Lambrecht, um $1735 / 40$

Als Dekor wählte der Konvent für das schwarzgefasste Möbel Grisaillemalereien. Zusammen mit ornamentalen Zierfomen präsentiert es auf seinen Außen- und Innenseiten allegorische Darstellungen. Beidseitig ist der Tod in Gestalt eines Skeletts vergegenwärtigt, rechts hält er in seinen Händen eine Sanduhr und einen Pfeil, links erkennt man ihn mit Sense und Buch. Auf der Mitteltür füllt ein Gemälde mit Maria im Strahlenkranz eine große Kartusche, am Auszug findet sich eine Darstellung des Gekreuzigten. Vor Christus kniet ein Mönch mit Geisel und Rute.

Es braucht nicht eigens erwähnt zu werden, dass das Möbel hinsichtlich seiner Form ebenso ungewöhnlich ist wie im Hinblick auf die Ikonographie. Inschriften erläutern den Sinngehalt der Bilder. Sie sollen die Sünder nicht nur zu einem gottesfürchtigen Leben anleiten, sondern lassen den Beichtstuhl in seiner

Gesamtheit zur Allegorie von Tod und Auferstehung, Paradies und Verdammnis werden. Hier verdichtet sich in einem einzigen Möbelstück die ganze Bandbreite einer Thematik, die andernorts mittels eines komplexen, auf mehrere Beichtstühle verteilten Skulpturenprogramms zum Ausdruck gebracht wird. ${ }^{438}$ In der österreichischen Kunstlandschaft ist kein zweiter Beichtstuhl bekannt, der dem in St. Lambrecht vergleichbar wäre.

\section{Vorau, Augustiner-Chorherrenstift}

Stifts-und Pfarrkirche hl. Thomas

Markgraf Ottokar III. ( I I 29-I I 64) gründete I I 63 das Stift in der Nähe einer dem Apostel Thomas geweihten Kirche, Augustiner-Chorherren aus Seckau besiedelten es. ${ }^{439} \mathrm{Nach}$

438 Etwa in der Klosterkirche des Stiftes St. Georgenberg (Abb. 345, 346) oder in der ehemaligen Stiftskirche zu Dürnstein. Bohr, Sakralmöbel (2017), 279-282.

439 Frank, Vorau (1925), bes. 6-I27, I33-I5 I; Meeraus, Vorau (1928), 5-24; Kohlbach, Stifte (1953), I67-196; Stift Vorau [1 954]; Hootz, Kunstdenkmäler (1965-1968), Bd. 2 (r 966), 323-326, 390; Röhrig, Alte Stifte (I 967), I 4-I6; Woisetschläger/Krenn, Steirische Herrlichkeiten (I 973), 74, 78, 80, Taf. I66, I77, I82; Stift Vorau [ca. 1970]; Stenzel, Stift ( I 977), 94-97; ÖKM, Oststeiermark (I 987), 297- 
einem verheerenden Brand mussten Kirche und Kloster nach I 237 wiederaufgebaut werden, die Fertigstellung der Anlage zog sich über sieben Jahrzehnte hin. Die Umformung der Abtei zu einer veritablen Burg geht auf das dritte Viertel des I 5. Jahrhunderts zurück, den Charakter einer wehrhaften Festung hat sie sich bis heute bewahrt. In der ersten Hälfte des I7. Jahrhunderts vereinheitlichte man die Klostertrakte, zwischen r66o und I662 wurde die Kirche vermutlich nach Plänen von Domenico Sciassia ( 1599/r603-I679) völlig neu errichtet, lediglich die beiden Türme, die die Westfassade flankieren, sind noch mittelalterlichen Ursprungs. Der Bau ist dreischiffig. Nach der Eingangstravée folgt ein vierjochiges Mittelschiff, beiderseits schließen sich ebenso viele Kapellen und Emporen an. Die Breite des Querhauses liegt in einer Flucht mit den Außenwänden der Seitenkapellen, das Presbyterium ist um einige Stufen erhöht. Der Konvent ließ die Decke der tonnengewölbten Kirche vollständig mit Fresken

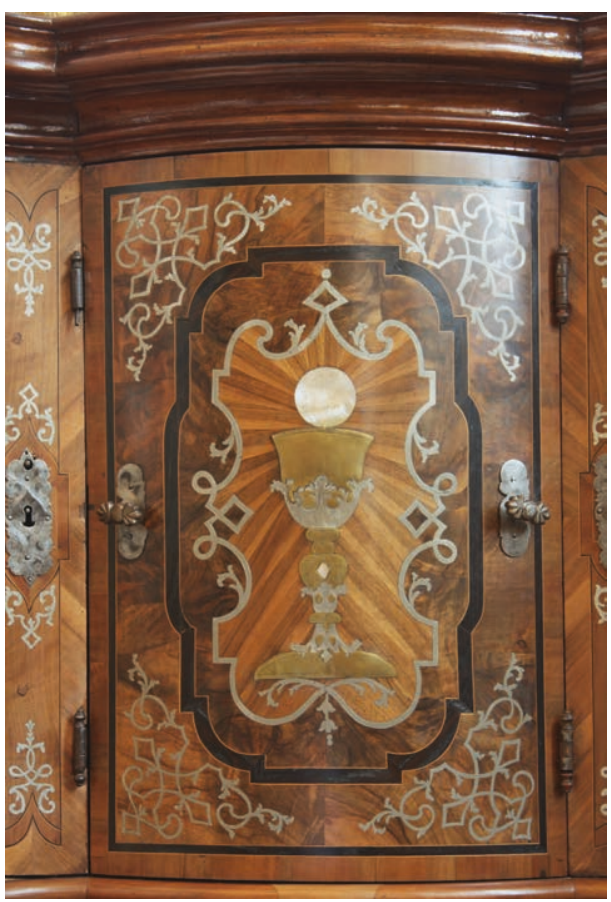

Farbtafel 28 Sakristeischrank, Detail eines Türchens. Vorau, I 7 I 6 bemalen, sie gilt als die erste Kirche in der Steiermark, in der auf Stuckarbeiten zwischen den Darstellungen verzichtet wurde. ${ }^{440}$

Die im vorliegenden Kontext interessierende Ausstattung der Kirche entstand im Wesentlichen unter den Pröpsten Johann Philipp Leisl (reg. I69I-I7 I7), Franz Sebastian Graf von Webersberg (reg. I 7 I 7-I 736) und Lorenz Leitner (reg. I 737-I 769). Einer der herausragenden Mitarbeiter bei der Neueinrichtung war Matthias Steinl (I643/44I 727). Aus Schriftquellen erfahren wir von zwei Tischlern, die in jener Zeit für das Stift gearbeitet haben: Caspar Püchler († I 720), der offenbar als Festangestellter im Haus tätig war, und Johann Georg Steiner (I698-I 758), einem externen Tischlermeister. ${ }^{441}$

305; Attems/Koren, Kirchen (1 988), 46-49; Hutz, Leisl (1 992); Dehio, Steiermark (2006), 587-591; Mayrhofer, Ausstattungsgeschichte (2015); ders., Stift Vorau (2017), 6-79.

440 Zur Beschreibung der Fresken vgl. etwa ÖKM, ebd., 299-300; Dehio, Steiermark (2006), 588-589; Mayrhofer, Ausstattungsgeschichte (2015), 22-23; ders., Stift Vorau (2017), I I3-I 23.

44I Kohlbach, Stifte (I 953), I 83. Püchler wurde am 05.01.I 720 beigesetzt, Steiner am 29.05.I 75 8. https:// data.matricula-online.eu/de/oesterreich/graz-seckau/vorau/ [Zugriff Juni 2020 ], Sterbebuch 3, I700I768, pp. II 3,506 . 


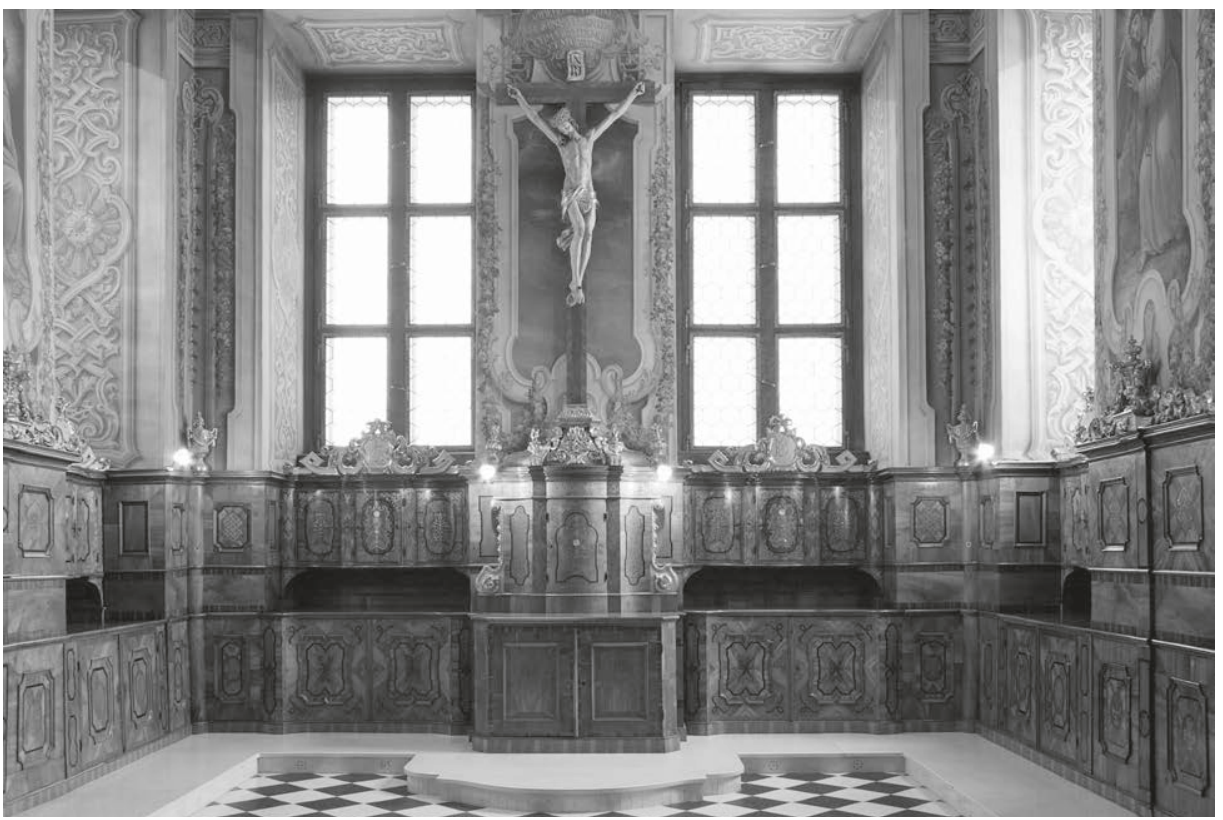

27 I Sakristei, Blick nach Osten. Schränke und Vertäfelung. Vorau, I 7 I 6

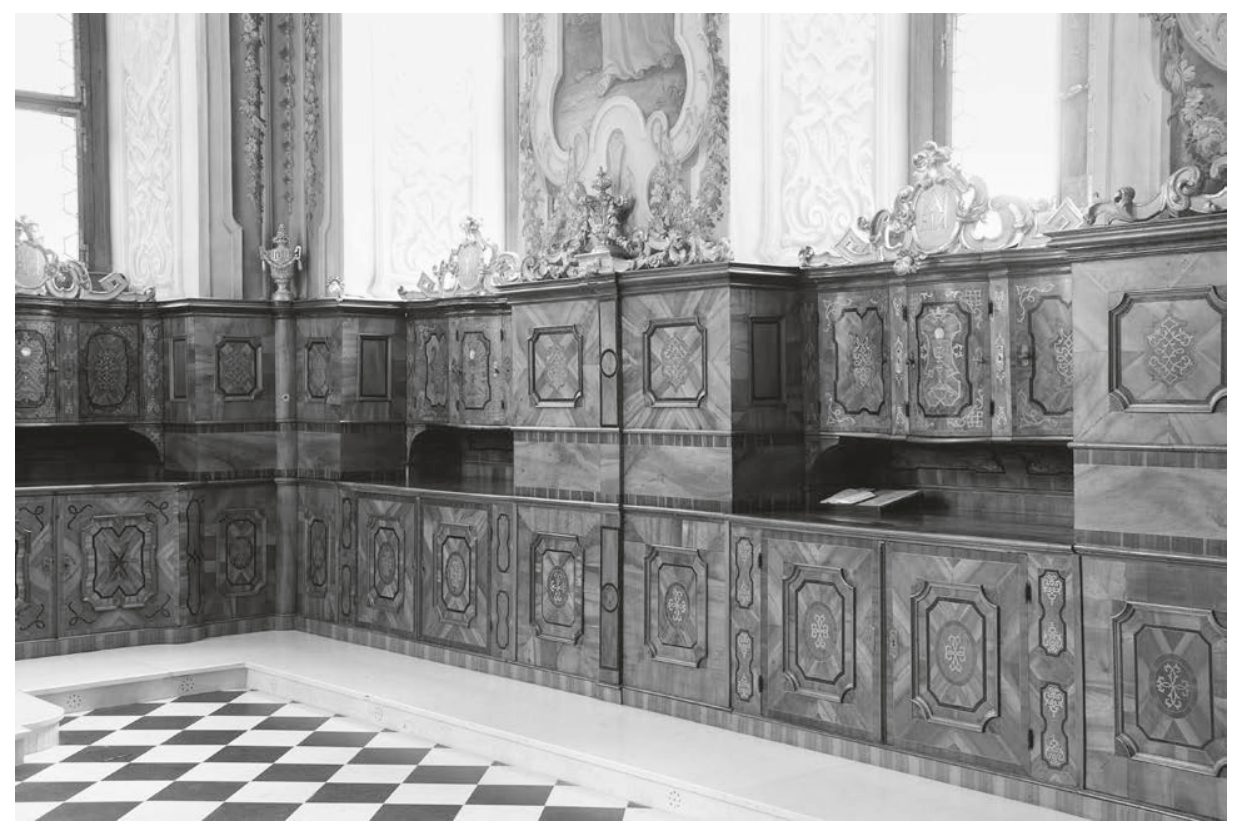

272 Sakristei, Ansicht der Südwand. Schränke und Vertäfelung. Vorau, I 7 I 6 


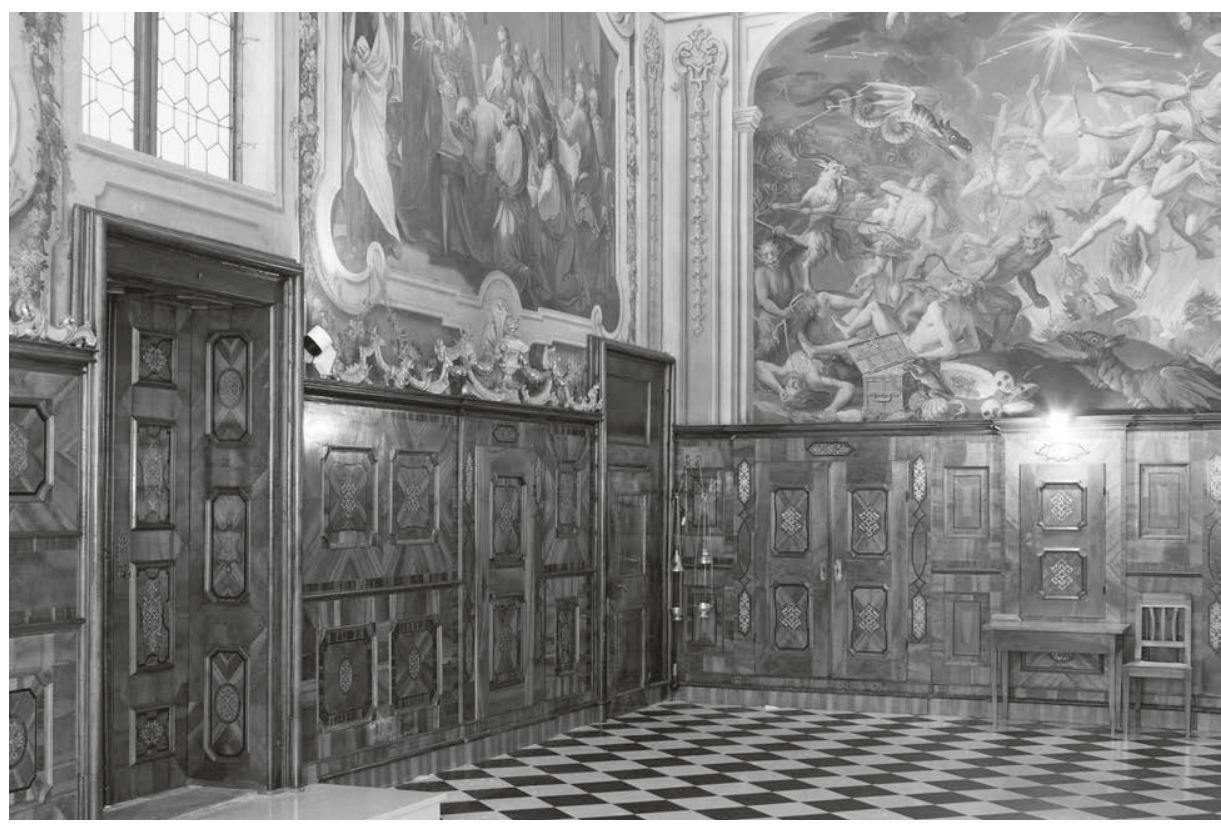

273 Sakristei, Ansicht von Süd- und Westwand mit Türen, Schränken und Wandvertäfelung. Vorau, I 7 r 6

\section{Sakristei}

\section{Schränke und Vertäfelung}

Vorau, datiert I 7 I 6

HS I $4 \mathrm{~cm}$

Gesimshöhe $\mathrm{H}_{20} \mathrm{Om}$ (+ I4 cm Sockel, +65 cm Schnitzaufsatz)

Raummaße H 6,65 m × L I 4,90 m × B 6, I 5 m/6,30 m

Nussbaum, Nussmaser, Ahorn, Holz geschwärzt, Zwetschke, Nadelholz, Möbel innen rot gestrichen.

Eisen, poliert, graviert, Messing, graviert, Zinn, graviert, geschwärzt, Perlmutt, graviert, geschwärzt

Die im Jahr I 708 über leicht trapezförmigem Grundriss errichtete Sakristei liegt an der Südflanke der Kirche. ${ }^{42}$ Durch große, auf drei Seiten in das Mauerwerk eingebrochene Fensteröffnungen wird der Raum beleuchtet. Fresken, die vermutlich I 7 I 5/I 6 unter der Leitung von Johann Cyriak Hackhofer (I675-I73 I) ausgeführt wurden, überziehen die

442 Frank, Vorau (1925), I37; Meeraus, Vorau (1928), I6-18; Kohlbach, ebd., I83, I 89-1 90; ÖKM, Oststeiermark (1 987), 303; Betz, Bildprogramme (2000), bes. 7-75; Dehio, Steiermark (2006), 589-590; Gierse, Bildprogramme (2010), 508-524; Mayrhofer, Ausstattungsgeschichte (2015), 24-25; ders., Stift Vorau (2017), I $48-156$. 


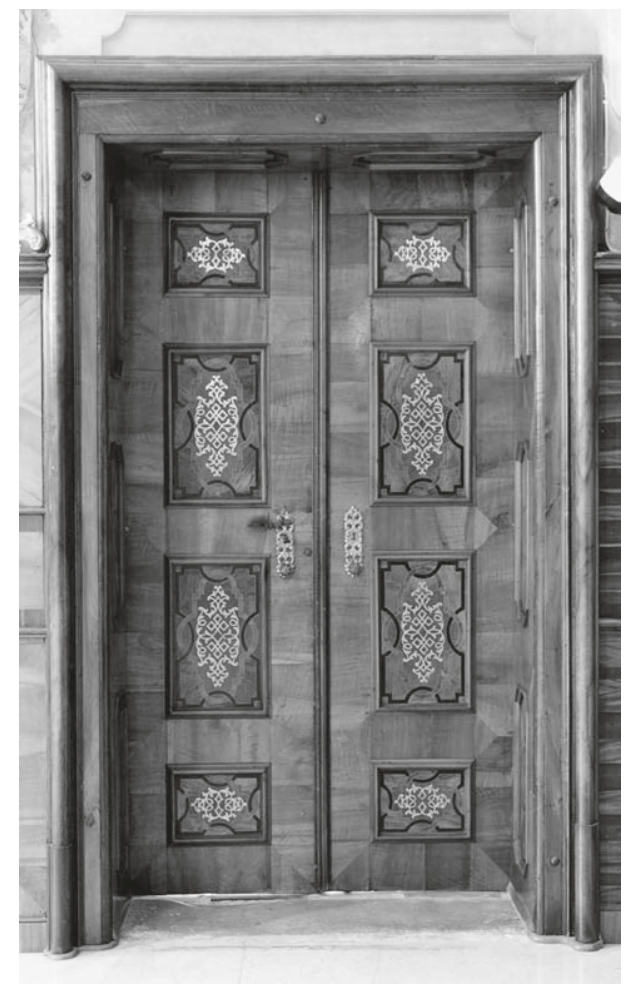

274 Sakristeitür. Vorau, I 7 I6

Decke und die oberen Wandzonen. Die unteren Wandbereiche sind mit Schränken verbaut und mit Holzvertäfelungen verkleidet (Farbtaf. 28; Abb. 271-274). Türen am westlichen Raumende vermitteln den Zugang zur Kirche, zur Klausur und zu einem Nebenzimmer.

Abgesehen von einer Kniebank bestehen die Möbel in den Fensternischen aus tiefen Unterschränken und flachen Hochschränken. Die Substruktionen sind zweitürig, während jeweils drei Türen die Oberschränke verschließen. Besitzen die unteren Schränke eine gerade Fassade, die sich im Getäfel vor den Wandpfeilern fortsetzt, bilden die Vorderseiten der oberen Kästen mit konkaven und konvexen Bögen eine weich fließende Kurve. Die an den ehemaligen Kreuzgang grenzende Westwand birgt weitere Kastenmöbel, das mittlere trägt die Jahreszahl i 7 I 6.

Je eine Viertelsäule verschleift die rechtwinkligen Raumecken zwischen der Ostwand und der Nord- bzw. Südwand. Ein ähnliches Motiv zeichnet das Chorgestühl auf der Empore aus (Abb. 275, 276). Die Herausforderung, ästhetisch problematische Teilstücke in der Wandverkleidung zu modifizieren, um sie gefälliger zu präsentieren, wird dadurch überzeugend gelöst. In der Mittelachse der Ostwand befindet sich wie in vielen anderen Sakristeien ein altarähnlicher Schrank, der nach vorn in den Raum reicht. Dem flächig konzipierten Unterschrank steht der bewegte Aufsatz gegenüber, dessen kurvierter Grundriss sich aus gegenläufigen Rundungen und verschiedenen hintereinanderliegenden Ebenen entwickelt. Die Möbel seitlich davon weisen einen ähnlichen Aufbau wie die Exemplare vor der Nord- und Südwand auf, von denen sie sich im Detail allerdings durch eine etwas qualitätvollere Ausgestaltung unterscheiden.

Die Tischler überzogen die Schränke und Vertäfelungselemente mit handverlesenen Furnieren. Markante, an den Ecken eingezogene Profile und geschwärzte Adern säumen die großen Rechteckfüllungen, die mit geometrischen Ornamenten und Abbildungen von Kelchen aus verschiedenen Hölzern, Zinn, Messing und Perlmutt dekoriert sind. Die Calices dürften ein Zitat der entsprechenden Ziermotive am Sakristeischrank in Pöllau sein (Abb. 224). Das Möbel vor der Ostwand trägt eine 
flache Halbkuppel, ein hohes Standkreuz und Flammenvasen, während Laub- und Bandlwerk sowie Girlanden und Vasen das übrige Interieur und die Vertäfelungselemente bekrönen. Darüber hinaus präsentieren Kartuschen auf der Nordseite das mit den Marterwerkzeugen versehene Monogramm Christi, auf der Südseite das Mariens. Die künstlerische und handwerkliche Qualität des Schnitzaufsatzes reicht nicht ganz an jene der Möbel heran. Und bei den Vasen handelt es sich nicht um barocke, sondern um klassizistische Erzeugnisse. Möglicherweise wurde auch der Unterschrank des altarähnlichen Möbels im späten i 8. Jahrhundert verändert. Durch Großform, Furnierbild und fehlende Intarsien wirkt er fast wie ein Fremdkörper im Gesamterscheinungsbild der Ausstattung.

Die Sakristeimöbel wurden nach r 958 restauriert, wobei man fehlende Furnierstücke ergänzte. Modern ist die hölzerne Sockelleiste, die die Möbel trägt. I 97 I wurden ein neuer Fußboden verlegt und der Marmorsockel eingebaut. ${ }^{443}$

\section{Kirchenraum}

Chorgestühl auf der Westempore

Vorau, I 747

HS I $5 \mathrm{~cm}(\mathrm{I} \mathrm{I} \mathrm{cm}+4 \mathrm{~cm}) / 25 \mathrm{~cm}$

Gesimshöhe $229 \mathrm{~cm} /$ Gesamthöhe $295 \mathrm{~cm}$ (jeweils $+25 \mathrm{~cm}$ )

Nuss, Nussmaser, Zwetschke, Ahorn, Holz, geschwärzt, gefasst, vergoldet

Das mit einer umlaufenden Stallenreihe und zwei seitlichen Bänken ausgestattete Chorgestühl wurde hinter der Orgel über U-förmigem Grundriss aufgerichtet (Abb. 275-278). ${ }^{444}$ Das Teilstück vor der Westwand mit der Abtstalle im Zentrum ist insofern ungewöhnlich, als es sich mit einem Bogen in die breite Fensternische schmiegt. Viertelzylinder fungieren dabei als Drehachsen zwischen geraden und abgerundeten Segmenten. Die westliche Brustwand zeichnet eine dreiachsige Struktur aus. Eingelegte Bänder sowie geometrische und vegetabile Ornamente bereichern zusammen mit einer Groteskmaske und der Jahreszahl I 747 die mittlere Füllung. Das in der Mitte nach oben geführte Gesims spiegelt die Anordnung der gegenüber den anderen Sitzen erhöhten Sessio des Abtes wider. Über der Abtstalle ist das Abschlussgebälk mit einem Giebel versehen. Er trägt ein intarsiertes Doppelwappen: das des Klosters (der kniende Apostel Thomas vor Christus und ein geflügelter Greifenfuß)

443 Betz, ebd., bes. I3, I 26, Qu. 2 vom 26. Juli r 958. Stift Vorau [ca. 1970], Abb. 39, zeigt noch das alte Podest.

444 Frank, Vorau (1 925), I 49-1 50; Kohlbach, Stifte (I 953), I 83; ÖKM, Oststeiermark (I 987), 303; Attems/Koren, Kirchen (I 988), 47; Dehio, Steiermark (2006), 589 ; Mayrhofer, Ausstattungsgeschichte (2015), 27; ders., Stift Vorau (2017), I36-138. 


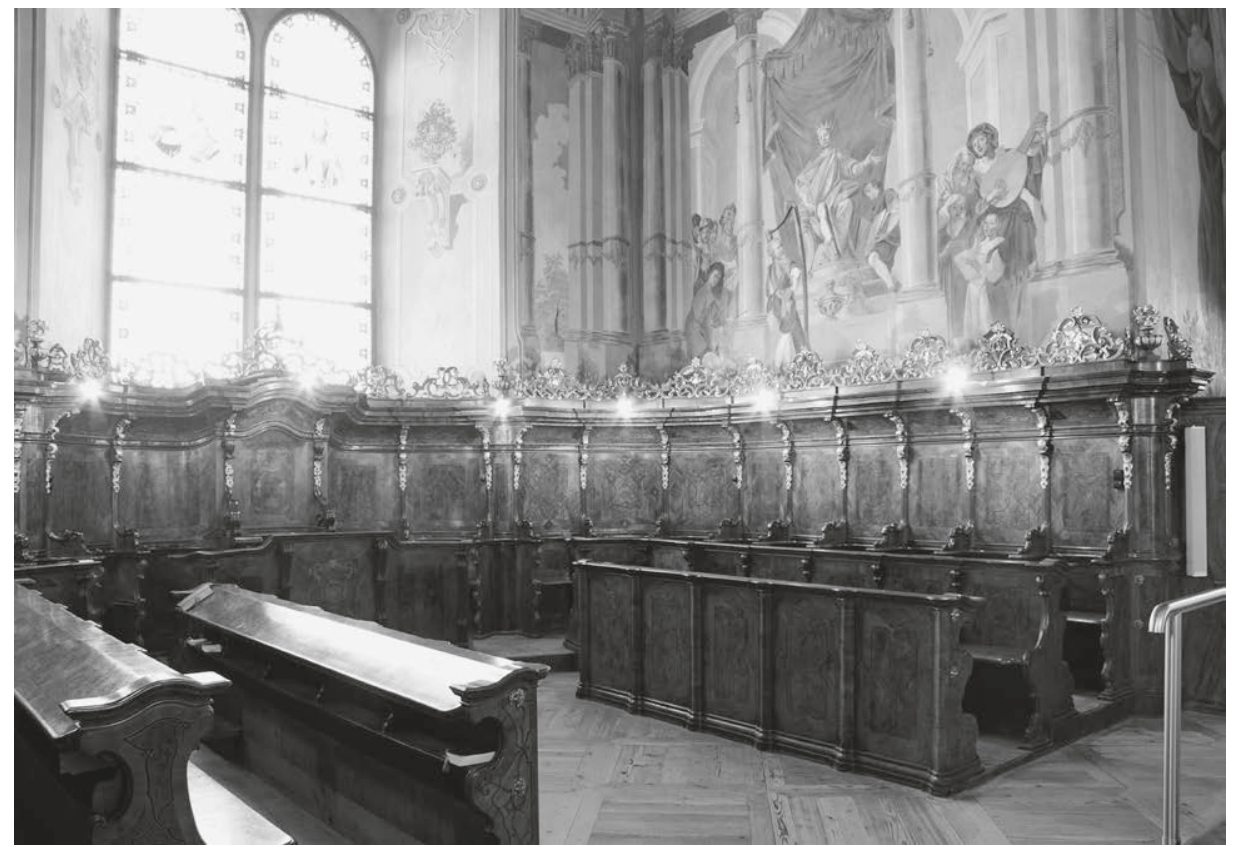

275 Westempore, Chorgestühl. Vorau, I747

sowie das des Propstes Lorenz Leitner (eine Treuhand zusammen mit einem Baum). Muschelwerk und ein Putto mit Abthut vervollständigen die Wappen. Hochkarätige Intarsienarbeiten veredeln überdies die Rückwand über dem Sitz des Klostervorstehers: Vasen und ein Korb voller Blumen stehen dort auf zweidimensionalen Podesten. Die Darstellungen kommen ohne räumliche Einbindung aus, sie scheinen in der Luft zu schweben, womit sie Vorlagendrucke von Jean Bérain d. Ä. (I637-I7 I I) oder Paul Decker d. Ä. (I677-I 7 I3) aus dem frühen I 8. Jahrhundert in Erinnerung rufen. ${ }^{445}$

Nicht ganz so aufwendig sind die Hauptreihen gestaltet. Im Querschnitt konkavkonvex-konkav geschwungene Lisenen, deren Basen und Kapitelle sich in der Sockelleiste bzw. im Abschlussgesims fortsetzen, unterteilen die seitlichen Brüstungen. Während wie üblich Zwischenwangen die hinteren Stallen voneinander trennen, strukturieren pilasterartige Stützen die Rückwand der Bänke und bewirken so eine nur unscharfe Trennung der Möbel in einzelne Sitzplätze. Ähnliche Gliederungselemente zieren das hohe Dorsale, dabei gehen sie allerdings aus geschweiften Konsolen hervor und tragen Voluten, auf denen der Baldachin und das stark profilierte Abschlussge-

445 Berliner/Egger, Vorlageblätter (I 98 I), Bd. I, 93-94, 99-Ioo, Bd. 3, bes. die Abb. I I 4 I, I I 43, I 2 I 5-I 2 I 7. 


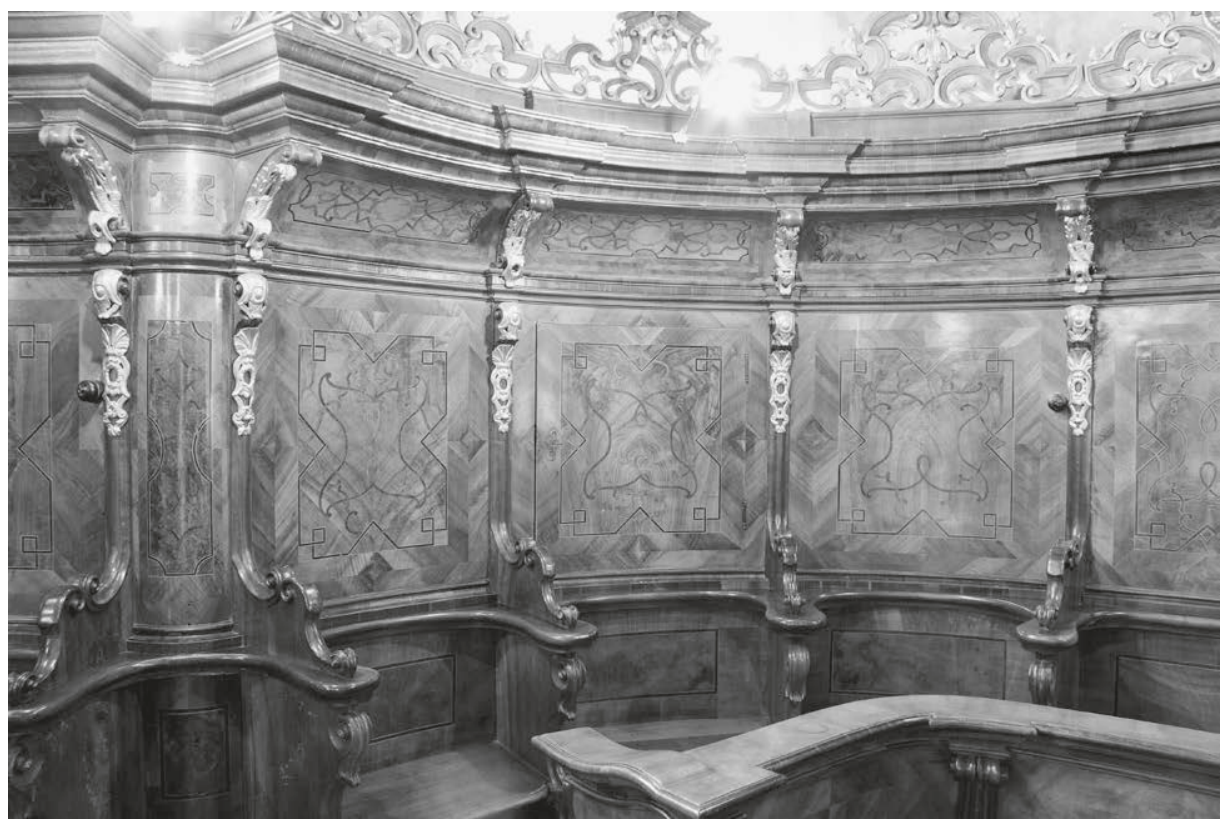

276 Chorgestühl (Detail). Eckverbindung zwischen West- und Nordwand. Vorau, I 747

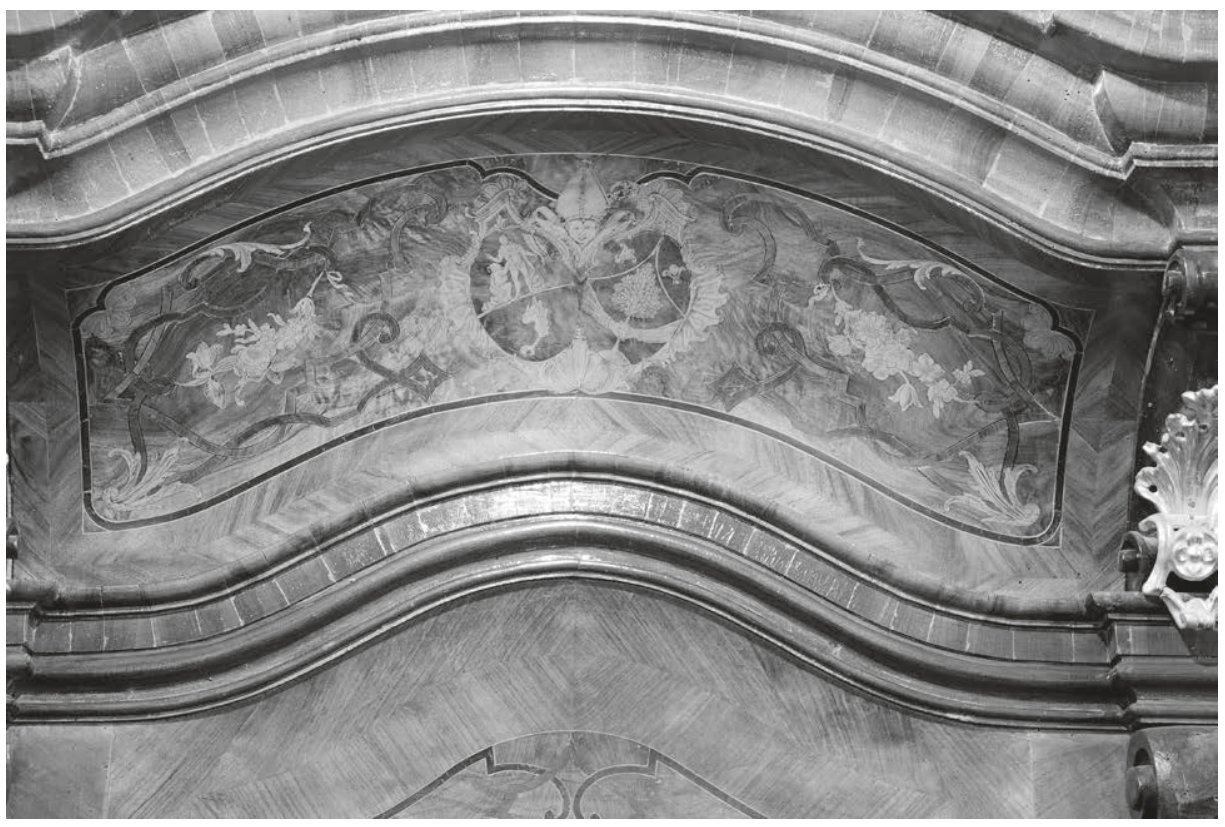

277 Chorgestühl (Detail). Gebälkstück über der Abtstalle. Vorau, I747 


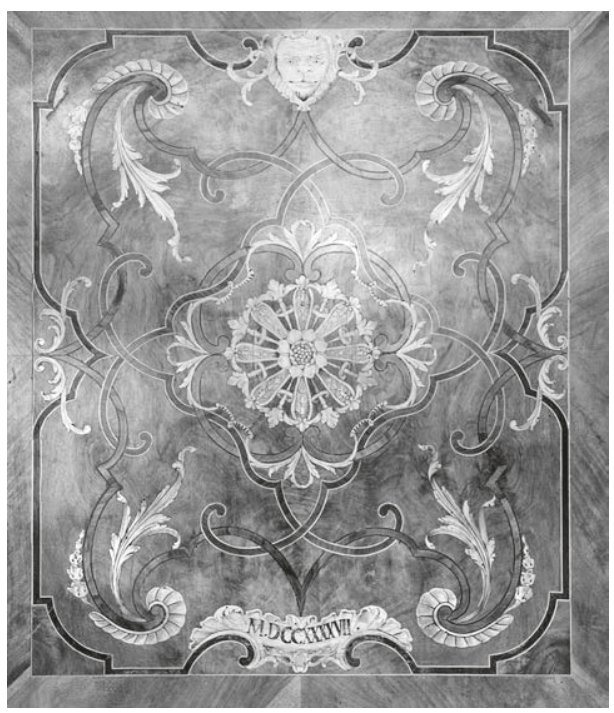

278 Brüstungsfüllung vor der Sessio des Abtes (Detail). Vorau, I747

bälk aufliegen. Feine vergoldete Schnitzarbeiten, die dem Aussehen von Metallbeschlägen ähneln, bereichern die Stützen der Rückwand.

Die Tischler dekorierten die Rahmensegmente des Gestühls mit gestreiftem Nussholz im Fischgratmuster, die Füllungen dagegen mit Maserholz aus Nuss. Geschwungene und miteinander verkettete Adern schmücken die zentralen Felder, Bandintarsien die Lehnen hinter den Sitzen und die Gebetbuchablagen. Zusammen mit den sauber ausgeführten Intarsienarbeiten und quer zur Längsrichtung des Blindholzes furnierten Gesimsen belegen sie die hohe Qualität der Möbelgarnitur, die mit einem Schnitzaufsatz aus filigranem Bandlwerk und Vasen mit Blumenbouquets schließt. Die Dekormotive sind teils in einem Braunton gefasst, teils auch vergoldet. Damit weisen sie den vorherrschenden Farbakkord der fast gleichzeitig entstandenen Schnitzarbeiten in der Sakristei der Grazer Domkirche auf (Abb. I65), von denen sie sich ansonsten jedoch grundsätzlich unterscheiden. Hier feine Stege und Gitterwerk, dort schwere Rocaillen und barocke Bögen vor geschlossenen Flächen.

Ein Vergleich des Gestühls in Vorau mit dem gleichzeitig entstandenen auf der Empore der Abtei Rein (Abb. 243-248) verdeutlicht weitere grundsätzliche formal-ästhetische Differenzen. ${ }^{446}$ Während nämlich in Rein die Arbeit des Bildschnitzers gleichberechtigt neben der des Intarsienkünstlers steht, wurden in Vorau die Schnitzarbeiten zugunsten der Intarsien verdrängt. Offensichtlich fühlte sich Propst Lorenz im Hinblick auf stilistische Fragen vor allem den in Wien und weiten Teilen Nordösterreichs gewählten Gestaltungsmitteln verpflichtet, die auf französische Vorlagen mit ausgewählten Furnieren und reichen Marketerien rekurrierten. Dem entsprechen auch die vielfach geschwungenen, miteinander verketteten und rechtwinklig gebrochenen Adern, die ebenso an französische Ornamentmotive erinnern wie die aufgeplatzt erscheinenden Rocaillen der Stützen. Im Vergleich mit Rein ist im Dekor der Ausstattung von Vorau eine fortschrittlichere Gesinnung spürbar.

446 Die Distanz zwischen den beiden Abteien beträgt keine roo Kilometer. 


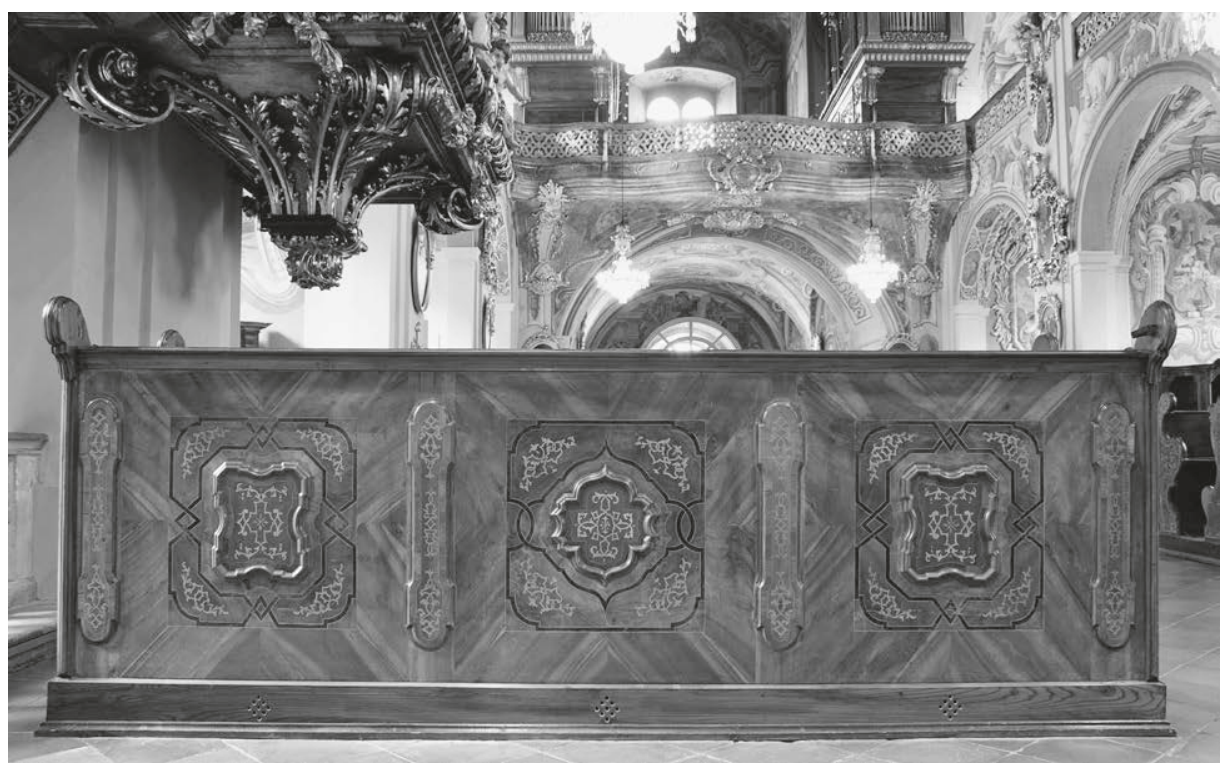

279 Laiengestühl, Brüstung. Vorau, I 724

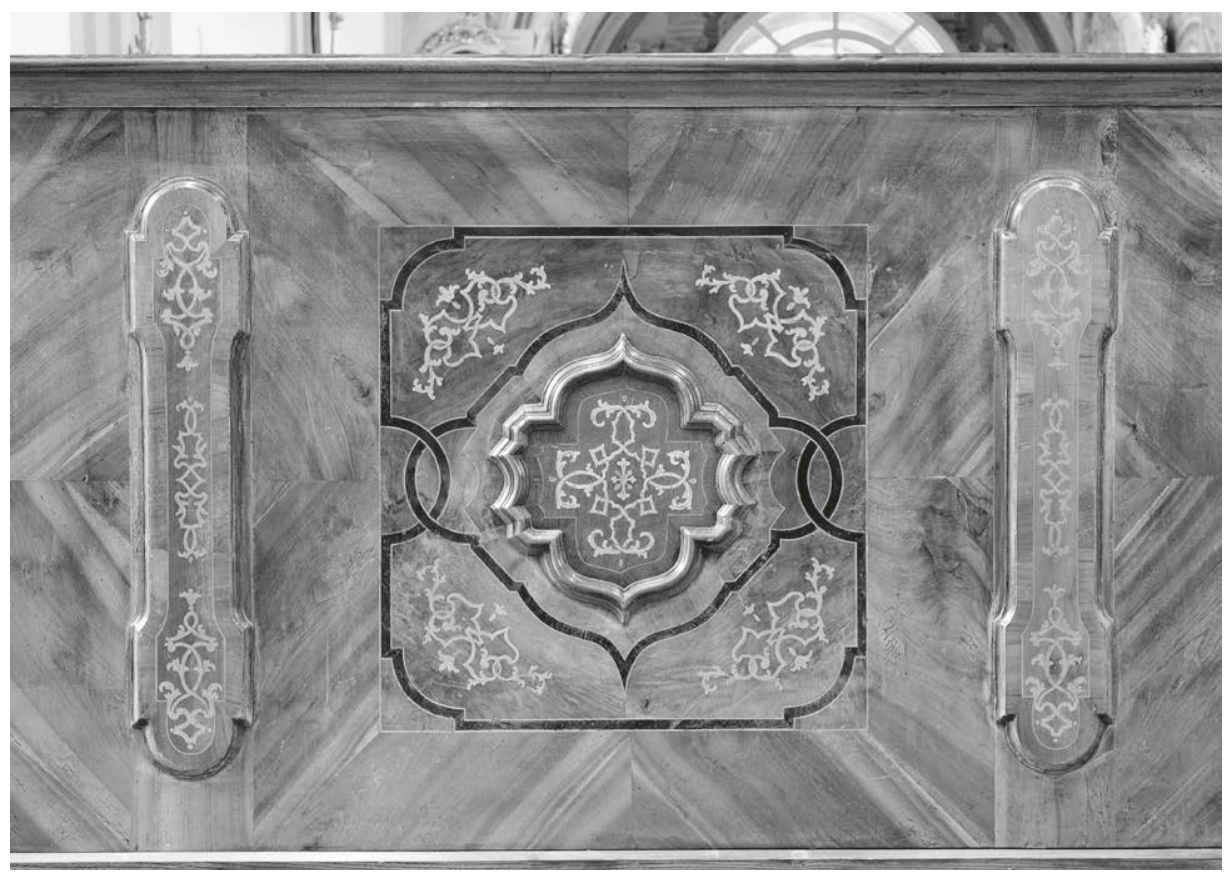

280 Teilansicht der Brustwand. Vorau, I 724 


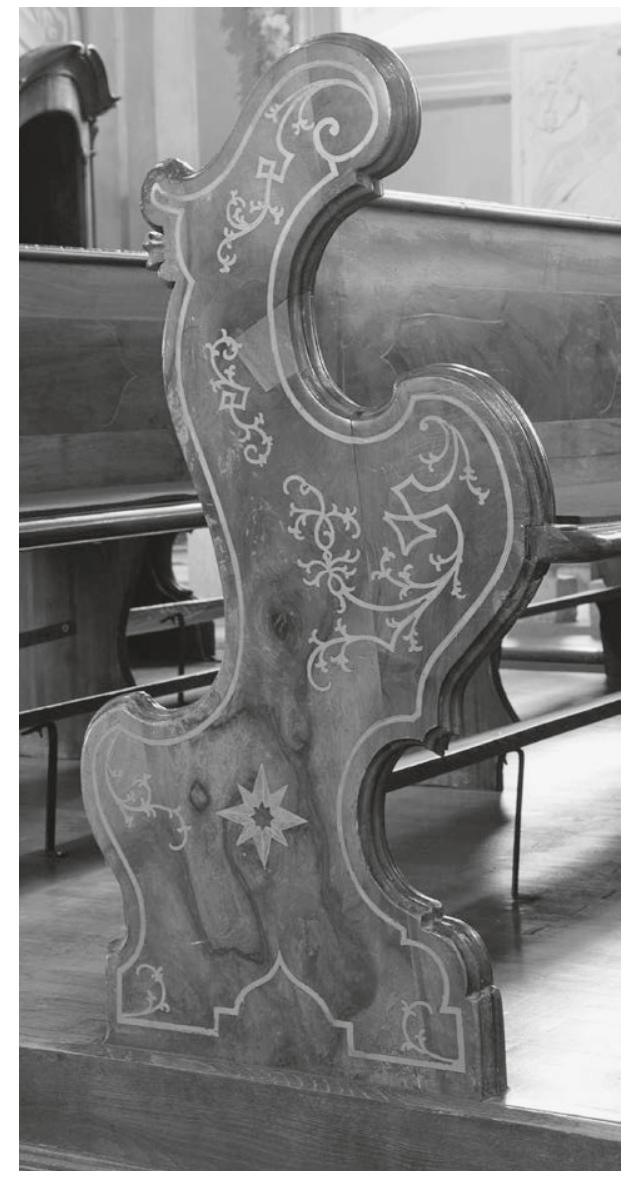

28 I Bankwange. Vorau, I724

\section{Kirchenbänke}

Vorau, I 724

HS $16 \mathrm{~cm}$

$\mathrm{H}$ I I I, $5 \mathrm{~cm}(+\mathrm{I} 6 \mathrm{~cm}) \times \mathrm{L} 340 \mathrm{~cm}$

Nuss, Nussmaser, Ahorn, Mooreiche, Holz, geschwärzt. Zinn, graviert, geschwärzt

Acht Postamente tragen die 42 Bankreihen in der Stiftskirche (Abb. 279-28I). ${ }^{447}$ Die beiden westlichen Blöcke umfassen je drei Möbel, die anderen sechs, hinzu kommen die nötigen Brustwände.

Vorder- und Rückwände ruhen ohne eigenen Sockel direkt auf dem Laufpodest. Lisenenartige Bänder mit aufgedoppelten schmalen Schollen ordnen die flächig gearbeiteten Brustwände, Vergleichbares kann in dieser Arbeit kein zweites Mal beschrieben werden. Breite Rahmen und Füllungsfelder besetzen wie üblich die Zwischenräume. Dabei bestehen die Füllungen aus Friesen und zentralen Kompartimenten, die markante, an die Ausgestaltung verschiedener Möbel in Stams (Abb. 363, 364) erinnernde Profile einfassen. Auch in diesem Kontext lohnt ein Blick nach Rein: Die dortigen Kirchenbänke (Abb. 240, 24I) entstanden I744, sind aber wie zahlreiche Laiengestühle
schwerer als die zierlichen Exemplare in Vorau. im Süden Österreichs optisch sehr viel schwerer als die zierlichen Exemplare in Vorau.
Das Bankensemble ist mit gestreiftem Nussholz und Maserholz aus Nuss furniert, das Besondere an ihnen sind nicht zuletzt die reichen Zinneinlagen, die Laub- und Bandlwerkstrukturen sowie Blüten und Sterne vergegenwärtigen. Hinzu kommen an den Brüstungen dunkle Adern und an den Wangen fein profilierte Kanten. Die Rückenlehne der ersten Bankreihe auf der Epistelseite trägt die Jahreszahl I 724. Die Laufböden sind modern.

447 Frank, Vorau (r 925), I38; Meeraus, Vorau (r 928), r6; Gerlach, Chorgestühl (I93 I), 40; Kohlbach, Stifte (1953), I83; Stift Vorau [1954], r9; ÖKM, Oststeiermark (1987), 303; Attems/Koren, Kirchen (I 988), 47; Dehio, Steiermark (2006), 589; Mayrhofer, Stift Vorau (2017), I 30. 


\section{Beichtstühle}

Vorau, um I $730 / 40$

$\mathrm{H} 232 \mathrm{~cm} \times \mathrm{B} 225 \mathrm{~cm} \times \mathrm{T}$ i IO $\mathrm{cm}$

Nuss, Nussmaser, massiv und furniert, Zwetschke, Ahorn, graviert, geschwärzt, Nadelholz. Messing, Eisen

Die Möbel befinden sich in drei Seitenkapellen sowie im Querhaus der Kirche (Abb. 282). ${ }^{448}$ Ihr Grundriss entspricht einem Halbkreis, wobei die Seitenjoche einen kurzen konkavkonvex-konkaven Bogen beschreiben. Schräg nach außen gerichtete Piedestale erheben sich über der verkröpften Sockelplatte und tragen schlanke Pilaster mit Blockkapitellen. Als Abschluss folgt ein Gesims, das über dem Eingang zur Priesterstalle in einen sphärischen Giebel übergeht, während es seitlich nicht parallel zum Grundriss verläuft, sondern mit einem Gegenbogen nach innen geführt ist. Eine

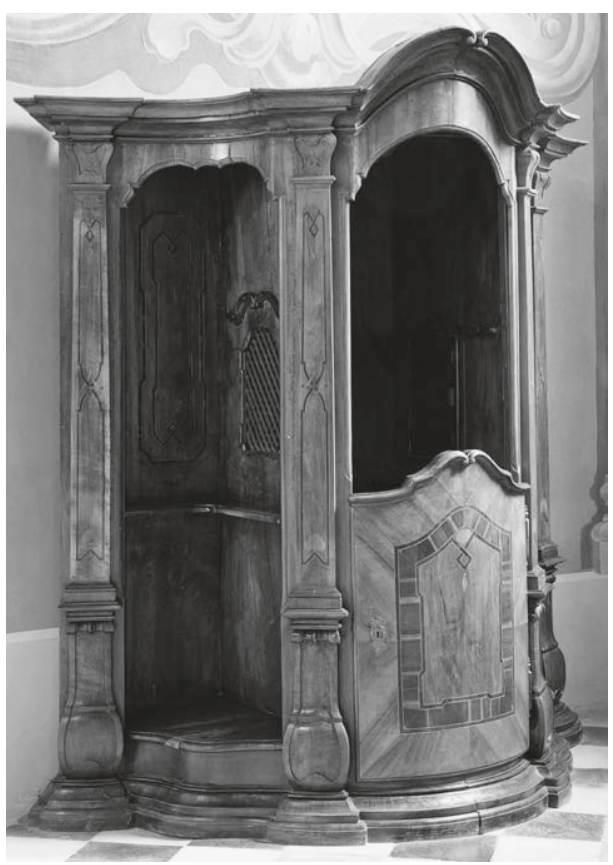

282 Beichtstuhl. Vorau, um I730/40 hüfthohe Tür verschließt das mittlere Gehäuse, die seitlichen Zellen stehen offen.

Flache Profile säumen an Kapitellen und Piedestalen vertieft liegende Binnenfelder, ein auffallend breiter Fries aus Zwetschkenholz umgibt die Türfüllung. Die Tatsache, dass die Öffnungen zu den Gehäusen nicht einfach ausgesägt, sondern mit feinen Rundstäben eingefasst sind, spricht für den Wunsch des Propstes Webersberg nach einer qualitätvollen Ausführung des Möbelensembles. Wie das häufig zu beobachten ist, wurden auch hier die Priesterstallen zweier Möbel nachträglich verglast.

\section{Beichtstüble}

Vorau, um I $760 / 70$

$\mathrm{H} 230 \mathrm{~cm} \times \mathrm{B} 210 \mathrm{~cm} \times \mathrm{T} 90 \mathrm{~cm}$

Nuss, Nussmaser, Ahorn, graviert, geschwärzt. Eisen

448 ÖKM, ebd., 30I-302; Dehio, ebd., 589 ; Mayrhofer, Ausstattungsgeschichte (201 5), 27. In der Literatur werden alle Beichtstühle in Vorau auf die Mitte des I 8. Jahrhunderts datiert, das ist nicht richtig, sondern trifft lediglich auf die Möbel im Querhaus der Kirche zu. 


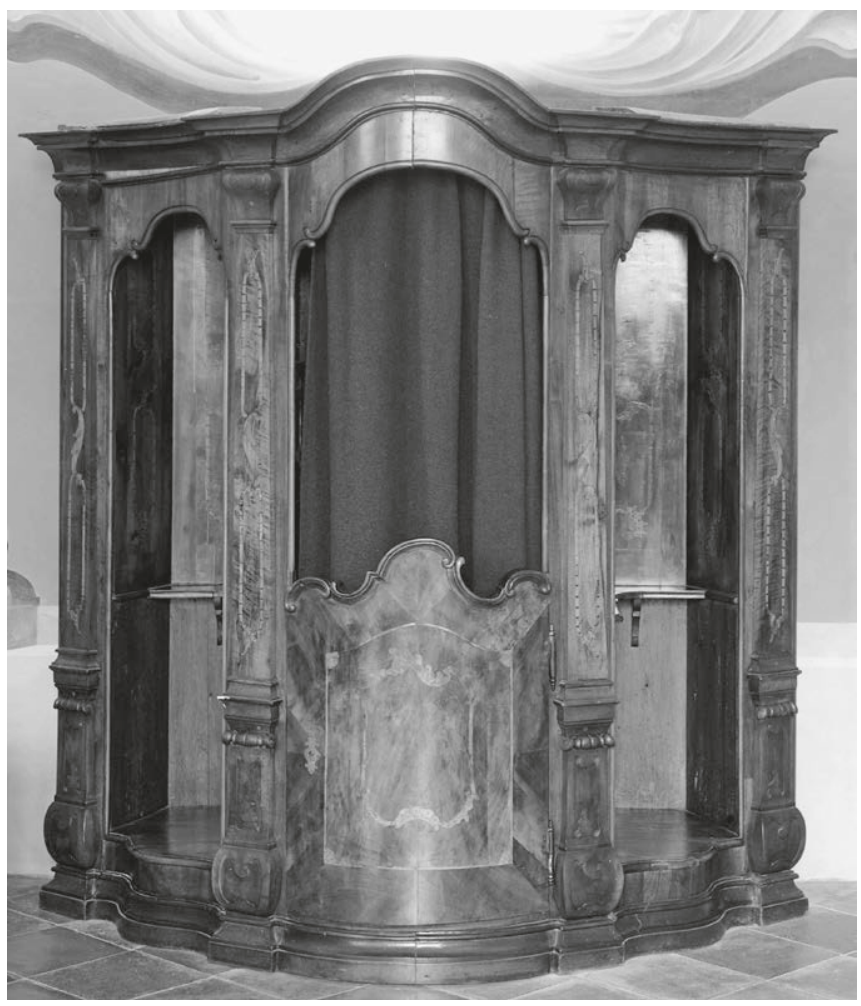

283 Beichtstuhl. Vorau, um I $760 / 70$

Und noch drei weitere Beichtstühle stehen den Gläubigen zur Verfügung (Abb. 283). ${ }^{449}$ Bei ihrem Bau orientierte man sich offensichtlich am Aussehen der anderen Möbel, doch verraten Details, dass sie zwei oder drei Jahrzehnte später gefertigt wurden. Während Grund- und Aufriss den früheren Exemplaren weitgehend entsprechen, ergeben sich gravierende Unterschiede aus dem Segmentgiebel, der die Möbel überfängt, sowie aus dem geschweiften und asymmetrisch angelegten Türabschluss. Zudem zeigen die Intarsien der drei jüngeren Beichtstühle Muschelornamente, die die Herstellung der Inventarstücke nach der Jahrhundertmitte belegen.

\section{Ehemaliger Kapitelsaal}

Der ehemalige Kapitelsaal befindet sich über der Sakristei. ${ }^{450}$ Eingerichtet ist der Raum mit einem Altar vor der Ostseite, mit Bänken für die Konventualen vor den

449 ÖKM, ebd.

450 ÖKM, ebd., 303; Attems/Koren, Kirchen (1988), 47; Dehio, Steiermark (2006), 590; Gierse, Bild- 

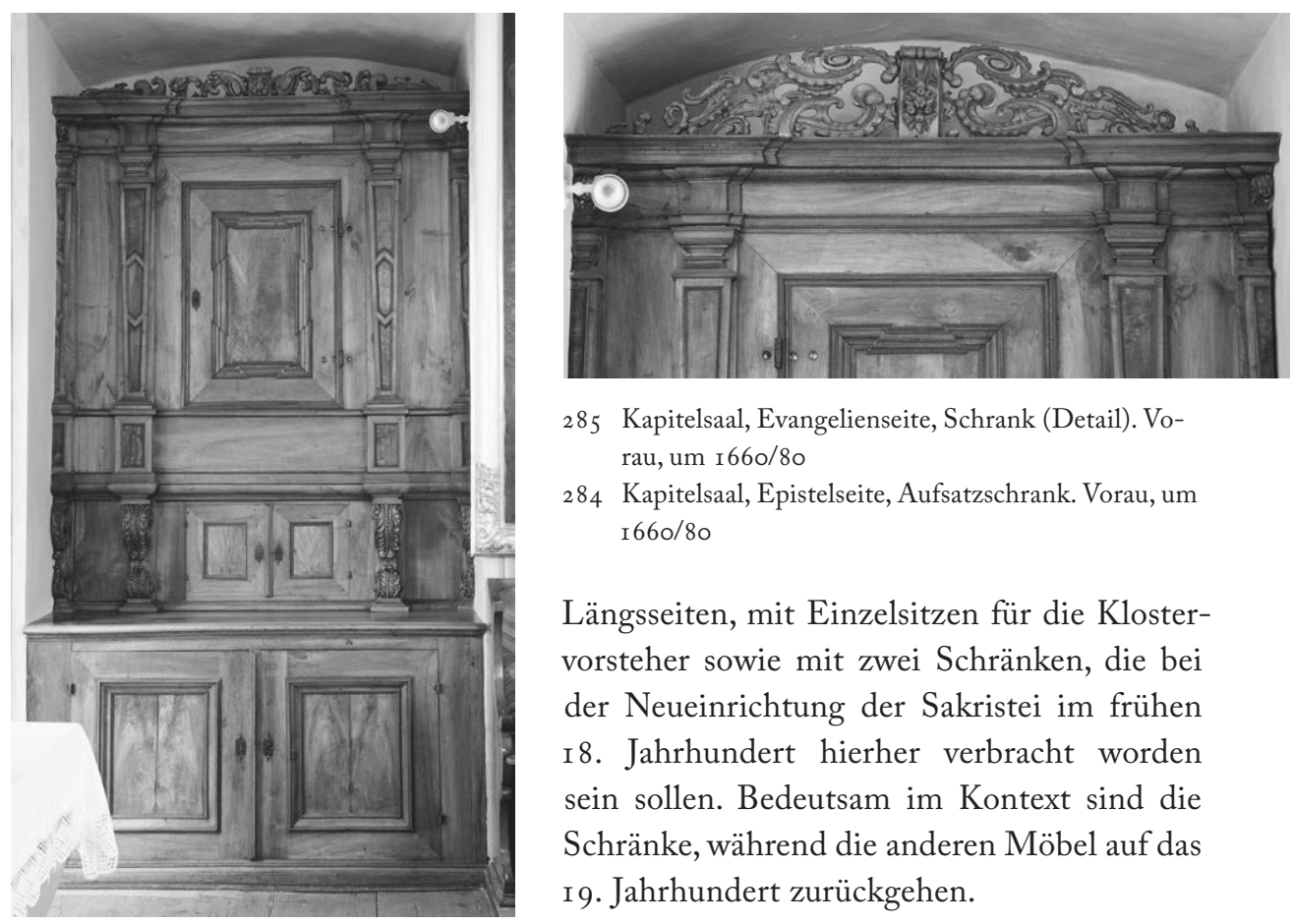

285 Kapitelsaal, Evangelienseite, Schrank (Detail). Vorau, um r 660/80

284 Kapitelsaal, Epistelseite, Aufsatzschrank. Vorau, um I $660 / 80$

Längsseiten, mit Einzelsitzen für die Klostervorsteher sowie mit zwei Schränken, die bei der Neueinrichtung der Sakristei im frühen I 8. Jahrhundert hierher verbracht worden sein sollen. Bedeutsam im Kontext sind die Schränke, während die anderen Möbel auf das I 9. Jahrhundert zurückgehen.

\section{Aufsatzschränke}

Vorau, um I660/80

$\mathrm{H}_{360,5} \mathrm{~cm} \times \mathrm{B}$ i $92 \mathrm{~cm} \times \mathrm{T}$ I I $5 \mathrm{~cm}$

Nuss, massiv und auf Nadelholz. Eisen, geschwärzt

Die beiden Aufsatzkästen stehen in tiefen Nischen am östlichen Raumende (Abb. 284, 285 ). Wie das bei manchen Sakristeimöbeln beobachtet werden kann, erhebt sich auch hier der Hochschrank mit Kelchfächern direkt über der Platte des Unterschranks. ${ }^{451}$ Die Substruktion ist schlicht, hochrechteckige Füllungen sind in die beiden Türen eingesetzt. Volutenkonsolen strukturieren das Zwischengeschoss, Keilpilaster den hohen Aufsatz. Das verkröpfte Gebälk trägt einen Schnitzauszug mit knorpeligen Motiven

programme (2010), 5 I4; Mayrhofer, Ausstattungsgeschichte (2015), 23; ders., Stift Vorau (2017), I $43^{-1} 47$.

45 I Als ein Vergleichsbeispiel kann das Inventarstück in der Domkirche zu Klagenfurt angeführt werden (Abb. 42, 43), weitere Exempel liegen in den Möbeln des Karmelitenklosters in Linz vor. Bohr, Sakralmöbel (2017), 567-569. 
und einem mittleren Postament mit Früchten. Der Auszug auf der Epistelseite ist beschnitten, ursprünglich muss er höher als heute gewesen sein. Flammleisten begleiten die Profile der Möbel.

Wie oben erwähnt, zählten die Schränke vermutlich einst zum Sakristeiinterieur, doch können sie nur einen kleinen Teil des ursprünglichen Bestandes ausgemacht haben. Der weitaus größere Teil der alten Sakristeieinrichtung ist verloren. Schon zur Zeit ihrer Herstellung besaß das Stift eine Tischlerei, in der I647 der Hoftischler Valentin Lindt aus Fulda tätig war. ${ }^{452}$ Von ihm ist leider nicht mehr bekannt, als dass er I6I 9 heiratete ${ }^{453}$ und somit wohl um r60o oder kurz zuvor geboren sein wird. Die beiden Schränke dürften in der klostereigenen Werkstätte gebaut worden sein.

$45^{2}$ Kohlbach, Stifte (1953), I 80.

453 Kohlbach, ebd. 


\title{
Sakralbauten in Tirol
}

\author{
Bad Mehrn, Filialkirche hl. Bartholomäus
}

Von dem ursprünglichen, seit 1357 archivalisch fassbaren Sakralbau ist kaum mehr als der gotische Nordturm und das spätmittelalterliche, mit einer eisernen Tür verschlossene Sakristeiportal erhalten. ${ }^{454}$ Bei der heutigen Kirche, die nach I66r ausgeführt wurde, handelt es sich um einen Saalbau, die Altarweihe fiel ins Jahr I698. Das Langhaus umfasst vier Joche, ein eingezogener Fronbogen trennt es vom einjochigen Chor. Während knorpelige Schnitzereien den auf I670/80 datierten Hochaltar zieren, weisen die um I69o entstandenen Seitenaltäre eine Mischung aus spätem Knorpelwerk und vegetabilen Ornamenten auf. An der um i 700 gebauten Kanzel finden sich ausschließlich Laubwerkformationen, die jedoch mit den Akanthusmotiven, die wir aus den östlichen Regionen oder aus dem Süden kennen, nur wenig gemein haben. Die seitlichen Außenwände zahlreicher Kirchen in der Steiermark und in Tirol sind hüft- oder brusthoch vertäfelt, das ist hier nicht anders.

\section{Sakristei}

Die Sakristei liegt nördlich des Presbyteriums. Von der Kirche aus betritt man zunächst einen kleinen Vorraum, um dann in den eigentlichen Sakristeiraum zu gelangen, der allerdings kaum größer als das Durchgangszimmer ist. Im Raum führte einst eine Treppe zur Kanzel, aus Platzgründen wurden die Stufen bis auf den Treppenabsatz entfernt.

\section{Aufsatzschrank mit Kelchkästen}

Höhe der Füße 6,5 cm

$\mathrm{H}$ I $28,0 \mathrm{~cm}(+6,5 \mathrm{~cm}) \times \mathrm{B} 326,5 \mathrm{~cm} \times \mathrm{T} 94,5 \mathrm{~cm}$

454 ÖKM, Tiroler Unterland (I97I), 90; Neuhardt, Brixlegg (I978), Io-I2; Dehio, Tirol (I980), 214; Rampold, Tirol (2014), 216-2 I 7 . 


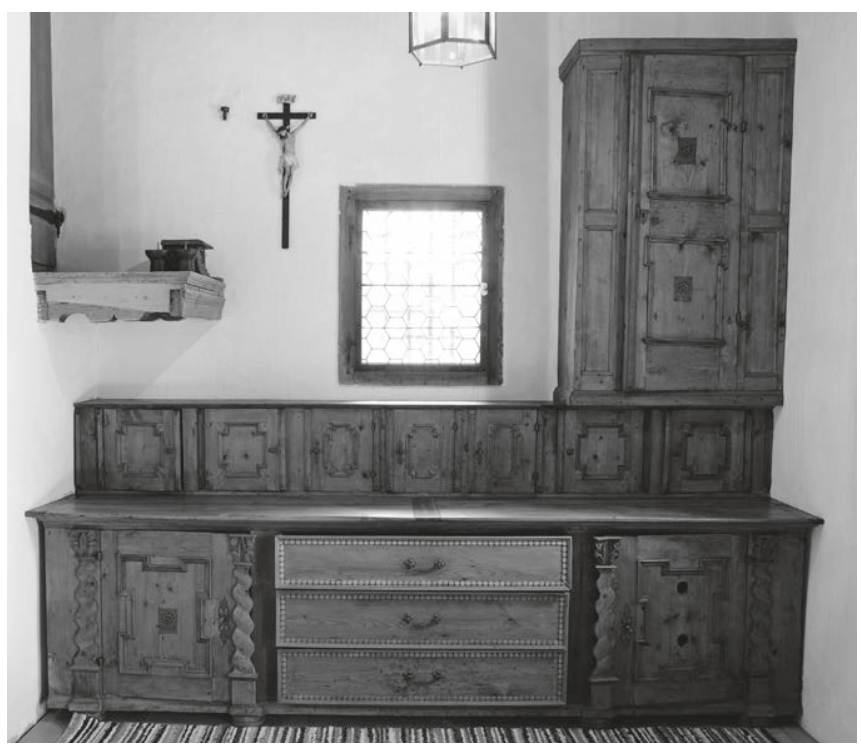

286 Sakristei, Aufsatzschrank. Bad Mehrn, 3. D. I 7. Jh.

\section{Oberschrank}

$\mathrm{H}$ I 6o, $5 \mathrm{~cm} \times \mathrm{B} 97 \mathrm{~cm} \times \mathrm{T}_{44} \mathrm{~cm}$

Bad Mehrn, 3. D. I7. Jh.

Nadelholz, Platte aus Nuss. Eisen geschwärzt

Das Inventarstück ruht auf modernen Ballenfüßen (Abb. 286). Der Unterschrank setzt sich aus zwei seitlichen, mit Türen verschlossenen Fächern und einem mittleren Teilstück mit Schubladen zusammen, quergehobelte Pilaster mit Fantasiekapitellen rhythmisieren die Möbelfront. Als Aufsatz trägt die Substruktion Kelchfächer, die durch die unterschiedliche Gestaltung der Füllungen auf die Dreiteilung des Unterschranks Bezug nehmen. Die Kelchkästen reichen bis unter eine Fensteröffnung, links davon befindet sich der erwähnte Treppenabsatz, rechts steht auf dem Möbel ein hoher Oberschrank.

Die Türfüllungen des Unterschranks sind mit ausspringenden, die Füllungen der Kelchfächer mit eingezogenen Ecken versehen, jene der drei mittleren Fächer sind überdies verkröpft. Öffnungen in den Türen der Substruktion sorgen für die nötige Belüftung. Der eintürige Oberschrank ist anders gestaltet: Dort besitzen die Türfüllungen geohrte Rahmen über Sockelleisten. Zudem ist er um einige Zentimeter tiefer als die Kelchkästen. Mit Sicherheit ist dies also nicht sein ursprünglicher Aufstellungsort.

Wegen fehlender Ornamente kann die Sakristeiausstattung nicht genau datiert werden. Die Form der Füllungen, Pilaster und Beschläge weist das Möbel dem fort- 
287 Altarraum, Dreisitz. Bad Mehrn, um I670/80

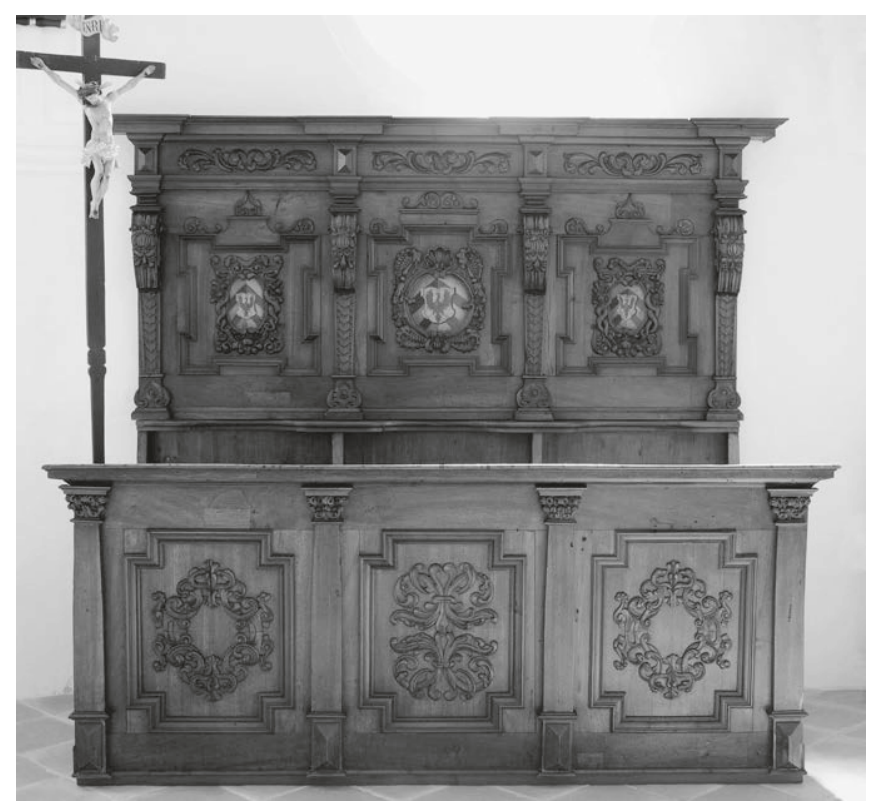

geschrittenen I7. Jahrhundert zu, die Bauchronologie lässt dabei an das letzte Drittel jenes Jahrhunderts denken. Die Schubladen, die ein kräftiges, mit einer Perlleiste dekoriertes Randprofil einfasst, unterscheiden sich durch die Farbe deutlich von den seitlichen Türen und den Kelchfächern. Die Laden erhielten vor nicht allzu langer Zeit ein neues Inneres. Aus der Barockzeit stammen lediglich die Vorderstücke, bei deren Überarbeitung allerdings die alte Patina entfernt wurde.

\section{Kirchenraum}

Im Altarraum der Kirche stehen sich ein Dreisitz und ein Zweisitz gegenüber. ${ }^{45}$

\section{Dreisitz}

Bad Mehrn, um i 670/80

HS $5 \mathrm{~cm} / \mathrm{II}, 5 \mathrm{~cm}$

$\mathrm{H} 215 \mathrm{~cm}(+5 \mathrm{~cm}) \times \mathrm{B} 243 \mathrm{~cm}$

Nuss, massiv und aufgedoppelt, Nadelholz, Holz polychrom gefasst

455 Dehio, ebd., 2 I 4. 


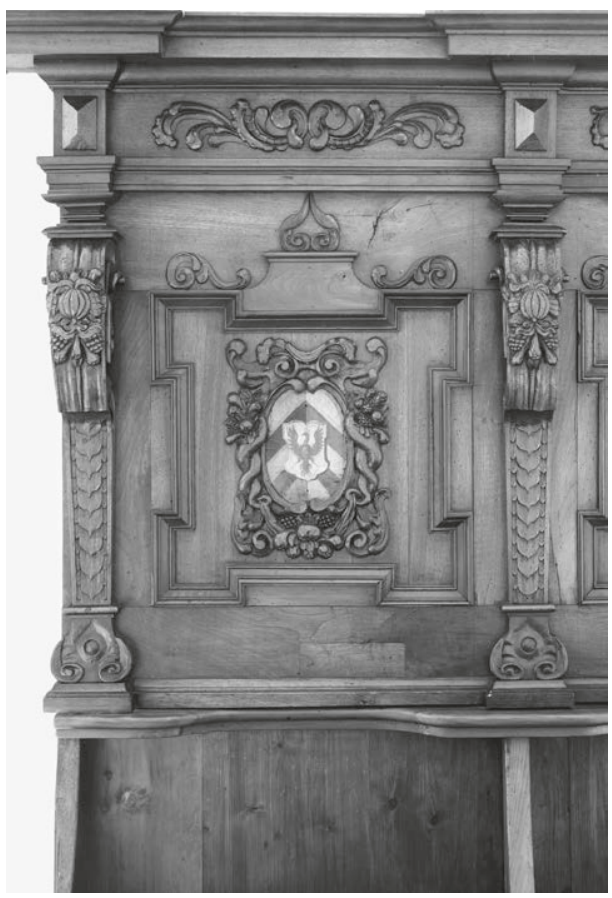

288 Detail der Abb. 287

Pilaster, Sockelleiste und Gesims fassen die dreiachsige Vorderbrüstung zusammen, wie üblich besteht sie aus Rahmen und Füllungen (Abb. 287, 288). Die Ecken der Binnenfelder sind eingezogen, kleinteilige Schnitzornamente den Flächen aufgelegt. Anders als sonst präsentiert sich die Seitenansicht der Brüstung, da die Vorderwand und die Wange optisch streng voneinander geschieden sind. Die Tischler beließen die seitlichen Außenkanten der Brüstungswand glatt und unverziert, sie verdeckten nicht einmal das Hirnholz der horizontalen Stollen. Dagegen dekorierten sie die Wangen mit Schnitzereien und rauten den Grund dazwischen mit Punzen auf.

Manieristische Volutenpilaster mit Blockkapitellen unterteilen das Dorsale. Giebelartige Aufsätze bekrönen die verkröpften Füllungen, Kartuschen werten deren Zentren auf. Sie tragen die Wappen der Faber von Lanegg, den früheren Besitzern eines in der Nähe der Kirche gelegenen Ansitzes. Schuppenfriese zieren die Pilasterschäfte, darüber hinaus wählten die Tischler als Schnitzmotive Fruchtgirlanden und andere vegetabile Formen sowie auffallend feine knorpelige Ornamente. Letztere definieren eine Stilvariante, die im Volksmund etwas despektierlich, aber durchaus passend als "Knöchelbarock« bezeichnet wird. ${ }^{456}$ Neu sind neben dem Laufboden die Sitzbank und die Rückwand dahinter.

\section{Zweisitz}

Bad Mehrn, um r670/80

HS II, $5 \mathrm{~cm}$

$\mathrm{H} 203,5 \mathrm{~cm} \times \mathrm{B} \mathrm{I} 95 \mathrm{~cm}$

Nuss, massiv und aufgedoppelt, Nadelholz, Holz gefasst

Hinsichtlich seiner Großformen entspricht das Möbel dem beschriebenen Dreisitz (Abb. 289). Auch der Zweisitz erhielt einen neuen Laufboden, eventuell auch einen

456 Vgl. hierzu auch Kap. VI der Einleitung sowie den Abschnitt zur Innsbrucker Servitenkirche. 
neuen Sockel, doch scheint alles andere auf den originalen Bestand zurückzugehen.

Gemäß der gewöhnlichen Konstruktionsweise ist das Dorsale auf die Rückenlehne der Bank gestellt, Volutenpilaster, Sockelleiste und Gebälk verleihen ihm einen architektonischen Aufbau. Vegetabile Ornamente zieren die Voluten, Fruchtgirlanden den Fries, an den Binnenfeldern befestigte man auch hier gewölbte und von kräftigem Schnitzwerk gesäumte Kartuschen, die nun mit einer olivgrünen Farbfassung überzogen sind. Die Sitzbank, die Rückwand darüber und die Innenseite der Brüstung bestehen aus nussfarben gebeiztem Nadelholz, der neue Boden aus naturbelassenem Weichholz, die restlichen Möbelteile aus massivem Nussholz und dickem Nussfurnier.

Die Autoren des Dehio vermuten eine Entstehung des Zweisitzes um r670, also bald

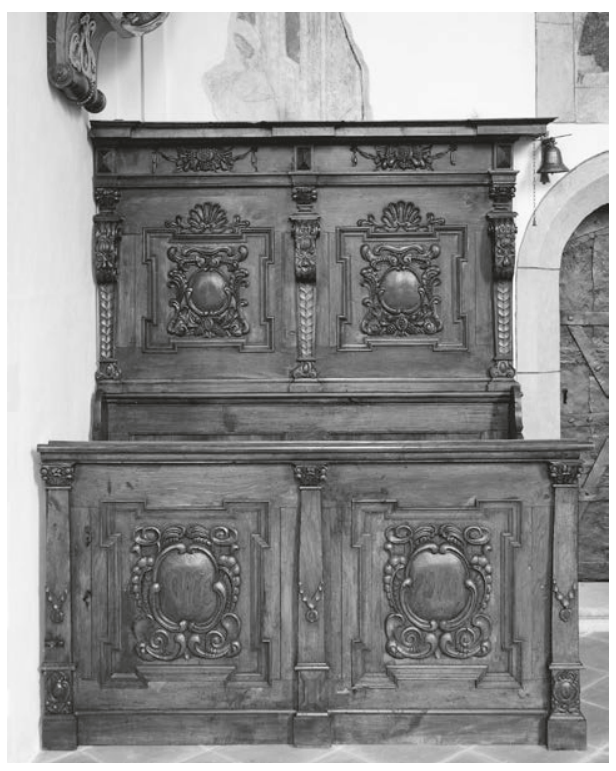

289 Altarraum der Kirche, Zweisitz. Bad Mehrn, um I670/80 nach der Errichtung der Kirche, die des Dreisitzes um i680. In der Tat lassen unterschiedliche Gestaltungsmerkmale darauf schließen, dass die Inventarstücke nicht gleichzeitig und eventuell in verschiedenen Werkstätten gebaut wurden. Fakt ist aber auch, dass frühbarocke Ornamentmotive beide Möbel schmücken, im Osten Österreichs würde man sie etwa auf die Jahrhundertmitte datieren, wobei dort allerdings im Möbelbau diese besonders kleinteilige Variante barocken Dekors unbekannt war. ${ }^{457}$ Eine chronologische Abfolge lässt sich unseres Erachtens aus den verwendeten Zierelementen nicht ableiten.

\section{Beichtstuhl}

Bad Mehrn, um i670/80

HS 9,5 cm

Gesimshöhe $204 \mathrm{~cm}(+9,5 \mathrm{~cm}) \times \mathrm{B} 209,5 \mathrm{~cm}$

$\mathrm{H}$ des Schnitzaufsatzes $45 \mathrm{~cm}$, das Kreuz besitzt eine $\mathrm{H}$ von etwa $83,5 \mathrm{~cm}$

Nadelholz, naturbelassen und braun gebeizt

457 Entwicklungsgeschichtlich stehen die Ausstattungsstücke auf einer Stilstufe beispielsweise mit dem Chorgestühl und dem Ratsherrengestühl von I640/50 in St. Stephan zu Wien. Bohr, Sakralmöbel (2017), 222-227. 


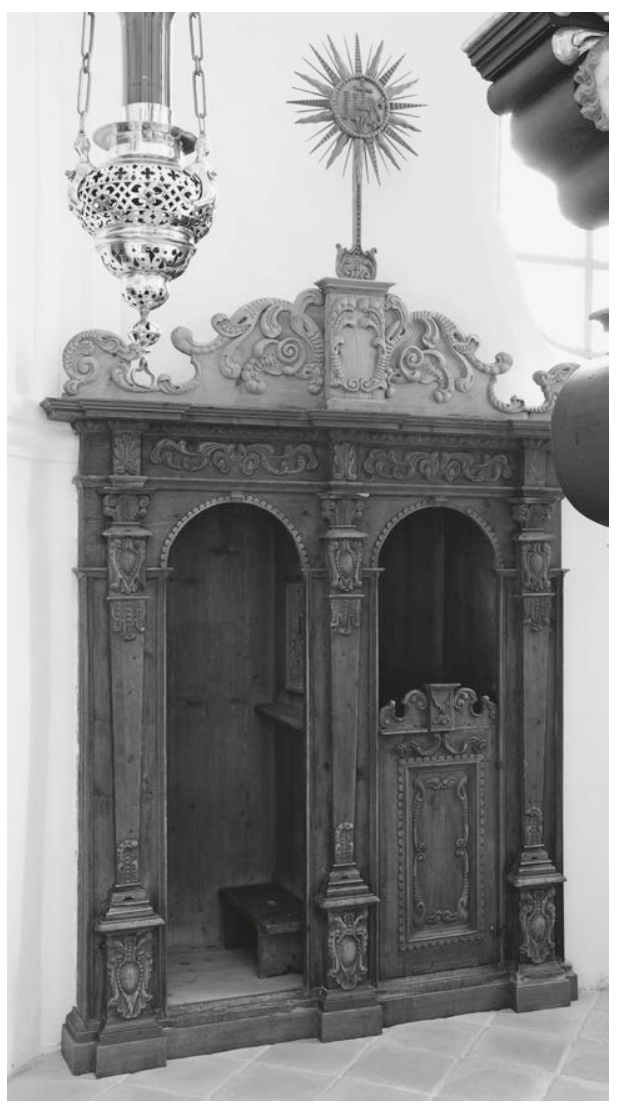

290 Beichtstuhl hinter dem Altar. Bad

Mehrn, um I670/80

Links hinter dem Altar setzten die Tischler in eine Mauernische der Chorwand einen zweizelligen Beichtstuhl ein (Abb. 290). Hochgesockelte Keilpilaster tragen ein verkröpftes Gebälk und einen hohen Auszug, halbrunde Arkaden bilden die Achsen zwischen den Stützen. Ein Bogenfries legt sich um die Arkadenöffnungen und die Türfüllung. Er greift ein Motiv auf, das schon von den Schubladen des Sakristeimöbels her bekannt ist. Auch dieses Möbel ist mit hochbarockem Schnitzzierrat geschmückt, schwere Knorpelschnitzereien spielen nun zumindest am Aufsatz eine größere Rolle. Der Beichtstuhl etwa dürfte gleichzeitig mit dem Hauptaltar gefertigt worden sein. Und entsprechend der Vorgehensweise bei der Restaurierung des Sakristeimöbels wurde hier die alte Patina teilweise entfernt, was zu dem inhomogenen Erscheinungsbild des Möbels führte.

\section{Brixlegg, Pfarritirche Unsere Liebe} FrAU

Schriftquellen erwähnen den Ort Brixlegg zwar erst seit 788, doch bezeugen Grabungsfunde in der Region bronzezeitliche und römische Siedlungen. ${ }^{458}$ Seit der Mitte des I 5 Jahrhunderts entstanden in der Gegend Schmelzhütten für Silber- und Kupfervorkommen, die dort erschlossen wurden. ${ }^{459}$ Die heutige Kirche geht auf das frühe r6. Jahrhundert zurück. Mit den Barockisierungsarbeiten wurde im folgenden Säkulum begonnen, als man die frühere flache Holzdecke durch ein Gewölbe ersetzte. Das Bauwerk besitzt ein fünfjochiges, mit einer Tonne überspanntes Langhaus und einen Chor mit drei polygonalen Konchen. Die Kanzel ist auf die Zeit um r 700 zu datieren, der Deckenstuck auf die späten r 76oer-Jahre. Aus-

\footnotetext{
458 ÖKM, Tiroler Unterland (I 97 I), 89; Neuhardt, Brixlegg (I 978), 2-9; Dehio, Tirol (I 980), 2 I 2-2 I 3 ; Rampold, Tirol (2014), 2 I 5-2 I 6.

459 Vgl. hierzu die verschiedenen Beiträge in Ammann, Bergbau (I 990).
} 
29I Sakristei, Ankleidekredenz. Brixlegg, um I $730 / 40$

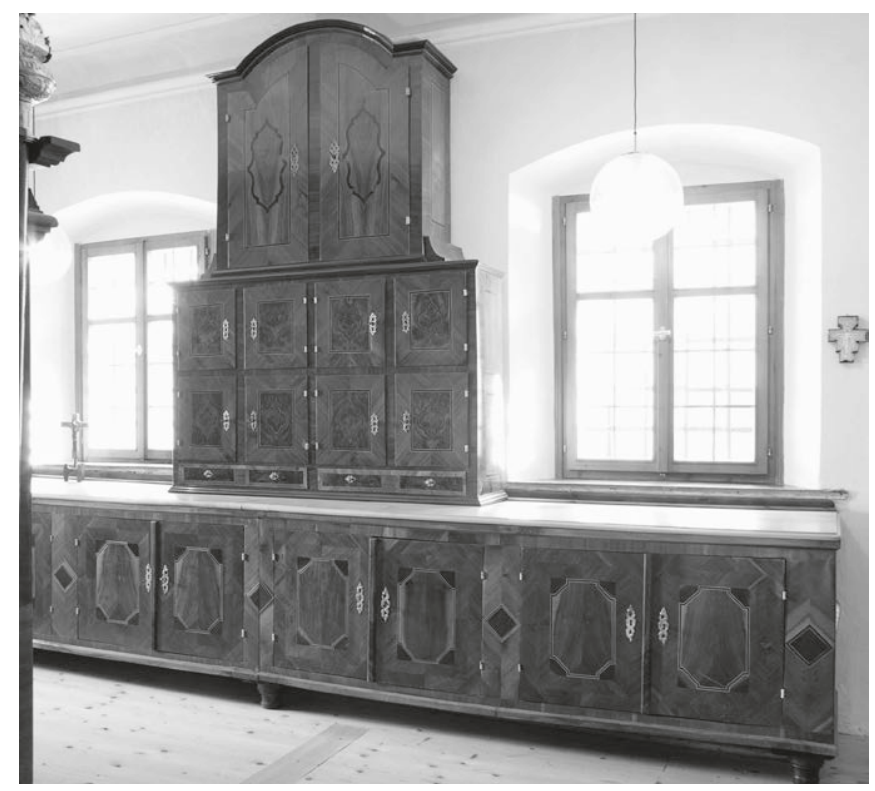

geführt wurde er von Anton Gigl II. ( I 70o-r 769) aus Innsbruck. Um I 768 bereicherte Christoph Anton Mayr aus Schwaz den Innenraum mit Deckenfresken.

\section{Sakristei}

Von den beiden nördlich des Langhauses situierten Sakristeiräumen ist nur der westliche mit einer an dieser Stelle interessierenden Einrichtung ausgestattet.

\section{Schrank vor der Fensterwand}

Brixlegg, um I $730 / 40$

$\mathrm{H}$ der Füße $\mathrm{r} 6 \mathrm{~cm}$

$\mathrm{H}_{32} 8 \mathrm{~cm}(+\mathrm{I} 6 \mathrm{~cm}) \times \mathrm{L} 495 \mathrm{~cm} \times \mathrm{T} 75 \mathrm{~cm}$

Nuss, Nussmaser, Ahorn, Mahagoni, Eibe, Holz, geschwärzt. Eisen, verzinnt

An breiten Stollen befestigte Türen verschließen den Unterschrank, den eine schmale Sockelleiste und ein ebenso schmales Gesims in der Horizontalen begrenzen (Abb. 29I). Er trägt einen zweigeschossigen Aufsatz mit Schubladen, Kelchkästen und hohen Kompartimenten, die ein Segmentgiebel überfängt.

Das Inventarstück ist furniert, Nussbaummaser und eingelegte Adern bestimmen das Erscheinungsbild der Füllungen. Unten formen die Adern ein Achteck, oben sind 
sie kantenparallel geführt, zusätzlich fassen dort breite Bänder ein gedrücktes Oval mit geschweiften Seiten und spitzen Enden ein. Das Furnier wurde teils diagonal, teils mit einem Fischgratmuster auf die Türrahmen aufgelegt. Auf der Spitze stehende Quadrate betonen die senkrechten Stollen der Substruktion. Die Füße und die Platte sind modern.

\section{Paramentenschrank}

Brixlegg, um I730/40

HS ca. $\mathrm{I} 2 \mathrm{~cm}$

$\mathrm{H} 332 \mathrm{~cm}(+\mathrm{I} 2 \mathrm{~cm}) \times \mathrm{L}_{48} 8 \mathrm{~cm} \times \mathrm{T} 69,5 \mathrm{~cm}$

Nuss, Nussmaser, Zwetschke, Ahorn, Pappelmaser (?), Holz gebeizt und geschwärzt, Nadelholz. Eisen verzinnt

Der mächtige Paramenten- oder Schatzkammerschrank vor der Südwand der Sakristei besteht aus zwei aufeinandergestellten sechstürigen Kästen (Abb. 292). Das Möbel ruht auf einem mäßig hohen Sockel, der in seiner jetzigen Gestalt nicht original zu sein scheint; Form und Furnierbild sprechen dagegen. In mittlerer Höhe verläuft ein schmales Gesims, ein schwereres bildet den oberen Abschluss. Die flächig gearbeiteten Schranktüren setzen sich aus Rahmen und hochrechteckigen, von einem breiten Fries gesäumten Füllungen zusammen. Die zentralen Felder sind mit Maserholz dekoriert und mit Adern bereichert. Einige Türen hat man zur Belüftung des Schrankinhaltes mit Öffnungen versehen, die verzinnte Metallplatten verschließen. Verzinnt wurden überdies die Schlossbeschläge und Türangeln. Gewellte Halterungen an der Möbelfassade dienen zum Aufhängen von Paramenten.

\section{Kirchenraum}

\section{Beichtstüble}

Die zweiachsigen Beichtstühle wurden massiv restauriert, falls sie nicht weitgehende Reproduktionen der originalen Möbel sind (Abb. 294). Auf den Sockeln des Aufsatzes standen einst Büsten von Franz Xaver Nissl (I73 I-I804). ${ }^{460}$ Sie werden momen$\tan (2020)$ in einem Depotraum aufbewahrt. ${ }^{461}$ Bis auf die unterschiedliche Anzahl der Gehäuse entsprechen die Beichtstühle in formaler Hinsicht weitgehend jenen der Innsbrucker Jesuitenkirche aus der Zeit um I630 (Abb. 302).

460 ÖKM, Tiroler Unterland (197r), 89.

46I Freundliche Mitteilung des früheren Pfarrkirchenobmanns und der Pfarrsekretärin. 
292 Paramentenschrank. Brixlegg, um I $730 / 40$

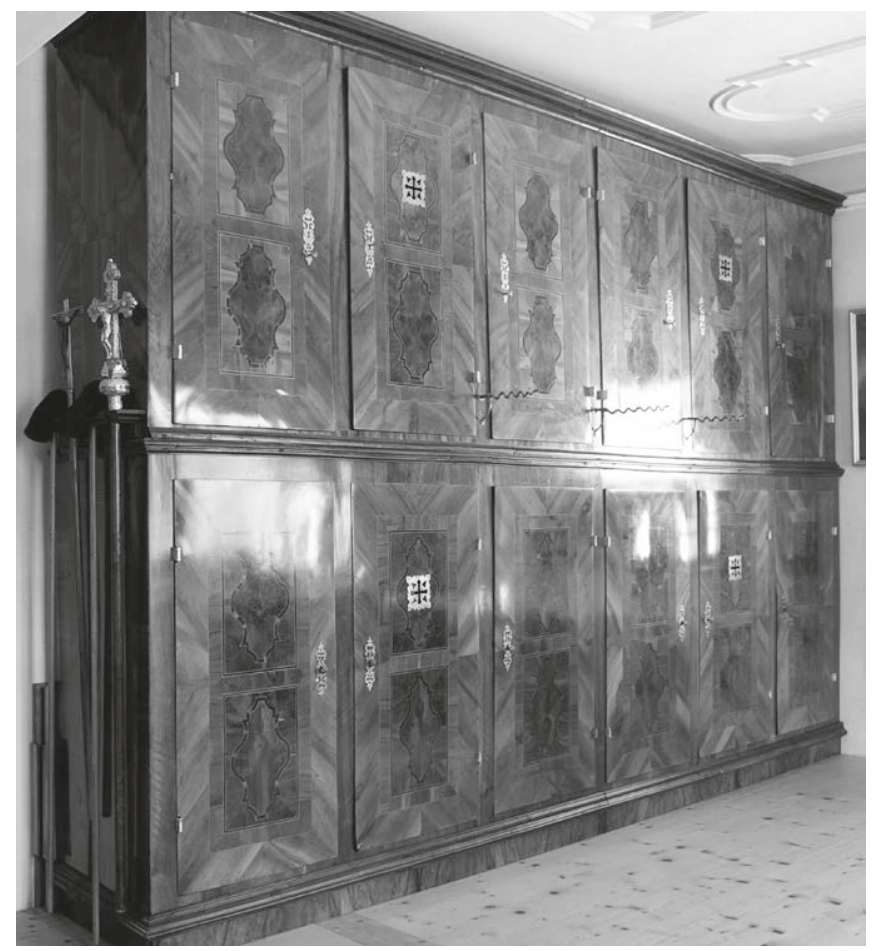

\section{Laiengestühl}

Brixlegg/Kundl, um I650/60

Leistenhöhe $3 \mathrm{~cm}$

$\mathrm{H}$ I06 $\mathrm{cm}(+3 \mathrm{~cm}) \times \mathrm{L}$ I 8 I cm $/ 335 \mathrm{~cm}$

Nuss und Eiche, massiv, Nadelholz. Eisen

Die Ausstattung der Kirche mit Sitzmöbeln geht auf zwei unterschiedliche Epochen zurück. ${ }^{462}$ Eine aus acht Bänken und zwei Brüstungen bestehende Garnitur befindet sich im vorderen Bereich des Sakralraums (Abb. 293). Die Möbel stehen nicht auf Podesten, sondern auf Leisten, das war einstmals vermutlich anders. Aus dem I 7. Jahrhundert stammen lediglich die Docken zur Mittelachse der Kirche hin, alles andere wurde in jüngerer Zeit erneuert. Die beiden Vorderbrüstungen befinden sich neben Seitenaltären, aus Platzgründen sind sie kürzer als die Bankreihen.

Ausgefallene Schnitzarbeiten zieren die dynamisch gestalteten Docken, die Motivwahl teilt sie etwas oberhalb der Sitzbank. Den unteren Bereich füllt ein Wirbel,

462 Neuhardt, Brixlegg ( 1978 ), 8; Dehio, Tirol (I 980), 2 I 3. 


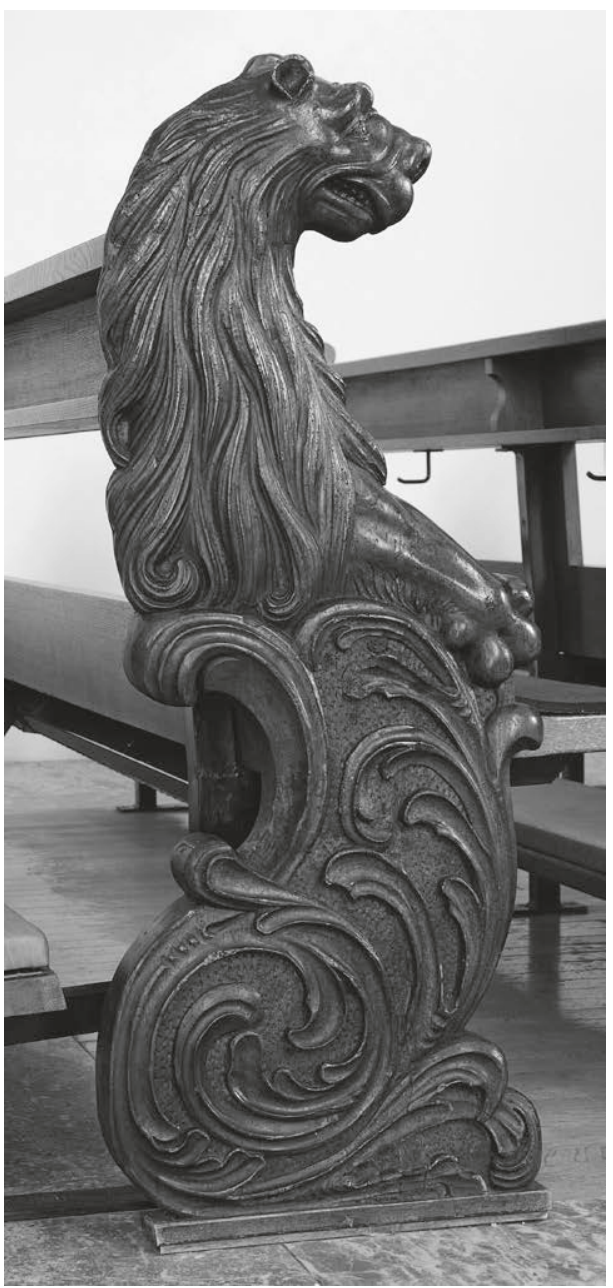

293 Bankwange. Brixlegg/Kundl, um I $650 / 60$

von dem stilisiertes Laubwerk ausgeht. Die größtenteils mit dem Hohleisen ausgeführten Formen gemahnen an früh- oder hochbarocke Ornamentmuster, Akanthus kommt nicht vor. Zwischen den Zierelementen eingeschlagene Punzen mattieren den Grund und lassen die Bögen mit ihrer glatten Oberfläche optisch stärker in Erscheinung treten. Die Darstellung eines steigenden Löwen nimmt die obere Dockenhälfte ein. Sein Kopf ist detailreich gearbeitet, die dichte Mähne des Tieres fällt in langen, gewellten Strähnen nach unten, eine Pranke legt sich schwer über den unteren Wangenteil. Die Docken bestehen aus massivem Nussholz, ansonsten wurden die (neuen) Bänke aus Eichenholz gefertigt. Die Literatur datiert die Wangen auf das Ende des I7. Jahrhunderts ${ }^{463}$, das ist korrekturbedürftig. Der auf frühbarocke Motive beschränkte Zierrat lässt auf eine Entstehung der Wangen um die Mitte des I7. Jahrhunderts oder bald danach schließen, vier Jahrzehnte später wäre veritables Akanthusblattwerk zu erwarten.

Nahezu identische Möbel werden in der Kirche St. Leonhard zu Kundl aufbewahrt, das nur wenige Kilometer von Brixlegg entfernt liegt (Abb. 337). Die Möbel dürften in ein und demselben Bildhaueratelier gefertigt worden sein, in der österreichischen Kunstlandschaft tritt das Löwenmotiv an den Stuhlwangen in Brixlegg und Kundl singulär auf. Johannes Neuhardt vermutet, es sei als Hinweis auf den Propheten Daniel zu verstehen, der zusammen mit dem hl. Leonhard als Schutzpatron der Bergleute gilt. ${ }^{464}$ Hier im Kontext besitzt dieser Hinweis insofern Relevanz, als das Hüttenwesen in der vorbürgerlichen Epoche eine der Haupteinnahmequellen Tirols darstellte, eingangs wurde bereits darauf hingewiesen. Damit waren

463 ÖKM, Tiroler Unterland (r 97r), 89; Dehio, ebd.

464 Neuhardt, Brixlegg ( 1978 ), 8; ders., Kundl (2005), I 2. 


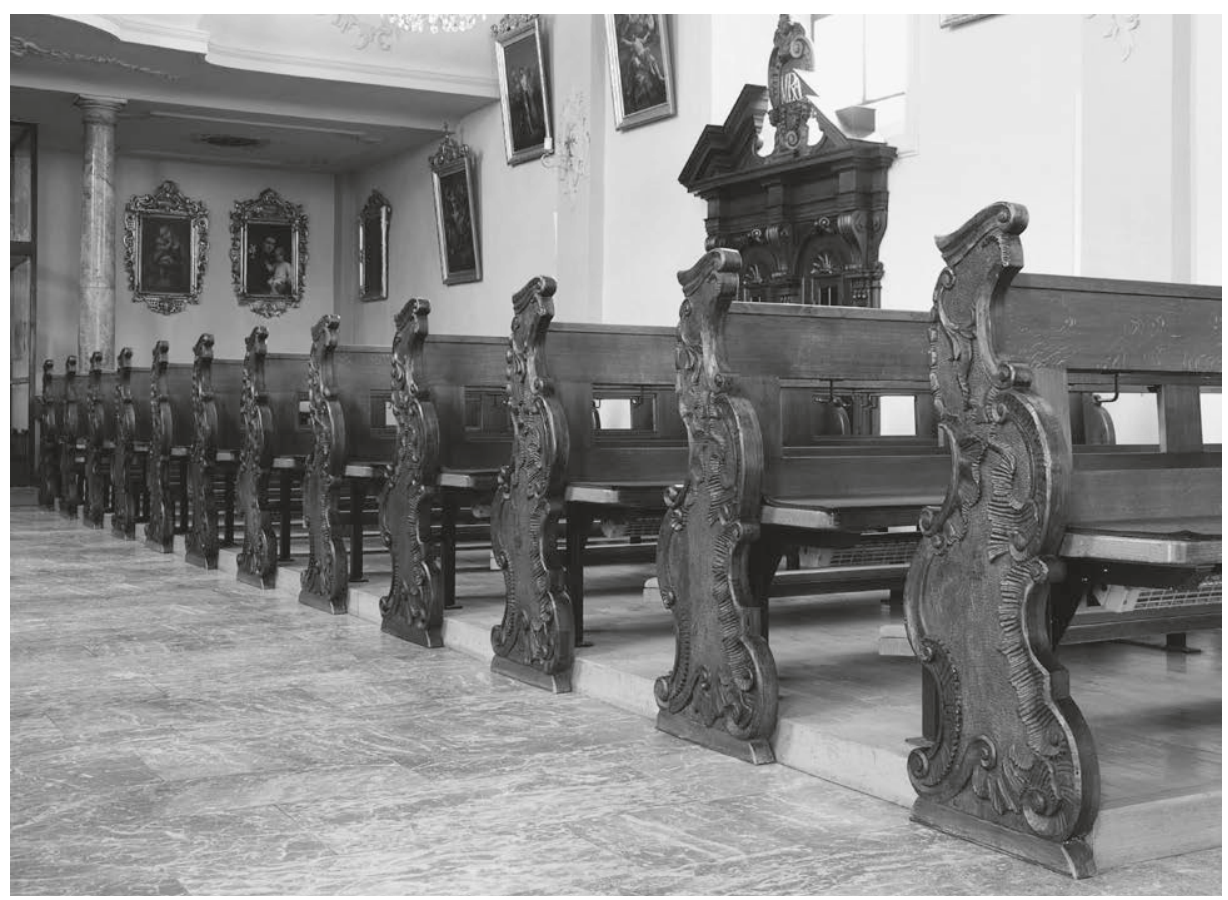

294 Kirchenraum, Laiengestühl. Bankwangen, Brixlegg, um I760/70

die finanziellen Ressourcen vorhanden, die zur Ausführung der Arbeiten durch einen renommierten Bildschnitzer benötigt wurden.

\section{Laiengestübl}

Brixlegg, um I760/70

Leistenhöhe $5 \mathrm{~cm}$

H I I $2 \mathrm{~cm}(+5 \mathrm{~cm}) \times \mathrm{L} 335 \mathrm{~cm}$

Nuss und Eiche, massiv. Eisen

Die zweite Gruppe von Kirchenbänken umfasst 24 Sitzreihen (Abb. 294, 295). ${ }^{465}$ Wieder gehen nur die zur Raummitte weisenden Docken auf das I 8. Jahrhundert zurück, der Rest ist modern.

Auch für diese Wangen wählten die Tischler eine geschwungene Umrissform, nun jedoch mit engen Bögen, die sich glatt, quergeriffelt und mit Rocaillen verziert vom

465 Dehio, Tirol (I 980), 2 1 3. 


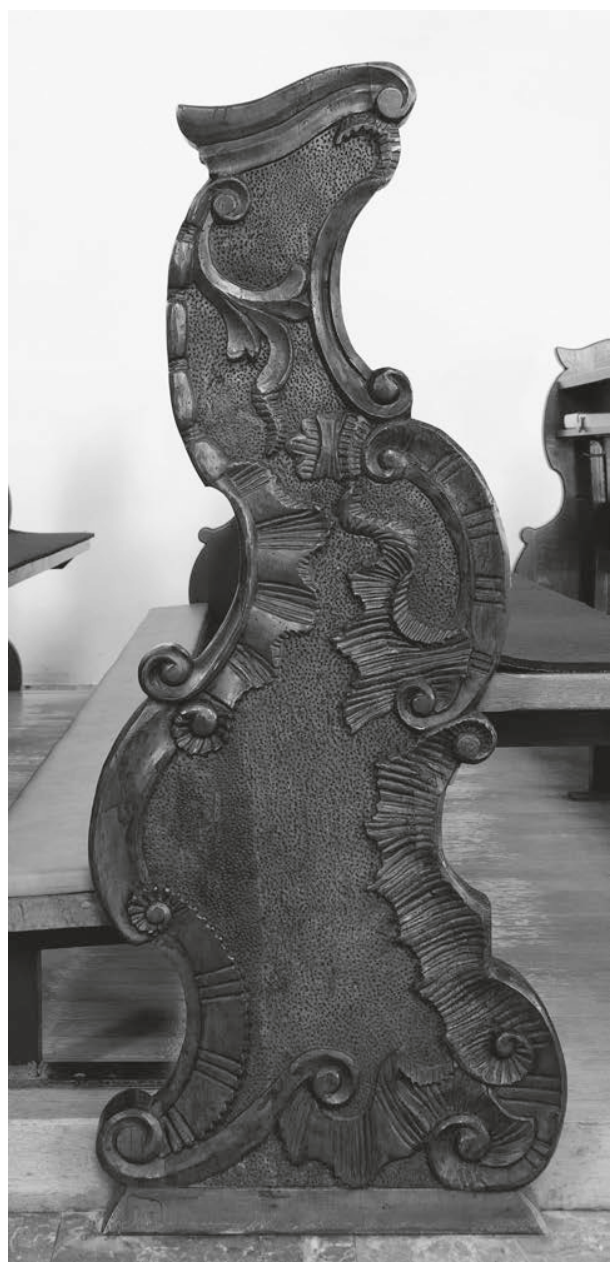

295 Bankwange. Brixlegg, um I 760/70

Sockel bis zum oberen Wangenabschluss hinziehen. Ein kurzer Blattzweig legt sich über das Binnenfeld, teilweise greifen auch die Muschelornamente nach innen, ansonsten sind die zentralen Flächen der Wangen weitgehend freibelassen. Nur die Punzen, die den Grund zwischen den Kantenverzierungen auflösen, sorgen für eine gewisse optische Unruhe und Spannung. Der Schnitzdekor ähnelt der Form und dem Duktus der Stuckarbeiten des Kirchengewölbes aus den späten I760erJahren.

Innsbruck, Hofkirche Zum hl. KreuZ

Die nach Süden weisende Hofkirche grenzt unmittelbar an die Hofburg und das Kloster der Franziskaner, die die Kirche betreuen. ${ }^{466}$ Errichtet wurde sie zwischen 1553 und ${ }_{15} 63$ zur Aufstellung des Grabmals Maximilians I., einem kostbaren Schrein für die sterblichen Überreste des I5I9 verstorbenen Monarchen. ${ }^{467}$ Auftraggeber war Kaiser Ferdinand I. (1503-1 564), die Bauleitung hatten zunächst Andrea Crivelli (um I470-nach 1554) und Niclas Türing d.J. († I 558), nach dessen Tod der Steinmetzmeister Marx della Bolla, von dem wir wissen, dass er Modelle des Sakralbaus anfertigte. Bei der Architektur handelt es sich um eine dreischiffige Hallenkirche nach dem Vorbild der Heiligkreuzkirche in Augsburg bzw. der Franziskanerkirche in Schwaz, die beide in den Jahrzehnten um die Wende vom 15. zum i6. Jahrhundert errichtet wurden. Der Haupteingang

466 Hootz, Kunstdenkmäler (1 965-1 968), Bd. I ( 1 965), 68-72, 3 1 7-3 1 8; Egg, Hofkirche (1 974); Dehio, Tirol (I980), го-I7; Caramelle/Frischauf, Stifte (1985), roo-I04; Felmayer, Hofkirche (I 986), bes. 237-278.

467 Dessen Leichnam wurde allerdings in Wiener Neustadt beigesetzt und nie nach Innsbruck überführt. 


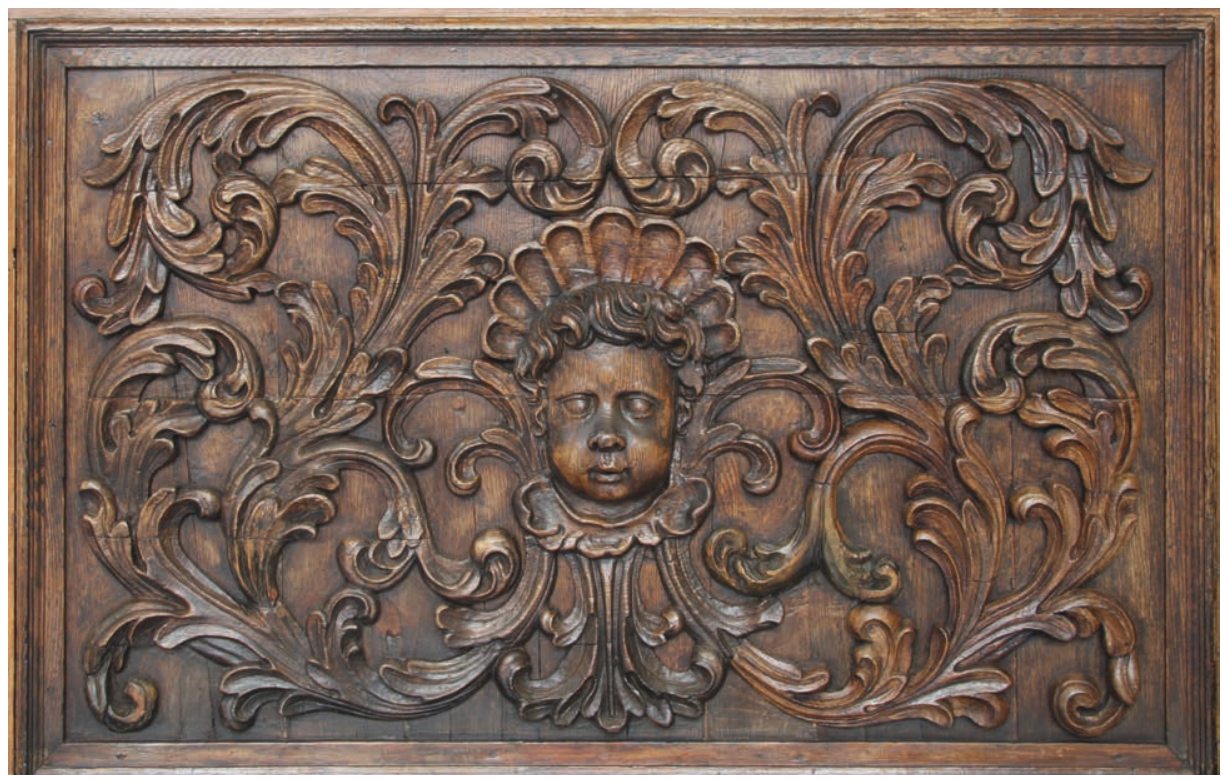

Farbtafel 29 Laiengestühl, Brüstung (Detail). Paul Hueber, um r686/87

der Hofkirche befindet sich im Norden, ein Seiteneingang auf der Evangelienseite öffnet sich zum Kreuzgang hin. Während der Raum unter der Empore noch mit dem ursprünglichen Rippennetzgewölbe versehen ist, wurde das Hauptgewölbe 1691/92 von Johann Martin nach Erdbebenschäden barockisiert, Stuckarbeiten im ausgehenden Knorpel- und frühen Akanthusstil zieren das Gewölbe. Für die Entwürfe war der Hofgoldschmied Johann (?) »Senex« Fries verantwortlich. Die Renovatio der Kirche hatte Leopold I. (I640-I 705) veranlasst.

Bekannt ist der Sakralbau vor allem wegen des (unvollendeten) Maximiliangrabmals, wegen der überlebensgroßen Bronzefiguren, die Angehörige der Habsburger vergegenwärtigen und seitlich des Grabmals Spalier stehen, sowie wegen des sogenannten Fürstenchors, einer mit großem Aufwand gebauten Empore im Chorraum der Kirche. Zusammen mit dem Chorgestühl darunter gilt sie als eines der Hauptwerke renaissancezeitlicher Tischlerarbeiten in Österreich. Hinsichtlich ihrer Qualität ist die barocke Tischlerausstattung diesen hochkarätigen kunsthandwerklichen Arbeiten durchaus ebenbürtig. 


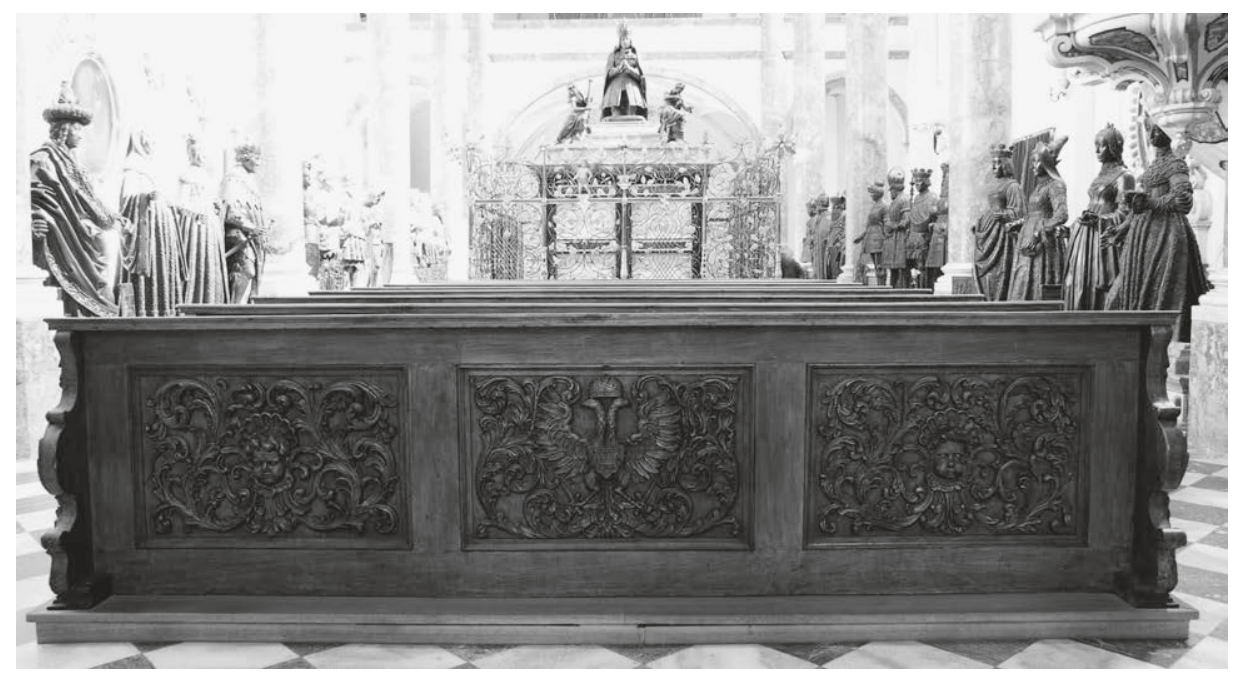

296 Brüstung des Laiengestühls (Typ A). Hoftischler Paul Hueber, um r686/87

\section{Bänke (Typ A)}

Hoftischler Paul Hueber, um r686/87

HS I I, $5 \mathrm{~cm}$

$\mathrm{H}_{98,5} \mathrm{~cm}(+\mathrm{I} \mathrm{I}, 5 \mathrm{~cm}) \times \mathrm{L}_{400 \mathrm{~cm}}$

Eiche, Nadelholz

Acht Bänke und die zugehörige Brüstung stehen im Mittelschiff zwischen dem Prunkgrabmal und dem Chorraum, in dem zwei weitere Bänke dieses Typs aufbewahrt werden (Farbtaf. 29; Abb. 296-299). ${ }^{468}$ Ein moderner Grundriss der Hofkirche zeigt die Anordnung der Sitzreihen. ${ }^{469}$

Rahmen unterteilen die vordere und hintere Brustwand in drei Achsen mit großen querrechteckigen Füllungen. Auf eine architektonische Strukturierung wurde verzichtet, doch zieren qualitätvolle Schnitzarbeiten die Binnenfelder, die Akanthusranken überwuchern. Im mittleren Feld säumen sie einen bekrönten Doppeladler mit Bindenschild und einem eingeschriebenen L, dem Monogramm Kaiser Leopolds I., seitlich umspielen sie je einen Cherub mit stilisiertem Federdiadem.

Die symmetrisch angelegten Wangen erinnern an die Form einer Violine. Sie bestehen aus zwei Querovalen, die eine akzentuierte Taille voneinander scheidet, und

468 Egg, Hofkirche (1974), 82; Dehio, Tirol (I 980), I7; Felmayer, Hofkirche (r 986), 245, 294-295, 298. 469 Felmayer, ebd., 264. 


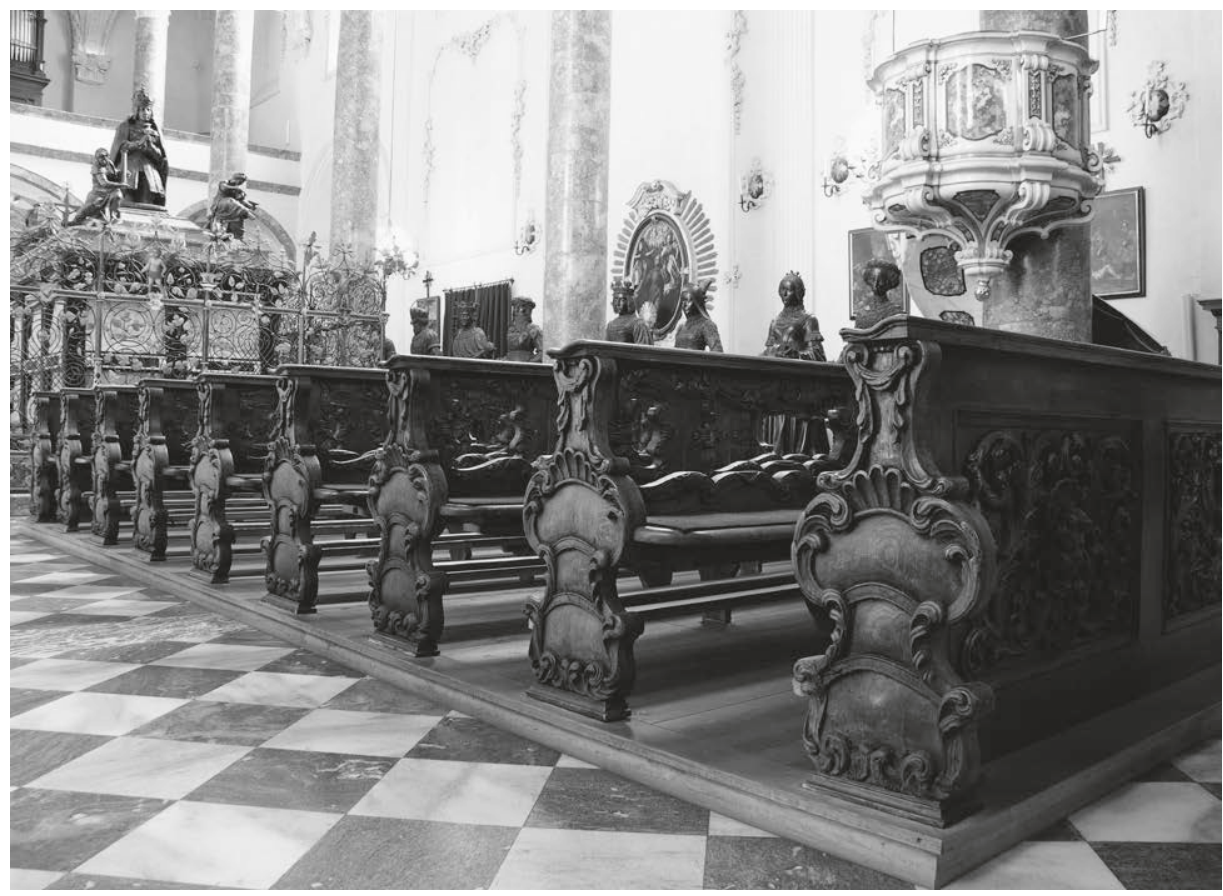

297 Laiengestühl. Paul Hueber, um I686/87

298 Laiengestühl, Bankwange. Paul Hueber, um I686/87

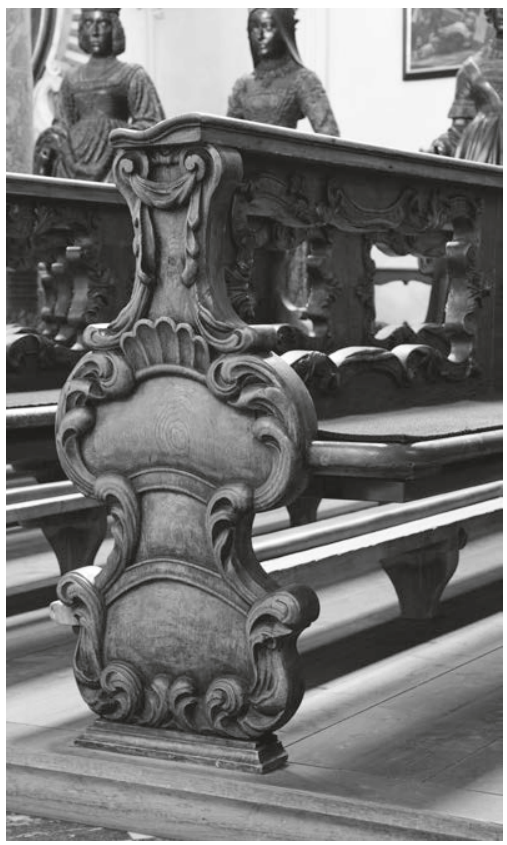




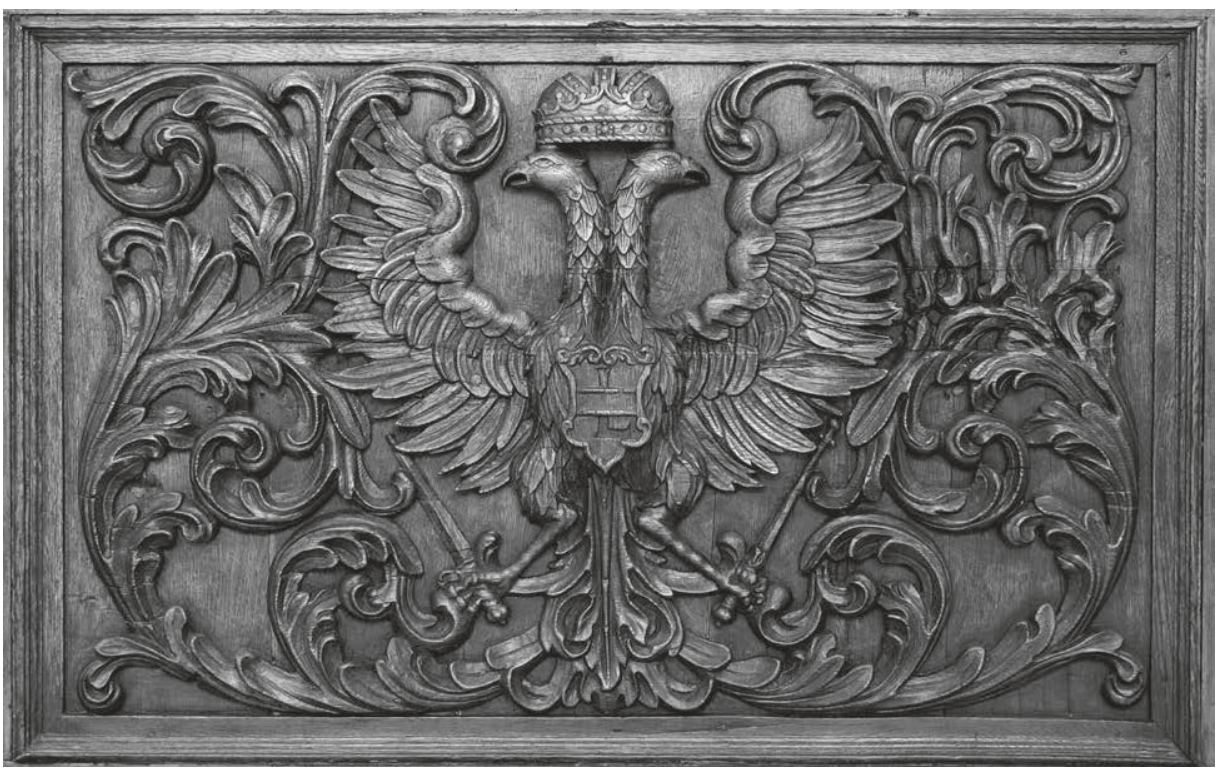

299 Laiengestühl. Detail der Brüstung mit bekröntem Doppeladler, Bindenschild und dem Monogramm Kaiser Leopolds I. Paul Hueber, um I686/87

einem hohen eingezogenen Hals, dessen seitliche Kanten in Voluten auslaufen und so ein stilisiertes ionisches Kapitell nachbilden. Von den Voluten hängt eine Stoffgirlande herab. Kräftiges Akanthusblattwerk begleitet die Wangenkonturen, die zwei Querbänder und am Halsansatz ein fächerförmiges, an das Federdiadem der Cherubim erinnerndes Ornament verbinden. Die im Querschnitt S-förmige Gebetbuchablage liegt auf der Wangenoberkante auf. Im Gegensatz zu den beiden Brustwänden zeichnen sich die Banklehnen durch geschweifte Rahmen ohne Füllungen aus, Schnitzarbeiten folgen dem Schwung der Öffnungen.

Paul Hueber fertigte Wangen und Gebetbuchablagen aus Eiche, die er abschnittsweise mit Nadelholz unterfütterte. Die zum Teil modernen Sitz- und Kniebänke, die Rückenlehnen und Rahmen der Brustwände bestehen aus nussfarben gebeiztem Nadelholz, die Füllungen ebenfalls aus Eiche. ${ }^{470}$

Die Herstellung der Bänke ist archivalisch belegt. Am 28. September I686 berichtet das hofcammerzahlmaisterambt, der Hoftischler habe eine Abschlagszahlung von

470 Diese Möbel und die in den Seitenschiffen (Typ B) wurden 2006 restauriert. Die Konstruktion der Kniebänke wurde dabei geändert, um sie nach oben klappen zu können. Freundliche Auskunft von Peter Kopp, dem Restaurator der Möbelgarnituren. 
$75 \mathrm{fl}$ erhalten. Das Schreiben ließ man dem allbiesigen hofpauschreiberambt zum wissen, und khonffigen beobachten [zukommen]: auch damit obbemelte arbeith angedingtermassen schleinig verfertiget werde ibn anzubalten hiemit angefiegt wirdt. ${ }^{471}$ Die Bänke Huebers ersetzten die alte Bestuhlung der Hofkirche. Vermutlich ähnelte sie den Garnituren in Neuberg und Mariahof (Farbtaf. 23; Abb. 203, 204, 209).

\section{Bänke (Typ B)}

Innsbruck, um I $705 /$ I 5

HS I 3,5

$\mathrm{H} 95,5 \mathrm{~cm}(+\mathrm{I} 3,5 \mathrm{~cm}) \times \mathrm{L} \mathrm{I} 75,5 \mathrm{~cm}$

Nussholz, massiv und geschnitzt, Pappelmaser,

Nadelholz

Die 18 Bänke stehen in den Seitenschiffen der Kirche auf vier Postamenten (Abb. 300). Vorn sind es jeweils sieben Möbel ohne Brüstung, hinten zwei Bänke mit Brustwänden. Ursprünglich befanden sich die Möbel im hinteren Bereich des Bauwerks zwischen dem Emporenjoch und dem Mausoleum. ${ }^{472}$ I955

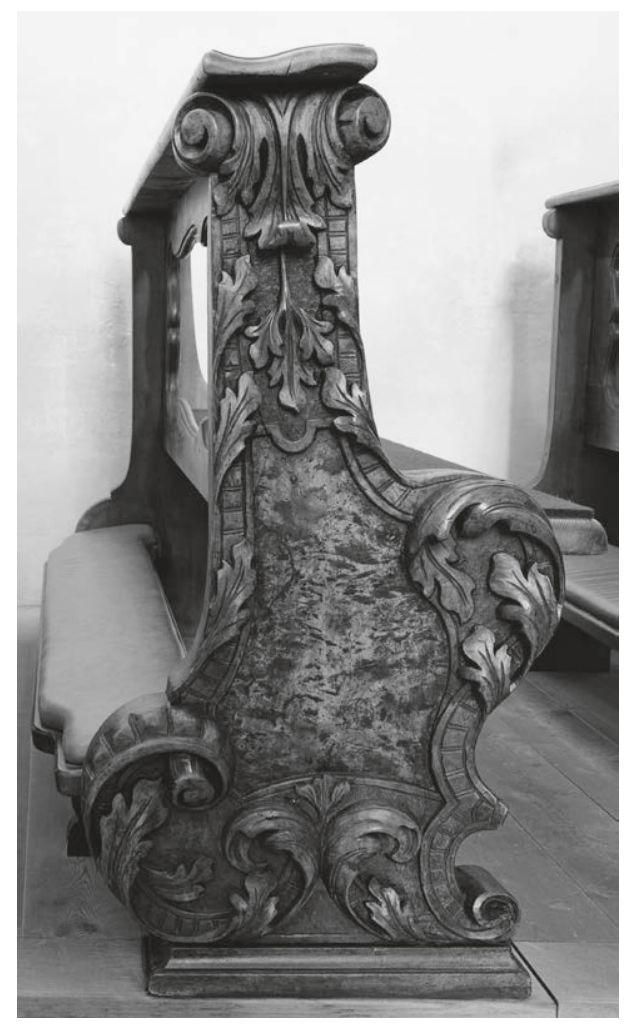

300 Laiengestühl, Bankwange (Typ B).

Innsbruck, um I705/I5 baute man sie um und transferierte sie in die Seitenschiffe.

Das Möbelensemble gehört dem frühen I8. Jahrhundert an. Vorder- und Rückseiten der relativ schlanken und asymmetrisch gestalteten Wangen sind wie üblich nach außen gewölbt, um die Stirnseiten von Sitz- und Kniebänken aufzunehmen. Der schmale Hals führt weit nach oben und endet mit zwei kräftigen Voluten, die die Buchablage stützen. Quergeriffelte Bänder säumen die Wangenaußenkanten und rollen sich an den Enden ein, Akanthuslaub vervollständigt die Schnitzarbeiten. An der Auswölbung, in die die Kniebank eingegratet ist, zeigen sich rudimentäre Reste von Knorpelwerk.

Das Binnenfeld zwischen den Bändern und Voluten ist als Füllung interpretiert und mit Pappelmaser furniert, wie wir das sonst nur von großen Flächen an Kasten-

47 I TLA, LRA Kammer-Kopialbücher I686, Entbieten und Befehl, Bd. Ioo8, fol. I 92 v.

472 Felmayer, Hofkirche (I 986), 295. 


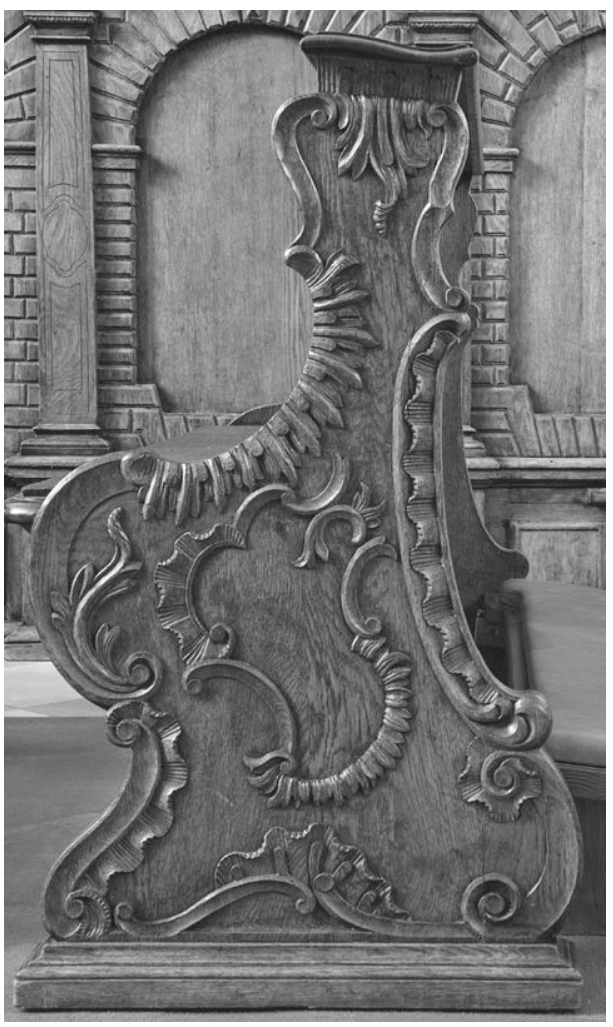

3 o Laiengestühl, Bankwange (Typ C). Innsbruck, um $1760 / 70$

möbeln her kennen. Heute fehlt das Maserfurnier an einigen Docken. Ansonsten bestehen die Wangen aus Nussholz, die Sitze und Rückenlehnen aus nussfarben gebeiztem $\mathrm{Na}-$ delholz. Letztere sind durchbrochen, Schnitzornamente aus Nuss fassen die Öffnungen jeweils an der ersten und letzten Bank sowie an den Brüstungen ein. Die Lehnen einiger Möbel erweisen sich bei genauer Betrachtung als Neuanfertigungen, an anderen Bänken hat man die originalen Lehnen zwar erhalten, aber umgebaut. Modern sind überdies die Kniebänke.

Bänke (Typ C)

Innsbruck, um I $760 / 70$

$\mathrm{H} 95 \mathrm{~cm} \times \mathrm{L} \mathrm{I} 42,5 \mathrm{~cm}$

Eiche, Nadelholz

Die I 2 Bänke befinden sich auf Höhe des oben erwähnten Renaissancegestühls vor dem Hauptaltar (Abb. 30I). ${ }^{473}$ Hinzu kommen die beiden Exemplare des Banktyps A, Brüstungen sind nicht vorhanden.

Im Prinzip entspricht die Großform der Wangen der bereits in Verbindung mit den Bänken des Typs B beschriebenen. Die Rückseite zieht sich ohne größere Brüche nach oben, vorn besitzen die Docken einen mäßig ausladenden Bauch, der zu einem schmalen Hals überleitet. Sich an den Enden einrollende Hohlkehlprofile folgen der Wangenkontur, Rocaillen und etwas Blattwerk zieren die Profile. Mit ähnlichen Schnitzornamenten dekorierten die Tischler das Binnenfeld. Die Möbel bestehen aus massivem Eichenholz, Lehnen und Bänke aus Nadelholz. Wie das im Tiroler Kunstraum immer wieder zu beobachten ist, charakterisieren die Lehnen auch hier große Öffnungen, denen nun jedoch keine Schnitzarbeiten, sondern schmale Profile folgen.

473 Felmayer, ebd., 289. 
Innsbruck, Jesuitenkirche zur hl. Dreifaltigkeit

\section{Jesuitenkommunität}

Die Gründung des Jesuitenkollegs in Innsbruck erfolgte I56r, als Sakralraum diente zunächst die gotische Salvatorkapelle. ${ }^{474}$ Etwa zehn Jahre danach entstand eine erste Dreifaltigkeitskirche, die sich schon bald als zu klein erwies. Zwischen I6 I 9 und I 622 ließ die Kommunität deshalb eine zweite Kirche errichten, aufgrund von Baumängeln stürzte sie wenig später ein. Der Neubau der heutigen Anlage ging im Wesentlichen in den Jahren zwischen 1627 und I 637 vonstatten. Der damals in Salzburg beschäftigte Santino Solari (I 576-I646) aus Verna bei Lugano sowie Elias Holl (I 573-I646) aus Augsburg bewerkstelligten die Grobplanungen, dagegen gehen Detailpläne auf den Maler Hans Schor († ז674) sowie auf den Hoftischler und Hofbaumeister Christoph Gumpp d.J. (г600-I672) zurück, die Bauleitung übernahm der Jesuitenpater Karl Fontaner (nachgew. I 56 I-I 636). ${ }^{475}$ Anfangs war Gumpp überdies für die Herstellung von Möbeln zuständig, doch gelangte I636 der Konverse Oswald Kaiser (ı6oo-ı686), ein gelernter Tischler, nach Innsbruck. Man überließ ihm im Kolleg eine Werkstatt, in der er zusammen mit mehreren Gesellen Sakralmobiliar erzeugte. ${ }^{476}$ Die Langhausmauern waren 1629 bereits bis zu den Emporen, teilweise sogar bis zum Dach gediehen, seit 1630 konnte die Kirche eingedeckt werden. 1636/37 stellte man die Arbeiten am Bauwerk aus finanziellen Gründen ein, ohne die Fassade fertiggestellt zu haben. Bis zur Weihe der nach Süden ausgerichteten Architektur, einer Kreuzkuppelkirche mit Seitenschiffen, verging ein weiteres Jahrzehnt. Das Mittelschiff ist zweijochig, entsprechend unterteilen Wandpfeiler die Seitenschiffe beidseitig in je zwei große Kapellen mit Emporen. Die Länge des Chors entspricht einer Travée, der Baukörper endet mit einer bogenförmigen Apsis. Über der Vierung erhebt sich ein achteckiger durchfensterter Tambour mit hoher Kuppel und Laterne. Süddeutsche Jesuitenkirchen, der Salzburger Dom, vor allem aber Il Gesù in Rom standen bei der Planung Pate. Nach schweren Kriegsschäden am I 5 . Dezember I 943, von denen besonders das Presbyterium, die Vierung und das Langhausgewölbe betroffen waren, erfolgte von

474 Hammer, Kunstgeschichte (1952), bes. I 8 I-г 87; Hootz, Kunstdenkmäler (1965-1 968), Bd. I (1965), 85, 320-32 I ; Jesuitenkirche [1 977]; Krapf, Gumpp (1 979), 61-70; Dehio, Tirol (1980), 43-45; Caramelle/Frischauf, Stifte (1 985), I33-1 37; Schneider-Prettner, Jesuitenkirche (1985); Schneider, Jesuitenkirche, I (I 995); dies., Jesuitenkirche, 2 (1995); Möller, Kirchen (2004), 25-29.

475 Gumpp wird seit I626 als Hoftischler bezeichnet, I633 wird er von Claudia de Medici (I604-I648) zum Hofbaumeister ernannt. Krapf, ebd., bes. 25.

476 Schneider-Prettner, Jesuitenkirche (1985), 102-103. Vgl zu Kaisers Vita außerdem Wartena, Süddeutsche Chorgestühle (2008), I 94. 
I 946 bis I953 die Wiederherstellung des Gebäudes. Weitere Renovierungsarbeiten wurden zwischen 2002 und 2004 durchgeführt. ${ }^{477}$

\section{Kirchenraum}

\section{Beichtstüble}

Hoftischler und Hofbaumeister Christoph Gumpp d.J., I 62 8/30

HS r $3,5 \mathrm{~cm}$

Gesamthöhe ca. $345 \mathrm{~cm}(+\mathrm{I} 3,5 \mathrm{~cm}) \times \mathrm{B} 308,5 \mathrm{~cm}$

Eiche, Rüster (?) und Nadelholz, dunkelbraun gebeizt. Messing, Eisen, Glas

I64I wurden die Beichtstühle in die Außenwände von Seitenkapellen und Fassade eingepasst, seit 1628 geleistete Zahlungen belegen jedoch, dass Christoph Gumpps Tischlerei die Möbel bereits über ein Jahrzehnt zuvor gebaut hatte (Abb. 302). ${ }^{478}$ Die Fronten der Beichtstühle zitieren das Aussehen architektonisch gestalteter Portale. Hohe Pilaster mit Blockkapitellen und Volutenkonsolen flankieren die Joche, in die arkadenförmige, mit verkröpften Füllungen und Muscheln verzierte Türen eingefügt sind. Über dem Gebälk folgt ein gesprengter Dreiecksgiebel, dessen Mitte eine schlanke, mit Cherubim und knorpeligen Schnitzarbeiten dekorierte Kartusche einnimmt. Die Möbel unter der Empore sowie jene der Epistelseite tragen das Mariensymbol, die anderen das Monogramm Christi.

An dieser Stelle verdienen es vor allem drei Aspekte, genannt zu werden: Zunächst fällt die Reduzierung der Dekormotive auf, die dem Horror vacui, der das Erscheinungsbild der Gestühle im Chorraum und in den Kapellen (Abb. 306, 308, 309) charakterisiert, diametral entgegengesetzt ist. Die Confessionalen stehen offensichtlich noch in der Tradition renaissancezeitlicher Möbelgarnituren. Außerdem bemühte Gumpp bei der Herstellung der Beichtstühle einen für den Möbelbau der Zeit bemerkenswerten architektonischen Kunstgriff: Statt wie an den nachfolgend beschriebenen Gestühlen die Pilaster von hohen Postamenten aufsteigen zu lassen, setzen die Stützen an den Beichtstühlen direkt auf der Sockelplatte an. Um die nötige Fassadenhöhe zu erreichen, tragen sie Voluten, auf denen das Gebälk ruht. Diese Invention sowie die klassisch strengen Formen der Beichtstühle lassen an eine Rezeption nord- bzw. zentralitalienischer Möbel der Zeit denken. ${ }^{479}$ Und

477 Schneider-Prettner, ebd., 66-68; Möller, Kirchen (2004), 27-28.

478 Krapf, Gumpp (I 979), 42, 56. Zu den Möbeln vgl. Jesuitenkirche [1 977], 8; Dehio, Tirol (1980), 45; Schneider-Prettner, ebd., I02; Schneider, Jesuitenkirche, I (1 995), 280, 299. Die Literatur datiert die Entwicklung des dreiteiligen Beichtstuhls bisweilen auf das späte 17 . Jahrhundert. Das ist nicht richtig. 479 Colombo, L'arte (I98I), Abb. 58, 288, 290, mit einem 1536 gefertigten Portal in S. Sigismondo zu Cremona sowie mit seicentesken Anrichten aus dem Veneto und aus Bologna. 
302 Geichtstuhl. Christoph
Gumpp d.J., um I628/30

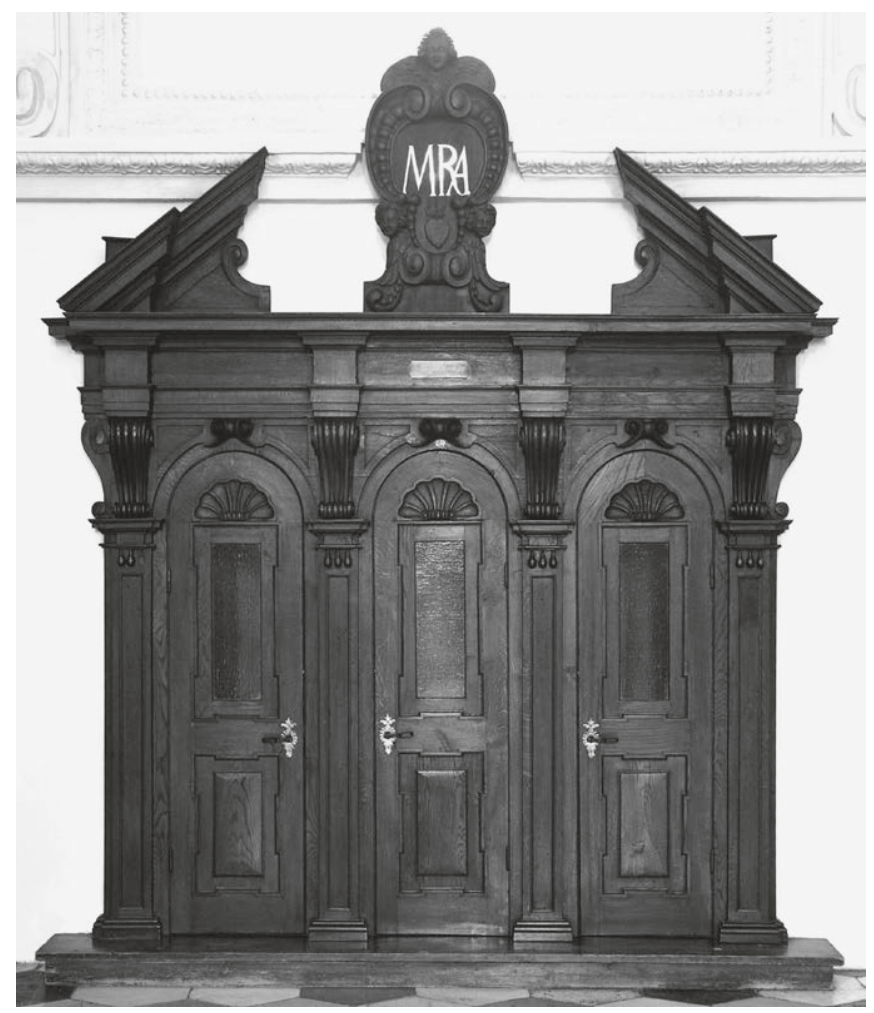

noch ein weiteres Faktum trägt zur Bedeutung der Beichtstühle bei: Sie zählen zu den ältesten, bislang bekannt gewordenen Exemplaren des fortschrittlichen Typs in Österreich mit einem allseitig geschlossenen Gehäuse. Als früheres Beispiel hierfür kann lediglich das r6 I 4 datierte Exemplar in Kundl (Abb. 332) angeführt werden. Ansonsten hat sich in der steiermärkischen Kirche St. Lorenzen ob Murau ein Möbel von I6o7 erhalten, das noch die althergebrachte Grundgestalt zeigt: Dem Priester steht dort ein schlichter Stuhl auf einem rundum offenen Podest zur Verfügung, der Pönitent kniete bei der Beichte neben dem Stuhl. ${ }^{480}$ Der moderne Typus wurde I 577 von Carlo Borromeo (I 538-I 584) vielleicht nicht entwickelt, aber doch bekannt gemacht und I 59I von Jacob Müller (I 550-I 597) in einer Zeichnung dargestellt. Müller gibt ein Exemplar mit zwei Kompartimenten wieder, das Aussehen des Beichtstuhls erinnert deutlich an den Korpus eines Kleiderschranks. ${ }^{481}$ Dagegen handelt es sich in der Jesuitenkirche um ein Möbel,

480 Bohr, Beichtstühle (2009), 2 I 3 und Abb. I.

48 I Borromeo, Instructiones fabricae (2000), Bd. I, Kap. 23, I08-I I 9; Müller, KirchenGeschmuck (I 59 I), I 59-I62; Bohr, Sakralmöbel (2017), 90-95. 
dessen Gestaltung an die von Tempelfassaden anknüpft. Vergleichbare Beichtstühle existieren in der Pfarrkirche Unsere Liebe Frau zu Brixlegg, in der Kirche St. Dominikus in Maria Thal bei Kramsach (Abb. 294, 3 I 8) und in der Innsbrucker Spitalskirche zum Heiligen Geist. ${ }^{482}$ Aus anderen Regionen Österreichs sind lediglich spätere Beispiele dieses Typs bekannt. Aus St. Florian etwa, die um r 700 entstandenen Möbel wurden im ersten Band der Untersuchung beschrieben, oder aus der ebenfalls in jener Periode errichteten Salzburger Kollegienkirche. ${ }^{483}$

\section{Laiengestühl}

Vermutlich Fr. Oswald Kaiser, um I640

HS i $8 \mathrm{~cm}$

H $106 \mathrm{~cm}(+\mathrm{I} 8 \mathrm{~cm}) \times \mathrm{L}_{542,5} \mathrm{~cm}$

Nuss, Ahorn (?), Nadelholz, dunkelbraun gebeizt

Leider musste nach I 945 ein Großteil der Bänke erneuert werden (Abb. 303-305). ${ }^{484}$ Die rekonstruierten Exemplare sind den alten perfekt nachempfunden, außerdem verfügt der gesamte Bestand über eine einheitliche Färbung und Oberfläche, sodass die auf einer makroskopischen Begutachtung beruhende Entscheidung, welche Exemplare der Barockzeit entstammen, in vielen Fällen sehr schwer fällt. Sicher können wir nur bei denjenigen Möbeln sein, die noch frühneuzeitliche Verarbeitungsspuren sowie altersgemäße Schäden und Gebrauchsspuren aufweisen.

Ein I6 I 9 gezeichneter Grundriss vom ersten Bau der Kirche zeigt beiderseits des Mitteldurchgangs vier Einheiten mit Sitzmöbeln. ${ }^{485}$ Dabei waren die Inventarstücke alternativ als gewöhnliche Bänke oder als Einzelstallen geplant. Bei der Ausführung des Entwurfs mit Einzelstallen wären auf jede Reihe sieben Sitzplätze gekommen, gute Vergleichsbeispiele für solche Möbel haben sich in Neuberg an der Mürz erhalten (Abb. 209). Die noch bestehenden originalen Bankreihen wurden I64I in der Jesuitenkirche aufgestellt. ${ }^{486}$ Einem Plan von I 78 I zufolge bildeten sie zwei Blöcke gleicher

482 Zum Möbel in der Spitalskirche, das im frühen r 8. Jahrhundert entstand, vgl. ÖKT, Innsbruck, I (1995), Abb. 33I.

483 Die Pläne zur Kollegienkirche gehen auf Johann Bernhard Fischer von Erlach (1656-1723) zurück. Vgl. dazu auch im vorliegenden Katalog die Beiträge zur Dreifaltigkeitskirche und zur St. Markuskirche in Salzburg mit Literaturhinweisen. Zu St. Florian vgl. Bohr, Sakralmöbel (2017), 59 I-594.

484 Schneider-Prettner, Jesuitenkirche (I 985), 66, 68, I03.

485 Schneider, Jesuitenkirche, I (1995), Abb. 249.

486 Jesuitenkirche [1977], 8; Dehio, Tirol (1980), 45; Schneider-Prettner, Jesuitenkirche (1985), 66, 68, I03; Schneider, ebd., 299-300; dies., Jesuitenkirche, 2 ( I 995), 55 O, Nr. 5 I, 55 I, Nr. 54. Im Dehio, ebd., werden die Bänke fälschlich um I648/49 datiert. 


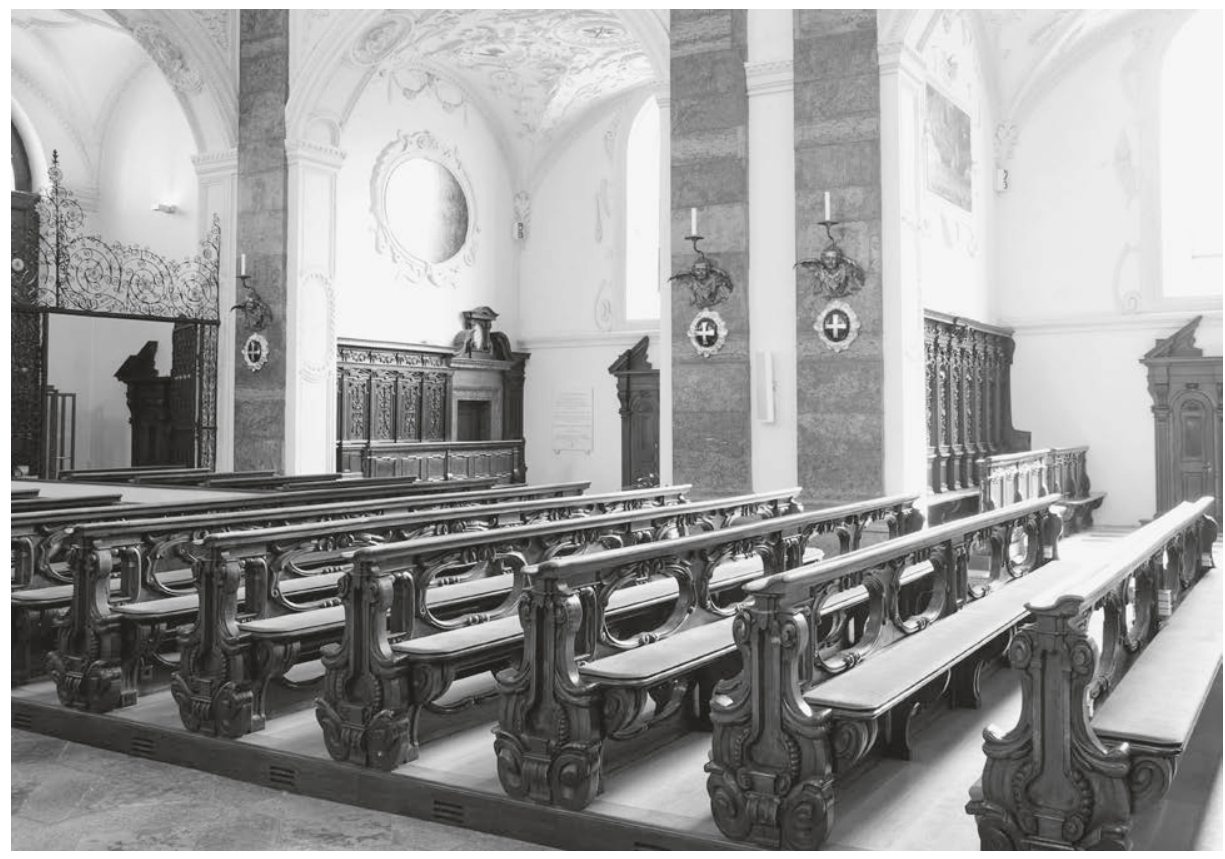

303 Laiengestühl. Verm. Fr. Oswald Kaiser, um I 640

Breite in der Mitte des Kirchenschiffs. ${ }^{487}$ Die gegenwärtige Verteilung der Bänke ist das Ergebnis einer Neugestaltung des Kircheninnenraums von 2004, als ein moderner Zugang zur Krypta angelegt wurde. Damals musste ein Teil der Möbel geändert werden. Man beließ die Länge der vorderen zwölf Reihen, während man die hinteren teilte, kürzte und seitlich des Abgangs zur Krypta platzierte. Außerdem wurden die Möbel zusammengerückt, um Platz für den Volksaltar zu schaffen.

Vermutlich baute die Stiftstischlerei unter der Leitung von Frater Oswald Kaiser die barocke Möbelgarnitur. Die Bankwangen besitzen die Gestalt von Vasen mit mäßig breitem Bauch und schlankem Hals. Eine Nische in Form eines langhalsigen, auf einer Volute ruhenden Kürbisses akzentuiert die Wangenmitte. Darüber folgt die Gebetbuchablage, deren Querschnitt einen gebrochenen S-Schwung beschreibt. Knorpelige Ornamente charakterisieren das Erscheinungsbild der Möbel. Den Bauch des Kürbisses rahmen sich erbsenartig verdickende Schnitzereien, massive Voluten und frühbarocke Bögen säumen die Wangen. Anders als sonst sind die Sitzbretter nicht in

487 Schneider, Jesuitenkirche, I (I 995), Abb. 250. 

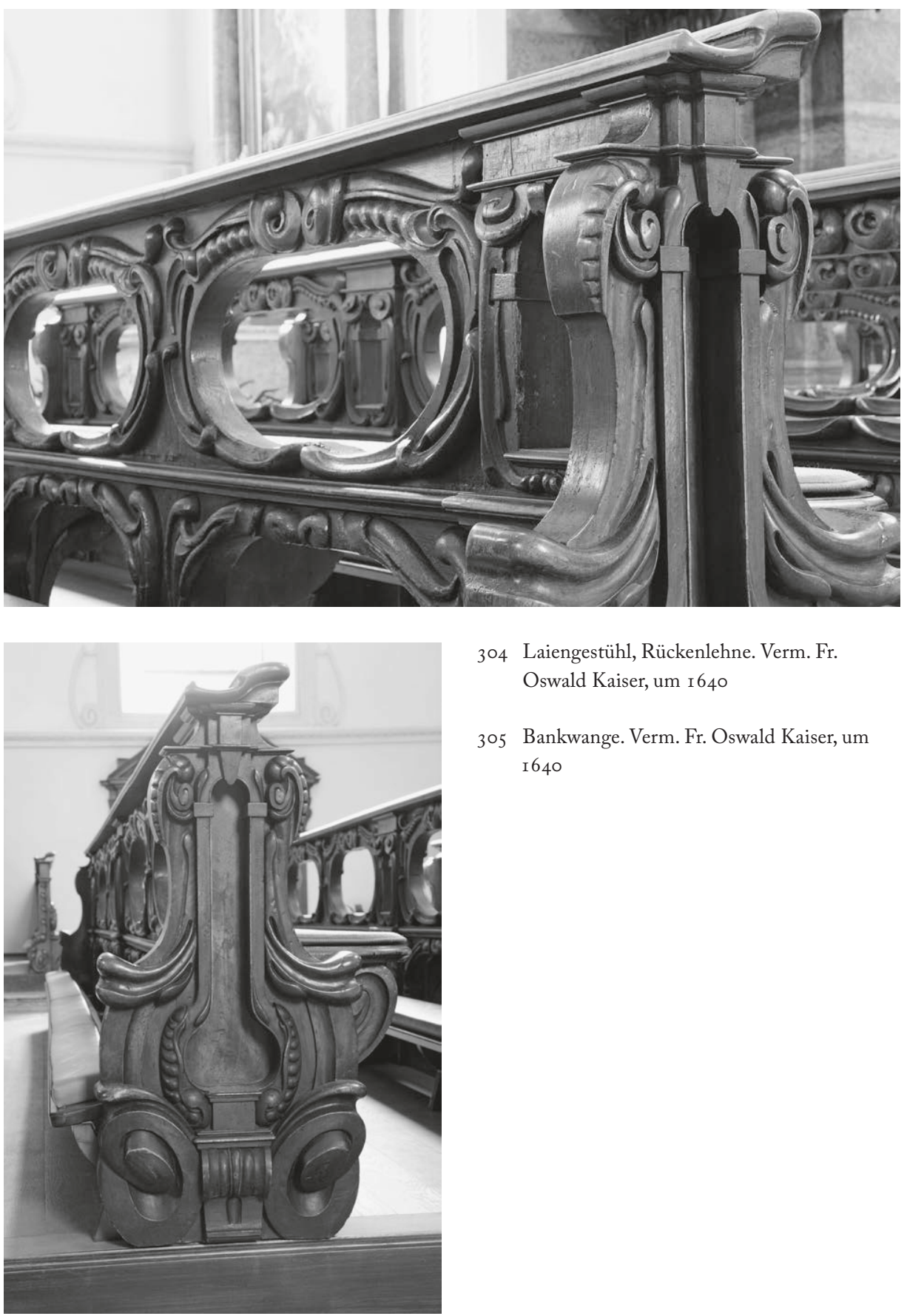

304 Laiengestühl, Rückenlehne. Verm. Fr. Oswald Kaiser, um I640

305 Bankwange. Verm. Fr. Oswald Kaiser, um I640 
die Docken eingegratet, sondern ruhen auf schweren Voluten, die hinter dem Wangenbauch aufsteigen.

Volutenpilaster teilen die mit Knorpelschnitzereien vervollständigten und geschlossenen Vorderbrüstungen in vier Achsen mit je zwei Füllungen. Dagegen besitzen die Bänke durchbrochene Rückenlehnen. Die Rahmen der Lehnen säumen oblonge sowie kleine arkadenähnliche Öffnungen, die auf der Vorder- und Rückseite von schweren knorpeligen Profilen eingefasst werden. Das Rückenbrett setzt sich unter den Sitzbänken fort, ist dort ebenfalls geöffnet und sogar hinter den Kniebänken mit Schnitzmotiven verziert. Die Qualität der Möbelgarnitur ist außergewöhnlich hoch, stilistisch steht sie um I640 auf der Höhe der Zeit. Ähnlich präsentieren sich die etwa zeitgleich entstandenen Wangen des Laiengestühls in der Innsbrucker Servitenkirche (Abb. 3I 7), die allerdings etwas dynamischer und fantasievoller gestaltet sind als die der Jesuitenkirche. Und nahezu identisch sind Kirchenbänke, mit denen erstaunlicherweise noch 1685 die Kreuzkapelle zu Mariastein bei Kufstein ausgestattet wurde. ${ }^{488}$

\section{Gestübl im Chorraum}

Vermutlich Fr. Oswald Kaiser, 1648

HS $22 \mathrm{~cm}$

$\mathrm{H} 294 \mathrm{~cm}(+22 \mathrm{~cm}) \times \mathrm{L} 525 \mathrm{~cm}$

Eiche, schwarzbraun gebeizt und lasiert

Das Gestühl nimmt im Chorjoch einen Platz zwischen zwei flachen Pilastern ein, gefertigt wurde es I 648 (Abb. 306, 307).$^{489} \mathrm{~W}$ ie Sybe Wartena erkannte, stand es ursprünglich in den Querhausarmen der Kirche und wurde nach dem Krieg transloziert, um das 1943 zerstörte Gestühl im Chorraum zu ersetzen. ${ }^{490}$ Tatsächlich zeigen Pläne von I6I9 und I78 I vor den Querschiffwänden Gestühle ${ }^{491}$, die dort heute nicht mehr vorhanden sind. Da der Altarraum gegenüber dem Chor um eine Stufe erhöht ist, musste der Sockel des Gestühls auf dieser Seite beschnitten werden. Kräftige Voluten, deren Vorderkanten mit Blattwerk und knorpeligen Verdickungen geschmückt sind, tragen Sitzbänke vor der Brustwand. Die Tischler setzten querrechteckige Füllungen unter den Bänken ein, darüber ohrengerahmte Ädikulen, die von amorphen Struktu-

488 Hörmann, Meister (2006), I 44, Abb. 39a. Die Entfernung zwischen Innsbruck und Mariastein beträgt etwa $75 \mathrm{~km}$.

489 Schneider-Prettner, Jesuitenkirche (1985), ro3; Schneider, Jesuitenkirche, I (1995), 298-299; dies., Jesuitenkirche, 2 (1995), 55 I, Nr. 54; Wartena, Süddeutsche Chorgestühle (2008), I 92, I 96-200.

490 Wartena, ebd., 192, 196.

49I Schneider, Jesuitenkirche, I (1995), Abb. 249, 250. 

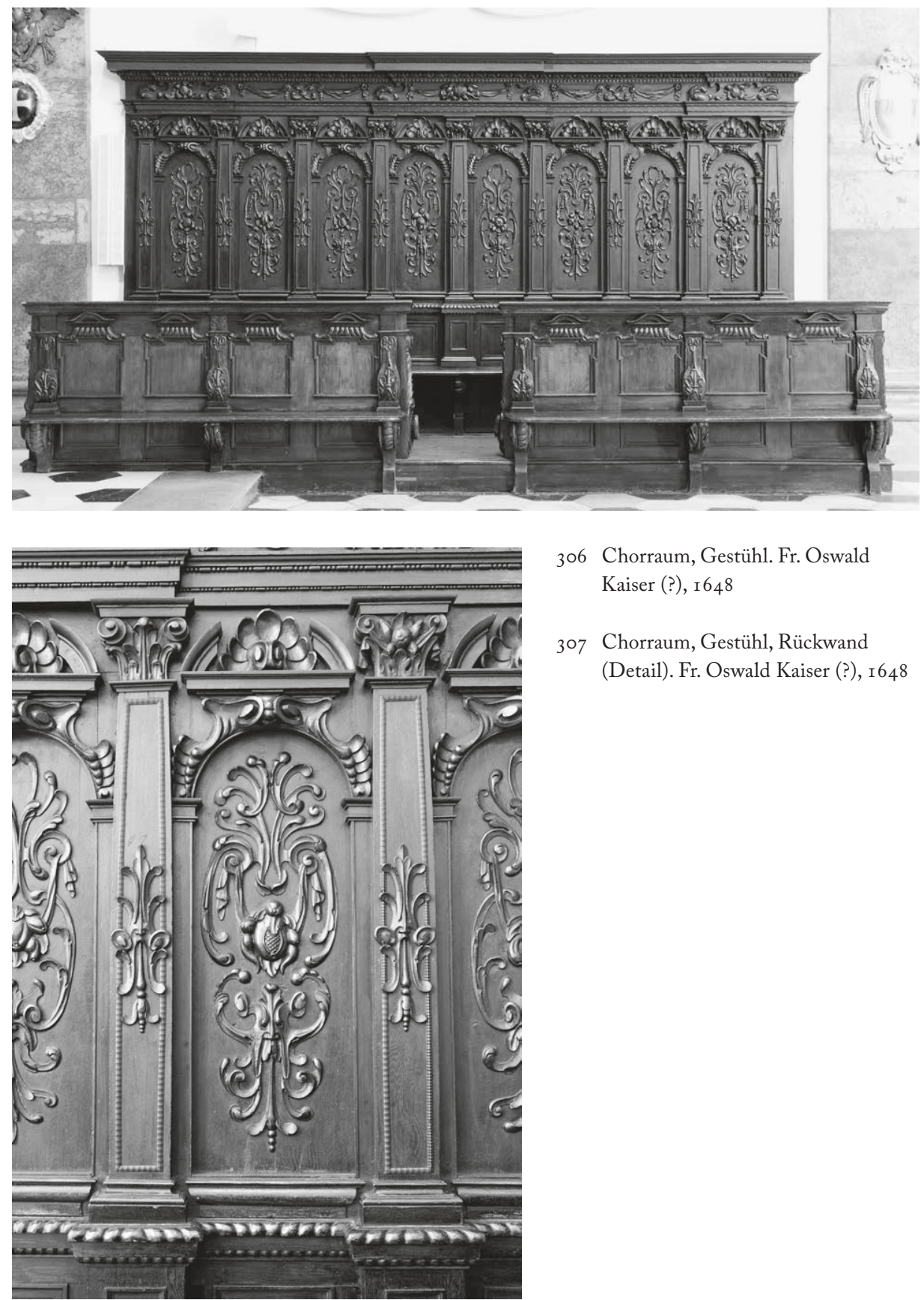

306 Chorraum, Gestühl. Fr. Oswald Kaiser (?), 1648

307 Chorraum, Gestühl, Rückwand (Detail). Fr. Oswald Kaiser (?), I648 
ren und Segmentgiebeln bekrönt werden. Vasenförmige Stützen nehmen dabei je zwei Binnenfelder in ihre Mitte.

Auch vor der Rückwand dient eine Bank als Sitzgelegenheit, auf Einzelstallen wurde verzichtet. Schlanke gekuppelte Pilaster rhythmisieren die architektonische Struktur des Dorsales. Das Gebälk tritt über den äußeren und beiden mittleren Achsen leicht nach vorn, wobei der Hauptakzent auf den mittleren Jochen liegt. Das Dorsale besitzt somit einen achsensymmetrischen Aufbau, wodurch es sich von Reihengestühlen mit ihrer Abfolge identischer Teilstücke unterscheidet (vgl. etwa Farbtaf. 30). Den Raum zwischen den Stützen füllen Arkaden, die knorpelige Schnitzereien und Segmentgiebel mit eingestellten Muscheln tragen. Fruchtfestons, frühbarocke Groteskmasken, Bögen und Schwünge, die durch ihre filigrane Struktur Schweifwerkmotive in Erinnerung rufen, vervollständigen die Arkaden. Ähnliche Formen kommen auf den Pilasterschäften vor. ${ }^{492}$ Perlreihen und Ochsenaugenfriese zieren den Architrav und das Gesims, Tuchfestons, Feldfrüchte und knorpelige Bögen den Gebälkfries. Neu sind an der Möbelgruppe zumindest die aus Nadelholz bestehenden Kniebänke und Laufböden.

\section{Gestüble in Seitenkapellen}

Vermutlich Fr. Oswald Kaiser, um I 648

HS I $7,5 \mathrm{~cm}$

Gesimshöhe $273 \mathrm{~cm} / 288 \mathrm{~cm}(+\mathrm{I} 7,5 \mathrm{~cm}) \times \mathrm{L} 602 \mathrm{~cm} / 637 \mathrm{~cm}$

Eiche, Nadelholz, dunkel gebeizt und lasiert

I648 erfolgte auch die Aufstellung der Gestühle in den vier Seitenkapellen (Abb. 308, 309). ${ }^{493}$ Bei den Möbeln handelt es sich um zwei unterschiedliche Garnituren, die ebenfalls mit Sitzbänken vor den Brüstungen und Rückwänden bestückt sind, wobei man im Aufriss wieder die Rückenlehnen über den Bänken architektonisch korrekt als Sockelzone für das Dorsale interpretierte. Erneut basiert das strukturelle Gerüst des Dorsales auf einer Pilasterstellung. An einer Garnitur fasst das verkröpfte Gebälk die beiden mittleren Stützen zusammen, ein Cherub mit ausgebreiteten Flügeln prangt dort am Fries (Abb. 308). Blütenmedaillons zieren die Zwickelfelder seitlich der arkadenförmigen Füllungen, Muscheln und filigrane Ornamentmotive die zentralen

492 Eine vergleichbare Großform und ähnlich filigrane Schnitzmotive finden sich am r670 entstandenen Gestühl im nordöstlich von Ulm gelegenen Langenau. Allerdings besitzt es einen Schnitzauszug, wodurch es etwas weniger hölzern als das Exemplar in der Jesuitenkirche wirkt. Wartena, Süddeutsche Chorgestühle (2008), 397-398, Abb. I 5.8.a, I 5.8.b.

493 Zu den Möbeln Schneider, Jesuitenkirche, I (I 995), 299; dies., Jesuitenkirche, 2 (I 995 ), 55 I, Nr. 54 ; Wartena, ebd., I 94-195, I 97-200. 

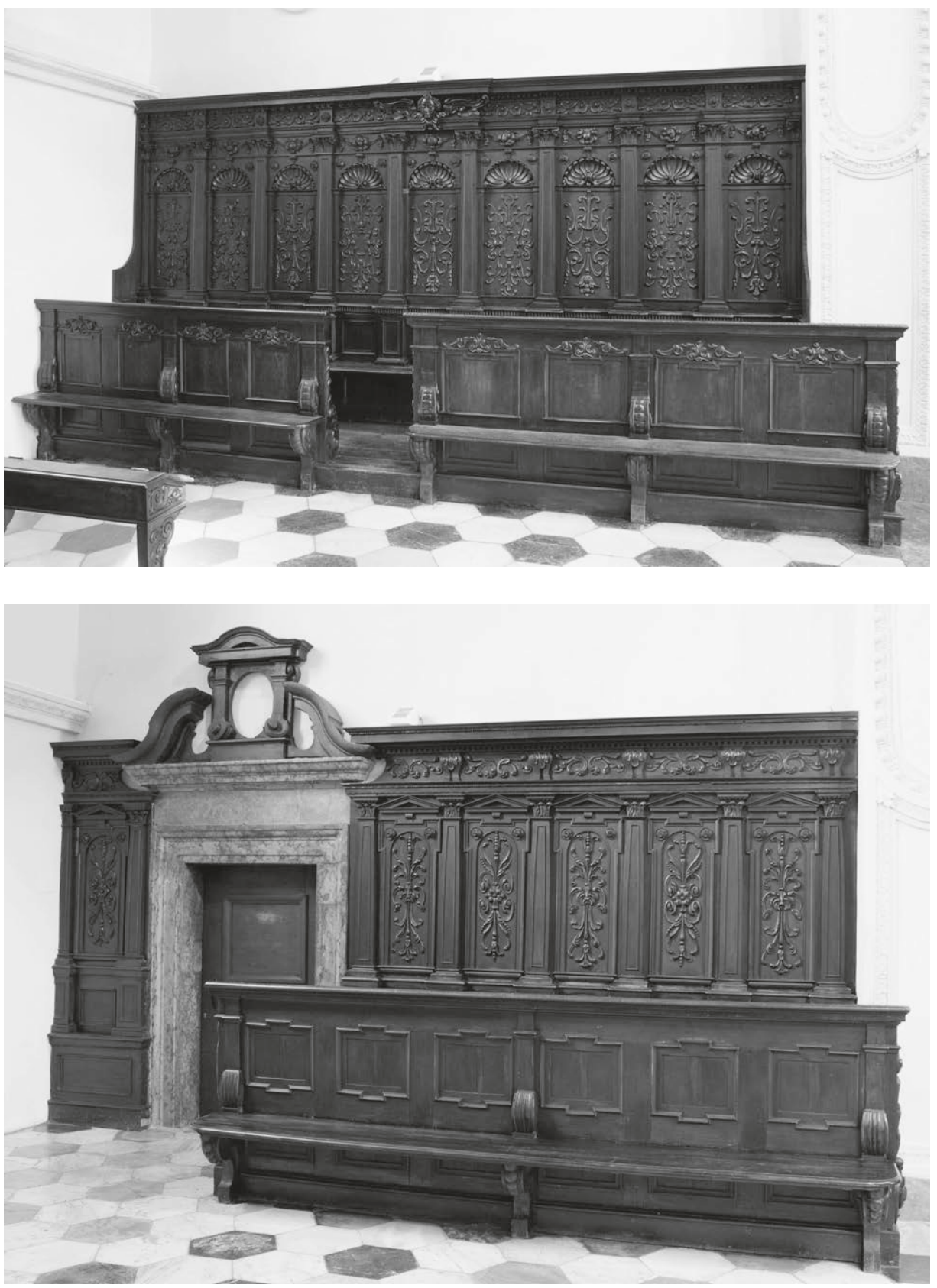

308, 309 Seitenkapellen, Gestühle. Innsbruck, I 648 


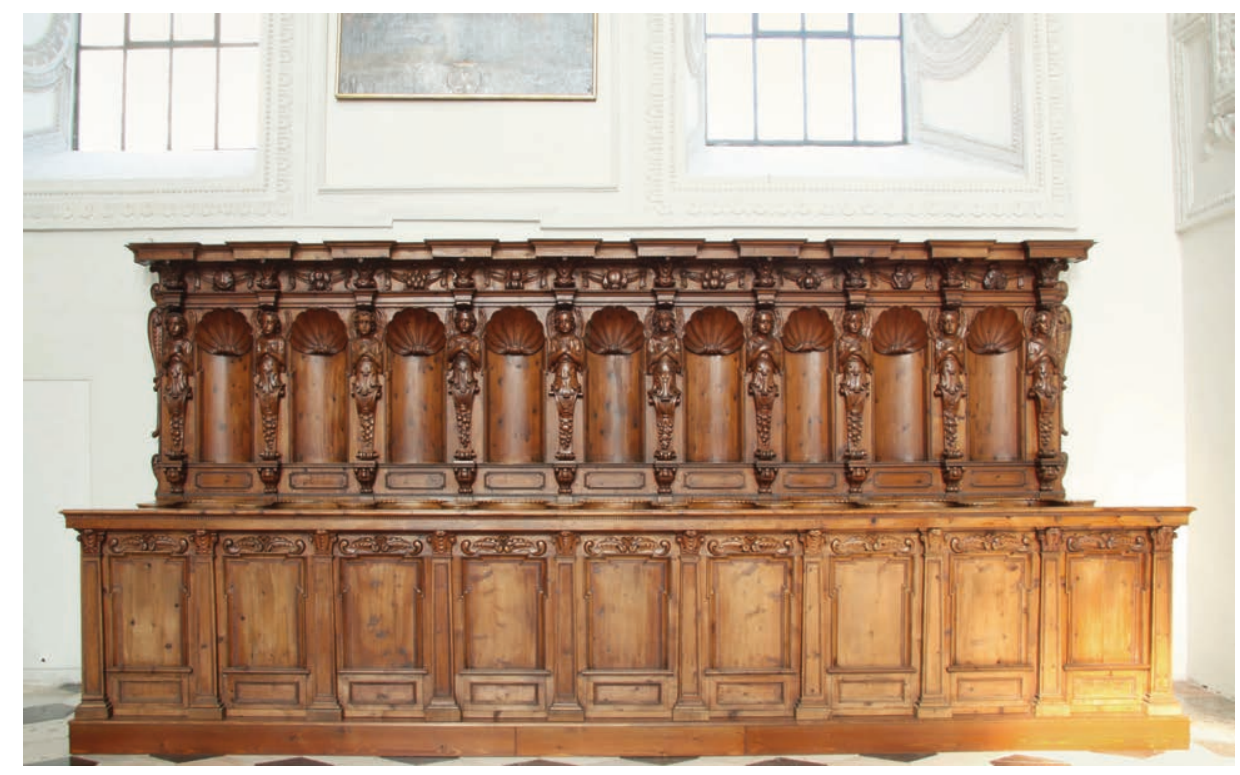

Farbtafel 30 Jesuitenkirche, Querschiff, Gestühl. Wilten, um I 668

Kompartimente, Früchtegirlanden die Kapitellzone. Portale unterbrechen die zweite Garnitur (Abb. 309). Nun füllen schlanke Ädikulä den Raum zwischen den Pilastern, mit ihren Dreiecksgiebeln reichen sie bis zum Gebälk. Delikate Schnitzornamente, wie wir sie schon in Verbindung mit dem Gestühl im Chorraum kennengelernt haben, werten die Inventarstücke auf.

\section{Gestühl im Querschiff der Jesuitenkirche}

Wilten, um I 668

HS $17,5 \mathrm{~cm}$

$\mathrm{H} 274 \mathrm{~cm}(+\mathrm{I} 7,5 \mathrm{~cm}) \times \mathrm{L} 640 \mathrm{~cm}$

Zirbenholz

Das vor den Außenwänden des Querschiffs situierte Gestühl bietet Sitzplätze für I 8 Personen (Farbtaf. 30; Abb. 3 10). ${ }^{494}$ Pilaster mit Fantasiekapitellen tragen das Gesims der Brustwand, Ädikulä auf hohen Sockeln bilden die Füllungen. Zwischen den oberen und unteren Binnenfeldern ist dort jeweils ein Brett eingeschoben, die starke Pro-

494 Schuler, Stiftskirche (I 920), 52; Wagner, Heiligenkreuz (2007), I 50; Wartena, ebd., 395-397. 


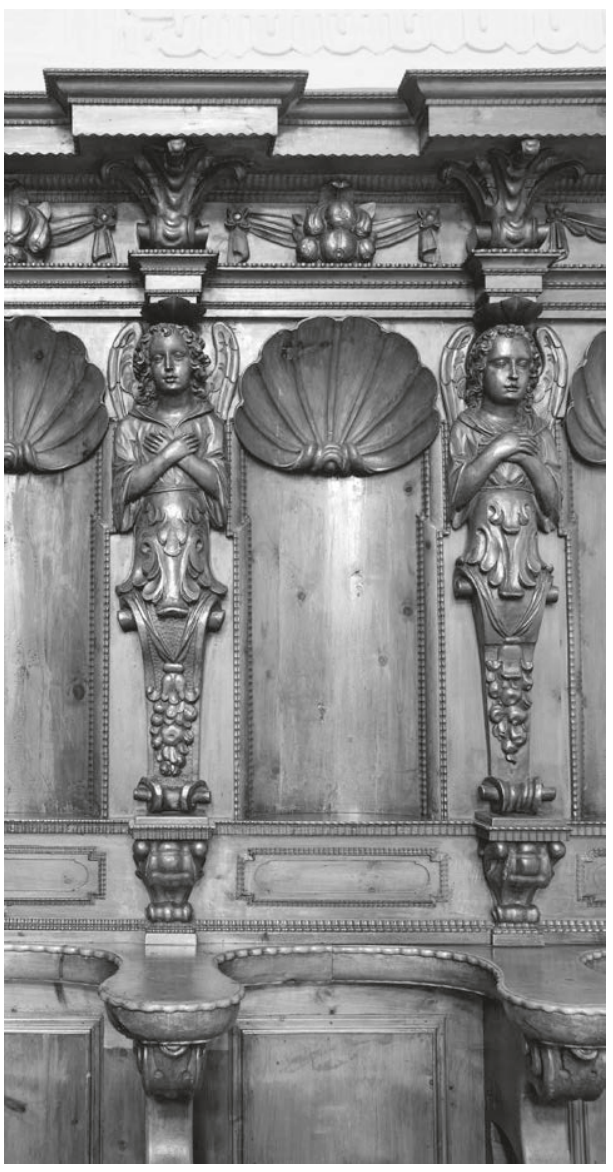

3 Io Teilansicht der Gestühlsrückwand. Wilten, um I 668 filleiste markiert seine Vorderkante. Wird es nach außen gezogen, ergeben sich zusätzliche Sitzmöglichkeiten. Knorpelschnitzereien auf den welschen Fenstern bestehen aus schotenartigen Formen, die mit Rundungen enden. Geflammt gehobelte Zierleisten fassen die zentralen Felder ein. Die Rückseite der Brüstung ist nicht offen, wie das sonst der Fall zu sein pflegt, sondern man fügte dort mit Türen verschlossene Kästen ein.

Dicht gereihte Engelhermen und tiefe $\mathrm{Mu}-$ schelnischen bestimmen zusammen mit dem schweren Gebälk das Aussehen der Rückwand. Die Hermen wachsen aus Voluten heraus, unter denen Früchte hängen, Fruchtfestons und amorphe Gebilde stellen die Ziermotive des Gebälks. Nach den Forschungen von Sybe Wartena wurde im süddeutschen Raum seit der Jahrhundertmitte auf die Verwendung von Engelshermen verzichtet. ${ }^{495}$ Dagegen kommen sie in Österreich auch noch I736/37 am Gestühl in Melk vor. Da über jeder Herme ein kurzes Stück des Architravs und des Gesimses nach vorn ragt, erscheint seine Struktur eigenartig gerastert. Den seitlichen Abschluss des Dorsales bilden Schleierbretter in Form langgestreckter Voluten.

Eine Gegenüberstellung dieses Gestühls mit den oben beschriebenen ist höchst aufschlussreich. Sind Flächigkeit, Blockhaftigkeit und gleichsam petrifizierte Formen charakteristische Wesensmerkmale der Möbel im Chorraum und in den Seitenkapellen, so ist die Rückwand des Exemplars im Querschiff durch die Verwendung plastischer Stilmittel durchmodelliert, sie ist in dynamische Bewegung versetzt, wobei die tiefen Nischen die eigentliche Wandfolie des Dorsales nachgerade eliminieren.

495 Wartena, ebd., roo. 
Die Translokation des Gestühls, das einst für das nahe gelegene Stift Wilten gebaut wurde, erfolgte $2005 .{ }^{496}$ In der Literatur wird vermutet, dass die Garnitur zusammen mit einem Prälatenstuhl entstand, der dort noch immer aufbewahrt wird (Abb. 378, 379). Zwar lassen sich auf den ersten Blick nicht allzu viele Übereinstimmungen zwischen den Möbeln erkennen, doch scheinen vor allem die Hermen im Atelier ein und desselben Bildhauers geschnitzt worden zu sein. Wie das östliche Ende des Chorgestühls dokumentiert, wurde das Möbel gekürzt. Allerdings geben alte Aufnahmen aus der Stiftskirche Wilten das Gestühl auch dort beidseitig mit nur neun Sitzplätzen wieder. Und sie bezeugen, dass es ursprünglich zweireihig war, wobei die derzeitige Brustwand früher als Zwischenwand fungierte. ${ }^{497}$ Die ehemalige Vorderbrüstung entsprach in ihrer Gestaltung weitgehend der heutigen, war aber etwas einfacher.

\section{Innsbruck, Servitenkloster}

Kirche St. Josef

Die Stiftung des Klosters durch Anna Katharina Gonzaga (I566-I62 I), der zweiten Gattin Erzherzog Ferdinands II. von Tirol (I 529-I595), datiert auf das Jahr I6I4, gleichwohl wurden die ersten Servitenpater und Laienbrüder bereits I6 I 2 nach Innsbruck berufen. ${ }^{498}$ Sie kamen aus Norditalien, I6 65 folgten ihnen weitere Mönche, nun aus dem nördlich von Florenz gelegenen Kloster Montesenario, dem die Kommunität in Innsbruck unterstand. Nachdem die Stiftskirche zusammen mit dem Kloster I 620 bei einem Brand zerstört worden war, wurde der Wiederaufbau unverzüglich in Angriff genommen. Die Weihe der neuen Kirche erfolgte I626, in den I63oer-Jahren konnten auch die Arbeiten an der Ausstattung beendet werden. Von Hoftischler Hans Pock stammt die Kanzel, der Bildhauer und Architekt Matthias Carneri (I 592-I673) aus Trient und der Maler Martin Theophilus Polak ( $\dagger_{\text {I } 639)}$ aus Polen schufen den Hochaltar. Weitere Eingriffe in den Bestand sind für die Jahre um und nach 1722 sowie für das I 9. Jahrhundert überliefert. I 943 wurde die Klosteranlage bei einem Angriff der Alliierten schwer beschädigt und mussten infolgedessen nach Kriegsende umfassend renoviert, teilweise auch neu errichtet werden. Um r 967/68 erfolgte die Modifikation des Kirchenraums entsprechend den Vorgaben des II. Vatikanischen Konzils.

496 Gombocz, Betbänke (2008), го3.

497 Wartena, Süddeutsche Chorgestühle (2008), Abb. I 5·7.a, I 5·7.b.

498 Caramelle, Servitenkirche [1973]; Dehio, Tirol (1980), 47-48; Caramelle/Frischauf, Stifte (I985), I68-I72; Felmayer, Servitenkirche (r990); dies., Servitenkirche (r995); Winkler, Servitenkirche (I 995); Möller, Kirchen (2004), 2 I-24; Naredi-Rainer/Madersbacher, Kunst, I (2007), 586-587. 
Refektorium

Lesekanzel

Innsbruck, um I $730 / 40$

HS $19 \mathrm{~cm}$

H I $6 \mathrm{~cm}(+\mathrm{I} 9 \mathrm{~cm}) \times \mathrm{B}$ I $88 \mathrm{~cm}$

Nuss, Nussmaser, Ahorn, graviert, brandschattiert, geschwärztes Holz. Messing, Eisen, teilweise geschwärzt

Wie wir das von den Franziskanerklöstern in Wien und Frauenkirchen (Abb. o8, o9) her kennen, war das Refektorium des Servitenklosters einstmals mit einer umlaufenden Wandvertäfelung sowie mit Bänken ausgestattet. ${ }^{499}$ Vom Getäfel haben sich zwei kurze Teilstücke erhalten, aufbewahrt wurde überdies die Lesekanzel (Abb. 3 I I), der Rest des originalen Interieurs ist verschollen. Das Möbel erhebt sich über einem geschwungenen Grundriss, wobei zwei seitliche Einzüge zu einem weit nach vorn reichenden konvexen Bogen in der Mitte überleiten. Die linke Kanzelseite öffnet sich mit einer Tür. In der Höhenentwicklung baut sich das Möbel über mehrere Register auf: Ein mit einer Trittstufe versehenes Podest bildet die unterste Zone. Darüber folgt der eigentliche Sockel. Ein geschwärztes Profil trennt ihn vom Hauptteil, der mit einem ebenfalls schwarzen Abschlussprofil endet.

Ausgewählte Furniere machen den Reiz des Möbels aus. Die Rahmen sind diagonal mit gestreiftem Nussholz belegt, die Füllungen mit Maserholz aus Nuss. Breite, stark geschwungene und miteinander verflochtene Adern lockern die Füllungen optisch auf. Sterne zieren die Binnenfelder der äußeren Achsen, in der Mitte trägt eine Kartusche aus dunklem Holz das Monogramm Mariens.

Ein Lesepult, das ursprünglich einmal vorhanden war, fehlt heute. Um dem Möbel eine größere Tiefe zu verleihen, wurde an beiden Seiten in jüngerer Zeit ein etwa $29 \mathrm{~cm}$ breites Stück angesetzt. Furnier und Intarsien sind dort aufgemalt.

\section{Sakristei}

Die Deckenverzierung mit Laub- und Bandlwerk geht auf die Stuckkünstler Hans Singer und Paul Wachter zurück, sie wurde I73 I ausgeführt. Türen führen zu Annexräumen, einer davon, ein großes Vorzimmer, schafft eine Art von Angelpunkt, der verschiedene Bereiche der Klosteranlage miteinander verbindet. Die Sakristei ist mit einem langen Aufsatzschrank vor der Fensterwand, mit mehreren Wandschränken, ei-

499 Bohr, Sakralmöbel (2017), I63-165. 


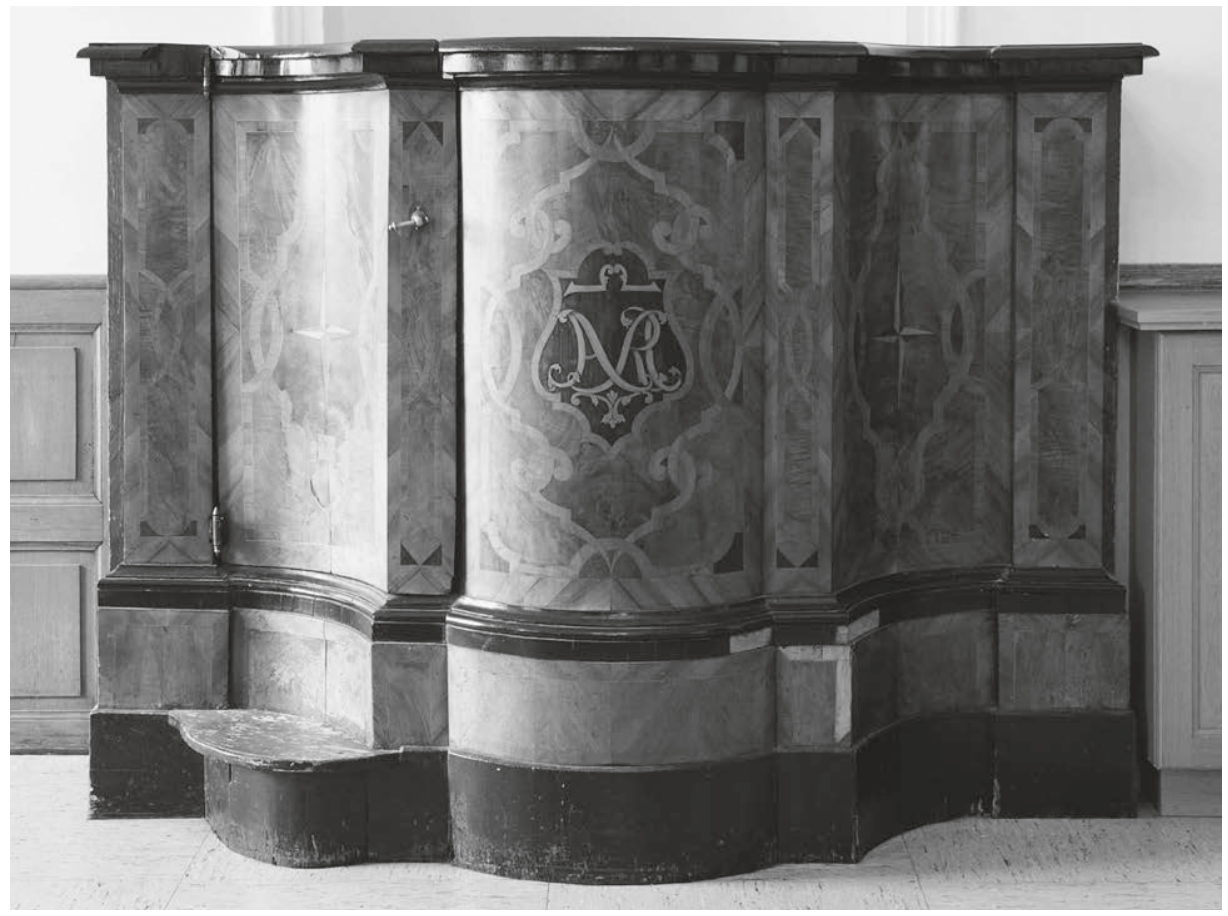

3 I I Refektorium, Lesekanzel. Innsbruck, um I730/40

nem kleinen Barocktisch in der Raummitte sowie mit zwei neobarocken Kniebänken eingerichtet. An dieser Stelle interessieren eine der Türen und die Ankleidekredenz.

Tür

Innsbruck, um I $730 / 35$

Lichtes Maß H $242 \mathrm{~cm} \times$ B I $33 \mathrm{~cm}$

Nuss, Nussmaser, furniert und massiv, geschwärztes Holz, Ahorn. Eisen

Abgesehen von einem Sockelbrett und schmalen Leisten, welche die zu einem kleinen Nebenraum führende Tür säumen, besitzt sie die traditionelle Form. Sie ist einflügelig, wobei in diesem Fall zwei nahezu quadratische Füllungen vom Rahmen gehalten werden (Abb. 3 I 2). Während Letzterer aus massivem Nussholz besteht, bedeckt Furnier die Füllungen. Dabei grenzt jeweils ein breiter Fries ein Rechteck mit einem auf der Spitze stehenden Quadrat ein. Der Fries und die Zwickelfelder wurden mit gestreiftem Nussholz diagonal furniert, das zentrale Feld mit Nussbaummaserholz. Sauber 


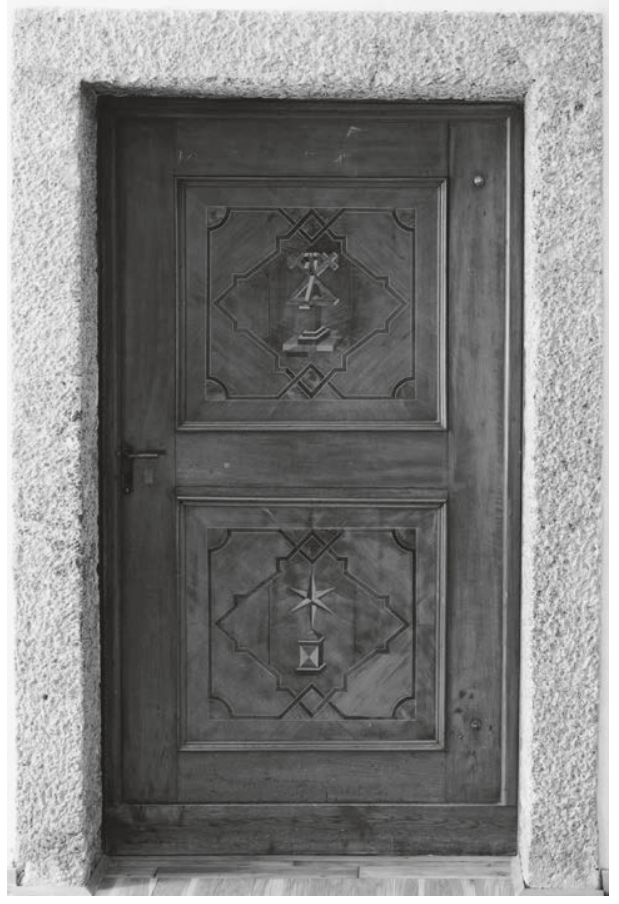

3 I 2 Tür von der Sakristei aus zu einem Annexraum. Innsbruck, um I 730/35 ausgeführte intarsierte Podeste mit Kreuzen und einem vielzackigen Stern vervollständigen die Arbeit. Die Motive erinnern an die Sakristeimöbel im Stift Lilienfeld von I747, deren Fronten der Zeit gemäß mit eingelegten Adern dekoriert sind, während die Schmalseiten Obelisken, Stufenpyramiden und Sterne präsentieren. ${ }^{500} \mathrm{Wie}$ in Lilienfeld vermittelt auch die Tür im Innsbrucker Servitenkloster fast den Eindruck einer von einem Stiftstischler ausgeführten Fleißarbeit, denn die Marketerien geben nicht jene Motive wieder, die wir sonst von barocken Arbeiten her kennen.

\section{Ankleidekredenz}

Innsbruck, um I $730 / 3$ I und um I $740 / 50$ (?)

HS Io, $5 \mathrm{~cm}$

$\mathrm{H}_{30} \mathrm{~cm}(+\mathrm{IO}, 5 \mathrm{~cm}) \times \mathrm{L} 753 \mathrm{~cm} \times \mathrm{T}$ ca. $105 \mathrm{~cm}$

Nussholz, Nussmaser, Ahorn, Zwetschke, Buchs

(?), geschwärztes Holz, Holz, gefasst und vergoldet. Messing, Eisen

Der lange Unterschrank trägt vor den Fensterpfeilern drei schmale Aufsatzmöbel (Abb. 3 I 3, 3 I 4). Vor- und Rücksprünge, zwischen denen Schrägen vermitteln, prägen die Fassade der flächig konzipierten Substruktion. Jeweils eine Tür verschließt die Segmente vor den Mauerpfeilern, zwei Türen die Abschnitte vor den Fensternischen. Die zweigeschossigen Oberschränke setzen direkt auf der Platte der Substruktion an. Von Schubladen flankierte Kelchfächer sind dort im Sockelbereich eingefügt, im Hauptteil folgen zweitürige Schränke zur Aufbewahrung von Paramenten und großen Altargarnituren. Die Vorderseiten der Hochschränke weisen langgezogene konkave Bögen auf. Am mittleren Schrank leitet eine nach innen verkröpfte Rundung zu den Schmalseiten über, an den äußeren Möbeln sind es abgeschrägte Kanten. Die Hochschränke schließen mit einem apart geformten Hut, der durch seine Dreiteilung an das Aussehen klassischer Gebälke anknüpft, jedoch ungewöhnliche Formen und Proportionen aufweist. Über dem mittleren Exemplar ist er mit einem Segmentgiebel versehen, während die seitlichen Möbel mit geraden Gesimsen enden. Unter dem

500 Bohr, ebd., 404-408. 


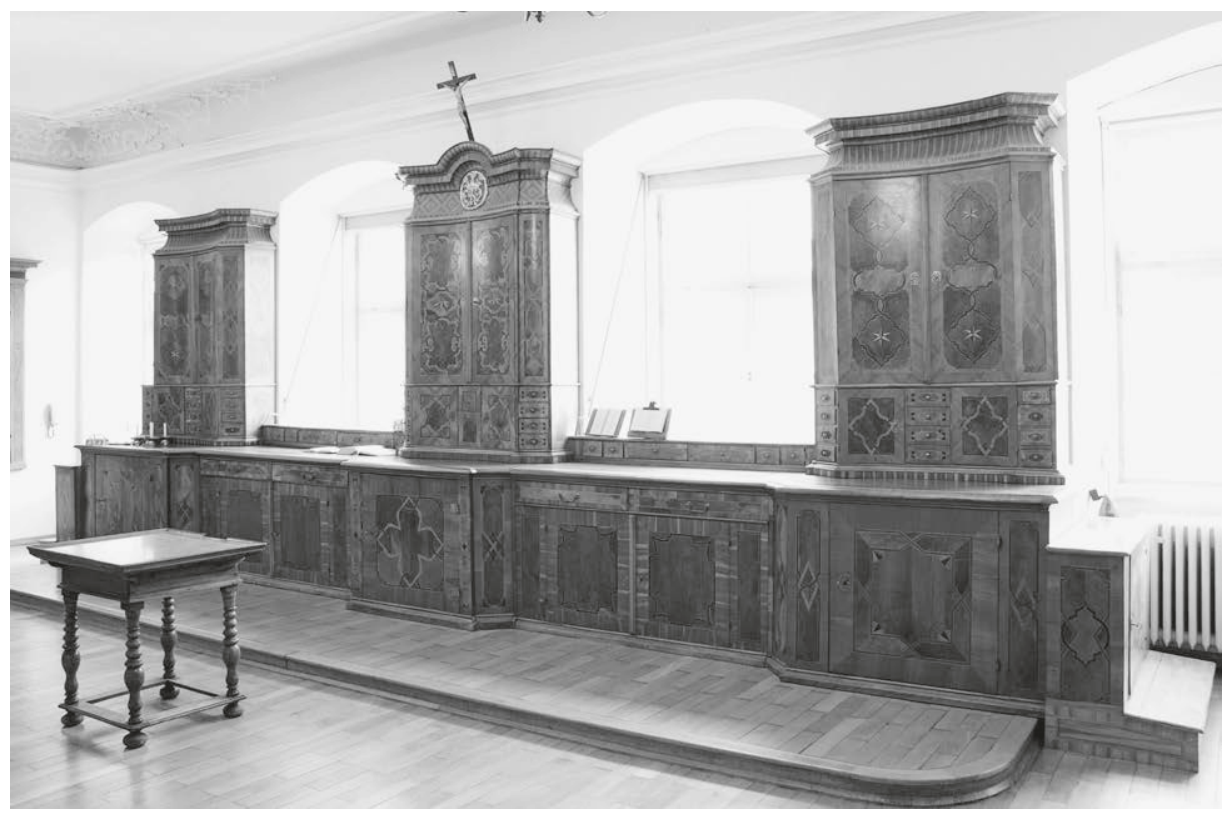

31 3 Sakristei, Ankleidekredenz. Der Unterschrank von Tischler Mathias Pinna, um I730/31, die Oberschränke wohl um I $740 / 50$

Giebel prangt auf einem dunkel gefassten und vergoldeten Hochoval das Emblem des Servitenordens.

Am Sakristeischrank überraschen die formalen Differenzen zwischen dem Unterschrank und den aufgesetzten Möbelteilen. Im Gegensatz zu den geraden Vorderfronten der Substruktion sind die Oberschränke geschweift - eine Art der Formgebung, die sich an zahlreichen zeitgenössischen Sakristeimöbeln findet. Die um i7i6 bzw. um 1755/65 entstandenen Möbelensembles von Vorau und Neuberg bieten hierfür gute Beispiele (Abb. 214, 272). Bedeutender im Zusammenhang sind allerdings die unterschiedlichen Furnierbilder. Präferierten die Tischler unten unprätentiös und relativ »trocken« erscheinende Darstellungen, legten sie oben mit vielfachen Bögen geschwungene und miteinander verkettete Bänder sowie vielzackige Sterne ein. Anders als die Marketerien des Unterschranks sind jene der Oberschränke anspruchsvoll, aufwendig und belebt, wobei der Dekorreichtum des mittleren Schranks den der beiden anderen noch übertrifft. Besonders qualitätvoll ist darüber hinaus der Schmuck seines Gebälks, denn dort verläuft die Maserung nicht nur senkrecht zur Richtung des Blindholzes, sondern die Frieszone des mittleren Möbels ist zusätzlich mit Rautenmustern bereichert. 


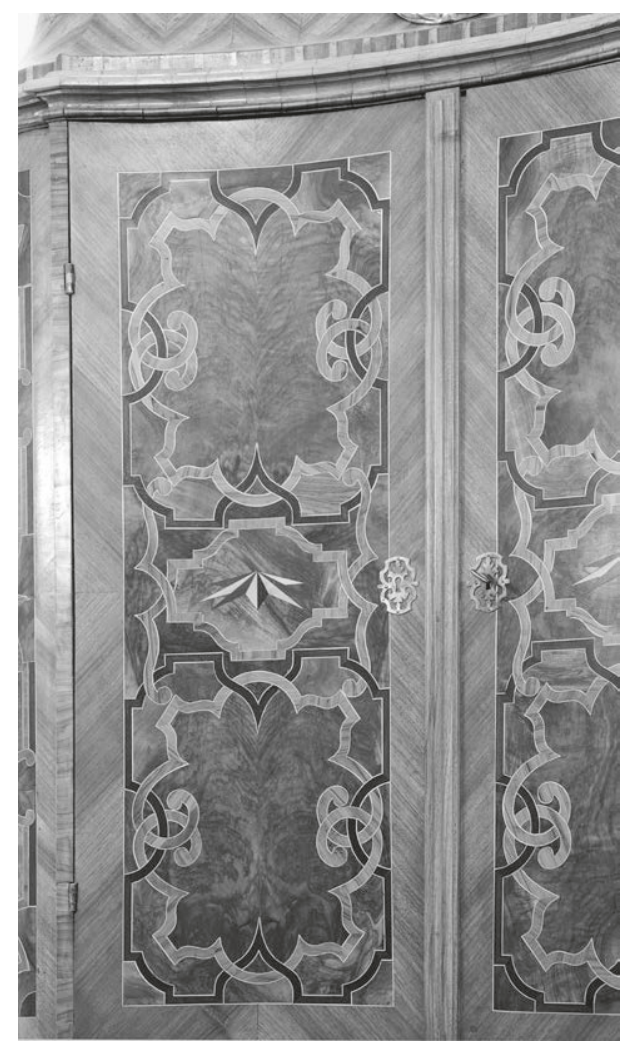

3I4 Sakristei, Ankleidekredenz, Detailansicht des mittleren Aufsatzes.

Schriftquellen zufolge erhielt ein Tischler I730 und 173I Zahlungen für Arbeiten in der Sakristei, vermutlich handelte es sich um Mathias Pinna. Unter anderem bekam er zehn Gulden, um den grossen Sacristei Khasten zu machen. ${ }^{501}$ Die Summe erscheint als viel zu gering, um sich auf das gesamte Möbel beziehen zu können. In Verbindung mit den gestalterischen Unterschieden stellt sich die Frage, ob der Tischler damals nicht lediglich die Substruktion gebaut haben könnte, während die Aufsatzschränke zu einem späteren Zeitpunkt hinzukamen. Denn die in komplizierte Bahnen gelegten Adern der oberen Möbelteile weisen auf eine Stilstufe, die beispielsweise die Sakristeimöbel in Lilienfeld von 1747 und in St. Josef zu Wien von $1745 / 55$ vertreten. ${ }^{502}$

\section{Kirchenraum \\ Laiengestübl}

Vermutlich Tischler Hans Pock, Entwurf evtl. Christoph Gumpp, um I630/40

HS ca. $5 \mathrm{~cm}$

H I IO $\mathrm{cm} \times \mathrm{L} 296,5 \mathrm{~cm}$

Nuss, Ramin, massiv, geschnitzt, Lärche, Fichte, massiv

Im hinteren Kirchenbereich befinden sich zwei Blöcke mit jeweils neun, vorn zwei Blöcke mit sechs Bankreihen. Das Gestühl zählt also 3 o Bänke und vier Vorderwände (Abb. 3I $5-3$ I 7 ) ${ }^{503}$

An Brüstungen und Rückwänden schließen geohrte Füllungen die Felder zwischen Balustern, ein Gesims trennt die Kapitell- von der Hauptzone. Je ein großes, aus einer ebenen Fläche bestehendes und nicht weiter geschmücktes Hochoval bezeichnet die

50 I Winkler, Servitenkirche (I 995), 537-538, Nr. I 28 , I 30 .

502 Bohr, Sakralmöbel (2017), 207-2 I0, 404-408.

503 Caramelle/Frischauf, Stifte (I 985), I68, I69; Felmayer, Servitenkirche (1995), I83; Winkler, Servitenkirche (1995), 533, 543, 546, Nr. 38, 21 2, 272. 


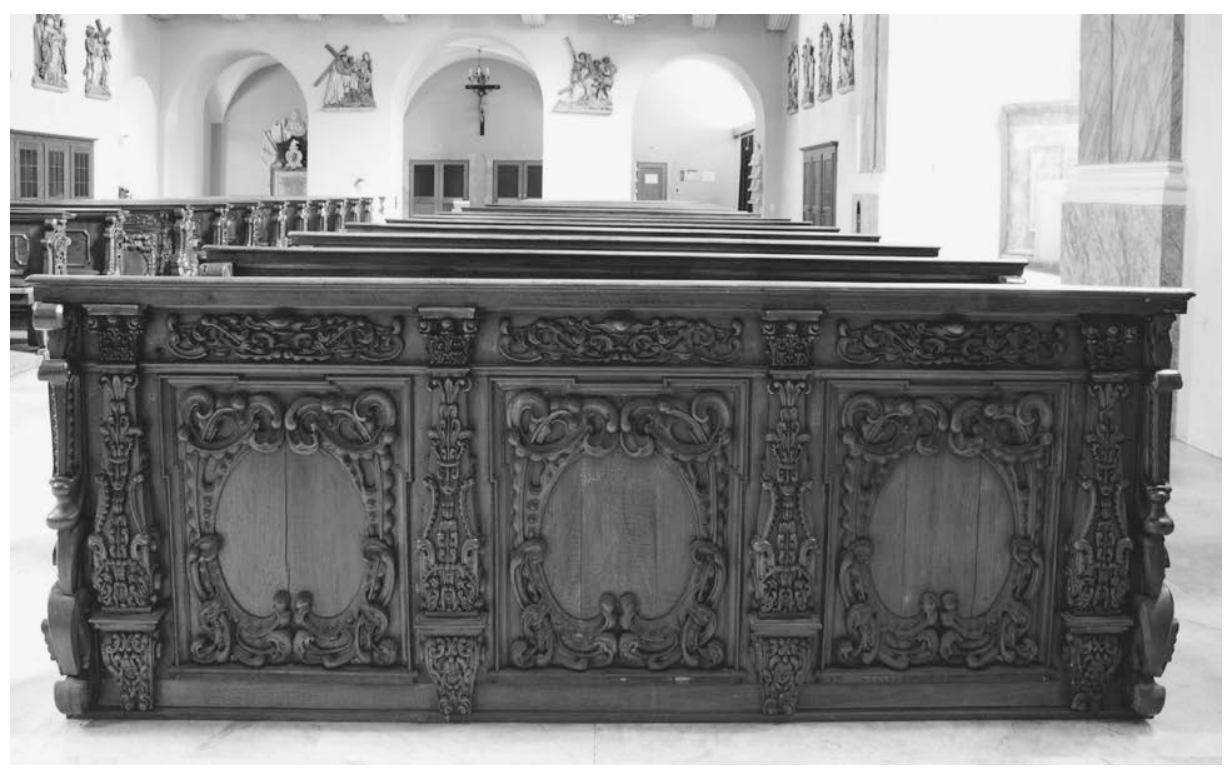

3 I 5 Laiengestühl. Verm. Tischler Hans Pock, um I630/40 (Aufnahme Juli 20 I 5. Zustand vor der jüngsten Restaurierung)

Mitte der Binnenfelder, ansonsten liegen virtuose Schnitzarbeiten auf Friesen und Balustern in mehreren Schichten übereinander. Einige dieser Schnitzereien weisen einen voll ausgebildeten Knorpelstil auf, andere erinnern mit ihren filigranen Motiven noch an frühbarocke Ornamentformen.

Die Brüstungswangen reichen über die Fläche der Brustwände hinaus, sie stehen nach vorn in den Raum, wie das an Bänken im Süden und Westen Österreichs immer wieder zu beobachten ist. Die Großform der Bankwangen entspricht derjenigen der Möbel in der Innsbrucker Jesuitenkirche (Abb. 305) und in der Stiftskirche zu Wilten (Abb. 373) von I640 resp. I665/75, doch sind die Docken in der Servitenkirche mit außerordentlich schweren und reichen Schnitzarbeiten fantasievoller und dynamischer als die anderen gestaltet. Der Abwechslungsreichtum der Ziermotive, die hier zur Anwendung kamen, übertrifft noch jenen der Brüstungsvorderwände. Die Dockenkontur ähnelt der eines schlanken Kegels, der oben in einem kapitellartigen Endstück ausläuft. Die Buchablagen liegen auf den Wangen auf, ihr Querschnitt folgt einem S-Schwung. Aus einer unterhalb des Endstücks platzierten Muschel quillt ein Stoffband, das sich am Wangenbauch auflöst, außerdem hängen an der Muschel große, von Blättern eingefasste Früchte - Granatäpfel, Ananasse, Artischocken und anderes. Bögen, die sich teils sanft abgerundet nach vorn wölben, teils auch mit einem Hohleisen ausgeho- 


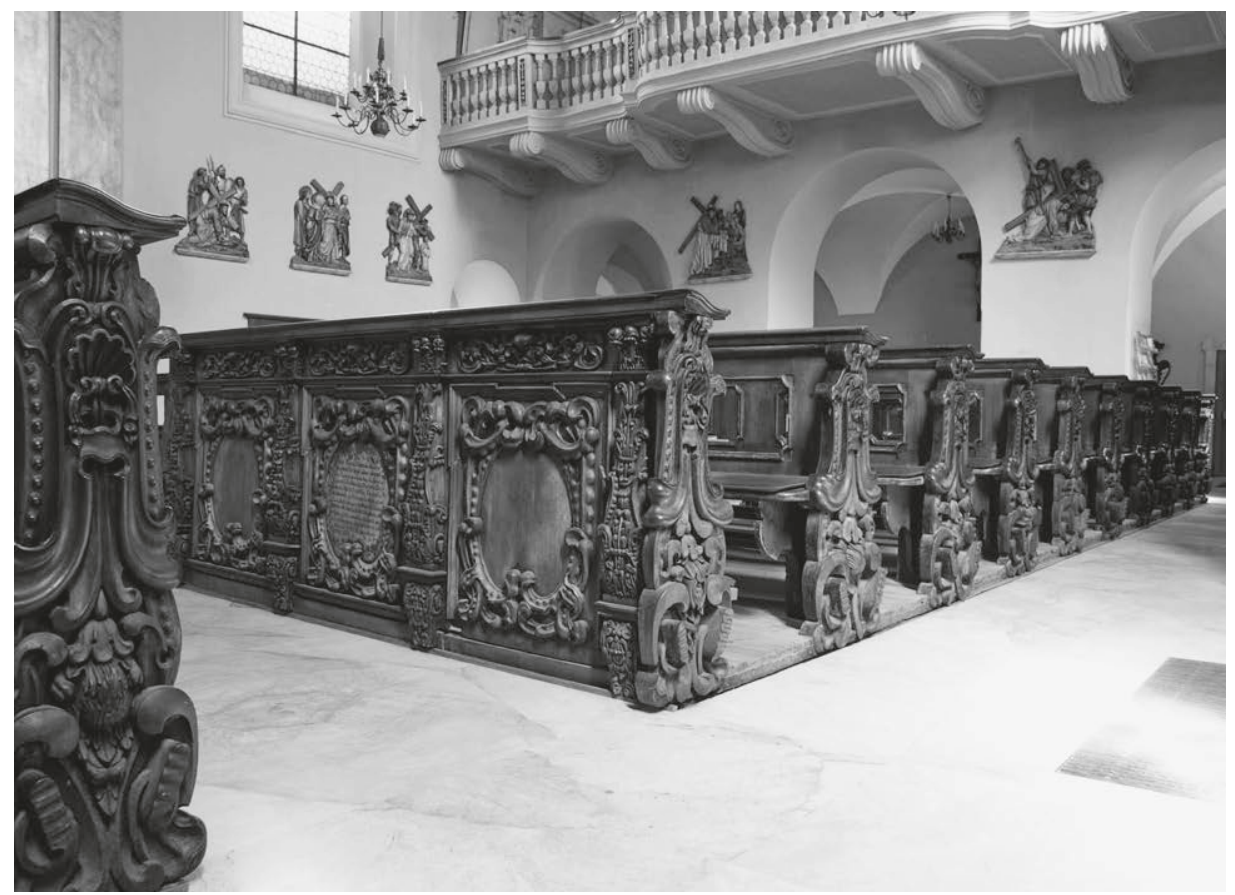

316 Laiengestühl. Verm. Tischler Hans Pock, um I630/40 (Aufnahme Juli 201 5. Zustand vor der jüngsten Restaurierung)

ben sind, fassen das Mittelmotiv ein. Erbsenartige Verdickungen und breite Querriffeln formen weitere Strukturen, gegenläufige Schwünge bilden den nur unwesentlich breiteren Fuß der Wangenkörper. Die größtenteils modernen Rückenlehnen sind wie üblich bei Gestühlen in jener Kunstlandschaft abschnittsweise durchbrochen. Dabei begrenzen hier schlichte Rundprofile die Öffnungen, während die Lehnen anderer Tiroler Kirchen häufig als Träger zusätzlichen Schnitzwerks dienen.

Bei einer Überarbeitung des Gestühls durch die Werkstatt von Josef Trenkwalder (1 845-1 897) wurden an den Innenseiten der Brustwände Blendvertäfelungen befestigt, die der Geselle Josef Sentobe signierte und mit 25/7 [I]879 bzw. 15/08 [18]79 datierte. Um die Platten montieren zu können, entfernte er vom alten Rahmengerüst Profile und Konsolen, deren Abdrücke noch deutlich zu erkennen sind. ${ }^{504}$ Trenkwal-

504 Die vorhergehenden Angaben sind dem ausführlichen Bericht von Walter Gombocz entnommen, dessen Betrieb die Möbel zwischen Mai und September 2016 restaurierte. Das BDA Innsbruck stellte mir die Aufzeichnungen freundlicherweise zur Einsicht zur Verfügung. Weitere Hinweise zu früheren Restaurierungen gibt Felmayer, ebd. 
ders Schreinerei restaurierte außerdem die Docken und fertigte neue Bänke an. ${ }^{505}$ Die Rechnung des Tischlers vom 6. September I 879 führt an: 28 Betbstühle samt Bodium neu gemacht, die alte Schnitzerei dazu restauriert I 846 fl. Das Anstreichen und Lackieren II 2 f. ${ }^{506}$ Bereits damals wurde die Bankgarnitur also massiv überarbeitet. Weitere Eingriffe in den Originalbestand erfolgten nach I945, zudem mussten r 967 und r968 einige Docken wegen eines starken Holzwurmbefalls vollständig oder teilweise erneuert werden. Allerdings stellte man sie nicht aus Nussbaum, sondern aus Raminholz her. ${ }^{507}$

2016 war eine umfassende Restaurierung der Möbel unumgänglich geworden. Die Tischler stießen dabei auf Anzeichen weiterer Modifikationen: An den Möbeln fanden sich Reste einer Fassung, die eine Holzmaserung imitierte, vermutlich der zwischenzeitlich abgenommene Anstrich von I 879. Ferner hatte man eine alte Sitzbank gegen eine Tischlerplatte ausgetauscht, sie trägt das Datum I9.9.[I9]77. Außerdem waren die Gebetbuchablagen einiger Bänke nach hinten gerückt

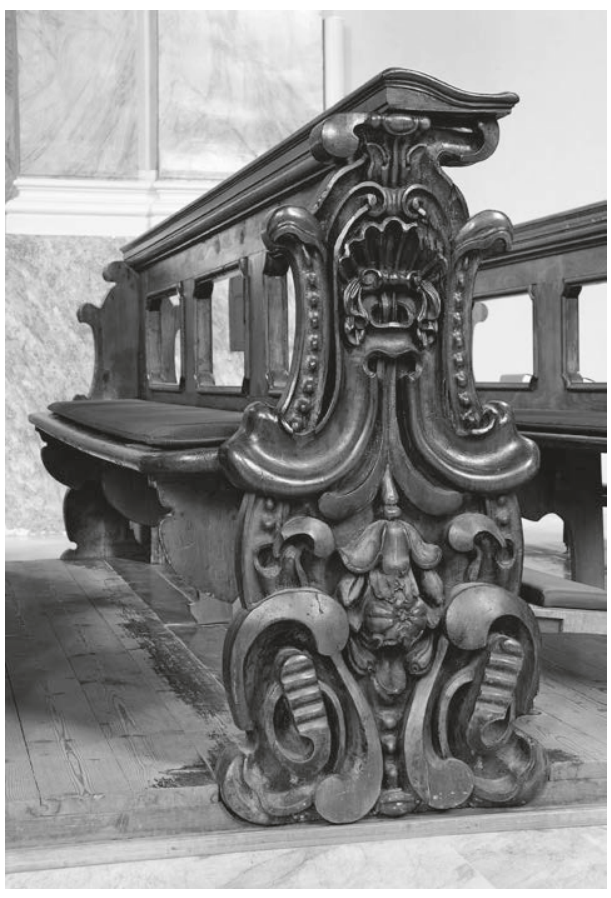

3 I 7 Bankwange. Verm. Tischler Hans Pock, um r630/40 (Aufnahme Juli 20 I 5. Zustand vor der jüngsten Restaurierung. Die Gebetbuchablage wurde bei einer früheren Überarbeitung der Möbel fälschlicherweise nach hinten versetzt.) worden (Abb. 3I7), während die Pulte ursprünglich mittig auf den Docken angebracht waren (Abb. 3 I6). Die Restauratoren dekonstruierten die Möbel und behandelten sie gegen Holzschädlinge. Zerstörte Partien wurden gefestigt oder durch Kopien ersetzt, fehlende Furniere und Schnitzarbeiten ergänzt, ausgebrochene Verbindungen nachgearbeitet. Die missglückte Nachbildung einer Wange aus Raminholz wurde aus ästhetischen Gründen durch ein neues Exemplar aus Nuss ersetzt, die übrigen Ra-

505 Felmayer, ebd. und Winkler, Servitenkirche (I 995), 543, Nr. 2 I 2.

506 Servitenarchiv. A-Isv-KA i 9 I (I879-1884). Servitenkirche: Restaurierung der Kirchenbänke. Neue Kirchenfenster.

507 Winkler, Servitenkirche (1995), 546, Nr. 272. Nach freundlicher Mitteilung von Walter Gombocz verwendete man Raminholz damals als kostengünstigen Ersatz für das teure Nussholz. Über all diese Restaurierungen liegen nur ungenaue oder gar keine Berichte vor. 
minholzdocken beließ man als Teil der Geschichte des Gestühls. Der alte Laufboden wurde erneuert.

In der Kunsttopographie publizierte Quellen und Regesten deuten auf eine Herstellung der Möbel um I630 ${ }^{508}$, tatsächlich stehen sie auf einer Entwicklungsstufe mit den Bänken in der Innsbrucker Jesuitenkirche (Abb. 303, 305) von r640. Beim Vergleich der Bankgarnitur in der Servitenkirche mit den Ausstattungen in Neuberg (Abb. 209) oder Mariahof (Abb. 203, 204) erstaunen das frühe Herstellungsdatum und die überragende Qualität des Ensembles. Fragen wirft jedoch der Umstand auf, dass den Schnitzarbeiten der Möbel in der Servitenkirche verschiedene Entwürfe zugrunde lagen. Einen Typus vertreten die Ziermotive der Bankwangen und Füllungsfelder, einen zweiten die der Kapitellzone, einen dritten die Schnitzereien an den Pilastern. Keinerlei Datierungsprobleme bereiten die Schnitzarbeiten an Wangen und Füllungen, die sich stilistisch gut zu einer Herstellung in der Zeit nach dem Wiederaufbau der Kirche, also um I630/40, fügen. Verschiedene Arten von Früchten kommen schon seit dem I6. Jahrhundert in Vorlagenstichen immer wieder vor, im Formenschatz der Schule von Fontainebleau waren sie ebenso vertreten wie bei niederländischen Ornamentisten. ${ }^{509}$ Ähnliches gilt für Entwürfe von Lukas Kilian ( 1579-r637) aus den Jahren um I630. Er kombinierte Früchte und Girlanden bereits mit jenen schweren und fleischigen Motiven, die die Brüstungen vervollständigen. ${ }^{510}$ Die Schnitzarbeiten stehen damit auf der Höhe der Zeit. Ungewöhnlich wegen seiner Dichte und Kleinteiligkeit ist der Schmuck der Kapitellzone, doch lässt auch er sich gut auf die r64oer-Jahre datieren; er erinnert an die Eigentümlichkeiten der Möbel in Bad Mehrn (Abb. 287, 289). Ein eigenartiges Aussehen ist dagegen den Zierornamenten an den Pilastern eigen. Johanna Felmayer erkannte in den dichtgedrängten und harten Formen zwar Übereinstimmungen mit Stuckarbeiten in der Innsbrucker Hofkirche aus dem frühen I 8. Jahrhundert, zog allerdings auch eine Entstehung der Pilaster um r 879 in Erwägung. ${ }^{511}$ Dagegen wird im Restaurierungsbericht von 2016 eine Datierung der Schnitzereien auf das späte I7. Jahrhundert vorgeschlagen, was dem Umstand Rechnung trägt, dass Johann Martin Gumpp d.Ä. (I643-I 729) um I680 Palais in Innsbruck mit ähnlichen Ziermotiven versehen ließ. Allerdings rekurrieren diese Motive auf Ornamententwürfe von Friedrich Brentel (I 580-I65 I) aus der

508 Felmayer, Servitenkirche (1995), I 83; Winkler, ebd., 533, Nr. 38.

509 So gab Cornelius Bos (um I 506-I 556) auf seinen Entwürfen Früchte wieder, die wie hier an Stoffgirlanden hängen. Berliner/Egger, Vorlageblätter ( I 98I), Bd. I, 56, 67, Bd. 2, Abb. 409-4I 2, 620, 626.

5 Io Berliner/Egger, ebd., Bd. I, $78-79$, Bd. 2, Abb. 868, 869 .

5 I I Felmayer, Servitenkirche (1995), I83. Zu den Stuckarbeiten in der Hofkirche vgl. etwa ÖKT, Innsbruck, Hofbauten (1986), Abb. 345, 346 . 
Zeit um I6 1 8. ${ }^{512}$ Wie in einem der einleitenden Kapitel erwähnt, bildeten sie seit den I6 2oer-Jahren die Vorlagen für etliche Stuckarbeiten in österreichischen Sakralbauten. Brentels Entwürfe könnten damit um I630/40 auch als Vorbild für die Schnitzarbeiten an den Pilastern gedient haben. Dennoch bleiben Fragen wegen des Kontrasts zwischen den kleinteiligen und harten Formen an der Front und den großen, weichen Ornamenten an den Wangen bestehen, denn offensichtlich kamen hier hetoregene ästhetische Vorstellungen zum Tragen. Eine sichere Antwort auf die Frage nach der Datierung der Schnitzereien an den Brüstungen kann zum gegenwärtigen Zeitpunkt jedenfalls nicht gegeben werden und wird wohl erst nach einer dentrochronologischen Untersuchung des verwendeten Holzes möglich sein.

Wie das bei barocken Kirchenbänken häufig zu beobachten ist, bestehen die Wangen nicht aus einer einzigen massiven, sondern aus zwei aufeinandergeleimten Bohlen. Im vorliegenden Fall wurden die Schnitzarbeiten der Wangen aus etwa neun Zentimeter dicken Nussholzbohlen herausgearbeitet, die mit einer drei Zentimeter starken Trägerplatte aus günstigerem Lärchenholz unterfüttert sind. Die Tischler fertigten die Vorderbrüstungen aus massivem Nussholz, aus Nadelholz dagegen die Sitz- und Kniebänke sowie die Rückenlehnen. Die Gebetbuchablagen besitzen einen Nadelholzkern, der mit Nuss geschwartet und mit "Umleimern« versehen wurde. ${ }^{513}$ Das Mittelfeld der Vorderbrüstung eines Bankblocks trägt eine Inschrift von I769, der zufolge eine gewisse Maria Theresia Schulern aus Schratenhofen, die sich um die Kirche besondere Verdienste erworben hatte, in einer dort verorteten Begräbnisstätte beigesetzt wurde.

Kramsach, Maria Thal, Pfarrkirche hl. Dominikus

\section{Ehemaliges Dominikanerinnenkloster}

I 267 gründeten Friedrich und Konrad von Freundsberg das Dominikanerinnenkloster und die Kirche. ${ }^{514}$ Nach einem Brand wurde der Sakralbau r680/82 weitgehend neu errichtet. Wenngleich der Literatur zufolge von dem mittelalterlichen Gebäude nur noch wenige Mauerreste erhalten sein sollen, belegt die nachfolgend beschriebene Ausstattung doch, dass die Feuersbrunst weniger zerstörerisch war, als es heute den Anschein haben mag. Denn einige Möbelstücke stammen noch aus dem zweiten Drittel des I7. Jahrhunderts, und das Marmorgewände des Sakristeiportals ist sogar auf

5 I 2 Berliner/Egger, Vorlageblätter ( I98 I), Bd. I, 8I, Bd. 2, Abb. 9I4-9I6.

5 I 3 Diese Hinweise finden sich im Restaurierungsbericht von Walter Gombocz.

5 I 4 Zum Bauwerk und seiner Geschichte Dehio, Tirol (I 980), 435-436. 


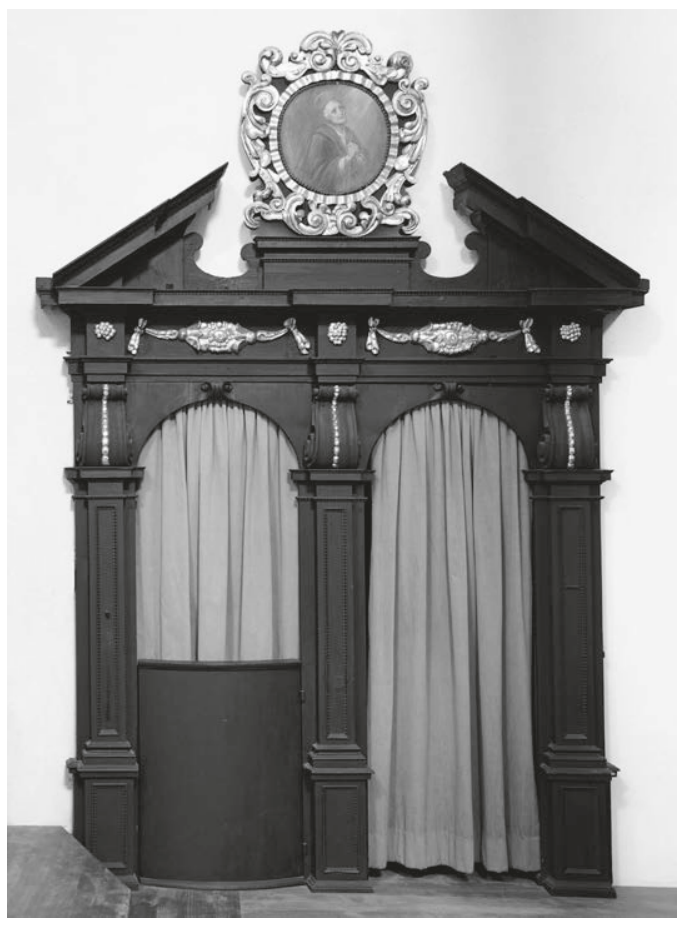

3 I 8 Beichtstuhl. Kramsach, um I640/60

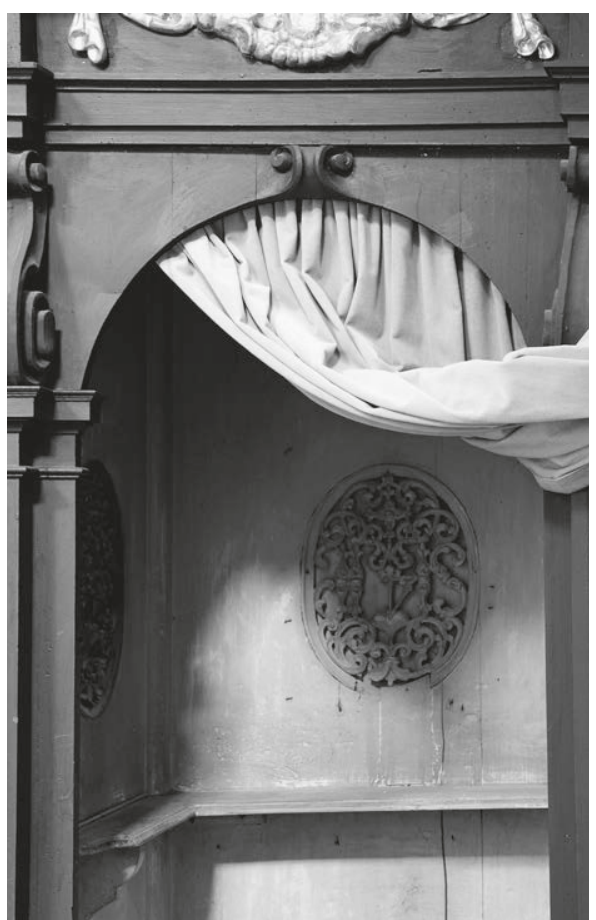

3 I9 Beichtstuhldetail mit einem Sprechgitter in der Rückwand. Kramsach, um 1640/60

das Jahr 1622 datiert. Nachdem das Kloster 1782 aufgehoben worden war, gliederte man es I 786 als Kaplanei der Pfarre Breitenbach an. I 804 riss man die Anlage bis auf einige Wirtschaftsgebäude und die Kirche ab, die r 89 I den Rang einer Pfarre erhielt.

Das erste Kirchenjoch nimmt die Westempore auf, die Vorhalle diente einstmals als Nonnenchor. Der heutigen Eingangshalle folgen im Langhaus zwei weitere Travéen und ein leicht eingezogener Chor mit polygonalem Abschluss. An die Südseite des Langhauses lehnen sich mit Sakristei und Marienkapelle niedrige Anbauten. Der Hochaltar, die mit Statuetten verzierte Kanzel sowie Teile der übrigen Ausstattung bis hin zum Gitter unter der Empore gehen nach den Angaben in der Literatur auf das Ende des I7. Jahrhunderts zurück.

\section{Beichtstühle}

Kramsach, um I640/6o

$\mathrm{H}$ ca. 3 I $8 \mathrm{~cm} \times \mathrm{B}_{2}$ I $5 \mathrm{~cm} \times \mathrm{T} 85 \mathrm{~cm}$

Nadelholz (?) geschwärzt, Holz vergoldet, innen graublau gestrichen 
Wandnischen am Ostende des Kirchenschiffs nehmen die beiden zweigliedrigen, durch ihre Gestaltung an Portalarchitekturen erinnernden Inventarstücke auf (Abb. 3I8, 3I 9). ${ }^{515}$ Drei hochgesockelte dorische Pilaster tragen schwere Volutenkonsolen, ein verkröpftes Gebälk und einen gesprengten Dreiecksgiebel, dessen Mitte ein flaches Postament mit dem Rundbild eines büßenden Heiligen einnimmt. Die Darstellung der Südseite vergegenwärtigt vermutlich den hl. Petrus, die der Nordseite Maria Magdalena. Knorpelschnitzereien und frühe Akanthusformationen rahmen die Gemälde, Flammleisten, Fruchtgirlanden und Blütenrosetten zieren die Möbel, vom schwarz gebeizten Korpus heben sich die vergoldeten Schnitzarbeiten effektvoll ab. Dieser Typus von Beichtstühlen ist uns schon in der Jesuitenkirche zu Innsbruck begegnet (Abb. 302). Christoph Gumpp d.J. (I600-I672) hatte sie dort um I628/30 entworfen und gebaut. Analog gestaltete Exemplare befinden sich außerdem in Brixlegg (Abb. 294).

Die Rückwand des südseitigen Kramsacher Möbels besitzt eine Öffnung mit einem Sprechgitter, dahinter ragt die Sakristeiwand auf. Möglicherweise liegt hier einer jener Fälle vor, bei denen ein Mauerdurchbruch die Beichte auch dann ermöglichte, wenn sich Geistlicher und Pönitent in verschiedenen Zimmern aufhielten. Im DehioHandbuch werden die beiden Beichtstühle auf das Ende des I7. Jahrhunderts datiert ${ }^{516}$, doch deutet die Großform der Beichtstühle ebenso wie der Schnitzzierrat auf ein früheres Herstellungsdatum hin. Späteren Datums dürften die Türen vor den Priesterstallen sein.

\section{Zweisitze}

Kramsach, um I640/60

$\mathrm{HS}_{\mathrm{I}} 3,5 \mathrm{~cm}$

$\mathrm{H}_{2} \mathrm{I}_{3} \mathrm{~cm} / 2 \mathrm{I} 7,5 \mathrm{~cm}(+\mathrm{I} 3,5 \mathrm{~cm}) \times \mathrm{B}_{5} 6 \mathrm{~cm}$

Nussbaum, massiv, aufgedoppelt, Nadelholz

Die Zweisitze stehen sich im Chorraum der Kirche gegenüber (Abb. 320, 32 I). ${ }^{517}$ An Brüstung und Rückwand flankieren Pilaster die als Ädikulen gestalteten und von $\mathrm{Mu}-$ scheln bekrönten Füllungen. Profile sind mit Flamm- und Perlleisten verziert, über die Flächen des Möbels legt sich feines knorpeliges Laubwerk. Vasen, in deren Öffnung schlanke Kegel zu stecken scheinen, zieren die Brüstungsfüllungen, Fruchtgirlanden den Gebälkfries. Die Schnitzornamente orientieren sich an einer Formensprache, die

5I 5 Dehio, ebd., 436.

5 I 6 Dehio, ebd.

5 17 Dehio, ebd. 


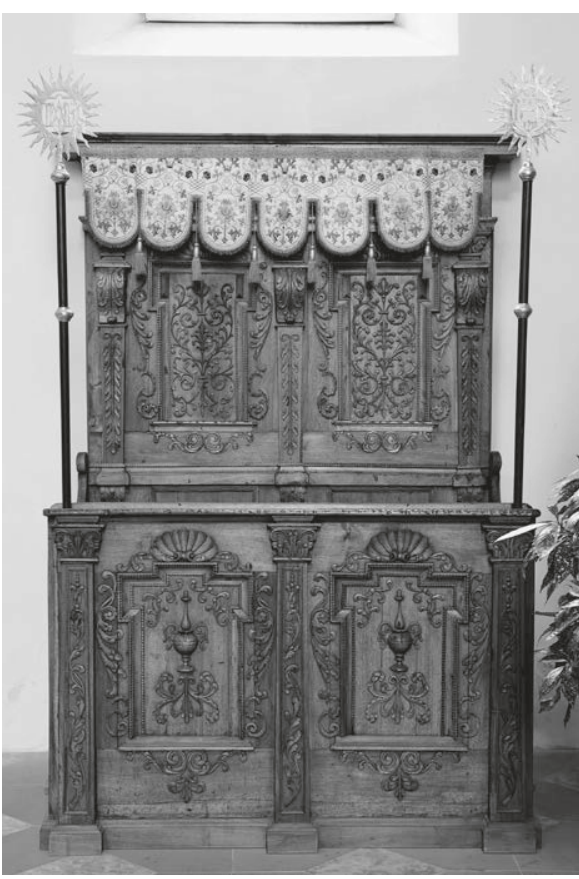

320 Zweisitz. Kramsach, um I640/60

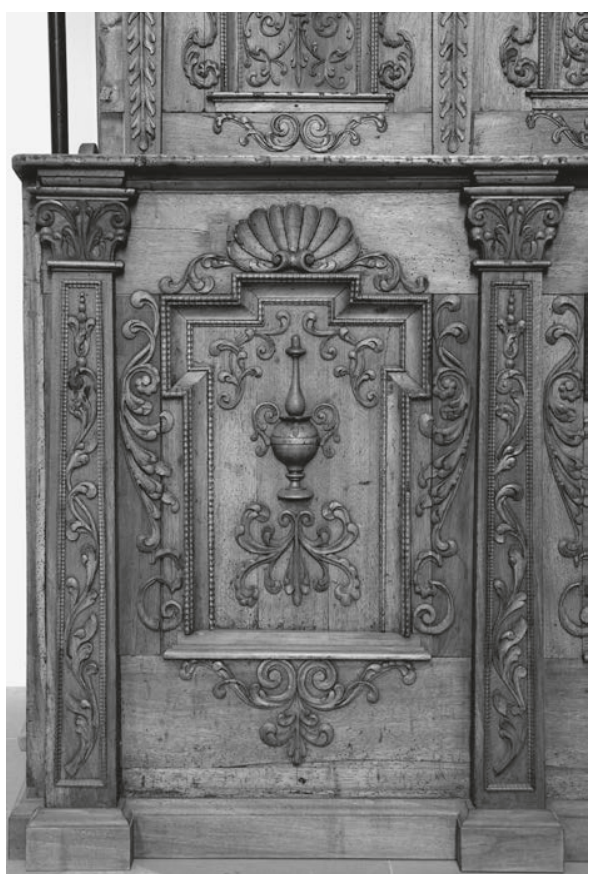

32 I Zweisitz (Detail). Kramsach, um I640/60

kaum nach der Jahrhundertmitte, eher zehn oder zwanzig Jahre früher gebräuchlich war. Die Sitzbänke, die Bankwangen, ein Teil der Banklehnen, der Laufboden und der Sockel sind Neuanfertigungen.

\section{Sakristeiportal}

Kramsach, um I650

Lichte Maße 2 I $4 \mathrm{~cm} \times$ I I I cm

Nuss, massiv und aufgedoppelt, Nadelholz. Eisen, getrieben, gemeißelt, verzinnt

Ein rundbogiger, auf r 622 datierter Architekturrahmen aus Marmor fasst die Sakristeitür ein (Abb. 322). Das Türblatt ist dem gemauerten Portal angepasst. Ein Gebälk in Höhe der seitlichen Pilasterkapitelle stützt schneckenförmige Voluten und ein schweres halbrundes Profil. Ein mittlerer Stollen teilt das Türblatt, in den Füllungen deuten geohrte Rahmen über einer Konsolleiste je eine hohe Ädikula an. Blattwerk und eine Fruchtgirlande zieren die Binnenfelder. 
Die Tür ist mehrschichtig aufgebaut. Auf der Sakristeiseite besteht sie aus massiven Nussbohlen, denen auf der Seite des Kirchenraums Nadelholz, massives Nussholz und dickes Nussfurnier aufgedoppelt wurden.

\section{Laiengestühl}

Typ A

Walchsee, um I650/6o

HS Io, $5 \mathrm{~cm}$

$\mathrm{H}$ 9I cm (+ IO,5 cm)/ IO3 cm $\times \mathrm{L}_{282,5} \mathrm{~cm} /$ I $4 \mathrm{I} \mathrm{cm}$

Eiche, Nadelholz, dunkelbraun gebeizt

Der Kirchenraum ist mit verschiedenen Bankgarnituren ausgerüstet. Vor der nördlichen Außenwand des Schiffs befinden sich elf Exemplare des Typs A, auf der Südseite sechs, hinzu kommen die üblichen Brüstungen,

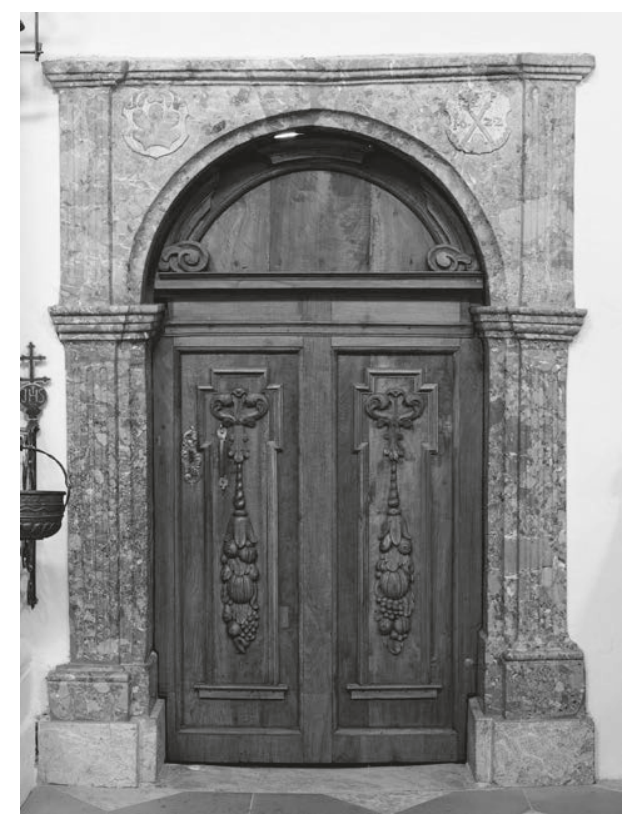

322 Sakristeitür. Kramsach, um I650 die um einige Zentimeter höher als die auf den Laufböden situierten Wangen sind (Abb. 323, 324). Die Schnitzarbeiten an Wangen und Brustwänden sind barockzeitlich, während die Möbel sonst weitgehend erneuert wurden.

Hermen flankieren die zweiachsige Vorderbrüstung der Möbel auf der Südseite. Sie besitzen Volutenfüße, einen geschuppten Schaft und tragen ionische Kapitelle. Die Ecken der Füllungen sind verkröpft, die Profile, die die Füllungen einfassen, mit Flammleisten verziert. Die Tischler legten den Binnenfeldern mit Knorpelschnitzereien gesäumte Kartuschen unterschiedlichen Aussehens auf und auch die Maße der Füllungen stimmen nicht überein: Die linke misst 70,5 $\mathrm{cm}$ in der Breite, die rechte nur $63 \mathrm{~cm}$. Das lässt die Interpretation zu, dass die Brüstung nicht im Originalzustand erhalten ist. Die nördliche Brustwand sowie die hinteren Brüstungsfelder sind weniger aufwendig, auf Hermen wurde dort verzichtet. Die Bankwangen besitzen grob die Umrissform einer asymmetrischen Violine. Die Taille ist nicht gleichmäßig modelliert, die Vorderseite des Halses etwas länger als die Rückseite. Kräftige Profile verlaufen längs der Kontur. Sie bilden Bögen aus, die sich teilweise nach innen drehen und mit einem Besatz aus perlenartigen Kugeln versehen sind. Der Grund zwischen den Stegen ist punziert. Laut der Auskunft des Mesners stammen die Bänke aus der etwa $50 \mathrm{~km}$ nordöstlich von Kramsach verorteten Gemeinde Walchsee. 


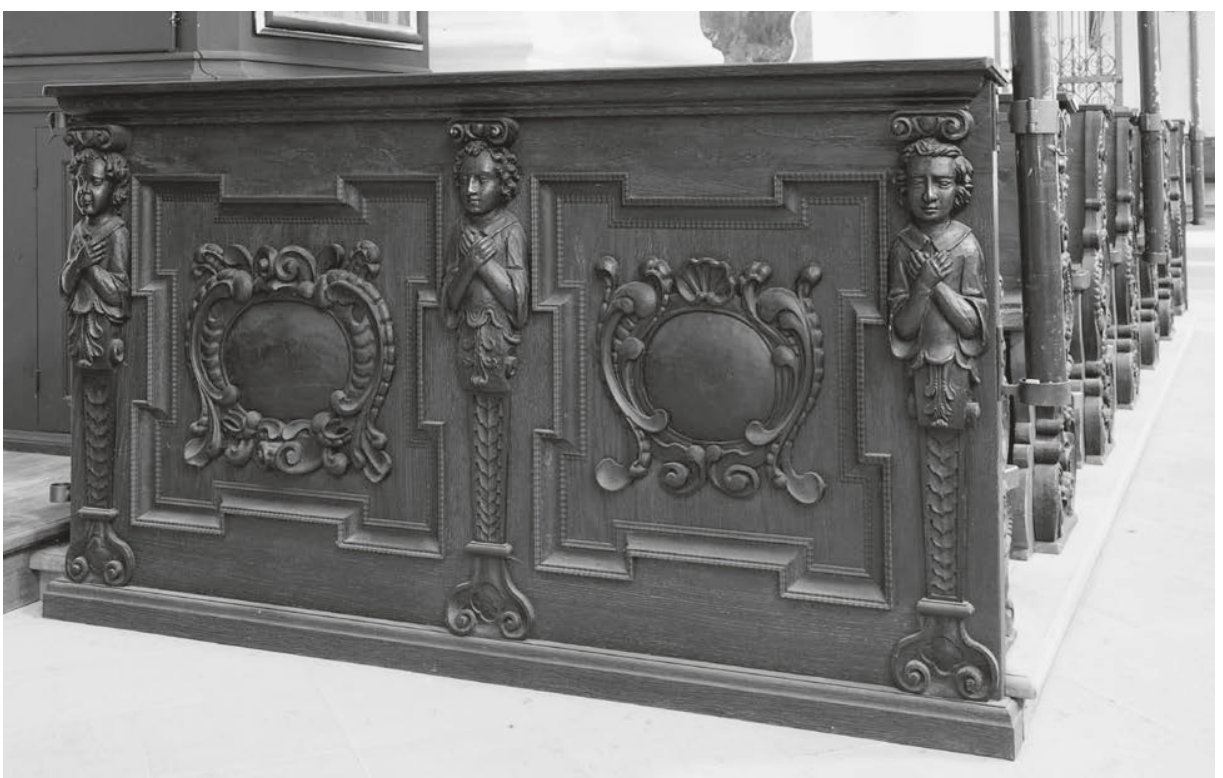

323 Kirchenbänke (Typ A), Brüstung. Walchsee, um r 650/60

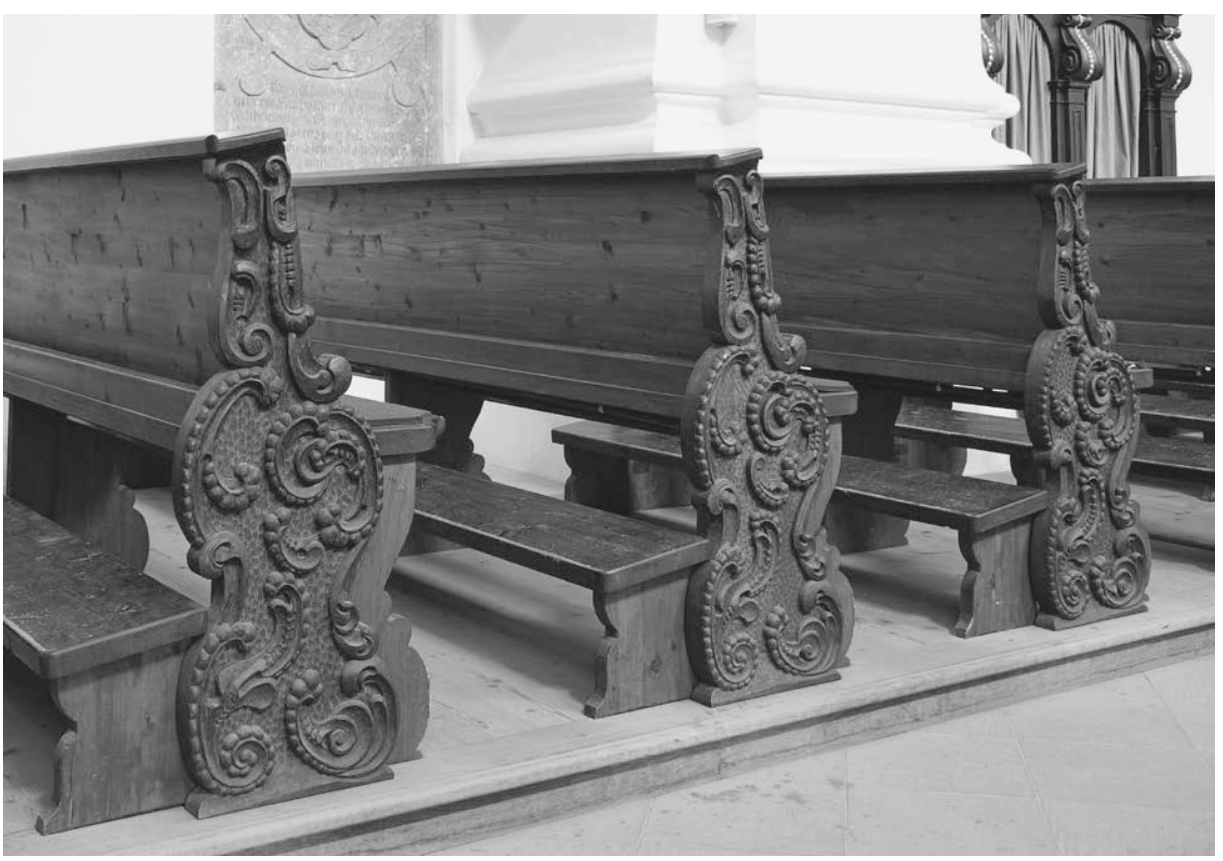

324 Kirchenbänke, Docken. Walchsee, um I650/60 
325 Kirchenbänke (Typ B), Docken. Kramsach, um I 650

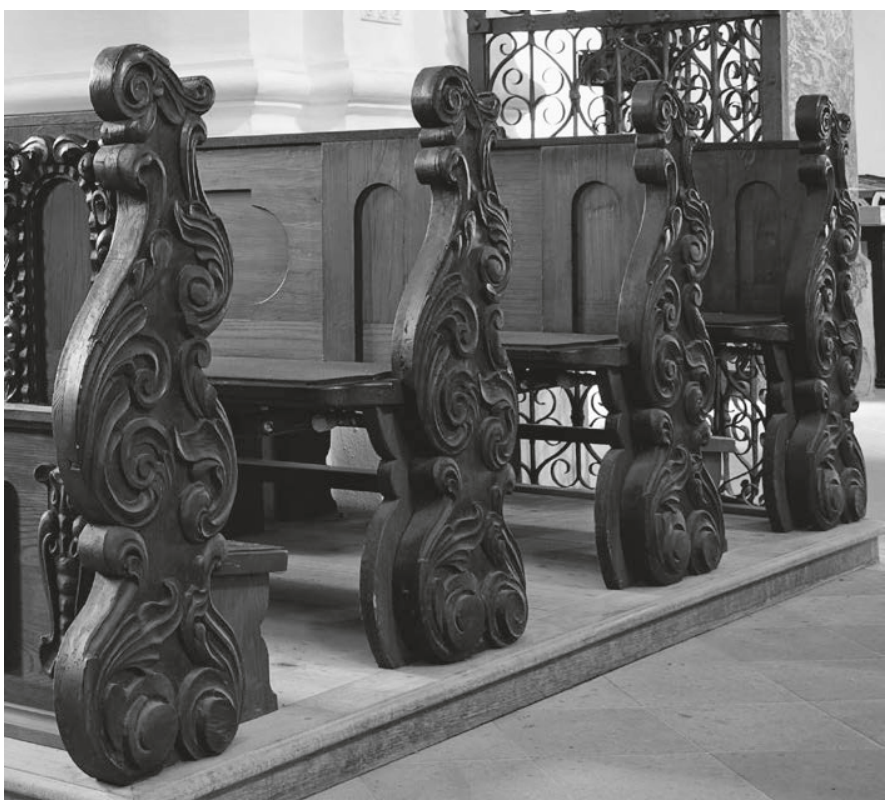

\section{Laiengestühl}

Typ B

Kramsach, Mitte I7. Jh.

HS I0, $5 \mathrm{~cm}$

$\mathrm{H}$ 104,5 $\mathrm{cm}(+\mathrm{IO}, 5 \mathrm{~cm}) \times \mathrm{L} 336 \mathrm{~cm} / 229 \mathrm{~cm} / 105 \mathrm{~cm}$

Nussbaum, Eiche, Nadelholz, dunkelbraun gebeizt

Der zweite Typ von Kirchenbänken umfasst drei Bänke unterschiedlicher Länge und die dazugehörende Brüstung am westlichen Ende der südlichen Kirchenschiffseite (Abb. 325).

Der Aufbau der Möbel entspricht dem der vorhergehend beschriebenen Exemplare. Brüstung, Banklehnen, Sitze und Kniebänke wurden erneuert. Ähnlich strukturiert wie die Lehnen des Typs C (Abb. 326), sind die Binnenfelder allerdings nicht geöffnet, sondern geschlossen, was dem ursprünglichen Aussehen wahrscheinlich nicht entspricht. Die Großform der Wangen gleicht im Prinzip der vorhergehend beschriebenen. Die Docken setzen wieder mit Voluten an, die sich nun jedoch mit markanteren Schwüngen nach oben fortsetzen, um in einer Liegevolute zu enden. Auf ausgeprägte Knorpelschnitzereien wurde weitgehend verzichtet, stattdessen gab man frühbarocken Bögen mit eingerollten Enden sowie stilisiertem Blattwerk den Vorzug. Damit stehen 


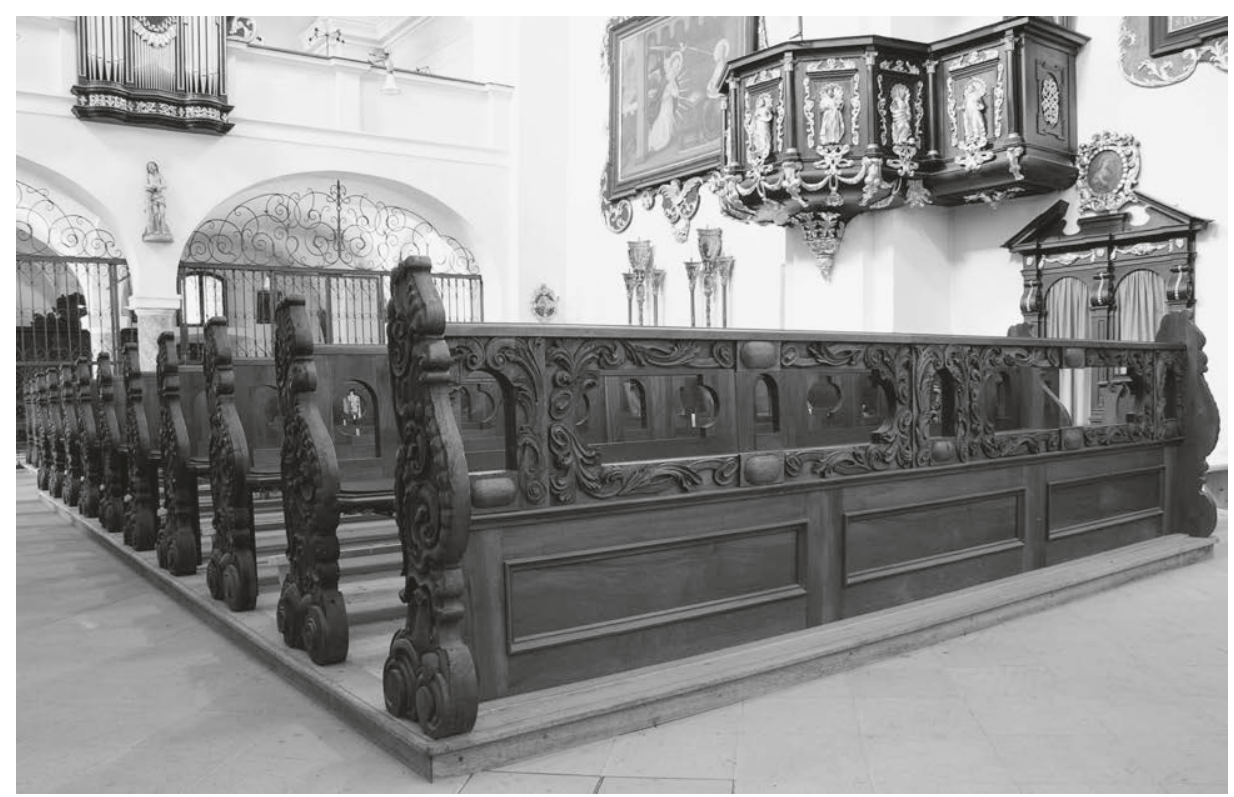

326 Kirchenbänke (Typ C). Kramsach, um I65o/6o

die Wangen auf einer Stilstufe mit den Möbeln in Kundl, die auf die Jahre um r650 oder I66o zu datieren sind (Abb. 337$)^{518}$.

\section{Typ $C$}

Kramsach, um i650/60

HS Io, $5 \mathrm{~cm}$

$\mathrm{H}$ IO7 cm (+ I0,5 cm) $\times \mathrm{L}_{343} \mathrm{~cm} / 40 \mathrm{Icm}$

Nuss, massiv und aufgedoppelt, Nadelholz

Zum Typ C gehören I 2 Sitzreihen in der Mittelachse des Längsschiffs, eine Bank unter der Empore sowie zwei Brüstungen (Abb. 326-328). Wie das nicht nur in Kramsach, sondern auch andernorts geschah, erneuerte man die Möbel größtenteils zusammen mit den Postamenten. Die Schnitzarbeiten gehören noch dem alten Bestand an, wohingegen die Trägerplatten komplett oder teilweise ausgetauscht wurden. ${ }^{519}$

5 I 8 Zwei weitere Bänke aus dem I7. Jahrhundert werden zusammen mit einer Brüstung seitlich des Eingangs aufbewahrt.

5 I 9 Freundlicher Hinweis des Restaurators Zeindl, in dessen Werkstatt die Bänke überarbeitet wurden. 


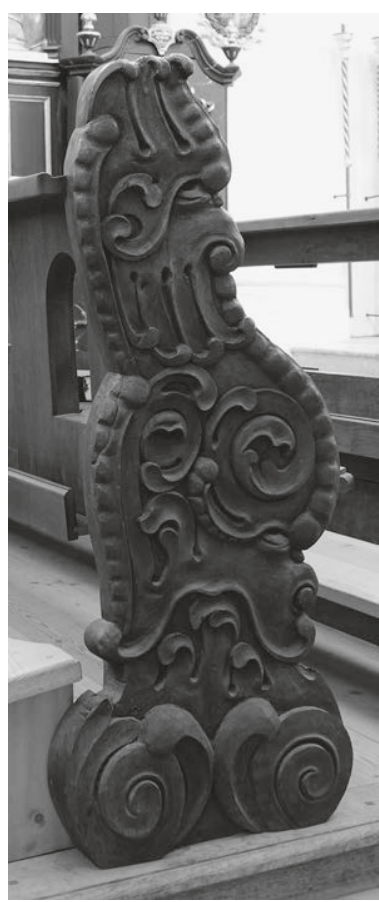

327 Bankwange. Kramsach, um I $650 / 60$

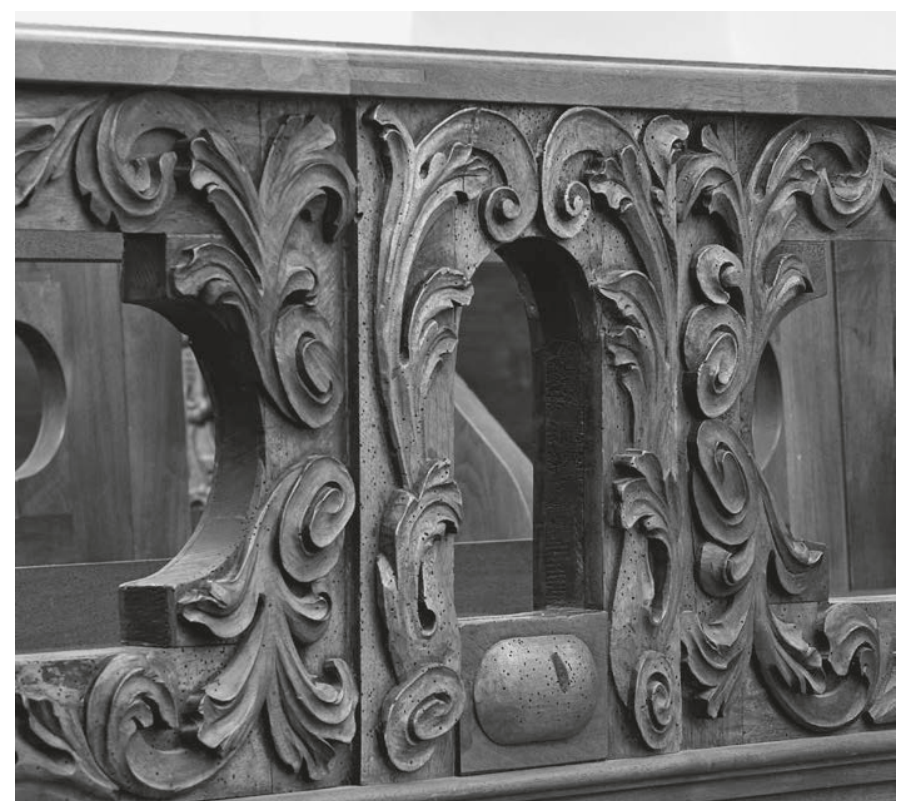

328 Kirchenbänke, Detailansicht der Brüstung. Kramsach, um I650/60. Die Bänke waren von Anobien befallen. Bei der Restaurierung musste das weiche Blindholz, das wesentlich stärkere Schäden als das harte Nussholz aufwies, ersetzt werden. Heute kann mit Hilfe moderner Techniken auch eine stark beschädigte Holzstruktur stabilisiert und erhalten werden.

Die Brustwände sind nicht geschwungen, sondern als gerade, aber horizontal zweigeteilte Wände konzipiert. Die untere Hälfte ist geschlossen, die obere ähnlich wie die Möbel in der Innsbrucker Jesuitenkirche (Abb. 303, 304) mit zwei breiten und drei schmalen Öffnungen durchbrochen. Während unten Rahmen und Füllungen glatt, flächig und nicht weiter verziert sind, vervollständigen stilisiertes Blattwerk und nach vorn gewölbte Querovale die obere Brüstungshälfte. Die stilistische Nähe dieser Möbel zu den Gestühlen in Innsbruck, Wilten (Abb. 372, 373) oder Stams (Abb. 349, $\left.35^{\circ}\right)$ ist frappierend, mit den Bänken aus übrigen Regionen Österreichs haben diese Exemplare nur wenig gemein.

Anders als in Salzburg und im Salzburger Land wurden die Wangen hier als konstruktive und optische Einheit aufgefasst, Holzbildhauer versahen sie mit kräftigen Schnitzarbeiten. Die Palette der Schnitzereien umfasst Voluten, keulenartige Bögen, schotenartige Gebilde und Masken. Beim Bau der Docken wurde massives Nussholz verwendet. 


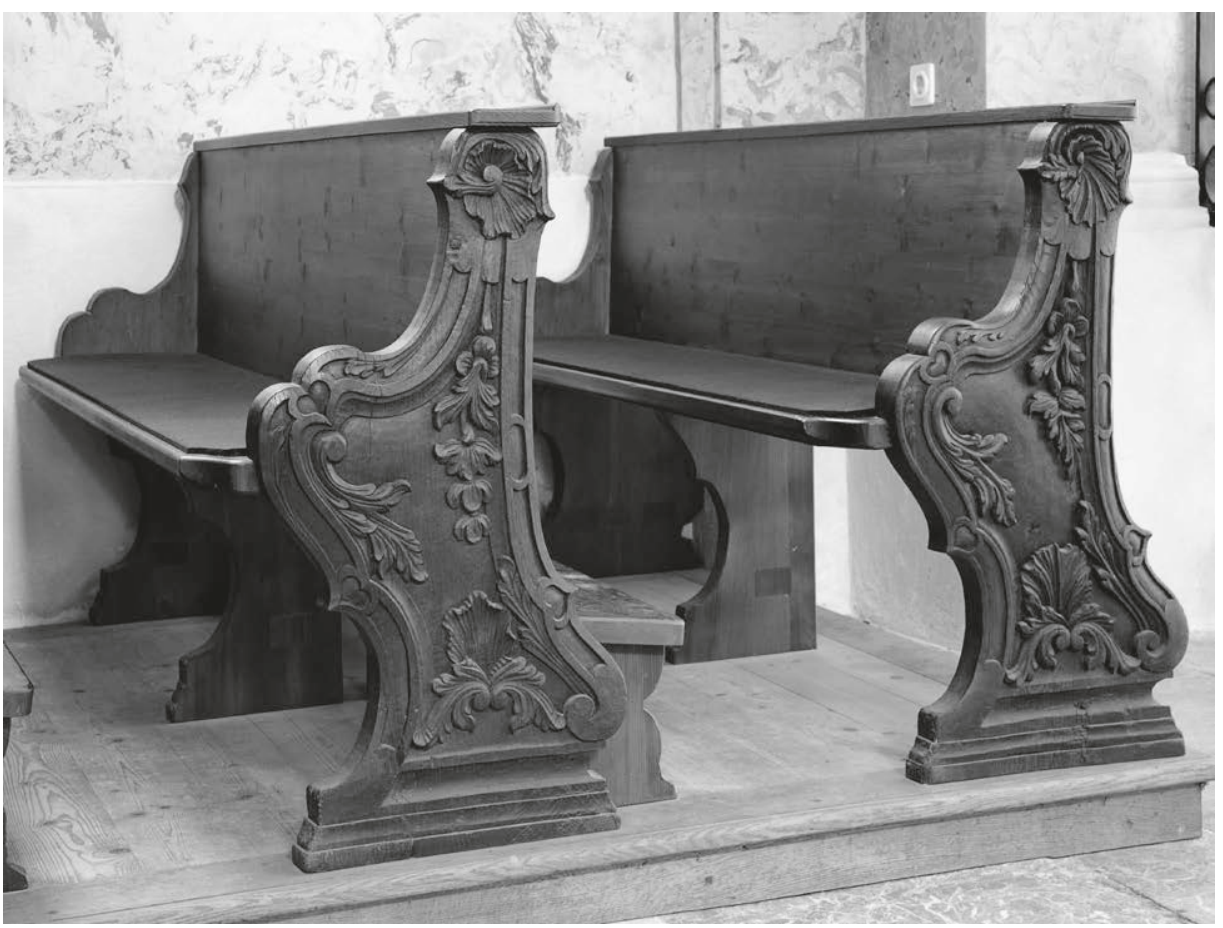

329 Kirchenbänke (Typ D). Walchsee, um I $745 / 55$

\section{Laiengestühl}

Typ D

Walchsee, um $\mathrm{I} 745 / 55$

HS I0, $5 \mathrm{~cm}$

$\mathrm{HW} 89,5 \mathrm{~cm}(+\mathrm{IO}, 5 \mathrm{~cm}) \times \mathrm{L} \mathrm{I} 72 \mathrm{~cm}$

Eiche, Nadelholz

Der mündlichen Überlieferung zufolge sind zusammen mit den Bänken des Typs A noch vier weitere Exemplare von Walchsee nach Kramsach gelangt (Abb. 329). Die Möbel werden in der Marienkapelle aufbewahrt.

Auch diese Garnitur wurde umgebaut, alte Wangen fügte man einer neuen Brüstung sowie modernen Bänken und Lehnen an. Während die Docken zum Gang zu mit Schnitzarbeiten verziert sind, beließ man sie auf der Wandseite schmucklos. Hier zeigt sich deutlich der formale Unterschied zwischen Möbeln des I7. und I 8. Jahrhunderts. Über einer Sockelleiste erhebt sich die konkav geformte Rückseite, während vorn ein 
großer gebrochener S-Bogen den Anlauf und den Bauch bildet. Darüber führt eine CSpange in die Höhe. Ein abgeflachter Halbkreis, auf dem die Buchablage befestigt ist, bildet den Abschluss. Breite Profile begleiten die Wangenaußenkanten, über die Binnenfelder legen sich Blütengirlanden und Blattwerk. Außerdem kommen hier frühe Rocailleornamente vor, die eine Datierung der Wangen kurz vor oder um die Jahrhundertmitte wahrscheinlich werden lassen. Wangen und Gebetbuchablagen bestehen aus Eiche, die übrigen Möbelteile aus Nadelholz.

\section{Kundl, Filial- und Wallfahrtskirche St. Leonhard auf der Wiese}

Schriftquellen berichten seit 788 von dem Weiler Kundl, der etwa 20 km von Brixlegg entfernt liegt. ${ }^{520}$ In der relevanten Literatur wird die Frage kontrovers diskutiert, ob ein Vorgängerbau von St. Leonhard bereits im I I. Jahrhundert existierte, unbestrittene Tatsache ist jedoch, dass die heutige Sakralarchitektur zwischen I 480 und dem frühen I6. Jahrhundert errichtet wurde. Der mit einem Netzrippengewölbe überspannte einschiffige Kirchenraum besitzt vier Joche, wobei die spätmittelalterliche Empore die erste Travée beherrscht. Ein Spitzbogen schiebt sich zwischen das Langhaus und den eingezogenen dreijochigen Chor, der mit einem 5/8 Schluss endet. Auf der Evangelienseite befindet sich im ersten Chorjoch neben dem Aufgang zur Kanzel ein spätgotisches Sakristeiportal. Hochaltar, Kanzel, ein bemerkenswertes Triumphbogenkreuz und andere Inventarstücke stammen aus dem I 7. Jahrhundert. Bekannt ist die Kirche nicht nur für die anspruchsvolle Architektur, sondern auch für die qualitätvollen spätgotischen Gewölbemalereien im Chor und Langhaus. Ebenso eindrucksvoll ist die in der Literatur nur am Rande erwähnte Tischlerausstattung. Eisenhütten und ein Schmelzwerk sorgten im I5. und I6. Jahrhundert in der Gegend für einen gewissen Wohlstand, eine wesentliche Voraussetzung für hochkarätige Aufträge. Ob in Kundl allerdings eine Tischlerei existierte, die auf solch hohem Niveau arbeitete, ist fraglich, wahrscheinlich ist eher von einer Herstellung der Tischlerarbeiten in Brixlegg auszugehen.

\section{Sakristei}

Zwei massive Türen öffnen die kleine Sakristei zur Kirche und zu einem Kirchenvorplatz hin. Hier im Kontext interessiert ein prachtvoller Aufsatzschrank.

520 Hootz, Kunstdenkmäler (1965-1968), Bd. I (1965), 107, 108, 324; Dehio, Tirol (1980), 447-449; Neuhardt, Kundl (2005), 2-3, 8-I 5 . 
Aufsatzkredenz

Kundl (Brixlegg?), um r640/60

$\mathrm{H}$ der Sockelleiste $7,5 \mathrm{~cm}$

$\mathrm{H} 293 \mathrm{~cm}(+7,5 \mathrm{~cm}) \times \mathrm{B} 273,5 \mathrm{~cm} \times \mathrm{T} 84,5 \mathrm{~cm}$

Nuss, massiv und aufgedoppelt, Nadelholz. Eisen, gemeißelt und verzinnt

Die architektonische Instrumentierung des Unterschranks basiert auf drei Stützenpaaren, zwischen denen hochovale Binnenfelder mit rechteckigen Kompartimenten wechseln (Abb. 330, 33I). Große Türen füllen den Raum zwischen den mit "geteilten« Füßen, Blockkapitellen und Schuppenfriesen dekorierten Volutenpilastern. Unten birgt das Möbel Fächer, mit den nach oben weisenden Handhaben lassen sich die Türen entriegeln. Das Sockelgeschoss des Aufsatzes ist mit Schubladen bestückt, Türen schließen die Hauptzone. Der Hut trägt einen hohen Auszug, den schwere Voluten optisch stützen. Glatte Profile und Flammleisten halten die verkröpften Binnenfelder.

Lisenen mit Muscheln, von denen Stoffdraperien und Blütengirlanden herabhängen, flankieren die Türen des Oberschranks. Das Motiv erinnert an die Ausgestaltung zentralitalienischer Möbel des späten 16 . Jahrhunderts ${ }^{521}$, findet sich aber auch an österreichischen Möbelstücken des folgenden Säkulums wieder, etwa am Chorherrengestühl in St. Stephan zu Wien von I647 oder an den Beichtstühlen in der Stiftskirche zu Wilten von $1665 / 75$ (Abb. 376). ${ }^{522}$ Dort handelt es sich um den Dekor an großen Füllungen und Pilasterschäften. Weitere Schnitzarbeiten am Aufsatz des Schranks in Kundl setzen sich aus kleinteiligen Bögen zusammen, schwere knorpelige Motive kommen lediglich an den Voluten seitlich des Auszugs vor. Eine ovale, sich nach außen wölbende Kartusche schmückt die mittlere Tür, Frauenköpfe mit Stoffgirlanden akzentuieren die Konsolen im Gebälkfries. Wie beim Eierstab, der das Gesims vervollständigt, handelt es sich bei den Frauenköpfen um renaissancezeitliche Ornamentmotive.

52 I Schottmüller, Wohnungskultur ( 192 I), Abb. 227. Die Abbildung zeigt eine toskanische Kredenz aus der zweiten Hälfte des I6. Jahrhunderts. Die tektonische Gestaltung ihrer Fassade beruht auf lisenenartigen Bändern, die mit einer Volute enden. An ihr sind kräftige Fruchtgirlanden befestigt.

522 Zum Chorherrengestühl s. Bohr, Sakralmöbel (2017), 222-225. 
330 Sakristei, Aufsatzschrank. Kundl (Brixlegg?), um r640/60

33 I Sakristei, Aufsatzschrank (Teilansicht). Kundl (Brixlegg?), um I640/60
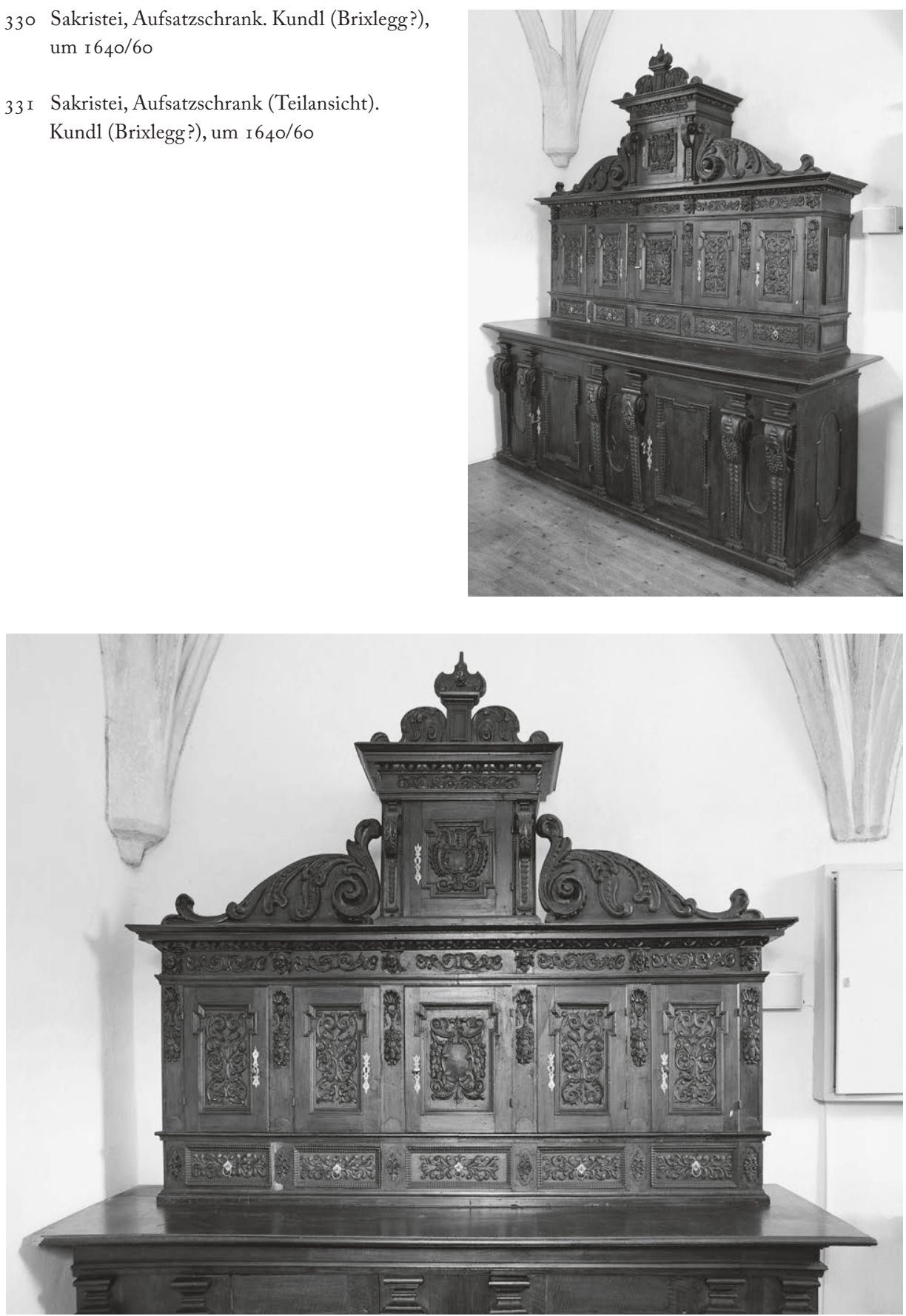


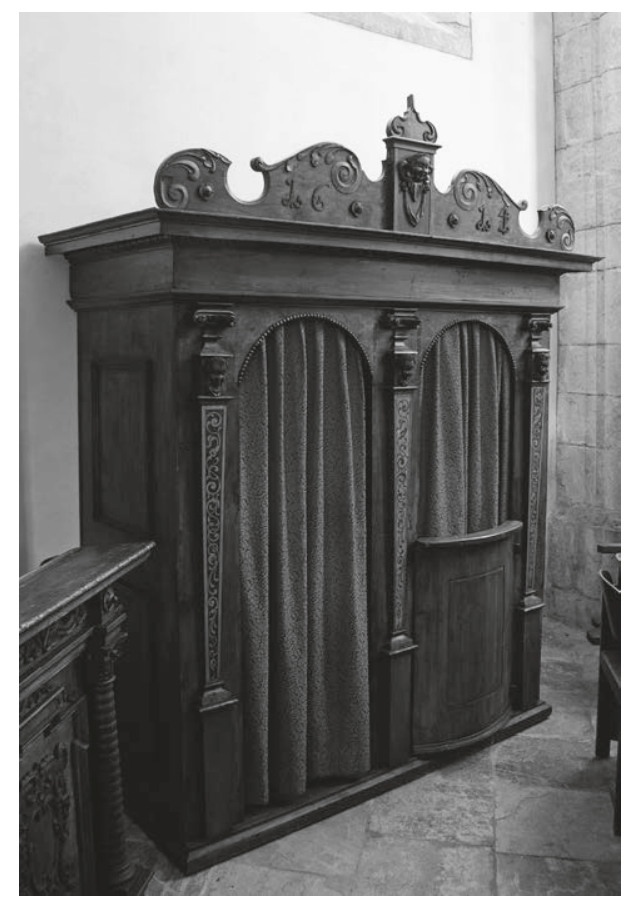

332 Beichtstuhl hinter dem Altar. Kundl (Brixlegg?), I6 I 4

\section{Kirchenraum}

Beichtstubl

Kundl (Brixlegg?), I6 I 4

$\mathrm{H}$ der Sockelleiste $8 \mathrm{~cm}$

$\mathrm{H} 243 \mathrm{~cm}(+8 \mathrm{~cm}) \times \mathrm{B} 205 \mathrm{~cm} \times \mathrm{T} 96 \mathrm{~cm}$

Nussholz, Nadelholz, Buche. Eisenbänder

Das Möbel steht hinter dem Altar auf der Evangelienseite (Abb. 332). ${ }^{523}$ Es besitzt einen fassadenartigen Aufbau, zwei von Keilpilastern flankierte Rundarkaden gestatten den Zutritt zu den Gehäusen. Eingelegte Schweifwerkornamente zieren die Stützen, die Intarsien der seitlichen Pilaster zeigen helle Ornamente in dunklem Grund, an der Mittelstütze wählten die Tischler eine Farbigkeit im Gegensinn. Die motivisch identischen Ornamente wurden vermutlich aus aufeinandergeleimten dunklen und hellen Furnierblättern in einem einzigen Arbeitsgang gesägt. Damit erinnern die Intarsien an die um I6 20 gebauten Schatzkammerschränke in Kremsmünster. ${ }^{524}$ Cherubim zieren die Schulterstücke unter den Kapitellen, aufgeleimte Rahmen deuten an den Schmalseiten je zwei Scheinfüllungen an. Der Beichtstuhl schließt mit einem hohen Gebälk und einem Auszug. Seine Mitte betont ein mit einem Frauenkopf verziertes Postament, das seitliche Schleierbretter flankieren. Sie sind mit frühbarocken Ornamenten dekoriert und I6 I4 datiert. Folglich ist das Möbel der früheste moderne Beichtstuhl mit dreiseitig geschlossenem Gehäuse, den wir bisher in österreichischen Kirchen nachweisen können. $^{525}$

523 Dehio, Tirol (1980), 449; Neuhardt, Kundl (2005), I 2.

524 Bohr, Sakralmöbel (2017), 5 I 7-522. Diese Arbeitsweise entspräche der späteren Boulle-Technik.

525 Bohr, ebd., 90-95. Vgl. außerdem den Abschnitt über die Beichtstühle in der Innsbrucker Jesuitenkirche. 


\section{Beichtstubl}

Kundl (Brixlegg?), um I640/60

HS $7,5 \mathrm{~cm}$

$\mathrm{H} 286 \mathrm{~cm}(+7,5 \mathrm{~cm}) \times \mathrm{B} 227 \mathrm{~cm} \times \mathrm{T} 87 \mathrm{~cm}$

Nussholz, massiv, Nussfurnier, Nadelholz

Im Groben entspricht der Aufbau des Beichtstuhls auf der Epistelseite dem vorhergehend beschriebenen Möbel, Unterschiede ergeben sich vor allem in der Qualität der handwerklichen Ausführung und in den Detailformen (Abb. 333). Rollvoluten tragen die mit Fantasiekapitellen versehenen Pilaster, die Bekrönung besteht aus einem Sprenggiebel mit hochovaler Kartusche, die die seitlichen Giebelschenkel weit überragt. Das Möbel zieren keine Intarsien, sondern kleinteilige Schnitzarbeiten an den Korpusflächen, kräftigere am Auszug. Die hohe künstlerische und technische Qualität zeigt sich unter anderem in der Verzierung der Arkadenbögen mit Flammleisten und im Schmuck der Zwickelfelder. Die Tatsache, dass lediglich die Fassade orna-

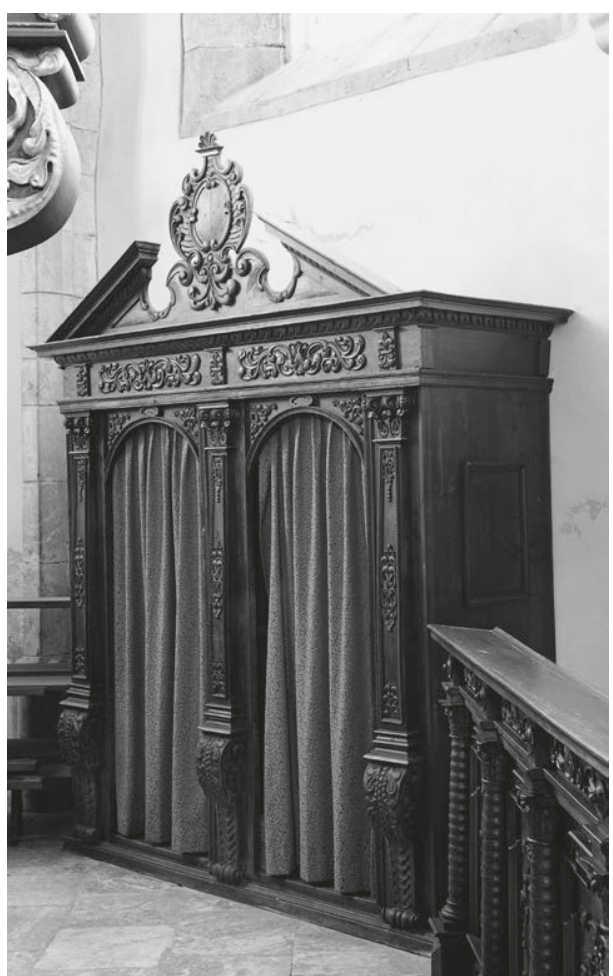

333 Beichtstuhl hinter dem Altar (Brixlegg?), um I640/60 mentiert ist, belegt, dass man wie an anderen Möbelstücken jener Epoche auch hier mit einer reinen Vorderansicht rechnete, die Ausgestaltung der Schmalseiten spielte eine untergeordnete Rolle. Entwicklungsgeschichtlich steht das Möbel zwischen den Beichtstühlen in der Innsbrucker Jesuitenkirche von etwa I6 30 und den Exemplaren in Wilten von $\mathrm{r} 665 / 75$ (Abb. 302, 376).

\section{Chorgestübl}

Kundl (Brixlegg?), um I640/60

HS I $6,5 \mathrm{~cm} / 2 \mathrm{I}, 5 \mathrm{~cm}$

$\mathrm{H} 258 \mathrm{~cm} / 270 \mathrm{~cm}$ (jeweils $+\mathrm{I} 6,5 \mathrm{~cm} / 2 \mathrm{I}, 5 \mathrm{~cm}$ ) $\times \mathrm{L} 246 \mathrm{~cm} / 255 \mathrm{~cm}$

Nuss, massiv, Nadelholz

Im zweiten, dritten und vierten Chorjoch stehen sich zwischen Wandstützen beidseitig je drei Teile eines Gestühls gegenüber, das insgesamt 24 Plätze umfasst (Abb. 334- 

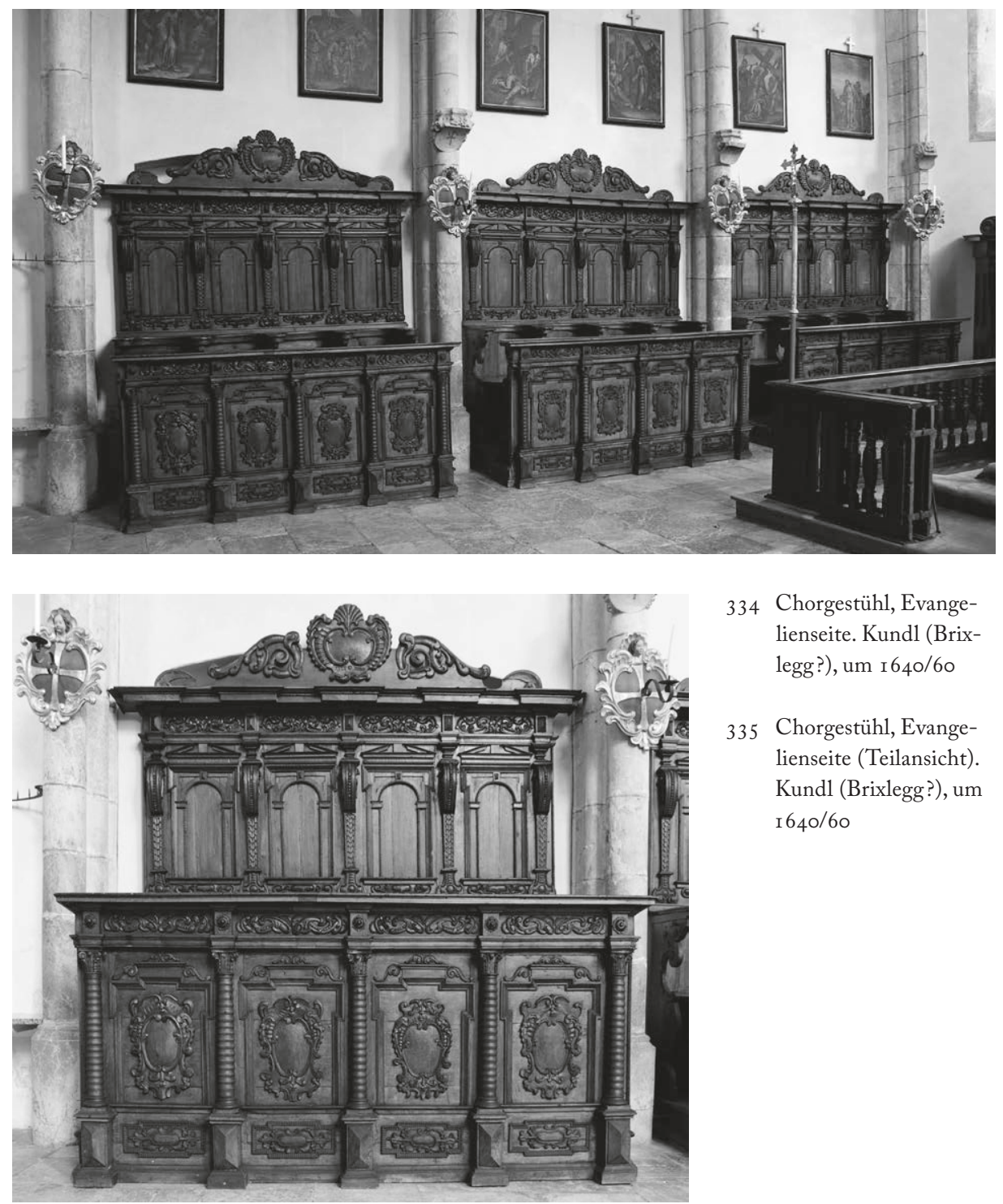

334 Chorgestühl, Evangelienseite. Kundl (Brixlegg?), um I640/60

335 Chorgestühl, Evangelienseite (Teilansicht). Kundl (Brixlegg?), um I640/6o

336). ${ }^{526}$ Die in jener Zeit im Möbelbau häufig gewählte und auf den Regeln der klassisch-antiken Architektur basierende Massengliederung definiert das Aussehen der Möbelgruppe. Brüstung und Dorsale sind jeweils in Sockelzone, Hauptteil und

526 Dehio, Tirol (1 980), 449. 
Gebälk unterteilt, ein Schnitzauszug bekrönt die Rückwand. An der Brüstung tragen mit Diamantquadern verzierte Piedestalli die aus Wülsten zusammengesetzten korinthischen Dreiviertelsäulen, Ädikulä bilden die Füllungen. Dagegen beruht die Strukturierung der Rückwand auf geschuppten Henkelpilastern, wieder wurden die Füllungen als welsche Fenster interpretiert, die nun jedoch auf veritablen Sockeln aufsitzen und mit Dreiecksgiebeln bekrönt sind. Rundbogige Arkaden vervollständigen die Dorsalefelder, wohingegen der Dekor der zentralen Brüstungsfelder aus hochovalen Kartuschen besteht. Teigiges Schnitzwerk mit eingefügten Groteskmasken überzieht einen Großteil der Flächen. Nicht kleinteilige Ornamentmotive wie an der Front, sondern kräftige Formen bereichern die $\mathrm{Au}-$ ßenwangen, Punzierungen sorgen für eine flirrende Oberfläche und ein spannungsgeladenes Wechselspiel zwischen hellen und dunklen Partien. Brustwand und Dorsale wurden aus Nuss-, Stallen und Kniebank aus

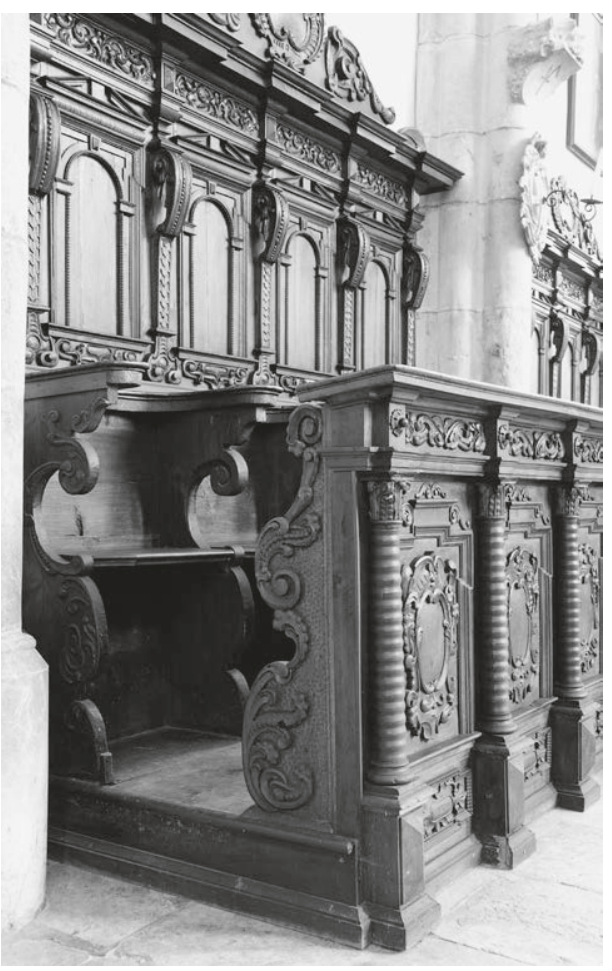

336 Chorgestühl (Schrägansicht). Kundl (Brixlegg?), um I640/60 Nadelholz gefertigt.

\section{Kirchenbänke}

Brixlegg/Kundl, um I650/6o

$\mathrm{HS} 9 \mathrm{~cm}$

$\mathrm{H}$ I $06,7 \mathrm{~cm}(+9 \mathrm{~cm}) \times \mathrm{L} 308 \mathrm{~cm} / 343 \mathrm{~cm} / 384 \mathrm{~cm}$

Nuss, Eiche, Nadelholz, nussfarben gebeizt

Im Langhaus wurden seitlich des Mittelgangs zwei Blöcke mit Bänken platziert, der Block auf der Nordseite zählt neun Möbel, der andere sechs (Abb. 337). ${ }^{527}$ Unter der Empore stehen weitere vier Exemplare dieses Typs, Brüstungen sind nicht vorhanden. Wangen schließen die Bänke nur auf der Gangseite ab, außen befestigte man sie an der

527 Hootz, Kunstdenkmäler (I 965-1968), Bd. I (1965), ro8, 324; Dehio, ebd.; Neuhardt, Kund1 (2005), I 2 . 


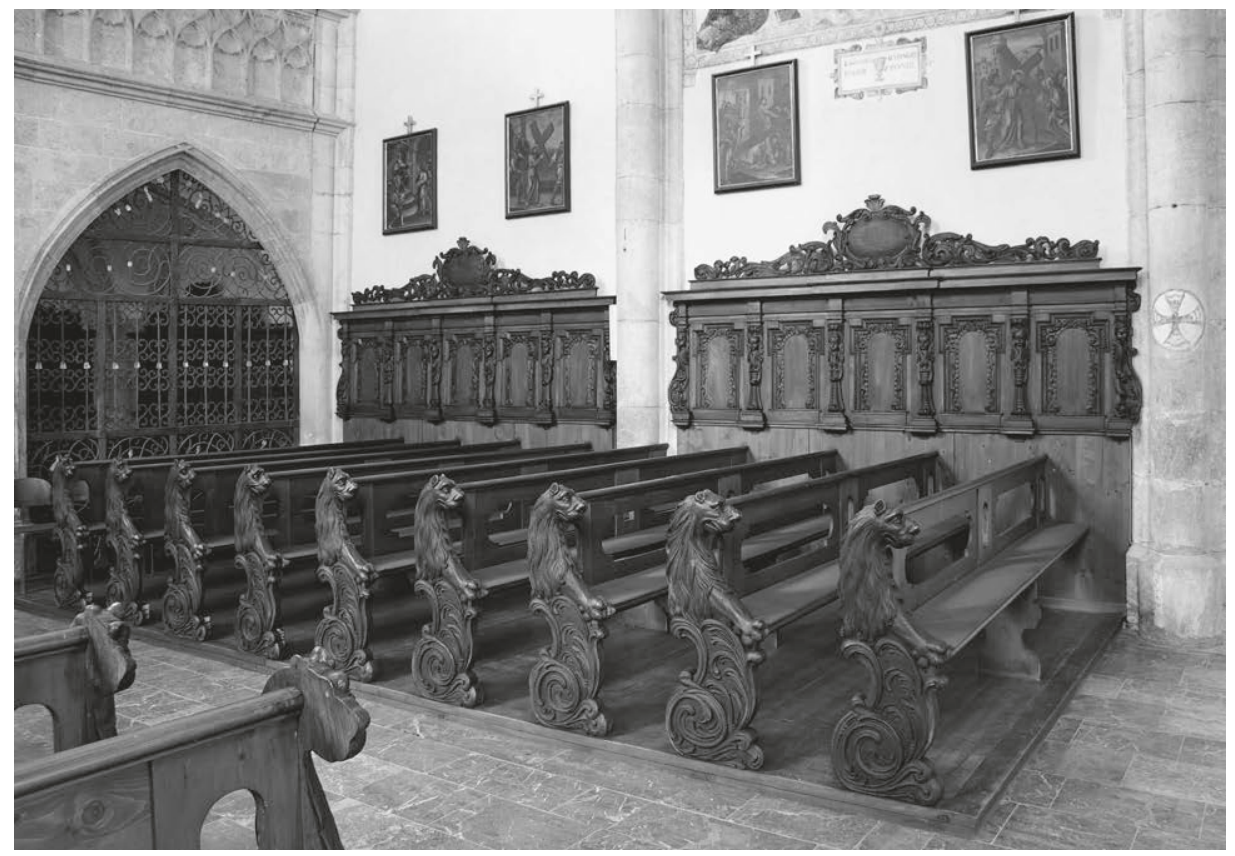

337 Bankwangen und Getäfel, Brixlegg / Kundl, um r650/60 (Sitzbretter, Lehnen, Laufböden und der untere Bereich der Wandverkleidung sind modern)

Wandverkleidung. Die Docken bestehen aus Nussholz oder nussfarben gebeizter Eiche, die neuen Rückenlehnen, Sitz- und Kniebänke dagegen aus dunkel eingefärbtem Nadelholz. ${ }^{528}$ Identische Bankwangen wurden bereits in Verbindung mit der Pfarrkirche in Brixlegg besprochen (Abb. 293), eine Beschreibung erübrigt sich daher.

Auf der Empore befindet sich ein weiteres Exemplar dieses Typs. Seine Höhe beträgt $107 \mathrm{~cm}$, seine Länge $222 \mathrm{~cm}$. Zur Raummitte hin mit einer geschnitzten Wange ausgestattet, wird die Bank außen von einer schlichten Stele getragen, die an der Wand angebracht ist. Die Tischler fertigten die geschnitzte Wange aus Nussholz, die Lehne aus Eiche, Nuss und einem Nadelholzkern. Gebetbuchablage und Sitzbank stellten sie ebenfalls aus Eichenholz her, die Stele aus Weichholz. Die Lehnen der Möbel im Kirchenschiff und auf der Empore entsprechen sich, doch weist die auf der Empore nur eine vollständige Queröffnung auf, die zweite ist angeschnitten. Offensichtlich wurde die barocke Bank gekürzt, ist sonst aber im Originalzustand erhalten.

528 Eine historische Abbildung der Bänke in: Hochenegg, Kirchen Tirols (1935), 97. 


\section{Getäfel}

Kundl (Brixlegg?), um I 650/60

$\mathrm{H}$ der modernen Verkleidung I $28,5 \mathrm{~cm}$

H Aufsatz ${ }_{1} 63 \mathrm{~cm} \times$ gesamte L ca. 22,60 $\mathrm{m}$

( $10,30 \mathrm{~m} / 7,70 \mathrm{~m} / 4,60 \mathrm{~m}$ )

Nuss, massiv und aufgedoppelt, Eiche, Nadelholz

Das Getäfel wurde an den Außenwänden des Emporenjochs sowie des ersten und zweiten Langhausjochs angebracht (Abb. 337, 338). ${ }^{529}$ Die Länge der einzelnen Segmente variiert.

Aufbau und Aussehen des Getäfels gleichen der Gestaltung von Chorgestühlrückwänden. Eine moderne hölzerne Verkleidung, deren Höhe etwa der der Rückwand einer Stallenreihe entspricht, trägt das originale Getäfel. Dessen Sockel schließt mit einem von Konsolen unterbrochenen Gesims, über dem sich mit Cherubim verzierte Pilaster aufrichten. Sie stützen ein verkröpftes Gebälk und einen

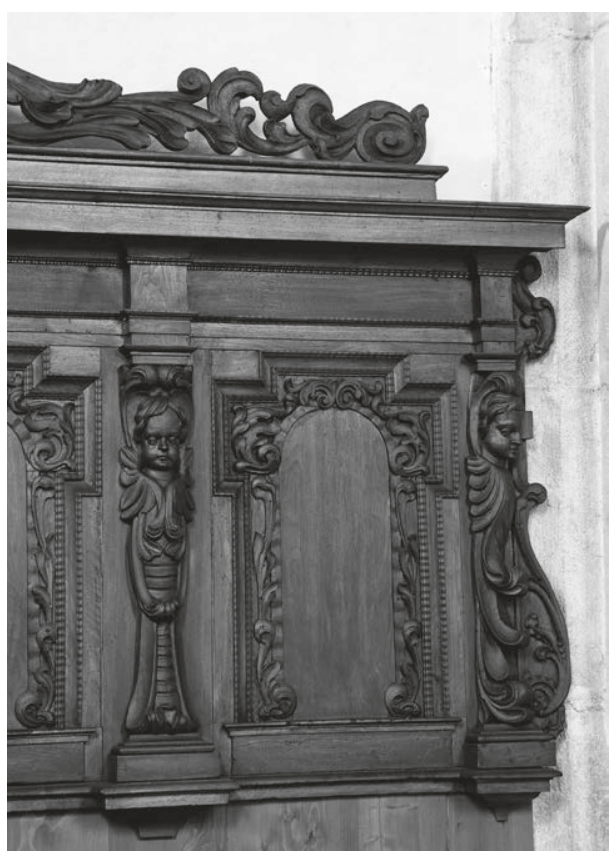

338 Getäfel, Rückwand (Detail). Kundl (Brixlegg?), um I650/60 Schnitzaufsatz, der aus einer mittleren Kartusche und seitlichen Akanthusranken zusammengefügt wurde. Ähnlich vielen anderen vormodernen Möbeln bilden Ädikulä mit rundbogigen Arkaden die Füllungen, hier sind die welschen Fenster allerdings auf Sockel und kreuzförmige Hochrechtecke reduziert. Flammleisten folgen ihrer Kontur, vegetabile Ornamentformen und ein Profil, das an ein Stoffband erinnert, dem Umriss der Arkaden. Die Basen und Kapitelle der Pilaster, deren Schaft sich mit einer sanften Kurve zur Basis hin verbreitert, sind zu Voluten umgearbeitet.

Das heutige Aussehen des modernen Teils des Getäfels entspricht vermutlich nicht dem historischen Zustand. Falls die originalen Substruktionen nicht ursprünglich Stallen oder Sitzbänke trugen, werden sie einst ebenfalls strukturiert gewesen sein. Zumindest aber dürfte eine kräftige Leiste das Dorsale getragen haben, denn die Pilaster der alten Verkleidung werden kaum ohne ein entsprechendes optisches Widerlager im unteren Wandbereich ausgekommen sein.

529 Dehio, Tirol (1980), 449. 


\section{St. Georgenberg, Benediktinerabtei}

\section{Stiftskirche zum hl. Josef, Vomp-Fiecht}

Rathold von Aibling (ca. 900-954 ?) aus Bayern gründete die Einsiedelei St. Georgenberg auf einem Felsmassiv nördlich von Schwaz. ${ }^{530}$ Ein erster, dem hl. Georg geweihter Sakralbau soll bereits damals errichtet worden sein. Um I Ioo erhielt die kleine Kommunität als bedeutende Dotation eine Reliquie ihres Namenspatrons, woraufhin die Kirche zum Ziel von Wallfahrten wurde. ${ }^{531}$ Nachdem die für das Überleben eines Klosters notwendigen Stiftungen erfolgt waren, erhob Bischof Reginbert von Brixen (reg. I I 25-I I39) in den I I 3oer-Jahren die frühere Einsiedelei zu einer Benediktinerabtei. Der Konvent begann alsbald mit dem Bau eines größeren Gotteshauses, dessen Weihe vermutlich in das Jahr I 204 fiel. Die unter den Patrozinien der Heiligen Georg und Jakob stehende Stiftskirche blieb auch weiterhin Wallfahrtskirche. ${ }^{532}$ Vom früheren Bauwerk sind nur wenige Reste erhalten, denn wiederholt wurde die Sakralanlage ein Raub der Flammen. ${ }^{533}$ I 705, nach mehreren Naturkatastrophen und einem letzten großen Brand, beschloss der Konvent, die Abtei ins Inntal nach Fiecht, einem Ortsteil von Vomp, zu verlegen. ${ }^{534}$ Die Mönche benötigten zweieinhalb Jahrzehnte für die Errichtung der neuen Konventtrakte. Den für die Folgezeit geplanten Bau der Stiftskirche stellte Abt Lambert Höllerer (reg. I732-I 772) jedoch zurück, da er zunächst die Wiederherstellung der alten Abtei- und Wallfahrtskirche St. Georgenberg in Angriff nehmen wollte. Erst im April I74 I ließ er den Grundstein für eine Klosterkirche in Fiecht legen. Unter der Leitung des Baumeisters Jakob Singer aus Schwaz wurde sie innerhalb von zwei Jahren ausgeführt. Die nach Nordwesten weisende Kirche besitzt einen kreuzförmigen Grundriss. Sie ist dreijochig, mit einem rechteckigen Querschiff ausgestattet und endet mit einem kleeblattförmigen Chor. Die Stuckarbeiten entstanden um I 743 und I75 I unter der Leitung von Meistern aus der Schule von Wessobrunn. ${ }^{535}$ Zwischen I 744 und I 755 malte Matthäus Günther (I705-I788) die Decken-

530 Kramer, Abteikirche (r 959), 2-7; Hootz, Kunstdenkmäler (1965-1968), Bd. I (1965), 3 I , 3 I I ; Röhrig, Alte Stifte (1967), 47-49; ÖKM, Tiroler Unterland (r971), 98-гог; Kramer, Geschichte (1977), bes. 3-68; Stenzel, Stift (1 977), I 54-I 55; Dehio, Tirol (1980), 860-862; Caramelle/Frischauf, Stifte (I 985 ), I 3-23; Naupp, Fiecht (2000), bes. 435-45 I, 470-477.

53 I Die Reliquie wird noch heute in der Kirche aufbewahrt.

532 Wie Wallfahrten in St. Georgenberg um die Mitte des I6. Jahrhunderts organisiert waren, beschreibt ausführlich Maurus Kramer: Kramer, Geschichte (1977), I 3 1 -16.

533 Kramer, Abteikirche (1959), 2-3. Zum Niedergang des Klosters vgl. auch ders., Geschichte (1977), bes. 32-43. Zur frühen Anlage s. Naupp, Fiecht (2000), 442-444, 470-474.

534 Überlegungen zur Transferierung des Klosters waren schon zuvor angestellt, aber aus verschiedenen Gründen nicht umgesetzt worden. Naupp, ebd., 443-444.

535 Kramer, Abteikirche (1959), I I D Dehio, Tirol (1980), 862. Stuckateure waren die Brüder Franz Xa- 
fresken mit Darstellungen aus dem Leben der Heiligen Familie. Noch bevor Fresken und Stuckverzierungen vollendet werden konnten, erfolgte die Weihe der Stiftskirche im August I750. 2018 wechselte der Konvent erneut seinen Standort. Er zog sich wieder nach St. Georgenberg zurück und übergab die Klostergebäude im Inntal einem neuen Eigentümer. Nur die barocke Abteikirche in Fiecht verblieb im Besitz des Ordens.

\section{Eingangsportal}

Zimmermeister Josef Schönherr, I 744

Lichtes Maß H $390 \mathrm{~cm} \times \mathrm{B}_{2} 34 \mathrm{~cm}$

Eichenholz, massiv. Eisen und Eisenblech, getrieben, ziseliert, geschwärzt

Die 1747 von Heinrich Renn errichtete Portalumrahmung besticht mit ausdrucksstarken Formen (Abb. 339). ${ }^{536}$ Durch die Verwendung von Marmor hebt sie sich deutlich vom Mauerverband aus verputztem und gekalktem Haustein ab. Schräggestellte Volutenpilaster auf hohen Postamenten tragen Gebälk und

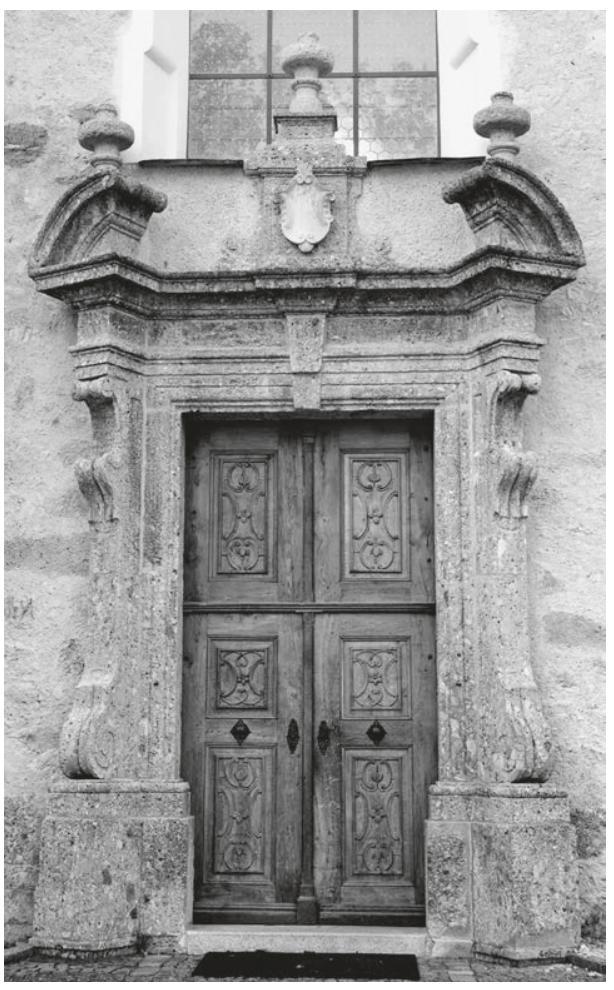

339 Fiecht, Eingangsportal. Zimmermeister Josef Schönherr, Steinmetz Heinrich Renn, I744 gesprengten Giebel, Vasen schmücken die Architektur.

Die aus massivem Eichenholz bestehenden Türflügel sind ein Werk des Zimmermeisters Josef Schönherr aus Schwaz; nach den Untersuchungen von Maurus Kramer hatte er sie bereits drei Jahre zuvor gefertigt. ${ }^{537}$ Wie üblich sind die Türblätter in Rahmenbauweise ausgeführt. Schönherr bossierte die hochrechteckigen Füllungen, wobei er aus den Binnenfeldern feine, Bandlwerk und Blüten vorstellende Reliefs herausarbeitete. Stellt man sie anderen Schnitzarbeiten der Zeit gegenüber, offenbart sich ihre Strenge und Klarheit. Schönherr verzichtete auf alles rokokohaft Verspielte. Für

ver (I705-I764) und Johann Michael Feichtmayr (I709/10-I772) sowie Johann Georg Übelher (Übelhör, Üblherr; I 703-I 763).

536 Kramer, ebd., 5-6; Dehio, ebd., 86r.

537 Kramer, ebd., 22. 
die Fertigung der Türbeschläge wurde getriebenes, geschwärztes und ziseliertes Eisen sowie Eisenblech verwendet.

\section{Stiftskirche}

\section{Laiengestühl}

Bildschnitzer Franz Xaver Nissl, I 77 I/73

HS $10,5 \mathrm{~cm}$

$\mathrm{H} 9 \mathrm{I}, 5 \mathrm{~cm}(+\mathrm{IO}, 5 \mathrm{~cm}) \times \mathrm{L} 260 \mathrm{~cm} / 399 \mathrm{~cm}$

Nussbaumholz, Kirschholz, massiv, Zirbelkiefer, Fichte

Die Garnitur besteht aus 40 Bänken, Vorderbrüstungen sind nicht vorhanden (Abb. 340, 34I). ${ }^{538}$ Entlang des Mittelgangs folgt die Aufstellung der Möbel einer geraden Flucht, während die Außenseiten den Grundriss des Kirchenschiffs mit Pfeilern und Seitenaltären widerspiegeln. Daher wechselt die Länge der Möbelgarnitur zwischen den angegebenen Maßen. Heute bilden die Sitzreihen insgesamt vier große Gruppen, zwei Blöcke mit jeweils fünf und zwei mit I 5 Bänken. ${ }^{539}$

Eine Reihe zum Teil gegenläufiger Bögen formt die Konturen der Wangen. Nur die Docken der beiden letzten Bänke im Westen präsentieren sich mit gerade beschnittener Rückseite und passen sich so einer Marmorbrüstung an, die den Eingangsbereich der Kirche vom Langhaus trennt. ${ }^{540}$ Die Stirnseiten der leicht abgerundeten Lesepulte erinnern durch ihre Gestaltung an die Deckplatte eines ionischen Kapitells, Muschelwerk säumt die Wangenkanten, Hoch- und Flachreliefs überziehen ihre Flächen. Die Ornamentmotive geben marianische Symbole wieder, Szenen aus dem Leben der Heiligen Familie und aus der Vita Benedikts, weiter Heilige, Papstinsignien, Sakralgerätschaften sowie die Wappen der Stifter des Klosters. Verschiedene moderne Studien stellen die Möbel vor und interpretieren die Darstellungen, sodass sich eine genaue Beschreibung an dieser Stelle erübrigt. ${ }^{541}$ Die letzte Gestühlswange der Nordseite trägt die römische Jahreszahl MDCCLXXIII, das Datum der Fertigstellung oder Aufstellung der Garnitur. ${ }^{542}$ Wie üblich in Tiroler Kirchen wurde auch hier auf die Füllungen an den Lehnen verzichtet. Die Öffnungen besitzen geschweifte Konturen,

538 Kramer, ebd., I 9-2 I ; ÖKM, Tiroler Unterland (1 97I), 99; Hölzl, Nissl (1976), bes. 56-67, 2 I 5 ; Fidler-Daxer, Stuhlwangen (1 995); Dehio, Tirol (1980), 862; Hörmann, Meister (2006), I 59 ; HörmannWeingartner, Kunsthandwerk (2007), I75.

539 Hölzl, ebd., 57. Ursprünglich war die Aufteilung der Bänke eine andere. Kramer, ebd., г 2-I 3.

540 Auf der Balustrade wurde I 8 I 9 ein Gitter montiert vgl. Kramer, ebd., 2 I ; Dehio, Tirol ( I 980 ), 862.

54I Hölzl, Nissl (1 976), 58-67; Fidler-Daxer, Stuhlwangen (I 995).

542 Hölzl, ebd., 67, liest MDCCLXXII. Das ist nicht richtig. 


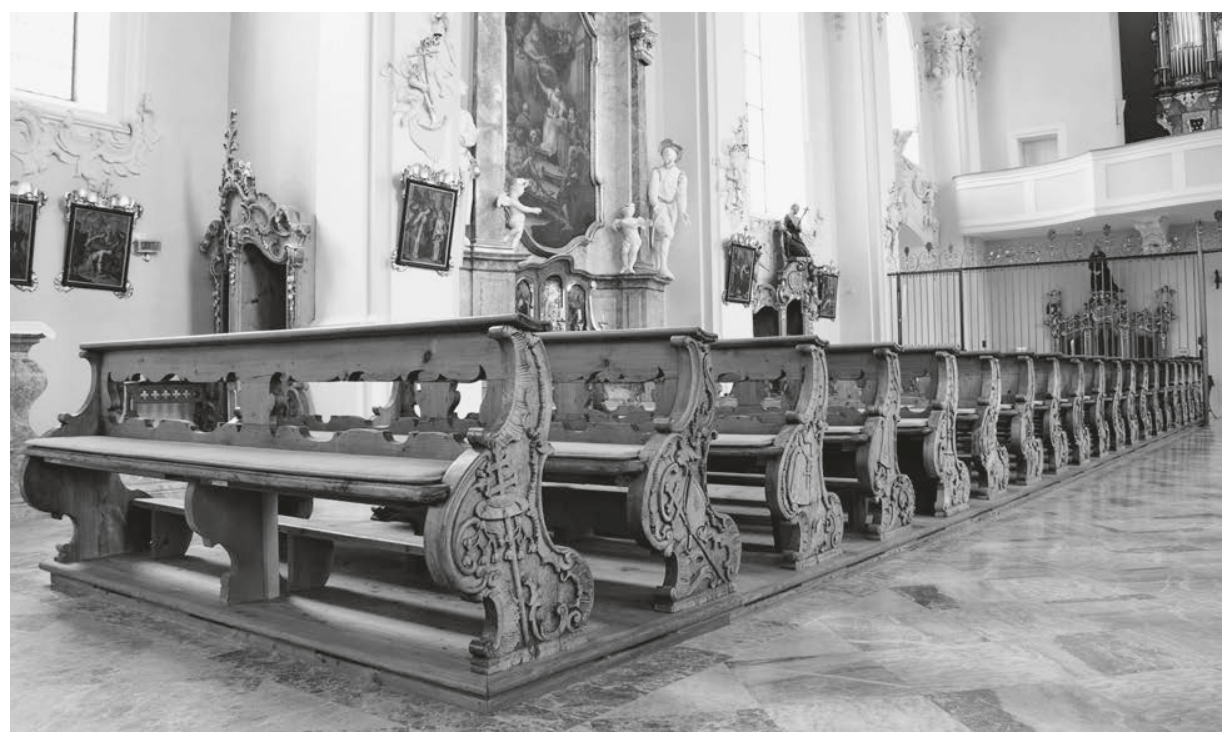

340 Fiecht, Laiengestühl. Entwurf (?) und Ausführung Bildhauer Franz Xaver Nissl, I77 I/73

wobei man die Vorderseite der Lehnen glättete, die Rückseiten der Lehnen aber mit kräftigen Rocailleornamenten verzierte. Die Handwerker fertigten die Bankwangen aus massivem Nuss-, die Lesepulte aus Kirschbaum-, Sitze und Rücklehnen aus Nadelholz. Modern sind die Kniebänke, die Gebetbuchablagen unter den Rückenlehnen sowie die Laufböden.

Abt Lambert Höllerer beauftragte I77I den Bildschnitzer Franz Xaver Nissl (I 73 II 804) mit der Herstellung von 80 Wangen für die Bänke der Stiftskirche, sie sind vollständig erhalten. Am 20. April jenen Jahres erhielt der Künstler 198 Gulden für seine Arbeit, anscheinend eine Abschlagszahlung, denn im folgenden Jahr erfolgte eine weitere Entlohnung, nun durch Höllerers Nachfolger, Abt Pirmin I. Seidl (reg. I772I789)..$^{53}$ Der aus Fügen in Tirol stammende Nissl absolvierte in den späten I740erJahren eine Lehrzeit bei dem Bildhauer Gregor Fritz (I693-I 774) in Hall, an die sich zwischen 1750 und 1757 eine Mitarbeit im Atelier des Münchner Hofbildhauers Johann Baptist Straub (I704-I 784) angeschlossen haben mag. ${ }^{544}$ Vermutlich kehrte Niss1 bald darauf nach Fügen zurück, um dort eine eigene Werkstatt zu führen. ${ }^{545}$ Einein-

543 Hölzl, ebd., 56; Fidler-Daxer, Stuhlwangen (1 995), I 5.

544 Zur Vita des Bildschnitzers vgl. Hölzl, ebd., bes. I6-28; Fidler-Daxer, ebd., I7-I 9.

545 Fidler-Daxer, ebd., I 8. 


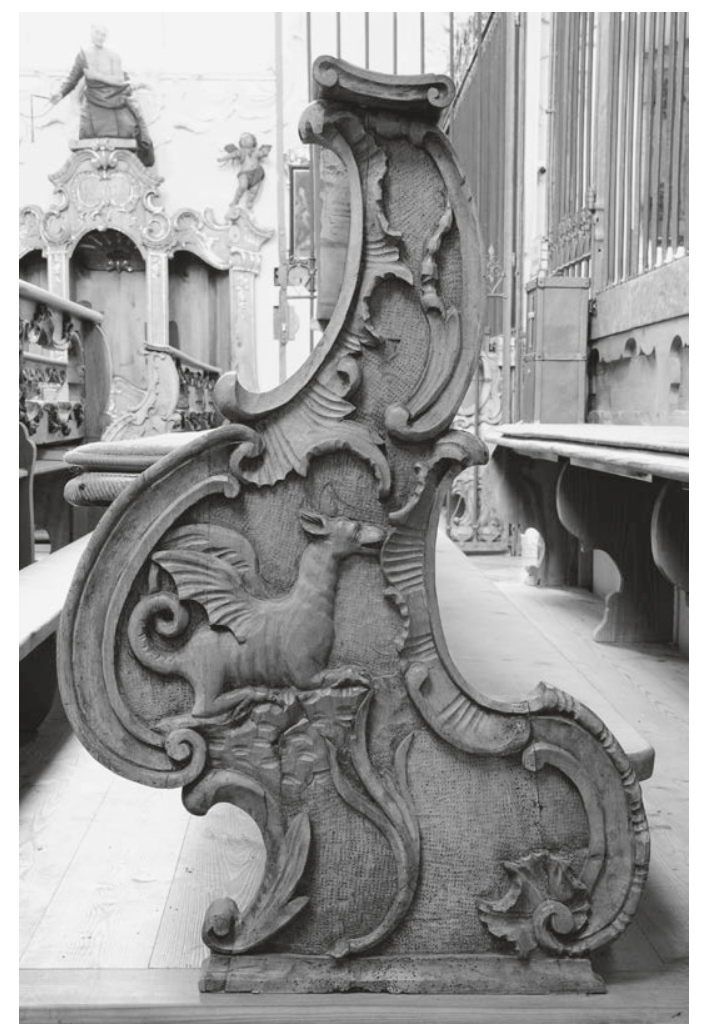

34I Fiecht, Bankwange. Bildhauer Franz Xaver Nissl, I 77 I/73

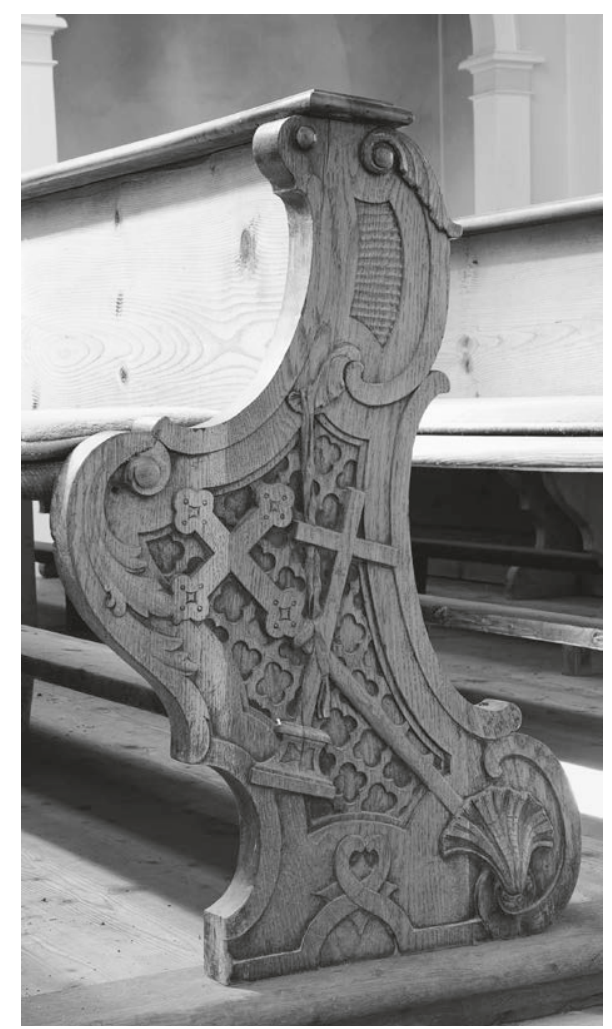

342 St. Georgenberg, Stifts- und Wallfahrtskirche, Bankwange, Vomp (?), um I 730/40

halb Jahrzehnte später schuf er das Laiengestühl für die Stiftskirche. Bei den Reliefs handelt es sich um volkstümliche Illustrationen mit einer auf das Allernotwendigste reduzierten Bildsprache, die durch ihre "rührende Einfachheit und Eindringlichkeit» beeindruckt. ${ }^{546}$ Die Invention, die Bänke auf diese Art zu dekorieren, ging auf das Gestühl der alten Stifts- und Wallfahrtskirche in St. Georgenberg zurück (Abb. 342). Bei vergleichbarer Kontur vervollständigen Darstellungen von Sakralgegenständen auch dort die Bankwangen, allerdings gehört die Formensprache einer früheren Stilstufe an. Akzentuierte, von strengem Bandlwerk begleitete Bögen dominieren die Kanten, Querschraffuren und Gitterwerk füllen die Flächen. Muscheln kommen nicht als Rokokoornament, sondern als Pilgermuscheln vor, zum Teil auch in Verbindung mit der

546 Hölzl, Nissl (1976), 58. 
typischen Kleidung der Wallfahrer sowie mit Trinkflasche und Wanderstab. Stilistische Gründe sprechen für eine Anfertigung der Bänke um I730/40. Zwischen I752 und I 756 entstand überdies eine ähnliche Möbelgarnitur für den Dom zu Brixen. Bei analoger Großform sind dort die Wangen abwechselnd mit Lamm und Fahne sowie mit Adler und Bischofsstab verziert. ${ }^{547}$ Der Entwurf zu den Möbeln geht vermutlich auf den Tiroler Bildhauer Josef Stapf ( I 7 I 8-I 785) zurück, ausführende Meister waren die Tischler Ferdinand Schwabl und Pankraz Töller aus Brixen. Stapf, der nachweislich auch in Nordtirol tätig war, dürfte das Möbelensemble in St. Georgenberg gekannt haben, es ist das älteste dieser Reihe.

\section{Beichtstüble}

In den I 77oer-Jahren baute Franz Xaver Nissl einige, vielleicht auch alle Beichtstühle für die Stiftskirche, Arbeiten, die die beste künstlerische Phase des Bildhauers markieren. ${ }^{548}$ In der Stiftskirche existieren vier weitgehend im Originalzustand erhaltene Exemplare, ein fünftes wurde nachträglich mit Türen ausgestattet, ein sechstes zu einem Ausspracheraum umgeformt. ${ }^{54}$ Zwei dieser Möbel stehen in Nischen in den beiden Seitenkapellen vor dem Chorraum (Abb. 343), zwei weitere im Mauerverband des Langhauses (Abb. 345). Den umgebauten Beichtstuhl und den Ausspracheraum platzierte man unter der Empore.

\section{Beichtstüble in den Seitenkapellen}

Franz Xaver Nissl (?), um I 770/80

$\mathrm{HS}_{3,5} \mathrm{~cm}$

H ca. $350 \mathrm{~cm}(+3,5 \mathrm{~cm}) \times \mathrm{B} 2$ I I cm $\times$ T ca. $95 \mathrm{~cm}$

Zirbelholz, Linde, teilvergoldet, Nussbaum, furniert. Messing

Der Grundriss der zweiteiligen Beichtstühle entspricht einem nach vorn schwingenden doppelten S-Bogen (Abb. 343, 344). Vor der mittleren Trennwand erhebt sich über hohem Postament und volutenförmiger Basis eine pilasterartige Stütze mit Fantasiekapitell. Die Stollen vor den Seitenwänden setzen über dem Sockel mit einem großdimensionierten und sich vor dem Mauerwerk nach außen wölbenden Bogen an. Über den Stützen und Kapitellen liegt ein Volutengiebel mit einem hohen dreieckigen Tableau, das Schnitzarbeiten zieren. Seine Seiten lösen sich in Bögen, Muscheln und

547 Hörmann, Meister (2006), I $57^{-1} 58$.

548 Fidler-Daxer, Stuhlwangen (1995), I 8; ÖKM, Tiroler Unterland (I 97 I), 99.

549 Kramer, Abteikirche ( I 959), 20-2 I ; Hölzl, Nissl (I 976), 74-82, 2 I 6-2 I 8; Dehio, Tirol (I 980), 862. 

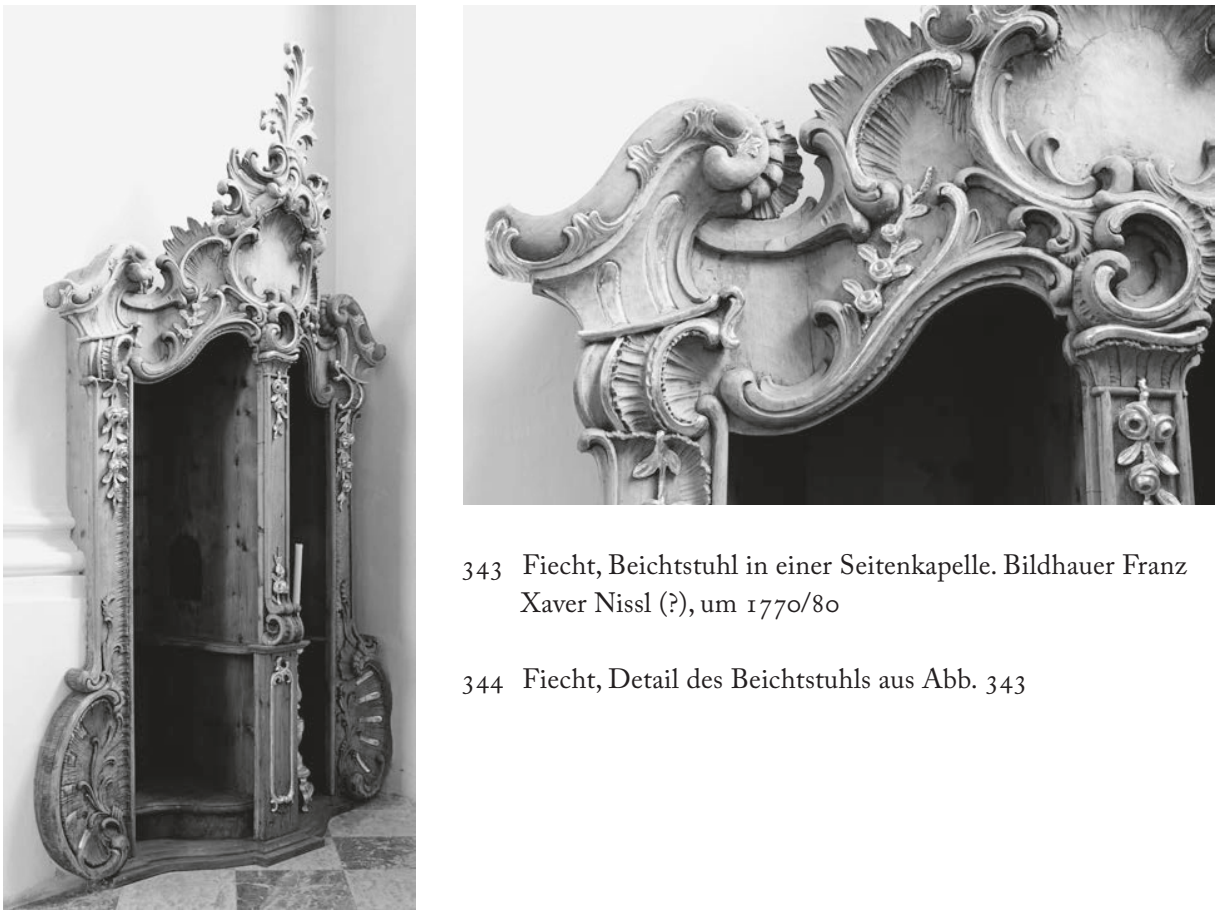

343 Fiecht, Beichtstuhl in einer Seitenkapelle. Bildhauer Franz Xaver Nissl (?), um I770/80

344 Fiecht, Detail des Beichtstuhls aus Abb. 343

Blattwerk auf, eine große Kartusche ziert die Mitte. Ein dichtes Netz von Rocailleornamenten und Rosenzweigen überzieht die Stützen der beiden Beichtstühle. Kaum eine Fläche, die nicht mit kraftvollen Schnitzarbeiten bereichert, kaum ein Profil, das gerade gezogen, kaum ein Winkel, der rechtwinklig gestaltet wäre. Der Bildhauer, vermutlich Franz Xaver Nissl, formte aus Möbeln, die mit Ornamenten verziert sind, im Grunde große Skulpturen, die als Möbel dienen. Von klassizistischen Stileinflüssen, die seit den späten r76oer-Jahren auf das Kunstschaffen in Wien und in den angrenzenden Regionen einwirkten, ist an diesen Möbeln nichts zu spüren. ${ }^{550} \mathrm{Zur}$ Herstellung der in Brettbauweise gefertigten Korpusse verwendeten die Tischler Nadelholz, die aufgesetzten Schnitzarbeiten bestehen aus Linde. Die Kniebänke wurden mit Nussholz furniert, die Sprechgitter aus Messing gefertigt. Anders als die nachfolgend beschriebenen Exemplare sind die beiden Beichtstühle in Schriftquellen nicht nachweisbar, doch sprechen stilistische Gründe für eine Herstellung der Möbel in Nissls Atelier.

550 Vgl. etwa Bohr, Sakralmöbel (2017), 309-3 I 3 mit dem Göttweiger Chorgestühl aus den I 76oer-Jahren. 


\section{Beichtstüble im Langhaus}

$\mathrm{HS}_{4,5} \mathrm{~cm}$

Gesimshöhe ca. $300 \mathrm{~cm}(+4,5 \mathrm{~cm}) \times \mathrm{B}$ ca.

$285 \mathrm{~cm} \times$ T ca. $95 \mathrm{~cm}$

$\mathrm{H}$ der mittleren Aufsatzfiguren ca. I $40 \mathrm{~cm}$

Kartusche am rechten Beichtstuhl mit der Inschrift: S. Landelinus Abbas OSB

Kartusche am linken Beichtstuhl mit der Inschrift:

S. Albertus Prior OSP

\section{Beichtstüble unter der Empore}

HS $6 \mathrm{~cm}$

Gesimshöhe ca. $300 \mathrm{~cm}(+6 \mathrm{~cm}) \times \mathrm{B}$

$285 \mathrm{~cm} / 306 \mathrm{~cm} \times$ T ca. I IO cm/ I $45 \mathrm{~cm}$

$\mathrm{H}$ der mittleren Aufsatzfiguren ca. I $20 \mathrm{~cm}$

Beichtstuhl links des Portals mit der Inschrift: S.

Nilus Abbas OSB

Beichtstuhl (Ausspracheraum) rechts des Portals: ohne Inschrift

Entwurf und Bildhauer Franz Xaver Nissl, Bildhauergeselle Josef Streiter oder Franz Christian

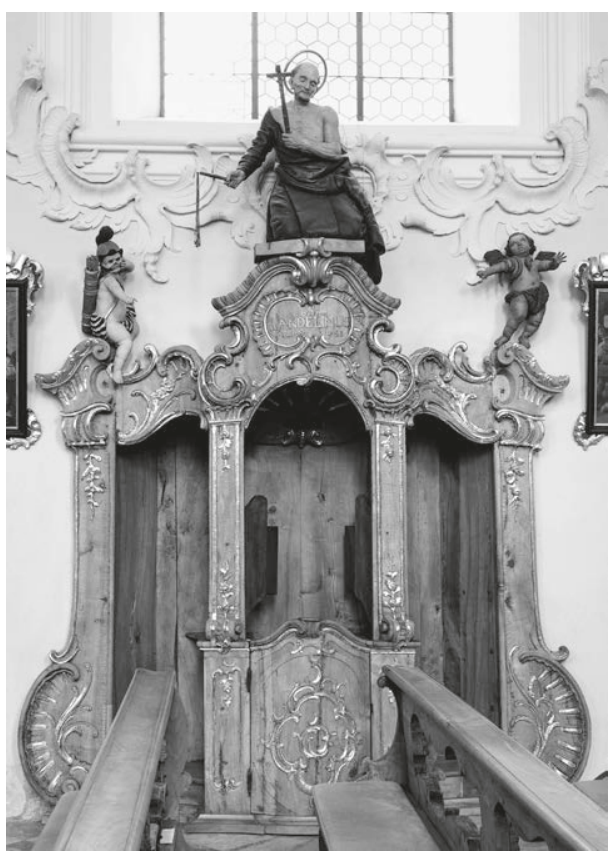

345 Fiecht, Beichtstuhl im Langhaus. Bildhauer Franz Xaver Nissl, I774/75

Thaler, I774/75

Zirbelholz, Nussholz, Linde, teilvergoldet, Polychromfassung. Messing

Die Möbel im Langhaus (Abb. 345, 346) und unter der Empore besitzen einen dreiachsigen Aufbau, auch ihr Grundriss schwingt leicht nach vorn. Als Architekturelemente kommen wieder jene auffallenden Stützen vor, an den Außenkanten auch die eigenartigen ohrmuschelförmigen Spangen sowie die Giebelfußstücke. Nun schließen aber zwei Voluten das mittlere Feld zu einem veritablen Giebel. Die Giebelspitzen tragen Plinthen mit knienden Aufsatzsatzfiguren, die seitlichen Volutenstücke stehende, kniende und sitzende Putten. Im Vergleich mit den Beichtstühlen in den beiden Seitenkapellen kommt hier der Zierrat mit Schnitzornamenten etwas verhaltener zur Anwendung. Halbhohe Türen verschließen die mittleren Zellen, über den Türen brachte Nissl Klappläden an, um die Beichtväter vor den Blicken neugieriger Kirchenbesucher zu schützen. Eine Muschel überfängt die Sitze der Geistlichen. Beichtstuhl und Ausspracheraum unter der Empore wurden in der jüngeren Vergangenheit mit 


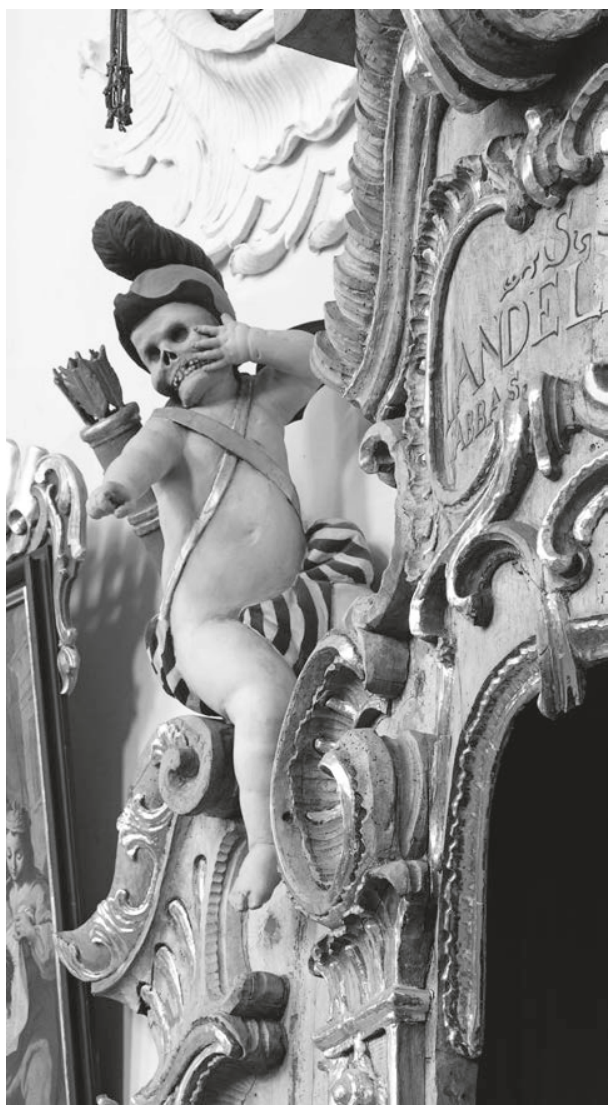

346 Fiecht, Detail der Abb. 345, Allegorie des Todes
Türen nachgerüstet, Letzterer auch im Innern umgebaut. ${ }^{551}$

Das ikonographische Programm der Möbel war schon mehrfach Thema erhellender Untersuchungen. ${ }^{552}$ Die Mittelfiguren auf den Aufsätzen vergegenwärtigen in den Ordenshabit der Benediktiner gekleidete Büßerfiguren, die nicht ohne Pathos Seelenkampf, Betroffenheit und Selbstanklage schildern. Die vielleicht bekanntesten, da ausdrucksstärksten Skulpturen sind die Plastiken auf dem Beichtstuhl rechts im Langhaus. Sie stehen am Ende der Reihe von Gewissenprüfung, Reue, Sündenbekenntnis und Buße, Letztere wird durch einen Mönch im Greisenalter versinnbildlicht. Bei seiner Modellierung wurde auf Hieronymus-Darstellungen rekurriert, denn gezeigt ist ein Zönobit, der sich mit einer Geißel kasteit. In seiner Linken hält er ein Kruzifix, doch schaut er den Gekreuzigten nicht an, sondern präsentiert ihn den Kirchenbesuchern. Die beiden Genien auf den seitlichen Voluten verdeutlichen die Folgen für diejenigen, die sich der Heilslehre verweigern: Der linke symbolisiert den Tod. Sein Körper entspricht dem eines Putto, wobei sein Schädel zu einem

Totenkopf mutiert ist. Er trägt einen Helm mit Federbusch, auf dem Rücken einen Köcher mit Pfeilen. Mit dem ausgestreckten Zeigefinger weist er auf die Kirchgänger, um ihnen zu bedeuten, dass der Zeitpunkt des Todes ungewiss ist. Der zweite Putto erinnert an die Qualen der Hölle. Er ist mit Flügeln versehen, doch sind es nicht die Flügel von Engeln, sondern jene von Drachen. Um seinen rechten Oberarm windet sich eine Schlange, die ihm die Brust aufreißt. Das Gesicht angstverzerrt, die Augen aufgerissen, richtet sich sein Blick nach oben. In Verbindung mit dem büßenden Mönch verkörpern die beiden Genien die vier letzten Dinge, von denen die christliche

55 I Kramer, Abteikirche (1959), 20, zeigt auf einer Abbildung den zu einem Ausspracheraum umgebauten Beichtstuhl in seiner ursprünglichen Form.

552 Hölzl, Nissl (1 976), 75-80; Schemper-Sparholz, Skulptur (I 999), 5 I 9. 
Eschatologie zu berichten weiß: Tod und Jüngstes Gericht sowie Himmel und Hölle. Direkte Vorbilder zu diesen und den anderen Figuren auf den Beichtstühlen sind nicht bekannt.

Das Skulpturenprogramm der Beichtstühle bezieht die Besucher der Stiftskirche in den das Beichtsakrament vergegenwärtigenden teatro sacro ein. Die im Einführungskapitel des ersten Bandes der Untersuchung erörterte These von Ursula Brossette, der zufolge die Gläubigen einem Schauspiel folgen, in einem performativen Akt zugleich aber selbst auch Mitwirkende einer Inszenierung sind, wird durch die Aufsatzfiguren der Fiechter Beichtstühle eindrucksvoll bestätigt. ${ }^{553}$

Vermutlich war es Nissl selbst, der die Entwürfe für die Möbel gezeichnet hatte. ${ }^{554}$ Zusammen mit Josef Streiter, vielleicht auch mit Franz Christian Thaler ( I 759-I 8 I 7), zwei seiner Gehilfen, führte er die Beichtstühle aus. Eine Abrechnung des Stiftsarchivs über Lindenholz, größere Mengen von Lebensmitteln sowie über den Arbeitslohn von Nissl und zwei Bildschnitzern legen dies nahe. ${ }^{55}$ Zudem konnten für das Jahr I 774 Zahlungen von $72 \mathrm{fl} 20 \mathrm{kr}$, $40 \mathrm{fl}$ und $74 \mathrm{fl} 40 \mathrm{kr}$ an Nissl sowie an einen oder beide Mitarbeiter des Bildschnitzers nachgewiesen werden. ${ }^{556}$ Für die Schlösser, Bänder und Messinggitter waren vom Konvent noch einmal $35 \mathrm{fl} 42 \mathrm{kr}$ aufzubringen. ${ }^{557}$

\section{Stams, Zisterzienserabtei}

Stiftskirche Mariae Himmelfahrt und hl. Johannes d. T.

Meinhard II. von Görz-Tirol (I 238/39-г 295) und seine Ehefrau Elisabeth von Wittelsbach (um I 227-r 273) gründeten die Abtei I $273 .{ }^{558}$ Noch in jenem Jahr kamen die ersten Mönche in das Stift, Mutterkloster war die ehemalige Zisterze Kaisheim bei Donauwörth in Schwaben. I 284 wurde die Stiftskirche, die als Begräbnisstätte der Ti-

553 Brossette, Inszenierung (2002), Bd. I, bes. 462-483; Bohr, Sakralmöbel (2017), 93-95.

554 Hölzl, Nissl (1 976), 2 I 8.

555 Hölzl, ebd.

556 Hölzl, ebd., 74, 2 I 8.

557 Hölzl, ebd.

558 Hammer, Baugeschichte (1 935); Hootz, Kunstdenkmäler (I 965-1968), Bd. I (1965), 267-270, 348, 349; Röhrig, Alte Stifte (1 967), 49-5 I; Ammann, Barock (1973); Bitschnau, Romanik (r 973); Caramelle, Gotik (1 973); Stenzel, Stift (r 977), I 56-1 58 ; ÖKM, Tiroler Oberland (1 978), 347-359; Krapf, Gumpp (1979), I33-136; Dehio, Tirol (r980), 748-754; Caramelle/Frischauf, Stifte (I 985), 76-87; Ammann, Stams (1990); Demetz, Baugeschichte (1995); Köfler, Gründung (1995); ders., Gründungsausstattung (I 995); Kundratitz, Geschichte (1995); Seebach, Rekonstruktion (I995); Haidacher, Chronik (2000); Wolfgang, Stams (2008); Ammann, Gebäudekomplex (2016); Caramelle, Kloster (2016); Riedmann, Gründung (2016) 
roler Landesfürsten und der Familie Meinhards diente, eingeweiht. Zudem übernahm der Konvent die Aufgabe, die Pilger zur bereits in Stams existierenden Wallfahrtskirche Johannes des Täufers seelsorgerisch zu betreuen. ${ }^{559}$

Schon bald nach seiner Inthronisierung leitete Abt Melchior Jäger (reg. I 6o I-I 6 I 5) die Renovierung der mittelalterlichen Klosteranlage ein, eine Feuersbrunst hatte Teile von ihr 1593 vernichtet. ${ }^{560}$ Die Arbeiten an der Klosteranlage dauerten bis gegen Ende des r7. Jahrhunderts an. Mit einer Überarbeitung der Ausstattung der Stiftskirche begannen die Äbte Augustin I. Haas (reg. I66o-I672), Georg Nußbaumer (reg. 1672-1690) und Edmund Zoz (reg. I690-r699), jedoch unternahm der Konvent bis ins frühe I 8. Jahrhundert hinein keinerlei Anstrengungen zur Erneuerung des romanischen Baukörpers. Der umfassenden Barockisierung der Kirche widmete sich erst Abt Augustin Kastner (reg. I7I4-I738). Zwischen I7I5 und I7I7 ließ er von den Architekten Johann Martin Gumpp d.Ä. (I643-I 729) und dessen Sohn Georg Anton ( 1682-г 754) zunächst die Heilig-Blut-Kapelle umbauen, die sich an die Südflanke der Kirche anlehnt. ${ }^{561}$ Spätestens seit I 729 beschäftigte sich Kastner auch mit der Neugestaltung der Kirche selbst, für die Planungen zeichnete ebenfalls Georg Anton Gumpp verantwortlich. ${ }^{562}$ Er schuf aus der früheren dreischiffigen Basilika einen einschiffigen Longitudinalraum mit sechs weiträumigen Seitenkapellen, die das Langhaus in Raumabschnitte annähernd gleicher Größe unterteilen. ${ }^{563}$ Bereits 1730 schloss der Abt mit Johann Georg Wolcker ( $700-1766$ ) einen Vertrag über die Freskierung der Kirche, I73 I erteilte er Franz Xaver Feichtmayr d.Ä. (I 705-I 764) und Joseph Fischer (I 704-I77I) den Auftrag, das Gotteshaus mit Stuckarbeiten zu bereichern. I732 waren die Arbeiten an der Sakralarchitektur weitgehend beendet.

\section{Portale}

Eingangsportal zur Stiftskirche

Stams, um r67o/80, Entwurf Johann Martin Gumpp d. Ä. (?)

Lichtes Maß H ca. $430 \mathrm{~cm} \times \mathrm{B} 260 \mathrm{~cm}$

Zirbelkiefer, dunkelbraun lasiert. Eisen, ziseliert, teilweise geschwärzt und verzinnt

559 Ammann, Grablege (1995); Köfler, Gründung (1995), 336-337.

560 Ammann, Barock (1973); Dehio, Tirol (1980), 749, 754; Wolfgang, Stams (2008), I 5.

56I Johann Martin Gumpp d.Ä. war wohl nur in der Vorbereitungsphase in die Planungen involviert. Diese und die folgenden Angaben aus ÖKM, Tiroler Oberland (1978), 358-359. Außerdem Krapf, Gumpp (1979), 317-3 18; Wolfgang, ebd., 37-42.

562 Ammann, Barock (1973), bes. 69-74; Wolfgang, ebd., 42-57.

563 Eine Beschreibung des Innenraums bei Wolfgang, ebd., bes. 66-7I. 


\section{Portal zur Heilig-Blut-Kapelle}

Stams, um r685/r 700, Entwurf Johann Martin Gumpp d.Ä. (?)

Lichtes Maß H $336 \mathrm{~cm} \times \mathrm{B}$ r $68 \mathrm{~cm}$

Nussbaum, massiv, dunkelbraun lasiert. Eisen, ziseliert, verzinnt, vergoldet

Die beiden Portale besitzen ein architektonisches Gepräge. An der Kirchentür (Abb. 347) umfassen Manschetten die Schäfte der mit Fantasiekapitellen versehenen Keilpilaster, über hochrechteckigen Ädikulä hängen Fruchtgirlanden an Ziernägeln. ${ }^{564}$ Eine große Akanthusvolute akzentuiert die Mittelachse der Lünette, seitlich tragen Postamente Schalen mit gedrückten Kugeln, schwere Fruchtkränze legen sich über den Fries des Bogens. Sie finden sich ebenso wie die Schalen mit den Kugeln am "Hofbau« im Kloster Stams wieder, der auf das Ende des I7. Jahrhunderts datiert. ${ }^{565}$

Stilisierte ionische Pilaster flankieren das Portal zur Heilig-Blut-Kapelle, ein weiterer dient als Schlagleiste (Abb. 348). ${ }^{566}$ Hochbarocke Formen zieren die sich verjüngenden und mit Schulterstücken versehenen quergehobelten Stützen, Manschetten legen sich um die Enden der mit Blattzweigen dekorierten Schäfte. Bossierte elliptische Mittelfelder bereichern die von schlichten Profilen gehaltenen Füllungen. In der Regel können Gesimse und Lünetten von Kirchenportalen geöffnet werden, das ist hier nicht der Fall, denn sie liegen vor dem geschlossenen Mauerverband.

Sowohl der ältere als auch der jüngere Gumpp nutzten noch im frühen I 8. Jahrhundert die an den Portalen vorkommenden Dekormotive zur Ausschmückung der von ihnen geplanten Gebäude, der Dekor entspricht folglich dem Zeitgeschmack. ${ }^{567}$ Bemerkenswert

${ }_{564}$ Eine Beschreibung der Westfassade bei Wolfgang, ebd., 7 I-76.

565 Hammer, Baugeschichte (1935), Abb. 25.

566 Eine Beschreibung der Kapelle bei Wolfgang, Stams (2008), 37-42.

567 Vgl. etwa die Pforten der Innsbrucker Spitalskirche und der Ursulinenkirche aus dem ersten Jahr- 


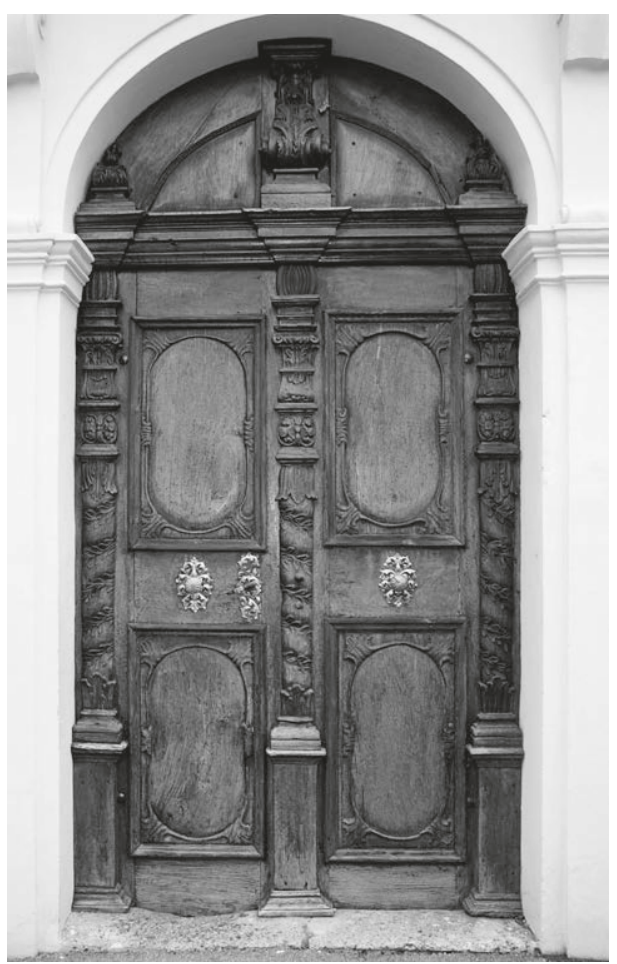

348 Portal zur Heilig-Blut-Kapelle. Stams, um I685/ I 700 ist allerdings die verschiedenartige Gestaltung der beiden Portale. Das betrifft die unterschiedlichen Proportionen und strengeren Formen der Kirchentür ebenso wie die Aufteilung der Flächen und die gewählten Zierornamente, selbst die verarbeiteten Werkmaterialien stimmen nicht überein. All das weist auf eine zeitlich versetzte Herstellung hin, vielleicht auch auf verschiedene Tischlerwerkstätten. Beim Versuch, die Frage nach der Datierung der Portale zu beantworten, führt die Bauchronologie in die Irre: Die Überformung der Fassaden von Kapelle und Kirche geht auf die Jahre um I 7 I 7 bzw. um I732 zurück. Normalerweise wären diese Jahre auch für die Entstehung der Türen anzunehmen, doch deuten die Ornamentmotive auf eine frühere Herstellung. Der Schmuck des Kirchenportals zeigt noch jenen kleinteiligen Dekor, der bereits an den Möbeln in Bad Mehrn und in der Innsbrucker Servitenkirche im fortgeschrittenen I7. Jahrhundert vorkam (Abb. 287-289, 315). Dagegen präsentieren die Beschläge an der Tür zur Heilig-Blut-Kapelle mit krautigem

Laubwerk ein Stilelement vom Ende jenes Säkulums. Abgesehen von den Akanthusvoluten, die die Keilsteine der gemauerten Rahmen zu stützen scheinen, spielt Akanthus als Dekor der Portale sonst keine Rolle. Wie wir in Verbindung mit dem Beichtstuhl in der Sakristei von St. Lambrecht (Abb. 264) festgestellt haben, konnten solche Voluten schon um die Jahrhundertmitte Möbel bereichern, und auch die übrigen Zierornamente speisen sich aus dem Vorrat, den das spätmanieristische und frühbarocke österreichische Formenvokabular zu bieten hatte. Wahrscheinlich erneuerte man bereits existierende Türen nicht zusammen mit der Fassade, sondern fasste sie mit modernen Architekturelementen ein. ${ }^{568}$ Bildliche Darstellungen aus der ersten Hälfte des I 7. Jahrhunderts dokumentieren, dass tatsächlich schon damals rundbogige Portale in beide Sakralräume führten. ${ }^{569}$

zehnt des i 8. Jahrhunderts. Krapf, Gumpp (1979), I 36-I40, 309-3 I I, Abb. I54, r6o; Felmayer, Spitalskirche (1 995), 332-349; Schneider, Ursulinenkirche (I 995), 352.

568 Zur Beschreibung der Fassade vgl. Wolfgang, Stams (2008), bes. 7 I -76.

569 Wolfgang, ebd., Abb. I3-15. 


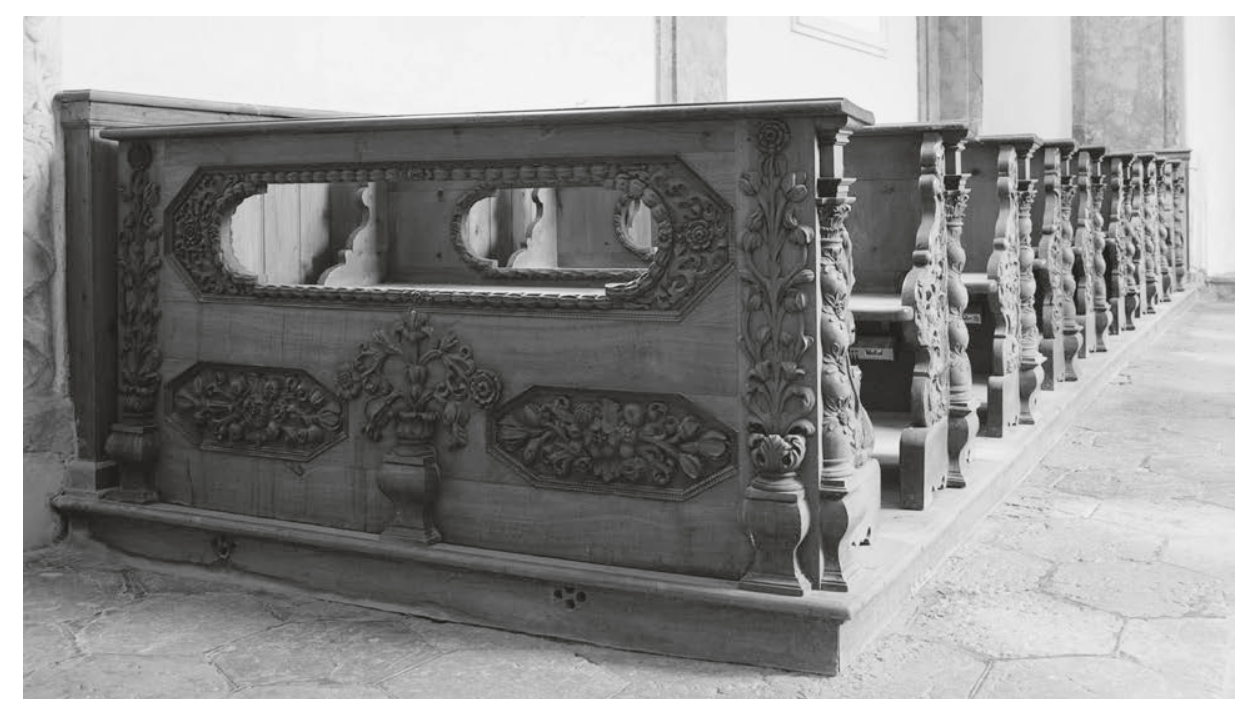

349 Heilig-Blut-Kapelle, Laiengestühl. Stams, um I 685/I 700

Die Bewahrung des Alten entspricht jedenfalls der Vorgehensweise des Konvents im Innern der Kirche, wo mittelalterliche Bauteile und frühbarocke Ausstattungsstücke erhalten und in das spätbarocke architektonische Ambiente integriert wurden. ${ }^{570} \mathrm{Fi}$ nanzielle Gründe werden dabei ebenso eine Rolle gespielt haben wie ideelle, ließen sich doch so Geschichte, Tradition und Kontinuität des Klosters und der Mönchsgemeinschaft anschaulich darstellen. Für die Selbstinszenierung der Kommunität war das von übergeordneter Bedeutung.

\section{Heilig-Blut-Kapelle \\ Laiengestübl}

Stams, um r 685/r 700, nach einem Entwurf von Johann Martin Gumpp d. Ä. (?)

HS ${ }_{14}, 5 \mathrm{~cm}$

$\mathrm{H} 99 \mathrm{~cm}(+\mathrm{I} 4,5 \mathrm{~cm}) \times \mathrm{L} 205 \mathrm{~cm}$

Nussholz, Zirbelholz

Das Laiengestühl in der Kapelle umfasst I 8 Bankreihen und zwei Vorderbrüstungen (Abb. 349, 350). Lisenen, die aus einem geschwungenen Sockel, einer Vase in Form eines Akanthuskelches und einer langstieligen Blume bestehen, flankieren die Brustwände. Diese Ornamentform, die in Stams vermutlich einen Lebensbaum symboli-

570 Wolfgang, Stams (2008), 89-9I. 


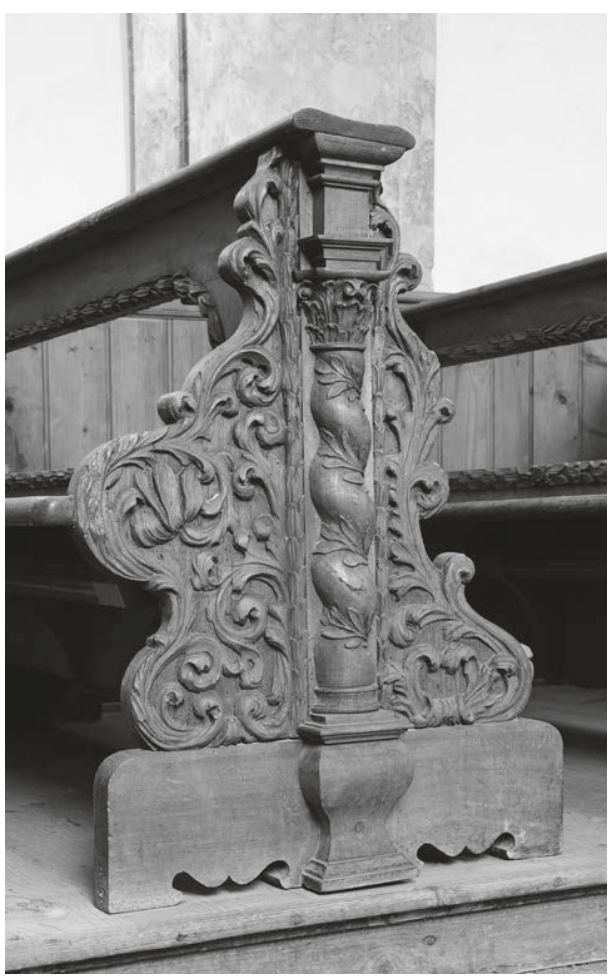

350 Wange des Gestühls aus Abb. 349

siert, basiert letztlich auf Groteskkandelabern, mit denen man seit der italienischen Renaissance Bauwerke und Möbel bereicherte. ${ }^{571}$ In der Brüstungsmitte steht eine Schale mit breitgefächertem Blumenbouquet, seitlich davon befinden sich vertieft liegende Felder mit Blüten und Früchten. Statt einer durchgehenden rechteckigen Füllung weisen die Brüstungen ein langgezogenes Achteck mit einer querovalen Öffnung auf. Blüten und teigiges Laubwerk vervollständigen die Zwickel, Kränze aus Blüten, Früchten und Blättern begleiten die Öffnungsränder der Bankaußenseiten, innen kommen Stoffschleifen und Blumengebinde hinzu.

Die asymmetrisch gestalteten Seitenwangen besitzen eine Form, die an jene der Kirchenbänke in Salzburg erinnert, da die Verzierung der Docken über einem hohen Sockelbrett ansetzt. Hier ist es jedoch durch ein Postament unterbrochen, das eine gewundene korinthische Halbsäule trägt. Sie ist mit einem Kranz verziert, ein Motiv, das von vie-

len hochbarocken Tischlerarbeiten her bekannt ist. In der vorliegenden Studie kehrt es nicht nur am zuvor beschriebenen Kapellenportal wieder, sondern beispielsweise auch am Gestühl im steirischen Gröbming von 1676 (Farbtaf. 22). Laubwerk folgt den Konturen der Docken, Blattwerk ziert die Flächen der zur Raummitte weisenden Exemplare, während die wandseitigen Wangen zwar geschwungene Kanten besitzen, ansonsten aber ohne Zierrat auskommen. Einige Bänke in Stams sind Neuanfertigungen, tragen aber noch die alten Schnitzarbeiten.

57 I Vgl. etwa Irmscher, Akanthus (2000), Abb. 6a und 6b. Zu entsprechend ornamentierten Möbeln aus dem I6. Jahrhundert s. Schottmüller, Wohnungskultur ( I92 I), beispielsweise die Abb. I72, I73, I95, 252,267 . 


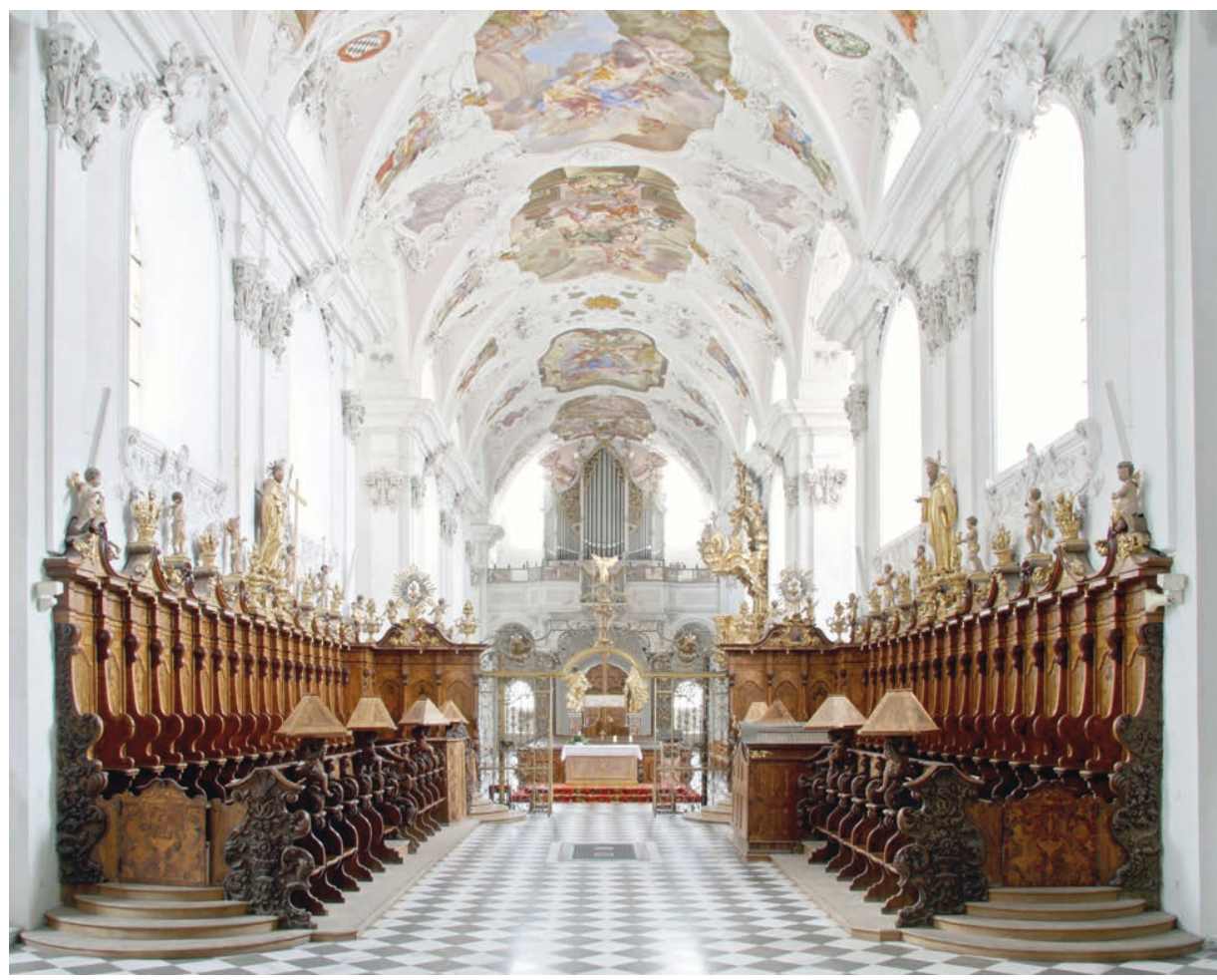

Farbtafel 3 I Stiftskirche, Blick in westliche Richtung, Chorgestühl. Stiftstischlerei unter der Leitung von Fr. Georg Zoller, Bildhauer Augustin Strigl (?), um I 735

\section{Stiftskirche \\ Chorgestübl}

Tischler Fr. Georg Zoller, Bildhauer verm. Augustin Strigl, um I 735

HS ro $\mathrm{cm} / 50 \mathrm{~cm}$

$\mathrm{H}$ ca. $350 \mathrm{~cm}(+50 \mathrm{~cm}) \times \mathrm{L} \mathrm{ca} . \mathrm{I}_{3}, 80 \mathrm{~m}$

Nussholz, Riegelnussbaum, Nussbaummaser, Nuss geschwärzt, Pappel, Zwetschke, Kirschholz, Buchs, graviert und geschwärzt, Eiche, auf Nadelholz furniert, Holz (Linde ?), vergoldet und gefasst

Abt Augustin Kastner ließ das zweireihige Gestühl für den Platz im Langhaus zwischen der östlichen und der mittleren Seitenkapelle anfertigen (Farbtaf. 3 I ; Abb. 35 I358). ${ }^{572}$ Damit steht es dort, wo auch schon das mittelalterliche Ensemble positioniert

572 Ammann, Barock (r 973), 76; ÖKM, Tiroler Oberland (I 978), 358; Dehio, Tirol (I980), 753 ; Am- 


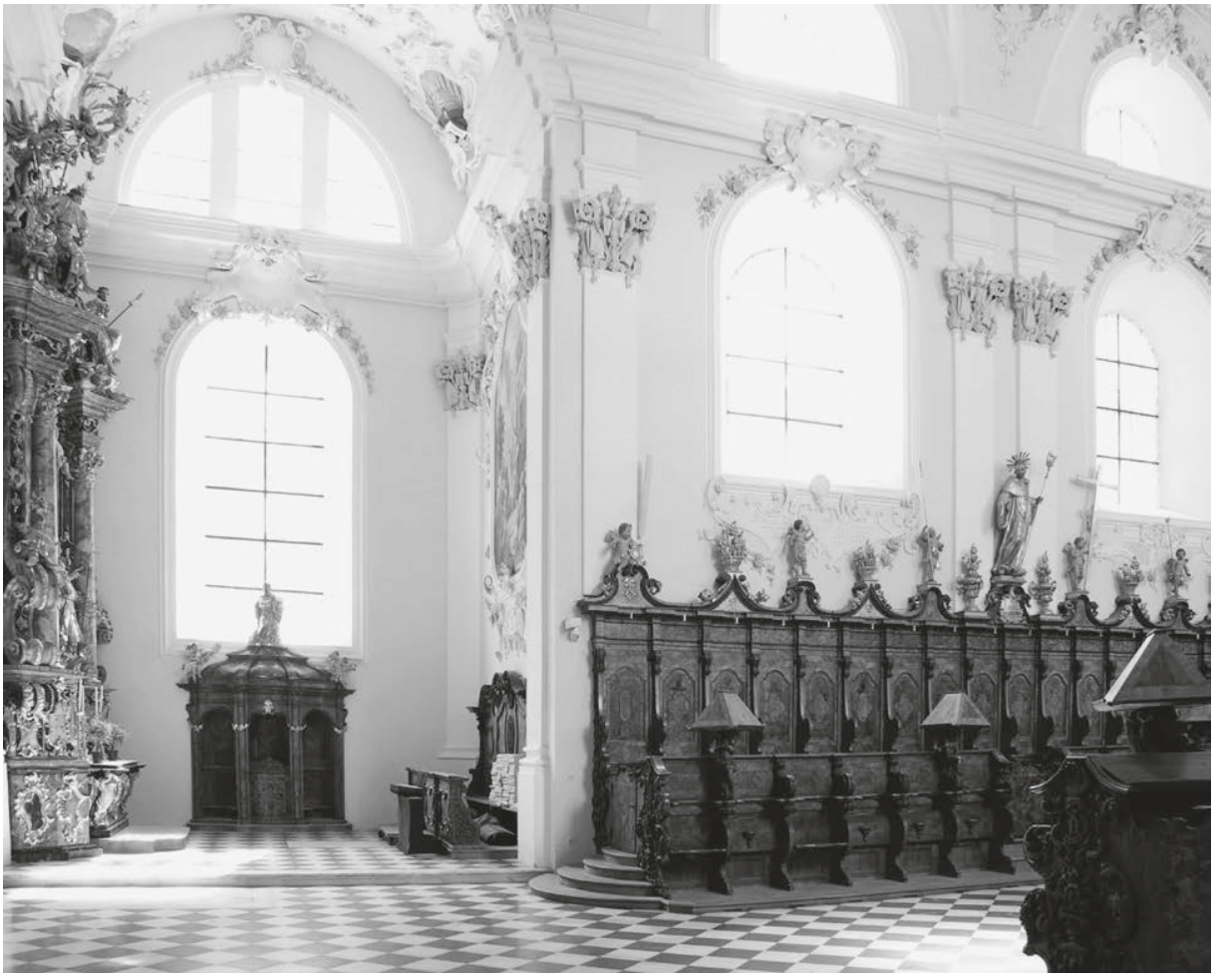

35 I Stiftskirche, Blick nach Süden. Chorraum mit östlicher Seitenkapelle und Teilansicht des Chorgestühls

war. Allerdings befand es sich nicht vor geschlossenem Mauerwerk, sondern vor Pfeilern und Arkaden, die in der frühen Kirche zwischen den Schiffen angeordnet waren. ${ }^{573}$ Das barocke Gestühl ruht auf einem mehrstufigen Sockel. Mit den beiden quer in den Raum reichenden Flügeln, die das Möbel im Westen begrenzen, besitzt es einen U-förmigen Grundriss. Ein prachtvolles Gitter verbindet die Querriegel und schließt den Mönchschor gegen das Laienhaus hin ab (Abb. 357, 358). ${ }^{574}$ Schriftquellen zufolge wurde es um I 734 oder I 735 vom Konversen Michael Neurauther († I 794)

mann, Stams (1990), 27, 33-36; Hörmann, Meister (2006), I60-I6I ; Hörmann-Weingartner, Kunsthandwerk (2007), I 8 I ; Wagner, Heiligenkreuz (2007), I $50-$ I 5 I ; Wartena, Süddeutsche Chorgestühle (2008), 743-754; Wolfgang, Stams (2008), 87-88.

573 Bitschnau, Romanik ( 1973 ), Abb. I, mit einem Grundriss des Chorraums der Kirche aus der zweiten Hälfte des I 7. Jahrhunderts.

574 Gritsch, Schmiedeeisengitter (I973), I I 2-I I4, I I7; Hörmann, Meister (2006), I90-I 9 I; Caramelle, Stamser Gitter (2016), bes. 236. 


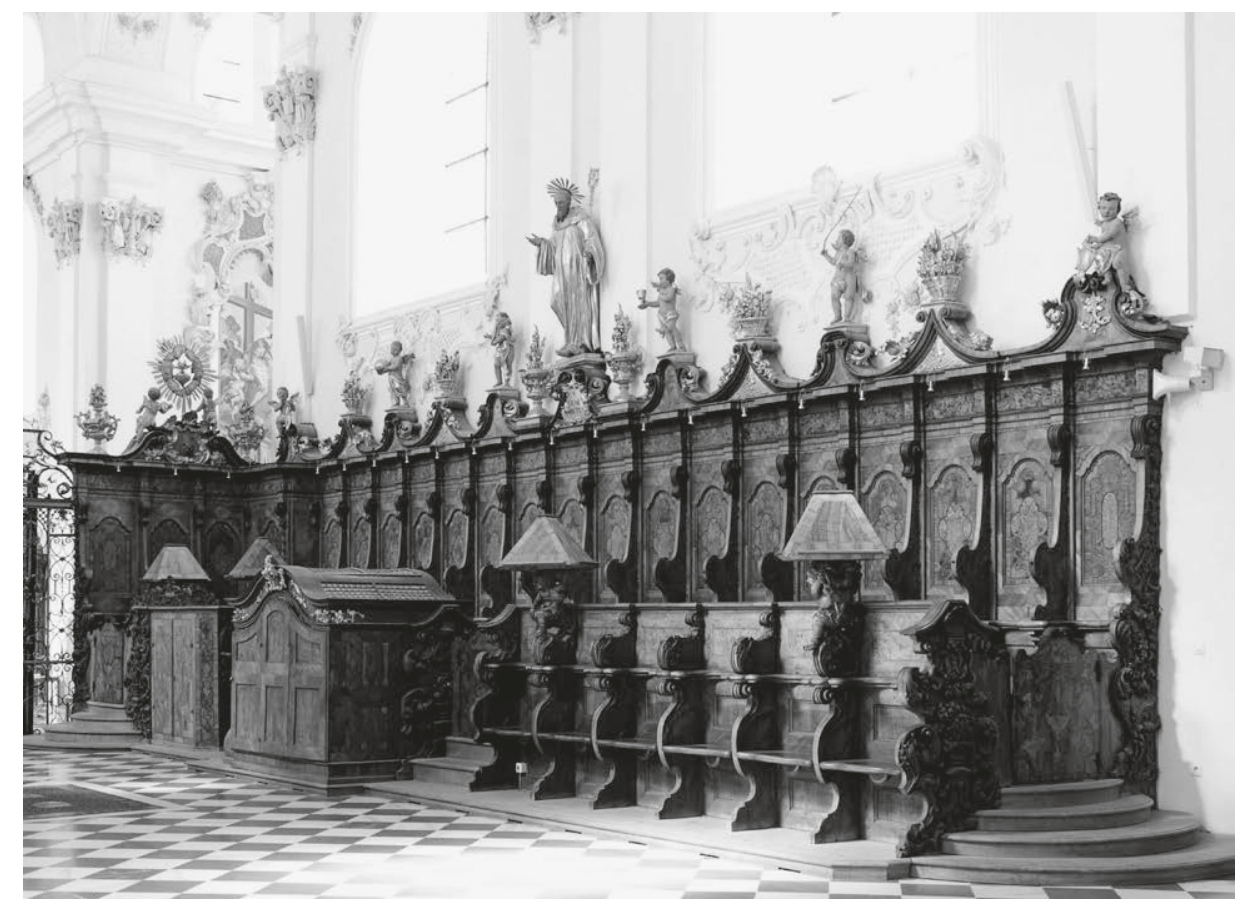

352 Chorgestühl, Evangelienseite. Fr. Georg Zoller und Augustin Strigl (?), um I 735

in der stiftsinternen Schlosserei geschaffen. ${ }^{575}$ Hinten befinden sich im Gestühl I7 Plätze, vorn auf der Epistelseite elf, auf der Evangelienseite sieben. ${ }^{576}$ Dort mussten einige Sitze der 1757 hinzugefügten Chororgel weichen. ${ }^{577}$ Die quer angeordneten Flügel bieten Raum für weitere Stallen, vor ihnen enden die Hauptreihen mit einem niedrigen Schrank. Das Möbel kommt ohne Brüstung aus, wahrscheinlich entspricht das der ursprünglichen Konzeption. ${ }^{578}$

Geschweifte Wangen trennen die Stallen voneinander. Über den Accoudoirs der Vorderreihe erhebt sich ein von Voluten gestützter Aufsatz mit der Buchablage der

575 Wolfgang, Stams (2008), 88.

576 Der Sitz hinter dem mittleren Eingang blieb normalerweise unbesetzt. Vermutlich berichtet deshalb Ammann von einem »sechzehnsitzigen Chorgestühl«. ÖKM, Tiroler Oberland (I 978), 358.

577 Reichling/Reichling, Orgelgeschichte (2016), bes. $256-257$.

578 Nach Wartena, Süddeutsche Chorgestühle (2008), 36, besaßen Chorgestühle in süddeutschen Zisterzienserkirchen keine eigenen Brüstungen. Die im ersten Band besprochenen Ensembles belegen, dass das in Österreich meist anders war. 


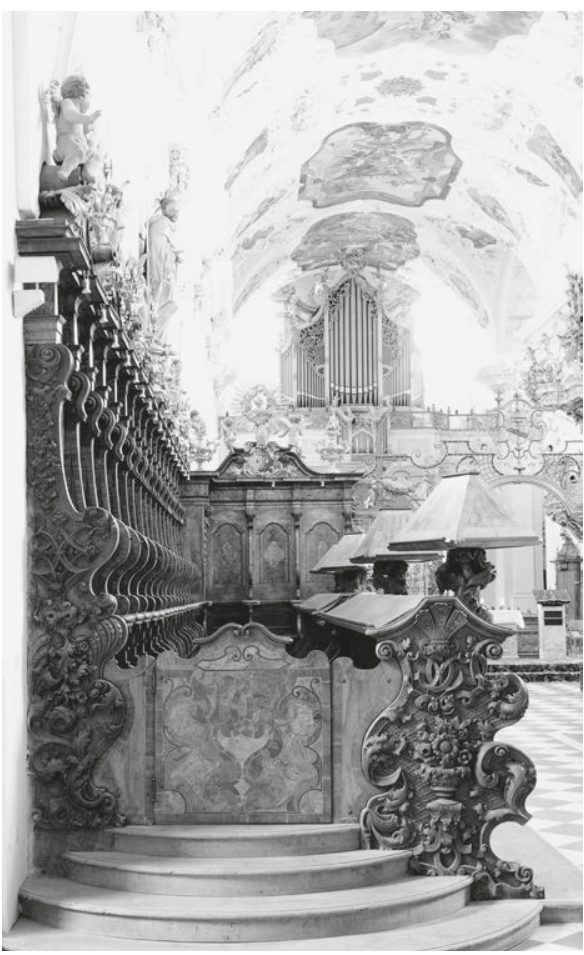

353 Chorgestühl, Außenwangen und Tür, Epistelseite. Fr. Georg Zoller und Augustin Strigl (?), um 1735

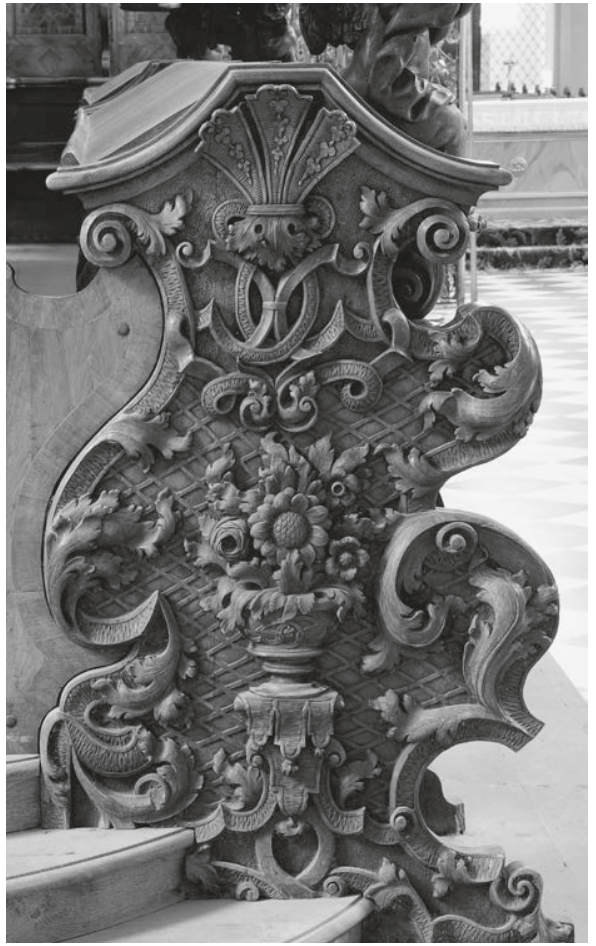

354 Chorgestühl, Brüstungswange. Augustin Strigl (?), um I 735

hinteren Sitzreihe. Auf einigen dieser Voluten kauern Putten, die drehbare Lesepulte tragen.

Asymmetrische Umrisslinien und kräftige Schnitzarbeiten kennzeichnen die $\mathrm{Au}$ ßenwangen (Abb. 353, 354). Vorn liegen die Zierformen vor einem Grund aus Gitterwerk. Das Hauptmotiv besteht aus einer mittleren Vase mit reichem Blumenschmuck auf einer mit Lambrequins verzierten Platte, eine Darstellung, die auf ähnliche Art in den Groteskentwürfen Jean Bérains ( I637- 7 I I ) häufig vorkommt. ${ }^{579}$ Bandlwerk folgt der Schweifung der Wangenaußenkanten, verläuft zum Teil auch quer und verbindet so die beiden Seiten. Im Gegensatz zu den gleichmäßig geriffelten Lambrequins, an denen der Bildhauer die Textur von Gewebe imitierte, schnitt er in die Bänder scheinbar beliebig Kerben ein, die eine unruhig flimmernde, von Lichtreflexen durchzogene

579 Berliner/Egger, Vorlageblätter ( I98 I), Bd. I, 93-94, Bd. 3, beispielsweise Abb. I I 42-I I 44, mit Vorlagen, die um I700 bzw. im frühen I8. Jahrhundert entstanden. 
Oberfläche entstehen lassen. Eine Palmette bekrönt die vorderen Docken. Die hinteren Wangen wurden bis unter das Gebälk der Rückwand nach oben geführt. Die dort vorkommenden Schnitzornamente ähneln den beschriebenen Motiven, doch griff der Bildhauer wegen der unterschiedlichen Proportionen der Flächen, die er zu verzieren hatte, auf andere Vorlagen zurück.

Querfurnierte Rahmen und vertieft liegende Kompartimente füllen die Räume zwischen den geschweiften Rückwandstützen (Abb. 355, 356). Hohe Spitz- und Volutengiebel überfangen das Dorsale, ohne an dessen Gliederung anzuknüpfen. Die Giebel tragen Standbilder der Heiligen Bernhard und Benedikt sowie Engel mit den Leidenswerkzeugen Christi und den Attributen der beiden Ordensgründer. Über den Querriegeln im Westen finden sich neben einem Marienbild und dem Wappen des Abtes Kastner weitere Engel, die jedoch nicht dem Altar, sondern dem Laienschiff zugewandt sind und von Wolkenaureole und Strahlenkranz gerahmte Flammenherzen vorweisen - ein deutlicher Hinweis auf den Namenspatron Kastners, den hl. Augustinus.

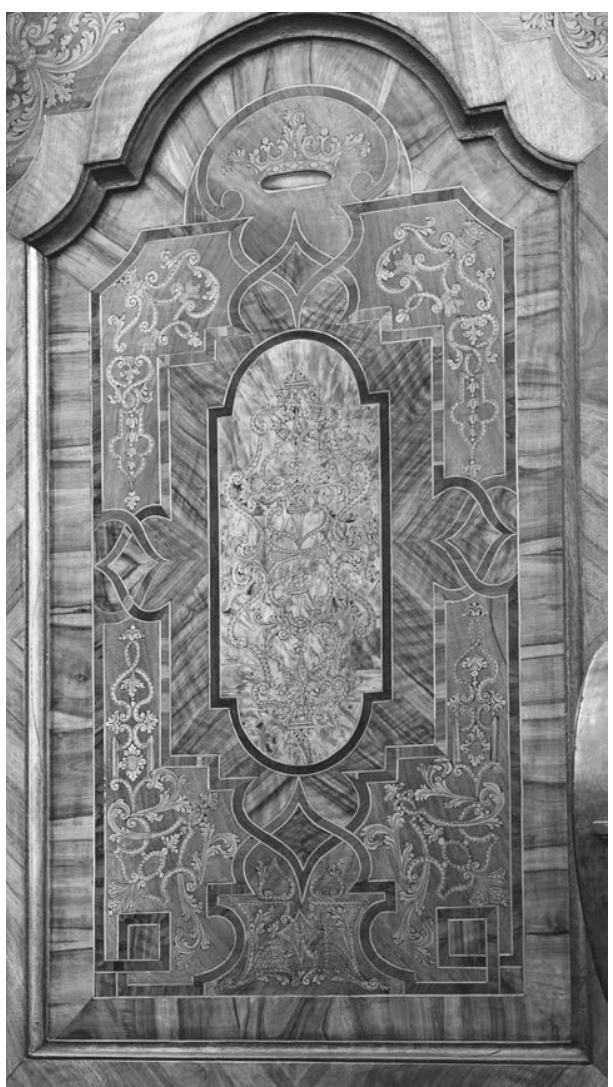

355 Chorgestühl, Detailansicht des Dorsalefeldes über der Abtstalle. Fr. Georg Zoller, um 1735

Zusammen mit den Schnitzarbeiten bereichern vor allem aus Nussbaum- und Pappelmaser bestehende Marketerien das Gestühl. ${ }^{580}$ An den wahrscheinlich etwas später angebrachten Türen (Abb. 353) treten breite Bänder aus Zwetschkenholz hinzu. Die Furnierbilder zeigen dort ein vasenförmiges Motiv, wohingegen man sich bei der Herstellung der Rückwandmarketerien (Abb. 356) mit schlichteren geometrischen Formationen begnügte. ${ }^{581}$ Nur die den Klostervorstehern vorbehaltenen Dor-

580 Wartena, Süddeutsche Chorgestühle (2008), 746, berichtet von Birkemaser, das sich durch Farbe und Maserung von Pappelmaser kaum unterscheidet. Nach heutigem Kenntnisstand wurde im österreichischen Möbelbau Birke allerdings nur selten verwendet.

58 I Die unterschiedlichen Furnierbilder sind es denn auch, die gegen eine gleichzeitige Entstehung von Türen und Gestühl sprechen. Wartena, Süddeutsche Chorgestühle (2008), 745 . 


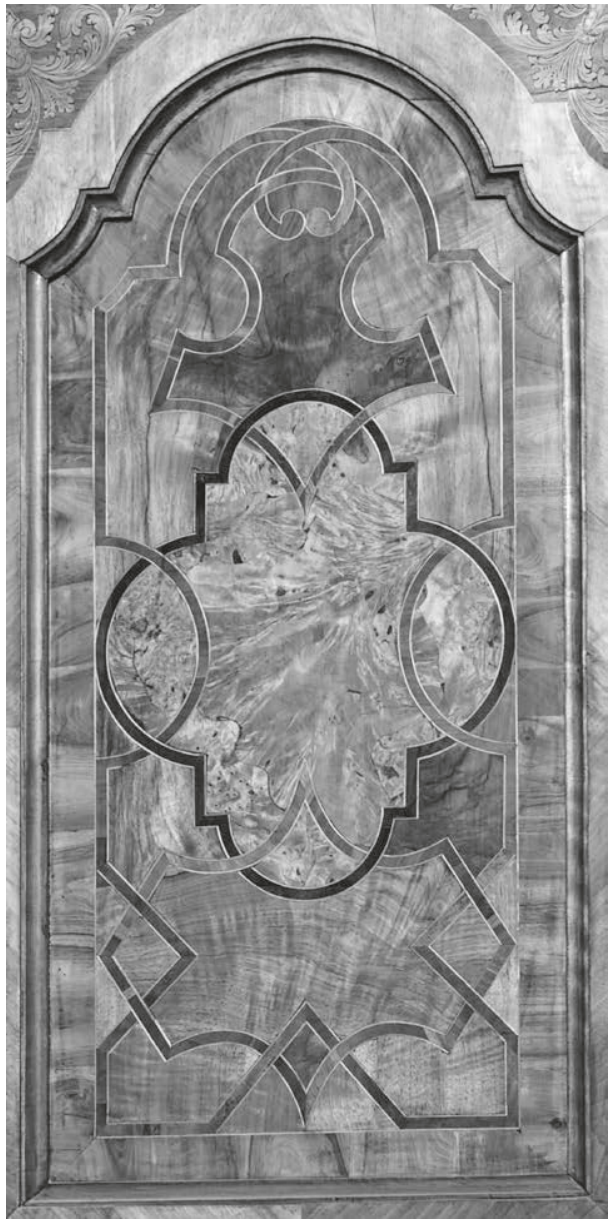

356 Chorgestühl, Detailansicht eines Dorsalefeldes der südlichen Hauptreihe. Fr. Georg Zoller, um I 735

salefelder (Abb. 355) zeichnen sich durch eine anspruchsvollere Gestaltung aus: Sie tragen graviertes und geschwärztes Laub- und Bandlwerk, Blüten, Blumenkörbe und eine Krone. ${ }^{582}$

Wie oben erwähnt, befinden sich die Hauptreihen des Gestühls vor den Außenwänden des Sakralbaus, auf eine Ausarbeitung der Stallenrückwände konnte damit verzichtet werden. Anders die freistehenden Querriegel, die auf der zum Laienschiff weisenden Seite wie Altäre anmuten. Von einem Sockel, der als Altarmensa dienen könnte, steigen dort Pilaster und Viertelsäulen auf. Sie säumen auf der Evangelienseite eine zwischen $\mathrm{I} 430$ und $\mathrm{I} 45^{\circ}$ entstandene anonyme Darstellung des Salvator mundi, auf der Epistelseite dagegen ein Bild des Erzengels Michael, der seine schützende Hand über die Stiftsanlage von Stams hält. Johann Georg Wolcker malte es um I733. ${ }^{583}$ Geschnitztes Gitterwerk, Blumenschmuck und Blattwerk schmückt die vergoldeten Rahmen der beiden Gemälde.

Aus dem Professbuch des Stiftes geht hervor, dass die Stiftstischlerei unter der Leitung von Georg Zoller die Schreinerarbeiten am Gestühl bewerkstelligte. Der Konverse wurde am I 8. März I 700 in dem nahe bei Stams gelegenen Weiler Silz geboren und legte 1727 in Stams die feierliche Profess ab, nachdem er den Beruf des Tischlers erlernt hatte. Zoller verstarb I $767 \cdot{ }^{584}$ Während für die Aufsatzfiguren Augustin Strigl († I 746) als Künstler anzunehmen ist ${ }^{585}$, kann noch keine Antwort auf die Frage nach dem Bildhauer geliefert werden, der die Docken schuf.

582 Außerdem sind sie um einige Zentimeter breiter als die übrigen Stallen. Die der Klostervorsteher messen in der Breite etwa $75 \mathrm{~cm}$, die übrigen ca. $67 \mathrm{~cm}$.

583 Dehio, Tirol (1980), 753; Ammann, Stams (1 990), 34-36.

584 Lindner, Album (I 898), 54, Nr. 2 I.

585 Wolfgang, Stams (2008), 88. 
357 Stiftskirche, Blick nach Osten auf die Querflügel des Chorgestühls und das Chorgitter

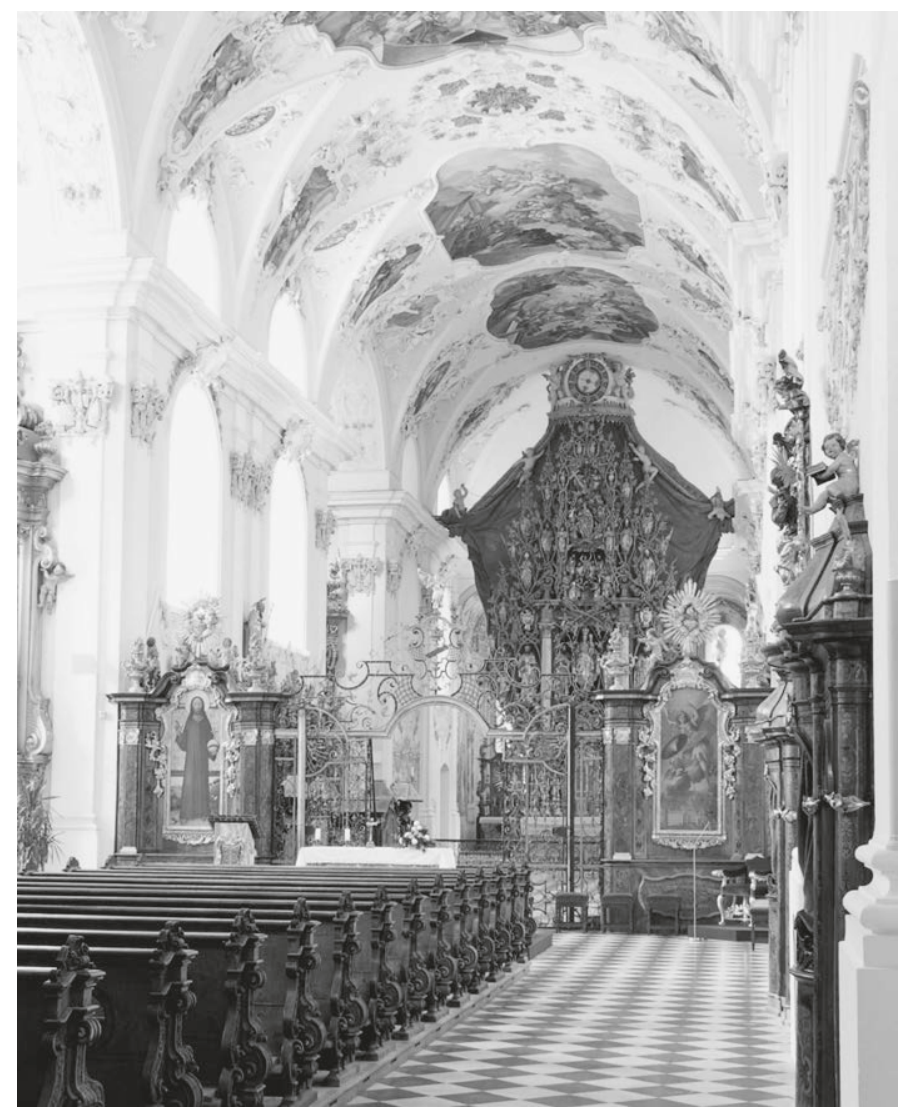

In der Fachliteratur wird gemutmaßt, Zoller habe das Gestühl unter Verwendung älterer Teile gebaut. Gert Ammann nahm für die Putten, die die Lesepulte tragen, eine Herstellungszeit um I680 an und folgerte daraus, sie seien als Spolien eingesetzt worden. ${ }^{586}$ Sybe Wartena lehnte Ammanns Datierungsvorschlag ab, vertrat aber die Theorie, dass die hinteren Stallen, die etwas einfacher als die vorderen sind, von einem älteren Gestühl stammen könnten. ${ }^{587}$ Das scheint möglich, doch existieren weder schriftliche Hinweise noch technische Befunde, die diese Überlegung untermauern würden. Nachdenklich stimmen allerdings auch die Rückwandstützen, deren Gestaltung an Hochwangen aus dem I7. Jahrhundert erinnert (Abb. 87). Und schließlich dürfte die These von der Wiederverwendung älterer Möbelteile beim Bau des Gestühls auf die Außenwangen zurückzuführen sein, die am unteren Rand, einige auch

586 Ammann, Stams (r 990), 26-27, 33.

587 Wartena, Süddeutsche Chorgestühle (2008), 743-744, 752-754. 


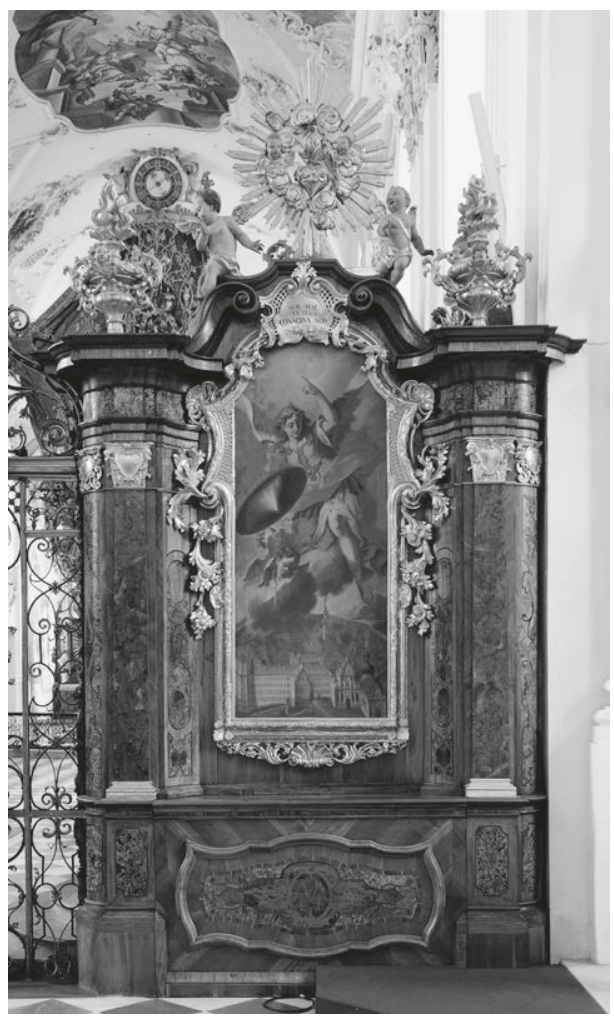

$35^{8}$ Querflügel des Chorgestühls, Westseite. Fr. Georg Zoller und Augustin Strigl (?), um I 735. Maler Johann Georg Wolcker, Erzengel Michael beschützt die Abtei Stams, um I 733

seitlich beschnitten sind (Abb. 353, 354). ${ }^{588}$ Allerdings können sie aus stilistischen Gründen kaum früher als auf die I73oer-Jahre datiert werden. Falls sie hier als Spolien eingearbeitet wurden, hieße das, dass man ein nur wenig früher entstandenes Gestühl durch ein neues ersetzt hätte. Bei der präkeren finanziellen Lage, in der sich die Abtei damals befand, scheint das eher unwahrscheinlich. Vielleicht handelt es sich bei den Wangen aber um Teile eines Gestühls, das in der Chorkapelle hätte aufgestellt werden sollen. ${ }^{589}$ Oder erhielt das Gestühl in den I75oer-Jahren, als man die Chororgel einfügte, einen neuen und breiteren Treppenaufgang, was zur Änderung der Wangen führte? Wir wissen es schlichtweg nicht, und der Nachweis, dass Zoller beim Bau des Gestühls ältere Teilstücke verwendet hätte, wäre noch zu erbringen.

Wartena verortete das Chorgestühl in der Tradition süddeutscher Tischlerarbeiten. In der Tat lassen sich frappierende Übereinstimmungen zwischen dem Möbel in Stams und dem im nördlich von Regensburg gelegenen Pielenhofen erkennen. ${ }^{590}$ Letzteres wurde in den frühen I72oer-Jahren gefertigt und diente beim Bau des Tiroler Möbels als Vorlage. Doch übernahm man das Vorbild aus Pielenhofen in modifizierter Form, denn wesentliche Unterschiede in der architektonischen Gliederung und in der Tiefenstaffelung der Flächen sind ebenfalls nicht zu übersehen.

588 Wagner, Heiligenkreuz (2007), I 49, Abb. 4.

589 Den Plan für die Aufstellung eines Gestühls in der Chorkapelle gab es durchaus. Wolfgang, Stams (2008), 36.

590 Beschreibungen und Abbildungen des dortigen Gestühls bei Wartena, Süddeutsche Chorgestühle (2008), 593-609 und Abb. I 9. I 4. Wie das Kloster Stams steht auch das in Pielenhofen in der Filiation von Kaisheim. 

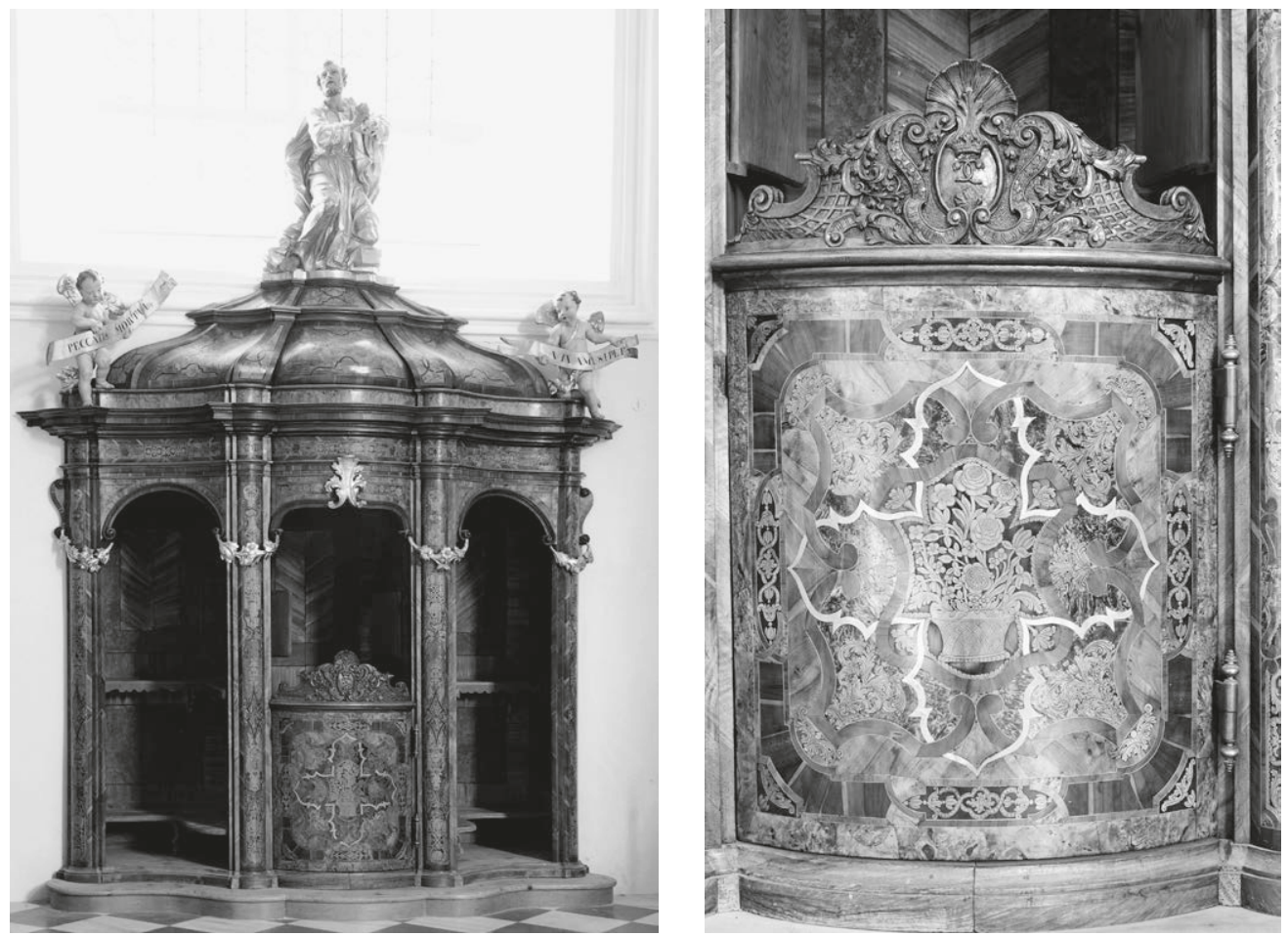

359 Stiftskirche, Epistelseite, östliche Seitenkapelle. Beichtstuhl mit der Aufsatzfigur des hl. Petrus.

Tischler Fr. Georg Zoller, Bildhauer Andreas Kölle und Augustin Strigl, um I732/35

360 Teilansicht von Abb. 359 mit dem bekrönten Wappen des Abtes Augustin Kastner

\section{Beichtstühle}

Die Außenwand der östlichen Seitenkapelle auf der Kirchennordseite ist für Türen geöffnet, ins Mauerwerk der übrigen Kapellen wurden fünf weitgehend identische, aber mit großem zeitlichem Abstand entstandene Beichtstühle eingesetzt. ${ }^{591}$

591 Ammann, Barock (r 973), 76; Dehio, Tirol (r 980), 753; Ammann, Stams (r 990), 26. Weitere Beichtstühle wurden im I9. Jahrhundert in die Außenwände des Langhauses eingepasst (Abb. 365). Bei ihrer Anfertigung übernahm man das Aussehen der Möbel in den Seitenkapellen. Ammann, Stams (I 990), 36. 


\section{Beichtstühle}

Tischler Fr. Georg Zoller, Bildhauer Andreas Kölle und Augustin Strigl, Fassmaler Josef Bernhard Strebele, um I732/35

HS I $2,5 \mathrm{~cm}$

Gesimshöhe $236 \mathrm{~cm}(+\mathrm{I} 2,5 \mathrm{~cm}) \times$ B $297 \mathrm{~cm} \times$ T ca. I $20 \mathrm{~cm}$

Nussholz, Nussbaummaser, Nuss geschwärzt, Eibe, Rosenholz, Pappel, Buchsbaum, graviert und geschwärzt, Ahorn, Holz brandschattiert, furniert auf Nadelholz, Holz (Linde ?) gefasst und vergoldet. Zinn, Messing, Eisen

Seitenkapelle im Osten der Kirche, Südseite

Aufsatzfigur: hl. Petrus

Spruchbänder: Peccatos MoRtui/vivamus I PET 2

Mittlere Seitenkapelle, Südseite

Aufsatzfigur: hl. Maria von Ägypten

Spruchbänder: CONVETERE AD DOMINUm/ET RECCINQUe PECCATA TUA ECC LUC ?

Mittlere Seitenkapelle, Nordseite

Aufsatzfigur: hl. Maria Magdalena

Spruchbänder: REMitTUNTUR EI PECCATAMI/ QUONIAM DiCEXIT MULTUM LUC 7

\section{Beichtstühle}

Stams, um I $780 / 90$

HS I $2,5 \mathrm{~cm}$

Gesimshöhe $236 \mathrm{~cm}(+\mathrm{I} 2,5 \mathrm{~cm}) \times \mathrm{B} 297 \mathrm{~cm} \times$ T ca. I $20 \mathrm{~cm}$

Nussholz, Nussbaummaser, Nuss geschwärzt, Eibe, Rosenholz, Buchsbaum, graviert und geschwärzt, Ahorn, Holz brandschattiert, furniert auf Nadelholz, Holz (Linde?) gefasst und vergoldet. Zinn, Messing, Eisen

Seitenkapelle im Westen der Kirche, Nordseite

Aufsatzfigur: König David

Spruchbänder: Misericordia S Domini / In AETERnAm CANTABo P 58

Seitenkapelle im Westen, Südseite

Aufsatzfigur: hl. Dismas

Spruchbänder: AMEN DICO TIBI/ MECUM ERIS PARADISO LUC 23

Halbrunde Lisenen strukturieren die bewegten Fassaden, deren Grundriss zwei seitliche S-Schwünge und einen mittleren konvexen Bogen nachzeichnet (Abb. 359-360). Während die seitlichen Gehäuse mit einem Rundbogen enden, überfängt die mittleren ein flacher Kielbogen. Die weit nach vorn ragenden Gebälke tragen mehrfach verkröpfte Kuppelkalotten, die den Aufsatzfiguren als Standflächen dienen. Die Bildwerke präsentieren Heilige, die durch Reue und Buße zu einem gottesfürchtigen Leben gefunden haben, seitlich davon befinden sich Engel mit den angeführten Spruch- 
bändern. Ganz im Sinne der Gegenreformation ließ sich der Abt von Stams beim Bau der Confessionalen von mahnenden und belehrenden Darstellungsmotiven leiten. ${ }^{592}$

Perfekt ausgeführte Marketerien aus verschiedenen Hölzern sowie aus Zinn vervollständigen die Beichtstühle. Detailreiche Darstellungen von Blumenbouquets in Vasen und Körben, von Muscheln, Laub- und Bandlwerk sowie von Blättern und Blütenzweigen zieren die Flächen. Schnitzornamente schmücken dreieckige Platten auf den Türen und säumen an einem Beichtstuhl eine Kartusche mit dem Wappen Kastners (Abb. 360). Vor den Lisenen hängen Blütengirlanden, am Bogenscheitel über dem Priestersitz ist ein geschnitztes Blatt befestigt.

Im Oktober 1733 vermerkt ein Eintrag im Rechnungsbuch der Abtei, dass Georg Zoller einen Firnis zur Vollendung der Beichtstühle erhalten habe. ${ }^{593}$ Die Möbel waren folglich in der Stiftstischlerei gefertigt worden - zumindest die drei älteren, wie aus weiteren Quellen hervorgeht. Zwei Jahre später erhielt Zoller eine größere Geldsumme zur Entlohnung von zwölf Gesellen, die in der Stiftstischlerei arbeiteten. ${ }^{594}$ Ein Vergleich der Marketerien an den Beichtstühlen mit jenen am Chorgestühl gibt Anlass zur Vermutung, dass am Bau der Möbel unterschiedliche Handwerker beteiligt waren. In beiden Fällen ist die handwerkliche und künstlerische Qualität außerordentlich hoch, doch bestehen gravierende Unterschiede bei den verwendeten Werkmaterialien, vor allem durch die Einlegearbeiten aus Zinn, die in Österreich nur selten zu finden sind. ${ }^{595}$

Unterrichtet sind wir ebenfalls über die Bildhauer, die bei der Herstellung der Beichtstühle beteiligt waren. Mit Andreas Kölle (I680-I722) war bereits I732 ein Vertrag über die Lieferung von drei Aufsatzfiguren und sechs Engeln geschlossen worden: Item accordiere vor drey statuen S. Petri, S. Mariae Magdalenae, und S. Mt. aegyptiacae sambt 6 engl zu den beichtstüellen [...]. ${ }^{596}$ Ein weiterer relevanter Hinweis findet sich in einer 1734 oder 1735 abgefassten Rechnungsaufstellung von Augustin Strig1: Mehr hab ich zu die beicht stiell verfertiget 3 bluembengeheng [... ${ }^{597}$ Die Statuen auf den drei Beichtstühlen in den östlichen Kapellen stammen also von Kölle, während Strigl

592 Vgl. die entsprechenden Angaben im Abschnitt über die Beichtstühle in der Stiftskirche St. Georgenberg in Fiecht.

593 24.IO.I733. StASt Rechnungsbuch Kastner I732-35. Wolfgang, Stams (2008), 88. Christiane Wolfgang stellte mir freundlicherweise Scans dieser und der nachfolgend genannten Archivalien zur Verfügung.

594 OI.IO.I735. StASt Rechnungsbuch Kastner I732-35.

595 Ohne besondere Ausbildung konnten Metallintarsien in dieser Qualität kaum hergestellt werden. Zu Wiener »Galanterietischlern«, die solche Arbeiten fertigten s. Wagner, Kenntnis (2010), 53-55.

596 03.03.1732. StASt Rechnungsbuch Kastner I 726-32; Wolfgang, Stams (2008), 87. Zu Andreas Kölle s. neuerdings auch Stainer, Bildhauerzeichnung (20I8), I 48 -I 54 .

597 StASt, GVan 2 I, Konto Strigl. Vgl. auch Wolfgang, ebd. 


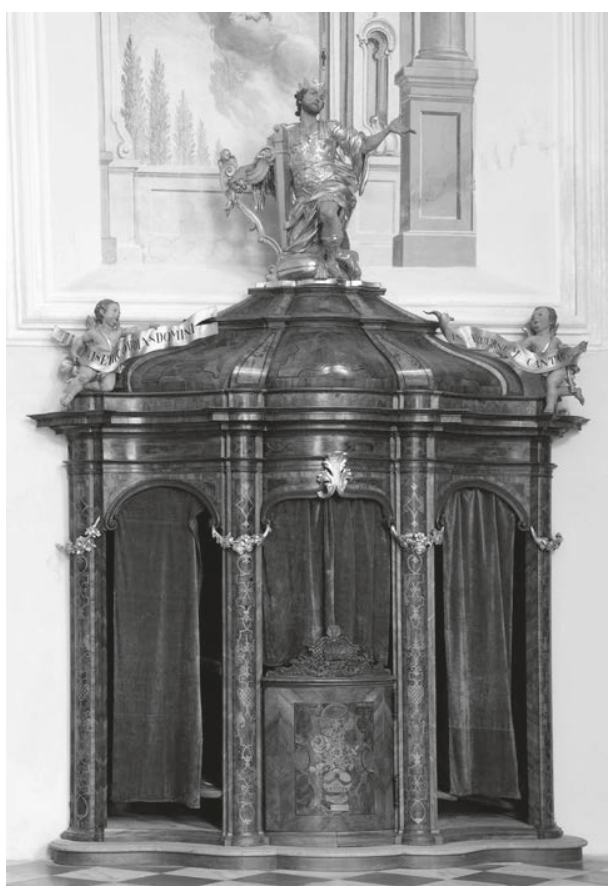

36I Stiftskirche, Evangelienseite, westliche Seitenkapelle. Beichtstuhl mit der Aufsatzfigur Davids. Stams, um I780/90

die Blumengirlanden schuf; er war für die ornamentalen Zierelemente zuständig. Gefasst wurden die Figuren von Josef Bernhard Strebele. ${ }^{598}$

Völlig zu Recht nimmt Christiane Wolfgang für die beiden Beichtstühle in den westlichen Kapellen eine spätere Herstellung an. Es handelt sich bei ihnen um relativ freie Kopien der beschriebenen Exemplare, denn ihre Ausführung unterscheidet sich zwar nicht hinsichtlich der Großform, wohl aber im Hinblick auf Details von der Gestaltung der anderen Möbel (Abb. 36r). ${ }^{599}$ Die künstlerische Qualität der Marketerien fällt bei den jüngeren Stücken deutlich zurück, zudem kommen Furniere aus Pappelmaserholz an den beiden Inventarstücken nicht vor. Vor allem aber geben die in die Türfüllungen eingelegten Vasen einen massiven Einfluss des Zopfstils zu erkennen, die Möbel stammen aus einer Zeit, als der vorherrschende Kunstgeschmack bereits einem tiefgreifenden Wandlungsprozess unterworfen war. Bislang war es nicht möglich, die beiden Beichtstühle in den Archivalien nachzuweisen, sodass wir nicht wissen, auf welche Meister die Möbel zurückgehen, doch werden sie die Inventarstücke kaum vor den späten I77oer-Jahren verfertigt haben.

\section{Bänke in den östlichen und westlichen Seitenkapellen}

HS $\mathrm{r} 3 \mathrm{~cm}$

H ca. $255 \mathrm{~cm}(+\mathrm{I} 3 \mathrm{~cm}) \times \mathrm{L}$ ca. $440 \mathrm{~cm}$

598 Ammann, Stams (1990), 36.

599 Wolfgang, Stams (2008), 87. Ammann ging in ÖKM, Tiroler Oberland (1 978), 358 und Stams (I 990), 36, noch von einer gleichzeitigen Anfertigung aller Beichtstühle aus. Dem schlossen sich die Verfasser des Dehio, Tirol (r 980), 753 an. 


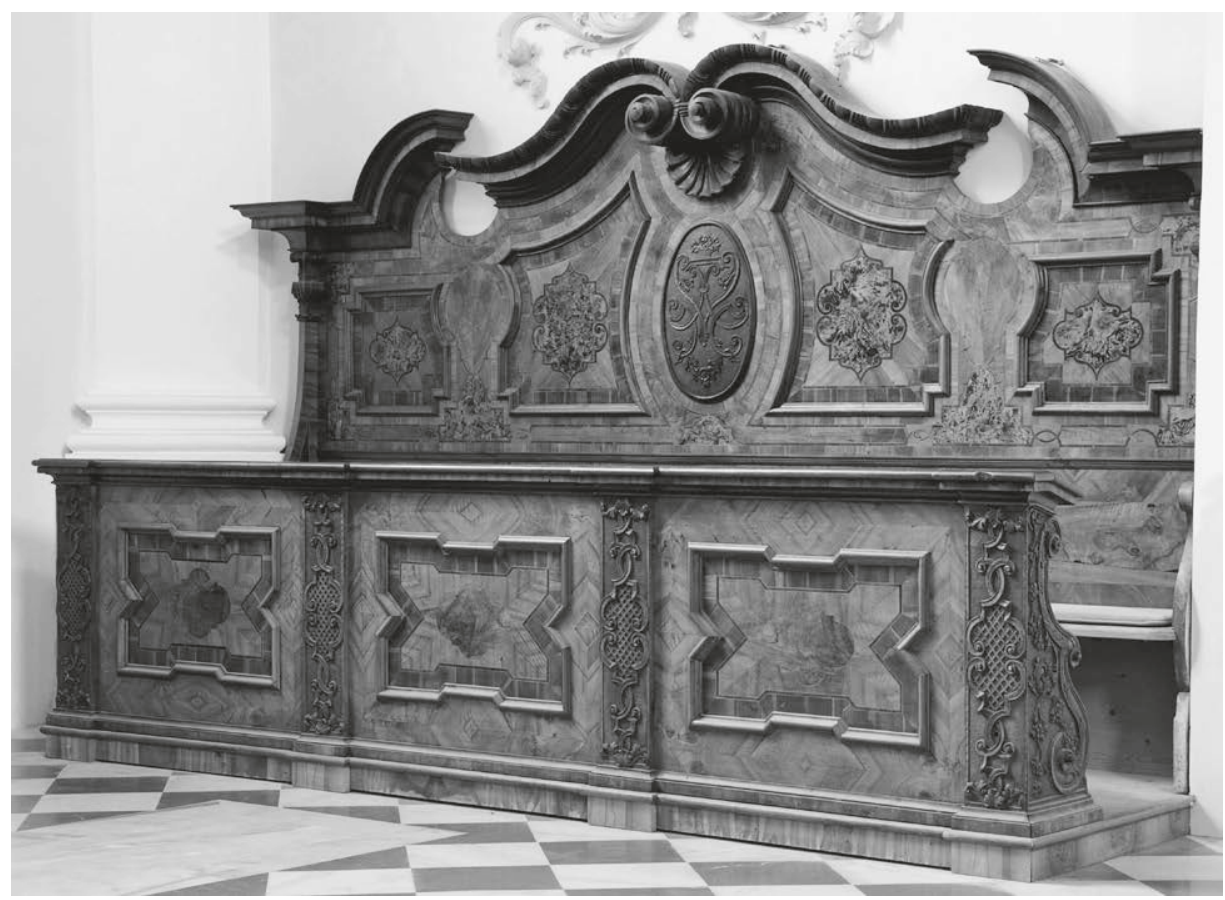

362 Epistelseite, Gestühl in der westlichen oder östlichen Seitenkapelle. Tischler Fr. Georg Zoller und Bildhauer Augustin Strigl, I 734/35

\section{Bänke in den mittleren Seitenkapellen}

HS I $2,5 \mathrm{~cm}$

$\mathrm{H}$ ca. $\mathrm{I} 96 \mathrm{~cm}(+\mathrm{I} 2,5 \mathrm{~cm}) \times \mathrm{L}$ ca. $450 \mathrm{~cm}$

Tischler Fr. Georg Zoller und Bildhauer Augustin Strigl, I 735

Nussbaum, massiv und furniert, Nuss geschwärzt, Nussmaser, Ahorn, Pappelmaser, Zwetschke, auf Nadelholz furniert

Die sechs Kirchenbänke stehen jeweils vor der Westwand der Seitenkapellen. Vier Bänke sind nahezu identisch (Abb. 362), wohingegen die beiden in den mittleren Abseiten größere Differenzen zu den übrigen Exemplaren aufweisen (Abb. 363, 364 ).

Pilasterartige Stützen unterteilen die Brüstungsvorderseiten der Möbel in drei Achsen. An den vier gleichen Bänken besitzen sie übereinstimmende Breitenmaße, während man die Brustwände der beiden anderen rhythmisierte. Die Schnitzmotive Laub- und Bandlwerk, Gitter und Blumenvasen - gehen auf Vorlagen zurück, die durch französische Ornamentisten beeinflusst waren. Das könnte auch den etwas metallisch 


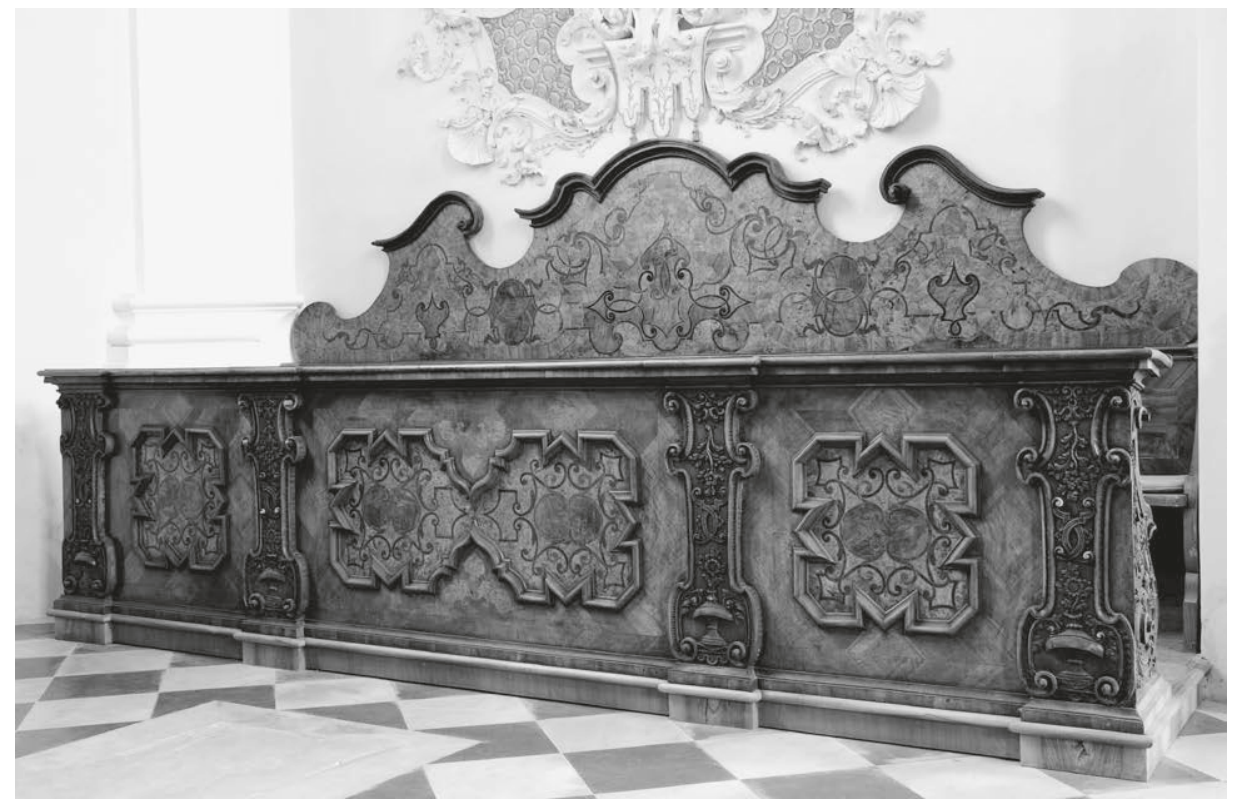

363 Epistelseite, mittlere Seitenkapelle, Gestühl. Georg Zoller und Augustin Strigl, I 734/35

wirkenden Duktus des Dekors erklären, der an Möbel in der Wiener Karlskirche erinnert. ${ }^{600}$ Die Tischler setzten die mit kräftigen Profilen umgebenen Brustwandfüllungen leicht vertieft in die Rahmen ein. Marketerien mit einem Fond aus Pappel- und Nussbaummaser zieren die Binnenfelder, während gestreiftes Furnier auf den Rahmen liegt.

Die stark geschwungenen Oberkanten der Rückenlehnen wurden an den beiden mittleren Bänken (Abb. 363) nur partiell mit einem Abschlussgesims versehen, dort leiten zwei Voluten zu einem geschweiften Giebel über. Die Rückwände dieser Möbel bestehen aus einer durchgehenden Fläche. Dagegen verfügen die vier anderen Bänke (Abb. 362) über schwere Gesimse mit Volutengiebeln zwischen seitlichen Teilstücken. Eingesetzte Füllungen strukturieren an diesen Möbeln die Lehnen, ein großes geschnitztes Hochoval ziert die Mittelachse, unter dem Giebel hängt eine Muschel.

Im Stiftsarchiv werden zwei Schreiben verwahrt, in denen der Bildhauer Augustin Strigl seine Arbeiten an den Möbeln in Rechnung stellte:

Firsander hab ich zu hauß 4 tockhen $z$ die bett stiell gemacht aine per I $f$ zo thuet 6 fl. [...] Widerumb hab ich gemacht mit dero gnedigen verlaub 2 oval, ains per I $A$ lo $\times$ thuet zu samb $3 f$. So

600 Bohr, Sakralmöbel (2017), I 80-1 82. 


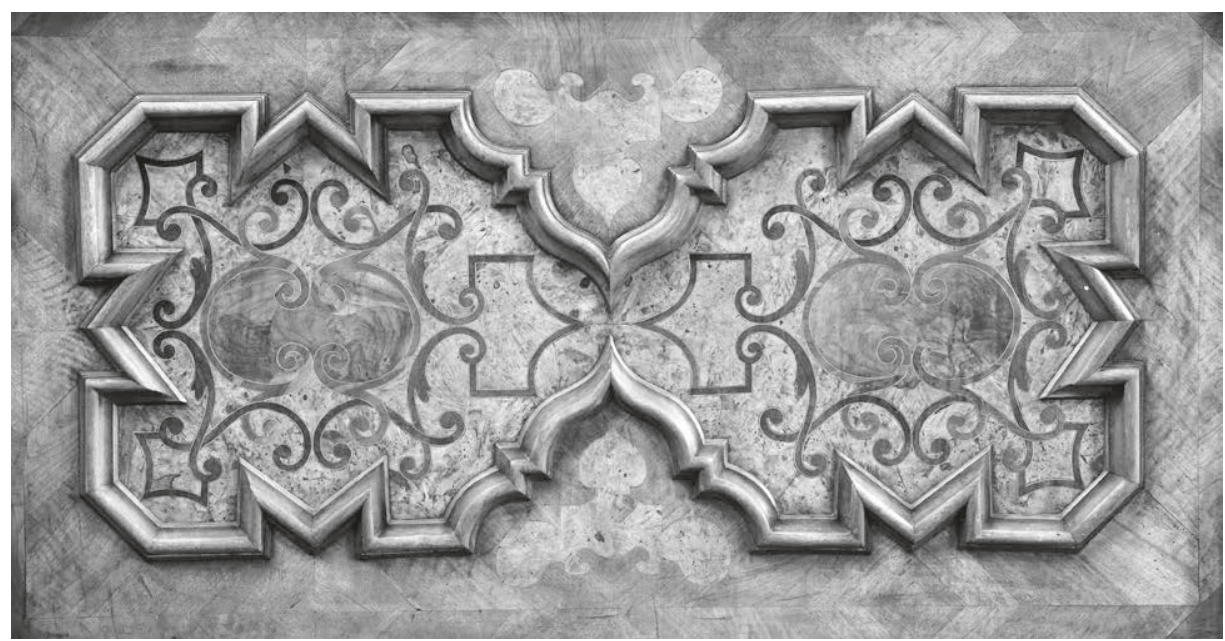

364 Detail aus Abb. 363. Fr. Georg Zoller und Bildhauer Augustin Strigl, I 734/35

dan auch 4 kragschnirggl ain per $20 \times$ macht Ifl $20 \times$. Abermablen 2 dachung schnirrgl sambt 2 muschlen geschniten per I fl. ${ }^{601}$

Nach einer Notiz in der Abtraittung Kastners wurde die Rechnung am 5. Januar I735 beglichen. Eine zweite Rechnung folgte, der Abt bezahlte sie am I7. August jenes Jahres. Darin vermerkte Strigl:

Erstlich hab ich 2 tockhen $z$ die bett stiell gemacht fir jede I $A$ lo $k$ thuet 3 fl. Firs ander hab ich 4 dachung schnirggl verfertiget ain per $30 k$ thuet $2 f$. Mehr hab ich 2 oval geschniten ains per I $A$ 3O $k$ thuet 3 f. Weiters hab ich 4 kragg schnirggl gemacht fir ieden $20 k$ thuet I $A$ 2o $k$. Erstlich hab ich 2 muschlen gemacht aine per $15 k$ thuet $-A$ 3 3 k. Summa $9 f 5_{50}{ }^{602}$

Strigl schnitzte demnach sechs tockhen, acht kragg schnirggl, sechs dachung schnirggl, vier oval und vier muschlen. Gemeint sind mit den tockhen selbstredend die Außenwangen der Brüstungen. Die sechs zur Raummitte zu sind geschnitzt, die Docken, die zur Wand hinweisen, nicht. Zudem fertigte der Bildhauer vier Muscheln und ovale Kartuschen. Das stimmt mit dem Befund an den Möbeln in den westlichen und östlichen Seitenkapellen überein. Mit den acht kragg schnirggl dürften die kapitellartigen

6or StASt GVa n. 2 I, Konto Strigl. Wolfgang, Stams (2008), 87 bezieht diese Quelle fälschlicherweise auf das Chorgestühl.

602 StASt GVa n. 22, Konto Strigl. 
Gebilde über den Hochwangen zu verstehen sein, mit den dachung schnirggl die Voluten der Giebel. Bei der Aufstellung fehlen allerdings zwei weitere Voluten sowie die Brüstungsbaluster. Das Möbelensemble entstand in der Stiftstischlerei unter der Leitung Zollers. Das dokumentiert ein Eintrag in einem der Rechnungsbücher, dem zufolge Zoller beim prandwein prenner Materialien zur Herstellung des Firnisses für die sechs Bänke erworben hatte. ${ }^{603}$

Die Möbel zeichnen sich durch mehrere Spezifika aus: durch die schweren Giebel, die massiven Profile, die kleinteilig gebrochenen Füllungen sowie durch die Form der Bandeinlagen. An der Sakristeitür (Abb. 369), auf die in einem der nächsten Abschnitte der Arbeit genauer eingegangen wird, kommt Vergleichbares noch einmal vor. Obschon die stiftsinterne Werkstatt für die Herstellung der Möbel nachgewiesen ist, besitzen die Tischlerarbeiten mit diesen Charakteristika ein Gepräge, das definitiv unösterreichisch wirkt. Es lässt an die Beteiligung eines italienischen Handwerkers bei der Herstellung der Möbel denken. ${ }^{604}$

\section{Laiengestühl}

Verm. Fr. Georg Zoller und Bildhauer Augustin Strigl, um I 740

HS I I, $5 \mathrm{~cm}$

$\mathrm{H}$ ca. I I I,5 cm (+ I I,5 cm) $\times \mathrm{L} 496 \mathrm{~cm}$

Nussbaum, massiv und furniert, Nussbaummaser, geschwärztes Nussbaumholz, Pappelmaser,

Zwetschke, Ahorn (?), graviert und geschwärzt, Nadelholz, polychrom gefasst

Das Laiengestühl im Langhaus der Stiftskirche zählt zwölf Bankreihen (Abb. 365367). ${ }^{605}$ Hinzu kommen im Westen zwei Einzelsitze sowie im Osten die obligatorische Vorderbrüstung.

Massive und sich weit in den Raum wölbende Volutenpilaster unterteilen die Vorderbrüstung in drei Segmente, deren mittleres breiter als die beiden seitlichen ist. Kräftige Rahmen fassen die Füllungen ein. Ein Fries aus Zwetschkenholz säumt die Marketerien der mit Maserholz furnierten Binnenfelder, in der mittleren Travée prangt das Wappen des Abtes Jakob Mülbeck (reg. I738-I742): ein Greif mit Rose und Krone. Über der Kartusche sind Abthut und Stab zu erkennen, seitlich Felder mit Rosetten-

603 I 9 . Februar $\mathrm{I} 735$. StASt Rechnungsbuch Kastner $\mathrm{I} 732-35$. Vielleicht handelte es sich unter anderem um Weingeist oder Spiritus (Ethanol), der als Lösungsmittel für Wachse, Harze und Farben benötigt wurde.

604 Ferrari, Legno [ca. 1928], I6r, Taf. 93 und 220, Taf. 20; Colombo, Larte (1981), Abb. I 19; Manni, Mobili (I 993), Abb. I 2 I-I 24, 21 5-235; Olivari, Sagrestie (I 994). Die Abbildungen zeigen Tischlerarbeiten aus dem I6., I7. und I 8 . Jahrhundert.

605 Dehio, Tirol (1980), 753 . 


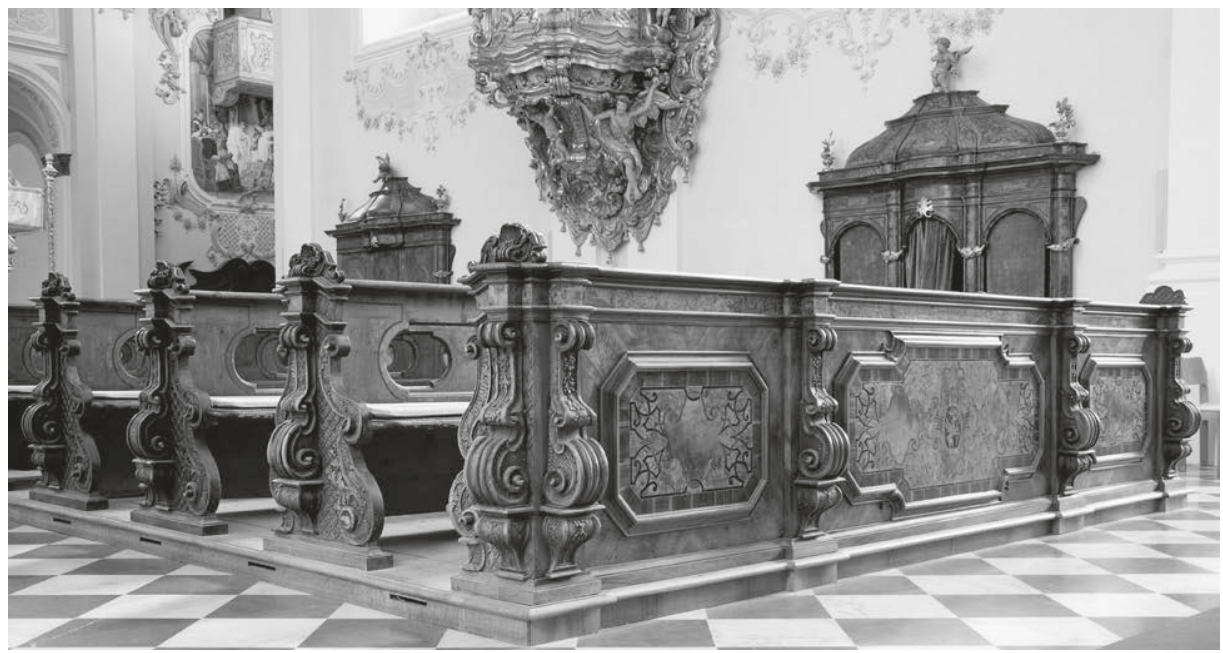

365 Stiftskirche, Laiengestühl. Verm. Fr. Georg Zoller, und Bildhauer Augustin Strigl, um I 740

366 Stiftskirche, Laiengestühl, Brüstungsdetail mit dem Wappen des Abtes Jakob Mülbeck. Verm. Fr. Georg Zoller und Bildhauer Augustin Strigl, um I740
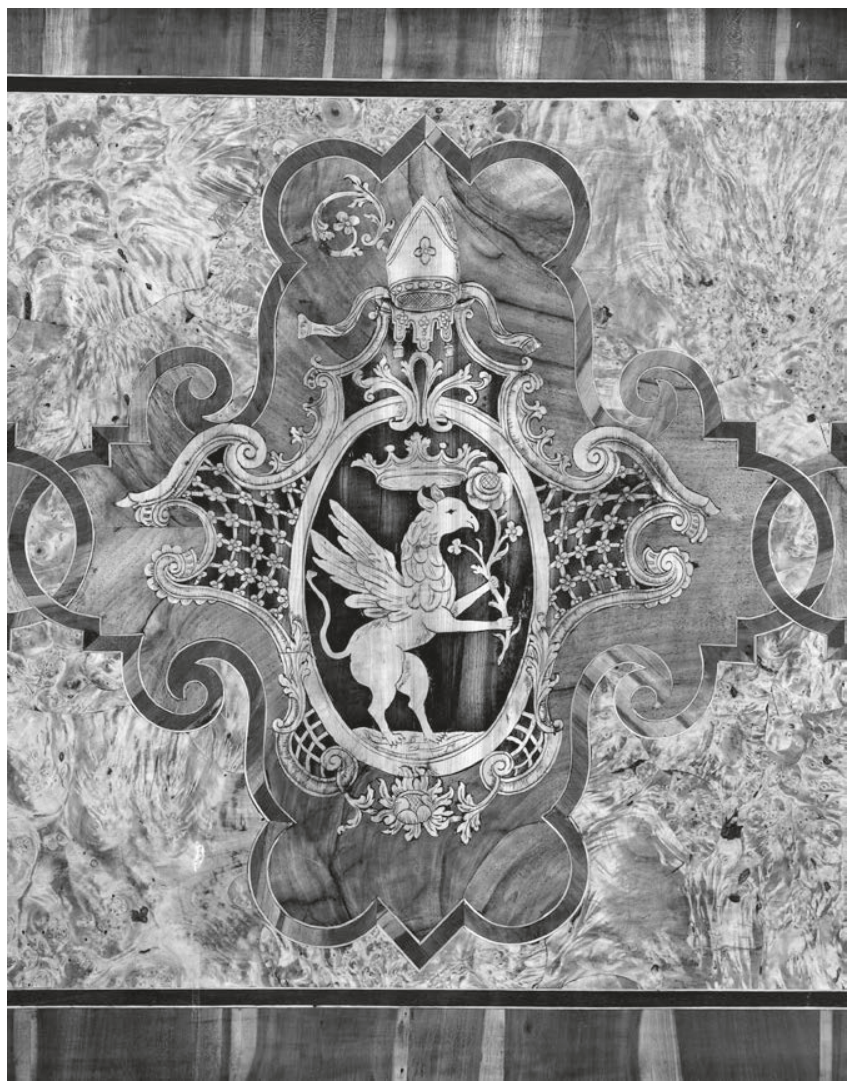


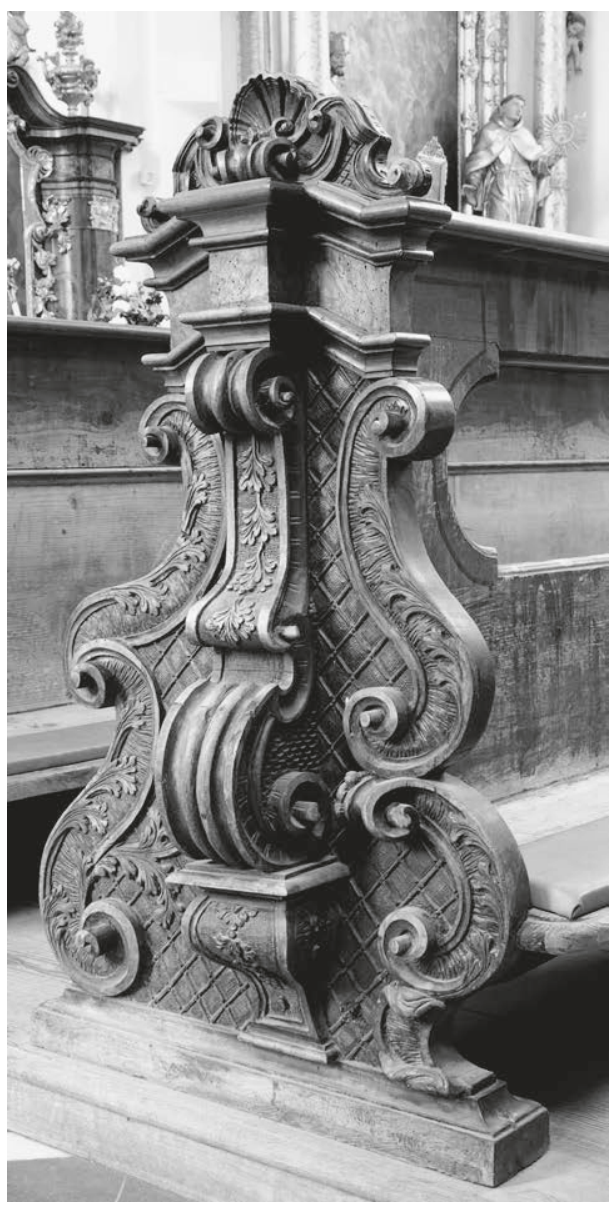

367 Stiftskirche, Laiengestühl, Gestühlswange. Verm. Fr. Georg Zoller und Bildhauer Augustin Strigl, um I740 gittern. Die Einlagen bestehen vermutlich aus Ahornfurnier, die Binnenzeichnungen wurden eingraviert und geschwärzt.

Ausgesprochen schwere Volutenpilaster, die formal den Balustern der Vorderseite entsprechen, akzentuieren die Mittelachsen der Seitenwangen. Die von Bändern gebildeten Seitenkanten der Docken setzen sich aus großen Schwüngen zusammen, ihre Enden rollen sich zu Schnecken ein. Schraffuren und Blätter lockern die Oberfläche der Bänder auf, Gitterwerk ziert die Binnenfelder. Die Docken schließen mit einem Gebälkstück, das wie ein gebrochener Giebel nach oben geführt ist. Schnitzwerk bekrönt die Wangen.

Der Gebälkfries ist mit Pappelmaser ausgelegt, die geschnitzten Möbelteile fertigte man aus massivem Nussholz, Rückenlehnen, Knie- und Sitzbänke aus Nadelholz. Aufgemalte schwarze Adern begleiten die Öffnungen der Lehnen, während die Binnenflächen mit einem hellbraunen Farbton gefasst sind. Wegen des in die Vorderbrüstung eingelegten Wappens ist die Datierung der Möbel auf die Jahre um I740 gesichert, das entspricht dem stilistischen Befund. Die Tischlerarbeiten wurden wahrscheinlich im Stift selbst hergestellt, für die Schnitzereien wird wieder der Bildhauer Strigl zuständig gewesen sein. Interessant ist eine Gegenüberstellung der Schnitzarbeiten am Laiengestühl mit jenen der Möbel in den Seitenkapellen. Denn bei ähnlichen Motiven muten sie an den sechs Bänken in den Seitenkapellen eigentümlich »trocken« an, ein krasser Gegensatz zu den schwungvollen und kräftigen Arbeiten an Wangen und Balustern des Laiengestühls. Der Laufboden ist modern. 


\section{Chorraum}

2 Türen

Stams, um I $770 / 75$

$\mathrm{H} 23 \mathrm{I} \mathrm{cm} \times$ B I $38 \mathrm{~cm}$ (lichtes Maß)

Nadelholz, polychrom gefasst, Holz (Linde?)

vergoldet. Eisen, geschwärzt

Völlig anders als die oben beschriebenen Portale präsentiert sich die Gestaltung zweier Türen, die im Osten der Kirche die Nordkapelle mit der Sakristei und dem Kreuzgang verbinden (Abb. 368). ${ }^{606}$ Auch sie sind in einen architektonischen Rahmen eingebettet, doch wurden den Stützen nun seitliche, nach außen weisende Wangen angefügt. Das in der Mitte aufgebrochene Gebälk ist stark geschwungen und hängt dabei nach unten durch, auf ihm ruht ein hoher Aufsatz, den Spangen und ein Segmentgiebel begrenzen. Die Türöffnung schließt mit einem Karniesbogen. Ein mittlerer Pilaster teilt das Türblatt optisch in zwei

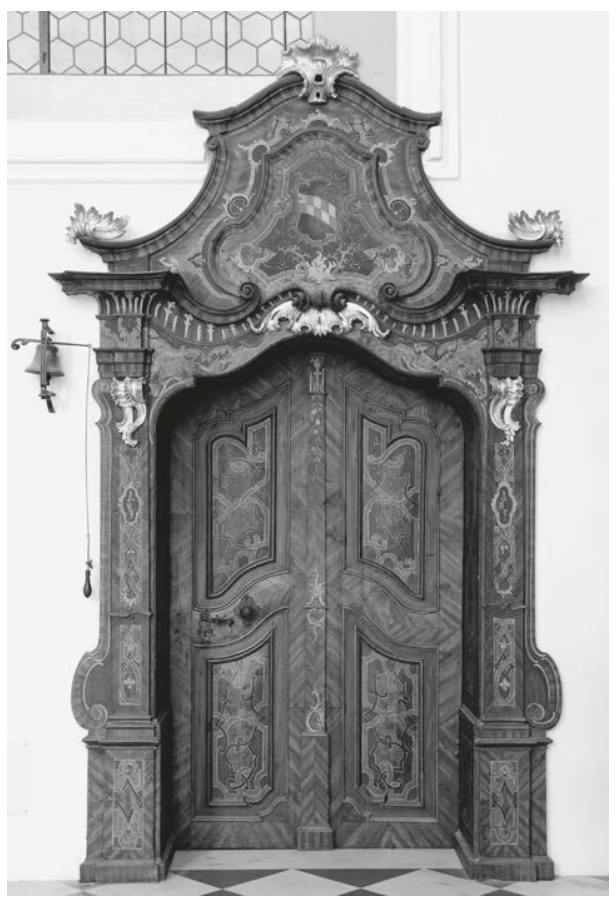

368 Stiftskirche, Chorraum, Sakristeiportal. Stams, um $1770 / 75$ Hälften, Füllungen strukturieren die mit Fassmalereien überzogenen Flächen, geschnitzte Teile wurden vergoldet. Die Marketerieimitationen scheinen aus Schildpatt, Ebenholz und Zinn zu bestehen. Im Giebelfeld der Sakristeitür ist das Stiftswappen über Korallenzweigen zu erkennen, über der zweiten Tür das Wappen des Abtes Vigil Kranicher (reg. I766-I786).

Die Tatsache, dass die Türen nicht furniert, sondern mit Malereien aufgewertet wurden, überrascht, doch sparte der Konvent so Kosten für teure Werkstoffe und zeitintensive Arbeitsprozesse. Tatsächlich war das Fassen von Möbeln zur Imitation von Furniertechniken und Einlegearbeiten in der Vormoderne eine in Österreich häufig geübte Praxis. ${ }^{607}$ Auf diese Weise wurde 1773 in Stams eine neue Orgel vervollständigt, zehn Jahre später profanes Mobiliar, das der Konvent zur Einrichtung verschiedener Zimmer benötigte. ${ }^{608}$

606 In Stams liegen Kreuzgang und Konventgebäude nördlich der Klosterkirche.

607 Koller, Farbgebung (2010).

608 StASt Rechnungsbuch Kranicher, I766-I 786. Die Einträge datieren vom I 8. September 1773 und 6. Mai 1783 . 


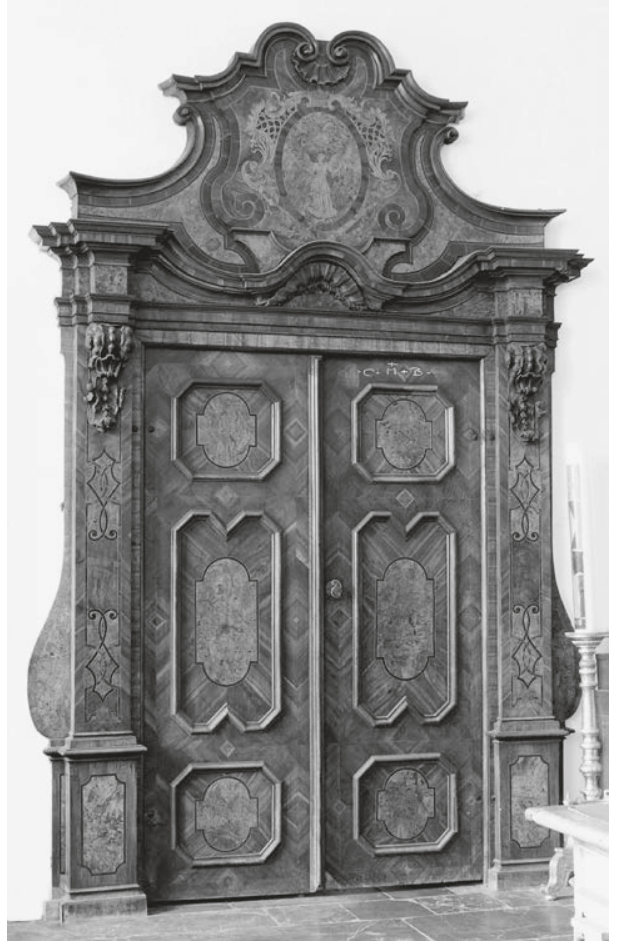

369 Sakristei, Portal zu Seitenraum. Fr. Georg Zoller (?), um I 745/50

\section{Sakristei}

Tür

Fr. Georg Zoller (?), um I 745/50

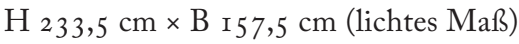

Nuss, massiv und furniert, Nussmaser, geschwärztes Nussbaumholz, Ahorn, Buchsbaum, Pappelmaser, Zwetschke, Nadelholz. Eisen, Messing

Ein mit Marketerien dekoriertes Portal führt von der Sakristei aus in einen kleinen Nebenraum (Abb. 369). Wieder tragen pilasterähnliche Stützen ein geschwungenes Gebälk, wobei nun eine mittlere konvexe Schweifung die beiden seitlichen konkaven Bögen miteinander verbindet. Erneut folgt ein hoher Aufsatz, den jedoch eine Kartusche mit dem Erzengel Michael ziert. Als Auftraggeber des Portals ist damit Abt Rogerius Sailer (reg. I742-I766) gesichert, der den Erzengel in seinem persönlichen Wappen führte.

Bei der Ausarbeitung gestalterischer Details des Portals orientierte sich der Tischler an Möbeln in der Stiftskirche. Das blockhaft verkröpfte Gebälk nimmt Bezug auf die Ausgestaltung der Chorstallen, während die Türfüllungen und der schwere Volutengiebel an das Gestühl der Seitenkapellen erinnern. Wie in Verbindung mit diesen Möbeln erörtert, dürfte der Entwurf zur Tür auf einen in Italien geschulten Meister zurückgehen. Das hochovale Medaillon im Aufsatz mit dem seitlichen Gitterwerk ist eine augenfällige Reminiszenz an die Vorderbrüstung des Laiengestühls. Zugleich ist offensichtlich, dass die Tür als Vorbild für die vorhergehend beschriebenen Exemplare im Chorraum diente. Interessant sind dabei die Unterschiede zwischen den Portalen: Das Gewicht des Aufsatzes drückt das kräftige Gesims der Tür in der Sakristei scheinbar bis auf den Architrav nach unten, während das Gebälk der anderen Türen aufgebrochen und in eine lockere und leichte Bewegung versetzt ist. Der Schwere und Strenge des einen Portals steht die Verspieltheit der anderen Exemplare gegenüber. Diese Differenz zeigt sich auch in den Türblättern : Formen sie am Portal in der Sakristei schlichte Hochrechtecke, sind sie an den späteren schwungvoll in die Höhe geführt. Analog müssen die Ornamentmotive 
an den Portalen verstanden werden. An der Sakristeitür sind es strenge geometrische Muster, an den beiden Portalen in der Kirche dagegen leichte Rocaillen und Korallengewächse.

\section{Wilten, Prämonstratenser-Chorherrenstift}

\section{Stiftskirche zu den bll. Laurentius und Stephanus}

Vielleicht schon in der Spätantike, spätestens aber zu Beginn des frühen Mittelalters existierte an der Stelle der heutigen Abteikirche eine Laurentiuskirche, seit 805 ist das Dorf Wilten in Schriftquellen fassbar. ${ }^{609}$ I I 28 oder I I 38 übertrug der Brixner Bischof Reginbert (reg. I I 25-I I39) ein Kollegiatstift, das bei der Kirche errichtet worden war, dem Prämonstratenserorden, besiedelt wurde das Kloster von der schwäbischen Reichsabtei Rot an der Rot. ${ }^{610}$

Im I 7. Jahrhundert befand sich die Stiftskirche wie viele mittelalterliche Sakralarchitekturen in einem derart schlechten Erhaltungszustand, dass es sich der Konvent unter dem Abbatiat von Dominikus Löhr (reg. I651-r687) angelegen sein ließ, die Kirche neu zu erbauen. Die Pläne stammten von Christoph Gumpp d.J. (I600-I672), die Bauleitung übernahm ein Maurermeister namens Scheffler. Nachdem das Gewölbe I 657 eingestürzt war, trat Hofmaurermeister Gallus Appeller (ca. I60o-ı685) an Schefflers Stelle. 1665 konnte die Kirche im Rohbau fertiggestellt werden. Die Ausstattung des Baus mit Fresken ist für die Jahre I702 bis I707 gesichert, Maler war Kaspar Waldmann (I657-1 720), während die Errichtung des außergewöhnlichen Kircheneingangs I7г3 bis I7r 9 nach Entwürfen von Johann Martin Gumpp d. Ä. ( 1643-I 729) erfolgte. Bei der Architektur handelt es sich um einen tonnengewölbten Bau mit einem Vorjoch, drei Langhausjochen und einem zweijochigen Chor. An das Langhaus lehnen sich beiderseits drei große Seitenkapellen, darüber liegen Emporen.

609 Schuler, Stiftskirche (I 920); Schuler, Stift Wilten (1938); Hammer, Kunstgeschichte (1952), bes. I $8-$ 24, I 88-1 95; Hubert, Leben (1954); Schuler, Stift Wilten (1956); Felmayer, Stiftskirche (1958); 3339; Gritsch/Trapp, Kriegsschäden (1958); Lentze, Geschichte (1958); Steinegger, Rundgang (1958); Hootz, Kunstdenkmäler (1965-1968), Bd. I (1965), 80-8 I, 3 19-320; Röhrig, Alte Stifte (1967), 4547; Stenzel, Stift (1977), I 52-153; Krapf, Gumpp (1979), 86-93, 3 16; Dehio, Tirol (1980), 8 I-85; Caramelle/Frischauf, Stifte (I985), 47-58; Caramelle, Barock (I 988); Halder, Geschichte (I 988); Hammerle, Zerstörung (1988); Schomers, Kunst (1988); Webhofer, Baugeschichte (I988); Möller, Kirchen (2004), 75-78; Caramelle, Stiftskirche Wilten (2008); Schomers, Wilten (2009).

6ro Schomers, Wilten (2009), 3, I2, gibt neben dem Jahr I I 38 auch das Jahr I I 28 an. Sonst wird in der Literatur I 138 genannt, das Jahr, in dem die Einsetzung der Prämonstratenser in Wilten urkundlich bestätigt wurde. 
Die am I 3. Juni I 944 bei Bombenangriffen stark beschädigte Kirche wurde zwischen I 946 und 1956 wiederhergestellt. ${ }^{611}$

\section{Sakristei}

Die Sakristei bildet mit Längswänden auf der Ost- und Westseite einen Querriegel hinter dem Presbyterium. ${ }^{612}$ Zwei zum Altarraum führende Türen flankieren die »Schrankwand « vor dem Mauerwerk der Westseite, vor der Ostwand stehen drei Aufsatzmöbel. ${ }^{613}$

\section{Schrank vor der Westwand}

Wilten, 1686

HS 3 cm

$\mathrm{H}_{45} 2 \mathrm{~cm}(+\mathrm{I} 3 \mathrm{~cm}) \times \mathrm{L} \mathrm{I} 9,80 \mathrm{~m}$

Zirbelkiefer, Fichte, Tanne, Nuss, andere Holzarten, teilweise gefasst. Eisen, gemeißelt, graviert, geschwärzt

Ein kräftiges Gesims unterteilt das Möbel in zwei Geschosse (Abb. 370). Es ruht auf einem mäßig hohen (neuen) Sockel und endet mit einem schweren Gebälk. Zwei Reihen mit Türen, die Lisenen paarweise zusammenfassen, verschließen die Front. Nur das eintürige Mitteljoch weicht von der gleichförmigen Sequenz ab, eine hohe Nische mit einer Marienstatue akzentuiert dort das Obergeschoss. ${ }^{614}$ Reduzierte Ädikulä mit verkröpften Ecken bilden die Türfüllungen. Oben tragen sie gesprengte Dreiecksgiebel mit mittleren Postamenten und einem tropfenförmigen Gebilde, unten Giebel aus knorpeligen Bögen sowie Halbkugeln auf weiteren Konsolen. Flammleisten fassen die zentralen Felder ein, am Gesims geben querovale Namensschilder Aufschluss über die jeweiligen Geistlichen, deren sakrale Bekleidungsstücke in den Schränken aufbewahrt werden. Den Gebälkfries zieren langgezogene vegetabile Ornamente. Schlösser und Türangeln bestehen aus Eisen, das gemeißelt, teilweise auch verzinnt und geschwärzt ist. Marien- und Heiligendarstellungen sowie die Wappen des Stiftes und des Abtes Dominikus Löhr in Verbindung mit dem Monogramm DAZW (Dominikus Abt zu Wilten) und der Jahreszahl r686 wurden in die Beschläge eingraviert. ${ }^{615}$

6I I Hammerle, Zerstörung (I988).

6I 2 Schuler, Stiftskirche (I 920), 5 I-52 ; ders., Stift Wilten (I 956), I4; Caramelle, Barock (I 988), I 99, 20 I.

61 3 Die spätmittelalterlichen Türen tragen die originalen Beschläge und frühbarocke Malereien. Knabl, Sakristeitüren (2008); Pfeifer, Türbeschläge (2008). Zur Restaurierung der Möbel vgl. Crisan, Sakristeischränke (2008).

6r 4 Eine Abbildung von Nische und Statue in Caramelle, Barock (1988), 202.

61 5 Abbildungen von Beschlägen und einem Schloss in Caramelle, ebd., 204. 


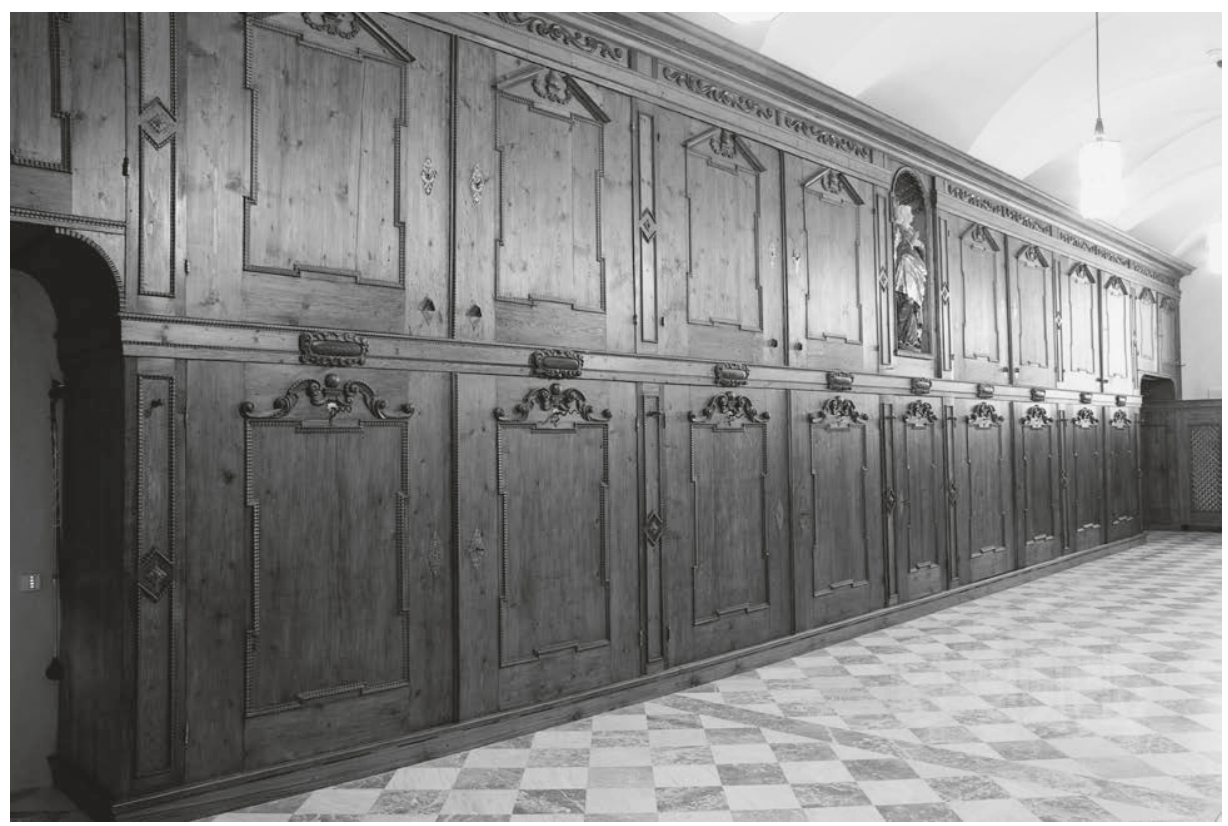

370 Sakristei, Paramenten- und Schatzkammerschrank vor der Westwand. Wilten, I686

\section{Ankleidekredenzen vor Ostwand}

Wilten, $\mathrm{I} 698$

$\mathrm{HS}$ I $4,5 \mathrm{~cm}$

$\mathrm{H}_{2} \mathrm{IO} \mathrm{cm}(+\mathrm{I} 4,5 \mathrm{~cm}) \times \mathrm{L} 505 \mathrm{~cm}$

Nussbaum, furniert, andere Hölzer, geschnitzt, Nadelholz. Eisen, getrieben, graviert, geschwärzt, verzinnt

Die Oberschränke auf den beiden seitlichen Aufsatzmöbeln (Abb. 37I) gehören vermutlich nicht zur ursprünglichen Einrichtung, während die mittlere Aufsatzkredenz weitgehend im Originalzustand erhalten zu sein scheint. Wahrscheinlich wäre aber das flache Abschlussgesims zu einem veritablen Gebälk zu vervollständigen, vielleicht trug es einstmals außerdem Schnitzarbeiten, die das Möbel bekrönten und ihm ein größeres optisches Gewicht verliehen. Im Katalog existieren hierfür mehrere Beispiele (Abb. I33, I 34, 223).

Drei massive Baluster strukturieren den Unterschrank, Lisenen trennen die Türen zwischen den Stützen. Dagegen beruht das architektonische Ordnungssystem des Aufsatzes auf einer Pilasterstellung. Im Sockelbereich des Oberschranks finden sich Laden, darüber die benötigten Kelchfächer. Unten besitzen die Füllungen lediglich 


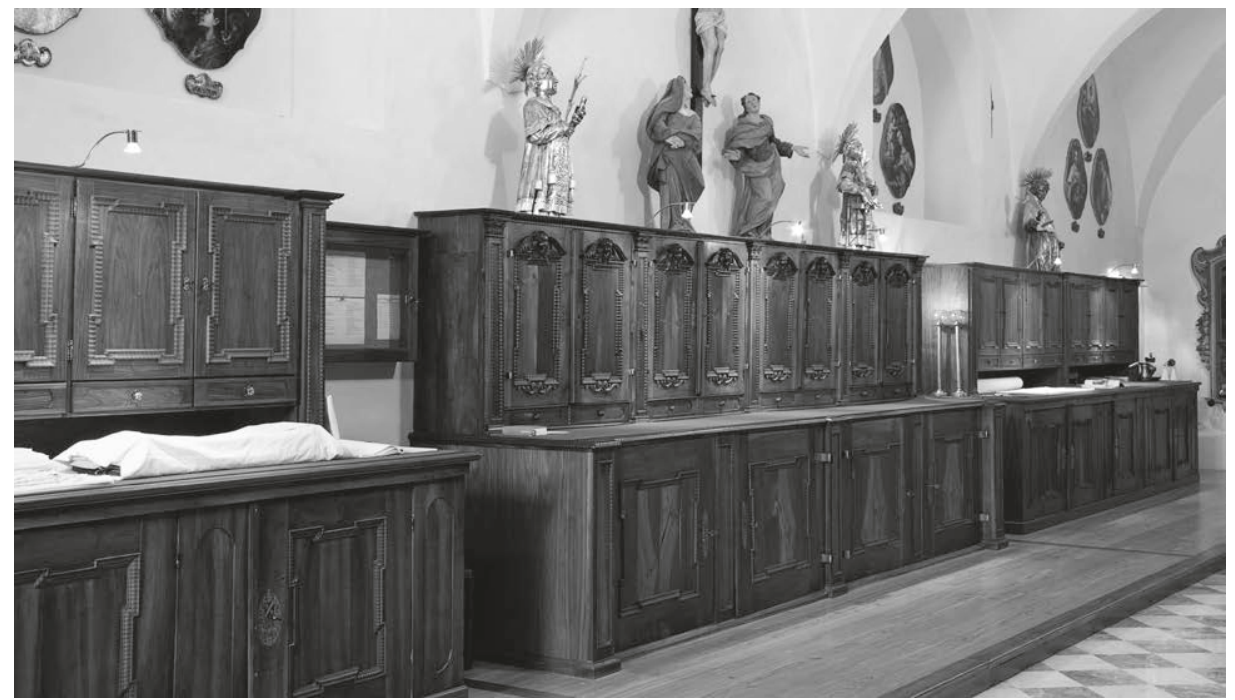

37I Sakristei, Ankleidekredenzen vor der Ostwand. Wilten, r698. Original sind die Unterschränke und der mittlere Oberschrank, die seitlichen Oberschränke sind vermutlich spätere Ergänzungen.

verkröpfte Ecken, während sie oben als Ädikulä zusätzlich mit gesprengten Giebeln versehen sind, deren Zentrum je ein Cherubskopf vor einer Muschel einnimmt.

Das Möbel ist mit Nussholz furniert und geschwartet, Flammleisten und Schnitzarbeiten bestehen aus verschiedenen Holzsorten. Die Schlösser und Eisenbeschläge sind getrieben, ziseliert, geschwärzt und verzinnt, einige Schlüsselschilder tragen Wappen und Monogramm des Abtes Gregor von Stremer (reg. 1693-17 19) sowie die Jahreszahl I 698 .

\section{Kirchenraum}

Laienbänke

Wilten, um $1665 / 75$

HS I $2 \mathrm{~cm}$

$\mathrm{HB} 95,5 \mathrm{~cm}(+\mathrm{I} 2 \mathrm{~cm}) \times \mathrm{L} 376 \mathrm{~cm}$

Lärche, Fichte, Ahorn, Nuss, Zirbenholz

Das auf mehrere Blöcke verteilte Laiengestühl zählt 36 Bänke und vier Vorderbrüstungen (Abb. 372, 373). ${ }^{616}$ Lisenen flankieren die als senkrechte Flächen konzipierten und

6 I6 Felmayer, Stiftskirche (1958), 38; Caramelle, ebd., I98; Gombocz, Betbänke (2008), ı00-102; Schomers, Wilten (2009), 45 . 


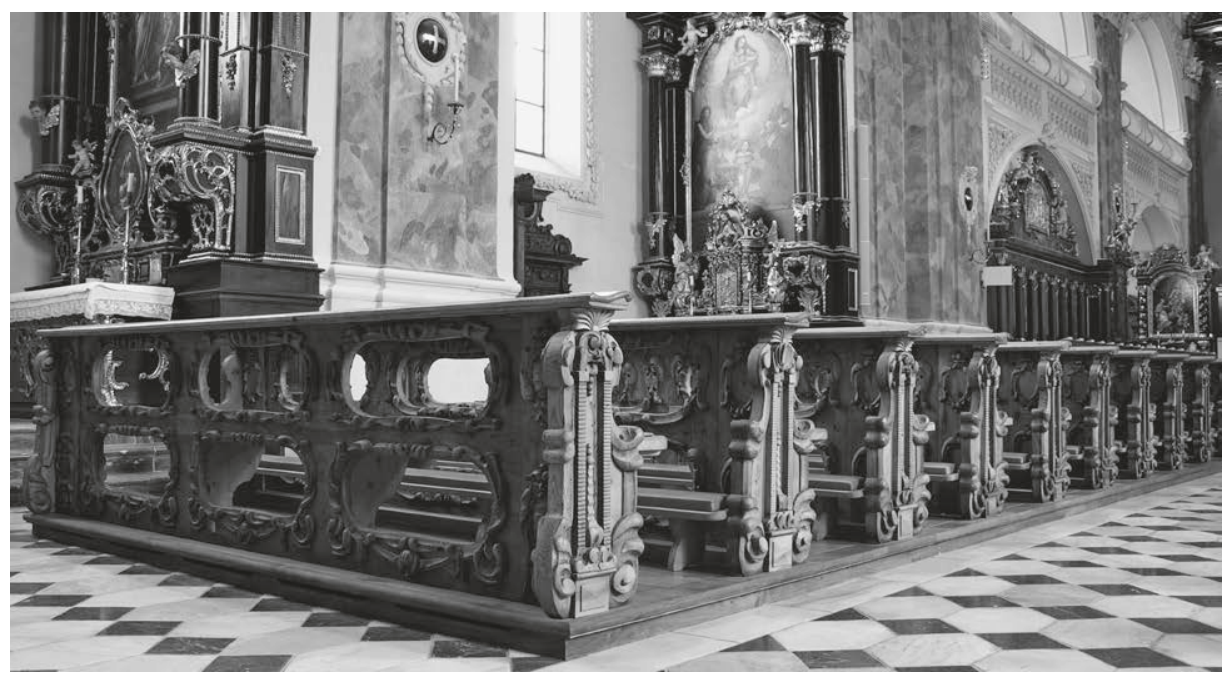

372 Stiftskirche, Kirchenbänke. Wilten, um 1665/75

mit zwei Reihen querovaler Öffnungen versehenen Brustwände. Fruchtfestons sowie keulenförmige und übereinandergeschichtete amorphe Gebilde säumen die Öffnungen, ähnliche Knorpelschnitzereien fassen Kartuschen ein, mit denen die Lisenen dekoriert sind. Wangen, deren geschwungene Vorderkante weit in den Raum reicht, bilden den seitlichen Abschluss der Brüstungen, die nicht nur auf der Außenseite, sondern auch auf der Innenseite verziert sind. Das Gleiche trifft auf die Rückenlehnen der Bänke zu, die beidseitig eine skulptierte Auszier aufweisen. Die Gebetbuchablagen befestigte man auch hier als eigenständige Teilstücke von oben auf dem Gerüst der Möbel.

Die symmetrisch gestalteten Docken besitzen die Form von Vasen mit eingezogenem Hals und groteskem Haupt, das, abgerundet und mit Voluten geschmückt, an ein ionisches Kapitell erinnert. Auf ihm ruhen ein fächerförmiges Element und die im Querschnitt S-förmige Buchstütze. Schwere Knorpelschnitzereien folgen der Kontur der Wangen, deren Fuß aus weiteren Voluten und einem mittleren Podest mit aufgesetztem Diamantquader besteht. Es trägt ein obeliskenähnliches Segment, das quergeriffelte Lisenen begrenzen. Die beim Bau der Möbel gewählten Ornamentformen belegen die Entstehung des Gestühls im Hochbarock. Dabei ähneln die unrunden Scheiben am Wangensockel vergleichbaren Zierelementen auf Vorlagendrucken von Friedrich Unteutsch (um I600-I670) aus der Mitte des I7. Jahrhunderts. ${ }^{617}$

6I 7 Berliner/Egger, Vorlageblätter ( I98 I), Bd. I, 82, Bd. 2, Abb. 948, 949. Auf dieses Motiv wurde damals häufig zurückgegriffen. Vgl. hierzu auch die in den folgenden Abschnitten beschriebenen Beichtstühle und den Prälatenstuhl (Abb. 377, 379). 


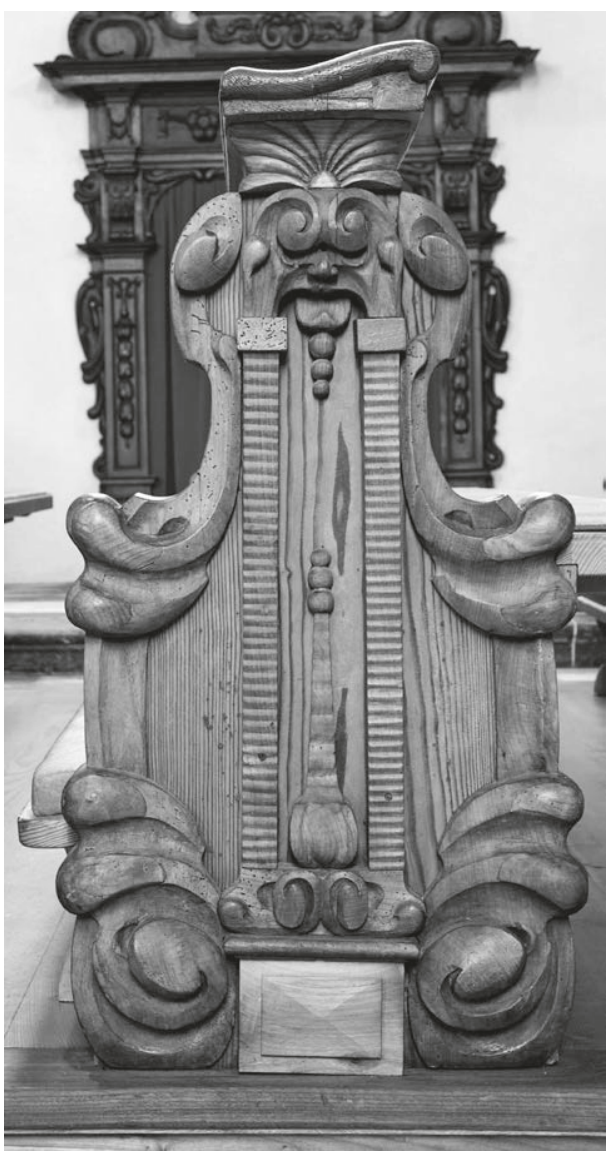

373 Bankwange. Wilten, um I665/75
Die Trägerplatten der Wangen bestehen aus Lärchenholz, die der Brüstungen aus Fichte. Dicke Nussbaumschwarten bedecken die $\mathrm{Au}-$ ßenseiten der Vorder- und Rückwände, die Schnitzornamente wurden vorwiegend aus Ahorn und Nuss gefertigt, einige aus Zirbenholz. Die Tischler verwendeten als Werkmaterial für die Gebetbuchablagen Ahorn, während sie Sitz- und Kniebänke ebenfalls aus Nadelholzbohlen zusammenfügten. ${ }^{618}$

Das Gestühl wurde mehrfach überarbeitet. Die ersten nachweisbaren Restaurierungen gehen auf das Jahr I 838 zurück, als die Stiftstischlerei verschiedene Sitzbänke erneuerte. Fotos, die nach den Verwüstungen im Juni 1944 aufgenommen wurden, bilden die Ausstattung unter herabgestürzten Gewölbeteilen ab, doch standen die meisten Bänke in der Stiftskirche noch an ihrem angestammten Platz. ${ }^{619}$ Die Verluste waren also überschaubar. Um r960 wurde das Möbelensemble abgebeizt ${ }^{620}$, da man es um die Wende vom I 9. zum 20. Jahrhundert dunkel gestrichen hatte. Bei einer genauen Befundung, die man im Zuge der umfassenden Restaurierung der Stiftskirche zwischen 2005 und 2008 durchführte, traten schwere, durch Anobienbefall verursachte

Schäden vor allem an den Weichholzteilen des Gestühls zutage. Aus Gründen der Stabilität mussten Sitz- und Kniebänke ausgetauscht sowie die zerstörten Partien an Brüstungen und Wangen gefestigt, teilweise auch erneuert werden. Die Schnitzornamente, die sich an manchen Stellen großflächig vom Untergrund gelöst hatten, wurden aufgeleimt, fehlende Stellen ergänzt. Als Abschluss erhielten die Möbel einen Überzug aus Bienenwachs. ${ }^{621}$

618 Gombocz, Betbänke (2008), roo.

619 Gritsch/Trapp, Kriegsschäden (I 958), 47, oder Hammerle, Zerstörung (I 988), 227.

620 Hammerle, ebd., 23r.

62 I Zu den vorhergehenden Angaben vgl. Gombocz, Betbänke (2008), bes. Io0-I02. Nach der Ansicht von Heinrich Schuler soll der Stiftstischler Johann Bodner die Bänke um I 836 gefertigt haben. Das 


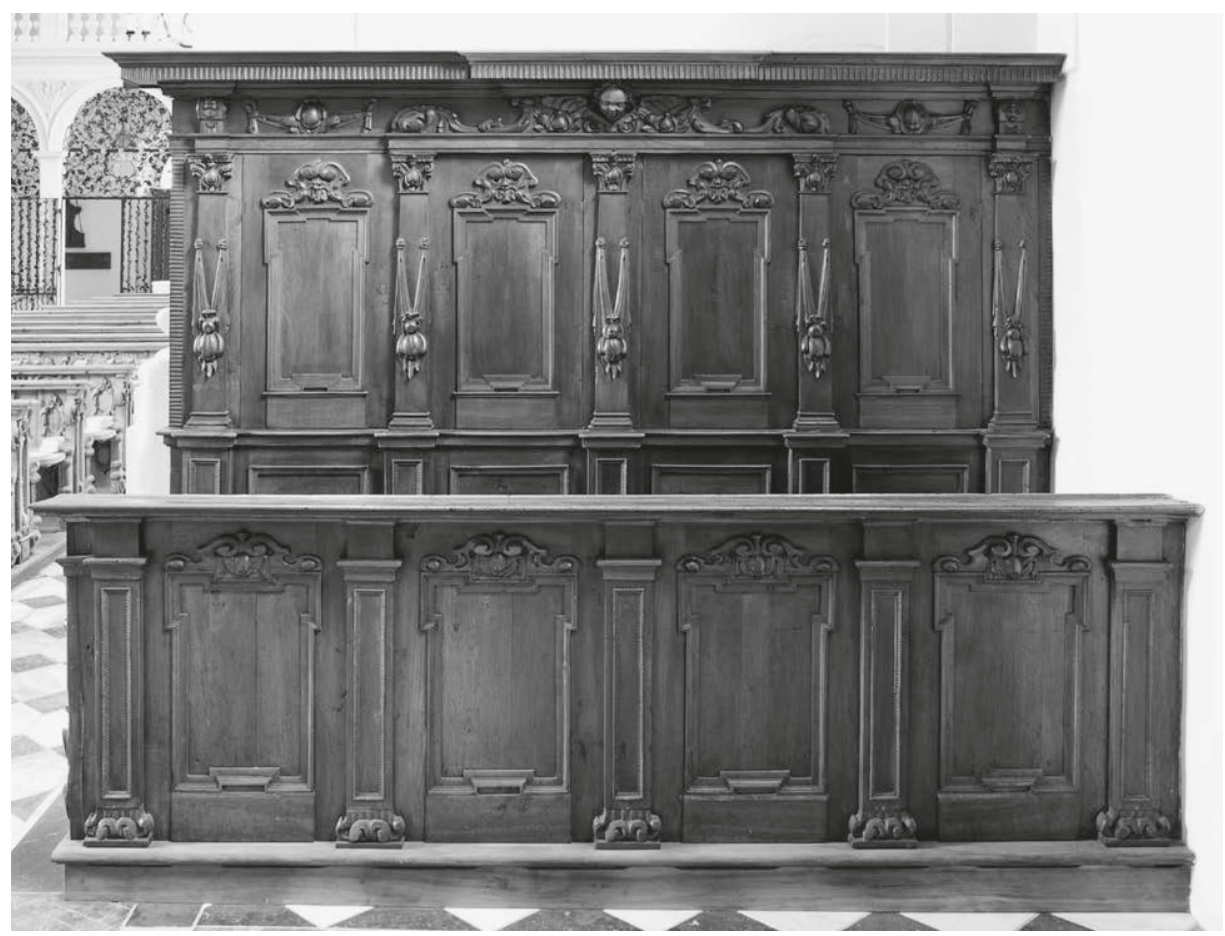

374 Gestühl in Seitenkapelle. Wilten, um I665/75

\section{Gestühle in Seitenkapellen}

Wilten, um $1665 / 75$

HS I $5 \mathrm{~cm}$

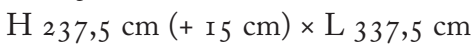

Nuss, massiv, Nussschwarten, Nadelholz

Die Bänke stehen wie in der Innsbrucker Jesuitenkirche vor den Westwänden der Kapellen, eines auf der Südseite musste mutmaßlich im I9. Jahrhundert einem Epitaph weichen (Abb. 374, 375). ${ }^{622}$ Bei ähnlicher Gestaltung zeigen sich erhebliche formale und qualitative Unterschiede zwischen den Inventarstücken. Darüber hinaus geht das Exemplar in der mittleren nordseitigen Kapelle entweder auf das I9. Jahrhundert zu-

trifft nicht zu. Schuler, Stiftskirche (I920), 49. Der jüngeren Literatur zufolge wurden damals aber Sitz- und Kniebänke erneuert.

622 Zum Gestühl vgl. Felmayer, Stiftskirche (I 958), 38, 43; Dehio, Tirol (r 980), 83; Caramelle, Barock (1988), I98; Schomers, Wilten (2009), 45. 


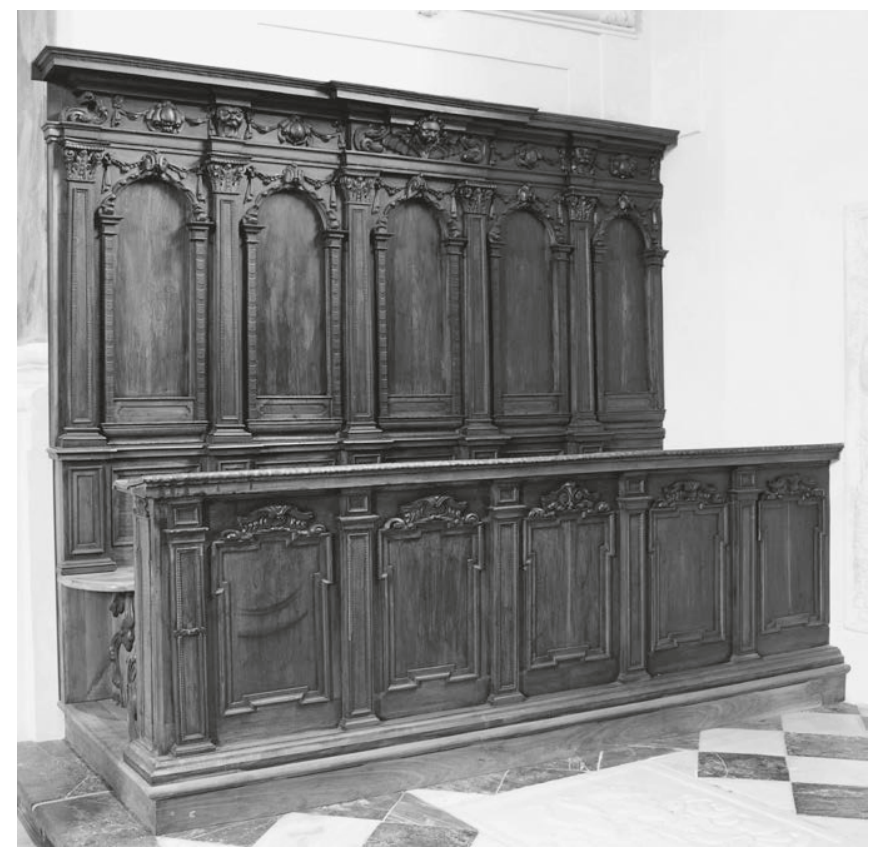

375 Gestühl in Seitenkapelle.

Wilten, um $1665 / 75$

rück oder wurde stark überarbeitet, sodass sich sein wirkliches Alter erst bei einer dentrochronologischen Untersuchung bestimmen ließe.

Wie Chorgestühle verfügen die Möbel über eine geschlossene Brüstung mit Kniebank sowie über Sitzgelegenheiten mit hohem Dorsale. Allerdings handelt es sich hier um durchgehende Bänke, also nicht um Einzelstallen. Pilaster und pilasterähnliche Stützen gliedern Brustwände und Rückenlehnen. Die Stützen einiger Gestühle besitzen aus kleinen Voluten bestehende moderne (?) Basen und Blockkapitelle, andere schlichte Basen und mit Schnitzarbeiten bereicherte Kapitelle. Die Gebälke sind verkröpft, wobei der Architrav jeweils die mittleren Achsen bzw. Pilaster zusammenfasst. Die Füllungsfelder weisen die Form von welschen Fenstern und rundbogigen Arkaden vor. Fruchtgirlanden und Groteskmasken zieren die Dorsalestützen und den Fries, dessen Mitte ein Cherub einnimmt.

\section{Beichtstüble}

Wilten, um $1665 / 75$

HS $6 \mathrm{~cm}$

Gesimshöhe 24I,5 cm/gesamte Höhe $355,5 \mathrm{~cm} \times \mathrm{B} 2$ IO cm

Nuss, Eiche, Nadelholz, Holz, gefasst 


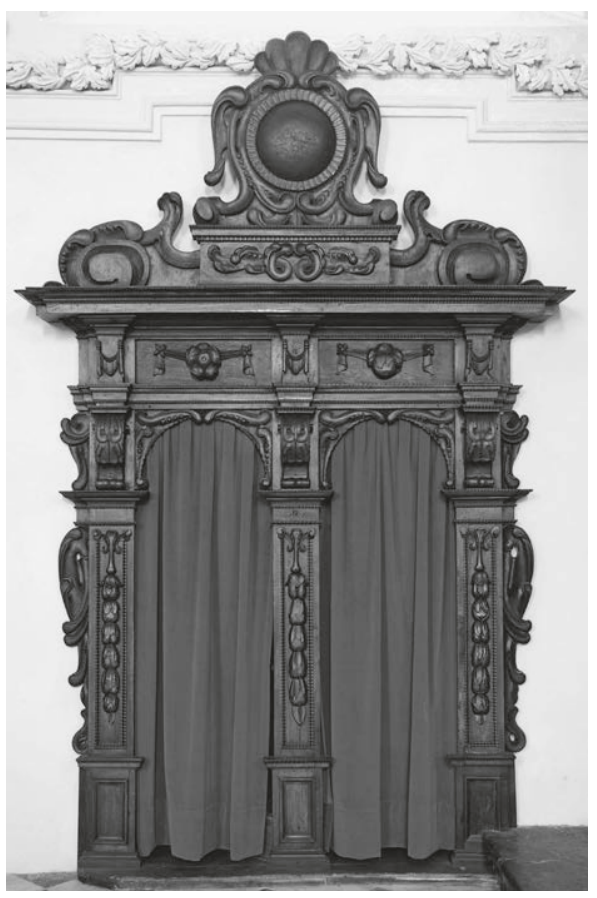

376 Beichtstuhl. Wilten, um I665/75

377

Beichtstuhl (Detail). Wilten, um I 665/75

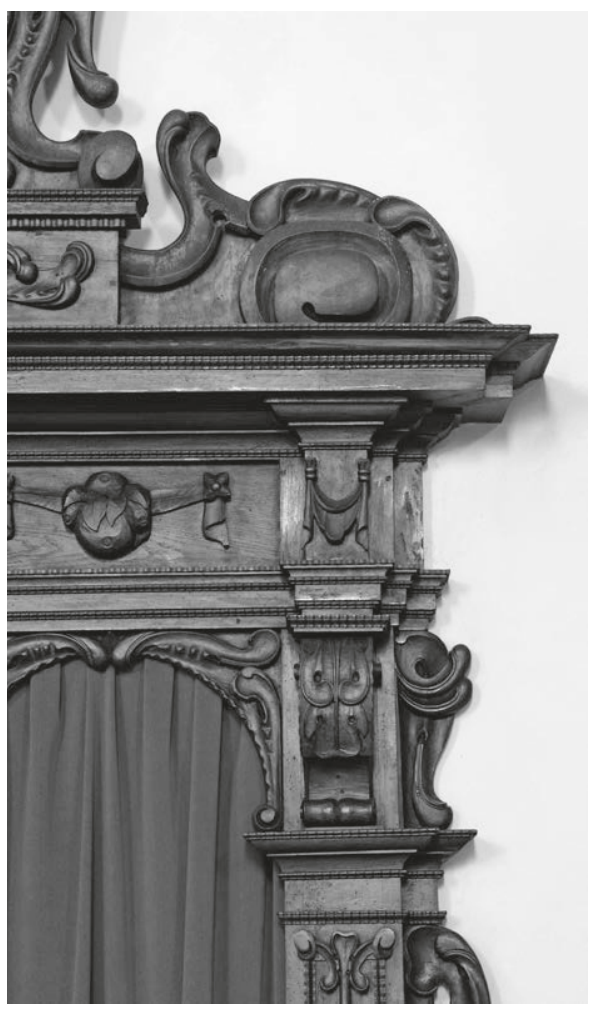

Die Möbel wurden ins Mauerwerk der Kapellen auf der Nord- und Südseite des Baukörpers eingesetzt (Abb. 376, 377). ${ }^{623}$ Entsprechend dem Laiengestühl und den Sitzmöbeln in den Seitenkapellen gehen die Beichtstühle auf die erste Einrichtungsphase des Sakralbaus zurück. Wie das bei frühen Exemplaren häufig der Fall ist, verfügen sie über zwei Kammern. Eine Arkadenarchitektur bildet die Vorderseite der Möbel. Von hohen Piedestalen aufsteigende Pilaster flankieren die Joche, die gestelzten Arkadenbögen ruhen auf den breiten Kapitellen. Letztere tragen darüber hinaus eine volutenverzierte Zwischenzone, ein schweres verkröpftes Gebälk sowie einen Auszug, der aus einer hohen skulptierten Kartusche zwischen großen Voluten besteht. Knorpeliger Schnitzzierrat, Fruchtgirlanden und -gehänge vervollständigen die Möbel, schmale geschweifte Schleierbretter leiten von der Front zum Mauerwerk über. Interessant ist

623 Felmayer, ebd. 38; Dehio, ebd.; Caramelle, ebd.; Schomers, ebd. Dehio erwähnt sechs, Caramelle sieben Exemplare. Nach mündlicher Auskunft von Nikolaus Albrecht (2015) befinden sich zwei Möbel im Depot der Diözese, während ein drittes umgebaut wurde. 
ein Vergleich dieser Möbel mit den nur wenige Jahrzehnte älteren in der Innsbrucker Jesuitenkirche (Abb. 302). Bei vergleichbarer Großform könnte der Eindruck, den die Beichtstühle vermitteln, kaum unterschiedlicher sein. Klassisch-strenge, etwas steif wirkende Möbel, die sich in einem renaissancezeitlichen Architekturlehrbuch wiederfinden könnten, stehen in Wilten Exemplaren gegenüber, die ein durch und durch barockes Formempfinden ausstrahlen. Es ist die Verbindung der Großform mit der Fülle an weich fließenden, amorphen Zierelementen, die den Gesamteindruck der Möbel in Wilten bestimmen.

\section{Konvent}

\section{Prälatenstubl}

Wilten, I668

HS $10 \mathrm{~cm}$

$\mathrm{H}_{3} 80 \mathrm{~cm}(+\mathrm{IO} \mathrm{cm}) \times \mathrm{B} \mathrm{I} 78 \mathrm{~cm}$

Zirbenholz

Die ionischen Pilaster, die die Joche der Brüstung flankieren, tragen ein Gesims mit dem Lesepult (Abb. 378, 379). ${ }^{624}$ Die zu Ädikulä uminterpretierten Füllungen ruhen auf vegetabil verzierten Voluten und schließen mit einer breiten Muschel. Durch einen Ring gezogene Bögen, die oben mit flachen Scheiben enden und an denen Fruchtgirlanden hängen, zieren die Binnenfelder.

Eine höchst ungewöhnliche Gestaltung weist die mit Engelhermen besetzte Rückwand des Möbels auf. Die Hermen tragen ein verkröpftes Gebälk mit kanneliertem Gesims. Ihm folgt ein hoher Auszug mit einem mittleren Schild, das zusammen mit dem Wappen des Klosters und des Auftraggebers die Jahreszahl i 668 zeigt. Durchbrochene Bögen mit knorpeligen Verdickungen säumen die Kartusche. Die Bögen enden am unteren Rand mit jenen zu Scheiben umgedeuteten Voluten, die auch am Laiengestühl und an den Beichtstühlen vorkommen. Hohe Nischen bilden die Rückwandfüllungen, über denen tiefe schirmartige Baldachine einen Hoheitsraum etablieren. Auch sie werden von den Hermen gestützt. Cherubim, von deren Flügeln Stoffbänder mit Fruchtsträußen herabhängen, bereichern die Flächen unter den Baldachinen.

Das Möbel wird momentan in einem Korridor des Konventgebäudes aufbewahrt, es soll zusammen mit dem Gestühl gebaut worden sein, das 2005 an die Gesellschaft Jesu in Innsbruck abgegeben wurde und im Querschiff der Jesuitenkirche einen überzeugenden Platz gefunden hat (Farbtaf. 30). Historischen Fotos zufolge stand das ba-

624 Schuler, Stiftskirche (I 920), 52 ; ders., Stift Wilten (1956), r4; Dehio, ebd., 82-83; Wartena, Süddeutsche Chorgestühle (2008), 397. 

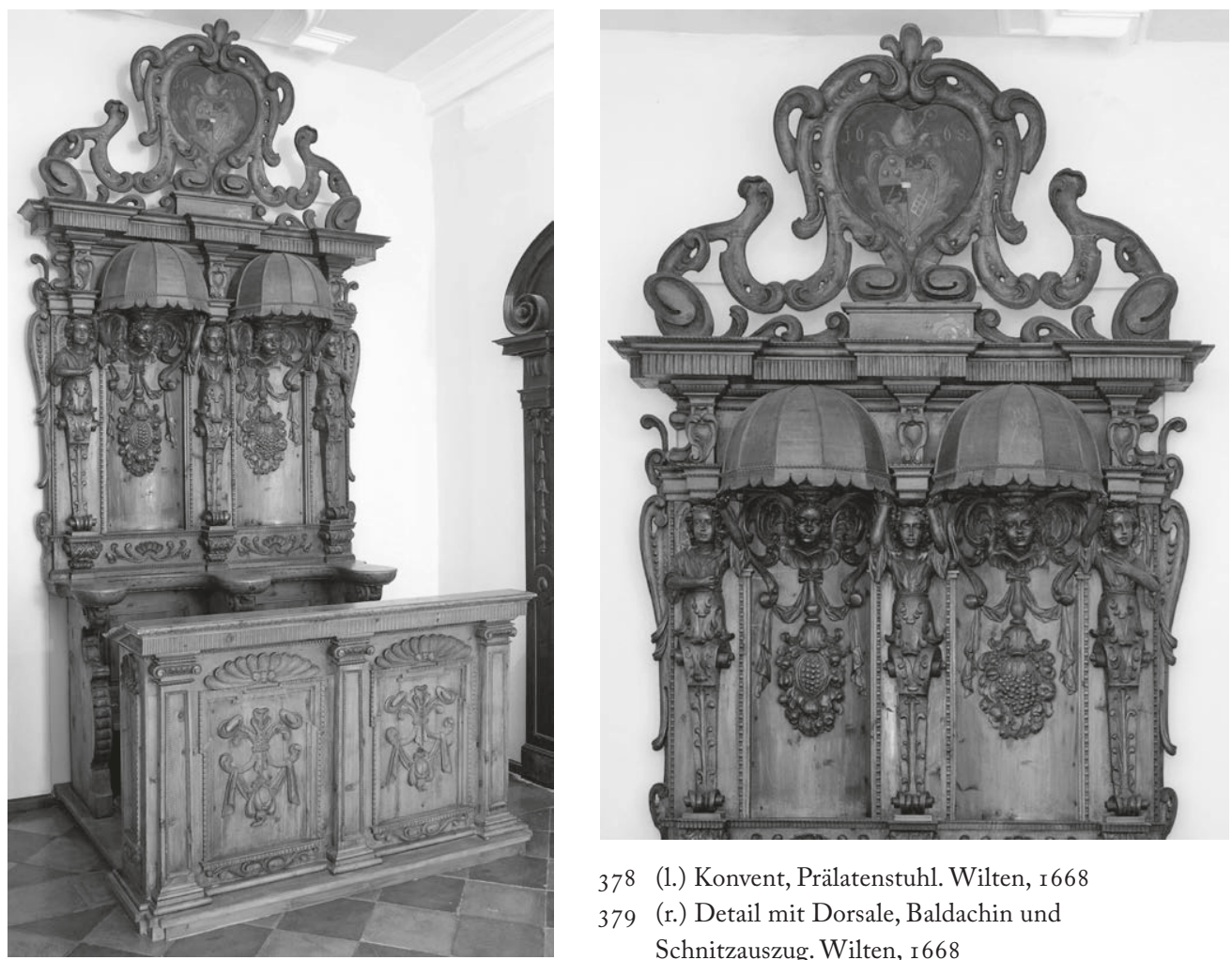

378 (1.) Konvent, Prälatenstuhl. Wilten, I 668

379 (r.) Detail mit Dorsale, Baldachin und Schnitzauszug. Wilten, r 668

rocke Gestühl an jener Stelle im Chorraum der Wiltener Stiftskirche, die jetzt wieder von einer klassizistischen Möbelgarnitur eingenommen wird, während der Prälatenstuhl östlich davon positioniert war. ${ }^{625}$ Zwischenzeitlich zählte das barocke Ensemble zur Einrichtung des einst über der Sakristei verorteten Betchors. ${ }^{626}$ Ein Vergleich des Doppelsitzes in Wilten mit der Gestühlsreihe in der Innsbrucker Kirche ergibt Übereinstimmungen vor allem in der Strukturierung der Rückwand mit Engelhermen sowie in der Einfügung von Nischen in die Dorsalefüllungen. Weitere Analogien, etwa die Schnitzmotive, entsprechen der Formensprache jener Zeit. Allerdings trifft das prinzipiell auch auf die Nischen der Rückwand zu, wie das Beispiel des I 647 geschaf-

625 Wartena, ebd., Abb. I 5.7.b. Das klassizistische Gestühl war I 967 an das Stift St. Georgenberg abgegeben worden, wurde aber 2005 wieder von Wilten übernommen. Gombocz, Betbänke (2008), 103. Zu dem Gestühl s. Gombocz, ebd., bes. I03-107.

626 Schuler, Stiftskirche (r 920), 52 ; ders., Stift Wilten (I 956), I4. 
fenen Domherrengestühls in St. Stephan zu Wien dokumentiert. ${ }^{627}$ Dort kommen überdies Fruchtgirlanden in ähnlicher Form vor. Ansonsten irritiert der Qualitätsunterschied zwischen den Hauptreihen und den Stallen der Klostervorsteher. Wie in Rein (Abb. 244, 245) können die Stallen der Konventualen eines Hauses untereinander zwar durchaus variieren, doch einen vergleichbaren Kontrast zwischen einander zugeordneten Inventarstücken haben wir bisher noch nicht beobachtet.

627 Bohr, Sakralmöbel (2017), 222-225. 
VI.

\title{
Sakralbauten in Vorarlberg
}

\author{
Bregenz, Stadtpfarrkirche St. Gallus
}

Von 6ro bis 6r 3 missionierten die Heiligen Kolumban von Luxeuil (540-6 I 5) und Gallus (* um 550), zwei Wandermönche, die Bevölkerung in der Gegend um Bregenz. ${ }^{628}$ Allerdings geht die Forschung davon aus, dass an der Stelle des heutigen Sakralbaus bereits im fünften, vielleicht sogar im vierten Jahrhundert eine der hl. Aurelia geweihte Kapelle existierte. Seit ro79 ist die Kirche St. Gallus in Schriftquellen fassbar, sie dürfte den spätantiken Bau ersetzt haben. ${ }^{629}$ Damit ist sie die älteste Kirche des Vorarlberger Unterlandes und Mutterkirche etlicher Pfarreien des Bregenzer Bistums. I 477 zerstörte ein Brand die mittelalterliche Architektur, die nach umfangreichen Renovierungsarbeiten I 480 wieder eingeweiht wurde. Für I737 ist ein erneuter Umbau unter der Leitung von Anton Beer aus Bregenz dokumentiert. Eine Empore wurde eingefügt und die alte Holzdecke durch ein Gewölbe ersetzt. Das Gebäude präsentiert sich seitdem als breiträumiger dreijochiger Saalraum mit einer flachen Stichkappentonne. Dem zweijochigen Chor mit 3/8-Schluss steht im Westen eine Doppelempore gegenüber. Josef Ignaz Wegscheider (I704-I758/60) aus Riedlingen an der Donau erhielt den Auftrag zur Ausführung der Deckengemälde, die Stuckarbeiten stammen von Abraham Bader (I694-I746 nachgew.) aus Wessobrunn, er schuf sie I746. Die Kirche ist auf einem kleinen Hochplateau situiert, das nur über eine Brücke zu erreichen ist. Sie führt direkt auf die Westfassade zu, deren Eingang ein hoher mittelalterlicher Wehrturm schützt.

628 Während Kolumbans Herkunft aus Irland offenbar gesichert ist, wird seit einiger Zeit eine mögliche Herkunft Gallus' aus dem elsässischen Raum bzw. aus den Vogesen diskutiert. Dörler/Klagian/Dörler, Koloman (2010).

629 Ulmer, St. Gallus (I938); Ulmer/Tiefenthaler, St. Gallus (r96r); Hootz, Kunstdenkmäler (I965I 968), Bd. I (I 965), 2 I-2 2, 3 Io; Ammann, Bregenz ( I 979); Dehio, Vorarlberg (I983), 60-64. 


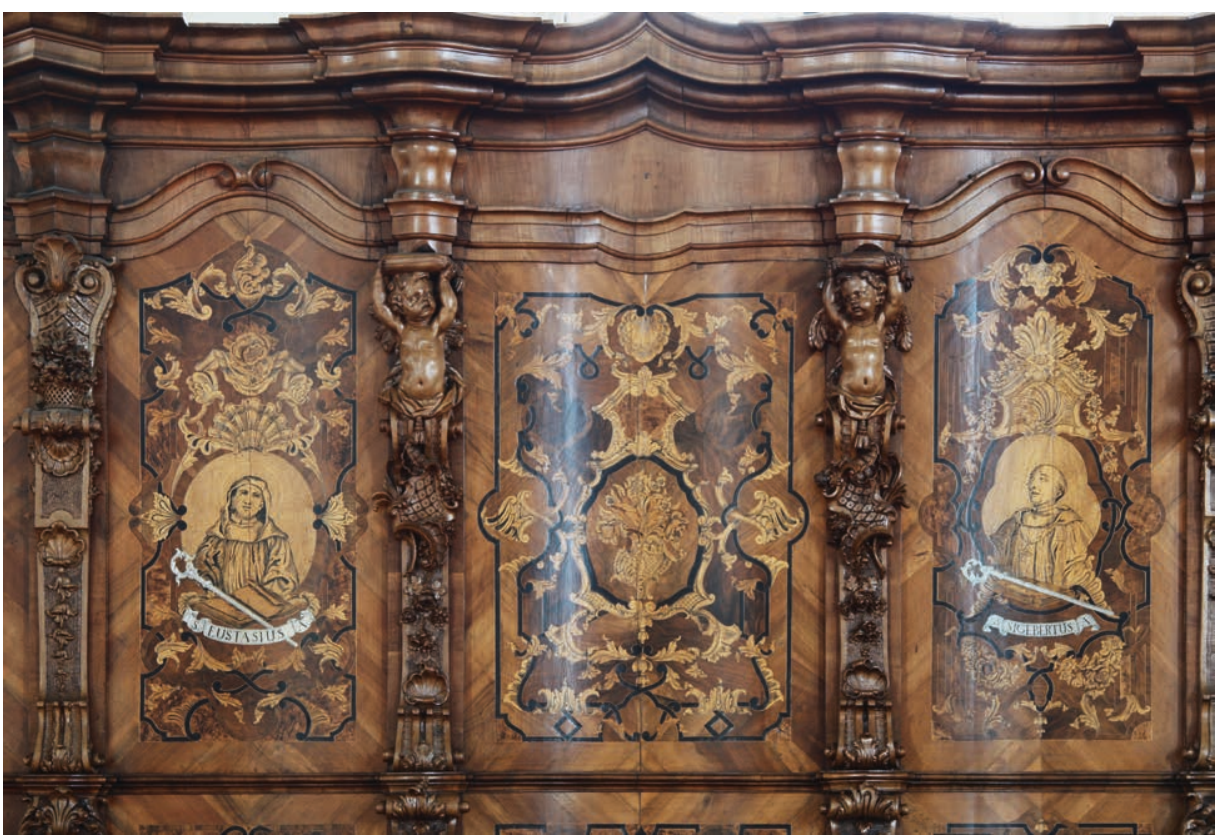

Farbtaf. 32 Stadtpfarrkirche St. Gallus, Chorraum, Epistelseite, Chorgestühl aus dem Stift Mehrerau.

Detailansicht mit den Brustbildern der hl. Äbte Eustachius und Sigebertus. Tischler Fr. Clemens Seehuber, Bildhauer Johann Joseph Christian und Josef Hofer, um I 74I/46

\section{Chorgestühl}

Tischler Fr. Clemens Seehuber, Bildhauer Johann Joseph Christian und Josef Hofer, Fassmaler Johann Geiger, I 74I/46

$\mathrm{HS} 7,5 \mathrm{~cm} / \mathrm{I} 7 \mathrm{~cm} / 26,5 \mathrm{~cm}$

$\mathrm{H}_{3} \mathrm{I} 3 \mathrm{~cm}(+26,5 \mathrm{~cm}) \times \mathrm{L}_{5} 60 \mathrm{~cm}$

Nussholz, massiv und furniert, Nussmaser, Ahorn, Pappelmaser, graviert und geschwärzt, Holz

(Birnbaum ?), schwarz gebeizt, Eiche. Zinneinlagen

Das Gestühl stammt aus dem früheren Benediktinerkloster Mehrerau, das vor den Bregenzer Stadttoren lag (Farbtaf. 32; Abb. 380-384). ${ }^{630}$ Nachdem das Kloster I805/06 aufgehoben worden war, riss man die Abteikirche ab, Baumaterialien und

630 Ulmer, ebd., 6; Huber, Christian ( 1960), 31-32, 73-74; Ulmer/Tiefenthaler, ebd., 7; Ammann, ebd., I 2 ; Dehio, ebd., 63; Weiß, Bilder (I 998), r66-r 68; Wagner, Kunsthandwerk (I999), 580-58 I ; Wagner, Heiligenkreuz (2007), I5 I ; Wartena, Süddeutsche Chorgestühle (2008), 736-74I ; Dörler/Klagian/ Dörler, Koloman (2010), 75-8 I. 


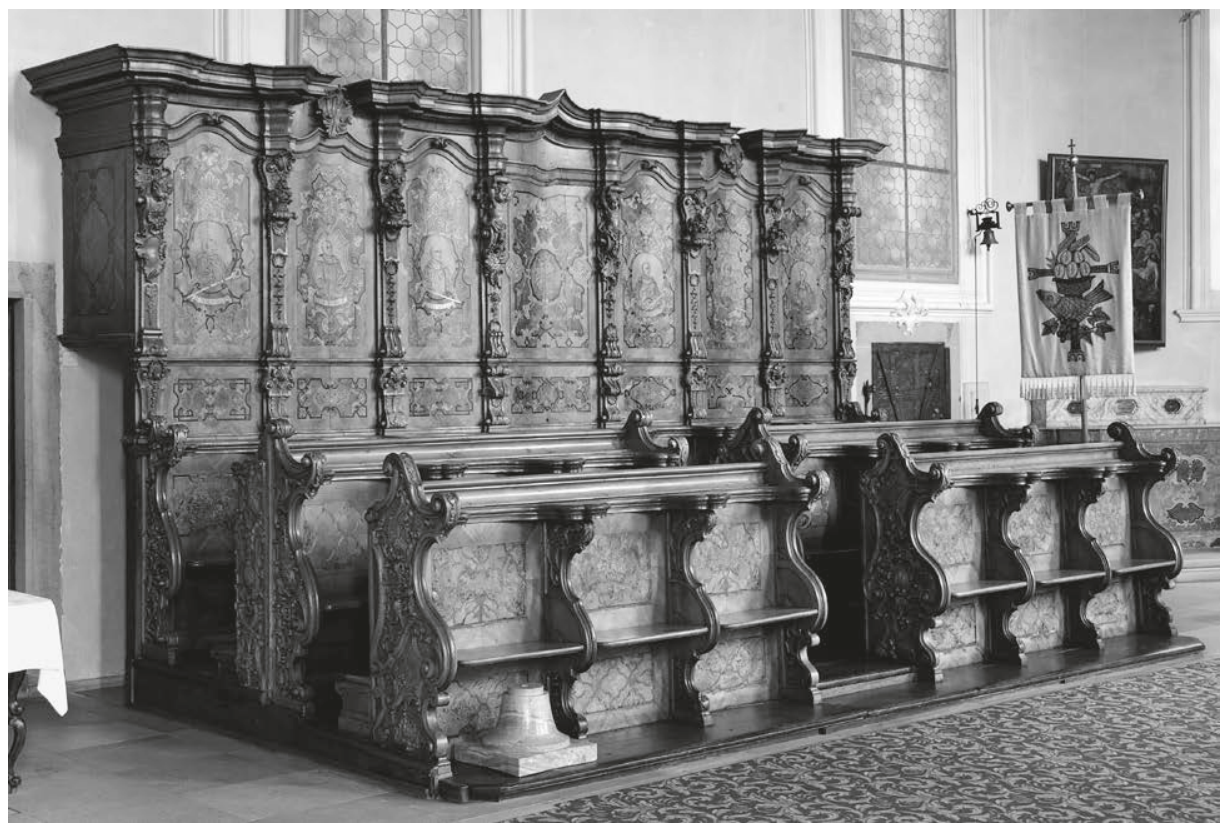

380 Chorraum, Evangelienseite. Chorgestühl aus Mehrerau. Tischler Fr. Clemens Seehuber, Bildhauer Johann Joseph Christian und Josef Hofer, um I74I/46

andere Überreste, für die man noch Verwendung fand, wurden aufbewahrt. ${ }^{631} \mathrm{Im}$ Zuge dieser Maßnahmen gelangte das Gestühl um I 808 in die Stadtpfarrkirche. Das dreireihige Möbel bietet 36 Geistlichen Platz. Es besitzt keine Brüstung, was für Gestühle in Abteikirchen der österreichischen Benediktiner unüblich war, in Süddeutschland aber vorkam. ${ }^{632}$ Offensichtlich sahen sich die Tischler in Vorarlberg und ihre Auftraggeber in einer anderen Traditionslinie als die Handwerker in den übrigen österreichischen Landschaften.

Das Gestühl in Bregenz entstand nur wenige Jahre nach dem in Stams (Farbtaf. 3 I ;

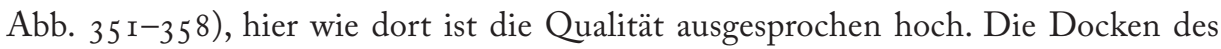
Vorarlberger Inventarstücks besitzen stark geschwungene Konturen, sie sind bewegter, als wir das von vielen Möbeln aus den anderen Landesteilen Österreichs her kennen. Dadurch erinnern die Außenlinien der Wangen mehr an die Physiognomie süddeut-

63 I Mitte des I9. Jahrhunderts wurde das alte Stift wiederbelebt, nun als Zisterzienserabtei WettingenMehrerau. Vgl. etwa Röhrig, Alte Stifte (1967), 64-65.

632 So etwa am Gestühl, das zwischen I $_{7} \mathrm{r}$ und ${ }_{1} 724$ für das ehemalige Kloster Weingarten gebaut wurde.

Wartena, Süddeutsche Chorgestühle (2008), 7 I 5-734. 


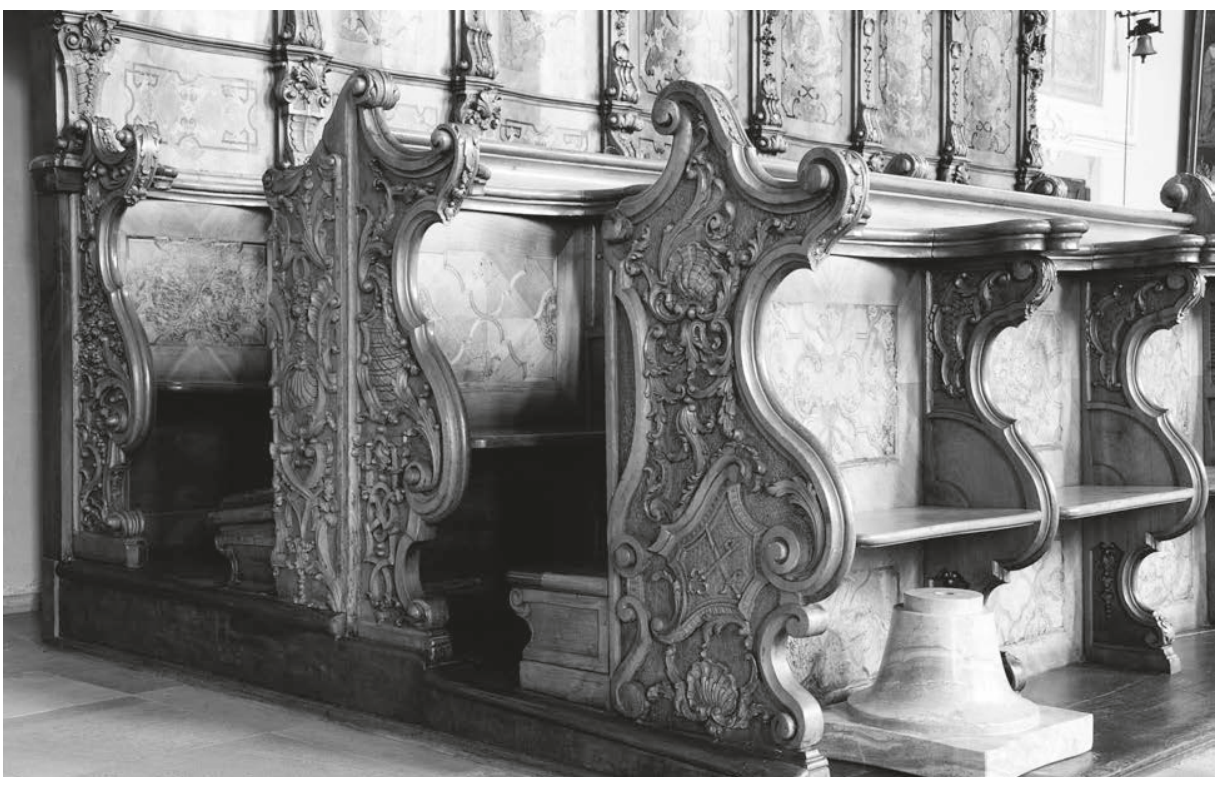

38 I Schrägansicht der Stallenreihen. Fr. Clemens Seehuber, Johann Joseph Christian, Josef Hofer, um I $74 \mathrm{I} / 46$

scher oder französischer Rokokomöbel als an hiesiges Mobiliar. Ein kräftiges, glatt ausgehobeltes Profil säumt die vertieft liegenden Binnenflächen. Feine und detailreich ausgearbeitete Schnitzereien heben sich mit ihrer geglätteten Oberfläche vom Untergrund $\mathrm{ab}$, den dichtgesetzte Punzenschläge aufrauen. Kurze Blattformationen sind zwischen Bändern und Muscheln zu erkennen, außerdem eine große geschwungene Kartusche mit dem Wappen des Stiftes Mehrerau - ein Schlüssel und ein Degen, Xförmig gekreuzt. Ein vertikales Profil teilt die Außenwangen der mittleren Stallenreihe in zwei Hälften, die erstaunlicherweise unterschiedliche Ornamentformen aufweisen. Die hintere Kante der Wangen verläuft von oben nach unten gerade, die Ziermotive sind zum Teil beschnitten. Augenscheinlich besaß das Gestühl wie das in Stams einst Türen, auf denen sich die Schnitzereien fortgesetzt haben werden.

Die Vertikalgliederung des Dorsales basiert auf Volutenkonsolen und pilasterähnlichen Stützen, die mit Putten, Blumenkörben, Rocaillen und Kartuschen geschmückt sind. Anders als diese Ornamente, die mit dem Schnitzmesser gefertigt wurden, dekorierten die Tischler die konkav eingezogenen und dynamisch modellierten Füllungen mit außergewöhnlich mannigfaltigen Marketerien. Im Gegensatz zur Situation im Osten Österreichs, wo die peinture en bois keine größere Rolle spielte, tragen die Binnenfelder des Gestühls, selbst jene der Lehnen und des Sockelbereichs, Furnierbilder, 
die neben Laub- und Bandlwerk, Blumengebinden und Muschelmotiven auch »Porträts« von Äbten, Bischöfen und Mönchen vergegenwärtigen. Bis auf eine Ausnahme lässt sich für sie ein direkter Bezug zum hl. Kolumban herstellen. Schriftbänder aus Zinn mit den eingravierten Namen der Geistlichen vervollständigen die Darstellungen: Auf der Evangelienseite nennen sie die Äbte Magnus, Theodorus, Attalus und Babolenus, den Bischof Chagnoald und den Märtyrer Merbod, gegenüber die Märtyrer Placidus und Sigebertus sowie die Äbte Eustachius, Sigebertus, Othmarus und Gallus. ${ }^{633}$ Als Vorlagen für die Heiligendarstellungen am Gestühl dienten Kupferstiche, die eigens in Göggingen bei Augsburg erworben worden waren. Das Gestühl schließt mit einem verkröpften und bewegten Gebälk, dessen Architrav konvexe und konkave Bögen ausbildet und das Dorsale rhythmisiert, während das Gesims in der horizontalen Ausrichtung weitgehend gerade verläuft, aber über den Stützen nach vorn in den

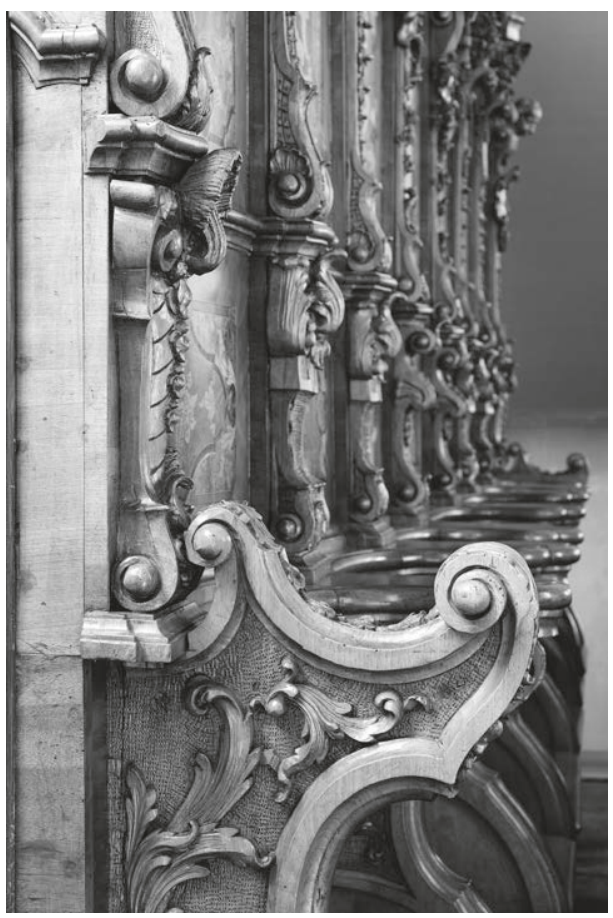

382 Schrägansicht der Rückwand. Fr. Clemens Seehuber, Johann Joseph Christian, Josef Hofer, um I74I/46 Raum weist. Muschelförmiges Blattwerk durchbricht an einigen Stellen das Gebälk.

Rechtwinklig wurden an den Außenkanten etwa $60 \mathrm{~cm}$ breite Querstücke angebracht, die die Aufstellung des Gestühls direkt vor den Außenwänden der Kirche verhindern. Hohe Öffnungen gestatten ein Betreten des schmalen Raumes hinter den Stallen. Den mit aufwendigen Marketerien dekorierten Traversen auf der Ostseite (Abb. 384 ) stehen relativ einfache im Westen gegenüber. Und schließen die westlichen jeweils mit einem geraden horizontalen Profil, so setzt das Gebälkstück im Osten die bewegte Struktur des Gebälks der Vorderseite fort. Der östliche Abschluss ist also wesentlich aufwendiger als der westliche gearbeitet, wahrscheinlich war das Gestühl ursprünglich im Gegensinn angeordnet. Über die Funktion dieses Raums können allenfalls Vermutungen angestellt werden, sie ist bisher nicht überzeugend geklärt, eine vergleichbare Großform ist bei keinem zweiten österreichischen Chorgestühl vorhanden.

633 Ammann, Bregenz (1979), I 2. 


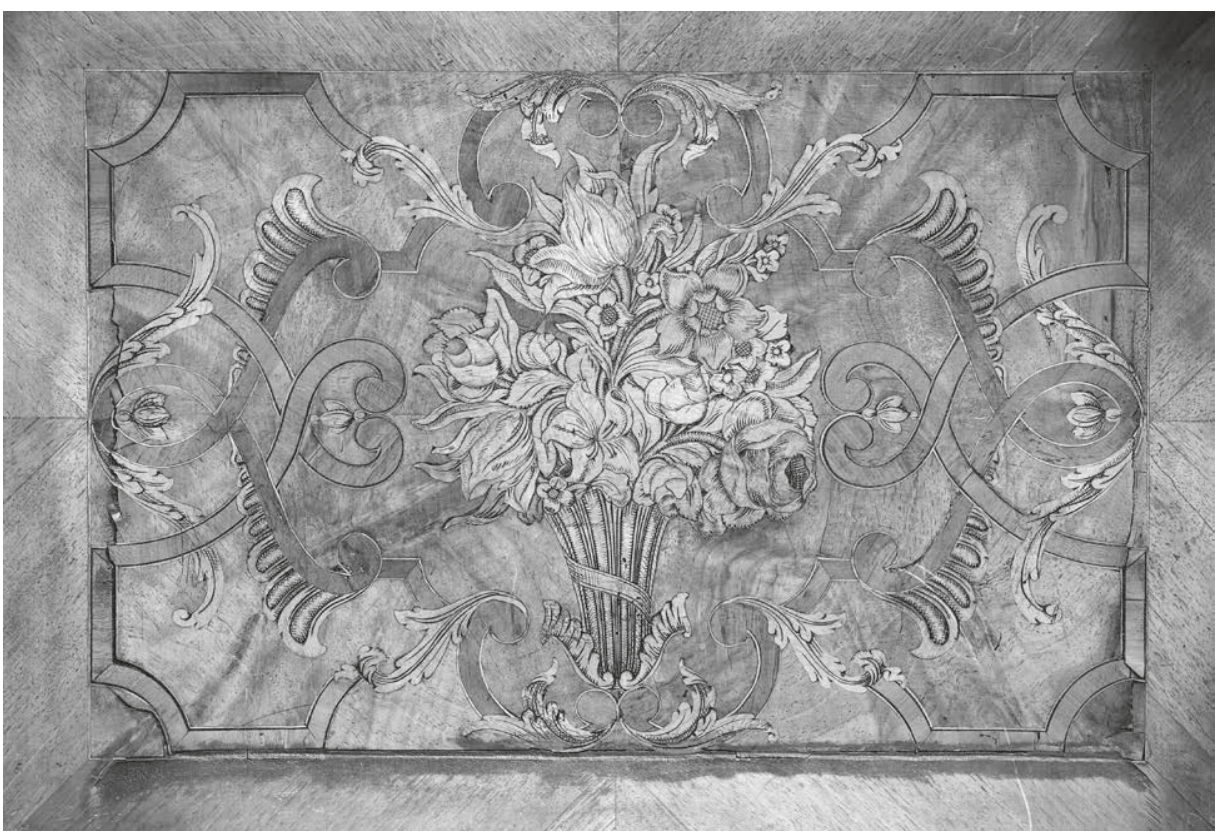

383 Rückenlehne der vorderen Stallenreihe, Intarsienbild. Fr. Clemens Seehuber, um I 74 I/46

Ein um I739/40 von Johann Michael Beer (I696-I780) gezeichneter Grundriss der Stiftskirche Mehrerau gibt das Gestühl in zwei Alternativentwürfen wieder. ${ }^{634}$ Beide Entwürfe gehen von einer dreireihigen Garnitur aus. Eine Variante rechnet mit fünf Sitzen pro Reihe, außerdem ist dort die Sessio des Abtes um 90 Grad gedreht. Sie steht vor der Rückseite eines Seitenaltars und damit quer zur Längsrichtung der Kirche. Die zweite Variante umfasst in den beiden vorderen Reihen ebenfalls fünf, in den hinteren aber sieben Sitze. Der letzte im Westen grenzt wieder an einen Seitenaltar, ist jedoch parallel zur Kirchenlängsachse situiert. Die erste Variante zeigt die Stallenreihen durchlaufend, die andere mit einem Zugang, der die beiden vorderen Sitzreihen in Blöcke mit drei bzw. zwei Plätzen unterteilt. Beide Entwürfe verorten das Gestühl freistehend im Psallierchor, die erwähnten Blenden sind jedoch nicht eingezeichnet.

Der Grundriss dokumentiert, dass Johann Michael Beer ursprünglich mit 30 Sitzen für die Priestermönche und zwei zusätzlichen Sitzgelegenheiten für die Klostervorsteher rechnete. Heute zählt das Gestühl 36, mit den beiden mittleren, die normalerweise frei bleiben, sogar 38 Stallen. Die zwölf Brustbilder fügen sich gut zur Überlieferung, die von Kolumban und seinen Gefährten berichtet. Schriftquellen geben zu verstehen, dass einst

634 Sandner, Barock (1962), Kat. I40, Abb. 24; Oechslin, Barockbaumeister (1 973), г28, Abb. I ro. 
ein Schnitzauszug die auf der Horizontalen liegende Betonung des Möbels abschwächte und dem Dorsale eine vertikale Ausrichtung verlieh. ${ }^{635} \mathrm{Aber}$ auch so entfaltet das Möbel eine starke raumbeherrschende Wirkung, wie sie österreichischen Gestühlen nur selten eignet. Ferner vermutet die relevante Forschung, dass ursprünglich Einzelstallen für Abt und Prior vorhanden waren. ${ }^{636}$ Das ist nicht zwingend notwendig, da Beers Grundriss Inventionen für ein Gestühl mit und ohne Einzelstallen bietet. Falls sie aber existierten, dürfte einer der beiden Sitze ein Bild von Kolumban getragen haben, eine Darstellung von ihm fehlt zur sinnvollen Vervollständigung der Reihe.

Das Gestühl, dessen Entwurf dem Bildhauer Johann Joseph Christian (I706-I777) aus Riedlingen zugeschrieben wird, entstand in der Nachfolge von Weingarten. ${ }^{637}$ Christian übernahm den Auftrag für die Schnitzarbeiten 1741. ${ }^{638}$ Allerdings fertigte er sie nur teilweise, weshalb der Konvent 1746 ihre Vollendung dem Bildhauer Josef Hofer überließ. ${ }^{639}$ Mit den Tischlerarbeiten am Gestühl wurde der Franziskanerkonvertit Clemens Seehuber aus Konstanz betraut, er schuf zwischen 1743 und 1745 die strukturellen Elemente und Furnierarbeiten. ${ }^{640}$ Das überrascht

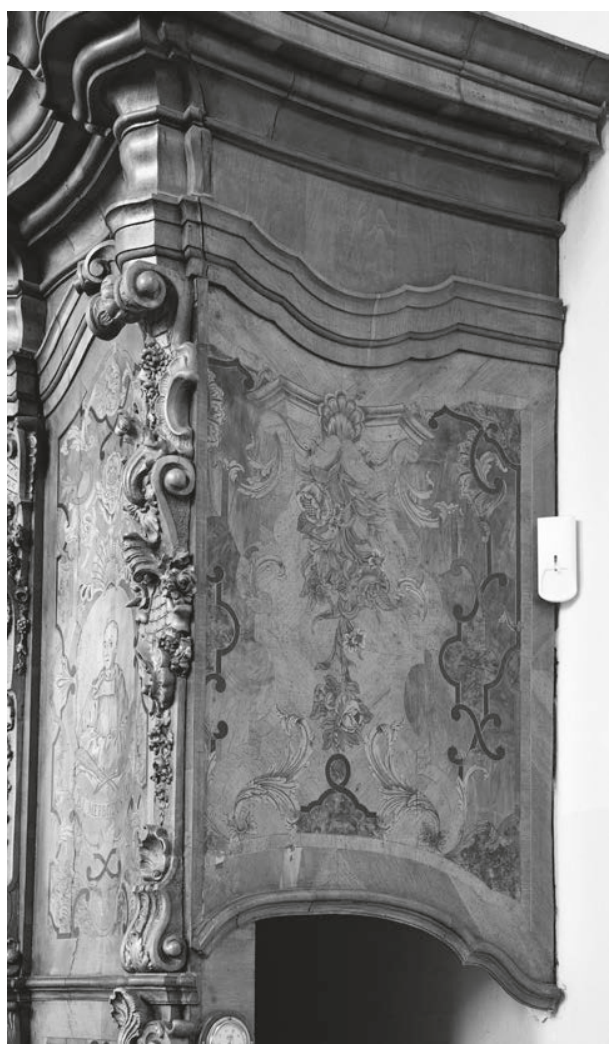

384 Chorgestühl, Evangelienseite. »Pilaster« und Eckverkröpfung am Übergang vom Dorsale zum Querstück am östlichen Gestühlsende. Fr. Clemens Seehuber, Johann Joseph Christian, Josef Hofer, I $74 \mathrm{I} / 46$ insofern, als das Kloster Mehrerau, für dessen Abteikirche das Gestühl ursprünglich geschaffen worden war, dem Benediktinerorden unterstand. Und am Gestühl selbst erstaunen neben den reichhaltigen Marketerien die Zinneinlagen, deren Verwendung

635 Wagner, Kunsthandwerk (1999), 580-58 I.

636 Wagner, ebd., 580.

637 Weiß, Bilder (1998), r66; Wartena, Süddeutsche Chorgestühle (2008), 736.

638 Wagner, Kunsthandwerk (I 999), 580-58 r. Ammann, Bregenz (r 979), I 2, nennt das Jahr 1742.

639 Ammann, ebd., I 2.

640 Frühere Beiträge nennen die Jahre I 740 und I 743. Ulmer/Tiefenthaler, St. Gallus ( I 96r), 7 ; Ammann, ebd.; Wagner, ebd., 580-58r. 
besondere handwerkliche Erfahrung und manuelle Fähigkeiten voraussetzte. Experten sehen in Johann Joseph Christian den Schöpfer der Puttenhermen, die sich in ähnlicher Anordnung am Chorgestühl im ehemaligen Kloster Zwiefalten wiederfinden, an dem der Bildhauer zwischen I744 und I75 I arbeitete. ${ }^{641}$ Die Putten werden indes keine Invention Christians gewesen sein, sondern könnten das Gestühl in Weingarten rezipieren, dessen Abschlussgesims dem in Bregenz ähnelt. ${ }^{642}$ Möglich scheint allerdings auch, dass die Putten auf jene am Chorgestühl in Melk rekurrieren, die eine vergleichbare Körperhaltung einnehmen. ${ }^{643}$ Christian hatte sich auf die Produktion von Erzeugnissen spezialisiert, die im Kontext neuer Kirchenausstattungen benötigt wurden. ${ }^{644}$ Über das Schaffen österreichischer Bildhauerwerkstätten muss er gut informiert gewesen sein, auf Analogien zwischen verschiedenen seiner Produkte und Bildwerken im oberösterreichischen Stift St. Florian wurde bereits verwiesen. ${ }^{645}$ Die Annahme, der Schnitzer könne das I736/37, somit nur einige Jahre zuvor verfertigte Melker Gestühl studiert und seine Arbeit dann entsprechend konzipiert haben, liegt auf der Hand. Die Aufgabe des Fassmalers Johann Geiger bestand darin, das »Chorgestühl zu ballieren «, also mit einem mattglänzenden Firnisüberzug zu versehen. ${ }^{646}$

\section{Dornbirn, Stadtpfarrkirche St. Martin}

Das Kloster St. Gallen stiftete im ı . Jahrhundert einen Vorgängerbau der heutigen, seit 1278 in Schriftquellen nachweisbaren Kirche. ${ }^{647}$ Nach einer wechselvollen Geschichte erwarb die Gemeinde Dornbirn r77 I die Rechte an St. Martin. Weil der mittelalterliche Chor bereits um die Mitte des i 8. Jahrhunderts abgerissen werden musste, entschloss man sich I 839 zur Neuerrichtung der Anlage, die als baufällig galt und wegen der stark angestiegenen Zahl an Gemeindemitgliedern zu klein geworden war. Letzteres war nicht zuletzt eine Folge des wirtschaftlichen Aufschwungs, den damals vor allem Dornbirn durch die rasante Entwicklung der Vorarlberger Textilindustrie nahm. I 857 wurde die Kirche eingeweiht.

\footnotetext{
64I Huber, Christian (1 960), 32, Abb. 26, 31 ; Sandner, Barock ( 1964), 7, Abb. 72 ; Wartena, Süddeutsche Chorgestühle (2008), 830-837.

642 Weiß, Bilder (1998), г66-г67. Ähnlich ist ebenfalls das Gebälk des Gestühls in Rot an der Rot, wie Weiß, ebd., feststellte. Zu den Gestühlen in Rot an der Rot und Weingarten Wartena, ebd., 4I 4-43 I, 7I5-734, Abb. I6.2, 24.8.

643 Bohr, Sakralmöbel (2017) 42 I-428.

644 Huber, Christian ( 1960), i 9.

645 Huber, ebd., I $9,22$.

646 Huber, ebd., 74. Vgl. hierzu auch Bohr, Sakralmöbel (2017), 53-54.

647 ÖKT, Feldkirch (1958), 90-95; Dehio, Vorarlberg (1 983), I32-I 34; Ulmer, St. Martin (2007).
} 
Unter der Leitung des Architekten Martin Kink (1800-1877) aus Bregenz entstand mit der Sakralanlage einer der bedeutendsten klassizistischen Kirchenbauten der Region. In die gewestete Kirche führt eine monumentale Portikus, vor der Südseite steht frei der Glockenturm. Ein breiter Saalbau mit halbrunder Chorapsis und einer von gekuppelten Pilastern gestützten flachen Segmentbogentonne bildet die architektonische Hülle. Zwischen I 967 und 1969 wurde das Gebäude restauriert, zugleich wählte man eine andere Raumaufteilung. Seitdem stehen nur noch wenige Bänke der Tradition entsprechend so, dass die Gläubigen frontal auf den Altar blicken. Der größere Teil der Sitzmöbel ist auf dem neuangelegten, zur Raummitte hin abfallenden Boden parallel zur Kirchenlängsachse vor den $\mathrm{Au}-$ ßenwänden im Norden und Süden angeordnet. Das Laiengestühl bildet nun eine große U-Form, die sich zum Altar hin öffnet. ${ }^{648}$ Das Zentrum zwischen den Möbeln nehmen das Taufbecken und der Zelebrationsaltar ein. ${ }^{649}$

\section{Laiengestübl}

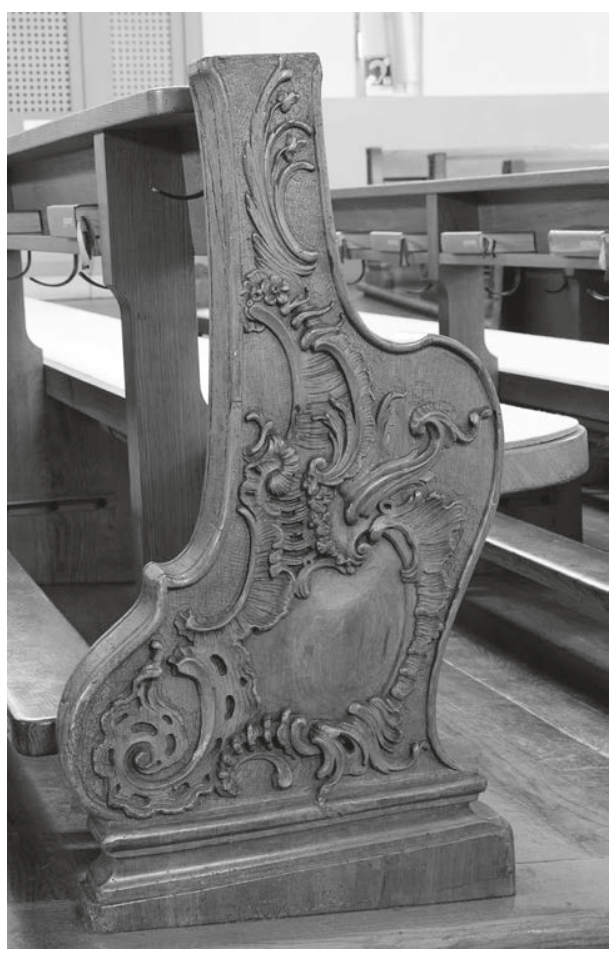

385 Bankwange. Dornbirn, I 752 . Die

Wange ist alt, die Buchablage war früher vermutlich auf der Wange befestigt, die Lehnen, Sitz- und Kniebänke sind modern.

Dornbirn, $\mathrm{I} 75^{2}$

HS $8 \mathrm{~cm}$

$\mathrm{H} 84 \mathrm{~cm}(+8 \mathrm{~cm})$

Nussholz, massiv

Erhalten sind 72 barocke Bank- und Brüstungswangen (Abb. 385). ${ }^{650}$ Sitz- und Kniebänke sowie die Rückenlehnen wurden erneuert, mehrere alte Wangen gegen neue

648 Eine Abbildung in der Kunsttopographie zeigt die Kirche vor der Umgestaltung in den I 96oer-Jahren. ÖKT, ebd., 92, Abb. 2 I.

649 Ulmer, St. Martin (2007), Abbildungen auf den Seiten 8-9, I6-1 7, 26-27.

650 ÖKT, Feldkirch (1958), 93; Dehio, Vorarlberg (I 983 ), I34; Ulmer, ebd., 25. 
ausgetauscht. Zudem kürzte man etliche Docken um einige Zentimeter, die Zierformen vieler Exemplare sind deshalb am oberen Ende beschnitten.

Weite Schwünge führen die Vorder- und Rückseite der asymmetrischen Wangen nach oben. In die vordere Auswölbung ist wie üblich die Sitzbank eingegratet, in die hintere die Kniebank. Ein schmales Rundprofil fasst die Wangen ein, Ornamente mit geglätteter Oberfläche stehen erhaben vor dem vertieften und aufgerauten Grund. Eine außergewöhnliche Variationsbreite an Formen und Motiven kennzeichnet die Docken, jede einzelne wartet mit einem Muster auf, das sich von dem der anderen unterscheidet. Die sich aus Blumengehängen, Laubwerk, Spangen und Muscheldekor entwickelnden Ziermotive kommen in stets abgewandelter Form immer wieder vor. Eine Brüstungsdocke präsentiert in einer Kartusche einen Birnbaum vor dem Bindenschild, das Stadtwappen Dornbirns sowie die Jahreszahl I 75 2. Darunter befindet sich eine weitere Kartusche mit einer Buchstaben- oder Zahlenkombination, die abgearbeitet und nahezu komplett ausgelöscht wurde, heute ist sie nur noch schemenhaft zu erkennen. Der Grund für dieses Vorgehen ist nicht bekannt. Andere Wangen zeigen das Monogramm JWP sowie als Adelswappen einen steigenden Löwen mit Pfeilen in den Pranken und den Initialen J.C.R.B., vermutlich das Wappen und das Monogramm eines Stifters.

Feldirirch-Altenstadt, Dominikanerinnenkloster

\section{Abteikirche Maria Verkündigung}

Die Frage nach dem Ursprung des Klosters konnte noch nicht abschließend geklärt werden, doch ist unbestritten, dass an seinem Standort in der ersten Hälfte des I 5. Jahrhunderts eine Klause existierte. ${ }^{651} \mathrm{Um}$ die Mitte des folgenden Säkulums berichtet die schriftliche Überlieferung von einer dominikanischen Gemeinschaft des III. Ordens (Tertiaren). Mitglieder der Gemeinschaft lebten nach einer lockeren Form der Ordensregeln oder waren als Laien an die Kommunität gebunden. Seit r 640 sind dort Angehörige des klausurierten II. Ordens ansässig, die sich an den strengen Regeln der Dominikaner orientierten und noch immer orientieren. ${ }^{652}$ Die Kirche selbst findet in Schriftquellen seit I 442 Erwähnung. I640 bis I642 ist der Bau eines Chors nachweisbar, 1695 wurde die Kirche neu errichtet. Der in jüngerer Zeit umgebaute Sakralraum

65 I ÖKT, Feldkirch (1958), 28I-295; Dehio, Vorarlberg (1983), r84-I85; Podhradsky, Dominikanerinnenkloster (I990).

652 Podhradsky, ebd., bes. I09-I I ; Horst, Dominikanerorden (2003); Schwaiger, Mönchtum (2003), 428-429. 
besteht aus einem vierjochigen Langhaus, das ein Tonnengewölbe auf Wandpilastern überspannt. Eine dreiachsige und zweijochige Halle bildet den Eingangsbereich, ein halbkreisförmiger Triumphbogen trennt den Chorraum ab. Er besitzt die gleiche Breite wie das Schiff.

\section{Portal}

Feldkirch, I 699

Lichte Maße H $258 \mathrm{~cm} \times$ B I $48,5 \mathrm{~cm}$

Nussholz. Eisen gemeißelt und verzinnt

Vor der Westfassade der Kirche liegt eine mit Arkaden geöffnete Vorhalle, in deren Mittelachse ein rundbogiges Portal den Zugang zur Kirche ermöglicht. Datiert ist es auf das Jahr r699 (Abb. 386). Die Tischler fügten die Türflügel aus breiten Rahmen und großen Füllungen zusammen. Während die unteren Binnenfelder als Hochrechtecke gestaltet sind, folgen die oberen dem Verlauf des gemauerten

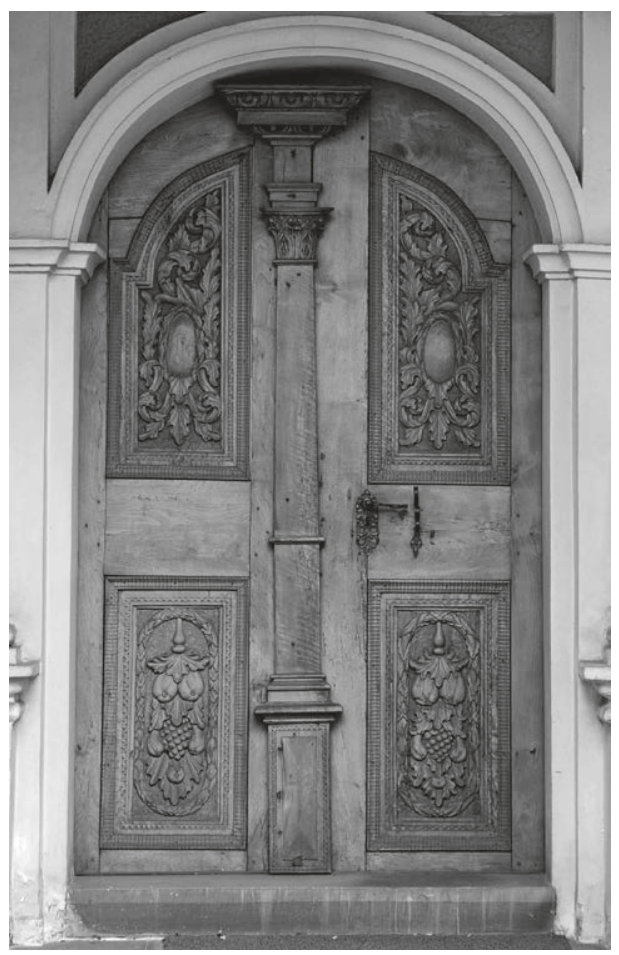

386 Eingangsportal zur Kirche. Feldkirch, I 699 Gewändes. Ein hochgesockelter schlanker Pilaster dient als Schlagleiste. Er trägt ein wuchtiges Gebälkstück, das unter den Scheitel des Arkadenbogens greift. Während die Türrahmen und der Pilaster eine geglättete Oberfläche aufweisen, zieren kraftvolle Schnitzarbeiten die von Flammleisten und Wellenfriesen gesäumten Füllungen. In den unteren Kompartimenten umfasst ein Lorbeerkranz Feldfrüchte, oben säumt Akanthusblattwerk, das durch seine Umrissform an Eichenblätter erinnert, eine hochovale gewölbte Kartusche. Dem Laubwerk lagen keine italienischen, sondern süddeutsche Entwurfszeichnungen zugrunde, die Verwendung solcher Akanthusornamente lässt sich bis ins frühe 18 . Jahrhundert hinein nachweisen. ${ }^{653}$

653 Berliner/Egger, Vorlageblätter (1981), Bd. I, 87-89, Bd. 3, Abb. 1046, 1047, го7 I. Die Abbildungen geben Drucke von Johann Conrad Reuttimann (nachw. I676-r69I) und Johannes Unselt (nachw. I68I-I696) von I678 und I695 wieder. Pechstein/Forssman, Goldschmiedekunst (I992), 2 I3-2 I4, Kat. I02, mit einem Silberbecher vermutlich von Joachim Andreas Schaar (nachw. I 7 I 2-vor I 753) von I 7 I 6. 
In der Wahl des Dekors, auf den man zur Ausschmückung des Portals zurückgriff, zeigt sich eine Verknüpfung moderner und althergebrachter Stilelemente. Akanthusblattwerk wurde von österreichischen Tischlern als flächendeckendes Ornamentmotiv in den r68oer-Jahren übernommen und steht infolgedessen auf der Höhe der Zeit, während Fruchtfestons hierzulande seit dem I6. Jahrhundert Kunstwerke schmücken. Das früheste mit Feldfrüchten verschönerte Beispiel, auf das wir in Verbindung mit der Studie über österreichische Kirchenmöbel gestoßen sind, bietet das I 647 gefertigte Chorherrengestühl in der Wiener Metropolitankirche St. Stephan. ${ }^{64}$ Diesen Motiven war eine überaus lange Lebensdauer beschieden. Sie kommen an den um r680 gefertigten Zelebrantenstühlen vor, die im Anschluss beschrieben werden (Abb. 387), sie finden sich als Schmuck von Nürnberger Goldschmiedearbeiten aus der Zeit um I680 bis r 690 oder als Zierform am Gestühl in der Heilig-Blut-Kapelle zu Stams von etwa I685/1700 (Abb. 349). ${ }^{655}$ Erstaunlich ist jedoch vor allem die Diskrepanz zwischen den verwendeten Formen, also die Tatsache, dass man keine einheitliche Auszier wählte, sondern eine Kombination unterschiedlicher Motive bevorzugte. ${ }^{66}$ Wie wir gleich sehen werden, wiederholt sich Ähnliches auch an Möbelstücken in der Kirche.

\section{Kirchenraum}

\section{Dreisitze}

Feldkirch, um 1680

HS $8,5 \mathrm{~cm}$

$\mathrm{H} 205 \mathrm{~cm}(+8,5 \mathrm{~cm}) \times \mathrm{B}_{20} 09,5 \mathrm{~cm}$

Nussbaumholz, Nadelholz

Die beiden Möbel stehen sich im Chorraum der Kirche gegenüber (Abb. 387, 388). ${ }^{657}$ Bis vor einigen Jahren waren sie um 90 Grad gedreht und lehnten mit der Rückwand an den Triumphbogenpfeilern, sodass die Zelebranten vom Gestühl aus frontal auf den Altar blickten. ${ }^{658}$

Die Möbel bieten jeweils drei Personen Platz. Lisenen und eine massive Querleiste in Kapitellhöhe bilden ein klares Ordnungssystem aus Waagrechten und Senkrech-

654 Bohr, Sakralmöbel (2017), 222-225.

655 Pechstein, Goldschmiedekunst (1987), I50-15 I, Kat. 62, mit einem Kugelbecher, den der Nürnberger Goldschmied Sigmund Bierfreund ( $\left.\mathrm{I}_{62} \mathrm{O}-\mathrm{I} 7 \mathrm{O}_{2}\right)$ fertigte. S. hierzu auch die folgende Anmerkung.

656 Allerdings können Goldschmiedearbeiten ebenfalls mit einer Kombination von Früchten und Akanthus verziert sein. Vgl. hierzu eine von Johann Philipp Höfler (I663-I 722 ) um I685/9o in Nürnberg gefertigte Silberplatte. Eine Abbildung der Arbeit in Pechstein, ebd., I67-I68, Kat. 8 I.

657 ÖKT, Feldkirch (1958), 282.

658 Freundlicher Hinweis von Sr. Agata Teresa. 
387 Chorraum, Evangelienseite, Dreisitz. Feldkirch, um I680

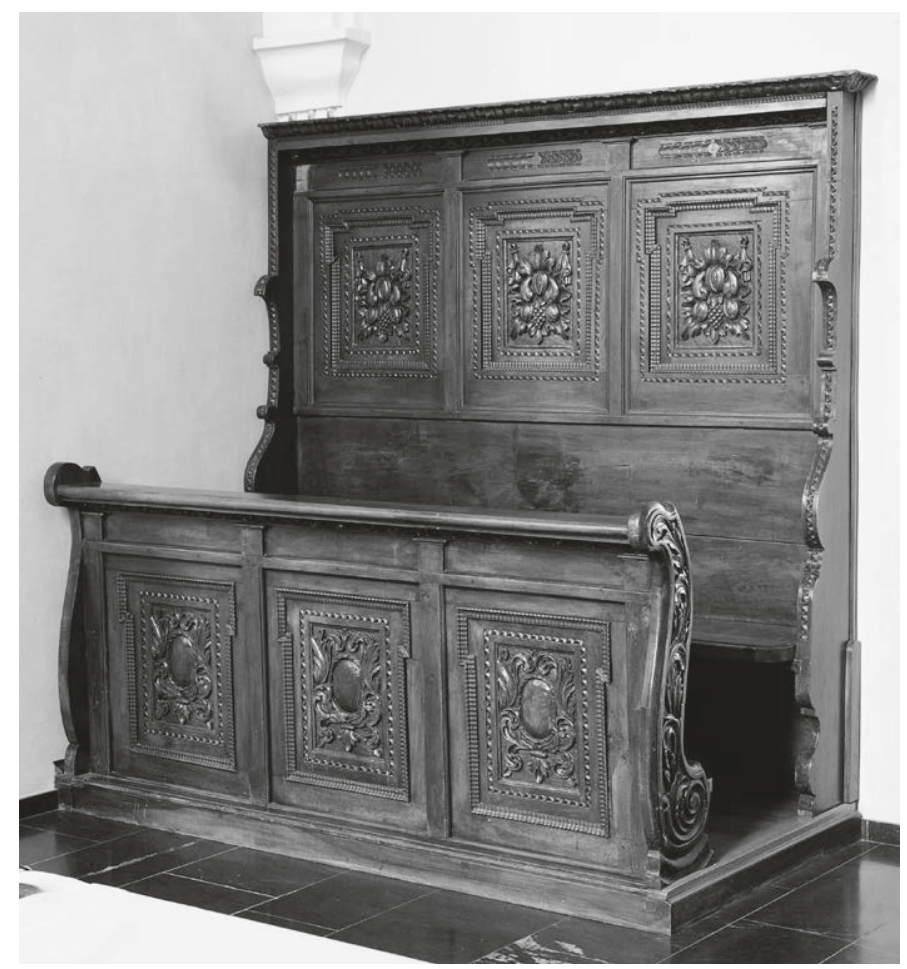

ten, das Brüstung und Rückwand parzelliert. Geohrte Rahmen säumen die Füllungen, die der Rückwand sind zusätzlich mit verkröpften oberen Schmalseiten ausstaffiert. Die mit dem Schnitzmesser gefertigten Dekormotive in den Binnenfeldern dürfen als Vorlagen für jene des Portals gelten: Am Dorsale sind Fruchtbündel zu erkennen, an der Brüstung hochovale, mit Laubwerk umgebene Kartuschen. Flammleisten und Wellenfriese säumen die zentralen Felder, wie so oft besitzen die Ornamente auch hier eine geglättete und glänzende Oberfläche, während Punzenschläge den Grund mattiert erscheinen lassen. Die Großform der Brüstungswangen entspricht einem langgezogenen S-Bogen. Sie stehen über die Fläche der Brustwände weit nach vorn, eine Art der Konstruktion, die sich häufig an Möbeln in Tirol und Kärnten sowie in der Steiermark findet (Abb. 56, 279). Die Tischler führten die ebenfalls dynamisch gestalteten hinteren Docken als Hochwangen bis unter das Abschlussgesims und dekorierten ihre Vorderkanten mit einem Wellenband. Sie statteten die Dreisitze nicht mit Einzelstallen, sondern mit Sitzbänken aus, als Werkmaterialien verwendeten sie massives Nussholz und nussfarben gebeiztes Nadelholz. Stilistische Gründe sprechen 


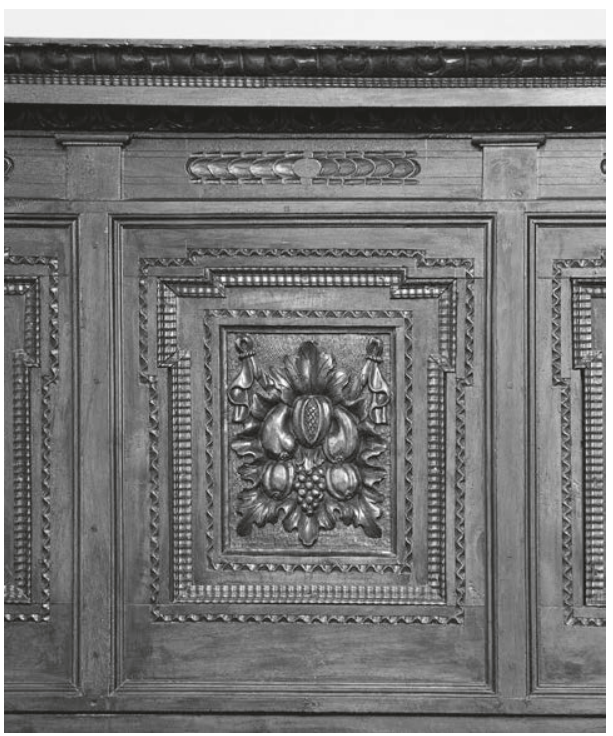

388 Chorraum, Dreisitz (Detail). Feldkirch, um 1680

für eine Herstellung der Möbel noch vor der Neuerrichtung der Kirche. Der Sockel ist modern.

\section{Empore}

Die zweijochige Empore nimmt die gesamte Breite des Baukörpers ein. Bei der Renovierung der Kirche in den I96oer-Jahren wurde die alte Emporenbrüstung entfernt und durch ein Metallgitter ersetzt. Es ist so fein gearbeitet, dass es keine wirkliche Schranke mehr zwischen dem für Laien zugänglichen Kirchenschiff und der Empore bildet, die zum Klausurbereich des Klosters zählt. Ursprünglich war das anders.

\section{Gestühl}

Feldkirch, um I685/ 700

HS $19 \mathrm{~cm} / 37,5 \mathrm{~cm}$

H IOI cm $(+37,5 \mathrm{~cm})$

Nussholz, Nadelholz, gebeizt

Das über einem U-förmigen Grundriss errichtete Gestühl kommt ohne Dorsale aus (Abb. 389-39 I). Seine Breite misst etwa Io, I 5 m, seine Tiefe auf der Evangelienseite 6,60 m, gegenüber etwa 5,80 m. ${ }^{659}$ Die hintere Reihe umfasst 22 Stallen sowie einen Einzelsitz für die Priorin, die vordere Reihe besteht aus Sitzbänken. Die Massengliederung der Brüstung entspricht jener des Dreisitzes im Chorraum, doch ist nun der Eindruck der Rasterung zugunsten einer klaren architektonischen Strukturierung zurückgenommen. Sich verjüngende pilasterartige Stützen mit Blattkapitellen unterteilen die Brustwand in einzelne Achsen und tragen ein Gebälk, dessen Gesims von der Vorderkante der Gebetbuchablage gebildet wird. Die Füllungen besitzen mit Flammleisten eingefasste geohrte Rahmen, Akanthusblätter und hochovale Kartuschen schmücken die Binnenfelder. Scheiben- und Schuppenfriese bereichern die Stützen und Gebälkfriese, ein Kymation das Gesims. Wie an den beiden Dreisitzen nähern

659 Ein Zapfenloch zur Befestigung eines weiteren Sitzes in der Außenseite der hinteren Wange deutet darauf hin, dass auch diese Seite ursprünglich länger gewesen sein dürfte. 


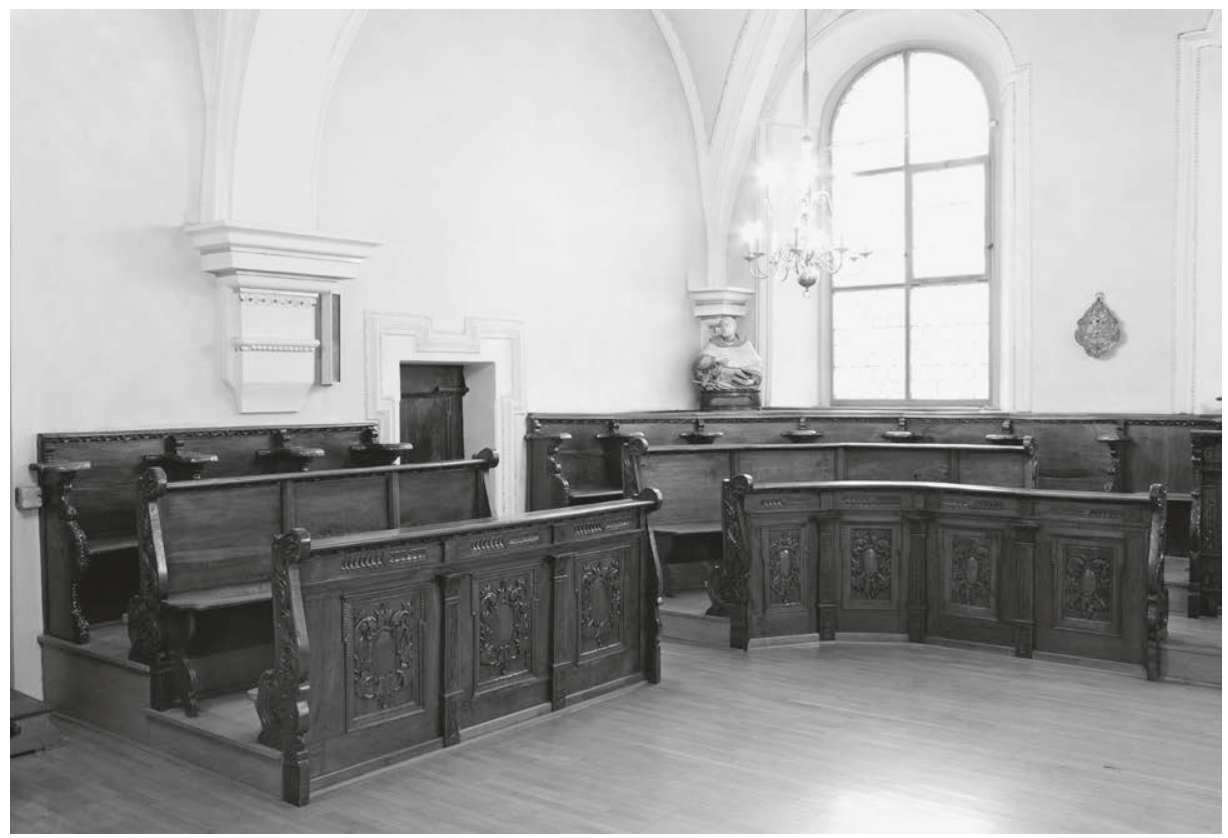

389 Empore, Chorgestühl. Feldkirch, um I685/I 700

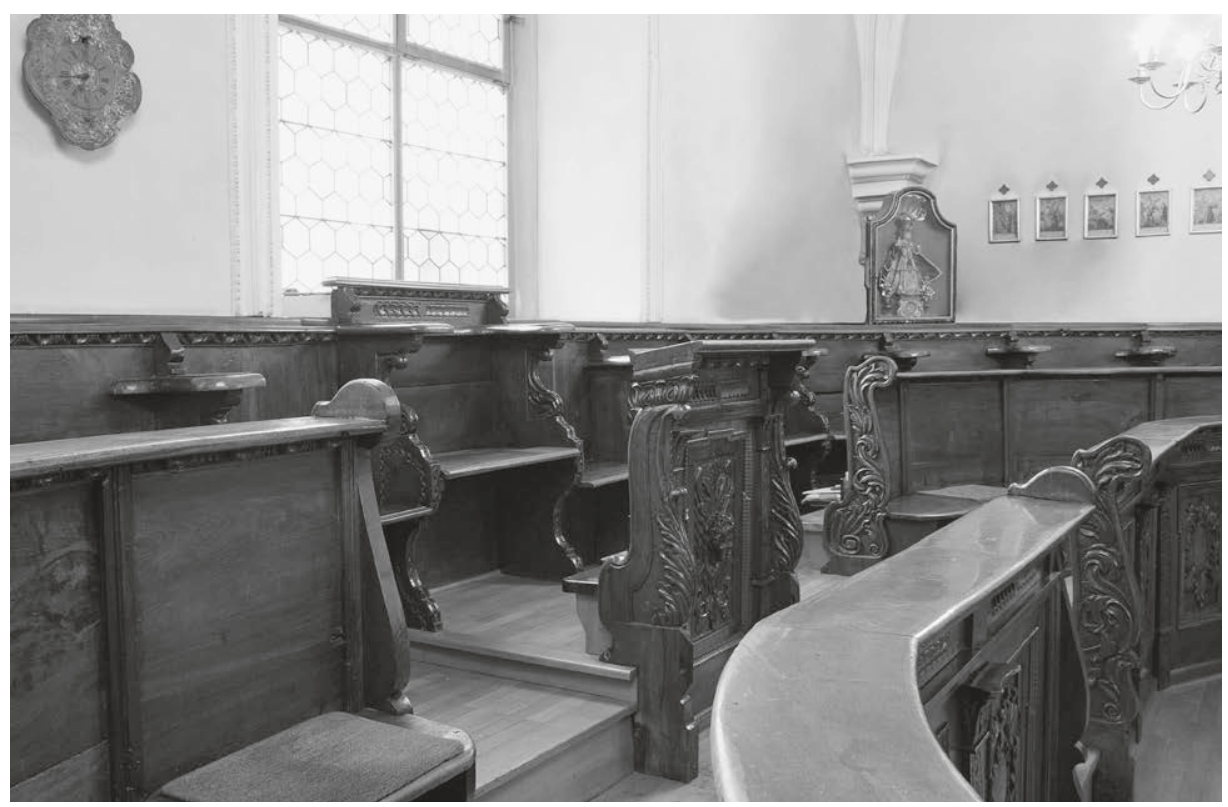

390 Teilansicht des Gestühls mit Stalle der Äbtissin. Feldkirch, um I685/I 700 


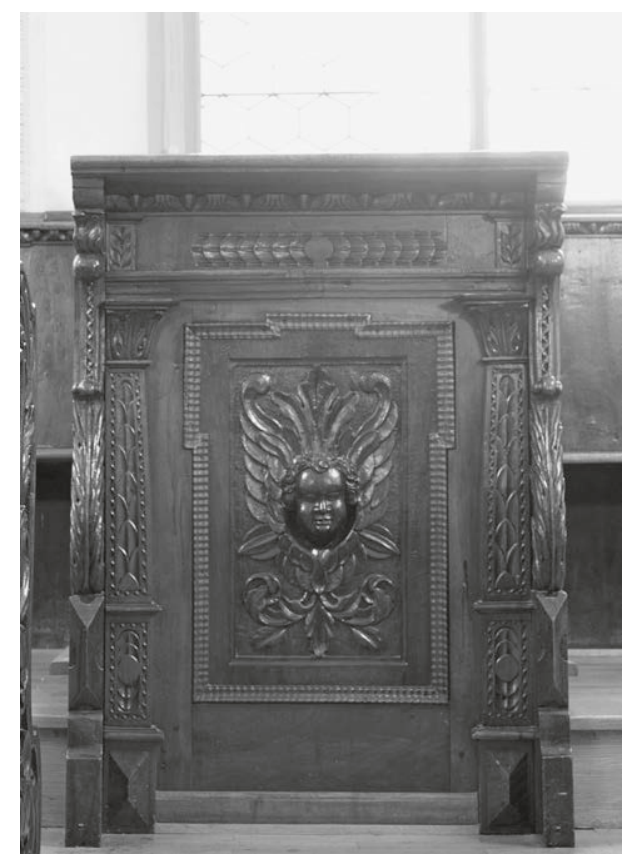

39I Brüstung vor dem Sitz der Klostervorsteherin. Feldkirch, um I685/1700

sich die schlanken Brüstungswangen mit ihrer Form auch hier einem langgezogenen SBogen an, verziert sind sie mit großflächigem Blattwerk und einer abgeflachten Volute im unteren Bereich. Diese Wangenform ist eher für die Docken eines Laiengestühls charakteristisch. Dagegen übernehmen die hinteren Wangen die für barocke Chorgestühle typische Gestaltung, wie sie im vorliegenden $\mathrm{Ka}^{-}$ talog und im ersten Band der Untersuchung immer wieder beschrieben wird. Die Vorderseite ist geschwungen und ähnlich dem Gestühl im Chorraum mit einem Wellenband verziert - offensichtlich ein Markenzeichen des Tischlers. Auf den Docken liegen die breiten Schulter- bzw. Armstützen, die hier kein durchgehendes Band bilden, sondern vor der Rückwand enden. Wie an den Chorgestühlen in Griffen und Pöllau (Farbtaf. 04, 25; Abb. 27) kommt das zwar selten, aber doch gelegentlich vor.

Im Hinblick auf die Großform entspricht die Sessio der Priorin (Abb. 39I) den anderen Exemplaren, doch hat man ihren Sitz etwas aufwendiger gearbeitet und leicht erhöht angeordnet. Reliefs zieren wieder die Seiten, ein großer Cherub schmückt die Füllung der Brustwand. Sein Federkleid nähert sich der Form von Blattwerk an, auch hier ist es verdickt und eingerollt, weshalb es noch an Formen aus der Zeit um r65o bis I670 denken lässt. Abgesehen vom Akanthuslaub im unteren Bereich der Füllung erinnert die Darstellung an bestimmte süddeutsche Arbeiten aus dem frühen I 7. Jahrhundert. ${ }^{660}$ Die Verbindung konservativer und moderner Ornamentformen ist hier ein weiteres Mal evident.

660 Bimbenet-Privat/Kugel, Orfèvrerie (2017), I 26-I 27, mit einem zwischen I609 und I629 entstandenen Nürnberger Buckelpokal von Franz Fischer († I653). 
392 Chorraum, Südseite, Levitensitze. Thüringen, um I $640 / 50$

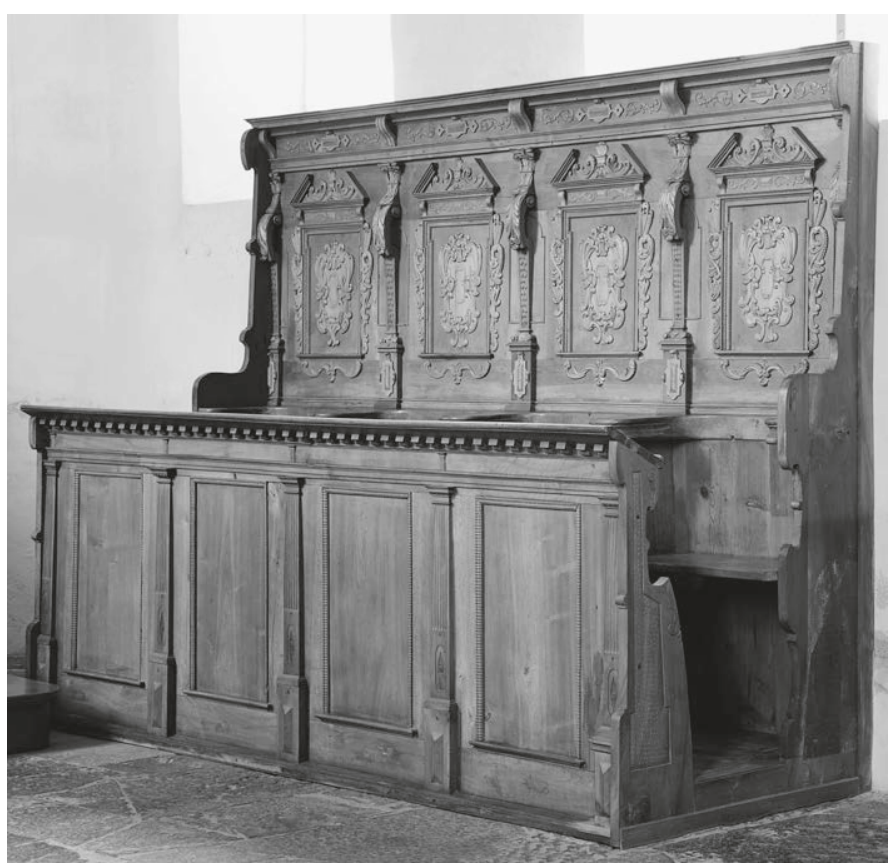

Thüringen, Kirche St. Anna

Die Gemeinde ist seit 842 in Schriftquellen fassbar, die Kirche St. Anna seit dem späten Mittelalter. ${ }^{61}$ Archivalien berichten davon, dass man I 509 einen älteren Sakralbau durch einen Neubau ersetzte, I 644 erhielt er bei einer Renovierung das heutige Aussehen. Die Kirche besitzt ein im Ursprung gotisches Langhaus und einen eingezogenen zweijochigen Chor mit großen rund- und spitzbogigen Fenstern. Eine flache Tonne, die über einem mäßig profilierten Gesims ansetzt, wölbt sich über das Schiff, ein Netzrippengewölbe überspannt den Chor.

\section{Chorraum}

\section{Sedilien}

Thüringen, um I640/50

$\mathrm{HS}{ }_{4} \mathrm{~cm}$

$\mathrm{H}_{2} \mathrm{I} 5,5 \mathrm{~cm}(+\mathrm{I} 4 \mathrm{~cm}) \times \mathrm{L}_{22} 3 \mathrm{~cm} / 303,5 \mathrm{~cm}$

Nuss, Linde (?), Weichholz, gefirnisst

66 I Dehio, Vorarlberg (1983), 391-393. 


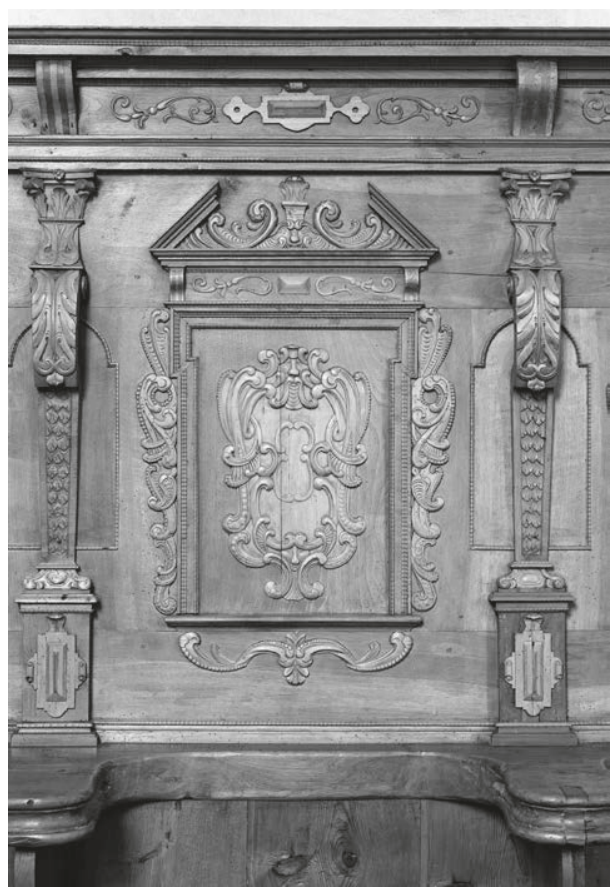

393 Chorraum, Levitensitze, Gestühlsrückwand (Detail). Thüringen, um I640/50
Das Gestühl verfügt auf der Evangelienseite über drei, auf der Epistelseite über vier Plätze (Abb. 392, 393). ${ }^{662}$ Bei nahezu identischen Großformen unterscheiden sich die beiden Sitzreihen vor allem in der Gestaltung der Rückwände.

An der Brüstung tragen hochgesockelte dorische Pilaster ein Gebälk, das mit schmalen kannelierten Konsolen und einem Würfelfries verziert ist, für die Füllungen wählten die Tischler schlichte Rechteckformen über Sockelleisten. Dagegen strukturieren korinthische Volutenpilaster, deren Postamente Beschlagwerkmuster tragen, das Dorsale. Ein Akanthusblatt legt sich auf die Voluten, den Schaft ziert jeweils eine Art von Schuppenoder Blattfries. Arkadenförmige, von schmalen Profilen gesäumte Binnenfelder liegen hinter den Stützen, Ädikulä mit Ohrrahmen und Sprenggiebeln füllen die Räume dazwischen. Konsolen und Beschlagwerkkartuschen sind den Gebälken vorgeblendet, auf der Südseite kommt feines Laubwerk hinzu. Zudem weisen die Gebälke eine unterschiedliche Profilierung auf. Die größten Unterschiede ergeben sich jedoch in Verbindung mit den welschen Fenstern der Rückwand. Bleiben sie auf der Nordseite unverziert, so säumen knorpelige Flachreliefs die Binnenflächen gegenüber. Aus Bögen und einer Groteskmaske bestehende Kartuschen ergänzen die zentralen Felder. Anders als die Sitze der Nordseite statteten die Tischler jene der Südseite mit Miserikordien aus.

\section{Laiengestühl}

Thüringen, um I640/60, um I690/I 7 10, I8./I 9. Jh.

HS $5,5 \mathrm{~cm}$

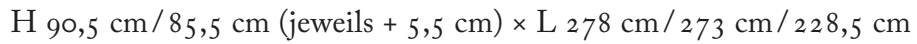

Zirbelkiefer, Lärche

662 Dehio, ebd., 393. 


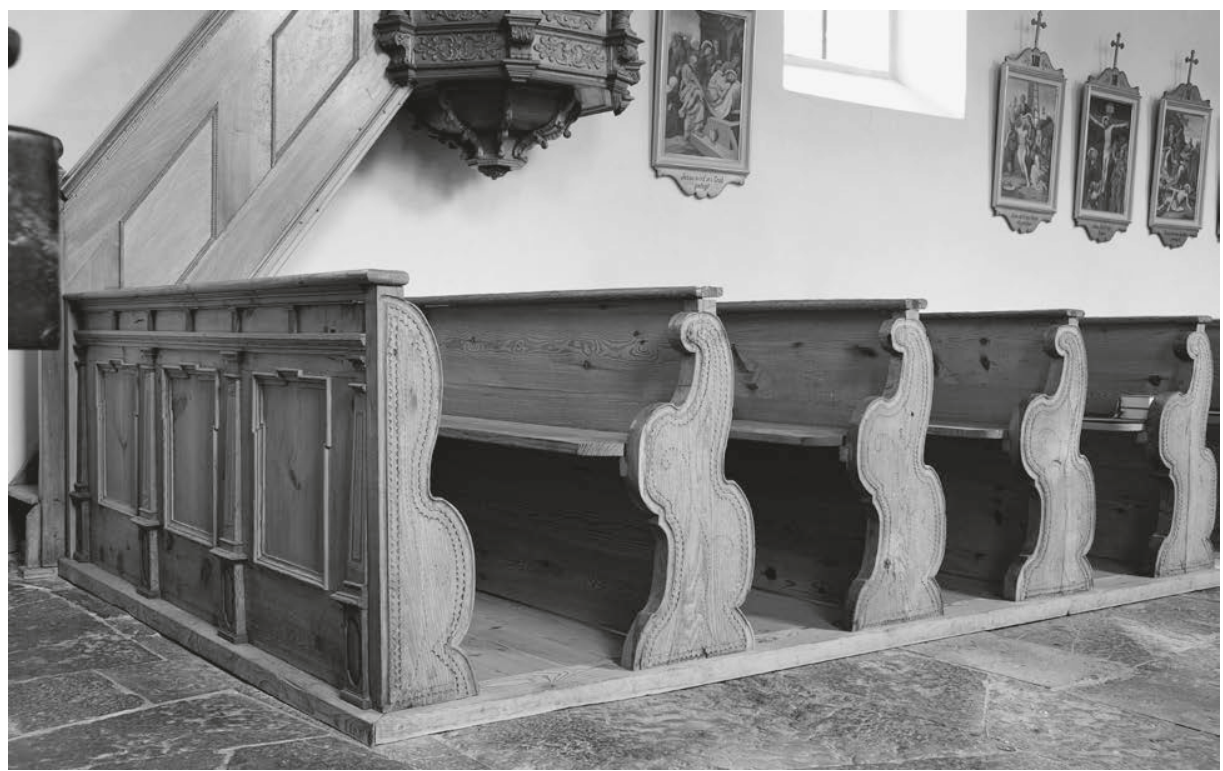

394 Kirchenbänke, Epistelseite. Thüringen, die Brüstung um r640/60, die Wangen r 8./rg. Jh.

Die beiden Bankblöcke stehen seitlich des Mittelgangs (Abb. 394-396). Eine Seite umfasst I 5 Reihen, die andere I7, hinzu kommen die Vorderbrüstungen. ${ }^{63}$ Zum Mittelgang zu schließen die Bänke wie üblich mit Docken ab, während man sie außen an der Wandvertäfelung befestigte.

Die Bänke entstanden nicht in einem Wurf, vermutlich wurden bei ihrer Fertigung Spolien verwendet. Das älteste Teilstück dürfte die Brüstung auf der Südseite sein (Abb. 394). Vier sich verjüngende Pilaster teilen sie in drei Joche. Triglyphen bereichern das Gebälk, die Füllungen sind nicht weiter dekoriert, besitzen aber verkröpfte Rahmen. Damit erinnert die Brustwand an das Laiengestühl in St. Lambrecht aus dem zweiten Drittel des I 7. Jahrhunderts (Abb. 260).

Eine davon abweichende Gestaltung weist die nördliche Vorderwand auf, die zusammen mit der vorderen Bank etwas kürzer und niedriger als die anderen Möbel ist (Abb. 395, 396). Hier sorgen Dreiviertelsäulen, die sich aus wulstigen Ringen zusammensetzen, für die Gliederung. Die Füllungen sind geohrt, das Gebälk ist verkröpft. Die Wangen von Brüstung und erster Bankreihe bestehen aus einem schmalen hochrechteckigen Brett, wie es an Gestühlen aus dem zweiten Drittel des i7. Jahrhunderts häufig zu finden ist. Allerdings zieren nun keine knorpeligen Schnitzereien die

663 Dehio, ebd. 

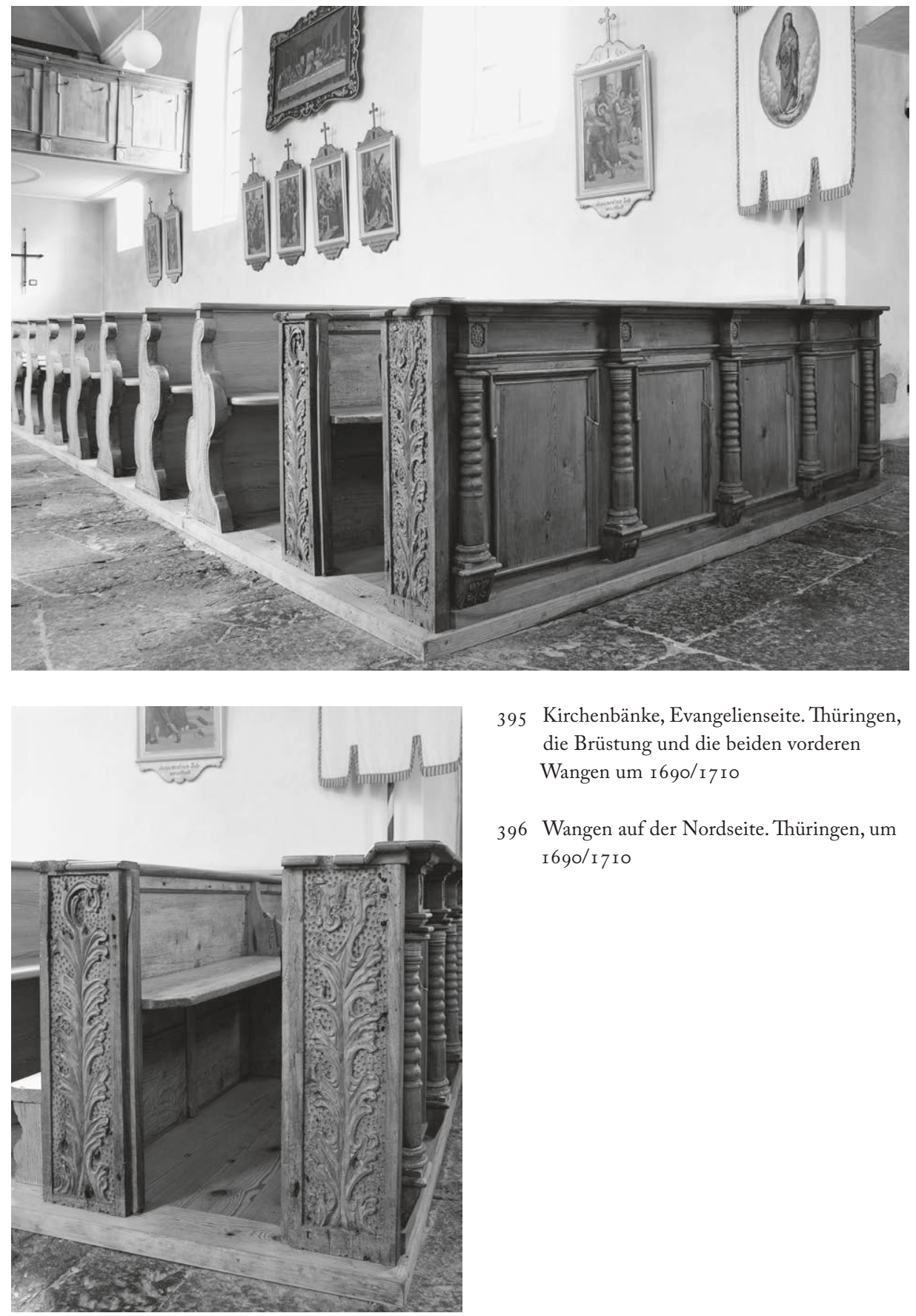

395 Kirchenbänke, Evangelienseite. Thüringen, die Brüstung und die beiden vorderen Wangen um I690/r7 10

396 Wangen auf der Nordseite. Thüringen, um I690/I 7 IO 
Wangen, sondern große Akanthusblätter, die vom Sockel aufsteigen und sich unter der Oberkante der Bohlen einrollen. Das Blattwerk spricht gegen eine Frühdatierung, es lässt an eine Herstellung der Docken etwa zwischen I69o und I7 Io denken. Durch ihre Gesamterscheinung erinnern sie an die stelenartigen Exemplare in Maria Loretto (Farbtaf. 02). Die übrigen Wangen besitzen eine Form, die wir ähnlich von Möbeln des I 8. Jahrhunderts her kennen, doch sind sie so schlicht, dass auch eine Anfertigung im frühen I9. Jahrhundert in Betracht gezogen werden muss. Kantenparallele Friese aus kleinen Bögen, die ein Tischler mit dem Geißfuß aushob, folgen der Kontur, ein mittleres, mit einer Reihe von aneinandergesetzten Punzen gezeichnetes Ornament schmückt die Wangen zusätzlich. Barocke Sitzbänke wurden normalerweise mit einfachen Bohlen abgestützt, beim Laiengestühl in St. Anna übernimmt diese Aufgabe jeweils eine in der Bankmitte angeordnete Zwischenwange, die wie die eines Chorgestühls bis unter die Abschlussleiste der Rückenlehne hinaufreicht. Als weitere Besonderheit sind hier die Bänke aufklappbar.

Auf der Evangelienseite erweisen sich die Brüstung, die vordere Bank sowie die Docken als alt, gegenüber sind es die Brüstung und sechs Bänke, sonst nur die Wangen. Modern ist neben einem Großteil der Bänke auch der Laufboden.

\section{Viktorsberg, Pfarrkirche hl. Viktor}

\section{Ehemaliges Franziskanerkloster}

Eine erste Sakralanlage lässt sich auf dem Viktorsberg seit 834 nachweisen. ${ }^{664}$ Lange Zeit befanden sich dort ein dem hl. Eusebius ( $†$ 884) geweihtes Schottenkloster und ein Spital, I 383 wurde der Gebäudekomplex dem Franziskanerorden überlassen. Ein Edikt der kaiserlichen Behörden löste I 785 die erst kurz zuvor barockisierte Anlage auf, seit I 835 ist die Kirche eine eigenständige Pfarre. Restaurierung und Erweiterung der Kirche gehen auf die Zeit um i 960 zurück.

Ein Stichkappentonnengewölbe überfängt das spätromanische Langhaus, die Südwand ist für große Rundbogenfenster geöffnet. Ein eingezogener und halbrund schließender Chorbogen trennt den Bereich der Laien von dem der Geistlichen. Der Chor hat seine gotische Form bewahrt, Konsolen tragen ein Netzrippengewölbe, in dessen Stichkappen Lanzettfenster hineinragen.

664 ÖKT, Feldkirch (1958), 544-552; Dehio, Vorarlberg (1983), 402-403. 


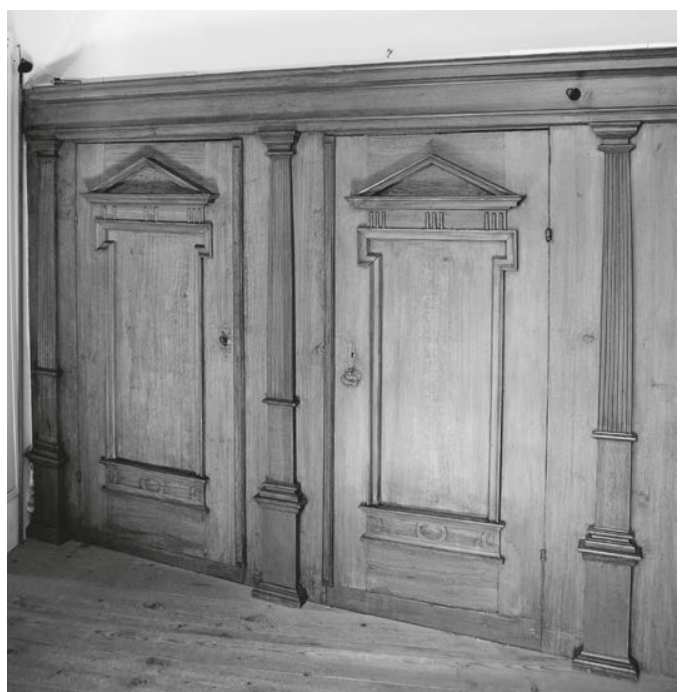

397 Sakristei, Westwand. Teilansicht der Schränke. Viktorsberg, 2. H. I7. Jh.

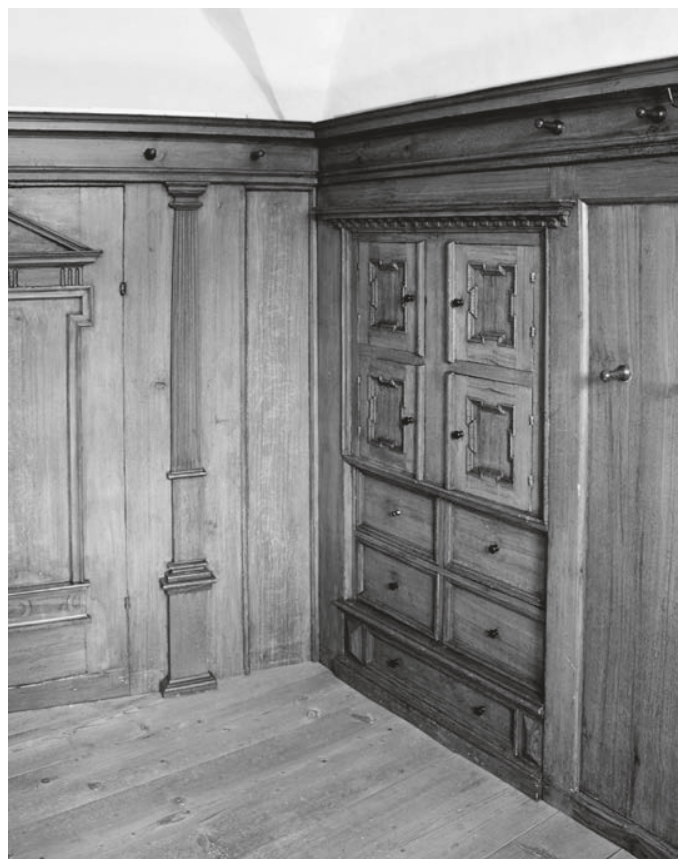

398 Sakristei, Nordwand. Schränke und Wandvertäfelung. Viktorsberg, 2. H. I 7. Jh.

\section{Sakristei}

Das kleine trapezförmige Zimmer lehnt sich an die Nordwand des Presbyteriums. Durch ein Fenster in der Ostwand fällt Licht in die Sakristei, unter dem Fenster befindet sich ein Aufsatzschrank, mit weiteren Möbeln hat man ihre Nordund Westwand verbaut.

\section{Schränke vor der West- und Nordwand}

Viktorsberg, 2. H. I7.Jh.

Gesimshöhe I $87 \mathrm{~cm} \times \mathrm{L} 273 \mathrm{~cm} / 315 \mathrm{~cm}$

Nadelholz gefasst. Eisen

Vor der Westwand befindet sich ein zweiachsiges Möbel, dessen architektonischer Dekor aus Türfüllungen in Ädikulaform, hochgesockelten dorischen Säulen und einem Abschlussgebälk besteht (Abb. 397). Dagegen beinhaltet der Holzverbau der Nordwand Kelchfächer und Schubladen sowie eine schlichte Wandvertäfelung (Abb. 398).

\section{Kirchenraum \\ Chorgestübl}

Vorarlberg, um I660/75

HS $16,5 \mathrm{~cm}$

$\mathrm{H}_{22} 23,5 \mathrm{~cm}(+\mathrm{I} 6,5 \mathrm{~cm}) \times \mathrm{L}_{4} 10 \mathrm{~cm}$

Nuss, massiv, Boden aus Nadelholz. Eisen

Die Südseite des U-förmigen Chorgestühls umfasst sechs Sitze, die hier gezeigte Nordseite fünf (Abb. 399, 


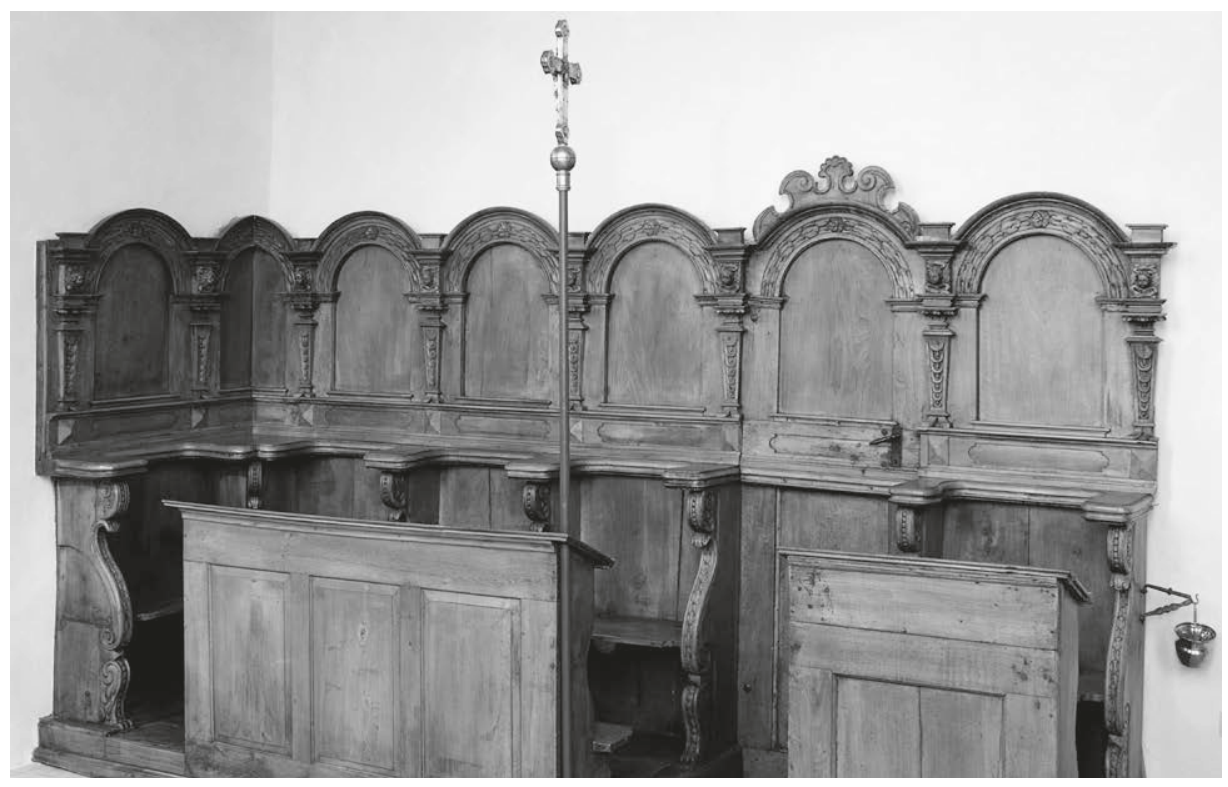

399 Chorraum, Nordseite. Gestühl und Sakristeitür. Vorarlberg, um r66o/75. Das Abschlussgebälk fehlt, das Möbel wurde gekürzt.

400). ${ }^{665}$ Hinzu kommt die schmale Tür zum ehemaligen Kreuzgang, heute führt sie in die Sakristei. Der ausgehobene Viertelkreis in den Außenwangen der querstehenden Gestühlssegmente, der der Führung eines aufklappbaren Sitzbrettes diente, belegt, dass sich die Stallenreihe einstmals fortsetzte. Untermauert wird diese Beobachtung durch den sonderbaren Dorsalabschluss darüber, das Gestühl wurde folglich gekürzt. Die mündliche Überlieferung berichtet, dass das Möbel aus einer nahegelegenen Kirche hierher verbracht wurde, doch geriet die genaue Herkunft in Vergessenheit.

Die Brüstung der Südseite bietet als flacher dreitüriger Schrank einigen Stauraum, auf der Nordseite verzichtete man auf diese ausgefallene Konstruktion. ${ }^{666}$ Hier besitzt die Brustwand die gewöhnliche Form, doch ist sie geteilt, um den Zugang zur Tür zu ermöglichen. Die Docken der Evangelienseite weisen die übliche Form mit geschweiften Kanten auf, ihnen stehen auf der Epistelseite hochrechteckige Brüstungswangen gegenüber, die zugleich die Stirnseiten des Schranks bilden. Wie an den Gestühlen

665 ÖKT, ebd., 547 ; Dehio, ebd., 403.

666 Sie kommt selten, aber doch gelegentlich vor. Ein weiteres Beispiel hierfür wäre die Brüstung des aus

Wilten stammenden Gestühls in der Innsbrucker Jesuitenkirche (Farbtaf. 30). 


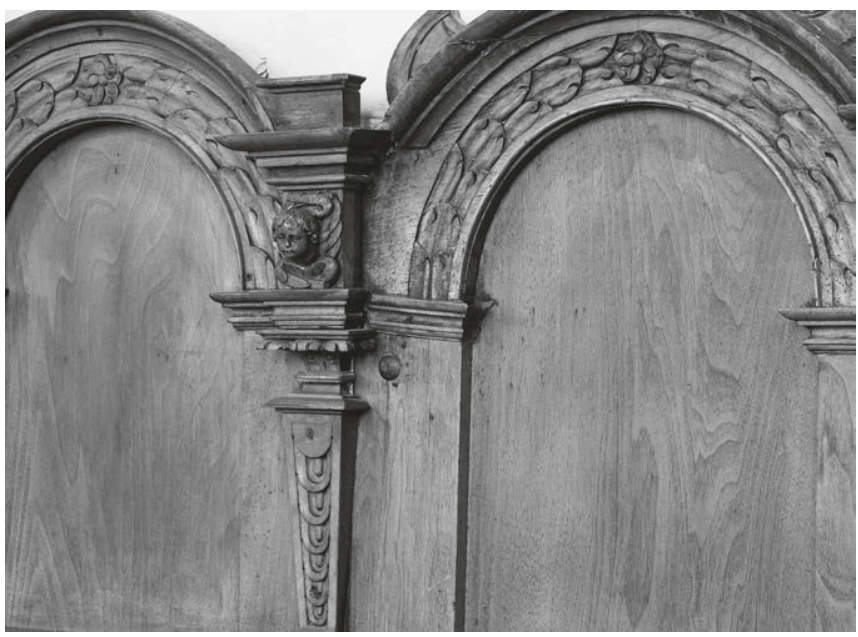

400 Chorraum, Nordseite. Gestühl (Rückwanddetail). Vorarlberg, um I $660 / 75$

in Feldkirch (Abb. 387, 389) schmücken feine Schnitzarbeiten die Vorderkanten der Docken. Keilpilaster mit Blattkapitell, geschupptem Schaft und geteiltem Fuß scheiden rundbogige Arkaden am Dorsale voneinander. Die Stützen tragen mit Cherubim verzierte Gebälkstücke und niedrige Podeste, die von den mit Lorbeer und Blütenrosetten ornamentierten Arkadenbögen in der Höhe weit überragt werden.

Werkmaterial des Gestühls ist massives Nussholz, nur den modernen Laufboden fertigte man aus Nadelholz. Kunsttopographie und Dehio datieren das Ensemble auf das Ende des I7. Jahrhunderts, dagegen lässt das Formenvokabular - manieristische Pilaster, Schuppenfriese, frühbarocke Bögen - eher an eine Datierung um r66o, mit einer gewissen Stilverschleppung vielleicht noch um I670 oder 75 denken. Ein abschließendes Gebälk ist nicht erhalten. Dübellöcher dokumentieren aber, dass man es einst mittels Zapfen auf den Postamenten über den Pilastern befestigt hatte, doch bleibt unsicher, wie es ausgesehen haben mag. Arkaden kommen an Gestühlen als Rückwandfüllungen häufig vor, enden im I7. Jahrhundert gemäß der klassischen Architekturlehre aber meist unter dem durchlaufenden Architrav (Abb. 302, 306, 333, 335). Hier dürfte ein Teilstück, vielleicht zusammen mit einer weiteren Volute (Abb. 302, 376), die Felder zwischen den Arkadenbögen geschlossen haben, darüber folgte dann mutmaßlich ein Gebälk, das die verschiedenen Segmente des Dorsales zusammengefasst haben wird. 
Teil 4

Zusammenfassung und Ausblick - Glossar VERZEICHNISSE - LITERATUR 
Publikation im Sinne der CC-Lizenz BY 4.0 


\section{Zusammenfassung und Ausblick}

\section{Ziele DeR UnTERSUChUNG}

Das vorliegende Buch über barocke Sakralmöbel knüpft direkt an den ersten Band zu diesem Thema an, der 2017 erschien. Zwar existieren einige monographische Beiträge zu entsprechenden Möbelensembles, doch wurde die Geschichte der Tischlerausstattungen in österreichischen Weltkirchen und Klöstern bisher noch niemals so detailliert beschrieben. Ihre Einbettung in einen chronologischen und geographischen Bezugsrahmen ist nun erstmals möglich. Zugleich trägt die Recherche dazu bei, ein wissenschaftlich belastbares Fundament mit Referenzstücken zu legen, deren Herstellungszeit und Provenienz vergleichsweise gut dokumentiert sind. In Verbindung mit dem noch ausstehenden dritten Band der Reihe, in dessen Fokus barocke Bibliotheken stehen, wird so auch die erforderliche Voraussetzung für das Schreiben eines umfassenden Katalogs über frühneuzeitliche profane Einrichtungen geschaffen. Angesichts der immensen Vielzahl an historischen Interieurs in österreichischen Palais und Schlossanlagen handelt es sich dabei um ein weiteres wichtiges Desiderat der Kunstgeschichte. Und schließlich verbindet sich mit dem Abschluss der Studie die Hoffnung, einen Beitrag zum Schutz barocker Kirchenmöbel zu leisten, die selbst heute noch dem Modernisierungswahn vieler Gemeindevorstände zum Opfer fallen.

\section{Zum strukturellen Aufbau der beiden Bücher}

Die Bücher sind in je zwei übergeordnete Abschnitte untergliedert. Der erste Teil des ersten Bandes beinhaltet Kapitel zur Geschichte der Kirchenmöbel, zur Wahl der Tischler durch Auftraggeber und Mäzene, zur Lage der Schreinereien in Wien und auf dem Land, zum Modus der Auftragsvergabe sowie zu den Entstehungsbedingungen der sakralen Inventarstücke. Der einleitende Abschnitt des zweiten Bandes beantwortet Fragen nach Verträgen zwischen Auftraggebern und Handwerkern, nach Planungsabläufen, Entwerfern, Entwürfen und Modellen sowie nach der Arbeitsteilung zwischen Tischlern, Bildhauern und anderen Gewerken. Ein weiterer Abschnitt ergründet, inwieweit barocke Sakralmöbel in das jeweilige räumliche Ambiente integriert waren und als maßgebliche Komponenten eines »Raumkunstwerkes« angesehen 
werden müssen. Unstreitig waren sie bedeutsame Elemente der Selbstinszenierung hoher Kirchenfürsten, wohlhabender Klöster und großer Orden. Das Schlusskapitel der Einführung präsentiert Hinweise zu stilistischen Charakteristika von Möbeln der österreichischen Kunstlandschaften. Wie schon der erste Band beruht auch der nun vorliegende auf der Erforschung des Denkmälerbestandes sowie auf ausgewählten Schriftquellen, die zum Teil erst neu erschlossen wurden.

Der zweite Hauptteil der beiden Bücher beinhaltet einen Katalog mit einer umfassenden Analyse exemplarischer Tischlerarbeiten. Sie basiert auf der Untersuchung von Chorgestühlen, Beichtstühlen und Kirchenbänken sowie von Sakristei- und Schatzkammermöbeln, doch wurden zu Vergleichszwecken auch Portale und Bibliothekseinrichtungen einiger Klöster in die Forschungsarbeit aufgenommen. Die einzelnen Katalognummern beginnen mit exakten Angaben zu den Maßen und den verwendeten Holzarten. Dann folgt eine Beschreibung der Stilmerkmale der jeweiligen Möbel, wobei erstaunlich große formale Differenzen zwischen den verschiedenen Kunsträumen zu konstatieren sind. Für einige Groß- und Zierformen, die das Aussehen österreichischer Möbel prägen, ließen sich frühere Beispiele aus anderen Kunstlandschaften ermitteln. Außerdem wird selbstverständlich auf Veränderungen an den Möbeln im Zuge früherer Restaurierungen, Umformungen und Rekonstruktionen hingewiesen.

Bis vor wenigen Jahren wurden Sakralmöbel vor allem wegen ihrer Funktion geschätzt, ihr kunst- und kulturhistorischer Wert galt als sekundär. Als Folge davon finden Möbel selbst in vielen monographischen Studien zu Sakralbauten keinerlei Beachtung. Und noch immer gilt es, Kirchen- und Gemeindevorstände dafür zu sensibilisieren, dass es auch ländliches Mobiliar wert ist, geschützt und erhalten zu werden, verkörpert es doch die Leistungen von Handwerkern in Regionen, die weitab von jedem Kunstzentrum liegen. Das ist mit ein Grund dafür, dass in die vorliegende Studie auch einige rurale Möbelgarnituren aufgenommen wurden, womit die Studie vielleicht stärker volkskundlich ausgerichtet ist, als man das von einer kunsthistorischen Forschungsarbeit erwarten würde. Hinzu kommt, dass die beiden Bände nur durch diesen methodischen Ansatz ihrem Anspruch gerecht werden, einen generellen Überblick über die stilistische Entwicklung des sakralen Barockmobiliars in Österreich zu liefern.

\section{Auftraggeber und Finanziers der Ausstattungen}

So wie es in Österreich vor allem die Orden waren, die im Mittelalter bedeutende Kirchenbauten errichteten, so waren sie es in erster Linie, die in der Barockepoche die Renovatio und den Neubau großer Sakralanlagen veranlassten. Gleichzeitig wurden aber auch Weltkirchen barockisiert und mit neuen Altären, Fresken und Möbelensem- 
bles ausgestattet. Tischlererzeugnisse wurden von den verantwortlichen Weltgeistlichen oder von den jeweiligen Bürgerschaften in Auftrag gegeben, wie in Verbindung mit dem Chorgestühl der Pfarrkirche St. Veit zu Krems gezeigt werden konnte. ${ }^{1}$ Die Kommittenten übernahmen natürlich die Finanzierung der Arbeiten. Darüber hinaus trugen das Kaiserhaus, die zuständigen Landesregierungen sowie der hohe Adel zur Deckung der immensen Kosten bei, die bei der Herstellung der sakralen Interieurs anfielen. Ein Beispiel hierfür ist die Errichtung der Karlskirche in Wien, ein anderes die Barockisierung des Zisterzienserstiftes zu Stams, ein drittes der Bau der Wallfahrtskirche Mariae Geburt in Frauenkirchen. ${ }^{2}$ Schließlich erhielten die Kirchen gelegentlich von bürgerlichen Mäzenen zweckgebundene Spenden zur Anschaffung einzelner Möbelgarnituren. In Verbindung mit dem Laiengestühl der Piaristenkirche zu Krems, das ein unbekannter Mäzen gestiftet hat, konnte das ebenso beschrieben werden wie für die Bänke der Welschen Kirche in Graz (Abb. I 85, r 86), für deren Anschaffungskosten ein gewisser Donatus Johannes Baptist Vanustele I 738 aufkam.

\section{Wer WAREN Die Tischler?}

Im Zuge der vorliegenden Recherche hat sich herausgestellt, dass die für den Bau von Kirchenmobiliar verantwortlichen Tischler oft anonym bleiben. Möbelgarnituren für Weltkirchen wurden in der Regel von Tischlern in der jeweiligen Gemeinde gefertigt, Möbel für Abteien häufig von Stiftstischlereien, in denen Laienbrüder und externe Handwerker tätig waren. In diesen Fällen konnte auf schriftlich abgefasste Arbeitsaufträge verzichtet werden, schon allein deshalb existieren zu vielen Möbelensembles keine archivalischen Belege. Darüber hinaus waren im ausgehenden I 8. Jahrhundert bei der Aufhebung der Klöster enorme Verluste an Archivalien zu verzeichnen. Mit etwas Glück beinhalten aber Stiftschroniken, Nekrologe oder Nachweise über finanzielle Aufwendungen Einträge mit den Namen der Stiftstischler und externen Mitarbeiter. Die Abtei Lilienfeld liefert hierfür ein gutes Exempel. Laienbrüdern war durch das

I In diesem Kapitel werden neben St. Veit die Stifte Altenburg, Dürnstein, Garsten, Göttweig, Heiligenkreuz, Klosterneuburg, Kremsmünster, Lambach, Lilienfeld, Melk, St. Florian, Schlägl, das Schottenstift und Seitenstetten erwähnt, weiter die Wiener Augustiner-, Jesuiten- und die Karlskirche, die Piaristenkirche zu Krems, die Domkirche in St. Pölten und die Priesterseminarkirche in Linz. Um den Anmerkungsapparat nicht unnötig aufzublähen, sei nur an dieser Stelle darauf hingewiesen, dass diese Sakralanlagen im ersten Band der Untersuchung vorgestellt werden. Vgl. hierzu die relevanten Abschnitte in Bohr, Sakralmöbel (2017).

2 Wolfgang, Stams (2008), bes. 46-5 r. Zu Stams und Frauenkirchen vgl. außerdem die entsprechenden Abschnitte im Katalogteil. 
Kloster eine lebenslange »Rundumversorgung" garantiert, während weltliche Tischler wie die des Jesuitenordens in Graz, die die Ausstattung der heutigen Domkirche schufen, verköstigt und entlohnt wurden. Ihre Namen scheinen in Rechnungsbüchern auf, in denen Klöster ihre Einnahmen und Ausgaben bilanzierten. Ein atypisches Arbeitsverhältnis wählte die Mönchsgemeinschaft in Göttweig im Falle von Heinrich Johann Holdermann (I697-I739) und seinem Nachfolger Franz Anton Staudinger (I705-I78I). Die beiden Handwerker besaßen eine eigene Tischlerwerkstatt in der am Fuße des Klosterberges gelegenen Ortschaft Furth, waren aber zugleich Leiter der stiftsinternen Tischlerwerkstätte. Holdermann und Staudinger führten Arbeitsbücher, um ihre Leistungen für das Kloster dokumentieren und verrechnen zu können. Neben dem Jahresgehalt für die Anstellung in der Stiftstischlerei erhielten sie nach dem Abschluss der Arbeiten einen Stücklohn. Mit dem garantierten Gehalt und der Ernennung der Handwerker zu Hoftischlern durch den Göttweiger Abt wurden sie an das Kloster gebunden, doch wie die Arbeitsverträge mit ihnen im Detail beschaffen waren, wissen wir nicht. Vermutlich verpflichtete sie der Konvent, im Bedarfsfalle für das Kloster zu arbeiten, was während des Wiederaufbaus der Anlage nach einer Brandkatastrophe von etwa I720 bis nach I740 hinweg durchgehend der Fall war. Ansonsten wird es ihnen freigestanden haben, Aufträge von Dritten anzunehmen. Solch eine Abmachung entspräche etwa dem Status von Hofhandwerkern im Hofdienst. ${ }^{3}$ Gelegentlich wird in der Literatur gemutmaßt, dass die Klöster gute Handwerker ordensintern vermittelt hätten. Tatsächlich begegnet uns I6 I 9 der Kunstschlosser Hanns Walz († um I648) bei der Fertigstellung zweier Portale im Benediktinerstift Kremsmünster und in den I640er-Jahren bei den Benediktinern im Wiener Schottenstift. Der Tischler Kaspar Schrezenmayer (I693-I782) legte I724 im Stift Heiligenkreuz die Profess ab, übersiedelte aber zehn Jahre später in die ungarische Zisterzienserabtei St. Gotthard, um dort sein Handwerk auszuüben. Aus dem ehemaligen Benediktinerstift Garsten wechselten um die Wende vom i 7. zum i 8. Jahrhundert der Bildschnitzer Fr. Marian Rittinger, ferner der Tischler Johann Jakob Pokorny und der Hofmaler Johann Carl von Reslfeld (I658-I 735) in das Benediktinerkloster Seitenstetten. Weiter erhielt der selbständige Tischler Balthasar Melber aus Enns Aufträge von den Benediktinerklöstern Kremsmünster und Lambach, während der ebenfalls in Eigenverantwortung arbeitende Hippolyt Nallenburg (I687-I733) für die ehemaligen AugustinerChorherrenklöster in St. Pölten, Dürnstein und St. Dorothea zu Wien tätig war. Ob selbständige Schreiner von den jeweiligen Klostergemeinschaften empfohlen wurden oder von Baumeistern und Architekten, wäre noch zu ermitteln. Die Handwerker er-

3 Haupt, Hofhandwerk (2007), bes. I 3-I64 und die relevanten Beiträge in Tacke/Fachbach/Müller, Hofkünstler (20I7). 
hielten jedenfalls Aufträge für repräsentative Werkstücke, für weniger anspruchsvolle Arbeiten griffen die Klöster auf Mitarbeiter vor Ort zurück, die in den Quellen oftmals nicht unter ihrem Namen, sondern lediglich als tischler allbier aufgeführt sind. Aber obgleich wir trotz allem Kenntnis von den Namen einiger Tischler besitzen, so lassen sich bisher kaum Angaben über profane Erzeugnisse der Handwerker machen. Denn anders als Bildschnitzer, Stuckkünstler, Maler oder Architekten, deren Arbeiten bestimmte stilistische Charakteristika aufweisen und deren Werke mithilfe der Händescheidung zu einem klar umrissenen CEuvre zusammengefasst werden können, verlieren sich die Spuren der Tischler im Dunkel der Geschichte. Selbst von so bedeutenden Kräften wie den Wiener Hoftischlern Matthias Rueff (I658-17 r 8) und Franz Andreas Bogner (um r663-I7r4), die für Heiligenkreuz resp. Melk arbeiteten, sind keine weiteren Möbel bekannt. Ausnahmen hiervon waren Stephan Jegg (I674-I 749) aus dem oberösterreichischen St. Florian und Simon Thaddäus Baldauf (I677-1753) aus Salzburg, denen zumindest einige weltliche Möbel zugeschrieben werden können.

\section{Wer waren die Entwerfer der Möbelgarnituren ?}

Aus Forschungsarbeiten von Ingeborg Schemper-Sparholz resultiert die Erkenntnis, dass in der Vormoderne weniger bekannten Bildhauern oft nur ausführende Tätigkeiten überlassen wurden, da das Skizzieren der notwendigen Entwürfe in den Verantwortungsbereich höfischer oder akademischer Bildschnitzer gefallen sei. ${ }^{4}$ Das entspricht im Wesentlichen unseren Beobachtungen in Bezug auf den Entstehungsprozess von Tischlerarbeiten. Entwürfe und Risse für Möbel kamen offenbar meist von Architekten oder Baumeistern. Die Möbel waren Teil einer räumlichen Inszenierung, wie anhand des Stiftes Melk, der Wiener Jesuitenkirche oder auch der Innsbrucker Jesuitenkirche (Abb. 302-309) verdeutlicht werden konnte. Modelle ließ man häufig in spezialisierten Werkstätten erzeugen, beispielsweise in der von Johann Gottlieb Hasselmann, der sich in den I76oer-Jahren als »kaiserlicher Modelltischler" in Wien einen Namen machte. ${ }^{5}$ Gleichwohl waren in vielen Fällen die Tischler selbst für das Entwerfen von Möbeln und für das Zeichnen von Rissen zuständig. In Verbindung mit weniger bedeutenden Aufträgen dürften allerdings auch mündliche Absprachen die Planungsgrundlage gewesen sein, die dann eventuell noch in einer Skizze festgehalten wurden. Arbeiten wie die Kirchenbänke im ehemaligen Stift Neuberg (Farbtaf. 23; Abb. 209) oder das Chorgestühl in Gröbming (Farbtaf. 22; Abb. I 87, I 88) erweisen sich in Form

4 Schemper-Sparholz, Barockbildhauer (1992), 333.

5 Haupt, Hofhandwerk (2007), 485; Wagner, Regesten (2014), ad vocem. 
und Auszier als so schlicht, dass ausführliche Vorgespräche, Entwürfe, detailgenaue Risse, geschweige denn aufwendige Modelle überflüssig waren. Den Handwerkern werden in solchen Fällen Anweisungen von Prälaten und Weltpriestern genügt haben, um die Aufträge zu deren Zufriedenheit auszuführen. Konstruktive Erfordernisse, die das Arbeiten mit dem Werkmaterial Holz mit sich brachten, sowie Sehgewohnheiten und Traditionen bestimmten dann das Aussehen des Mobiliars.

\section{Zusammenarbeit von Tischlern mit anderen Gewerken}

Möbel konnten ein Gemeinschaftsprodukt von Meistern aus unterschiedlichen Gewerken sein oder das Erzeugnis eines einzelnen versierten Handwerkers, falls er Aufträge für den hohen Adel und den Klerus erledigte, den Titel eines Hofhandwerkers führte oder einen Freibrief erworben hatte. Diese Handwerker waren in Österreich nicht an die Regeln der Zunftordnungen gebunden ${ }^{6}$, womit sie offiziell berechtigt waren, Arbeiten auszuführen, die in den Tätigkeitsbereich unterschiedlicher Berufsgruppen fielen. Meist ist die Auftragsabwicklung beim Bau der Möbel in Archivalien nur schwer und unvollständig nachzuvollziehen, doch wurden in Verbindung mit der Studie auch Möbelensembles untersucht, die erwiesenermaßen in Zusammenarbeit mehrerer Berufsgruppen entstanden. Häufig scheint dann in Archivalien die Kooperation von Tischlern und Bildschnitzern auf, gelegentlich auch die von Tischlern und Schmieden, Vergoldern oder Fassmalern. Die Chorgestühle in den Stiften Klosterneuburg, Dürnstein und Heiligenkreuz sowie in der Grazer Domkirche (Abb. 157) und in der Stadtpfarrkirche zu Bregenz (Farbtaf. 32; Abb. 38o-384) liefern hierfür gute Beispiele. Allerdings kennen wir auch etliche Tischler, die als Bildhauer arbeiteten, und von einigen Bildhauern wissen wir, dass sie als Nebenberuf den des Tischlers ausübten. Vergleichbares gilt für Polsterer und Sattler. ${ }^{7}$ Und wer überzog die Möbel mit einem Firnis oder lackierte sie? Die für die Studie herangezogenen Quellen dokumentieren, dass es nicht ausschließlich Fassmaler waren, denen nach den Zunftregeln solche Arbeiten zustanden, sondern dass dieser letzte Arbeitsschritt beim Bau von Möbeln durchaus auch von Tischlern selbst übernommen werden konnte. Die Sakristeimöbel in Melk bieten hierfür ein ebenso probates Exempel wie das Laiengestühl der Priesterseminarkirche in Linz. Folgerichtig kommen wir wegen des komplexen Beziehungsgeflechtes zwischen den verschiedenen Berufsgruppen nicht umhin, entsprechenden Fragestellungen für jedes Kunstwerk mithilfe von Schriftquellen aufs Neue nachzugehen.

6 Haupt, ebd., bes. I $3-59$.

7 Sangl, Hofschreinerhandwerk (1990), 53. 
Und noch ein weiteres Missverständnis muss an dieser Stelle ausgeräumt werden: Anthony Blunt unterstellt eine Trennung des Tischlerhandwerks in zwei Gruppen. Eine hätte größtenteils aus Konversen bestanden und Kirchenausstattungen produziert, während die andere für die Einrichtungen von Schlössern zuständig gewesen sei. ${ }^{8}$ Diese These trifft lediglich auf eine kleine Minderheit von Tischlern zu. Einer davon war Matthias Steinl (I643/44-I 727 ). Er unterhielt in den I69oer-Jahren in Wien eine Werkstatt, die sich auf die Herstellung sakralen Mobiliars spezialisierte. ${ }^{9}$ Sehr viel häufiger förderten die Recherchen für die vorliegenden Bücher dagegen die Namen von Tischlern zutage, die sowohl sakrale als auch profane Stücke erzeugten. So schufen die bereits erwähnten Heinrich Johann Holdermann und Franz Anton Staudinger in Göttweig Einrichtungsgegenstände für die Stiftskirche und die Klosterräume, wobei zumindest Staudinger, der über viele Jahre hinweg vom Stift keine Aufträge erhielt, auch für private Auftraggeber tätig gewesen sein muss. Wolfgang Rachinger aus Linz, Haustischler des Grafen von Salburg, arbeitete nicht nur für Salburg, sondern hatte an der Ausstattung der Linzer Seminarkirche maßgeblichen Anteil. Weiter wäre auf Stephan Jegg aus St. Florian hinzuweisen, der Möbelensembles für die dortige Abteikirche und profanes Mobiliar für das Kloster baute. ${ }^{10}$ In Verbindung mit dem Interieur der Salzburger Domherrensakristei (Farbtaf. I3; Abb. I I 7-I 20) begegnet uns der Name des Hoftischlers Simon Thaddäus Baldauf, der für Erzbischof Leopold Anton Freiherr von Firmian (reg. I 727-I 744) eine Prunkuhr in Boulle-Technik schuf. ${ }^{11} \mathrm{Wir}$ dürfen mit ziemlicher Sicherheit davon ausgehen, dass sich der Fürsterzbischof von einem Tischler, der über derart außergewöhnliche handwerkliche Fähigkeiten verfügte, nicht nur Möbelensembles für die Metropolitankirche, sondern auch zur Ausstattung seines Palais liefern ließ. ${ }^{12}$ Und schließlich wäre an die Handwerker zu erinnern, die die Sakristeimöbel für die Abteien in Dürnstein und Lambach fertigten, oder an die Tischler, die die Bänke für die Kirchen in Gösseling und Griffen (Abb. 23, 24, 26) schufen. Man benötigte selbstredend keine Spezialisten, um derart rustikales Mobiliar zu zimmern. Schränkte man Blunts These ein und bezöge sie lediglich auf den Bau bedeutender Altäre und prunkvoller Kanzeln, würde eine entsprechende Studie aber vermutlich zu einem anderen Forschungsergebnis führen.

8 Blunt, Kunst (1979), I75.

9 Pühringer-Zwanowetz, Steinl (1966), bes. 24-29.

ıo Wagner, Kunsthandwerk (1999), 577 und Lorenz, GbKÖ (1999), Taf. S. I90 mit einem prachtvollen Schrank, den Franz Wagner, ebd., Jegg zuschreibt.

i I Wagner, Baldauf (1 978).

I 2 Der aus Wien stammende Hofschreiner Franz Anton Herrmann (I7 I I-I770) baute I 764 ein Chorgestühl für den Mainzer Dom und zur gleichen Zeit eine Ehrenpforte anlässlich der Krönung Josephs II. (I74I-I 790) in Frankfurt. Dobras, Hofhandwerker (2017), 33. 


\section{Sakralmöbel und Ambiente}

Private und öffentliche Sammlungen bewahren unzählige Vorlagendrucke auf, die zusammen mit zeitgenössischer Literatur belegen, dass man bei der Ausstattung von Räumen in Schlossanlagen penibel auf die Wertigkeit eines Zimmers innerhalb des Hofzeremoniells achtete. Je bedeutender ein Zimmer im Raumgefüge eines Schlosses war, umso prachtvoller waren die Einrichtungen. $\mathrm{Zu}$ dieser Beobachtung liegt eine ganze Reihe erhellender Untersuchungen vor, während in Bezug auf Sakralräume, die ebenfalls mit einem deutlichen Bedeutungsgefälle behaftet waren, hinsichtlich dieser Fragestellung noch immer große Forschungslücken bestehen. Zwar wurden die Raumhülle, die Freskenprogramme und Gemäldezyklen längst im Hinblick auf diese Thematik interpretiert, doch haben sich bisher vor allem zwei AutorInnen, nämlich Carolyn Renz-Krebber und Sybe Wartena, in ihren Arbeiten über süddeutsche Sakristeischränke und Chorgestühle dem Thema aus der Perspektive des Möbelbaus genähert. ${ }^{13}$ Für Kirchen in Wien wäre in diesem Zusammenhang auf die Dissertation von Franziska Hladky sowie auf die Diplomarbeit von Lucia Laschalt hinzuweisen ${ }^{14}$, doch eine Studie, die sich mit der Gesamtsituation in Österreich beschäftigen und die komplette Ausstattung von Sakralräumen mit Möbeln einbeziehen würde, wurde noch nicht geschrieben.

Recherchen zur vorliegenden Untersuchung ergaben, dass nur in relativ wenigen Fällen seitens der Auftraggeber und Architekten der Anspruch bestand, sakrale Möbel inhaltlich und formal-ästhetisch mit dem Ambiente, für das sie geschaffen wurden, zu verknüpfen. Dennoch dürfen an dieser Stelle einige Ausnahmen nicht unerwähnt bleiben: Die Sakristeischränke in Schlägl sind das früheste Beispiel in Österreich dafür, dass die Größe von Möbelstücken direkt von den Maßen des Raumes bestimmt sein konnte, für den sie gedacht waren. Ein weiteres gutes Beispiel für die Einbindung von Sakristeimöbeln in die Architektur liegt in Altenburg vor, wo die in Nischen eingepassten Aufsatzschränke mit ihrer konkav gewölbten Fassade die ovale Konstruktion der Kuppel über dem Rechteckraum widerspiegeln. Sonst besitzen Paramenten- und Kelchschränke im I7. und I8. Jahrhundert häufig eine Großform, die es gestatten würde, die Möbel in jedweder Sakristei aufzustellen. Gelegentlich nehmen auch Chorgestühle, Beichtstühle und Kirchenbänke eine optische oder gedankliche Verbindung mit dem sie umgebenden Baukörper auf. An Laiengestühlen wären in erster Linie die in der Dreifaltigkeitskirche zu Salzburg zu nennen (Abb. Io6-I Io), die an den seitlichen Außenmauern des Sakralraums entlanggeführt sind und sich so dem Zuschnitt

I3 Renz-Krebber, Sakristeischränke (1998); Wartena, Süddeutsche Chorgestühle (2008).

I4 Hladky, Kirchenmöbel (2003); Laschalt, Sakristeischränke (2012). 
des Kirchengrundrisses anpassen. Es spricht einiges dafür, dass die entsprechenden Entwürfe auf Johann Bernhard Fischer von Erlach (I656-I723) zurückgehen. Weiter können die Bänke in der Wiener Augustinerkirche angeführt werden, die Reliefs mit Sakralgegenständen sowie mit Szenen aus dem Alten und Neuen Testament bereichern. Damit ist das Gestühl durch seine programmatische Aussage an den Standplatz in einem Sakralraum gebunden. Unübertroffenes Beispiel für das harmonische Ineinandergreifen von raumschaffender Architektur, Plastik, Malerei und Möbeln ist jedoch das Chorgestühl in der Melker Stiftskirche. Sowohl durch seine Ausgestaltung mit vergoldeten Reliefs, die denen an den Altären der Kirche ähneln, als auch im Hinblick auf den Inhalt der Darstellungen, die Szenen aus dem Leben des hl. Benedikt versinnbildlichen, ist das Gestühl in das Ambiente integriert. Es könnte nicht entfernt werden, ohne im ikonographischen Programm des Raums eine große Lücke zu hinterlassen. Jedoch wurde Vorsorge dafür getroffen, dass es für immer an der ihn zugedachten Stelle verblieb, denn Stuckarbeiten, mit denen das Gemäuer verziert ist, legen sich über das Abschlussgesims des Möbels und lassen es auf diese Weise zu einem festen Bestandteil der Architektur werden. Allerdings blieb dieses Ensemble in Österreich eine absolute Ausnahme. Vergleichbares sollte nie wieder erreicht, möglicherweise auch nie wieder angestrebt werden. In dieser Hinsicht unterscheiden sich die sakralen Interieurs deutlich von vielen profanen Repräsentationsräumen des fortgeschrittenen I7. und des I 8. Jahrhunderts, bei deren Planung man Wandgestaltung und Einrichtung aufeinander bezog, denn nur so war es möglich, Räume mit einem einheitlichen Gesamtbild zu kreieren.

Was nun den künstlerischen und materiellen Aufwand beim Bau der Möbelgarnituren anbelangt, so lässt sich häufig eine Steigerung von den im Zeremoniell weniger bedeutenden Laienräumen hin zum Hochaltar, dem spirituellen Zentrum des Kirchenraums, feststellen. Während sich die Tischler bei der Herstellung der Laienbänke oft mit einer vergleichsweise einfachen Gestaltung begnügten, wählten sie für die Chorgestühle eine prachtvolle Ausarbeitung. Gute Beispiele für diese Beobachtung bieten die Ausstattungen der ehemaligen Stiftskirchen in St. Pölten und Dürnstein. Der materielle und künstlerische Aufwand steht in einem angemessenen Verhältnis zur vorgesehenen Nutzung. Dabei verblüfft die Tatsache, dass der Prunk nicht nur Möbelgarnituren betrifft, die von allen Kirchgängern gesehen wurden, sondern ebenso Möbel auf Emporen und in Sakristeien, die vor den Blicken der Laien verborgen waren. In solchen Fällen richtete sich der Aufwand offenbar an die eigenen Konventmitglieder und an Ordensangehörige, die die betreffende Abtei besuchten. Diese Möbel dienten der Selbstinszenierung und der Repräsentation nach innen hin. 
Vermittlung und Weitergabeneuer Formen - Österreichische Kunstlandschaften

Im Hinblick auf österreichische Sakralmöbel lassen sich bis gegen Ende des I 7. Jahrhunderts Weichholzmöbel aus alpenländischen und ruralen Regionen von Eiche- und Nussholzmöbeln in den Kunstzentren und wohlhabenderen Landesteilen scheiden. Österreichweit waren die Möbel zunächst mit nordischem Knorpelwerk, dann mit italienischem Akanthus verziert. Erst seit dem späten I7. oder frühen I 8. Jahrhundert zeichnen sich hierzulande einige Kunstlandschaften ab, für die unterschiedliche Stilrichtungen charakteristisch wurden: Im Nordosten sowie in Vorarlberg griff man seit der Jahrhundertwende häufig auf französische oder von Frankreich beeinflusste süddeutsche Dekorationssysteme zurück, während man im Fürsterzbistum Salzburg, in Tirol und in den südlichen Regionen Österreichs Gestaltungsmerkmale bevorzugte, die eine starke Orientierung an italienischen Vorlagen und italienischem Formenvokabular erkennen lassen. ${ }^{15}$ Von der Fachwelt werden diese Erkenntnisse seit langem geteilt, im Hinblick auf den überregionalen Kunsttransfer weist die Forschung generell Frankreich und Italien die Rolle des gebenden und Österreich die des empfangenden Kunstraums zu. Für verschiedene Kunstgattungen mag diese These zutreffen, in Verbindung mit dem Möbelbau gilt sie jedoch nur eingeschränkt. Denn sie ignoriert das Faktum, dass im I6., I7. und I8. Jahrhundert eine ganze Reihe von Tischlern aus dem deutschen Sprachraum in Italien und Frankreich als Mitarbeiter in Tischlereien Beschäftigung fand, falls sie dort nicht sogar eigene Werkstätten unterhielten. Die außerordentlichen Leistungen der Hofwerkstätten in Florenz oder Paris wären ohne das Zutun der fremden Handwerker kaum möglich gewesen. Dieser Sachverhalt ist schon lange bekannt, doch müsste er mit der Frage einhergehen, ob der Kunsttransfer unter dieser Voraussetzung wirklich nur von Süden und Westen nach Norden und Osten verlief. Da die emigrierten Tischler in der Fremde neben ihrer überragenden handwerklichen Kompetenz vermutlich auch ihre jeweiligen ästhetischen Stilvorstellungen wenigstens ansatzweise einbrachten, dürfte die Annahme eines einseitigen Kulturtransfers die Rezeptionsgeschichte des Möbelbaus nur unkorrekt wiedergeben. De facto werden in den Schatzkammern von Klöstern und Museen etliche Reliquiare und Kabinettschränke aus der vorbürgerlichen Epoche aufbewahrt, deren Lokalisierung der Provenienzforschung enorme Probleme bereitet. In vielen Fällen werden die Exponate ungenau als »süddeutsch oder norditalienisch« bezeichnet, da sich Inven-

I5 In Bezug auf den österreichischen Möbelbau wäre überdies nach künstlerischen Einflüssen aus Regionen des östlichen Mitteleuropas und Südosteuropas zu fahnden. 
tarstücke aus den beiden Kunsträumen formal mitunter kaum unterscheiden. ${ }^{16}$ Aus welcher Richtung die ausschlaggebenden stilistischen Impulse kamen, ob aus dem Norden oder aus dem Süden, ist bislang oft nicht zu klären. Sicher können wir allerdings im Hinblick auf andere Inventarstücke sein: Gemeint sind toskanische Möbel, die mit Flammleisten verziert sind. Ohne den unmittelbaren Einfluss süddeutscher oder österreichischer Handwerker ist der Gebrauch der Zierleisten in dieser Region Zentralitaliens nicht überzeugend zu erklären. ${ }^{17}$ Es wäre mithin zu ergründen, ob die Stilentwicklung des Mobiliars nicht auf reziproken Wirkungsprozessen beruhte und sehr viel komplexer war, als in der Vergangenheit dargestellt. Bisher klammerte die deutschsprachige Forschung diese Möglichkeit nahezu komplett aus. ${ }^{18}$

Als Konsequenz aus dem internationalen Austausch von stilbildendem Formenvokabular lassen sich manchmal Überlagerungen vielfältiger Stilmerkmale und formaler Ausdrucksmöglichkeiten feststellen, gelegentlich wohl auch eine gewisse Vereinheitlichung des Stilcharakters. Doch bedeutet das nicht, dass es innerhalb eines großen und relativ gleichförmigen Kunstraums nicht auch Auftraggeber gegeben hätte, die bereitwilliger als andere fremde stilistische Artikulationsmöglichkeiten übernahmen oder sie im Gegenteil auch ablehnten. Vergleichbar mit dialektalen Sprachvarietäten ist innerhalb der österreichischen Kunstproduktion bei allen Übereinstimmungen auch mit autochthonen Entwicklungstendenzen zu rechnen, die die Grenzen vorgegebener Muster überwanden und regionalspezifische Ausformungen von Möbeln zur Folge hatten. Die Bänke in Gröbming, Pürgg und Frauenberg (Farbtaf. ı 7; Abb. I 96, 232) sprechen hierfür eine ebenso deutliche Sprache wie das Mobiliar im Stift Schlägl, die Tischlerarbeiten in St. Paul (Abb. 57, 6o) oder die Möbel in Nordtirol (Abb. 287-289, 3 I 5, 335 usw.). ${ }^{19}$ Bei solch ausgefallenen Formen und Motiven handelt es sich um eigenständige stilistische Entwicklungen in eingegrenzten räumlichen Arealen, in den übrigen Regionen Österreichs sind diese Stilmerkmale weniger stark ausgeprägt, wenn nicht sogar unbekannt. Gleichwohl rückt die moderne Geschichtswissenschaft zunehmend von der Vorstellung regionaler oder innerstaatlicher Kulturräume ab, um Kunstobjekte im europäischen, ja sogar außereuropäischen Kontext zu verorten, was schon alleine im Hinblick auf die Tischler in der habsburgischen Residenzstadt als

I6 Hierzu etwa KHM, Schatzkammer (I99I), 246-250, Kat. 30-38; Haag, Meisterwerke (20 I0), I I 4-I I 5.

I7 Eines der frühesten italienischen Möbel mit einer entsprechenden Dekoration ist ein im Palazzo Vecchio zu Florenz aufbewahrter Kabinettschrank von I630/35. Giusti, Splendori (1 988), I 48-I 49.

I8 Vgl. hierzu auch die relevanten Beiträge in Möseneder/Thimann/Hofstetter, Barocke Kunst (20I4). Die

These von Berthold Haendcke, der beinahe die gesamte italienische Kunst von der Gotik bis zum Barock - und zwar sowohl die arti maggiori als auch die arti minori - unter dem Einfluss nordischer Künstler entstanden sieht, kann an dieser Stelle getrost übergangen werden. Haendcke, Einfluss (r 925 ).

I9 Bohr, Kunsttransfer (2019), I66-I 79 . 
zweckmäßig erscheint. Zwar wurde bislang noch nicht abschließend geklärt, welche Erzeugnisse die Werkstätten von Wiener Hofschreinern und "Galanterietischlern« verließen ${ }^{20}$, doch ist davon auszugehen, dass sie sich in direkter Konkurrenz zu ihren Kollegen aus anderen österreichischen Kunstzentren sowie aus Prag, Augsburg, Mantua und weiteren Städten mit florierendem und hochstehendem Tischlerhandwerk sahen. In Verbindung mit Kirchenmöbeln, nicht nur mit österreichischen, wäre ein methodischer Ansatz, der den Blick über die Landesgrenzen hinweg fördert, sicher lohnenswert.

\section{Fazit und Ausblick}

Um den Kreis zu schließen und die vielen Facetten, die das Thema bietet, zu einem Gesamtbild zusammenzuführen, steht noch eine Bearbeitung der Einrichtungen barocker Bibliotheken aus. Kunsthistoriker gehen in der einschlägigen Literatur zwar auf ikonographische Programme in den Räumen ein, nur selten jedoch auf die Tischlerarbeiten. Wie Sakralmöbel wurden auch Bibliotheksmöbel in der näheren Umgebung der heutigen Standorte gefertigt. Damit bilden diese Interieurs eine ideale Schnittstelle zwischen sakralem Mobiliar und rein profanen Exemplaren. Mithilfe der Bibliotheksausstattungen kann überprüft werden, ob sich Inventarstücke aus dem profanen Bereich hinsichtlich ihrer stilistischen Besonderheiten im Gleichklang mit den Kirchenmöbeln entwickelten. Das ist prinzipiell zu erwarten, muss aber noch verifiziert werden, zumal die bisherigen Recherchen einen bemerkenswerten Unterschied erkennen lassen: Während nämlich profane österreichische Möbel in der gesamten Barockzeit furniert und mit Intarsien verziert wurden, verzichtete man an sakralen Stücken in den Jahrzehnten zwischen I630 und I700 in der Regel auf solchen Dekor. Die sakralen Exemplare jener Periode bestehen häufig aus Massivholz oder sind mit dickem Furnier überzogen, oft auch mit Schnitzarbeiten aufgewertet, jedoch kaum intarsiert.

Darüber hinaus wird der einleitende Teil des geplanten dritten Bandes von österreichischen Zünften handeln und sich der Lebensrealität der Tischler widmen, deren Handwerk wie jenes der Bäcker, Schneider oder Schmiede zu den sogenannten Massengewerken gehörte. Forschungen von Franz Wagner, der frühneuzeitliche Wiener Schriftquellen auswertete und auf die Namen von weit über 2000 Tischlern stieß, die in der zweiten Hälfte des I7. und im I 8. Jahrhundert in der Residenzstadt tätig waren, bekräftigen diese Feststellung eindrucksvoll. ${ }^{21}$ Allerdings war die Situation in

20 Wagner, Ebenisten (20 I I).

2I Wagner, Kenntnis (2010), 49. 
der Residenzstadt eine besondere, denn sie ist als direkte Folge des jahrzehntelangen Baubooms zu werten, der in den 168 oer-Jahren nach der Vertreibung der osmanischen Heere aus Österreich in Wien und im Umland der Stadt einsetzte. Für die Zeit davor geben sozial- und wirtschaftshistorische Forschungen Anlass zur Vermutung, dass auch dort Tischlereien in weit geringerer Anzahl angesiedelt waren, als es die oben genannte $\mathrm{Zahl}$ zu suggerieren scheint. ${ }^{22}$

In ihrer Gesamtheit lassen die drei Bände folglich erstmals eine Standortbestimmung österreichischer Barockmöbel zu. Die Tischlererzeugnisse können somit in einen historischen Kontext eingebettet und als Teil der mitteleuropäischen Kunstproduktion verortet werden. Die Studie zu Kirchenmöbeln trägt in Verbindung mit der Arbeit über barocke Bibliotheken dazu bei, die kulturgeschichtliche Dimension österreichischer Möbel aus der Frühen Neuzeit zu begreifen. Eventuell bestimmten sie die Entwicklung des Mobiliars in Mitteleuropa stärker als bislang angenommen.

22 Vgl. hierzu die entsprechenden Angaben im zweiten Kapitel der Einleitung. 


\section{Glossar}

Accoudoir: Auf den $\rightarrow$ Wangen aufliegender Teil des Chorgestühls, Schulterringe. Stehen die Mönche, dienen die Accoudoirs als Armstützen.

Ädikula: $\rightarrow$ Welsches Fenster. Mit Säulen, Pilastern und Giebeln gestaltete architektonische Rahmung eines Fensters, eines Portals oder einer Nische. An Möbeln kommen sie in der zweiten Hälfte des I6. und im I 7. Jahrhunderts häufig als Zierelement von $\rightarrow$ Füllungen vor.

À jour: Durchbrochen gearbeitetes Schnitzwerk.

Akanthusstil: Der aus Italien kommende Stil löste im letzten Viertel des I 7. Jahrhunderts das $\rightarrow$ Knorpelwerk ab. Matthias Echter (1653-1 701/03) aus Graz übernahm es um r680 ebenso in seinen Vorlagenstichen wie einige Jahre später der Wiener Hoftischler Johann Indau ( 65 II690). Um die Wende vom I7. zum I 8. Jahrhundert war es im österreichischen Möbelbau das Ornamentmotiv schlechthin.

Akzessgebete: Gebete des Priesters vor Beginn der Messfeier.

Alberbaum: Bei Jacob Müller ( $555^{0-1} 597$ ) vorkommende Bezeichnung für Pappelholz.

Ambo: Lesepult.

Antependium: Textile, hölzerne oder metallene Verkleidung der Vorderseite, manchmal auch der Schmalseiten des $\rightarrow$ Stipes.

Antiphonarpult: Freistehendes Lesepult für Chorbücher.

Arbeiten des Holzes: Ändert sich die Luftfeuchtigkeit, nimmt Holz Feuchtigkeit auf bzw. gibt Feuchtigkeit ab, wobei es sich ausdehnt oder zusammenzieht, also »schwindet«. Um zu verhindern, dass Flächen dabei reißen oder sich verziehen, werden Kastenmöbel und Türen in $\rightarrow$ Rahmenbauweise hergestellt.

Arabeske: (von italienisch »rabeschi« = Ranken). Als Arabeske wird die naturferne Ornamentik der islamischen Kunst bezeichnet, die aus kalligraphisch angeordneten dünnen Rankenstengeln mit einzelnen akanthusartigen Blättern und Blüten besteht. Tierische oder menschliche Wesen können das Ornament bereichern. Sie ist zwar ein Flächenornament, versucht aber im Gegensatz zur $\rightarrow$ Maureske durch Überschneidungen und Durchbrechungen eine gewisse räumliche Tiefe zu erzeugen.

Armarium: (Wand-)Schrank oder Bibliotheksraum zur Aufbewahrung von Büchern.

Armarius: In seinen Zuständigkeitsbereich fiel in Klöstern die Aufbewahrung von Büchern und Manuskripten.

Aufsatzschrank: Aus Unter- und Oberschrank bestehendes Möbel.

Ausspringende Ecken: Zeitgenössische Bezeichnung für verkröpfte Ecken.

Außenwange: $\rightarrow$ Wange, $\rightarrow$ Docke.

Bandlwerk (Bandelwerk) $\rightarrow$ Laub- und Bandlwerk. 
Bankpult: Kleines kastenartiges Möbel mit schräger Platte $(\rightarrow$ Kastenpult) und vorgebauter Kniebank.

Beschlagwerk: Im späten I6. und zu Beginn des I7. Jahrhunderts war es in Österreich das vorherrschende Ornament. Wichtige Ornamentformen bilden gerade oder gerundete, häufig metallisch wirkende Stege, die auf einen Träger aufgenagelt zu sein scheinen und flach auf der Fläche liegen. Weitere häufige Motive setzen sich aus »Nagelköpfen«, Diamantquadern, Masken und Figuren zusammen.

Betschemel: Kniebank.

Blindholz: In Österreich meist aus einem Nadelholz bestehendes Trägerholz, das mit $\rightarrow$ Furnier überzogen wurde und damit von außen nicht mehr sichtbar war.

Blockintarsien: Zur Herstellung werden Furniere und Stäbe aus unterschiedlichen Holzarten zu einem Holzblock verleimt, von dem dünne Schollen abgesägt werden. So ergeben sich Rechtecke, Dreiecke, Würfel, Mäander oder andere geometrische Gebilde, die einen Rapport entstehen lassen.

Bosse: Erhabenes Binnenfeld einer Fläche, $\rightarrow$ Spiegel.

Bastionsfüllung: Füllung mit $\rightarrow$ Bosse

Boulle-Technik: Besondere, nach André-Charles Boulle (I642-I732) benannte Handwerkstechnik. Aus Elfenbein, Perlmutt, Schildpatt und Metall bestehende $\rightarrow$ Marketeriearbeit, die Boulle auf höchstes handwerkliches und künstlerisches Niveau brachte.

Buffet: Zweiteiliges Möbel mit geschlossenem Unterbau und teilweise oder völlig offenem Aufsatz. Seine Funktion bestand in der Aufbewahrung von Geschirr, Bestecken und Tischwäsche, in Repräsentationsräumen diente das Möbel auch als Schauschrank.

Calix: Kelch.

Cassapanca: Italienischer Möbeltypus. Truhe mit Rückenlehne, eventuell auch mit Armlehnen.

Chorgestühl: Dient den Geistlichen zum Stehen, Sitzen und Knien bei Chorgebet und Eucharistiefeier.

Chorschranke: Eine häufig nur brusthohe, oft aber auch mehrere Meter hohe gemauerte Abschrankung, die den Chor gegen das Langhaus sowie das Mittelschiff eines mehrschiffigen Chors gegen die Seitenschiffe abtrennt. Die Räume von Geistlichkeit und Laien werden dadurch geschieden.

Chorus maior: Größerer oder Oberer Chor der Zisterzienser. Platz der Priestermönche, die am Stundengebet teilnahmen. Er liegt in der Vierung, falls sie denn errichtet wurde, sowie in den östlichen Jochen des Mittelschiffs.

Chorus minor: Kleinerer oder Vorchor. Schließt sich westlich an den Chorus maior an. Dort nahmen $\rightarrow$ Konversen an Chorgebet und Messfeier teil, aber auch alte und kranke Mönche, für die die Teilnahme am Chorgesang nicht obligatorisch war.

Confessarium: $\rightarrow$ Sprechgitter in Beichtstühlen.

Confessionale: Beichtstuhl.

Cordellen: Im Vertrag zur Anfertigung des Laiengestühls für die Stiftskirche zu Rein werden die pilasterartigen Stützen der Brustwände als Cordellen bezeichnet. 
Cosmatenarbeit: Aus dem arabischen Raum stammende Technik, bei der kleine Steinschollen zu geometrischen Motiven in gemauerte Gewände eingelegt werden.

Familiaris: Zur Familie, zum Hause oder zum Kloster gehörig.

Docke: $\rightarrow$ Wange.

Dominikanische Gemeinschaft des III. Ordens: $\rightarrow$ Tertiaren.

Dormitorium: Schlafsaal.

Dorsale: Rückwand.

Dreikonchenanlage: Anders als Apsiden, die in eine Richtung weisen, formen die drei um die Vierung angeordneten halbrunden oder polygonalen Konchen eine Art von regelmäßigem Kleeblatt. Sie weisen also in der Regel nach Nord, Ost und Süd und bilden auf diese Weise einen zentralisierenden Abschluss.

Dreisitz: Levitenstuhl. Sitz des zelebrierenden Priesters und der Diakone im Levitenhochamt. Kam der Dreisitz im frühen Mittelalter als Nische in der südlichen Chorwand vor, wird er seit dem späten Mittelalter aus Holz gebaut und kann alleine oder in Verbindung mit einem $\rightarrow$ Chorgestühl stehen.

Eigenkloster: Von Laien oder Geistlichen auf privatem Grund und Boden gegründetes Kloster, über das der jeweilige Grundherr gewisse Rechte hatte, unter anderem das der Berufung und Absetzung der Ordensgeistlichen. Damit konnte die Abtwahl direkt und indirekt beeinflusst werden. Vgl. hierzu auch $\rightarrow$ Exemtion.

Epistelseite: Die Südseite des Chorraums einer geosteten Kirche.

Evangelienseite: Die Nordseite des Chorraums einer geosteten Kirche.

Exemtion: Hier die Ausgliederung eines Klosters (etwa Göttweigs oder Melks) aus der Jurisdiktion der eigentlich zuständigen Instanz (früher das Passauer Bistum) und Unterstellung des Klosters unter die nächsthöhere oder eine andere Instanz (im Falle Göttweigs und Melks unter den päpstlichen Stuhl). Vgl. hierzu auch $\rightarrow$ Eigenkloster.

Fassadenschränke: Schränke aus dem späten I6. und I7. Jahrhundert, deren Vorderseiten wie Architekturfassaden konzipiert sind. Architekturbücher für Schreiner sorgten unter den Handwerkern für das nötige Verständnis der klassischen Architekturtheorie.

Flammleisten: Profilstäbe mit gewellter Oberfläche. Selten wird zusätzlich zwischen Wellen und Flammleisten unterschieden. Unter Wellenleisten versteht man dann Profilstäbe, deren Oberfläche in nur einer Richtung schwingt, unter Flammleisten Profile, deren Oberfläche mehrere Richtungen bewegt ist.

Frankfurter (Wellen-)Schrank: Der Name »Frankfurter (Wellen-) Schrank« oder »Zürcher Schrank« ist als Bezeichnung für einen bestimmten Möbeltypus zu verstehen, nicht als Hinweis auf die Provenienz. Diese Möbel wurden im ausgehenden I 7. und im I 8. Jahrhundert vor allem im süddeutschen Raum und in der Schweiz, gelegentlich auch in Österreich gefertigt. An ihren Fassaden sorgt eine Reihe unterschiedlich breiter, querfurnierter Wulst- und Kehlprofile für eine wellenartige Oberfläche.

Frater: $\rightarrow$ Konverse.

Fraterie: An Kreuzgang grenzender Mönchsaal, seitlich des Kapitelsaals. Der Raum liegt unter dem Dormitorium. 
Füllung: Meist dünnes Brett, das an Türen oder Schränken von Rahmen gehalten wird. Es kann auf einer Ebene mit den Rahmen oder auch vertieft bzw. erhöht liegen. Vgl. auch $\rightarrow$ Überschobene Füllung.

Furnier: Dünne, meist aus einem Hart- oder Edelholz bestehende Blätter, die auf einen Holzträger, das $\rightarrow$ Blindholz oder Trägerholz, aufgeleimt werden. Furnierblätter oder dünne Bretter mit einer Stärke von vier oder fünf Millimetern werden in Österreich auch als $\rightarrow$ Schwarte bezeichnet.

Fußwaschungsgang: $\rightarrow$ Kollationsgang.

Gehrung: Beschreibt die Art einer Eckverbindung zweier länglicher Teilstücke, etwa von Türen oder Bilderrahmen. Die Teilstücke stoßen dabei nicht »stumpf«, also mit geraden, sondern mit abgeschrägten Enden aufeinander. Soll beispielsweise ein Winkel von $90 \mathrm{Grad}$ erzeugt werden, so besitzen die Enden beider Teile meist einen Gehrungswinkel von 45 Grad.

Gestaffelte Hallenkirche (Staffelkirche): Bei Architekturen dieses Typs sind die Seitenschiffe etwas niedriger als das Mittelschiff.

Gestühle der »offenen Form«: $\rightarrow$ Zwischenwangen reichen bis unter die $\rightarrow$ Accoudoirs.

Gestühle der "geschlossenen Form«: $\rightarrow$ Zwischenwangen setzen sich als $\rightarrow$ Hochwangen über den $\rightarrow$ Accoudoirs fort.

Gestürzt: Gespiegeltes Furnier.

Geteilte Füße: Basis einer manieristischen Stütze. Die Basis besteht nicht wie üblich aus einem Block, sondern aus zwei nach außen gerichteten Spangen.

Guttae: »Tropfen« unter den Triglyphen eines Gebälks.

Herme: Hermenpilaster. Pilaster, der mit einer Halbfigur abschließt.

Hochwange: Bis unter das Gesims nach oben geführte $\rightarrow$ Wange am $\rightarrow$ Chorgestühl, die die einzelnen $\rightarrow$ Stallen voneinander trennt und das Gestühl in Einzelgehäuse aufteilt. Letzteres kommt namentlich bei Kartäusern vor.

Inginocchiatoio: Italienischer Kniebanktypus. Der Gläubige kniet auf einem liegenden kastenförmigen Segment, das oft wie eine Truhe mit einem Deckel verschlossen ist. Über dem hinteren Bereich des Kastens erhebt sich ein niedriger Schrankaufsatz, dessen Deckplatte als Ablage für das Gebetbuch dient.

In situ: Am ursprünglichen Aufstellungsort erhalten.

Intarsie: Ursprünglich in eine Trägerplatte versenkte Einlage aus gefärbtem Holz, Bein, Elfenbein, Zinn oder einem anderen Material. Sie kann mit der Oberfläche des Trägerholzes auf einer Ebene liegen oder als Reliefintarsie erhaben über der Oberfläche stehen. Im allgemeinen Sprachgebrauch werden allerdings auch $\rightarrow$ Marketeriearbeiten als Intarsien bezeichnet.

Kastenpult: Kleines kastenartiges Möbel mit schräger Platte ohne Kniebank. Vgl. auch $\rightarrow$ Bankpult.

Kastentisch: Niedriger Schrank mit Leerfächern oder Schubladen und einer großen Arbeitsplatte.

Kathedra: Sitz des Bischofs.

Keilstab: $\rightarrow$ Winkelstab.

Kelchfächer: $\rightarrow$ Kelchkästen. Die Patres eines Konvents bewahren dort ihre für den täglichen 
Ritus benötigten Gegenstände wie Kelche, Hostienbehälter u.a. auf. Die Kelchfächer befinden sich im Aufsatz der $\rightarrow$ Sakristei- oder $\rightarrow$ Paramentenschränke.

Kelchkästen $\rightarrow$ Kelchfächer.

Kirchenstuhlschild: An einer Kirchenbank angebrachtes Metall- oder Papierschild mit dem Namen des Besitzers oder Mieters eines Sitzplatzes.

Knieschemel: Kniebank.

Knorpelwerk: Dekorationsstil, der im frühen I7. Jahrhundert $\rightarrow$ Beschlag- und $\rightarrow$ Schweifwerk ablöste. Das Knorpelwerk setzt sich aus abstrakten Gebilden zusammen, die fleischig und weich erscheinen und dabei mit an- und abschwellenden schotenartigen Verdickungen versehen sind. Häufig steht es in Verbindung mit Fratzen und Groteskmasken, oft vermittelt es unterschwellig-erotische Bilder. Seit den späten I 67oer- oder frühen I68oer-Jahren wird das Knorpelwerk vom $\rightarrow$ Akanthusstil verdrängt.

Koinobiten: $\rightarrow$ Zönobiten

Koinobitentum: Monastische Lebensform von Mönchen unter der Aufsicht eines Klostervorstehers und an einem bestimmten Ort.

Kollationsgang: $\rightarrow$ Lektionsgang, $\rightarrow$ Lesegang, $\rightarrow$ Fußwaschungsgang. Teil des Kreuzgangs, der sich an das Seitenschiff der Kirche anlehnt, in Österreich meist der nördliche Flügel des Kreuzgangs. Zisterziensern dient er der Lesung vor der $\rightarrow$ Komplet, in manchen Klöstern findet dort am Gründonnerstag außerdem die Fußwaschung statt.

Kollegiatkapitel: Leitet ein $\rightarrow$ Kollegiatstift. Für die Durchführung von Stundengebet und Konventmesse in der Stiftskirche zuständige Weltkleriker. Im Gegensatz zu Mönchen besaßen sie Privateigentum und lebten in eigenen Häusern oder Wohnungen. Das gemeinsame Leben beschränkte sich meist auf den Chordienst und die Kapitelsitzungen.

Kollegiatstift: Von einem $\rightarrow$ Kollegiatkapitel geleitetes Stift.

Komplet: Schlussandacht oder Nachtgebet.

Konvent: Mönchsgemeinschaft.

Konventuale : Mönch, $\rightarrow$ Zönobit, $\rightarrow$ Koinobit.

Konverse: Frater, Laienbruder. Mönch ohne Priesterweihe. Die Konversen legten Gelübde ab und banden sich dadurch an ein Kloster oder einen Orden, womit sie Teil der Klosterfamilie bzw. der Ordensfamilie wurden.

Kuppelkalotte: Angeschnittene Kuppel, hier meist eine Halbkuppel.

Laden: Mit dem Begriff "Laden« wurden und werden in Österreich noch heute umgangssprachlich dünne Bretter bezeichnet.

Laienbruder: $\rightarrow$ Konverse

Laub- und Bandlwerk: In Frankreich vor allem durch Jean Bérain d. Ä.( I637-I 7 I I) und Daniel Marot (I66I-I752) entwickeltes Ornament, bei dem sich miteinander verflochtene Bänder in Schleifen oder Mäandern über eine Fläche legen. Die Bänder werden von Laubwerk begleitet und enden häufig in Blättern. Tischlerarbeiten werden im Osten Österreichs seit dem ersten Jahrzehnt des I 8. Jahrhunderts mit Bandlwerk verziert, doch nahm der Wiener Juwelier Friedrich Jacob Morisson schon in den I69oer-Jahren Bandlwerk in seine Formensprache auf. 
Lektionsgang: $\rightarrow$ Kollationsgang.

Lesegang: $\rightarrow$ Kollationsgang.

Lettner: Querwand, die den Altarraum und den Chor der Priestermönche vom Laienschiff abtrennt.

Levitenstuhl: $\rightarrow$ Dreisitz

Marketerie: Aus verschiedenen Hölzern oder anderen Werkstoffen zusammengesetztes mosaikartiges Bild, das als Furnier auf einen Träger aufgeleimt wird.

Matutin: Auch Vigil. Sie wird zwischen Mitternacht und dem frühen Morgen gebetet.

Maureske: Verwandt mit der $\rightarrow$ Arabeske, überspinnt sie die Fläche gleichmäßig mit ihrem zartgliedrigen Linienspiel, wobei sie jedoch den plastischen Eindruck vermeidet. Das Ornament setzt sich aus stilisierten Ranken, Blüten und Blättern zusammen, anders als bei der Arabeske kommen keine anderen Motive vor. Die Maureske wurde im I 5 . Jahrhundert durch den Import islamischer Kunstgegenstände in Italien bekannt und fand um I 530 allgemeine Verbreitung. In Ornamentik und Kunstgewerbe war die Maureske vor allem zwischen I 530 und 1550 beliebt.

Miserikordie: Konsole auf der Unterseite des Sitzes im $\rightarrow$ Chorgestühl. Stehen die Mönche beim Chorgesang, werden die Sitze nach oben geklappt. Die Konventualen können sich so während des Stehens abstützen.

Negatives Beizbild: Es entsteht beim Beizen weicher Holzarten. Das dunkle und harte Kernholz nimmt weniger Beize als das helle und weiche Splintholz auf, sodass das Kernholz nach dem Beizen heller erscheint. Der optische Effekt erinnert an eine Negativaufnahme beim Fotografieren.

Ohrmuschelstil: Sonderform des $\rightarrow$ Knorpelwerks im dritten und vierten Jahrzehnt des I7. Jahrhunderts.

Opfergangsportal: Ein Opfergangsaltar, eine besondere Art von Altären, ermöglichte das Umrunden des Altars zum sogenannten Opfergang, bei dem unter anderem gespendet werden konnte. Manche dieser Altäre haben rechts und links je ein Portal, das Opfergangsportal.

Palladio-Motiv: Gruppe dreier Öffnungen, wobei die mittlere mit einem Rundbogen und die seitlichen waagrecht schließen.

Paramente: Oberbegriff für die bei der Eucharistiefeier verwendeten Textilien: liturgische Gewänder und Insignien sowie jene Textilien, die zur Ausstattung von Altären und sakralen Gerätschaften benötigt werden. Die liturgischen Farben der Paramente orientieren sich am Kirchenjahr sowie am Anlass der jeweiligen Feier und folgen damit einem festgelegten Kanon.

Paramentenschrank: »Kleider«-, aber auch $\rightarrow$ Sakristeischrank, der häufig aus einem Unterschrank mit Schubladen für Textilien sowie einem weniger tiefen Aufsatz mit $\rightarrow$ Kelchfächern besteht. Manchmal folgt auf die Kelchfächer noch eine Reihe von Oberschränken für die hängende Aufbewahrung von Paramenten oder die Unterbringung großformatiger Altargarnituren.

Paramententisch: Tisch in einer Sakristei zum Auslegen der Messgewänder. In der Barockzeit wurde er häufig durch einen $\rightarrow$ Kastentisch ersetzt. Vgl. auch $\rightarrow$ Prothesis. 
Pasticcio: Hier im Zusammenhang bezeichnet der Begriff ein Möbel, das aus Teilstücken verschiedener älterer Möbel zusammengesetzt wurde.

Peinture en bois: Mosaikbilder, die Blumenstillleben, szenische Darstellungen, Innenräume, Landschaften oder Ähnliches aus verschiedenen, zum Teil gefärbten Hölzern wiedergeben.

Piedestal: Sockel, Postament.

Piedestallo: $\rightarrow$ Piedestal.

Pönitent: Der Beichtende oder Büßende.

Pönitentiar: Der Beichtvater.

Presbyterium: Altarraum.

Profess: Gelübde.

Prothesis: In Sakristei stehender Tisch, auf dem die für die Eucharistiefeiern notwendigen Sakralgegenstände vorbereitet werden. Vgl. auch $\rightarrow$ Paramententisch in der Kirche.

Psallierchor: Den Geistlichen vorbehaltener Raumabschnitt.

Rahmenbauweise: Konstruktion aus Rahmen und $\rightarrow$ Füllungen, die Holzspannungen entgegenwirkt und das Reißen des Holzes verhindern soll. Vgl. auch $\rightarrow$ Arbeiten des Holzes.

Refektorium: Speisesaal.

Reihenbeichtstuhl: Im Gegensatz zu Einzelbeichtstühlen mit einer $\rightarrow$ Stalle für den Priester und einem oder zwei Gehäusen für die Beichtenden formen Reihenbeichtstühle ein einziges langes Möbel mit einer Vielzahl von Zellen.

Reihengestühl: Die in Österreich am häufigsten vorkommende Gestühlsform. Es besteht aus einer Aneinanderreihung gleichartiger $\rightarrow$ Stallen und könnte im Prinzip gekürzt oder verlängert werden, ohne dass dies seiner Form abträglich wäre.

Rezessgebete: Gebete, die der Priester am Ende der Messe spricht.

Rollwerk: Ein Ornament mit aufgebogenen oder volutenförmig eingerollten Rändern und dreidimensional gestalteten Endungen. Stuckarbeiten in Fontainebleau waren seit den I 53 oerJahren für die Verbreitung des Rollwerks von immenser Bedeutung. Das Ornament wurde mit der Zeit plastischer, es wurde knorpelig und teigartig, womit es auch im fortgeschrittenen I 7. Jahrhundert noch eine wichtige Rolle zu spielen vermochte.

Sakristeischrank: $\rightarrow$ Paramentenschrank. Die Begriffe werden oft synonym verwendet.

Salomonika (Salomonica): Säule mit gewundenem oder gewendeltem Schaft.

Sarbaum: Bei Jacob Müller (I550-I597) vorkommende Bezeichnung für Pappeln oder Pappelholz.

Schildpatt: Aus dem Panzer der Karettschildkröte gewonnene Hornplatten, die gesägt, geschliffen und gedrechselt werden können. Es wurde unter anderem als Möbelfurnier verwendet, häufig bei Arbeiten in der $\rightarrow$ Boulle-Technik.

Schultermesser: Die Klinge des Werkzeugs steckt in einem langen Schaft, dessen Ende beim Schneiden auf die Schulter gelegt wird. Beim Arbeiten kann dadurch ein stärkerer Druck auf das Messer ausgeübt werden.

Schwarte, schwarten: In Deutschland werden so die äußersten Bretter bezeichnet, die von einem Stamm geschnitten werden und größtenteils aus Splintholz und Rinde bestehen. In schrift- 
lichen Beiträgen aus Österreich findet sich der Begriff »Schwarte« aber auch in Verbindung mit $\rightarrow$ Furnier, das eine Stärke von etwa einem halben Zentimeter oder mehr aufweist.

Schweifung: Wellenförmige Gestaltung von Möbelteilen.

Schweifwerk: Mit dieser Ornamentform wurden in den Jahrzehnten um r6oo häufig Kunstobjekte verziert. Es besteht aus einer Verbindung von relativ starrem $\rightarrow$ Beschlagwerk und bewegten C- und S-Bögen, deren Enden sich keulenähnlich verdicken können.

Scenae frons: Architektonisch gegliederte Bühnenrückwand.

Sedile: Sedilie. Sitz oder Stuhl des die Messe lesenden Priesters, der Diakone und der Messdiener.

Serliana: „Palladio-Motiv«. Sie besteht aus einem großen mittleren Bogen und zwei seitlichen Öffnungen, die schmaler und niedriger sind.

Sessio: Sitz oder $\rightarrow$ Stalle.

Skriptorium: Schreibstube.

Speisgitter: Kommuniongitter, Kommunionbank. Schranke mit Kniebank zwischen Altar- und

Laienraum. Den knienden Gläubigen wurde hier das Sakrament der Kommunion gespendet.

Spiegel: Die ebene Oberfläche einer $\rightarrow$ Bosse.

Sprechgitter: $\rightarrow$ Confessarium. Gitter, das die Öffnung in den Trennwänden zwischen den Gehäusen von Geistlichen und Pönitenten verschließt.

Stalle: Synonym für Sitz. In der Mehrzahl verwendet, kann der Begriff »Stallen« aber auch als Bezeichnung für das gesamte $\rightarrow$ Chorgestühl stehen.

Stipes: Altarunterbau. Auf ihm liegt die Mensa, die Altarplatte.

Subsella: Sitz.

Tabernakelsekretär: Umgangssprachlich für ein Schreibmöbel, das aus einem kommodenförmigen Unterbau, einem Mittelfach mit Schreibplatte und kleinen Laden für Briefe und Schreibgeräte sowie einem hohen Aufsatz mit einem von Laden umgebenen mittleren Fach besteht.

Tableau: Hier im Zusammenhang werden damit Schnitzaufsätze bezeichnet.

Tempietto: Kleiner Tempel, über rundem oder polygonalem Grundriss errichtet.

Tertiaren: Dominikanische Gemeinschaft des III. Ordens. Die Mitglieder der Gemeinschaft lebten nach einer vereinfachten Form der Ordensregeln oder waren lediglich als Laien an die Kommunität gebunden.

Triglyphe: Dreischlitzplatte am Fries eines dorischen Gebälkes.

Trophées d'Église: Stuck- oder Holzornamente, die an Stoffbändern hängende liturgische Ausstattungsstücke zeigen.

Trompe l'œil-Darstellung: Illusionistisches, das Auge täuschendes Bild.

Truhenbank: Mit einer hohen Rückwand, gelegentlich auch mit Armlehnen versehene Truhe.

Überbauschrank: Möbeltyp, bei dem auf einem Unterschrank ein niedriger, schmaler und in der Tiefe zurückversetzter Aufsatz zu stehen kommt. Sein Haupt besitzt die Größe der Substruktion und wird von Säulen, Pfeilern oder $\rightarrow$ Hermen getragen.

Überschobene Füllung: $\rightarrow$ Füllung, die nicht auf einer Ebene mit den Rahmen oder vertieft liegt, sondern erhaben nach vorn steht, da sowohl die Kanten der Rahmen als auch jene 
der Füllung Nuten besitzen. Die Möbelteile werden ineinander gesteckt und so miteinander verzahnt.

Umleimer: Furnierstreifen auf den Kanten einer Holzplatte. Der Begriff findet im modernen Möbelbau Verwendung.

Vasa non sacra: Liturgische Gefäße, die bei der Eucharistiefeier benötigt werden, z. B. Weihwasserkessel, Kerzenleuchter, Weihrauchfass, Weihrauchschiffchen usw.

Vasa sacra: Geweihte liturgische Gerätschaften, die wie Patene, Messkelch, Opferschale, Monstranz, Versehgarnitur usw. als Gefäße für die gewandelten Hostien und den gewandelten Wein dienen.

Wange: Vertikal stehende Holzbohlen an Tischen, $\rightarrow$ Chorgestühlen oder Kirchenbänken. An den Wangen der Sitzmöbel werden $\rightarrow$ Stallen sowie Sitz- und Kniebänke befestigt, außerdem tragen sie die $\rightarrow$ Accoudoirs der Chorgestühle

Waschkasten: Möbeltypus, der seit der Renaissance im größeren süddeutschen Kunstraum zu finden ist. Meist hoher und schmaler Schrank mit geschlossenem Unterbau, offenem Mittelteil und geschlossenem Oberschrank. Das Möbel ist mit einem Gießgefäß, einem kleinen Waschbecken und einem Eimer versehen, der das abrinnende Wasser auffängt. Häufig sind diese Möbel fest in eine Wandverkleidung eingebaut, kommen aber auch frei stehend oder in Verbindung mit einem $\rightarrow$ Buffet vor.

Wasseralbenholz: Zeitgenössischer Ausdruck für Pappelmaserholz.

Welsches Fenster: Zeitgenössischer Ausdruck für $\rightarrow$ Ädikula.

Weltgeistliche: Geistliche, die keinem Orden angehören.

Weltkirche: Kirche, die sich nicht im Besitz eines Ordens befindet.

Winkelstab: Geometrischer Körper, der meist aus einem länglichen Sechseck besteht.

Zönobiten: Als Zönobiten oder $\rightarrow$ Koinobiten werden in einem Kloster lebende Mönche bezeichnet.

Zwischenwange $\rightarrow$ Wange. Trennt am $\rightarrow$ Chorgestühl die $\rightarrow$ Stallen voneinander. 


\section{Ortsindex}

Admont: 40, 255, 26I-263, 3I 2

Altenburg: 57, 59, 62, 553, 558

Altenstadt, Dominikanerinnenkloster: $\rightarrow$

Feldkirch-Altenstadt

Angerburg (Węgorzewo): 335

Augsburg: 36, 202, 268, 368, 396, 430, 437, 562

Augsburg-Göggingen: 529

Bad Mehrn, Filialkirche hl. Bartholomäus: 63, 70,

83, 419-424, 458, 490

Bad Reichenhall: 58, 398

Bad Windsheim: 40

Bamberg: 22, I 22, I7 I

Baumgartenberg: 40, 43, 55, 69, 75, 80, 342

Berlin: 22

Birnau: 82

Braunau: 3 I 2

Bregenz: 533,525

Bregenz, Stadtpfarrkirche St. Gallus: 73, 87,

$$
\text { 525-532, } 533,556
$$

Breitenbach: 460

Brixen: 478,483

Brixlegg, Pfarrkirche Unsere Liebe Frau: 56, 424- $^{-}$ 430, 440, 46I, 469-477

Cleveland (USA, Ohio): 72

Commezzadura: 162

Donauwörth: 487

Dornbirn, Stadtpfarrkirche hl. Martin: 532-534

Dürnstein: $27,30,33,35,37,38,43,46,5$ I , 52, 54, $57,6 \mathrm{I}, 63,65-67,69,72,73,75,77,79,325,375$, $404,553,554,556,557,559$

Ebrach: 365

Eisenstadt, Rektoratskirche St. Michel: 93-98, Iо I

Escorial: 155

Feldkirch-Altenstadt, Dominikanerinnenkloster: I $26,534-540,548$

Feldsberg (Valtice): 263
Felgen: 263

Fiecht: $\rightarrow$ Vomp-Fiecht

Florenz: $23,27,47,50,449,560$

Florenz, Baptisterium: 85

Florenz, Palazzo Vecchio: $56 \mathrm{I}$

Fontainebleau: 458,570

Frauenberg, Pfarrkirche Mariä Opferung: 46, 83 , $84,255^{-262}, 317,56$ I

Frauenkirchen, Franziskanerkloster: 96, 98-103, $393,450,553$

Friedrichshafen: 82

Friesach, Stadtpfarrkirche hl. Bartholomäus: 85 , II4-II9, 365

Fügen: $48 \mathrm{I}$

Fulda: 4 I 8

Furth (Göttweig): 40, 554

Geras: 325

Göggingen: $\rightarrow$ Augsburg-Göggingen

Gösseling, Filialkirche hl. Michael: I20-I22, 557

Göttweig: I 8, 27, 29-31, 35, 36, 40-43, 48, 52, 57 , 62, 69, 71 , 72, 75, 76, І І03, I I 8,2 I 7, 484, 553, $554,557,566$

Granada: 263

Graz: 21, 30, 7 I , 83, 202, 263, 274, 293, 301, 309, 3 Iо, $334,348,365,383,564$

Graz, Barmherzigenkirche: 59, 263-272

Graz, Dom- und Pfarrkirche hl. Ägidius: 21,28 , 30, 38, 46, 52, 58, 7 I , 72, I32, 26I , 272-289, $29 \mathrm{I}$, 296, 308, 3 I0, 355, 37 I , 375, 4I 2, 554, 556

Graz, Franziskanerkloster: 289-292

Graz, Mariatrost: 26I, 292-305

Graz, St. Andrä: 305-309

Graz, Welsche Kirche: 309-3I2, 553

Grein: 30

Griffen: 122

Griffen, Alte Pfarrkirche Unsere Liebe Frau:

I22-I25, 557

Griffen, Pfarrkirche Mariä Himmelfahrt: 75, I 25-I 29, I 72, 540 
Gröbming, Pfarrkirche Mariä Himmelfahrt: 46, 84, $262,312-323,340,342,36 \mathrm{I}-363,492,555,56 \mathrm{I}$

Güns (Köszeg) : 273

Güssing: IO3

Gurk: I 30, I 3 I, I 46

Gurk, Konkathedrale und Pfarrkirche Mariae

Himmelfahrt: 37, 60, 62, 129-146, $29 \mathrm{I}$

Hall: $48 \mathrm{I}$

Heiligenkreuz: 43, 44, 53, 55-57, 62, 66, 69, 71, 72, 75,76, I03, I32, I48, 274, 294, 333, 342, 349, $553-556$

Herzogenburg: 75, 2 I I

Hirsau: I 54

Horn: 43, 52

Innsbruck: $36,76,8$ I , 83, 425, 443, 449, 456, 458, 489

Innsbruck, Hofkirche: 56, 70, 82, 430-436, $45^{8}$

Innsbruck, Jesuitenkirche: I 8, I 9, 2 I, 50, 63, 70, $8 \mathrm{I}, 82,200,243,426,437-449,455,45^{8}, 46 \mathrm{I}$, $467,472,473,5$ 1 9, 522, 523, 547, 555

Innsbruck, Servitenkloster: 70, 83, 84, I 70, 422, 443, 449-459, 490

Innsbruck, Spitalskirche: 82, 440, 489

Innsbruck, Ursulinenkirche: 489

Jerusalem: 85

Kaisheim: 487, 500

Klagenfurt: 83, I 30, I 46

Klagenfurt, Dom- und Stadtpfarrkirche St. Peter und Paul: 80, I 34, I46-I 5 I, 4 I 7

Klosterneuburg: 27, 30, 35, 39, 4I-43, 5 I, 57, 553 , 556

Konstanz: 4I, I 5 I, 53 I

Kramsach: $\rightarrow$ Maria Thal

Krems: 3 I, 53

Krems, Piaristenkirche: 43, 55, 57, 60, 69, 72, 75 , 76, I I 7, 553

Krems, St. Veit: 27, 32, 43, 53, 57, 62, 66, 69, 229,553

Kremsmünster: 43, 46, 75, 77, 79, I I 7, I 28, I 77, 206, 2 I 5, 257, 276, 383, 472, 553, 554

Kundl, St. Leonhard: 428, 439, 466, 469-477

Laibach (Ljubljana): 30, 274
Lambach: 27, 30, 43, 46, 75, 79, I 28, 2 I 5, 276, 553 , 554, 557

La Verna: 100

Leibnitz: 348

Lettowitz (Letovice): 263

Lilienfeld: $35,39,52,57,58,62,66$, I I 7, I 88, 45 2, 454,553

Linz: $34,46,77,78,557$

Linz, Jesuitenkirche: 75,78

Linz, Karmelitenkirche: 354, 358, 4I 7

Linz, Priesterseminarkirche H1. Kreuz: 27, 32, $34,43,48,52,75,77,393,553,556,557$

Linz, Stadtpfarrkirche Mariae Himmelfahrt (Liebfrauenkirche) : 78

Lockenhaus, Pfarrkirche hl. Nikolaus: 103-I Io

Loschental, Filialkirche hl. Josef: I 5 I-154, I63, I 64

Lugano: 85,437

Mainz: 36, 39, 380, 557

Mantua: 562

Mariahof, Pfarrkirche hl. Maria: 46, 64, 68, I 20, I 24, 323-333, 339, 359, 395, 396, 435, $45^{8}$

Maria Loretto, Pfarrkirche Zur Unbefleckten Empfängnis: I Io-II3, I 20, 330, 545

Maria Plain, Wallfahrtskirche: 5 I, I83-189, 248, 253

Maria Thal (Kramsach), Pfarrkirche hl. Dominus: $63,82,268,440,459-469$

Mariazell: 403

Mattsee: I 92, I 95

Mattsee, Kollegiatstift: I I O, I89-195, 207

Mehrerau: 526-528, 530, 53 I

Meißen: I 34

Melk: 27, 29, 32, 34, 35, 37, 42, 43, 45, 47, 53-55, 57,6 I, 62, 65-67, 69, 7 I, 72, 75-77, 224, 22 5, 294, 448, 532, 553, 555,556,559, 566

Michaelbeuern, Benediktinerstift: 196-206, 207, 249

Millstatt: 359

Montesenario: 449

Mülln, Pfarrkirche zu Unserer Lieben Frau Mariae Himmelfahrt: $\rightarrow$ Salzburg-Mülln

München: 22, 80, 2 I 7

Murau: 342, 439

Neuberg an der Mürz: 335 
Neuberg an der Mürz, Pfarrkirche Maria

Himmelfahrt: 50, 63, 83, 330, 333-347, 390, $435,440,453,45^{8}, 555$

Neumarkt: 46, 255, 324, 387, 389, 391, 393, 394

Nürnberg: $55,536,540$

Oberwölz: 340

Paris: 24, 45, 67, 7 I, 560

Passau: 82, 273, 566

Piber: $36,397,402$

Pielenhofen: 82, 500

Pirna: I 34

Pöllau, Pfarrkirche St. Veit: 36, 50, I 26, 347-359, 409, 540

Prag: I 5 I, 562

Pressburg (Bratislava): 53

Pürgg, Pfarrkirche hl. Georg: 46, 64, 82, 84, 85 , I $62,262,3$ I $7,352,359-365,56$ I

Rein, Zisterzienserstift: $16,27,28,30-32,39,46$, $57,66,73,26$ I , 283, 297, 336, 365-38 I, 4I 2, 4I 4, 524,565

Riedlingen: 525, 53 I

Riva del Garda: 80

Rom: 23, 32, 50

Rom, Il Gesù : 437

Rom, Sankt Peter: 43

Rom, San Giovanni in Laterano: 85

Rom, Sant'Agnese: 2 I 9

Rot an der Rot: 513, 532

Rottenmann, Stadtpfarrkirche hl. Nikolaus: 355 , $381-386$

Salzburg: I 9, 32, 34, 36, 46, 48, 5 I, 69, 77, 79-8 I,

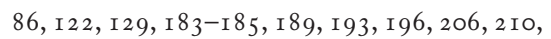
2I I , 2 I 7, 224, 24 I, 244, 246, 250, 3 I 2, 437, 467, $492,555,560$

Salzburg, Benediktiner-Erzabtei: 2 I, 84, I90, 204, 206-2 I 8, 355

Salzburg, Domkirche hll. Rupert und Virgil: I 8, I 9, 2 I , 52, 59, 66, 69, 83, 85, I 83, I 87, 220 , 222, 225, 229-243, 437, 557

Salzburg, Dreifaltigkeitskirche: $48,49,64,72$, 2 I0, 2 I9-229, 246, 440, $55^{8}$

Salzburg, Kollegienkirche : 440

Salzburg, St. Markus: 48, 223, 244-248, 440
Salzburg-Mülln, Pfarrkirche zu Unserer Lieben

Frau Mariae Himmelfahrt: 2 I 2, 248-2 54, 340

Sankt Blasien: I 54, 386

Sankt Florian: 35, 4 I , 43, 55, 60, 66, 67, 69, 7 I, 75, 77, 79, 103, I 57, 440, 532, 553, 555, 557

Sankt Gallen: I 5, 43, 532

Sankt Georgenberg, Benediktinerstift: 2 I, 53, 374, 404, 478-487, 503, 523, $\rightarrow$ Vomp-Fiecht

Sankt Gotthard (Szentgotthárd): 274, 554

Sankt Lambrecht, Benediktinerstift: 2 I, 27, 32, 36, $39,46,57,58,64,66,96,98$, г 24, I 76, 200, 255 , 3 I 4, 3 I 7, 323, 328, 330, 339, 340, 365, 386-404, 490, 543

Sankt Lorenzen ob Murau: 439

Sankt Paul im Lavanttal, Benediktinerstift: 2 I, 68, $77,82,85$, I 34, I 48, I 52 , I 53 , I 54-I 7 I, I 77, 326 , $342,364,56$ I

Sankt Pölten: I 8, 33, 35, 43, 46, 5 I, 54, 57, 60, 6 I, $66,67,69,72,553,554,559$

Schlägl: $57,58,75,77-79,398,553,55^{8}, 56$ I

Schlierbach: 75,80

Schluckenau (Šluknov): 42

Schratenhofen: 459

Schwaz: $425,430,478,479$

Seefeld (Tirol) : 85

Sessa: 85

Stams, Zisterzienserstift: 2 I , 36, 4I, 47, 48, 68, 75, 77, 8 I , 82, I66, I 90, 207, 299, 4I 4, 467, 487-5 I3, $527,528,536,553$

Stanz im Mürztal: 335

Steyr: 30

Straßburg (Kärnten): I30, I35, I 37

Thüringen, St. Anna: 54 I-545

Trient: 449

Triest: 30,274

Trostberg (Bayern): 204-206

Tyrnau (Trnava): 273

Überlingen: 335

Urfahr: 46

Vaihingen an der Enz: I 34

Velden: 85 , I 59, I6o,

Venedig: 22, 7 I, 84, I 52

Veßra: I 22

Verna (Lugano): 437 
Viktorsberg, Pfarrkirche hl. Viktor: $207, \mathbf{5 4 5}-548$

Villach: I75

Villach, Stadthauptpfarrkirche hl. Jakob d. Ä.: $69, \mathbf{I} 7 \mathbf{I}-\mathbf{I} 77$

Völkermarkt, Stadtpfarrkirche hl. Maria

Magdalena: 82, I77-182, 365, 386

Vomp-Fiecht, Klosterkirche: 2 I, 40, 63, 65, 206, 478-487, 503, $\rightarrow$ St. Georgenberg

Vorau, Augustiner-Chorherrenstift: 59, 63, 66, 73, 83, 348, 38 I, 404-4I8, 453

Walchsee: $463,464,468$

Weingarten: $527,531,532$

Weitra: 42

Weiz: 30, 202, 274

Wettingen-Mehrerau: $\rightarrow$ Mehrerau

Wien: I 5, 2 I, 22, 30, 32, 34, 36, 39, 43-45, 49-52, 55,7 I , 76, 77, 83, I 5 I, I 93, 2 I 7, 263, 273, 274, $340,342,4 \mathrm{I} 2,484,503,55 \mathrm{I}, 555,557,55^{8}$, $562-564,568$

Wien, Augustinerkirche: 57, 64, 72, 553, 559

Wien, Dominikanerkirche: 55, 75, 76

Wien, Domkirche $\rightarrow$ Wien, St. Stephan

Wien, Franziskanerkloster: 57, 65, 93, 96, I I I, IO2, $45^{\circ}$
Wien, Hofburg: 24, 43

Wien, Jesuitenkommunität: 57, 64, 273, 553, 555

Wien, Karlskirche: 43, 44, 49, 57, 64, 75, 79, 506, 553

Wien, Kloster Barmherzige Brüder: 263

Wien, Mariahilf: 55

Wien, Salvatorianerkloster: 8 I

Wien, St. Dorothea: 35, 43, 46, 38 I, 554

Wien, St. Josef: $54,75,77,454$

Wien, St. Peter: 43, 5 I , 57, 64, 65

Wien, St. Stephan: 43, 46, 70, 7 I, 75, 77, 85, I 54, 288, 301, 326, 340, 423, 470, 524, 536

Wien, Schottenkirche: $27,32,35,36,57,63,69$, $72,288,301,553,554$

Wiener Neustadt: 72, I $37,359,430$

Wilhering: $35,40,43,56$

Wilten: 273

Wilten, Prämonstratenser-Chorherrenstift: i 8, I 9, 2 I , 70, 7 I, 3 I 4, 447-449, 45 5, 467, 470, $473, \mathbf{5} 1 \mathbf{3}-\mathbf{5 2 4}, 547$

Worms: 206

Zagreb: 273

Zwettl: 35, 42, 43, 5 I, 63, 75, 87

Zwiefalten: 532 


\section{Künstlerverzeichnis}

Ein Großteil der angeführten Lebensdaten von Künstlern und Handwerkern ist den Einträgen in die üblichen Künstlerlexika entnommen, deren Angaben sich gelegentlich von den Biographien in Fachbeiträgen unterscheiden. Meist handelt es sich jedoch nur um eine Differenz von wenigen Jahren, in unserem Zusammenhang ist das ohne wirkliche Relevanz. Ein weiterer Unsicherheitsfaktor besteht bei Handwerkerfamilien in der häufigen Namensgleichheit von Vätern, Söhnen und Verwandten, was natürlich die Gefahr von Verwechslungen in sich birgt. Die biographischen Angaben sind daher als Näherungswerte zu verstehen, doch schien es mir wichtig, die genannten Personen zumindest in einen ungefähren historischen Kontext zu stellen. Tischler, zumal jene, die keine internationale Reputation genossen, werden in Lexika nur selten erwähnt. Hier konnte ich mich jedoch vielfach auf Ergebnisse der jeweiligen Fachliteratur sowie auf Archivrecherchen von Franz Wagner und Herbert Haupt stützen, die an passender Stelle im Anmerkungsapparat zitiert werden. Weitere Daten wurden Sterbelisten in Pfarrmatrikeln entnommen, in denen häufig auch Herkunft und Alter des Toten verzeichnet sind. Auch dies ist in den Fußnoten entsprechend vermerkt. Von den Lebensdaten sehr vieler Handwerker besitzen wir jedoch bisher keinerlei Kenntnis. Die Namen von Tischlern sind durch Fettdruck hervorgehoben.
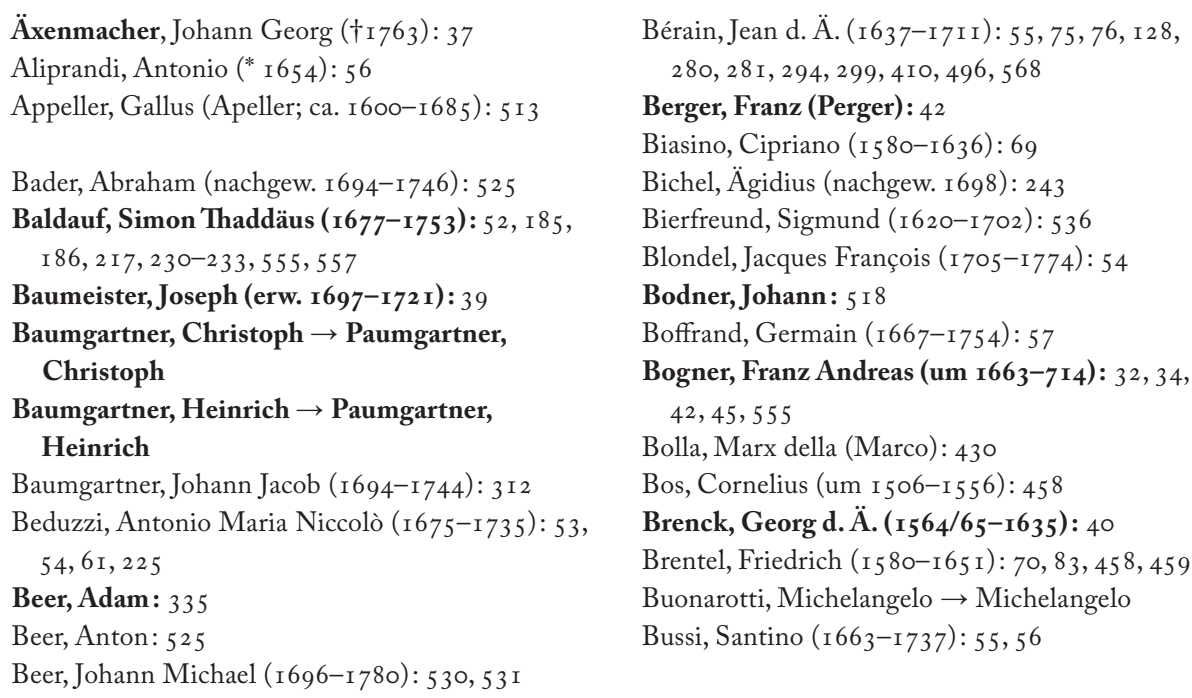
Caccon, Anton (I742-I 8 I I): 40

Camin, Mattias († I673): 284

Carlone, Archangelo ( $†$ I 635): 305

Carlone, Carlo Antonio (um r635-r 708): 255, 348

Carlone, Diego Francesco (I674-I750): 2 I 9, 244

Carlone, Giovanni Battista (um I642-I 72 I): 255

Carlone, Joachim (I653-I 7 I3): 348

Carlone, Leopold Joseph (I678-I 739): 3 10

Carlone, Pietro Francesco (um r6o6-i68 I) : 78

Carneri, Matthias (I 592-I673): 449

Castellazzi, Passibili ( $†$ I 656): 78

Christian, Johann Joseph (Franz Joseph; I 706I 777): 526-529, 53 I, 532

Clain, Georg: I9 I, I 93

Colombo, Luca Antonio (r66I-I 737): 98

Conti, Pietro Antonio (nachgew. I697-I 7 I I) : 98

Crivelli, Andrea (um I 470-nach I 554): 430

Dankl, Ulrich: 249

Dario, Giovanni Antonio (Daria; † I 702): I 83

Decker, Paul d. Ä. (I677-I 7 I 3): I 2 8, 294, 3 I 2 , 4 Io

Deutsch, Hans Rudolf Manuel (I 525-I 57 I): I 32

Dietrich, Johann ( $†$ I 774): 45

Donner, Georg Raphael (I693-I 74I): 53, I30

Drentwett, Abraham d. J. (I696-I 735): 3 I 2

Ducerceau, Jaçques Androuet d. Ä. (um I 5 ro-nach I 584$):$ I 32,388

Echter, Matthias (I653-I701/03): 202, 24I, 243, 564

Eissler, Caspar Gottlieb (Eisler): 268

Erasmus, Georg Caspar (wohl I620/30-nach I695): 24I, 243

Faber, Hans $\rightarrow$ Schmid, Hans

Feichtmayr, Franz d. Ä. (I 705-I 764): 488

Feichtmayr, Johann Michael (I 709/10-I 772): 56, 479

Fenninger, Christof (nachgew. I735 und I758): 249

Fieß, Matthias : 52

Fischer, Franz (Vischer; † I653): 540

Fischer, Joseph (Joseph Anton; I 704-I 77I) : 488

Fischer, Joseph Emanuel (I693-I 742): 49

Fischer von Erlach, Johann Bernhard (I656-I 723 ): $44,48,49,64,73,2$ I 9-22 5, 243-246, 440, 559

Fontaner, Karl (1 56 I-nachgew. I636): 437
Formentini, Carlo Federico (um I662-I 742 ?): 3 Io

Fries, Johann (?) „Senex“: 56, 43 I

Fritz, Friderich : 43, 45

Fritz, Gregor (I693-I 774) : 48 I

Galli Bibiena, Giuseppe (I696-I 757): 53, 54, 6I

Geiger, Johann: 526, 532

Gigl, Anton II (1 700-I 769) : 425

Giuliani, Giovanni (I663-I 744): 44

Görz, Matthias von (um I670-I 73 I) : 348

Götz, Joseph Matthias (I696-I 760): 3 I, 53

Gourmont, Jean de (*um I 483 ): I 32

Gratwohl, Joseph : 53

Grim, Johann Bernhard: 2 I 2

Günther, Matthäus (I 705-I 788): 478

Guggenbichler, Meinrad (I 649-I 723): 196

Gumpp, Christoph d. J. (I6oo-1672) : 50, 437439, 45 4, 46 I, 5 I 3

Gumpp, Georg Anton (r682-r 754): 488

Gumpp, Johann Martin d. Ä. (I643-I 729): 47, 83, $45^{8}, 488,489,49$ I , 5 I 3

Hackhofer, Johann Cyriak (I675-I 73 I) : 408

Härmler, Lorenz (Härmbler): 207, 208

Hasselmann, Johann Gottlieb : 45, 555

Heckenauer, Leonard d. J. (I669-I 704): 202, 243, 35 I

Heel, Johann Wilhelm (r637-I 709): 54

Hegenwald, Michael Joseph (I666-I 722): 27

Helmich, Anton (ca. I 7 I9-1 744) : 335

Herrmann, Franz Anton (I 7 I I-I 770): 36, 39, 557

Hildebrandt, Johann Lukas von (I668-I 745): 48, $52,53,73$

Hillebrand, Gregor: 138

Hinterseer, Philipp († I 780): 207

Hirschvogel, Augustin (I 503-I 553): 354

Hitzl, Johann Georg (um I 706-I78 I): I 85, I 86, 249

Höfler, Johann Philipp (I663-I 722): 536

Hönel, Michael (um I 590-um I653): r 30, I 33 , I 34, I 36

Hofer, Josef: 526-529, 53 I

Holdermann, Heinrich Johann (1697-1739): 30, $42,554,557$

Holl, Elias (I 573-r 646): 437

Hooch, Pieter de (I629-I684): 72

Horeß, Lorenz: 2 Io 
Horner, Remigius (1670-I750): 50, 348-352

Hueber, Joseph (Huber; † I 787 ): 3 I0

Hueber, Paul : 43 I-435

Indau, Johann (I65 I-I690): $54,55,69,70$, I 5 I , 202, 24I, 243, 35 I, 564

Jänggl, Franz (I 654-I 734): 48

Jegg, Stephan (I674-I749): 79, 555, 557

Kaiser, Fr. Oswald (I6oo-r686) : 437, 440-445

Kapfer, Johann: 204-206

Kaut, Valentin: 27

Keller, Augustin (1680-1748): 37

Kerner, Johannes : 30

Kienast, Franz: $273,274,277$

Kilian, Lukas (I 579-1637): 70, 458

Kink, Martin (I 800-1 877): 533

Knöpl, Martin : 3 I 3, 3 I 5, 3 I 6, 3 I 9-323, 36 I-363

Köbl, Balthasar (Kölbl; I645-I 7 I I): 64, 220-223, $239^{-242,244-247}$

Kögel, Ludwig ( I 7 I0/I I-I 74I): 39, 52

Kölle, Andreas (I680-I722): 50I-503

Kössler, Adam : 273, 274, 277

Kraus, Johann Jakob II. ( I642-I 701) : 396

Kraxner, Georg (Kräxner; r688-I 755): 272, 279, 280

Kreuzer, Ferdinand (1692-1767): 37

Kuontz, Jacob : 36

Lackner, Blasius: 397

Lantscher, Johann : 273, 274, 277

Leitner, Johann Matthias († I 763): 263, 366, 367

Lepautre, Jean (Le Pautre; I6 I 8-I682): 49, 54, 354

Le Fort du Plessy, Claude (nachw. I 707-r 757): 49

Lindemayr, Chrysostomus (Georg; 1678-1739): $52,273,274,276-278$

Lindt, Valentin (* um I60o? ): 4 I 8

Mader, Hans Georg: 335

Maderno, Anton (Antonio Maderni): 255, 349

Maleg, Fr. Ladislaus ( $†$ I 749): 42

Marot, Daniel (I66 I-I 752): 55, 76, I 28, 568

Martinelli, Francesco (I65 I-I 708): 98

Mayr, Christoph Anton: 425

Mayrhofer, Georg: I 3 I

Melber, Balthasar: 554
Michelangelo (I 475-I 564): 43

Michlodt, Niclas: I $38-$ I 4 I

Mölck, Josef Adam (um I 7 I 4-I 794): 366

Morder, Leopold: 30

Morisson, Friedrich Jacob (nachgew. I693 und г697): 55,7 I, 76, 568

Müller, Jakob ( I664-1 746) : 36

Munggenast, Joseph (I680-I 74I): 5 I, 54, 6 I

Murauer, Heinrich: 249

Nallenburg, Hippolyt (1687-1 733): 33, 35-38, 46, 52, 60, 6I, 65, 554

Neuberg, Martin : 255

Neumann, Johann Balthasar (I687-I 753): 45

Neurauther, Fr. Michael († I 794): 494

Nissl, Franz Xaver (I73 I-I 804): 40, 53, 426, $480-487$

Nonnenmacher, Markus (Marco; 1653-1720): I 5 I

Olm, Valentin (1666-1720): 335

Orsolini, Pietro: 104

Orthner, Fr. Marzellin Georg (I633-I692): 4I

Ott, André : I 4 I

Pacobello, Martin († I630): г6o

Palladio, Andrea (I 508-I 580): 569, 57 I

Pauer, Lorenz: 207, 208

Paumgartner, Christoph (Baumgartner): 39, 46, $98,255,324,327-329,387-396$

Paumgartner, Heinrich (Baumgartner; 1624I683): 45

Perchtoldt, Gregor ( $†$ I659): 36, 397-403

Pinna, Mathias : 453, 454

Pock, Hans : 449, 454-457

Polak, Martin Theophilus (Pollak; † I639): 449

Pomis, Giovanni Pietro de (I 569-1633): 284

Prandtauer, Jakob (I66o-I 726): 35, 225

Primbsch, Philipp ( $†$ I772): 335,346

Püchler, Caspar († I 720): 405

Rachinger, Wolfgang: 32, 34, 52, 557

Ramschüssl, Franz Anton (Ramschissl): 282, 284

Regauer, Stephan (nachw. I606 bis I628): I I 7

Reiff, Johann Conrad († I 726): 294

Reißmayer, Balthasar: 39

Renn, Heinrich : 479 
Reuttimann, Johann Conrad (nachw. I676-i69i): 54, 24I, 243, 535

Rieger, Georg: I 3 I

Rogg, Joseph Anton: 367, 369

Rottmayr, Johann Michael (I654-I 730): I 96, 2 I 9

Rueff, Matthias (I658-I 7 I 8): 45, 342, 555

Rumpp, Johannes (I 702-I 755): 368, 369

Ruspiliati, Andreas : 45

Sangallo, Antonio da d. J. (I 484-I 546): 43, 50

Sandtner, Jakob : 4 I

Sattler, Leonhard (1676-1 744): 79

Scamozzi, Vincenzo (I 55 2-I6 I6): 229

Schaar, Joachim Andreas (nachw. I 7 I 2-vor I 753): 535

Schärenstein, Peter von: 32

Schaider, Ruep: $249^{-2} 5^{2}$

Schapper (Schopper), Georg (I664-I724): I 54

Schaukegl, Joseph (I 72 I-I 798): 49

Schaumberger, Johann Martin († I 7 I 2): 196

Scheffler: 5 I 3

Schenck, Johann Caspar (um I620-I674): 4I

Scherer, Konrad (Meister aus Velden): 85 , I 59-I 6 I

Schiffer, Thomas (Schüffer): I6, 27-3 I, 33, 39, $367-374,38 \mathrm{I}$

Schildknecht, Jakob : 4I

Schlackwein, Hans: I 33, I 34, I 36

Schlögl, Franz Josef: 374,375

Schmerlaib, Jakob: 348

Schmid, Hans (Hans Faber): 335

Schmidt, Johann (r684-I76r): 37, 38, 40

Schönherr, Josef: 479

Schött, Martin : 50, 335

Schokotnigg, Joseph (I 700-I 75 5): 293, 296, 300-302

Schor, Hans († I 674): 437

Schorn, Philipp: 5 I

Schram, Lukas von (I702-I 765): 293

Schrezenmayer, Fr. Kaspar (I693-I782): 274, 554

Schwabl, Ferdinand: 483

Schwath, Joseph: 293

Sciassia, Domenico d. J. (I 599/I603-I679): 323, 386, 405

Seehuber, Fr. Clemens : 87, 526-53 I

Seitlinger, Bartholomäus (I632-I683): I33-I 37
Seitlinger, Johann (Hans; I 596-I666): I32, I 33, I 37

Seltenreich, Hans (Johannes; I643-1715): $26 \mathrm{I}-263$

Seltenreich, Jacobus : 263

Sentobe, Josef: 456

Serlio, Sebastiano (I 475-ca. I 5 54): 78, 257

Siegenbrock, Fr. Sophronius (Siegenbruck; I737-I802): 263, 265-27 I

Sießenbacher, Emilian : I $33^{-1} 37$

Singer, Hans: $45^{\circ}$

Singer, Jakob : 478

Solari, Santino (I 576-I646): 69, 229, 24 I, 437

Stammel, Josef (I695-I 765): 40

Stapf, Josef (I 7 I 8-1 785 ) : 483

Staudinger, Franz Anton (I705-I 78I): I 8, 29, 3 I, $40-42,52,62,554,557$

Steidl, Melchior ( $\left.\dagger_{\text {I }} 727\right): 2$ I 6

Steiner, Johann Georg (I698-I 758): 405

Steinl, Matthias (I643/44-I 727): 36, 5 I, I 93, I 96, 348, 405, 557

Steinle, Matthäus (Steinl): I 90-I 95, I 97-200

Stengg, Andreas (I660-I 74I): 292

Stengg, Johann Georg (I689-I 753): 36, 263, 292, 365-368

Straub, Johann Baptist (I 704-I 784): 274, 48 I

Straub, Philipp Jakob (I 706-I 774): 274, 280-284, 286, 288, 289

Strauch, Lorenz (Laurentius; I 5 54-I630?): 82

Strebele, Josef Bernhard: 502, 504

Streiter, Josef (Streitter) : 485, 487

Strigl, Augustin († I 746): 493, 495, 496, 498, 500-5 10

Sundermayer, Benedict (Sondermayr): 44

Supacher, Wolfgang $(\dagger$ I 72 I $): 335$

Tauffer, Fr. Mauritius (I692-I776): 39, 370-372, $374-380$

Thaler, Franz Christian (I 759-1 8 I 7): 485, 487

Töller, Pankraz: 483

Trarer, Andreas : 274

Trenkwalder, Josef (I845-r897): 456

Troger, Paul (1698-1762): 27

Türing, Niclas d. J. († I 558): 430

Übelher, Johann Georg (Übelhör, Üblherr; I 703I 763$): 56,479$ 
Unselt, Johannes (nachgew. I68 I-r696): 54, 55, 69, 70, 202, 243, 535

Unteutsch, Friedrich (um I600-I670): 70, 85, 5 I 7

Vasari, Giorgio (I 5 I I-I 574): 50

Vogl, Johann Chrysostomos (I679-I748): 3 Io

Wachsmuth, Jeremias (I 7 I 2-I 779) : 268

Wachter, Paul: 450

Walden, Peter: 273, 274, 277

Waldmann, Kaspar (I657-I 720): 5 I 3

Walz, Hanns (Hans; † um I648): 554

Wegscheider, Josef Ignaz (I 704-I 758/60): 525

Weiß, Johann (I 738-1776): 207

Wendtner, Georg: 196

Wessicken, Simon Mathias (I740-I8 I5): 209-2 I 2

Windpichler, Lorenz (um I65 I-I 724): 2 I I

Wolcker, Johann Georg (I 700-I 766): 488, 498, 500
Zaar, Johann Peter († I 726): 3 Io

Zängerl, Johann Georg: 2 I 8

Zengerle, Johann : 2 I 7, 2 I 8, 252-254

Zoller, Fr. Georg (I 700-I 767) : 41 , 82, 493, 495$503,505-5$ IO, 5 I 2

Zuccari, Federico (I 542-r609): 70, 75

Nur mit Vornamen bekannt Handwerker und

Meister mit Notnamen

Tischler Christian : I 30

Tischler Georg:

Tischler Fr. Laurentius : 292

Tischler Fr. Lazarus : 292

Tischler Fr. Sydinius : 292

Tischlerin Magdalena : 130

Tischler Matthes : I 30

Tischlermeister aus Stein : 52

Tischlermeister aus Velden $\rightarrow$ Scherer, Konrad 


\section{Abkürzungsverzeichnis}

Literatur:

AKL

GbKÖ

JbKSW

Jb.K1.

KHM

$\mathrm{KJbG}$

LdK

LThK

NDB

ÖKM

ÖKT

ÖK-T

ÖZKD

RDK

RGG

SMGB

TRE

WJbKG

ZfKG

Archive:

DOZA BÖ

HHStA

StAA

StAGö

StAH

StAHo

StALa

StAM

StAR

StAS

StASchl

StASe
Allgemeines Künstlerlexikon

Geschichte der bildenden Kunst in Österreich

Jahrbuch der kunsthistorischen Sammlungen in Wien

Jahrbuch des Stiftes Klosterneuburg

Kunsthistorisches Museum Wien

Kunsthistorisches Jahrbuch Graz

Lexikon der Kunst

Lexikon für Theologie und Kirche

Neue Deutsche Biographie

Österreichische Kunstmonographie

Österreichische Kunsttopographie

Österreichische Kunst-Topographie

Österreichische Zeitschrift für Kunst- und Denkmalpflege

Reallexikon zur deutschen Kunstgeschichte

Religion in Geschichte und Gegenwart

Studien und Mitteilungen zur Geschichte des Benediktinerordens und seiner Zweige

Theologische Realenzyklopädie

Wiener Jahrbuch für Kunstgeschichte

Zeitschrift für Kunstgeschichte

Deutschordens-Zentralarchiv, Ballatei Österreich

Haus-, Hof- und Staatsarchiv, Wien

Stiftsarchiv Altenburg

Stiftsarchiv Göttweig

Stiftsarchiv Herzogenburg

Stadtarchiv Horn

Stiftsarchiv Lambach

Stiftsarchiv Melk

Stiftsarchiv Rein

Stiftsarchiv Schottenkloster

Stiftsarchiv Schlägl

Stiftsarchiv Seitenstetten 
StASt

StAW

StAZ

TLA

Allgemein:

Abb.

Anm.

Aufl.

Ausst.-Kat.

AVA

B

Bd. (Bde.)

BDA

Bearb.

bearb.

begr.

bes.

BR

bzw.

c.

cap.

$\mathrm{cm}$

d. A.

d.J.

ders.

dems.

dies.

Dipl.

Diss.

ebd.

ehem.

einschl.

erschien.

erw.

Ex

Farbtaf.

$\mathrm{f}$

ff

fl

fol.
Stiftsarchiv Stams

Stiftsarchiv Wilhering

Stiftsarchiv Zwettl

Tiroler Landesarchiv

Abbildung

Anmerkung

Auflage

Ausstellungskatalog

Allgemeine Verwaltungsakten

Breite

Band, Bände

Bundesdenkmalamt

BearbeiterIn

bearbeitet

begründet

besonders

Bauamtsrechnung

beziehungsweise

Carta

capitulum

Zentimeter

der Ältere

der Jüngere

derselbe

demselben

dieselbe/dieselben

Diplomarbeit

Dissertation

ebendort

ehemalige (-r, $-\mathrm{s})$

einschließlich

erschienen

erweitert

Buch Exodus

Farbtafel

folgende

folgende

Gulden

Folio 
Fr.

gen.

Gen

geschr.

$\mathrm{H}$

$\mathrm{HO}$

Hochsch.

Hg.

hg. v.

HS

$\mathrm{Hs}$

$\mathrm{HU}$

Jb.

Jg.

Joh

Kap.

Kat.

$\mathrm{kr}$

kult.-gesell. Fakultät

L

Lk

$\mathrm{m}$

Mag.

MAK

masch.

masch. phil. Diss.

masch. phil. Dipl.

$\mathrm{Mk}$

Mos

Mt

musikwiss. Diss.

Nachdr.

nachgew.

nachw.

neubearb.

Neudr.

$\mathrm{NF}$

NÖ

nördl.

Num

o. Ä.
Frater

genannt

Buch Genesis

geschrieben

Höhe

Höhe der Oberschränke

Hochschule

Herausgeber

herausgegeben von

Höhe des Sockels

Handschrift

Höhe des Unterschranks / der Unterschränke

Jahrbuch

Jahrgang

Evangelium des Johannes

Kapitel

Katalog/Katalogbeitrag

Kreuzer

Kultur- und Gesellschaftswissenschaftliche Fakultät

Länge

Evangelium des Lukas

Meter

Magisterarbeit

Wien, Museum für angewandte Kunst

maschinengeschrieben

maschinengeschriebene Dissertation, Fachbereich Philosophie

maschinengeschriebene Diplomarbeit, Fachbereich Philosophie

Evangelium nach Markus

Buch Mose

Evangelium nach Matthäus

musikwissenschaftliche Dissertation

Nachdruck

nachgewiesen

nachweisbar

neubearbeitet

Neudruck

Neue Folge

Niederösterreich

nördlich

Buch Numeri

oder Ähnliches 
o. J.

o. O.

O.Praem.

o. S.

O.S.B.

OÖ

ÖAW

ÖNB

östl.

p.

P.

r

reg.

Repr.

resp.

$\mathrm{RR}$

s.

S.

Sam

Sp.

südl.

$\mathrm{T}$

Taf.

techn.

theol. Dipl.

u.a.

überarb.

unbek.

$\mathrm{v}$

v.

verb.

verm.

vgl.

westl.

$\mathrm{xr}$

z. B.

zugeschr. ohne Erscheinungsjahr

ohne Druckort

Ordo Praemonstratensis

ohne Seitenangabe

Ordo Sancti Benedicti

Oberösterreich

Österreichische Akademie der Wissenschaften

Österreichische Nationalbibliothek

östlich

pagina

Pater

recto

regierte

Reprint

respektive

Rentamtsrechnungen

siehe

Seite

Buch Samuel

Spalte

südlich

Tiefe

Bildtafel

technisch

theologische Diplomarbeit

unter anderem/ und andere

überarbeitet

unbekannt

verso

von

verbesserte

vermutlich

vergleiche

westlich

Kreuzer

zum Beispiel

zugeschrieben 


\section{Abbildungsnachweis}

Archiv der Erzdiözese Salzburg: Abb. I 23, I 24

Stift Rein, historische Aufnahme: Abb. 243

Alle anderen Fotos: Autor 


\section{Literaturverzeichnis}

LEXIKA

AKL - Allgemeines Künstlerlexikon. Die bildenden Künstler aller Zeiten und Völker, Bd. I ff, München/Leipzig I $992 \mathrm{ff}$

Biedermann, Symbole (1989) - Hans Biedermann: Knaurs Lexikon der Symbole, München I 989

Handbuch der Kirchengeschichte - Handbuch der Kirchengeschichte (hg. v. Hubert Jedin), 7 Bde., Freiburg I 985 [Nachdr. I999]

Fattinger, Requisitenkunde (I954) - Rudolf Fattinger: Liturgisch-praktische Requisitenkunde für den Seelsorgeklerus, für Theologen, Architekten, Künstler, Kunst- und Paramentenwerkstätten, Freiburg I954

Frank, Mönchtum (2005) - Isnard W. Frank: Lexikon des Mönchtums und der Orden, 2. Auf., Stuttgart 2005

Haslinger/Mittermayr, Kulturlexikon (200I) - Adolf Haslinger und Peter Mittermayr (Hg.): Salzburger Kulturlexikon, Salzburg/Wien/Frankfurt am Main 200 I

LDK - Lexikon der Kunst (hg.v. Harald Olbrich, Dieter Dolgner, Hubert Faensen u.a.), Nachdr. der 2., neubearb. Aufl., 7 Bde., München 1996

LKK - Lexikon für kirchliches Kunstgut (hg. v. Arbeitskreis für Inventarisation und Pflege des kirchlichen Kunstgutes), Regensburg 2010

Lexikon des Mittelalters (1980-1999) - Lexikon des Mittelalters (hg. v. Norbert Angermann, Robert Auty und Robert-Henry Bautier), 9 Bde., München/Stuttgart I980-I 999

LThK - Lexikon für Theologie und Kirche (hg. v. Walter Kasper), I I Bde., 3. Aufl., Freiburg/ Wien r 993-200I

NDB - Neue Deutsche Biographie, Bd. I ff, Berlin 1953 ff

RDK - Reallexikon zur deutschen Kunstgeschichte (begr. v. Otto Schmitt), Bd. I ff, München I $937 \mathrm{ff}$

RGG - Religion in Geschichte und Gegenwart (hg. v. Hans Dieter Betz, Don S. Browning, Bernd Janowski u.a.), 8 Bde., 4., neubearb. Aufl., Tübingen I 998-2007

Saur, Künstlerlexikon ( 1992 ff) - Saur allgemeines Künstlerlexikon: die bildenden Künstler aller Zeiten und Völker (hg. v. Günter Meißner, Andreas Beyer, Bénédicte Savoy u.a.), Bd. I ff, München/Leipzig I $992 \mathrm{ff}$

Schwaiger, Mönchtum (2003) - Georg Schwaiger (Hg.): Mönchtum, Orden, Klöster. Von den Anfängen bis zur Gegenwart. Ein Lexikon (Beck'sche Reihe), München 2003

Thieme-Becker, Künstlerlexikon ( 1992 ) - Ulrich Thieme und Felix Becker (Hg.): Allgemeines 
Lexikon der bildenden Künstler von der Antike bis zur Gegenwart, 37 Bde., Leipzig r907I 950 [Nachdruck Leipzig 1992]

TRE - Theologische Realenzyklopädie (hg. v. Gerhard Krause und Gerhard Müller), ${ }_{3} 6$ Bde., Berlin u.a. 1976-2004

Zedler, Universal-Lexicon ( 1732 ff) - Johann Heinrich Zedler: Großes vollständiges Universal-Lexicon aller Wissenschaften und Künste, Bd. I ff, Halle/Leipzig I732 ff [Repr. Graz I 993-1999]

\section{INVENTARB ÄNDE}

Dehio

Dehio Handbuch. Die Kunstdenkmäler Österreichs. Topographisches Denkmälerinventar. Hg. v. Institut für österreichische Kunstforschung des Bundesdenkmalamtes/Hg. v. Bundesdenkmalamt, Bd. I ff, Wien I 933 ff

Dehio, Burgenland (1980) - Dehio, Burgenland (bearb. v. Adelheid Schmeller-Kitt, mit Beiträgen v. Friedrich Berg, Clara Prickler-Wassitzky und Hannsjörg Ubl), 2., verb. Aufl., Wien I 980

Dehio, Graz (1979) - Dehio, Graz (bearb. v. Horst Schweigert), Wien I 979

Dehio, Kärnten (200I) - Dehio, Kärnten (bearb. v. Ernst Bacher, Ilse Friesen, Géza Hajos u.a., neubearb. v. Gabriele Russwurm-Biró,), 3., erw. und verb. Aufl., Wien 200 I

Dehio, NÖ nördl. der Donau (2ого) - Dehio, Niederösterreich nördlich der Donau (bearb. v. Evelyn Benesch, Bernd Euler-Rolle, Claudia Haas u.a.), 2. Aufl., Wien/Horn 2010

Dehio, NÖ südl. der Donau, I (2003) - Dehio, Niederösterreich südlich der Donau, Teil I (bearb. v. Peter Aichinger-Rosenberger, Evelyn Benesch, Kurt Bleicher u.a.), Horn/Wien 2003

Dehio, NÖ südl. der Donau, 2 (2003) - Dehio, Niederösterreich südlich der Donau, Teil 2 (bearb. v. Peter Aichinger-Rosenberger, Evelyn Benesch, Kurt Bleicher u.a.), Horn/Wien 2003

Dehio, Salzburg ( 1 986) - Dehio, Salzburg. Stadt und Land (bearb. v. Bernd Euler, Ronald Gobiet, Horst R. Huber, u.a.), Wien I 986

Dehio, Steiermark (2006) - Dehio, Steiermark (ohne Graz) (bearb. v. Kurt Woisetschläger und Peter Krenn), 2., unveränderte Aufl., Horn/Wien 2006

Dehio, Tirol ( 1980) - Dehio Tirol (bearb. v. Gert Ammann, Erich Egg, Johanna Felmayer u.a.), Wien 1980

Dehio, Vorarlberg (1983) - Dehio Vorarlberg (bearb. v. Gert Ammann, Martin Bitschnau, Paul Rachbauer u.a.), Wien 1983

Dehio, Wien (1993) - Dehio, Wien, II. bis IX. und XX. Bezirk (bearb. v. Wolfgang Czerny, Robert Keil, Andreas Lehne u. a.), Wien I 993

Hootz, Kunstdenkmäler (1 965-1 968) - Reinhardt Hootz (Hg.): Kunstdenkmäler in Österreich. Ein Bildhandbuch, 4 Bde., München/Berlin I965-1968

Kunstdenkmäler Kärntens - Die Kunstdenkmäler Kärntens (Veröffentlichungen des I. Kunst- 
historischen Instituts der Universität Wien, hg. v. Karl Ginhart), Bd. I ff, Klagenfurt [ I 929I934]

Kunstdenkmäler Kärntens, St. Veit (1930) - Die Kunstdenkmäler des politischen Bezirkes St. Veit: Gerichtsbezirke Gurk und Friesach (Bd. VI, I, bearb. v. Karl Ginhart), Klagenfurt I 930

Kunstdenkmäler Kärntens, St. Veit (193 I) - Die Kunstdenkmäler des politischen Bezirkes St. Veit: Gerichtsbezirke St. Veit, Althofen und Eberstein (Bd. VI, 2, bearb.v. Karl Ginhart), Klagenfurt I 93 I

Kunstdenkmäler Kärntens, Stadt Klagenfurt ( 993 I) - Die Kunstdenkmäler des politischen Bezirkes Klagenfurt. Die Stadt Klagenfurt (Bd. V, I, bearb. v. Otto Demus), Klagenfurt I 93 I

Kunstdenkmäler Kärntens, Villach ( I 929) - Die Kunstdenkmäler des politischen Bezirkes Villach (Bd. III, bearb. v. Anna Spitzmüller), Klagenfurt I 929

Kunstdenkmäler Kärntens, Völkermarkt (I933) - Die Kunstdenkmäler des politischen Bezirkes Völkermarkt (Bd. VII, bearb. v. Hermann L'Estocq, Karl Ginhart und Anton Macku), Klagenfurt 1933

Kunstdenkmäler Kärntens, Wolfsberg ( 1933 ) - Die Kunstdenkmäler des politischen Bezirkes Wolfsberg (Bd. VIII, bearb. v. Karl Ginhart, Hugo Graf Henckel-Donnersmarck und Leopold Speneder), Klagenfurt I933

\section{ÖKM}

Österreichische Kunstmonographie. Bd. I ff, Salzburg I 963 ff

ÖKM, Burgenland ( I968) - ÖKM. Das Burgenland. Seine Kunstwerke, historischen Lebensund Siedlungsformen (Bd. 2, bearb. v. Alfred Schmeller), 2. Aufl., Salzburg I 968

ÖKM, Kärnten (1977) - ÖKM. Kärnten: Der Bezirk St. Veit an der Glan: Seine Kunstwerke, historischen Lebens- und Siedlungsformen (Bd. 8, bearb. v. Siegfried Hartwagner), Salzburg I 977

ÖKM, Klagenfurt Stadt ( 1980 ) - ÖKM. Klagenfurt Stadt: Ihre Kunstwerke, historischen Lebens- und Siedlungsformen (Bd. Io, bearb. v. Siegfried Hartwagner), Salzburg I 980

ÖKM, Oststeiermark ( I 987 ) - ÖKM. Die Oststeiermark (Bd. I I, bearb. v. Peter Krenn), 2., verb. Aufl., Salzburg 1987

ÖKM, Tiroler Oberland (1978) - ÖKM. Das Tiroler Oberland. Die Bezirke Imst, Landeck und Reutte. Seine Kunstwerke, historischen Lebens- und Siedlungsformen (Bd. 9, bearb. v. Gert Ammann), Salzburg 1978

ÖKM, Tiroler Unterland ( 197 I) - ÖKM. Das Tiroler Unterland. Die Bezirke Kufstein, Kitzbühel und Schwaz. Seine Kunstwerke, historischen Lebens- und Siedlungsformen (Bd. 6, bearb. v. Erich Egg), Salzburg I 97 I

\section{ÖKT}

Österreichische Kunsttopographie. Hg. v. d. k. k. Zentral-Kommission für kunst- und historische Denkmale/Hg. v. Kunsthistorischen Institute der k. k. Zentral-Kommission für Denkmalpflege/Hg. v. Institut für Österreichische Kunstforschung des Bundesdenkmalamtes/Hg. 
v. Bundesdenkmalamt, Abteilung für Inventarisation und Denkmalforschung, Bd. I ff, Wien I $907 \mathrm{ff}$

ÖKT, Eisenstadt (1932) - ÖKT. Die Denkmale des politischen Bezirkes Eisenstadt und der Freien Städte Eisenstadt und Rust (Bd. 24, bearb. v. André Csatkai und Dagobert Frey), Wien 1932

ÖKT, Feldkirch ( 1958 ) - ÖKT. Die Kunstdenkmäler des politischen Bezirkes Feldkirch (Bd. 32, bearb. v. Dagobert Frey), Wien I 958

ÖKT, Innsbruck (1972) - ÖKT. Die profanen Kunstdenkmäler der Stadt Innsbruck. Altstadt Stadterweiterungen bis zur Mitte des I 9. Jahrhunderts (Bd. 38, bearb. v. Johanna Felmayer), Wien 1972

ÖKT, Innsbruck, I (I 995) - ÖKT. Die sakralen Kunstdenkmäler der Stadt Innsbruck. Innere Stadtteile (Bd. 52, Teil I, bearb. v. Johanna Felmayer, Karin Schmid, Brigitte Schneider u.a.), Wien 1995

ÖKT, Innsbruck, 2 (1995) - ÖKT. Die sakralen Kunstdenkmäler der Stadt Innsbruck. Äußere Stadtteile (Bd. 52, Teil 2, bearb. v. Martha Fingernagel-Grüll, Karin Schmid, Brigitte Schneider u.a.), Wien I 995

ÖKT, Innsbruck, Hofbauten (r 986) - ÖKT. Die Kunstdenkmäler der Stadt Innsbruck. Die Hofbauten (Bd. 47, bearb. v. Johanna Felmayer, Karl und Ricarda Oettinger, Elisabeth Scheicher u.a.), Wien I 986

ÖKT, Krems (1 907) - ÖKT. Die Denkmale des politischen Bezirks Krems (Bd. I, bearb. v. Hans Tietze), Wien 1907

ÖKT, Kremsmünster, I (I 977) - ÖKT. Die Kunstdenkmäler des Benediktinerstiftes Kremsmünster. Das Stift - Der Bau und seine Einrichtung (Bd. 43, Teil r, bearb. v. Erika Doberer, Willibrord Neumüller, Benedikt Pitschmann u.a.), Wien 1977

ÖKT, Kremsmünster, 2 (I 977) - ÖKT. Die Kunstdenkmäler des Benediktinerstiftes Kremsmünster. Die stiftlichen Sammlungen und die Bibliothek (Bd. 43, Teil 2, bearb. v. Hans Bertele-Grenadenberg, Ivan Fenyö, Eva Frodl-Kraft u.a.), Wien I 977

ÖKT, Linzer Kirchen ( I964) - ÖKT. Die Linzer Kirchen (Bd. 36, bearb. v. Justus Schmidt), Wien 1964

ÖKT, Melk ( I 909) - ÖKT. Die Denkmale des politischen Bezirkes Melk in Niederösterreich (Bd. 3, bearb. v. Hans Tietze), Wien I 909

ÖKT, Neusiedl (2O I 2) - ÖKT. Die Kunstdenkmäler des politischen Bezirkes Neusiedl am See (Bd. 59, bearb. v. Henny Liebhart-Ulm), Horn 2012

ÖKT, Oberpullendorf (2005) - ÖKT. Die Kunstdenkmäler des politischen Bezirks Oberpullendorf (Bd. 56, bearb. v. Judith Schöbel), Horn 2005

ÖKT, Salzburg (r9r 2) - ÖKT. Die kirchlichen Denkmale der Stadt Salzburg mit Ausnahme von Nonnberg und St. Peter (Bd. 9, bearb. v. Hans Tietze und Franz Martin), Wien I 9 I 2

ÖKT, Salzburg-Land, I (г913) - ÖKT, Die Denkmale des politischen Bezirks Salzburg. Salzburg-Land (Bd. ıo, Teil r, bearb. v. Paul Buberl und Franz Martin), Wien r 9r 3

ÖKT, Salzburg-Land, 2 ( I gr6) - ÖKT, Die Denkmale des politischen Bezirks Salzburg. Salzburg-Land (Bd. I I, Teil 2, bearb. v. Paul Buberl und Franz Martin), Wien I 9r6 
ÖKT, St. Lambrecht (195I) - ÖKT, Die Kunstdenkmäler des Benediktinerstiftes St. Lambrecht (Bd. 3 I, bearb. v. P. Othmar Wonisch), Wien I95 I

ÖKT, St. Paul ( r 969) - ÖKT, Die Kunstdenkmäler des Benediktinerstiftes St. Paul im Lavanttal und seiner Filialkirchen (Bd. 37, bearb. v. Karl Ginhart), Wien I 969

ÖKT, St. Peter (г13) - ÖKT, Die Denkmale des Benediktinerstiftes St. Peter in Salzburg (Bd. I 2, bearb. v. Hans Tietze), Wien I 9I 3

ÖK-T, Kärnten (I889) - Österreichische Kunst-Topographie des Herzogtums Kärnten (Bd. I, hg. v. d. K. K. Central-Commission für die Erforschung und Erhaltung von kunst- und historischen Denkmalen), Wien I 889

Rampold, Tirol (20 I 4) - Reinhard Rampold (Hg.): Kunstführer Tirol, Innsbruck/Wien 2014

\section{Literatur sowie ungedruckte und gedruckte Quellen}

Alberti, Maß (1957) - Hans-Joachim von Alberti: Maß und Gewicht. Geschichtliche und tabellarische Darstellungen von den Anfängen bis zur Gegenwart, Berlin 1957

Allmaier, Dom (20 I I) - Peter Allmaier: Der Dom zu Klagenfurt (Peda-Kunstführer 829), Passau 20 I I

Allmer, Pöllau ( r 993) - Gottfried Allmer: Geschichte des Marktes Pöllau, Pöllau r 993

Allmer, St. Veit (2003) - Gottfried Allmer: Stifts- und Pfarrkirche St. Veit in Pöllau (Christliche Kunststätten Österreichs 224), 3. Aufl., Salzburg 2003

Ammann, Barock (1973) - Gert Ammann: Barock in Stams, in: Siebenhundert Jahre Stams (1 973), 47-90

Ammann, Bergbau (1990) - Gert Ammann (Hg.): Silber, Erz und weisses Gold: Bergbau in Tirol (Tiroler Landesausstellung I 990), Ausst.-Kat. Schwaz I 990

Ammann, Bregenz (1 979) - Gert Ammann: Bregenz St. Gallus (Kunstführer 297), 3., neubearb. Aufl., München/Zürich I 979

Ammann, Gebäudekomplex (20r6) - Gert Ammann: Der barocke Gebäudekomplex entsteht, in: Forcher, Stams (2016), I 86-203

Ammann, Grablege (I 995) - Gert Ammann: Die Stiftskirche als Grablege der Tiroler Landesfürsten, in: Riedmann, Traum (I 995), 449-450

Ammann, Stams ( I 990) - Gert Ammann: Stift Stams (Große Kunstführer i I I), 2. Aufl., München/Zürich 1990

Amon, Geschichte (1979) - Karl Amon: Aus der Geschichte von Rein, in: Rappold/Amon, Stift Rein (1 979), 28-47

Arens, Meisterrisse (I 955) - Fritz Arens (Hg.): Meisterrisse und Möbel der Mainzer Schreiner (Beiträge zur Geschichte der Stadt Mainz I 4), Mainz I 955

Attems/Koren, Kirchen (1988) - Franz Attems und Johannes Koren: Kirchen und Stifte der Steiermark, Innsbruck 1988

Aurenhammer, Fischer (1973) - Hans Aurenhammer: J. B. Fischer von Erlach [The Architect and Society, hg. v. John Flemming und Hugh Honour], London 1973 
Barocchi/Bertelà, Arredi (1990) - Paola Barocchi und Giovanna Gaeta Bertelà: Arredi principeschi del Seicento fiorentino: Disegni di Diacinto Maria Marmi, Turin I 990

Batári/Vadászi, Furniture-Making (2000) - Ferenc Batári und Erzsébet Vadászi: The Art of Furniture-Making from the Gothic to the Biedermeier, Budapest 2000

Beales, Klöster (2008) - Derek Beales: Europäische Klöster im Zeitalter der Revolution: I650I 8 I 5 , Wien/Köln/Weimar 2008

Benedetti, Sangallos Holzmodell ( 1995 ) - Sandro Benedetti: Antonio da Sangallo d.J., I455I 534: Holzmodell des Entwurfs von St. Peter im Vatikan, erbaut unter der Leitung von Antonio Labacco, in: Evers, Architekturmodelle (I 995), 35 I-359

Benedetti, Sangallos Modell (r995) - Sandro Benedetti: Sangallos Modell für St. Peter, in: Evers, Architekturmodelle (I995), I Io-I I 5

Bergemann, Meisterrisse (1999) - Uta-Christiane Bergemann: Architektur im Möbelentwurf. Die Meisterrisse der Ingolstädter Schreiner I6I7-I742 (Beiträge zur Geschichte Ingolstadts), Ingolstadt I 999

Berliner/Egger, Vorlageblätter ( 198 I ) - Rudolf Berliner und Gerhard Egger: Ornamentale Vorlageblätter des I 5. bis I 9. Jahrhunderts, 3 Bde., 2. Aufl., München I98 I

Berthold, Maria Trost [ca. I 996] - Eugen Berthold: Wallfahrtskirche Maria Trost Graz, Graz o. J. [ca. 1996]

Betz, Bildprogramme (2000) - Gilda Betz: Die Bildprogramme der Sakristeien der Stiftskirche Vorau und der Pfarrkirche Pöllau, masch. phil. Dipl., Graz 2000

Bierbauer, Mariatrost (2005) - Josef Bierbauer: Basilika Mariatrost Graz (Christliche Kunststätten Österreichs 27), 5., überarb. Aufl., Salzburg 2005

Bierbauer, Mariatrost (20I I) - Josef Bierbauer: Graz Mariatrost Basilika (Peda-Kunstführer 8 I $3 / 20$ I I), Passau 20 I I

Bierbauer/Kaind1/Thaller, Mariatrost (200o) - Josef Bierbauer, Heimo Kaindl und Angelika Thaller (Hg.): Basilika Mariatrost in Graz. Festschrift zur Basilika-Erhebung, Graz 2000

Bimbenet-Privat/Kugel, Orfèvrerie (2017) - Michèle Bimbenet-Privat und Alexis Kugel: Chefsd'œuvre d'orfèvrerie allemande. Renaissance et baroque, Dijon 2017

Bitschnau, Romanik ( 1973 ) - Martin Bitschnau: Romanik in Stams, in: Siebenhundert Jahre Stams (1973), 9-24

Blazicek, Stuckateure (1964) - Oldrich J. Blazicek: Das Werk der lombardischen und Tessiner Stuckateure in der Tschechoslowakei, in: Edoardo Aslan (Hg.): Arte e artisti dei laghi lombardi. Gli stuccatori dal barocco al rococo (Società Archeologica Comense), Como I 964, I I 5 - 28

Blondel, Distribution (1737/38) - Jacques François Blondel: De la distribution des maisons de plaisance et de la décoration des édifices en général, 2 Bde., Paris I737/I 738 [https://digi. ub.uni-heidelberg.de/diglit/blondeli 737/0005/image; Zugriff Januar 201 9]

Blunt, Kunst ( 1 979) - Anthony Blunt: Kunst und Kultur des Barock und Rokoko: Architektur und Dekoration, Freiburg/Basel/Wien 1979

Boffrand, Livre d'architecture ( 1745 ) - Germain Boffrand: Livre d'architecture, contenant les principes généraux de cet art, et les plans, élévations et profils de quelques-uns des bâti- 
mens faits en France et dans les pays étrangers, Paris I 745 [https://archive.org/details/gri 33 I 25010919435; Zugriff Juni 2019]

Bogner, St. Markus (2003) - Georg Bogner: St. Markus in Salzburg. Ehem. Ursulinenkirche und -kloster (Christliche Kunststätten Österreichs 400), Salzburg 2003

Bogner, Ursulinerinnen ( 1999) - Georg Bogner: Die Kirche der »Ursulinerinnen zu San Marco« in Salzburg als Gesamtkunstwerk unter Berücksichtigung neuer Archivfunde über die Urheberschaft von Johann Bernhard Fischer von Erlach, masch. phil. Dipl., Salzburg I 999

Bohr, Beichtstühle (2009) - Michael Bohr: Barocke Beichtstühle in österreichischen Cistercienserkirchen, in: Analecta Cisterciensia 59 (2009), 2 1 $0-235$

Bohr, Handwerkersaläre (20 I I) - Michael Bohr: Stift Göttweig: Tischlerarbeiten und Handwerkersaläre in der Barockzeit, in: Heidemarie Specht und Tomáš Černušák (Hg.): Leben und Alltag in böhmisch-mährischen und niederösterreichischen Klöstern in Spätmittelalter und Neuzeit (Monastica Historia I), St. Pölten/Brünn 201 I, 337-357

Bohr, Göttweig (2009) - Michael Bohr: Barocke Möbel für Stift Göttweig, in: SMGB I 20 (2009), 509-528

Bohr, Kunstlandschaften (2019) - Michael Bohr: Barocke Tischlerarbeiten in österreichischen Sakralanlagen - Ein Beitrag zur Entwicklung überregionalen Kulturtransfers, regionaler Kunstlandschaften und autochthoner Stilformen, in: Barockberichte 66 (2019), 33-42

Bohr, Kunsttransfer (2019) - Michael Bohr: Barocke Tischlerarbeiten im Stift Schlägl und die Frage nach dem Kunsttransfer, in: Ulrich G. Leinsle und Petrus A. Bayer (Hg.): Stift Schlägl - Beiträge zu Geschichte und Kultur (im Auftrag des Prämonstratenserstiftes Schlägl), Linz 201 9, I 59-1 82

Bohr, Sakralmöbel (20r7) - Michael Bohr: Sakralmöbel aus Österreich: Von Tischlern und ihren Arbeiten im Zeitalter des Absolutismus, Bd. I, Wien/Köln/Weimar 2017

[https://e-book.fwf.ac.at/detail/o: I I I 2 \#?q=Bohr\&page= I \&pagesize= Io; Zugriff: September 2020]

Bohrloch, Rekonstruktion (20 I I) - Annette Bohrloch: Grenzfall Rekonstruktion - zur Bewahrung von Originalbestand? Die Wiederherstellung der Wohnräume des Grafen Gotter im Schloss Molsdorf, in: Grenzen und Möglichkeiten (20 I I), 270-284

Boisits, Schlackwein (200I) - Barbara Boisits: Art. "Schlackwein, Hans«, in: Oesterreichisches Musiklexikon online, 200 I [https://www.musiklexikon.ac.at $/ \mathrm{ml} / \mathrm{musik}$ _S/Schlackwein_Hans. xml; Zugriff: August 2020]

Bond, Fonts ( 1908) - Francis Bond: Fonts and Font Covers, London u. a. I 908

Borromeo, Instructiones fabricae (I 577) - Carlo Borromeo: Instructiones fabricae et supellectilis ecclesiasticae libri II, Mailand I 577 [http://www.memofonte.it/home/files/pdf/scritti_ borromeo.pdf; Zugriff: September 2018]

Borromeo, Instructiones fabricae (2000) - [Instructionum fabricae et supellectilis ecclesiasticae libri II (Monumenta Studia Instrumenta Liturgica 8), Nachdr. mit italienischer Übersetzung hg. v. Stefano della Torre und Massimo Marinelli], Rom 2000.

Borsook, Business (1983) - Eve Borsook: Art and Business in Renaissance Florence, in: Heinrich Lutz (Hg.): Humanismus und Ökonomie (Deutsche Forschungsgemeinschaft: Kommission für Humanismusforschung, Mitteilung VIII), Weinheim I 983, I35-I 55 
Braham/Hager, Fontana ( 1977 ) - Allan Braham und Hellmut Hager: Carlo Fontana. The Drawings at Windsor Castle, London 1977

Braun, Altar (1924) - Joseph Braun: Der christliche Altar in seiner geschichtlichen Entwicklung, 2 Bde., München I 924

Braunfels, Klosterbaukunst (I 969) - Wolfgang Braunfels: Abendländische Klosterbaukunst, Köln I 969

Bredekamp, Modellkritik (I 995) - Horst Bredekamp: Michelangelos Modellkritik, in: Evers, Architekturmodelle (I 995), i I6-I 23

Brenner, Himmel (2014) - Elisabeth Brenner: Ein Himmel auf Erden. Basilika Stift Rein: Meisterwerk des Barock, Graz 20I4

Brenner, Stift Rein (2018) - Elisabeth Brenner (Hg.): Stift Rein: Geschichte, Kultur, Glaube, Kumberg 2018

Brossette, Inszenierung (2002) - Ursula Brossette: Die Inszenierung des Sakralen (Marburger Studien zur Kunst- und Kulturgeschichte, hg. v. Ingo Herklotz, Klaus Niehr und Ulrich Schütte 4), 2 Bde., Weimar 2002

Brunner, Prediger-Orden (I 867) - Sebastian Brunner: Der Prediger-Orden in Wien und Österreich, Wien 1867

Brunner, Seitenstetten (1988) - Karl Brunner (Hg.): Seitenstetten. Kunst und Mönchtum an der Wiege Österreichs (Katalog des Niederösterreichischen Landesmuseums NF 105), Ausst.-Kat. Stift Seitenstetten, Wien I 988

Brunner-Hammerl, Frauenkirchen (2007) - Erika Brunner-Hammerl: Die Wallfahrtskirche und der Kalvarienberg von Frauenkirchen, masch. phil. Dipl., Wien 2007

Buchwinkler, Salzburg-Mülln (r 968) - Petrus Buchwinkler: Salzburg-Mülln (Christliche Kunststätten Österreichs 80), Salzburg 1968

Büscher, Künstlerverträge (2002) - Mareile Büscher: Künstlerverträge in der Florentiner Renaissance (Studien zur europäischen Rechtsgeschichte. Veröffentlichungen des Max-PlanckInstituts für europäische Rechtsgeschichte, Frankfurt am Main I57), Frankfurt am Main 2002

Busch, Chorgestühl (I 928) - Rudolf Busch: Deutsches Chorgestühl in sechs Jahrhunderten, Hildesheim/Leipzig 1928

Calliari, Mattsee (1977) - Franz Calliari (Hg.): Festschrift zur I 200-Jahr-Feier des Stiftes Mattsee, Mattsee I 977

Caramelle, Barock ( 988 ) - Franz Caramelle: Barock im Stift Wilten. Baugeschichte - Baubeschreibung, in: Stift Wilten, Chorherrenstift Wilten (I 988), I 83-220

Caramelle, Gotik (1973) - Franz Caramelle: Die Gotik in Stams, in: Siebenhundert Jahre Stams (1973), 25-46

Caramelle, Kloster (20I6) - Franz Caramelle: Was vom mittelalterlichen Kloster erhalten ist, in: Forcher, Stams (2016), I 72-I 85

Caramelle, Servitenkirche [1973] - Franz Caramelle: Die Servitenkirche zu Innsbruck, Innsbruck o. J. [1973] 
Caramelle, Stamser Gitter (2016) - Franz Caramelle: Von der Eleganz der Stamser Gitter, in: Forcher, Stams (2016), 228-237

Caramelle, Stiftskirche Wilten (2008) - Franz Caramelle: Die Stiftskirche Wilten. Ein geschichtlicher und künstlerischer Überblick, in: Prämonstratenserstift, Stiftskirche Wilten (2008), 9-i 9

Caramelle/Frischauf, Stifte (1985) - Franz Caramelle und Richard Frischauf: Die Stifte und Klöster Tirols, Innsbruck/Wien I 985

Cavazzini, Patto fermo (2010) - Patrizia Cavazzini: »Patto fermo« o cortesia negli accordi tra pittori e committenti a Roma nel Seicento, in: Ricerche di Storia dell'Arte ror (2010), 5-20

Clark, Care (r go9) - John Willis Clark: The Care of Books. An Essay on the Development of Libraries and their Fittings, from the earliest times to the end of the Eighteenth Century, Cambridge I 909

Colle, Mobili ( I 997) - Enrico Colle: I mobili di Palazzo Pitti. Il periodo dei Medici I 537-I 737 (Ministero per i Beni Culturali e Ambientali. Palazzo Pitti, Firenze. Museo degli Argenti 7 , hg. v. Kirsten Aschengreen Piacenti), Florenz I 997

Colombo, L'arte ( 198 I) - Silvano Colombo: L'arte del legno e del mobile in Italia, Busto Arsizio I 98 I

Coreth, Pietas (1959) - Anna Coreth: Pietas Austriaca, Ursprung und Entwicklung barocker Frömmigkeit in Österreich, Wien 1959

Crisan, Sakristeischränke (2008) - Bela Crisan: Restaurierung der Sakristeischränke, in: Prämonstratenserstift, Stiftskirche Wilten (2008), I I 3-I I 6

Csáky, Aufklärung ( 1988) - Moritz Csáky: Aufklärung - Kirche - Benediktiner, in: Brunner, Seitenstetten (I 988), 477-480

Czeike, Burgenland ( 1988 ) - Felix Czeike: Das Burgenland. Land der Störche und der Burgen. Kultur, Landschaft und Geschichte zwischen Ostalpen und Pußta, Köln I 988

Dal Prà, Madruzzo (I 993) - Laura Dal Prà: I Madruzzo e l'Europa I539-I658. I principi vescovi di Trento tra Papato e Impero, Ausst.-Kat., Trient/Riva del Garda/Mailand I993

Decker, Baumeister (I I I/I6) - Paul Decker d.Ä.: Fürstlicher Baumeister oder Architectura civilis [...] 3 Teile, Augsburg I7 I I/I7I6 [https://digi.ub.uni-heidelberg.de/diglit/decker I 7 I I/ooor; Zugriff Januar 2019]

Demetz, Baugeschichte (I 995) - Stefan Demetz: Baugeschichte von Stift Stams, in: Riedmann, Traum (I995), 4I6-4i 8

Deuer, Bauliche Anlage (1 99r) - Wilhelm Deuer: Die bauliche Anlage des Klosters St. Paul bis um I 500 - Versuch einer Rekonstruktion, in: Schatzhaus Kärntens (I 99I), Bd. 2, 505-5 I 5

Deuer, Gurk (1995) - Wilhelm Deuer: Der Dom zu Gurk, Gurk I 995

Deuer, Kunstgeschichte (2013) - Wilhelm Deuer: Kunstgeschichte, in: Suppan, Chronik (2013), $427-496$

Dictionary of Art (1996) - The Dictionary of Art (hg. v. Jane Turner), 34 Bde., New York 1996

Dobras, Hofhandwerker (2017) - Wolfgang Dobras: »Zu Euer Churfürstlichen Gnaden, dero Ertzstift und dieser Stadt Dienst und Nutzen«: Die Mainzer Hofhandwerker von der Mitte 
des I 7. Jahrhunderts bis zum Ende des Kurstaats, in: Tacke/Fachbach/Müller, Hofkünstler (2017), 27-57

Dobrzecki/Volk, Rokokoplastik (1985) - Alina Dobrzecki und Peter Volk: Bayerische Rokokoplastik. Vom Entwurf zur Ausführung, Ausst.-Kat., München 1985

Dörler/Klagian/Dörler, Koloman (2ого) - Philipp Dörler, Thomas Klagian und Karl Dörler: Koloman und Gallus - Mitgestalter eines kulturellen Umbruchs (Schriften der Vorarlberger Landesbibliothek 22, hg. v. Harald Weigel), Graz 2010

Dom von Salzburg ( 928 ) - Der Dom von Salzburg. Zum 30ojährigen Jubiläum r628-r 928 (hg. v. Domweihjubiläums-Komitee, Salzburg), Salzburg 1928

Dom zu Salzburg ( 1959) - Der Dom zu Salzburg. Symbol und Wirklichkeit (hg. v. d. Erzbischöflichen Domkustodie u. Seelsorgeamt), Salzburg I 959

Dopsch, Klöster (1983) - Heinz Dopsch: Klöster und Stifte, in: Dopsch/Spatzenegger, Geschichte Salzburgs (1983), 1002-1053

Dopsch, Weihe (1998) - Heinz Dopsch: Die Weihe der Müllner Kirche durch Erzbischof Eberhard I. im Jahr I I 48, in: Hahnl/Lebesmühlbacher, Mülln (I 998), 67-74

Dopsch/Hahnl/Koll, Michaelbeuern (200I) - Heinz Dopsch, Adolf Hahnl, Beatrix Koll u.a.: Michaelbeuern, in: Faust/Krassnig, Germania Benedictina III/2 (200I), 655-758

Dopsch/Hoffmann, Geschichte (r 996) - Heinz Dopsch und Robert Hoffmann: Geschichte der Stadt Salzburg, Salzburg/München 1996

Dopsch/Juffinger, St. Peter (1982) - Heinz Dopsch und Roswitha Juffinger (Hg.): St. Peter in Salzburg: Das älteste Kloster im deutschen Sprachraum (3. Landesaustellung I 5. Mai-26. Oktober I 982 : Schätze europäischer Kunst und Kultur), Ausst.-Kat., Salzburg 1982

Dopsch/Lipburger, Entwicklung (1983) - Heinz Dopsch und Peter M. Lipburger: Die Entwicklung der Stadt Salzburg, in: Dopsch/Spatzenegger, Geschichte Salzburgs (r 983), 675746

Dopsch/Spatzenegger, Geschichte Salzburgs (1983) - Heinz Dopsch und Hans Spatzenegger (Hg.): Geschichte Salzburgs: Stadt und Land, Bd. I, 2 : Vorgeschichte, Altertum, Mittelalter, Salzburg 1983

Eberl, Zisterzienser (2002) - Immo Eberl: Die Zisterzienser. Geschichte eines europäischen Ordens, Stuttgart 2002

Eberle, Zisterzienserklöster (20г I) - Jürgen Eberle: Mittelalterliche Zisterzienserklöster in Deutschland, Österreich und der Schweiz, Petersberg 20 I I

Ebhardt, Barockkirchen (I 975) - Manfred Ebhardt: Die Salzburger Barockkirchen im I 7. Jahrhundert. Beschreibung und kunstgeschichtliche Einordnung (Studien zur deutschen Kunstgeschichte 354), Baden-Baden I 975

Egg, Hofkirche (1 974) - Erich Egg: Die Hofkirche in Innsbruck. Das Grabmal Kaiser Maximilians I. und die Silberne Kapelle, Innsbruck/Wien/München 1974

Egg, Kunst (1970/r972) - Erich Egg: Kunst in Tirol, 2 Bde., Innsbruck/Wien/München I $970 / 1972$

Egger, Beschläge (1973) - Gerhart Egger: Beschläge und Schlösser an alten Möbeln, München I 973 
Ehalt, Ausdrucksformen ( 1980 ) - Hubert Ch. Ehalt: Ausdrucksformen absolutistischer Herrschaft. Der Wiener Hof im I 7. und i 8. Jahrhundert (Sozial- und wirtschaftshistorische Studien, hg. v. Alfred Hoffmann und Michael Mitterauer I 4), Wien r 980

Ehalt, Zeremoniell (I98I) - Hubert Ch. Ehalt: Zur Funktion des Zeremoniells im Absolutismus, in: Europäische Hofkultur im I6. und I7. Jahrhundert (Wolfenbütteler Arbeiten zur Barockforschung, Bd. 8-ı, hg. v. Martin Bircher), Bd. 9, Hamburg I 98 I , 4I I-4I 9

Ehmer, Zünfte (2002) - Josef Ehmer: Zünfte in Österreich in der frühen Neuzeit, in: Haupt, Zünfte (2002), 87-I 26

Eikelmann, Prunkmöbel (2or I) - Renate Eikelmann (Hg.): Prunkmöbel am Münchner Hof. Barocker Dekor unter der Lupe, Ausst.-Kat., München 20 I I

Eisenhofer, Handbuch (1932/33) - Ludwig Eisenhofer: Handbuch der katholischen Liturgik, 2 Bde., Freiburg $1932 / 33$

Elam, Sangallo (2017) - Caroline Elam: Giuliano da Sangallo architetto legnaiuolo, in: Amedeo Belluzzi, Caroline Elam und Francesco Paolo Fiore (Hg.): Giuliano da Sangallo, Mailand $2017,75^{-86}$

Elias, Höfische Gesellschaft (1969) - Norbert Elias: Die höfische Gesellschaft. Untersuchungen zur Soziologie des Königtums und der höfischen Aristokratie, Neuwied r 969

Elkar, Schreiner (I99I) - Rainer S. Elkar: Schreiner in Franken. Handwerk zwischen Zunft, Kunst und Fabrik, in: Möbel aus Franken: Oberflächen und Hintergründe (hg. v. Bayerischen Nationalmuseum München), Ausst.-Kat. Nürnberg, München I99 I, 28-45

Eltz-Hoffmann/Anrather, Kirchen Salzburgs ( ( 993) - Lieselotte von Eltz-Hoffmann und Oskar Anrather: Die Kirchen Salzburgs. Irdische Metaphern einer überirdischen Welt, Salzburg I 993

Engelberg, Barock (2014) - Meinrad von Engelberg: »Bayerischer« vs. »Österreichischer« Barock: »Kunstlandschaftliche« Differenzierungen zwischen Konstruktion und Empirie, in: Möseneder/Thimann/Hofstetter, Barocke Kunst (2014), Bd. 2, 408-423

Engelberg, Einleitung (20 14) - Meinrad von Engelberg: Einleitung zur Sektion, in: Möseneder/ Thimann/Hofstetter, Barocke Kunst (2014), Bd. 2, 323-328

Engelberg, Renovatio ecclesiae (2005) - Meinrad von Engelberg: Renovatio ecclesiae: die "Barockisierung« mittelalterlicher Kirchen (Studien zur internationalen Architektur- und Kunstgeschichte 23), Petersberg 2005

Erichsen, Gesamtkunstwerk (201 I) - Johannes Erichsen: Gesamtkunstwerk und Raumkunst, in: Grenzen und Möglichkeiten (20 I I), I 28-г 37

Erker, Chronologie (2009) - Erich Erker: Chronologie der Zerstörung und des Wiederaufbaus des Domes, in: Peter Keller (Hg.): Ins Herz getroffen. Zerstörung und Wiederaufbau des Domes I 944-I 959, Salzburg 2009, 9-19

Euler-Rolle, Akanthusaltäre ( 1987 ) - Bernd Euler-Rolle: Akanthusaltäre: zum »Dekorativen« und zum »Provinziellen« Stil des Barock, in: WJbKG 40 ( 1987 ), 67-82, 345-348

Euler-Rolle, Form (1983) - Bernd Euler-Rolle: Form und Inhalt kirchlicher Gesamtausstattungen des österreichischen Barock bis I 720/30, masch. phil. Diss., Wien I 983

Evers, Architekturmodelle (1995) - Bernd Evers (Hg.): Architekturmodelle der Renaissance: 
die Harmonie des Bauens von Alberti bis Michelangelo, Ausst.-Kat. Berlin I995/1996, München/New York I 995

Fabiankowitsch/Witt-Dörring, Fantasie ( 1996) - Gabriele Fabiankowitsch und Christian WittDörring: Genormte Fantasie: Zeichenunterricht für Tischler; Wien I 800-I 840, Ausst.-Kat. Wien r 996-r997, Wien/Köln/Weimar 1996

Faust, Gurk (200I) - Ulrich Faust: Gurk, in: Faust/Krassnig, Germania Benedictina III/2 (2001), 47-49

Faust, St. Paul (2002) - Ulrich Faust: St. Paul im Lavanttal, in: Faust/Krassnig, Germania Benedictina III/3 (2002), 74-I4I

Faust/Krassnig, Germania Benedictina (I 999-2002) - Ulrich Faust und Waltraud Krassnig (Bearb.): Germania Benedictina. Die benediktinischen Mönchs- und Nonnenklöster in Österreich und Südtirol (hg. v. d. Bayerischen Benediktinerakademie München in Verbindung mit dem Abt-Herwegen-Institut Maria Laach), 3 Bde., St. Ottilien I 999-2002

Felmayer, Hofkirche (1986) - Johanna Felmayer: Hofkirche, Franziskanerkloster und Neues Stift, in: ÖKT, Innsbruck, Hofbauten (I 986), 237-326

Felmayer, Servitenkirche (I 990) - Johanna Felmayer: Servitenkirche Innsbruck, Innsbruck I 990 Felmayer, Servitenkirche (r995) - Johanna Felmayer: Servitenkirche und Kloster, in: ÖKT, Innsbruck, I (1995), I 59-277

Felmayer, Spitalskirche (I 995) - Johanna Felmayer: Spitalskirche zum hl. Geist und ehemaliger Friedhof, in: ÖKT, Innsbruck, I (I995), 332-349

Felmayer, Stiftskirche (1958) - Johanna Felmayer: Stiftskirche und Basilika Wilten, in: Steinegger, Wilten (1 958), 33-44

Ferrari, Legno [ca. I928] - Giulio Ferrari: Il legno e la mobilia nell'arte italiana, 2. Aufl., Mailand o. J. [ca. I 928 ]

Feuchtmüller, Umgestaltung (1982) - Rupert Feuchtmüller: Die spätbarocke Umgestaltung der Stiftskirche unter Abt Beda Seeauer, in: Festschrift St. Peter (I 982), 653-693

Feulner, Kunstgeschichte (1927) - Adolf Feulner: Kunstgeschichte des Möbels seit dem Altertum CPropyläen Kunstgeschichte, Ergänzungsband I), Berlin 1927

Feulner, Kunstgeschichte (I980) - Adolf Feulner: Kunstgeschichte des Möbels (Propyläen Kunstgeschichte, Sonderband II; neubearb. v. Dieter Alfter), Frankfurt am Main/Berlin/ Wien 1980

Fidler-Daxer, Stuhlwangen ( 1995 ) - Elisabeth Fidler-Daxer: Ikonographie der Fiechter Stuhlwangen, Brünn 1995

Fierens, Chaires (1 943) - Paul Fierens: Chaires et confessionnaux baroques. L'art en Belgique, Brussel i 943

Fink, Neuberg (1967) - Anton Fink: Kurzer Führer durch Kirche und Stift Neuberg, Graz I 967 Fleischer, Karl Eusebius ( І 9го) - Victor Fleischer: Fürst Karl Eusebius von Liechtenstein als Bauherr und Kunstsammler i6 I I-I684 (Veröffentlichungen der Gesellschaft für neuere Geschichte Österreichs I), Wien/Leipzig I 9 Iо

Forcher, Stams (2016) - Michael Forcher (Hg.): Stift Stams. Ein Tiroler Juwel mit wechselvoller Geschichte, Innsbruck/Wien 2016 
Frank, Einheit (2000) - Karl Suso Frank: Einheit und Vielfalt im Mönchsleben, in: Vavra, Suche (2000), 57-73

Frank, Geschichte (2010) - Karl Suso Frank: Geschichte des christlichen Mönchtums, 6. Aufl., Darmstadt 2010

Frank, Vorau (1925) - Pius Frank: Das Chorherrenstift Vorau und sein Wirken in Vergangenheit und Gegenwart, Graz I 925

Frankl/Tropper, Gurk (2005) - Karl Heinz Frankl und Peter G. Tropper: Gurk I I 23-1 787 , in: Röhrig, Ehemalige Stifte (2005), I 73-204

Franz, Bandlwerck (2006) - Rainald Franz: Das "Laub- und Bandlwerck«. Ein Ornament als Signet des Kunsttransfers im Mitteleuropa des frühen I 8. Jahrhunderts, in: ÖZKD $3-4,60$ (2006), 4 I 8-427

Franz, Pourtraicture (2009) - Rainald Franz: Pourtraicture ingénieuse de plusieurs Facons de Masques [...], in: Wir sind Maske, Ausst.-Kat. Wien, Mailand 2009, 346-349

Franz, Ornamentvorlagen (20 I I) - Rainald Franz: Ornamentvorlagen für Boulle-Marketerien Ein Medium des Kunsttransfers in Mitteleuropa an der Wende vom i 7. zum I 8. Jahrhundert, in: Eikelmann, Prunkmöbel (201 I), 33-45

Frauenkirchen, Burgenland (I96r) - Frauenkirchen. Burgenland (Christliche Kunststätten Österreichs I7), Salzburg I96 I

Freed, Dienstmannschaft (1982) - John B. Freed: Die Dienstmannschaft von St. Peter, in: Festschrift St. Peter (1982), $56-78$

Friedhoff, Wohnen (I998) - Jens Friedhoff: „Magnificence« und »Utilité«. Bauen und Wohnen I600-1 800, in: Ulf Dirlmeier (Hg.): Geschichte des Wohnens, Bd. 2 (500-1800: Hausen/Wohnen/Residieren), Stuttgart I 998, 503-788

Friese, Ceremonial-Politica (I705-I7r6) - Friedrich Friese: Der vornehmsten Künstler und Handwercker Ceremonial-Politica ... Erster Theil, in welchem zu finden der Schmiedt, Schneider, Tischer (!), Beuttler, Böttger, Drechsler, Kürschner u. Schuster, Leipzig I 705- I 7 I 6

Fuhrmann, Baugeschichte (1982) - Franz Fuhrmann: Die Baugeschichte von Kirche und Kloster, in: Dopsch/Juffinger, St. Peter (I982), I 74-1 80

Fuhrmann, Dom (1 974) - Franz Fuhrmann: Der barocke Dom - Form und Herkunft, in: Spatzenegger, Dom zu Salzburg (1 974), 90-I I 9

Fuhrmann, Dom (1999) - Franz Fuhrmann: Der Dom zu Salzburg (Christliche Kunststätten Österreichs 4), I8. Aufl., Salzburg 1999

Fuhrmann, Kirchen (1 949) - Franz Fuhrmann: Kirchen in Salzburg (Wolfrumbücher I 9), Wien I 949

Fuhrmann, Romanische Dome (1959) - Franz Fuhrmann: Die romanischen Dome zu Salzburg auf Grund der bisherigen Grabungsergebnisse, in: Dom zu Salzburg (1959), 86-102

Gaehtgens/Castor/Bussmann, Versailles (2017) - Thomas W. Gaehtgens, Markus A. Castor, Frédéric Bussmann u.a. (Hg.): Versailles et l'Europe. L'appartement monarchique et princier, architecture, décor, cérémonial, Bd. I, Paris 2017 [https://books.ub.uni-heidelberg.de/arthis toricum/catalog/book/234; Zugriff Juni 20I 9] 
Galli Bibiena, Architetture (I 964) - Giuseppe Galli Bibiena: Architetture e prospettive dedicate alla maestà Carlo sesto [...] I 740, Ausst.-Kat. (bearb. v. A. Hyatt Mayor), New York 1964

Gamerith, Non otiose (2006) - Andreas Gamerith: Non otiose, sed laboriose! Überlegungen und Fragen zur spätbarocken Umgestaltung des Stiftes Altenburg anlässlich des 250. Todestages von Abt Placidus Munch, in: Das Waldviertel 4, 55 (2006), 369-385

Ganz/Seeger, Chorgestühl (I946) - Paul Leonhard Ganz und Theodor Seeger: Das Chorgestühl in der Schweiz, Frauenfeld I 946

Gasser, Beiträge ( 1959) - Josef Gassner: Beiträge zu einer Bibliographie der Geschichte des Salzburger Domes, in: Dom zu Salzburg (I 959), I 35-I 53

Gerlach, Chorgestühl (193 I) - Georg Gerlach: Die Entwicklung des Chorgestühls in Steiermark und Kärnten, masch. phil. Diss., Graz I 93 I

Gierse, Bildprogramme (2010) - Julia Gierse: Bildprogramme barocker Klostersakristeien in Österreich, Marburg 2010

Gigler, Umbauten ( 1924 ) - Herbert Johannes Gigler: Die Um- und Neubauten des Stiftes Rein im I 8. Jahrhundert, masch. phil. Diss., Graz I 924

Ginhart, Hönel (1959) - Karl Ginhart: Michael Hönel und seine Beziehungen zum Stifte St. Paul i. L., in: Moro, Festgabe (1959), I $52-198$

Ginhart, Stift (1953) - Karl Ginhart: Das Stift St. Paul im Lavanttal, St. Paul im Lavanttal I 953

Ginhart/Münzer, Stift St. Paul ( 1983 ) - Karl Ginhart und Wolfgang Münzer: Stift St. Paul im Lavanttal, München/Zürich I 983

Ginhart/Grimschitz, Gurk (1930) - Karl Ginhart und Bruno Grimschitz: Der Dom zu Gurk (Denkmäler deutscher Kunst, hg. v. Kunsthistorischen Institut des Bundesdenkmalamtes unter Leitung von Dagobert Frey u.a.), Wien I 930

Giometti, Formule (2010) - Cristiano Giometti: Formule per scolpire. Committenza, mercato e pratiche di bottega nei contratti notarili romani del Seicento, in: Ricerche di Storia dell'Arte IOI (2010), 33-40

Giusti, Splendori (1988) - Annamaria Giusti: Splendori di pietre dure. L'arte di corte nella Firenze dei granduchi, Ausst.-Kat. Florenz, I 988/ı 989 , Florenz I 988

Glasser, Artist's contracts (1965) - Hannelore Glasser: Artist's contracts of the early Renaissance, masch. phil. Diss., Columbia Univ., New York 1965

Gombocz, Betbänke (2008) - Walter Gombocz: Restaurierung der Betbänke, des Chorgestühls und des Abtstuhles, in: Prämonstratenserstift, Stiftskirche Wilten (2008), 100-107

Graf, Besprechung (2016) - Henriette Graf: Besprechung Thomas Wilke: Innendekoration. Graphische Vorlagen und theoretische Vorgaben für die wandfeste Dekoration von Appartements im I7. und I 8. Jahrhundert in Frankreich, 2 Bde, München 2016, in: RECS-Buchbesprechungen, or/I I/20I6 [https://recs.hypotheses.org/790; Zugriff Juni 20 I 9]

Graf, Residenz (2002) - Henriette Graf: Die Residenz in München. Hofzeremoniell, Innenräume und Möblierung von Kurfürst Maximilian I. bis Kaiser Karl VII. (Bayerische Verwaltung der staatlichen Schlösser, Gärten und Seen. Forschungen zur Kunst- und Kulturgeschichte VIII), München 2002 
Graf, Zeremoniell (r 997) - Henriette Graf: Das kaiserliche Zeremoniell und das Repräsentationsappartement im Leopoldinischen Trakt der Wiener Hofburg um I 740, in: ÖZKD ${ }_{3}-4$, 5 I (I 997), 57 I -587

Gregor, Dialogi ( I 494/95) - Gregorius <Papa, I.>, Dialogi de vita et miraculis patrum italicorum, Paris I 494/95

[https://daten.digitale-sammlungen.de/ db/ooo//bsbooo72572/images/; Zugriff Oktober 2020]

Grenzen und Möglichkeiten (20 I I) - Das Kunstwerk in der Residenz. Grenzen und Möglichkeiten der Präsentation höfischer Kultur (Jahrbuch der Stiftung Thüringer Schlösser und Gärten I 4), Regensburg 20 I I

Gritsch, Schmiedeeisengitter (I 973) - Johanna Gritsch: Schmiedeeisengitter im Stift Stams, in: Siebenhundert Jahre Stams (1973), I05-I I7

Gritsch/Trapp, Kriegsschäden (I 958) - Johanna Gritsch und Oswald Trapp: Die Kriegsschäden, in: Steinegger, Wilten (I 958), 45-5 I

Gruber, Stephansdom (20 I ) - Reinhard H. Gruber: Der Wiener Stephansdom. Porträt eines Wahrzeichens, Innsbruck/Wien 20 I I

Guinomet, Sakramentstabernakel (2017) - Claire Guinomet: Das italienische Sakramentstabernakel im I6. Jahrhundert. Tempietto-Architekturen en miniature zur Aufbewahrung der Eucharistie (Römische Studien der Bibliotheca Hertziana 38), München 2017

Gutkas, Österreich (1976) - Karl Gutkas: Das Land Österreich zur Zeit der Staufer, in: Eintausend Jahre Babenberger ( I 976), 26-37

Haag, Meisterwerke (2010) - Sabine Haag (Hg.): Meisterwerke der Kunstkammer (Kurzführer durch das Kunsthistorische Museum I 2), Wien 2010

Haag, Schenck (1996) - Sabine Haag: Johann Caspar Schenck (um r620-1674)»Cammerdrechsler von Ynsprug" und „Cammerpainstecher« am Hof Kaiser Leopolds I. in Wien, in: Christoph Daniel Schenck r633-r69r (hg. v. Rosgartenmuseum Konstanz, Augustinermuseum Freiburg und Württembergischen Landesmuseum Stuttgart), Ausst.-Kat., Konstanz/ Freiburg/Stuttgart/Sigmaringen I 966, 93-106

Haendcke, Einfluß (1925) - Berthold Haendcke: Der französisch-deutsch-niederländische Einfluss auf die italienische Kunst von etwa I 200 bis etwa I650: eine entwicklungsgeschichtliche Studie (Études sur l'art de tous les pays et de toutes les époques 4), Straßburg 1925

Hahnl, Kunstgeschichte (1974) - Adolf Hahnl: Zur Bau- und Kunstgeschichte des Plainer Heiligtums, in: SMGB 85 (I974), I72-224

Hahnl, Kunsthandwerk (2003) - Adolf Hahnl: Das Kunsthandwerk, in: Keller/Neuhardt/Heinisch, Erzbischof Lodron (2003), 107-1 I 6

Hahnl, Mülln (г 998) - Adolf Hahnl: Salzburg-Mülln (Christliche Kunststätten 8o), 4., überarb. Aufl., Salzburg 1998

Hahnl, Rein (I 973) - Adolf Hahnl: Stift Rein (Christliche Kunststätten I04), Salzburg 1973

Hahnl, St. Peter ( 1982 ) - Adolf Hahnl: St. Peter und die Stadt Salzburg, in: Dopsch/Juffinger, St. Peter (1982), 44-48

Hahnl/Bachler, Wallfahrtsbasilika (2009) - Adolf Hahnl und Winfried Bachler: Wallfahrtsba- 
silika Maria Plain bei Salzburg. Geschichte, Kunst, Spiritualität (Christliche Kunststätten Österreichs 500), Salzburg 2009

Hahnl/Lebesmühlbacher, Mülln ( 1998$)$ - Adolf Hahnl und Siegfried Lebesmühlbacher (Hg.): Mülln. Ein Juwel erstrahlt wieder, Salzburg I 998

Haidacher, Chronik (2000) - Christoph Haidacher: Pater Wolfgang Lebersorgs Chronik des Klosters Stams, Innsbruck 2000

Haidenthaler, Michaelbeuern (200I) - Paulus Haidenthaler: Abtei Michaelbeuern (Christliche Kunststätten Österreichs 375), Salzburg 200 I

Hajdecki, Indau ( 1907 ) - Alexander Hajdecki: Johann Indau und sein »Wienerisches Architekturbuch«, in: Berichte und Mitteilungen des Altertums-Vereines zu Wien 40 (I 907), 89-1 I6

Halder, Geschichte ( I 988) - Klemens Halder: Die Geschichte des Stiftes Wilten seit I I 38 , in: Stift Wilten, Chorherrenstift Wilten ( 1 988), I 9-6o

Hamm, Altartabernakel (2о го) - Johannes Hamm: Barocke Altartabernakel in Süddeutschland, Petersberg 2010

Hammer, Baugeschichte (1 935) - Heinrich Hammer: Zur Baugeschichte des Zisterzienserstiftes Stams, in: WJbKG ro (1935), 24-42

Hammer, Kunstgeschichte (1952) - Heinrich Hammer: Kunstgeschichte der Stadt Innsbruck, Innsbruck/Wien/München 1952

Hammerle, Zerstörung ( 1988 ) - Lukas Hammerle: Zerstörung des Stiftes Wilten im 2. Weltkrieg und Wiederaufbau, in: Stift Wilten, Chorherrenstift Wilten ( 1988 ), 22 I-240

Hann, Gurker Dom ( I 897) - Franz G. Hann: Kunstgeschichtlicher Führer durch den Gurker Dom, Klagenfurt I 897

Hann, Gurker Dom ( г g Io) - Franz G. Hann: Der Gurker Dom. Seine Entstehung, Architektur und Kunstgeschichte, Klagenfurt I 9 ro

Hanzl, Möbelkunst (r 994) - Lieselotte Hanzl: Die Möbelkunst am Wiener Hof zur Zeit Franz I. (II.) (I 792-I 835), masch. phil. Diss., Wien I 994

Hanzl-Wachter, Hofburg (2004) - Lieselotte Hanzl-Wachter: Hofburg zu Innsbruck. Architektur, Möbel, Raumkunst. Repräsentatives Wohnen in den Kaiserappartements von Maria Theresia bis Kaiser Franz Joseph (Museen des Mobiliendepots I 7), Wien/Köln/Weimar 2004

Harhammer, Barocke Holzskulptur (1988) - Ulrike Harhammer: Barocke Holzskulptur im Kremser Raum. Studien zur Kunstgeschichte des Donautales, masch. phil. Diss., Wien I 988

Hartwagner, Gurk ( I 969) - Siegfried Hartwagner: Der Dom zu Gurk, 2., erw. Aufl., Klagenfurt/ Wien/Frankfurt am Main r 969

Haupt, Hofhandwerk (2007) - Herbert Haupt: Das Hof- und hofbefreite Handwerk im barocken Wien I620-I770 (Forschungen und Beiträge zur Wiener Stadtgeschichte. Publikationsreihe des Vereins für Geschichte der Stadt Wien 46, hg. v. Susanne Claudine Pils), Innsbruck/Wien 2007

Haupt, Wege (2002) - Heinz-Gerhard Haupt: Neue Wege zur Geschichte des Zünfte in Europa, in: Haupt, Zünfte (2002), 9-37

Haupt, Zünfte (2002) - Heinz-Gerhard Haupt (Hg.): Das Ende der Zünfte: Ein europäischer 
Vergleich (Kritische Studien zur Geschichtswissenschaft, hg. v. Helmut Berding, Jürgen Kocka, Hans-Peter Ullmann u.a. I 5 I), Göttingen 2002

Hautecœur, Histoire (I 948) - Louis Hautecœur: Histoire de l'architecture classique en France. Le reigne de Louis XIV, Paris 1948

Heidelmann/Meissner, Beichtstühle (200I) - Hildegard Heidelmann und Helmuth Meissner: Evangelische Beichtstühle in Franken (Schriften und Kataloge des Fränkischen Freilandmuseums 33), Bad Windsheim 200 I

Heimann/Hilsebein/Schmies/Stiegemann, Armut (201 2) - Heinz-Dieter Heimann, Angelica Hilsebein, Bernd Schmies und Christoph Stiegemann (Hg.): Gelobte Armut. Armutskonzepte der franziskanischen Ordensfamilie vom Mittelalter bis in die Gegenwart, Paderborn/ München/Wien 2012

Heinz, Orgeln (2012) - Otmar Heinz: Frühbarocke Orgeln in der Steiermark: zur Genese eines süddeutsch-österreichischen Instrumententyps des I 7. Jahrhunderts, Wien u.a. 2012

Heisel, Bauzeichnungen ( 1993 ) - Joachim Heisel: Antike Bauzeichnungen, Darmstadt I 993

Hellwag, Geschichte ( I 924) - Fritz Hellwag: Die Geschichte des deutschen Tischlerhandwerks vom I 2. bis zum 20. Jahrhundert, Berlin I 924

Hermann, Geschichte (I 974) - Friedrich Karl Hermann: Maria Plain - Geschichte und Leben, in: SMGB 85 (1974), I7-16 I

Hermann, Geschichte (1996) - Friedrich Karl Hermann: Geschichte der Erzabtei St. Peter zu Salzburg (Bd. I, Frühgeschichte 696-I I 93), Salzburg I 996

Hermann, Maria Plain ( 1998 ) - Friedrich Karl Hermann: Maria Plain (Christliche Kunststätten Österreichs 5), I 4. Aufl., Salzburg I 998

Hermann, Maria Plain (200I) - Friedrich Karl Hermann: Maria Plain, in: Faust/Krassnig: Germania Benedictina III/2 (200I), 38 I-394

Hermann, Mattsee (200I) - Friedrich Karl Hermann: Mattsee, in: Faust/Krassnig, Germania Benedictina III/2 (200I), 485-490

Hermann, Trennung (1982) - Friedrich Karl Hermann: 987: Trennung der Abtei vom Bistum, in: Festschrift St. Peter (1982), S. 26-55

Hermann, St. Peter (196r) - Friedrich Karl Hermann: St. Peter (Christliche Kunststätten Österreichs I), 4., verb. Aufl., Salzburg I 96 I

Hermann/Hahnl, St. Peter (2002) - Friedrich Karl Hermann und Adolf Hahnl: Salzburg, St. Peter, in: Faust/Krassnig: Germania Benedictina III/3 (2002), 263-408

Hersche, Bauen (1988) - Peter Hersche: Barockes Bauen: Last oder Lust? Eine Duplik, in: Frühneuzeit-Info I, 9 (I 998), 52-53

Hersche, Klosterkultur (2012) - Peter Hersche: Klosterkultur im Barock, vornehmlich im romanischsprachigen Europa. Ein Überblick, in: Landa/Stöttinger/Wührer, Lambach (2OI 2), 43-57

Hersche, Muße (2006) - Peter Hersche: Muße und Verschwendung. Europäische Gesellschaft und Kultur im Barockzeitalter, 2 Bde., Freiburg/Basel/Wien 2006

Heydenreich, Architekturmodelle (1937) - Ludwig Heinrich Heydenreich: Architekturmodelle, in: RDK, Bd. I, Stuttgart I937, Sp. 91 8-940 
Himmelheber, Kleine Möbel ( I 979) - Georg Himmelheber: Kleine Möbel. Modell-, Andachtsund Kassettenmöbel vom I3.-20. Jahrhundert, Ausst.-Kat., München/Frankfurt am Main I 979

Hladky, Kirchenmöbel (2003) - Franziska Hladky: Kirchenmöbel des I 7. und I 8. Jahrhunderts in Wien, 2 Bde., masch. phil. Diss., Wien 2003

Hochenegg, Kirchen Tirols ( 1935 ) - Hans Hochenegg: Die Kirchen Tirols. Die Gotteshäuser Nord- und Osttirols in Wort und Bild (hg. von der katholischen Aktion für Tirol), Innsbruck I 935

Hölzl, Nissl (1 976) - Gisela Hölzl: Franz Xaver Nissl (I 73 I-1 804). Ein Tiroler Bildhauer des Spätbarocks, masch. phil. Diss., Innsbruck 1976

Hoppe, Wiederaufbau (1959) - Theodor Hoppe: Der Wiederaufbau des Salzburger Domes und die Denkmalpflege, in: Dom zu Salzburg (1959), го3-1 го

Hörmann, Meister (2006) - Magdalena Hörmann: Alles Meister. Kunsthandwerk in Tirol (hg. v. Südtiroler Kulturinstitut und Stiftung Südtiroler Sparkasse), Bozen 2006

Hörmann-Weingartner, Kunsthandwerk (2007) - Magdalena Hörmann-Weingartner: Kunsthandwerk des I7. und I8. Jahrhunderts, in: Naredi-Rainer/Madersbacher, Tirol (2007), Bd. 2, I69-I 82

Horst, Dominikanerorden (2003) - Ulrich Horst: Dominikanerorden, in: Schwaiger, Mönchtum (2003), I 5 6-i 77

Horvath/Weiger, Lockenhaus (2005) - Wolfgang Horvath und Alexander Weiger: Lockenhaus, Burgenland (Christliche Kunststätten Österreichs 244), 3. Aufl., Salzburg 2005

Hubala, Rottmayr (198I) - Erich Hubala: Johann Michael Rottmayr, Wien/München r 98 I

Huber, Christian (1960) - Rudolf Huber: Joseph Christian der Bildhauer des schwäbischen Rokoko, Tübingen I 960

Hubert, Leben (1954) - Szántó Stefan Hubert: Das Leben im Stifte Wilten vom Spätmittelalter bis in die Barockzeit: Ein Beitrag zur Geschichte des Prämonstratenserordens, masch. phil. Diss., 2 Bde., Innsbruck I 954

Hübl, Baugeschichte (I9r4) - Albert Hübl: Baugeschichte des Stiftes Schotten in Wien, in: Berichte und Mitteilungen des Altertumsvereins zu Wien 46/47 (I9I4), 35-88

Huth, Künstler (1923) - Hans Huth: Künstler und Werkstatt der Spätgotik, Augsburg 1923 [Neudr. Darmstadt I 967]

Hutz, Leisl ( 1992) - Ferdinand Hutz: Johann Philipp Leisl, Propst von Vorau (I691-I 71 7), in: Schwarzkogler, Lust (1 992), 265-270

Hutz, Pöllau (2005) - Ferdinand Hutz: Pöllau I 504-I 785 , in: Röhrig, Ehemalige Stifte (2005), $205-236$

Ilg, Interieurs (1 895) - Albert Ilg: Interieurs von Kirchen und Kapellen in Österreich, Wien I 895

Irmscher, Akanthus (2000) - Günter Irmscher: Akanthus. Zur Geschichte der Ornamentform, in: Barockberichte 26/27 (2000), 46I-532

Irmscher, Bandlwerk (I 99I) - Günter Irmscher: Das Laub- und Bandlwerk - Ein vergessenes Ornament, in: Barockberichte 3 ( 
Irmscher, Kunstgeschichte (I 984) - Günter Irmscher: Kleine Kunstgeschichte des europäischen Ornaments seit der frühen Neuzeit (I 400-I 900), Darmstadt I 984

Irmscher, Säulenbücher (1 999) - Günter Irmscher: Kölner Architektur- und Säulenbücher um I600 (Sigurd Greven-Studien 2), Bonn I 999

Jahn, Hildebrandt (20 I I) - Peter Heinrich Jahn: Johann Lucas von Hildebrandt (I 668-I 745). Sakralarchitektur für Kaiserhaus und Adel, Petersberg 20 I I

Jaksch/Fischer/Kroller, Bibliotheksbau (1992) - Walter Jaksch, Edith Fischer und Franz Kroller: Österreichischer Bibliotheksbau, Bd. I : Von der Gotik bis zur Moderne, Graz I 992

Jávor, Donner ( 1996) - Anna Jávor: Georg Raphael Donner als Unternehmer. Kollektive Monumentalwerke und Werkstattarbeiten, in: Ingeborg Schemper-Sparholz (Hg.): Georg Raphael Donner: Einflüsse und Auswirkungen seiner Kunst, in: JbKSW 92 NF LVI (1996), I $39-$ I 48

Jernej, Kollegiatstift ( 1997 ) - Renate Jernej: Das Kollegiatstift St. Bartholomäus in Friesach von den Anfängen bis zum Jahr I 848, masch. phil. Diss., Salzburg 1997

Jernej, Kollegiatstift (200I) - Renate Jernej: Das Kollegiatstift St. Bartholomäus in Friesach (Archiv für vaterländische Geschichte und Topographie, hg. v. Geschichtsverein für Kärnten 85), Klagenfurt 200 I

Jesuitenkirche [1 977] - Die Jesuitenkirche zu Innsbruck o. O., o. J. [Innsbruck r 977]

Jungmann, Symbolik (1960) - Josef Andreas Jungmann: Symbolik der katholischen Kirche (Symbolik der Religionen, hg. v. Ferdinand Herrmann 6), Stuttgart I 960

Kain/Penz, Inszenierung (2010) - Johanna Kain und Helga Penz: Die Inszenierung des Kirchenraumes durch Propst Hieronymus Übelbacher, in: Penz/Zajic, Dürnstein (2010), I30-I6 I

Kalinowski, Werkstattpraxis ( 1992 ) - Konstanty Kalinowski (Hg.): Studien zur Werkstattpraxis der Barockskulptur im I7. und I 8. Jahrhundert (Uniwersytet Im. Adama Mickiewicza w Poznaniu. Seria historia sztuki i 8), Posen 1992

Kalousek, Hofburginterieurs (2016) - Petra Kalousek: Hofburginterieurs in der ersten Hälfte des i8. Jahrhunderts, in: Hellmut Lorenz und Anna Mader-Kratky (Hg.): Die Wiener Hofburg I705-I835. Die kaiserliche Residenz vom Barock bis zum Klassizismus (Österreichische Akademie der Wissenschaften. Veröffentlichungen zur Kunstgeschichte I 4 , hg. v. Werner Telesko), Wien 2016, 355-380

Karner/Telesko, Jesuiten (2003) - Herbert Karner und Werner Telesko (Hg.): Die Jesuiten in Wien. Zur Kunst- und Kulturgeschichte der österreichischen Ordensprovinz der »Gesellschaft Jesu« im I7. und I8. Jahrhundert (Österreichische Akademie der Wissenschaften. Veröffentlichungen der Kommission für Kunstgeschichte 5, hg. v. Artur Rosenauer), Wien 2003

Keller/Neuhardt/Heinisch, Erzbischof Lodron (2003) - Peter Keller, Johannes Neuhardt, Reinhard Rudolf Heinisch u.a. (Hg.): Erzbischof Paris Lodron (I619-I653). Staatsmann zwischen Krieg und Frieden, Ausst.-Kat., Salzburg 2003

Kempkens, Kirchenausstattungen (2009) - Holger Kempkens: Spätmittelalterliche Kirchenausstattungen des Benediktinerordens im deutschsprachigen Raum, in: Sitar/Kroker, Macht des Wortes (2009), Bd. I, 34 I-37 I 
Kerschbaum, Mattsee (2010) - Roland Peter Kerschbaum: Mattsee. Stiftspfarrkirche St. Michael (Christliche Kunststätten Österreichs 520 ), Salzburg 2010

KHM, Schatzkammer (199r) - Kunsthistorisches Museum Wien (Hg.): Weltliche und geistliche Schatzkammer. Bildführer (Führer durch das Kunsthistorische Museum 35), 2., verb. Aufl., Salzburg/Wien I 99 I

Kienzl, Bildhauer (1996) - Barbara Kienzl: Der Bildhauer - Handwerker oder freier Künstler. Zur Situation in der ersten Hälfte des I 8. Jahrhunderts in den österreichischen Ländern, in: Michael Braunsteiner (Hg.): famosus statuarius Josef Stammel I 695-I 765 : Barockbildhauer im Auftrag des Benediktinerstiftes Admont (Schriften zur Kultur- und Kunstgeschichte des Benediktinerstiftes Admont I), Ausst.-Kat., Admont I 996, 50-59

Kienzl, Kanzeln (1986) - Barbara Kienzl: Die barocken Kanzeln in Kärnten (Das Kärntner Landesarchiv I 3 ; hg. v. d. Direktion des Kärntner Landesarchivs), Klagenfurt I 986

Klemm, Ausstattungsprogramme ( 1 997) - David Klemm: Ausstattungsprogramme in Zisterzienserkirchen Süddeutschlands und Österreichs von I620 bis I 720 (Europäische Hochschulschriften. Kunstgeschichte 293), Frankfurt am Main/Berlin/Bern/New York u. a. I 997

Kloster Stams, Stift Stams (1963) - Kloster Stams: Stift Stams, Tirol (Kleine Kunstführer 289), 6., neubearb. Aufl., München/Zürich I 963

Knabl, Sakristeitüren (2008) - Gerhard Knabl: Restaurierung der Sakristeitüren, in: Prämonstratenserstift, Stiftskirche Wilten (2008), i i 6- i 8

Knefelkamp, Zisterzienser (200I) - Ulrich Knefelkamp (Hg.): Zisterzienser. Norm, Kultur, Reform - 900 Jahre Zisterzienser, Berlin/Heidelberg/New York 200 I

Köfler, Gründung (1995) - Werner Köfler: Die Gründung von Stift Stams, in: Riedmann, Traum (1995), 335-34I

Köfler, Gründungsausstattung ( 1995 ) - Werner Köfler: Die Gründungsausstattung des Stiftes Stams, in: Riedmann, Traum (1 995), 367-370

Kölb1/Resch, Wege (2002) - Alois Kölbl und Wiltraud Resch: Wege zu Gott. Die Kirchen und die Synagoge von Graz, Graz 2002

König, Geschicke (1959) - Anton König: Geschichte und Geschicke der Salzburger Dome, in: Dom zu Salzburg (1959), 73-85

König, Mülln ( I968) - Anton König: Salzburg-Mülln: ehem. Klosterkirche der AugustinerEremiten und Stadtpfarrkirche zur H1. Dreifaltigkeit, zu Unserer Lieben Frau Himmelfahrt u. hl. Alexius der Benediktinerabtei Michaelbeuern (Christliche Kunststätten Österreichs 80), Salzburg I 968

Körner, 750 Jahre (1998) - Günther Körner (Hg.): 750 Jahre Kapitel- und Stadtpfarrkirche St. Maria Magdalena (Beiträge zur Geschichte der Stadt Völkermarkt), Klagenfurt I 998

Kohlbach, Barocke Kirchen [r 95 I] - Rochus Kohlbach: Die barocken Kirchen von Graz, Graz o. J. [I 95 I]

Kohlbach, Dom ( 1 948) - Rochus Kohlbach: Der Dom zu Graz. Die fünf Rechnungsbücher der Jesuiten, Graz I 948

Kohlbach, Gotische Kirchen (1950) - Rochus Kohlbach: Die gotischen Kirchen von Graz, Graz I $95^{\circ}$ 
Kohlbach, Kirchenrechnungen [ca. I 946] - Rochus Kohlbach: Kirchen- und Schlösserrechnungen, masch. Manuskript. BDA Graz und Diözesanarchiv Graz o. J. [ca. I 946]

Kohlbach, Stifte (r953) - Rochus Kohlbach: Die Stifte Steiermarks: Ein Ehrenbuch der Heimat, Graz 1953

Kolb/Angermüller, Festschrift St. Peter (1982) - Aegidius Kolb und Rudolph Angermüller (Hg.): Festschrift St. Peter zu Salzburg 582-1982, Salzburg 1982

Koller, Entwurf (1998) - Manfred Koller: Entwurf, Material und Technik der Barockaltäre und ihrer Modelle, in: Krapf, Triumph (1 998), 39-47

Koller, Farbgebung (2010) - Manfred Koller: Typologie der Farbgebung historischer Holzbauten, in: Holzobjekte und ihre Oberflächen. Untersuchung - Konservierung - Restaurierung (Restauratorenblätter 29, hg. v. d. österreichischen Sektion des IIC), Klosterneuburg 2010, I09-I I 8

Koller, Universitätskirche (2003) - Manfred Koller : Die Wiener Universitätskirche als Gesamtkunstwerk. Befunde und Restaurierungen I984-1998, in: Karner/Telesko, Jesuiten (2003), $57^{-6 \text { I }}$

Kopp, Beichtstühle (2014) - Peter Kopp: Restaurierung der Beichtstühle, in: Brenner, Himmel (2014), 72-73

Kopp, Chorgestühl (20 I 4) - Peter Kopp: Chorgestühl, in: Brenner, Himmel (20I4), I 44-I 45

Koren/Attems, Schlösser (I 986) - Johannes Koren und Franz Attems: Schlösser und Burgen der Steiermark, Innsbruck I 986

Kramer, Abteikirche (1959) - Maurus Kramer: Abteikirche Fiecht (Christliche Kunststätten Österreichs 8), Salzburg 1959

Kramer, Geschichte (1977) - Maurus Kramer: Geschichte der Benediktinerabtei St. Georgenberg-Fiecht bei Schwaz in Tirol, 2. Aufl., St. Ottilien 1977

Krapf, Gumpp (197 I) - Michael Krapf: Die Baumeister Gumpp I600-I765, masch. phil. Diss. Innsbruck I 97 I

Krapf, Gumpp (1979) - Michael Krapf: Die Baumeister Gumpp (Große Meister, Epochen und Themen der österreichischen Kunst. Barock), Wien/München I 979

Krapf, Modelle (1998) - Michael Krapf: Triumph der Phantasie: Vom Weg der Modelle als Vorstellungshilfe zur gebauten Wirklichkeit, in: Krapf, Triumph (I 998), I5-25

Krapf, Triumph (1998) - Michael Krapf (Hg.): Triumph der Phantasie. Barocke Modelle von Hildebrandt bis Mollinarolo, Ausst.-Kat. Wien, Wien/Köln/Weimar I 998

Krassnig, Gurk (200I) - Waltraud Krassnig: Gurk, in: Faust/Krassnig, Germania Benedictina $\mathrm{III} / 2$ (200I), $50-63$

Krause, Frauenberg [1949] - Adalbert Krause: Die Pfarr- und Wallfahrtskirche Frauenberg a.d. Enns bei Admont, Linz o. J. [1 949]

Krause, Frauenberg (1978) - Adalbert Krause: Die Pfarr- und Wallfahrtskirche Frauenberg a.d. Enns bei Admont, 4., verb. Aufl., Linz (1978)

Kreise1/Himmelheber, Deutsche Möbel (1981-1983) - Heinrich Kreisel: Die Kunst des deutschen Möbels (bearb. v. Georg Himmelheber), 3 Bde., 2./3. Aufl., München r 98 I/I 983 
Kreul, Fischer von Erlach (2006) - Andreas Kreul: Johann Bernhard Fischer von Erlach. Regie der Relation, Salzburg/München 2006

Kreytenberg, Orcagna (2000) - Gert Kreytenberg: Orcagna, Andrea di Cione: Ein universeller Künstler der Gotik in Florenz, Mainz 2000

Kreuzer, Stifte (1986) - Anton Kreuzer: Die Stifte und Klöster Kärntens, Klagenfurt 1986

Kriechbaum, Klöster (2008) - Reinhard Kriechbaum: Klöster in Österreich, Rosenheim 2008

Kuba-Hauk/Saliger, Diözesanmuseum (1987) - Waltraut Kuba-Hauk und Arthur Saliger:

Dom- und Diözesanmuseum Wien (Schriftenreihe des Erzbischöflichen Dom- und Diözesanmuseums Wien, NF го), Wien I 987

Kundratitz, Geschichte (1995) - Wilhelm Kundratitz: Geschichte des Stifts Stams, in: Riedmann, Traum (1 995), 533-540

Kurth, Raumkunst (1923) - Wilhelm Kurth: Die Raumkunst im Kupferstich des I7. und I 8. Jahrhunderts (Bauformen-Bibliothek I9), Stuttgart I923

Langen, Verzeichnus (I 704) - Johann Georg Langen: Richtige Verzeichnus aller derjenigen Manns- und Weibs-Personen, Jung-Gesellen und Jungfrauen, Söhne und Töchtern, welche das zuruck-gelegte I 703. Jahr in dieser Heiligen Römischen Reichs-Stadt Augsburg, evangelischen Theils, gestorben sind und begraben worden [...], Augsburg I 704

Langer, Zeremoniell (2002) - Brigitte Langer (Hg.): Pracht und Zeremoniell. Die Möbel der Residenz München, Ausst.-Kat., München 2002

Laschalt, Sakristeischränke (2012) - Lucia Laschalt: Wiener Sakristeischränke des Barock, masch. phil. Dipl., Wien 2012

László, Loretto (1994) - Stefan László: Loretto im Burgenland. Beiträge zur Geschichte des Wallfahrtsortes und des Servitenkonventes (hg. v. Pfarramt Loretto und Freunde des Gnadenortes), Loretto I 994

Laur, Gruber (1933) - Wilhelm Friedrich Laur: Esaias Gruber der Alt und Jung: Zwei Lindauer Bildhauer. Ein Beitrag zur Renaissanceplastik am Bodensee (Neujahrsblätter des Museumsvereins Lindau-Bodensee 8), Lindau r 933

Lechner, Ansichten ( 1980 ) - Gregor Martin Lechner: Stift Göttweig. Göttweig in alten Ansichten, Ausst.-Kat. Stift Göttweig, Krems I 980

Lechner, Göttweig (2000) - Gregor Martin Lechner: Göttweig, in: Faust/Krassnig, Germania Benedictina III/I (2000), 768-843

Lechner/Grünwald, Bessel (1999) - Gregor Martin Lechner und Michael Grünwald: Stift Göttweig. Gottfried Bessel (r672-r 749) und das barocke Göttweig. Zum 250. Todesjahr des Abtes, Ausst.-Kat. Stift Göttweig, Bad Vöslau I 999

Lehmann, Bibliotheksräume (I996) - Edgar Lehmann: Die Bibliotheksräume der deutschen Klöster in der Zeit des Barock, 2 Bde., Berlin 1996

Lehr, Collectaneum - Alanus Lehr: Collectaneum sive Diplomatarium Runense, StAR Hs ro7 [vor I 775]

Leitner, Bautätigkeit (199I) - Friedrich Wilhelm Leitner: Bautätigkeit und künstlerische Ausstattung unter Abt Hieronymus Marchstaller, in: Schatzhaus Kärntens (r99I), 553-570 
Lentze, Geschichte (1958) - Hermann (Hans) Lentze: Geschichte des Stiftes Wilten, in: Steinegger, Wilten (1958), 9-16

Lenzi/Bentini, Bibiena (2000) - Deanna Lenzi und Jadranka Bentini (Hg.): I Bibiena - una famiglia europea, Ausst.-Kat. Bologna, Venedig 2000

Lepik, Architekturmodell ( 1995 ) - Andreas Lepik: Das Architekturmodell der frühen Renaissance, in: Evers, Architekturmodelle (I 995), ro-20

Leroux-Dhuys, Zisterzienser (1998) - Jean-François Leroux-Dhuys: Die Zisterzienser. Geschichte und Architektur, Köln 1998

Lindner, Album (I 898) - Pirmin Lindner: Album Stamsense seu Catalogus Religiosorum [...] in Stams 1 272-1898, Salzburg 1898

Linhardt, Neuberg (2003) - Erich Linhardt: Neuberg an der Mürz (Christliche Kunststätten Österreichs I 73), 4. Aufl., Salzburg 2003

Lippmann, Salzburger Dom (1 999) - Wolfgang Lippmann: Der Salzburger Dom I 598-1630 unter besonderer Berücksichtigung der Auftraggeber und des kulturgeschichtlichen Umfeldes, Weimar I 999

Lobendanz, Geschichte (1995) - Gabriel Lobendanz: Geschichte des Zisterzienserordens Geschichte des Stiftes Stams. Die Zisterzienser, in: Riedmann, Traum (I 995), 522-527

Loescher, Kistlerhandwerk (2000) - Wolfgang Loescher: Veränderungen des Augsburger Kistlerhandwerks durch Überseeimporte im späten i6. und I7. Jahrhundert, in: Zeitschrift des Historischen Vereins für Schwaben 92 (I 999/2000), 55-73

Löw, Domführer (1927) - Josef Löw: Kleiner Gurker Domführer, 2., verb. und erw. Aufl., Klagenfurt 1927

Löw, Domführer ( 1930) - Josef Löw: Kleiner Gurker Domführer, 3., neubearb. Aufl., Klagenfurt 1930

Loibersbeck, Lockenhaus, I ( 1972 ) - Josef Loibersbeck: Lockenhaus, in: Burgenländische Heimatblätter I, 34 (I 972), 32-4I [https://www.zobodat.at/pdf/Burgenlaendische-Heimatblaet ter_34_0032-004I.pdf; Zugriff August 2020]

Loibersbeck, Lockenhaus, 2 ( 1972 ) - Josef Loibersbeck: Lockenhaus, in: Burgenländische Heimatblätter 3, 34 (I972), I $38-$ I $42^{2}$

Loibersbeck, Lockenhaus, 3 ( 1972 ) - Josef Loibersbeck: Lockenhaus, in: Burgenländische Heimatblätter 4, 34 (1972), I70-1 87

Loose, Chorgestühle (I93I) - Walter Loose: Die Chorgestühle des Mittelalters, Heidelberg I 93 I

Lorenz, Architektur ( I 999) - Hellmut Lorenz: Architektur, in: Lorenz, GbKÖ (I 999), 2 I 9-2 34

Lorenz, Barocke Kunst ( 1 999) - Hellmut Lorenz: Barocke Kunst in Österreich - Facetten einer Epoche, in: Lorenz, GbKÖ (r999), I I-r 6

Lorenz, GbKÖ ( I 999) - Hellmut Lorenz (Hg.): Geschichte der bildenden Kunst in Österreich 4 (Barock), München/London/New York r 999

Lorenz, Raumfolge (1993) - Hellmut Lorenz: Zur repräsentativen Raumfolge und Ausstattung der barocken Stadtpaläste Wiens, in: Götz Pochat und Brigitte Wagner (Hg.): Barock: regional - international, KJbG 25 ( I 993), 29I-304 
Lünig, Theatrum ceremoniale (I7I9-I720) - Johann Christian Lünig: Theatrum ceremoniale historico-politicum oder historisch- und politischer Schau-Platz aller Ceremonien [...], 2 Bde., Leipzig I 7 I 9-1 720

Lukács, Catalogus generalis (I988) - Ladislaus Lukács: Catalogus Generalis seu Nomenclator biographicus personarum Provinciae Austriae Societatis Iesu (I55 I-I773), 3 Bde., Rom I $987 / 88$

Lukács, Catalogi personarum (I990) - Ladislaus Lukács: Catalogi personarum et officiorum Provinciae Austriae S. I., 4, Rom I 990

Mahlknecht, Stadtpfarrkirche ( 1998 ) - Eduard Mahlknecht: Die Stadtpfarrkirche und ehemalige Propsteikirche St. Maria Magdalena, in: Körner, 750 Jahre (r 998), i I I-I 33

Mahlknecht, Völkermarkt (r993) - Eduard Mahlknecht: Völkermarkt: Stadtpfarrkirche St. Maria Magdalena. Bezirk Völkermarkt. Diözese Gurk-Klagenfurt (Christliche Kunststätten Österreichs 236), Salzburg I 993

Maier, Stuckmarmor (2012) - Eva Maier: Stuckmarmor und Raumgestaltung. Johann Michael Feichtmayrs Stuckmarmorausstattungen sakraler Innenräume und deren Bedeutung (Inhalte - Projekte - Dokumentationen: Schriftenreihe des Bayerischen Landesamtes für Denkmalpflege 5), München 20 I 2

Malle, Wessicken (2012) - Annemarie Malle: Vom Tischlerhandwerk zur Architektur. Die Familie Wessicken - ihr Wirken in Österreich und Deutschland vom I 8.-20. Jahrhundert, masch. phil. Diss, Salzburg 2012

Mand1, Geschichte (1934) - Johann Mandl (Hg.): Kurze Geschichte der Welschen Kirche und der Ecce-Homo-Säule am Griesplatz in Graz, Graz 1934

Mannewitz, Admont ( I 989) - Martin Mannewitz: Stift Admont. Untersuchungen zu Entwicklungsgeschichte, Ausstattung und Ikonographie der Klosteranlage (Beiträge zur Kunstwissenschaft 3i), München I 989

Manni, Mobili (r 993) - Graziano Manni: Mobili antichi in Emilia Romagna, Modena 1993

Martin, St. Peter ( 1927 ) - Franz Martin: Stift St. Peter in Salzburg (Österreichische Kunstbücher 55), Wien/Augsburg 1927

Martin, St. Peter (1 94I) - Franz Martin: St. Peter in Salzburg, Erzabtei (Kunstführer, Reihe Süddeutschland 493/94), München I 94 I

Massinelli, Mobile (I993) - Anna Maria Massinelli: Il mobile toscano I 200-I80o, Mailand I 993

Mathis, Bevölkerungsstruktur ( I 977) - Franz Mathis: Zur Bevölkerungsstruktur österreichischer Städte im I 7. Jahrhundert (Sozial- und wirtschaftshistorische Studien I I, hg. v. Alfred Hoffmann und Michael Mitterauer), Wien 1977

Maurer/Rabl/Schmid, Campililiensia (2015) - Pius Maurer, Irene Rabl und Harald Schmid (Hg.): Campililiensia. Geschichte, Kunst und Kultur des Zisterzienserstiftes Lilienfeld, Lilienfeld 2015

Mauß, Weihwasserbecken (2018) - Cordula Mauß: Weihwasserbecken des I 5. und I6. Jahrhunderts in Italien: Gestaltung - Funktion - Bedeutung (Römische Studien der Bibliotheca Hertziana 42), München 2018 
Mausser, Stift Rein ( 1 949) - Maria Mausser: Stift Rein unter den Äbten Placidus Mailly und Marianus Pittreich (I 7 Io-I 77I), masch. phil. Diss., Graz 1949

Mayer, Neuberg ( 1953 ) - Inge Mayer: Die Stiftskirche und die mittelalterliche Klosteranlage von Stift Neuberg a. d. Mürz, masch. phil. Diss., Graz I 953

Mayer-Himmelheber, Kunstpolitik ( 1984 ) - Susanne Mayer-Himmelheber: Bischöfliche Kunstpolitik nach dem Tridentinum. Der Secunda-Roma-Anspruch Carlo Borromeos und die mailändischen Verordnungen zu Bau und Ausstattung von Kirchen (tuduv-Studien, Reihe Kunstgeschichte I I), München I984

Mayr, Michaelbeuern ( 1958 ) - Werigand Mayr: Abtei Michaelbeuern (Kunstführer 660), München/Zürich I 958

Mayrhofer, Ausstattungsgeschichte (2015) - Bernhard Christoph Mayrhofer: Die Ausstattungsgeschichte der Vorauer Stiftskirche, in: Barockberichte 63 (2015), I 7-28

Mayrhofer, Stift Vorau (2017) - Bernhard Christoph Mayrhofer: Stift Vorau. Die Bau- und Ausstattungsgeschichte (mit Beiträgen von Manfred Koller und Gudrun Ponn-Lettner; Peda-Kunstführer Ioor/2017), Passau 2017

Meeraus, Vorau (I928) - Robert Meeraus: Das Chorherrenstift Vorau (Österreichische Kunstbücher 58, hg. v. Dagobert Frey), Wien/Augsburg/Köln 1928

Michaelsen/Barthold/Weißmann, Helffenbein (2003) - Hans Michaelsen, Janko Barthold und Robert Weißmann: »Marmelirtes Helffenbein«. Rekonstruktionsversuche zu einer Imitationstechnik in der Mitte des I7. Jahrhunderts, in: Restauro. Zeitschrift für Kunsttechniken, Restaurierung und Museumsfragen 3, I09 (April/Mai 2003), I 94-202

Milesi, Manierismus ( 1973 ) - Richard Milesi: Manierismus in Kärnten. Zur Kunst des späten I6. Jahrhunderts, Klagenfurt 1973

Millon, Architekturmodelle (I995) - Henry A. Millon: Italienische Architekturmodelle im I6. Jahrhundert, in: Evers, Architekturmodelle (I 995), 2 I-27

Millon/Magnago Lampugnani, Representation ( 1994) - Henry A. Millon und Vittorio Magnago Lampugnani: The Renaissance from Brunelleschi to Michelangelo: The Representation of Architecture, Ausst.-Kat. Venedig, Mailand 1994

Millon/Smith, Gewölbe ( 1995 ) - Henry A. Millon und Craig Hugh Smith: Holzmodell für das Gewölbe der südlichen Apsis von St. Peter 1 556/57, in: Evers, Architekturmodelle (1 995), 379-38I

Millon/Smith, Tambour (r995) - Henry A. Millon und Craig Hugh Smith: Modell einer Hälfte des Tambours und der Kuppel von St. Peter I 556/57, in: Evers, Architekturmodelle (1 995), 385-389

Möller, Kirchen (2004) - Norbert Möller: Die Kirchen Innsbrucks, 2. Aufl., Innsbruck 2004

Möseneder, Passauer Dom (2014) - Karl Möseneder: Der Passauer Dom und seine Wirkung im Donauraum, in: Möseneder/Thimann/Hofstetter, Barocke Kunst (20I4), Bd. I, I 8-42

Möseneder/Thimann/Hofstetter, Barocke Kunst (2or4) - Karl Möseneder, Michael Thimann und Adolf Hofstetter (Hg.): Barocke Kunst und Kultur im Donauraum (Beiträge zum Internationalen Wissenschaftskongress 9.-I3. April $20{ }_{3} 3$ in Passau und Linz), 2 Bde., Petersberg 2014 
Moro, Festgabe (1959) - Gotbert Moro (Hg.): Festgabe zur I 50-Jahr-Feier der Wiederbesiedlung des Benediktinerstiftes St. Paul im Lavanttal durch die Mönche von St. Blasien im Schwarzwald, Klagenfurt 1959

Moser, Hof-Recht (I755) - Friedrich Carl von Moser: Teutsches Hof-Recht in I 2 Büchern, 2 Bde., Frankfurt am Main/Leipzig I755 [https://digitale-bibliothek-mv.de/viewer/toc/ PPN642900949/o/; Zugriff Juni 2020]

Moser, Welsche Kirche ( 1928 ) - Karl Moser: Die Welsche Kirche in Graz (Kunstdenkmäler der Steiermark I, hg. v. Hermann Egger), Wien/Graz/Leipzig 1928

Mühlmann, Dom ( 1925 ) - Josef Mühlmann: Der Dom zu Salzburg (Artes Austriae. Studien zur Kunstgeschichte Österreichs 3), Wien 1925

Müller, Abriß ( 1979) - Norbert Müller: Abriß der Baugeschichte des Stiftes Rein, in: Rappold/ Amon, Stift Rein (1979), 40 I-4 Io

Müller, Abriss (1979) - Eugen Müller: Geschichtlicher Abriss des Stiftes Lilienfeld seit I70o. Mit besonderer Berücksichtigung äußerer Einflüsse auf das Leben im Konvent, Lilienfeld I 979

Müller, Basilika (2or 8) - Norbert Müller: Die barocke Basilika von Stift Rein, in: Brenner, Stift Rein (2018), 44-68

Müller, KirchenGeschmuck (I59I) - Jacob Müller: KirchenGeschmuck. Das ist: Kurtzer Begriff der fürnembsten Dingen, damit ein jede recht und wol zugerichte Kirchen geziert und auffgebutzt seyn solle. Allen Prelaten und Pfarrherren durch das ganzte Bistumb Regenspurg sehr notwendig [...], München I 59 I

[https://www.deutsche-digitale-bibliothek.de/item/UGW $4 \mathrm{CK}_{3} \mathrm{BW}_{5} \mathrm{~V}_{3} 6 \mathrm{QTUXU} \mathrm{UUK}_{3} \mathrm{BKT}$ ${ }_{7} \mathrm{NAGIH}_{2} \mathrm{X}$; Zugriff Oktober 2020]

Müller, Profeßbuch (1996) - Eugen Müller: Profeßbuch des Zisterzienserstiftes Lilienfeld (SMGB 38. Ergänzungsband), St. Ottilien 1996

Müller, Gründungsgeschichte (2018) - Norbert Müller: Zur Gründungsgeschichte des Zisterzienserklosters Rein, in: Brenner, Stift Rein (2018), I 2-38

Mund, Stadtpfarrkirche (2004) - Monika Mund: Die Stadtpfarrkirche Mariae Himmelfahrt zu Salzburg-Mülln, masch. Dipl., kult.-gesell. Fakultät, Salzburg 2004

Mussbacher, Lilienfeld ( I 976) - Norbert Mussbacher: Das Stift Lilienfeld, Wien 1976

Myssok, Konzeption (1999) - Johannes Myssok: Bildhauerische Konzeption und plastisches Modell in der Renaissance (Beiträge zur Kunstgeschichte des Mittelalters und der Renaissance 8, hg. v. Joachim Poeschke), Münster 1999

Naredi-Rainer/Madersbacher, Tirol (2007) - Paul Naredi-Rainer und Lukas Madersbacher (Hg.): Kunst in Tirol (Kunstgeschichtliche Studien - Innsbruck, Neue Folge 3 und 4), 2 Bde., Innsbruck/Wien 2007

Naschenweng, Geschichte (2013) - Hannes P. Naschenweng: Geschichte der Pfarre Pürgg und seiner Pfarrer, Vikare und Kapläne, in: Suppan, Chronik (2013), 335-426

Naschenweng, Rottenmann (2005) - Hannes P. Naschenweng: Rottenmann, in: Röhrig, Ehemalige Stifte (2005), 285-327 
Naupp, Fiecht (2000) - Thomas Naupp: Fiecht - St. Georgenberg, in: Faust/Krassnig: Germania Benedictina III/I (2000), 434-500

Neckheim, Stadthauptpfarrkirche (1957) - Günther Hermann Neckheim: Die Stadthauptpfarrkirche zum hl. Jakobus d.Ä. in Villach, Klagenfurt 1957

Neubauer-Kienzl/Deuer/Mahlknecht, Barock (2000) - Barbara Neubauer-Kienzl, Wilhelm Deuer und Eduard Mahlknecht: Barock in Kärnten, Klagenfurt 2000

Neuhardt, Brixlegg ( 1978 ) - Johannes Neuhardt: Brixlegg: Pfarrkirche zu U. L. Frau Vermählung (Christliche Kunststätten Österreichs I r6), Salzburg 1978

Neuhardt, Dom ( I 980) - Johannes Neuhardt: Der Dom zu Salzburg (Große Kunstführer 78), München/Zürich I 980

Neuhardt, Dom ( 1998 ) - Johannes Neuhardt: Der Dom zu Salzburg (Große Kunstführer 78), 2., neubearb. Aufl., Regensburg 1998

Neuhardt, Dreifaltigkeitskirche (1998) - Johannes Neuhardt: Dreifaltigkeitskirche und Priesterhaus in Salzburg (Christliche Kunststätten Österreichs I2), 4., neubearb. Aufl., Salzburg I 998

Neuhardt, Kundl (2005) - Johannes Neuhardt: Die Kirchen von Kund1/Tirol (Christliche Kunststätten Österreichs 9I), 3., überarb. Aufl., Salzburg 2005

Neumann, Handwerk (I879) - Wilhelm Anton Neumann: Handwerk und Kunst im Stifte Heiligenkreuz vom XVII. bis zur Mitte des XVIII. Jahrhunderts, in: Berichte und Mittheilungen des Alterthums-Vereines zu Wien I 8 ( 1879 ), г 23 - 66

Neunhundert Jahre Benediktiner (1989) - [Neunhundert] 900 Jahre Benediktiner in Melk (hg. v. Stift Melk), Ausst.-Kat., Melk I 989

Oberhammer, Klosterführer (1998) - Monika Oberhammer: Pustets Klosterführer. Österreich, Salzburg/München I 998

Oberhofer/Hahnl, Handwerk (1978) - Rupert Oberhofer: Ein ehrsames Handwerk der Tischler zu Salzburg (kunsthistorischer Überblick von Adolf Hahnl), Salzburg 1978

Oechslin, Barockbaumeister (1973) - Werner Oechslin (Hg.): Die Vorarlberger Barockbaumeister: Ausstellung in Einsiedeln und Bregenz zum 250. Todestag von Br. Caspar Mossbrugger, Ausst.-Kat. Einsiedeln und Bregenz, Einsiedeln/Zürich I 973

Oettinger/Matschik/Fitz, Lilienfeld (1952) - Karl Oettinger, Martin Matschik, Justin Fitz u.a.: Stift Lilienfeld I 202-I95 I, Wien 1952

Ohmann, Architektur [1896-r9I I] - Friedrich Ohmann: Architektur und Kunstgewerbe der Barockzeit, des Rokoko und Empires aus Böhmen und anderen österreichischen Ländern, 2 Bde., Wien o. J. [1896-I9i I]

Ohmann, Barock (I897) - Friedrich Ohmann: Barock. Eine Sammlung von Plafonds, Cartouchen, Consolen, Gittern, Möbeln, Vasen, Öfen, Ornamenten, Interieurs etc. etc., 2. Aufl., Wien 1897

Olivari, Sagrestie (1994) - Mariolina Olivari (Hg.): Le sagrestie di Alzano Lombardo nella Basilica di San Martino, Mailand 1994

O'Malley, Business (2005) - Michelle O'Malley: The Business of Art: Contracts and the Commissioning Process in Renaissance Italy, New Haven/London 2005 
Otruba, Gewerbe (1989) - Gustav Otruba: Gewerbe und Zünfte in Niederösterreich (Wissenschaftliche Schriftenreihe Niederösterreich 88/89/90), St. Pölten I989

Ottillinger/Hanzl, Interieurs ( 1997 ) - Eva B. Ottillinger und Liselotte Hanzl: Kaiserliche Interieurs. Die Wohnkultur des Wiener Hofes im r 9. Jahrhundert und die Wiener Kunstgewerbereform (Museen des Mobiliendepots 3, hg. v. Ilsebill Barta-Fliedl und Peter Parenzan), Wien/Köln/Weimar 1997

Pagitz, Mittelalterliche Dome (1974) - Franz Pagitz: Die mittelalterlichen Dome in historischer Sicht, in: Spatzenegger, Dom zu Salzburg (I 974), 3 I-62

Panagl-Holbein, Aufgelassene Klöster ( 1988 ) - Carl F. Panagl-Holbein: Zeugen einer großen Vergangenheit. Aufgelassene Klöster in Österreich, Wien I 988

Pater, Baugeschichte (1915) - Hans Pater: Die Baugeschichte des Zisterzienserstiftes Rein, masch. phil. Diss., Graz I 91 5

Pauker, Kirche (I 9ro) - Wolfgang Pauker: Die Kirche und das Kollegiatsstift der ehemaligen regulierten Chorherrn zu Dürnstein. Ein Beitrag zur österreichischen Kunst- und Kulturgeschichte des I 8. Jahrhunderts, in: Jb.K1., 3 (1910), I79-344

Pechstein, Goldschmiedekunst ( 1987 ) - Klaus Pechstein (Hg.): Deutsche Goldschmiedekunst vom I 5. bis zum 20. Jahrhundert aus dem Germanischen Nationalmuseum, Ausst.-Kat., Nürnberg/Hanau/Ingolstadt/Berlin I 987

Pechstein/Forssman, Goldschmiedekunst ( 1992 ) - Klaus Pechstein und Erik Forssman (Hg.): Schätze deutscher Goldschmiedekunst von I 500 bis 1920 aus dem Germanischen Nationalmuseum, Ausst.-Kat. Ingolstadt, Berlin 1992

Penz, Kalendernotizen (2013) - Helga Penz: Die Kalendernotizen des Hieronymus Übelbacher, Propst von Dürnstein I 7 Io-I740. Edition und Kommentare (Mitarbeit v. Edeltraud Kando, Ines Weissberg und Harald Tersch. Quelleneditionen des Instituts für Österreichische Geschichtsforschung I I, hg. v. Brigitte Merta und Andrea Sommerlechner), Wien/München 2013

Penz/Zajic, Dürnstein (2oro) - Helga Penz und Andreas Hermengild Zajic (Hg.): Stift Dürnstein. 600 Jahre Kloster und Kultur in der Wachau, Horn/Waidhofen a. d. Thaya 20 io

Peter, Wappen (20 I 5) - Bernhard Peter: Galerie: Photos schöner alter Wappen Nr. 2 I 78 (Gurk Bundesland Kärnten, Österreich), 20I5 [www.welt-der-wappen.de/Heraldik/aktuell/gale rien3/galerie2 I 78.htm; Zugriff April 2018]

Pfeifer, Türbeschläge (2008) - Beatrice Pfeifer: Restaurierung der Sakristei-Türbeschläge, in: Prämonstratenserstift, Stiftskirche Wilten (2008), I I 9-I 2 I

Pichler, Neuberg (1884) - Franz Sales Pichler: Die Habsburger Stiftung Cistercienser Abtei Neuberg in Steiermark (ihre Geschichte und ihre Denkmale), Wien I 884

Pickl, Geschichte (1996) - Othmar Pickl: Die Geschichte des Zisterzienserklosters Neuberg an der Mürz, in: Otto Fraydenegg-Monzello (Hg.): Schatz und Schicksal (Steirische Landesausstellung I 996), Ausst.-Kat. Mariazell und Neuberg an der Mürz, Graz I 996, 34 I-352

Pickl/Kanzler, Geschichte ( 1996) - Othmar Pickl und Walter Kanzler: Geschichte des Klosters und der Marktgemeinde Neuberg an der Mürz, 2., erw. Aufl., Neuberg I 996

Plank, Geschichte (1978) - Benedikt Plank: Geschichte der Abtei St. Lambrecht. Festschrift 
zur 900. Wiederkehr des Todestages des Gründers Markward von Eppenstein ı076-ı 976, 2. Aufl., St. Lambrecht 1978

Plank, Mariahof ( I 995) - Benedikt Plank: Pfarrkirche Mariahof. Bezirk Murau, Diözese GrazSeckau (Christliche Kunststätten Österreichs 268), Salzburg 1995

Plank, St. Lambrecht (1991) - Benedikt Plank: Abtei St. Lambrecht (Schnell Kunstführer 93 I), 4., neubearb. Aufl., München/Zürich I 99 I

Plank, St. Lambrecht (200I) - Benedikt Plank: St. Lambrecht, in: Faust/Krassnig: Germania Benedictina III/2 (200I), 3 I 8-380

Plank/Romirer, St. Lambrecht (2002) - Benedikt Plank und Gerwig Romirer: Benediktinerabtei St. Lambrecht, Ried im Innkreis 2002

Podhradsky, Dominikanerinnenkloster ( I 990) - Gerhard Podhradsky: Das Dominikanerinnenkloster Altenstadt: Geschichte, Professen, Regesten (Quellen und Untersuchungen hg. vom Archiv der Diözese Feldkirch 3), Feldkirch 1990

Polleroß, Einflüsse (2014) - Friedrich Polleroß: Zwischen Konfrontation und Imitation: Französische Einflüsse am Wiener Hof um I 7oo, in: Möseneder/Thimann/Hofstetter, Barocke Kunst (20 I 4), Bd. 2, 530-547

Posch, Dom (2006) - Waldemar Posch: Dom zu Gurk, I 2., verb. Aufl., Innsbruck 2006

Porstmann, Chorgestühle (2007) - Gisbert Porstmann: Ausgewählte Chorgestühle in Nonnenund Mönchsklöstern des Zisterzienserordens. Ansätze ihrer ikonographischen Deutungen Ein Überblick, in: Schuhmann, Sachkultur (2007), I $23-150$

Pozsgai, Germain Boffrand (2012) - Martin Pozsgai: Germain Boffrand und Joseph Effner: Studien zur Architektenausbildung um I 700 am Beispiel der Innendekoration, Berlin 2012

Prämonstratenserstift, Stiftskirche Wilten (2008) - Prämonstratenserstift Wilten (Hg.): Stiftskirche Wilten zu den hll. Laurentius und Stephanus: Restaurierung 2005-2008, Innsbruck 2008

Preimesberger, Stukkatur (1964) - Rudolf Preimesberger: Notizen zur italienischen Stukkatur in Österreich, in: Edoardo Arslan (Hg.): Arte e artisti dei laghi lombardi. Gli stuccatori dal barocco al rococo (Società Archeologica Comense), Como r 964, 325-350

Pribram, Geschichte (1907) - Karl Pribram: Geschichte der österreichischen Gewerbepolitik von I 740 bis I 860, Leipzig I 907

Princi, Architectural Drawings (2O I 2) - Eliana Princi: Architectural Drawings from the $\mathrm{I} 3$ th to the I 9 th Century (Dessins d'architecture du treizième au dix-neuvième siècle; Architekturzeichnungen vom I3. bis zum I 9. Jahrhundert), Florenz 2012

Pühringer-Zwanowetz, Steinl ( 1 966) - Leonore Pühringer-Zwanowetz: Matthias Steinl, Wien/ München 1966

Puzicha, Kommentar (2012) - Michaela Puzicha: Kommentar zur «Vita Benedicti«: Gregor der Große: das zweite Buch der Dialoge - Leben und Wunder des ehrwürdigen Abtes Benedikt, St. Ottilien 2012

Rabensteiner/Hensle-Wlasak, Pürgg (2003) - Christine Rabensteiner und Helga Hensle-Wlasak: Pfarre Pürgg im Ennstal, Ried im Innkreis 2003 
Raber, Frauenkirchen ( 1 975) - Ludwig Raber: Wallfahrtsort Frauenkirchen - Burgenland (hg. v. Franziskanerkloster Frauenkirchen), Frauenkirchen I 975

Rabl, Ausstattungsgeschichte (I 998) - Gernot Rabl: Die Bau- und Ausstattungsgeschichte der Pfarr- und Wallfahrtskirche Frauenberg bei Admont, masch. phil. Dipl., Graz I 998

Rainer, Dom (r939) - Otto Rainer: Der Dom zu Klagenfurt (Kunstführer 376/377), München I 939

Rampold, Tirol (2014) - Reinhard Rampold (Hg.): Kunstführer Tirol. Die 400 bedeutendsten Kunstschätze in Nord- und Osttirol, Innsbruck/Wien 2014

Rappold/Amon, Stift Rein (r 979) - Paulus Rappold und Karl Amon (Hg.): Stift Rein I I 29I 979. 850 Jahre Kultur und Glaube. Festschrift zum Jubiläum, Rein I 979

Reichling/Reichling, Orgelgeschichte (2016) - Alfred Reichling und Matthias Reichling: Stamser Orgelgeschichte und ihre heutigen Zeugen, in: Forcher, Stams (2016), 254-263

Reichmann-Endres, St. Bartholomäus (200I) - Elisabeth Reichmann-Endres: Die Kirchen der Stadtpfarre St. Bartholomäus. Friesach - Kärnten (Christliche Kunststätten Österreichs 363), Salzburg 200 I

Reinhardt, Rekonstruktion (2or I) - Holger Reinhardt: Grenzfall Rekonstruktion. Die Nachbildung als methodisches Instrument im Spannungsfeld denkmalpflegerischen und restauratorischen Handelns, in: Grenzen und Möglichkeiten (20 I I), 64-74

Reinle, Ausstattung (1988) - Adolf Reinle: Die Ausstattung deutscher Kirchen im Mittelalter: Eine Einführung, Darmstadt 1988

Reininghaus, Entstehung ( 1980 ) - Wilfried Reininghaus: Zur Entstehung der Gesellengilden im Spätmittelalter, phil. Diss., Münster r 980

Renz-Krebber, Sakristeischränke (1998) - Carolyn Renz-Krebber: Sakristeischränke in oberbayerischen Prälatenklöstern und Kollegiatsstiftskirchen im i 7. und I 8. Jahrhundert (Dissertationen der Universität Salzburg 49), Wien I 998

Rescher, Jurisdiktion (20 I 7) - Yasmin-Sybille Rescher: Die Jurisdiktion der Wiener Hofbefreiten, in: Tacke/Fachbach/Müller, Hofkünstler (20 I 7), I 42-1 56

Reuther/Berckenhagen, Architekturmodelle ( 1994) - Hans Reuther und Hans Berckenhagen: Deutsche Architekturmodelle: Projekthilfe zwischen I 500 und I 9oo, Berlin 1994

Richter, Furniture ( 1966) - Gisela Marie Augusta Richter: The Furniture of the Greeks, Etruscans and Romans, London 1966

Riedmann, Gründung (2016) - Josef Riedmann: Wie es zur Gründung von Stams kam, in: Forcher, Stams (2016), I6-25

Riedmann, Traum (1995) - Josef Riedmann (Hg.): Eines Fürsten Traum: Meinhard II. - Das Werden Tirols (Tiroler Landesausstellung I 995), Ausst.-Kat. Schloss Tirol und Stift Stams, Dorf Tirol 1995

Riesenhuber, Barockkunst (1 924) - Riesenhuber, Martin: Die kirchliche Barockkunst in Österreich: ein Heimatbuch, Linz 1924

Ritter, Bauherr (1972) - Emmeram Ritter: Gottfried Bessel als Bauherr und Kunstmäzen, in: Gottfried Bessel (I672-I 749). Diplomat in Kurmainz - Abt von Göttweig, Wissenschaftler 
und Kunstmäzen (Quellen und Abhandlungen zur mittelrheinischen Kirchengeschichte I6, hg. v. Franz Rudolf Reichert), Mainz I 972, 93-I40

Ritter, Forschungsergebnisse (196r) - Emmeram Ritter: Neue Forschungsergebnisse zur Bauund Kunstgeschichte des Stiftes Göttweig, in: Mitteilungen des Kremser Stadtarchivs I (196r), 57-104

Ritter, Regesten [o. J.] - Emmeram Ritter: Regesten, masch. Exemplar, Stift Göttweig [o. J.]

Röhrig, Alte Stifte ( I 966) - Floridus Röhrig: Alte Stifte in Österreich, Bd. I : Wien, Niederösterreich, Oberösterreich (Schroll Kulturführer), Wien/München r 966

Röhrig, Alte Stifte ( I 967) - Floridus Röhrig: Alte Stifte in Österreich, Bd. 2 : Steiermark, Kärnten, Salzburg, Tirol, Vorarlberg (Schroll Kulturführer), Wien/München I 967

Röhrig, Ehemalige Stifte (2005) - Floridus Röhrig (Hg.): Die ehemaligen Stifte der AugustinerChorherren in Österreich und Südtirol (Österreichisches Chorherrenbuch. Die Klöster der Augustiner-Chorherren in der ehemaligen Österreichisch-Ungarischen Monarchie), Klosterneuburg 2005

Rohr, Ceremonial-Wissenschaft ( I 729) - Julius Bernhard von Rohr: Einleitung zur Ceremoniel-Wissenschafft der großen Herren [...], Berlin I 729 [http://www.deutschestextarchiv.de/ book/view/rohr_einleitung_I 729 ; Zugriff Juni 2020]

Rohrer, Maria Trost ( 1962 ) - Hans Rohrer: Wallfahrtskirche Maria Trost. Graz, Steiermark (Christliche Kunststätten Österreichs 27), Salzburg I 962

Ronzoni, Altarmodelle (r 998) - Luigi A. Ronzoni: Altarmodelle: Überlegungen und Beobachtungen zu einer Sonderform von Architekturmodellen, in: Krapf, Triumph (1 998), 27-37

Rothe, Akanthusornament (1938) - Felicitas Rothe: Das deutsche Akanthusornament des I7. Jahrhunderts: Zur Frage seiner Selbständigkeit (Forschungen zur deutschen Kunstgeschichte, hg. v. Deutschen Verein für Kunstwissenschaft 29), Berlin I 938

Ruhri, Ursprünge (2000) - Alois Ruhri: Mittelalterliche Ursprünge, Kloster und Pfarre von Mariatrost, in: Bierbauer/Kaind1/Thaller, Mariatrost (2000), , 2-г 8

Rust, Stengg (2009) - Sandra Maria Rust: Der steirische Barockarchitekt Johann Georg Stengg (1689-I753), masch. phil. Diss., Wien 2009

Saliger, Stuck (1987) - Arthur Saliger: Stuck um I600, in: Ulrike Engelsberger und Franz Wagner (Hg.): Fürsterzbischof Wolf Dietrich von Raitenau: Gründer des barocken Salzburg (4. Salzburger Landesausstellung), Ausst.-Kat., Salzburg I 987, 25 I-257

Sandner, Barock (1962) - Oscar Sandner: Barock am Bodensee/ Architektur, Ausst.-Kat., Bregenz 1962

Sandner, Barock (1964) - Oscar Sandner: Barock am Bodensee/Plastik, Ausst.-Kat., Bregenz I 964

Sang1, Hofschreinerhandwerk (r 990) - Sigrid Sang1: Das Bamberger Hofschreinerhandwerk im I 8. Jahrhundert (Bayerische Verwaltung der Staatlichen Schlösser, Gärten und Seen. Forschungen zur Kunst- und Kulturgeschichte I, hg. v. Gerhard Hoyer), München I 990

Sangl, Modelle (2006) - Sigrid Sangl: Modelle, in: Renate Eikelmann und Ingolf Bauer (Hg.):

Das Bayerische Nationalmuseum I 888-2005, München 2006, 464-468

Schatzhaus Kärntens (I99I) - Schatzhaus Kärntens: Landesausstellung St. Paul I99r: 900 
Jahre Benediktinerstift (redigiert von Johannes Grabmayer u.a.), Ausst.-Kat. St. Paul, 2 Bde., Klagenfurt I99I

Schedl, Klosterleben (2009) - Barbara Schedl: Klosterleben und Stadtkultur im mittelalterlichen Wien. Zur Architektur religiöser Frauenkommunitäten, Innsbruck 2009

Schedl, St. Gallen (2014) - Barbara Sched1: Der Plan von St. Gallen. Ein Modell europäischer Klosterkultur, Wien/Köln/Weimar 20I 4

Schemper-Sparholz, Barockaltäre (1998) - Ingeborg Schemper-Sparholz: Barockaltäre in Österreich - Möbel, Schaubühne, Denkmal: Versuch einer typologischen Ordnung, in: Krapf, Triumph (1998), 49-63

Schemper-Sparholz, Barockbildhauer (1 992) - Ingeborg Schemper-Sparholz: Barockbildhauer im Dienst der Klöster in Österreich - zwischen Künstlertum und Handwerkerstand, in: Kalinowski, Werkstattpraxis (1992), 327-340

Schemper-Sparholz, Hochaltarprojekt (I 998) - Ingeborg Schemper-Sparholz: Erstes Modell zum Hochaltarprojekt, I723, in: Krapf, Triumph (I 998), I 8 I- I 82

Schemper-Sparholz, Skulptur ( 1999$)$ - Ingeborg Schemper-Sparholz: Skulptur und dekorative Plastik, in: Lorenz, GbKÖ (I 999), 46 I-548

Schellhorn, Maria Plain [r 95 I] - Maurus Schellhorn: Maria Plain, Salzburg o. J. [I 95 I ]

Scherf, Frauenberg ( I 904) - Irimbert Scherf: Maria Frauenberg. Zum 5oojährigen Jubiläum der Wallfahrt, Frauenberg 1904

Schindler, Chorgestühle (1983) - Herbert Schindler: Keysers kleine Kulturgeschichte. Chorgestühle, München 1983

Schlacher, Vergangenheit (i 966) - Johannes Schlacher: Aus der Vergangenheit von Mariahof, in: Josef Reichenpfader (Hg.): 900 Jahre Mariahof, ecclesia Grazluppa I066-ı 966, Judenburg 1966, 9-26

Schlager/Tropper, Stadthauptpfarrkirche (2014) - Susanne Schlager und Peter G. Tropper: Stadthauptpfarrkirche St. Jakob in Villach (Christliche Kunststätten Österreichs 560), Salzburg 2014

Schlatzer, Frauenkirchen (2000) - Michael Schlatzer: Franziskanerkloster Frauenkirchen (Christliche Kunststätten Österreichs 355), Salzburg 2000

Schlombs, Entwicklung (1965) - Wilhelm Schlombs: Die Entwicklung des Beichtstuhls in der katholischen Kirche. Grundlagen und Besonderheiten im alten Erzbistum Köln (Studien zur Kölner Kirchengeschichte 8, hg. v. Historischen Archiv des Erzbistums Köln), Düsseldorf I 965

Schmid, Altäre (2O I 5) - Harald Schmid: Der Weg ins Stift und die Altäre der Stiftsbasilika, in: Maurer/Rabl/Schmid, Campililiensia (2015), 75-96

Schmid, Klosterkirche [ 1965] - Isfried Schmid, Die Klosterkirche der Barmherzigen Brüder zu »Maria Verkündigung« in Graz, Graz o. J. [1965]

Schmid, Klosterkirche Wien (I976) - Isfried Schmid, Die Klosterkirche der Barmherzigen Brüder in Wien II zum hl. Johannes dem Täufer, Wien 1976

Schmitz, Möbelwerk (ı929) - Hermann Schmitz, Das Möbelwerk. Die Möbelformen vom 
Altertum bis zur Mitte des i 9. Jahrhunderts (Wasmuths Werkkunst-Bücherei r), 2. Aufl., Berlin 1929

Schneider, Jesuitenkirche, I (1995) - Brigitte Schneider: Jesuitenkirche und ehemaliges Kolleg, in: ÖKT, Innsbruck, I (I 995), 278-33 I

Schneider, Jesuitenkirche, 2 (I995) - Brigitte Schneider: Jesuitenkirche und ehemaliges Kolleg, in: ÖKT, Innsbruck, 2 (I 995), 547-5 52

Schneider, Ursulinenkirche (I 995) - Brigitte Schneider: Ehemalige Ursulinenkirche und -kloster, in: ÖKT, Innsbruck, I ( I 995), 350-357

Schneider-Prettner, Jesuitenkirche (I 985 ) - Brigitte Schneider-Prettner: Die Innsbrucker Jesuitenkirche: Baugeschichte, Urheberschaft und kunstgeschichtlicher Stellenwert, masch. phil. Diss., Innsbruck I 985

Schnell, Dom (1969) - Hugo Schnell: Dom und Mausoleum in Graz (Kunstführer 490), 2. neubearb. Aufl., München /Zürich I 969

Schnerich, Dom (1925) - Alfred Schnerich: Der Dom zu Graz und seine nächste Umgebung (hg. v. Kunsthistorischen Institut des Bundesdenkmalamtes), 2., verm. und verb. Aufl., Wien I 925

Schomers, Kunst (1988) - Florian Norbert Schomers: Die Kunst im Wandel der Geschichte am Beispiel des Prämonstratenserstiftes Wilten I I $38-$ i 988 , masch. theol. Dipl., Innsbruck I 988

Schomers, Wilten (2009) - Florian Norbert Schomers: Prämonstratenser-Chorherrenstift Wilten in Innsbruck (Peda-Kunstführer Nr. 735/2009), Passau 2009

Schommers, Goldschmiedearbeiten (2003) - Annette Schommers: Augsburger Goldschmiedearbeiten in Salzburg, in: Keller/Neuhardt/Heinisch, Erzbischof Lodron (2003), I I 7-I 20

Schottmüller, Wohnungskultur ( I 92 I) - Frida Schottmüller: Wohnungskultur und Möbel der italienischen Renaissance (Bauformen-Bibliothek I 2), Stuttgart I 92 I

Schroll, Marchstaller (189I) - Beda Schroll: Hieronymus Marchstaller, Abt des BenedictinerStiftes St. Paul im Lavantthale [...] I6r6-1638. Nach seinem Leben und Wirken dargestellt, Klagenfurt I 89 I

Schütte, Zeremoniell ( I 995) - Ulrich Schütte: Höfisches Zeremoniell und sakraler Kult in der Architektur des I7. und I 8. Jahrhunderts. Ansätze zu einem strukturellen Vergleich, in: Jörg Jochen Berns und Thomas Rahn (Hg.): Zeremoniell als höfische Ästhetik in Spätmittelalter und Früher Neuzeit (Frühe Neuzeit 25), Tübingen I 995 (Repr. 2010), 410-43 I

Schütte, Zeremoniell (2006) - Ulrich Schütte: Die Räume und das Zeremoniell, die Pracht und die Mode, in: Peter-Michael Hahn und Ulrich Schütte (Hg.): Zeichen und Raum. Ausstattung und höfisches Zeremoniell in den deutschen Schlössern der Frühen Neuzeit (Rudolstädter Forschungen zur Residenzkultur 3), München/Berlin 2006, I67-204

Schütz, Barockarchitektur (2000) - Bernhard Schütz: Die kirchliche Barockarchitektur in Bayern und Oberschwaben I $580-$ I 780 , München 2000

Schütz, Interieur (2009) - Karl Schütz: Das Interieur in der Malerei, München 2009

Schuhmann, Sachkultur (2007) - Dirk Schuhmann (Hg.): Sachkultur und religiöse Praxis (Studien zur Geschichte, Kunst und Kultur der Zisterzienser 8), Berlin 2007

Schuler, Stiftskirche (1920) - Heinrich Schuler: Die Stiftskirche des hl. Laurentius zu Wilten 
in Vergangenheit und Gegenwart. Festschrift zum 8oojährigen Jubiläum des Prämonstratenserordens, Innsbruck 1920

Schuler, Stift Wilten (1938) - Heinrich Schuler: [Achthundert] 800 Jahre Stift Wilten/Innsbruck. Führer durch die Abteikirche (Kunstführer S 3I6/3 I 7), München 1938

Schuler, Stift Wilten (I 956) - Heinrich Schuler: Stift Wilten/Innsbruck (Kunstführer 3 I 6), 2., neubearb. Aufl., München I 956

Schultes, Kanzelmodell (1998) - Lothar Schultes: Kanzelmodell, in: Krapf, Triumph (1998), 227

Schultes/Schultes, Kanzel (I 995) - Ulrike Schultes und Lothar Schultes: Die verschollene Kanzel der Kapuzinerkirche in Linz, in: Kunstjahrbuch der Stadt Linz r 994/95 (hg. v. Stadtmuseum Linz-Nordico), Wien/München I995, I 37-146

Schwaiger/Heim, Orden (2002) - Georg Schwaiger und Manfred Heim: Orden und Klöster. Das christliche Mönchtum in der Geschichte, München 2002

Schwarzkogler, Bankrott ( 1992 ) - Ileane Schwarzkogler: Bankrott im Barock. Das Schicksal der Augustiner Chorherren in Rottenmann, in: Schwarzkogler, Lust (I992), 27 I-274

Schwarzkogler, Lust (1992) - Ileane Schwarzkogler (Hg.): Lust und Leid: Barocke Kunst, barocker Alltag, Ausst.-Kat. Pürgg-Trautenfels, Graz 1992

Schweigert, Barmherzigenkirche (1999) - Horst Schweigert: Barmherzigenkirche, Graz (Christliche Kunststätten Österreichs 207), 2. Aufl., Salzburg I 999

Schweigert, Barockbildhauer (2004) - Horst Schweigert: Die Barockbildhauer Johannes Georg und Josef Stammel. Eine stilkritische und rezeptionsgeschichtliche Untersuchung (Beiträge zur Kunstgeschichte Steiermarks, Neue Folge, hg. v. Horst Schweigert 2), Graz 2004

Schweigert, Plastik (1979) - Horst Schweigert: Plastik und Gemälde in Stift Rein und seinen Pfarren, in: Rappold/Amon, Stift Rein (1979), 45 2-46 I

Schweigert, Stadtpfarrkirche (1974) - Horst Schweigert: Zur Frage der ehemaligen barocken Innenausstattung der Stadtpfarrkirche in Graz. Der plastische Schmuck der Kanzel und des Chorgestühls - ein Werk Philipp Jakob Straubs, in: Historisches Jahrbuch der Stadt Graz 5/6 (I973/I 974), 89-I I 7

Schweigert, Studien (2017) - Horst Schweigert: Studien zur Kunstgeschichte Steiermarks. Ausgewählte Schriften zur Kunst des Mittelalters bis zur Kunst der Gegenwart, Kumberg 20I 7

Schweikert, Brenck (2002) - Christine Schweikert: Brenck. Leben und Werk einer fränkischen Bildschnitzerfamilie im I7. Jahrhundert, Fränkisches Freilandmuseum, Bad Windsheim 2002

Scott, Interior (1995) - Katie Scott: The rococo interior: decoration and social spaces in early eighteenth-century Paris, New Haven u.a. 1995

Sedlmayr, Fischer von Erlach (r956) - Hans Sedlmayr: Johann Bernhard Fischer von Erlach, Wien/München 1956

Sedlmayr, Fischer von Erlach ( 1 976) - Hans Sedlmayr: Johann Bernhard Fischer von Erlach, 2., neubearb. und erw. Aufl., Wien 1976

Sedlmayr, Fischer von Erlach (r 997) - Hans Sedlmayr: Johann Bernhard Fischer von Erlach [Neuausgabe d. Ausgabe von I 976], Stuttgart I 997 
Seebach, Rekonstruktion (1995) - Gerhard Seebach: Rekonstruktion der baulichen Struktur der Klosterkirche des I 3. Jahrhunderts, in: Riedmann, Traum (I 995), 4I 9-424

Serlio, Architettura (1 584 ) - Sebastiano Serlio, Tutte l'Opere d'Architettura di Sebastiano Serlio Bolognese [...], Venedig I 584. [http://digi.ub.uni-heidelberg.de/diglit/serlio I 5 84/ooor ; Zugriff August 2018]

Sicca, Sculture (2010) - Cinzia Maria Sicca: Sculture per l'Europa. Modalità della contrattazione nelle opere per l'estero durante il Seicento, in: Ricerche di Storia dell'Arte ro r (2010), $53-63$

Siebenhundert Jahre Stams (1973) - [Siebenhundert] 700 Jahre Stift Stams I 273-r 973 (hg. v. Stift Stams), Stams I 973

Sitar, St. Paul (2000) - Gerfried Sitar: Die Abtei im Paradies. Das Stift St. Paul im Lavanttal, Wien 2000

Sitar, St. Paul (2005) - Sitar, Gerfried: Stift St. Paul im Lavanttal. Schatzhaus Kärntens, St. Paul/ Lavanttal o. J. [2005]

Sitar/Kroker, Macht des Wortes (2009) - Gerfried Sitar und Martin Kroker (Hg.): Macht des Wortes. Benediktinisches Mönchtum im Spiegel Europas, 2 Bde., Regensburg 2009

Spatzenegger, Dom zu Salzburg ( I 974) - Hans Spatzenegger (Hg.): [Eintausendzweihundert] I 200 Jahre Dom zu Salzburg 774-1974, Salzburg I 974

Spatzenegger, Geschichte ( 1977 ) - Hans Spatzenegger: Zur I 2oojährigen Geschichte des Stiftes Mattsee, in: Calliari, Mattsee (1977), I 3-37

Stainer, Bildhauerzeichnung (2018) - Nina Stainer: Die Bildhauerzeichnung als Medium der Ausbildung und des Formentransfers. Eine Studie anhand dreier Konvolute aus dem Umkreis Thomas Schwanthalers, masch. phil. Diss., Wien 2018

Steinböck, Domkirche (1989) - Wilhelm Steinböck: Die Domkirche zum hl. Ägidius. Die Katharinenkirche. Das Mausoleum Kaiser Ferdinands II., Graz I 989

Steinegger, Rundgang (1958) - Fritz Steinegger: Ein kunstgeschichtlicher Rundgang durch das Stift Wilten, in: Steinegger, Wilten (I958), I 7-32

Steinegger, Wilten (I 958 ) - Fritz Steinegger (Hg.): Das Stift Wilten, Innsbruck 1958

Steiner, Loretto (1994) - Matthias Steiner: Maria Loretto im Burgenland. Festschrift zum 350-Jahre-Jubiläum der Gnadenkapelle Loretto. Ein Führer zur Geschichte und zu den Kunstwerken der Gnadenkapelle und der Wallfahrtskirche (hg. v. Pfarramt Loretto), Mödling I 994

Stenzel, Stift (1977) - Gerhard Stenzel: Von Stift zu Stift in Österreich, Wien I 977

Stephan, Sakristeien (2007) - Carl Maria Stephan: Die Sakristeien in St. Lambrecht und Mariazell. Der St. Lambrechter Hoftischler Gregor Perchtoldt, in: Barockberichte 48/49 (2007), 220-238

Stiegel, Projekte (2009) - Achim Stiegel: »Lauter Projekte« - Möbel für den Luxusmarkt, in: Andreas Büttner und Ursula Weber-Woelk (Hg.): David Roentgen. Möbelkunst und Marketing im I 8. Jahrhundert, Regensburg 2009, 52-66

Stift Vorau [1954] - Stift Vorau, Graz o. J. [1 954]

Stift Vorau [ca. I970] - Das Stift Vorau in Bildern, o. O., o. J. [ca. I 970] 
Stift Wilten, Chorherrenstift Wilten (1988) - Stift Wilten (Hg.): [Achthundertfünfzig] 850 Jahre Praemonstratenser Chorherrenstift Wilten, Innsbruck 1988

Stolberg, Uhrmacher (1 979) - Lukas Stolberg: Die steirischen Uhrmacher, Graz I 979

Strauß, Akanthus (1937) - Ernst Strauß: Akanthus, in: RDK, Bd. I, Stuttgart I937, Sp. 262273

Strauß, Loretto (1959) - Irmgardis Strauß: 300 Jahre Maria Loretto (Heiligtümer der Heimat. Schriftenreihe über die kirchlichen Denkmäler des Burgenlandes 2), Eisenstadt 1959

Stürmer, Handwerk (1982) - Michael Stürmer: Handwerk und höfische Kultur. Europäische Möbelkunst im I 8. Jahrhundert, München I 982

Stürmer, Herbst (1 979) - Stürmer, Michael: Herbst des Alten Handwerks. Quellen zur Sozialgeschichte des r 8. Jahrhunderts, München I 979

Suppan, Chronik (2013) - Wolfgang Suppan (Hg.): An der Wiege des Landes Steiermark. Die Chronik Pürgg-Trauenfels, Gnas 2013

Tacke, Statua pictorum (2018) - Andreas Tacke (Hg.): Statua pictorum. Kommentierte Edition der Maler(zunft)ordnungen im deutschsprachigen Raum des Alten Reichs (artifex. Quellen und Studien zur Künstlersozialgeschichte), 5 Bde., Petersberg 2018

Tacke/Fachbach/Müller, Hofkünstler (2017) - Andreas Tacke, Jens Fachbach und Matthias Müller: Hofkünstler und Hofhandwerker in deutschsprachigen Residenzstädten der Vormoderne (Quellen und Studien zur Künstlersozialgeschichte, hg. v. Andreas Tacke), Petersberg 2017

Taubinger, Refektorium (2010) - Barbara Taubinger: Das Refektorium im ehemaligen Zisterzienserstift Neuberg an der Mürz - Studien zur barocken Freskenausstattung, masch. phil. Mag., Wien 2010

Tauch, Beichtstuhl ( I 969) - Max Tauch: Der Beichtstuhl in den katholischen Kirchen des deutschen Barock, Bonn I 969

Thaller, Mariatrost (2000) - Angelika Thaller: Mariatrost - Kunstgeschichtlicher Abriß, in: Bierbauer/Kaind1/Thaller, Mariatrost (2000), 26-34

Telesko, Benedictus triumphans (2006) - Werner Telesko: "Sanctus Benedictus triumphans«: die Langhausfresken der Stiftskirche von Melk (I720/r72I) und die Rolle Abt Berthold Dietmayrs, in: SMGB I I 7 (2006), 2 I $3^{-2} 35$

Telesko, Ecclesia militans (2010) - Werner Telesko: „Ecclesia militans et triumphans«: Heilsgeschichte und Universaltheorie als Leitmotive in der Ausstattung des Presbyteriums der Benediktinerstiftskirche in Melk, in: SMGB I 2 I (20 Io), 32 I-348

Telesko, Kosmos Barock (2013) - Werner Telesko: Kosmos Barock. Architektur, Ausstattung, Spiritualität. Die Stiftskirche Melk, Wien/Köln/Weimer 201 3

Teufert, Handwerk (1988) - Gabriele Teufert: Handwerk und Gewerbe in Wiener Neustadt im Mittelalter, masch. phil. Diss. Wien I 988

Thoenes, St. Peter (1 995) - Christof Thoenes: St. Peter I 534-I 546: Sangallos Holzmodell und seine Vorstufen, in: Evers, Architekturmodelle (1 995), ro I-Io9

Thomas, Vorzeichnungen ( 1969 ) - Bruno Thomas: Zwei Vorzeichnungen zu kaiserlichen Gar- 
destangenwaffen von Hans Stromaier I 577 und Johann Bernhard Fischer von Erlach I 705, in: JbKSW 65, NF XXIX ( 1969), 6 $1-78$

Thornton, Form (1998) - Peter Thornton: Form and Decoration. Innovation in the Decorative Arts $1470-1870$, London 1998

Tomaschek, Gröbming (200I) - Johann Tomaschek: Gröbming, Steiermark (Christliche Kunststätten Österreichs 368), Salzburg 200 I

Tremmel-Endres, Denkmalarchitektur (1996) - Jutta Tremmel-Endres: Denkmalarchitektur oder Architektur mit Denkmalcharakter? Studien zur Kunst Johann Fischers von Erlach, masch. phil. Diss., Trier I 996

Triendl, Seefeld Tirol (2006) - Anton Triendl: Seefeld Tirol, Pfarrkirche St. Oswald (Schnell Kunstführer 727), I I., neubearb. Aufl., Regensburg 2006

Tropper, Geschichte (1998) - Christine Tropper: Aus der Geschichte des Kollegiatstiftes, in: Körner, 750 Jahre (I 998), 37-5 I

Ulmer, St. Martin (2007) - Anton Ulmer: Pfarrkirche St. Martin (Peda-Kunstführer 679/2007), Passau 2007

Ulmer, St. Gallus (1938) - Andreas Ulmer: St. Galluskirche/Bregenz (Kirchenführer S 297/298), München 1938

Ulmer/Tiefenthaler, St. Gallus (I96r) - Andreas Ulmer und Meinrad Tiefenthaler: St. Gallus / Bregenz (Kunstführer 297), 2., verb. Aufl., München/Zürich I 96 I

Untermann, Architektur (2012) - Matthias Untermann: Architektur und Armutsgebot. Zur Charakteristik franziskanischer Kirchen- und Klosterbauten, in: Heimann/Hilsebein/ Schmies/Stiegemann, Armut (2012), 335-346

Untermann, Bauvorschriften (200I) - Matthias Untermann: Gebaute Unanimitas. Zu den Bauvorschriften der Zisterzienser, in: Knefelkamp, Zisterzienser (2001), 239-266

Untermann, Platz (2007) - Matthias Untermann: Der Platz der Laien in der Zisterzienserkirche, in: Schuhmann, Sachkultur (2007), i I-i 9

Vasari, Vite (I 55 o) - Giorgio Vasari: Le vite de più eccellenti architetti, pittori et scultori italiani, da Cimabue insino a'tempi nostri, Florenz 1550 (Repr. hg. v. Luciano Bellosi und Aldo Rossi, Turin I 986) [http://www.letteraturaitaliana.net/pdf/Volume_5/ti 29.pdf; Zugriff Oktober 2020]

Vavra, Suche (2000) - Elisabeth Vavra (Hg.): Die Suche nach dem verlorenen Paradies. Europäische Kultur im Spiegel der Klöster, Ausst.-Kat. Melk, St. Pölten 2000

Volk, Bemerkungen ( I 992) - Peter Volk: Bemerkungen zu einigen Altarmodellen des I 8. Jahrhunderts, in: Kalinowski, Werkstattpraxis (1992), 269-290

Volk, Entwurf (1986) - Peter Volk (Hg.): Entwurf und Ausführung in der europäischen Barockplastik: Beiträge zum internationalen Kolloquium des Bayrischen Nationalmuseums und des Zentralinstituts für Kunstgeschichte, München 24.-26.06.I 985 (Ergänzungsband zum Katalog), München I 986

Waagen, Frauenberg (193 I) - Hildebrand Waagen: Die Wallfahrtskirche Frauenberg an der Enns, Graz I93 I

Wackernagel, Lebensraum (1938) - Martin Wackernagel: Der Lebensraum des Künstlers in 
der florentinischen Renaissance. Aufgaben und Auftraggeber, Werkstatt und Kunstmarkt, Leipzig 1938

Wagner, Baldauf (1 978) - Franz Wagner: Simon Baldaufs Schränke in der Salzburger Domherrensakristei und die »Boulle«-Uhr Erzbischof Firmians, in: Alte und moderne Kunst: österreichische Zeitschrift für Kunst, Kunsthandwerk und Wohnkultur 23, I 58 (I 978), 20-27

Wagner, Barockisierung (1982) - Franz Wagner: Die erste Barockisierung der Stiftskirche St. Peter und die Altäre des Hans Waldburger, in: Kolb/Angermüller, Festschrift St. Peter (I 982 ), 627-652

Wagner, Benediktinerabtei Michaelbeuern ( 1985 ) - Nicolaus Wagner (Hg.): Benediktinerabtei Michaelbeuern: eine Dokumentation anläßlich der Eröffnung und der neu adaptierten Räume für Internat, Schule und Bildungsarbeit, Michaelbeuern 1985

Wagner, Ebenisten (201 I) - Franz Wagner: Ebenisten, Silberkistler, Galanteriearbeiter, Hoflaubschneider, Kammertischler. Gewerbegeschichtliche Notizen zur barocken Möbelkunst in Augsburg, München und Wien. Mit biographischen Daten zu einigen Meistern, in: Barockberichte $57 / 58$ (201 I), 61 7-652

Wagner, Heiligenkreuz (2007) - Franz Wagner: Von Heiligenkreuz zur Mehrerau - zu einigen Chorgestühlen des Barock in Österreich, in: Barockberichte 48/49 (2007), I45-I 53

Wagner, Kenntnis (2010) - Franz Wagner: Zur Kenntnis der Wiener Tischler des I7. und I 8. Jahrhunderts und ihrer Arbeiten, in: Holzobjekte und ihre Oberflächen. Untersuchung Konservierung - Restaurierung (Restauratorenblätter 29), Klosterneuburg 2010, 49-6I

Wagner, Kirchenbänke (2000) - Franz Wagner: Unbeachtet, unbearbeitet, vergessen: Historische Kirchenbänke in Österreich, in: Barockberichte $26 / 27$ (2000), 558-568

Wagner, Kunsthandwerk (1994) - Franz Wagner: Kunsthandwerk, in: Die Kunst des Barock in Österreich (hg. v. Günter Brucher), Salzburg/Wien I 994, 375-409

Wagner, Kunsthandwerk (r 999) - Franz Wagner: Kunsthandwerk, in: Lorenz, GbKÖ (I 999), 549-606

Wagner, Mattsee (1982) - Franz Wagner: Stift Mattsee. Salzburg, Stiftskirche (Christliche Kunststätten Österreichs I 27), Salzburg I 982

Wagner, Mattsee (I 997) - Franz Wagner: Stift Mattsee. Salzburg, Stiftskirche (Christliche Kunststätten Österreichs I 27), 4., überarb. Aufl., Salzburg 1997

Wagner, Regesten (2014) - Franz Wagner: Biographische Regesten zu den Tischlern des I7. und I 8. Jahrhunderts in Wien, masch. Exemplar, Salzburg 2014

Wagner, Testament (2007) - Franz Wagner: Testament und Nachlassinventar des 1659 verstorbenen Gregor Perchtoldt, Hoftischler der Benediktinerabtei St. Lambrecht (Stmk.), in: Barockberichte 48/49 (2007), 239-245

Wartena, Süddeutsche Chorgestühle (2008) - Sybe Wartena: Die süddeutschen Chorgestühle von der Renaissance bis zum Klassizismus, phil. Diss. München 2008 [https://edoc.ub.unimuenchen.de/7999/_/Wartena_Sybe.pdf; Zugriff Oktober 2020]

Waschgler, Kunstgeschichte Vorarlbergs ( 1930 ) - Heinrich Waschgler: Kunstgeschichte Vorarlbergs (Heimatkunde von Vorarlberg 9), Wien/Leipzig I 930

Watson, Furniture (1960) - Francis John Bagott Watson: Louis XVI Furniture, London I96o 
Webernig, Geschichtliches (2005) - Evelyne Webernig: Geschichtliches über Griffen (Ausstellungskatalog des Kärntner Landesarchivs I 5), Ausst.-Kat., Klagenfurt 2005

Webhofer, Baugeschichte (1988) - Trude Webhofer: Die mittelalterliche Baugeschichte des Stiftes Wilten, in: Stift Wilten, Chorherrenstift Wilten (1 988), I 47-1 82

Weingartner, Kunstgewerbe (1927) - Josef Weingartner: Das kirchliche Kunstgewerbe der Neuzeit, Innsbruck/Wien/München 1927

Weingartner, Südtirol (1985) - Josef Weingartner: Die Kunstdenkmäler Südtirols 2, 7. Aufl., Bozen/Innsbruck/Wien I 985

Weichesmüller, Schaukegl (1978) - Roland Weichesmüller: P. Joseph Schaukegl. Priester, Künstler und Gelehrter (I 72 I-I 798), in: SMGB, 89 (I 978), 38 I-47 I

Weiß, Bilder ( 1998 ) - Ulrike Weiß: Geschnittene Bilder. Zu Ort, Funktion und Entstehungsbedingungen des Reliefs in schwäbischen Kirchen zwischen I7 I 5 und I 780 (Tübinger Studien zur Archäologie und Kunstgeschichte I7, hg. v. Klaus Schwager), Tübingen [u.a.] I 998

Welt des Barock ( I 986) - Welt des Barock (hg. v. Rupert Feuchtmüller und Elisabeth Kovács), Ausst.-Kat. St. Florian, 2 Bde., Wien/Freiburg/Basel I 986

Werner, Bussi (1992) - Jakob Werner: Santino Bussi r664-I736, masch. phil. Dipl., Wien 1992

Wild, Totenbuch - Martin Wild: Totenbuch Rein - Hohenfurth/Necrologium Runense - A1tovadense, masch. Registerbände, StAR

Wilke, Innendekoration (2016) - Thomas Wilke: Innendekoration. Graphische Vorlagen und theoretische Vorgaben für die wandfeste Dekoration von Appartements im I 7. und I 8. Jahrhundert in Frankreich (Schriftenreihe des kunsthistorischen Instituts der Universität Stuttgart 3, hg. v. Sabine Poeschel), 2 Bde., München 2016

Windisch-Graetz, Barocke Möbel ( I 974) - Franz Windisch-Graetz: Barocke Möbel aus dem Stift Kremsmünster, in: alte und moderne kunst I 34 ( I 974), I6-23

Windisch-Graetz, Barocke Möbelkunst ( 197 I ) - Franz Windisch-Graetz: Barocke Möbelkunst in Österreich. Überblick und Forschungslage - Die Möbel des Stiftes St. Florian. In: Mitteilungen des Oberösterreichischen Landesarchivs ro (197 I), 346-396

Windisch-Graetz, Möbelkunst ( (977) - Franz Windisch-Graetz: Möbelkunst aus vier Jahrhunderten im Stift Kremsmünster, in: Cremifanum (r 977), 243-278

Windisch-Graetz, Möbel Europas (1982-1983) - Franz Windisch-Graetz: Möbel Europas, 2 Bde., München 1982-1983

Winkler, Entwicklung (2004) - Gerhard B. Winkler: Die besondere Entwicklung und Eigenart der österreichischen Zisterzienser, in: Zisterzienser in Österreich (hg. v. d. Österreichischen Zisterzienserkongregation), Salzburg 2004, 23-37

Winkler, Servitenkirche (r 995) - Robert Winkler: Servitenkirche und Kloster, in: ÖKT, Innsbruck, 2 (I 995), 530-546

Winkler/Krassnig/Brandes, Salzburg (2005) - Gerhard B. Winkler, Waltraud Krassnig und Katharina Brandes: Salzburg I I 22-I 5 I 4, in: Röhrig, Ehemalige Stifte (2005), 329-355

Winner, Klosteraufhebungen (1967) - Gerhard Winner: Die Klosteraufhebungen in Niederösterreich und Wien, Wien I 967 
Winterfeld, Chorgestühl (I 999) - Dethard v. Winterfeld: Chorgestühl, in: RGG, Bd. 2 (I 999), Sp. $175-176$

Witt-Dörring, Möbelkunst ( 1978 ) - Christian Witt-Dörring: Die Möbelkunst am Wiener Hof zur Zeit Maria Theresias ( I740-I780), 2 Bde., masch. phil. Diss., Wien 1978

Witte, Gotteshaus (I 939) - Robert B. Witte: Das katholische Gotteshaus. Sein Bau, seine Ausstattung, seine Pflege, Mainz I 939

Woisetschläger, Kunstschaffen ( 1979 ) - Kurt Woisetschläger: Das Kunstschaffen im Bereich des Klosters Rein, in: Rappold/Amon, Stift Rein (I 979), 77-ro I

Woisetschläger/Krenn, Steirische Herrlichkeiten ( 1968 ) - Kurt Woisetschläger und Peter Krenn: Alte steirische Herrlichkeiten. 8oo Jahre Kunst in der Steiermark, Graz/Wien/Köln I 968

Woisetschläger/Krenn, Steirische Herrlichkeiten (1973) - Kurt Woisetschläger und Peter Krenn: Alte steirische Herrlichkeiten. 800 Jahre Kunst in der Steiermark, 2. Aufl., Graz/ Wien/Köln I 973

Wolf, Aufhebung (1871) - Wolf, Adam: Die Aufhebung der Klöster in Innerösterreich I782I 790 , Wien I 87 I

Wolf, Identifikation (1988) - Peter A. Wolf: Zur Identifikation von Meisterstücken, in: Zinnkann, Meisterstücke (1988), 77-85

Wolfgang, Stams (2008) - Christiane Wolfgang: Die barocken Bau- und Ausstattungsphasen der Stiftskirche Stams im I7. und I 8. Jahrhundert unter besonderer Berücksichtigung des Umbaus ab I 729, masch. phil. Dipl., Wien 2008

Zacherl, Wiederaufbau (1959) - Peter Zacherl: Wiederaufbau und technische Einrichtungen des Domes, in: Dom zu Salzburg (I 959), i i I-I I 8

Zajic, Klosterhandwerk (1998) - Andreas Hermengild Zajic: Zwischen Kloster, Zunft und Landesherren. Klosterhandwerk in Spätmittelalter und Früher Neuzeit unter besonderer Berücksichtigung niederösterreichischer Quellen, masch. phil. Dipl., Wien 1998

Zatschek, Geschichte (1952) - Heinz Zatschek: Geschichte des Tischlerhandwerks in Wien, masch. Exemplar, Wien 1952 (Manuskript im Besitze der Wiener Tischlerinnung)

Zatschek, Gewerbe ( 1949) - Heinz Zatschek: Handwerk und Gewerbe in Wien. Von den Anfängen bis zur Erteilung der Gewerbefreiheit im Jahre I 859, Wien 1949

Zelfel, Franziskanerkirche (2005) - Hans Peter Zelfel: Franziskanerkirche mit Kloster, Diözesanmuseum (Peda-Kunstführer 579/2005), Passau 2005

Zimmermann, Kirchenbänke (20I4) - Katja Zimmermann: Kirchenbänke und Emporengitter, in: Brenner, Himmel (2014), 88-89

Zinnkann, Meisterstücke (I988) - Heidrun Zinnkann: Meisterstücke: Mainzer Möbel des I 8. Jahrhunderts (Museum für Kunsthandwerk Frankfurt am Main), Ausst.-Kat., Frankfurt am Main 1988

Zündel, Franziskanerkirche (2005) - Sophie Zündel: Die Franziskanerkirche in Graz. Kunstund baugeschichtliche Aspekte, masch. Dipl., Graz 2005 


\section{EIN LEBENDIGES BILD DER TISCHLER, IHRER ARBEITEN UND LEBENSUMSTÄNDE IN DER FRÜHEN NEUTZEIT}

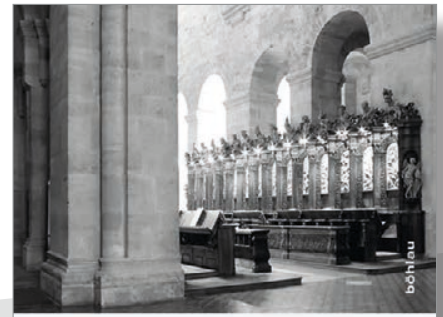

\section{SAKRALMÖBEL AUS ÖSTERREICH}

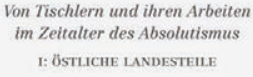

MICHAEL BOHR
Michael Bohr

\section{Sakralmöbel aus Österreich}

Von Tischlern und ihren Arbeiten im Zeitalter des Absolutismus.

I: Östliche Landesteile

Sakralmöbel aus Österreich. Band I

2017. 728 Seiten, gebunden

$€ 97,00 \mathrm{D} \mid € 100,00 \mathrm{~A}$

ISBN 978-3-205-20512-8

Der Band ist in einer Open Access Version verfügbar

Die zweibändige Studie über österreichisches Barockmobiliar untersucht Interieurs von Klöstern und Weltkirchen. Der vorliegende erste Band präsentiert in einem umfassenden Katalog Möbel aus den östlichen Landesteilen (Wien, Niederösterreich, Oberösterreich). Ausgehend vom St. Gallener Klosterplan, von Bildquellen und zeitgenössischen Schriften beschreibt er zudem die Geschichte sakraler Einrichtungen und begegnet damit einem Desiderat der Kunstgeschichte. Die Recherche geht dabei über eine rein deskriptive Analyse des Bestandes weit hinaus. Neben genuin kunsthistorischen Fragestellungen streift sie Bereiche der Wirtschafts- und Sozialgeschichte und zeichnet so ein lebendiges Bild der Tischler, ihren Erzeugnissen und ihren Lebensumständen in der Frühen Neuzeit. Ergänzend wird der zweite Band der Studie Möbel der übrigen österreichischen Regionen sowie Fragen zum Zunftwesen, zu Migrationsbewegungen und zur allgemeinen Lebenssituation von Tischlern behandeln.

Vandenhoeck \& Ruprecht Verlage

www.vandenhoeck-ruprecht-verlage.com 
Publikation im Sinne der CC-Lizenz BY 4.0 